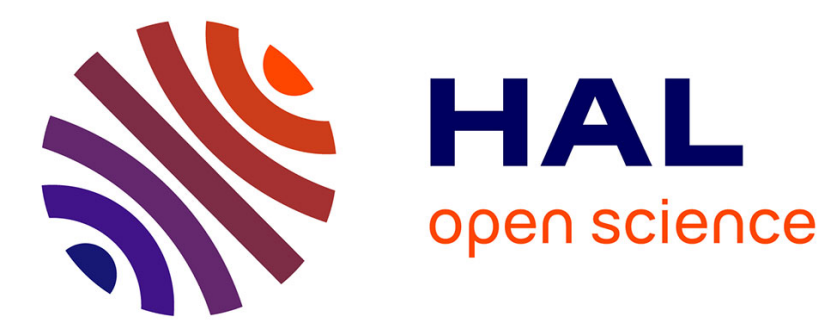

\title{
Histoire de la régulation des banques en Suisse (1914-1972) \\ Thibaud Giddey
}

\section{To cite this version:}

Thibaud Giddey. Histoire de la régulation des banques en Suisse (1914-1972). Librairie Droz, 41, pp.576, 2019, Publications d'histoire économique et sociale internationale, 978-2-600-05937-4. 10.47421/droz59374 . hal-03036199

\section{HAL Id: hal-03036199 \\ https://hal.science/hal-03036199}

Submitted on 26 Jan 2021

HAL is a multi-disciplinary open access archive for the deposit and dissemination of scientific research documents, whether they are published or not. The documents may come from teaching and research institutions in France or abroad, or from public or private research centers.
L'archive ouverte pluridisciplinaire HAL, est destinée au dépôt et à la diffusion de documents scientifiques de niveau recherche, publiés ou non, émanant des établissements d'enseignement et de recherche français ou étrangers, des laboratoires publics ou privés. 


\section{Histoire de la régulation des banques en Suisse}

(1914-1972)

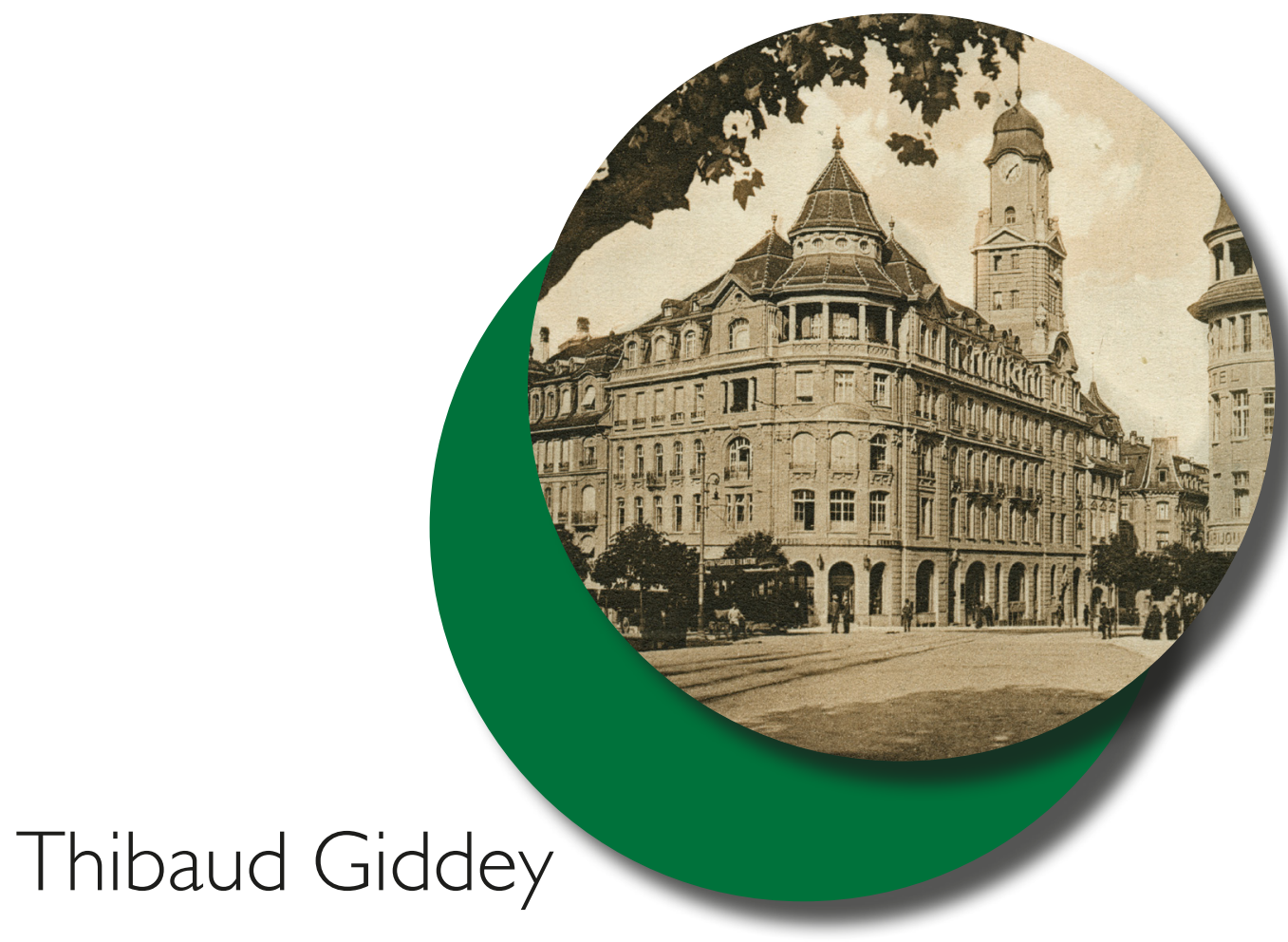




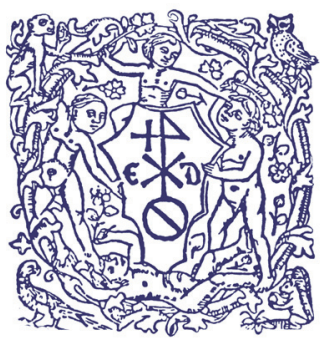

Tous droits réservés par la Librairie Droz SA en vertu des règles de propriété intellectuelle applicables.

Sans autorisation écrite de l'éditeur ou d'un organisme de gestion des droits d'auteur dûment habilité et sauf dans les cas prévus par la loi, l'œuvre ne peut être, en entier ou en partie, reproduite sous quelque forme que ce soit, ni adaptée, représentée, transférée ou cédée à des tiers.

Pour toutes informations supplémentaires, merci de contacter l'éditeur : rights@droz.org
All rights reserved by Librairie Droz SA as proscribed by applicable intellectual property laws.

Works may not, fully or in part, be reproduced in any form, nor adapted, represented, transferred or ceded to third parties without the written authorization of the publisher or a duly empowered organization of authors' rights management and except in instances provided for by law.

For any additional information, please contact the publisher : rights@droz.org 
PUBLICATIONS D'HISTOIRE ÉCONOMIQUE ET SOCIALE INTERNATIONALE

No 41 


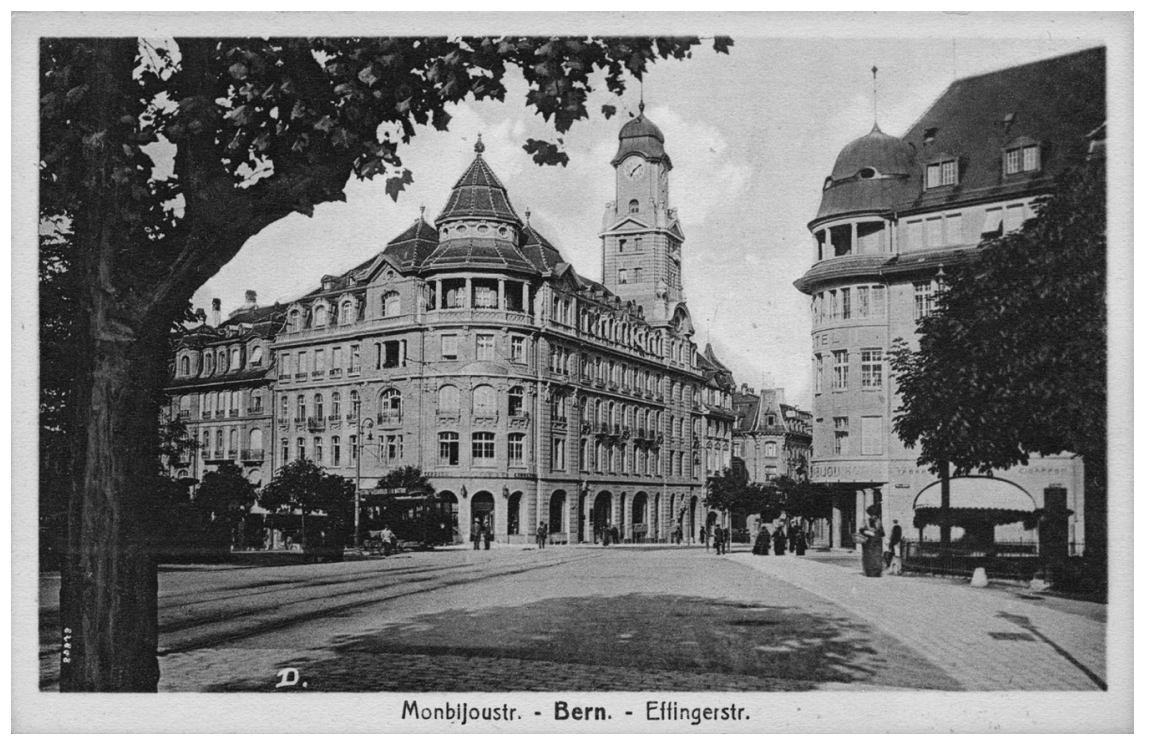

Siège de la Commission fédérale des banques à Berne (Effingerstrasse 1) durant l'entre-deux-guerres, Archives de l'État de Berne, T. A Bern Hirschengraben 11. En couverture: détail. 
THIBAUD GIDDEY

\section{HISTOIRE \\ DE LA RÉGULATION DES BANQUES EN SUISSE \\ (1914-1972)}

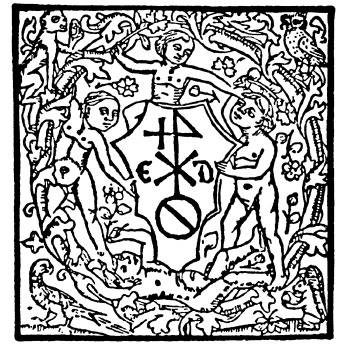

DROZ 
Ouvrage publié avec le soutien du

Fonds national suisse de la recherche scientifique et de la Société Académique Vaudoise

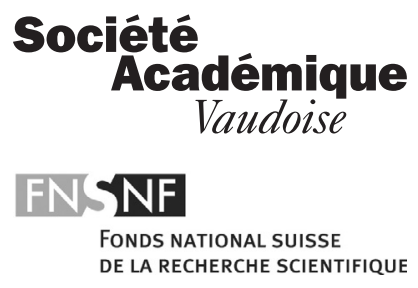

www.droz.org

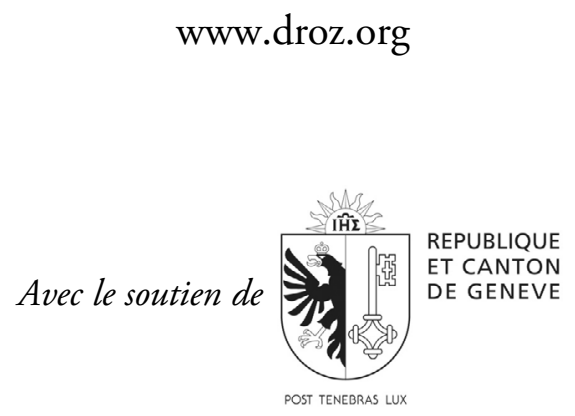

ISBN : 978-2-600-05937-4

ISBN PDF : 978-2-600-15937-1

ISBN EPUB : 978-2-600-35937-5

ISSN : $1422-7630$

(C) 2019 by Librairie Droz S.A., 11, rue Firmin-Massot, Genève.

All rights reserved. No part of this book may be reproduced, translated, stored or transmitted in any form or by any means, electronic, mechanical, photo copying or otherwise without written permission from the publisher. 


\section{INTRODUCTION}

L'illégalisme des biens a été séparé de celui des droits. Partage qui recouvre une opposition de classes, puisque, d'un côté, l'illégalisme qui sera le plus accessible aux classes populaires sera celui des biens transfert violent des propriétés; que d'un autre la bourgeoisie se réservera, elle, l'illégalisme des droits: la possibilité de tourner ses propres règlements et ses propres lois; de faire assurer tout un immense secteur de la circulation économique par un jeu qui se déploie dans les marges de la législation - marges prévues par ses silences, ou libérées par une tolérance de fait.

Michel Foucault, Surveiller et punir. Naissance de la prison, Paris: Gallimard, 2008 (1975) ${ }^{\mathrm{I}}$ ), p. I03-IO4.

Je suis heureux de participer à votre comité. Il ne m'a pas non plus échappé que les compétences de la Commission des banques ne sont pas très étendues. Mais nous ne devons pas déplorer cela comme un inconvénient; grâce à cela, la Commission se préserve de prendre une responsabilité qu'elle ne saurait peutêtre pas assumer ${ }^{1}$.

Max Rohr (I890-1980), conseiller national conservateur argovien, lors de son intronisation à la Commission fédérale des banques, le $\mathrm{I}^{\mathrm{er}}$ juin 1955 .

Le concept de régulation bancaire fait partie des formules en vogue, qui, depuis 2007-2008, sont employées dans des contextes variés. Dans la sphère médiatique, il n'est plus exclusivement réservé à la rubrique d'actualité économique et financière, mais fait parfois la une de la presse grand public. Dans la sphère politique, il s'invite désormais régulièrement dans de nombreux comités de réflexion et sa thématisation devient presque un phénomène banal. Cette résurgence est essentiellement due à la profonde crise économique et financière, parfois appelée Grande Récession, qui a frappé les pays industrialisés à partir de

1 AFB, E 6520(A), I000/1059, vol. I0, 66*, PV CFB, or.06.1955, p. 58. Sauf indications contraires, les citations sont traduites de l'allemand par l'auteur. 
2008. Le rôle de détonateur et de contagion des intermédiaires financiers dans la propagation des mécanismes récessionnistes a également suscité un regain d'intérêt dans la recherche académique. La plus large diffusion des études portant sur la régulation bancaire doit beaucoup aux conséquences sociales plus immédiates que les citoyens des pays affectés par la crise ont subies: une faillite bancaire provoque une intervention gouvernementale de sauvetage, qui, à son tour, engendre une crise des finances publiques dont les contribuables font les frais, en dernier ressort. Divers économistes ont donc cherché, au-delà du diagnostic immédiat, à comprendre les origines de cette grave crise, ce qui les a parfois conduits à remettre en question un certain nombre de dogmes - dérégulation, discipline de marché autocorrective - qu'ils avaient jusqu’alors promus.

Ce mouvement général a également provoqué la mobilisation d'historiens. Le recours à l'histoire devient alors souvent un outil pour porter un jugement sur l'actualité: il s'agit par exemple de savoir si la crise de 2008 atteint le degré de gravité de celle des années 1930 ou si elle n'était pas prévisible à la lumière des antécédents historiques. Depuis une dizaine d'années, la thématique de la surveillance bancaire et de son rôle dans le déclenchement ou la résolution d'une crise financière a ainsi fait l'objet de nouvelles études historiques.

Le présent ouvrage s'inscrit, jusqu'à un certain point, dans ce nouvel élan de recherche. Certes, il ne s'agit pas de décortiquer les rouages de la récente crise financière, ni même de souligner les carences des systèmes de contrôle contemporains. Le lecteur qui cherche à trouver ici des réponses permettant de guider les décideurs politiques et dirigeants économiques actuels sera sans doute tout autant déçu : notre propos ne cherche pas à tirer les leçons du passé, l'histoire retracée ici n'a pas de visée pédagogique ${ }^{2}$. En revanche, ce travail tente de remonter aux sources des configurations institutionnelles, politiques et économiques qui caractérisent le régime de surveillance bancaire dont les autorités actuelles ont hérité. Comprendre le contexte de mise en place, puis de développement, du cadre réglementaire en vigueur aujourd'hui permet de mieux appréhender ses lacunes et ses incohérences. En ce sens, ce travail pourrait apporter un éclairage, au moins indirect, sur les racines de la crise post-2008.

2 Contrairement à d'autres travaux historiques qui s'adressent plus directement aux régulateurs d'aujourd'hui. Voir par exemple: Stefano Battilossi, Jaime Reis (éd.), State and Financial System in Europe and the USA. Historical Perspectives on Regulation and Supervision in the Nineteenth and Twentieth Centuries, Burlington: Ashgate, 20IO, p. 2. Voir également: Eugene N. White (éd.), Crashes and Panics: the Lessons from History, New York: New York University, Leonard N. Stern School of Business, 1990; Eugene N. White, «Lessons from the History of Bank Examination and Supervision in the United States I863-2008 ", in Alfredo Gigliobianco, Gianni Toniolo (éd.), Financial Market Regulation in the Wake of Financial Crises: The Historical Experience, Roma: Banca d'Italia Eurosistema, 2009, p. 15-43. 


\section{INTÉRÊT DU SUJET ET HYPOTHĖSES DE RECHERCHE}

Les banques jouent un rôle crucial dans la vie économique des sociétés capitalistes modernes. En tant qu'intermédiaires incontournables, elles fournissent des services financiers à de nombreuses entreprises et collectivités publiques et font partie du quotidien de la plupart des citoyens, qui utilisent des comptes pour recevoir leurs salaires, payer leurs factures et placer leur épargne. En ce sens, le bon fonctionnement et la stabilité du système bancaire sont devenus des préoccupations de premier plan pour les pouvoirs publics. Cette attention accrue provient non seulement de la place centrale qu'occupent les banques dans le système économique, mais aussi de leur grande fragilité et des lourdes conséquences qu'une faillite bancaire entraîne. Il ne s'agit pas là d'un phénomène récent; le statut particulier des entreprises bancaires dans les systèmes économiques capitalistes est bien connu, au moins depuis la profonde crise financière des années 1930. Le gouvernement fédéral suisse, dans le message accompagnant son projet de loi sur les banques de 1934, exprime sans équivoque la responsabilité spécifique de ce secteur:

Le fait prépondérant qui caractérise l'économie moderne est peut-être moins le phénomène de la concentration des richesses que l'accumulation d'une puissance économique considérable entre les mains d'un petit nombre de personnes qui n'en sont point propriétaires, mais seulement dépositaires et dont le rôle est de placer les capitaux qu'elles ont mission d'administrer. Le pouvoir des détenteurs du commerce de l'argent qui dispensent le crédit est incontestablement une des grandes puissances modernes. Dans ces conditions, l'activité bancaire est devenue une sorte de fonction publique ${ }^{3}$.

Pour les gouvernements et les législateurs, assurer un système de crédit solide et efficace devient un enjeu de taille. Savoir comment cet objectif général est poursuivi constitue une des questions que ce travail aborde.

Outre les raisons qui font de l'industrie bancaire en général un secteur particulièrement sensible pour les autorités publiques, l'étude du cas suisse se révèle digne d'un intérêt singulier. Ce n'est un secret pour personne, la Suisse accueille aujourd'hui une des principales places financières du monde. En 20I7, les services financiers et d'assurance contribuent à la création de valeur à hauteur de 9.I \% du PIB, contre par exemple 7.2\% au Royaume-Uni ou 3.9\% en Allemagne; ils emploient $2 \mathrm{I} 3400$ personnes, soit $5.6 \%$ de l'emploi total en Suisse, et fournissent aux pouvoirs publics des rentrées fiscales correspondant en 2014 à $8.9 \%$ de l'ensemble des recettes ${ }^{4}$. Les intermédiaires financiers helvétiques sont en particulier performants dans le domaine de la gestion de fortune

3 "Message du Conseil fédéral à l'Assemblée fédérale concernant le projet de loi sur les banques et les caisses d'épargne, (du 2 février 1934)", Feuille fédérale, I, I934, p. I72.

4 Département fédéral des finances, Place financière suisse. Chiffres-clés octobre 20I7, Berne: Secrétariat d'État aux questions financières internationales SFI, octobre 2017. 
internationale : en 20I4, la Suisse y occupe toujours la position de leader mondial, avec une part de marché globale de $22 \%$. UBS et Credit Suisse, les deux groupes bancaires dominants, qui représentent à eux seuls $47 \%$ des bilans bancaires suisses en 20I5, figurent encore en 2017 parmi la liste des 30 banques systémiques dressée par le Conseil de stabilité financière (Financial Stability Board) ${ }^{6}$. Ces performances résultent en partie du développement à plus long terme, au cours du XXe siècle, d'une place financière dont l'envergure n'est pas proportionnelle à la dimension géographique, démographique ou même commerciale du pays ${ }^{7}$.

Partant de ce constat, la présente étude vise à comprendre sur quel environnement réglementaire la forte croissance de la place bancaire suisse a reposé. Autrement dit, il s'agit d'analyser l'évolution des conditions-cadres légales dont bénéficient les établissements financiers en Suisse. Plus précisément, c'est le rôle joué par l'État dans la mise en place et l'évolution du régime de régulation bancaire qui est au cœur du questionnement. Dans quelles conditions des législations régissant l'activité des banques sont-elles mises en place? Au-delà des textes légaux promulgués, ce travail s'interroge aussi sur la façon dont les principes ancrés dans les réglementations sont effectivement mis en œuvre. En ce sens, la focale adoptée ici se concentre sur la surveillance bancaire (en anglais supervision) plutôt que sur la notion très large de régulation ${ }^{8}$. En effet, le concept de régulation englobe des phénomènes disparates, qui vont de la simple définition de règles qui affectent les activités privées à des notions beaucoup plus précises comme la détermination, parfois par les acteurs eux-mêmes, des ratios de liquidité ou de solvabilité exigibles des banques. La surveillance bancaire, dans un sens plus restreint, se limite à l'activité de contrôle et d'observation exercée par une institution qui cherche en principe à améliorer la sécurité des déposants en imposant certains mécanismes prudentiels. Autre différence: la régulation concerne en premier lieu la définition des règles dans un sens normatif, tandis que la surveillance est axée sur la mise en application des prescriptions.

5 Soit 2040 milliards de \$ d'actifs. Cf. The Deloitte Wealth Magagement Centre Ranking 2015. Capturing value in a shifting environment, Zurich: Deloitte Consulting, 20I5.

6 Financial Stability Board, 2017 list of global systemically important banks (G-SIBs), 2I November 2017. Du point de vue de la surveillance nationale, la FINMA, autorité fédérale de surveillance des marchés financiers, considère que la Banque cantonale de Zurich, Raiffeisen Suisse et PostFinance font également partie des groupes financiers qui présentent une importance systémique. Cf. rapport annuel de la FINMA 20I5, p. 40.

7 Pour une synthèse sur le développement de la place financière suisse au XXe siècle, voir Malik Mazbouri, Sébastien Guex, Rodrigo Lopez, «Finanzplatz Schweiz», in Patrick Halbeisen, Margrit Müller, Béatrice Veyrassat (éd.), Wirtschaftsgeschichte der Schweiz im 2o. Jahrhundert, Basel: Schwabe, 2012, p. 467-518.

8 Par commodité de langage, nous emploierons parfois le termes de surveillance et régulation comme synonymes. Par extension, les vocables superviseur et régulateur désigneront aussi indifféremment les membres des autorités de surveillance bancaire. Pour un récapitulatif récent et international sur la thématique, voir Catherine R. Schenk, Emmanuel MourlonDruol, "Bank Regulation and Supervision", in Youssef Cassis, Richard S. Grossman, Catherine R. Schenk (éd.), The Oxford Handbook of Banking and Financial History, Oxford : Oxford University Press, 2016, p. 395-419. 
Le cadre chronologique n'est pas anodin non plus. L'analyse débute dans les années 19I4-I916, lorsqu'un premier projet de loi bancaire fédérale prend forme en Suisse, mais n'aboutit pas. Après avoir parcouru les stratégies d'autorégulation pendant les années 1920, l'étude se concentre sur les années 1930, lorsque la loi fédérale sur les banques voit le jour dans le sillage d'une profonde crise bancaire. Les activités de surveillance bancaire de la Confédération sont observées jusqu'au début des années 1970, quand intervient la première révision du cadre légal. Autrement dit, la période 1930-1970 est au cœur de ce travail. Or, dans la littérature internationale sur la régulation bancaire, cette phase historique est régulièrement présentée comme la période de mise en place de régimes de «répression financière" (financial repression) ${ }^{9}$. Dans cette perspective, la période de l'après-guerre, qui s'étend de 1945 aux années 1970, serait caractérisée par l'établissement, à partir d'institutions souvent instaurées dans les années 1930, d'un ensemble de contraintes sur les intermédiaires financiers visant à reconstruire les économies affectées par la guerre. Il s'agit de mesures telles que le plafonnement des crédits, le contrôle des taux d'intérêt et le financement du déficit public par la banque centrale, avec une domination des banques publiques ou semi-publiques ${ }^{10}$. Les distorsions du marché et l'allocation inefficace des ressources rendraient, selon les partisans de la dérégulation, les régimes de répression financière particulièrement "nocifs", en empêchant les banques d' " exploiter leur plein potentiel ${ }^{11}$.

L'un des axes principaux de cette étude consiste donc dans la confrontation entre le cas d'étude de la Suisse d'une part et d'autre part l'interprétation globale de l'évolution de la régulation bancaire entre les années 1930 et les années I970, considérée en tant que période d'oppression étatique contre le développement naturel des banques. Mais avant d'aller plus loin dans la mise en regard entre le cas helvétique et cette interprétation globale, décrivons d'abord, en deux mots, la configuration suisse. En novembre 1934, dans des circonstances que nous étudierons attentivement, le Parlement fédéral adopte une loi sur les banques qui instaure certaines dispositions : les banques doivent être contrôlées annuellement par une société fiduciaire, respecter des ratios de liquidité et de fonds

9 Voir par exemple Stefano Battilossi, «The Second Reversal : The ebb and flow of financial repression in Western Europe, 1950-9I", Paper presented at: The Sixth Conference of the European Historical Economics Society (EHES), Istanbul, September 9-IO, 2005, 2005 ; Battilossi, Reis (éd.), op. cit., 20Io ; Donato Masciandaro, Marc Quintyn, "The Evolution of Financial Supervision: the Continuing Search for the Holy Grail», in Morten Balling, Ernest Gnan (éd.), so years of Money and Finance: Lessons and Challenges, Vienna: Larcier, 2013, p. 263-318. Sur le cas anglais: John D. Turner, Banking in Crisis: the Rise and Fall of British Banking Stability, I80o to the Present, Cambridge : Cambridge University Press, 20I4, p. I82-203.

10 L'expression "financial repression" est théorisée pour la première fois par les économistes américains McKinnon et Shaw en 1973. Ronald Ian McKinnon, Money and capital in economic development, Washington D.C: The Brookings Institution, I973; Edward S. Shaw, Financial deepening in economic development, New York: Oxford Univ. Press, 1973. 
propres, mais elles bénéficient aussi de mesures d'assainissement particulières. Une nouvelle instance est créée à cette occasion pour mettre en application cette nouvelle régulation : la Commission fédérale des banques. Ces deux objets - la loi bancaire et l'autorité chargée de sa mise en exécution - sont au cœur de la présente étude. Une fois ces éléments mis en place, la question est la suivante: le type de contrôle établi en I934 et l'activité de surveillance de la Commission fédérale des banques exercée jusque dans les années I970 cadrentils bien avec la théorie de la répression financière? L'objectif principal de cet ouvrage est donc simple: elle cherche à comprendre comment le régime de surveillance bancaire en Suisse s'est développé en un système de contrôle peu contraignant, au moment même où la tendance internationale serait caractérisée par un filet réglementaire strict et rigide. Ce décalage trouve son origine dans la formulation du cadre légal dans les années 1930, raison pour laquelle la phase d'élaboration de la loi sera observée avec une attention particulière.

Au-delà de cet axe de recherche principal, trois hypothèses complémentaires nourrissent les réflexions de l'analyse qui va suivre. La première est relative à la question des conditions d'émergence d'un régime de surveillance bancaire. Dans la perspective de ce travail, promulguer une loi sur les banques ne constitue pas une opération purement réglementaire et technique, au cours de laquelle une lacune normative est comblée par l'introduction de mesures spécialisées unanimement considérées comme optimales. Il ne s'agit pas de décrire des prescriptions légales dans une perspective strictement juridique. Au contraire, la formalisation d'un contrôle étatique sur les banques par le biais d'une législation représente un enjeu éminemment politique. Pour en mesurer la portée, il faut donc non seulement tourner son attention sur le produit final - le texte juridique adopté - mais surtout analyser le processus de décision, en amont, qui conduit à l'adoption par les législateurs d'une régulation, et examiner, en aval, la façon dont les normes sont appliquées. Ce postulat tient aussi lieu d'avertissement méthodologique. Dans les pages qui suivent, l'on trouvera peu d'approfondissements sur la qualité intrinsèque des normes édictées, sur l'efficacité prouvée - pour autant qu'elle puisse être mesurée - des interventions de la Commission fédérale des banques, ou encore sur la pertinence ou l'inadéquation du niveau de réserve exigé des établissements financiers. En revanche, les négociations qui précèdent les prises de décisions ou les tensions entre acteurs qui en résultent feront l'objet d'un examen minutieux.

Dans ce contexte, l'hypothèse avancée est la suivante. La mise en place ou la révision d'un régime de surveillance répond à une logique de cycle de régulation ${ }^{12}$. Ce concept analyse les corrélations entre trois phénomènes: l'émergence

12 Sur la notion de regulatory cycle, voir Alfredo Gigliobianco, «Introduction. Regulatory Responses To Financial Crises. In Search of a Pattern", in Alfredo Gigliobianco, Gianni Toniolo (éd.), Financial Market Regulation in the Wake of Financial Crises: The Historical Experience, Roma: Banca d'Italia Eurosistema, 2009, p. 9-I2. Voir aussi, Hubert Bonin, Jean-Marc Figuet (éd.), Crises et régulation bancaires. Les cheminements de linstabilité et de la stabilité bancaires, Genève: Librairie Droz, 2016. 
d'une crise bancaire ou d'une innovation financière, l'inscription dans l'agenda politique et médiatique, puis l'adoption de normes réglementaires répondant aux problématiques soulevées. L'équilibre nouveau créé par la réforme du cadre réglementaire est amené à se rompre lors de la prochaine crise ou innovation financière, qui initie ainsi un prochain cycle. Cette logique d'explication de la régulation bancaire fonctionne effectivement dans de nombreuses situations, mais elle est à notre avis insuffisante pour bien appréhender le phénomène. Elle suppose en effet une certaine concordance entre le problème détecté au moment de l'éruption de la crise et les réponses apportées dans la réaction législative finale. Or, cette adéquation de vues n'est pas toujours donnée.

Pour aller au-delà de cette interprétation fonctionnaliste, il faut interroger le processus de décision qui conduit à l'adoption ou l'échec d'un projet de régulation. Cette opération constitue en effet une cristallisation des rapports de force socio-politiques. Les confrontations ont lieu d'une part entre différents acteurs institutionnellement distincts, par exemple entre les pouvoirs publics, les banquiers centraux, les superviseurs bancaires et les groupes d'intérêts représentant les banques. L'analyse génétique d'un projet de réglementation est aussi l'occasion d'appréhender, d'autre part, les conflits internes au sein de l'industrie qui fait l'objet de la régulation. Définir les règles du jeu communes devient alors une question centrale ; l'accouchement d'une législation, puis ses éventuelles révisions, constituent de potentielles sources d'antagonismes internes au monde bancaire, que les associations d'intérêts doivent surmonter pour fédérer leurs membres. La question de recherche résumant cette problématique peut être formulée de la manière suivante: dans quelles conditions et sous l'influence de quel rapport de forces sociopolitiques, un régime de surveillance bancaire est-il mis en place?

Une fois la législation bancaire adoptée, la focale se déplace vers la mise en application de cette régulation et plus précisément vers l'autorité chargée d'assurer le respect des prescriptions légales. En Suisse, l'élaboration du statut légal des banques aboutit en 1934 à l'établissement d'un nouvel organisme, créé de toutes pièces pour l'occasion. La Commission fédérale des banques, devenue depuis 2009 l'autorité de surveillance du marché financier suisse (FINMA), est désignée pour garantir le contrôle des banques. Il convient d'interroger ce choix. Pourquoi ne pas avoir confié ce rôle à une section de la banque centrale ou à un office gouvernemental? Le second axe de recherche se concentre donc sur cette configuration institutionnelle particulière et ses conséquences sur le type d'activités pratiquées par la Commission fédérale des banques. D'une part, il s'agira de comprendre comment les législateurs aboutissent à cette désignation d'un nouvel organisme. D'autre part, le statut institutionnel, l'autonomie à l'égard du gouvernement et des milieux intéressés, les ressources mises à disposition par l'État constituent des facteurs qui devront être examinés attentivement pour saisir la nature de cette agence de régulation. À cet égard, il faut se garder d'étiqueter les différents acteurs mobilisés de manière trop rigide selon la dichotomie public/privé. Les dirigeants de la Commission fédérale des 
banques ou de la Banque nationale suisse, même s'ils tiennent les rênes d'institutions établies par l'État, ne peuvent pas être catalogués comme d'ardents partisans de la puissance publique. Une grille d'analyse plus fine doit donc être employée pour identifier le statut institutionnel relativement ambigu des acteurs principaux de la régulation bancaire helvétique.

Après avoir mesuré plus précisément les dimensions, les moyens d'intervention et l'indépendance de la Commission fédérale des banques tels qu'ils sont prévus dans la loi et tels qu'ils sont mis en œuvre durant les premières années d'activité, il s'agira de savoir comment le poids de cette institution a évolué à plus long terme. L'autorité de surveillance devient-elle un acteur majeur dans la politique bancaire fédérale, sa capacité d'influence se développe-t-elle? En outre, il faudra aussi observer comment évoluent les relations entre l'organisme et les entreprises qui sont soumises à son contrôle : la dimension de collaboration avec les administrés prend-elle le pas sur le rapport conflictuel inhérent à toute négociation entre régulateur et régulé? Encore une fois, nous n'entendons pas aborder cette seconde thématique sous l'angle fonctionnaliste, consistant à comparer les bienfaits de chaque configuration d'agence de régulation bancaire dans le but de déterminer la solution optimale qu'il convient d'adopter; il ne s'agit pas de mesurer les pour et les contre d'une autorité indépendante par rapport à une section d'une banque centrale ou du ministère des Finances ${ }^{13}$. L'objectif est plutôt de saisir comment la structure institutionnelle de l'organisme de surveillance a pesé sur ses activités et sa capacité d'intervention. Ces différents aspects de l'étude peuvent donc être synthétisés par la question suivante: dans quelle mesure le choix d'un organisme indépendant et faiblement doté a-t-il influencé le rôle joué par la Commission fédérale des banques au cours de ses quarante premières années d'existence?

Dans ce contexte, une attention particulière sera également portée à la volonté des autorités de réformer, de moderniser, ou d'adapter le régime de régulation instauré dans les années 1930. Malgré une relative stabilité du système bancaire et un essor de la place financière suisse, un certain nombre de carences du système de contrôle étatique des banques seront révélées pendant la période examinée (1935-197I). Ce sont parfois les superviseurs eux-mêmes qui détectent des lacunes importantes dans leurs pouvoirs de sanction. Or, pendant une longue période d'environ un quart de siècle, entre 1945 et 1970, les diverses propositions - officielles ou inofficielles - visant à réformer le cadre législatif fédéral régissant la régulation bancaire en Suisse n'aboutissent pas. Cet axe de recherche, en des termes plus généraux, interroge donc les raisons qui

13 Ce type de questionnements sont abordés dans une perspective historique dans les travaux suivants: Richard S. Grossman, "The Emergence of Central Banks and Banking Supervision in Comparative Perspective ", in Stefano Battilossi, Jaime Reis (éd.), State and Financial Systems in Europe and the USA. Historical Perspectives on Regulation and Supervision in the Nineteenth and Twentieth Centuries, Burlington: Ashgate, 20IO, p. I23-137; Richard S. Grossman, Unsettled Account: the Evolution of Banking in the Industrialized World since I800, Princeton: Princeton University Press, 20I0, p. I62-167. 
permettent de comprendre la grande force d'inertie dont bénéficie le régime légal de régulation en place. Pour le dire autrement, il s'agit d'analyser la préférence inaltérable, ou presque, des banquiers et des superviseurs bancaires pour un statu quo réglementaire, c'est-à-dire leur volonté d'éviter toute révision parlementaire de la loi sur les banques de I934. Paradoxalement, l'examen des amendements à la législation bancaire qui sont finalement adoptés en 1971, par lequel nous conclurons notre étude du cas suisse, confirme cette tendance. Pour quelles raisons, malgré certaines lacunes, le cadre législatif de I934 reste-t-il si longtemps en vigueur et pourquoi la révision de I97I n'apporte-t-elle que des changements mineurs? Telle serait donc notre troisième question de recherche.

\section{APPORTS À L'HISTORIOGRAPHIE}

La problématique qui vient d'être esquissée s'inscrit au croisement entre plusieurs approches disciplinaires. Si les travaux d'historiens - et en particulier les études en histoire économique - forment l'essentiel des références sollicitées, le sujet traité est également abordé dans des publications d'économistes, de juristes ou encore de politologues. Il faut aussi distinguer au moins trois champs historiques auxquels ce travail peut contribuer. Tout d'abord, il s'insère évidemment dans l'élan de recherche consacré à l'histoire de la place bancaire suisse. Deuxièmement, cet ouvrage peut représenter un apport aux recherches qui s'intéressent au rôle de l'État fédéral et à ses interactions avec les agents économiques privés. Troisièmement, à l'échelle internationale, elle constitue une étude de cas sur un exemple particulier, la Suisse; pour les historiens qui cherchent à comprendre la grande diversité des configurations nationales de surveillance bancaire avant les efforts de standardisation menés par le Comité de Bâle dès la fin des années 1970, ce travail apporte sans doute un éclairage nouveau. Les lignes qui suivent visent donc à insérer et confronter notre travail, selon ces catégorisations, à la littérature existante.

Disons-le d'emblée, la présente étude, du point de vue thématique, se place principalement dans la continuité d'un ouvrage, qui a jusqu'ici constitué l'unique référence scientifique sur le sujet. Il s'agit de la thèse de doctorat de Hugo Bänziger, soutenue à l'Université de Berne en 1984 sous la direction de Walther Hofer et Paul Risch, et publiée sous deux formes différentes en 1985 et $1986^{14}$. Cette contribution retrace une histoire bien documentée de l'évolution du contrôle étatique sur les banques en Suisse, depuis les premières

14 Hugo Bänziger, "Vom Sparerschutz zum Gläubigerschutz - die Entstehung des Bankengesetzes im Jahre 1934", in Urs Zulauf (éd.), so ans de surveillance fédérale des banques, Zürich : Schulthess Polygraphischer Verlag, 1985, p. 3-8I ; Hugo Bänziger, Die Entwicklung der Bankenaufsicht in der Schweiz seit dem I9. Jahrhundert, Bern ; Stuttgart: P. Haupt, 1986. Dans ce travail, nous ferons référence à cette seconde version publiée chez l'éditeur Haupt dans la série Bankwirtschaftliche Forschungen. La version de 1986 est plus complète que le manuscrit de 1984 et l'extrait édité dans la publication jubilaire célébrant le $50^{\mathrm{e}}$ anniversaire de la Commission fédérale des banques. 
réglementations sur les caisses d'épargne au XIXe siècle jusqu'à l'adoption de la loi fédérale en 1934. Ce travail fournit une première mise en perspective du sujet et l'a défriché de manière synthétique. À plusieurs égards, la thèse de Bänziger a signalé des pistes de recherche qui seront développées dans ce travail. Une reprise de la thématique se justifie toutefois pour au moins trois raisons. D'une part, la présente étude apporte un éclairage nouveau sur le sujet en intégrant les renouvellements importants que l'histoire de la place financière suisse a connus pendant les trente ans qui nous séparent de la publication de Bänziger. Nous pensons par exemple aux travaux relevant de la "sociologie financière » menés à l'Université de Lausanne ${ }^{15}$, mais aussi aux avancées significatives réalisées par le volume de la Commission indépendante Suisse-Seconde Guerre mondiale portant sur le rôle des banques suisses ${ }^{16}$, ou encore à la thèse de Jan Baumann sur les crises bancaires des années $1930^{17}$. D'autre part, le cadre chronologique adopté dans ce travail, dont plus de la moitié des chapitres sont consacrés aux activités concrètes de la Commission fédérale des banques entre 1935 et I97I, insiste sur la mise en application de la surveillance; chez Bänziger, cet aspect et cette période ne sont traités que sommairement. Troisièmement, la présente étude privilégie une approche qui contraste avec celle de son prédécesseur. En insistant sur les acteurs en présence et en étant particulièrement attentif aux rapports de forces qui influencent les processus de décision, nous entendons dépoussiérer un récit historique par trop descriptif et désincarné chez Bänziger.

Au-delà de la contribution précitée, ce travail s'insère dans le courant historiographique des études sur la place financière suisse. La production historique dans le domaine bancaire a longtemps connu en Suisse de graves déficits ${ }^{18}$. Il faut attendre les années 1980 pour que des historiens, et non plus seulement des économistes, juristes ou banquiers, investissent ce champ de recherche. La "disette historiographique» qui caractérise la thématique des banques connait depuis une trentaine d'années une sorte de rémission ${ }^{19}$. Ces

15 Sébastien Guex, La politique monétaire et financière de la Confédération I900-1920, Lausanne: Payot, I993; Olivier Longchamp, La politique financière fédérale (1945-1958), Lausanne: Antipodes, 2014; Christophe Farquet, La défense du paradis fiscal suisse avant la Seconde Guerre mondiale: une histoire internationale, Neuchâtel : Alphil, 2016.

16 Marc Perrenoud, et al., La place financière et les banques suisses à l'époque du nationalsocialisme: les relations des grandes banques avec l'Allemagne (I93I-I946), Zurich: Chronos, vol. $13,2002$.

17 Jan Baumann, «Bundesinterventionen in der Bankenkrise 193I-1937. Eine vergleichende Studie am Beispiel der Schweizerischen Volksbank und der Schweizerischen Diskontbank ", Doktorarbeit, Philosophische Fakultät, Universität Zürich, 2007.

18 Deux articles proposent un survol de l'historiographie des banques en Suisse: Sébastien Guex, «The Historiography of Swiss Banks from 1970 to Date », in Olivier Feiertag, Ioanna Pepelasis Minoglou (éd.), European Banking Historiography: Past and Present, Athens : Alpha Bank Historical Archives, 2009, p. 2II-255; Sébastien Guex, Malik Mazbouri, "L'historiographie des banques et de la place financière suisse, XIX $-\mathrm{XX}^{\mathrm{e}}$ siècles ", in Sandra Bott, et al. (éd.), L'histoire économique en Suisse : une esquisse historiographique, Zurich : Chronos, 2010, p. 203-228.

19 Guex, Mazbouri, art. cit., in Bott, et al. (éd.), op. cit., 20Io, p. 203. 
progrès sont réalisés de manière inégale selon les questions et les périodes abordées. Du point de vue thématique, l'internationalisation de la place bancaire suisse et en particulier le rôle de plaque tournante des capitaux européens joué par les établissements helvétiques ont été mis à jour, de même que les liens entre défense des intérêts financiers et politique étrangère ${ }^{20}$. Du point de vue chronologique, c'est en particulier les périodes de l'entre-deux-guerres et de la Seconde Guerre mondiale qui sont désormais parmi les mieux connues de l'histoire des banques suisses ${ }^{21}$. Malgré de nombreuses divergences, ces travaux

20 Gérard Arlettaz, "Crise et déflation. Le primat des intérêts financiers en Suisse au début des années 1930 ", Relations Internationales, n 30, 1982, p. I59-175; Marc Perrenoud, "Banques et diplomatie suisses à la fin de la Deuxième Guerre mondiale: politique de neutralité et relations financières internationales ", Études et Sources. Revue des Archives Fédérales Suisses, $\mathrm{n}^{\circ}$ I3-I4, I988, p. 3-I24; Marc Perrenoud, "L'intervention de la Confédération dans les relations financières internationales de la Suisse (1936-1946)", in Paul Bairoch, Martin Körner (éd.), La Suisse dans l'économie mondiale ( $15^{e}-20^{e}$ s.), Zurich: Chronos, I990, p. 37I-389; Guex, op. cit., I993, p. 9-I2, I73-I78; Malik Mazbouri, «Place financière suisse et crédits aux belligérants durant la Première Guerre mondiale», in Sébastien Guex (éd.), La Suisse et les Grandes puissances I9I4-1945, Switzerland and the Great Powers 19I4-I945, Genève: Droz, 1999, p. 59-90; Michel Fior, Les banques suisses, le franc et l'Allemagne. Contribution à une histoire de la place financière suisse (I924-I945), Genève: Droz, 2002 ; Perrenoud, et al., op. cit., 2002 ; Marc Perrenoud, "Secret bancaire et politique étrangère de la Suisse (I932-I962)", Relations internationales, $\mathrm{n}^{\mathrm{O}} \mathrm{II} 3,2003$, p. 27-40; Malik Mazbouri, L'émergence de la place financière suisse (I890-I9I3). Itinéraire d'un grand banquier, Lausanne: Antipodes, 2005; Marc Perrenoud, "La place financière suisse en tant qu'instrument de la politique étrangère helvétique", Relations internationales, $\mathrm{n}^{\mathrm{o}} 2 \mathrm{I}, 2005$, p. 25-42; Jakob Tanner, «Der diskrete Charme der Gnomen : Entwicklungen und Perspektiven des Finanzplatzes Schweiz", in Christoph Maria Merki (éd.), Europas Finanzzentren. Geschichte und Bedeutung im 20. Jahrhundert, Frankfurt; New York: Campus Verlag, 2005, p. I27-I47; Tobias Straumann, "Der kleine Gigant: Der Aufstieg Zürichs zu einem internationalen Finanzplatz", in Europäische Finanzplätze im Wettbewerb: 27. Symposium des Instituts für bankhistorische Forschung e. V. am I6. Juni 2004 im Hause der Deutschen Bundesbank, Hauptverwaltung Frankfurt am Main, Stuttgart: Franz Steiner Verlag, 2006, p. 139-169; Malik Mazbouri, Marc Perrenoud, "Banques suisses et guerres mondiales ", in Valentin Groebner, Sébastien Guex, Jakob Tanner (éd.), Kriegswirtschaft und Wirtschaftskriege, Zürich : Chronos, 2008, p. 233-253; Marc Perrenoud, Banquiers et diplomates suisses (I938-1946), Lausanne: Antipodes, 20II ; Mazbouri, Guex, Lopez, art. cit., in Halbeisen, Müller, Veyrassat (éd.), op. cit., $2 \mathrm{OI} 2$; Malik Mazbouri, "La Première Guerre mondiale et l'essor de la place bancaire helvétique. L'exemple de la Société de Banque Suisse", Histoire, économie \& société, vol. 32, $\mathrm{n}^{\circ}$ I, 20I3, p. 73-94; Alain Laurent, Guillaume Vallet, "La construction progressive de l'avantage compétitif financier suisse (I914-1936) ", Revue d'économie financière, vol. II3, $\mathrm{n}^{\circ} \mathrm{I}$, 2014, p. 259-274; Yves Sancey, Quand les banquiers font la loi: aux sources de l'autorégulation bancaire en Suisse et en Angleterre, de I9I4 aux années I950, Lausanne: Antipodes, 20I5; Farquet, op. cit., 2016.

21 En plus des titres cités dans la note précédente: Willi Loepfe, Geschäfte in spannungsgeladener Zeit. Finanz- und Handelsbeziehungen zwischen der Schweiz und Deutschland. I923 bis I946, Weinfelden : Wolfau-Druck, 2006. L'historien officiel du Crédit Suisse a également produit ou dirigé quelques publications sur la période : Joseph Jung (éd.), Zwischen Bundeshaus und Paradeplatz. Die Banken der Credit Suisse Group im Zweiten Weltkrieg: Studien und Materialien, Zürich: Neue Zürcher Zeitung, 20oI; Joseph Jung, "Swiss Banking in World War II", in Robert U. Vogler, et al. (éd.), Financial Markets of Neutral Countries in World War II, Zurich : Neue Zürcher Zeitung Publishing, 20I2, p. 207-243. 
s'accordent pour considérer l'entre-deux-guerres comme la phase au cours de laquelle les banques suisses préparent structurellement leur croissance phénoménale des Trente Glorieuses. À cet égard, les travaux publiés en 2002 dans le cadre de la Commission Indépendante d'Experts Suisse - Seconde Guerre mondiale marquent un tournant. L'ouverture exceptionnelle des archives des entreprises privées a permis de mettre en lumière un matériel documentaire inédit, qui souligne notamment le poids international pris par les établissements suisses et l'importance du marché de la gestion de fortune ${ }^{22}$.

La thématique plus précise des rapports entre la finance suisse et les autorités publiques, qui est au cœur de cet ouvrage, connait un développement historiographique analogue à celui de l'histoire bancaire en général.

Dans un premier temps, jusque dans les années 1980, le terrain est uniquement occupé par des études de juristes et, plus rarement, d'économistes. Aux premières réflexions sur les faillites bancaires initiées par la crise des années I9IO-I9I4 succèdent, à la suite de l'adoption de la loi sur les banques en I934, de nombreux commentaires juridiques ${ }^{23}$. Ces ouvrages, qui s'adressent souvent à

22 En plus du volume i3 déjà cité à la note 16 , relevons encore Hanspeter Lussy, Barbara Bonhage, Christian Horn, Schweizerische Wertpapiergeschäfte mit dem "Dritten Reich": Handel, Raub und Restitution, Zürich: Chronos, vol. I4, 200I ; Hanspeter Lussy, Barbara Bonhage, Marc Perrenoud, Nachrichtenlose Vermögen bei Schweizer Banken: Depots, Konten und Safes bei Opfern des nationalsozialistischen Regimes und Restitutionsprobleme in der Nachkriegszeit, ibid., vol. I5, 200I ; Stefan Karlen, et al., Schweizerische Versicherungsgesellschaften im Machtbereich des "Dritten Reichs", Zürich: Chronos, vol. I2, 2002; Marc Perrenoud, Rodrigo López, Aspects des relations financières franco-suisses (1936-1946), Zurich : Chronos, vol. 25, 2002.

23 Sur les crises bancaires du début du siècle: Albert Meyer, Zur Frage eines eidgenössischen Bankgesetzes, Zürich : Orell Füssli 19ı4; Ernst Wetter, Bankkrisen und Bankkatastrophen der letzten Jahre in der Schweiz, Zürich : Orell Füssli, I9I8. Parmi les nombreux commentaires juridiques produits dans la foulée de l'adoption de la loi de 1934, mentionnons: Walther Brühlmann, Kommentar zum Bundesgesetz über die Banken und Sparkassen vom 8. November 1934, Weinfelden: A.-G. Neuenschwander'sche Buchdruckerei und Verlagsbuchhandlung, I935; Paul Rossy, Robert Reimann, Commentaire de la loi fédérale du 8 novembre 1934 sur les banques et les caisses d'épargne et du règlement d'exécution du Conseil fédéral du 26 février 1935 , Zurich : Ed. Polygraphiques, 1935; Paul Graner, Revidiertes Obligationenrecht und Bankengesetz, Zürich : Polygraphischer Verlag, 1937; Paul Graner, Der Geltungsbereich des Bankengesetzes, Zürich : Polygraphischer Verlag, I937; Pierre Uldry, "Le concordat des instituts bancaires d'après la nouvelle législation fédérale ", Thèse de doctorat, Faculté de droit, Université de Fribourg, I937; Franz Hartmann, «Der strafrechtliche Schutz des Bankkredites nach dem Bundesgestz über die Banken und Sparkassen vom 8. November 1934", Doktorarbeit, Juristischen Fakultät, Universität Bern, 1938 ; Adolf Jann, «Der Umfang und die Grenzen des Bankgeheimnisses nach schweizerischem Recht ", Doktor beider Rechte, Jurisitischen Fakultät, Universität Bern, I938 ; François Delachaux, «Le secret professionnel du banquier en droit suisse ", Thèse de doctorat, Faculté de Droit, Université de Neuchâtel, 1939; Hans Bachmann, "Fälligkeitsaufschub und Stundung im schweizerischen Bankrecht ", Doktor beider Rechte, Rechts- und staatswissenschaftliche Fakultät, Universität Zürich, I94I ; Louis Dollfus, « Probleme der Bankenaufsicht und -kontrolle und ihre Lösung im schweizerischen und italienischen Bankenrecht unter spezieller Berücksichtigung der historischen Entwicklung", Doktorarbeit, Juristischen Fakultät, Universität Basel, I94I; Otto Burki, Pflichtprüfung und Verantwortlichkeit der Pflichtprüfer nach schweizerischem 
un public d'intéressés, n'obéissent pas à des questionnements d'ordre historique, mais se contentent de gloser les textes légaux et de paraphraser la jurisprudence. Ils conservent néanmoins une valeur documentaire et une vocation informative très précieuse pour saisir les préoccupations des contemporains et mieux interpréter un jargon juridique et économique souvent obscur pour un profane du XXI ${ }^{\mathrm{e}}$ siècle. Il faut distinguer dans ce vaste corpus l'étude de Daniel Bodmer publiée en $1948^{24}$. Celui qui deviendra chef du secrétariat de la Commission fédérale des banques pendant une vingtaine d'années (1955-1976) après avoir collaboré au secrétariat central de l'Association suisse des banquiers (1945-1954) soutient une thèse de doctorat en sciences commerciales fort bien documentée. Au terme d'un exposé rétrospectif agrémenté de quelques données chiffrées, l'auteur salue "l'ingérence modérée» de l'intervention de la Confédération en matière bancaire. Il fournit également la première analyse rétrospective du déroulement de la crise bancaire des années I930.

Entre les années 1950 et les années 1980, le sujet de la régulation financière perd de son actualité. Quelques thèses juridiques - parfois dans une perspective qui est celle du droit comparé - et des rééditions de commentaires viennent cependant mettre à jour la jurisprudence, au fil des rares réformes réglementaires ${ }^{25}$. À partir des années 1970, les économistes prennent le pas sur les

Bankengesetz und revidiertem Obligationenrecht, Aarau : Sauerländer, 1942 ; Willy Urech, Die staatliche Beaufsichtigung der Banken in der Schweiz: nach dem Bundesgesetz über die Banken und Sparkassen vom 8. Nov. 1934, Aarau: Keller, 1944. Dans une perspective d'économie politique, voir: Alfred Böckli, Bemerkungen zum Entwurf für ein schweizerisches Bankengesetz, 1934; Horace Mende, Unterlagen und Vorarbeiten für eine schweizerische Bankenkontrolle, Bern: P. Haupt, I935; Max Cluseau, La règlementation des banques. Économie libérale ou économie dirigée? Étude critique de quelques expériences étrangères récentes, Paris: Librairie du Recueil Sirey, 1938 ; Erwin Schubert, «Zur Frage der Bankenkontrolle», Doktorarbeit, Philosophisch-Historische Fakultät, Universität Basel, I939; Willi Schwander, Das schweizerische Bankengesetz unter spezieller Berücksichtigung seiner wirtschaftlich wichtigen Bestimmungen, Zürich : E. Lang, 1943.

24 Daniel Bodmer, L'intervention de la Confédération dans l'économie bancaire suisse, Bâle: National-Zeitung, 1948.

25 Walter Peter, "Kapitalherabsetzung nach Bankenrecht», Rechts- und staatswissenschaftliche Fakultät, Universität Zürich, 195I; Denis Piguet, La banque dans le cadre de la réglementation bancaire suisse, Yverdon: Imprimerie des Remparts, 1953; Götz-Dieter Schober, "Vergleichende Betrachtung des deutschen und schweizerischen Bankenaufsichtsgesetzes ", Doktorarbeit, Ludwig-Maximilians-Universität, 1957; Martin Peltzer, "Organisation, Aufgaben und Probleme der allgemeinen Bankaufsicht in der Bundesrepublik Deutschland und in der Schweiz unter besonderer Berücksichtigung der Verhältnisee nach dem Zweiten Weltkrieg", Doktorarbeit, Hohe rechtswissenschaftliche Fakultät, Universität Basel, 1958; Robert Reimann, Kommentar zum Bundesgesetz über die Banken und Sparkassen vom 8. November 1934 und zur Vollziehungsverordnung vom 30. August I96I, Zürich: Polygraphischer Verlag, I963; Hans-Dietrich Winkhaus, "Die Rechnungslegungspflicht der deutschen und schweizerischen Aktienbanken - Vergleichende Analyse und Möglichkeiten zur Verbesserung -», Doktorarbeit, Hohen Staatswirtschaftlichen Fakultat, Ludwig-Maximilians-Universität, 1966; Remo Cottini, Die Bankrevision in der Schweiz unter besonderer Berücksichtigung ihrer Bedeutung für die Bankleitung, Aarau : Buchdruckerei Keller, 1970; Peter Riniker, "Die Bankenaufsicht», Doctor iuris, Recht- und 
juristes, notamment par l'intermédiaire de la série Bankwirtschaftliche Forschungen dirigée par des professeurs de l'Institut für Bankwirtschaft de la Haute école d'économie de Saint-Gall et de l'Institut für schweizerisches Bankwesen de l'Université de Zurich ${ }^{26}$. Ces ouvrages collectifs réunissent des textes de praticiens et d'académiciens - la frontière étant souvent floue - abordant la problématique du contrôle bancaire dans une perspective peu historique.

À partir des années 1980, les recherches sur la surveillance bancaire entrent dans un nouvel âge. Ce tournant s'opère sous le double effet des anniversaires commémorant les cinquantièmes anniversaires des législations et des institutions héritées de la crise économique des années 1930 et, d'autre part, de la remise en question de ces mêmes régimes de régulation dans la mouvance de la libéralisation financière. Les législations bancaires et, plus rarement, leur mise en application intéressent alors pour la première fois les historiens. Il s'agit là d'une tendance historiographique plus générale, valable pour les études historiques internationales sur la régulation bancaire ${ }^{27}$. En Suisse, l'étude de Bänziger, décrite plus haut, marque cette évolution et constitue un saut qualitatif dans la connaissance du rôle de l'État fédéral dans le contrôle des banques. En plus de cette contribution, un article de Paul Ehrsam paru dans l'ouvrage célébrant le cinquantième anniversaire de la Commission fédérale des banques balise le déroulement de la crise bancaire en Suisse de manière précise ${ }^{28}$. Dans

Wirtschaftswissenschaftliche Fakultät, Universität Bern, 1974; Herbert Schönle, Jürgen Dohm, Die Unabhängigkeit der Revisionsstellen von Banken und Anlagefondsleitungen. Untersuchung nach schweizerischem Recht mit rechtsvergleichenden Hinweisen, Zürich : Schulthess Polygraphischer Verlag, 1974; Heinz Schütz, «Die Revision der Schweizerischen Bankengesetzgebung in den Jahren 1971 und 1972", Doctor rerum politicarum, Rechts- und wirtschaftswissentschaftliche Fakultät, Universität Bern, 1974.

26 Voir notamment: Leo Schuster (éd.), Schweizer Banken in der Welt von morgen, Bankwirtschaflitche Forschungen, Bern ; Stuttgart : Paul Haupt, 1975; Theo Keller (éd.), Revision und Sicherheit im Bankbetrieb, Bankwirtschaftliche Forschungen, Bern; Stuttgart: Paul Haupt, 1976; Theo Keller, Die Bankrevision in der Schweiz, Bern ; Stuttgart: Paul Haupt, 1978 ; Leo Schuster (éd.), Schweizer Banken im Spiegel von Wirtschaft und Politik, Zürich : Orell Füssli, 1978 .

27 Sur la Belgique: Guy Vanthemsche, «L'élaboration de l'arrêté royal sur le contrôle bancaire (1935) ", Revue belge d'histoire contemporaine, vol. II, 1980, p. 389-437; pour une comparaison internationale : Sergio Ortino, «La legislazione bancaria degli anni Trenta negli Stati Uniti e in Svizzera, Germania e Belgio ", in Banca e industria fra le due guerre. Le riforme istituzionali e il pensiero giuridico, Bologna : Il Mulino, vol. 2, 198I, p. 349-400; Sabino Cassese, «The Long Life of the Financial Institutions Set up in the Thirties ", Journal of European Economic History, vol. 13, $\mathrm{n}^{\circ}$ 2, 1984, p. 273-294; sur les États-Unis : Eugene N. White, The Regulation and Reform of the American Banking System, 1900-1929, Princeton: Princeton University Press, 1983.

Paul Ehrsam, «Die Bankenkrise der 3 oer Jahre in der Schweiz », in Urs Zulauf (éd.), 50 ans de surveillance fédérale des banques, Zürich: Schulthess Polygraphischer Verlag, 1985, p. 83-II8. Paul Ehrsam (1917-2008), juriste de formation, est un spécialiste bien informé des problématiques de surveillance bancaire: il a collaboré successivement avec les trois instances centrales de la régulation bancaire en Suisse. Consultant du service juridique du Département fédéral des finances et des douanes dès les années 1960, il rejoint la Banque nationale suisse en 1967, avant d'être nommé membre de la Commission fédérale des banques en 1976. 
les années 1990 et 2000, une poignée de publications reprennent la question de la régulation bancaire d'un point de vue historique. Il y a tout d'abord l'article de Patrick Halbeisen, qui postule que la lutte contre la crise bancaire, couronnée de succès, conforte les dirigeants de la Confédération, de la Banque nationale et des banques dans le rejet d'une solution législative rigide; ce credo n'est pas remis en question, mais confirmé par la loi sur les banques de 1934, très libérale dans sa conception ${ }^{29}$. L'historien et politologue Yves Sancey poursuit cette piste de recherche, et l'élargit aux relations entre la Banque nationale et les banques autour du problème de l'exportation de capitaux ${ }^{30}$. En concentrant son attention sur le développement d'accords non contraignants au cours de l'entre-deux-guerres, Sancey déploie la notion de capitalisme de gentlemen pour caractériser la forte préférence à l'autorégulation qui s'impose alors. La promulgation de la législation bancaire de 1934 s'intègre pleinement, malgré un paradoxe apparent, dans le mécanisme d'autodiscipline à l'œuvre dans le domaine de l'exportation de capitaux. Une autre thèse de doctorat, soutenue en 2007, apporte un éclairage nouveau sur les liens de causalité entre le phénomène de crise bancaire, les réponses politiques qui y sont apportées et pour finir la réussite ou l'insuccès d'un sauvetage bancaire ${ }^{31}$. L'historien Jan Baumann, dans une étude de cas sur deux exemples contradictoires, y démontre la relation étroite entre le déroulement conjoncturel des crises financières et, entre autres, le processus de légifération; pour Baumann, les facteurs politiques priment pour expliquer le succès du sauvetage de la Banque Populaire Suisse et l'échec de celui de la Banque d'Escompte Suisse. Enfin, la contribution récemment publiée de Malik Mazbouri et Janick Marina Schaufelbuehl témoigne du regain d'intérêt de cette problématique, en Suisse également, après la crise de $2008^{32}$. Les auteurs y analysent deux projets successifs de législation bancaire - celui de 1916, qui n'aboutit pas, et celui

29 Patrick Halbeisen, «Bankenkrise und Bankengesetzgebung in den zoer Jahren », in Sébastien Guex, et al. (éd.), Krisen und Stabilisierung. Die Schweiz in der Zwischenkriegszeit, Zürich: Chronos, 1998, p. 6I-77. Pour une version en anglais de cet article: Patrick Halbeisen, "The Banking Crisis and its Implications for Swiss Banking Legislation in the I930s ", in Manfred Pohl, Teresa Tortella, Hermann van der Wee (éd.), A Century of Banking Consolidation in Europe, Aldershot, etc. : Ashgate, 200I, p. IO2-I2O.

30 Yves Sancey, Le gentlemen's agreement de 1927: lutte autour de la (non)-politisation de l'exportation du capital, Lausanne: Lausanne: Université de Lausanne Institut de science politique, 1995; Yves Sancey, «Les banques et l'État en Suisse. Éléments pour une genèse de la politique bancaire de la Confédération (1914-1927)", Revue suisse d'histoire, vol. 46, $\mathrm{n}^{\mathrm{O}} \mathrm{I}$, I996, p. 8I-I04; Yves Sancey, "Place financière suisse et émergence d'une régulation paraétatique durant l'Entre-deux-guerres", in Sébastien Guex (éd.), Krisen und Stabilisierung. Die Schweiz in der Zwischenkriegszeit, Zürich: Chronos, 1998, p. 8I-93. Ce mémoire de licence et ces articles trouvent leur aboutissement dans une thèse de doctorat soutenue en 2004 et publiée récemment: Sancey, op. cit., 20I5.

32 Malik Mazbouri, Janick Marina Schaufelbuehl, «A Legislator under Surveillance: The Creation and Implementation of Swiss Banking Legislation 1910-1934", European History Quarterly, vol. 45, $\mathrm{n}^{\circ} 4$, 2015, p. 662-688. 
des années 1930, finalement adopté - dans une perspective comparative. En mettant l'accent sur les rapports de force manifestés pendant les processus de décision plutôt que sur la qualité intrinsèque des réponses législatives aux crises, ils adoptent une perspective de recherche qui sera développée dans le présent livre.

Malgré ce bilan historiographique encourageant, par rapport à l'état général des connaissances historiques sur les établissements financiers en Suisse, et en dépit des avancées récentes, notre travail entend contribuer à ce champ de recherche de diverses manières. En étendant le cadre chronologique d'analyse des premiers projets de législations en I9I4 à la première révision législative de la loi bancaire au début des années I970, il est possible d'envisager une remarquable continuité dans les rapports de force et la dynamique des relations entre banques et pouvoirs publics. Cette perspective de long terme ouvre également notre sujet à la période des années I950 et I960, qui est à ce jour encore très peu étudiée par les historiens de l'économie suisse ${ }^{33}$. De plus, ce travail renouvelle ce champ de recherche du point de vue méthodologique : non seulement par la prise en considération attentive des intérêts défendus par les acteurs impliqués, mais aussi par la consultation et le croisement de fonds d'archives provenant à la fois des autorités publiques et de l'association faitière des banques. Il se situe enfin dans le prolongement de plusieurs articles écrits au cours de son élaboration ${ }^{34}$.

En plus des études mentionnées ci-dessus, la loi sur les banques de 1934 a également suscité l'attention des historiens travaillant sur la naissance et la consolidation du secret bancaire en Suisse. Au tournant du XXI siècle, les contributions de Sébastien Guex, et dans un deuxième temps de Peter Hug, ont déconstruit les mythes qui entouraient l'origine du secret bancaire helvétique $^{35}$. Celui-ci n’a pas été introduit dans la réglementation des années 1930

33 Dans le domaine de l'histoire des banques, l'ouvrage de Willi Loepfe, ancien collaborateur de l'UBS, sur la place financière suisse durant les Trente Glorieuses fait partie des rares exceptions. Willi Loepfe, Der Aufstieg des schweizerischen Finanzplatzes in der Nachkriegszeit. 1945 bis 1975, Weinfelden : Wolfau-Druck, 2011.

34 Thibaud Giddey, "Gendarme ou médecin des banques? Les premières années d'activité de la Commission fédérale des banques (1935-1943)", Traverse. Revue suisse d'histoire, $\mathrm{n}^{\circ}$ 3, 20I2, p. I45-I63; Thibaud Giddey, "The Regulation of Foreign Banks in Switzerland (19561972)", in Melanie Aspey, et al. (éd.), Foreign Financial Institutions \& National Financial Systems, Frankfurt a.M.: The European Association for Banking and Financial History, 2013, p. 449-485; Thibaud Giddey, «La surveillance bancaire belge de 1935 façonnée sur le modèle suisse: un discret transfert de politique publique? ", Revue Belge de Philologie et d'Histoire, vol. 92, $\mathrm{n}^{\mathrm{o}}$ 4, 20I4, p. I2II-I243. Mon mémoire de maittrise portait déjà sur la question : Thibaud Giddey, «La genèse et les premières années d'activités de la Commission fédérale des banques (193I-I943)", Mémoire de maitrise, Faculté des lettres, Université de Lausanne, 2010.

35 Sébastien Guex, «Les origines du secret bancaire suisse et son rôle dans la politique de la Confédération au sortir de la deuxième guerre mondiale ", Genèses, vol. 34, nº I, I999, p. I-27; Sébastien Guex, «The Origins of the Swiss Banking Secrecy Law and Its Repercussions for Swiss Federal Policy", Harvard Business History Review, vol. 74, n 2, 2000, p. 237-266; Peter Hug, «Steuerflucht und die Legende vom antinazistischen Ursprung des 
pour protéger les clients juifs des banques suisses contre les confiscations décidées par les autorités nazies, comme le laissait croire un récit - dénué de tout fondement par des documents d'archives - produit par les milieux bancaires dans les années 1960. Le respect du secret professionnel relève davantage d'une pratique bien ancrée dans les opérations bancaires depuis la fin du $\mathrm{XIX}^{\mathrm{e}}$ siècle, un usage qui est juridiquement renforcé - puisque sa violation tombe désormais sous le droit pénal - dans l'article 47 de la loi bancaire de 1934. D'autres chercheurs, tout en acceptant le rejet de l'ancienne version de l'origine du secret bancaire comme geste philanthropique, contestent en revanche l'idée selon laquelle sa codification en 1934 serait le résultat d'un marchandage politique et minimise son impact sur l'attractivité de la place financière suisse ${ }^{36}$. Enfin, dans une récente thèse de doctorat, l'historien Christophe Farquet nourrit ce débat historiographique, en replaçant le renforcement du secret bancaire par le fameux article 47 dans le contexte juridique national et international de la délimitation de la confidentialité des banques, notamment à l'égard du fisc ${ }^{37}$. Selon son interprétation, la formalisation légale de 1934 ne constitue qu'une étape dans la consolidation juridique du secret bancaire, qui s'effectue progressivement dans la jurisprudence ultérieure. Même si la facette «secret bancaire» de la loi de 1934 est sans doute la mieux connue et la plus discutée par l'historiographie, ce travail cherche à compléter ces axes de recherches de deux façons: d'une part en analysant avec précision le processus d'insertion des dispositions relatives au secret bancaire dans les différentes versions de projet de loi, d'autre part, en fournissant quelques exemples de l'instrumentalisation de cette question par les dirigeants et les surveillants bancaires au cours de l'après-guerre.

Au-delà de l'historiographie sur la place bancaire suisse et ses relations avec l'État, cette recherche s'appuie sur la littérature internationale sur le phénomène de la régulation, et plus précisément encore sur celui de la surveillance des banques. Ce vaste corpus d'études qui conceptualisent le phénomène de

Bankgeheimnisses. Funktion und Risiko der moralischen Überhöhung des Finanzplatzes Schweiz ", in Jakob Tanner, Sigrid Weigel (éd.), Gedächtnis, Geld und Gesetz. Vom Umgang mit der Vergangenheit des zweiten Weltkrieges, Zürich: vdf Hochschulverlag, 2002, p. 26932I. Voir aussi : Sébastien Guex, "Le secret bancaire: une perspective historique», Revue économique et sociale: bulletin de la Société d'Études Économiques et Sociales, vol. 6o, no $\mathrm{I}$, 2002, p. 9-19; Sébastien Guex, "1932: l'affaire des fraudes fiscales et le gouvernement Herriot I ", L'Économie politique, vol. 33, n' I, 2007, p. 89-104.

36 Robert Urs Vogler, "The genesis of Swiss banking secrecy: political and economic environment ", Financial History Review, vol. 8, no I, 200I, p. 73-84; Robert Urs Vogler, Swiss Banking Secrecy: Origins, Significance, Myth, Zurich: Association for Financial History, 2006.

37 Farquet, op. cit., 2016, p. 353-363, 492-495. 
régulation bancaire peut être schématiquement divisé en deux catégories: d'une part les contributions d'économistes et d'historiens de l'économie, d'autre part les recherches de politologues ${ }^{38}$.

Chez les économistes, les débats autour de la régulation bancaire se sont longtemps cristallisés autour de deux conceptualisations dominantes qui se sont succédé39. Dans un premier temps, le phénomène de régulation est essentiellement compris selon le point de vue de l'intérêt public (public interest $v i e w)^{40}$. Cette approche postule qu'une réglementation économique est mise en place pour répondre et corriger des défaillances du marché, avec pour but essentiel de défendre l'intérêt général et d'améliorer le bien-être social. Les insuffisances, dans le cas des banques, peuvent être dues à l'asymétrie d'information entre un emprunteur et un prêteur sur la qualité d'un investissement, ou encore entre un déposant privé et un banquier effectuant un placement. Les régulateurs étatiques, qui selon les tenants de cette approche sont bien informés, agissent rationnellement et en fonction de l'intérêt commun, viseraient à corriger ces défaillances de marché pour rétablir un système plus efficace et plus solide.

À partir des années 1970, cette conception est remise en question par les partisans de la private interest theory ${ }^{41}$. Ceux-ci affirment que l'intervention réglementaire n'améliore pas l'efficacité des marchés, mais conduit plutôt à des distorsions. Les régulateurs et décideurs politiques chercheraient en fait à favoriser certains intérêts privés, et imposeraient des coûts qui dépassent les

38 Pour éviter toute confusion, précisons ici que nous faisons référence au terme de régulation dans son acception dérivée de l'anglais regulation. Nous ne pensons pas à l'école française de la régulation, développée dans les années 1970 par Michel Aglietta et Robert Boyer, qui propose une définition plus large du terme. La régulation y devient «l'étude de la transformation des rapports sociaux créant de nouvelles formes à la fois économiques et non économiques, formes organisées en structures, et reproduisant une structure déterminante ". Cf. Robert Boyer, Yves Saillard (éd.), Théorie de la régulation, l'état des savoirs, Paris: La Découverte, 2002.

39 Pour une mise en perspective récente, voir par exemple: Sophie Harnay, Laurence Scialom, "The influence of the economic approaches to regulation on banking regulations: a short history of banking regulations ", Cambridge Journal of Economics, vol. 40, n⿳2 2, 20I6, p. 40I426.

40 Pour une synthèse critique sur cette approche: Michael Hantke-Domas, "The Public Interest Theory of Regulation: Non-Existence or Misinterpretation?», European Journal of Law and Economics, vol. I5, no 2, 2003, p. 165-194.

41 L'article de 1971 de George Stigler, précisé en 1976 par Sam Peltzman, est généralement considéré comme le texte fondateur de cette théorie. George J. Stigler, "The Theory of Economic Regulation ", The Bell Journal of Economics and Management Science, vol. 2, $\mathrm{n}^{\circ} \mathrm{I}$, I97I, p. 3-2I ; Sam Peltzman, "Toward a More General Theory of Regulation », The Journal of Law and Economics, vol. 19, n ${ }^{\circ}$ 2, 1976, p. 2II-240. Dans le domaine de la régulation bancaire et financière, voir aussi : Friedrich Heinemann, Martin Schüler, «A Stiglerian view on banking supervision ", Public Choice, vol. I2I, 2004, p. 99-130. Pour une critique de la théorie du public choice, dont dérive la private interest view, voir: Jessica Leight, «Public Choice : A Critical Reassessment ", in Edward J. Balleisen, David A. Moss (éd.), Government and Markets. Toward a New Theory of Regulation, Cambridge; New York: Cambridge University Press, 20I0, p. 213-255. 
bénéfices. La régulation étatique empêcherait une saine concurrence et assurerait une profitabilité artificielle pour certains acteurs en place. La notion de capture régulatoire, qui postule que les agences censées défendre le bien commun sont en fait corrompues par des groupes particuliers qui parviennent à y imposer leurs intérêts privés, dérive également de cette remise en question de la réglementation. Implicitement ou explicitement, les théoriciens de la private interest view proposent la dérégulation des marchés financiers comme solution aux distorsions provoquées par la réglementation. Entre le milieu des années I970 et la fin des années I980, on assiste donc, notamment sous le double effet de la promotion d'une conceptualisation pessimiste de la régulation et du développement de la théorie de l'efficience des marchés, au démantèlement des réglementations et contrôles mis en place dans les années 1930. Parallèlement, un mouvement vers une approche davantage orientée vers les mesures micro-prudentielles (niveau de fonds propres) et au détriment des dispositions macro-prudentielles (réformes structurelles, prise en compte des risques systémiques) se fait jour ${ }^{42}$.

Chez les historiens de l'économie - ou économistes historiens -, ces débats théoriques sont repris pour comprendre la grande variété de formes que prend la régulation au gré des époques et selon les cas nationaux étudiés ${ }^{43}$. Il se dégage un consensus pour considérer que la surveillance bancaire est un phénomène essentiellement réactif, c'est-à-dire étroitement lié à l'émergence de crises, et dont la configuration institutionnelle est guidée par une perspective nationale. Relevons au passage que parmi la production scientifique à dimension historique sur la régulation bancaire, les études qui ont recours à des documents d'archives sur le travail concret effectué par les surveillants bancaires, pour en proposer une lecture qualitative, ne sont pas légion. Trop souvent, le phénomène n'est appréhendé qu'à partir des grands changements de l'environnement réglementaire ou comme épiphénomène des grandes évolutions générales qui caractérisent la vie économique des banques. Notre travail contribue donc indirectement à ce champ de recherche, en proposant une analyse du développement d'un cas spécifiques : celui de la Commission fédérale des banques en Suisse. Il permet de passer les théories globales sur la régulation bancaire à l'épreuve des études de cas particulières.

Harnay, Scialom, art. cit., 2016.

Cf. Alfredo Gigliobianco, Gianni Toniolo (éd.), Financial Market Regulation in the Wake of Financial Crises: The Historical Experience, Roma: Banca d'Italia Eurosistema, 2009; Battilossi, Reis (éd.), op. cit., 2010 ; Grossman, op. cit., 20IO, p. I28-168; Eugene N. White, «"To Establish a More Effective Supervision of Banking" : How the Birth of the Fed altered Bank Supervision ", in Michael D. Bordo, William Roberds (éd.), The Origins, History, and Future of the Federal Reserve: A Return to Jekyll Island, Cambridge: Cambridge University Press, 2013, p. 7-54; Catherine R. Schenk, «Summer in the City: Banking Failures of 1974 and the Development of International Banking Supervision", The English Historical Review, vol. I29, $\mathrm{n}^{\circ}$ 540, 20I4, p. II29-II56; Schenk, Mourlon-Druol, art. cit., in Cassis, Grossman, Schenk (éd.), op. cit., 20I6; Hubert Bonin, Jean-Marc Figuet (éd.), op. cit., 2016. 
Les chercheurs en sciences politiques ont également investi le terrain de la régulation et apporté un certain renouvellement dans la compréhension du phénomène. L'accent est alors mis non pas sur l'impact économique d'une réglementation et ses interactions avec le marché, mais plutôt sur la régulation comme mode de gouvernance. Le développement de l'État régulateur (regulatory state) devient tout d'abord l'objet au cour des études ${ }^{44}$. Cette forme de gouvernance, qui aurait succédé durant le dernier tiers du XXe siècle à l'Étatprovidence, serait caractérisée par une politique publique plus modeste, qui délègue davantage de services au secteur privé, se contentant d'assurer les grands équilibres économiques et sociaux. Les réflexions plus précises menées dans ce domaine nourrissent notre questionnement. Il s'agit par exemple de comprendre pourquoi l'État choisit de déléguer des compétences à des agences indépendantes, qu'il ne contrôle plus que partiellement ${ }^{45}$. Le cas de la Commission fédérale des banques, s'il déborde clairement du cadre chronologique fixé par les politologues de l'État régulateur, gagne à être étudié à la lumière de cette littérature.

Dans le domaine plus précis de la régulation des services financiers, les politistes ont également identifié plusieurs tendances fortes. William Coleman observe par exemple la grande résistance des arrangements institutionnels nationaux de régulation financière à l'ère de la mondialisation et de la convergence qui marque la fin du XX ${ }^{e}$ siècle ${ }^{46}$. Il met aussi en avant le renforcement de la tendance à confier la politique à l'égard des banques à des cercles d'experts et de praticiens, censés être les seuls à même de maitriser la complexité des activités concernées. Cette évolution se fait au détriment du pouvoir décisionnel des représentants politiques démocratiquement élus. On retrouve ici une forme précoce du cadre d'analyse établi plus récemment par Pepper Culpepper, selon lequel le degré de pertinence politique (political salience) d'une thématique détermine la capacité d'une industrie régulée à imposer ses préférences: moins un objet attire l'attention médiatique et celle du grand public, plus il sera traité dans des cercles restreints, et plus les milieux concernés seront capables d'influencer le processus de décision ${ }^{47}$. Cette conclusion, avancée sur la base d'une étude du contrôle des entreprises au tournant du XXI ${ }^{\mathrm{e}}$ siècle dans quatre pays, se révèle aussi opératoire dans le cas de la surveillance bancaire suisse au cours du XXe siècle. Les groupes d'intérêts bancaires adoptent régulièrement des stratégies consistant à éviter un traitement de la réglementation qui les

44 Pour une introduction, cf. par exemple Jacint Jordana, David Levi-Faur (éd.), The Politics of Regulation. Institutions and Regulatory Reforms for the Age of Governance, Cheltenham; Northampton: Edward Elgar, 2004.

45 Voir à ce sujet: Fabrizio Gilardi, Delegation in the Regulatory State. Independent Regulatory Agencies in Western Europe, Cheltenham: Edward Elgar, 2008.

46 William D. Coleman, Financial Services, Globalization and Domestic Policy Change, Basingstoke; New York: Macmillan Press; St. Martin's Press, 1996.

47 Pepper D. Culpepper, Quiet Politics and Business Power: Corporate Control in Europe and Japan, Cambridge: Cambridge University Press, 2011. 
concerne dans des cercles de décision soumis aux aléas des élections démocratiques, et privilégient l'espace confiné des négociations entre quelques acteurs spécialisés.

Également construites essentiellement à partir de l'étude d'une période plus récente, à savoir les années 1970 et I980, les recherches du politologue Michael Moran insistent sur le tournant, durant ces années, vers une dérégulation progressive du secteur financier (concurrence intensifiée, intégration globale accrue axée autour de multinationales basées dans un nombre limité de places financières) ${ }^{48}$. Or, paradoxalement, pour Moran, cette dérégulation est menée sous l'impulsion d'agences gouvernementales, qui préconisent une uniformisation et une formalisation selon des standards internationaux. Si le cas suisse ne semble pas confirmer ces conclusions, puisque l'organisation informelle et néocorporatiste de la surveillance bancaire - définie dans une perspective essentiellement nationale - semble perdurer au-delà des années I990, le cadre d'analyse fourni par Moran alimente nos réflexions. Il confirme l'idée qu'il est pertinent de traiter des phénomènes financiers en dehors d'une analyse purement économique, et que le regard historique sur les institutions et les acteurs qui forgent la régulation est indispensable pour comprendre les enjeux politiques de la régulation bancaire.

Au-delà de la croissance de l'État régulateur en général et des analyses relatives à la mondialisation de la finance au cours des trente dernières années et de sa régulation, d'autres politologues ont également permis récemment un certain renouvellement des études autour du concept de capture régulatoire (regulatory capture ${ }^{49}$. Conceptualisée dès les années I950, mais popularisée surtout dans les années 1970 à la suite des travaux de l'économiste George Stigler cités plus haut ${ }^{50}$, cette notion désigne le phénomène par lequel une régulation est détournée de l'intérêt commun vers les intérêts particuliers de l'industrie régulée, par l'action de cette même industrie ${ }^{51}$. Longtemps considérée comme un simple effet collatéral et inévitable de la régulation et une manifestation patente des dysfonctionnements de l'État (government failure), la capture trouvait sa réponse politique dans la dérégulation, sous la forme d'une suppression «à la racine» du mal diagnostiqué. Ce constat pessimiste était donc

Michael Moran, The Politics of Banking. The Strange Case of Competition and Credit Control, London: Macmillan Press, 1984 ; voir surtout: Michael Moran, The Politics of the Financial Services Revolution: The USA, UK and Japan, Basingstoke: Palgrave Macmillan, I991.

49 Voir en particulier: Edward J. Balleisen, David A. Moss (éd.), Government and markets: toward a new theory of regulation, Cambridge; New York: Cambridge University Press, 2010 ; Daniel Carpenter, David A. Moss (éd.), Preventing Regulatory Capture: Special Interest Influence and How to Limit It, New York: Cambridge University Press, $20 \mathrm{I} 4$.

50 Pour un petit historique du concept, cf. Richard A. Posner, "The Concept of Regulatory Capture: A Short, Inglorious History ", in Daniel Carpenter, David A. Moss (éd.), Preventing Regulatory Capture: Special Interest Influence and How to Limit It, New York: Cambridge University Press, 20I4, p. 49-56.

51 Selon la définition proposée par Carpenter et Moss. Carpenter, Moss (éd.), op. cit., 2or4, p. I3. 
souvent accompagné d'un programme idéologique prescrivant l'assouplissement réglementaire. Les réflexions plus récentes sur la capture régulatoire cherchent à dépasser ce programme politique, à la fois en nuançant les degrés de capture, en établissant des critères permettant de repérer empiriquement le phénomène, en proposant des remèdes plus variés que la seule dérégulation, et en identifiant de potentielles sources de capture. Plus précisément, James Kwak, dans une des contributions au volume précité, propose un mécanisme de capture qui va au-delà de la simple corruption selon le phénomène de "pantouflage porte-tambour» (revolving door), qui pousse les régulateurs à adopter délibérément des choix en faveur de l'industrie, en vue d'une reconversion future au sein de celle-ci. Kwak introduit la notion de cultural capture $^{52}$. Il s'agit d'une variante plus ambiguë de la capture régulatoire : les régulateurs y mèneraient des actions qui conduisent également à servir les intérêts des régulés, mais de manière inconsciente, parce qu'ils s'identifient aux groupes qu'ils contrôlent, ou qu'ils partagent les mêmes réseaux de sociabilité. Un employé d'une agence de régulation bancaire se verrait par exemple opter pour des choix qui favorisent les préférences d'un groupe bancaire, parce qu'il considère sincèrement que les intérêts défendus par l'établissement financier sont identiques à l'intérêt général (celui des déposants, des consommateurs ou plus largement des contribuables) qu'il est censé protéger.

Relevons encore que la régulation bancaire suisse, même dans ces évolutions les plus récentes, n'a que peu attiré l'attention des politistes. Les travaux comparatifs d'Andreas Busch et la récente thèse de doctorat de Roy Gava forment deux exceptions notables ${ }^{53}$. Mais le décalage chronologique de ces études qui se concentrent sur la période 1980-20IO, ainsi que l'absence de toute documentation archivistique, en font des références de moindre importance pour ce travail.

\section{PRÉSENTATION DES SOURCES ET STRUCTURE DU LIVRE}

Nous l'avons dit, l'élaboration des politiques à l'égard du domaine bancaire se déroule essentiellement dans des cercles de décision confidentiels. Les négociations mettent aux prises un nombre réduit d'acteurs, qui se consultent à l'abri du regard médiatique et du contrôle parlementaire. Or, la démarche méthodologique de cette recherche consiste en une analyse génétique des processus de décision. Elle s'appuie donc principalement sur des sources

52 James Kwak, "Cultural Capture and the Financial Crisis ", in Daniel Carpenter, David A. Moss (éd.), Preventing Regulatory Capture: Special Interest Influence and How to Limit It, New York: Cambridge University Press, 20I4, p. 7I-98.

53 Andreas Busch, Banking Regulation and Globalization, Oxford: Oxford University Press, 2009; Roy Gava, "Trusting Bankers. Continuity and Change in Swiss Banking Policy", Thèse de doctorat, Faculté des sciences économiques et sociales, Université de Genève, 2014. 
d'archives internes aux organisations étudiées et encore peu exploitées. Parmi la littérature secondaire existante sur le sujet, cela la distingue à la fois des publications de type juridique et économique des contemporains, et des études menées en science politique et même parfois en histoire économique ${ }^{54}$. Ces dernières se contentent en effet souvent de tirer des bilans généraux pour caractériser la surveillance bancaire et son évolution, tout en faisant l'impasse sur une consultation de la documentation produite par les instances chargées de mettre en œuvre la régulation. Ce livre est élaboré en grande partie à partir de sources provenant des quatre acteurs principaux : la Commission fédérale des banques, le Département fédéral des finances et des douanes, la Banque nationale suisse et l'Association suisse des banquiers.

Dans ce travail, les archives de la Commission fédérale des banques sont au cœur de l'analyse. Conservées aux Archives fédérales, elles sont en principe accessibles librement dans le cadre du délai habituel de protection de trente ans. Elles renferment notamment des documents essentiels sur le processus d'élaboration de la loi sur les banques, qui précède la naissance de la Commission fédérale des banques. Mais elles recueillent aussi de nombreuses sources produites par l'institution, qui mettent en lumière son activité: les procès-verbaux des séances, les rapports annuels, les circulaires émises, ou encore certaines correspondances classées thématiquement. Les procès-verbaux en particulier ont été intégralement dépouillés sur la période 1935-1972. Ils forment un matériel très utile, car les secrétaires les ont dressés de manière relativement détaillée, en reproduisant les différentes opinions émises en discours rapporté direct. Cette retranscription précise offre à l'historien les éventuelles sources de tension interne existantes. Les procès-verbaux de la CFB contiennent même parfois des documents chiffrés intéressants. Pourtant, pour l'historien qui s'intéresse à l'activité de surveillance bancaire en Suisse, les archives de la Commission fédérale des banques se distinguent non seulement par ce qu'elles contiennent, mais aussi par ce qu' elles ne renferment pas. Il est en effet frappant de constater que les opérations des principales banques qui dominent la place bancaire suisse (grandes banques, banques cantonales), ne sont que rarement évoquées dans les discussions de la Commission fédérale des banques. En ce sens, appréhender la vie de la place financière suisse par le biais des activités de son instance de surveillance présente le risque de porter un regard biaisé sur la réalité économique du secteur. Citons un seul exemple: au cours des années I950, une petite banque frauduleuse et récalcitrante - la Kredit- und Verwaltungsbank Zug - accapare une grande part de l'attention des superviseurs, tandis que les géants que sont le Crédit Suisse, l'UBS ou la SBS n'apparaissent que rarement sur leur radar. Ce contraste étonnant, sur lequel nous reviendrons dans l'analyse, doit beaucoup d'une part au système de surveillance adopté, qui confie le contrôle direct de la comptabilité bancaire à des sociétés privées,

54 Pour les études juridiques et économiques, cf. notes 23 à 26 de l'introduction. Pour les travaux de politologues, cf. notes 44 à 53 de l'introduction. 
d'autre part à l'essor des grandes banques pendant la période étudiée, qui ne connaissent pas de crises durant les Trente Glorieuses.

En plus des fonds de la Commission fédérale des banques, les archives fédérales comportent d'autres dossiers pertinents. Les archives de l'Administration fédérale des finances - c'est-à-dire la section gouvernementale en charge des questions financières - sont particulièrement riches à cet égard. Elles comprennent une importante documentation sur les processus d'élaboration et de révision des législations touchant au domaine bancaire. En effet, la loi sur les banques de 1934, et ses tentatives de révision, émanent essentiellement de l'Administration fédérale des finances. À ces dossiers sur le volet législatif s'ajoutent ceux sur la composition de la Commission fédérale des banques. En effet, étant donné que les candidats pour devenir membres de l'organe de surveillance sont officiellement proposés par le Département fédéral des finances et des douanes, on trouve dans ses archives de riches sources d'information. L'Administration fédérale des finances constitue donc l'interlocuteur principal des fonctionnaires de la Commission fédérale des banques à l'échelon gouvernemental. Le croisement des sources provenant de ces deux institutions permet également de mesurer le grand degré de cohésion entre les deux administrations en charge de la régulation, parfois émaillée par des tensions ponctuelles. À ces deux fonds principaux qui ont fait l'objet de dépouillements abondants se joignent quelques dossiers du Département politique fédéral - le ministère des Affaires étrangères -, notamment autour des débats sur la régulation des banques étrangères dans les années 1960, ainsi que les procès-verbaux du Conseil fédéral consultés sporadiquement pour examiner les discussions au sommet de l'État lors de l'approbation de décisions réglementaires.

À côté de la Commission fédérale des banques et de l'Administration fédérale des finances, la Banque nationale suisse constitue le troisième acteur d'importance dans les discussions de régulation bancaire. La banque centrale, en Suisse, est une organisation au statut institutionnel ambigu: elle est une société anonyme privée, mais est régie par le droit public et gérée avec le concours de la Confédération. Fondée tardivement en 1907, elle participe, parfois avec réticence, aux négociations sur l'établissement d'une législation bancaire, puis joue à contrecœur un rôle dans son application. Ses archives possèdent deux types de documentation pertinents: d'une part, les procèsverbaux des organes dirigeants de la banque, d'autre part, une douzaine de cartons relatifs à l'adoption de la loi sur les banques en 1934 et à sa révision à la fin des années 1960. Ces sources sont essentielles pour comprendre la relation complexe qui se lie entre les dirigeants de la banque centrale et les superviseurs de la Commission fédérale des banques, laquelle relation est teintée de concurrence, collaboration et conflictualité.

Le quatrième protagoniste principal dans les négociations de régulation bancaire est l'Association suisse des banquiers, le groupe d'intérêts fédérant le monde bancaire helvétique, fondé en I9I2. La consultation de ses archives est essentielle dans l'élaboration du propos de ce travail. Elle permet en effet de 
comprendre la réaction des milieux concernés aux propositions faites par les législateurs en vue d'introduire ou de modifier le cadre réglementaire. Étant donné la nature confidentielle des discussions qui, dans le cadre du Conseil de l'ASB, ne réunissent qu'une dizaine d'éminents banquiers, les propos rapportés atteignent un degré de véracité qui ne se retrouve pas lors des concertations avec les autorités publiques. En plus des procès-verbaux des organes de cette association patronale, nous avons consulté quelques dossiers thématiques, sur la période de l'après-guerre, contenant des échanges de correspondance entre représentants des banques et superviseurs fédéraux. Cette documentation permet également d'appréhender les tensions internes au monde bancaire que les tractations sur la régulation mettent en évidence: dans la définition de la position commune de l'ASB, il n'est pas rare de voir les représentants des grandes banques et des banques cantonales, par exemple, s'affronter. Pour développer cette piste de recherche, les archives de l'Union des banques cantonales suisses ont été consultées. Il s'agit de la fédération d'une catégorie de banques, au caractère étatique plus ou moins prononcé et en principe confiné au rayon géographique cantonal, qui occupe une place importante dans le système bancaire suisse. Les procès-verbaux de ses organes dirigeants laissent entrevoir les prises de position spécifiques des banques cantonales à l'égard de la législation bancaire ou des interventions de la Commission fédérale des banques.

Enfin, divers fonds d'archives secondaires ont été ponctuellement mobilisés. Il s'agit d'une part des archives du Vorort de l'Union suisse du Commerce et de l'Industrie, le comité directeur de la principale association patronale du pays, d'autre part de celles du Parti socialiste suisse. Le dépouillement, très limité dans son ampleur, vise ici à documenter les positions respectives de deux acteurs importants de la politique suisse face aux questions de législation bancaire. Il s'avère que cet objet n'occupe qu'une place très restreinte dans leurs discussions: une donnée certes décevante pour l'historien, mais en soi révélatrice du traitement des enjeux de régulation bancaire en Suisse. Signalons encore l'intérêt des Archives économiques suisses (Schweizerisches Wirtschaftsarchiv) de Bâle: en plus des nombreux dossiers sur des personnes et des sociétés, contenant essentiellement des coupures de presse et des brochures, elles abritent aussi la correspondance manuscrite de Julius Landmann, professeur d'économie et auteur du premier projet de loi fédérale sur les banques en I9I6.

Il est évident qu'au-delà des archives de l'ASB et de l'UBCS, il aurait été d'un intérêt primordial de pouvoir consulter les documents provenant des principales banques de Suisse. Malgré des demandes répétées, tant UBS AG que Credit Suisse Group AG ont refusé de nous accorder une consultation de leur documentation. Cette attitude de fermeture de la part des deux poids lourds de la finance helvétique est d'autant plus regrettable que ces deux établissements ont obtenu, au fil des acquisitions et des fusions, le contrôle d'un patrimoine archivistique considérable. Nos requêtes de consultation 
adressées au Groupement des banquiers privés genevois et à l'Association des banques étrangères en Suisse sont quant à elles restées sans réponse.

Cette recherche considère le développement de la surveillance étatique des banques en Suisse sur une période relativement étendue. Les investigations débutent en 1914-1916, à l'occasion de la rédaction d'un premier projet de législation fédérale sur les banques, qui n'aboutit pas. Elles se terminent sur la première révision de la loi fédérale sur les banques qui intervient en 19711972.

Ce travail se structure essentiellement en deux parties principales : il s'agit de comprendre d'une part les conditions de mise en place d'une surveillance bancaire et sa mise en application par la Commission fédérale des banques d'autre part. En plus de l'introduction et de la conclusion, cette étude est composée de neuf chapitres qui se succèdent dans un ordre chronologique. La première partie, à savoir les chapitres premier à IV, retrace la longue histoire de l'élaboration de la loi sur les banques, depuis les premiers projets avortés de I916 jusqu'au régime réglementaire finalement adopté en 1934-1935. La seconde partie, dans les chapitres V à IX, analyse la formation, le rôle et les activités de l'instance chargée de mettre en application la législation, la Commission fédérale des banques.

Le chapitre premier revient sur la phase "préhistorique» de la régulation fédérale des banques, à savoir la période qui va de la Première Guerre mondiale à la fin des années 1920. Le projet de loi fédérale sur les banques avorté de 1916, dit projet Landmann, sera au centre de l'attention. Sa genèse, sa teneur, son abandon et ses conséquences à plus long terme seront étudiés.

Dans le deuxième chapitre, nous examinons de plus près le contexte dans lequel la première législation bancaire aboutira finalement. Plus précisément, nous déplaçons la focale vers la profonde crise qui affecte l'économie suisse et mondiale. Les difficultés de certains établissements bancaires seront en particulier analysées. Il s'agira alors de mettre en évidence les liens entre l'émergence de ces crises bancaires et les réponses politiques qui sont formulées.

Le troisième chapitre reprend cette même phase du début des années 1930, mais cette fois-ci en plaçant au cœur de l'analyse les différents avant-projets de loi qui jalonnent le long parcours qui débouchera sur l'adoption d'une législation en novembre 1934. Là aussi, il apparaitra que le processus d'élaboration législative est largement conditionné par le développement conjoncturel de la crise: chaque déconfiture bancaire qui implique une intervention étatique engendre également une contrepartie politique sous la forme d'un renforcement du projet de loi sur les banques. La grande réticence des autorités publiques à intervenir par une loi dans le secteur bancaire, malgré l'aggravation de la crise, sera alors soulignée. 
Dans le quatrième chapitre, nous marquons une pause dans le récit chronologique et examinons de plus près le régime de surveillance bancaire qui résulte du processus de décision analysé dans les sections précédentes. En fait, ce n'est pas seulement la loi elle-même qui sera présentée, mais également son ordonnance d'exécution, qui à plusieurs égards se révèle même plus importante que le texte de loi. Pour éviter le risque d'une grande monotonie descriptive dans un tel chapitre, nous ferons de fréquents allers-retours entre la phase d'élaboration des dispositions légales en amont, leur formulation définitive dans la loi, et leur application effective en aval.

Les chapitres V, VI, VII, VIII et IX forment le noyau central de ce livre. Ils examinent la mise en place et l'évolution entre 1935 et 1972 de l'organisme de surveillance chargé de garantir l'application de la loi bancaire : la Commission fédérale des banques. Le chapitre $\mathrm{V}$ présente succinctement l'institution, ses moyens, son statut et ses compétences. Il contient en outre une rapide analyse prosopographique des 35 premiers membres de la Commission fédérale des banques.

Le chapitre VI aborde trois thématiques qui marquent les dix premières années d'existence de la Commission fédérale des banques (I935-1945): la reconnaissance des sociétés de révision chargées de pratiquer le contrôle bancaire, son rôle dans les assainissements de banques en difficulté et ses relations avec la Banque nationale suisse.

La phase 1945-196I, statique en apparence, est traitée dans le septième chapitre. Il y est question, entre autres, de la restructuration du groupe des grandes banques à la fin de la guerre, à laquelle la Commission fédérale des banques participe. Nous développerons ensuite deux autres points: d'une part, la grande faiblesse des moyens d'intervention disciplinaire de la Commission, avec l'exemple d'une petite banque zougoise qui échappe longtemps à toute sanction, d'autre part, la modification du règlement d'exécution qui aboutit en 196I à un assouplissement des exigences de fonds propres au bénéfice des grandes banques.

Dans le huitième chapitre, nous analyserons la période du début des années 1960. Trois questions y seront traitées successivement. Tout d'abord, le problème de la régulation des fonds de placement, un instrument financier nouveau et alors en pleine effervescence sera abordé. La Commission fédérale des banques y jouera un rôle de surveillance contre son gré. Dans un second temps, les premières velléités en faveur d'une modification de la loi fédérale sur les banques, dont plusieurs lacunes sont progressivement détectées, seront examinées. Nous verrons qu'elles se heurtent à une forte résistance auprès des milieux bancaires, une résistance qui est même partagée par les autorités chargées d'appliquer la réglementation. Enfin, nous mettrons en lumière un scandale qui, en compromettant le président de la Commission fédérale des banques, ébranle considérablement cette institution.

Le chapitre IX prolonge cette analyse en retraçant les différentes étapes qui, dans la seconde moitié des années 1960, conduisent à la première révision de la 
loi sur les banques en 1971. Celle-ci est tout d'abord retardée par la priorisation d'une question annexe: celle de la lutte contre l'"Überfremdung» de la place bancaire. S'ensuit un processus d'élaboration législative, qui sera attentivement examiné, au cours duquel les projets initiaux de la Commission fédérale des banques en vue de renforcer le contrôle bancaire sont assouplis. La révision législative finalement adoptée ne modifie pas fondamentalement le système de surveillance en vigueur; les principaux changements consistent justement en des entraves à l'installation de banques étrangères en Suisse, introduites sous l'impulsion des milieux bancaires helvétiques. 
PREMIÈRE PARTIE

LA LOI FÉDÉRALE SUR LES BANQUES DE 1934 ET SA GENÈSE 
广

N

$\stackrel{\circ}{\circ}$

(1)

.

2

2

(a) 


\section{CHAPITRE PREMIER}

\section{LE PROJET LANDMANN DE 1916 : UNE PREMIÈRE TENTATIVE DE RÉGULATION AVORTÉE}

S’il faut attendre le 8 novembre 1934 pour assister à l'adoption en Suisse d'une législation sur les banques à l'échelon fédéral, les premiers projets de réglementation sont bien plus anciens. Le projet officiel initial - rédigé sur demande du gouvernement - est élaboré entre I9I4 et I916. Ce projet de loi, auquel on se réfere souvent en tant que "projet Landmann ", du nom de son auteur, n'aboutira pas, pour diverses raisons que nous éclaircirons plus loin. Toujours est-il qu'il s'agit là de la première tentative de soumettre l'ensemble du secteur bancaire national à une réglementation fédérale.

L'objectif de ce chapitre est de retracer la préhistoire de la surveillance bancaire, telle qu'elle s'est développée à partir de I9IO-I9I6, des années charnières dans l'histoire de l'évolution de la place financière suisse. Ce retour en arrière n'est pas seulement digne d'intérêt dans une perspective de simple contextualisation. Les nombreuses ressemblances et divergences entre les projets de I9I6 et de I934 - tant dans leurs conditions d'émergence que dans leur élaboration - permettent de dresser des parallèles intéressants. L'expérience du projet échoué de I9I6 sera d'ailleurs encore bien présente dans les esprits des acteurs des années 1930 et nourrira leurs débats.

En septembre 1931, la rentrée estivale du monde politico-financier helvétique est perturbée par les événements liés au krach de la Banque de Genève de juillet I93I, et les différents projets de sauvetages étatiques visant à protéger cet institut. En plus de nombreuses interventions parlementaires, l'émergence fracassante de la crise financière en Suisse a fait renaître, dans la presse et dans le débat politique, l'idée d'une surveillance étatique des banques. Dans ce contexte particulièrement tendu, sur lequel nous reviendrons, le conseiller fédéral catholique-conservateur Jean-Marie Musy (I876-I952) demande à son collaborateur à la tête de l'Administration des finances, Eduard Kellenberger (1889-1976), de préparer un rapport sur le contrôle bancaire. L'essentiel de ce texte d'une douzaine de pages a pour objet 
de résumer les dispositions du projet Landmann. Le jugement final sur le projet de loi de 1916 est sans ambages : «Il s'agit d'ailleurs d'une loi-cadre, qui laisse une large place à des développements futurs vers une plus grande ingérence dans le système bancaire, et qui, en conséquence, ouvrirait la voie à sa socialisation. ${ }^{1}$

Ressorti des tiroirs de l'administration fédérale quinze ans après sa rédaction, le projet Landmann suscite encore de la part d'un fonctionnaire fédéral une certaine méfiance. Promulguer une loi sur les banques revient à ouvrir une boîte de pandore. Notons donc d'emblée que le premier projet de loi sur les banques - malgré son échec - a marqué sur le long terme les positions des législateurs, en matière de politique bancaire.

Avant de présenter plus avant l'histoire de l'élaboration du projet Landmann, il est nécessaire de dépeindre rapidement l'état de développement de la place financière suisse et le contexte dans lequel les premiers appels à une réglementation fédérale de la branche se font entendre.

\section{I.1. L'ÉMERGENCE DE LA PLACE FINANCIÈRE SUISSE (1890-1914) : QUELQUES JALONS}

L'élaboration du premier projet de réglementation fédérale du secteur bancaire prend place à un moment charnière dans l'histoire du développement des banques en Suisse ${ }^{2}$. La phase d'émergence des banques helvétiques (I890I9I3) s'achève en effet avec le déclenchement de la Première Guerre mondiale. Cette époque, qualifiée par Franz Ritzmann, spécialiste de l'histoire bancaire suisse, de "période de mise à l'épreuve et de consolidation", est celle durant laquelle la morphologie caractéristique du paysage bancaire helvétique s'établit $^{3}$. Un système dualiste, fractionné entre des agents orientés vers le marché intérieur et des institutions dirigées vers les opérations internationales, prend forme. En effet, deux types d'institutions - les banques cantonales et les grandes banques - s'affirment au cours de la période comme les acteurs dominants du champ financier suisse.

Les banques cantonales, fondées par vagues successives pour l'essentiel durant les dernières décennies du XIX ${ }^{\mathrm{e}}$ siècle ${ }^{4}$, dominent le marché intérieur.

1 AFB, E6520(A), I000/I059, vol. 2, Rapport de l'AFF sur «Bankenkontrolle» (Eduard Kellenberger), OI.09.193I.

2 Mazbouri, Schaufelbuehl, art. cit., 2015, p. 665.

3 Citation de Franz Ritzmann, «Die Entwicklung des schweizerischen Geld- und Kreditsystems" ", in Ein Jahrhundert schweizerischer Wirtschaftsentwicklung. Festschrift zum hundertjährigen Bestehen der Schweizerischen Gesellschaft für Statistik und Volkswirtschaft. I864-1964, Bern: Stämplfi \& Cie, 1964, p. 235-272, p. 243. Cf. Mazbouri, Guex, Lopez, art. cit., in Halbeisen, Müller, Veyrassat (éd.), op. cit., 20I2, p. 468.

4 Sébastien Guex, "Au carrefour de l'économie et de la politique. La genèse des banques cantonales en Suisse et leur développement jusqu’à la Première Guerre mondiale ", in Laurence Fontaine, et al. (éd.), Des personnes aux institutions. Réseaux et culture du crédit du XVI ${ }^{e}$ au XXe siècle en Europe, Louvain-la-Neuve: Academia Bruylant, 1997, p. 332-347. 
La catégorie regroupe des instituts hétérogènes, dont les formes d'organisation et la taille varient beaucoup. Leur activité se limite en principe au territoire cantonal. Souvent fondées, capitalisées et contrôlées par la puissance publique, les banques cantonales bénéficient d'ailleurs dans la plupart des cas d'une garantie étatique sur leurs engagements. Suivant la tendance de la banque universelle, elles pratiquent tous types d'opérations, avec, selon la structure économique du canton, une prédominance des crédits hypothécaires, de l'épargne ou des affaires commerciales ${ }^{5}$. Dans la chronologie de l'histoire de la régulation bancaire, c'est aussi avec la création des banques cantonales que sont adoptées les premières lois ayant pour objet le domaine bancaire. Il s'agit de lois cantonales, qui se limitent en général à définir l'organisation, le champ d'activité et la répartition des bénéfices de l'établissement en devenir ${ }^{6}$. Le drainage des épargnes cantonales dans le but de financer des crédits hypothécaires à bon marché fait partie des objectifs avoués lors de la fondation des banques cantonales. Reposant souvent sur les articles de "bien-être commun" des constitutions cantonales, les lois sur les banques cantonales ne réglementent en tout cas pas l'activité des autres agents bancaires actifs sur le territoire cantonal ${ }^{7}$.

Les grandes banques sont au nombre de huit en I9I3, selon la statistique officielle. Ces établissements de type «Crédit mobilier» s'affirment au cours du dernier quart du XIX ${ }^{\mathrm{e}}$ siècle. Souvent fondés pour répondre aux besoins $\mathrm{du}$ financement ferroviaire, ces instituts prennent le relais des banquiers privés dans le domaine des opérations internationales. Bénéficiant de liens privilégiés avec les secteurs les plus dynamiques de l'économie, dont l'industrie d'exportation, ils pratiquent tous types d'opérations, selon le modèle dominant en Europe continentale; ils sont à la fois banques d'affaires (investissements) et banques commerciales ${ }^{8}$. Leur affirmation s'accompagne de la création, en collaboration avec de puissants partenaires étrangers, de nombreuses sociétés financières - en particulier dans les investissements électriques. Par la création d'autres sociétés affiliées, notamment dans le domaine de l'assurance ou du conseil fiduciaire, ces sociétés financières permettent à la banque-mère de former une véritable "nébuleuse », démultipliant les capacités d'investissement et augmentant leur surface financière ${ }^{9}$. Relevons au passage le caractère

5 Yves Froidevaux, "Banques cantonales", in Marc Jorio (éd.), Dictionnaire historique de la Suisse, Hauterive: Attinger, vol. 2, 2003, p. I4-I5, p. I4-I5.

6 Daniel Zuberbühler, «Die Kantonalbanken im Bankengesetz », in Carlo Matti (éd.), Union des Banques Cantonales Suisses. 1907-2007, Bâle: Union des Banques Cantonales Suisses, 2007, p. I59-177.

7 Bänziger, op. cit., 1986, p. 8.

8 Mazbouri, op. cit., 2005, p. I69; Malik Mazbouri, «L'affirmation de la place financière suisse. 1900-1930 ", Contribution non-publiée au colloque "Switzerland as a financial centre in an international perspective (1913-1965), Lausanne, I999.

9 Mazbouri, op. cit., 2005, p. 352-357; Malik Mazbouri, «A retrospective illusion? Reflections on the "longevity" of Swiss big banks. I850-2000", in Michel Lescure (éd.), Immortal Banks. Strategies, Structures and Performances of major Banks, Genève: Librairie Droz, 20I6, p. 23I-25I. 
anachronique de la catégorie des "grandes banques", si l'on considère l'ensemble de la période 1890-1913; les instituts réunis sous ce nom ne forment un groupe qu'en 1915 , lors de la parution de la troisième statistique bancaire de la BNS qui donne lieu à un remaniement des catégories de banques ${ }^{10}$.

Le système bancaire suisse, dominé à la fin de sa phase d'émergence d'une part par les banques cantonales tournées vers le marché intérieur, et d'autre part par les grandes banques versées dans le financement industriel et les opérations internationales, comporte bien sûr d'autres acteurs financiers importants. Les banques locales et régionales, les banques hypothécaires, les banquiers privés - qui ne disparaissent pas du champ, mais spécialisent et modernisent leurs activités, et que l'on retrouve à l'origine de la fondation de nombreuses sociétés -, les banques étrangères, les compagnies d'assurances et les sociétés holding. Par ailleurs, le mouvement du petit crédit rural coopératif, qui prend bientôt la forme d'une Union des Caisses Raiffeisen (I9O2) s'organise au tournant du siècle. Du point de vue géographique, trois centres financiers jouent un rôle important: à côté de Zurich, le pôle économique du pays, Genève et Bâle se maintiennent comme places bancaires et boursières d'envergure internationale. Comme l'affirment Malik Mazbouri, Sébastien Guex et Rodrigo Lopez:

La place financière suisse, telle qu'elle émerge un peu en amont du premier conflit mondial et se développe au $\mathrm{XX}^{\mathrm{e}}$ siècle, forme donc un espace hiérarchisé, dualiste et polycentrique, à dominante bancaire. À la fois complémentaires et concurrentes, les banques cantonales et les grandes banques sont les deux institutions-types majeures de cette armature bancaire $[\ldots]^{11}$.

La phase d'émergence de la place financière suisse, entre i890 et 19I4, est balisée par deux accomplissements politiques qui entrainent de profonds changements de la structuration du champ bancaire suisse: la création d'une banque centrale en 1907 et la nationalisation des chemins de fer en I898. Ces deux évolutions sont pertinentes pour notre sujet, car elles mettent en place les conditions nécessaires à une tentative de régulation fédérale.

L'ouverture des guichets de la Banque nationale suisse, en juin 1907, marque une césure importante dans l'évolution du champ financier helvétique. Achevant un processus d'une quinzaine d'années, qui avait vu le rejet d'une banque centrale étatique pure (projet Hauser 1897), la mise sur pied, entre 1905 et 1907 , de la BNS met un terme à un régime monétaire décentralisé ${ }^{12}$. Ce régime, qui confiait l'émission monétaire à une trentaine d'établissements

10 Sur ce point, voir Mazbouri, op. cit., 2005, p. 175-185. Voir également: Hermann Schneebeli, "Das Schweizerische Bankwesen in den Jahren I906-I9I3", Zeitschrift für schweizerische Statistik und Volkswirtschaft, I9I5, p. 369-435.

11 Mazbouri, Guex, Lopez, art. cit., in Halbeisen, Müller, Veyrassat (éd.), op. cit., 20I2, p. 472.

12 Rolf Zimmermann, Volksbank oder Aktienbank? Parlamentsdebatten, Referendum und zunehmende Verbandsmacht beim Streit um die Nationalbankgründung. I89I-I905, Zürich: Chronos, 1987; Guex, op. cit., 1993, p. 19-39. 
concurrents, principalement les banques cantonales, constitue un frein au développement de la place financière suisse pour au moins trois raisons. D'une part, il contribue à maintenir la Confédération dans l'orbite monétaire de la finance parisienne. Dans le cadre de l'Union Monétaire Latine, la Suisse entretient une dépendance vis-à-vis de la place financière parisienne, en particulier dans ses capacités de paiement à l'étranger ${ }^{13}$. De plus, le régime d'émission monétaire décentralisée renforce la faiblesse conjoncturelle du franc suisse, surtout vis-à-vis du franc français. En effet, la politique d'escompte concurrentielle des divers instituts d'émission n'est pas homogène, et la faiblesse de moyens individuels empêche de maintenir un cours de la devise helvétique fort ${ }^{14}$. Troisièmement, enfin, la politique d'escompte peu restrictive de la trentaine d'établissements pratiquant l'émission monétaire contribue à fragiliser le système bancaire suisse. En accordant beaucoup de facilités contre des encours de mauvaise qualité, les banques d'émission perturbent les activités bancaires. De plus, l'absence d'un prêteur de dernier ressort aux reins solides, capable en temps de difficultés d'empêcher la propagation de crises systémiques, signifie un manque de sécurité et de stabilité pour le système bancaire. Du point de vue législatif, le régime d'émission monétaire décentralisé est encadré par une loi fédérale de I88I, qui régit l'activité des quelque 36 banques d'émission et institue l'Inspectorat des banques d'émission. Cet office, sousdoté en personnel, n'exerce qu'une faible influence sur l'activité des banques d'émission. Il constitue malgré tout la première instance étatique, à l'échelon fédéral, de contrôle des banques ${ }^{15}$. L'émergence tardive d'une banque d'émission centralisée, au terme d'un processus législatif s'étendant sur une quinzaine d'années (I89I-I907), signifie également que la question de l'émission monétaire domine largement le débat politique dans le domaine bancaire. Les questions relatives à la protection des déposants ou à la réglementation de l'activité des banques commerciales passent au second plan.

Il faut ici signaler que la mise en place d'une banque centrale mixte, sous la forme d'une société anonyme par actions disposant d'une autonomie relativement grande à l'égard de l'État fédéral, a pour corollaire l'absence de compétence de contrôle sur les banques commerciales privées ${ }^{16}$. Alors même que l'institut d'émission doit parfois intervenir pour participer au sauvetage de banques défaillantes, la loi sur la Banque nationale ne prévoit aucune tâche prudentielle dans le but de sauvegarder la stabilité du système bancaire ${ }^{17}$. Cette I

16 Voir Guex, op. cit., 1993, p. 39-45. Michael Bordo, Harold James, «De 1907 à 1946 : enfance heureuse ou adolescence difficile?», in Werner Abegg (éd.), Banque Nationale Suisse 19072007, Zurich : Neue Zürcher Zeitung, 2007, p. 29-II5, p. 85-9I.

17 Hermann Schneebeli, La Banque Nationale Suisse 1907-1932, Zurich: Orell Füssli, I932, p. 360-363, p. 474-489. 
absence de rôle de supervision bancaire dans les attributs de la banque centrale, du moins jusqu'à l'adoption de la loi sur les banques de 1934 - qui n'a pas souvent été relevée par les historiens - détonne pourtant avec la tendance générale dans l'histoire des banques centrales à l'international. Selon l'historien américain Richard Grossman, la Suisse forme ainsi une exception à la règle selon laquelle les banques centrales les plus jeunes - celles qui sont fondées tardivement - obtiennent en général plus rapidement des pouvoirs de surveillance que les banques centrales les plus anciennes ${ }^{18}$. Ainsi, la Réserve fédérale américaine (1914), la Banca d'Italia (I926) ou la Nippon Ginko japonaise (1928), toutes trois relativement jeunes, font figure des banques centrales ayant obtenu des compétences de contrôle sur les banques commerciales.

L'ouverture de la Banque nationale suisse, en 1907, modifie donc considérablement la morphologie du système bancaire national. Elle conduit à un renforcement général de la concurrence interbancaire, sous la conjonction de deux évolutions. D'une part, la politique d'escompte plus restrictive menée par la BNS provoque la disparition des établissements plus fragiles, en particulier certaines banques locales et régionales. D'autre part, la trentaine de banques d'émission, essentiellement les banques cantonales, doivent compenser la suppression du privilège d'émission en diversifiant leurs activités dans d'autres secteurs ${ }^{19}$. Ce « resserrement strict des règles du jeu ${ }^{20}$ opéré par l'apparition d'un interlocuteur unique en matière de refinancement, couplé au renforcement général de la concurrence entre banques, est à l'origine d'un vaste mouvement de concentration et de fusions dans le monde bancaire entre 1906 et 1914. Pendant ce laps de temps, plus de 82 raisons sociales bancaires disparaissent ${ }^{21}$. En termes de pertes subies et de nombre d'instituts affectés, les chiffres varient ${ }^{22}$. Sans nous prononcer sur l'exactitude des diverses

Grossman, art. cit., in Battilossi, Reis (éd.), op. cit., 20IO, p. I33-136 ; Grossman, op. cit., 20IO, p. $162-167$.

Mazbouri, Guex, Lopez, art. cit., in Halbeisen, Müller, Veyrassat (éd.), op. cit., 20I2, p. 48o. Mazbouri, op. cit., 2005, p. 218.

Parmi ces 82 établissements, 27 entrent en liquidation, tandis que 35 sont reprises par de grandes banques ou des banques cantonales. Bruno Pfister, Beiträge zur Entwicklung der schweizerischen Klein- und Mittelbanken, Zürich: Orell Füssli, I9I6, p. 9-I2. Voir aussi Wetter, op. cit., I9I8; Beatrix Purchart, "Die Finanzkrise von 1907 und ihre Übertragung auf die Schweiz", in Thomas David, Tobias Straumann, Simon Teuscher (éd.), Neue Beiträge zur Wirtschaftsgeschichte, Zürich: Chronos, 2015, p. 199-220, p. 213-219.

Pour Albert Meyer, 20 banques ont subi entre I9IO et I9I4 de 70 à 80 millions de francs suisses de pertes. Meyer, op. cit., I9I4, p. Io. Selon Ernst Wetter (I877-I963), futur conseiller fédéral radical (DFFD, I938-43), vice-président du Vorort (I926-I938), président de la Commission fédérale des banques (I944-1950), qui reprend lui-même les chiffres de l'exposé des motifs du projet de loi sur les banques de Julius Landmann, les pertes de 50 à 69 banques s'élèvent à II2.5 millions de francs. Julius Landmann, Projet d'une loi fédérale concernant l'exploitation et la surveillance des banques avec exposé des motifs à l'appui, Berne: Schweizerisches Volkswirtschaftdepartment, 1916, p. 30-32 ; Wetter, op. cit., I918, p. 2. Pour Fritz Ritzmann enfin, 60 caisses d'épargne et banques locales sont victimes de la grande "agonie bancaire" des années I9I0-I9I4. Franz Ritzmann, Die Schweizer Banken. Geschichte-Theorie - Statistik, Bern; Stuttgart: Haupt, I973, p. I05. 
estimations, retenons que IO-I5 \% des banques que compte la Suisse en I9IO disparait du registre du commerce, suite à une reprise ou à une liquidation ${ }^{23}$. Pour illustrer l'importance des pertes subies, dont plus de la moitié est à la charge des déposants, il s'agit d'un montant à peine inférieur aux dépenses de la Confédération pour l'année $1912^{24}$. Le processus de concentration, en partie initié par les changements structurels provoqués par la mise en place de la Banque nationale, profite essentiellement aux grandes banques et aux banques cantonales, dont le poids relatif croît rapidement; la part de ces deux groupes au bilan total des banques en Suisse passant de $50 \%$ en 1900 à $66 \%$ en $1914{ }^{25}$. En outre, l'ampleur de la crise bancaire - les fraudes qu'elle met à jour - suscite l'émergence politique du débat sur le contrôle fédéral de la branche et donne l'impulsion au développement du projet Landmann, dont il sera question plus loin. Nous voyons donc que la création de la Banque nationale, par l'intermédiaire de la grave crise bancaire qu'elle provoque, constitue une pièce essentielle pour comprendre les appels en faveur d'une loi sur les banques qui se font entendre en I9I4.

La seconde transformation politique qui marque la phase d'émergence de la place financière suisse se réalise quelques années plus tôt, au tournant du siècle. Il s'agit du rachat par la Confédération helvétique des compagnies ferroviaires privées, qui aboutit finalement en 1898 , après un premier échec en votations populaires en 1891. La nationalisation des chemins de fer, en plus des conséquences sociopolitiques qu'elle entraîne, en faisant de l'État fédéral le premier employeur du pays ${ }^{26}$, provoque surtout la formation d'une véritable dette publique fédérale. Sous l'effet du rachat des chemins de fer, la dette publique de la Confédération passe de moins de 70 millions de francs suisses (moins de $3 \%$ du PIB) en I9OO à I.5 milliard de francs suisses à la veille de la Première Guerre mondiale (soit 4I \% du PIB) ${ }^{27}$. Le marché de cette nouvelle dette publique constitue un enjeu majeur pour le monde bancaire suisse. Pour contrer la concurrence des grands établissements français, qui se taillent la part du lion de la dette publique de la Confédération, les banques suisses entament un processus de cartellisation et de structuration. À la formation, en I897, du Cartel des banques suisses, regroupant les grandes banques et la Banque cantonale bernoise, répond, en 1907, la création de l'Union des banques cantonales suisses. En I9II, les deux groupements s'associent pour former le Syndicat d'émission des banques suisses ${ }^{28}$. Dès lors, les membres des deux cartels, c'est-à-dire les acteurs dominants du système bancaire suisse, s'entendent pour opérer en commun, et obtiennent une forme de monopole

La Suisse compte 449 banques en I9IO. Heiner Ritzmann-Blickenstorfer (éd.), Statistique historique de la Suisse, Zurich : Chronos, 1996, tableau O.I3, p. 819.

Landmann, op. cit., I9I6, p. 3I ; Bänziger, op. cit., I986, p. 30.

Ritzmann-Blickenstorfer (éd.), op. cit., I996, p. 8Io-8II, 8I9 (tableaux O.8 et O.I3).

Mazbouri, op. cit., 2005 , p. 78.

Ibid., p. 78.

Sur ce point, voir Guex, op. cit., 1993, p. 37. 
sur le marché des émissions publiques, renforçant, par là même, leur position vis-à-vis des emprunteurs publics ${ }^{29}$. En 19I2, la constitution de l'Association suisse des banquiers (baptisée jusqu'en I919 Association des représentants de la banque en Suisse) achève ce mouvement de cartellisation et de structuration des milieux bancaires helvétiques ${ }^{30}$. Ceux-ci disposent désormais d'une organisation capable non seulement d'agréger les intérêts internes à la branche, par le biais de conventions cartellaires, mais aussi de renforcer le poids et l'influence du secteur bancaire face aux autres acteurs économiques et aux autorités publiques ${ }^{31}$. Dans sa composition et son fonctionnement, l'Association suisse des banquiers consolide, dès ses premières années, le poids des acteurs dominants du système bancaire suisse. Ces derniers - grandes banques et banquiers privés pour les opérations internationales et banques cantonales d'importance pour le marché intérieur - occupent les premiers rangs dans les instances décisionnelles et sont donc en mesure d'imposer au reste de la branche ce qui en constituerait les intérêts généraux. Il n'est d'ailleurs pas anodin que la formation de l'ASB s'accomplisse au milieu de la crise bancaire des années I9IO1914. Les nombreuses déconfitures bancaires, nous le verrons, donnent lieu à une remise en question du cadre réglementaire très libéral dont bénéficie le secteur. Au moment où les premières velléités d'interventionnisme menacent le monde bancaire, la formation d'une association faîtière a également pour but d'organiser le secteur au-delà des dissensions internes, et de signifier ainsi qu'une immixtion de l'État est superflue ${ }^{32}$.

On peut d'ailleurs supposer que, pour une partie des milieux bancaires suisses, imposer une législation fédérale sur les banques revient également à unifier les règles du jeu. Pour autant que la réglementation ne fournisse pas à l'État des prérogatives trop importantes, la généralisation à l'ensemble des établissements financiers de certaines pratiques et règles prudentielles viendrait ainsi compléter le mouvement d'organisation et de structuration de la place financière qui s'opère depuis le tournant du siècle.

\section{kenverbände) ", Doktorarbeit, Rechts- und staatswissenschaftliche Fakulät, Universitä} Zürich, I922, p. 64-III.

31 Sur la genèse de l'ASB : Sébastien Guex, Malik Mazbouri, «De l'Association des représentants de la banque en Suisse (1912) à l'Association suisse des banquiers (1919). Genèse et fonctions de l'organisation faitière du secteur bancaire suisse ", in Danièle Fraboulet, Pierre Vernus (éd.), Genèse des organisations patronales en Europe (I ${ }^{e}-20^{e}$ siècles), Rennes: Presses Universitaires de Rennes, 20I2, p. 205-225. Voir aussi : Georg Lehmann, «Das Verbandswesen im schweizerischen Bankgewerbe", Doctor rerum politicarum, Rechts- und Wirtschaftswissenschaftlidren Fakultät, Universität Bern, 1956. Sur les conventions cartellaires conclues en son sein : Sébastien Guex, Malik Mazbouri, «L’Association suisse des banquiers et l'organisation du marché bancaire au XXe siècle ", in Danièle Fraboulet, Michel Margairaz, Pierre Vernus (éd.), Réguler l'économie. L'apport des organisations patronales. Europe, XIXe$X X^{e}$ siècles, Rennes: Presses Universitaires de Rennes, 2016, p. 23I-252. 
La phase d'émergence de la place financière suisse a ainsi produit à double titre un terrain favorable à l'expression d'une réglementation nationale du secteur bancaire. D'une part, le contexte conjoncturel des années I9IO-I9I4 marqué par une forte concentration bancaire provoque un renforcement des pressions politiques en faveur d'une régulation. D'autre part, les changements structurels vers une plus forte organisation corporative du secteur bancaire trouvent leur aboutissement dans le combat politique pour ou contre une législation bancaire au sein de l'Association suisse des banquiers.

\section{I.2. L'ÉLABORATION DU PROJET LANDMANN (1914-1916): UNE RÉPONSE POLITIQUE À LA CRISE BANCAIRE}

En janvier 1914, le Conseil fédéral, sous l'impulsion d'Edmund Schulthess (I868-I944) ${ }^{33}$, entame les démarches en vue d'une loi sur les banques. Ainsi prend forme l'embryon de ce qui deviendra le projet Landmann. Que s'est-il passé pour que l'autorité exécutive du pays, en la personne du conseiller fédéral radical Edmund Schulthess, membre du conseil d'administration de deux importantes sociétés financières proches du Crédit Suisse (Motor-Columbus et Elektrobank) avant son élection au gouvernement, menace d'intervenir aussi lourdement dans un secteur économique bénéficiant jusqu'alors d'un régime très libéral?

Les "catastrophes bancaires" des années I9IO-I9I4, dont nous avons déjà mesuré l'ampleur, sont les principales responsables de la première tentative de législation fédérale sur les banques. La crise atteint presque toutes les régions de Suisse, mais certains cantons, comme Thurgovie ou le Tessin, sont particulièrement affectés ${ }^{34}$. Cette saignée bancaire, symptôme du mouvement de

33 Edmund Schulthess est un avocat, conseiller juridique et politicien argovien. Au moment de son élection au gouvernement fédéral en I9I2 à l'âge de 44 ans, il bénéficie déjà d'une longue carrière politique sous les rangs du parti radical, d'abord à l'échelon cantonal (député cantonal dès I893 à 25 ans), puis fédéral (sénateur dès 1905). Spécialiste des questions économiques, il obtient également avant son élection au Conseil fédéral de nombreux mandats d'administrateurs, notamment auprès de l'industrie des machines (Brown, Boveri $\& \mathrm{C}^{\mathrm{ie}}$, Schlieren) et de l'énergie (Kraftwerke Beznau Löntsch) et dans le domaine financier (Aargauische Hypothekenbank, Rentenanstalt). Cf. Urs Altermatt, Conseil fédéral: dictionnaire biographique des cent premiers conseillers fédéraux, Yens: Cabédita, 1993, p. 321-322; Base de données "Élites suisses au XXe siècle ".

34 En Thurgovie, les caisses d'épargne d'Aadorf, Steckborn et Eschlikon entrent en liquidation en I9IO et 1912, entraînant d'importantes pertes pour les déposants malgré la garantie communale; en I9I4 suit la grave crise de la Thurgauische Hypothekenbank, finalement reprise par la Schweizerische Bodenkreditanstalt. Pfister, op. cit., 1916, p. I07; Wetter, op. cit., I9I8, p. 5-46. Au Tessin, les faillites en I9I4 du Credito Ticinese, de la Banca Cantonale Ticinese et de la Banca Popolare Ticinese provoquent un tel mécontentement populaire que les troupes fédérales interviennent pour disperser les émeutes. Ibid., p. I2O-I45. Voir aussi : Carl Kuster, Die Tessiner Bankkrise 19I4, Lugano : Druckerei Sanvito \& C., I920 ; Sergio Bello, " "Ai ladri! Ai ladri! Ai ladri!” Dalla bufera bancaria del gennaio I9I4 all creazione della Banca di Stato : un pagina oscura della finanza ticinese ", Mémoire de licence, Université de Lausanne, 2006. 
concentration qui traverse la branche depuis la fin du XIX siècle, est en grande partie due à la mise en place de la BNS en $1907^{35}$. Le renforcement général de la concurrence interbancaire joue un grand rôle dans de nombreux cas de faillites et reprises bancaires. Rappelons que la Suisse connaît alors un régime de réglementation bancaire dont les barrières à l'entrée étaient très faibles. Autrement dit, un système de régulation très ouvert favorise également une forme de concurrence qui peut conduire à une plus forte instabilité ${ }^{36}$. Les défaillances bancaires de I9IO-I9I4 sont causées essentiellement par la concentration croissante du secteur et la difficulté pour les petits instituts de faire face à cette concurrence ${ }^{37}$. Mais d'autres facteurs entrent en ligne de compte. Le recours excessif et inapproprié à des capitaux étrangers, les prises de risques démesurées en particulier dans l'octroi de crédits industriels, le dépassement du domaine d'activité naturel, l'agiotage sont autant de phénomènes observés ${ }^{38}$. Ces dysfonctionnements sont favorisés par une organisation interne lacunaire - notamment un cumul de fonctions fréquent entre direction des affaires courantes et administration, par un manque de transparence et un contrôle insuffisant. Landmann, dans l'exposé des motifs de son projet de loi bancaire, estime également que les causes des faillites résident dans une organisation et une gestion techniquement fausses :

Un grand nombre de ces catastrophes n'auraient probablement pas eu lieu si les établissements en cause n'avaient pas été administrés auparavant d'une façon techniquement défectueuse. L'organisation et la gestion insuffisantes, nous pourrions presque dire dilettantes, ont causé plus de préjudice [sic] que les actes dolosifs ${ }^{39}$.

Il souligne aussi parmi les autres facteurs responsables de la crise une concentration de pouvoirs excessive dans les mains d'une seule personne, l'incompétence des organes de contrôle, le dépassement de la sphère d'activité naturelle, une répartition inappropriée des risques, et la violation du principe de concordance des échéances qui entraîne des problèmes de liquidité (asymétrie des échéances dans le jargon contemporain) ${ }^{40}$.

Les conséquences des défaillances bancaires sont parfois dramatiques. En l'absence de dispositions protégeant les épargnes en cas de faillites, de

35 Elle n'est en revanche pas déclenchée par la crise financière américaine de 1907 liée au tremblement de terre de San Franciscso, comme prétendu par Suzanne Ziegler-Peter, «Bankinsolvenz und Einlegerschutz: Analyse und Beurteilung der Entwicklung in der Schweiz", Doktorarbeit in Wirtschaftswissenschaften, Universität Zürich, 20I4, p. 73.

36 Sur les rapports entre les conditions d'entrée, la concurrence et la stabilité bancaire, voir par exemple: Kris James Mitchener, Matthew Jaremski, «The Evolution of Bank Supervisory Institutions: Evidence from American States ", The Journal of Economic History, vol. 75, $\mathrm{n}^{\mathrm{o}}$ 03, 2015, p. 819-859.

37 Wetter, op. cit., I9I8, p. 322-323.

38 Ibid., p. 322-323.

39 Landmann, op. cit., I916, p. 32.

40 Ibid., p. 32-34. Voir aussi Schwander, op. cit., 1943, p. 16-20. 
nombreux déposants subissent d'importantes pertes. Aussi n'est-il pas étonnant que, dans les régions les plus touchées par la crise, des initiatives cantonales en vue d'un renforcement de la protection des épargnes voient le jour. Landmann est d'ailleurs bien conscient de la crise de légitimité que traversent certains dirigeants bancaires et politiques. Il estime que l'État doit combattre les abus par le moyen de la législation, quitte à assumer une plus grande responsabilité pour les instituts surveillés:

La responsabilité que l'État assume en promulguant la loi n'est certes pas minime, mais plus grande encore serait celle qui pèserait sur lui si, par peur des responsabilités, il négligeait de prendre une mesure reconnue nécessaire, car il refuserait ainsi d'accomplir une obligation morale qu'il impose lui-même à chacun de ses fonctionnaires et, dans une démocratie, à chacun de ses citoyens ${ }^{41}$.

Rappelons qu'en 19I4, il n'existe pas de législation fédérale sur le domaine bancaire. Seules quelques lois cantonales régissent ce domaine à l'échelle de leur territoire. En plus des lois sur les banques cantonales, évoquées plus haut, un certain nombre de cantons ont promulgué des lois sur les caisses d'épargne ${ }^{42}$. Entre I862 et 1917, de telles législations sont introduites dans I4 cantons. Or, ces réglementations sur les caisses d'épargne sont très hétérogènes et ne s'appliquent qu'à l'intérieur du rayon géographique cantonal. Elles se révèlent souvent inefficaces, car les institutions appelées caisses d'épargne et soumises aux lois cantonales pratiquent d'autres opérations que la collecte d'épargnes. Ainsi, dans le canton du Tessin, les «livrets d'épargne » deviennent des « livrets de dépôts " pour soustraire à la protection de la loi entrée en vigueur les fonds concernés, dont le caractère économique ne change par ailleurs pas. De même, les banques commerciales, alors non soumises aux mesures de protection, offrent également à leur clientèle de recueillir des dépôts, qui, du point de vue économique, constituent bien des épargnes. L'organisation bancaire suisse, caractérisée par la banque universelle pratiquant tous types d'opérations, se révèle peu adaptée à un système de protection de l'épargne limité à une catégorie d'institut et de dépôt ${ }^{43}$.

41 Landmann, op. cit., I916, p. 43.

42 Pour plus d'informations au sujet des lois cantonales sur les caisses d'épargne, nous renvoyons à notre manuscrit de thèse: Thibaud Giddey, «Surveiller et servir: la Commission fédérale des banques et la régulation des banques en Suisse (1914-I97I) ", Thèse de doctorat, Université de Lausanne, 2017, p. 38-4I. Cf. aussi Rudolf Huggenberg, Die Sparkassen und das Sparkassengeschäft (nach schweizerischem Recht), Affoltern am Albis : J. Weiss, 1906, p. 25-29; Pfister, op. cit., I916, p. 69-I2I; Hans Rudolf Schiller, Die Sparkassengesetzgebung in der Schweiz, Affoltern am Albis: J. Weiss, 1933; Paul Graber, Die Sicherung der Spareinlagen, Solothurn : Buchdruckerei Vogt-Schild, I935, p. 34-7I ; Markus Winiger, «Le secret bancaire suisse avant 1914 : législation fiscale fribourgeoise, comptes-joints, législations cantonales et fédérales sur les banques ", Mémoire de licence, Faculté des lettres, Université de Lausanne, 2007, p. I26-I36.

43 Cf. Karl Strasser, "Sparkassen", in Handbuch der schweizerischen Volkswirtschaft, Bern: Benteli, vol. 2, 1939, p. 332-334. 
Revenons donc à janvier I9I4 et à la décision de Schulthess d'entreprendre un projet de loi fédérale sur les banques. Nous avons vu que le processus d'élaboration du projet Landmann est à comprendre à la fois dans le contexte conjoncturel - la grave crise bancaire de I9IO-I9I3 - et dans une évolution structurelle - le mouvement d'organisation de la place financière suisse. Ces développements ne sont pas sans conséquences politiques. Au contraire, l'augmentation de la pression politique, également relayée dans les médias, trouve son expression dans une intervention parlementaire, en juin I9I3. Il s'agit de la motion Affolter, déposée au Conseil national le i8 juin I9I3. Hans Affolter (1870-1936), conseiller national socialiste soleurois, dans une motion munie de 17 signatures provenant du groupe socialiste, demande au Conseil fédéral de réviser le droit des obligations, dans le sens d'un renforcement de la responsabilité du conseil d'administration et de l'office de contrôle dans les sociétés anonymes. Relevons que la motion n'évoque pas l'adoption d'une législation spéciale sur le domaine bancaire, mais simplement le renforcement des dispositions de contrôle et de responsabilité qui concernent l'ensemble des sociétés anonymes, et pas uniquement les instituts de crédit.

Dans un premier temps, lors de la séance du 20 janvier 19ı4, le Conseil fédéral refuse d'entrer en matière sur une révision des seules questions de responsabilité et de contrôle, alors que l'ensemble du droit sur les sociétés anonymes est en cours de révision. Seule une accélération du processus législatif est souhaitée ${ }^{44}$. Lors de la séance suivante, le 23 janvier 19I4, le chef du Département du commerce, de l'industrie et de l'agriculture (futur Département de l'économie publique), le radical argovien Edmund Schulthess propose à ses collègues l'idée de soumettre les banques à une législation fédérale. Il estime que les dispositions cantonales sur l'épargne sont insuffisantes et que la législation doit viser à "protéger la fortune nationale confiée aux instituts de crédit " ${ }^{45}$. Schulthess envisage les mesures suivantes: premièrement, l'introduction d'une surveillance avec un système de concessions, comme pour les sociétés d'assurance; deuxièmement, le respect d'un rapport entre fonds propres et fonds de tiers et d'un ratio de liquidité; troisièmement, des dispositions sur la façon de porter au bilan et sur la responsabilité en complément du droit des obligations. Enfin, Schulthess aborde également l'épineuse question de l'application de la loi. Il exclut d'emblée les offices cantonaux et ajoute:

Il pourrait donc s'agir de créer un organe de surveillance fédéral, mais il faudrait aussi se demander si une organisation privée ne devrait pas être introduite, compte tenu du grand nombre d'entreprises concernées et de la protection souhaitable du secret des affaires ${ }^{46}$.

Dès les toutes premières réflexions gouvernementales sur la surveillance bancaire, le problème de la mise en œuvre du contrôle est abordé. Ayant en tête

AFB, Procès-verbal de décisions du Conseil fédéral, I9I4, vol. 255, $7^{\mathrm{e}}$ séance du 20.0I.I9I4. AFB, Procès-verbal de décisions du Conseil fédéral, I9I4, vol. 255, $8^{\mathrm{e}}$ séance du 23.0I.I9I4. AFB, Procès-verbal de décisions du Conseil fédéral, I9I4, vol. 255, $8^{\mathrm{e}}$ séance du 23.0I.I9I4. 
le modèle du contrôle des assurances privées existant depuis 1885 , Schulthess envisage la mise en place d'un organe étatique accordant des concessions. Or cette option, d'après la citation de Schulthess, se heurte à la délicate question de la confidentialité des opérations bancaires; il examine donc aussi une solution privée. Celle-ci prendrait une forme similaire à celle des syndicats de révision. La seule décision prise lors de la séance est celle de confier au Département du commerce, de l'industrie et de l'agriculture, en collaboration avec le Département des finances et celui de la justice, l'examen de la question, et, si une loi est jugée nécessaire, l'élaboration d'un projet de loi. Quelles sont les motivations de Schulthess qui propose ces mesures législatives? En plus de la pression politique exercée par les conséquences de la crise bancaire, il y a également un aspect tactique aux propositions du conseiller fédéral argovien : en agissant de manière préventive, il cherche à couper l'herbe sous le pied des groupes parlementaires favorable à une législation bancaire ${ }^{47}$.

À partir de janvier 19I4, les travaux préparatoires avancent relativement rapidement. Schulthess recueille également des avis externes, notamment celui d'Albert Meyer (I870-1953), alors rédacteur économique de la NZZ. Remarquons au passage que ces deux personnages qui débattent en I9I 4 d'un projet de loi sur les banques se retrouveront en 1934-I935 lors de la mise en application de loi sur les banques, qui aboutira finalement, mais sous d'autres fonctions. Albert Meyer sera alors conseiller fédéral en charge des finances et nommera Edmund Schulthess, fraîchement démissionnaire du Conseil fédéral, premier président de la Commission fédérale des banques. Dans un rapport de 25 pages daté du 27 mars 19I4, Albert Meyer réalise un diagnostic de la crise bancaire des années 1910-1913 et propose quelques remèdes à intégrer dans une législation ${ }^{48}$. Il insiste notamment sur les problèmes liés à la mauvaise répartition des risques et au dépassement du rayon naturel d'activité. Une amélioration de la transparence bancaire et des mesures sur l'établissement du bilan sont préconisées. De plus, toujours selon Meyer, des règles de ce qu'on appellerait aujourd'hui la corporate governance doivent être établies : les fonctions et compétences entre la direction, l'administration et le contrôle d'une banque doivent être séparées et clairement définies.

Parallèlement, Schulthess entre en contact avec les représentants du monde bancaire. Dès le 26 janvier I9I4 - soit seulement 3 jours après que le Conseil fédéral a abordé la question! -, le comité de l'ASB discute des projets du gouvernement ${ }^{49}$. Sur proposition de l'administrateur-délégué de la SBS Léopold Dubois, l'ASB décide de prendre l'avis des différentes places avant de

AASB, Procès-verbaux du Conseil de l'ASB, $8^{\mathrm{e}}$ séance, 22.06.19I4, p. I.

48 AFB, E6520(B), 2007/62, vol. 16, Dossier «Entwurf Landmann », rapport de Dr. A. Meyer au chef du Département du commerce, de l'industrie et de l'agriculture, 27.03.19I4. Ce rapport donnera lieu à une conférence de Meyer devant la Statistisch-volkswirtschaftlichen Gesellschaft de Zurich le 8 mai I9I4, qui sera publiée: Meyer, op. cit., I9I4.

49 AASB, Procès-verbaux du Conseil de l'ASB, 6e séance, 26.oI.I9I4, p. 8-Io. Toutes les citations du paragraphe qui suit sont extraites de ce document. 
définir une position commune. La tactique est claire: «il ne faut pas marcher trop vite». Autrement dit, mieux vaut attendre les propositions du Conseil fédéral et "ne pas faire trop de bruit». Là aussi, il est frappant de constater que l'idée d'un inspecteur fédéral des banques, sur le modèle du Bureau fédéral des assurances, est particulièrement crainte. La réalisation d'un tel projet serait, selon Rudolf Ernst (1865-1956) - président de l'Union des Banques Suisses récemment formée suite à la fusion en I9I2 de la Bank in Winterthur et de la Toggenburger Bank -, propre à engendrer de graves dommages pour les banques. Henri Chauvet (I856-1934) ajoute : «À Genève les banquiers n'aimeraient pas avoir une commission de surveillance. Une telle commission pourrait empêcher toutes les affaires».

Durant le printemps 19I4, Schulthess poursuit la consultation de divers représentants du monde bancaire : Julius Frey (I855-1925), président du Crédit Suisse, Friedrich Frey (I839-I928), président de l'ASB et membre du CA de la SBS, Heinrich Kundert (1853-I924), président de la BNS, ainsi que le banquier privé bâlois Alfred Sarasin (I865-1953) et son collègue genevois Henri Darier (I850-193I ${ }^{50}$. Nous reviendrons plus loin sur les réactions des banquiers aux propositions de Schulthess. En avril 19I4, après une première prise de contact, Schulthess confie à Julius Landmann la charge d'examiner la législation étrangère et de rédiger un avant-projet de loi ${ }^{51}$. Qui est donc cet expert et pourquoi fait-on appel à lui ?

Julius Landmann-Kalischer (I877-193I) est, en avril 19I4, professeur d'économie politique à l'Université de Bâle depuis $19 \mathrm{IO}^{52}$. Originaire de Galicie, alors en Autriche-Hongrie, Landmann obtient son doctorat à l'Université de Berne en 1900. Il participe à l'organisation du fonctionnement interne de la Banque nationale suisse (1906-1909) en tant que secrétaire général suppléant et chef du bureau statistique. Sa nomination à l'Université de Bâle en I9Io est en grande partie patronnée par le soutien des milieux bancaires bâlois. Non seulement la nouvelle chaire d'économie est financée par une fondation créée par la Société de Banque Suisse, mais le choix du candidat Landmann doit beaucoup aux soutiens influents de Friedrich Frey, Albert Burckhardt

AASB, Procès-verbaux du Conseil de l'ASB, $8^{e}$ séance, 22.06.I9I4, p. I-2, 7.

Schweizerisches Wirtschaftsarchiv (SWA), Handschriften Julius Landmann, HS 426, B2, Lettres d'E. Schulthess à J. Landmann, 04.04.1914 et 25.04.1914.

Sur le parcours de Landmann et ses interactions avec la finance et la politique helvétiques, voir: Guex, op. cit., 1993, p. 218-219; Sébastien Guex, "Est-il encore possible de vivre heureux dans notre patrie?" Splendeurs et misères d'un expert financier du Conseil fédéral : l'éviction de Julius Landmann (1914-1922) ", Revue suisse d'histoire, vol. 45, $\mathrm{n}^{\circ}$ 3, 1995, p. 3984I4; Annette Baudraz, "Julius Landmann (I877-193I). Législateur du Prince», Mémoire de licence, Faculté des lettres, Université de Lausanne, I997; Malik Mazbouri, «Le démon du pouvoir? Idéal scientifique et pratiques politiques. Réflexions sur le cas de Julius Landmann (I877-193I)", in Franziska Metzger, François Vallotton (éd.), L'historien, l'historienne dans la cité, Lausanne : Antipodes, 2009, p. 53-73; Korinna Schönhärl, Wissen und Visionen: Theorie und Politik der Ökonomen im Stefan-George-Kreis, Berlin : Akademie Verlag GmbH, 2009, p. 83-93, 208-231, 345-37I. 
(I854-19II) et Traugott Geering (1859-1932) ${ }^{53}$. Le parcours professionnel de Landmann et le réseau d'influence dont il bénéficie, notamment par son activité dans la Statistisch-volkswirtschaftliche Gesellschaft zu Basel, semblent indiquer une intégration relativement rapide à l'élite économique bâloise et nationale. Dès le début de son professorat, Landmann complète son enseignement universitaire par une importante activité d'expert. Le jeune professeur joue d'ailleurs un rôle important dans la création, toujours à Bâle, de l'Association suisse des banquiers. Sa conférence, donnée le 6 novembre I9II à la société susmentionnée, aurait fourni l'impulsion initiale en faveur d'une organisation corporative des banquiers ${ }^{54}$. Comme l'ont montré Mazbouri et Guex, la caution de Landmann est précieuse pour placer la naissance de ce groupe d'intérêts sous un patronage académique plutôt que sous celui des milieux financiers bâlois 55 . En 19I4, moment où le conseiller fédéral Schulthess fait appel à lui pour la rédaction de l'avant-projet de loi sur les banques, Landmann fait figure d'autorité académique bien intégrée dans les cercles dirigeants bâlois, et proche de banquiers influents.

Une seconde raison au moins peut expliquer le choix de Landmann par Schulthess. Dès I899, le futur professeur bâlois avait publié une étude sur la loi sur la Reichsbank allemande ${ }^{56}$. Nous l'avons vu, entre 1900 et 1910 , il se consacre presque entièrement à des questions liées à l'émission monétaire et à l'organisation de la Banque nationale suisse. En I9IO, le Conseiller d'État en charge des finances de Bâle-Ville, le libéral Paul Speiser (I846-I935), beau-frère du banquier privé Alfred Sarasin, confie déjà à Landmann un projet de révision de la loi sur la Banque cantonale de Bâle. Pour faire suite au rapport du professeur, la loi est en effet révisée dans le sens d'une amélioration du contrôle de l'organe externe. Speiser propose alors en I9I3 à Landmann la fonction de membre du comité de contrôle externe de la Banque cantonale de Bâle, poste que ce dernier occupera jusqu'en $1918^{57}$.

53 En I9IO, Friedrich Frey, ancien directeur de la Bank in Basel, est membre du conseil d'administration de la Société de Banque Suisse. Il deviendra le premier président de l'ASB en 1912. Albert Burckhardt, ancien professeur d'histoire suisse à l'Université de Bâle, est alors conseiller d'État libéral en charge de l'instruction publique. Quant à Traugott Geering, il est à la fois privat-docent d'économie politique à l'Université de Bâle et secrétaire de la Chambre de commerce bâloise.

54 ASB, Rapport à l'Assemblée générale du I8 octobre I9I3 à Genève sur le premier exercice du I6 novembre I9I2 jusqu'au 30 juin I9I3, Bâle, I9I3, p. 3. Il est intéressant de noter qu'une fois tombé en disgrâce auprès de milieux bancaires, Julius Landmann n'est plus mentionné nommément dans les publications sur la genèse de l'association. Par ailleurs, celles-ci passent sous silence les liens entre la création de la chaire de Landmann et les volontés des dirigeants bancaires bâlois, par l'intermédiaire de la fondation Bank in Basel Stiftung. Cf. Von Moos, op. cit., I922, p. 64; Lehmann, op. cit., 1956, p. I7-18. Guex, Mazbouri, art. cit., in Fraboulet, Vernus (éd.), op. cit., 2012. Landmann, "Zur Abänderung des deutschen Bankgesetzes », Bank-Archiv, nº 8, 1908-09, p. 56.

57 Baudraz, op. cit., 1997, p. 35-36. 
Lorsqu'en avril I9I4 Schulthess mandate le professeur Landmann, il s'adresse donc non seulement à un expert en législation bancaire, bénéficiant de connaissances à la fois théoriques et pratiques dans le domaine des opérations de crédit et du contrôle bancaire, mais également à un spécialiste reconnu qui occupe une "position de médiateur", d'intermédiaire entre les milieux financiers et l'État ${ }^{58}$.

En moins de deux mois, Landmann produit un premier avant-projet contenant $6 \mathrm{I}$ articles $^{59}$. Le projet prévoit de ne pas soumettre les banques cantonales et les banquiers privés à toutes les dispositions de la loi ; les gestionnaires de fortune et les sociétés de trust ne seraient pas concernées non plus. L'octroi d'une concession serait nécessaire pour entreprendre l'activité bancaire; les critères d'autorisation incluraient l'attestation d'un certificat de bonnes mœurs, de droits de bourgeoisie, le choix d'une raison sociale appropriée, la présentation de statuts adéquats définissant les compétences des organes dirigeants et le rayon d'activité, le dépôt d'une caution auprès de la Banque nationale, ainsi que la constitution d'un fonds de réserve à hauteur de $20 \%$ du capital. Un rapport minimal entre les fonds propres et les fonds de tiers et un rapport de liquidité sont prévus. Des mesures sur l'établissement du bilan et des comptes annuels, sur la révision externe par un organe indépendant font aussi partie de ce premier projet. Un office de surveillance des banques (Aufsichtsamt über das Bankwesen), inspiré de l'inspecteur des banques d'émission et de l'office fédéral des assurances, serait créé. Cet office aurait pour tâche principale de contrôler l'activité des instituts de révision, et ne devrait intervenir qu'en cas de dénonciation ou d'irrégularité. Une commission bancaire, composée de cinq à sept praticiens, serait adjointe à l'office de surveillance.

La réaction des banquiers face à cette ébauche de réglementation fédérale, telle qu'elle ressort d'un débat au sein du comité de l'ASB, est très critique. Pourtant, le programme envisagé n'est pas une réforme radicale du système bancaire. La liberté de mouvement des banques ne doit pas être restreinte. Selon Julius Frey, le rapporteur en la matière parmi le cénacle de dirigeants bancaires, le principal instigateur du projet, le conseiller fédéral Schulthess, aurait même tenu des propos rassurants : «La législation bancaire ne doit pas se faire contre, mais avec les banques. " $" 00$

Pour Julius Frey, les questions de contrôle, de compétences et responsabilités des dirigeants d'entreprise devraient plutôt être réglées dans la révision du

\section{Ibid., p. 40.}

$59 \mathrm{AFB}, \mathrm{E}_{7350,}$ I000/IIO4, vol. 36-37, dossier «Bankengesetz: Gutachten, Berichte, Korrespondenz, Strafbestimmungen, etc. » Schulthess reçoit l'aval du Conseil fédéral pour mandater Landmann fin avril et lui l'annonce dans une lettre du 27 avril I9I4. Landmann lui transmet un texte le is juin I9I4 dont Schulthess fait un commentaire transmis le 22 juin. Ce texte est débattu par le Comité de l'ASB le 22 juin. Même si le Vorentwurf zum Bankgesetz n'est pas daté, on peut estimer qu'il est produit entre les mois de mai et la première quinzaine de juin I9I4.

60 Edmund Schulthess, cité par Julius Frey. AASB, Procès-verbaux du Conseil de l'ASB, $8^{\mathrm{e}}$ séance, 22.06.1914, p. 4. 
droit des obligations en cours ${ }^{61}$. Le président du Crédit Suisse désapprouve également les mesures sur la liquidité. Un office des banques ne serait pas capable de définir si une banque est liquide ou non, et de telles mesures pourraient être néfastes à la rentabilité des banques. L'ensemble des banquiers qui s'exprime sur la question du rapport de liquidité partage les craintes de Julius Frey ${ }^{62}$. Enfin, la question de l'office des banques et de la commission bancaire soulève un certain scepticisme. Paul Appia souhaite que la Banque nationale "n'ait rien à faire avec ces organes", tandis que Henri Chauvet, banquier privé genevois, suggère d'éviter que la commission soit "composée de politiciens ». La stratégie à venir est relativement claire parmi les banquiers : même s'ils sont réticents à l'idée d'une législation spéciale et au principe d'une loi sur les banques, ils estiment qu'il vaut mieux collaborer aux projets, plutôt que de s'y opposer d'emblée. Une commission est formée pour étudier la possibilité d'adopter volontairement un modèle de bilan plus détaillé et une position stratégique attentiste établie ${ }^{63}$.

Suite à cet accueil peu enthousiaste du projet Landmann chez les milieux intéressés en juin 19I4, le processus législatif est provisoirement mis en veille. Le déclenchement de la Première Guerre mondiale fin juillet I9I4 joue également un rôle dans le ralentissement de la procédure. Les autorités helvétiques, tablant sur une guerre de courte durée, ne disposent pas de préparation économique sérieuse, à la fois en matière d'approvisionnement et dans le domaine financier et monétaire ${ }^{64}$. Dans ces circonstances, le Département du commerce, de l'industrie et de l'agriculture dirigé par Schulthess néglige le projet de législation bancaire. Quelles que soient les raisons exactes de la mise en veille du projet de loi sur les banques, il faut attendre plus de 18 mois, soit janvier 1916, pour que les travaux reprennent.

61 AASB, Procès-verbaux du Conseil de l'ASB, $8^{e}$ séance, 22.06.19I4, p. 4. Sur la révision du droit des obligations, voir Martin Lüpold, «Der Ausbau der "Festung Schweiz” : Aktienrecht und Corporate Governance in der Schweiz, I88I-I96I ", Doktorarbeit, Philosophische Fakultät, Universität Zürich, 20I0, p. I75-177.

62 Les I8 membres de l'Ausschuss présents le 22 juin I9I4 se répartissent comme suit : 8 représentants des banquiers privés, 6 représentants des grandes banques, 2 représentants des banques cantonales et 2 représentants d'autres banques (Banque de Dépôt et de Crédit, GE, et la Banca Populare di Lugano, TI).

63 La composition de cette commission interne à l'ASB n'est pas dévoilée. AASB, Procèsverbaux du Conseil de l'ASB, 8 e séance, 22.06.1914, p. II.

64 Cf. Guex, op. cit., 1993, p. I62-164. Heinz Ochsenbein, Die verlorene Wirtschaftsfreiheit, I9I4I9I8: Methoden ausländischer Wirtschaftskontrollen über die Schweiz, Bern : Stämpfli, I97I, p. 24 . 


\section{I.3. BLOCAGE ET ABANDON DU PROJET LANDMANN (1916-1917): LES RÉACTIONS CONTRASTÉES DES MILIEUX BANCAIRES AVANT LE COUPERET FINAL}

En janvier 1916, Schulthess et son ministère, devenu en i9is le «Département de l'économie publique ", reprennent les travaux préparatoires en vue de l'adoption d'une loi fédérale sur les banques. Ce n'est qu'en août I9I6 que le projet de loi sera traduit en français, l'exposé des motifs ne sera prêt qu'en novembre de la même année ${ }^{65}$. En quoi consiste ce projet de loi ?

Le "projet d'une loi fédérale concernant l'exploitation et la surveillance des banques» constitue en fait bien plus qu'une simple ébauche de texte réglementaire. Les 69 articles du projet de loi à proprement parler sont accompagnés d'un exposé des motifs qui, non seulement, à la manière d'un commentaire juridique, interprète et explicite les dispositions prévues, mais, dans sa partie générale, met en perspective les mesures envisagées à la lumière de l'expérience de la récente crise suisse et des exemples de législations étrangères. L'ensemble forme un texte extrêmement riche et substantiel (222 pages!). Il restera d'ailleurs, malgré l'omerta dont il fera l'objet, une étude de référence sur la question qui inspirera nombre de juristes et d'économistes abordant le sujet durant l'entre-deux-guerres ${ }^{66}$. Après avoir stigmatisé les défauts ayant provoqué la crise de 1910-1913, Landmann souligne l'incompatibilité des modèles étrangers d'intervention législative avec les spécificités du système bancaire helvétique ${ }^{67}$. Le type de la banque universelle, tel qu'il prévaut en Suisse, s'accommode mal d'une réglementation qui ne s'appliquerait qu'à une forme d'instituts, comme les banques hypothécaires, ou qu’à une catégorie de dépôts, comme les épargnes.

La crise bancaire récente et les manquements qu'elle a mis à jour, l'insuffisance des législations cantonales sur l'épargne, l'inadéquation des réglementations étrangères ainsi que la position particulière des banques - tributaires de la confiance du public - justifient pour Landmann l'adoption d'une législation fédérale sur les banques. L'objectif de loi serait le suivant: «imposer aux établissements où elles font défaut l'organisation et la gestion rationnelles que les institutions bien dirigées se sont données par leur initiative et leurs propres moyens" ${ }^{68}$. Conformément à la promesse de Schulthess faite aux banquiers au printemps I9I4, la loi n'est pas projetée contre les banques; au contraire, pour son auteur, elle soutient leurs intérêts. Pour l'essentiel, le projet Landmann repose sur quatre ensembles de dispositions.

Premièrement, il introduit un système de concessions et soumet la pratique des opérations bancaires à certaines conditions. Ce principe veut mettre un

65

66

68

Baudraz, op. cit., I997, p. 37.

Cf. Schwander, op. cit., I943, p. I5; Mende, op. cit., I935, p. II6-I37; Urech, op. cit., I944, p. 3-4.

Landmann, op. cit., I9I6, p. 30-36, 46-54.

Ibid., p. 37-38, 43. 
terme à la liberté de commerce absolue qui permet à "tout escroc notoire sortant de prison [de] fonder une banque par actions et prendre des acolytes comme administrateurs ou directeurs ${ }^{69}$. Selon le projet de loi, le Conseil fédéral peut donc octroyer ou refuser des concessions après l'examen des statuts, l'organisation interne et la capitalisation de la banque. Cette analyse des statuts préalable à l'ouverture d'une banque a également pour objectif de garantir que le rayon d'activité de l'institut soit clairement défini et que les compétences de direction, d'administration et de contrôle au sein de l'entreprise soient distinctement séparées. La clause du besoin, c'est-à-dire un examen de l'opportunité économique de l'ouverture d'une banque par rapport aux conditions de marché, ne peut pas être invoquée pour refuser la création d'une nouvelle banque.

Deuxièmement, le projet Landmann prévoit des mesures sur l'établissement et la publication des bilans et des rapports annuels, ainsi que l'introduction d'un rapport entre fonds propres et fonds de tiers et entre fonds disponibles et engagements à court terme (liquidité). Ce type de dispositions prudentielles, aménagées dans une législation fédérale, est relativement novateur à l'époque ${ }^{70}$. Certains types d'établissements sont ménagés par la définition de différentes catégories de banques. Ainsi, les instituts financiers qui ne font pas appel au public pour recueillir des dépôts, qui ne font pas figurer le mot "épargne", dont le capital n'est pas formé de souscriptions publiques et dont les actions ne sont pas cotées en bourse, sont dispensés de l'obligation de publier annuellement un rapport de gestion, les comptes et le bilan. L'on comprend vite que cette dérogation concerne avant tout les banquiers privés. Relevons que Landmann introduit ici une notion juridique qui sera reprise dans les années I930 et posera certains problèmes d'application. Il s'agit du concept de « recommandation au public pour l'acceptation de dépôts ", qui deviendra un critère pour mesurer le champ d'application de la réglementation. En outre, il faut souligner que Landmann est tout à fait conscient des limites de l'efficacité de la publication des bilans, «la pratique très courante qui consiste à retoucher les bilans» en fin d'année ne lui est pas inconnue ${ }^{71}$. Il prévoit donc la publication de bilans intermédiaires sommaires pour exercer un contrôle plus continu. Quant à la fixation de ce qu'on appellerait aujourd'hui des ratios de solvabilité et de liquidité, le projet évite de déterminer un rapport chiffré et universel, mais laisse à l'autorité de surveillance la compétence d'appliquer cette disposition générale en tenant compte des spécificités de chaque type d'établissement.

69

70 Hubert Bonin estime que la véritable naissance de l'architecture prudentielle (transparence bilancielle, ratios de solvabilité et de liquidité) a lieu au cours de la crise de i929-1935. Hubert Bonin, "Crises et réglementation bancaire dans l'histoire européenne. Quelques rappels pour nourrir les débats actuels ", in Loïc Grard, Pascal Kaufmann (éd.), L'Europe des banques. Approches juridique et économique. Concurrence, Réglementation, Marché Unique, Paris: Pedone, 20Io, p. 8I-96, p. 89.

71 Landmann, op. cit., I9I6, p. I37. 
Troisièmement - et il s'agit là d'un des aspects les plus novateurs du projet Landmann, il met en place «la révision fiduciaire " (Treuhandrevision) ${ }^{72}$, c'està-dire un contrôle obligatoire par des instituts de révision externes, agréés par le Conseil fédéral. Ce point mérite qu'on s'y attarde un instant, pour au moins deux raisons. D'une part, la question de la révision fiduciaire constitue un élément-clé dans le système de surveillance, puisque c'est sur ce contrôle que repose l'exécution effective des mesures légales auprès de chaque banque. D'autre part, Landmann, en introduisant cette innovation, joue un rôle de précurseur. Le même type de dispositions sera en effet repris dans les projets qui verront le jour dans les années I930.

De quoi s'agit-il ? Cette révision est singulière, dans le sens où elle s'ajoute, pour les banques organisées sous forme de sociétés anonymes, au contrôle du conseil d'administration et au contrôle obligatoire selon le droit des obligations. Cette révision fiduciaire peut être réalisée par deux types d'institutions: les sociétés fiduciaires organisées sous forme de sociétés anonymes et les syndicats de révision mutuelle, un type d'organisation préconisé par les banques locales dans les régions rurales. Si cette disposition s'inspire vaguement du rôle des Chartered accountants dans le système économique britannique, elle se distingue assez nettement du point de vue de la gouvernance d'entreprise du modèle anglais, puisque la révision fiduciaire selon Landmann vise aussi à renforcer la responsabilité et le pouvoir du conseil d'administration vis-à-vis de la direction. En revanche, l'institut de révision et ses rapports ne sont pas présentés publiquement lors de l'assemblée générale des actionnaires, pour éviter que les informations ne soient complètement édulcorées en prévision de l'audience trop large à laquelle elles seraient soumises.

Cette solution accordant un rôle prépondérant aux sociétés fiduciaires et aux syndicats de révision est véritablement originale et innovante. Ceci est d'autant plus remarquable que la branche économique des fiduciaires est alors très jeune en Suisse. La Schweizerische Treuhandgesellschaft, première société fiduciaire de Suisse, est fondée à Bâle en 1906, en tant que société affiliée à la nébuleuse de la $\mathrm{SBS}^{73}$. Les trois autres principales sociétés fiduciaires helvétiques sont fondées en I912 : la Fides Treuhand-Vereinigung en 1912 à Zurich (reprise en 1928 par le Crédit Suisse), la Allgemeine Treuhand- und Revisionsgesellschaft en I9I2 à Bâle, et la Schweizerische Revisionsgesellschaft AG à Zurich par les banques du groupe UBS ${ }^{74}$. Quant aux syndicats de révision mutuelle, ils sont également d'apparition très récente au moment où

72 Les termes révision et réviseur employés dans le sens de vérification comptable sont orthographiés avec la graphie revision et reviseur par les acteurs contemporains jusqu'au dernier tiers du XXe siècle. Nous avons choisi de moderniser cette graphie, mais la maintenons dans les citations.

73 Carl Helbling, Geschichte der Treuhand-und Revisionsbranche. Die Igo6 gegründete Schweizerische Treuhandgesellschaft im Wandel der Zeiten, Zürich : Verlag Neue Zürcher Zeitung, 2006.

74 Ibid., p. 40-4I. 
Landmann les intronise dans son projet de loi. Le Revisionsverband bernischer Banken und Sparkassen est fondé en $1912^{75}$. Le syndicat argovien et le syndicat saint-gallois suivent en 1913 , puis le syndicat lucernois en $1915^{76}$. L'organisation faîtière, le Verband schweizerischer Bücherexperten, voit le jour en $1913^{77}$. Comment comprendre le recours à ce type de contrôle externe qui n'a pas encore fait ses preuves? Bänziger avance que l'introduction de la révision fiduciaire chez Landmann est due aux bonnes expériences faites avec ce système ${ }^{78}$. La relative jeunesse des organisations permet de douter de cette interprétation. En revanche, Landmann voyait assurément deux avantages en confiant le contrôle direct à des sociétés fiduciaires. D’une part, il cherche à renforcer le poids du conseil d'administration et à lui permettre de surveiller l'activité de la direction de la banque ${ }^{79}$. D'autre part, l'officialisation du rôle des fiduciaires s'intègre parfaitement dans la philosophie générale de la loi, qui vise à étendre à toutes les banques les principes de gestion que les instituts bien dirigés se sont donnés par eux-mêmes. Or, la révision fiduciaire, que ce soit par l'intermédiaire d'une société formellement indépendante ou par le biais des inspectorats internes, est une pratique que les grandes banques connaissent déjà en 1916.

Quatrièmement, le projet prévoit l'établissement d'un «Office fédéral des banques" (Bundesamt für das Bankwesen), chargé de l'application de la surveillance. Cette nouvelle autorité serait intégrée à l'administration fédérale et nommée par le Conseil fédéral. L'office fédéral des banques prévu - et donc, le Conseil fédéral - dispose de certaines compétences pour assurer l'application de la loi. Il peut " prendre toutes mesures utiles pour assurer la conformité de la gestion des banques avec les prescriptions légales et pour mettre fin aux abus qui compromettraient les intérêts des établissements mêmes ou de leurs créanciers ou bien qui mettraient la gestion en conflit avec l'intérêt public ou les bonnes mœurs ${ }^{80}$. Cette définition extensive revient à une forme de blanc-seing renforçant les pouvoirs discrétionnaires dont dispose l'État. Comme mesure la plus radicale, il peut en outre retirer l'autorisation d'exercer à une banque, ce qui a pour conséquence la liquidation de l'établissement ${ }^{81}$. Comme autre mesure répressive, le projet prévoit des amendes pouvant aller jusqu'à IO 000 francs directement prononçables par l'Office fédéral des banques. Les dispositions pénales prévoient en outre des amendes - celles-ci ordonnées par les organes juridiques cantonaux compétents - de 300 à 20000 francs et des

Lehmann, op. cit., 1956, p. 33-52.

Ibid., p. 54.

Max Oetterli, «Die rechtliche Stellung der Revisionsverbände und Treuhandgesellschaften nach Bankengesetz », Doktor beider Rechte, Juristischen Fakultät, Universität Bern, 194I, p. 5 .

8 Bänziger, op. cit., 1986, p. 45.

Landmann, op. cit., 1916, p. 86-87.

Ibid., art. 50, p. I2, voir aussi p. I54.

Ibid., p. I55. 
peines d'emprisonnement cumulables. Pour contrebalancer les pouvoirs relativement étendus de l'Office fédéral des banques, Landmann prévoit une commission consultative composée "d'hommes versés dans les opérations de banque ${ }^{82}$, qui doit être entendue avant l'exécution de toutes les lourdes peines. Landmann conjecture d'ailleurs que l'autorité de surveillance ne pourra pas entrer en contradiction avec les intérêts des banques, si elle veut connaître le succès et acquérir la confiance des cercles dirigeants de la banque. Si par hasard l'autorité de surveillance cherchait à administrer les banques de manière arbitraire et par abus de compétence, elle disparaittrait sans tarder. Landmann ajoute, plein de clairvoyance:

Cela [la disparition de l'autorité de surveillance] se ferait d'autant plus rapidement et d'autant plus sûrement que la banque suisse est représentée par des intéressés capables, possédant des relations très ramifiées et particulièrement influentes ${ }^{83}$.

Conscient du poids dont disposent les dirigeants bancaires en Suisse, Landmann a déjà apporté au projet de 1914 quelques modifications significatives. Ainsi, comme le demandait la majorité du comité de l'ASB, les banques cantonales sont en partie soumises, dans le projet de 1916, à la réglementation fédérale. Elles échappent certes aux dispositions sur la révision fiduciaire et sur les concessions, mais sont assujetties à toutes les autres mesures, ainsi qu'à la surveillance de l'Office fédéral des banques ${ }^{84}$. De plus, en réponse aux critiques des banquiers helvétiques, le projet inclut également des mesures plus contraignantes pour l'établissement de succursales de banques étrangères en Suisse ; il introduit en particulier la clause de réciprocité, qui exige qu'une banque suisse puisse être active dans le pays d'origine d'une banque étrangère qui souhaiterait ouvrir en Suisse. En plus de ces modifications qui répondent directement aux vœux de l'ASB exprimés en juin 19I4, Landmann, dans son exposé des motifs, cherche aussi à rassurer les banques sur la portée de l'interventionnisme étatique prévu. En décrivant le rôle de l'Office fédéral des banques, il se montre très prudent:

Aucun fonctionnaire de l'État ne pourra contrôler une banque; aucune autorité de l'État ne pourrait examiner les affaires internes de la gestion des divers établissements; le projet prévoit un contrôle organisé par l'État, mais non pas un contrôle direct de l'État ${ }^{85}$.

Malgré ces concessions et propos rassurants, le projet Landmann ne reçoit pas un accueil très favorable auprès des milieux intéressés lorsque le conseiller fédéral Schulthess reprend le processus législatif en 1916. La position finale des

Ibid., art. 54, p. I3.

Ibid., 94 .

Cf. art. I, lettre b. Ibid., p. I.

Ibid., p. 9I. 
dirigeants de banques helvétiques consiste en un rejet du projet de loi, en faisant recours, comme le montrent Mazbouri et Schaufelbuehl, à une stratégie en deux temps: une tactique dilatoire visant d'abord à repousser l'entrée en négociation officielle, puis une politique de censure, dans le but d'empêcher la publication du projet de loi ${ }^{86}$. Mais, au départ, il n'existe pas, parmi les élites bancaires suisses, de front commun pour s'opposer au principe d'une législation bancaire. Il faut au contraire distinguer deux positions.

D’un côté, Julius Frey-Gamper, malgré les critiques qu'il émet sur le premier projet Landmann de 1914, est le principal expert et consultant, parmi les dirigeants bancaires, pour les questions relatives au projet de loi. Le président du Crédit Suisse entretient une riche correspondance avec Schulthess et Landmann. Les relations anciennes et le respect mutuel entre les trois hommes conduisent à une collaboration intense ${ }^{87}$.

Face à ce pôle favorable à une intervention législative se dresse une tendance moins encline au compromis, qui remportera finalement l'adhésion d'une majorité des dirigeants bancaires. Les représentants de la haute banque genevoise $^{88}$ - et les banquiers privés en général - sont les plus virulents dans leur opposition à l'intervention législative, sous la forme proposée par Landmann. Cette dichotomie interne ressort d'ailleurs très clairement dans un article paru dans le Journal de Statistique et Revue économique Suisse en 1916. Dans le cadre d'un débat différent, qui porte sur l'opportunité ou non d'une intervention fédérale dans le domaine des bourses, l'organe de la Société suisse de statistique publie les réactions de divers dirigeants bancaires helvétiques à une proposition d'Albert Meyer, rédacteur économique de la $N Z Z$ et conseiller national radical zurichois, qui suggère de mettre en place un Office fédéral d'admission des cotes à la bourse chargé de limiter en particulier l'admission de valeurs étrangères ${ }^{89}$. Henri Darier, dans sa prise de position publiée dans le Journal de statistique et Revue économique Suisse, rejette l'interventionnisme étatique fédéral à la fois dans le domaine des bourses et dans celui des banques:

Il semble vraiment qu'une sorte de levée de boucliers soit en train de se dessiner contre les banques, les banquiers, la bourse et les émissions, en un mot contre tout ce qui touche de près ou de loin à la finance. [...] La plupart de ces projets sont malheureusement orientés dans un sens étatiste et centralisateur $[\ldots]^{90}$.

Mazbouri, Schaufelbuehl, art. cit., 20I5.

Cf. SWA, Handschriften Landmann, HS 426, B2, B3, B4.

Henri Darier, pourtant prévu comme expert romand dans l'élaboration du projet Landmann, refuse même en mai 1916 de revoir la traduction française du texte législatif. Cf. SWA, Handschriften Landmann, HS 426, B3, Lettre d'H. Darier à J. Landmann, I0.05.1916. La traduction française du projet sera donc l'œuvre d'Eugène Péquignot (I889-1962), fonctionnaire au Département de l'économie publique.

89 C. F. W. Burckhardt, et al., «Zur Frage der Neuordnung des Effektenbörsen- und Emissionswesens ", Journal de statistique et revue économique suisse, vol. 52, 1916, p. 329-365.

90 Henri Darier dans ibid., p. 33I. 
À l'inverse, Julius Frey-Gamper, tout en remettant en question une partie des propositions de réglementation de l'émission de titres, estime, dans cette même publication, que la législation bancaire est prioritaire : «l'adoption d'une loi de surveillance bancaire visant en général à un contrôle plus strict de l'activité de nos banques est encore plus urgente que l'établissement de règles uniformes pour l'admission de titres dans les bourses suisses ${ }^{91}$. Il envisage même que la commission d'experts bancaires prévue par le projet Landmann puisse jouer un rôle, en collaboration avec l'ASB, en tant qu'instance d'admission.

Avant d'aborder le dénouement de cette affaire - à savoir la mise au placard du projet Landmann -, interrogeons-nous sur cette opposition interne aux milieux bancaires. Au-delà des relais personnels, qui jouent certainement un grand rôle, notamment dans le cas de l'implication de Julius Frey-Gamper auprès de Schulthess et Landmann, comment comprendre ses dissensions internes? On peut supposer, avec Mazbouri et Schaufelbuehl, que les grandes banques universelles, dont Frey-Gamper était un éminent représentant, constituaient la catégorie de banques qui avait le plus à gagner dans l'introduction d'une régulation bancaire sur le modèle de celle projetée par Landmann ${ }^{92}$. Car, pour l'essentiel, le projet de loi aurait eu pour effet d'étendre à toutes les institutions des réglementations formelles et prudentielles déjà en vigueur dans la plupart des grandes banques. Tant les dispositions sur la gouvernance d'entreprise que celles sur la révision fiduciaire ou les rapports de liquidité et de fonds propres ne nécessitent pas de lourds aménagements chez les acteurs dominants. Frey-Gamper ne s'en cache d'ailleurs pas dans une des nombreuses lettres qu'il écrit à Landmann en vue de remanier le projet de loi. Alors qu'il félicite le professeur bâlois d'avoir pris en compte ses remarques sur la révision fiduciaire, il suggère encore que le Conseil fédéral accepte la possibilité de nommer les inspectorats internes déjà présents dans les grandes banques en tant qu'instances de révision ${ }^{93}$. En revanche, l'instauration chez les plus petits instituts des mesures réglementaires aurait pour effet de renforcer la stabilité du marché et de limiter le domaine d'activité des banques régionales. Les grandes banques pourraient ainsi poursuivre leur expansion sur le marché intérieur et accentuer le mouvement de concentration à l'œuvre depuis le début du siècle ${ }^{94}$.

De plus - et ce point prend toute son importance dans la réaction contrastée des banquiers privés genevois -, Frey-Gamper et les représentants des grandes banques alémaniques voient sans doute d'un bon œil une législation qui consacre le modèle de la banque à tout faire de type continental, dont le Crédit Suisse est un représentant par excellence. Au contraire, la haute banque genevoise, malgré sa réticence habituelle à toute intervention étatique, aurait plutôt été encline à l'introduction d'une spécialisation des activités bancaires sur le

91 Julius Frey dans ibid., p. 334.

92 Mazbouri, Schaufelbuehl, art. cit., 2015.

93 SWA, Handschriften Landmann, HS 426, B3, Lettre de Julius Frey à Julius Landmann, 04.02.1916.

94 Mazbouri, op. cit., 2005, p. 218-22I. 
modèle anglais ${ }^{95}$. Landmann, dans le débat théorique classique entre tenants de la banque universelle à l'allemande et banque spécialisée de type anglo-saxon, penche clairement pour le maintien en Suisse du modèle en place ${ }^{96}$.

Le troisième argument émis par Frey-Gamper en faveur du projet Landmann est celui de son but préventif. En préparant une réglementation sur les banques, Schulthess cherche aussi à couper l'herbe sous les pieds des partisans politiques d'une intervention étatique dans le domaine. L'initiative du conseiller fédéral argovien aurait permis d'éviter le dépôt de quatre motions parlementaires relatives à la protection de l'épargne ${ }^{97}$.

Finalement, le dernier élément à prendre en compte pour comprendre l'attitude de coopération dont fait montre une partie des milieux bancaires dans l'élaboration d'une législation qu'ils ne désirent pas, réside dans les particularités du système politique suisse. En effet, les banquiers n'ignorent pas qu'entre le projet initial de Landmann - dont la portée est certes relativement grande - et les ordonnances d'exécution finalement adoptées au terme du processus de décision, ils auraient encore l'occasion de remanier le projet selon leurs vœux, par le biais des nombreuses commissions et conférences d'experts pré-parlementaires. Léopold Dubois n'émet-il pas dès I9I4 le souhait que «l'on examine soigneusement le règlement d'exécution ", c'est-à-dire l'ordonnance plus malléable qui précise les principes généraux gravés dans la loi ?98

L'autre tendance au sein des banquiers suisses, dont le banquier privé genevois Henri Darier ou encore le banquier privé bâlois et vice-président de l'ASB Alfred Sarasin sont les principaux porte-paroles, refuse le principe même de l'intervention législative. Deux préoccupations principales animent le rejet du projet Landmann, et même celui de sa publication ou d'une discussion publique à son sujet.

Premièrement, alors même que le projet prévoit un statut particulier pour les banquiers privés qui les autorisent par exemple à ne pas publier leur bilan ${ }^{99}$, toutes les dispositions relatives à la transparence des bilans et à la révision fiduciaire sont vivement contestées. Ainsi Henri Chauvet, banquier privé genevois, déclare-t-il lors de la discussion du comité de l'ASB en juin 19I4: «C'est trop [sic] par exemple qu'on demande qu'il soit dit dans le compte des

Cf. Landmann, op. cit., 1916, p. 63-65.

Ibid., p. 67. Sur le débat théorique entre banque universelle et banque spécialisée, voir notamment : Caroline Fohlin, «Universal Banking in Pre-World War I Germany : Model or Myth?", Explorations in Economic History, vol. 36, no 4, 1999, p. 305-343; Caroline Fohlin, «Economic, Political and Legal Factors in Financial System Development: International Patterns in Historical Perspective», Social Science Working Paper I089, Pasadena: California Institute of Technology, 2000.

97 Selon les dires de Julius Frey. Cf. AASB, Procès-verbaux du Conseil de l'ASB, $8^{\mathrm{e}}$ séance, 22.06.1914, p. I.

8 AASB, Procès-verbaux du Conseil de l'ASB, 8 e séance, 22.06.I9I4, p. 9.

Sous prétexte que la confiance personnelle accordée à un banquier privé n'est pas mesurable à l'importance des fonds propres portés au bilan et que la fortune personnelle et familiale constitue une forme de réserves latentes. Cf. Landmann, op. cit., I916, p. I50. 
profits et pertes d'où vient chaque bénéfice. " ${ }^{100}$ L'on peut comprendre cette forte résistance à l'introduction d'une meilleure publicité de la comptabilité bancaire de diverses manières. D'une part, ces craintes reflèteraient hypothétiquement la volonté de ne pas dévoiler des situations financières plus fragiles que le prestige de certaines maisons pourrait laisser croire. D'autre part, dans les oppositions au projet Landmann émises cette fois-ci en 1916, on pourrait également voir une forme d'appréhension face à l'augmentation de la transparence comptable dans le contexte de l'introduction d'une fiscalité sur les bénéfices. L'impôt sur les bénéfices de guerre introduit en septembre I9I6, mais dont les premières discussions datent d'août I9I5, pourrait en effet effrayer les banques sur la portée des données comptables dont disposerait l'administration fédérale en cas d'adoption du projet ${ }^{101}$.

La deuxième inquiétude, celle qui fédérera le monde bancaire suisse autour du rejet du projet Landmann, est relative à la position particulière qu'occupe la place financière suisse en tant que refuge pour les capitaux internationaux. L'adoption d'une loi qui donnerait à l'État un quelconque droit de regard sur les activités bancaires serait de nature à effrayer la clientèle étrangère qui attache une grande importance aux qualités de discrétion dont se targuent les instituts suisses.

C'est en effet l'argument fort qui est repris en février 1917, lors du musellement du projet Landmann par l'action conjointe de l'ASB et de la BNS. Le I2 février, Schulthess transmet deux exemplaires du projet Landmann corrigé au directoire de la BNS et à Friedrich Frey-Bourquin, le président de l'ASB, en les invitant à en faire un usage strictement confidentiel jusqu'au Io mars ${ }^{102}$. C'est alors que ces deux institutions - les dirigeants de l'association faittière et de la banque centrale - lancent une offensive pour empêcher la publication du texte législatif. Deux courriers quasiment simultanés sont adressés au Département de l'économie publique de Schulthess ${ }^{103}$. L'argumentaire développé dans la lettre de la BNS à Schulthess du 5 mars 1917 met en avant les liens entre l'attractivité internationale des banques suisses, le bien-être général du pays et la dépendance de la Confédération vis-à-vis de ses banques en matière de politique financière:

Le bon crédit et la confiance dont jouissent les banques suisses auprès de la clientèle étrangère, et les sommes qui de ce fait ont été versées en Suisse, ont fortement soutenu nos banques dans la promotion du développement économique de notre pays. Cette influence avantageuse des conditions générales a contribué à ce que la Confédération, depuis le début de la guerre, puisse couvrir ses besoins financiers de

100 AASB, Procès-verbaux du Conseil de l'ASB, 8 e séance, 22.06.1914, p. II.

101 Sur l'impôt sur les bénéfices de guerre, voir Guex, op. cit., 1993, p. 362-374.

102 SWA, Handschriften Landmann, HS 426, B4, Lettre d'Edmund Schulthess à Julius Landmann, I2.02.1917.

103 La lettre de l'ASB à Schulthess date du I $^{\text {er }}$ mars 1917, celle du directoire de la BNS du 5 mars I917. 
manière étonnamment aisée. Elle a donc toutes les raisons, en ce moment, de ne pas toucher à la position de nos banques par la publication d'un projet de mesures législatives dans un domaine aussi sensible ${ }^{104}$.

La menace des dirigeants de la banque centrale est à peine voilée : l'afflux de capitaux étrangers en Suisse permet de financer les dépenses extraordinaires de la Confédération par le biais d'emprunts, il serait donc dangereux pour l'État fédéral de faire tarir ce mouvement de capitaux en effrayant la clientèle internationale. Dans le débat au comité de la BNS qui a précédé la rédaction de la lettre, les dangers d'instrumentalisation du projet sont exprimés encore plus clairement. Ainsi Rodolphe de Haller (I874-I962) annonce-t-il :

Une publication et une discussion publique ne doivent donc pas avoir lieu pendant la durée de la guerre, car les dispositions du projet fournissent à la concurrence étrangère un instrument opportun pour poursuivre efficacement leurs efforts dirigés contre les banques suisses. Si le projet est publié, l'on ne manquera pas de signaler que les autorités - ou les réviseurs - pourront avoir accès à tous les dépôts, si bien que le secret professionnel serait remis en question. On effraie ainsi les déposants étrangers au détriment de notre secteur bancaire ${ }^{105}$.

Lors de cette même séance, Friedrich Frey-Bourquin, qui est à la fois membre du conseil d'administration de la SBS, président de l'ASB et membre du comité de la BNS, annonce que l'ASB va également intervenir auprès du Conseil fédéral pour exiger un report de la publication du projet. Il ajoute une petite phrase prémonitoire, pleine de perspicacité :

Les banques doivent se battre maintenant, pour tirer leur épingle du jeu après la guerre ; car il y aura alors sans doute beaucoup à faire, et un rôle important les attend peut-être. Mais elles ne doivent pas être entravées dans leur développement par des interventions législatives ou de pareilles discussions ${ }^{106}$.

L'un des principaux dirigeants de banque suisse est donc parfaitement conscient des perspectives profitables qui pourraient s'offrir à la place financière dans l'après-guerre.

Pour comprendre la vigueur de l'opposition de la plupart des banquiers suisses à une intervention régulatrice de l'État, il faut avoir à l'esprit la position spécifique, à l'international, de la place bancaire suisse durant la Première Guerre mondiale. Ce point mérite que l'on s'y arrête un instant, parce qu'il joue un rôle à la fois dans les discussions autour de la régulation de banques et dans celles relatives à l'exportation de capitaux, dont il sera question plus avant.

104 ABNS, I.3/I2I2, Entwurf Landmann, Lettre de la BNS (signée par le président Auguste Burkchardt et le vice-président Rodolphe de Haller) à Schulthess, 05.03.I9I7.

105 ABNS, Procès-verbaux du Comité de banque de la BNS, 28.02.1917, p. 85.

106 ABNS, Procès-verbaux du Comité de banque de la BNS, 28.02.1917, p. 86. 
Le premier conflit mondial représente en effet un tournant dans le développement de la place financière suisse ${ }^{107}$. Profitant de la neutralité, les banques suisses parviennent à attirer une partie des activités financières depuis les pays belligérants. L'afflux de capitaux vers le havre helvétique se combine avec une forte croissance des exportations de capitaux, dont le volume augmente de 25 à I00 \%, selon les estimations, pendant les années de guerre par rapport à leur niveau d'avant-guerre ${ }^{108}$. Ces mouvements de capitaux, qui sont réexportés par les banques suisses vers leur pays d'origine, permettent aux banques suisses, au-delà de la source de profits que représentent les commissions, de créer de nouveaux liens internationaux susceptibles de se maintenir en temps de paix. Selon Farquet, la transformation de la Suisse en havre fiscal au cours de la Grande Guerre et surtout dans l'après-Première Guerre mondiale est tributaire à la fois de facteurs push - en premier lieu le désir, dans les pays belligérants limitrophes, d'échapper à l'alourdissement de la charge fiscale sous l'effet des dépenses de guerre -, et de facteurs pull - au rang desquels il faut compter les atouts d'attractivité du capital en Suisse, à savoir la neutralité, la stabilité politique, la force du franc suisse et une fiscalité clémente ${ }^{109}$. Alors qu'avant la Première Guerre mondiale, les capitaux étrangers déposés dans les banques suisses représentent environ 2 milliards de francs suisses (sur un total de 5 milliards de valeurs administrées) ${ }^{110}$, en 1920 , les estimations les plus fréquentes évaluent le volume des fonds étrangers déposés en Suisse à une fourchette située entre Io et 20 milliards de francs suisses ${ }^{111}$.

Dans un tel contexte international, la mise en place d'une surveillance étatique contrôlant les opérations bancaires en Suisse constitue pour les banquiers helvétiques un obstacle indésirable. Ces derniers brandissent donc la menace des retraits des dépôts étrangers dans le cas d'une publication du projet Landmann et de sa discussion publique. L'argumentaire va même plus loin : en publiant un projet de législation fédérale, le Conseil fédéral ferait le jeu de la concurrence étrangère, en lui fournissant des raisons d'effrayer la clientèle des établissements suisses. Comme le relève avec justesse Bänziger ${ }^{112}$,

107 Sur le rôle de la Première Guerre mondiale dans l'évolution des banques suisses: cf. Perrenoud, et al., op. cit., 2002, p. 44-49; Mazbouri, Perrenoud, art. cit., in Groebner, Guex, Tanner (éd.), op. cit., 2008, p. 234-243; Mazbouri, Guex, Lopez, art. cit., in Halbeisen, Müller, Veyrassat (éd.), op. cit., 20I2, p. 483-488; Mazbouri, art. cit., 20I3; Sébastien Guex, "Conflits et marchandages autour du secret bancaire en Suisse à l'issue de la Grande Guerre ", L'Année sociologique, vol. 63, n ${ }^{\circ}$ I, 2013, p. I57-187, p. I6I-I62 ; Farquet, op. cit., 2016, p. 77-92; Christophe Farquet, Histoire du paradis fiscal suisse. Expansion et relations internationales $d u$ centre offshore suisse au XX ${ }^{e}$ siècle, Paris: Presses de Sciences Po, 2018, p. 75-109.

108 Guex, op. cit., 1993, p. 237.

109 Farquet, op. cit., 2016, p. 82-87.

110 Guex, op. cit., I993, p. I50.

111 Guex, art. cit., 2013. p. I62. Entre I9I4 et I920, l'indice des prix à la consommation augmente de IOO à 224, ce qui relativise, en tenant compte de cette inflation, le gonflement des fonds étrangers. Pour un essai de quantification de l'afflux de capitaux étrangers en Suisse, voir aussi Farquet, op. cit., 2018, p. 84-94.

112 Bänziger, op. cit., I986, p. 49. 
l'argumentation incriminant le projet Landmann comme portant atteinte au secret bancaire est difficile à justifier en regard du texte proposé. S'il ne met certes pas en place une protection pénale renforcée contre toute atteinte à la confidentialité similaire au futur article 47 de la loi sur les banques de 1934, il prévoit néanmoins un devoir de réserve particulier en ce qui concerne les communications des instituts de révision. Toute communication nonautorisée à des tiers, tout abus de confiance devient passible d'une amende fixée par convention (poursuite civile), ainsi que d'action en dommagesintérêts et de poursuites pénales ${ }^{113}$. Le projet Landmann, contrairement à ce que clamaient certains banquiers, ne représentait donc pas une brèche dans la confidentialité des transactions bancaires.

C'est donc la position de rejet et de censure du projet Landmann qui remporte, d'abord sous l'impulsion des représentants de la banque privée genevoise, l'adhésion des milieux bancaires helvétiques ${ }^{114}$. Les démarches conjuguées de l'ASB et de la BNS, en mars 1917, suffisent à impressionner Schulthess, et signent l'arrêt de mort du projet Landmann. Dans un premier temps, le conseiller fédéral argovien résiste encore : dans une lettre à son expert Landmann, il affirme vouloir mettre un terme au «jeu » de Darier, le projet doit être publié, sa publication n'impliquant aucun risque d'inquiétude ${ }^{115}$. Mais un revirement a lieu entre le 2 et le 8 mars i917. Selon les dires de Friedrich Frey, le désir de repousser la publication du projet a été approuvé "an höchster Stelle ${ }^{116}$. Schulthess a donc jeté l'éponge. La publication du projet est reportée à une date indéterminée et tous les exemplaires doivent être retournés au Département ${ }^{117}$.

C'est une conjonction de quatre facteurs qui permet de comprendre le rejet du projet Landmann, d'abord par la haute banque genevoise, puis par l'ensemble des cercles bancaires et enfin par le Conseil fédéral. Premièrement, le contexte international est évidemment important. L'alourdissement des charges fiscales sur la fortune et le revenu dans les pays belligérants dès la fin de la Première Guerre mondiale et plus généralement l'accroissement de l'interventionnisme étatique généré par la mobilisation totale dans l'effort de guerre contribuent grandement à un mouvement d'afflux de capitaux étrangers vers

113 Landmann, op. cit., 1916, art. 26 p. 8, art. 63, p. 15 ; voir aussi p. I44-I45.

114 Comme le note Schulthess dans une lettre à Landmann, dans laquelle le conseiller fédéral évoque l'opposition injustifiée et doctrinaire des banquiers: "Die Ansichten des Herrn Darier haben nun offenbar auch Herrn Frey beeinflusst, aber ich gestehe, dass dieses Spiel meines Erachtens einmal ein Ende nehmen muss ». SWA, Handschriften Landmann, HS 426, B4, Lettre d'Edmund Schulthess à Julius Landmann, 02.03.1917.

115 SWA, Handschriften Landmann, HS 426, B4, Lettres d'E. Schulthess à J. Landmann, 02.03.1917.

116 SWA, Handschriften Landmann, HS 426, B4, Lettre de Friedrich Frey à Landmann, 08.03.1917.

117 Seuls deux exemplaires sont conservés par des banquiers, à savoir Alfred Sarasin et Adolf Jöhr, à titre personnel et confidentiel. Cf. AFB, J.I.6 (fonds Schulthess), 1000/1355, vol. 2, lettre de Landmann à Hermann Kurz (direction générale du CS), II.02.1922. 
les banques suisses ${ }^{118}$. Les banquiers suisses estiment alors que la position du pays en tant qu'îlot libéral au centre de l'Europe ouvre des perspectives de développement qui ne doivent pas être entravées par des débats politiques autour d'une éventuelle intervention législative de l'État fédéral.

En plus de la facette internationale, trois facteurs internes à la Suisse exercent une influence dans le rejet du projet Landmann. Premièrement, la Première Guerre mondiale a modifié l'équilibre de pouvoir entre les collectivités publiques et les principales banques helvétiques. L'explosion des besoins financiers de la Confédération, et les choix politiques de couvrir ses dépenses excédentaires par le biais d'emprunts, plutôt que par la charge fiscale, augmentent considérablement l'influence politique des milieux bancaires. Le financement de la dette publique fournit non seulement un marché de substitution, qui plus est en l'absence de concurrence étrangère, pour les poids lourds de la finance helvétique, mais accentue aussi la dépendance financière des pouvoirs publics à leur égard ${ }^{11}$. Il ne fait donc pas de doute que, dans le cadre de la négociation d'un texte aussi important qu'une loi fédérale, les autorités gouvernementales soient particulièrement sensibles aux suggestions de leurs principaux créditeurs ${ }^{120}$.

Deuxièmement, il faut aussi lire l'échec du projet Landmann dans le contexte des différents projets législatifs et débats politiques impliquant les établissements bancaires des années I9I4-1916. D’autres projets législatifs ou revendications politiques sont en effet en cours. La question de la révision du droit des actionnaires, discutée pendant la Première Guerre mondiale, et à laquelle Julius Frey-Gamper participe aussi activement au sein de la commission présidée par Eugen Huber (1849-1923), est en lien étroit avec les propositions de réglementations bancaires ${ }^{121}$. En juin 19I4, l'ASB avait en effet privilégié une solution générale dans le cadre de la révision du Code des obligations, plutôt qu'une loi spécifique aux entreprises bancaires. L'élaboration en parallèle des projets de révision du droit des actionnaires jouait donc en faveur des milieux bancaires helvétiques, puisqu'elle permettait de mettre en œuvre quelques réformes également souhaitées dans le domaine bancaire, telles que la publication régulière des bilans et leur établissement, ainsi que la révision fiduciaire, tout en évitant les risques politiques liés à l'introduction d'un cadre réglementaire propre au domaine bancaire. De plus, il s'agissait là aussi d'une forme de tactique dilatoire, puisque la réforme du droit des sociétés représentait un chantier législatif de grande ampleur dont l'aboutissement ne se fera d'ailleurs qu'en 1937. Parmi les autres débats législatifs menés parallèlement au projet Landmann, l'on compte aussi celui sur l'introduction d'une loi fédérale

118 Sur ce point: Farquet, op. cit., 20I6, p. 6I-92.

119 Cf. Guex, op. cit., 1993, p. 216-217.

120 Cf. L[ouis] Schulthess, Die Bankreform, ein Kampf ums Recht. Tatsachen zur Bankengestzgebung, Erlenbach-Zürich; Leipzig: Eugen Rentsch Verlag, 1934, p. 75.

121 Sur la révision du droit des actionnaires, et les avant-projets d'Eugen Huber : Lüpold, op. cit., 20I0, p. I65-178. Voir aussi : Bänziger, op. cit., I986, p. 6I-63. 
sur les bourses, et celui sur une éventuelle régulation de l'exportation de capitaux. Entre décembre I9Is et avril 1916, des propositions en faveur d'une législation fédérale des bourses sont formulées ${ }^{122}$. Sans entrer dans les détails, signalons simplement que le but d'une telle législation aurait été d'améliorer la transparence des émissions boursières dans le but de protéger le public qui serait mieux informé. Or, Landmann exclut les bourses de son projet de loi fédérale sur les banques. Il propose cependant dans son exposé des motifs un certain nombre de mesures, telles que la fixation de règles sur l'établissement des prospectus, dans le but d'améliorer la transparence des risques liés à telle ou telle émission de valeurs, ainsi que de renforcer la responsabilité de l'émetteur ${ }^{123}$. Quant au second problème - celui de l'exportation de capitaux - par ailleurs étroitement lié au premier, le conseiller fédéral Schulthess envisage également, fin 1915 , de prendre des mesures législatives, en partie pour répondre à la pression politique en faveur d'un contrôle de l'exportation de capitaux exercée par le monde paysan ${ }^{124}$. En février 1916, c'est une solution d'autolimitation du secteur bancaire, par le biais de circulaires émises par l'ASB à ses membres qui s'impose à la suite de négociations entre le tandem SchulthessLandmann, la BNS et l'ASB ${ }^{125}$. Nous reviendrons plus loin sur l'enjeu que constitue la question de l'exportation des capitaux dans l'élaboration de la loi sur les banques de 1934. Retenons pour l'instant qu'au même titre que les débats sur une réglementation de l'émission de titres, la discussion parallèle d'un contrôle sur l'exportation de capitaux, qui tous deux se soldent par une solution non législative et non contraignante, joue en la défaveur d'un aboutissement du projet Landmann. Suite au recul des positions interventionnistes dans les dossiers de la régulation boursière et de l'exportation de capitaux, le rapport de force se déplace en faveur des banquiers réticents à toute réglementation et au détriment des propositions du Département de l'économie publique. On peut également émettre l'hypothèse - et ceci expliquerait en partie les ambivalences et revirements du conseiller fédéral Schulthess - que le projet de loi sur les banques de Landmann sert de moyen de pression pour le chef du Département de l'économie publique pour obtenir des concessions sur d'autres dossiers.

Le troisième aspect interne à la Suisse expliquant en partie l'échec du projet Landmann tient au rapport de force entre pouvoirs publics et milieux intéressés. La crise bancaire qui a amorcé les impulsions politiques en faveur d'une

122 Bänziger, op. cit., I986, p. 50-52. Cf. Albert Meyer, «Die Neuordnung des Effektenbörsenund Emissionswesens ", Journal de statistique et revue économique suisse, vol. 52, 1916, p. 109II5.

123 Cf. Landmann, op. cit., I916, p. 94-IOI.

124 Cf. Bänziger, op. cit., 1986, p. 53. Sur la question de l'exportation de capitaux au cours de la Première Guerre mondiale: Guex, op. cit., 1993, p. 219-250; Mazbouri, art. cit., in Guex (éd.), op. cit., I999; Sancey, op. cit., 2015, p. I24-I3I ; Julius Landmann, "Der schweizerische Kapitalexport ", Journal de statistique et revue économique suisse, vol. 52, 1916, p. 389-415; Kellenberger, op. cit., I939.

125 Sancey, op. cit., 20I5, p. I27-I28. 
législation fédérale a affecté en particulier des instituts d'importance moyenne, voire régionale. Aucune des grandes banques suisses, aucun poids lourd de la finance helvétique n'est directement concerné par la grande mortalité bancaire (Bankensterben) des années I9IO-I9I4 ${ }^{126}$. Au contraire, par le jeu des fusions, reprises et de l'ouverture de succursales, les grandes banques confortent et poursuivent leur expansion sur le marché domestique ${ }^{127}$. Contrairement à la configuration qui présidera à l'élaboration d'une législation bancaire dans les années 1930, les agents financiers qui disposent de l'influence politique la plus importante - en premier lieu les grandes banques - ne sont pas, entre I9I4 et I916, dans une position de faiblesse vis-à-vis des pouvoirs publics, en tant que victimes d'une crise. Les pertes subies dans les faillites bancaires ont lieu dans des établissements plutôt modestes tels que certaines caisses d'épargne locales, et/ou dans des régions périphériques (Thurgovie, Tessin). Le rapport de force entre autorités et représentants bancaires dominants, durant les négociations concernant la publication et l'opportunité du projet de loi bancaire, n'est donc pas le même qu'au cours de la crise des années 1930, qui touche lourdement les grandes banques suisses. Il faut ajouter à cela la tactique de temporisation adoptée par les cercles bancaires à partir des premières velléités gouvernementales en janvier 1914, qui permet de repousser la décision sur une éventuelle publication du projet Landmann jusqu'en février 1917. À ce moment-là, les pressions politiques et médiatiques qui avaient suivi la crise de I9IO-I9I3 étaient complètement retombées. La suspension (Schubladisierung) du projet Landmann par le Conseil fédéral en mars I9ı était donc facilitée par la longue attente - également due à l'irruption du premier conflit mondial - qui faisait apparaître le projet législatif comme une loi d'occasion, dont l'urgence immédiate était contestée. Du point de vue de l'ASB, fondée en I9I2, le torpillage du projet marque également une première victoire politique d'importance. L'association d'intérêts, à partir de positions pourtant contradictoires entre grandes banques et banques privées, est parvenue à fédérer les forces du secteur bancaire pour s'opposer à la mise en place d'une loi fédérale sur les banques ${ }^{128}$.

\section{I.4. LA POSTÉRITÉ DIFFICILE DU PROJET LANDMANN ET LES DÉBATS DE POLITIQUE BANCAIRE DES ANNÉES 1920}

Avant de poursuivre notre récit en abordant la période des années 1920, il est intéressant de souligner le flou qui entoure, dans la littérature juridique spécialisée entre 1930 et 1986, l'échec du projet Landmann. Pendant cette longue période, à quelques exceptions près, le projet Landmann est présenté, dans une visée téléologique, comme un précurseur de la loi sur les banques de 1934 «en

126 Ritzmann, op. cit., I973, p. I05.

127 Mazbouri, op. cit., 2005, p. 2I8-22I.

128 Sancey, op. cit., 20I5, p. II2-II3. 
devenir ». En raison de la censure qui a marqué le projet, le texte lui-même n'est que rarement étudié. Parmi les exceptions à cette règle du silence figure une petite publication datant de 1922 du directeur du Crédit Suisse, Hermann Kurz (I857-1943), sur les grandes banques dans la vie économique suisse ${ }^{129}$. Dans la littérature secondaire, les raisons de l'échec ou de l'abandon du projet sont très grossièrement esquissées. Dans leur grande majorité, les commentaires juridiques ou économiques sur la surveillance bancaire en Suisse reprennent la version officielle de l'abandon du projet Landmann, telle qu'annoncée par le Conseil fédéral dans son rapport sur l'année I9I6 (publié le 25 avril I9I7, soit à peine six semaines après le revirement de Schulthess fatal au projet Landmann) : la publication prévue a été différée, «le moment actuel ne paraissant pas propice pour une discussion approfondie et objective du projet et des questions qui s'y rattachent ${ }^{130}$. Le second avis mortuaire auréolé d'un caractère officiel se trouve dans la publication jubilaire pour les 25 ans de la Banque nationale suisse, parue en 1932 sous la direction d'Hermann Schneebeli (I8761950), ancien chef du bureau statistique. Voici le récit de l'échec du projet Landmann et du rôle joué par l'institut d'émission:

[...] en 1917, le Département fédéral de l'économie publique chargea le professeur Landmann d'élaborer un projet de loi concernant la surveillance des établissements de banque. La direction générale et le comité de banque en prirent connaissance. Vu les circonstances extraordinaires du moment, il parut inopportun de faire intervenir l'État ; toute mesure prise en ce domaine était appelée en effet à exercer sur le système de crédit des répercussions immédiates, dont il était impossible de prévoir les conséquences. C'est pourquoi la direction générale, d'accord avec les autorités de la Banque, recommanda au Conseil fédéral de renoncer à édicter des prescriptions législatives tant que la vie économique du pays n'aurait pas repris un cours normal ${ }^{131}$.

À partir de ces deux comptes rendus officiels, la grande majorité des commentaires sur le projet Landmann reprend la même ligne argumentative: des problèmes plus urgents ont occupé le Conseil fédéral pendant les années de guerre $^{132}$ et de plus, dans l'après-guerre, "le climat politique n'était guère

129 Hermann Kurz, Die Grossbanken im schweizerischen Wirtschaftsleben, Zürich: Orell Füssli, 1922. Le banquier zurichois ne se gêne pas pour citer et critiquer ouvertement le projet qu' il avait lui-même cherché à torpiller, suscitant ainsi une réponse vindicative de la part de Landmann, qui révèle son amertume qui nourrit face au sort réservé à son travail législatif plus de cinq ans après son torpillage. Cf. AFB, J.I.6 Fonds Schulthess, I0oo/I355, vol. 2, lettre de Julius Landmann à Hermann Kurz, II.O2.I922.

130 «Rapport du Conseil fédéral à l'Assemblée fédérale sur sa gestion en I9I6 " (publié le 25 avril 1917), Feuille fédérale, 1917, $69^{\mathrm{e}}$ année, vol. II, p. 421.

131 Schneebeli, op. cit., 1932, p. 349.

132 Voir par exemple Dollfus, op. cit., 194I, p. 28: «In Folge der dringenden Aufgaben der Kriegs- und Nachkriegszeit konnte sich der Bundesrat nicht weiter mit der Sache befassen. Auch liess die Konsolidierung des Bankwesens und die Prosperität der zweiten Hälfte der zwanziger Jahre das ganze Problem in den Hintergrund treten. »; Schwander, op. cit., 1943, 
propice à de nouvelles réalisations à l'esprit interventionniste » ${ }^{133}$. Quelques commentateurs mieux renseignés se risquent à évoquer «la résistance de certains milieux, surtout en Suisse romande ${ }^{134}$. La seule exception à cette version aseptisée de l'échec du projet Landmann se trouve chez Louis Schulthess qui, dans son essai Bankreform. Ein Kampf ums Recht, estime que plus que les dispositions mêmes contenues dans le projet, c'est le rapport de force des positions s'affrontant qui a engendré la censure du projet Landmann ${ }^{135}$. Il faut attendre les travaux d'historiens sur la question pour appréhender l'abandon du projet Landmann de manière plus circonstanciée. À partir de la thèse d'Hugo Bänziger, Sébastien Guex, Annette Baudraz, puis Malik Mazbouri ont successivement mis à jour le travail de sape de certains milieux bancaires dans l'avortement du projet Landmann ${ }^{136}$.

L'échec du projet de loi de surveillance des banques ne signifie pas pour Landmann la fin de ses altercations avec les milieux bancaires. Dans le cadre des autres expertises qu'on lui confie, cette fois dans le domaine fiscal - à savoir l'introduction de droits de timbre fédéraux en I916-1917 et la mise en place d'un droit de timbre sur les coupons en I9I9-, le professeur bâlois est confronté aux représentants des banques ${ }^{137}$. À la fois dans la tonalité des attaques échangées entre les milieux bancaires et Landmann et dans l'opposition directe des

p. 15: «Die Kriegsjahre und die Konzentration im Bankgewerbe drängten die Vorschläge Landmanns in den Hintergrund"; Urech, op. cit., 1944, p. 4: "Zu einer gesetzlichen Vorlage kam es damals jedoch noch nicht, da die Kriegs- und Nachkriegszeit den BR vor andere dringliche Probleme stellte. Der Entwurf blieb liegen. »; Schober, op. cit., 1957, p. 4 : «Zunächst wurden die Bundesbehörden durch den inszwischen ausgebrochenen Weltkrieg vor dringendere Probleme gestellt. "; Reimann, op. cit., 1963, p. I0: " Professor Landmann lieferte nach einem Jahr seinen Bericht (mit zwei Gesetzesentwürfen) ab, den das Departement in Druck gab, in der Absicht, ihn einer Expertenkommission zu unterbreiten. Das geschah nicht, da die Kriegs- und Nachkriegszeit dem Bund dringendere Aufgaben brachte.»; Riniker, op. cit., 1974, p. 20 : «Die Absicht, diesen Bericht einer Expertenkommission zu unterbreiten, konnte indessen wegen dringlicher Aufgaben, vor die sich der Bund wegen Kriegsausbruches gestellt sah, nicht mehr realisiert werden ".

133 Bodmer, op. cit., 1948, p. 127.

134 Piguet, op. cit., 1953, p. 175. Voir aussi Brühlmann, op. cit., 1935, p. 8: «Entgegen der früheren Absicht des Bundesrates ist der Entwurf von Landmann weder einer Expertennoch einer parlamentarischen Kommission zur Beratung unterbreitet worden. Neben den Widerstand, der dem Entwurfe in bestimmten Kreisen entgegengesetzt wurde, haben der Krieg und die Nachkriegszeit, mit ihren dringenderen Problemen die Frage des Erlasses eines schweizerischen Bankengesetzes in den Hintergrund treten lassen.»

135 Schulthess, op. cit., 1934, p. 75.

136 Bänziger, op. cit., 1986, p. 46-49; Guex, art. cit., I995, p. 405-406; Baudraz, op. cit., I997, p. 36-4I ; Mazbouri, art. cit., in Metzger, Vallotton (éd.), op. cit., 2009, p. 65-68; Mazbouri, Schaufelbuehl, art. cit., 2015 .

137 Sur ces législations fiscales et le rôle de Landmann dans leur élaboration : Guex, op. cit., I993, p. 379-389; Sébastien Guex, "L'introduction du droit de timbre fédéral sur les coupons, I9I9-I92I ", in Sébastien Guex, Martin Körner, Jakob Tanner (éd.), Staatsfinanzierung und Sozialkonflikte (I4.-20. Jh.), Zurich : Chronos, 1994, p. 209-239; Guex, art. cit., 1995, p. 4064II ; Baudraz, op. cit., I997, p. 4I-48. 
intérêts défendus, la rupture entre l'expert bâlois et les représentants des banques semble consommée.

Alors que les échanges étaient encore confinés aux cercles restreints de comités d'experts lors du premier débat sur les droits de timbre, le conflit s'étend à la sphère publique, par voie de presse et dans les discussions parlementaires, durant les négociations sur l'imposition des coupons. Deux évolutions parallèles sont à l'œuvre dans cet antagonisme croissant. D'une part, Landmann évolue progressivement vers une position idéologique moins favorable aux intérêts bancaires. Sa conception de l'État en tant que garant des intérêts d'une communauté opposée à l'étroitesse de vues des partisans de l'intérêt individuel, le pousse vers des positions moins conciliantes à l'égard des couches possédantes ${ }^{138}$. D'autre part, les soutiens institutionnels dont bénéficiait l'expert bâlois auprès de l'administration fédérale s'affaiblissent. Tandis que le projet de loi sur les banques de I9I4-I9I6 avait été rédigé sur mandat de Schulthess, du Département de l'économie publique, dont la relation avec Landmann est marquée par une admiration réciproque, les dossiers de législation fiscale sont gérés par le Département des finances. Or un changement de direction a lieu en janvier 1920 lorsque Jean-Marie Musy remplace Giuseppe Motta à la tête du Département. Dès lors, la collaboration entre l'expert et le ministre fribourgeois, qui fera preuve d'une attitude particulièrement conciliante envers les desiderata bancaires ${ }^{139}$, sera de plus en plus compliquée. Finalement, en 1922, Landmann démissionne et est remplacé par un de ses anciens étudiants, Eduard Kellenberger. Progressivement déchu de son ancrage institutionnel en tant qu'expert gouvernemental, le professeur bâlois doit subir des attaques de la part de ses contradicteurs qui prennent parfois une couleur xénophobe, voire antisémite $^{140}$. La fin de la collaboration avec le Département des finances marque une étape décisive dans la retraite de Landmann de la vie publique suisse. Après avoir subi un échec auprès des instances dirigeantes de l'Université de Bâle dans son projet de créer un cursus d'économie politique indépendant de la Faculté de philosophie, Landmann est également poussé à la démission, fin I922, de son lieu de sociabilité favori, la Statistisch-volkswirtschaftliche Gesellschaft ${ }^{141}$. Finalement, durant l'hiver 1926-1927, le Bâlois d'adoption quitte la Suisse en obtenant la chaire de sciences économiques publiques (Wirtschaftliche Staatswissenschaften) à l'Institut für Weltwirtschaft de l'Université de Kiel. Le 8 novembre 193I, à l'âge de 54 ans, Landmann met fin à ses jours. Les raisons du suicide du professeur d'économie restent difficiles à élucider clairement. Elles tiennent à la fois aux problèmes d'acclimatation à son nouvel environnement à Kiel, à des problèmes de santé récurrents, à des chocs émotionnels suite au décès prématuré de sa fille en 1925, ainsi que d'autres proches amis en $1930-1931^{142}$.

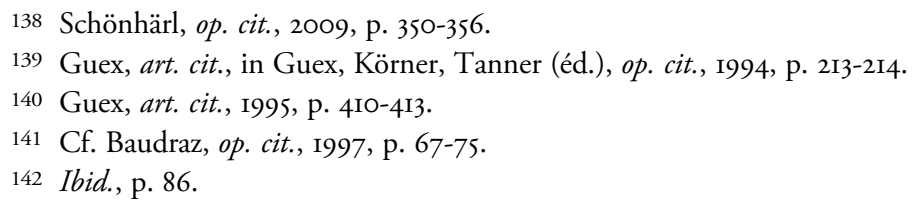


D'autres motifs sont encore évoqués: la montée de l'antisémitisme, ainsi que d'éventuelles pertes financières subies durant la crise mondiale ${ }^{143}$.

Dans ce même contexte de crise financière, l'administration fédérale ressort de ses tiroirs le projet de la loi fédérale sur la surveillance des banques rédigé par Landmann, qu'elle avait soigneusement gardé secret pendant une quinzaine d'années. C'est dans un premier temps Edmund Schulthess, toujours à la tête du Département d'économie publique, qui écrit à Landmann en septembre 193I pour lui demander l'autorisation de publier le projet ${ }^{144}$. Parallèlement, dans les bureaux voisins du Département des finances, toujours dirigé par JeanMarie Musy, Eduard Kellenberger, désormais suppléant du directeur de l'Administration fédérale des finances, se livre à une critique vigoureuse du projet concocté par son ancien professeur d'économie. Nous renvoyons ici au jugement sévère exprimé dans un rapport interne et cité en ouverture de ce chapitre, dans lequel Kellenberger estimait que le projet Landmann ouvrait la voie à la socialisation du monde bancaire ${ }^{145}$. Kellenberger, en septembre I93I, propose donc de ne pas s'engager dans la voie législative suggérée par son ancien professeur. Au contraire, son rapport conclut qu'une loi peut être évitée via des mesures moins strictes telles que l'adoption d'accords sur base volontaire entre les banques commerciales et la Banque nationale, ou encore la formation, là aussi sous forme non contraignante, de syndicats de révision. Nous y reviendrons.

En mars 1934, alors que la crise bancaire s'est approfondie et que les travaux d'élaboration de la future loi sur les banques sont déjà bien avancés, le projet Landmann est présenté sous un autre jour par un autre acteur important de la politique bancaire fédérale, le président de la Banque nationale suisse, Gottlieb Bachmann (I874-1947). Après avoir noté que le projet Landmann n'avait "curieusement» pas été mis à disposition du public, Bachmann regrette l'absence d'un système de contrôle tel que celui envisagé par le professeur bâlois :

Aujourd'hui, vingt ans plus tard, on peut se demander, compte tenu du projet de la loi bancaire actuel, si le projet Landmann allait vraiment trop loin et si sa mise en œuvre réglementaire n'aurait pas pu contenir l'expansion très souvent malsaine des banques entre 1924 et 1929 et aurait montré à notre secteur bancaire une voie plus saine à suivre ${ }^{146}$.

Il est souvent hasardeux de se livrer, comme le fait ici Bachmann, à des observations d'ordre hypothétique sous forme d'histoire contrefactuelle. Il est difficile de savoir dans quelle mesure la réalisation du projet Landmann aurait permis d'éviter les crises bancaires des années I93I-I934. Toujours est-il que, du

143 Schönhärl, op. cit., 2009, p. 89.

144 Cf. Baudraz, op. cit., 1997, p. 82.

145 AFB, E6520(A), I000/I059, vol. 2, Rapport interne de l'Administration fédérale des finances sur le contrôle bancaire, signé Eduard Kellenberger, or.09.193I.

146 Gottlieb Bachmann, «Eidgenössische Bankengesetzgebung», Neue Zürcher Zeitung, I8.03.1934, ${ }^{\circ} 476$, Blatt 7 . 
point de vue des intérêts bancaires helvétiques, la censure du projet Landmann en 1916 a permis de repousser efficacement la menace d'une loi de surveillance étatique durant près de vingt ans. Elle a en outre contribué à rendre possible l'expansion extraordinaire de la place financière suisse au cours de la seconde moitié des années 1920 - et en particulier la croissance des opérations internationales des grandes banques -, sans entraves ni immixtion étatiques.

Coïncidence fortuite, trois ans jour pour jour après le suicide de Julius Landmann, le Parlement suisse adoptera, le 8 novembre 1934, une loi fédérale sur les banques trouvant en partie son inspiration dans les projets avortés en I916 ${ }^{147}$.

Avant d'aborder dans le prochain chapitre la phase d'élaboration ayant conduit à la promulgation de cette loi, il est nécessaire de résumer en quelques mots l'évolution des débats sur la régulation bancaire au cours des années 1920 ${ }^{148}$. Dans la chronologie de l'histoire de la réglementation bancaire en Suisse, les années I917-I93I peuvent apparaître comme une sorte de passage à vide dans le développement de la surveillance. En effet, entre la mise de côté du projet Landmann en février 1917 et la réapparition des revendications en faveur d'une législation bancaire en septembre 1931, la question d'une réglementation fédérale sur le contrôle des banques est absente de l'agenda politique en Suisse. L'interpellation du socialiste Schneider de décembre 1928, restée sans suites, constitue à ce titre l'unique exception ${ }^{149}$. À vrai dire, cette accalmie cache surtout l'émergence de deux débats politiques dans le domaine bancaire qui occupent le devant de la scène: d'une part, la question de l'exportation de capitaux opérée par les banques suisses et de sa limitation, d'autre part, la révision du droit des actionnaires. Autrement dit, dans la perspective de l'histoire de la surveillance bancaire propre à ce travail, ces deux débats annexes, qui constituent en soi des enjeux de luttes politiques essentiels, jouent le rôle de palliatifs qui permettent d'éviter l'introduction d'une loi spécifique au domaine bancaire.

Dans le cas de la révision du droit des sociétés et de la publicité des bilans, les milieux bancaires se servent de ce débat pour proposer certaines dispositions réglementaires à l'ensemble des entreprises et ainsi couper l'herbe sous les pieds

147 Relevons que dans le Message du Conseil fédéral du 2 février 1934 proposant l'adoption de la loi, il n'est pas fait mention des travaux «préparatoires » de Julius Landmann. Les différents débats en commission pré-parlementaires et en chambre, en revanche, feront allusion au projet en question. Cf. aussi Dollfus, op. cit., I94I, p. 29.

148 Pour de plus amples développements, cf. Giddey, op. cit., 2017, p. 66-80.

149 Munie de 27 signatures socialistes, l'intervention parlementaire du bâlois Friedrich Schneider (1886-1966) datée du 20 décembre 1928 demande au Conseil fédéral de «déposer un projet de loi sur la surveillance et le contrôle des bourses et d'autres établissements financiers" pour protéger les petits épargnants. Cette interpellation est restée sans suites. Cf. Procès-verbaux de l'Assemblée fédérale, séance 17, 2I.I2.I928, p. 482. 
des partisans d'une régulation propre aux banques ${ }^{150}$. Ils privilégient l'intégration de quelques mesures isolées - notamment sur la transparence, le bilan et le contrôle fiduciaire - dans la refonte générale du droit des actionnaires. La révision du Code des obligations, en comparaison avec l'introduction d'une législation sur les banques ou les bourses, possède l'avantage de ne pas être considérée comme une loi d'occasion, tributaire de crises survenues récemment, et ne représente qu'une modification de dispositions qui ont déjà fait leurs preuves ${ }^{151}$. En dépit de cette configuration qui rend une réforme du droit des obligations en principe moins difficile, l'élaboration de cette révision durera au total un quart de siècle, puisque le Code des obligations révisé ne sera adopté qu'en 1936.

Dans le cas de l'exportation des capitaux, le projet d'une loi bancaire est agité comme une menace pour inciter les banques commerciales à plus de concessions et à accepter un accord non contraignant avec la banque centrale ${ }^{152}$. La question de l'exportation de capitaux constitue un enjeu qui monopolise l'attention des pouvoirs publics en matière bancaire en 1916 et 1927. Sa politisation trouve son origine dans la corrélation perçue entre les flux de capitaux en Suisse et le mouvement du taux d'intérêt. Les secteurs économiques particulièrement sensibles à la hausse du taux d'intérêt - notamment en raison de leur endettement, comme la paysannerie ou la petite industrie critiquent l'exportation de capitaux effectuée par les banques en estimant qu'elle contribuerait à rétrécir la masse de capitaux disponibles sur le marché intérieur et provoquerait un renchérissement du loyer de l'argent. Au cours des années 1920 , le débat refait régulièrement surface, à mesure qu'une augmentation du taux d'intérêt devient menaçante ou effective. L'instrumentalisation de la problématique par les représentants de la paysannerie permet d'obtenir des concessions sur d'autres dossiers. Ces tensions débouchent sur une solution non contraignante sous la forme d'un gentlemen's agreement conclu à l'été 1927 entre les milieux bancaires et la BNS. Cet accord, qui participe à l'établissement d'une forme d'autorégulation du secteur bancaire, permet d'enrayer les critiques politiques et de rendre inutile le recours à des mesures législatives, et conduit à une dépolitisation de la question. Les négociations sur le contrôle de l'exportation de capitaux au cours des années 1920 constituent à double titre une étape importante dans la genèse de la surveillance bancaire en Suisse. D’une part, elles sont caractérisées par la légitimation d'un principe directeur qui marque sur le long terme les rapports entre l'État et le monde bancaire en Suisse, «celui d'une forme de surveillance lâche, reposant essentiellement sur

150 Sur la révision du droit des sociétés : Graner, op. cit., 1937, Bänziger, op. cit., 1986, p. 59-67; Lüpold, op. cit., 2010; Thomas David, et al., De la "Forteresse des Alpes» à la valeur actionnariale. Histoire de la gouvernance d'entreprise en Suisse (I880-20I0), Zurich: Seismo, 2015, p. 47-96.

151 Lüpold, op. cit., 20Iо, p. I70.

152 Sur l'exportation de capitaux : Sancey, art. cit., 1996; Sancey, art. cit., in Guex (éd.), op. cit., I998; Sancey, op. cit., 2015. 
une confiance singulièrement profonde des autorités envers la volonté et la capacité des banques à s'autoréguler » ${ }^{153}$. D'autre part, ce débat met en évidence l'utilisation tactique de la menace d'une législation bancaire au cours des années 1920. Les dirigeants de la banque centrale et du Département des finances cherchent à obtenir des concessions dans la voie d'une autorégulation non contraignante, en agitant la menace d'une réglementation bancaire. L'ensemble des acteurs de la politique bancaire suisse semble être, avant la crise des années 1930, unanimes à vouloir éviter le recours à une loi bancaire. Mais le risque de légifération est utilisé par les uns pour obtenir des concessions des autres par la voie plus flexible de l'autorégulation.

153 Sébastien Guex, « La politique de la Banque nationale suisse (1907-1939) modèles, références, spécificités », in Olivier Feiertag, Michel Margairaz (éd.), Politiques et pratiques des banques d'émission en Europe (XVII ${ }^{e}-X X^{e}$ siècle), Paris : Albin Michel, 2003, p. 526-548, p. 538. 
广

N

$\stackrel{\circ}{\circ}$

(1)

.

2

2

(a) 


\section{CHAPITRE II}

\section{CRISE ÉCONOMIQUE MONDIALE, FAILLITES BANCAIRES EN SUISSE ET DEMANDES DE RÉGULATION (1931-1933)}

La grande crise économique mondiale des années 1930 constitue, selon l'historien Eric Hobsbawm, «le plus grand séisme mondial jamais mesuré sur l'échelle de Richter des historiens de l'économie : [...] l'économie capitaliste a paru s'écrouler ${ }^{1}$. Le cataclysme affecte coup sur coup divers rouages de la vie économique : au krach de Wall Street d'octobre 1929 succède une chute des prix, à laquelle s'ajoute ensuite une crise bancaire. Un enchaînement de causes explique l'ampleur du phénomène. Il faut avoir à l'esprit la diversité des manifestations d'une crise qui est à la fois boursière, économique, financière et monétaire. Il est nécessaire, dans le cadre de cette étude, de mesurer la profondeur de la crise qui affecte les économies du monde entier entre 1929 et le déclenchement de la Seconde Guerre mondiale. Les années 1930 représentent en effet un laboratoire de l'interventionnisme étatique, dont la place augmente globalement ${ }^{2}$. Dans le domaine plus précis de la régulation bancaire, la crise des années 1930, à l'échelle mondiale, constitue le creuset de nombreuses législations sur les banques ${ }^{3}$. L'objet de ce chapitre est donc de souligner le rôle joué par le phénomène de la crise dans l'émergence d'une législation bancaire. Après avoir rapidement survolé le déroulement de la grande dépression en Suisse et les réponses politiques qui y ont été apportées, nous examinerons dans quelle mesure ces développements et le déclenchement de crises financières contribuent à l'élaboration d'une loi fédérale sur les banques.

Il n'est pas le lieu de discuter ici en profondeur les différentes interprétations des causes de la grande crise économique mondiale des années 1930. Le sujet est si vaste que l'ancien président de la Réserve fédérale américaine, l'économiste Ben Bernanke a décrit la recherche des causes de la grande crise économique

1 Eric John Hobsbawm, L'âge des extrêmes: le court vingtième siècle, I9I4-I99I, Bruxelles : Éd. Complexe, 2003, p. I25.

2 Pierre Léon, Histoire économique et sociale du monde. Tome 5. Guerres et crises, I9I4-I947, Paris : Armand Colin, 1977, p. 297-34I.

3 Cf. Cassese, art. cit., 1984. 
comme «la quête du Graal» de la macro-économie ${ }^{4}$. Nous renvoyons à la littérature spécialisée pour comprendre la diversité des interprétations qu'a suscitée cette grande césure dans l'histoire économique mondiale ${ }^{5}$. Retenons simplement l'existence d'un consensus chez la majorité des historiens et économistes pour considérer que la grande dépression plonge ses racines dans les déséquilibres structurels du système économique international hérité de la Première Guerre mondiale. La crise économique internationale est d'une ampleur sans précédent. Entre 1929 et 1932, le commerce mondial diminue d'un quart, en termes de volume, et de moitié, en termes de valeur ${ }^{6}$. La production industrielle mondiale (sans tenir compte de l'URSS) chute de $36 \%$ durant la même période 7 . Le chômage de masse fait son apparition: parmi les ouvriers industriels, il atteint $36.3 \%$ aux États-Unis et $43.2 \%$ en Allemagne en 1932; ce dernier pays, en février 1932, compte six millions de chômeurs, soit $16.2 \%$ de la population totale, contre douze millions de personnes actives ${ }^{8}$.

\section{II.1. LA CRISE ÉCONOMIQUE DES ANNÉES 1930 EN SUISSE}

En tant que "petite économie ouverte », en grande partie dépendante de son commerce extérieur, la Suisse est rapidement touchée par la crise ${ }^{9}$. Depuis les travaux de l'historien Philipp Müller, les spécificités du déroulement en Suisse de la grande crise des années 1930 et les réponses politiques qu'elle a suscitées

4 Ben S. Bernanke, "The Macroeconomics of the Great Depression: A Comparative Approach ", Journal of Money, Credit and Banking, vol. 27, n' ${ }^{\circ}$ I, 1995, p. I-28, p. I.

5 Pour une vue d'ensemble synthétique voir: Nicholas F. R. Crafts, Peter Fearon, «Depression and Recovery in the I930s: An Overview ", in Nicholas F. R. Crafts, Peter Fearon (éd.), The Great Depression of the I930s: Lessons for Today, Oxford: Oxford University Press, 2013, p. I-45. Parmi les classiques: Milton Friedman, Anna Jacobson Schwartz, A monetary history of the United States: 1867-1960, Princeton: Princeton University Press, 1963; Barry Eichengreen, Golden Fetters. The Gold Standard and the Great Depression, I919-1939, New York; Oxford: Oxford University Press, 1992; Charles Poor Kindleberger, La grande crise mondiale: 1929-1939, Paris: Economica, I988; p. 297-314. Au rang des interprétations "hétérodoxes » : Isaac Johsua, La crise de 1929 et l'émergence américaine, Paris : Presses Universitaires de France, 1999; Robert Boyer, Théorie de la régulation, Paris: La Découverte, 2004.

6 Charles Hilliard Feinstein, Peter Temin, Gianni Toniolo, The World Economy between the World Wars, New York: Oxford University Press, 2008, p. 94.

7 Eichengreen, op. cit., 1992, édition 1996, p. 259.

8 Barry Eichengreen, Tim Hatton, «Interwar Unemployment in International Perspective : An Overview ", in Barry Eichengreen, Tim Hatton (éd.), Interwar Unemployment in International Perspective, Dordrecht: Kluwer Academic Publishers, 1988, p. I-59.

9 Sur l'imbrication de l'économie suisse dans l'économie mondiale, voir notamment: Margrit Müller, "Internationale Verflechtung», in Patrick Halbeisen, Margrit Müller, Béatrice Veyrassat (éd.), Wirtschaftsgeschichte der Schweiz im 20. Jahrhundert, Basel: Schwabe, 2012, p. 339-465, sur l'entre-deux-guerres, voir en part. p. 361-396. Voir également: Paul Bairoch, "L'économie suisse dans le contexte européen I913-1939", Revue suisse d'histoire, vol. $34, \mathrm{n}^{\circ} 4$, 1984, p. 468-497. 
sont mieux connues ${ }^{10}$. Esquissons rapidement les grandes tendances de l'évolution conjoncturelle en Suisse.

Dès 1930, l'industrie d'exportation est frappée par la crise. Les secteurs des machines, de la soie, de la broderie et de l'horlogerie sont victimes à la fois de la chute de la demande internationale, de la montée des barrières douanières protectionnistes et des turbulences monétaires ${ }^{11}$. Les exportations baissent de plus de moitié entre 1929 et $1932^{12}$. Entre 1933 et 1936 , alors que la plupart des économies mondiales connaissent une forme de reprise, les exportations helvétiques continuent de stagner. La cause du prolongement de la crise du commerce extérieur est essentiellement monétaire: tandis que les principaux importateurs de produits suisses ont dévalué leur monnaie, le franc est maintenu à la parité-or ; cette surévaluation de la devise helvétique porte préjudice à ses exportations.

L'évolution des secteurs extravertis de l'économie suisse contraste avec la situation du marché intérieur. Entre 1929 et I932, ce dernier connaît une période de croissance, en particulier dans le domaine de la construction. Ce n'est qu'à partir de I933, avec la fin du boom dans l'industrie du bâtiment, que la crise se généralise en Suisse ${ }^{13}$. Le maintien du marché intérieur suisse se traduit également par la bonne santé des importations, qui malgré des mesures protectionnistes introduites en décembre I93I, continuent de progresser jusqu'en I936, creusant ainsi le déficit commercial du pays. Dans un premier temps, entre 1929 et 1933, ce décalage entre les trajectoires des industries d'exportation et du marché intérieur fait apparaître les indices économiques comme contradictoires sous l'effet de la bonne tenue du marché intérieur. Puis, durant une seconde phase, entre 1932 et I936, l'économie suisse "glisse de la stagnation dans la dépression $"{ }^{14}$, alors que les économies les plus touchées par la crise, comme les États-Unis ou l'Allemagne, entament leur reprise. Le bilan chiffré de la conjoncture économique en Suisse est donc contrasté en comparaison internationale.

10 Philipp Müller, La Suisse en crise (I929-1936). Les politiques monétaire, financière, économique et sociale de la Confédération helvétique, Lausanne: Antipodes, 20Io. Voir aussi les diverses contributions dans le dossier thématique de Traverse - revue d'histoire: Thomas David, Sébastien Guex, Marc Perrenoud, "La crise des années '3o en Suisse et dans le monde. Quelques remarques préliminaires", Traverse, vol. 4, $\mathrm{n}^{\circ}$ I, 1997, p. 17-20. Voir également Sébastien Guex, et al. (éd.), Krisen und Stabilisierung: die Schweiz in der Zwischenkriegszeit, Zürich: Chronos, 1998. Pour une synthèse récente sur l'évolution conjoncturelle de l'économie suisse, cf. : Margrit Müller, Ulrich Woitek, Manuel Hiestand, «Wohlstand, Wachstum und Konjonktur", in Patrick Halbeisen, Margrit Müller, Béatrice Veyrassat (éd.), Wirtschaftsgeschichte der Schweiz im 20. Jahrhundert, Basel: Schwabe, 20I2, p. 9I-222, p. I42-156. Une revue statistique synthétique de l'évolution économique suisse durant la période se trouve chez: Matthias Zurlinden, "Goldstandard, Deflation und Depression : Die schweizerische Volkswirtschaft in der Weltwirtschaftskrise", Schweizerische Nationalbank, Quartalsheft, vol. 2, 2003, p. 86-II6.

11 Müller, op. cit., 20Io, p. 36-68.

12 Les exportations sont ici exprimées en tant que composantes de la demande. Müller, Woitek, Hiestand, art. cit., in Halbeisen, Müller, Veyrassat (éd.), op. cit., 20I2, p. I49. Historische Statistik der Schweiz Online, Tab. Q.I6a. 
L'effondrement économique au début de la décennie n'est pas aussi brutal que dans d'autres économies capitalistes; en revanche, en Suisse, la dépression se prolonge plus longtemps. Ainsi, dans l'ensemble, entre 1929 et 1939, le produit intérieur brut réel par habitant recule en moyenne de $0.65 \%$, alors qu' il s'accroît en moyenne de I.39\% dans huit pays européens (Allemagne, Autriche, Belgique, Danemark, France, Italie, Pays-Bas, Royaume-Uni) ${ }^{15}$.

Le secteur agricole suisse, malgré une contribution au produit intérieur brut relativement stable pendant la crise, fait face à des difficultés de trois ordres : la contraction de la demande pour les produits d'exportation traditionnels (produits laitiers), la hausse des importations céréalières et une augmentation des coûts de production ${ }^{16}$. En effet, l'agriculture fait face à un accroissement du poids relatif de la dette hypothécaire, à laquelle s'ajoute une chute du revenu paysan réel. Alors que le service de la dette représente un quart du revenu d'exploitation entre I928 et I930, il passe à $30 \%$ en I93I, puis $38 \%$ en $1932{ }^{17}$. D'après un rapport interne de l'administration fédérale de juillet 1935, plus de 20 ooo exploitations - soit un dixième des domaines - seraient susceptibles de bénéficier d'une aide étatique pour rembourser leurs dettes ${ }^{18}$. La vigueur des débats autour de la fixation des taux d'intérêt se comprend mieux dans ce contexte de fort endettement. Comme nous le verrons, dans le cadre de l'élaboration de la loi sur les banques, les questions autour de l'exportation de capitaux et de la régulation des taux d'intérêt constituent un terrain d'affrontement quasi permanent entre représentants paysans et milieux bancaires.

Les conséquences sociales de la crise sont de grande ampleur. Comme le montre le graphique I, la Suisse passe d'une situation de quasi-plein emploi à la fin des années 1920 (moins de IO ooo chômeurs sur une population active de près de deux millions) à un taux de chômage de $8 \%$ à la fin I935. Si l'on ajoute au nombre de chômeurs complets du graphique I, les chômeurs partiels, plus de I60 ooo personnes sont touchées ${ }^{19}$. Il faut aussi avoir à l'esprit, quelle que soit la qualité de données statistiques existantes, qu'il existe toujours un certain décalage entre le chômage tel qu'il est enregistré par le nombre de demandeurs d'emploi ayant droit à certaines prestations et le chômage effectif ${ }^{20}$.

Il est vrai qu'en comparaison internationale, les taux de chômage recensés en Suisse sont relativement restreints. À titre d'exemple, le chômage industriel

15 Patrick Halbeisen, Tobias Straumann, «Die Wirtschaftspolitik im international Kontext ", in Patrick Halbeisen, Margrit Müller, Béatrice Veyrassat (éd.), Wirtschaftsgeschichte der Schweiz im 20. Jahrhundert, Basel: Schwabe, 2012, p. 983-1075, p. 996.

16 Sur l'évolution de l'agriculture pendant la crise des années 1930: Werner Baumann, Peter Moser, Bauern im Industriestaat: agrarpolitische Konzeptionen und bäuerliche Bewegungen in der Schweiz 19I8-1968, Zürich : Orell Füssli, 1999, p. 76-84; Müller, op. cit., 20I0, p. 75-8I.

17 Müller, op. cit., 20IO, p. 80.

18 Ibid., p. 8I.

19 Ibid., p. 90.

20 Bernard Degen, "Arbeit und Kapital», in Patrick Halbeisen, Margrit Müller, Béatrice Veyrassat (éd.), Wirtschaftsgeschichte der Schweiz im 20. Jahrhundert, Basel: Schwabe, 20I2, p. 873-922, p. 895 . 
Graphique I. La crise économique en Suisse (1927-1939) : exportations, production industrielle et chômage

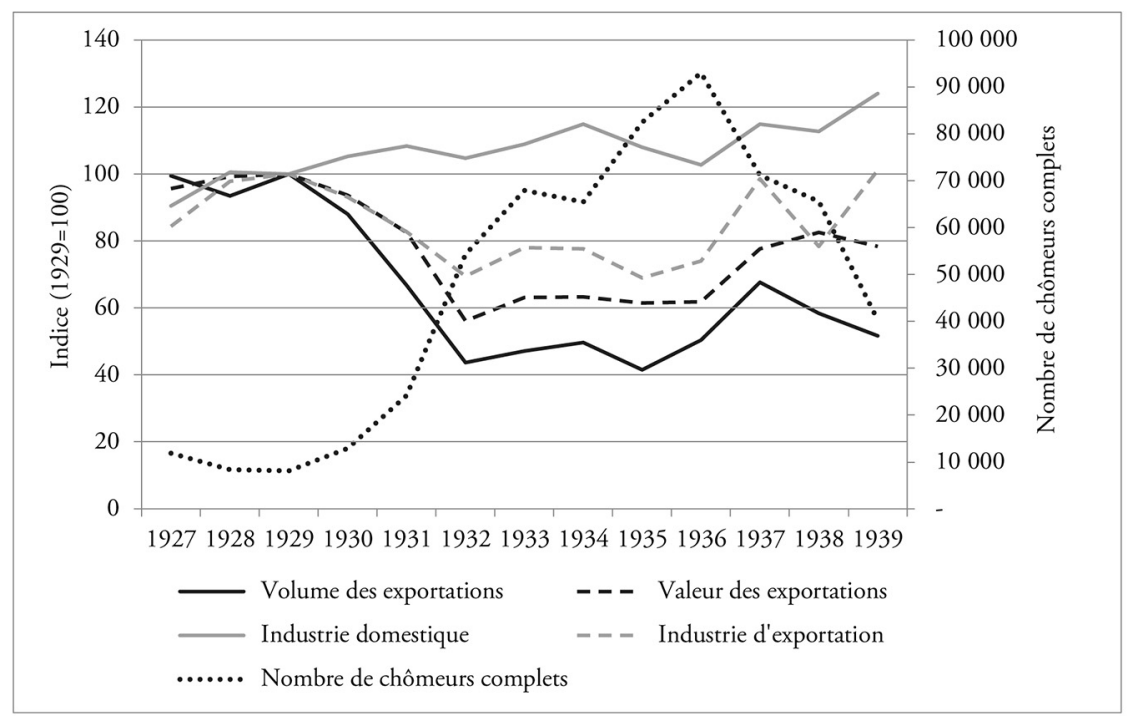

Sources: Volume et valeur des exportations : Ritzmann-Blickenstorfer (éd.), op. cit., 1996, L.3, p. 668 (Valeur des exportations déflatée par l'IPG, Ibid., H.IOa, p. 492). Industrie d'exportation, industrie domestique : Ritzmann-Blickenstorfer (éd.), op. cit., 1996, K.I4, p. 629. Cf. Thomas David, Un indice de la production industrielle de la Suisse durant l'entre-deux-guerres, 1995. Nombre de chômeurs : Ritzmann-Blickenstorfer (éd.), op. cit., I996, F.I8, p. 422.

moyen entre I930 et 1938 dans sept pays européens varie entre I4 et 26.6\% (par ordre décroissant: Norvège, Pays-Bas, Danemark, Allemagne, Suède, Royaume-Uni, Belgique) ${ }^{21}$. À l'échelle de la Suisse cependant, le chômage dû à la crise des années 1930 a atteint des proportions inconnues jusqu'alors et qu'on ne retrouve pas avant la fin des années $1990^{22}$. Corollaire de la croissance du chômage, la pauvreté augmente également. En l'absence d'une assurance chômage générale, les licenciements déploient souvent des effets dramatiques ${ }^{23}$. Les soupes populaires, institutions d'utilité publique et œuvres d'entraide sont submergées de demandes. Dans l'ensemble, plus de i $8 \%$ de la population suisse est en partie ou intégralement concernée par l'assistance publique en 1937, alors que ce même taux ne s'élevait qu'à II \% en $1929^{24}$.

Pour terminer ce rapide survol de l'ampleur de la crise économique des années 1930 en Suisse, relevons encore que les conséquences de la crise varient remarquablement d'une région à l'autre, en suivant la fracture sectorielle entre

Eichengreen, Hatton, art. cit., in Eichengreen, Hatton (éd.), op. cit., 1988, p. 9 ; Feinstein, Temin, Toniolo, op. cit., 2008, p. II6.

Cf. Müller, Woitek, Hiestand, art. cit., in Halbeisen, Müller, Veyrassat (éd.), op. cit., 2oI2, p. I37-I42. 
branches économiques tournées vers le marché intérieur ou extérieur ${ }^{25}$. Les cantons à dominante rurale comme Fribourg ou le Valais sont nettement moins touchés que des régions industrielles, par exemple la broderie saint-galloise et appenzelloise ou l'horlogerie neuchâteloise ${ }^{26}$. Nous verrons que dans le domaine bancaire, certains établissements locaux fortement liés à un secteur économique particulier seront touchés par la crise. La fragilité de ces instituts apparaîtra alors clairement.

\section{Les réponses politiques à la crise}

En Suisse, comme ailleurs, la grande dépression a été le creuset de la politique économique moderne. En effet, les recettes utilisées lors des difficultés antérieures se sont révélées insuffisantes, et il a bien fallu réexaminer complètement le rôle de l'État qui, jusqu'alors, s'était contenté de veiller sur la prospérité résultant de l'initiative privée, se limitant à des interventions parfois très importantes quant à leur coût financier, mais toujours conduites comme des actions ponctuelles ${ }^{27}$.

Le constat de l'historien Roland Ruffieux, spécialiste de l'entre-deuxguerres en Suisse, est également valable à une plus large échelle. Les politiques élaborées par les divers gouvernements en réponse au phénomène de crise ont été déterminées par diverses variables: l'expérience de crises antérieures, la structure économique du pays dans la division internationale du travail, ou les partis au pouvoir ${ }^{28}$. Une ligne de fracture commune et principale a cependant été décisive dans les politiques mises en œuvre : l'abandon ou le maintien de l'adhésion à l'étalon-or. La seconde option était intimement liée à ce que Barry Eichengreen et Peter Temin nomment la mentalité de l'étalon-or : «the mentality of the gold standard was integral to the ideology of those segments of society that controlled economic policies, including central bankers and national politicians in Europe and the United States $"{ }^{29}$. Dans un deuxième temps, après la vague de dévaluations monétaires, les gouvernements ayant déprécié leurs monnaies, en plus de l'amélioration de la compétitivité de leurs produits

Cf. Heiner Ritzmann-Blickenstorfer, "Kantone und Städte im Zeichen der Grossen Depression", Traverse, vol. 4, no I, 1997, p. 68-80; Müller, op. cit., 20I0, p. 35-36.

Sur le cas de Neuchâtel et de la crise horlogère, voir notamment: Marc Perrenoud, "Crises horlogères et interventions étatiques le cas de la Banque cantonale neuchâteloise pendant l'entre-deux-guerres ", in Youssef Cassis, Jakob Tanner (éd.), Banques et crédit en Suisse, (I850-1930), Zurich: Chronos, I993, p. 209-240; Marc Perrenoud, "Contrastes et paradoxes de la crise dans l'horlogerie", Traverse, vol. 4, no I, I997, p. I08-II6.

Ruffieux, op. cit., I974, p. 206.

Philipp Müller, «La bataille pour le franc: la Suisse entre déflation et dévaluation (I93I1936) ", in Philipp Müller, Isabelle Paccaud, Janick Marina Schaufelbuehl (éd.), Franc suisse, finance et commerce, Lausanne: Antipodes, 2003, p. 7-I45, p. 19.

Barry Eichengreen, Peter Temin, "The Gold Standard and the Great Depression », Contemporary European History, vol. 9, $\mathrm{n}^{\mathrm{o}}$ 2, 2000, p. 183-207, p. 185. 
d'exportation, disposaient d'une marge de manœuvre plus grande dans leurs politiques de crises. Celles-ci ont pu prendre la forme de mesures protectionnistes destinées à renforcer le marché intérieur, ou encore de politiques économiques d'inspiration keynésienne de stimulation de la demande ${ }^{30}$.

La Suisse est un des rares pays à traverser la crise des années 1930 sans connaître ni modification de son régime politique, ni rupture fondamentale dans l'orientation de sa politique de crise. Cependant, le rôle de l'État évolue au cours de la décennie. Pour Erich Gruner, la Confédération entrerait alors dans la phase de "l'interventionnisme pessimiste», dont le bilan est le suivant: «Le libéralisme économique se trouvait manifestement sur la défensive. La politique économique effectivement suivie correspondait à un croisement entre le socialisme d'État et l'interventionnisme des associations économiques. $»^{31}$ L'analyse de Philipp Müller sur la portée de l'interventionnisme de la Confédération permet de nuancer ce jugement. Pour Müller, les politiques de crises fédérales ont gravité autour des trois points forts interdépendants : la défense de la parité-or, une politique financière d'équilibre budgétaire, et une politique économique d'interventionnisme sélectif ${ }^{32}$. Revenons brièvement sur ces trois axes qui caractérisent l'attitude des milieux dirigeants helvétiques face à la crise.

Il semble régner une certaine unanimité parmi les historiens et économistes, pour considérer que le long maintien, jusqu'en septembre 1936, de la parité-or du franc suisse est en grande partie responsable du prolongement de la crise économique en Suisse ${ }^{33}$. L'acharnement du Conseil fédéral et de la BNS à

30 Peter Alexis Gourevitch, "Breaking with Orthodoxy: The Politics of Economic Policy Responses to the Depression of the 1930s ", International Organization, vol. 38, n I, I984, p. 95-I29.

31 Erich Gruner, "Ioo Jahre Wirtschaftspolitik: Etappen des Interventionismus in der Schweiz ", Schweizerische Zeitschrift für Volkswirtschaft und Statistik, vol. I/II, n 2, I964, p. 35-70, p. 60.

32 Müller, op. cit., 20Io, p. 736.

33 Wilfried Rutz, Die schweizerische Volkswirtschaft zwischen Währungs- und Beschäftigungspolitik in der Weltwirtschaftskrise: wirtschaftspolitische Analyse der Bewältigung eines Zielkonfikts, Zürich, St. Gallen: Polygraphischer Verlag, 1970; Arlettaz, art. cit., I982; Jan Baumann, Patrick Halbeisen, "Die Internationalisierung des Finanzplatzes Schweiz und ihre Folgen für die Währungspolitik. Konsens und Konflikte zwischen der Nationalbank und den Geschäftsbanken I919-I939", Contribution non publiée au colloque "Switzerland as a financial centre in international perspective (1913-1965)", Lausanne, 1999, p. 20-25; Jakob Tanner, "Goldparität im Gotthardstaat: Nationale Mythen und die Stabilität des Schweizer Frankens in den 1930er- und 40er-Jahren ", Etudes et Sources. Revue des Archives Fédérales Suisses, vol. 26, 2000, p. 45-82 ; Perrenoud, et al., op. cit., 2002, p. 49-68; Guex, art. cit., in Feiertag, Margairaz (éd.), op. cit., 2003; Müller, art. cit., in Müller, Paccaud, Schaufelbuehl (éd.), op. cit., 2003, p. 7-II ; Michael Bordo, Thomas Helbling, Harold James, "Swiss Exchange Rate Policy in the 1930s. Was the Delay in Devaluation Too High a Price to Pay for Conservatism?", Open Economies Review, vol. I8, nº I, 2007, p. I25; Patrick Halbeisen, "Open Financial Markets in Switzerland and their Impact on Monetary and Financial Policy", in Margrit Müller, Timo Myllyntaus (éd.), Pathbreakers. Small European Countries Responding to Globalisation and Deglobalisation, Berne: Peter Lang, 2008, p. 24I-270; Tobias Straumann, Fixed Ideas of Money. Small States and Exchange Rate Regimes in Twentieth-Century Europe, Cambridge: Cambridge University Press, 20IO; 
défendre une politique monétaire axée sur le franc-or constitue la " clé de voûte de l'édifice orthodoxe des politiques de crises bourgeoises ${ }^{34}$. Cette position était liée au second point fort défini ci-dessus, à savoir une politique financière d'équilibre budgétaire. En effet, les milieux dirigeants ont mis en œuvre une politique déflationniste, qui, par une réduction des prix et des salaires, visait à rétablir la compétitivité internationale des produits suisses.

Ce constat global est donc largement accepté. En revanche, la question des raisons qui ont mené les dirigeants suisses à ne pas dévaluer, et à chercher un soulagement de la crise par une politique de déflation fait l'objet d'un débat historiographique ${ }^{35}$. Retenons dans le cadre de ce travail que la défense du franc-or par le Conseil fédéral, les responsables de la Banque nationale, ainsi que le patronat industriel et les milieux financiers, apparait comme nécessaire à la fois pour préserver le statut du franc suisse comme symbole de la position du pays comme place financière internationale et aussi pour protéger le rétablissement d'un système économique mondial basé sur la libre circulation des capitaux et des marchandises. Le rôle des dirigeants de l'industrie d'exportation dans ce contexte est central. Ceux-ci, malgré des difficultés croissantes dans leurs secteurs en raison de la surévaluation de la devise helvétique, maintiennent leur adhésion à la parité or du franc. Les craintes injustifiées des effets inflationnistes et les incertitudes générales sur les conséquences d'une dévaluation semblent avoir joué un rôle dans l'attitude des industriels ${ }^{36}$. Aussi, nombre d'auteurs mettent en avant le large consensus qui règne autour de l'adhésion au franc-or, du moins jusqu'en 1935; cette attitude s'étend au-delà des milieux financiers, et même au sein du mouvement ouvrier, la politique monétaire ne fait pas débat et une dévaluation n'est pas revendiquée ${ }^{37}$. Enfin, il faut également souligner que la défense du franc-or occupe une fonction de légitimation de la politique de déflation menée par ailleurs. Maintenir l'équilibre budgétaire est une condition pour conserver la parité. Pour les milieux dirigeants suisses, l'argument monétaire, qui n'est pas remis en question, sert à justifier l'ensemble

Müller, op. cit., 20ıо ; Halbeisen, Straumann, art. cit., in Halbeisen, Müller, Veyrassat (éd.), op. cit., 2012, p. 1009-IOI7.

Müller, op. cit., 20Io, p. 24.

Pour une présentation synthétique et récente des diverses positions, voir ibid., p. 13-15; Halbeisen, Straumann, art. cit., in Halbeisen, Müller, Veyrassat (éd.), op. cit., 20I2, p. Ioo9IOII.

Halbeisen, Straumann, art. cit., in Halbeisen, Müller, Veyrassat (éd.), op. cit., 20I2, p. IOIo.

Baumann, Halbeisen, "Die Internationalisierung... », art. cit., 1999, p. 20 ; Müller, op. cit., 20I0, p. I25-I42. Le "mouvement pour la monnaie franche" (Freigeldbund) constitue une exception et s'oppose à la politique monétaire officielle dès septembre 1931. Sur cette association, voir: Markus Schärrer, Geld- und Bodenreform als Brücke zum sozialen Staat: die Geschichte der Freiwirtschaftsbewegung in der Schweiz (I9I5-1952), Zürich : Zentralstelle der Studentenschaft, 1983. Pour contrer l'offensive de la théorie de la "monnaie franche", l'«Association pour une monnaie saine" (Vereinigung für eine gesunde Währung) est fondée en juin 1934. Cf. Baumann, Halbeisen, "Die Internationalisierung... ", art. cit., 1999, p. 293I ; Müller, op. cit., 2010, p. 670-675. 
des autres politiques suivies. Il permet également de marginaliser la gauche dans le cadre des débats autour de l'initiative de crise déposée le 30 novembre 1934 et rejetée en votations le 2 juin 1935 . Cette initiative populaire "pour la lutte contre la crise et la détresse économique ", dite "initiative de crise ", lancée par l'USS et soutenue par le Parti socialiste et les jeunes paysans, représente la seule alternative sérieuse à la politique déflationniste en vigueur ${ }^{38}$. D'inspiration proto-keynésienne, elle propose des mesures de relance de la consommation en améliorant le pouvoir d'achat des salariés ${ }^{39}$. Le nombre record de signatures qu'elle a recueillies, correspondant à plus du quart de l'électorat inscrit, et la vigueur de la campagne dont elle fait l'objet ${ }^{40}$ en font une «épreuve de force globale entre mouvement ouvrier et milieux dirigeants " ${ }^{41}$. Les opposants à l'initiative brandissent alors l'argument monétaire, qui consiste à associer l'acceptation de l'initiative à la dévaluation du franc et à la catastrophe nationale. Il s'agit donc d'un affrontement entre la théorie du surinvestissement demandant une adaptation et une baisse des prix, soutenue par le Conseil fédéral et les milieux bourgeois, et la théorie de la sous-consommation, défendue par les syndicalistes et une partie des socialistes - Max Weber (I897-1974) et Friedrich Marbach (I892-1974) en tête - et exigeant une plus grande intervention de l'État ${ }^{42}$. Le 2 juin 1935 , l'initiative de crise est rejetée par le peuple, recueillant tout de même $43 \%$ des voix.

Sur le contexte dans lequel l'initiative est lancée et les positions des divers syndicats, voir: Eduard Kobelt, Die Wirtschaftspolitik der Gewerkschaften, 1920-I950 : der Einfluss einzelner Gewerkschaftsverbände und Persönlichkeiten auf die Wirtschaftspolitik des Schweizerischen Gewerkschaftsbundes, Zürich: Chronos, 1987, p. 96-II3. Voir également: Wolf Linder, Christian Bolliger, Yvan Rielle (éd.), Handbuch der eidgenössischen Volksabstimmungen I848 - 2007, Bern: Haupt, 2010, p. I78-I80.

39 Sur le poids marginal du keynésianisme dans la politique économique de la Confédération au Xx siècle: Sébastien Guex, "L'État fédéral et les crises économiques du début du XXe siècle à nos jours : la Suisse, un bastion anti-keynésien ", in Thomas David, Jon Mathieu, Janick Marina Schaufelbuehl (éd.), Krisen : Ursachen, Deutungen und Folgen, Zürich : Chronos, 20I2, p. I5I-169.

40 La campagne contre ce qui est surnommé «l'initiative de banqueroute étatique " (Staatsbankrott-Initiative) est d'ailleurs largement financée par les dirigeants bancaires. Le comité d'action des opposants à l'initiative formé en novembre 1934 dispose de 750000 francs pour la campagne de votations. Un tiers de ce montant est fourni par l'ASB, en prélevant $5 \%$ du bénéfice réalisé sur le dernier emprunt fédéral. AASB : Note confidentielle pour la $60^{\mathrm{e}}$ séance du Comité de l'ASB, 26 octobre 1934. À ce sujet, voir aussi : Geneviève Billeter, Le pouvoir patronal: les patrons des grandes entreprises suisses des métaux et des machines (I9I91939), Genève : Droz, 1985, p. I47-155; Baumann, Halbeisen, « Die Internationalisierung... », art. cit., 1999, p. 28-31; Christian Werner, Für Wirtschaft und Vaterland: Erneuerungsbewegungen und bürgerliche Interessengruppen in der Deutschschweiz, 1928-1947, Zürich : Chronos, 2000, p. I44-I49; Müller, op. cit., 2010, p. 582-583. vestition oder Unterkonsumtion? Die Grosse Depression in der Schweiz. Beiträge der Wirtschaftstheorie zu ihrer Erklärung", in Thomas Geiser, Hans Schmid, Emil WalterBusch (éd.), Arbeit in der Schweiz des 20. Jahrhunderts. Wirtschaftliche, rechtliche und soziale Perspektiven, Bern : Paul Haupt, 1998, p. I87-216. 
En plus de la défense du franc-or combinée à une politique déflationniste de baisse des prix et de rigueur budgétaire, le troisième axe de la réponse à la crise de la Confédération prend la forme d'un «interventionnisme sélectif renforcé " ${ }^{43}$. La formule de Philipp Müller permet d'envisager la politique économique de la Confédération sous différentes facettes. D’une part, à partir des expériences passées notamment pendant et au sortir du premier conflit mondial, l'État fédéral fonctionne comme arbitre au sein des tensions internes au bloc bourgeois; dans ce sens, une politique agricole généreuse vise à neutraliser une potentielle source de contestation de la part de la paysannerie. D'autre part, les réponses à la crise de la Confédération mettent en jeu la faiblesse structurelle de l'État fédéral et des partis politiques nationaux, avec laquelle contraste la situation des associations économiques puissantes et bien organisées ${ }^{44}$.

Quelle forme concrète prend donc cet interventionnisme sélectif? Du point de vue quantitatif, il se décline de la manière suivante ${ }^{45}$. La politique financière suisse est conforme à la politique de déflation mise en œuvre : l'équilibre budgétaire doit être atteint, sans augmenter la pression fiscale, mais au contraire en réduisant les dépenses. Le programme financier du Conseil fédéral de juin 1932, mieux connu sous le nom de Lex Musy, qui prévoyait une réduction des salaires des employés de la Confédération, est rejeté en votations le 28 mai I933 par $55 \%$ des votants ${ }^{46}$. Malgré ce désaveu populaire, le Conseil fédéral maintient le cap de la politique déflationniste et fait adopter, en octobre 1933, un programme financier de crise muni d'une clause d'urgence, empêchant ainsi le recours au référendum. En plus d'une réduction des salaires des fonctionnaires fédéraux et d'une baisse des subventions, le programme inclut, du côté des recettes, un impôt fédéral direct provisoire de crise, une utilisation et une augmentation des ressources issues de l'impôt sur l'alcool et le tabac prévu pour financer l'AVS, et enfin, un accroissement de l'imposition sur les coupons ${ }^{47}$.

Müller, op. cit., 2010, p. 19-23, p. 737.

Sur le développement des associations faîtières et leur rôle en Suisse: Erich Gruner, Die Wirtschaftsverbände in der Demokratie: vom Wachstum der Wirtschaftsorganisationen im schweizerischen Staat, Erlenbach-Zürich Stuttgart: E. Rentsch, 1956; Beat Hotz, Politik zwischen Staat und Wirtschaft. Verbandsmässige Bearbeitung wirtschaftlicher Probleme und die daraus resultierenden Konsequenzen für die Aktivitäten des Staates im Falle der Schweiz, Diessenhofen: Verlag Rüegger, 1979; Peter Farago, Hanspeter Kriesi (éd.), Wirtschaftsverbände in der Schweiz: Organisation und Aktivitäten von Wirtschaftsverbänden in vier Sektoren der Industrie, Grüsch: Rüegger, 1986; André Mach, "Associations d'intérêts », in Ulrich Klöti, et al. (éd.), Handbuch der Schweizer Politik. Manuel de la politique suisse, Zurich : Neue Zürcher Zeitung, 2002, p. 297-333; Pierre Eichenberger, André Mach, «Organized capital and coordinated market economy. Swiss business interest associations between socio-economic regulation and political influence», in Christine Trampusch, André Mach (éd.), Switzerland in Europe: Continuity and Change in the Swiss Political Economy, London: Routledge, 20II, p. 63-8I.

Müller, op. cit., 20I0, p. 362-37I.

6 Sur le rejet de la Lex Musy, voir Heinz Dickenmann, Das Bundespersonal in der Wirtschaftskrise 193I-I939, Zürich : Zentralstelle der Studentenschaft, 1983, p. 68-223; Müller, op. cit., 20Io, p. 385-387; Linder, Bolliger, Rielle (éd.), op. cit., 20IO, p. I73-174.

Müller, op. cit., 20Io, p. 387-468. 
La Confédération traverse donc la crise des années 1930 pratiquement sans subir de déficits dans ses comptes. Les dépenses fédérales subissent une forte baisse en 193I, de l'ordre de I2 \% en termes réels, sous l'effet de la politique déflationniste. Entre 1932 et 1936, au plus fort de la crise, les dépenses de la Confédération augmentent en termes réels d'environ $2 \mathrm{I} \%{ }^{48}$. Les principaux bénéficiaires de cette augmentation du budget de l'État sont la paysannerie, les milieux bancaires et certains secteurs industriels ${ }^{49}$. Les subventions agricoles représentent près d'un tiers des dépenses supplémentaires pendant la période 1930-1937; en 1935, le soutien à l'agriculture (en particulier pour soutenir le prix du lait et du blé) représente $20 \%$ des dépenses de l'État fédéral ${ }^{50}$. La Confédération consacre en outre près de 230 millions - représentant la moitié du budget de I933 - pour soutenir les banques en difficultés. Nous y reviendrons. Dans le domaine industriel, l'horlogerie bénéficie d'une injection de liquidités de la part de la Confédération, tandis que l'industrie des machines dispose de subsides de fabrication et de la mise en place de la garantie des risques à l'exportation ${ }^{51}$. La politique sociale reste en revanche modeste: les subventions destinées aux employeurs pour combattre le chômage atteignent, entre 1930 et 1937, I2 \% des dépenses supplémentaires de l'État fédéral ${ }^{52}$. Comme le résume Philipp Müller, «les politiques de crise ciblées de la Confédération dans le domaine industriel, bancaire, agricole ainsi qu'artisanal et commercial, contrastent fortement avec les réponses déficientes lacunaires et discriminatoires de l'État fédéral face au chômage et à la pauvreté " ${ }^{53}$.

Ces quelques considérations sur l'étendue de la crise en Suisse permettent non seulement de situer le contexte social et économique particulièrement tendu dans lequel s'inscrit l'élaboration d'une surveillance bancaire en Suisse. Elles rendent également compte des tensions qui traversent l'ensemble de la classe politique - et les dirigeants de la banque centrale - face à un phénomène de crise profond.

\section{II.2. LA CRISE BANCAIRE EUROPÉENNE ET SES AVATARS EN SUISSE (BANQUE DE GENÈVE, BANQUE D'ESCOMPTE SUISSE)}

Seule la vigueur de la crise bancaire qui a affecté la Suisse à partir de I93I permet d'expliquer l'émergence d'une régulation fédérale des banques. Ce n'est que sous l'effet d'une intervention massive de la Confédération dans le cadre du

\footnotetext{
48 Sébastien Guex, "Öffentliche Finanzen und Finanzpolitik", in Patrick Halbeisen, Margrit Müller, Béatrice Veyrassat (éd.), Wirtschaftsgeschichte der Schweiz im 20. Jahrhundert, Basel : Schwabe, 2012, p. I077-II29, p. IIO6.

49 Ibid., p. IIo6.

50 Müller, op. cit., 20Io, p. 365 ; Guex, art. cit., in Halbeisen, Müller, Veyrassat (éd.), op. cit., 2012, p. IIO6.

51 Müller, op. cit., 20Io, p. 295-309, 486-495.

52 Guex, art. cit., in Halbeisen, Müller, Veyrassat (éd.), op. cit., 20I2, p. IIo6.

53 Müller, op. cit., 20Iо, p. 738.
} 
sauvetage de la Banque Populaire Suisse, en novembre 1933, que la farouche résistance des dirigeants bancaires contre une réglementation fédérale des activités bancaires peut être brisée. Mais n'anticipons pas. Étant donné l'importance primordiale des difficultés bancaires dans la mise en place d'un cadre de surveillance des banques, il est nécessaire de présenter dans les grandes lignes le déroulement de la crise bancaire. À l'échelle européenne également, la crise bancaire des années 1930 met en branle un mouvement de régulation. Les faiblesses du système financier révélées à cette occasion suscitent des revendications en faveur d'une plus forte réglementation du secteur bancaire ${ }^{54}$.

Les historiens s'accordent à dire que la crise bancaire européenne, c'està-dire plus précisément les séismes financiers que représentent la faillite de l'Österreichische Creditanstalt fin mai I93I, suivie de la fermeture des guichets de la Darmstädter und Nationalbank en juillet 193I, et les graves crises de paniques qui s'ensuivirent, sont à l'origine de la crise financière en Suisse ${ }^{55}$. De manière générale, la crise financière européenne qui éclate à l'été I93I est étroitement liée à la défaillance des pays créanciers à maintenir des financements capables de surmonter les effets de la dépression économique ${ }^{56}$. L'effondrement de la confiance entraine des vagues de retraits massifs; l'interruption des flux de capitaux depuis les États-Unis vers l'Europe centrale et orientale joue un rôle moteur dans la propagation internationale de la crise ${ }^{57}$. En plus des difficultés de paiements liées aux retraits des capitaux étrangers, les institutions financières d'Europe centrale étaient également intrinsèquement fragiles dans leur structure. La domination du système économique par une poignée de très grands établissements fortement exposés aux chocs internationaux se révèle être une combinaison précaire en période de dépression. Ainsi le Credit-Anstalt autrichien contrôlait de fait, par des prises de participations, plus de deux tiers des entreprises autrichiennes ${ }^{58}$. L'année 1931 marque ainsi «la némésis» des

54 Harold James, "General trends: A Search for Stability in Uncertain Conditions ", in Hans Pohl (éd.), Europäische Bankengeschichte, Frankfurt am Main: Fritz Knapp Verlag, 1993, p. $345-357$, p. 346.

55 Bänziger, op. cit., 1986, p. 87; Ehrsam, art. cit., in Zulauf (éd.), op. cit., 1985, p. 87; Halbeisen, art. cit., in Guex, et al. (éd.), op. cit., 1998, p. 63; Perrenoud, et al., op. cit., 2002, p. 80.

56 Derek Howard Aldcroft, The European Economy I9I4-I99o, London ; New York : Routledge, I993, p. 72.

57 Harold James, "International capital movements and the global order», in Larry Neal, Jeffrey G. Williamson (éd.), The Cambridge History of Capitalism. Volume II: The Spread of Capitalism: From I848 to the Present, Cambridge: Cambridge University Press, 20I4, p. 264300, p. 280-28I.

58 Patricia Clavin, The Great Depression in Europe. 1929-1939, Basingstoke; London : Macmillan, 2000, p. I22. Pour une revue historiographique récente sur la chute du Credit-Anstalt, et notamment ses éventuels liens avec la crise bancaire allemande, voir: Nathan Marcus, "Credibility, Confidence and Capital. Austrian Reconstruction and the Collapse of Global Finance : I92I to I93I ", PhD Thesis, Department of History, New York University, 20II, p. 294-327. Voir encore: Aurel Schubert, The Credit-Anstalt Crisis of I93I, Cambridge: Cambridge University Press, 2006. 
banques de type mixte ou universel d'Europe centrale ${ }^{59}$. Leurs actifs sont fortement dépréciés suite à l'effondrement des prix ; les tentatives désespérées de rachat de leurs propres actions pour rétablir la confiance se soldent par des échecs et aggravent leurs difficultés. Parallèlement, la non-concordance des échéances entre actif et passif créée des problèmes de liquidité. La nervosité des investisseurs et des déposants, notamment vis-à-vis de l'actualité politique, forme un rouage dans la transmission internationale de la crise financière. Le rapatriement vers les pays créditeurs des investissements en Europe centrale, combiné aux difficultés domestiques de grandes banques universelles provoquées par la dépression dans le secteur industriel, forme le cocktail toxique qui explose en Autriche, puis en Hongrie, en Allemagne, en Tchécoslovaquie et en Pologne ${ }^{60}$. Le mécanisme de crise, très grossièrement esquissé ici, aurait pu faire l'objet d'une intervention massive des banques centrales pour soutenir les banques commerciales ou d'une atténuation de la politique de déflation: l'orthodoxie monétaire du gold standard s'y opposait ${ }^{61}$.

En Allemagne, la crise bancaire, dont les retombées seront les plus directes sur l'évolution des banques suisses, se déploie de manière singulière ${ }^{62}$. Dès septembre 1930, suite aux élections fédérales qui voient le renforcement à la fois du Parti communiste et surtout du Parti national-socialiste, les retraits de capitaux étrangers s'accélèrent ${ }^{63}$. Le I3 juillet 193I, la fermeture des guichets de la Danat-Bank, suite à de lourdes pertes subies dans la faillite frauduleuse de la firme d'industrie textile Nordwolle AG, provoque une ruée des déposants des autres grandes banques allemandes. L'absence de coordination entre les grands établissements financiers allemands, en proie à une concurrence exacerbée, ainsi que les difficultés de refinancement auprès de la Reichsbank, dont les réserves en or sont tombées sous le minimum statutaire, aggravent la crise bancaire. Le gouvernement Brüning décrète ainsi deux jours de fermeture de banques le I3 et I4 juillet, avant d'instaurer le contrôle des changes le is juillet. Seule la Finanzen und Politik, München: Piper, 1967; Harold James, The German Slump: Politics and Economics, 1924-1936, Oxford: Clarendon Press, 1986, p. 283-323; Theo Balderston, "The banks and the gold standard in the German financial crisis of I93I", Financial History Review, vol. I, n ${ }^{\circ}$ I, I994, p. 43-68. Pour un débat récent sur les origines et la nature de la crise, voir : Thomas Ferguson, Peter Temin, "Made in Germany : The German currency crisis of July 193I", Research in Economic History, vol. 2I, 2003, p. I-53, Isabel Schnabel, "The German Twin Crisis of 1931", The Journal of Economic History, vol. 64, $\mathrm{n}^{\circ} 3,2004$, p. 822-87I, Christopher Kopper, «New perspectives on the 193I banking crisis in Germany and Central Europe", Business History, vol. 53, n 2, 20II, p. 216-229, Albert Fischer, "Die Bankenkrise von 1931. Anstoß zur staatlichen Bankenregulierung", in Dieter Lindenlaub, Carsten Burhop, Joachim Scholtysek (éd.), Schlüsselereignisse der deutschen Bankengeschichte, Stuttgart: Franz Steiner Verlag, 2013, p. 257-269.

63 Gunther Aschhoff, et al. (éd.), Deutsche Bankengeschichte, Frankfurt am Main : Fritz Knapp Verlag, vol. 3, 1983, p. I05. 
Reichsbank, par l'intermédiaire des Devisenstellen, était autorisée à vendre et acheter des devises étrangères; le cours du Reichsmark était gelé à l'ancienne parité-or; la fuite de capitaux et titres vers l'étranger strictement interdite ${ }^{64}$. Relevons au passage que la fuite de capitaux allemands vers des safe haven n'est pas un phénomène nouveau en I93I; dans les années précédentes, les capitaux allemands avaient déjà cherché refuge à l'étranger, en particulier auprès d'instituts néerlandais et suisses, et dans une moindre mesure belges ${ }^{65}$. Dans la foulée, en septembre 1931, de premiers accords de prorogation sont signés entre les débiteurs allemands et leurs créanciers internationaux, représentés sous la forme de comités nationaux. Le Basler Abkommen, initialement prévu pour six mois, sera de fait renouvelé jusqu'en 1939 ou 1945 selon les pays créanciers. Les créanciers s'engageaient à proroger les crédits à court terme consentis à un débiteur allemand, renonçant ainsi à exiger un remboursement des crédits à la date d'échéance. En contrepartie, ils obtenaient le maintien du versement des intérêts et commissions des crédits concernés ${ }^{66}$. Enfin, troisième forme d'intervention des autorités publiques allemandes dans la crise bancaire, l'État s'implique dans la reconstruction des grandes banques affectées : il détient plus de $90 \%$ du capital de la banque issue de la fusion de la Danat-Bank et la Dresdner Bank, la même part de la Commerz-Bank et plus de $30 \%$ de la Deutsche Bank et de la Disconto-Gesellschaft ${ }^{67}$. Cette socialisation des pertes du système bancaire s'accompagne souvent d'un renouvellement des instances dirigeantes. La reprivatisation des grandes banques se fera sous le régime national-socialiste.

Après l'Allemagne, c'est au tour de l'Angleterre de subir les contrecoups de la crise financière européenne. En plus des difficultés de certaines merchants banks, lourdement touchées par la baisse des échanges internationaux et engagées vers le financement du commerce allemand, la City est également fragilisée par des attaques contre la Livre sterling. Considérée comme surévaluée, la monnaie britannique subit des pressions ; la Banque d'Angleterre fait face à une diminution de ses réserves d'or. Le 2I septembre I93I, le gouvernement d'union nationale qui remplace le cabinet travailliste fraîchement démissionné décide de suspendre la convertibilité-or de la Livre sterling. Son change devient flottant et perd rapidement environ $25 \%$ de sa valeur face au dollar. L'abandon de l'étalon-or est suivi par I8 pays ${ }^{68}$. Fin 1932, seuls les États-Unis et le bloc-or, à savoir la Belgique, la France, les Pays-Bas, la Pologne et la Suisse, s'accrochent encore à l'étalon-or. Le régime monétaire international laborieusement rétabli en 1925 avait vécu.

64 Stefan Frech, Clearing: der Zahlungsverkehr der Schweiz mit den Achsenmächten, Zürich : Chronos, 200I, p. 47.

65 James, op. cit., I986, p. 298-30I.

66 Perrenoud, et al., op. cit., 2002, p. I59-I6I ; Suzanne Peters, «Les "Stillhalteabkommen" et les banques suisses (I93I-I945). Quatorze années de prorogation des créances bancaires suisses ", Mémoire de licence, Faculté des lettres, Université de Lausanne, I999, p. 34-38.

67 Fischer, art. cit., in Lindenlaub, Burhop, Scholtysek (éd.), op. cit., 2013, p. 262.

68 Crafts, Fearon, art. cit., in Crafts, Fearon (éd.), op. cit., 20I3, p. I8. Voir aussi : Liaquat Ahamed, Lords of finance: the bankers who broke the world, London: W. Heinemann, 2009, p. $422-450$. 


\section{La crise bancaire en Suisse}

Contrairement au déroulement de la crise économique générale, qui déploie ses effets en Suisse de manière sournoise, avec un certain retard par rapport aux autres pays, la crise financière européenne se propage vers les banques helvétiques sans détour. Pour le dire rapidement, les difficultés des banques suisses sont proportionnelles à l'exposition internationale de leurs actifs, et en particulier de leurs crédits gelés dans les pays concernés par des moratoires de paiement. L'introduction en Allemagne, puis dans d'autres pays d'Europe centrale - en Autriche, en Hongrie ou en Pologne, du contrôle des changes est une source de grandes difficultés pour les établissements financiers qui y sont fortement engagés. Les crédits bloqués conduisent en effet à une dépréciation des créances, qui s'explique par la perte de rendement ainsi que par la perte de confiance qui suit la publication de l'ampleur des crédits octroyés ${ }^{69}$. Les banques tentent alors de réaliser rapidement leurs actifs pour enrayer la crise de confiance du public et les retraits des déposants. La liquidation à perte des avoirs gelés ou la liquidation d'actifs rémunérateurs dépend de la rentabilité de la banque concernée. Les instituts financiers qui, au cours du boom des années 1920 , avaient démesurément octroyé des crédits à des clients étrangers, étaient les plus affectés par la crise financière déclenchée en I93I. Les taux de croissance impétueux qu'avaient connus les bilans des grandes banques suisses entre I92I et I930 - I78 \% pour la Banque Commerciale de Bâle, I44 \% pour la Banque Fédérale, II $7 \%$ pour le Crédit Suisse - provenaient en grande partie de l'extension des activités internationales de ces instituts ${ }^{70}$.

Les investissements excessifs durant la seconde moitié des années 1920 étaient liés aux profits substantiels qui étaient escomptés dans ces opérations. Le rendement moyen des emprunts étrangers est en effet nettement supérieur à celui des emprunts suisses, de l'ordre de $7 \%$ pour les premiers contre $5 \%$ pour les seconds en $1929^{71}$. Comme le relève l'ancien directeur général de la BNS Max Iklé dans son étude sur le développement de la place bancaire suisse, les transactions financières entre la Suisse et l'Allemagne qui fleurissent au cours des années 1920 étaient d'une importance capitale pour les banques helvétiques: "Ainsi affluèrent d'Allemagne en Suisse des fonds considérables, qui furent à leur tour déposés en Allemagne, car ils ne trouvaient pas d'utilisation dans notre propre pays. " ${ }^{72}$ Les financiers suisses pouvaient alors tirer profit de la différence entre les taux d'intérêt pratiqués en Allemagne et ceux du marché suisse. Cette extension démesurée de l'exportation de capitaux vers l'Allemagne gulation bancaire en Suisse et en Angleterre (I9I4-I940) ", Thèse de doctorat, Faculté des sciences sociales et politiques, Université de Lausanne, 2004, graphique 9, p. I25; Sancey, op. cit., 2015, p. I6I.

72 Max Iklé, Die Schweiz als internationaler Bank-und Finanzplatz, Zürich : Orell Füssli, I970, p. 32-33. 
et l'Europe centrale n'était pas dénuée de risques. Les banquiers suisses ont eu tendance à transformer leurs crédits commerciaux en crédits industriels d'investissement fixe, plus fortement immobilisés ${ }^{73}$. La politique de crédit déséquilibrée poursuivie dans les années 1920 a donc contribué de manière décisive à la gravité de la crise.

À l'été 1931, lorsque les avoirs étrangers sont gelés en Allemagne et que les premiers accords de prorogation sont négociés, les capitaux suisses occupent une place non négligeable parmi les créances internationales. Les banques suisses détiennent à mi-juillet $16 \%$ des crédits prorogés (I047 millions de francs), ce qui plaçait la Suisse en troisième position derrière les États-Unis (36\%) et la Grande-Bretagne (20\%), mais devant les Pays-Bas ou la France ${ }^{74}$.

Du point de vue des banques suisses, les crédits allemands bloqués représentent donc un risque substantiel: les fonds propres (capital et réserves ouvertes) des grandes banques de fin 1931, s'élevant à I.2 milliard de francs, couvrent à peine les montants concernés par des accords de prorogation ${ }^{75}$. Ce risque sur la dette à court terme allemande n'affecte évidemment pas tous les établissements dans la même mesure. Ce sont en premier lieu les huit grandes banques, à savoir, par ordre décroissant d'importance en termes de bilan en 1931, le Crédit Suisse, la Société de Banque Suisse, la Banque Populaire Suisse, l'Union de Banques Suisses, la Banque Fédérale, la Banque Commerciale de Bâle, le Comptoir d'Escompte de Genève et la Banque Leu, qui sont touchées. La suite de ce sous-chapitre a pour but d'examiner, d'un point de vue quantitatif, les dynamiques de changement de la place bancaire suisse au cours des années 1930. Nous aborderons donc successivement l'évolution de la somme des bilans, du compte pertes et profits et du nombre de liquidations et de reprises.

La morphologie du paysage bancaire suisse est chamboulée par la grave crise des années 1930. Celle-ci atteint essentiellement les grandes banques, en raison de leur plus fort enchevêtrement international. C'est ce qui ressort du graphique 2, qui met en évidence le renversement sous l'effet de la crise, des dynamiques internes au système bancaire suisse. Tandis que le groupe des grandes banques avait, en 1928, dépassé pour la première fois les banques cantonales par la taille de ses bilans, la tendance s'inverse sous l'effet de la crise après 1931. Le groupe des banques cantonales connaît une forme de stabilité et le volume de son bilan cumulé croît jusqu'en 1937: en termes réels, les bilans des banques cantonales connaissent une augmentation de

73 Bodmer, op. cit., 1948, p. 34. Daniel Bodmer (1917-1980), après une dizaine d'années au secrétariat de l'ASB, deviendra secrétaire (1956-1976), puis membre (1976-1980) de la Commission fédérale des banques. Voir aussi Claudius Terrier, «Les grandes banques commerciales sous l'influence de la crise", Bulletin de l'Association suisse des Experts-comptables, $\mathrm{n}^{\circ}$ IO, 1936, p. 24.

74 Perrenoud, et al., op. cit., 2002, p. 158-159. Willi Loepfe confirme cette estimation à partir d'archives allemandes: Loepfe, op. cit., 2006, p. 85-86.

75 Statistisches Handbuch des schweizerischen Geld-und Kapitalmarktes: Manuel statistique du marché financier suisse, Zürich : Schulthess, 1944, p. 157. 
Graphique 2. Bilans des grandes banques et des banques cantonales, en millions de CHF de 1929 (I925-1945)

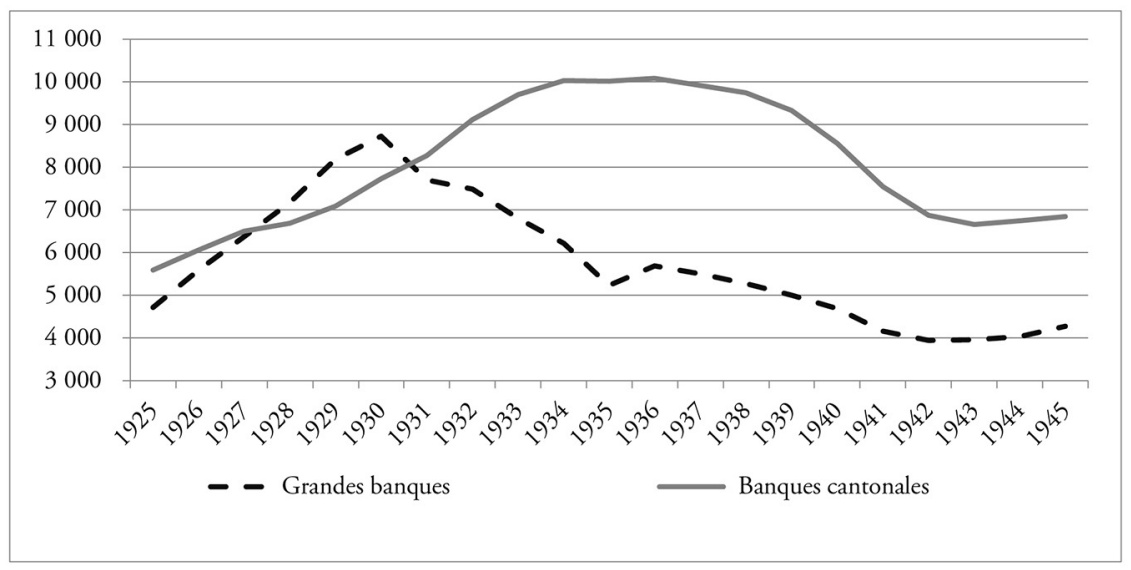

Source: Ritzmann-Blickenstorfer (éd.), op. cit., I996, tab. O.I3, p. 818-819, tab. H.23, p. 504.

$40 \%$ entre 1929 et I937. Certains instituts cantonaux atteignent même des dimensions comparables aux grandes banques commerciales. Fin 1936, la Banque cantonale de Zurich devient le plus grand établissement de Suisse avec un bilan de I.4 milliard de francs, et devance la Société de Banque Suisse $^{76}$; d'autres établissements, comme la Banque cantonale vaudoise, ont également un volume d'affaires digne d'une grande banque ${ }^{77}$. Même si, comme nous le verrons, d'autres banques cantonales, comme celles de $\mathrm{Neu}$ châtel, des Grisons et de Berne, connaissent des difficultés durant la deuxième phase de la crise bancaire et doivent faire appel aux autorités publiques pour assainir leur situation, le groupe des établissements cantonaux sort renforcé de la crise des années 1930. Une des raisons qui expliquent cette tendance est la garantie étatique dont bénéficient ces banques publiques ou semi-publiques ${ }^{78}$. Leur importance augmente à la fois de manière relative au groupe des grandes banques, mais également en termes absolus, puisque certains des retraits de capitaux dont souffrent les grandes banques sont déposés dans les banques

76 Theo Keller, Das Verhältnis der Banken zur Industrie: mit besonderer Berücksichtigung der Schweiz, St. Gallen: Fehr, 1937, p. II8. Sur la Zürcher Kantonalbank, voir: Andreas Russenberger, " "Die Welt ist aus den Fugen geraten”: die Unternehmenstheorie der Zürcher Kantonalbank in der Zwischenkriegszeit (I919-I939) unter besonderer Berücksichtigung der frühen dreissiger Jahre ", Zürich, 1996.

77 Sur la Banque cantonale vaudoise, voir: Samuel Beroud, «La Banque cantonale vaudoise, I9I8-1939: le rôle d'une banque semi-publique entre crises économiques, tensions politiques et concurrence interbancaire ", Mémoire de Master, Faculté des lettres, Université de Lausanne, 20II. Voir également: Alfred Hartmann, Der Konkurrenzkampf zwischen den schweizerischen Grossbanken und Kantonalbanken, Zürich: Kommerzdruck- und Verlags AG, 1947 . 
cantonales ${ }^{79}$. En temps de crise, les déposants se tournent vers des établissements considérés comme plus sûrs, et la baisse de confiance à l'égard des grandes banques se reporte ainsi positivement pour les banques cantonales. Il s'agit là d'une tendance générale à l'international durant les années 1930: dans tous les grands pays européens, les plus petits établissements (caisses d'épargne, banques locales publiques, etc.) gagnent des parts de marché dans le domaine des dépôts, au détriment des grandes banques ${ }^{80}$.

Les grandes banques helvétiques, quant à elles, connaissent un puissant recul, et sont les principales victimes de la crise bancaire des années 1930. En francs courants, la somme des bilans des grandes banques passe de 8.5 milliards de francs en 1930 à 4.I milliards de francs en 1935. En termes réels, cela correspond à une baisse de $40 \%$. En considérant l'ensemble des banques helvétiques, la contraction de la somme des bilans entre 1930 et 1935 est de l'ordre de $17 \%$ en francs nominaux : ils enregistrent une baisse de 2I.2 milliards à 17.5 milliards.

La fluctuation des bénéfices enregistrés au cours des années I930 confirme la tendance esquissée par l'évolution des bilans. Selon les chiffres fournis par la BNS, établis à partir des comptes profits et pertes transmis par les banques, les grandes banques souffrent gravement de la crise, tandis que les banques cantonales connaissent une évolution plus stable.

Graphique 3. Évolution des bénéfices nets (selon le compte de profits et pertes), par groupe bancaire (1929-1940)

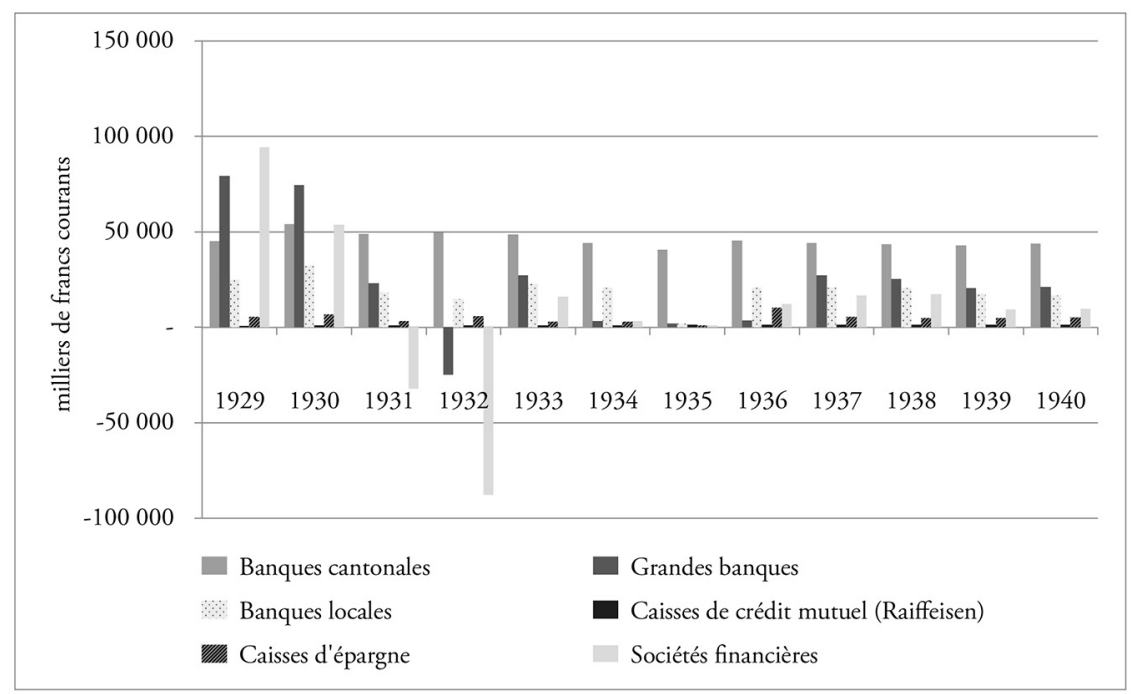

Source: BNS, Das schweizerische Bankwesen im Jahre..., Zürich: Orell Füssli, I929-1940 (Gewinn- und Verlustrechnung).

79 Keller, op. cit., 1937, p. II8. Sur le concurrence entre banques cantonales et grandes banques dans le domaine de l'attraction des fonds de tiers, voir: Hartmann, op. cit., I947, p. 65-I2I. 
Le graphique 3 montre clairement que les banques cantonales parviennent à maintenir des bénéfices nets constants au cours de la période, fluctuant entre 54 millions en 1930 et 43 millions en 1939 (francs nominaux) ${ }^{81}$. Les grandes banques, en revanche, voient leurs bénéfices nets passer de 74.4 millions en 1930 à 2.I millions en 1935 - en termes réels, la chute est à peine moins marquée, les bénéfices de 1935 ne représentant que 3.5\% des ceux de 1930 . Elles enregistrent même des pertes de 24.6 millions en I932. Les résultats de I934 à 1936 se soldent par un bénéfice presque insignifiant. Quant aux sociétés financières, souvent fortement liées aux grandes banques, elles subissent également de lourdes pertes en I93I et I932, respectivement de 32.2 et 87.7 millions. Cette chute spectaculaire trouve son explication principale dans la contraction des crédits internationaux et le gel des avoirs des établissements financiers suisses en Allemagne et en Europe centrale. Ainsi, les pertes et amortissements bruts, c'est-à-dire sans tenir compte de recettes bancaires, s'élèvent pour 1932 au total de 260 millions de francs, dont 138 millions à la charge des sociétés financières et 90 millions à la charge des grandes banques ${ }^{82}$. Dans l'ensemble, les bénéfices nets de toutes les banques en Suisse, à l'exception des sociétés financières, passent de I68.5 millions nominaux en I930 à 47.I millions en 1935 - en termes réels, une baisse de $65 \%$.

Si l'on observe la courbe du nombre de banques et de la structure bancaire, on constate que la crise des années I930 n'a pas provoqué, en apparence, une forte concentration bancaire. Le nombre d'établissements qui entrent en liquidation est sans commune mesure avec la grande purge qui affecte par exemple le système bancaire américain pendant la Grande dépression; près de Io ooo établissements, sur un total de 25 ooo banques commerciales américaines, ont suspendu leurs activités entre 1929 et $1933^{83}$. Même à l'échelle de la Suisse, d'autres périodes, comme les années I9IO-I9I4 ou I92I-I924, connaissent une plus forte mortalité bancaire ${ }^{84}$. Le nombre total de banques, n'incluant pas les banquiers privés, est même très stable durant les années I930, oscillant entre 357 (I934) et 365 (1936) ${ }^{85}$. D'après les données fournies par le spécialiste des banques suisses Franz Ritzmann, pendant la période I929-I945, II6 établissements disparaissent, suite à une liquidation, une faillite ou une reprise, tandis que Ioo nouvelles banques sont fondées. Sur la seule décennie des années I930, 92 raisons sociales sont supprimées (62 sans compter les sociétés financières) ${ }^{86}$. Comme il ressort du graphique 4, la grande majorité des instituts qui font faillite durant l'ensemble de la période est classée dans les catégories des sociétés financières $(27 \%)$, des

81 Nous avons choisi d'exprimer les chiffres sur les bénéfices et pertes bancaires en valeur nominale, c'est-à-dire sans tenir compte de l'inflation - ou plutôt de la déflation en l'occurrence. Plutôt que l'évolution diachronique, c'est ici la comparaison entre les différents groupes bancaires à un moment donné qui nous intéresse en premier lieu.

BNS, Das schweizerische Bankwesen im Jahre 1932, Zürich : Orell Füssli, I933, p. 35.

Kris James Mitchener, "Bank Supervision, Regulation, and Instability during the Great Depression ", The Journal of Economic History, vol. 65, n ${ }^{\circ}$ I, 2005, p. I52-185, p. I52.

Ritzmann, op. cit., I973, p. I08-II5. 
banques locales (24\%), et des autres banques (18\%). Les grandes banques n'apparaissent qu'à trois occasions dans le graphique: en I93I, avec la fusion entre le Comptoir d'Escompte de Genève et l'Union financière de Genève, en 1934, lors de la faillite de la Banque d'Escompte suisse, et en 1945, avec les reprises de la Banque Commerciale de Bâle par la Société de Banque Suisse et celle de la Banque Fédérale par l'Union de Banques Suisses. Cette représentation, qui enregistre les départs de la liste des banques, ne reflète pas du tout l'ampleur de la crise bancaire, puisqu'elle ne tient pas compte de la dimension des instituts concernés. De plus, ces données ne font figurer que les cas qui ont mené à la disparition d'une raison sociale, mais occultent les nombreuses occurrences de difficultés bancaires qui ont pu être résolues par une opération d'assainissement interne, ou par une intervention de sauvetage externe.

Graphique 4. Nombre de liquidations ou reprises bancaires (I929-I945)

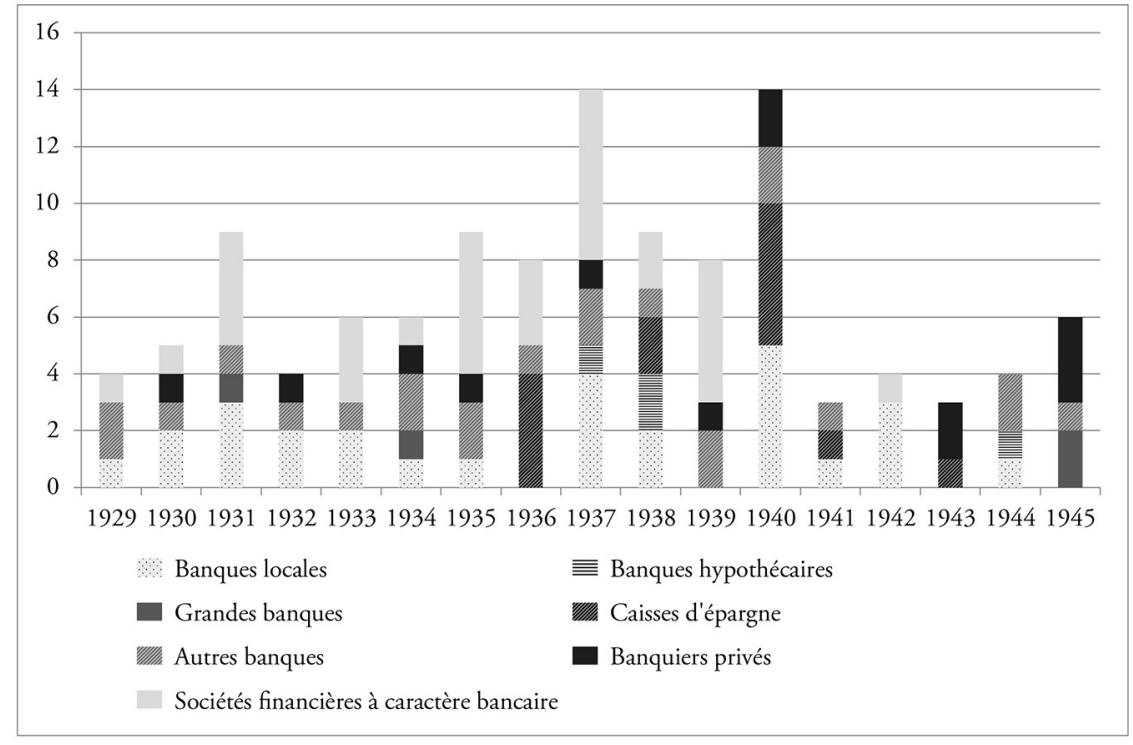

Source : Calculé par l'auteur d'après Franz Ritzmann, Die Schweizer Banken. Geschichte - Theorie - Statistik, Bern; Stuttgart: Haupt, 1973, p. 356-364.

Il est difficile d'évaluer avec certitude l'ampleur des pertes subies par les banques suisses durant la crise des années 1930. Le chiffre le plus fréquemment avancé par la littérature est celui d'un total de I.4 milliard de pertes et amortissements entre 193I et 1937, soit $7 \%$ de la somme des bilans de toutes les banques en 193I. Cette estimation a été à l'origine calculée par Paul Rossy, et publiée en 1937 dans la retranscription d'une conférence ${ }^{87}$. Ce même Rossy a

87 Paul Rossy, «Die Reorganisation des schweizerischen Bankwesens», Schweizerische Bankpersonal-Zeitung, $\mathrm{n}^{\circ}$ 6-7, 1937, p. I-3. Claudius Terrier (I893-1977), professeur d'économie à l'Université de Genève, avance le chiffre de I.I milliard de pertes pour la période I93I-I936 
également établi les pertes subies par les actionnaires et déposants de six grandes banques entre I93I et I937. Voici les résultats auxquels il aboutit.

Tableau I. Pertes subies par les actionnaires et les déposants de six grandes banques fin I937 (en millions de francs)

\begin{tabular}{|c|c|c|c|c|c|}
\hline \multirow{2}{*}{ Banque } & \multicolumn{2}{|c|}{ Pertes } & \multirow{2}{*}{ Total } & \multirow{2}{*}{$\begin{array}{l}\text { Bilan fin } \\
\text { I930 }\end{array}$} & \multirow{2}{*}{$\begin{array}{l}\text { Pertes totales } \\
\text { en } \% \text { du bilan }\end{array}$} \\
\hline & Actionnaires & Déposants & & & \\
\hline Banque d'Escompte Suisse & 165 & 85 & 250 & 677 & 36.9 \\
\hline Banque Leu \& Co. AG & 33 & $3 \mathrm{I}$ & 64 & 416 & 15.4 \\
\hline Banque Populaire Suisse & 195 & & 195 & I 680 & II.6 \\
\hline Basler Handelsbank & 55 & & 55 & 835 & 6.6 \\
\hline Union de Banques Suisses & 40 & & 40 & 983 & 4.I \\
\hline Banque Fédérale S.A. & 33 & & 33 & 854 & 3.9 \\
\hline Total & 521 & II6 & 637 & 5445 & \\
\hline
\end{tabular}

Sources: Paul Rossy, Die Reorganisation des schweizerischen Bankwesens, 1937, cité in Ehrsam, art. cit., in Zulauf (éd.), op. cit., 1985, p. 90.

Dans l'ensemble, si l'on rapporte ces chiffres au total de I.4 milliard de pertes, on constate qu'un peu moins de la moitié des pertes subies entre I93I et I937 par la place bancaire suisse ont atteint les actionnaires et déposants des six grandes banques suisses, sur un total d'environ 360 établissements. Il apparaît aussi clairement que les instituts qui ont essuyé les plus lourdes pertes par rapport à leur bilan, à savoir la Banque d'Escompte Suisse, la Banque Leu et la Banque Populaire Suisse, sont également celles qui ont fait l'objet des plus importantes opérations d'assainissement de la part des autorités publiques.

À partir des données publiées par Daniel Bodmer, on peut aussi ventiler les chiffres des pertes bancaires par catégorie de banques ${ }^{88}$. Il en ressort, comme le montre le graphique 5, que les huit grandes banques (sept après la faillite de la Banque d'Escompte en I934) subissent les plus lourdes pertes entre I93I-I937. En moyenne sur l'ensemble de la période, elles sont responsables de $67.7 \%$ des pertes, contre I6.8\% pour les banques locales et II.9\% pour les banques cantonales. Avançons encore un bémol sur l'ensemble des chiffres fournis par la BNS. Ceux-ci ne donnent qu'une image imparfaite des pertes essuyées

(dont $68 \%$ à la charge des grandes banques et $16 \%$ imputables aux banques cantonales). Cf. Claudius Terrier, "Risques, pertes et réserves des Banques suisses », in Association suisse des experts-comptables A.S.E (éd.), Journées d'études bancaires, Genève : E. Delachaux, I937, p. $45-62$, p. $45-46$.

88 Bodmer n'indique pas clairement ces sources. On peut cependant affirmer que ses données proviennent de la publication annuelle de la BNS, Das schweizerische Bankwesen im Jahre..., qui à partir de 1933, inclut un tableau sur les assainissement et amortissements. 
par les banques. Il s'agit là des pertes manifestes telles qu'elles apparaissent dans les comptes profits et pertes. Mais ces données ne tiennent pas compte des amortissements qui ont été effectués en touchant aux réserves internes des établissements. Or, comme le montre Tobias Straumann dans son analyse de la comptabilité interne de la Schweizerische Rückversicherungsgesellschaft, un établissement financier pouvait très bien traverser une période de forte crise sans subir de pertes dans sa comptabilité publique, en puisant profondément dans ses réserves latentes pour couvrir des pertes extraordinaires ${ }^{89}$.

Graphique 5. Pertes et amortissements bancaires, par catégorie de banque (1931-I937), en millions de francs courants

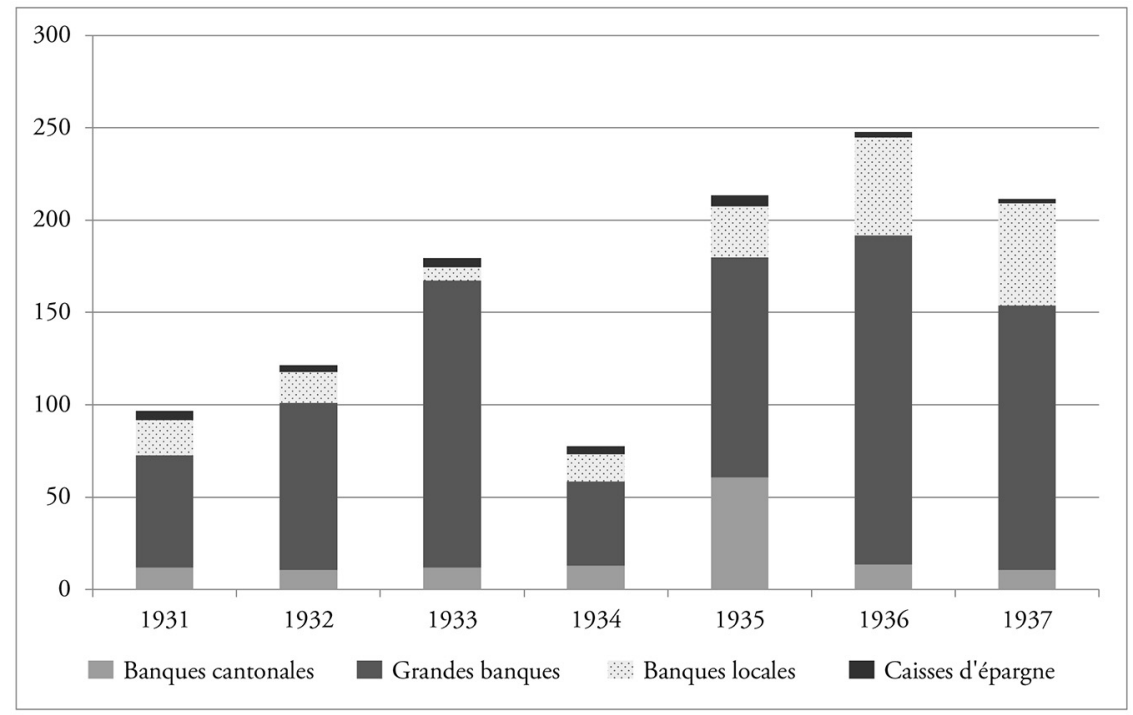

Source: Daniel Bodmer, L'intervention de la Confédération dans l'économie bancaire suisse, Bâle : National-Zeitung, 1948, p. 199-200.

On constate également, à l'analyse du graphique 5 , que du point de vue des pertes et amortissements la crise se prolonge jusque dans la seconde moitié des années 1930. Notons au passage que l'évolution diachronique à l'année près n'est pas pertinente avec ces données. En effet, selon la date à laquelle les dirigeants bancaires décident de procéder à une mesure d'assainissement ou à enregistrer les amortissements dans leurs comptes profits et pertes, les conséquences comptables sont visibles sur une année ou sur l'autre. Il faut malgré tout remarquer à partir du graphique 5 une certaine tendance dans l'évolution

89 Tobias Straumann, «The Discreet Charm of Hidden Reserves: How Swiss Re Survived the Great Depression ", in Piet Clement, Harold James, Hermann Van der Wee (éd.), Financial Innovation, Regulation and Crises in History, London : Pickering \& Chatto, 20I4, p. 55-64. La Schweizerische Rückversicherungsgesellschaft, entreprise de réassurance aujourd'hui connue sous le nom de Swiss Re, est fondée en I863 en partie par la Basler Handelsbank et le Crédit Suisse. 
de la crise bancaire au cours des années 1930. Tandis que les pertes des premières années sont presque exclusivement du ressort des grandes banques ( $74 \%$ entre 193I et 1933), la seconde moitié voit l'extension de la crise à des établissements majoritairement orientés vers le marché intérieur, puisqu'entre I934 et 1937, les banques locales, les banques cantonales - en particulier celle de Neuchâtel - et les caisses d'épargne comptent pour $35 \%$ des pertes. Nous reviendrons plus loin sur les différentes formes, au cours de diverses phases, que prend la crise bancaire en Suisse.

Après avoir mesuré l'ampleur de la crise, il reste à en déterminer les principales causes. En ce qui concerne le groupe des grandes banques, il apparaît qu' il existe un lien entre le poids des engagements d'un établissement bancaire suisse dans des avoirs soumis à restrictions de transfert en Allemagne et en Europe centrale d'une part, et sa difficulté à surmonter la crise bancaire ${ }^{90}$. Aussi les huit grandes banques existantes en I93I connaissent-elles des trajectoires inégales au cours du marasme financier. Le tableau 2 indique nettement à quel point le degré d'exposition aux crédits gelés en Allemagne variait d'un institut à l'autre.

Tableau 2. Actifs des grandes banques suisses placés à l'étranger et soumis à des restrictions de transfert fin 1934 (en millions de francs courants)

\begin{tabular}{|l|c|c|c|c|c|c|}
\hline \multicolumn{1}{|c|}{ Banque } & I & 2 & 3 & 4 & 5 & 6 \\
\cline { 2 - 7 } & Bilan & Dépôts & $\begin{array}{c}\text { Fonds } \\
\text { propres }\end{array}$ & $\begin{array}{c}\text { Avoirs à } \\
\text { l'étranger }\end{array}$ & $\begin{array}{c}\text { Dont soumis } \\
\text { à des } \\
\text { restrictions } \\
\text { de transfert }\end{array}$ & $\begin{array}{c}\text { Avoirs soumis à } \\
\text { des restrictions } \\
\text { de transferts } \\
\text { en du bilan }\end{array}$ \\
\hline $\begin{array}{l}\text { Banque Commerciale } \\
\text { de Bâle }\end{array}$ & 415.9 & 297.8 & 90.3 & 224 & I53 & 36.8 \\
\hline Banque Fédérale & 435.2 & 301.3 & I06.5 & I72 & I43 & 32.9 \\
\hline Banque Leu & 307.2 & 243.9 & 46.6 & IO2 & 84 & 27.3 \\
\hline $\begin{array}{l}\text { Union de Banques } \\
\text { Suisses }\end{array}$ & 557.8 & 420.3 & II2.3 & I9O & II5 & 20.6 \\
\hline Crédit Suisse & I I45.8 & 889.5 & 205.2 & $?$ & 200 & I7.5 \\
\hline Banque Populaire Suisse & 937.0 & 730 & 200 & I76 & I44 & I5.4 \\
\hline $\begin{array}{l}\text { Société de Banque } \\
\text { Suisse }\end{array}$ & I I98.8 & 955.5 & 200.1 & $?$ & I50 & I2.5 \\
\hline
\end{tabular}

Sources: Perrenoud, et al., op. cit., 2002, p. 8I. Colonnes I, 2 et 3: Rapports de gestion des banques concernées, 1934 .

La colonne 6 du tableau 2, qui exprime le montant des placements à l'étranger soumis à des restrictions de transfert relativement au bilan de chaque banque, donne une image explicite de la charge de ces crédits gelés. Les avoirs bloqués de la Banque Commerciale de Bâle, la Banque Fédérale et la Banque Leu pèsent très lourd dans leur bilan respectif. En revanche, chez les deux plus 
grandes banques, la Société de Banque Suisse et le Crédit Suisse, et dans une moindre mesure, chez l'Union de Banques Suisses, les actifs gelés constituent un cinquième ou moins du bilan. La Banque Populaire Suisse, disposant d'un large réseau de succursales et plutôt active sur le marché domestique, est, de ce point de vue, relativement ménagée.

Cette diversité d'engagements dans les économies affectées par des moratoires de paiements se retrouve dans les réactions des banques à la crise ${ }^{91}$. Les établissements aux reins les plus solides, bénéficiant d'importantes réserves, étaient capables d'atténuer ce choc externe en effectuant des amortissements de leurs investissements douteux, et en liquidant parfois à perte leurs avoirs gelés. D'autres établissements, comme la Banque Commerciale de Bâle et la Banque Fédérale, ont dû maintenir leurs avoirs problématiques jusqu'à la fin de la Seconde Guerre mondiale. Ce n'est qu'avec leur absorption par deux autres grandes banques en 1945, respectivement la SBS et l'UBS, que la Banque Commerciale de Bâle et la Banque Fédérale purent assainir leurs crédits dépréciés, hérités de la crise financière européenne des années 1930.

Dans l'ensemble, parmi les huit établissements qui composent le groupe des grandes banques en 1931, seuls les deux plus grands - le Crédit Suisse et la Société de Banque Suisse - parviennent à traverser la décennie mouvementée sans avoir recours à un assainissement apparent. La Banque d'Escompte Suisse, seule grande banque dont le siège est situé en Suisse romande, fait faillite en avril 1934, après plusieurs opérations de sauvetage infructueuses. La Banque Populaire Suisse ne doit son salut qu'à l'intervention massive de la Confédération en novembre 1933. La Banque Commerciale de Bâle et la Banque Leu, quant à elles, sont en 1935 parmi les premières bénéficiaires des nouvelles procédures d'assainissements et de moratoires bancaires mis en place par la loi fédérale sur les banques; dans le cas de la Banque Leu, un régime spécial est même promulgué par arrêté fédéral en avril 1936 pour faciliter sa réorganisation ${ }^{92}$. L'Union de Banques Suisses, à deux reprises en décembre 1933 et en février 1936, opère un rachat de ses propres actions et une réduction de capital pour surmonter ses difficultés ${ }^{93}$. Enfin, la Banque Fédérale opte pour la même méthode en intensifiant sa politique de rachat de ses propres actions, avant de réduire son capital. Comme nous le verrons dans le sous-chapitre suivant, rares sont les banques à survivre à la crise financière des années I930 sans s'adresser à une instance publique ou paraétatique: Banque nationale suisse, Département fédéral des finances, Caisse de prêts de la Confédération (dès juillet 1932) ou Commission fédérale des banques (dès avril 1935).

91 Sur ce point et ce qui suit: ibid., p. 8I-82.

92 La Banque Commerciale de Bâle avait antérieurement, en décembre 1933, décidé une réduction de capital de IOo à 75 millions de francs.

93 Perrenoud, et al., op. cit., 2002, p. 244; Baumann, op. cit., 2007, p. 353. Notons au passage que la Commission fédérale des banques n'est pas informée par l'UBS de la réduction de capital de février 1936 et l'apprend par la presse. Cf. Ehrsam, art. cit., in Zulauf (éd.), op. cit., I985, p. II5. 
Pour terminer cet aperçu des manifestations de la crise financière en Suisse, relevons encore que les facteurs déterminant les difficultés de chaque institut sont bien plus hétérogènes que ce que nous avons pu avancer ici. Les répercussions pour les banques suisses des mesures de moratoires bancaires, de contrôle de change et autres restrictions de transfert introduites en Allemagne et en Europe centrale ne constituent pas les seules causes de la crise bancaire helvétique. En plus des pertes enregistrées sur les dévalorisations des avoirs gelés, les banques font en effet face à un recul général du volume d'affaires, sous l'effet de la dépression économique. Celle-ci induit une diminution des dépôts bancaires domestiques, tandis que l'introduction du contrôle des changes à l'étranger implique souvent - du moins théoriquement - un rapatriement hors de Suisse des avoirs qui y sont investis. Plus largement, les difficultés conjoncturelles de certaines branches économiques se répercutent directement sur la place bancaire. L'insolvabilité d'entreprises débitrices signifie souvent de lourdes pertes pour les établissements financiers. Dans les régions fortement dépendantes d'un secteur économique, comme l'arc jurassien pour l'horlogerie, ou encore le tourisme dans la Riviera vaudoise, certaines banques locales souffrent proportionnellement à leurs engagements auprès de secteurs touchés par la crise. Le cas de la Banque cantonale neuchâteloise, qui doit être réorganisée sous les auspices du canton et de la BNS en 1935, ou encore la faillite de la Banque de Montreux, qui est liquidée avec le concours de la Banque cantonale vaudoise dès octobre I932, en témoignent ${ }^{94}$. Rappelons que sur la période I93II937, les banques locales sont en moyenne responsables de I6.7\% des pertes totales enregistrées par la place bancaire suisse (cf. graphique 5). Dans le domaine des banques locales et régionales, l'intervention des pouvoirs publics - souvent moins retentissante que dans les cas qui vont nous occuper dans le sous-chapitre suivant - n'est pas à négliger. Les banques cantonales, quand leur propre santé financière le permet, jouent dans le contexte local un rôle stabilisateur et de prêteur de dernier ressort qui n'a été que très peu étudié par la littérature.

Quoi qu'il en soit, il faut se garder de noircir complètement le tableau des conséquences néfastes de la crise bancaire en Suisse, et ce pour deux raisons. D'une part, en comparaison internationale, la place financière suisse peut profiter des périodes d'instabilité internationale pour attirer des flux de capitaux à la recherche d'un refuge à l'abri des changements politiques. En témoigne, par exemple, l'important afflux de capitaux qui suit, en septembre I936, la dévaluation du franc suisse. D'autre part, certains secteurs de l'industrie bancaire, orientés vers le marché intérieur, échappent aux difficultés suscitées par la dépréciation et au blocage de certains investissements étrangers. Nous avons déjà mentionné le renversement opéré au cours des années I930 dans la dynamique de la concurrence entre banques cantonales et grandes banques. De même, les caisses Raiffeisen sont en plein essor au cours de la période; le 
nombre de caisses passe de 510 en 1930 à 684 en 1940, tandis que le bilan total connaît aussi une croissance stable ${ }^{95}$. En ce sens, la crise financière européenne met en branle un processus d'assainissements et de restructuration de la place bancaire suisse ${ }^{96}$.

\section{II.3. INTERVENTION ÉTATIQUE DANS LE CADRE DES FAILLITES BANCAIRES : BANQUE D'ESCOMPTE, CAISSE DE PRÊTS DE LA CONFÉDÉRATION ET BANQUE POPULAIRE SUISSE}

Au-delà des grandes tendances de réorganisation de la place financière suisse esquissées ci-dessus, la crise bancaire en Suisse provoque également des difficultés spécifiques à certains établissements, et, face à l'imminence d'une crise de confiance généralisée, des interventions des pouvoirs publics. Dans ce souschapitre, nous présenterons donc le développement de l'interventionnisme étatique à la rescousse de banques entre I93I et I933. Plus précisément, les deux cas du Comptoir d'Escompte de Genève (devenu Banque d'Escompte Suisse après sa fusion avec l'Union financière en septembre 1931), et de la Banque Populaire Suisse seront exposés ${ }^{97}$. Nous reviendrons également sur la constitution d'une nouvelle Caisse de prêts de la Confédération (eidgenössische Darlehenskasse) en juillet 1932, en tant qu'instrument fédéral d'assistance en faveur des banques défaillantes. Ces éléments sont essentiels pour comprendre l'émergence d'une surveillance étatique des banques, sur laquelle nous nous concentrerons dans le chapitre suivant.

Certains historiens considèrent la faillite de la Banque de Genève, qui doit fermer ses guichets le II juillet I93I - soit deux jours avant la fermeture de la Danat-Bank, comme le premier symptôme helvétique de la contagion de la crise financière européenne ${ }^{98}$. Un examen plus attentif de la situation de cet institut montre qu'il est très hasardeux d'établir un lien direct entre la crise bancaire internationale et les difficultés de la Banque de Genève ${ }^{99}$. Fondé en I848 en tant qu'institut monétaire dans la foulée de la constitution de James Fazy, cet établissement d'envergure locale se rapproche d'une banque cantonale sous de nombreux aspects comme la participation de l'État au capital (25\% en 1929) ou la nomination de certains membres du conseil d'administration par le gouvernement cantonal. La Banque de Genève connaît une forte expansion au

95 Arnold Edelmann, L'Union suisse des caisses de crédit mutuel 1902-1952, St-Gall : Union suisse des caisses de crédit mutuel (système Raiffeisen), [1953], p. 292-294.

96 Cf. Baumann, op. cit., 2007, p. I26.

97 Nous nous appuierons essentiellement sur la thèse de Jan Baumann : ibid.. Voir également Bodmer, op. cit., 1948, p. 40-80; Werner Scheuss, Der Zusammenbruch und die Liquidation der Schweizerischen Diskontbank: ein Kapitel Bankpolitik aus der Zwischenkriegszeit, Winterthur: Keller, 1960.

99 Marc Alberisio, «Le krach de la Banque de Genève », Mémoire de licence, Faculté des lettres, Université de Lausanne, 2009, p. 43-45. 
cours des années I920; suite à plusieurs augmentations, son capital s'élève à 20 millions de francs en I929, tandis que son bilan double entre 1925 et 1930 pour atteindre 97 millions de francs ${ }^{100}$. Cette expansion s'effectue, non pas vers les crédits internationaux, mais plutôt par l'ouverture de lignes de crédits au bénéfice des administrateurs mêmes de la banque, compensée par des engagements de plus en plus lourds auprès de la Banque nationale suisse, qui exige des renseignements plus détaillés sur les affaires de la banque dès la fin des années $1920^{101}$.

S'il faut donc davantage lire le krach de la Banque de Genève en juillet I93I comme le résultat d'une gestion aventureuse pendant les années I920 que comme le premier chaînon de transmission de la crise européenne en Suisse, il n'en reste pas moins que ses difficultés donnent lieu à la première intervention étatique dans le domaine bancaire et au premier débat politique sur la crise bancaire dans les années I930. Le 25 juin I93I a lieu une première réunion de crise sur l'initiative de la BNS; cette dernière suggère à la place financière genevoise de "laver son linge sale en famille»: le Comptoir d'Escompte, l'Union financière et la Banque de Dépôt et de Crédit acceptent d'octroyer un crédit de réescompte de 2 millions à la Banque de Genève ${ }^{102}$. Début juillet I93I, des conférences de sauvetage sont organisées. La question prend une dimension nationale puisque, en plus des acteurs genevois, le Département fédéral des finances et des douanes, la Société de Banque Suisse et le Crédit Suisse sont également invités. Un projet de sauvetage incluant la souscription par le Canton de Genève d'un nouveau capital-actions de Is millions de francs, fourni par la Confédération sous la forme d'un prêt à quatre ans d'échéance à $4 \%$, est alors prévu sous les auspices du Conseil fédéral ${ }^{103}$. De leur côté, les banques genevoises et suisses renforceraient la liquidité de la banque défaillante en souscrivant à des bons de caisse. Enfin, la BNS accepte de maintenir les crédits de réescompte déjà accordés. Mais ce projet échoue devant les instances politiques cantonales. Le ıo juillet I93I, dans une session extraordinaire et à la suite d'un long débat, le Grand conseil genevois rejette l'action de sauvetage ${ }^{104}$. Les socialistes genevois, renforcés par des voix des chrétiens-sociaux, parviennent de justesse -48 voix contre 47 à refuser le projet de loi que soutiennent radicaux, conservateurs, et l'Union de Défense Économique (ancêtre de l'Union nationale frontiste). La Banque de Genève ferme définitivement ses guichets le lendemain. La liquidation de

100 Baumann, op. cit., 2007, p. I50. Baumann ne précise pas si son calcul tient compte de la variation des prix ou non. Dans l'éventualité où ses chiffres ne sont pas déflatés, l'augmentation réelle entre 1925 et 1930 serait tout de même de $94 \%$.

101 Alberisio, op. cit., 2009, p. 54-86.

102 Baumann, op. cit., 2007, p. 153 .

103 Bodmer, op. cit., 1948, p. 43; Alberisio, op. cit., 2009, p. 49.

104 Alex Spielmann, L'aventure socialiste genevoise: 1930-1936: de l'opposition à l'émeute, de l'émeute au pouvoir, du pouvoir à l'opposition, Lausanne: Payot, I98I, p. 77-79. Michel Rey, Genève 1930-1933: la révolution de Léon Nicole, Berne etc. : Lang, 1978, p. 69. 
l'établissement se déroule sur une longue période de près dix ans et ne s'achèvera qu'en mai $194 \mathrm{I}^{105}$.

À l'été 1931, la faillite de la Banque de Genève - établissement d'importance somme toute modérée - est cependant le détonateur d'un processus de gestion de crise à l'échelon fédéral ${ }^{106}$. Le plan de sauvetage qui échoue constitue un prototype des mécanismes d'intervention de crise qui seront à l'œuvre ultérieurement. De plus, à la mi-juillet I93I, banquiers suisses et autorités fédérales craignent la contagion de la crise de confiance, par effet domino, à d'autres établissements financiers. En septembre, le conseiller fédéral Jean-Marie Musy, devant le Conseil national, exprime de la manière suivante le discrédit subi par la place financière :

Jusqu'à l'affaire de la Banque de Genève, les banques suisses étaient considérées comme un rocher de bronze inébranlable. Dans une large mesure, l'économie générale de notre pays a profité de cette confiance dont nous jouissions. La brèche qu'on a faite dans la muraille de cette forteresse bancaire, à Genève, a eu des conséquences douloureuses et il est probable, je n'insiste pas, que d'autres profiteront de ce que nous avons perdu ${ }^{107}$.

\section{La Banque d'Escompte Suisse}

Le Comptoir d'escompte de Genève, seule grande banque de Suisse romande, fait figure de seconde victime de la crise de l'été 193I. Bodmer attribue une double origine aux retraits de fonds que subit le Comptoir d'escompte de Genève en juillet 193I ${ }^{108}$. Aux rumeurs sur les intérêts du Comptoir d'escompte dans la Banque de Genève défaillante s'ajoutent celles sur l'importance de ses engagements immobilisés à l'étranger. Les dimensions et la nature des activités du Comptoir d'escompte, sans commune mesure avec celles de la Banque de Genève, laissaient présager d'une crise systémique. Fondé en 1855 et opérant d'abord comme banque commerciale locale, le Comptoir d'escompte connaît une expansion prodigieuse dans les opérations étrangères. Son bilan passe de 256 millions en 1920 à 472 millions en 1930, tandis que son capital-actions quadruple, en francs nominaux, passant de 15 millions en 1917 à 60 millions en $1928^{109}$. La banque étend également son réseau de succursales entre I9I8 et I922, notamment à Bâle et à Zurich ${ }^{110}$. Du côté de l'actif, elle connaît un fort développement du poste des débiteurs bancaires, ce qui témoigne d'une politique d'expansion sous la forme de lourds engagements auprès de banques

\footnotetext{
105 Bodmer, op. cit., I948, p. 44-49; Baumann, op. cit., 2007, p. 156.

106 Baumann, op. cit., 2007, p. I57.

107 Bulletin officiel de l'Assemblée fédérale, Conseil national, séance du 25.09.1931, p. 664.

108 Bodmer, op. cit., I948, p. 50.

109 Scheuss, op. cit., I960, p. I00-IOI. Baumann, op. cit., 2007, p. I44.

110 Scheuss, op. cit., I960, p. Io.
} 
étrangères à court terme et à taux d'intérêt élevés ${ }^{111}$. Cette expansion à l'étranger se fait essentiellement auprès de débiteurs d'Europe centrale et orientale : en Tchécoslovaquie, en Autriche et en Hongrie ${ }^{112}$. La Banque d'Escompte est donc fortement affectée par les mesures de restriction de transfert adoptées à l'été I93I.

Il convient de distinguer trois phases dans l'opération de sauvetage du Comptoir d'escompte de Genève de l'été I93I ${ }^{113}$. Dans un premier temps, pour prévenir une cessation de paiements, les autorités fédérales doivent intervenir dès le I7 juillet I93I, sous la forme d'un prêt de la Confédération à hauteur de 20 millions de francs, pour une durée de deux ans à un taux de $3.75 \%{ }^{114}$. Deuxièmement, un consortium de garantie composé des huit grandes banques, sous l'égide de la BNS, est conclu le I2 août I93I. L'accord prévoit un mécanisme de solidarité entre les grandes banques qui permet de mobiliser auprès de la BNS des actifs gelés selon une répartition entre les banques membres du consortium. L'unique application concerne le Comptoir d'escompte, qui reçoit un crédit de 15 millions de francs. Troisièmement, à partir de négociations menées le 7 août I93I entre les banquiers et les autorités politiques et monétaires de la Confédération, une fusion du Comptoir d'escompte avec l'Union financière genevoise est organisée ${ }^{115}$. Ce projet de fusion prévoit surtout une recapitalisation, ainsi qu'un élargissement de l'actionnariat. La recapitalisation implique une prise de participation des grandes banques alémaniques dans le nouvel établissement genevois : sur les 40 millions d'actions prioritaires nouvellement émises, 30 millions proviennent des poids lourds bâlois et zurichois - la Société de Banque Suisse et le Crédit Suisse ${ }^{116}$. Des représentants des deux grandes banques siègent par ailleurs dans le conseil d'administration de la banque issue de la fusion. La Banque d'Escompte Suisse voit le jour, après ratification de l'acte de fusion le 22 septembre I93I lors d'une assemblée générale extraordinaire du Comptoir d'escompte.

La politique d'intervention des autorités fédérales (Département des finances et des douanes et directoire de la Banque nationale suisse) dans la

111 Baumann, op. cit., 2007, p. I45.

112 Ibid., p. I47-I48.

113 Ibid., p. I57-I74.

114 Bodmer, op. cit., I948, p. 5I ; Scheuss, op. cit., I960, p. I5.

115 L'Union financière genevoise, société fondée en I890, constitue la plateforme commune des banquiers privés genevois. Son conseil d'administration est composé exclusivement d'associés de banques privées. Elle joue le rôle de centre de coordination pour l'opération d'émissions et de société faittière des banquiers privés genevois. Il s'agit donc plutôt d'une holding gérant un portefeuille de participations que d'une banque. Elle possède des sociétés filiales importantes, telles que la Société Financière Franco-Suisse et la Société Financière ItaloSuisse. Son bilan en 1930 s'élève à IIo.8 millions de francs, pour un capital-actions de 50 millions de francs. Bodmer, op. cit., I948, p. I40-I42.

116 Sur la fusion Comptoir d'Escompte-Union financière: Baumann, op. cit., 2007, p. I60-I65. Au final, les autres grandes banques alémaniques (Banque Fédérale, UBS, BCB, Leu, BPS) prendront également des participations dans le capital-actions de la future Banque d'Escompte, ce qui réduira la part de la SBS et du CS à II,25 millions chacun. 
crise bancaire se caractérise à l'été I93I par la volonté de favoriser des plans de sauvetage permettant d'endiguer la contagion de la crise, tout en maintenant un mode opératoire peu coercitif, par pression morale. Les rencontres entre dirigeants bancaires et autorités fédérales poursuivent ainsi les relations informelles entretenues depuis les années 1920 autour des questions d'exportation de capitaux.

Malgré l'intervention combinée de l'été 193I, la situation de la nouvelle Banque d'Escompte Suisse s'aggrave. Les retraits de dépôts se poursuivent, en particulier de la part de créanciers étrangers ${ }^{117}$. Les banques cantonales également cherchent à retirer leurs placements à terme auprès de la Banque d'Escompte Suisse et retirent plus de I6 millions de francs entre août et novembre $193 \mathrm{I}^{118}$. Le conseiller fédéral Musy doit intervenir auprès des banques cantonales pour les inciter, dans un élan de solidarité, à maintenir leurs actifs dans la banque genevoise. Le I5 novembre 1931, un second plan d'assainissement est décidé entre dirigeants des banques commerciales et de la banque centrale. Au total, en décembre 1931, la Banque d'Escompte Suisse avait déjà bénéficié de 95 millions de francs suisses de fonds de soutien, sous diverses formes, dont 27 provenaient directement de la Confédération ${ }^{119}$. À titre de comparaison, l'«aide extraordinaire de crise» introduite en janvier 1932 par la Confédération, en tant que subventions fédérales aux caisses de chômage, s'élève à 20,5 millions de francs ${ }^{120}$.

\section{La Caisse de prêts de la Confédération}

La crise de confiance de la place financière genevoise de l'été et de l'automne I93I met en branle le processus qui inscrit à l'agenda politique les questions de contrôle bancaire, comme nous le verrons dans le chapitre suivant. D'autre part, les difficultés persistantes de la Banque d'Escompte Suisse sont à l'origine de la mise en place d'une nouvelle Caisse de prêts de la Confédération (eidgenössische Darlehenskasse), après celle qui avait été active entre I9I4 et $1924^{121}$. Alors que les buts statutaires de la Caisse de prêts de la Confédération, établie par un arrêté fédéral du 8 juillet I932, étaient définis assez largement, sa raison d'être pragmatique ne faisait pas de doute. Comme le formule Jan Baumann:

La Caisse de prêts de la Confédération était l'instrument employé pour répercuter au moins partiellement les risques liés au financement de la Banque d'Escompte Suisse sur la Confédération. En outre, on

117 Ibid., p. I77.

118 Scheuss, op. cit., I960, p. 28 ; Baumann, op. cit., 2007, p. I77-I79.

119 Baumann, op. cit., 2007, p. 184.

120 Müller, op. cit., 20IO, p. 275.

121 Sur la Caisse de prêts de la Confédération des années 1930: Ernst Kull, "Sechs Jahre Darlehenskasse der Schweizerischen Eidgenossenschaft", Journal de statistique et revue économique suisse, vol. 74, $\mathrm{n}^{\circ}$ 3, 1938, p. 333-351 ; Bodmer, op. cit., 1948, p. 98-II7; Bänziger, op. cit., 1986, p. 98-100; Baumann, op. cit., 2007, p. 197-229. 
établissait ainsi un outil préventif, par lequel on pouvait empêcher l'extension de la crise bancaire genevoise à l'ensemble du système financier helvétique, dans l'éventualité où une telle réaction en chaîne devait se produire ${ }^{122}$.

Après les coûteuses tentatives d'assainissement sous la forme de pool de garantie bancaire accompagné d'investissements publics de l'été I93I, il s'agit de mettre en place une institution indépendante de la banque centrale pour permettre aux banques commerciales de mobiliser les actifs qui ne sont pas acceptés en réescompte par la BNS ou d'autres banques. Alors que Musy avait d'abord ouvertement exclu une telle solution devant le Conseil national en septembre I93I, il obtient de ses collègues un mois plus tard l'autorisation secrète d'entamer des travaux pour établir une caisse de prêts fédérale ${ }^{123}$. Les raisons de ce changement d'opinion sont difficiles à établir précisément. On peut émettre l'hypothèse que le discours prononcé publiquement devant le parlement avait aussi pour but de rétablir la confiance dans le système bancaire suisse.

La Caisse de prêts de la Confédération prend finalement forme en mai I932, sous l'impulsion décisive de la BNS, tandis que la situation de la Banque d'Escompte Suisse empire. Les réflexions encore très théoriques de l'automne I93I à ce sujet laissent place à un débat beaucoup plus urgent sur les moyens à mobiliser pour mettre sur pied une telle institution de secours. Qui fournirait le capital social de l'institution? Qui assumerait la responsabilité des risques encourus? La résistance des banques face aux projets initiaux du DFFD et de la BNS portait en partie sur ces questions. L'idée de ressusciter une institution du type de celle qui avait été à l'œuvre durant la Première Guerre mondiale pour surmonter la crise de liquidité de certaines banques s'impose alors. Une fois obtenue l'approbation du collège gouvernemental le 25 mai 1932 - à l'exception du conseiller fédéral PAB Rudolf Minger (I88I-I955) ${ }^{124}$-, JeanMarie Musy entre en tractations avec la BNS pour dessiner les contours plus précis de la future institution. Un des points de friction entre le gouvernement et la banque centrale porte sur la proximité et la relation entre la future Caisse de prêts et la Banque nationale ${ }^{125}$. La Banque nationale refuse alors d'assumer la responsabilité de la nouvelle institution, contrairement à ce que souhaite le Département fédéral des finances. L'argument principal avancé par les dirigeants de l'institut monétaire consiste à souligner les lourdes charges qui leur incombent déjà. Au terme de négociations intensives, la direction générale de la BNS, soutenue pour le Comité de banque, obtient finalement que la Caisse

122 Baumann, op. cit., 2007, p. 198.

123 Bulletin officiel de l'Assemblée fédérale, Conseil national, séance du 25.09.1931, réponse de Jean-Marie Musy à diverses interventions parlementaires, p. 66I. Ibid., p. 207.

124 Le procès-verbal secret de la séance du Conseil fédéral est reproduit dans Mauro Cerutti (éd.), Documents diplomatiques suisses, Berne: Benteli, vol. Io (1930-1933), 1982, ${ }^{\circ}$ 168, p. 383-389.

125 Baumann, op. cit., 2007, p. 216-217. 
devienne une entité formellement distincte, disposant de sa propre personnalité juridique et de ses propres organes dirigeants.

Après un rapide débat au sein du gouvernement, le message du Conseil fédéral est transmis au Parlement le 24 juin 1932. La Caisse de prêts prévue dispose d'un fonds de garantie de Ioo millions de francs, dont 75 millions à la charge de la Confédération et 25 millions à la charge des banques ${ }^{126}$. Les prêts consentis par la Caisse contre les valeurs gagées ne peuvent pas dépasser la limite globale de 300 millions; ce montant sera réduit à 200 millions par le parlement. Cela signifie qu'au total la part étatique des risques encourus par la Caisse de prêts s'élève à 275 millions de francs ${ }^{127}$.

Au vu de l'importance des sommes en jeu, du contexte de la crise et de la politique de rigueur qui lui répond, l'approbation du Parlement n'était pas une mince affaire. Les procès-verbaux de la direction du Parti socialiste suisse indiquent par exemple que le projet y est reçu avec circonspection. Le président du parti, Ernst Reinhard (I889-1947) y voit « une subvention cachée au monde bancaire suisse " ${ }^{128}$, qu'il ne faut pas accepter sans obtenir en contrepartie la mise en place du contrôle bancaire. À cette même séance du 28 juin 1932, il déclare à ses collègues du Comité directeur : «Quoi qu’il en soit, il faut profiter de l'occasion pour faire de l'agitation de toutes nos forces en faveur du contrôle bancaire. ${ }^{129}$

Une session extraordinaire du Parlement est organisée pour l'occasion du 4 au 8 juillet 1932. Le groupe socialiste, après avoir vainement proposé de renvoyer le projet au Conseil fédéral dans la commission du Conseil national, essuie aussi un échec au plénum lors du débat sur l'entrée en matière. Les députés socialistes souhaitent que les mesures de soutien soient liées «au contrôle des banques et à la réglementation du crédit " ${ }^{130}$. Cette proposition de la minorité est rejetée par IO2 voix contre 47. On lui rétorque que les mesures de contrôle bancaire n'ont pas empêché, aux États-Unis ou en Suède, de nombreuses faillites de banques. Ruggero Dollfus (I876-1948), conseiller national catholique-conservateur tessinois et membre du conseil d'administration de la Société de Banque Suisse ${ }^{131}$, souligne également que la question de la constitution d'une Caisse de prêts est une matière bien plus urgente que la délicate discussion sur le contrôle bancaire. Il file la métaphore en comparant les tergiversations socialistes à l'attitude de villageois refusant l'intervention de pompiers lors de l'incendie d'un village:

126 "Message du Conseil fédéral à l'Assemblée fédérale concernant la création d'une caisse fédérale de prêts", 24.06.1932, Feuille fédérale, 1932, vol. 2, p. I56-175, ici art. 3, p. I7I.

127 Baumann, op. cit., 2007, p. 220.

128 Schweizerisches Sozialarchiv, Protokolle der Geschäftsleitung der Sozialdemokratischen Partei der Schweiz, AR.I.IIO.2I (1932), 28.06.I932.

129 Schweizerisches Sozialarchiv, Protokolle der Geschäftsleitung der Sozialdemokratischen Partei der Schweiz, AR.I.IIo.2I (I932), 28.06.1932.

130 Bulletin officiel de l'Assemblée fédérale, Conseil national, séance du 04.07.1932, p. 387.

131 Hans Bauer, Schweizerischer Bankverein. 1872-1972, Basel: Schweizerischer Bankverein, I972, p. 478. 
Un village est menacé par une terrible tempête. De tous côtés, la foudre risque de tomber sur les maisons. Le commandant des pompiers appelle ses hommes pour qu'ils sortent la pompe. Mais quelques habitants s'y opposent en disant qu'il faut au préalable décider si, en principe, les toits de chaume seront encore permis dans le village. On raisonnerait de la même façon si l'on voulait lier la question de la caisse de prêts à celle du contrôle des banques ${ }^{132}$.

Le député socialiste bernois Ernst Reinhard reprend la même image dans son intervention, estimant au contraire qu'un pompier ne peut pas se placer n'importe où pour éteindre un incendie, mais qu'il a besoin d'une organisation et d'instructions soigneusement planifiées ${ }^{133}$. Aux voix dissidentes de gauche viennent s'ajouter les protestations de quelques représentants de la paysannerie. Une minorité du groupe parlementaire $\mathrm{PAB}$ - fort de 30 députés - propose également de renvoyer le projet au Conseil fédéral et de refuser l'entrée en matière. Après un débat parlementaire relativement long pour la discussion d'un simple arrêté fédéral, à savoir quatre jours de délibérations totalisant une centaine de pages de procès-verbal, le projet de Caisse de prêts est adopté, doté de la clause d'urgence qui le soustrait à un éventuel référendum, par 94 contre $4 \mathrm{I}$ voix à la chambre du peuple et 28 contre I à la chambre des cantons ${ }^{134}$.

Le Conseil fédéral nomme ensuite rapidement le conseil d'administration de la Caisse de prêts de la Confédération, dont la composition exacte figure dans le tableau A.I en annexe du PDF ${ }^{135}$. Formé au total de onze membres, il reflète un certain équilibre entre branches économiques, affinités partisanes et origines régionales. Cette composition initiale de la part de Jean-Marie Musy est ingénieuse. Sous couvert d'une représentation des diverses tendances politiques, puisque l'ancien leader de la Grève générale Robert Grimm et le député $P A B$, proche d'Ernst Laur, Richard König, y siègent, on distingue pourtant une forte délégation des dirigeants de banques et des assurances. La présence du Ministre de Suisse à Berlin indique la nécessité d'obtenir des compétences diplomatiques dans le domaine des crédits gelés en Allemagne ${ }^{136}$.

La Caisse de prêts, basée à Berne, amorce son activité dès le 25 juillet 1932. $\mathrm{Au}$ total, entre juillet 1932 et 1942 , elle accorde des prêts pour un montant cumulé de 286.7 millions de francs, dont $77 \%$ (220.7 millions) au bénéfice des banques, I5\% sur avoirs en clearing (44.I millions), et $6 \%$ (I7.6 millions) au

132 Bulletin offciel de l'Assemblée fédérale, Conseil national, séance du 04.07.1932, Ruggero Dollfus, p. 395 .

133 Bulletin officiel de l'Assemblée fédérale, Conseil national, séance du 05.07.1932, Ernst Reinhard, p. $4 \mathrm{I} 7$.

134 Bulletin officiel de l'Assemblée fédérale, Conseil national, séance du 06.07.1932, p. 470, Conseil des États, séance du 08.07.1932, p. 450. Sur le droit de nécessité dans les sauvetages bancaires, voir aussi: Andreas Kley, "Die UBS-Rettung im historischen Kontext des Notrechts ", Zeitschrift für Schweizerisches Recht, vol. I30, n 2, 20II, p. I23-138.

135 AFB, Eıo04.I, Iooo/9, vol. 335, Procès-verbaux du Conseil fédéral, séance du 20.07.1932 (sur proposition du DFFD du I9 juillet 1932).

136 Baumann, op. cit., 2007, p. 225. 
bénéfice du commerce et de l'industrie ${ }^{137}$. Selon Paul Rossy, la Caisse de prêts aurait dû jouer un rôle plus important au cours de la crise. De nombreux établissements ont préféré surmonter la crise en se refinançant par le biais de lettres de gage à long terme et fort taux d'intérêt, pour éviter une ingérence de la Confédération ${ }^{138}$. Jan Baumann partage le diagnostic mitigé de Rossy en ce qui concerne l'activité de la Caisse de prêts auprès de la Banque d'Escompte Suisse. L'institut fédéral d'aide aux banques aurait en fait, par ses crédits, créé une forte dépendance de la part de la grande banque genevoise ${ }^{139}$. Au fur et à mesure que la banque genevoise déposait davantage d'actifs en gage auprès de la Caisse de prêts pour obtenir des crédits, elle perdait le contrôle sur ces actifs et sa marge de manœuvre diminuait.

La Caisse de prêts connaît un épilogue relativement long, avant de disparaître définitivement. Ce n'est qu'en septembre i955 que le Parlement décide de liquider cette institution. Après liquidation en juin 1956, un excédent de I2.6 millions est dégagé, dont, conformément à l'arrêté de juillet 1932, trois quarts reviennent à la Confédération et un quart aux garants privés encore en activité $^{140}$. Malgré les avancées amenées par les travaux de Baumann et les quelques éléments soulignés ci-dessus, l'histoire de la seconde Caisse de prêts de la Confédération et de son fonctionnement précis reste encore à écrire et ouvre des perspectives de recherche intéressantes.

\section{Le projet de secours de 1933-1934 et la liquidation de la Banque d'Escompte}

Malgré l'assistance publique fournie par le biais de la Caisse de prêts à partir de juillet 1932, la situation de la Banque d'Escompte Suisse ne s'améliore guère. Résumons les évolutions principales qui séparent l'intervention de l'institution d'aide aux banques en juillet 1932 de la fermeture définitive des guichets en avril 1934. Cette phase est avant tout marquée par un projet d'assainissement et de réorganisation de la banque genevoise, élaboré dès fin 1932 et présenté au Parlement fédéral en avril 1933, qui échouera en avril $1934^{141}$. Ce projet consiste en un paquet de mesures censé assurer la pérennité de l'établissement en difficulté. Il prévoyait premièrement une recapitalisation à hauteur de 35 millions, dont 20 millions émargent au budget de la Confédération. Deuxièmement, il intègre un moratoire sur les dépôts effectués par les grandes banques et les banques cantonales, qui sont prolongés jusque fin 1934. Troisièmement, 30 millions de capitaux nouveaux, répartis entre l'État fédéral (I5 millions), les

137 Statistisches Handbuch des schweizerischen Geld- und Kapitalmarktes : Manuel statistique du marché financier suisse, op. cit., 1944, p. 186.

138 Rossy, art. cit., 1937.

139 Baumann, op. cit., 2007, p. 228.

140 Procès-verbaux de l'Assemblée fédérale, Conseil national, I5.06.1956, séance I2, p. 529.

141 Sur cette réorganisation: Bodmer, op. cit., 1948, p. 55-63; Scheuss, op. cit., 1960, p. 32-49; Baumann, op. cit., 2007, p. 243-30I. 
banques (Io millions) et le canton de Genève ( 5 millions) doivent aider à améliorer la liquidité de la Banque d'Escompte Suisse. Enfin, les conditions d'octroi de crédits de la Caisse de prêts sont assouplies; le plafond des prêts augmenté. Avec cette nouvelle intervention de sauvetage, le montant des capitaux investis par les autorités publiques (Confédération, banques cantonales et Caisse de prêts de la Confédération) auprès de la Banque d'Escompte Suisse atteint la somme considérable de Ioo millions de francs ${ }^{142}$. Jamais la Confédération n'avait consenti un investissement aussi massif pour venir au secours d'une société privée aux perspectives d'avenir incertaines ${ }^{143}$.

Le projet de secours d'avril 1933 suscite un vif débat au sein du collège gouvernemental Il fait en effet partie des nombreux dossiers sur lesquels s'accentue l'opposition entre le chef du Département des finances, le catholique-conservateur fribourgeois Jean-Marie Musy, et le ministre de l'Économie publique, le radical argovien Edmund Schulthess ${ }^{144}$. Malgré l'opposition de Schulthess, qui donne une lecture peu optimiste du bilan de la banque genevoise, une majorité du Conseil fédéral se rallie à l'opinion de Musy et valide le projet du DFFD, lui-même soutenu par une majorité de banquiers. L'action de secours présentée aux Chambres en avril 1933 passe la rampe, malgré un débat parlementaire animé. Par 87 voix contre 46, l'assainissement est accepté par le Conseil national. L'opposition socialiste et celle des parlementaires libéraux anti-interventionnistes ne suffisent pas à renverser la majorité bourgeoise, par ailleurs fort peu enthousiaste, qui vote le projet presque "par défaut » ${ }^{145}$. À Genève également, le Grand Conseil à majorité bourgeoise donne son blancseing au sauvetage de la Banque d'Escompte.

Après un court répit, l'établissement genevois est à nouveau secoué à l'automne 1933 sous l'effet conjugué de deux événements ${ }^{146}$. L'éclatement de la crise de la Banque Populaire Suisse en octobre 1933, d'une part, ébranle la confiance à peine restaurée dans les capacités de paiement des établissements helvétiques et déstabilise les déposants. D'autre part, l'élection d'un gouvernement à majorité socialiste à Genève, avec à sa tête Léon Nicole en novembre 1933, remet en question la politique bienveillante à l'égard de la Banque d'Escompte Suisse du gouvernement précédent et en particulier la part du canton de Genève prévu par le plan d'assainissement d'avril 1933 (dépôt de 5 millions).

S'ensuit, durant les quatre premiers mois de 1934, un enchaînement de déconvenues qui vont sceller le sort de la banque genevoise. C'est tout d'abord un conflit avec la Caisse de prêts de la Confédération qui affaiblit la Banque

142 Baumann, op. cit., 2007, p. 246.

143 Müller, op. cit., 20Iо, p. 317.

144 Baumann, op. cit., 2007, p. 263-264. Sur les antagonismes entre Musy et Schulthess, voir aussi : Daniel Sebastiani, «Jean-Marie Musy (I876-1952), un ancien conseiller fédéral entre rénovation nationale et régimes autoritaires ", Faculté des Lettres, Université de Fribourg, 2004, p. 335-342.

145 Baumann, op. cit., 2007, p. 280-290.

146 Ibid., p. 294-295. 
d'Escompte. L'institut de secours mis en place par l'État fédéral en juillet 1932 interprète en effet de manière beaucoup plus restrictive que la banque genevoise les possibilités de refinancement prévues dans l'arrêté fédéral. La Caisse de prêts refuse en effet d'augmenter sa limite de crédit de 30 millions, sans recevoir en échange de nouvelles valeurs de garantie ${ }^{147}$. Le conflit oppose alors la Caisse de prêts non seulement à la banque en difficulté, mais également aux autres acteurs impliqués, en particulier la BNS. Les démarches des dirigeants de la Banque d'Escompte auprès du Conseil fédéral, accusant le conseil d'administration de la Caisse de prêts, sont d'ailleurs soutenues par la banque centrale et les autres banques créancières. "Ce serait l'établissement même, créé pour nous venir en aide, qui nous condamnerait à mort ", estiment les administrateurs de la banque genevoise dans une lettre au Conseil fédéral de janvier $1934^{148}$. Il faut préciser que les banques créancières, c'est-à-dire essentiellement les grandes banques, étaient bien représentées au sein des organes dirigeants de la Banque d'Escompte depuis leur renouvellement en mai 1933 ; il n'est donc pas surprenant de les voir tirer à la même corde ${ }^{149}$. L'exécutif fédéral, en tant qu'instance d'arbitrage dans la différence d'interprétation, donne raison à la Caisse de prêts, qui, forte de ce soutien, maintient sa position restrictive. Le in avril I934, le refus définitif de la Caisse de prêts force la Banque d'Escompte à faire appel aux 30 millions de dépôts promis par la Confédération, le canton de Genève et les banques commerciales dans le cadre du plan d'assainissement. Or, à Genève, le nouveau gouvernement à majorité socialiste refuse à son tour, le 29 avril 1934, de fournir le dépôt de 5 millions à la Banque d'Escompte Suisse ${ }^{150}$. Le refus des autorités genevoises fait suite à une sorte d'ultimatum adressé par les dirigeants de la banque défaillante, incluant la menace - qui sera mise à exécution - de fermer les guichets si le canton ne fournit pas le dépôt en question. Le déséquilibre des finances publiques genevoises rend la question très délicate; les autorités cantonales menant par ailleurs des négociations avec la Confédération pour obtenir un crédit-relais de Io millions. La défection du canton de Genève entraîne l'annulation des engagements conditionnels de la part de la Confédération (I5 millions) et des banques privées (Io millions) au dépôt de 30 millions. Le lundi 30 avril I934, la Banque d'Escompte Suisse dépose son bilan auprès du juge cantonal. Aux éléments mentionnés ci-dessus, il faut ajouter un facteur secondaire qui participe au dénouement funeste de la grande banque genevoise. Avec la démission de JeanMarie Musy, annoncée le 22 mars 1934, la Banque d'Escompte Suisse perd en effet son défenseur le plus acharné à la tête de l'État fédéral; son absence lors des négociations finales peut avoir joué en la défaveur de l'établissement genevois ${ }^{151}$.

147 Scheuss, op. cit., 1960, p. 51.

148 Copie d'une lettre du conseil d'administration de la Banque d'Escompte Suisse au Conseil fédéral, 13.0I.1934, archives UBS AG/SBV, 655/5. Cité par Baumann, op. cit., 2007, p. 299.

149 Ibid., p. 293.

150 Bodmer, op. cit., 1948, p. 62-63; Scheuss, op. cit., 1960, p. 52-53.

151 Sur la démission de Jean-Marie Musy: Chantal Kaiser, Bundesrat Jean-Marie Musy: IgI91934, Freiburg: Universitätsverlag, 1999, p. 216-250; Sebastiani, op. cit., 2004, p. 391-408. 
La liquidation de la Banque d'Escompte Suisse se révèlera être un processus long et délicat ${ }^{152}$. Les autorités fédérales tentent dès 1934 de mettre au point une action au bénéfice des petits déposants. Les avoirs jusqu’à 3 ooo.- francs sont remboursés prioritairement en partie contre l'abandon de la créance de la Confédération ${ }^{153}$. Dès 1935, la liquidation de la banque se fera sous le nouveau régime introduit par la loi sur les banques du 8 novembre 1934. En vertu de son article 36 , une procédure de faillite plus adaptée aux banques, qui comptent parfois plusieurs milliers de créanciers, est mise en place. La liquidation ne prend fin qu'en 1949.

Selon Jan Baumann, l'échec du sauvetage de la Banque d'Escompte Suisse s'explique essentiellement par deux raisons ${ }^{154}$. D'une part, les sombres perspectives de rétablissement économique rendaient un assainissement à long terme de moins en moins réaliste. D'autre part, les changements dans la configuration politique ont diminué le capital de soutien dont bénéficiait la banque genevoise. Pour les autorités fédérales et cantonales, malgré les nombreux efforts déjà consentis, le maintien artificiel de l'établissement ne se justifiait plus. Dans ce contexte, la décision de l'exécutif genevois à majorité socialiste de refuser le dépôt de 5 millions ne constitue pas la cause profonde de l'échec du sauvetage, mais plutôt un prétexte opportun pour justifier un retrait généralisé des mesures de soutien.

\section{La Banque Populaire Suisse}

Comme nous le verrons dans le chapitre suivant, dès le début de la crise bancaire en Suisse à l'automne 1931, la question d'une loi de contrôle des banques ressurgit à l'agenda politique. Sous pression en raison de l'adoption du second plan d'assainissement de la Banque d'Escompte Suisse, Jean-Marie Musy fait préparer un premier projet de loi en février 1933. Les problèmes de la Banque Populaire Suisse, qui éclatent au grand jour en octobre 1933, marquent un véritable saut qualitatif dans le processus d'élaboration d'une loi sur les banques. En raison de l'investissement massif pour recapitaliser la Banque Populaire Suisse que le Conseil fédéral doit faire passer au parlement, le projet de loi de surveillance des banques connait à la fois un renforcement de ses dispositions et une accélération de sa discussion. Comme il constitue un tournant dans l'aboutissement du contrôle bancaire en Suisse, le projet d'assainissement de la Banque Populaire Suisse fait l'objet d'une brève synthèse ici ${ }^{155}$.

Contrairement à la Banque d'Escompte Suisse, la Banque Populaire Suisse bénéficie d'une image lui donnant le statut de banque de la classe moyenne et

\footnotetext{
152 Scheuss, op. cit., 1960, p. 56-64.

153 Bodmer, op. cit., 1948, p. 64.

154 Baumann, op. cit., 2007, p. 316-318.

155 Sur l'assainissement de la Banque Populaire Suisse: ibid., p. 319-47I. Voir aussi Bodmer, op. cit., I948, p. 68-8I ; Ehrsam, art. cit., in Zulauf (éd.), op. cit., I985, en part. p. 87-IOI.
} 
de "grande banque des petites gens " ${ }^{156}$. Fondée en tant qu'association en 1869 à Berne, la Banque Populaire Suisse se distingue des autres instituts du groupe des grandes banques par plusieurs aspects. Elle est, depuis I877, organisée sous la forme d'une société coopérative et non d'une société anonyme. Alors que son siège est situé dans la capitale politique et non dans une des principales places financières de Suisse, elle dispose de plus d'un important réseau de succursales - fort de 75 unités en I93I - qui s'étend à toutes les régions du pays. Son rayon d'activité differe également. Elle est à l'origine spécialisée dans le drainage des épargnes d'un large public et l'octroi de petits et moyens crédits, notamment sous forme de prêts hypothécaires ou prêts de cautionnement. Son modèle d'entreprise se situe donc entre celui des banques cantonales et celui des grandes banques commerciales. En termes de sommes de bilan, la Banque Populaire Suisse fait figure de poids lourd de la finance helvétique. Depuis le tournant du siècle, elle se positionne au troisième rang des grandes banques suisses, derrière la Société de Banque Suisse et le Crédit Suisse, avant de dépasser ce dernier entre I92I et 1929. En 1930, avec un bilan de I.683 milliards de francs, la Banque Populaire Suisse, talonne de près ses deux concurrentes ${ }^{157}$. Le gouverneur de la Banque d'Angleterre, Montagu Norman, n'hésite d'ailleurs pas à qualifier la BPS de «probably the largest co-operative bank in the world " ${ }^{158}$. Dans la seconde moitié des années 1920, à la suite de sérieuses pertes subies pendant la crise de reconversion dans la broderie, l'hôtellerie et l'horlogerie, elle cherche à compenser ce recul en s'orientant plus nettement vers les opérations internationales, à plus gros rendements ${ }^{159}$. Les crédits de comptes-courants à la fois très risqués et très lucratifs octroyés pendant cette période sont à l'origine de ses difficultés durant la crise bancaire des années 1930. Comme le dit le message du Conseil fédéral adressé au Parlement en novembre 1933:

Le fait que la banque populaire suisse, de par sa forme coopérative, son organisation et la structure de son bilan, n'était pas outillée pour traiter les affaires étrangères, d'autant plus qu'elle ne possédait pas les relations nécessaires et les directeurs stylés pour ce genre d'opérations, a indubitablement aggravé ses pertes dans une forte mesure ${ }^{160}$.

Les bénéfices enregistrés sur les opérations étrangères à haut rendement ayant servi à compenser les pertes subies dans l'après-guerre, la constitution de

156 Baumann, op. cit., 2007, p. 320.

157 Les sommes de bilan sont extraits des rapports annuels des banques correspondantes.

158 BoE Archive, OV63/I, Letter from Montagu Norman to Leslie Lefeaux on Swiss banking law, 17.0I.I935.

159 Les pertes sont évaluées en 1922 à 50 millions de francs. Cf. «Message du Conseil fédéral à l'Assemblée fédérale concernant la participation financière de la Confédération à la réorganisation de la banque populaire suisse", 29.II.I933, Feuille fédérale, vol. 2, n 50, p. 809-831, ici p. 8I4.

160 Ibid., p. 815. 
nouvelles réserves est négligée. L'absence d'un réseau d'affaires international compromet également l'expansion menée au cours de la seconde moitié des années 1920. Ce déficit organisationnel pousse la BPS à s'engager dans des affaires jugées moins intéressantes par ses concurrentes, et entraîne d'importantes pertes sur investissements ${ }^{161}$. Au moment de l'éclatement de la crise, à la mi-juillet 1931, les engagements étrangers de la BPS s'élèvent à 386 millions de francs, soit environ $28 \%$ de son bilan, dont plus de la moitié en Allemagne ${ }^{162}$. Malgré cette réorientation majeure vers un modèle de grande banque commerciale active à l'international, la Banque Populaire Suisse est encore présentée, au moment de son sauvetage par l'État fédéral, comme une banque des petits épargnants. Il est vrai que, fin octobre 1933, 225 ooo de ses carnets d'épargne sur un total 350 ooo, soit $64 \%$, sont inférieurs à 500 francs ${ }^{163}$. Il faut donc souligner la situation paradoxale de cet établissement qui, comme les autres grandes banques suisses, connait des difficultés suite à de trop forts engagements internationaux désormais gelés, mais qui bénéficie en même temps d'un fort capital de soutien politique en raison de l'importance de son extension territoriale et du nombre de ses petits épargnants et sociétaires. C'est avec cet argument que le message du Conseil fédéral conclut son plaidoyer en faveur du sauvetage de la banque : «il est peu de familles suisses qui ne soient, d'une façon ou d'une autre, en relations avec la banque populaire " ${ }^{164}$.

Dès fin septembre 193I, à Zurich, la Banque Populaire Suisse connaît une première vague de retraits. L'institut réagit en introduisant des limitations de remboursement sur les carnets d'épargne et de dépôts; de longues files se forment devant ses succursales zurichoises ${ }^{165}$. Ces événements se déroulent en parallèle au débat sur les banques au Conseil national du 25 septembre 193I, où il est plutôt question des difficultés de la place financière genevoise. En réaction à ces premiers signes de faiblesse, un changement est opéré à la tête de la banque bernoise: Alfred Hirs (I889-1978), vice-directeur du premier département de la BNS, est nommé directeur général de la BPS avec l'accord du Conseil fédéral. La nomination est prévue comme une solution intérimaire de gestion de crise, mais durera pour finir onze ans avant qu'Alfred Hirs ne retourne à la banque centrale, cette fois en tant que membre du directoire. Seconde intervention : sur demande de Musy, le Conseil fédéral accorde à la fin de l'année I93I un dépôt de Io millions ${ }^{166}$. Alors que la situation de la Banque Populaire Suisse ne s'est guère améliorée depuis l'automne 1931, les dirigeants de la banque décident au printemps 1932 d'ajourner les démarches

161 Perrenoud, et al., op. cit., 2002, p. 231.

162 Ibid., p. 233.

163 «Message du Conseil fédéral à l'Assemblée fédérale concernant la participation financière de la Confédération à la réorganisation de la banque populaire suisse", 29.II.1933, Feuille fédérale, vol. 2, nº 50, p. 809-83I, ici p. 8I6.

164 Ibid., p. 828.

165 Baumann, op. cit., 2007, p. 327-330.

166 Ibid., p. 334. 
d'assainissement, encouragés dans ce sens par les autorités politiques et monétaires du pays. Il s'agit, pour la BNS, d'éviter de mettre en évidence publiquement un second foyer de crise bancaire, en plus de la situation compromise de la Banque d'Escompte Suisse à Genève. Cette tactique de retardement est menée de manière délibérée. Elle a également pour fonction de faire retomber les critiques portées contre l'absence d'une surveillance bancaire étatique. $\mathrm{Ne}$ pas ouvrir un second grand chantier d'assainissement permet à la banque centrale d'éviter d'entrer dans une crise bancaire d'ordre systémique, et d'autre part de remettre à plus tard, au gré du développement conjoncturel futur, les négociations sur une loi de contrôle bancaire.

À l'automne 1933, l'assainissement de l'établissement devient incontournable. La situation financière est telle que les bénéfices attendus ne suffisent plus à couvrir les amortissements les plus urgents. La stratégie à suivre est claire : il s'agit de réduire les engagements internationaux douteux et de renforcer la forte position sur le marché domestique des petits et moyens crédits ${ }^{167}$. Un assainissement sans aide extérieure étant jugé irréalisable, la Banque Populaire Suisse se tourne vers le Conseil fédéral et la Banque nationale. Après les expériences mitigées d'autres formes d'assistance dans le cas de la Banque d'Escompte Suisse en 1931, en particulier par la constitution de pools bancaires et consortium de garantie, la grande banque bernoise sollicite directement une aide étatique sous la forme d'une prise de participation. La réaction gouvernementale, en fort contraste avec la situation plus équivoque dans le cas de la Banque d'Escompte Suisse, est unanimement favorable à un soutien de la Banque Populaire Suisse. Le rapport de Musy sur la marche à suivre ne laisse pas de place au doute:

D'autre part, il est hors de question, pour la délégation du Conseil fédéral et de la direction générale de la Banque nationale, d'abandonner à son sort la Banque Populaire; les conséquences financières, économiques et politiques seraient incalculables. Le soutien extraordinaire de la Confédération semble donc être inévitable. Pour que l'aide ne nécessite pas des moyens démesurés, il faut rétablir la confiance du public par une action d'assainissement rapide ${ }^{168}$.

Malgré quelques réserves de la part de Marcel Pilet-Golaz et Rudolf Minger, le principe d'une contribution de la Confédération à la réorganisation de la Banque Populaire Suisse n'est pas contesté par le collège gouvernemental. La Banque nationale suisse soutient vigoureusement l'objectif d'un assainissement rapide, tout en insistant sur le fait qu'elle obtient ses informations comptables sur la BPS indirectement - c'est-à-dire par l'intermédiaire de dirigeants de la BPS, à l'instar de Hirs, proche de la BNS - et qu'elle n'engage aucunement sa responsabilité ${ }^{169}$. Alors qu'à la même époque, comme nous l'avons vu, d'autres

167 Ibid., p. 348-35I.

168 AFB, Eıoo4.I, I00o/9, vol. 343, Procès-verbaux du Conseil fédéral, séance du I8.Io.I933, $\mathrm{n}^{\circ} \mathrm{I} 630$.

169 Baumann, op. cit., 2007, p. 359. 
grandes banques suisses - l'UBS et la Banque Commerciale de Bâle - procèdent à des réductions de capital, l'assainissement de la Banque Populaire Suisse est plus profond. Il prévoit d'une part la réduction de moitié du capital social - 93 au lieu de I86 millions -, au détriment des sociétaires, puisque la valeur des parts sociales serait divisée par deux. D'autre part, une recapitalisation sous la forme d'une prise de participation de la Confédération en souscrivant pour Ioo millions de parts sociales au capital social de la Banque Populaire Suisse.

Les événements conduisant à l'aboutissement de cette solution s'accélèrent nettement sous la pression médiatique. La parution d'un article dans la NationalZeitung - quotidien bâlois fondé en 1842 de tendance radicale-démocratique - du I8 novembre 1933 révélant le projet gouvernemental de renflouement de la grande banque force le Conseil fédéral à agir rapidement. En attendant la publication d'un message à l'Assemblée fédérale en vue de concrétiser le projet d'assainissement, la Caisse de prêts et la BNS doivent intervenir pour soulager la trésorerie de la BPS, mise à mal par les révélations de l'intervention étatique imminente ${ }^{170}$.

Le message du Conseil fédéral publié le 29 novembre 1933 développe le plan d'assainissement en deux volets décrits ci-dessus. La prise de participation massive de l'État est cependant liée à deux conditions: le Conseil fédéral doit obtenir une représentation "suffisante» dans les organes dirigeants de la banque, il se réserve de plus le droit d'examiner les responsabilités de l'ancienne direction dans la gestion de l'entreprise ${ }^{171}$.

La discussion parlementaire qui suit, rapidement menée entre le 2 et le 8 décembre 1933, est placée sous le signe du consensus ${ }^{172}$. Alors que les débats de juillet 1932 sur la constitution de la Caisse de prêts dans le cadre du soutien à la Banque d'Escompte Suisse avaient donné lieu à de vifs échanges, notamment entre représentants socialistes et le ministre des finances catholique-conservateur Jean-Marie Musy, la discussion sur le projet d'assainissement de la BPS est beaucoup moins polémique. Ce contraste est avant tout dû à la plus grande unanimité qui régnait sur la nécessité de soutenir la Banque Populaire Suisse. La position du groupe socialiste à cet égard est significative. Alors qu'il s'était opposé, en juillet 1932, à l'entrée en matière sur le projet de sauvegarde de la banque genevoise, il soutient cette fois-ci le projet, tout en proposant quelques amendements, dont le rejet par la majorité bourgeoise ne remet pourtant pas en question l'acceptation par la gauche du projet d'ensemble. Ainsi, tant dans la commission que dans le plénum, les députés socialistes proposent sans succès une étatisation intégrale de la Banque Populaire Suisse, au lieu d'une simple prise de participation au capital social. D'autres interventions socialistes,

\footnotetext{
170 Ibid., p. 375-376.

171 «Message du Conseil fédéral à l'Assemblée fédérale concernant la participation financière de la Confédération à la réorganisation de la banque populaire suisse», 29.II.1933, Feuille fédérale, vol. $2, \mathrm{n}^{\circ}$ 50, p. 809-831, ici p. 827.

172 Sur le débat parlementaire autour de la réorganisation de la BPS en décembre 1933 : Baumann, op. cit., 2007, p. 382-396.
} 
demandant par exemple un examen des responsabilités de l'ancienne direction à la fois en procédure civile et pénale, sont acceptées. Nationalisée ou non, la Banque Populaire Suisse bénéficie du soutien des députés socialistes. L'importance des petits épargnants qui seraient affectés par une faillite de l'établissement n'est sans doute pas étrangère au positionnement du groupe socialiste sur la question; les trois quarts des carnets d'épargne de la banque seraient inférieurs à IOo francs ${ }^{173}$.

À l'autre extrémité de l'hémicycle, quelques voix dissidentes se font entendre. Plus précisément, lors du débat au Conseil des États, certains représentants conservateurs s'inquiètent de l'extension que prend l'interventionnisme fédéral dans l'économie privée par cet investissement massif. Ainsi, le sénateur valaisan catholique-conservateur Raymond Evéquoz (I863-1945) déclare-t-il : «Pour empêcher ce que je considère comme un mal, à savoir la fermeture des guichets de la Banque Populaire Suisse, on commet, à mes yeux, une faute plus grave encore : c'est celle de la création en réalité d'un établissement bancaire fédéral nouveau. " ${ }^{174}$ Ces protestations de principe chez les adversaires de «l'étatisation fédérale» ne donnent pas lieu à des actions; Evéquoz vote d'ailleurs comme l'ensemble de ses collègues l'entrée en matière.

Relevons encore au passage que la question de la loi sur les banques en préparation est souvent évoquée dans les débats parlementaires. Robert Grimm, rapporteur de la minorité socialiste, estime ainsi que l'intervention au bénéfice de la Banque Populaire Suisse est rendue nécessaire par la négligence dont ont fait preuve les autorités fédérales, en ne remettant pas au préalable de la sécurité et de l'ordre dans le monde bancaire ${ }^{175}$. Le tribun socialiste est rejoint sur ce point par le représentant du PAB, le Bernois Friedrich Siegenthaler (I872-I942), qui réclame l'instauration d'un contrôle bancaire sévère. L'absence d'une loi bancaire qui aurait pu donner un droit de regard à l'État est considérée comme une des causes de la situation urgente et délicate dans laquelle se trouvent certaines grandes banques. C'est ainsi que le groupe socialiste dépose le 4 décembre 1933 une motion exigeant du Conseil fédéral un projet de loi de surveillance bancaire qui puisse être discuté au Parlement à la session de mars $1934^{176}$. Cette intervention pousse Musy à préciser son calendrier d'élaboration d'une loi sur les banques, il promet qu'il fera des propositions aux Chambres d'ici au Is janvier 1934. Satisfaits, les députés socialistes retirent leur motion.

Quant à l'argumentation du Conseil fédéral, elle se révèle assez simple. Elle consiste, dans le discours de Jean-Marie Musy, à établir des liens de connexité entre divers phénomènes: la défaillance de la Banque Populaire Suisse, la généralisation d'une crise de confiance et une panique bancaire, la ruine du

173 Selon l'exposé du rapporteur du Conseil national, le radical saint-gallois Bruno Pfister (I8891955). Procès-verbaux de l'Assemblée fédérale, Conseil national, 04.I2.1933, p. 747.

174 Procès-verbaux de l'Assemblée fédérale, Conseil des États, 07.I2.1933, p. 407.

175 Procès-verbaux de l'Assemblée fédérale, Conseil national, 05.I2.1933, p. 756-757.

176 Procès-verbaux de l'Assemblée fédérale, Conseil national, 06.12.1933, p. 782. 
crédit de la Confédération et celle du franc suisse. Cet argumentaire est couronné de succès puisque "l'arrêté fédéral concernant la participation de la Confédération au capital social de la banque populaire suisse" est accepté à l'unanimité le 8 décembre 1933 .

Comme l'ont relevé de nombreux commentateurs, la prise de participations de l'État fédéral dans une entreprise privée à hauteur de Ioo millions représentait un investissement massif. Pour Philipp Müller, il s'agit de «l'intervention publique la plus importante en termes financiers dans l'économie privée helvétique depuis l'étatisation des chemins de fer au tournant du XXe siècle» ${ }^{177}$. Rapportée au budget de l'État fédéral, cette somme constitue un montant considérable. Elle équivaut à plus du quart des recettes de la Confédération en I933 (4IO millions), ou à plus d'un cinquième de ses dépenses (482 millions) ${ }^{178}$.

Suite à ce renflouement, la Confédération devait encore renouveler la direction de la Banque Populaire Suisse. L'arrêté fédéral prévoyait d'ailleurs que le Conseil fédéral, en tant que sociétaire majoritaire de la coopérative, nomme la majorité de membres du conseil d'administration. Le choix du Conseil fédéral pour prendre les rênes de la nouvelle BPS se porte sur l'ancien conseiller fédéral radical zurichois Robert Haab (I865-1939), ancien directeur général des CFF (1912-1917), puis chef du Département fédéral des postes et des chemins de fer (I918-1929). Haab est également membre du conseil d'administration de la Société de Banque Suisse depuis 1929 et de la Rentenanstalt depuis 1930. Les éventuels conflits d'intérêts entre la position de président du conseil d'administration de la BPS et celle de membre de celui de la SBS, soulevée par la presse socialiste, n'inquiètent guère le collège gouvernemental ${ }^{179}$. Le choix des dix autres membres - sur un total de $2 \mathrm{I}$ - nommés par le Conseil fédéral tient compte, conformément à l'arrêté fédéral, des principaux milieux économiques du pays. La composition exacte de ce conseil d'administration remanié figure dans le tableau A.2 en annexe du PDF. Parmi les onze administrateurs sur 2I nommés par le gouvernement, on compte donc deux radicaux, deux catholiques-conservateurs, deux socialistes, un représentant du Parti paysans, artisans et bourgeois, auquel il faut ajouter un second paysan bernois. Sur les trois autres membres sans couleur politique évidente, on compte un représentant de la Banque cantonale de Zurich et un représentant du Crédit Suisse. Notons enfin la présence étonnante d'une femme dans ce cénacle: Jeanne Schwyzer. Ce choix est sans doute lié à l'importance des sociétaires féminines dans la Banque Populaire Suisse; elles constituent en effet la moitié des sociétaires de la coopérative ${ }^{180}$. Sans même tenir compte des dix autres administrateurs nommés l'Assemblée générale de la coopérative, soulignons que les milieux économiques conservent une influence prépondérante. Les deux plus grandes banques, le Crédit Suisse et la Société de Banque Suisse, sont représentées.

177 Müller, op. cit., 20IO, p. 3I7.

178 Baumann, op. cit., 2007, p. 425.

179 Ibid., p. 397-398.

180 Ibid., p. 344. 
La SBS, en plus du nouveau président du conseil d'administration Robert Haab, possède une certaine influence sur la gestion courante de la coopérative bernoise. En effet, un de ses anciens directeurs, John Alfred Meyer (I890-?), est parachuté à la tête de la direction générale de la BPS en janvier 1934.

La composition de cette liste d'administrateurs nous intéresse également sous un autre aspect. Elle révèle, de même que les nominations à la tête de la Caisse de prêts de la Confédération en juillet 1932, la formation d'une sorte de réseau d'experts financiers proche de l'administration fédérale. Avec ces deux nominations qui précèdent la formation de la Commission fédérale des banques dont il sera question plus bas, le Conseil fédéral est confronté à une problématique similaire: mettre en place un comité équilibré tenant compte d'une part des compétences en matière financière, d'autre part de critères politiques, économiques et régionaux. Il n'est d'ailleurs pas indifférent que deux des administrateurs de la BPS nommés en janvier 1934 - Emil Walch et Albert Zust, se retrouveront, un an plus tard, élus parmi les membres de la Commission fédérale des banques. La recomposition du conseil d'administration et de la direction de la BPS en décembre 1933 porte d'ailleurs la marque de la médiation décisive d'Edmund Schulthess, l'homme même qui deviendra président de la première Commission fédérale des banques ${ }^{181}$.

$\mathrm{Du}$ point de vue financier, la situation de la BPS reste délicate après l'investissement massif de la Confédération. Le bilan poursuit sa baisse - I.I5 milliard fin 1933 contre I.683 milliard trois ans plus tôt ; les engagements étrangers représentent encore 182 millions, dont la moitié est concernée par des restrictions de transfert ${ }^{182}$. Tandis que les enquêtes sur la responsabilité civile et pénale de ses anciens dirigeants s'enlisent, la Banque Populaire Suisse doit subir un second assainissement en 1937. En effet, alors qu'en chiffres absolus, les engagements étrangers douteux ont connu une forte baisse, en termes relatifs, ils représentent, fin 1936 , toujours un cinquième du bilan total ${ }^{183}$. En décembre 1936, les dirigeants de la banque bernoise entreprennent les négociations avec le Conseil fédéral en vue d'un assainissement de bilan. Les banquiers envisagent d'effectuer une réduction de capital, au détriment de la part étatique du capital social, afin d'employer les capitaux libérés pour liquider des créances dévalorisées. Cette opération devrait se faire, pour eux, en contournant le parlement. Le gouvernement et la banque centrale n'approuvent pas entièrement ce projet. Ils s'opposent à l'idée d'une réduction de capital subie uniquement par les parts étatiques; les sociétaires doivent passer à la caisse également. C'est cette solution qui est finalement retenue et validée par le Conseil fédéral le 29 janvier 1937: le capital social est réduit de 190 à 95 millions de francs, de manière paritaire entre la Confédération et les sociétaires individuels ${ }^{184}$. Enfin, entre

181 Ibid., p. 403.

182 Ibid., p. 422.

183 Ibid., p. 447.

184 AFB, Eioo4.I, I000/9, vol. 362, nº 192. Procès-verbaux du Conseil fédéral, séance du 06.0I.I934. 
octobre 1946 et février I948, une reprivatisation d'une partie du capital social de la BPS encore en mains de la Confédération est opérée. En 1993, la Banque Populaire Suisse est rachetée par le Crédit Suisse.

\section{Épilogues}

Les épisodes contrastés des interventions de l'État fédéral dans les sauvetages de deux grandes banques - la Banque d'Escompte Suisse et la Banque Populaire Suisse - sont riches en enseignements sur le développement chaotique d'une politique fédérale de stabilisation du système bancaire. Dans le cas de la grande banque genevoise, il faut souligner d'une part l'inefficacité de la méthode des petits pas qui caractérise les interventions d'assainissement entre l'été I93I et le dépôt de bilan d'avril I934. La succession de diverses étapes de sauvetage - dépôt de la Confédération, constitution d'un consortium de garantie des banques commerciales, création de la Caisse de prêts de la Confédération, puis enfin l'extension de ses conditions d'octroi de crédits - s'est révélée inopérante. D'autre part, les perspectives de survie à long terme de la Banque d'Escompte étaient prétéritées par le manque de consensus politique sur la nécessité de maintenir à flot l'établissement ${ }^{185}$. Ni au sein du Conseil fédéral, ni parmi les représentants du peuple, et encore moins parmi les instances politiques genevoises, ne régnait l'unanimité sur la viabilité de la banque et, partant, sur les bienfaits d'un nouvel assainissement. La Banque Populaire Suisse, grâce à son étiquette de banque de la classe moyenne installée dans le pays entier auprès d'une clientèle très large, était placée, en termes d'enjeu politique, dans une bien meilleure position. L'identification de la clientèle de cette banque avec un électorat très prisé par les partis politiques lui octroyait d'emblée un capital de soutien très important. La comparaison entre les débats parlementaires dans les deux cas, en juillet 1932 et décembre 1933, montre clairement que la Banque Populaire Suisse, considérée comme too big to fail, bénéficiait d'une assistance considérable de la part des autorités fédérales. Les facteurs politiques priment sur les déterminants économiques pour comprendre les destins divers des deux instituts ${ }^{186}$.

D'un point de vue quantitatif, l'interventionnisme fédéral à la rescousse des établissements bancaires se distingue des mesures entreprises dans d'autres domaines, en particulier la politique sociale, par l'importance de moyens mis à disposition. Philipp Müller et Sébastien Guex avancent les sommes de 200, respectivement 230 millions, pour chiffrer les montants injectés par l'État fédéral entre I93I et I935 pour aider les instituts financiers ${ }^{187}$. En nous limitant aux deux investissements majeurs durant cette période - Banque d'Escompte Suisse et BPS, la part cumulée de la Confédération aux opérations de sauvetage

185 Baumann, op. cit., 2007, p. 478-483.

186 Ibid., p. 473-483. Pour un parallèle entre les crises bancaires des années I930 et la recapitalisation de l'UBS AG en 2008, cf. Kley, art. cit., $201 \mathrm{I}$.

187 Müller, op. cit., 20Io, p. 737 ; Guex, art. cit., in David, Mathieu, Schaufelbuehl (éd.), op. cit., 20I2, p. I57. 
dépasse en effet 200 millions. En faveur de la Banque d'Escompte Suisse, on obtient un total de I02.25 millions, en ajoutant aux 27.25 millions de dépôts jusqu'en décembre 193r les 75 millions de participations à la Caisse de prêts de la Confédération. En ce qui concerne la Banque Populaire Suisse, la prise de participation au capital social s'élève à Ioo millions de francs. Il est cependant trompeur d'évoquer la somme totale, étant donné que les différents investissements revêtent différentes formes. Tandis qu'une partie du capital social public de la BPS sera perdu lors de la réduction de capital opérée en 1937, d'autres financements fédéraux ne se font pas à perte, comme dans le cas de la Caisse de prêts de la Confédération.

Enfin, il faut insister sur l'importance de la dynamique réciproque entre trois phénomènes : l'avènement de crises bancaires, l'appel à l'aide des pouvoirs publics, et la question d'une mise en place d'une surveillance étatique des banques. Comme nous le verrons dans le chapitre suivant, les liens de causalité entre ces manifestations sont très clairs. Retenons pour l'instant deux choses.

Premièrement, que les crises bancaires retentissantes des années I93I-I934 agissent en Suisse comme de formidables accélérateurs de la mise en place d'une législation bancaire. Cela apparaît de manière plus évidente encore lorsqu'une intervention de l'État nécessite la ratification par un organe législatif donnant lieu à un débat public. Pour Jean-Marie Musy, la validation d'un assainissement bancaire devant l'Assemblée fédérale est un exercice délicat; l'approbation des députés pour la mise à disposition de deniers publics ne pouvant être obtenue qu'au prix de promesses quant au contrôle réglementaire des banques.

Deuxièmement - et c'est là un phénomène sans doute moins universel dans le cas de la Banque d'Escompte Suisse, la dynamique fonctionne aussi dans le sens inverse. La question d'une législation bancaire y joue également le rôle d'une menace que Jean-Marie Musy agite auprès des milieux bancaires pour exiger leur coopération dans le sauvetage de banques concurrentes. Muni de cet épouvantail, le conseiller fédéral parvient à obtenir des banques encore saines la constitution d'un consortium de garantie. Autrement dit, du point de vue du Département des finances et des douanes, l'instrumentalisation des avant-projets de loi bancaire est double. D'un côté, elle agit comme un moyen de pression pour stimuler une forme de "solidarité de place» de la part des dirigeants bancaires. De l'autre, elle est utilisée auprès des courants d'opinion favorables à une régulation bancaire comme une monnaie d'échange contre le renflouement étatique des banques défaillantes. 


\section{CHAPITRE III}

\section{L'ÉLABORATION DE LA LÉGISLATION BANCAIRE DE NOVEMBRE 1934: UN PARCOURS D'OBSTACLES (1931-1934)}

Les spécialistes s'accordent à le dire: les crises jouent un rôle moteur dans l'instauration ou la modification de régimes de régulation bancaire:

Crises often lead policy makers to make changes to banking regulations. Following crises, reforms aimed at making the banking system more resistant to crises are politically popular; at the same time, interest groups take advantage of the sentiment in favor of reform to advance their own agendas ${ }^{1}$.

La citation de Grossman souligne les deux interprétations majeures du concept de régulation. En tant que réponse à un dysfonctionnement économique, elle viserait à corriger des défaillances du marché (public interest theory). Dans la seconde partie de la citation, l'auteur oriente aussi l'idée de régulation vers une interprétation différente. L'intervention politique serait également un champ où pourraient s'exprimer des intérêts particuliers, et ainsi créer d'autres déséquilibres (private interest theory).

Sans partager les conclusions fonctionnalistes de cette approche théorique de la régulation, nous constatons qu'elle trouve cependant une application concrète dans le cas de la loi bancaire suisse du 8 novembre 1934. Comme souvent, nous verrons qu'un certain écart sépare les motivations, objectifs et discours officiels des législateurs d'une part, et les procédures d'élaboration, les rapports de force et le résultat législatif d'autre part.

Ce chapitre a pour objet de retracer les dynamiques qui marquent la conception de la loi fédérale sur les banques, entre les premières réflexions gouvernementales de septembre I93I, à la suite de l'éclatement de la crise financière européenne, et l'adoption du texte au Parlement le 8 novembre I934. Notre récit est structuré autant par les circonstances internes à la procédure législative (formation de commission d'experts, débats parlementaires, etc.), que par des événements externes qui influencent 
considérablement les négociations politiques (crises bancaires, mesures de sauvetage étatiques).

Il est d'ailleurs frappant de constater à quel point la chronologie de la crise bancaire en Suisse et celle de l'élaboration de la loi sur les banques s'entrecroisent. Le tableau 3 synthétise les principales étapes de l'évolution de ces deux phénomènes.

Tableau 3. Chronologie de la crise bancaire en Suisse et de l'élaboration de la loi fédérale sur les banques (I93I-I935)

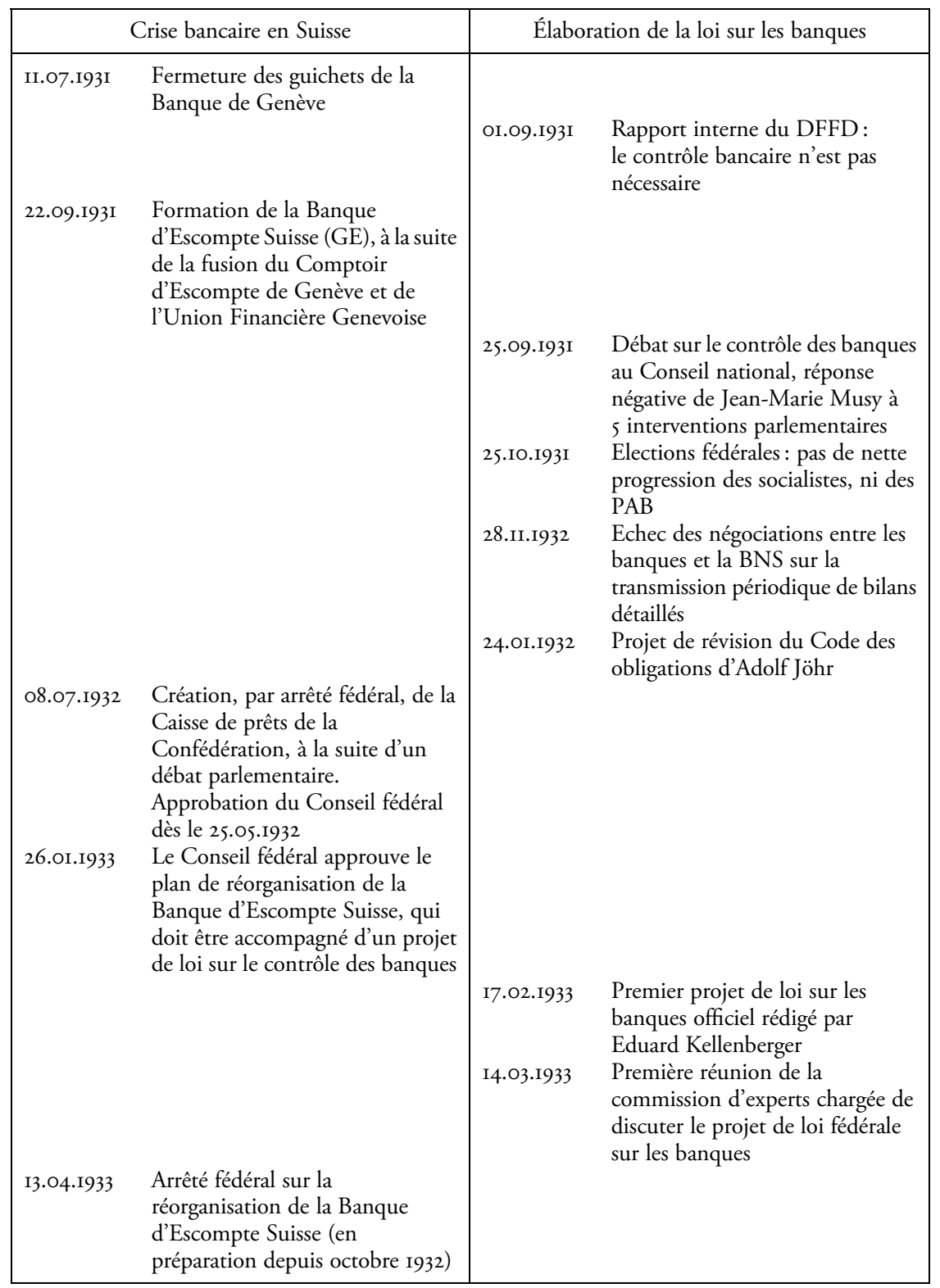




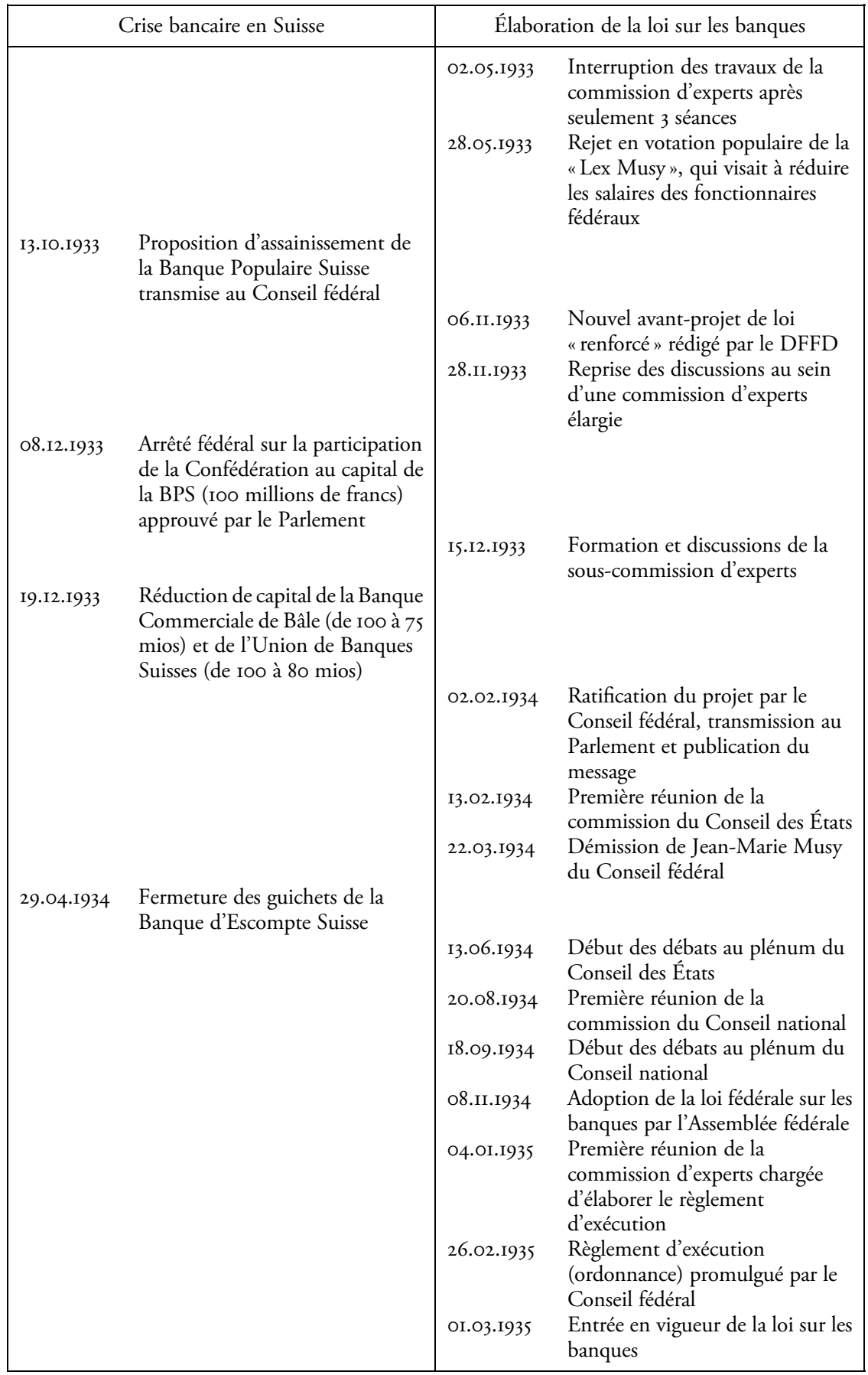


La juxtaposition d'une chronologie propre aux événements de la crise bancaire en Suisse et une autre recensant l'avancement des avant-projets de loi bancaire souligne une étroite corrélation entre les deux phénomènes. Il y a en fait trois étapes successives dans la dialectique entre défaillances bancaires, intervention de la Confédération et élaboration d'un projet de loi.

En septembre 1931, la thématique du contrôle bancaire apparaît à l'agenda politique helvétique sous l'effet de la faillite de la Banque de Genève et de l'éclatement de la crise financière européenne à l'été 1931. Pour diverses raisons, une solution d'autorégulation, c'est-à-dire l'extension de conventions entre la banque centrale et les banques privées, ainsi que l'introduction d'une forme minimale de régulation bancaire dans le droit des sociétés sont privilégiées.

La deuxième étape a pour toile de fond la crise de la Banque d'Escompte Suisse, basée à Genève. La mise sur pied de la Caisse de prêts de la Confédération, en juillet 1932, puis surtout, le second plan d'assainissement de la Banque d'Escompte Suisse de janvier 1933, incluant une recapitalisation par l'État central à hauteur de 20 millions de francs, provoquent un revirement au sein du Département des finances. La solution d'une simple réforme du Code des obligations est abandonnée; un projet de loi spéciale sur les activités bancaires doit être présenté pour obtenir l'aval du Parlement sur le sauvetage de la banque genevoise. Entre janvier et mai 1933, les premiers avant-projets officiels sont rédigés et une commission d'experts réunie.

Enfin, se produit, en novembre 1933, la troisième étape d'émergence d'une loi fédérale sur les banques. Après une longue interruption qui laissait presque supposer un abandon du projet, les travaux d'élaboration sont sortis de leur torpeur dans le contexte de la crise d'une autre grande banque, la Banque Populaire Suisse. Parallèlement à la ratification par l'Assemblée fédérale d'une prise de participation à la grande banque d'un montant colossal de IOo millions de francs, le Département des finances décide de reprendre l'élaboration du projet de loi. Ce dernier connait plusieurs renforcements et la composition de la commission d'experts s'élargit au profit de délégués du mouvement ouvrier et de la paysannerie.

On constate donc la reproduction, à trois reprises en l'espace de trois ans, d'un même cycle de régulation ${ }^{2}$. L'éclatement d'un foyer de crise financière nécessite l'appel au secours de l'État, ce qui, à son tour, incite l'administration publique à introduire des mesures réglementaires. Le cycle s'achève par l'enlisement ou l'adoption du projet de régulation, avant qu'une nouvelle crise n'amorce le prochain cycle. La reprise de cette théorie de la régulation dans le contexte de l'élaboration de la loi fédérale sur les banques dans les années I930 permet de mettre en avant un trait caractéristique. Il est en effet significatif que

2 La notion de regulatory dialectic ou regulatory cycle connaît un fort développement dans le cadre des travaux sur la reregulation au cours des années 1980. Cf. Edward J. Kane, «Interaction of Financial and Regulatory Innovation", The American Economic Review, vol. 78, $\mathrm{n}^{\mathrm{o}} 2, \mathrm{1} 988, \mathrm{p} .328-334$. 
la répétition à trois reprises d'une demande d'assainissement bancaire soit nécessaire pour voir le principe d'une réglementation bancaire s'imposer. Ce n'est qu'avec l'aggravation progressive de la crise bancaire et, partant, les différents paquets de sauvetage ficelés par le Département des finances que la pression politique en faveur d'une régulation bancaire a pu vaincre la résistance, non seulement des milieux intéressés, mais également celle des représentants de la puissance publique. Les nombreuses manœuvres, rétractations et hésitations observées chez Jean-Marie Musy et ses collaborateurs au cours de la période I93I-I933, montrent bien qu'ils n'éprouvent que peu de sympathie à imposer aux banques une loi dont elles ne veulent pas. Une des caractéristiques de la législation qui en résultera, soit son orientation très libérale et peu interventionniste, trouve donc son origine dans la position ambiguë de ses auteurs. Pour Musy, comme en grande partie pour les dirigeants de la BNS, la loi fédérale sur les banques est soutenue bon gré mal gré, avec comme objectif fondamental de limiter les responsabilités étatiques liées à l'instauration d'un contrôle. Devant la petite commission d'experts, le conseiller fédéral fribourgeois présente, avec la finesse d'analyse qu'il affectionne, à la fois l'origine et le fondement idéologique du projet de loi discuté:

De toutes parts on a sollicité la Confédération de renflouer le Comptoir d'Escompte de Genève, l'Union financière de Genève et la Banque Populaire Suisse. Il faut choisir [entre] le système du libéralisme total, auquel on a renoncé, ou bien laisser intervenir l'État et le renseigner en temps voulu. Le contrôle des banques est la solution intermédiaire entre le libéralisme complet et l'étatisme ${ }^{3}$.

Reprenons désormais les principales étapes de l'évolution survolées ci-dessus dans une analyse plus détaillée.

\section{III.1. STRATÉGIES D'ÉVITEMENT (1931-1933) : RENFORCEMENT DU CONTRÔLE INTERNE DES BANQUES, GENTLEMEN'S AGREEMENT, TRANSMISSION DES BILANS À LA BNS ET RÉFORME DU CODE DES OBLIGATIONS}

Durant une première phase, on assiste à un jeu tactique entre les représentants bancaires, les autorités fédérales et les dirigeants de la banque centrale d'une part et les milieux favorables à l'adoption d'une loi de contrôle bancaire, par ailleurs très hétérogènes, d'autre part. La pression politique et médiatique en faveur des mesures réglementaires à l'échelon national ne cesse de grandir à mesure que s'accumulent les nouvelles sur la mauvaise santé financière de certains instituts et les interventions subséquentes de soutien des autorités publiques. Face à cette contrainte, les acteurs centraux du processus 
maintiennent et développent, dans un premier temps, les stratégies d'évitement amorcées au cours des années 1920. L'Association suisse des banquiers, la Banque nationale suisse et le Département des finances présentent donc en septembre 193I un front commun pour s'opposer à la mise en place d'une loi spécifique aux activités bancaires. En lieu et place d'une telle mesure, on explore diverses pistes: le renforcement du contrôle interne, la transmission volontaire d'informations comptables détaillées à la banque centrale - au besoin sous la forme d'un gentlemen's agreement-, ou encore une réforme du droit des sociétés commerciales, c'est-à-dire une révision du Code des obligations.

Fin août 1931, la question de la surveillance des banques ressurgit à l'agenda du Département des finances et des douanes. Rappelons que les mois de juillet et août I93I avaient vu éclater au grand jour les difficultés du Comptoir d'escompte de Genève, et que diverses opérations d'assainissement avaient déjà été entreprises en quelques semaines. Plus précisément encore, JeanMarie Musy, conseiller fédéral en charge des finances, anticipe pendant l'été la délicate rentrée politique à venir. Il sait déjà que lors de la session de l'Assemblée fédérale de septembre, plusieurs interventions parlementaires aborderont la crise bancaire genevoise et sonderont les intentions du gouvernement en la matière ${ }^{4}$. Ce n'est donc pas de plein gré que le conservateur fribourgeois reprend cette question, mais sous une certaine pression. Le 28 août a lieu une réunion entre la direction générale de la BNS et des représentants des grandes banques. L'objectif est clair: cette conférence vise à examiner «la question de l'empêchement d'une législation bancaire, qui soumettrait les banques à une surveillance et un contrôle public " ${ }^{5}$. Par cette expression même, on comprend qu'il ne s'agit pas d'un débat sur l'opportunité ou non d'une loi de surveillance bancaire, mais bien de savoir comment éviter la tenue d'un tel débat.

Quelles sont les mesures palliatives proposées par le gotha bancaire? En lieu et place d'une réglementation bancaire, il s'agit de promouvoir une collaboration renforcée entre la banque centrale et les grandes banques commerciales. Ces dernières s'engagent à transmettre des bilans intermédiaires mensuels contenant les informations souhaitées. Plus précisément, deux points devraient faire partie des renseignements transmis : l'état de la liquidité et la répartition des risques ${ }^{6}$. Au cours des quatre derniers mois de 1931, les négociations en matière de contrôle bancaire tournent autour de l'établissement d'un schéma de bilan pour ces transmissions, qui serait formalisé par un gentlemen's agreement. Ces négociations restent confinées à un cercle très confidentiel. Leur résultat n'est pas destiné, dans un premier temps, à être rendu public.

Pendant que les banquiers organisent un accord non contraignant, le grand argentier de la Confédération est chargé de justifier, dans l'opinion publique, le

4 D'après le rapport du procès-verbal du directoire de la BNS. ABNS, Procès-verbaux de la Direction générale de la BNS, 27.08.1931, $\mathrm{n}^{\circ} 689$, p. 760 .

5 ABNS, Procès-verbaux de la Direction générale de la BNS, 31.08.193I, nº 699, p. 774.

6 ABNS, Procès-verbaux de la Direction générale de la BNS, 27.08.I93I, $\mathrm{n}^{\circ}$ 689, p. 762. 
choix de la non-intervention législative. Il commande un rapport sur la question à un collaborateur, Eduard Kellenberger, directeur suppléant de l'Administration fédérale des finances. Ce document contient une sévère critique des diverses revendications, en Allemagne comme en Suisse, visant à instaurer une surveillance étatique des banques. Après les projets socialistes, Kellenberger s'attaque à celui de son ancien professeur à l'Université de Bâle, en affirmant que le projet Landmann de 1916 est " une loi-cadre [...] qui ouvrirait la voie à la socialisation du monde bancaire ${ }^{7}$. Kellenberger propose trois mesures en conclusion de son rapport : inciter les banques locales et moyennes à former ou à rejoindre un syndicat de révision, inviter les cantons qui ne connaissent pas encore cette pratique à adopter des lois sur les caisses d'épargne et enfin favoriser la conclusion d'un gentlemen's agreement entre la BNS et les grandes banques sur la transmission régulière d'informations. Notons au passage qu'après avoir vigoureusement combattu le principe même de la surveillance publique, Kellenberger sera l'un des protagonistes les plus actifs de l'élaboration de la loi, et qu'il dirigera entre 1946 et 1955 le secrétariat de la Commission fédérale des banques.

L'objectif du rapport interne de Kellenberger est aussi de fournir à JeanMarie Musy un argumentaire pour s'opposer aux revendications de contrôle bancaire. Dès le 2 septembre, le sujet est soulevé au sein du Conseil fédéral ${ }^{8}$. Edmund Schulthess, chef du Département de l'économie publique, rappelle à ses collègues l'existence du projet Landmann qu'il avait commandé une quinzaine d'années plus tôt. Il propose que le Département des finances reprenne en main ce dossier et que les travaux de Landmann soient enfin diffusés à un public plus large. Musy rétorque qu'il s'est déjà attelé à cette tâche, en prévision des interventions parlementaires à venir. Le Fribourgeois distingue deux aspects: l'établissement des comptes et la surveillance générale des banques. Sur cette seconde question, Musy n'est pas enthousiaste : "Cette dernière tâche semble particulièrement délicate, parce que l'État aurait à assumer une énorme responsabilité avec la surveillance des banques. ${ }^{9}$ La seule décision prise est la validation par le collège gouvernemental du passage de témoin entre Schulthess et Musy. Dans le contexte de la grande rivalité entre les deux hommes d'État, cette transmission du dossier "contrôle bancaire " peut surprendre ${ }^{10}$. À titre d'hypothèse, gageons que le traitement par le DFFD des questions relatives à la crise bancaire genevoise pendant l'été I93I en faisait le successeur désigné pour prendre en charge une éventuelle réponse législative.

7 AFB, E6520(A), I000/I059, vol. 2, Rapport de l'AFF sur «Bankenkontrolle» (Eduard Kellenberger), OI.09.193I.

8 AFB, Eıo04.I, I000/9, vol. 330, Procès-verbaux du Conseil fédéral, séance du 02.09.I93I, $\mathrm{n}^{\circ} \mathrm{I} 48 \mathrm{O}$.

9 Ibid.

10 Sur l'antagonisme entre Musy et Schulthess, par exemple autour du projet d'AVS de l'Argovien, voir: Sebastiani, op. cit., 2004, p. 335-342. 
Quelles qu'en soient les raisons exactes, le transfert du dossier «loi de contrôle bancaire » du Département de l'économie publique au Département des finances et des douanes, dirigé par un Jean-Marie Musy réputé moins "étatiste» et interventionniste que son rival argovien, réjouit les grands dirigeants bancaires. Le banquier privé bâlois Alfred Sarasin déclare d'ailleurs en septembre I93I :

Nous devons être heureux que le mouvement actuel relatif à la surveillance bancaire soit dans les mains de M. le conseiller fédéral Musy. Monsieur Musy est convaincu qu'aucun contrôle étatique ne peut éviter des situations comme celles qui ont eu lieu à Genève ${ }^{11}$.

Rappelons que Musy n'est pas insensible aux desiderata de la place financière suisse. Avant d'entamer sa carrière politique fédérale, il avait dirigé un institut bancaire régional, le Crédit Gruyérien entre I9II et $1919^{12}$. En I9I2, en tant que chef des Finances cantonales fribourgeoises, il est devenu président du conseil d'administration de la Banque d'État de Fribourg, et membre du conseil de surveillance de la Banque cantonale fribourgeoise et de la Caisse Hypothécaire de Fribourg ${ }^{13}$. Il s'est également lié d'amitié avec Charles Schnyder von Wartensee (I874-1957), qui deviendra vice-président de la BNS (1920-1937). En 1913, Musy est nommé membre du Conseil de banque de la Banque nationale suisse. Enfin, dès 1917, il siège au conseil d'administration de la Rentenanstalt, grande compagnie d'assurances zurichoise proche du Crédit Suisse. Au moment de son élection au Conseil fédéral, en décembre 1919, Musy, par ailleurs farouchement anti-socialiste, bénéficie d'une forte intégration et d'un important réseau d'influence au sein des élites financières helvétiques.

Au lendemain des félicitations reçues au sein du comité de l'ASB, le conseiller fédéral fribourgeois renvoie l'ascenseur à l'Association suisse des banquiers lors de son discours devant son assemblée générale annuelle le I2 septembre I93I à Lausanne. Il y réaffirme son soutien à une solution d'autorégulation. Ce discours, révélateur de l'état d'esprit de l'homme d'État responsable de la mise en place de la surveillance bancaire en Suisse, mérite d'être cité amplement :

Comme ce fut déjà le cas précédemment, à l'occasion de chaque crise importante, l'idée a surgi, dans certains milieux, d'instituer en Suisse le contrôle officiel des banques. Cette intéressante question doit être examinée avec calme et objectivité, c'est-à-dire sans parti-pris, au-dessus de toute préoccupation d'ordre politique et avec le désir et une volonté ferme d'appliquer dans ce domaine les mesures vraiment utiles

11 AASB, Procès-verbaux du Conseil de l'ASB, 84 ééance, II.09.I93I, p. 9. Alfred Sarasin est à la fois président d'honneur de l'ASB (1927-1953) après avoir l'avoir dirigée (I917-1927), et président du Comité de la BNS (1927-1935).

12 Sebastiani, op. cit., 2004, p. 95.

13 Guex, op. cit., 1993, p. 26I-262. 
qui nous vaudraient effectivement plus de sécurité. Constatons en premier lieu que le contrôle officiel des banques qui existe dans certains États n'a pas empêché de nombreuses défaillances et faillites retentissantes. S'il suffisait, pour assurer la prospérité d'une banque, de la soumettre au contrôle d'une fiduciaire, le problème serait facilement résolu. Mais le personnel et le contrôle ne suffisent pas à garantir la bonne administration d'une banque. Le contrôle est nécessaire, il doit être sérieux, mais ne nous y trompons pas, il ne signifie pas tout. Ce qui reste la condition essentielle c'est une direction habile et probe. [...] La banque peut-elle, doit-elle être placée sous le contrôle officiel de l'État? Cela ne paraît pas nécessaire. Le contrôle officiel de la banque n'est désirable ni pour l'État, ni pour la banque. Le contrôle officiel exigerait en effet la création d'un appareil très compliqué. Le contrôle matériel des opérations d'une seule grande banque exige la présence permanente et le travail ininterrompu d'un groupe important de spécialistes. [...] Ensuite, je redouterais la responsabilité formidable qui résulterait pour l'État de l'institution du contrôle officiel. Puis, l'intervention des contrôleurs officiels inquiéterait peut-être, à tort ou à raison, la clientèle qui attache une très grande importance à la discrétion sur laquelle elle veut pouvoir compter. La fuite des capitaux déposés dans nos banques qui pourrait être la conséquence de l'institution du contrôle officiel causerait à notre économie nationale un mal dont le peuple tout entier aurait à souffrir ${ }^{14}$.

Plutôt que le « contrôle officiel ", la voie à suivre pour Musy est précisément celle mise en avant par les cercles bancaires fin août I93I : renforcement du contrôle par des fiduciaires privées en modifiant le droit des sociétés, et engagement des banques à transmettre à la Banque nationale des bilans mensuels détaillés. Le discours développé par le Fribourgeois recycle un argumentaire très classique. Après avoir remis en question l'efficacité préventive de toute norme restrictive, il joue sur la double crainte liée d'une part à d'hypothétiques retraits de capitaux en réponse à l'introduction de mesure de contrôle, d'autre part à l'alourdissement insupportable de la responsabilité de l'État. Retenons de cette prise de position qu'à l'automne I93I, malgré la sévère crise financière qui secoue l'Europe, le plus haut magistrat suisse responsable du dossier s'oppose à une surveillance des banques par l'État.

Pourquoi ce remue-ménage autour de la question du contrôle bancaire vient-il troubler la rentrée de septembre I93I ? L'impulsion provient en fait de cinq interventions parlementaires auxquelles le gouvernement devra répondre lors de la session de septembre. Ces cinq demandes, dont trois interpellations et deux postulats, sont toutes en lien avec la fermeture des guichets de la Banque de Genève survenue le II juillet I93I. Il est intéressant de relever que ces cinq interventions parlementaires couvrent un spectre politique relativement large. Deux d'entre elles - l'interpellation de Léon Nicole et le postulat

14 Association Suisse des Banquiers, Procès-verbal de la dix-huitième Assemblée générale ordinaire du I2 septembre 1931, p. 33-34. En partie cité par Sancey, op. cit., 2015, p. 353-354. 
d'Ernest-Paul Graber - proviennent de manière attendue des rangs socialistes ${ }^{15}$. Plus surprenant, le postulat de Gustav Adolf Seiler (I875-1949), conseiller national et conseiller d'État de Bâle-Campagne du Parti démocratique progressiste puis radical, est soutenu par 4I représentants bourgeois. Ce texte demande notamment au Conseil fédéral de présenter un rapport et des propositions en vue « de prendre des mesures législatives pour protéger les dépôts d'épargne et d'étendre, pour les banques qui acceptent des dépôts et d'autres fonds étrangers, les dispositions du droit des obligations sur la publicité» ${ }^{16}$. Pour sa part, l'interpellation de Philipp Schmid (I889-1972), radical zurichois et secrétaire de la Société Suisse des employés de commerce ${ }^{17}$, demande au Conseil fédéral de soumettre l'exportation de capitaux à une surveillance plus étroite et d'obliger les banques à publier des renseignements plus complets sur leur situation. Enfin, l'interpellation du chrétien-social genevois JulesÉdouard Gottret (I865-1953) invite le gouvernement à venir en aide aux déposants de la Banque de Genève.

Certes, les cinq interventions discutées les 24 et 25 septembre au Conseil national proposent diverses orientations, tant sur le diagnostic de la situation que sur les mesures à prendre. Mais elles trouvent toutes leur origine dans les événements de l'été 193I qui ont secoué la place financière genevoise, et demandent au Conseil fédéral de prendre position sur la question. Le fait que certaines des signatures proviennent des partis bourgeois complique donc considérablement la tâche de Jean-Marie Musy dans la réponse qu'il fournit devant la Chambre du peuple. Les représentants bancaires regrettent d'ailleurs également que les partis " modérés » suggèrent aussi une réglementation de l'épargne et ne combattent pas plus vigoureusement dans la presse les attaques «démagogiques» que subissent par exemple les banquiers genevois ${ }^{18}$. Sans surprise, le chef du Département des finances reprend devant le Conseil national les arguments qu'il avait servis à la réunion annuelle des banquiers une quinzaine de jours plus tôt. Sur la question de la surveillance des banques, il distingue trois voies à suivre: celle du contrôle officiel par l'État, qu'il exclut à cause de la « terrible responsabilité » qui serait ainsi imposée à la Confédération, celle du contrôle par une fiduciaire, qu'il rejette chez

15 L'interpellation Nicole du I6 septembre 193I est appuyée par 27 signatures de députés socialistes; le postulat Graber peut compter sur 2I co-signataires de son parti.

16 Procès-verbaux de l'Assemblée fédérale, Conseil national, séance du 24.09.1931, p. 639. Sur Gustav Adolf Seiler, voir sa notice biographique in Sancey, op. cit., 2004, p. 449.

17 Ancien employé de banque (I908-I9I8), Philipp Schmid-Ruedin est un représentant de l'aile gauche du Parti radical (membre du Parti démocratique zurichois). Cf. Michael Gehrken, Im Zeichen einer wahrhaft eidgenössischen Solidarität: Krise und Stabilisierung des Freisinns zwischen 1929 und 1947, Bern: Selbstverlag, 2002. Sur le rôle de Schmid-Ruedin comme opposant aux milieux économiques dans la révision du droit des sociétés, notamment sur la question de la constitution d'un fonds de réserve, voir Lüpold, op. cit., 20IO, p. 596-6Io. Il votera également en faveur de l'initiative de crise en mars I935 (Müller, op. cit., 20IO, p. 589).

18 Cf. par exemple les déclarations du secrétaire de l'ASB, Max Vischer (I888-1975), devant le comité de l'ASB, le ir septembre I93I : «Sogar von der freisinnig-demokratischen Partei wird eine Sparkassengesetzgebung und die gesetzlich Statuierung vermehrter Publizitätsvorschriften postuliert werden. » AASB, Procès-verbaux du Conseil de l'ASB, 84 éance, II.09.I93I, p. I3. 
les grandes banques en raison du double travail qui en résulterait et de l'inquiétude qui naîtrait chez les déposants face à cette "inquisition ", enfin l'approche qu'il préconise, celle d'un meilleur échange d'informations entre les banques et la Banque nationale ${ }^{19}$. Le débat sur les banques de septembre 1931 s'achève par un résultat peu contraignant pour le gouvernement. Tandis qu'il n'est pas donné de suite aux interpellations, les deux postulats sont acceptés et feront l'objet d'un rapport du Conseil fédéral.

En plus de la pression politique institutionnelle au sein de l'Assemblée fédérale, la question du contrôle bancaire devient aussi un sujet de débat médiatique au cours de l'été 193I. Le I9 août 193I, l'économiste socialiste Fritz Marbach publie dans la Berner Tagwacht, l'organe du parti socialiste bernois, une série de revendications sur le thème du contrôle bancaire. Marbach demande notamment une représentation étatique dans les conseils d'administration des banques, l'adhésion des banques à des syndicats de révision, une extension de la transparence comptable, un contrôle des crédits communs, ou encore l'institution d'un office de contrôle des émissions ${ }^{20}$. L'influence directe de l'État dans la gestion des banques a également pour but, selon les vœux socialistes, de pouvoir orienter l'octroi des crédits, par exemple en faveur de la petite clientèle négligée. Il semble qu'une partie de ces revendications soient développées en parallèle à l'étranger. Les syndicats allemands et la Fédération syndicale internationale formeraient alors des recommandations similaires ${ }^{21}$.

La réaction de la Neue Zürcher Zeitung aux propositions socialistes ne se fait pas attendre. Dans un long article à la une de son édition du soir, le grand quotidien, souvent porte-parole du radicalisme et de l'économie zurichois, s'en prend aux postulats socialistes ${ }^{22}$. "Mit Speck fängt man Mäuse " (On n'attrape pas les mouches avec du vinaigre) résume l'article en commentant la volonté de fournir des crédits à des chômeurs ou des ouvriers. Quelques jours plus tard, la $N Z Z$ revient sur la thématique dans un double article au ton moins réprobateur ; le quotidien libéral, tout en fustigeant les tenants du " contrôle bancaire " étatique se risque même à formuler quelques propositions. Il faut améliorer la publicité par la transmission périodique des bilans à la banque centrale. Cette amélioration doit se faire par la voie de l'autorégulation, en établissant des conventions collectives entre banques. «L'État pourrait dans ce cas se limiter à assurer que toutes les informations pertinentes qui proviennent de

Procès-verbaux de l'Assemblée fédérale, Conseil national, séance du 25.09.1931, p. 662-663.

Cité in Bänziger, op. cit., I986, p. 91.

21 Selon le rapport de Kellenberger, les syndicats socialistes allemands (freie Gewerkschaften) devancent leurs homologues suisses en adressant en août I93I au ministère de l'économie des revendications en vue de créer un Bankenamt. Sur la Fédération syndicale internationale, voir Geert van Goethem, The Amsterdam International: the world of the International Federation of Trade Unions (IFTU), I9I3-1945, Aldershot; Burlington: Ashgate, 2006, p. 44-47.

22 [s.a.], «Sozialistische "Bankenkontrolle” ", Neue Zürcher Zeitung, 28.08.1931, Abendausgabe, $n^{\circ} \mathrm{I} 628$. 
l'autocontrôle soient transmises à l'institut monétaire "23, conclut la Neue Zürcher Zeitung. Au fond, le journal zurichois reproduit à quelques nuances près le raisonnement suivi par le Conseil fédéral dans sa séance du 2 septembre 193I. On retrouve le même son de cloche dans le Journal de Genève, le portevoix de la grande bourgeoisie et de la haute banque du bout du lac. Le futur directeur du quotidien, Jean Martin (1879-1962), y condamne ceux qui «sont persuadés que du jour où des fonctionnaires et des politiciens se mêleraient des affaires de banque tout irait pour le mieux dans le meilleur des mondes. [...] Les étatistes cherchent à exploiter la crise actuelle pour faire triompher leur point de vue : c'est la structure même de l'État qu'ils mettent ainsi en danger ${ }^{24}$. La voie à suivre, au contraire, est celle des propositions « sages » et "mûrement pesées " de Jean-Marie Musy: une mission de surveillance confiée à la Banque nationale, exercée par la remise périodique de bilans détaillés.

Quelle est la stratégie de défense du monde bancaire face à cette pression politique et ses répercussions médiatiques? Le constat de départ est relativement clair : tous les banquiers sont opposés à une législation fédérale spécifique à l'activité bancaire. Parmi les raisons évoquées pour justifier ce refus, l'une est exprimée avec une surprenante clairvoyance par Max Brugger (I882-1945), administrateur-délégué de la Banque Commerciale de Bâle:

Nous sommes tous contre une loi bancaire. Une loi sur les banques, pour être efficace, devrait entraîner une ingérence étatique malvenue dans les affaires. Si on n'allait pas aussi loin, la sécurité ne serait pas accrue $^{25}$.

Plus que l'opposition de principe à une législation, qui est récurrente chez les banquiers, l'intérêt de cette prise de position réside dans l'affirmation qu'une ingérence de l'État est nécessaire pour obtenir une régulation bancaire efficace. La tactique à adopter est définie au cours de la séance du Conseil de l'ASB du II septembre 193I. Il faut, dans un premier temps, entrer en négociation avec la Banque nationale pour discuter de la transmission volontaire de renseignements sur la liquidité et sur la qualité des actifs étrangers. Ces négociations s'étendraient certainement sur plusieurs mois. Ainsi, la réponse du Département des finances aux interventions parlementaires pourrait être reportée jusqu'au printemps 1932. C'est dans ce sens que Brugger espère gagner du temps: «Si nous pouvons obtenir par des consultations avec la Banque nationale qu'une décision définitive soit reportée à plus tard, nous avons déjà gagné beaucoup. ${ }^{26}$ Alfred Sarasin, dont la double casquette de membre du Comité de l'ASB et de président du Comité de la BNS en fait un personnage central du processus, rejoint Brugger sur ce point. Remettre ce débat à plus tard 
permettrait un règlement facilité du dossier. Le premier axe de la stratégie des banquiers est donc d'opter pour une tactique dilatoire.

Parallèlement se dessine, dans les discussions internes entre représentants bancaires, une autre dynamique. De premières dissensions surgissent. La position des délégués des grandes banques se distingue de celle des autres groupes de banques (banques cantonales, banques locales, banquiers privés). Les grandes banques sont les premières visées par la transmission des bilans avec la BNS - elles sont d'ailleurs les seules invitées à la première conférence avec la banque centrale de fin août 1931. De plus, il est notoire que la situation de certaines grandes banques est considérablement affectée par les restrictions de transfert sur leurs opérations internationales. À ce titre, elles cherchent d'une part à convaincre les autres groupes bancaires du bien-fondé de la démarche entreprise avec l'institut monétaire. D'autre part, elles tentent d'étendre à tous les groupes bancaires l'application d'une éventuelle convention sur la transmission des bilans. Cette volonté de présenter un front bancaire uni face à l'institut d'émission se heurte à la résistance des banques cantonales. Vexés de ne pas avoir été conviés à la conférence de fin août 193I, les représentants des banques cantonales sont très réservés quant à leur engagement dans la voie d'une convention avec la BNS. Les autres groupes bancaires ne s'impliquent que très peu. L'unique porte-parole des banques locales et régionales dans le Conseil de l'ASB, Robert Suter, est prêt à accepter la remise de bilans détaillés périodiques à la BNS, mais à intervalles moins réguliers (fréquence trimestrielle). Les banquiers privés, quant à eux, se tiennent à l'écart de la discussion, étant donné que leur situation dans l'éventuelle convention n'a pas été tranchée par la Banque nationale. Ces désaccords internes sont confirmés par la transcription, dans le procès-verbal, d'une décision qui n'est pas prise à l'unanimité, ce qui est plutôt rare. En effet, seuls io des 19 membres du comité de l'ASB présents soutiennent la proposition Jöhr visant à annoncer à la BNS la volonté des banques de collaborer à un projet de schéma de bilan à transmettre ${ }^{27}$.

Alors que les élections fédérales du 25 octobre I93I se profilent, la question du contrôle bancaire devient un sujet de campagne pour les socialistes suisses. Lors du congrès national de septembre 1931, le contrôle bancaire figure en bonne place parmi les promesses électorales du Parti socialiste suisse. Parmi les résolutions de la campagne de l'automne 193I, on retrouve certaines des idées avancées dans la Berner Tagwacht par Fritz Marbach. Le PSS exige la transition vers une économie planifiée. Il propose comme modalités le catalogue de mesures suivantes: "la prise d'influence de l'État sur les structures économiques monopolistiques privées et leur contrôle public, la surveillance étatique du capital financier dans l'intérêt de protéger les épargnes du peuple confiées aux banques, l'établissement des caisses postales d'épargne publiques pour assouplir les liens de dépendance de l'État envers la domination et la dictature 
du capital financier $[\ldots]{ }^{28}$. Pour les socialistes suisses, le contrôle bancaire, au même titre que la lutte contre les trusts et les cartels - les deux questions figurants souvent côte à côte - est considéré comme une étape dans l'adaptation de l'économie suisse vers la planification ${ }^{29}$.

Les élections fédérales du 25 octobre I93i se concluent par une remarquable continuité : les forces en présence restent stables. Alors que la députation totale au Conseil national a été réduite de 198 à 187 pour la nouvelle législature, les radicaux passent de 58 à 52 sièges, et poursuivent l'érosion de leur représentation entamée en 1919, mais restent la première force politique du pays ${ }^{30}$. Les catholiques-conservateurs (de 46 à 44 sièges), et les PAB (de 3 I à 30 députés) se maintiennent également. Le Parti socialiste possède désormais, avec 49 sièges au lieu de 50, la deuxième députation à la Chambre du Peuple. Le PSS, selon la répartition des mandats par canton, perd un siège à Berne et en Thurgovie, mais en gagne un à Genève. Le Conseil des États reste très largement dominé par les partis bourgeois, puisque les socialistes, en I93I, ne reprennent que deux des 44 sièges de la Chambre des cantons, contre respectivement I9 et I8 aux radicaux et catholiques-conservateurs. Il s'agit donc d'un résultat en demiteinte pour le PSS, qui espérait obtenir une plus large victoire. Après avoir fait un bilan mitigé du résultat des élections fédérales devant ses camarades de la direction du parti, le président du PSS Ernst Reinhard annonce qu'il faudrait « tenir les promesses » de la campagne et « s'occuper » des questions du contrôle bancaire et des cartels ${ }^{31}$. Son collègue, le vice-président Konrad Ilg (I877-I954) rétorque que quelques banques devraient encore faire faillite avant que la population suisse ne soit "mûre» pour leur étatisation. Ces tergiversations parmi les dirigeants socialistes révèlent le caractère peu abouti des revendications faites au cours de la campagne de l'automne I93I : il n'y a pas d'unanimité sur la suite concrète à donner aux promesses électorales.

La remarquable stabilité qui caractérise les rapports de force politiques issus de la campagne fédérale d'octobre I93I semble aussi avoir exercé une influence sur l'attitude des grandes banques dans le dossier de la transmission de bilans détaillés à la Banque nationale ${ }^{32}$. À la fin du mois de novembre i93i a lieu un revirement de la part des grandes banques, qui surprend les responsables de la banque centrale. Le président du directoire, Gottlieb Bachmann avoue sa

Schweizerisches Sozialarchiv, Protokolle der Geschäftsleitung der Sozialdemokratischen Partei der Schweiz, AR.I.IIo.20 (I93I), "Resolution zu den Nationalratswahlen », [s.d.].

Sur les conceptions de la crise financière au sein du PSS, et les revendications à ce sujet, voir : Oskar Scheiben, Krise und Integration: Wandlungen in den politischen Konzeptionen der Sozialdemokratischen Partei der Schweiz, I928-1936: ein Beitrag zur Reformismusdebatte, Zürich : Chronos-Verlag, I987, p. II8-II9.

30 Ritzmann-Blickenstorfer (éd.), op. cit., 1996, tab. X.6, p. I044; voir aussi Office fédéral de la Statistique (éd.), Atlas politique de la Suisse. Elections au Conseil national (IgII-20II) et votations populaires fédérales (I866-20I2): cartes interactives et données, Neuchâtel, 2012.

1 Schweizerisches Sozialarchiv, Protokolle der Geschäftsleitung der Sozialdemokratischen Partei der Schweiz, AR.I.IIO.20 (I93I), séance du 03.II.I93I, p. I79.

Bänziger, op. cit., I986, p. 93. 
désillusion dans une lettre au conseiller fédéral Musy : « la Banque nationale n’a temporairement plus rien à faire avec cette affaire de bilans ${ }^{33}$. Des mois de négociations et de travail pour établir un schéma de bilan sont réduits à néant, se plaint le président de la Banque nationale. En effet, les représentants du Crédit Suisse, de la Société de Banque Suisse et de la Banque Commerciale de Bâle sont revenus sur leurs engagements et refusent de communiquer à la banque centrale leurs créances étrangères. Ils avancent des difficultés techniques dans la distinction entre actifs suisses et étrangers et une violation du secret bancaire ${ }^{34}$. Introduire une différenciation entre la clientèle étrangère et suisse (classée alphabétiquement) représenterait un surcroît de travail et des frais de gestion superflus. Ce n'est donc pas le principe d'une communication générale des bilans globaux avec la BNS, mais la volonté de fournir des données détaillées sur les engagements par pays, qui pose problème aux grandes banques. Sans ces informations particulières, toute la démarche est inutile pour la banque centrale. Très amer face à ce dénouement décevant, Bachmann relève encore qu'il est très gênant, dans le cadre de négociations avec des partenaires internationaux, en Autriche ou en Hongrie, de devoir apprendre l'ampleur des engagements des banques suisses par la partie adverse, sans pouvoir vérifier les données. Enfin, il émet l'hypothèse que les résultats des élections à l'Assemblée fédérale ont suscité cette réorientation dans l'attitude des grandes banques : la stabilité du rapport de force politique aurait donc renforcé la position des grandes banques dans leurs négociations avec les autorités publiques et monétaires.

L'échec des négociations sur la transmission des bilans détaillés incite la BNS à entreprendre des démarches moins conciliantes à l'égard des banques commerciales. Dans la foulée, le 2 décembre 1931, Ernst Weber (I88I-1967), directeur général de la Banque nationale, écrit à Jean-Marie Musy pour demander, au nom du directoire, l'introduction d'une loi fédérale sur les caisses d'épargne, qui remplacerait les différentes lois cantonales, et assurerait une meilleure protection des épargnants ${ }^{35}$.

Au cours du mois de janvier 1932, les deux dossiers du contrôle bancaire et de la transmission des bilans à la BNS connaissent une évolution singulière. Dans la seconde question, un accord est finalement atteint entre représentants des grandes banques et l'institut d'émission. Cette entente est d'une portée largement réduite par rapport aux discussions de l'automne 193i. De trimestrielle, la transmission de bilans détaillés devient semestrielle et ne concerne plus que les grandes banques. De plus - et c'est là le cœur du problème -, la

33 AFB, E6Ioo(A), I0oo/ı9Io, vol. 4, «Banken-Zwischenbilanzen» (dossier n. 286), lettre de Gottlieb Bachmann à Jean-Marie Musy, 28.II.I93I.

34 Pour une problématisation de la question de l'élaboration de statistiques officielles en Suisse, en particulier sur la balance des paiements: cf. Sébastien Guex, Janick Marina Schaufelbuehl, "Les vertus de l'ignorance. Enjeux et conflits autour des statistiques sociales et économiques en Suisse au XXe siècle», Économies et Sociétés, vol. 44, nº 9, 20II, p. I555I574, p. I56I-I565.

35 ABNS, I.3/I2I2, I3I.2I "Gesetzgebungsverfahren zum Bankengesetz vom 8. Nov. 1934», Lettre d'Ernst Weber à Jean-Marie Musy, O2.I2.193I. 
BNS renonce à exiger la communication d'une annexe au schéma de bilan contenant les chiffres sur les actifs étrangers : «Partant de la considération qu’il est préférable d'obtenir quelque chose plutôt que rien et que le nouveau schéma de bilan permet tout de même un bien meilleur aperçu de la structure des banques que le schéma précédent, l'intervenant [n.d.a. il s'agit de Gottlieb Bachmann] a renoncé à exiger de remplir le formulaire annexe. " ${ }^{36}$ L'arrangement conclu prend donc la forme d'un pis-aller. Les dirigeants de la banque centrale sont pourtant satisfaits sur deux points : d'une part, l'accord n'inclut pas la publication par l'institut monétaire des données recueillies, d'autre part, la transmission des bilans reste une affaire strictement interne entre la Banque nationale et les banques qui n'affecte pas la question du contrôle bancaire et le Département des finances ${ }^{37}$. Il était important pour les banquiers centraux que l'arrangement demeure un accord strictement privé qui n'implique pas de responsabilité vis-à-vis du public: non seulement pour éviter le travestissement des comptabilités si elles étaient destinées à être publiées, mais aussi pour ne pas endosser une responsabilité dans toute cette affaire.

Parallèlement, le dossier du contrôle bancaire, que la Banque nationale cherche à isoler de celui de la transmission des bilans, connaît une avancée. Face à la réticence des grandes banques, Musy "prend en considération ", en janvier 1932, la mise en place d'une loi bancaire ${ }^{38}$. C'est alors qu'intervient la seconde stratégie d'évitement échafaudée par les milieux bancaires, après la tactique dilatoire mise en action par une discussion infructueuse sur la transmission de bilans détaillés. Si une solution législative ne peut plus être contournée par un accord non-contraignant avec la banque centrale, alors elle doit prendre la forme de l'introduction de quelques dispositions particulières dans le Code des obligations. C'est ce qui ressort du rapport de la conférence du I4 janvier 1932 que fournit le procès-verbal du directoire de la BNS :

Tandis que M. le Conseiller fédéral Musy a en vue la création d'une véritable loi sur les banques, une autre opinion tend à ce que les dispositions sur la façon de porter au bilan, la production des comptes, etc. soient simplement étendues dans le Code des obligations ${ }^{39}$.

Cette « autre opinion » est en fait celle des banquiers les plus influents, et en particulier Adolf Jöhr (I878-1953), le directeur général du Crédit Suisse. En effet, moins de dix jours plus tard, Jöhr fait parvenir à Musy un projet de révision du Code des obligations en vue d'un contrôle bancaire ${ }^{40}$. En quoi consiste la solution alternative proposée par le dirigeant de la grande banque

recht ", Entwurf Jöhr, Vorschläge für eine Revision des Obligationenrechts hinsichtlich der

Bankenkontrolle, 24.0I.1932 (9 pages). 
zurichoise ? ${ }^{41}$ La révision de certaines dispositions du droit des sociétés doit viser à renforcer la responsabilité des organes dirigeants des banques. Elle ne concerne que les banques organisées sous la forme de sociétés anonymes, sociétés en commandite ou coopératives; les banques cantonales (de droit public) et les banquiers privés (sociétés individuelles ou collectives) en sont exclus. Jöhr renonce aussi à toute mesure sur la publicité des comptes - qui est réglée par les gentlemen's agreements -, à la réglementation des dépôts d'épargne, ainsi qu'à la mise en place d'un office de surveillance étatique. Selon le directeur général du Crédit Suisse, les immixtions étatiques ont toujours failli à leur tâche. Dans un secteur bancaire qui a besoin de liberté d'action, elles représentent un danger de bureaucratisation ${ }^{42}$. Le cœur du projet réside dans la révision fiduciaire, effectuée par une association de révision ou une société fiduciaire reconnue par le Conseil fédéral - les réviseurs individuels sont exclus, car ils sont plus susceptibles de succomber à la tentation d'être moins rigoureux. Il faut limiter la portée de l'adage «wess' Brot ich ess', dess' Lied ich sing! » (Qui paie les violons, donne le ton), en assurant l'indépendance de la révision. De plus, le rapport de révision doit être communiqué confidentiellement au conseil d'administration, pour renforcer sa responsabilité et éviter l'édulcoration des rapports qui seraient destinés à publication. Jöhr conclut sa description des bienfaits de la révision fiduciaire par une réserve de poids :

Un point qui est souvent source de préoccupation lors des inspections par des contrôleurs extérieurs à la banque est la protection de la confidentialité. Il est donc impératif de déterminer dans la loi les responsabilités à ce sujet. Une sanction de droit pénal contre de telles ruptures de confiance serait urgemment souhaitable, mais ne peut pas être introduite dans le cadre de la révision du Code des obligations ${ }^{43}$.

L'obligation d'ouvrir les livres de comptes à des réviseurs externes représenterait une menace pour le secret bancaire. Face à ce constat, Jöhr appelle de ses vœux des sanctions pénales contre la violation de la discrétion. Mais il est face à un dilemme: des dispositions pénales protégeant le secret bancaire ne peuvent pas être entreprises dans le cadre du droit des sociétés. Or, c'est la voie privilégiée pour obtenir une réglementation moins contraignante. Cette première mention, dans le cadre de l'élaboration de la loi sur les banques de I934, de l'objet qui en deviendra l'élément le plus célèbre, se comprend aussi sous l'angle de la forme législative à privilégier. Du point de vue des banquiers, l'un des rares avantages d'une loi fédérale spécifique aux banques par rapport à une révision du Code des obligations, réside dans la possibilité de renforcer la protection du secret bancaire.

Cf. Bänziger, op. cit., I986, p. I00-IOI.

AFB, E6520(B), 2007/62, vol. 17, dossier n 66 « Bankengesetz und Revision Obligationenrecht », Entwurf Jöhr, Vorschläge für eine Revision des Obligationenrechts hinsichtlich der Bankenkontrolle, 24.0I.1932, p. 4.

Ibid., p. 8. 
Rappelons encore que la stratégie d'évitement des milieux bancaire consistant à favoriser une réglementation minimale dans le droit des sociétés n'est pas nouvelle en 1932. Lors de la discussion du projet Landmann en 19I4, puis dans le cadre de la révision du droit des actionnaires en I92I-1922, l'Association suisse des banquiers avait pris position dans ce sens.

Il devient en outre de plus en plus clair que la Banque nationale suisse, après les désillusions autour de la question de la communication des actifs étrangers des grandes banques, refuserait de jouer un rôle dans une éventuelle surveillance fédérale des banques. Cela ressort très clairement des discussions de janvier 1932 tenues au sein du directoire de la BNS. En la présence exceptionnelle d'Eduard Kellenberger, représentant de l'Administration des finances, les dirigeants de la banque centrale arrivent au constat suivant:

Alors que le représentant du Département des finances exprime l'opinion qu'un certain contrôle est attendu de la part de la Banque nationale, la direction générale [de la BNS] est d'avis qu'elle ne peut en aucun cas assumer la responsabilité, parce que la Banque nationale n'est pas en mesure d'examiner les bilans ou les engagements des banques quant à leur solvabilité ${ }^{44}$.

Une semaine plus tard, alors qu'il est cette fois question de savoir quelle autorité sera chargée de superviser les rapports des sociétés fiduciaires, si ceux-ci révèlent des difficultés, la BNS se distancie à nouveau clairement de toute implication dans le contrôle bancaire. Le choix d'une instance de supervision "pose des difficultés pratiques, puisque ni la banque d'émission ni le Département fédéral des finances ne peuvent ou ne veulent accepter une quelconque responsabilité $»^{45}$.

Ces deux facteurs, à savoir l'élaboration par un banquier influent d'un projet détaillé de révision du Code des obligations et le refus de la Banque nationale de prendre en charge une éventuelle surveillance bancaire organisée dans une loi spéciale, semblent avoir suscité un second revirement au sein du Département des finances. Musy, qui depuis janvier 1932 n'était pas fondamentalement opposé à une loi bancaire, annonce le 8 juin 1932 qu'il poursuit désormais la voie d'une intégration de dispositions sur la révision fiduciaire dans la refonte du Code des obligations ${ }^{46}$. Ce projet rencontre l'opposition du groupe socialiste, qui estime non seulement que la notion de ce que Musy comprend comme "contrôle bancaire" est trop limitée, et qu'une simple révision du Code des obligations ne suffit pas.

Dans le cadre des discussions sur la révision du Code des obligations, en juin 1932, ce revirement ne tarde pas à trouver une manifestation concrète. Ernst Thalmann (I88I-I938), radical bâlois rapporteur de la Commission du Conseil 
des États, qui sera également rapporteur lors de l'élaboration de la loi sur les banques, tente en effet d'intégrer dans l'article 717 amendé du Code des obligations une disposition rendant la révision fiduciaire obligatoire pour les sociétés faisant appel au public pour obtenir des fonds dont le capital-actions est supérieur à 5 millions de francs ${ }^{47}$. Plus précisément, Thalmann reprend mot pour mot une proposition de Max Staehelin (I880-1968), ancien directeur de la Schweizerische Treuhandgesellschaft puis président de la Société de Banque Suisse. Mais la commission du Conseil national supprime les amendements proposés par le banquier bâlois. Le Code des obligations ne servira pas de réglementaion subsidiaire à un contrôle bancaire.

Entre juin et septembre 1932, l'actualité politique dans le domaine bancaire est, nous l'avons vu, monopolisée par la crise de la Banque d'Escompte Suisse et la mise sur pied de la Caisse de prêts de la Confédération. Souvenons-nous qu'en cherchant à obtenir le blanc-seing du Parlement pour la Caisse de prêts, Musy avait quelque peu modifié sa vision des choses sur la forme que devrait prendre le contrôle des banques: «il me paraît très difficile d'insérer dans le Code fédéral des obligations les dispositions que le Département des finances a préparées pour régler le contrôle matériel des banques " ${ }^{48}$.

Il y a au moins trois raisons qui permettent de comprendre la valse-hésitation que mène Musy entre septembre I93I et septembre 1932 sur le choix entre une loi spéciale sur les banques ou l'intégration de dispositions dans le Code des obligations révisé. Ce qui semble avoir fait pencher la balance en faveur d'une loi spéciale réside d'une part dans le renforcement de la pression politique favorable à des mesures plus strictes de surveillance des banques, avec pour contrepartie la mise sur pied d'une Caisse de prêts de la Confédération en juillet 1932. D'autre part, l'élaboration d'une loi fédérale spécifique aux banques serait restée la compétence du Département des finances et des douanes, et donc sous le contrôle de Musy et Kellenberger, tandis que la révision du Code des obligations serait à la charge du Département de justice et police de Heinrich Häberlin (I868-1947). Troisièmement enfin, quelle que soit la forme précise que prendront les dispositions de régulation bancaire, Musy cherche également en septembre 1932 à limiter autant que possible les discussions publiques et politiques sur le contrôle bancaire, pour ne pas déclencher une crise de confiance dans les établissements financiers helvétiques. Il semble donc qu'une combinaison de facteurs politiques internes et de craintes de répercussions externes sur la place financière suisse soit à l'origine des nombreuses pirouettes du ministre des finances fribourgeois.

À l'automne 1932, la position des banquiers reste inchangée. L'association de banquiers ne perd pas espoir de voir la solution d'une révision du Code des

Bulletin officiel de l'Assemblée fédérale, Conseil des États, séance du 22.06.1932, p. 327-328. Cf. Brühlmann, op. cit., I935, p. I2 ; Lüpold, op. cit., 2010, p. 624.

48 Bulletin officiel de l'Assemblée fédérale, Conseil national, séance du 05.07.1932, Jean-Marie Musy, p. 435. 
obligations triompher. Adolf Jöhr, directeur général du Crédit Suisse, résume la stratégie à adopter :

Il faut naturellement chercher à pousser M. Musy à envisager de nouveau la réglementation bancaire par une modification du Code des obligations. Les banques cantonales et les banquiers privés, pour autant que ces derniers ne soient pas organisés sous la forme de sociétés anonymes ou de coopératives, resteraient préservés. Les autres banques n'auraient qu'à se soumettre à une révision fiduciaire, ce que n'importe quelle banque peut supporter ${ }^{49}$.

Les avantages de la voie du droit des sociétés sont exprimés clairement. Elle ne toucherait qu'une partie des établissements financiers, et ce dans une mesure acceptable. Le second aspect de la stratégie est également rappelé par le secrétaire de l'Association suisse des banquiers, Max Vischer (I888-1975) : «En ce qui concerne le "contrôle bancaire" également, nous ferions probablement mieux d'aspirer à un traitement dilatoire de la question. " ${ }^{50}$

Alors que la ligne de conduite des intérêts bancaires - privilégier l'autorégulation par transmission des bilans, l'insertion de dispositions sur la révision fiduciaire dans le Code des obligations, tout cela en temporisant - semble porter ses fruits, la détérioration de la crise bancaire à l'automne 1932 change la donne. La Banque d'Escompte Suisse, malgré le soutien de la Caisse de prêts de la Confédération, ne parvient qu'avec grandes difficultés à maintenir sa capacité de paiement ${ }^{51}$. Une nouvelle réorganisation de l'institut genevois est nécessaire, impliquant une recapitalisation à hauteur de 35 millions, dont 20 millions à la charge de la Confédération. Le projet, ficelé par le Département des finances fin I932, nécessite l'approbation du Parlement. Anticipant l'opposition politique à laquelle se heurtera un nouveau renflouement étatique, après la mise en place mouvementée de la Caisse de prêts en juillet 1932, Musy décide de préparer en parallèle un projet de loi de surveillance des banques. C'est ce qui ressort clairement des procès-verbaux du Conseil fédéral. Le 26 janvier 1933, Musy présente en effet toute l'entreprise à ses collègues de la manière suivante:

Le projet de participation de la Confédération à la reconstitution du capital de la Banque d'escompte par conversion en actions de nos dépôts, à concurrence de 20 millions, sera soumis à l'approbation des Chambres en mars prochain. Simultanément, cette proposition sera accompagnée d'un projet de loi sur le contrôle des banques ${ }^{52}$.

Le collège gouvernemental, malgré quelques réticences, valide l'ensemble du projet. C'est donc sous la pression de devoir obtenir l'approbation des

49 AASB, Procès-verbaux du Conseil de l'ASB, $90^{\mathrm{e}}$ séance, 05.IO.1932, p. 6-7. $\mathrm{n}^{\mathrm{o}}$ II 
députés pour le sauvetage de la Banque d'Escompte Suisse que Musy opère un ultime revirement de stratégie. Le contrôle bancaire ne se fera pas dans le Code des obligations, mais dans une loi fédérale spécifique. Le conseiller fédéral fribourgeois donne à son collaborateur Eduard Kellenberger le mandat de rédiger un premier avant-projet de loi fédérale sur les banques ${ }^{53}$.

\section{III.2. PREMIERS AVANT-PROJETS DE LOI ÉMANANT DU DÉPARTEMENT DES FINANCES, PUIS MISE EN VEILLE (PRINTEMPS 1933)}

Le coup d'envoi de ce qui deviendra effectivement la loi sur les banques du 8 novembre 1934 est donné le 26 janvier 1933, avec la validation des intentions de Musy par le Conseil fédéral. Étant donné que le projet devrait pouvoir être présenté aux Chambres lors de la session de printemps (27 mars au I3 avril I933), en même temps que la recapitalisation de la Banque d'Escompte Suisse, la rédaction des avant-projets progresse rapidement. Deux premiers avant-projets, l'un du I7 février 1933 signé par Eduard Kellenberger, l'autre du I9 février 1933 portant l'inscription manuscrite «Entwurf Jöhr » (projet Jöhr), sont produits en moins d'un mois. Les deux textes, constitués de IO à I5 articles et ne dépassant pas la demi-douzaine de pages, possèdent la même teneur générale ${ }^{54}$.

Ils respectent le programme dressé par Musy et se limitent à quelques dispositions ${ }^{55}$. En voici le contenu: la loi projetée s'applique aux entreprises pratiquant les opérations de banque et de caisse d'épargne en faisant appel au public pour obtenir des fonds. Ce champ d'application assez large inclurait donc en principe et sauf exception les banques cantonales et les banquiers privés. Les banques doivent se soumettre à une révision fiduciaire, exercée par des experts-comptables. Ces derniers, organisés sous forme de sociétés fiduciaires ou de syndicats de révision et indépendants de la banque à contrôler, doivent être reconnus par le Conseil fédéral selon des critères à établir. Les deux projets prévoient également la transmission de bilans bancaires détaillés à destination de la Banque nationale, selon une fréquence qui dépend de la taille des instituts. Les dépôts d'épargne sont protégés par un droit de gage et doivent être couverts par des actifs particulièrement sûrs. Enfin, une certaine régulation de l'exportation des capitaux (emprunts étrangers supérieurs à 5 millions de francs) est également présente.

53 Voir le récit d'Adolf Jöhr, qui met également en relation l'élaboration d'un projet de loi sur les banques avec l'adoption par le Parlement de l'assainissement de la Banque d'Escompte Suisse. AASB, Procès-verbaux du Conseil de l'ASB 93 ${ }^{\mathrm{e}}$ séance, 13.03.1933, p. 2.

54 ABNS, I.3/I2I4, "Vorentwurf. Bundesgesetz über die Beaufsichtigung der Banken und Sparlassen », 17.02.1933, et "Bundesgesetz über die Beaufsichtigung von Banken und Sparkassen (Entwurf Jöhr)», I9.02.1933.

55 D'après la lettre de Jean-Marie Musy au directoire de la BNS datée du 3 février 1933. ABNS, I.3/I2I2. 
Mais il existe aussi certaines divergences entre les deux projets. La version Jöhr inclut par exemple des dispositions sur l'organisation interne des banques, à savoir l'obligation de distinguer clairement la véritable direction du conseil d'administration. Les deux textes different également sur la définition des règles de confidentialité qui doivent faire l'objet de sanctions. Le projet Kellenberger, d'une part, met en place un secret professionnel, mais uniquement pour des communications indiscrètes faites dans le cadre de la révision obligatoire: "Quiconque transmet à des tiers non autorisés des données découvertes dans le cadre de la révision fiduciaire, est puni d'un emprisonnement maximal de quatre mois ou d'une amende maximale de trente mille francs. " ${ }^{56} \mathrm{Chez} \mathrm{Jöhr,} \mathrm{le}$ secret bancaire voit sa portée grandement étendue. «D'une amende de Fr. Ioo.à Fr. 30 ooo.- ou d'un emprisonnement de 6 mois au maximum est puni quiconque, en tant que fonctionnaire ou employé de banque viole le secret bancaire au bénéfice de tiers non autorisés, et quiconque, en tant qu'expertcomptable ou assistant d'untel, transmet à des tiers non autorisés des données découvertes dans le cadre de la révision bancaire. ${ }^{57}$ Dans la version du directeur général du Crédit Suisse, le secret bancaire s'applique non seulement aux réviseurs prévus par la loi, mais également aux employés d'une banque.

À partir de ces deux projets initiaux, une troisième mouture est préparée par le Département des finances, à peine une semaine plus $\operatorname{tard}^{58}$. Cette version, datée du 24 février 1933, privilégie sur presque tous les points de divergences la formulation adoptée par le projet Jöhr. Plus généralement, ce projet $\mathrm{n}^{\circ} 3$ est plus souple sous de nombreux aspects. Par exemple, la révision fiduciaire obligatoire doit, si un inspectorat existe (ce qui est le cas chez les grandes banques), éviter les doublons avec le travail interne. Ce système, comme le note Gottlieb Bachmann dans son rapport sur la question au Comité de banque de la BNS, permettrait aux grandes banques de faire effectuer la révision obligatoire par des sociétés fiduciaires qui leur sont proches ${ }^{59}$. De plus, le bilan minimal à partir duquel un établissement financier est concerné par les mesures sur la transmission de bilans détaillés, ainsi que le montant minimal pour l'entrée en vigueur des dispositions sur l'exportation de capitaux ont été augmentés. Autre modification sur laquelle nous reviendrons, les experts-comptables autorisés à pratiquer la révision bancaire ne sont plus reconnus par le Conseil fédéral, mais par la Banque nationale. Enfin, nous remarquons une nouvelle extension du secret bancaire. Cette fois-ci, non seulement les réviseurs - comme dans le projet Kellenberger -, non seulement les employés de banque - comme dans la version Jöhr -, mais également

56 ABNS, I.3/I2I4, "Vorentwurf. Bundesgesetz über die Beaufsichtigung der Banken und Sparkassen ", art. Io, p. 4.

57 ABNS, I.3/I2I4, "Bundesgesetz über die Beaufsichtigung von Banken und Sparkassen (Entwurf Jöhr)», 19.02.1933, art. IO, p. 5.

58 ABNS, I.3/I2I4, "Vorentwurf des Finanz- und Zolldepartementes vom 24. Februar 1933. Bundesgesetz über die Beaufsichtigung der Banken und Sparkassen».

59 ABNS, Procès-verbaux du Comité de banque de la BNS, oI.03.1933, p. Ioo. 
"quiconque incite ces réviseurs et employés à violer le secret professionnel ou tente d'y inciter $"{ }^{60}$ sera puni par les sanctions pénales prévues. En l'espace d'une semaine et trois projets, ce qui deviendra le fameux article 47 protégeant le secret professionnel des banques a connu trois renforcements progressifs pour aboutir à peu de choses près à la formulation qui sera retenue dans le texte adopté. Le tableau 4 propose une synthèse de l'évolution des projets successifs.

Avant même la constitution d'une première commission d'experts officielle, Musy discute ce projet du 24 février lors d'une petite réunion à laquelle participent Jean-Marie Musy, Eduard Kellenberger (DFFD), un membre du directoire de la BNS, Adolf Jöhr (Crédit Suisse), Armand Dreyfus (directeur général de la Société de Banque Suisse, I875-1942) et Arthur Wolf (Association des banques locales, I884-196I) ${ }^{61}$. Les modifications exigées par ce comité très exclusif seront prises en compte avant le début de la procédure préparlementaire.

La Banque nationale suisse est informée des intentions du Département des finances dès le début du mois de février 1933. Dans une lettre du 3 février 1933 au directoire de la BNS dans laquelle il demande de connaître la position des dirigeants de la banque centrale sur les points essentiels de l'avant-projet de loi bancaire, Musy annonce d'emblée vouloir s'assurer la collaboration du directoire de la BNS dans ce projet. La réaction de la banque centrale face au programme du Département des finances est fort peu enthousiaste.

Tant au sein du directoire que dans le comité de la BNS ${ }^{62}$, les avis sont presque unanimes pour rejeter toute attribution officielle dans la surveillance des banques instituées par la loi. La publication des bilans détaillés qui sont remis à la BNS, par exemple, n'est pas l'affaire de l'institut monétaire ${ }^{63}$. Comme l'explique sans ambages Bachmann, il faut sauvegarder la véracité des bilans transmis confidentiellement à la Banque nationale et éviter que la perspective d'une publication n'incite les banquiers à travestir leurs comptabilités. Autre point de friction, la question de la reconnaissance officielle des sociétés de révision. "La Banque nationale ne peut pas prendre en charge la désignation des organes de révision qu'on lui a attribuée, et ne peut assumer la responsabilité qui y est liée. Une autre instance doit être créée pour cela. ${ }^{64}$

Cet avis est partagé par Alfred Sarasin, président du Comité de la BNS, qui confirme à ses collègues du comité que la banque centrale doit se tenir à l'écart de la nomination et du contrôle de l'activité des fiduciaires: «Ce ne peut pas

60 ABNS, I.3/I2I4, "Vorentwurf des Finanz- und Zolldepartementes vom 24. Februar 1933. Bundesgesetz über die Beaufsichtigung der Banken und Sparkassen", art. II, p. 4-5.

61 ABNS, Procès-verbaux du Comité de banque de la BNS, oı.03.1933, p. 99. Cf. Bänziger, op. cit., 1986, p. I05.

62 Le directoire ou direction générale (Direktorium), composé de 3 membres choisis par le Conseil fédéral, constitue le plus haut pouvoir décisionnel et exécutif de la BNS. Le Comité de banque (Ausschuss) est un organe de 7 membres qui se réunit I-2 fois par mois, et dispose d'importants pouvoirs décisionnels. Cf. Guex, op. cit., 1993, p. 45-58.

63 AFB, E6520(A), I000/ı059, vol. 2, lettre de Gottlieb Bachmann au Département fédéral des finances et des douanes, 20 février 1933.

64 ABNS, Procès-verbaux du Comité de banque de la BNS, OI.03.1933, p. IO2. 


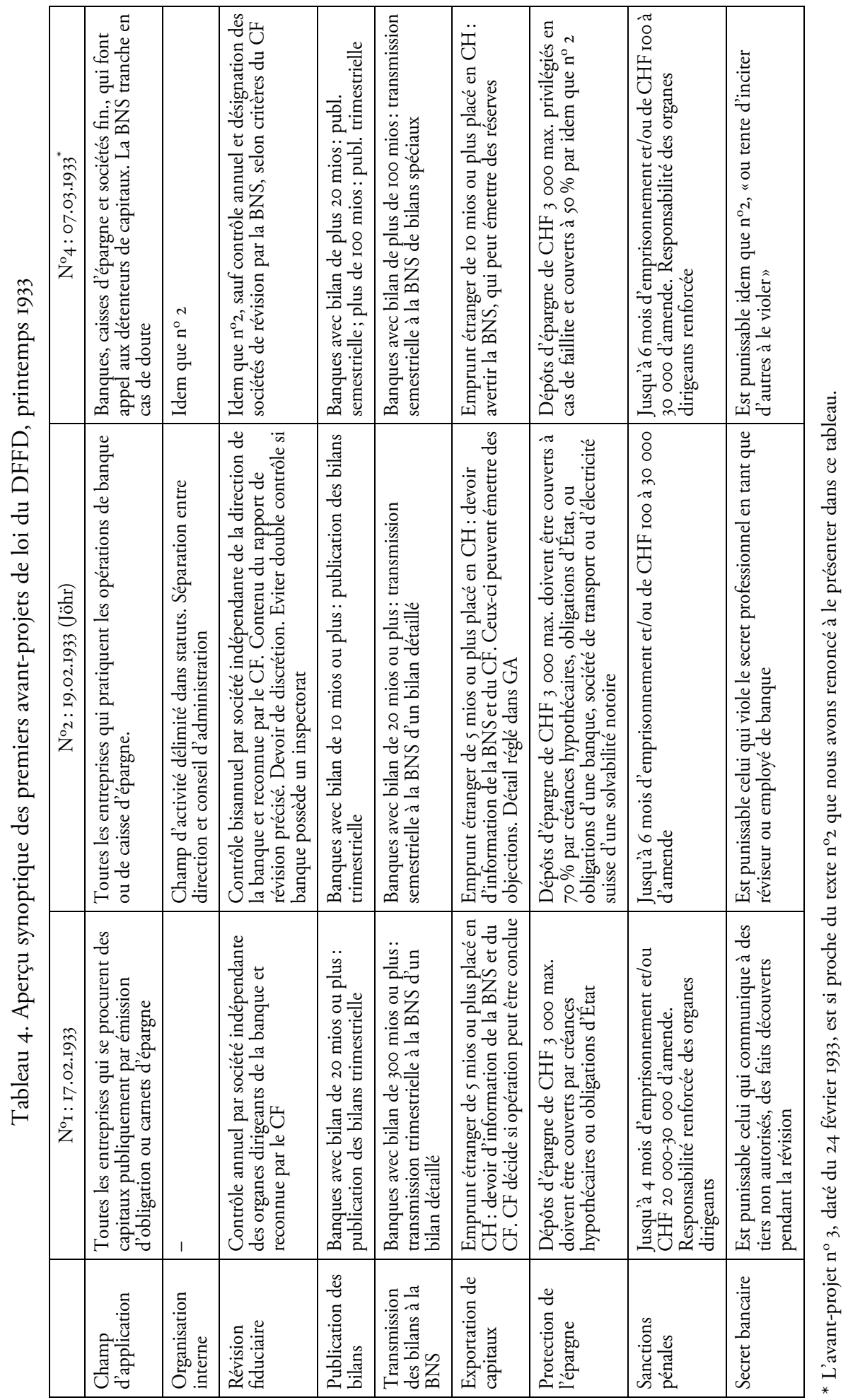


être l'affaire de la Banque nationale de prendre en charge la désignation et la surveillance des sociétés fiduciaires. La Banque nationale recevrait ainsi une tâche pour laquelle elle n'est pas configurée, sans compter la lourde charge que cela constituerait pour la direction générale. " ${ }^{65} \mathrm{~A}$ l'argument de la trop grande responsabilité, Sarasin ajoute la question des attributions de la BNS qui ne correspondent pas à ce rôle et celle de la charge de travail trop importante.

Mais la question demeure de savoir quelle organisation prendra en charge l'admission et la surveillance des réviseurs si une loi sur les banques est mise en place. Dès février 1933, la Banque nationale étudie la question attentivement. En effet, même si elle ne veut pas assumer cette tâche directement, elle ne voit pas d'un bon œil que son pouvoir soit compromis par la mise en place d'une autorité concurrente. "D'autre part, si une telle législation bancaire aboutit, la Banque nationale a toutefois un certain intérêt à ce que ne soit pas créé un organisme de surveillance situé à côté ou au-dessus de la Banque nationale » ${ }^{66}$, avance Bachmann.

Les dirigeants de la Banque nationale ont donc procédé à un rapide examen de l'organisation de la surveillance bancaire en vigueur au niveau international. Les systèmes américain et scandinave sont rejetés, car jugés trop étatiques et ayant obtenu de mauvais résultats pendant la crise. L'agencement italien en vigueur depuis 1926, qui confie la surveillance à un département de la Banca d'Italia, est également repoussé, car il implique une charge officielle pour la banque centrale. Seule l'organisation allemande, incluant la mise en place d'un Bankenkuratorium lié à la Reichsbank, mais suffisamment indépendant, est jugée digne d'être prise en considération ${ }^{67}$. Chronologiquement, c'est donc bien la Banque nationale suisse qui a la première exploré la solution de la mise en place d'une commission spéciale, sur le modèle allemand, en tant qu'alternative à une prise en charge directe par la banque centrale. La stratégie des dirigeants de la BNS dans le cadre de l'élaboration de la loi sur les banques transparaît de manière relativement claire. Il s'agit, d'une part, de rejeter l'attribution de nouvelles responsabilités de surveillance, et ainsi de favoriser la création d'une commission bancaire chargée d'assurer l'application de la loi ${ }^{68}$. D'autre part, la banque centrale entend profiter du cadre législatif pour pérenniser, voire étendre les compétences qu'elle a obtenues jusqu'alors par voie de conventions dans le domaine de l'exportation de capitaux et de la transmission de bilans détaillés.

Du côté de l'Association suisse des banquiers, les plans de bataille sont échafaudés le I3 mars 1933, à la veille de la première réunion de la commission d'experts. En premier lieu, la position de principe des représentants bancaires

65 ABNS, Procès-verbaux du Comité de banque de la BNS, oI.03.1933, p. I03-I04.

66 ABNS, Procès-verbaux du Comité de banque de la BNS, oI.03.I933, p. IO2.

67 Les discussions à ce sujet au sein du Comité BNS du I mars I933 sont confirmées par une lettre de la division de la Justice du DFJP à Eduard Kellenberger (DFFD), 04.03.I933. AFB, E6520(B), 2007/62, vol. 16, Vorarbeiten BR \& SNB I933.

68 ABNS, Procès-verbaux de la Direction générale de la BNS, 09.03.1933, $\mathrm{n}^{\circ} 220$. 
doit être définie: faut-il s'opposer d'entrée au projet de loi fédérale sur les banques ou doit-on plutôt chercher à influencer l'élaboration de la législation? Henri Bersier (1870-194I), directeur de la Banque cantonale vaudoise, estime qu'il faut clairement exprimer le mécontentement face au projet, et à la manière dont il est présenté : « je ne puis approuver le procédé de l'autorité fédérale, qui consiste à vouloir mettre sur pied, avec une précipitation dangereuse, une loi qui, à mon avis, met en cause la question du secret des banques et soulève d'autres points extrêmement délicats » ${ }^{69}$. Staehelin (président de la SBS) et Jöhr (directeur général du Crédit Suisse) défendent au contraire une attitude plus pragmatique. Il serait même dangereux de se braquer dans une opposition de principe, ce qui pourrait renforcer la position des partis qui souhaitent un contrôle bancaire plus «rigoureux». C'est la stratégie qui est finalement retenue. Une autre question difficile à trancher est celle du rythme auquel il convient de faire avancer les discussions au sein de la commission d'experts. D'un côté, Jöhr estime qu'en gagnant du temps, les intérêts bancaires pourraient se retrouver dans un rapport de force plus favorable, d'un autre côté, il faut aussi tenir compte du fait que le dossier est actuellement en mains de Musy, un adversaire du contrôle étatique.

Un second point, de portée bien plus grande, fait débat au sein de l'association faîtière du monde bancaire. Il s'agit de la délicate question du champ d'application de la loi. Quels instituts doivent être soumis à la loi ? C'est en particulier le statut des banquiers privés d'une part et des banques cantonales d'autre part, qui fait débat. Les tensions internes au monde bancaire se ravivent et une certaine difficulté à agréger des opinions divergentes apparait. Les représentants des banques cantonales revendiquent le non-assujettissement à la surveillance fédérale. Il en va pour eux du fédéralisme et de la souveraineté cantonale; étant soumises aux lois cantonales qui les régissent, les banques cantonales n'ont pas besoin d'une réglementation fédérale, dont la constitutionnalité est d'ailleurs remise en question ${ }^{70}$. Cette position autonomiste des banquiers cantonaux avait été préalablement débattue et mise au point au sein de l'Union des banques cantonales suisses. Il existe en effet au sein des banquiers cantonaux des avis divergents quant à la stratégie à adopter pour obtenir un meilleur statut: les jusqu'au-boutistes souhaitent le maintien de la requête de l'exclusion intégrale des banques cantonales, tandis qu'une minorité privilégie l'acceptation d'un assujettissement partiel, compensé par de nombreuses dérogations ${ }^{71}$. Parmi cette minorité, certains représentants considèrent également qu'une exclusion complète des banques cantonales pourrait se retourner contre elles : ne pas être soumis à la loi fédérale serait vu comme une atteinte à

71 AUBCS, Protokolle der Komitee-Sitzungen, 96 ${ }^{\mathrm{e}}$ séance, I2.06.1934, p. 4-6; Protokolle der Kantonalbanken-Konferenzen, $59^{\mathrm{e}}$ séance, 09.06.1934. 
leur réputation et diminuerait la sécurité des déposants ${ }^{72}$. Au sein de l'ASB, les représentants des grandes banques (Hermann Grüebler, UBS, Adolf Jöhr, CS) reprochent aux banques cantonales leur manque de solidarité: «Soit il s'agit d'une loi pour toutes les banques, ou alors cela devient une loi tendancieuse (ein Tendenzgesetz). $»^{73}$ Le différend est tel que la question reste ouverte, en perspective de la séance du lendemain au cours de laquelle les banquiers devront affronter des représentants de l'administration fédérale et des autres associations économiques : la ligne de fracture demeure.

Les discussions au sein de la première commission d'experts s'étendent de mars à mai 1933, au cours de trois séances. La mise en place d'une telle commission est une pratique courante dans le système politique suisse. La croissance de l'organisation commissionaliste au cours de l'entre-deux-guerres, en parallèle à une attribution grandissante de pouvoirs publics aux associations faîtières, est un trait distinctif du système politique suisse ${ }^{74}$. La phase préparlementaire occupe ainsi une place centrale dans le processus décisionnel ${ }^{75}$. Selon la thèse de Leonhard Neidhart, l'existence des outils de démocratie directe aurait favorisé en Suisse l'essor des commissions extra-parlementaires ${ }^{76}$. En incorporant par le biais de ces commissions les positions des intérêts économiques à capacité référendaire, le système politique suisse développe précocement une intégration des points de vue dominants.

La figure I simplifie le processus d'élaboration très riche qui est à l'œuvre dans le cadre de la loi sur les banques. Les travaux de rédaction et d'amendement sont centralisés au Département fédéral des finances et des douanes, la section gouvernementale chargée du dossier. Mais les impulsions initiales (le projet Jöhr) proviennent également en partie des milieux bancaires concernées et fédérés au sein de l'ASB. La banque centrale est également consultée à un stade très précoce d'avancement des travaux. Ces deux instances externes à Ladner, et al. (éd.), Manuel d'administration publique suisse, Lausanne : Presses polytechniques et universitaires romandes, 20I3, p. I6I-I76. Pour un exemple, voir l'analyse de la Commission d'observation conjoncturelle (1932-1947) proposée in : Sophie Pavillon, «Les affinités économiques et le bon usage du diagnostic conjoncturel en Suisse, 1932-1947", Traverse, $\mathrm{n}^{\circ}$ 2, 20OI, p. IIO-I23.

75 Hanspeter Kriesi, Entscheidungsstrukturen und Entscheidungsprozesse in der Schweizer Politik, Frankfurt a.M.; New York: Campus Verlag, 1980; sur le rôle de la phase de consultation préparlementaire dans la faiblesse structurelle du parlement suisse, voir Andrea Pilotti, Entre démocratisation et professionnalisation : le Parlement suisse et ses membres de IوIo à 2016, Zurich, Genève: Seismo Verlag, 2016, p. 93-96.

76 Leonhard Neidhart, Plebiszit und pluralitäre Demokratie. Eine Analyse der Funktion des schweizerischen Gesetzesreferendums, Bern: Francke Verlag, I970. 
Figure I. Schéma du processus d'élaboration de la loi sur les banques

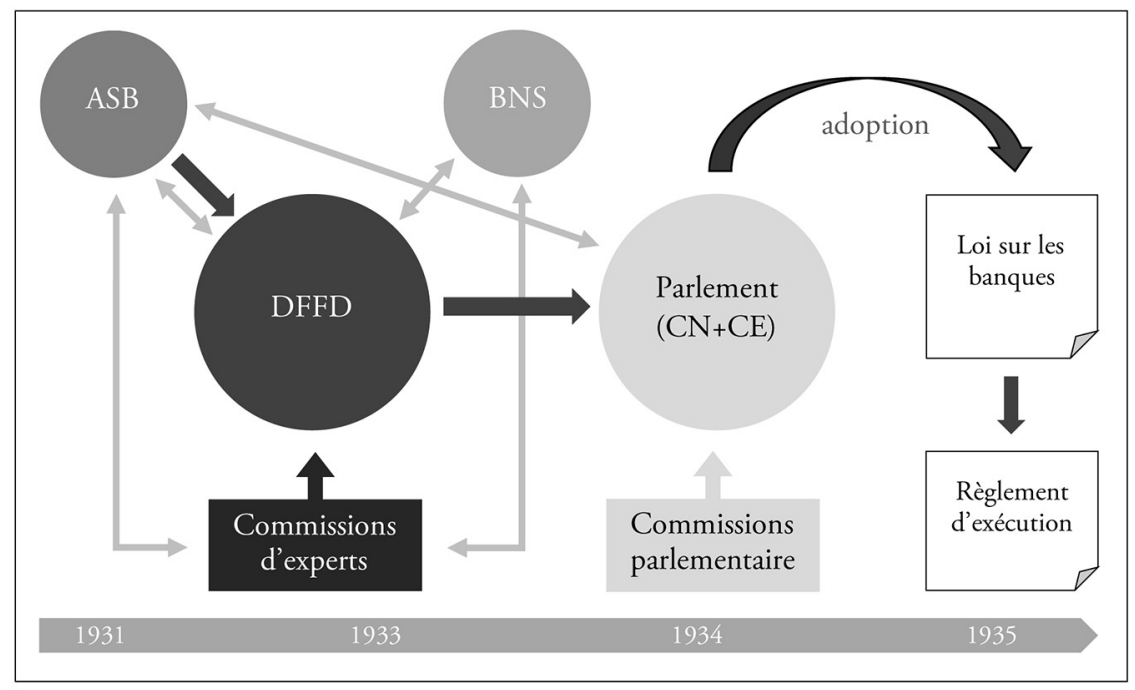

l'administration fédérale - l'ASB et la BNS - fournissent l'essentiel des spécialistes invités par le DFFD dans la commission d'experts qui se réunit pour discuter et modifier les premiers avants-projets (mars-décembre 1933). Ce n'est que dans un deuxième temps, une fois cette phase préparlementaire achevée par l'acceptation d'un projet de loi gouvernemental (janvier 1934) que les députés démocratiquement élus ont accès au débat dans les commissions parlementaires, puis au plénum (janvier-novembre 1934).

La commission d'expert constituée par Musy dans le cadre de l'élaboration de la loi sur les banques s'insère bien dans le cadre conceptuel qui met l'accent sur l'importance de la phase préparlementaire et le rôle qu'elle joue dans l'intégration des préférences des acteurs concernés. Sa composition laisse une place prépondérante aux «experts» représentant les milieux bancaires. En ce sens, Musy ne faisait pas que suivre une pratique propre au système politique : il répondait également aux vœux exprimés de longue date par la corporation des banquiers ${ }^{77}$.

77 Dès 1922, Alfred Sarasin, alors président de l'ASB, avait, lors de l'assemblée générale de l'association faîtière et en présence de Musy, exprimé « le désir que l'on consulte plus souvent des hommes de métier dans les travaux législatifs ». Association Suisse des Banquiers, Procèsverbal de la neuvième Assemblée générale ordinaire du 9 septembre 1922, p. 3. En septembre I932, l'ASB réitère son souhait d'être consulté dans le cas de l'élaboration d'une loi sur les banques. AFB, E6520(B), 2007/62, vol. 16, "Memorandum der Schweizerischen Bankiervereinigung (Herrn Bundesrat Musy überreicht am 23. September 1932)». 
Tableau 5. Composition de la commission d'experts de printemps 1933 (I4 mars, 5 avril, 2 mai)

\begin{tabular}{|c|c|c|c|c|}
\hline Nom & Affiliation économique et/ou politique & $\begin{array}{c}\mathrm{I} 4.03 . \\
\mathrm{I} 933\end{array}$ & $\begin{array}{c}05.04 . \\
1933\end{array}$ & $\begin{array}{c}02.05 . \\
1933\end{array}$ \\
\hline $\begin{array}{l}\text { Jean-Marie Musy (I876- } \\
\text { I952) }\end{array}$ & $\begin{array}{l}\text { Préside la séance. Conseiller fédéral cath.- } \\
\text { conserv. (FR), chef du DFFD }\end{array}$ & $\mathrm{x}$ & & \\
\hline $\begin{array}{l}\text { Dr. Eduard Kellenberger } \\
\text { (1889-1976) }\end{array}$ & $\begin{array}{l}\text { Préside les séances en l'absence de Musy. } \\
\text { Administration fédérale des finances }\end{array}$ & $\mathrm{x}$ & $\mathrm{x}$ & $\mathrm{x}$ \\
\hline $\begin{array}{l}\text { Dr. Emil Alexander } \\
\text { (1889-1964) }\end{array}$ & $\begin{array}{l}\text { Délégué du Département fédéral de justice } \\
\text { et police (Adjoint à la division de Justice) }\end{array}$ & $\mathrm{x}$ & $\mathrm{x}$ & $\mathrm{x}$ \\
\hline $\begin{array}{l}\text { Prof. Gottlieb } \\
\text { Bachmann (I874-1947) }\end{array}$ & Prés. du directoire de la BNS & $\mathrm{x}$ & $\mathrm{x}$ & $\mathrm{x}$ \\
\hline Alfred Aellig (I855-1935) & $\begin{array}{l}\text { Dir. de la Banque cantonale de Berne, } \\
\text { Fédération des experts-comptables de Berne }\end{array}$ & $\mathrm{x}$ & $\mathrm{x}$ & \\
\hline $\begin{array}{l}\text { Dr. Max E. Bodmer } \\
\text { (1888-1953) }\end{array}$ & $\begin{array}{l}\text { Associé de la banque privée Rahn \& } \\
\text { Bodmer (ZH), futur prés. de l'Association } \\
\text { des Banquiers Privés de Suisse. Membre du } \\
\text { CdA du Crédit Foncier Suisse } \\
\text { (Bodenkreditanstalt) }\end{array}$ & & $\mathrm{x}$ & \\
\hline $\begin{array}{l}\text { Dr. Heinrich Däniker } \\
\text { (I883-196I) }\end{array}$ & $\begin{array}{l}\text { Dir. de la Banque cantonale de Zurich, } \\
\text { membre du Comité ASB (Comité } \\
\text { Allemagne). Ancien v-dir. du siège central } \\
\text { du Crédit Suisse (I919-1924). Membre actif } \\
\text { du Parti radical (ZH) }\end{array}$ & $\mathrm{x}$ & $\mathrm{x}$ & $\mathrm{x}$ \\
\hline W. Eichenberger (?-?) & $\begin{array}{l}\text { Anc. dir. de la Banque Populaire Suisse. V- } \\
\text { pdt de l'Association de révision bernoise } \\
\text { (192I-I934) }\end{array}$ & & & $\mathrm{x}$ \\
\hline $\begin{array}{l}\text { Gustave A. Hentsch } \\
\text { (I880-1962) }\end{array}$ & $\begin{array}{l}\text { Associé de la banque privée genevoise } \\
\text { Hentsch \& Cie. Membre du Conseil de } \\
\text { l'ASB (1925-I94I). Pdt de la Société } \\
\text { Financière Italo-Suisse. V-pdt du CdA de } \\
\text { l’Union financière de Genève. Membre du } \\
\text { CdA de la Banque de Genève }\end{array}$ & & $\mathrm{x}$ & \\
\hline $\begin{array}{l}\text { Johann Heuberger } \\
\text { (I890-1950) }\end{array}$ & $\begin{array}{l}\text { Dir. de l'Union des Caisses de Crédit } \\
\text { Mutuel (Raiffeisen), dir. de la Caisse de } \\
\text { prêts de la Confédération }\end{array}$ & $\mathrm{x}$ & $\mathrm{x}$ & $\mathrm{x}$ \\
\hline $\begin{array}{l}\text { Dr. Adolf Jöhr } \\
\text { (I878-1953) }\end{array}$ & $\begin{array}{l}\text { Dir. gén. Crédit Suisse, vice-présid. ASB, } \\
\text { ancien dir. gén. de la BNS (I9I5-19I8), } \\
\text { membre d'une vingtaine de CdA, dont } \\
\text { BBC, Elektrobank, Motor Columbus, } \\
\text { Nestlé }\end{array}$ & $\mathrm{x}$ & $\mathrm{x}$ & $\mathrm{x}$ \\
\hline A. Kern & Dir. de la Banque Coopérative Suisse (SG) & & $\mathrm{x}$ & \\
\hline $\begin{array}{l}\text { Robert La Roche } \\
\text { (I877-1946) }\end{array}$ & $\begin{array}{l}\text { Prés. ASB, associé de la banque privée La } \\
\text { Roche \& Cie }\end{array}$ & $\mathrm{x}$ & & $\mathrm{x}$ \\
\hline $\begin{array}{l}\text { Albert Lombard } \\
\text { (1880-1960) }\end{array}$ & $\begin{array}{l}\text { Vice-prés. ASB, associé de la banque privée } \\
\text { Lombard, Odier \& Cie. V-pdt du CdA de } \\
\text { l'Union financière de Genève }\end{array}$ & $\mathrm{x}$ & & $\mathrm{x}$ \\
\hline $\begin{array}{l}\text { Louis Reymond } \\
\text { (1874-1959) }\end{array}$ & $\begin{array}{l}\text { Dir. Crédit Foncier Vaudois. Député } \\
\text { radical vaudois }\end{array}$ & $\mathrm{x}$ & $\mathrm{x}$ & $\mathrm{x}$ \\
\hline
\end{tabular}




\begin{tabular}{|c|c|c|c|c|}
\hline Nom & Affiliation économique et/ou politique & $\begin{array}{c}\text { I4.03. } \\
\text { I933 }\end{array}$ & $\begin{array}{c}05.04 . \\
1933\end{array}$ & $\begin{array}{c}02.05 \\
1933\end{array}$ \\
\hline $\begin{array}{l}\text { Dr. Max Staehelin } \\
\text { (I880-I96I) }\end{array}$ & $\begin{array}{l}\text { Prés. du CdA de la SBS, membre de l'USCI, } \\
\text { ancien adm. de la Schweizerische } \\
\text { Treuhandgesellschaft AG (BS), membre } \\
\text { d'au moins } 33 \text { CdA dès } 1934\end{array}$ & $\mathrm{x}$ & $\mathrm{x}$ & $\mathrm{x}$ \\
\hline Robert Suter (?-?) & $\begin{array}{l}\text { Prés. du Verband Schweizerischer } \\
\text { Lokalbanken, Spar-und Leihkassen, } \\
\text { membre du CdA de l'ASB }\end{array}$ & $\mathrm{x}$ & $\mathrm{x}$ & $\mathrm{x}$ \\
\hline $\begin{array}{l}\text { Dr. Max Vischer } \\
(\mathrm{I} 888-\mathrm{I} 975)\end{array}$ & Premier Secrétaire de l'ASB (I9I7-I935) & $\mathrm{x}$ & $\mathrm{x}$ & \\
\hline $\begin{array}{l}\text { Bernhard Widmer } \\
\text { (1876-1952) }\end{array}$ & $\begin{array}{l}\text { Conseiller national cath.-conservateur } \\
\text { (1928-1947, ZH), présid. de la Banque } \\
\text { Coopérative Suisse }\end{array}$ & $\mathrm{x}$ & & $\mathrm{x}$ \\
\hline $\begin{array}{l}\text { Rudolf Wittmer } \\
\text { (I878-I965) }\end{array}$ & $\begin{array}{l}\text { Dir. de la Banque cantonale de Bâle. } \\
\text { Membre Comité ASB }\end{array}$ & $\mathrm{x}$ & $x$ & $\mathrm{x}$ \\
\hline $\begin{array}{l}\text { Dr. Arthur Wolf } \\
\text { (I884-I96I) }\end{array}$ & $\begin{array}{l}\text { Verband Schweiz. Lokalbanken, Spar-und } \\
\text { Leihkassen, ZH }\end{array}$ & $\mathrm{x}$ & $\mathrm{x}$ & $\mathrm{x}$ \\
\hline $\begin{array}{l}\text { Dr. Johann Laurenz } \\
\text { Cagianut (I880-I94I) }\end{array}$ & $\begin{array}{l}\text { Président du Schweizer. Baumeisterverband } \\
\text { (Société Suisse des Entrepreneurs), et } \\
\text { membre de la Gewerbekammer. Vice-pdt de } \\
\text { l'Union suisse des arts et métiers }\end{array}$ & $\mathrm{x}$ & $\mathrm{x}$ & $\mathrm{x}$ \\
\hline $\begin{array}{l}\text { Dr. Oskar Howald } \\
\text { (I897-I972) }\end{array}$ & $\begin{array}{l}\text { Sous-directeur de l'Union suisse des paysans } \\
\text { (I929-I939). Privat-docent de politique } \\
\text { agricole à l'ETHZ }\end{array}$ & $\mathrm{x}$ & $\mathrm{x}$ & $\mathrm{x}$ \\
\hline Emile Losey (I892-I974) & Société suisse des commerçants (NE) & $\mathrm{x}$ & $\mathrm{x}$ & $\mathrm{x}$ \\
\hline $\begin{array}{l}\text { Dr. Max Weber } \\
(\mathrm{I} 897-\mathrm{I} 974)\end{array}$ & $\begin{array}{l}\text { Expert économique et collaborateur } \\
\text { scientifique de l'Union syndicale suisse }\end{array}$ & $\mathrm{x}$ & $\mathrm{x}$ & $\mathrm{x}$ \\
\hline $\begin{array}{l}\text { Dr. Ernst Wetter } \\
(1877-1963)\end{array}$ & $\begin{array}{l}\text { Vice-présid. Vorort de l'USCI, conseiller } \\
\text { national radical (ZH), membre de plusieurs } \\
\text { CdA dont Rentenanstalt, AG Leu, } \\
\text { Elektrobank, futur prés. de la CFB (I944- } \\
\text { I950) }\end{array}$ & $\mathrm{x}$ & $\mathrm{x}$ & $\mathrm{x}$ \\
\hline \multicolumn{2}{|l|}{ Total } & 22 & 2I & 20 \\
\hline
\end{tabular}

Sources: ABNS, I.3/1213, Expertenkonferenz protokolle 1933-1934. Renseignements biographiques: DHS, Dodis.ch, Base de données «Les élites suisses au XXe siècle».

Comme le montre le tableau 5 , les banquiers disposent d'une très confortable majorité. Sur une commission forte d'une vingtaine de membres, une douzaine de sièges leur reviennent. L'administration fédérale, la Banque nationale et les principales associations patronales forment l'essentiel des membres restants. En définitive, les forces politiques et sociales qui soutiennent un contrôle bancaire consolidé, à savoir la paysannerie et le mouvement ouvrier, ne sont représentées

78 Sur Johann Laurenz Cagianut, voir Pierre Eichenberger, Mainmise sur l'État social: Mobilisation patronale et caisses de compensation en Suisse (1908-1960), Neuchâtel : Éditions Alphil, 2016, notamment p. 165-167. 
que par deux membres, qui plus est, des représentants de tendance modérée, respectivement Oskar Howald et Max Weber. L'Union syndicale suisse, dans un courrier adressé au Département des finances le 28 avril 1933, ne manque pas de manifester son mécontentement face à cette composition unilatérale, et le caractère décisionnel plutôt que consultatif de la commission :

Les délégués des banques, à quelques exceptions près, se sont déclarés être des adversaires fondamentaux d'une loi sur les banques. Ils sont néanmoins activement impliqués dans les discussions, dans le but, comme cela a été annoncé en toute franchise par un de ces messieurs, de rendre la loi «aussi inoffensive que possible». Comme le président des séances, assez étrangement, ne prend pas seulement connaissance des diverses opinions, à l'attention du département, mais demande de voter sur chaque proposition, le résultat de la conférence d'experts sera ainsi influencé de manière décisive par les opposants de principe d'une telle $\operatorname{loi}^{79}$.

La confrontation entre banquiers et représentants des syndicats et de la paysannerie s'exprime dès le débat d'entrée en matière. Les porte-paroles des grandes banques des banquiers privés et de l'USCI estiment que le projet n'est pas nécessaire et peut susciter de la méfiance à l'étranger. De l'autre côté, le projet est salué par le syndicaliste et le secrétaire de l'USP. Le commissaire de l'Union suisse des arts et métiers va dans le même sens. Les représentants des banques locales et des caisses Raiffeisen, quant à eux, accueillent avec bienveillance l'unification fédérale des différentes lois cantonales sur les caisses d'épargne.

En guise de conclusion du débat d'entrée en matière, le conseiller fédéral Musy tient à rassurer le comité très exclusif formé de banquiers qu'il a réuni, et dévoile la raison essentielle qui l’a conduit à élaborer le projet:

Le projet discuté représente la cristallisation d'un usage très répandu. Il ne constitue pas une création nouvelle, mais il est l'extension d'un système de contrôle qui a déjà fait ses preuves. C'est le passage de l'usage à la loi [...]. M. le Conseiller fédéral Musy observe à nouveau qu'il ne se fait pas d'illusions sur la portée de cette loi, mais il reconnaît qu'elle est nécessaire pour permettre à la Confédération de soutenir efficacement la Banque d'Escompte Suisse ${ }^{80}$.

Afin de surmonter les réticences des milieux bancaires, le ministre des Finances rappelle clairement le rapport de causalité avec le plan d'assainissement de la grande banque genevoise, et insiste sur le caractère inoffensif, voire inefficace, des mesures proposées. 
Quels ont été, sur le fond, les principaux objets de débat au sein de la commission d'experts de printemps 1933? Il faut distinguer quatre points qui font l'objet de vifs débats.

Premièrement, le champ d'application de la loi est âprement négocié. Les banques cantonales, d'une part, réitèrent leur exigence de ne pas être soumises à la loi. Les représentants des grandes banques répliquent que la loi en ellemême est une législation d'exception, et qu'il serait malvenu d'introduire à l'intérieur des statuts spécifiques. Les banquiers privés, pour leur part, réclament également une position particulière dans le cadre de la loi. Il est par exemple inconcevable de publier des comptabilités transparentes, ce qui reviendrait à exposer l'état de fortune des associés d'une maison. Il faut donc trouver un critère permettant de distinguer les banques à part entière, les banquiers privés, et les agents de bourses et gestionnaires de fortune. Face à ces tensions internes au monde bancaire, la position des représentants des associations économiques et de l'administration fédérale est très prudente. On remet à plus tard une prise de décision formelle. Finalement, en mai 1933, Musy avance en des termes encore vagues la direction à suivre: "Le Conseil fédéral proposera de soumettre au régime du contrôle toutes nos banques, cantonales et privées. ${ }^{81}$

Deuxièmement, la limitation de l'exportation des capitaux, présente dès les tout premiers avant-projets de loi, est vivement débattue. L'affrontement a lieu entre les banquiers, partisans d'une simple formalisation des conventions établies avec la Banque nationale, et les représentants des syndicats, de la paysannerie, des commerçants et des arts et métiers, qui exigent un renforcement des dispositions. Les banquiers demandent de ne pas répondre par la loi à une opinion publique nerveuse, manipulée par des revendications démagogiques. Leurs opposants, et en particulier le syndicaliste Weber, demandent une extension de la régulation de l'exportation des capitaux. La limite à partir de laquelle un emprunt étranger doit être annoncé doit être abaissée de Io à 5 millions de francs, les bons du Trésor et avances doivent également être inclus et l'admission de valeurs étrangères dans les bourses suisses doit être restreinte. Enfin, Weber propose la création d'une commission consultative sur l'exportation de capitaux, au sein de laquelle siègeraient les principales associations économiques du pays. La réponse du principal porte-parole des banquiers, Jöhr, est cinglante. En freinant les opérations internationales des banques suisses, on porte atteinte à plus de la moitié des Io ooo employés de banque du pays, ainsi qu'aux perspectives de développement de la place bancaire suisse lorsque la crise sera résorbée. Le débat s'achève sans qu'un vote soit organisé sur les différentes propositions.

Troisièmement, l'étendue de la révision fiduciaire obligatoire fait l'objet de délibérations. Quels sont les pouvoirs des réviseurs et que doivent-ils faire

81 ABNS, I.3/1213, Expertenkonferenz protokolle 1933-1934, Protokoll der Expertenkonferenz zur Begutachtung des Entwurfes zu einem eidgenössischen Bankgesetze, 02.05.1933, p. II. 
lorsqu'une irrégularité est constatée? Pour les banquiers, le devoir de procéder au contrôle de la gestion de la banque (Geschäftsführung) va trop loin. Le travail des fiduciaires doit se limiter à une analyse des données comptables. De même, ils fustigent la possibilité octroyée aux réviseurs de convoquer une assemblée générale des actionnaires; une telle mesure signifierait une grave atteinte à la réputation de l'établissement. Le représentant des banques locales, Robert Suter, relève cependant le caractère très théorique de cette discussion. Selon lui, une telle situation serait fort peu courante: "D'après notre expérience, les réviseurs sont en général plutôt trop laxistes que trop stricts. ${ }^{82}$ De plus, le syndicaliste Weber, soutenu sur ce point par le représentant des commerçants Emile Losey, demande une plus grande indépendance des sociétés fiduciaires à l'égard des banques qu'elles doivent contrôler. Pour Weber, qui essuie en la matière un nouvel échec, le réviseur doit non seulement être indépendant de la direction de la banque, mais plus généralement de la banque elle-même.

Enfin, il s'agit de déterminer quelle autorité sera chargée de mettre en application la loi. Plus précisément, deux dispositions en particulier nécessitent la présence d'une instance décisionnelle: d'une part, pour statuer si oui ou non une entreprise constitue une banque au sens de la loi, d'autre part, pour admettre officiellement une société fiduciaire ou un syndicat de révision en tant qu'institut de révision bancaire. Cette question est très délicate à résoudre pour l'administration fédérale et les banquiers, suite au refus de la Banque nationale d'endosser l'une ou l'autre de ces tâches. Le vide créé par le retrait de la banque centrale est difficile à combler. L'idée d'une commission, composée, selon le modèle allemand, de délégués de l'administration fédérale et de l'institut monétaire, est évoquée ${ }^{83}$. Celle-ci est accueillie avec bienveillance par le directeur général de la BNS Gottlieb Bachmann; ce dernier promet même que la Banque nationale participerait à une telle commission. En revanche, ni les grandes banques, qui y voient l'introduction d'un système de concessions ${ }^{84}$, ni Musy, qui "y verrait le commencement d'un "Bankamt" " ${ }^{85}$, ne sont favorables à la mise en place d'un organe de décision sous la forme d'une commission. Sur ces considérations, la troisième séance de discussions de l'avant-projet de loi s'achève, sans même que tous les articles aient pu être abordés ${ }^{86}$. Il faudra attendre sept mois avant la reprise des travaux.

ABNS, I.3/1213, Expertenkonferenz protokolle 1933-1934, Protokoll der Expertenkonferenz zur Begutachtung des Entwurfes zu einem eidgenössischen Bankgesetze, I4.03.1933, p. 26. ABNS, I.3/1213, Expertenkonferenz protokolle 1933-1934, Protokoll der Expertenkonferenz zur Begutachtung des Entwurfes zu einem eidgenössischen Bankgesetze, 05.04.I933, p. II (Eduard Kellenberger).

Ibid., p. Iо.

ABNS, I.3/1213, Expertenkonferenz protokolle 1933-1934, Protokoll der Expertenkonferenz zur Begutachtung des Entwurfes zu einem eidgenössischen Bankgesetze, 02.05.1933, p. IO.

86 L'article sur la protection pénale du secret bancaire, placé à la fin du texte, n'est ainsi pas discuté dans cette commission d'experts. 
Comment expliquer la mise en veilleuse de l'élaboration de la loi sur les banques entre mai et novembre 1933 ? Trois faisceaux d'explication complémentaires peuvent être avancés. Premièrement, comme le relève Bänziger, l'échec en votation populaire de la "Lex Musy», ce projet de réduction des salaires versés par la Confédération, le 28 mai 1933, implique une modification de l'agenda de travail au Département fédéral des finances ${ }^{87}$. En plus de la campagne qui a précédé le scrutin, Musy et ses collaborateurs sont occupés, dans les semaines qui suivent la votation, par l'élaboration d'un nouveau programme financier - programme qui sera finalement adopté en octobre 1933, soustrait au référendum populaire en ayant recours au droit de nécessité. Deuxièmement, les débats de la commission d'experts lors des trois premières séances ont indiqué que sur de nombreux points cruciaux - comme l'assujettissement des banques cantonales, l'instance d'application et l'étendue de la régulation de l'exportation des capitaux - régnaient encore de profonds désaccords entre les différents acteurs impliqués. Le processus d'élaboration était tombé dans une forme d'impasse difficile à contourner. Au vu de la facilité avec laquelle l'opération est suspendue par le DFFD, on peut se demander si la voie sans issue n'était pas justement le but de l'exercice des quelques réunions du printemps 1933. Troisièmement, il semble que la principale motivation politique qui avait justifié la réunion de la commission d'experts, à savoir d'obtenir l'approbation du Parlement sur la réorganisation financière de la Banque d'Escompte Suisse, n'existait plus. En effet, la participation financière de la Confédération à la banque genevoise ayant été ratifiée par les Chambres le I3 avril I933, on peut supposer que, pour Musy, l'élaboration des avant-projets de loi de contrôle bancaire était devenue moins urgente ${ }^{88}$. Elle l'était certainement aussi pour les influents banquiers qui prenaient part au processus de discussion : ces derniers n'avaient-ils pas suggéré, dans la mise au point interne de leur stratégie, qu'il était préférable de reporter le traitement de cette question à des temps plus calmes ? ${ }^{89}$

Quelles qu'en soient les raisons, la longue interruption des travaux de la commission d'experts suscite des protestations de la part de l'Union syndicale suisse ${ }^{90}$. Pendant l'été, le Département des finances semble même avoir accepté que la démarche piétine, et poursuit de nouveau la réalisation de certains objectifs, comme une stabilisation des taux d'intérêt des bons de caisse et une extension de la limitation de l'exportation de capitaux, par voie de gentlemen's agreement. D'après le récit de Max Weber, au comité fédéral de l’USS, le 30.II.I933. AFB, E6520(B),
2007/62, vol. I6. Protokoll der Sitzung des Bundeskomittees des Schweizerischen Gewerkschaftsbundes, 30.II.I933, p. III3-III4. 


\section{III.3. LA CRISE DE LA BANQUE POPULAIRE SUISSE COMME ÉLÉMENT MOTEUR DE L'ABOUTISSEMENT DE LA LOI SUR LES BANQUES (NOVEMBRE 1933-FÉVRIER 1934)}

L'aggravation des difficultés de la Banque Populaire Suisse, à l'automne 1933, relance l'élaboration du projet de loi sur les banques. Les dirigeants de la grande banque basée à Berne avaient délibérément retardé le déclenchement d'un assainissement financier pour éviter l'ouverture d'un second foyer de crise dans la place bancaire suisse. Fin octobre 1933, le Conseil fédéral donne son accord de principe à une réorganisation de la Banque Populaire Suisse ${ }^{91}$.

Corollairement, les tractations reprennent entre le Département fédéral des finances et la Banque nationale à propos de l'élaboration d'une loi fédérale sur les banques. Entre fin octobre et mi-novembre 1933, la BNS prend position en faveur de trois modifications dans le projet de loi. Elle revendique premièrement la mise en place d'une commission bancaire fédérale. Cette instance hybride, ancêtre de ce qui deviendra la Commission fédérale des banques, est alors un croisement entre la simple commission d'application de la loi sur modèle allemand, déjà évoqué, et la commission consultative sur l'exportation de capitaux proposée par le syndicaliste Max Weber et soutenue par le représentant de l'USP Oskar Howald. Elle réunirait une quinzaine de personnes: membres de l'administration fédérale (DFFD et DFEP), de la Banque nationale, des banques et des associations économiques ${ }^{92}$. Elle fonctionnerait comme comité consultatif et établirait les directives de la politique bancaire, par exemple sur les exigences en matière liquidité et d'exportation de capitaux. Cette commission serait flanquée non seulement d'un comité exécutif (Ausschuss) - sorte de triumvirat formé par les représentants du DFFD, du DFEP et de la BNS, qui agirait comme instance de décision - mais aussi d'un secrétaire permanent. Constatons que la banque centrale, assez habilement, prend appui sur les propositions du mouvement ouvrier et de la paysannerie pour avancer une solution plus modérée, qui possède surtout l'avantage de résoudre l'épineuse question de l'autorité d'application de la loi. En instituant une commission autonome, la banque centrale et l'administration fédérale se déchargent ingénieusement des responsabilités liées à l'application de la loi, qu'elles étaient toutes deux peu enclines à endosser. Les deux autres requêtes exprimées par la banque centrale sont d'une part, de maintenir la protection cantonale des épargnants dans les cantons où elle dépasserait celle prévue par la loi fédérale, d'autre part, de soumettre les banques cantonales à la loi, contre leur gré, éventuellement en ménageant quelques dérogations.

En plus de négociations sur le contenu de l'avant-projet de loi, l'administration fédérale et la banque centrale sont également en pourparlers au sujet

92 AFB, E6520(A), I000/1059, vol. 2, Lettre d'Eduard Kellenberger à Jean-Marie Musy, OI.II.I933. 
d'un collaborateur particulier. En effet, Musy avait demandé dès fin septembre I933 au directoire de la BNS l'autorisation de débaucher Paul Rossy (I8961973), alors directeur et suppléant du deuxième département de la BNS à Berne, en tant qu'expert chargé de l'élaboration de la loi sur les banques ${ }^{93}$. Malgré de fortes réticences chez les dirigeants de la Banque nationale, qui s'offusquent de voir l'État central accaparer ses meilleurs éléments, Musy obtient gain de cause et Rossy entre en fonction au Département des finances le $\mathrm{I}^{\text {er }}$ novembre 1933 .

L'une de ses premières tâches sera d'introduire dans le nouveau projet de loi un certain nombre de renforcements par rapport au texte dont la discussion inachevée s'était enlisée en mai 1933. Trois nouvelles versions sont rédigées par l'équipe Kellenberger-Rossy, en collaboration avec la BNS, portant les dates des 6 , I3 et 25 novembre 1933. Sur sept points au moins, les moutures du projet de loi de novembre contiennent des modifications importantes, par rapport à celle de mars $1933^{94}$.

Premièrement, la délicate question du statut des banques cantonales et des banquiers privés est tranchée dans le sens de leur assujettissement à la loi. Mise à part une dérogation sur l'organisation interne pour les premières et sur la publication des bilans pour les secondes, ces deux types d'instituts ne bénéficient pas de régimes d'exception. Pour les banquiers cantonaux, l'inclusion sous le nouveau régime constitue certes un revers sur la forme, puisqu'ils avaient officiellement demandé d'en être exclus, mais le sort qui leur est réservé dans les nouveaux projets est jugé par eux-mêmes «non défavorable ${ }^{95}$.

Deuxièmement, les limitations de l'exportation de capitaux deviennent plus restrictives. En plus des emprunts, les rescriptions, bons du Trésor et crédits à destination de débiteurs étrangers sont également concernés par le devoir d'information et le droit de réserve de la BNS. La limite minimale à partir de laquelle une telle opération doit faire l'objet d'une consultation fluctue entre 5 et io millions selon les projets successifs.

Troisièmement, les projets de novembre introduisent le principe d'une régulation des taux d'intérêt des obligations de caisse. Ces dernières sont des instruments de financement des banques propres au système bancaire suisse. Il s'agit de titres placés par les banques suisses à des taux variables selon les conditions du marché, à échéance de trois à cinq ans et qui leur permettent d'obtenir à relativement long terme d'importantes liquidités. Du point de vue de l'obligataire, ces titres sont intéressants, car la perception des intérêts est ap. cit., I986, p. II3

95 AUBCS, Protokolle der Komitee-Sitzungen, $93^{\mathrm{e}}$ séance, 22.0I.1934. Ce sont en particulier l'exemption de la révision et la régulation des taux d'intérêt des obligations de caisse qui sont jugées très satisfaisantes. 
simplifiée et le placement dénué de fluctuations ${ }^{96}$. À l'été 1933, le taux d'intérêt de ces obligations à échéance fixe, souvent lié à celui des crédits hypothécaires en raison de l'importance des obligations de caisse dans certaines caisses d'épargne, connaît une forte augmentation, suscitant des protestations chez les paysans et une tentative de convention d'autorégulation ${ }^{97}$. L'intégration de l'article qui contraint les banques à consulter la BNS avant de procéder à une augmentation du taux d'intérêt de leurs obligations de caisse constitue une réponse législative aux pressions politiques formulées pendant l'été $1933^{98}$.

Quatrièmement, de nouveaux principes de régulation prudentielle sont intégrés dans la loi. Il s'agit essentiellement des dispositions sur les fonds propres et la liquidité. Le projet de loi intègre ici l'idée selon laquelle chaque établissement soumis à la loi doit respecter une certaine proportion entre les fonds propres et les engagements d'une part et, entre les actifs facilement mobilisables et les engagements à court terme d'autre part. À ces deux ratios de fonds propres et de liquidité s'ajoute un troisième coefficient à respecter. Il s'agit d'un rapport entre les avoirs placés à l'étranger et la somme du bilan. Ce troisième ratio, qui sera supprimé au cours de la négociation de la loi, aurait permis d'inciter une banque à diminuer ses placements à l'étranger.

Cinquièmement, les dispositions sur la comptabilité bancaire et la transparence du bilan sont renforcées. Les projets de novembre 1933 stipulent ainsi que les banques annoncent dans des rubriques distinctes les avoirs auprès de sociétés qui sont en leur possession ainsi que les intérêts arriérés non amortis (qui ne peuvent plus figurer comme revenus). Elles doivent en outre alimenter un fonds de réserve obligatoire destiné à couvrir des pertes.

Sixièmement, on assiste à la création d'une "commission fédérale de contrôle" (Bankenaufsichtskommission), chargée de l'application de la loi. Le vide laissé par le refus de la BNS et du DFFD de jouer le rôle d'autorité exécutive est ainsi comblé, selon les vœux de la banque centrale. Notons cependant que la composition et les compétences de cette commission de contrôle évoluent encore beaucoup d'un projet à l'autre. Dans le texte du 3 novembre 1933, il est encore question d'une composition purement étatique

Julius Landmann, "L'économie nationale suisse », in Département fédéral de l'Économie publique (éd.), La Suisse économique et sociale, Einsiedeln: Benziger, 1927, p. I-384, p. 318320. Cf. aussi Emilio Albisetti, Daniel Bodmer, Ernst Rutschi, Handbuch des Bank-, Geldund Börsenwesens der Schweiz, Thun: Verlags Aktiengesellschaft, 1964, p. 483.

97 Selon le récit de Gottlieb Bachmann devant le comité de la BNS, le I4 décembre I933. ABNS, Procès-verbaux du comité BNS, I4.I2.1933, p. 397-398.

98 L'influence de cet instrument d'intervention de la BNS est très limitée. Les obligations de caisse perdront en importance durant la seconde moitié du $\mathrm{XX}^{\mathrm{e}}$ siècle, avant que cette compétence ne soit supprimée en 1995 lors de la révision de la loi sur les banques. Guido Boller, "L'abandon des interventions directes sur le marché», in Werner Abegg (éd.), Banque Nationale Suisse 1907-2007, Zurich: Neue Zürcher Zeitung, 2007, p. 318-328. Pour une description sommaire de l'application de cette mesure par la BNS, voir également : Markus Zimmerli, Zinspolitik der Nationalbank mit Hilfe von Artikel Io des Bankengesetzes, Zürich : Schweizerische Nationalbank, I983. 
- sur le modèle allemand du Bankenkuratorium - qui se limite à trois membres, issus du Département des finances, du Département de l'économie publique et de la Banque nationale. Le projet suivant, daté du I3 novembre, évoque simplement une commission de trois à cinq membres, dans laquelle le Département des finances et la BNS seront représentés. Enfin, la version du 25 novembre supprime la mention explicite du DFFD et de la BNS, et indique simplement que les membres devront être experts en matière bancaire. Alors que le projet initial de la BNS envisageait même une commission élargie à une quinzaine de membres incluant les associations économiques, on assiste à une désétatisation progressive de la commission d'application de la loi. Ses compétences sont également progressivement réduites. Dans la variante du 3 novembre, la commission avait un droit de veto sur les opérations d'exportation de capitaux et sur les augmentations du taux d'intérêt des obligations de caisse; elle fixait de plus les exigences en matière de fonds propres et de liquidité. Le projet du 13 et, à plus forte raison, celui du 25 novembre sont plus avares en ce qui concerne les pouvoirs de la commission: elle dispose cependant encore de la compétence de déterminer le ratio d'engagements étrangers et de demander à une banque de changer d'institut de révision. Il y a donc bien un assouplissement graduel à la fois du statut institutionnel et des pouvoirs de la nouvelle instance.

Dernière modification digne d'attention : dans le projet du 25 novembre, les dispositions pénales, qui contiennent la mesure de protection du secret bancaire, subissent une altération aux conséquences importantes. En effet, la violation du secret professionnel est désormais punissable non seulement chez un membre de la commission, d'un institut de révision ou chez un employé de banque, mais tout simplement pour «quiconque». Il y a donc une extension du champ d'application de la protection du secret bancaire.

En plus de ces modifications, Musy décide d'ouvrir la commission d'experts aux partisans politiques d'un contrôle bancaire plus musclé. Ces deux mesures, à savoir le renforcement relatif du projet de loi - avec notamment l'introduction de dispositions sur les taux d'intérêt des obligations de caisse, sur la liquidité et les fonds propres et la création d'une commission chargée de superviser l'application de la loi - et l'élargissement de la commission d'experts, font figure de compensations accordées en échange de l'approbation parlementaire de la prise de participation de la Confédération au capital de la Banque Populaire Suisse en difficultés, décidée le 8 décembre 1933.

La commission d'experts réunie fin novembre 1933 par Musy est rééquilibrée, en atténuant légèrement la confortable majorité dont disposaient les représentants des banques. Alors qu'au printemps 1933, il y avait une douzaine de banquiers sur une vingtaine de commissaires, ils ne sont plus que 17 sur 36 dans la commission de novembre 1933. L'élargissement se fait surtout au profit de sept conseillers nationaux. Il s'agit de quatre députés socialistes, Robert Grimm (BE), Konrad Ilg (BE), Fritz Marbach (BE) et Robert Weber (ZH), et trois $\mathrm{PAB}$, Gottfried Gnägi (BE, également membre du Conseil de banque de 
la BNS), Richard König (BE) et Eduard Pfister (TG). Si l'on ajoute à ces députés les deux représentants de l'USS et de l'USP, la coalition en faveur d'une forte surveillance bancaire compte neuf voix dans la Commission d'experts. Plus de poids est également accordé aux représentants de l'administration fédérale et de la banque centrale. La première dispose de quatre représentants, tandis que la Banque nationale est représentée par le directoire in corpore.

Davantage que sur la composition de la "grande commission d'experts " qui se réunit trois fois, les 28 et 29 novembre 1933 et le I8 janvier 1934, il est essentiel de se pencher sur la formation de la sous-commission ou "petite commission d'experts » qui se réunit à quatre reprises, les 15 , I6, et 20 décembre 1933 et le II janvier 1934. En effet, sous prétexte d'accélérer la discussion du projet de loi pour pouvoir le présenter aux Chambres lors de la session de mars 1934, Musy décide de ne débattre que des principes fondamentaux du projet de réglementation dans la grande commission et de privilégier la discussion détaillée par articles dans une sous-commission.

Tableau 6. Composition de la sous-commission d'experts de décembre 1933 - janvier 1934

\begin{tabular}{|c|c|c|c|c|}
\hline Nom & Affiliation économique et/ou politique & 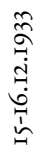 & 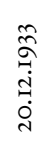 & $\begin{array}{l}\stackrel{+}{2} \\
\stackrel{+}{+} \\
\dot{J}\end{array}$ \\
\hline $\begin{array}{l}\text { Jean-Marie Musy } \\
(1876-1952)\end{array}$ & $\begin{array}{l}\text { Préside les séances. Conseiller fédéral cath.- } \\
\text { conserv. (FR), chef du DFFD }\end{array}$ & $\mathrm{x}$ & $\mathrm{x}$ & $\mathrm{x}$ \\
\hline $\begin{array}{l}\text { Dr. Eduard Kellenberger } \\
\text { (1889-1976) }\end{array}$ & $\begin{array}{l}\text { Dir. suppl. de l'Administration fédérale des } \\
\text { finances }\end{array}$ & $\mathrm{x}$ & & \\
\hline Paul Rossy (1896-1973) & $\begin{array}{l}\text { Expert financier de l'Administration fédérale } \\
\text { des finances }\end{array}$ & $\mathrm{x}$ & $\mathrm{x}$ & $\mathrm{x}$ \\
\hline $\begin{array}{l}\text { Dr. Emil Alexander } \\
\text { (1889-1964) }\end{array}$ & $\begin{array}{l}\text { Délégué du Département fédéral de justice et } \\
\text { police (Adjoint à la division de Justice) }\end{array}$ & $\mathrm{x}$ & $\mathrm{x}$ & $\mathrm{x}$ \\
\hline $\begin{array}{l}\text { Prof. Gottlieb Bachmann } \\
\text { (I874-1947) }\end{array}$ & $\begin{array}{l}\text { Prés. du directoire et chef du I }{ }^{\text {er }} \text { département } \\
\text { de la BNS }\end{array}$ & $\mathrm{x}$ & & $\mathrm{x}$ \\
\hline $\begin{array}{l}\text { Charles Schnyder von } \\
\text { Wartensee (I874-1957) }\end{array}$ & V-pdt et chef du $2^{\mathrm{e}}$ dép. de la BNS & & $\mathrm{x}$ & \\
\hline Ernst Weber (I88I-I967) & $\begin{array}{l}\text { Directeur général, chef du } 3^{\mathrm{e}} \text { département de } \\
\text { la BNS }\end{array}$ & & $\mathrm{x}$ & \\
\hline $\begin{array}{l}\text { Rodolphe de Haller } \\
\text { (I874-1962) }\end{array}$ & $\begin{array}{l}\text { Membre du Conseil de banque de la BNS. V- } \\
\text { pdt de la Banque Commerciale de Bâle. } \\
\text { Ancien v-pdt de la BNS (1907-1920) }\end{array}$ & $\mathrm{x}$ & $\mathrm{x}$ & $\mathrm{x}$ \\
\hline Alfred Aellig (1855-1935) & $\begin{array}{l}\text { Dir. de la Banque cantonale de Berne, } \\
\text { Fédération des experts-comptables de Berne }\end{array}$ & $\mathrm{x}$ & $\mathrm{x}$ & $\mathrm{x}$ \\
\hline
\end{tabular}




\begin{tabular}{|c|c|c|c|c|}
\hline Nom & Affiliation économique et/ou politique & 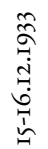 & 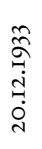 & 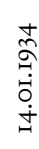 \\
\hline $\begin{array}{l}\text { Dr. Max E. Bodmer } \\
\text { (1888-1953) }\end{array}$ & $\begin{array}{l}\text { Associé de la banque privée Rahn \& Bodmer } \\
\text { (ZH), futur prés. de l'Association des } \\
\text { Banquiers Privés de Suisse. Membre du CdA } \\
\text { du Crédit Foncier Suisse (Bodenkreditanstalt) }\end{array}$ & $\mathrm{x}$ & $\mathrm{x}$ & $\mathrm{x}$ \\
\hline $\begin{array}{l}\text { Johann Heuberger } \\
\text { (1890-1950) }\end{array}$ & $\begin{array}{l}\text { Dir. de l'Union des Caisses de Crédit Mutuel } \\
\text { (Raiffeisen), dir. de la Caisse de prêts de la } \\
\text { Confédération }\end{array}$ & $\mathrm{x}$ & $\mathrm{x}$ & \\
\hline $\begin{array}{l}\text { Dr. Adolf Jöhr } \\
\text { (I878-1953) }\end{array}$ & $\begin{array}{l}\text { Dir. gén. Crédit Suisse, vice-présid. ASB, } \\
\text { ancien dir. gén. de la BNS (I915-1918), } \\
\text { membre d'une vingtaine de CdA, dont BBC, } \\
\text { Elektrobank, Motor Columbus, Nestlé }\end{array}$ & $\mathrm{x}$ & $\mathrm{x}$ & $\mathrm{x}$ \\
\hline $\begin{array}{l}\text { Louis Reymond } \\
\text { (I874-1959) }\end{array}$ & $\begin{array}{l}\text { Dir. Crédit Foncier Vaudois. Député radical } \\
\text { vaudois }\end{array}$ & $\mathrm{x}$ & $\mathrm{x}$ & $\mathrm{x}$ \\
\hline $\begin{array}{l}\text { Dr. Max Staehelin } \\
\text { (I880-I96I) }\end{array}$ & $\begin{array}{l}\text { Prés. du CdA de la SBS, membre de l'USCI, } \\
\text { ancien adm. de la Schweizerische } \\
\text { Treuhandgesellschaft } A G \text { (BS), membre } \\
\text { d'au moins } 33 \text { CdA dès } 1934\end{array}$ & $\mathrm{x}$ & & $\mathrm{x}$ \\
\hline $\begin{array}{l}\text { Rudolf Wittmer } \\
\text { (I878-1965) }\end{array}$ & $\begin{array}{l}\text { Dir. de la Banque cantonale Bâloise. Membre } \\
\text { du Comité ASB }\end{array}$ & $\mathrm{x}$ & $\mathrm{x}$ & $\mathrm{x}$ \\
\hline $\begin{array}{l}\text { Dr. Arthur Wolf } \\
\text { (I884-I96I) }\end{array}$ & $\begin{array}{l}\text { Verband Schweizerischer Lokalbanken, Spar- } \\
\text { und Leihkassen, } \mathrm{ZH}\end{array}$ & $\mathrm{x}$ & $\mathrm{x}$ & $\mathrm{x}$ \\
\hline $\begin{array}{l}\text { Dr. Max Weber } \\
\text { (I897-1974) }\end{array}$ & $\begin{array}{l}\text { Expert économique et collaborateur } \\
\text { scientifique de l'Union syndicale suisse }\end{array}$ & $\mathrm{x}$ & $\mathrm{x}$ & \\
\hline $\begin{array}{l}\text { Gottfried Gnägi } \\
\text { (I878-1939) }\end{array}$ & $\begin{array}{l}\text { Conseiller national (BE/PAB). Membre de } \\
\text { Conseil de banque de la BNS. Membre du } \\
\text { comité de l'Union suisse des paysans }\end{array}$ & $\mathrm{x}$ & & \\
\hline $\begin{array}{l}\text { Robert Grimm } \\
\text { (I88I-I958) }\end{array}$ & Conseiller national (BE/PSS) & $\mathrm{x}$ & $\mathrm{x}$ & $\mathrm{x}$ \\
\hline $\begin{array}{l}\text { Giovanni Polar } \\
\text { (I868-194I) }\end{array}$ & $\begin{array}{l}\text { Conseiller national (TI/PCC). Fondateur de } \\
\text { la Società bancaria ticinese }\end{array}$ & $\mathrm{x}$ & $\mathrm{x}$ & $\mathrm{x}$ \\
\hline \multicolumn{2}{|l|}{ Total } & I8 & 16 & I4 \\
\hline
\end{tabular}

Sources: ABNS, I.3/1213, Expertenkonferenz protokolle 1933-1934. Renseignements biographiques: DHS, Dodis.ch, Base de données «Les élites suisses au XXe siècle».

Malgré l'élargissement de la commission d'experts à des éléments extérieurs au monde bancaire, on constate que, dans la sous-commission également, les représentants des banques disposent toujours d'une majorité et peuvent donc influencer considérablement l'élaboration du texte de loi.

Avant de revenir sur le contenu des débats de la commission d'experts, relevons encore que les deux mesures compensatoires prises par Musy en novembre 1933 - l'intégration de députés socialistes et paysans dans la 
commission et le renforcement du projet de loi -, ont suscité de fortes protestations de la part des banquiers. Alfred Sarasin, banquier privé bâlois et président du Conseil de banque de la BNS, exprime ainsi son mécontentement dans une lettre datée du II novembre 1933 dans laquelle il évoque en des termes peu élogieux les nouveaux articles apparus dans l'avant-projet de loi :

Son contenu va bien au-delà de ce qui avait été prévu jusqu'alors et de ce qui serait sans doute souhaitable. Il ne s'agit pas de déterminer tout ce que l'on peut introduire dans une loi sur les banques, mais de savoir ce qui est nécessaire, pour d'une part donner plus d'influence à la Confédération et à la Banque nationale sur l'activité bancaire, et d'autre part calmer l'opinion publique ${ }^{99}$.

Avant même de déterminer sa tactique future lors de la réunion de son comité, l'Association suisse des banquiers adresse, sous la plume de son secrétaire Max Vischer, une lettre de protestation au Département des finances relative à deux points précis ayant connu un renforcement dans le nouvel avantprojet de loi. D'une part, il s'agit des dispositions sur la réglementation des taux d'intérêt sur les obligations de caisse, dont Vischer exige la suppression. D'autre part, l'ASB s'attaque aux compétences octroyées à l'État par l'instauration d'une commission de surveillance. Pour Vischer, il suffit de prévoir une instance, à savoir le Département des finances éventuellement en collaboration avec la BNS, qui assure l'application de la loi, de manière plus ou moins passive.

Il serait à mon avis dangereux de transférer à une commission de surveillance particulière la mise en application des dispositions légales qui revient au Conseil fédéral ; car une surveillance étatique, qui entrânerait un affaiblissement de la responsabilité des organes de la banque et une responsabilité intenable de l'État, doit justement être évitée ${ }^{100}$.

Pour l'ASB, il faut donc supprimer la commission de surveillance prévue dans le nouveau projet, ou alors au moins éliminer ses compétences les plus interventionnistes, à savoir celle de contrôler la proportion entre placements à l'étranger et bilan, celle d'ordonner une révision extraordinaire et celle d'exiger en tout temps un rapport de révision à un institut de révision.

Lors de la réunion suivante du comité de l'ASB, le compte rendu de Jöhr sur l'avancement de l'élaboration de la loi est emprunt des mêmes sentiments généraux. Le projet de loi a connu des "renforcements regrettables» ${ }^{101}$. Le directeur général du Crédit Suisse annonce alors ce qui doit être l'objectif principal des représentants des banques:

99 AFB, E6520(A), I000/I059, vol. 2, correspondance avec la BNS, lettre d'Alfred Sarasin au DFFD, II.II.I933.

100 AFB, E6520(A), I000/I059, vol. 2, lettre de Max Vischer (ASB) à Jean-Marie Musy (DFFD), O2.I2.I933.

101 AASB, Procès-verbaux du Conseil de l'ASB, 98 ééance, 05.0I.1934, p. 7. 
Il convient de faire en sorte qu'une législation qui ne peut plus être évitée soit conçue de manière aussi raisonnable que possible, et d'éviter, si possible, que l'État interfère dans la gestion des banques sous la forme d'une commission fédérale. Si l'on parvient, lors des dernières consultations, à supprimer du projet encore certaines dispositions qui vont trop loin, la loi ne se révélera pas trop mauvaise à mon avis ${ }^{102}$.

Même s'il regrette certaines des modifications intervenues dans le projet à la suite de la prise de participations de la Confédération à la Banque Populaire Suisse, Jöhr tente ici de former un consensus au sein du monde bancaire pour accepter une loi bancaire dans sa version la plus modérée. Il est vrai qu'en consultant la très riche correspondance reçue par le Département des finances relative au projet de loi, au cours des mois de novembre 1933 à janvier I934, on se rend compte de la grande diversité des opinions parmi les milieux intéressés.

En anticipant sur la procédure de consultation officielle (Vernehmlassungsverfahren), de nombreux banquiers soumettent des propositions de modifications de certains articles précis. On constate ici aussi que la formation de commission d'experts, essentiellement composée de représentants de la branche faisant l'objet de la législation, octroie aux initiés une longueur d'avance dans le marchandage politique. L'accès privilégié aux avant-projets préparés par l'administration fédérale donne à ces acteurs une capacité d'influence décisive, à un stade de l'élaboration encore peu avancé. Les archives consultées regorgent ainsi de lettres et de commentaires sur les articles de loi transmis au Département des finances ${ }^{103}$. Sans entrer dans les détails, retenons pour l'instant que l'objectif principal de ces démarches est d'obtenir, sur des points souvent très précis, une modification des dispositions permettant de sauvegarder les intérêts particuliers de leurs auteurs. Ces courriers sont aussi un indicateur de la forte hétérogénéité du tissu bancaire suisse, et de la difficulté pour l'Association suisse des banquiers d'incorporer en son sein les différentes catégories de banques et de s'en faire l'unique porte-parole ${ }^{104}$.

102 Ibid.

103 Alfred Sarasin (is novembre, I décembre), Jean Lombard (2 décembre), Revisionsverband bernischer Banken und Sparkassen (2 décembre), l'Association Suisse des Employés de Banque (4 décembre), Edmund Albert Barth et Hermann Korrodi (Bank für elektrische Unternehmungen, 5 décembre), Adolf Jöhr (26 décembre), Stellungnahme der PrivatBanquiers (28 décembre), Paul Jaberg (UBS, 9 janvier). AFB, E6520(A), I000/I059, vol. 2, correspondance. ABNS, I.3/1213.

104 Sur l'ASB, voir les récents travaux de Sébastien Guex et Malik Mazbouri : Guex, Mazbouri, art. cit., in Fraboulet, Vernus (éd.), op. cit., 2012 ; Sébastien Guex, Malik Mazbouri, "Une grande association patronale dans la sphère publique : l'exemple de l'Association suisse des banquiers (de I9I2 à nos jours)", in Danièle Fraboulet, Clotilde Druelle-Korn, Pierre Vernus (éd.), Les organisations patronales et la sphère publique, Rennes: Presses Universitaires de Rennes, 20I3, p. 205-235; Sébastien Guex, Malik Mazbouri, «L'Association suisse des banquiers, les relations entre patronat et salariat bancaires au début du XXe siècle et leur postérité ", in Danièle Fraboulet, Cédric Humair, Pierre Vernus (éd.), Coopérer, négocier, s'affronter. Les organisations patronales et leurs relations avec les autres organisations collectives, Rennes: Presses Universitaires de Rennes, 20I4, p. 83-99; Guex, Mazbouri, art. cit., in Fraboulet, Margairaz, Vernus (éd.), op. cit., 2016. 
En effet, malgré les efforts d'organisation et d'agrégation de l'association faitière, de nombreux points de frictions internes au monde bancaire subsistent. Adolf Jöhr, le directeur du Crédit Suisse qui s'établit en tant qu'intermédiaire principal des banques auprès de l'administration fédérale, déplore ce manque de cohérence des banquiers, ces "tiraillements malencontreux", au sein de la commission d'experts: "Malheureusement les banques ne s'entendent pas entre elles sur certains points au sein de la commission d'experts. Il serait très souhaitable que les représentants bancaires puissent se mettre d'accord entre eux. " ${ }^{105}$ À quoi fait-il référence en particulier? Voici deux exemples de mesures au sujet desquelles existe une véritable opposition entre banquiers. En insistant sur ces points de désaccord, notre analyse de l'élaboration de la loi sur les banques s'éloigne du récit généralement prédominant, qui envisage la régulation sous l'angle d'une opposition uniquement entre des sphères publique et privée homogènes et clairement distinctes l'une de l'autre.

Il y a tout d'abord la question de la régulation des taux d'intérêt des obligations de caisse, une des nouvelles mesures introduites dans le projet de loi renforcé de novembre 1933. Les grandes banques tentent vainement de s'y opposer, car ce sont sans doute elles les premières visées par la mesure, étant donné le plus fort impact de la détermination du taux de leurs obligations de caisse sur le marché de capitaux. Alors qu'elles réclament la suppression de l'article incriminé, les représentants des banques cantonales et des banques locales souhaitent au contraire son renforcement qui prévoirait des sanctions si la disposition était enfreinte ${ }^{106}$. Jöhr suggère de régler cette question par voie de convention entre les banques et la banque centrale, argument auquel Rudolf Wittmer, le directeur de la Banque cantonale de Bâle, rétorque qu'un accord avait déjà été établi, mais n'avait pas été respecté ${ }^{107}$. Une majorité de la petite commission d'experts se rallie à l'avis des banquiers cantonaux et locaux en se prononçant en faveur du maintien de l'article. Dans un rapport interne destiné au DFEP d'Edmund Schulthess, l'antagonisme est dévoilé encore plus clairement: "les banques cantonales et les banques locales tiennent à cette disposition [l'obligation d'annoncer une augmentation du taux d'intérêt des obligations de caisses à la BNS] pour se protéger contre les grandes banques ${ }^{108}$. En juillet 1934, ces mesures législatives sont présentées lors de l'assemblée générale de l'Union des banques cantonales suisses comme "une impulsion de nos milieux", et une réponse à l'inefficacité des conventions volontaires interbancaires pour stabiliser ce taux d'intérêt ${ }^{109}$. Ce contentieux interne au monde bancaire est une illustration caractéristique de l'utilisation d'un processus de régulation législatif par l'État pour régler des rapports de

105 AASB, Procès-verbaux du Conseil de l'ASB, 98 séance, 05.0I.1934, p. 7.

106 Cf. ABNS, I.3/1213, Protokoll der 4. Sitzung der Expertenkonferenz, 28.II.I933, p. 25.

107 Cf. ABNS, I.3/1213, Protokoll der I. Sitzung der Subkommission, I5.12.1933, p. 33-40.

108 AFB, E6520(B), 2007/62, vol. I6, "Réponse du Département fédéral des Finances et des Douanes aux remarques de M. le Conseiller fédéral Schulthess ", 29.0I.1934.

109 AUBCS, Protokolle der 29. ordentlichen Generalversammlung, 07.07.1934, p. 5. 
concurrence entre acteurs privés. Il se situe en outre dans la continuité de l'opposition entre banques cantonales et banquiers privés qui apparaît en I9I6I9I7 autour d'une éventuelle soumission des obligations de caisse émises par les banques à la convention de l'ASB qui établit un tarif uniforme pour la garde et la gestion de titres ${ }^{110}$.

Second exemple: l'épineuse question du champ d'application de la loi fait débat au sein des milieux bancaires. Quel critère faut-il choisir pour définir ce qu'est une banque au sens de la loi ? Max E. Bodmer, banquier privé zurichois, revient à la charge en essayant d'obtenir une dérogation générale pour les banquiers privés qui les libérerait de tout assujettissement à la loi. Il n'est pas suivi par la majorité des experts. On préfere alors, pour déterminer quelles sociétés doivent être soumises à la loi, adopter le critère suivant : « faire appel au public pour recueillir des dépôts de fonds ». Les banquiers privés, de même que les sociétés financières qui renoncent à faire appel au crédit public, peuvent ainsi bénéficier de quelques exceptions. Toujours est-il que les banquiers privés, dans leurs demandes de régimes d'exception, ne rencontrent pas systématiquement un accueil favorable auprès de leurs collègues représentants d'autres banques. Ainsi, dans son courrier adressé au DFFD contenant de nombreuses remarques au sujet du projet de loi, Adolf Jöhr n'est pas tendre avec les banquiers privés. Il suggère ainsi de supprimer un alinéa permettant aux banquiers privés de ne pas être soumis aux mêmes exigences en matière de fonds propres. Jöhr ajoute: "Je sais bien que Dr. Bodmer exige toutes les exceptions possibles en faveur de cette guilde d'intérêts [les banquiers privés], mais est-ce vraiment justifié sur ce point? J'en doute. ${ }^{111}$ Lors de la séance suivante de la petite commission d'experts, l'opposition entre Bodmer et Jöhr se poursuit. Le directeur du Crédit Suisse propose ainsi de préciser dans un sens restrictif la disposition qui permet aux banquiers privés de ne pas publier leurs bilans ${ }^{112}$. Il propose d'intégrer le critère d'appel au public au lieu du critère de la forme juridique (société en nom collectif ou individuel), ce qui, de fait, oblige de nombreux banquiers privés à publier leurs bilans comme n'importe quelle autre banque. La négociation se termine alors avec les regrets de Max E. Bodmer, qui demande amèrement que le procès-verbal prenne note de son opposition aux changements obtenus par Jöhr. Un peu plus tard, en septembre I934, ce même Jöhr critique à nouveau au sein de l'ASB le manque de discipline dont font preuve certains membres de la corporation, qui font parvenir au Département diverses pétitions contenant des requêtes qu'il juge déloyales ${ }^{113}$.

En revanche, lorsqu' ils présentent un front uni, les banquiers parviennent à obtenir des modifications de portée relativement importante. Pour aller à l'essentiel, notons qu'un certain nombre des renforcements apportés par le

110 Cf. Guex, Mazbouri, art. cit., in Fraboulet, Margairaz, Vernus (éd.), op. cit., 2016, p. 245247.

111 AFB, E6520(A), I000/ı059, vol. 2, lettre d'Adolf Jöhr à Paul Rossy, 26.I2.1933.

112 ABNS, I.3/I213, Protokoll der 4. Sitzung der Subkommission, II.oI.I934, p. IO-II.

113 AASB, Procès-verbaux du Conseil de l'ASB, IO2 ${ }^{\mathrm{e}}$ séance, 07.09.1934, p. 5. 
projet de novembre 1933 sont supprimés, ou du moins affaiblis, par les demandes homogènes des représentants des banques. Ainsi, le ratio qui demandait que les banques maintiennent un rapport équilibré entre les placements à l'étranger et leur bilan est progressivement évacué du projet de loi. Alors que cette disposition constituait un article à part entière, au même titre que le ratio de liquidité, les banquiers obtiennent, par une faible majorité, qu'elle soit transférée en un alinéa de l'article qui précise le contenu du rapport de révision. De même, les exigences sur la façon de comptabiliser les intérêts arriérés et les avoirs des sociétés filiales des banques sont atténuées.

En plus de ce «roll-back» sur un certain nombre de mesures, les banquiers parviennent sans peine à repousser toutes les demandes de renforcement supplémentaires avancées par les représentants du mouvement ouvrier et des paysans. Un système de concession, revendiqué par les socialistes, qui aurait permis à l'instance de contrôle d'empêcher l'ouverture d'une banque non désirée, est rejeté, au profit du système de l'autorisation (Bewilligung), qui fait dépendre une nouvelle fondation uniquement de critères formels. Les efforts conjugués de Jöhr, soutenus en ce sens par Musy, sont symptomatiques de cette mainmise des cercles bancaires sur le déroulement des travaux de la commission d'experts. Ils conduisent à la modification du titre du projet de loi et de la dénomination de l'instance d'application prévue. Alors que la question de la régulation bancaire apparaissait encore à maintes reprises sous le titre "contrôle bancaire" jusqu'en I933, l'expression «loi sur la surveillance des banques" prend le dessus tout au long de l'année 1933. Puis, incidemment, au cours de la réunion d'experts du II janvier 1934, Jöhr suggère de renommer la loi plus simplement: «Bundesgesetz über die Banken und Sparkassen. »"14 Le terme de surveillance (Beaufsichtigung) est évacué. La désignation de l'organe d'exécution subit le même sort. Tandis que les projets de novembre 1933 évoquent encore une Commission de surveillance des banques (Bankenaufsichtskommission), Jöhr regrette la prolixité et la connotation policière de l'expression et propose de la renommer Commission fédérale des banques (Eidgenössische Bankenkommission) ${ }^{115}$. Le glissement sémantique discrètement opéré à la fois dans l'intitulé de la loi et de sa principale émanation permet d'altérer la portée et le sens donnés au texte législatif. Ce dernier n'est pas considéré comme un vote de défiance à l'égard du monde bancaire, qu'il s'agirait d'avoir attentivement à l'œil, mais comme une simple législation commerciale ayant pour objet le domaine bancaire.

Le bilan de cette demi-douzaine de séances de la commission d'experts chargée d'élaborer la loi sur les banques reste largement positif pour les milieux bancaires. Lorsqu'ils se présentent en rang serré, ils réussissent à empêcher tout renforcement du projet de loi allant à l'encontre de leurs intérêts généraux et donc à limiter l'impact du durcissement du projet de novembre 1933. En

114 ABNS, I.3/I213, Protokoll der 4. Sitzung der Subkommission, II.OI.I934, p. I2.

115 ABNS, I.3/I213, Protokoll der I. Sitzung der Subkommission, I5.I2.1933, p. 3. 
revanche, du moment que subsistent des lignes de fraction internes au monde bancaire, le rapport de force se déplace au sein de la commission d'experts. La coalition très hétérogène de l'administration fédérale, de la banque centrale et des quelques représentants de la politique et de l'économie parvient à prendre le dessus. Dans ces cas de dissensions interbancaires, il faut relever que la balance penche le plus souvent en faveur des grandes banques et au détriment des banquiers privés, dont la capacité d'influence semble inférieure.

Du côté du mouvement ouvrier, soulignons également le grand écart réalisé par les représentants de la social-démocratie au sein de la commission d'experts. Ils y font preuve d'une attitude très pragmatique, en réduisant leurs propositions d'amendements au strict minimum. Sur la question de l'exportation des capitaux par exemple, le ton de Robert Grimm est sans rapport avec celui qu'il avait adopté en 1926 devant le plénum du Conseil national, lorsqu'il parlait encore de trahison nationale ${ }^{116}$. Dans la commission d'experts, il s'agit pour les syndicalistes et les socialistes d'obtenir le soutien des représentants de l'Administration des finances ou de la Banque nationale. Ainsi Robert Grimm déclaret-il: «Nous ne devons pas entraver l'exportation de capitaux, mais seulement la réglementer. ${ }^{117} \mathrm{La}$ tactique du Bernois semble porter ses fruits sur certains points. Il parvient notamment à faire passer provisoirement la possibilité de constituer une commission consultative dans laquelle seraient représentés les milieux économiques pour établir certains principes dans l'application des mesures de limitations de l'exportation de capitaux par la BNS ${ }^{118}$. En dépit de ces maigres résultats, on remarque avant tout la distance qui sépare les positions très modérées défendues par les socialistes dans la commission d'experts et les revendications programmatiques adoptées parallèlement par la direction du parti. En effet, quelques jours avant le début des travaux de la commission d'experts, le 26 novembre 1933, la direction du PSS avait décidé d'adopter les exigences suivantes:

Il faut établir un contrôle bancaire grâce à une loi sur les banques, qui réponde à toutes les demandes du peuple travailleur. L'exportation de capitaux doit être organisée seulement selon les exigences de la création d'emplois. La publicité des banques doit être renforcée. L'organisme de contrôle doit assurer que les ouvriers, les paysans, les artisans et les employés puissent exercer une influence significative. Les travaux préparatoires pour une étatisation des banques et du système de crédit doivent être entrepris immédiatement ${ }^{119}$.

116 Procès-verbaux de l'Assemblée fédérale, Conseil national, 1926, vol. 27, $\mathrm{n}^{\circ}$ 6, $18^{\mathrm{e}}$ séance, 22.12.1926, p. 379-380.

117 ABNS, I.3/I213, Protokoll der 2. Sitzung der Subkommission, I6.I2.1933, p. 28.

118 Après de nombreux revirements, et malgré le scepticisme de Musy et les protestations de Jöhr contre cette "Misstrauenskommission" sur l'exportation de capitaux, le Conseil fédéral décide de maintenir l'éventualité de la commission consultative proposée par Robert Grimm.

119 Schweizerisches Sozialarchiv, Protokolle der Geschäftsleitung der Sozialdemokratischen Partei der Schweiz, Ar.I.IIO.22 (1933), 25.II.I933, Beschluss des Parteivorstandes. 
Au moment d'entrer en négociations concrètes, les principaux porte-paroles de la gauche politique - Robert Grimm et Max Weber - mettent de côté ces revendications générales au profit d'une stratégie des petits pas, consistant à réduire considérablement la portée de leurs exigences. Rappelons que l'aboutissement imminent d'une législation fédérale réglementant le domaine bancaire constituait en tant que tel une victoire pour les représentants de la social-démocratie. C'est dans ce sens qu'il faut comprendre leur volonté d'accélérer les discussions en commissions : dans leur esprit, la crainte de voir le projet tomber aux oubliettes de l'administration fédérale est encore bien présente.

La finalisation du projet de loi par le Conseil fédéral, décidée entre le 26 janvier et le 2 février 1934, marque l'achèvement de la phase préparlementaire. Dans un rapport de I2 pages, le Conseiller fédéral en charge du Département de l'économie publique, Edmund Schulthess, tente d'apporter une série de modifications au texte avant de le transmettre aux chambres ${ }^{120}$. Étant donné la position centrale qu'occupera Schulthess dans l'application de la loi en tant que premier président de la future Commission fédérale des banques, il est très intéressant de connaitre son avis sur les lacunes du projet. Parmi le catalogue de mesures préconisées, on trouve l'interdiction de la forme juridique de la société individuelle, collective ou en commandite - propres aux banquiers privés - et celle de la société coopérative, l'introduction d'un système de concessions, le non-assujettissement de certaines sociétés financières et enfin la suppression des dispositions sur les taux d'intérêt des obligations de caisse.

En outre, ce qui constitue une situation cocasse pour l'historien qui connaît la destinée future d'Edmund Schulthess, ce dernier remet en question le bienfondé et la composition de la Commission fédérale des banques. Pour lui, cette instance fait endosser à l'État une immense responsabilité quant à la capacité de paiements de banques. Il ajoute alors :

Il sera aussi très difficile de trouver les bonnes personnes. [...] Est-ce que la Confédération est en mesure d'indemniser adéquatement les spécialistes nécessaires? Quels sont, en outre, les experts qui ne sont liés à aucune banque ni société financière? Lorsque cette condition est remplie, la qualité pour l'exécution des tâches n'est pas au rendez-vous ${ }^{121}$.

Sans imaginer à ce moment-là qu'il en fera partie, Schulthess met le doigt sur certaines des difficultés qui traverseront l'histoire de la Commission fédérale des banques : comment attirer et rémunérer des personnalités à la fois indépendantes des banques et suffisamment compétentes? La réponse de Musy aux problèmes soulevés par son rival Schulthess sur ce point est très intéressante. Sur le rôle de la Commission fédérale des banques, le conservateur fribourgeois

\footnotetext{
120 AFB, EIOO4.I, I000/9, vol. 345, Procès-verbaux du Conseil fédéral, séance du 2 février 1934, annexe confidentiel intitulé «Bemerkungen des Chefs des Volkswirtschaftsdepartement zum Entwurf eines Bankgesetzes », 27.0I.1934.

121 Ibid., p. II.
} 
insiste sur la faiblesse de l'organe prévu : «Le rôle de la commission est essentiellement de trancher les différends possibles entre une banque et ses réviseurs. Ses attributions sont réduites au minimum, ainsi que la responsabilité directe de l'État. Toutes les législations étrangères vont plus loin que la nôtre. » ${ }^{122} \mathrm{Il}$ refuse d'ailleurs de créer un poste de directeur qui donnerait plus de pouvoir, et donc de responsabilité, et qui induirait le risque d'instituer, selon ses termes, une sorte de "dictateur de la banque».

Les remarques de Schulthess ne débouchent donc pas sur des modifications conséquentes du projet de loi en partie à cause de l'opposition de Musy. Le 2 février 1934, le collège gouvernemental ratifie donc le projet de loi et le transmet aux Chambres fédérales, muni d'un message d'introduction relativement bref et rédigé à la hâte sur la base de rapports fournis par la BNS et le directeur du Crédit Suisse Hermann Kurz ${ }^{123}$. Est-ce par simple négligence que ce message aux chambres oublie de mentionner les travaux initiaux de Julius Landmann? Il est permis d'en douter. En revanche, ce texte de promotion attribue très clairement trois objectifs au projet de loi : augmenter la sécurité des déposants par l'établissement des mesures prudentielles du contrôle fiduciaire, «assurer à l'économie nationale les crédits qui lui sont nécessaires» et enfin améliorer la qualité des informations destinées à la Banque nationale ${ }^{124}$.

\section{Ratification parlementaire sans grands débats (février-novembre 1934)}

En février 1934, la phase parlementaire du processus législatif débute. La discussion par les députés de l'avant-projet finalisé par le Conseil fédéral se fait, conformément à la procédure habituelle, en deux temps. Chacun des organes de l'Assemblée fédérale, le Conseil des États et le Conseil national, discute le projet, d'abord dans une commission parlementaire ad hoc, puis en séance plénière. Ce système, caractérisé par la formation de nombreuses commissions ad hoc plutôt que de commissions permanentes implique un faible degré de spécialisation des parlementaires suisses, et, partant, une marge de manœuvre accrue des acteurs et des «spécialistes» qui interviennent en amont ${ }^{125}$. Les commissions parlementaires, formées selon l'équilibre politique de la chambre concernée, peuvent également inclure certains «experts» externes. Sans surprise, le Département des finances décide d'inviter, en plus du président de la BNS, trois représentants des banques, à savoir Adolf Jöhr, Max Staehelin et Arthur Wolf. Ces invitations, qui n'allaient sans doute pas de soi dans les usages des commissions parlementaires fédérales, suscitent d'ailleurs de vifs remerciements de la part des

122 AFB, Eıoo4.I, I000/9, vol. 345, Procès-verbaux du Conseil fédéral, séance du 2 février 1934, annexe intitulé « Réponse du Département fédéral des Finances et des Douanes aux remarques de M. le Conseiller fédéral Schulthess ", 29.0I.1934, p. 5.

123 Bänziger, op. cit., I986, p. II4.

124 «Message du Conseil fédéral à l'Assemblée fédérale concernant le projet de loi sur les banques et les caisses d'épargne, (du 2 février 1934) ", Feuille fédérale, I, I934, p. 176-I77.

125 Pilotti, op. cit., 2016, p. IO2-IO4. 
banquiers concernés ${ }^{126}$. Le projet de loi sur les banques est d'abord traité par le Conseil des États entre février et juin 1934, puis par le Conseil national entre août et novembre 1934. La discussion par le Parlement n'implique pas une réforme radicale du projet de loi présenté. Le président de la SBS Staehelin estime même ressentir "un certain manque d'intérêts" au cours des délibérations parlementaires ${ }^{127}$. Sur au moins quatre points cependant, d'importantes modifications sont adoptées par les commissions parlementaires et le Parlement.

Premièrement, la commission du Conseil des États «sous l'impulsion des représentants des banques ${ }^{128}$ instaure de nouveaux régimes d'assainissements bancaires. Il s'agit des mesures de sursis concordataires et de sursis bancaires, qui permettent à une banque en difficulté de paiement d'instaurer un moratoire avant d'envisager un assainissement ou une faillite. À ces dispositions proposées conjointement par Jöhr et Staehelin ${ }^{129}$, s'ajoute la prorogation des échéances, qui apparaît dans le texte au Conseil national grâce au président de la commission parlementaire du Conseil national, l'Argovien PAB Roman Abt (1883-1942) ${ }^{130}$. Cette mesure vise à sauvegarder spécialement les intérêts des banques saines, lorsqu'elles sont provisoirement menacées par des retraits de capitaux. Cet ensemble de mesures, qu'il faut considérer comme la principale innovation amenée au cours des délibérations de l'Assemblée fédérale, suscite tout d'abord des réactions mitigées parmi les milieux bancaires. Ces procédures d'assainissement sont perçues comme une épée à double tranchant: d'une part, elles peuvent être utiles pour protéger certains instituts affaiblis, de l'autre, elles

126 AASB, Procès-verbaux du Conseil de l'ASB, Ioo ééance, 21.03.1934, p. 4.

127 Max Staehelin, Das schweizerische Bankgesetz: Vortrag (gehalten in der Statistisch-Volkswirtschaftlichen Gesellschaft Basel am) I2. November 1934, Basel, 1934, p. 17. Staehelin relate par exemple que le rapporteur francophone prononce son discours devant seulement sept députés romands présents.

128 AASB, Procès-verbaux du Conseil de l'ASB, IOI ééance, 07.07.I934, p. 8.

129 AFB, E6520(A), I000/1059, vol. 4, Commission du Conseil des États pour l'examen du projet de loi fédérale sur les banques et les caisses d'épargne. PV de la deuxième session, I3.04.I934, p. II6-I2I.

130 Il est nécessaire de présenter brièvement ce personnage clé du processus d'élaboration de la loi sur les banques, puisque c'est lui qui est chargé d'organiser les débats parlementaires dans la Chambre du peuple, en tant que président de la commission ad hoc du Conseil national. Heinrich Roman Abt est conseiller national PAB de I9I9 jusqu'à sa mort en 1942 ; il y prend la succession directe de son père, Heinrich Eugen Abt (1854-1937), membre de l'élite paysanne (directeur de l'école d'agriculture de Brugg, leader de l'USP, membre du CdA des CFF). Roman Abt est d'origine radicale et fait partie des membres fondateurs du Parti Paysans, Artisans et Bourgeois argovien. Après une double formation en agronomie (EPFZ) et droit (Université de Zurich), il se tourne vers une carrière d'avocat et de notaire. Abt n'est donc pas un simple agrarien, mais se profile comme médiateur entre les intérêts des paysans et ceux de l'industrie et de la finance. Il est membre de nombreux conseils d'administration, dont celui de l'Elektrobank (I915-1933), puis celui de la SBS dès 1937. Cf. Ernst Schaffner, «Abt, Heinrich Roman », in Biographisches Lexikon des Aargaus, I803-1957, Aarau : Sauerländer, 1958, p. I4-15; Anton Wohler, "Abt, Heinrich Roman ", in Dictionnaire historique de la Suisse, Hauterive: Attinger, vol. I, 2002, p. 36 ; cf. Base de données «Élites suisses au XXe siècle». 
remettent en cause le prestige de l'ensemble de la place financière suisse ${ }^{131}$. Avec l'introduction de ces nouvelles dispositions, on changeait également l'esprit de la loi qui voulait à l'origine protéger le public déposant contre les banques, mais qui protégeait désormais aussi les banques contre le public cherchant à retirer ses dépôts ${ }^{132}$.

Deuxièmement, le Conseil des États adopte une disposition qui autorise une banque à contester une décision de la CFB par voie de recours administratif au Tribunal fédéral. Ainsi, un certain nombre des jugements émis par la Commission fédérale des banques pourront être juridiquement récusés. Il s'agit, selon le président de la Société de Banque Suisse Staehelin, d'une mesure susceptible de tranquilliser le monde bancaire, inquiété par les pouvoirs interventionnistes de l'organe de surveillance ${ }^{133}$. L'autorité et les pouvoirs de cette dernière sont donc considérablement réduits.

Troisièmement, sous la pression cette fois-ci des groupes paysans et socialistes, le Conseil national demande une régulation plus forte de l'exportation de capitaux. Mais les mesures plus fortes prises par la Chambre basse ne seront finalement pas adoptées dans le texte définitif, le Conseil des États demeurant intraitable. Autre nouveauté, le Conseil national exige une plus grande indépendance de la part des instituts de révision, auxquels on interdit la pratique d'opérations de type bancaire. Nous reviendrons sur ce point.

Enfin, les représentants du peuple se montrent aussi plus sévères envers l'indépendance des membres de la CFB. En effet, les dirigeants de banques et de sociétés fiduciaires sont exclus de l'autorité de surveillance. Les simples conseillers d'administration par contre sont autorisés à y siéger. Le débat sur cette question repose sur un dilemme difficile à résoudre : comment trouver des personnalités à la fois expertes en technique bancaire et indépendantes des établissements à surveiller?

Insistons enfin sur le déséquilibre, au cours des débats parlementaires, entre des discussions très approfondies sur certaines dispositions, qui se révèleront peu significatives dans leur application, et la ratification sans aucun débat d'autres articles, qui deviendront, ex post, des points cruciaux de cette législation. La régulation de l'exportation de capitaux et des taux d'intérêt sur les obligations de caisse, cheval de bataille des groupes socialistes et paysans, accapare une partie substantielle de l'attention des politiques. Dans leur application, ces articles de loi ne seront cependant pas cruciaux ${ }^{134}$. Par contre,

131 Lors de la IO3 ${ }^{\mathrm{e}}$ séance du Comité ASB, le 3 octobre I934, le débat est animé à ce sujet et l’on ne peut trouver d'accord sur la question.

132 Bänziger, op. cit., I986, p. II9.

$133 \mathrm{AFB}, \mathrm{E} 652 \mathrm{O}(\mathrm{A})$, I000/1059, vol. 4, Commission du Conseil des États pour l'examen du projet de loi fédérale sur les banques et les caisses d'épargne, PV de la deuxième session, I2.04.I934, p. 80-87.

134 Les mesures octroyant un devoir d'information à la BNS pour toute augmentation du taux d'intérêt des obligations de caisse ne mènent qu'à une influence très mesurée de la banque centrale sur ce point entre 1935 et 1958. Zimmerli, op. cit., 1983, p. 4I-44. Quant au droit de veto de la BNS sur l'exportation de capitaux, son impact est également très modeste dans un 
d'autres dispositions de la loi, qui feront plus tard l'objet de nombreux commentaires juridiques, sont à peine discutées au Parlement. Il en va ainsi du fameux article 47 qui introduit des sanctions pénales en cas de violation du secret bancaire (cf. chap. IV.2.5). Un second exemple de mesure relativement imprécise qui n'a pas suscité de débat parmi les parlementaires est l'article qui définit les moyens de sanction de la Commission fédérale des banques si elle constate une irrégularité chez une banque. Sa formulation très floue provoquera une véritable impuissance de l'autorité de surveillance, qui n'avait probablement pas été anticipée dans la phase d'élaboration de la loi ${ }^{135}$. Il existe donc un fort contraste entre la richesse des débats sur certains objets devenus par la suite moins centraux et des dispositions ultérieurement considérées comme essentielles, mais passées inaperçues lors de leur élaboration.

Au-delà des changements de contenu opérés pendant cette phase parlementaire, il faut également souligner la tactique adoptée par les milieux bancaires pour imposer leurs vues au cours des négociations. En tenant compte de la composition politique des deux chambres législatives, les représentants des banques profitent du bicamérisme pour exercer une influence plus forte sur l'un des deux cénacles et susciter ainsi des divergences entre eux.

En l'occurrence, les banquiers ont rapidement compris que le Conseil des États serait beaucoup plus à l'écoute de leurs desiderata. En effet, à la Chambre des cantons, les partis bourgeois disposent d'une écrasante majorité: sur 44 sénateurs, on ne compte que trois PAB et deux socialistes. Aussi, aucun socialiste et un seul représentant paysan siège à la commission du Conseil des États en vue d'examiner le projet de loi sur les banques. De plus, cette commission est présidée par Ernst Thalmann (I88I-1938), conseiller aux États radical bâlois, une personnalité proche des milieux bancaires et économiques bâlois ${ }^{136}$. Aussi, c'est par son intermédiaire que l'ASB tente de faire passer l'introduction de la révision fiduciaire dans le droit des sociétés pour éviter une loi sur les banques ${ }^{137}$. Dans le contexte de l'élaboration de la loi sur les banques, Thalmann fonctionne aussi comme le relais privilégié des intérêts bancaires au Conseil des États, dans la commission comme au plénum. Il n'est donc pas

premier temps, tant à cause des circonstances conjoncturelles qui conduisent à une forte diminution des emprunts étrangers à long terme visés par cette mesure, qu'en raison des nombreuses possibilités de contournement du contrôle. Sancey, op. cit., 20I5, p. 363-366. Piguet, op. cit., 1953, p. 355-360.

135 L'article 23, al. 3, lit. 1 stipule que la Commission fédérale des banques peut «inviter l'établissement en question à régulariser sa situation dans un délai approprié ou déférer le cas aux autorités administratives ou judiciaires compétentes ».

136 Avocat et notaire, Thalmann fait partie à sa mort en 1938 de plus de 26 conseils d'administration, dont Ciba, Wever-Bank, Rheinische Rückversicherung. Il est en particulier proche de Max Staehelin, président de la SBS et ancien directeur de la Schweizerische Treuhandgesellschaft. SWA, Personaldossier Ernst Thalmann; Perrenoud, et al., op. cit., 2002, p. II3 et II5; Lüpold, op. cit., 2010, par exemple p. 522.

137 AASB, Procès-verbaux du Conseil de l'ASB, $97^{\mathrm{e}}$ séance, 08.II.I933, p. 6. 
étonnant qu'une fois la loi entrée en vigueur, et après sa non-réélection en I935, les deux grandes banques du pays, le Crédit Suisse et la Société de Banque Suisse, lui offrent la présidence de la nouvelle Gesellschaft für Bankenrevision qu'elles viennent de fonder. Le bilan que tirent les banquiers des conséquences de l'intervention du radical bâlois en tant que président de la Commission du Conseil des États est très clair : «Grâce au traitement attentif de la question par la Commission du Conseil des États sous la présidence de M. le Conseiller aux États Thalmann, le projet a fait l'objet d'importantes améliorations. " ${ }^{138}$

Les efforts de lobbyisme des délégués des banques ont donc porté leurs fruits. Le traitement par le Conseil des États a, de leur point de vue, apporté des progrès par rapport au projet soumis par le Conseil fédéral : à titre d'exemple, la commission consultative en matière d'exportation de capitaux proposée par Grimm est supprimée, tandis que sont introduites les dispositions sur le sursis bancaire qui protègent les banques contre des vagues de retrait de la part du public. Les articles de loi les plus débattus à la Chambre haute, à savoir le statut des banques cantonales, et la souveraineté cantonale, notamment en matière de protection de l'épargne, constituaient des questions secondaires pour les grandes banques commerciales. Le choix du gouvernement de transmettre le projet de loi en priorité au Conseil des États a donc favorisé les intérêts bancaires. Les représentants de ces derniers ont pu y exprimer leurs préférences en l'absence d'opposants politiques, et ce sous la présidence d'un rapporteur acquis à leur cause.

En revanche, le passage du projet amendé par le Conseil des États au Conseil national, en août et septembre 1934, est plus délicat pour les banquiers. En effet, la présence de socialistes et de $\mathrm{PAB}$, voire celle de représentants radicaux favorisant les intérêts des employés, tel le Bâlois Victor Emil Scherer (I88I-194I), comportait un certain nombre de risques de renforcement du projet. Ainsi, un amendement visant à inscrire dans la loi sur les banques un passage mentionnant que les relations de travail entre employés et banques doivent être réglées par conventions collectives n'est repoussé que par une faible majorité. Les banquiers avaient donc mis en place, dès juillet 1934, une stratégie qui consistait à se mettre en retrait pendant les délibérations de la commission $\mathrm{du}$ Conseil national et d'adopter une position attentiste visant à défendre le statu quo, c'est-à-dire la version du Conseil des États ${ }^{139}$. Cette attitude semble avoir bien fonctionné. Même si Adolf Jöhr regrette, en commentant les changements opérés par le Conseil national, qu'il n'existe à Berne que très peu de compréhension pour «la psychologie des capitalistes " ${ }^{140}$, les dommages sont très limités, du point de vue des banquiers. Ceux-ci décident pourtant de combattre un certain nombre des renforcements introduits par le Conseil national, en envoyant un commentaire détaillé aux membres de la commission

138 AASB, Procès-verbaux du Conseil de l'ASB, Ior e séance, 04.07.1934, p. 8 (Max Vischer).

139 AASB, Procès-verbaux du Conseil de l'ASB, IoI $^{\mathrm{e}}$ séance, 04.07.1934, p. 8.

140 AASB, Procès-verbaux du Conseil de l'ASB, Io3 ${ }^{\mathrm{e}}$ séance, 03.IO.I934, p. I. 
du Conseil des États. Sont notamment rejetées la disposition octroyant un droit de veto à la BNS en cas d'augmentation du taux d'intérêt des obligations et celle qui rend l'activité de gestion de fortune incompatible avec celle de révision de banque. Durant la finalisation du projet, au cours de la procédure dite d'élimination des divergences entre les deux Chambres, en novembre 1934, le Conseil des États défend systématiquement la position moins interventionniste prônée par l'ASB. Du point de vue du processus de décision, il est important de relever l'efficacité avec laquelle les milieux bancaires parviennent à tirer avantage du système bicaméral suisse. En pesant fortement sur les décisions du Conseil des États, tout en se faisant plus discrets au Conseil national, les représentants des banques obtiennent de nombreuses concessions.

La loi fédérale sur les banques et les caisses d'épargne est adoptée par l'Assemblée fédérale le 8 novembre 1934, au terme d'une session parlementaire extraordinaire. Une seule voix s'y oppose au Conseil national, tandis que le Conseil des États vote la loi à l'unanimité; le référendum n'est pas saisi. Quelques jours plus tard, l'ASB ne cache pas sa satisfaction face aux derniers développements dans la finalisation du projet de loi, et se félicite notamment de l'efficacité de son action de pression sur les membres influents du Conseil des États : «Heureusement, grâce à l'attitude ferme du Conseil des États, on a tenu compte de presque tous nos souhaits exprimés dans le courrier du 9 octobre. ${ }^{141}$

Le processus de délibérations parlementaire aura donc été relativement rapide, et n'aura pas nécessité, de la part du Conseil fédéral, des procédures d'urgence court-circuitant le système législatif démocratique standard, manœuvre pourtant fréquente au cours de l'entre-deux-guerres ${ }^{142}$. Treize mois s'écoulent entre la publication du message du Conseil fédéral en février 1934 et l'entrée en vigueur de la loi le $\mathrm{I}^{\mathrm{er}}$ mars 1935 . La vitesse de finalisation de la législation, dans la phase parlementaire, contraste donc avec la relative lenteur d'émergence des projets de loi entre I93I et 1934, lorsque les solutions palliatives d'autorégulation et de révision du Code des obligations prônées par les banquiers avaient considérablement freiné les timides velléités de réglementation de l'administration fédérale. La rapidité d'achèvement contraste de manière plus saisissante encore avec le traitement réservé au projet Landmann en 1917.

141 AASB, Procès-verbaux du Conseil de l'ASB, Rapport préliminaire (Vorbericht) de la IO4 $4^{\mathrm{e}}$ séance du Comité ASB, 28.II.I934.

142 Cf. Georg Kreis, «Parlamentarismus und Antiparlamentarismus in den Jahren 1933-1945 ", in Madeleine Bovey Lechner, Martin Graf, Annemarie Huber-Hotz (éd.), Das Parlament"Oberste Gewalt des Bundes"?, Bern: Paul Haupt, 199I, p. 30I-319. 
广

N

$\stackrel{\circ}{\circ}$

(1)

.

2

2

(a) 


\section{CHAPITRE IV}

\section{LE RÉGIME DE SURVEILLANCE BANCAIRE \\ DE 1934-1935}

En l'espace de vingt mois de délibérations, entre février 1933 et novembre I934, la loi sur les banques s'était considérablement étoffée. Alors que le premier projet ne comptait que quinze articles décrits en seulement cinq pages, le produit final était long de 2I pages et comprenait 56 articles. Cette extension du texte de loi ne signifiait pas pour autant que la réglementation était exhaustive et prête à être mise en application.

\section{IV.1. L'ORDONNANCE DE LA LOI BANCAIRE DU 26 FÉVRIER 1935 : UN COURT-CIRCUITAGE DES POUVOIRS RÉGLEMENTAIRES DE LA FUTURE COMMISSION FÉDÉRALE DES BANQUES}

Comme très souvent en droit, un règlement d'exécution - ou ordonnance - (Vollziehungsverordnung) était prévu pour déterminer la portée de certaines dispositions et fixer les normes précises dont la loi n'évoquait que vaguement les principes généraux. Contrairement à une loi fédérale, qui est adoptée par le parlement, une ordonnance d'exécution est du ressort du Conseil fédéral, qui devient ainsi de fait un organe législatif important ${ }^{1}$. La possibilité de modifier une ordonnance sans passer par le Parlement en fait aussi un texte normatif plus malléable. Certains commentateurs avisés ont souligné la signification toute particulière de l'ordonnance dans le cas de loi sur les banques, et les compétences importantes qui ont ainsi été transférées au Conseil fédéral ${ }^{2}$.

Dès septembre 1934, alors que la loi n'avait pas encore abouti, les milieux bancaires avaient anticipé la dimension primordiale du règlement d'exécution qui allait être négocié en aval. Paul Jaberg (1878-1955), le directeur général de l'UBS, annonce en effet lors d'une réunion du comité de l'ASB que

1 Cf. Luzius Mader, "Législation", in Andreas Ladner, et al. (éd.), Manuel d'administration publique suisse, Lausanne: Presses polytechniques et universitaires romandes, 2013, p. 245265.

2 Brühlmann, op. cit., I935, p. VI et 2I-22. 
«l'ordonnance d'exécution pourra être plus importante que la loi même» ${ }^{3}$. Face à ce constat partagé par ses collègues, tout est mis en œuvre pour assurer aux milieux intéressés un accès privilégié et précoce aux avant-projets d'ordonnance. À demi-mot, les banquiers laissent du reste entendre qu'ils souhaitent prendre connaissance de la teneur de l'ordonnance avant même que la loi ne soit adoptée ${ }^{4}$. Du côté de l'administration fédérale, on est d'ailleurs bien conscient de l'importance d'obtenir le blanc-seing des grands pontes de la finance pour garantir l'adoption des mesures. Ainsi, en juillet 1934, Paul Rossy adresse-t-il à Gottlieb Bachmann, Adolf Jöhr et Max Staehelin les lignes suivantes:

Avant de proposer l'adoption de nouvelles dispositions dans la loi sur les banques, je me permets de recourir à votre obligeance coutumière pour vous soumettre les dispositions qui, si elles rencontrent une opposition justifiée dans les milieux bancaires, ne sortiront pas des tiroirs des bureaux fédéraux ${ }^{5}$.

L'étroitesse des liens et des échanges entre les législateurs étatiques et une poignée de grands banquiers se développe encore dans le cadre de l'examen du règlement d'exécution. Un avant-projet d'ordonnance « strictement confidentiel » est mis à disposition des représentants du monde bancaire dans la souscommission d'experts. Cet avant-projet, portant la date du I4 novembre I934, est donc réalisé moins d'une semaine après l'adoption de la nouvelle législation. Cette préconsultation des représentants bancaires a pour but explicite d'adapter l'ordonnance avant même qu'elle ne soit soumise à une conférence d'experts officielle ${ }^{\sigma}$. Une poignée de banquiers - Adolf Jöhr, Max Staehelin, Arthur Wolf, Emil Zachmann, Hermann Korrodi et Rudolf Wittmer - obtiennent ainsi le projet d'ordonnance en avant-première. Le texte qui est discuté dans la petite commission d'experts qui se réunit une première fois le 7 janvier 1935 a donc une origine double ${ }^{7}$. La première version, rédigée par Paul Rossy (DFFD) et Gottlieb Bachmann (BNS), a été "profondément transformée " à la demande d'Adolf Jöhr et Max Staehelin.

En plus de l'accès privilégié au texte discuté, les milieux bancaires bénéficient également d'une forte représentation au sein de la commission d'experts. Comme le montre le tableau 7 , sur une quarantaine de commissaires, seul Max Weber, uniquement convié à la grande commission, représente les partisans d'un contrôle bancaire renforcé. Il est vrai que des hommes politiques comme Robert Grimm ou Richard König, moins perméables aux souhaits des milieux

\footnotetext{
AASB, Procès-verbaux du Conseil de l'ASB, IO2 $^{\mathrm{e}}$ séance, 07.09.1934, p. 5.

AASB, Procès-verbaux du Conseil de l'ASB, I03 ${ }^{\mathrm{e}}$ séance, 03.IO.1934, p. 7.

AFB, E6520(B), 2007/62, vol. I8, dossier 99*, Lettre de Paul Rossy à Gottlieb Bachmann, Adolf Jöhr et Max Staehelin, I2.07.1934.

AASB, Procès-verbaux du Conseil de l'ASB, IO4 e séance, 28.II.1934, p. 2.

7 Selon le récit qu'en donne Adolf Jöhr devant ses collègues du Comité de l'ASB. AASB,

Procès-verbaux du Conseil de l'ASB, I05 ${ }^{\mathrm{e}}$ séance, 30.0I.1935, p. 4.
} 
intéressés, avaient décliné l'invitation du Département des finances ; les raisons de leur absence demeurent inexpliquées ${ }^{8}$.

Tableau 7. Composition des Commissions d'experts chargés de discuter le règlement d'exécution de la loi sur les banques (janvier-février 1935)

\begin{tabular}{|c|c|}
\hline \multicolumn{2}{|c|}{ Petite commission d'experts, 7-8 janvier 1935} \\
\hline Albert Meyer (I870-1953) & $\begin{array}{l}\text { Préside les séances. Conseiller fédéral radical zurichois en charge } \\
\text { du DFFD }\end{array}$ \\
\hline Dr. Paul Rossy (1896-1973) & Suppléant du $2^{\mathrm{e}}$ dép. de la BNS, expert financier du DFFD \\
\hline Dr. Emil Alexander (I889-I964) & Délégué du DFJP \\
\hline $\begin{array}{l}\text { Prof. Gottlieb Bachmann } \\
\text { (I874-1947) }\end{array}$ & Prés. du directoire de la BNS \\
\hline Paul Bachmann & Bureau statistique de la BNS \\
\hline Max E. Bodmer (1888-1953) & $\begin{array}{l}\text { Associé de la banque privée Rahn \& Bodmer }(\mathrm{ZH}) \text {, futur prés. } \\
\text { de l'Association des Banquiers Privés de Suisse }\end{array}$ \\
\hline Hermann Korrodi (I884-?) & Dir. de l'Elektrobank \\
\hline Johann Heuberger (I890-I950) & $\begin{array}{l}\text { Dir. de l'Union des Caisses de Crédit Mutuel (Raiffeisen), dir. } \\
\text { de la Caisse de prêts de la Confédération }\end{array}$ \\
\hline Paul Jaberg (I878-1955) & Dir. gén. de l'UBS \\
\hline Dr. Adolf Jöhr (I878-1953) & $\begin{array}{l}\text { Dir. gén. Crédit Suisse, vice-présid. ASB, ancien dir. gén. de la } \\
\text { BNS (1915-1918), membre d'une vingtaine de CdA, dont BBC, } \\
\text { Elektrobank, Motor Columbus, Nestlé }\end{array}$ \\
\hline Max Staehelin (I880-I96I) & $\begin{array}{l}\text { Prés. du CdA de la SBS, membre de l'USCI, ancien adm. de la } \\
\text { Schweiz. Treuhandgesellschaft (BS), membre d'au moins } 33 \\
\text { CdA dès } 1934\end{array}$ \\
\hline Dr. Arthur Stampfli (I887-?) & Spécialiste des banques suisses \\
\hline Rudolf Wittmer (1878-1965) & $\begin{array}{l}\text { Dir. de la Banque cantonale bâloise, Prés. de l'Union des } \\
\text { banques cantonales suisses, membre du Comité ASB }\end{array}$ \\
\hline Dr. Arthur Wolf (I884-I96I) & $\begin{array}{l}\text { Verband Schweizerischer Lokalbanken, Spar- und Leihkassen, } \\
\text { ZH }\end{array}$ \\
\hline Emil Zachmann (1874-I938) & Dir. gén. de la Schweizerische Treuhandgesellschaft (BS) \\
\hline \multicolumn{2}{|c|}{$\begin{array}{l}\text { À ces membres s'ajoutent les personnes suivantes pour la grande commission d'experts, } \\
\qquad 4-5 \text { février } 1935\end{array}$} \\
\hline Henri Bersier (I870-I94I) & $\begin{array}{l}\text { Dir. de la Banque cantonale vaudoise. Membre du CdA de } \\
\text { Nestlé, Rentenanstalt. Membre du Conseil de banque de la } \\
\text { BNS }\end{array}$ \\
\hline Joseph Blöchlinger & $\begin{array}{l}\text { Dir. de la Leih- und Sparkasse vom Seebezirk und Gaster, } \\
\text { Uznach (GL) }\end{array}$ \\
\hline Dr. Erwin Christen (1885-1982) & Dir. de la Basellandschaftl. Hypothekenbank \\
\hline
\end{tabular}

8 Le procès-verbal des séances de la " grande " commission d'experts les recense sous la liste des participants excusés. AFB, E6520(A), I000/1059, vol. 5, Protokolle der grossen Expertenkommission für die Vollziehungsverordnung zum Bankengesetz, 04.02.1935, p. 2. 


\begin{tabular}{|l|l|}
\hline Rodolphe de Haller (I874-1962) & $\begin{array}{l}\text { Membre du Conseil de banque de la BNS. V-pdt de la Banque } \\
\text { Commercial de Bâle }\end{array}$ \\
\hline Alfred Häuptli & $\begin{array}{l}\text { Dir. de la Banque cantonale de Berne. Membre du Vorstand du } \\
\text { Revisionverband bernischer Banken und Sparkassen }\end{array}$ \\
\hline Alfred Hirs (I889-1976) & Dir. gén. de la Banque Populaire Suisse \\
\hline Dr. Carl Jäger (I869-1947) & Juge fédéral, spécialiste du droit des poursuites et des faillites \\
\hline Dr. Hermann Kurz (I857-1943) & $\begin{array}{l}\text { Prés. du CdA de l'Elektrobank. Membre du CdA du Crédit } \\
\text { Suisse. Membre du Conseil de banque de la BNS }\end{array}$ \\
\hline Robert La Roche (I877-1946) & Prés. ASB, associé de la banque privée La Roche \& Cie \\
\hline Lachat & Chef de l'Office des poursuites et faillites de Genève \\
\hline Jean Lombard (I875-1957) & Associé de la banque privée Lombard, Odier \& Cie \\
\hline Dr. Leo Merz (I869-1952) & $\begin{array}{l}\text { Ancien Conseiller d'État radical bernois (Justice et instruction } \\
\text { publique) }\end{array}$ \\
\hline Max von Pfyffer (I888-?) & Adm. de la Caisse de prêts de la Confédération \\
\hline Salvisberg & Expert-comptable (BE) \\
\hline A. Santschi & Inspecteur de la Banque cantonale de Berne \\
\hline Dr. Alfred Sarasin (I865-1953) & Prés. du Conseil de la BNS \\
\hline Francesco Sidler & Dir. de la Banque cantonale du Tessin \\
\hline Dr. Karl Strasser & Inspecteur de caisse d'épargne \\
\hline Dr. Max Vischer (I888-1975) & Premier Secrétaire de l'ASB \\
\hline Bernhard Widmer (I876-1952) & $\begin{array}{l}\text { Conseiller national cath.-conservateur (I928-I947, ZH), présid. } \\
\text { de la Banque Coopérative Suisse }\end{array}$ \\
\hline Dr. Ernst Thalmann (I88I-1938) & $\begin{array}{l}\text { Conseiller aux États radical (BS), pdt de la commission du } \\
\text { Conseil des États }\end{array}$ \\
\hline Dr. Max Weber (I897-1974) & $\begin{array}{l}\text { Expert économique et collaborateur scientifique de l'Union } \\
\text { syndicale suisse }\end{array}$ \\
\hline & \\
\hline
\end{tabular}

Source: AFB, E6520(A), 1000/1059, vol. 5.

La stratégie des représentants des banques, au cours de l'élaboration de l'ordonnance d'exécution, est relativement claire. Il s'agit non seulement d'atténuer, dans ce cadre moins politisé et plus confidentiel, la portée de certaines dispositions jugées indésirables, mais aussi de préciser le plus possible l'étendue d'autres mesures, et de limiter ainsi la marge de manœuvre discrétionnaire de la future Commission fédérale des banques, qui suscite alors encore de la méfiance. Sous prétexte de trancher des questions techniques et de préciser certains détails, les banquiers profitent de la rédaction du règlement d'exécution pour obtenir des règles prudentielles peu contraignantes et restreindre les compétences de la future instance de surveillance, dont la composition est alors encore inconnue. À titre d'exemple, Jöhr estime qu'en matière de normes sur l'établissement du bilan, il est «préférable d'avoir des prescriptions aussi précises que possible, si cela permet d'éviter ainsi l'ingérence éventuelle de la 
Commission des banques»". Au sein de l'ASB, Jöhr s'impose à nouveau comme porte-parole principal du monde bancaire, n’hésitant pas à intimer les mots d'ordre sur les diverses propositions.

Quatre questions, entre autres, font l'objet d'âpres négociations et de longues discussions dans la la petite puis de la grande commission d'experts.

Premièrement, la notion-clé de "faire appel au public pour obtenir des dépôts de fonds " y est définie. Il s'agit là du critère qui permet d'opérer une distinction entre deux catégories de banquiers privés : ceux qui sont soumis à l'ensemble des articles de la loi et ceux qui, en renonçant à faire appel au public, obtiennent des dérogations sur les fonds propres, la mise en réserve, la publication des bilans et des comptes. Tandis que la réclame en vue d'obtenir des capitaux faite dans les bureaux d'une banque ou par voie de circulaires destinées uniquement aux clients n'est pas considérée comme appel au public, la publicité affichée en vitrine est du ressort de la sphère publique. Max E. Bodmer, banquier privé zurichois, insiste pour maintenir une différence claire entre deux catégories, ce qui permettra, une fois la loi entrée en vigueur, aux banquiers privés de choisir l'un ou l'autre modèle d'entreprise. Au fond, ils peuvent adapter le niveau de transparence qu' ils sont prêts à accepter dans la publication des bilans et la tenue de leurs comptes selon le type d'activités privilégiés.

Deuxièmement, la définition et la détermination des ratios de fonds propres et de liquidités sont ancrées dans le règlement d'exécution. Il faut bien distinguer deux variables, c'est-à-dire d'un côté la définition de ce que constituent, du point de vue matériel, les fonds propres et les actifs facilement mobilisables, et de l'autre la fixation du rapport minimal qui doit être maintenu. En effet, en vue d'obtenir un assouplissement des prescriptions, les banquiers peuvent exiger soit un abaissement du pourcentage du ratio, soit, plus subtilement, argumenter en faveur d'une définition plus large des notions de fonds propres et d'actifs liquides qui entreront dans le calcul du coefficient. Le principe qui a guidé les législateurs en la matière a été de connaître le plus précisément possible la proportion de fonds propres et de liquidité des différentes catégories de banques, pour ensuite fixer le niveau minimal requis en fonction de la situation existante. Cette démarche très pragmatique s'oppose à celle qui aurait vu l'administration déterminer les règles prudentielles en fonction d'une limitation des risques théoriques, auxquelles les banques auraient dû s'adapter. Le président de la BNS, Gottlieb Bachmann, annonce que la solution proposée est compatible avec l'état de fonds propres existant : « Nous avons essayé de trouver une solution qui puisse être adaptée aux conditions existantes sans grandes difficultés. ${ }^{10}$ Les banquiers parviennent, grâce à la confortable majorité dont ils disposent dans la commission, à imposer un élargissement significatif de ce qui est comptabilisé : en plus du capital-actions versé et des réserves - ce qui constitue la définition standard

9 AASB, Procès-verbaux du Conseil de l'ASB, IO5 ééance, 30.0I.I935, p. 7.

10 AFB, E6520(A), I000/1059, vol. 5, Protokolle der kleinen Expertenkommission über die Vollziehungsverordnung zum Bankengesetz, 07.0I.1935, p. 2I. 
des fonds propres - une partie du capital non versé, la garantie de solidarité des coopérateurs (qui concerne les caisses Raiffeisen) et le dépôt de garantie de sociétaires d'une banque privée. Ces modifications signifient donc indirectement un allégement des exigences de fonds propres.

En ce qui concerne la liquidité, les seuils minimaux sont largement inférieurs aux taux de liquidité réels: "Afin de permettre à toutes les banques de remplir les normes, nous avons maintenu les exigences considérablement en deçà de ce que la plupart des banques observent déjà. ${ }^{11}$ Malgré cet état d'esprit relativement clément à l'égard des banques, la proposition du Département des finances sera remise en question par Jöhr, qui présente un mode de calcul alternatif. Le Département des finances prévoyait en effet à l'origine de faire varier les exigences de liquidité en fonction d'un critère double, c'est-à-dire à la fois l'importance des engagements couverts par des garanties hypothécaires et la taille de l'institut. Selon ce système, un établissement local actif dans le crédit hypothécaire aurait dû disposer de liquidités inférieures à une grande banque commerciale. Jöhr propose un système faisant dépendre les exigences de liquidité uniquement de la somme des engagements à court terme. Plus une banque a octroyé des crédits à court terme, plus elle doit être liquide. C'est ce mode de calcul "Jöhr», qui, selon les calculs de l'expert Arthur Stampfli, avantage les grands établissements commerciaux au détriment des plus petites banques hypothécaires ${ }^{12}$, qui est finalement retenu par le Département des finances. Les représentants des banquiers privés et des caisses Raiffeisen sont aussi contrariés par la modification du calcul de la liquidité minimale, car la prise en compte de la taille de la banque leur concédait certains allégements. En plus de ce succès, Jöhr obtient également que la Commission fédérale des banques ne puisse pas intervenir sur la fixation des taux de fonds propres et de liquidité, mais seulement octroyer des dérogations ${ }^{13}$.

Troisièmement, le contenu de deux documents essentiels dans l'application de la loi, à savoir le schéma des bilans à transmettre à la Banque nationale et le rapport de révision qui résulte de l'activité annuelle des réviseurs, est durement négocié. Il faut relever que les dirigeants bancaires recourent sur ces deux points à deux tactiques différentes. Dans le cas de l'établissement d'un schéma de bilan commun, les banquiers acceptent des prescriptions détaillées sur la définition de chacun des postes, en espérant ainsi court-circuiter une intervention de la Commission fédérale des banques. Les alinéas qui prévoyaient que la CFB édicte des directives sur l'établissement des bilans sont d'ailleurs supprimés sans autre forme de procès, sur demande de Jöhr ${ }^{14}$. En revanche, lors des discussions

11 AFB, E6520(A), I000/1059, vol. 5, Protokolle der kleinen Expertenkommission über die Vollziehungsverordnung zum Bankengesetz, 07.01.1935, p. 31. Citation d'Arthur Stampfli.

12 AFB, E6520(A), I000/I059, vol. 5, Protokolle der kleinen Expertenkommission über die Vollziehungsverordnung zum Bankengesetz, 08.0I.1935, p. 40-48.

13 AASB, Procès-verbaux du Conseil de l'ASB, I0 $5^{\mathrm{e}}$ séance, 30.0I.1935, p. 7.

14 AFB, E6520(A), I000/1059, vol. 5, Protokolle der grossen Expertenkommission für die Vollziehungsverordnung zum Bankengesetz, 05.02.1935, p. 55. 
sur le contenu du rapport de révision, les milieux bancaires utilisent la tactique inverse. Ils tentent de réduire le plus possible le catalogue de prescriptions proposé, en arguant qu'il faut laisser une marge de manœuvre suffisante à chaque institut de révision et que l'ensemble des points exigés n'est pas pertinent pour tous les types de banques. En fin de compte, la liste des points faisant l'objet de la révision passe tout de même de 2I à I3. Ce faisant, les banquiers exigent aussi la suppression de la disposition qui demande que le rapport de révision se prononce sur la proportion de placements à l'étranger, par rapport au bilan total ${ }^{15}$. Ce n'est que suite à l'opposition conjuguée du DFFD, de la BNS et du juge fédéral Jäger que la disposition est maintenue. Rappelons qu’à l'origine, dans les projets de novembre 1933, cette disposition figurait en tant qu'article à proprement parler dans la loi et était beaucoup plus contraignante. Ces deux tactiques opposées - dans un cas énumérer précisément le contenu du bilan, dans l'autre simplifier la nature du rapport de révision - signalent aussi que les banquiers se méfient alors d'une éventuelle intervention de la future Commission fédérale des banques, tandis qu'ils accordent une grande confiance aux instituts de révision privés.

Enfin, le quatrième domaine central abordé par le règlement d'exécution se réfere à l'organisation des instituts de révision. Il s'agit de déterminer notamment les critères de reconnaissance, par la Commission fédérale des banques, des sociétés fiduciaires et syndicats de révision qui seront autorisés à pratiquer le contrôle des banques au sens de la loi. Faut-il privilégier une révision bancaire ouverte à un grand nombre d'instituts et éviter le monopole de quelques sociétés et associations dominantes, ou plutôt favoriser la concentration et empêcher la profusion de petites organisations qui seraient encore moins indépendantes à l'égard des banques à contrôler? Une majorité se prononce en faveur de la seconde option. Le Conseil fédéral, dans sa finalisation de l'ordonnance, instaurera des exigences pour éviter une prolifération du nombre d'instituts reconnus: un syndicat de révision doit contrôler au moins douze banques, tandis qu'une société fiduciaire doit disposer d'un capital-actions versé d'au moins Ioo ooo francs et obtenir des mandats de révision pour des banques dont le bilan accuse un total de 100 millions de francs au minimum. Quant à la question de l'incompatibilité des activités de révision bancaire et de gestion de fortune, de justesse maintenue dans la loi par le Conseil national, au grand dam des banquiers qui avaient protesté contre cette disposition, elle est confirmée par l'ordonnance. Les banquiers obtiennent tout de même deux succès dans le domaine de la révision. Ils éliminent tout d'abord de l'ordonnance une clause qui interdisait les relations de parenté entre un réviseur et un directeur de la banque contrôlée. En outre, la question du contrôle des banques cantonales est réglée de manière très souple. Invoquant les promesses faites

15 AFB, E6520(A), I000/1059, vol. 5, Protokolle der kleinen Expertenkommission über die Vollziehungsverordnung zum Bankengesetz, 08.or.1935, p. 82-83; Protokolle der grossen Expertenkommission für die Vollziehungsverordnung zum Bankengesetz, 05.02.1935, p. $8 \mathrm{I}-89$. 
durant l'élaboration de la loi, on limite le droit de regard de la Commission fédérale des banques dans la révision des banques cantonales au minimum. Le texte final de l'ordonnance stipule simplement qu'elle "peut exiger que les banques cantonales l'informent si elles sont révisées par un service qualifié, faisant partie de l'établissement ${ }^{16}$.

Après avoir accepté quelques ajustements demandés par la BNS, le Conseil fédéral promulgue le règlement d'exécution le 26 février 1935. La loi sur les banques et son ordonnance entrent en vigueur le $\mathrm{I}^{\mathrm{er}}$ mars.

\section{IV.2. LES PRINCIPALES DISPOSITIONS DE LA LÉGISLATION BANCAIRE}

Les pages précédentes (chap. III.3 et IV.I) ont mis l'accent sur les dynamiques qui ont marqué l'élaboration de la loi sur les banques et de son ordonnance, en mettant en avant les facteurs qui permettent de comprendre l'évolution diachronique des positions des divers acteurs et rapports de force politiques. Avant de porter notre regard sur l'application de cette nouvelle réglementation par la principale autorité de surveillance mise en place, marquons une pause dans notre récit chronologique pour proposer un aperçu du résultat auquel le processus d'élaboration législative a abouti. Il ne s'agit pas pour autant de donner ici un commentaire exhaustif des dispositions de la loi sur les banques de 1934. Non seulement une telle ambition dépasserait le cadre de ce travail et aurait une valeur analytique limitée, mais elle ne ferait que répéter les études déjà disponibles dans la littérature juridique qui s'est attelée, dès les années 1930, à décortiquer pour un public informé les 56 articles de la loi bancaire ${ }^{17}$.

Dans ce sous-chapitre, nous allons pour notre part dégager les lignes de force du régime de réglementation bancaire qui entre en vigueur en mars 1935 . Nous allons successivement aborder cinq ensembles de dispositions qui constituent des points essentiels de la loi : son champ d'application, ses mesures de régulation prudentielle, son système de surveillance, son autorité d'application

16 Règlement d'exécution de la loi sur les banques et les caisses d'épargne (du 26 février 1935), art. 30, al. I.

17 En nous limitant aux quinze premières années d'existence de la loi sur les banques et sans tenir compte des articles de revue, la listes des publications scientifiques sur la loi bancaire suisse est relativement bien fournie: Rossy, Reimann, op. cit., 1935; Brühlmann, op. cit., 1935; Graner, op. cit., 1937; Graner, op. cit., I937; Uldry, op. cit., I937; Hartmann, op. cit., I938; Jann, op. cit., I938; Walter Müller, «Das Bilanzrecht der schweizerischen Banken», Doktor beider Rechte, Rechts- und staatswissenschaftliche Fakultät, Universität Zürich, I938; Delachaux, op. cit., 1939 ; Schubert, op. cit., I939; Bachmann, op. cit., 194I ; Dollfus, op. cit., 194I ; Max Oetterli, «Die rechtliche Stellung der Revisionsverbände und Treuhandgesellschaften nach Bankengesetz », Doktor beider Rechte, Universität Bern, I94I ; Hans Andrea Tarnutzer, «Entstehung, Organisation und Funktion der eidgenössischen Bankenkommission", Doktorarbeit, Universität Bern, 1941 ; Burki, op. cit., 1942; Schwander, op. cit., I943; Urech, op. cit., I944; Bodmer, op. cit., I948; Peter, op. cit., I95I. 
et enfin le renforcement du secret bancaire. En plus de ces cinq domaines, d'autres dispositions auraient pu faire l'objet d'une analyse. Il s'agit par exemple de l'ensemble de mesures contenues dans la loi sur les banques de i934 qui accorde à la Banque nationale suisse des compétences avec pour objectif une meilleure information des opérations du marché, pour mieux orienter sa politique monétaire. Il s'agit ici essentiellement de trois tâches : l'examen des bilans fournis par les banques, le contrôle de l'exportation des capitaux et la surveillance du taux d'intérêt des obligations de caisse. Retenons ici seulement que les articles de loi se contentent de formaliser et de pérenniser les accords non contraignants conclus précédemment entre la banque centrale et les banques commerciales, et que l'application concrète de ces mesures n'aura qu'un impact limité ${ }^{18}$.

Avant d'amorcer l'analyse, rappelons les objectifs principaux de la législation. Le message gouvernemental de février 1934 ne mentionnait que l'amélioration de la sécurité des déposants, la circulation des crédits dans l'économie nationale, et l'information au bénéfice de la Banque nationale. À ces principes généraux vient s'ajouter, dans la version adoptée en novembre 1934, un quatrième objectif: la protection des banques elles-mêmes. Ce principe se matérialise à la fois par les mesures qui visent à assurer une organisation interne appropriée, mais surtout par l'ensemble des dispositions qui offrent des procédures d'assainissement particulières, telles que la prorogation des échéances, le sursis bancaire ou la procédure concordataire ${ }^{19}$. Retenons ici uniquement le caractère improvisé et désordonnés de ces mesures, ainsi que leur statut exceptionnel en comparaison internationale.

18 Pour un développement de l'analyse des dispositions impliquant la BNS dans le régime de régulation bancaire de 1934: Giddey, op. cit., 2017, p. 213-217. Voir également: Gottlieb Bachmann, "L'exportation des capitaux et la Banque Nationale ", in Association suisse des experts-comptables A.S.E (éd.), Journées d'études bancaires, Genève: E. Delachaux, I937, p. 7-25; Zimmerli, op. cit., 1983 ; Roland Äppli, et al. (éd.), $75^{e}$ anniversaire. Banque nationale suisse: les années 1957 à 1982, Zurich: Banque nationale suisse, 1982, p. 187-190.

19 Pour une analyse de ces régimes spéciaux pour banques en difficulté sont analysés, voir Giddey, op. cit., 20I7, p. 224-227. Voir également: Erwin Gersbach, Der Nachlassvertrag ausser Konkurs nach dem schweizerischen Bundesgesetz über die Banken und Sparkassen und seinen Ausführungserlassen, Zug: Kündig, I937; Josef Henggeler, "Die Verrechnung bei Fälligkeitsaufschub und Stundung gemäß dem Bundesgesetz über die Banken und Sparkassen vom 8. November 1934 nebst den dazugehörigen Verordnungen und Ergänzungen ", in Fritz Mangold (éd.), Festgabe für Bundesrat Dr. h. c. Edmund Schulthess zum siebzigsten Geburtstag am 2. März 1938, Zürich: Polygraphischer Verlag, I938, p. 299-314; Willy Brühlmann, "Bankensanierungen», in Paul Keller, et al. (éd.), Handbuch der Schweizerischen Volkswirtschaft, Bern : Benteli A.G, I939, p. I68-I70 ; Bachmann, op. cit., I94I ; Thomas Holenstein, «Das Bankensanierungsrecht nach Bankengesetz und nach dem BRB über die Sanierung von Banken", in Beiträge zum Wirtschaftsrecht: Festgabe für den Schweizerischen Juristentag 1944 in St. Gallen, St. Gallen : Fehr, 1944, p. 4I-7I ; Bodmer, op. cit., 1948, p. 138I4I, I45-I48; Verena Schipke, Die Weiterentwicklung des Bankeninsolvenzrechts durch das Gesetz zur Reorganisation von Kreditinstituten: Eine Untersuchung unter besonderer Berücksichtigung des Schweizer Rechts, Berlin, Heidelberg: Springer, 2015, p. 48. 
Il faut donc garder à l'esprit qu'en plus du but principal - à savoir augmenter la protection des créanciers bancaires - la plupart des dispositions légales répondent aussi à des objectifs secondaires et parfois contradictoires: le développement de crédits au bénéfice de l'économie nationale ou encore la protection des banques elles-mêmes. La loi de surveillance devient aussi une loi d'assainissement du monde bancaire.

\section{IV.2.1. Le champ d'application : régimes particuliers pour les banques cantonales et les banquiers privés}

Nous l'avons vu au cours de l'analyse de l'élaboration de la loi, la question de son champ d'application constituait évidemment un objet de vives négociations. Quelles sociétés devaient tomber sous le coup de la loi et y être - intégralement ou partiellement - soumises? ${ }^{20}$ Le texte final a renoncé à prescrire une définition précise et positive de la notion de banque; le législateur a préféré énoncer les domaines professionnels et types d'instituts situés à la lisière de l'activité bancaire, qui ne sont pas assujettis à la réglementation. À ce titre, les agents de change, maisons de bourse, gérants de fortune, notaires et hommes d'affaires "qui n'exercent pas une activité bancaire proprement dite " sont exclus du champ d'application ${ }^{21}$. Aussi longtemps qu'un gestionnaire de fortune ou agent de bourses ne se porte pas débiteur de son client de manière durable, il n'est pas soumis à la loi fédérale sur les banques, alors même qu'il reçoit des dépôts de fonds ${ }^{22}$. Pour être considéré comme banquier, il faut donc bénéficier d'une certaine marge de manœuvre avec les capitaux confiés, et ne pas simplement exécuter des ordres contre une commission.

Les sociétés financières - ces instruments mis en place en partenariat entre groupes bancaires et commerciaux servant pour le financement à long terme de certains secteurs, notamment industriels - sont soumises à trois degrés d'assujettissement selon la loi sur les banques ${ }^{23}$. Deux critères différencient

Sur la question du champ d'application, voir en particulier la publication du secrétaire de la Commission fédérale des banques: Graner, op. cit., 1937. Voir également: Brühlmann, op. cit., 1935, p. 29-40.

21 Loi fédérale sur les banques et les caisses d'épargne du 8 novembre 1934, art. I, al. 2.

22 Rossy, Reimann, op. cit., 1935, p. I2.

23 Pour une analyse plus développée sur le régime d'assujettissement des sociétés financières, cf. Giddey, op. cit., 20I7, p. I87-I89. Sur le développement des sociétés financières en Suisse, depuis la fin du XIX ${ }^{e}$ siècle: Peter Hertner, "Les sociétés financières suisses et le développement de l'industrie électrique jusqu'à la Première Guerre mondiale", in Fabienne Cardot (éd.), I880-1980: Un siècle d'électricité dans le monde, Paris: PUF, 1987, p. 341-355; Luciano Segreto, "Financing the electric industry worldwide: Strategy and structure of the Swiss electric holding companies, I895-1945", Business and Economic History, vol. 23, n' I, 1994, p. 162-175; Serge Paquier, "Swiss holding companies from the mid-nineteenth century to the early I930s: the forerunners and subsequent waves of creations ", Financial History Review, vol. 8, $\mathrm{n}^{\circ}$ 02, 200I, p. I63-182; Mazbouri, op. cit., 2005, p. 195-199. Pour une présentation qualitative et quantitative (bilans et profits et pertes) des sociétés financières liées aux grandes banques suisses de leur fondation à 1930, voir Jules Düblin, Die 
juridiquement la grande variété des sociétés financières : celui de leur caractère bancaire, à savoir si les entreprises financées n'appartiennent pas au même groupe, et celui et de l'appel au public pour obtenir des fonds. Tandis que les sociétés financières à caractère bancaire et faisant appel au public sont soumises à toutes les dispositions, celles qui ne font pas appel au public ne sont que très partiellement assujetties à la loi, puisque seules les dispositions sur l'exportation des capitaux et la transmission des bilans à la BNS leur sont appliquées. Enfin, les sociétés financières à caractère industriel ou commercial ne sont pas du tout soumises à la législation bancaire. Ce compartimentage des sociétés financières en trois catégories distinctes ouvre la voie à un risque "d'arbitrage réglementaire ", c'est-à-dire la pratique qui consiste à utiliser une faille réglementaire pour contourner des dispositions légales ${ }^{24}$. En effet, en excluant de son champ d'application les sociétés financières industrielles ou commerciales, quand bien même celles-ci reçoivent des fonds par appel au crédit public, la loi bancaire présente une lacune potentielle. Comme l'indique le spécialiste en lois bancaires Willi Schwander, cette imperfection risque de rendre toute la législation inopérante et illusoire: "En pratique, la loi sur les banques peut donc être contournée d'une manière relativement simple par l'intermédiaire des sociétés financières à caractère commercial et industriel. " $^{25}$

En plus des catégories d'intermédiaires financiers énumérés ci-dessus, deux types d'établissements bénéficient de régimes particuliers. Il s'agit, dans l'ordre croissant du degré d'assujettissement, des banques cantonales et des banquiers privés.

Les banques cantonales avaient, pendant la phase d'élaboration de la loi, redoublé d'efforts pour justifier de nombreuses dérogations. Il faut cependant constater une évolution dans leur attitude à l'égard de la loi sur les banques. Alors qu'elles envisageaient et exigeaient dans un premier temps une exclusion intégrale du champ d'application de la loi, les banques cantonales acceptent progressivement et tardivement d'y être partiellement soumises, mais revendiquent une série d'exceptions ${ }^{26}$. L'argumentaire des banquiers cantonaux, et de leurs puissants relais dans les chambres fédérales, en particulier au Conseil des États, reposait alors sur quatre points liés entre eux. De leur point de vue, une surveillance fédérale n'apporterait rien de nouveau ni de bénéfique pour les banques cantonales. Celles-ci sont organisées et contrôlées selon le droit cantonal. I9 des 27 instituts considérés comme banque cantonale, possèdent déjà

Finanzierungs- und Kapitalanlage-Gesellschaften der schweizerischen Grossbanken, Basel: Philographischer Verlag, 1937.

24 Sur la notion de regulatory arbitrage, voir par exemple: Eugene N. White, " "To Establish a More Effective Supervision of Banking" : How the Birth of the Fed altered Bank Supervision ", NBER Working Paper Series, $\mathrm{n}^{\circ}$ Working Paper I6825, 20II, p. I-55.

26 Sur la position initiale des banquiers cantonaux, cf. chap. III.I ; AASB, Procès-verbaux du Conseil de l'ASB, $93^{\mathrm{e}}$ séance, 13.03 .1933$. 
des inspectorats internes ${ }^{27}$. De plus, elles transmettent déjà volontairement des bilans intermédiaires à la Banque nationale. Quant aux questions relatives à l'exportation de capitaux et à l'organisation interne, elles ne les concerneraient pas. Les banques cantonales rappellent d'autre part qu'aucun de leurs créanciers n'a subi de pertes, et qu'en raison de la garantie cantonale, une intervention de la Confédération est peu probable. Finalement, elles évoquent une atteinte à la souveraineté cantonale et, conscientes de leur capacité d'influence au parlement, portent des menaces à peine voilées, en cas d'assujettissement à la loi fédérale. Dans une lettre au Département des finances datée du I4 octobre I933, la présidence de l'Union des banques cantonales suisses terminait son réquisitoire par la phrase suivante:

Nous espérons néanmoins avec confiance, Monsieur le Conseiller fédéral, vous avoir convaincu que l'assujettissement des banques cantonales est non seulement superflu et peu judicieux, mais aussi qu'il mettrait sérieusement en péril l'adoption par l'Assemblée fédérale, et éventuellement par le peuple, d'une loi sur les banques généralement souhaitée ${ }^{28}$.

Les banquiers cantonaux, au cours de l'élaboration de la loi, faisaient donc planer la menace référendaire, du moins tactiquement, en plus d'une opposition parlementaire déjà certaine, si leur statut n'était pas jugé satisfaisant. Au parlement, et en particulier au Conseil des États, les revendications des banques cantonales ont en effet été accueillies avec beaucoup de bienveillance. Le sénateur obwaldois Walter Amstalden (I883-1966), également président du conseil d'administration de la Banque cantonale d'Obwald, se fait le porteparole des banquiers cantonaux dans la Chambre haute. Sa proposition d'exclure entièrement les banques cantonales du champ d'application de la loi n'échoue qu'à une faible majorité de I9 contre is voix, malgré le soutien d'un autre président de banque cantonale, le conseiller aux États bernois PAB Carl Moser (I867-1959) ${ }^{29}$. C'est donc de justesse qu'elles demeurent en principe soumises à la loi. Il est vrai qu'il aurait été surprenant d'édicter une loi sur les banques, à laquelle échapperait la catégorie de banques la plus importante du pays, du point de vue de la taille des bilans publiés.

Malgré cet assujettissement de principe, les établissements cantonaux bénéficient selon le texte final adopté en novembre 1934, de dérogations sur quatre points précis. Ces assouplissements doivent être vus comme le prix à payer pour

27 Sur les 27 banques cantonales, I9 possèdent leur propre inspectorat, 3 se font contrôler par une société fiduciaire, 3 sont membres d'un syndicat de révision. AFB, E6520(B), 2007/62, vol. I8, Dossier 87*, Diverse Eingaben und Stellungnahmen. I93I-I934, Lettre du Präsidium des Verbandes Schweizerischer Kantonalbanken à l'Administration fédérale des finances, I4.IO.1933.

28 AFB, E6520(B), 2007/62, vol. 18, Dossier 87*, Diverse Eingaben und Stellungnahmen. 193II934, Lettre du Präsidium des Verbandes Schweizerischer Kantonalbanken à l'Administration fédérale des finances, I4.IO.I933, p. 6.

29 Bulletin officiel de l'Assemblée fédérale, Conseil des États, séance du i4.06.1934, p. 209-217. 
obtenir l'acceptation du projet par le Conseil des États. Premièrement, les banques cantonales ne sont pas tenues de respecter les prescriptions sur l'organisation interne, à savoir les règles de gouvernance d'entreprise exigeant par exemple de délimiter clairement le rayon d'activité dans des statuts et de séparer les organes de direction des organes de surveillance (art. 3, al. 4). Ces questions restent donc régies par le droit cantonal. Deuxièmement, elles échappent à l'obligation de constituer et d'alimenter un fonds de réserve (art. 5, al. 2). Ici aussi, on préfere maintenir les fonds de réserve prévue par chaque juridiction cantonale. Troisièmement, les dispositions qui prévoient une responsabilité civile plus sévère à l'égard des dirigeants de banque ne s'appliquent pas aux banques cantonales. Là aussi, les dispositions cantonales priment. Enfin, quatrièmement, - et c'est là la dérogation la plus significative - les banques cantonales sont dispensées de se soumettre à une révision fiduciaire externe, "si elles possèdent un service de révision exercé par des personnes qualifiées " (art. 18, al. 2). L'article 30 du règlement d'exécution du 26 février 1935 précise la portée de cette exemption. La Commission fédérale des banques y obtient le droit d'exiger que les banques cantonales l'informent si elles sont révisées par un service qualifié. Les moyens et les critères pour juger de la qualité de cette révision interne ne sont cependant pas précisés, ce qui engendrera certaines difficultés dans la pratique. Cette dispense répond également au souhait des banquiers cantonaux de ne pas tomber dans l'orbite des sociétés fiduciaires proches des grandes banques. Comme l'écrit Henri Bersier au conseiller national radical vaudois Henry Vallotton (189I-197I) : "Si les banques cantonales devaient se faire réviser par des fiduciaires, elles n'auraient pour le moment en Suisse que deux établissements, dépendant tous deux d'une grosse banque (Société fiduciaire suisse, émanant du Bankverein, et Fides, dépendant du Crédit Suisse); il y aurait de gros inconvénients à ce que les banques cantonales introduisent ces organes chez elles.» ${ }^{30}$ Même si le pronostic de Bersier se révèlera inexact, puisque les deux sociétés fiduciaires citées seront contraintes de renoncer à la révision bancaire, ce témoignage manifeste l'hostilité des banquiers cantonaux à l'égard des sociétés fiduciaires et la persistance de la concurrence avec les grandes banques.

Une fois ces dérogations ancrées dans la loi, il restait à définir précisément quels établissements allaient en bénéficier. En effet, alors que la garantie cantonale des engagements d'une banque constitue en principe le seul critère justifiant des mesures particulières, il est rapidement apparu que les trois établissements genevois et vaudois, la Caisse hypothécaire du Canton de Genève, la Banque cantonale vaudoise et le Crédit foncier vaudois, ne jouissent pas de la garantie cantonale. Il a donc fallu trouver une définition par laquelle ces établissements généralement considérés comme des banques cantonales et faisant partie de l'Union des banques cantonales suisses puissent y être

30 Cité par Beroud, op. cit., 20II, p. 207. (Archives de la Banque cantonale vaudoise, XXVI, carton «1927-1972 fusion CFV BCV », Rapport d'Henri Bersier à Henry Vallotton, conseiller national, I4.09.1934, p. 6-7). 
assimilés. C'est ce qui explique la tournure alambiquée de l'alinéa 4 de l'article 3 , qui cherche à faire une exception pour ces trois banques sans pour autant le nommer par leurs raisons sociales. Cette manœuvre est le résultat de l'important travail d'influence exercé par la Banque cantonale vaudoise ${ }^{31}$. La promesse est expressément faite au Parlement que les trois instituts obtiendront le même statut que les autres banques cantonales ${ }^{32}$. Selon la définition formulée dans la loi sur les banques - première définition juridique de la notion de banque cantonale, 3I établissements sont assujettis en tant que banques cantonales ${ }^{33}$.

La seconde catégorie de banques à profiter d'un régime d'exception est celle des banquiers privés ${ }^{34}$. Comme nous l'avons vu, leurs représentants, à l'image du Zurichois Max E. Bodmer, n'ont eu de cesse de revendiquer des dérogations pour échapper à l'une ou l'autre disposition légale. Ainsi, les banquiers privés avaient insisté, dans leurs démarches auprès de l'administration fédérale, à la fois sur la forme juridique spécifique de leurs institutions, à savoir les raisons sociales individuelles, sociétés en nom collectif et société en commandite, et sur les particularités de leur structure financière, qui repose davantage sur la confiance et la fortune personnelle des associés que sur la taille des bilans. Ainsi, un groupement de banquiers privés avait écrit au Département des finances en décembre 1933, en insistant «sur le nombre considérable de représentants de leur corporation [...], sur la fonction qu'ils remplissent dans la vie économique suisse, mais aussi sur le fait que de nombreux banquiers privés existent depuis plus d'un siècle et qu'ils n'ont jamais, à notre connaissance, fait appel à l'aide financière de la Confédération ou d'un canton ${ }^{35}$.

31 Sur ce point, cf. Ibid., p. $205-207$.

32 Bulletin officiel de l'Assemblée fédérale, Conseil des États, séance du I4.06.1934, p. 219. Bulletin officiel de l'Assemblée fédérale, Conseil national, séance du 26.09.1934, p. 64I-644.

33 Selon Graner, op. cit., I937, p. 26-27. Il s'agit des 3I banques suivantes: AG: Aargausiche Kantonalbank; AI : Appenzell-Innerrhodische Kantonalbank; AR: Appenzell-Ausserrhodische Kantonalbank; BE: Kantonalbank von Bern, Hypothekarkasse des Kantons Bern ; BL: Basellandschaftliche Kantonalbank; BS: Basler Kantonalbank; FR: Banque de l'État de Fribourg; GE : Caisse Hypothécaire du Canton de Genève, Caisse d'Épargne de la République et Canton de Genève; GL: Glarner Kantonalbank; GR: Graubündner Kantonalbank; LU : Einzinserkasse des Kantons Luzern, Luzerner Kantonalbank; NE: Banque cantonale Neuchâteloise ; NW : Nidwaldner Kantonalbank ; OW : Obwaldner Kantonalbank ; SG : St-Gallische Kantonalbank; SH: Schaffhauser Kantonalbank; SO : Kantonal-Ersparniskasse Solothurn, Solothurner Kantonalbank; SZ: Kantonalbank Schwyz; TG : Thurgauische Kantonalbank; TI: Banca dello Stato del Cantone Ticino; UR: Urner Kantonalbank; VD: Banque Cantonale Vaudoise, Caisse d'épargne cantonale vaudoise, Crédit Foncier Vaudois; VS: Banque Cantonale du Valais; ZG : Zuger Kantonalbank; ZH : Zürcher Kantonalbank.

34 Sur ce point, voir par exemple: Max Ernst Bodmer, Zur Tätigkeit und Stellung der Privatbankiers in der Schweiz, Zürich : Schulthess \& Co, 1934, p. 32-39.

35 AFB, E6520(A), I000/I059, vol. 2, Stellungnahme der Privat-Banquiers der Schweiz zum Vorentwurf des Bundesgesetzes über die Beaufsichtigung der Banken und den Schutz der Spareinlagen, 28.12.1933, p. 6. 
Seuls les banquiers privés qui ne font pas appel au public pour obtenir des dépôts de fonds peuvent tirer avantage des dérogations prévues par la loi ${ }^{36}$. Précisons que la grande majorité des banquiers privés ne font pas appel au crédit public - ou y renonce dès l'entrée en vigueur de la loi; fin 1937, 90\% des maisons tombent sous cette catégorie ${ }^{37}$. Ces derniers bénéficient donc de quatre dérogations. Premièrement, les banquiers privés ne sont pas tenus de respecter un ratio de fonds propres (art. 4, al. 4). Cette exception est justifiée par les banquiers privés en soulignant le fait que les maisons privées ne disposent pas d'un capital social à la manière des sociétés par actions, mais qu'elles s'appuient sur la fortune personnelle du ou des propriétaires. Il serait donc hasardeux de déterminer l'importance des fonds propres par rapport aux engagements. En revanche, les dispositions sur la liquidité s'appliquent aux banquiers privés. Deuxièmement, au même titre que les banques cantonales, les banquiers privés sont dispensés de la constitution et de l'alimentation d'un fonds de réserve (art. 5, al. 2). Là aussi, l'élément déterminant pour légitimer cette exception est le fait que le sociétaire d'une banque privée soit personnellement et indéfiniment responsable des engagements. Troisièmement, les banquiers privés ne sont pas tenus de publier leurs bilans intermédiaires ni leurs comptes annuels (art. 6, al. 6, ordonnance art. 24). Qui plus est, la dispense de la publication de la comptabilité bancaire s'étend même en partie aux banques privées qui font appel au crédit public. En effet, ces dernières ne doivent pas publier leurs bilans, mais seulement les tenir à disposition du public, qui peut les consulter aux guichets. Cette limitation de la transparence comptable des banquiers privés trouve son explication dans le fait que la publicité bancaire, dans le cas des banquiers privés, ne renforce pas la responsabilité des sociétaires à l'endroit des créanciers. Quatrièmement, comme les banques cantonales, les banquiers privés sont exemptés des articles qui imposent une responsabilité civile renforcée aux dirigeants de banque (art. 38). En effet, en raison des formes juridiques particulières des maisons privées, leurs sociétaires demeurent soumis aux dispositions du Code des obligations.

Ces quatre dérogations permettent donc de maintenir un régime particulier qui tient compte à la fois de leurs formes juridiques caractéristiques et de leurs activités bancaires privilégiées, à savoir la gestion de fortune, les opérations sur titres et le placement d'emprunts. Les banquiers privés ont donc su contourner l'opposition des grandes banques qu'elles ont rencontrée au sein de l'ASB sur certains points précis, en déployant leurs propres canaux d'influence à destination des législateurs. Les nombreux courriers adressés par des financiers comme Max E. Bodmer, Robert La Roche ou encore Jean Lombard à l'Administration fédérale des finances et aux parlementaires en témoignent. À l'Assemblée fédérale, les banquiers privés peuvent d'ailleurs compter sur le

Le critère de "faire appel au public pour obtenir des dépôts de fonds » est déterminant pour bénéficier de dérogations. Il est formulé par Adolf Jöhr, au détriment d'une proposition alternative moins contraignante des banquiers privés.

37 Theo Keller, «Banken», in Keller, et al. (éd.), op. cit., 1939, p. I6o. 
soutien actif de certains députés. Ainsi, le conseiller national catholique-conservateur tessinois Giovanni Polar (I868-194I), dans une comparaison avec les grandes banques, en dresse un portrait élogieux:

Le banquier privé, au contraire, n'est lié par aucune entrave. Il peut être l'ami, l'associé du client (il peut arriver aussi qu'il le mène à la ruine, malheureusement); il est en général le confident, le confesseur, l'avocat, le conseiller habituel pour l'administration de sa fortune. Au client de choisir un ami, et pas un voleur. Rien de commun entre la formidable machine d'argent et un banquier qui est un corps vivant et qui, surtout, possède une $\mathrm{âme}^{38}$.

C'est en recourant à un argumentaire de ce type, auquel il faut ajouter l'inquiétude de voir le nombre de banquiers privés, qui diminue depuis la fin du XIX siècle, accélérer son déclin, que cette branche particulière du paysage bancaire suisse parvient à obtenir une position relativement favorable dans la loi de 1934. Ajoutons encore que les négociations autour de cette législation ont donné lieu à la création, le 29 novembre 1934 à Berne, de "l'Association des banquiers privés de Suisse » (Vereinigung Schweizerischer Privatbankiers), chargée de défendre les intérêts spécifiques de cette catégorie d'instituts. Alors que les autres groupes de banques disposaient déjà de groupements spécifiques, tels que le Cartel des banques suisses, l'Union des banques cantonales suisses ou encore l'Union suisse de banques régionales, caisses d'épargne et de prêts (Verband schweizerischer Lokalbanken, Spar-und Leihkassen, fondée I920 et basée à Zurich), les banquiers privés, attachés aux traditions propres à chacune des places de Zurich, Bâle ou Genève, ne s'étaient pas encore regroupés au sein d'une association d'intérêts nationale. L'Association des banquiers privés de Suisse avait ainsi pour but à la fois de défendre les intérêts spécifiques de ses membres, en particulier dans la concurrence interne avec les grandes banques, mais aussi de différencier les banquiers privés d'un certain rang des simples agents de bourses et autres spéculateurs ${ }^{39}$. Aussi, seulement une trentaine de maisons y entrent dans un premier temps, les conditions d'adhésion étant relativement exigeantes. Fin I944, 40 sociétés de banquiers privés en font partie ${ }^{40}$.

En plus des sociétés financières, des banques cantonales et des banquiers privés, les succursales de banques étrangères connaissent aussi un statut particulier selon la loi bancaire de 1934. Présentes en Suisse, et en particulier à Genève

Bulletin officiel de l'Assemblée fédérale, Conseil national, séance du 26 septembre 1934, p. 638. Perrenoud, et al., op. cit., 2002, p. II8-II9. Sur l'ABPS, voir aussi : Lehmann, op. cit., 1956, p. 97-IO3.

Wegelin, W., "Vereinigung schweizerischer Privatbankiers », in Rudolph J. Kaderli, Edwin Zimmermann (éd.), Handbuch des Bank-, Geld- und Börsenwesens der Schweiz, Thun: Verlags Aktiengesellschaft, 1947, p. 445-446. 
et à Bâle, depuis la fin du XIX ${ }^{e}$ siècle, les établissements étrangers sont essentiellement des succursales de grandes banques françaises, voire italiennes ou anglaises (cf. chap. VIII.2). L'article 2 de la loi précise donc que les sièges, succursales, agences et représentants de banques étrangères entrent dans son champ d'application ; leur activité en Suisse est soumise à des conditions particulières, comme l'octroi de la réciprocité aux banques suisses - c'est-à-dire qu'une banque suisse doit pouvoir ouvrir une succursale dans le pays d'origine d'une banque étrangère pour que celle-ci soit admise en Suisse - et le dépôt d'une garantie. L'assujettissement à la loi des banques juridiquement étrangères est précisé par la Commission fédérale des banques dans une ordonnance datant du Is février $1936^{41}$. Ces dispositions exigent de présenter à la Commission fédérale des banques les statuts et la comptabilité annuelle de la succursale comme de la maison-mère, et de désigner un gérant responsable domicilié en Suisse. Elles prévoient également la provision d'une caution, en particulier si la banque accepte des dépôts d'épargne. Ces mesures s'appliquent cependant uniquement aux agences, comptoirs et succursales des banques étrangères, ainsi qu'à leurs représentants, qui eux ne disposent pas d'une personnalité juridique; les banques constituées de manière indépendante sous le droit suisse à partir de capitaux étrangers - c'est-à-dire de simples filiales - y échappent entièrement. L'un des auteurs de l'ordonnance du is février, Paul Graner, la commente de manière élogieuse, estimant qu'elle protège les intérêts suisses, sans pour autant entraver l'activité loyale des banques étrangères, mais suffisamment pour " tenir à l'écart ou éliminer les éléments malsains et déloyaux " ${ }^{42}$. Cet autosatisfecit, puisque Graner est employé du secrétariat de la CFB, cache cependant certaines des tensions qui ont présidé à l'élaboration de cette ordonnance. En fait, les membres de la Commission fédérale des banques ont formulé ce décret de manière très peu interventionniste à l'égard des banques étrangères, dans la crainte de représailles françaises ou anglaises ${ }^{43}$. L'ordonnance du is février 1936 est de plus le résultat d'une étroite consultation avec la Société de Banque Suisse, qui est en 1935 encore la seule banque à disposer d'une succursale à l'étranger, en l'occurrence celle de Londres établie en $1898^{44}$.

Alors que la question des banques étrangères en Suisse jouera un rôle important dans la révision de loi sur les banques dans les années 1960, il faut ici constater que dès le départ, le cadre réglementaire prévoit des mesures protectionnistes. Relevons que l'introduction dans la loi d'une clause de réciprocité est l'œuvre d'Adolf Jöhr, le directeur général du Crédit Suisse ${ }^{45}$.

41 ABNS, I.3/I220, "Ordonnance de la commission fédérale des banques concernant les banques étrangères qui exercent une activité en Suisse ", I5.02.1936.

42 Graner, op. cit., 1937, p. II5.

43 Cf. E6520(A), I000/I059, vol. 6, PV CFB, I0.09.I935, p. I89-I90, II.IO.I935, p. 2IO, II.I2.I935, p. 28I.

44 Sur le siège londonien de la SBS: Mazbouri, op. cit., 2005, p. 306-315.

45 ABNS, I.3/1215, Procès-verbal de la $\mathrm{I}^{\text {re }}$ session de la Commission du Conseil des États pour l'examen du projet de loi fédérale sur les banques et les caisses d'épargne, I4.02.I934, p. 4O-4I. 
Ce principe de la réciprocité, discrètement intégré dans la loi de 1934 par le dirigeant de la plus grande banque suisse et sans effet pendant longtemps, deviendra dans les années 1970 le principal frein à l'installation en Suisse des banques étrangères jugées indésirables. Dans les années 1930, le nombre relativement restreint de succursales bancaires étrangères installées en Suisse rend la question moins préoccupante. À la suite de l'entrée en vigueur de l'ordonnance de la CFB de février 1936, seules neuf banques juridiquement étrangères sont soumises à la loi ${ }^{46}$.

Ces considérations nous amènent à la délicate question des conditions requises pour ouvrir une banque, qu'elle soit d'origine étrangère ou suisse. Nous y reviendrons plus bas. L'ouverture ou la fermeture des critères d'entrée dans le marché (entry conditions) constitue en effet une variable essentielle pour comprendre la nature concurrentielle ou monopolistique d'un régime de régulation ${ }^{47}$. Retenons pour l'instant la faiblesse d'intervention des autorités publiques, qui statue sur la base d'un matériel documentaire très limité, souvent sans aucun contact direct avec les dirigeants de l'établissement. Aucune sanction n'est prévue pour sévir contre une banque qui néglige de s'annoncer à la CFB ${ }^{48}$. Malgré les propositions dans ce sens faites au cours de l'élaboration de la loi, il n'existe pas, en Suisse, de système de concession qui aurait permis à la Commission fédérale des banques de refuser une ouverture de banque jugée indésirable. Un tel système est pourtant fréquent dans les législations étrangères et figurait aussi dans le projet Landmann de 1916. Le système de l'autorisation choisi en 1934 est bien plus ouvert: à partir du moment où les statuts et règlements d'une banque requérante sont jugés conformes à la loi, c'està-dire s'ils délimitent le champ d'activité et prévoient une organisation interne adéquate, la CFB remet à l'établissement une autorisation lui permettant de s'inscrire au registre du commerce. Il n'existe donc pas de clause de besoin ou de critères moraux sur la probité des dirigeants prévus qui permettraient d'empêcher l'ouverture d'une banque. Même l'économiste Denis Piguet, peu enclin à formuler des observations critiques sur le système bancaire suisse et sa régulation $^{49}$, regrette ce manque:

46 Selon le rapport annuel de la Commission fédérale des banques au Conseil fédéral pour l'année 1936. AFB, E6520(A), 1983/50, vol. I3, Geschäftsberichte. La liste des banques pour 1936 révèle le nom de ces instituts. Cf. AFB, E6520(B), 2009/28, vol. 162, «Bankenverzeichnis 1935-I954". Il s'agit des banques suivantes: The American Express Company (6 succursales, siège à Hartford et New York), Crédit Industriel d'Alsace et de Lorraine (Bâle, siège à Strasbourg), H. Glorieux et Cie (Bâle, siège à Bruxelles), Banque de Paris et des Pays-Bas (Genève, siège à Paris), Banque Parisienne de Crédit au Commerce et à l'Industrie (Genève, siège à Paris), Crédit Lyonnais (Genève, siège à Lyon et Paris), Lloyds and National Provincial Foreign Bank Limited (Genève, siège à Londres), Banco di Roma (Lugano, siège à Rome), Société Générale Alsacienne de Banque (Zurich, siège à Strasbourg).

47 Grossman, op. cit., 20I0, p. I34-I45.

48 Rossy, Reimann, op. cit., I935, p. 80.

49 Denis Piguet, après avoir défendu une thèse en sciences commerciales et économiques à HEC Lausanne en 1953, devient associé de la maison de banque privée familiale, Piguet \& Cie, à Yverdon. Il épouse la petite-fille de Rodolphe de Haller (I874-1962) - premier vice- 
Il y a lieu de remarquer à ce propos que la loi suisse, contrairement à celle de plusieurs autres pays, n'a prescrit aucune disposition particulière traitant de la capacité, de la moralité, de la malhonnêteté, etc. des banquiers. Quand on songe qu'un dirigeant de banque puni pénalement peut continuer à exercer son activité, on ne peut nier qu'il y ait là une lacune de la loi ${ }^{50}$.

\section{IV.2.2. Mesures de régulation prudentielle : ratios de fonds propres et de liquidité, organisation interne adéquate, privilège sur les dépôts d'épargne}

Après avoir défini son champ d'application, la loi fédérale sur les banques prescrit une première série de mesures à but préventif. Il s'agit de l'article décrétant le respect d'une proportion appropriée entre les fonds propres et les engagements d'une part, et entre les actifs facilement mobilisables et les engagements à court terme d'autre part (art. 4, ordonnance art. IO-19). Parmi les autres règles prudentielles introduites, il faut mentionner les mesures sur l'organisation interne des banques, sorte de gouvernance d'entreprise exigeant une séparation claire entre conseil d'administration et direction. L'article is mettant en place un privilège sur les dépôts d'épargne jusqu'à concurrence de 5000 francs constitue la troisième disposition visant explicitement la protection de créanciers.

L'institution de ratios de fonds propres et de liquidité minimaux dans la loi a pour but d'accroître la sécurité du public et la stabilité du système bancaire. En empêchant un accroissement démesuré des engagements d'une banque, le rapport de fonds propres, aujourd'hui appelé ratio de solvabilité, vise à éviter que des pertes de la banque conduisent inéluctablement à des pertes pour son créancier. Il agit comme un matelas de sécurité. Quant au ratio de liquidité, il vise aussi à limiter l'impact des paniques bancaires, en assurant aux banques des liquidités suffisantes pour permettre aux déposants de retirer leurs fonds sans que la banque doive recourir à la Banque nationale.

Nous avons vu que la prescription d'exigences sur les fonds propres et la liquidité était déjà au programme du contrôle bancaire prôné par Schulthess en I9I4, et s'était concrétisée dans le projet Landmann de I9I6. Ce dernier évitait cependant de déterminer un pourcentage figé, et laissait à l'autorité de surveillance le soin de fixer la teneur et l'application des ratios. Puis, dans les années 1930, ce n'est que dans la version renforcée du projet de novembre 1933, sous l'effet de la crise de la Banque Populaire Suisse, que les dispositions sur les fonds

président de la BNS (1907-1920) et président de la Basler Handelsbank (1920-1947). La thèse de Denis Piguet est dirigée par le professeur Henri Borle, membre de la CFB, et Piguet bénéficie d'une relecture attentive de son manuscrit par le secrétariat de la Commission fédérale des banques. 
propres et la liquidité sont reprises dans l'ébauche de loi. Le projet Landmann a sans doute exercé une forte influence, comme semble indiquer la formulation proche des deux articles. Les dispositions sur les fonds propres et la liquidité passent les différentes étapes de discussion entre novembre 1933 et novembre I934 sans susciter d'importants débats; il est vrai que la loi elle-même ne fait qu'établir le principe de deux coefficients, laissant au règlement d'exécution la délicate tâche d'en déterminer la composition précise.

C'est donc au cours de l'hiver 1935, au sein des commissions d'experts réunies par le Département des finances pour rédiger l'ordonnance de la loi bancaire, que sont arrêtées la teneur et la portée des dispositions sur les fonds propres et la liquidité. Les discussions se basaient alors sur des recherches effectuées au cours de l'année 1934, et mandatées à l'expert Arthur Stampfli ${ }^{51}$. Dès le départ, l'administration fédérale adopte une démarche très pragmatique. Elle cherche à fixer les exigences légales en fonction de la situation existante chez les banques, plutôt qu'à partir de considérations théoriques ou d'exemples étrangers ${ }^{52}$. Au cours de la négociation de l'ordonnance de la loi bancaire, nous l'avons vu, le projet initial du Département des finances, qui prévoyait une liquidité variable en fonction de la taille de l'institut et de l'importance relative du portefeuille hypothécaire, est concurrencé par un projet émanant d'Adolf Jöhr qui propose de faire dépendre le ratio de liquidité uniquement de l'importance des engagements à court terme. C'est le projet Jöhr qui l'emporte. La réglementation en vigueur, modelée de manière décisive par le directeur général du Crédit Suisse, et dont le principe restera en application jusqu'en $1987^{53}$, fonctionne de la façon suivante. Elle distingue en fait deux taux de liquidités qui doivent être respectés : la liquidité de caisse (Kassenliquidität) d'une part et la liquidité générale (Gesamtliquidität ou zweite Liquidität) d'autre part.

La liquidité de caisse se calcule en tant que rapport entre les engagements à court terme et les disponibilités. Le niveau minimal de la liquidité de caisse varie en fonction de l'importance des engagements à court terme. Plus un établissement a le caractère d'une banque commerciale (c'est-à-dire avec une forte proportion d'engagements à court terme), plus sa liquidité doit être élevée. Les taux exigés fluctuent entre $2.5 \%$ et $5 \%$.

Quant à la liquidité générale, il s'agit du rapport entre les engagements à court terme et les actifs facilement mobilisables. Ces actifs-là sont par exemple des effets et bons du Trésor admis par la Banque nationale suisse. Au cours de la négociation du règlement d'exécution, les discussions sur la définition des actifs facilement mobilisables avaient donné lieu à des débats animés. Certains banquiers ont cherché à imposer une acception la plus large possible, en

51 ABNS, I.3/I2I7, Bericht über die statistischen Grundlagen für die Aufstellung von Ausführungsbestimmungen zu Art. Io des Entwurfes zu einem Bundesgesetz über die Banken und Sparkassen vom 2. Februar 1934, 28.06.1934.

52 Sur ce point, voir aussi : Hugo Bänziger, Die Entwicklung der schweizerischen Liquiditätsvorschriften, Zürich : [s.n.], I988, p. I3-18.

53 Ibid., p. I4. 
proposant par exemple de comptabiliser aussi les avoirs en compte de virements (Giroguthaben) déposés auprès des banques cantonales et des grandes banques de la même façon que ceux placés à la BNS ${ }^{54}$. S'ils n'ont pas obtenu gain de cause sur ce point, le catalogue des actifs facilement mobilisables a cependant connu une extension significative. Les taux minimaux exigés par la loi, pour la liquidité générale, sont fixés au décuple de ceux de la liquidité de caisse. Ils varient donc entre $25 \%$ et $50 \%$, toujours selon l'importance des engagements à court terme de l'établissement. Il semble que pour la stabilité durable d'une banque, la liquidité générale est d'une importance supérieure à la liquidité de caisse : un établissement bénéficiant d'une liquidité générale suffisante pourra se procurer les disponibilités nécessaires en réalisant certains actifs.

La fixation de ces taux en fonction de la situation existante chez les banques suisses, pour ne pas nécessiter une adaptation de la part des banques, a conduit à l'instauration de taux de liquidité minimaux extrêmement bas. Moins de vingt ans après l'entrée en vigueur de la loi, Denis Piguet émet le jugement suivant: "L'expérience a montré que les prescriptions précisées dans le règlement d'exécution sur la liquidité ne remplissent à vrai dire plus leur but; aucune banque ne saurait, en effet, se contenter de la liquidité légale actuelle. " ${ }^{55} \mathrm{La}$ faiblesse relative des niveaux minimaux requis est rapidement apparue à l'examen des niveaux de liquidité requis et effectifs, qui ressortent clairement du tableau 8 , élaborés selon les statistiques de la Banque nationale.

On constate qu'il existe un écart significatif entre la liquidité exigée par la loi et celle dont disposent effectivement les banques. En prenant en compte l'ensemble des banques en Suisse, la liquidité de caisse reportée dans la statistique est en moyenne entre 1935 et 19408 fois plus élevée que le minimum exigé. Quant à la liquidité générale, les niveaux effectivement reportés par les banques s'élèvent au triple du minimum légal. Ces écarts entre liquidité exigée et liquidité exposée peuvent d'ailleurs être interprétés diversement. S'agit-il d'un signe de sagesse des dirigeants bancaires qui ont su maintenir des niveaux plus élevés que les coefficients exigés ou plutôt d'une certaine timidité de la part du législateur, réticent à mettre en vigueur une mesure qui entraverait la liberté d'entreprise des banques?

Après avoir fixé les exigences minimales de liquidité, les législateurs devaient encore mettre en place des mesures de contrôle. Comment pouvait-on assurer le maintien d'une liquidité suffisante de manière constante durant l'année et éviter que les banques ne procèdent à une "Frisur " (un toilettage) des comptes en fin d'année pour afficher officiellement des taux convenables? Diverses propositions, formulées notamment par le représentant de la banque centrale, visant à garantir un contrôle plus régulier de la liquidité, qui incluaient par exemple des échantillons statistiques établis par les réviseurs, ou la constitution

\footnotetext{
54 AFB, E6520(A), I000/1059, vol. 5, Protokolle der kleinen Expertenkommission über die Vollziehungsverordnung zum Bankengesetz, 07.0I.1935, p. 33.

55

Piguet, op. cit., 1953, p. 379-380.
} 


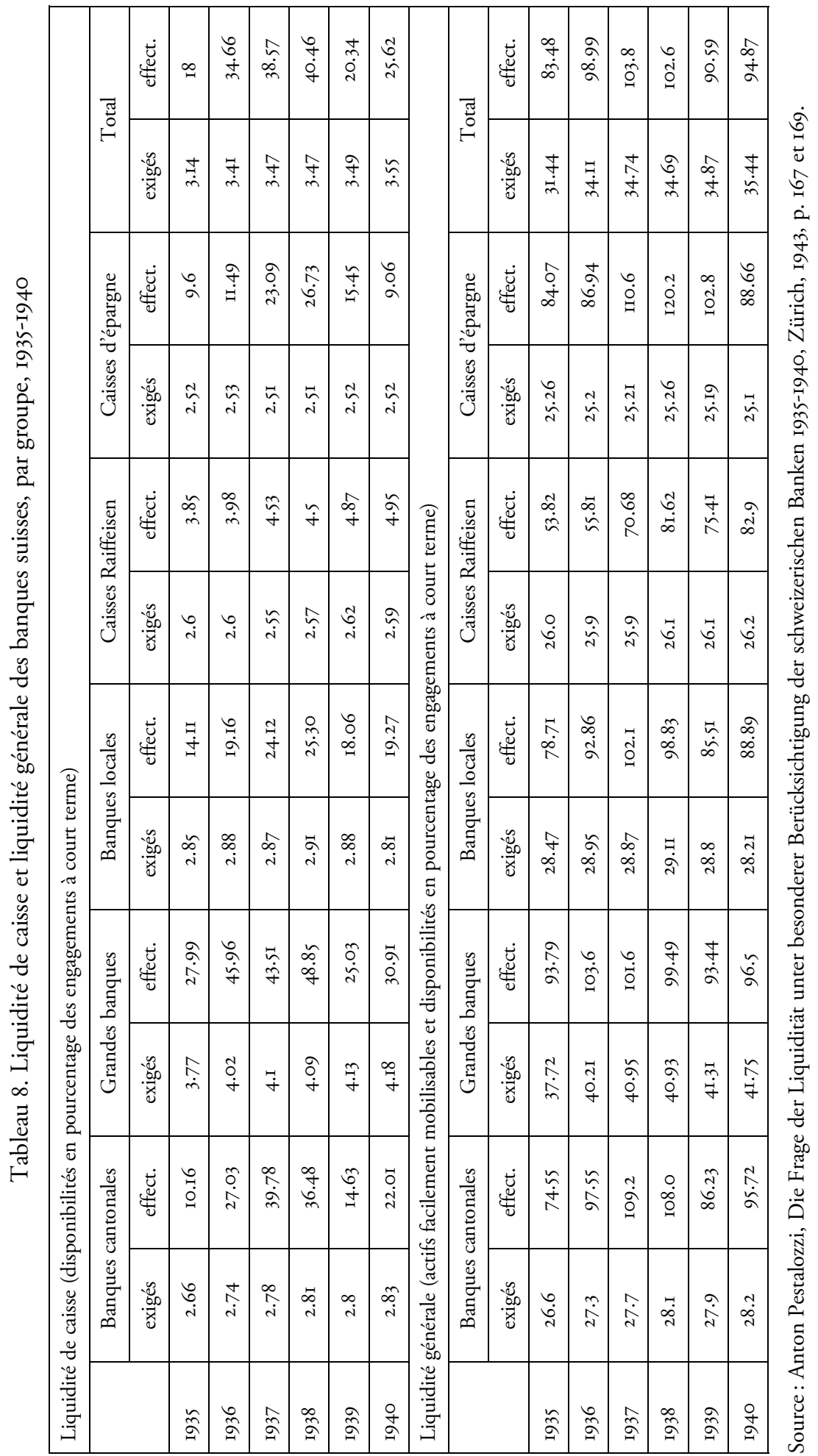


par les banques de bilan de liquidité à transmettre à la BNS ou à la CFB, sont repoussées par la commission d'experts en janvier $1935^{56}$. La solution adoptée est pour le moins minimaliste: les banques doivent établir un état de leur liquidité, annuel ou semestriel, et l'annexer à leurs comptes annuels. Il revient ensuite aux réviseurs procédant à la révision annuelle de l'établissement d'attester, dans leur rapport de révision, que les prescriptions légales de fonds propres et de liquidité sont respectées (ordonnance, art. 38, al. 2, lit. c et d). Rien n'empêche une banque à la trésorerie déficiente de procéder à un window dressing de fin d'année, au moment d'établir l'état de la liquidité. D'ailleurs, la valeur même d'un niveau de liquidité qui est vérifié avec plusieurs mois de décalage, comme c'est le cas au moment où un réviseur s'y attèle, est très relative.

De fait, les dispositions sur la liquidité, plus que des mesures qui accroissent la sécurité des déposants, deviendront dans leur application des instruments de la politique monétaire de la Banque nationale. Comme le montre Hugo Bänziger, l'institut d'émission utilise les informations sur la liquidité qu'il obtient dans le cadre de la loi sur les banques pour orienter sa politique d'escompte ${ }^{57}$. Cette tendance se renforcera durant les Trente Glorieuses, comme nous le verrons, lorsque la banque centrale tentera de durcir les exigences de liquidité pour combattre la surchauffe économique (cf. chap. VII.4).

Quant aux dispositions sur les fonds propres, elles suivent un développement semblable. Ces derniers sont définis par la loi comme le capital social versé, ainsi que la moitié du capital non versé. S'ajoutent au capital les réserves affichées au bilan, ainsi que les bénéfices de l'exercice précédent. Les réserves latentes, qui jouent un rôle important dans l'économie suisse, ne peuvent pas être incluses dans le calcul des fonds propres. La somme du capital versé et des réserves figurant au bilan, considérée comme fonds propres, doit être maintenue dans une certaine proportion par rapport aux engagements de la banque. Le rapport est déterminé de la manière suivante : pour les banques cantonales et les sociétés coopératives, il est fixé à $5 \%$. Pour les autres banques, il varie entre 5 et ro \%, selon la nature des engagements. Plus une banque est engagée dans des créances hypothécaires en Suisse, ainsi que dans le financement public helvétique (obligations de la Confédération, des CFF, des cantons, etc.), moins ses exigences de fonds propres seront élevées. Là aussi, il s'agit de taux extrêmement faibles, par rapport aux montants de fonds propres dont disposent déjà les banques suisses. Le niveau des fonds propres exigé légalement représente un

\footnotetext{
56 AFB, E6520(A), I000/1059, vol. 5, Protokolle der kleinen Expertenkommission über die Vollziehungsverordnung zum Bankengesetz, 08.oI.1935, p. 48-5I.

57

Bänziger, op. cit., 1988, p. I6.
} 
enjeu crucial pour les banquiers. En effet, un ratio de fonds propres élevés, même s'il augmente théoriquement la solvabilité, implique une rémunération actionnariale coûteuse pour la banque. Comme le niveau exigé dépend de la croissance ou de la baisse des engagements, une politique d'expansion des crédits peut être freinée lorsque les minimas légaux de fonds propres sont atteints, ce qui nécessite une augmentation de capital, par exemple sous la forme de mise en réserve. Il était donc essentiel que la fixation légale des proportions dans l'ordonnance soit suffisamment élevée pour constituer en apparence un garant de sécurité, mais surtout assez faible pour ne pas devenir une contrainte à l'expansion des crédits. Plus les exigences légales étaient basses, plus la marge de manœuvre des banquiers dans leur politique de mise en réserve augmentait, et - partant - leur capacité à dégager des profits au détriment de la sécurité des déposants.

Tableau 9. Fonds propres des groupes bancaires suisses (capital et réserves en pourcentage des engagements portés au bilan), I925-1937

\begin{tabular}{|c|c|c|c|c|c|}
\hline & $\begin{array}{c}\text { Banques } \\
\text { cantonales }\end{array}$ & $\begin{array}{c}\text { Grandes } \\
\text { banques }\end{array}$ & $\begin{array}{c}\text { Banques locales } \\
\text { et moyennes }\end{array}$ & $\begin{array}{c}\text { Caisses } \\
\text { Raiffeisen }\end{array}$ & $\begin{array}{c}\text { Caisses } \\
\text { d'épargne }\end{array}$ \\
\hline I925 & I3.5 & I7.4 & I6.I & 4.27 & 5.9 \\
\hline I926 & I3 & I6.5 & I5.9 & 4.24 & 6.1 \\
\hline I927 & I3.I & I6.3 & I5.9 & 4.52 & 6.3 \\
\hline I928 & I2.9 & I6.7 & I5.4 & 4.54 & 6.3 \\
\hline I929 & I2 & I6.2 & I5.6 & 4.52 & 6.4 \\
\hline I930 & I2.I & I5.4 & I4.8 & 4.46 & 6.5 \\
\hline I93I & II.9 & 20.2 & I4.4 & 4.38 & 6.2 \\
\hline I932 & I2 & 23.5 & I4.4 & 4.42 & 6.4 \\
\hline I933 & I2 & 23.3 & I4.3 & 4.56 & 6.4 \\
\hline I934 & II.8 & 25.1 & I4.6 & 4.7 & 6.5 \\
\hline I935 & II.6 & 28.8 & I5.4 & 4.97 & 6.4 \\
\hline I936 & II.4 & 20.4 & I5.8 & 5.28 & 7.3 \\
\hline I937 & II.6 & I7.8 & I6.2 & 5.39 & 7.3 \\
\hline
\end{tabular}

Source: Schwander, op. cit., 1943, p. 55-56.

Ici aussi, il faut relever que les fonds propres affichés par les banques suisses - à l'exception des caisses Raiffeisen et des caisses d'épargne - dépassent de beaucoup les minimas légaux oscillant entre 5 et io \%. Cela signifie que ces dispositions n'incitent pas la grande majorité des établissements financiers à faire preuve de plus de retenue et de prudence dans l'octroi de nouveaux crédits; sans même enfreindre les exigences légales des fonds propres, une banque pourrait augmenter ses engagements dans une forte mesure. Cet état de fait conduit l'économiste Willi Schwander à émettre une critique à l'égard 
des rapports de couverture minimaliste exigés par la loi : "On peut difficilement parler d'une protection des créanciers dans ces cas, car une banque commerciale qui présente à peine le taux de couverture légal minimal n'est à notre avis plus très éloignée de la faillite. ${ }^{58}$ Cet avis est partagé par un expert international, le professeur de droit français Max Cluseau : «Inutile d'insister longuement sur la faiblesse relative de ces pourcentages qui sont légèrement inférieurs à ceux déjà existants dans la plupart des grandes banques suisses, car ce qu'a voulu fixer la loi c'est un pourcentage minimum et non un pourcentage normal d'exploitation. " ${ }^{59}$ Le matelas de sécurité que représentent les fonds propres, qui se justifie par la garantie accrue qu'il offre aux déposants, perd de sa valeur dans la réglementation suisse en raison de la faiblesse du rapport de couverture requis. Le contrôle du maintien du rapport de couverture de fonds propres souffre des mêmes défauts que celui de la liquidité. Il s'agit uniquement d'une vérification formelle effectuée chaque année par l'institut de révision, sur la base de la comptabilité annuelle fournie par la banque. Aucun contrôle ponctuel n'est prévu.

Soulignons finalement que la loi bancaire suisse, dans le domaine des ratios de fonds propres et de liquidité, ne laisse que peu de marge de manœuvre à l'instance de surveillance - la Commission fédérale des banques. Cette dernière peut uniquement prévoir des dérogations aux taux fixés dans le règlement d'exécution "dans des cas spéciaux" (ordonnance art. I8). Les juristes ne s'accordent pas sur la portée exacte de ce que sont les "conditions normales" de l'art. 4 de la législation et les "cas spéciaux». Toujours est-il qu'au cours de l'élaboration de l'ordonnance, les banquiers, en la personne de Max Staehelin, avaient obtenu la promesse que ces dérogations ne devaient s'entendre que dans le sens d'un assouplissement des exigences et non d'un renforcement ${ }^{60}$. La Commission fédérale des banques est donc mal pourvue pour modifier ou assurer l'application des dispositions sur la liquidité et les fonds propres. Cela contraste avec d'autres législations bancaires introduites dans les années I930. En Allemagne, c'est l'Aufsichtsamt für das Kreditwesen qui remplace en 1934 le Kuratorium mis en place en I93I comme organe chargé de fixer les rapports de couverture $^{61}$. En Belgique aussi, la Commission bancaire devient l'instance responsable de fixer les coefficients, dont la loi ne fait qu'énoncer le principe ${ }^{62}$. Au-delà de la façon d'appliquer les mesures prudentielles sur les fonds propres et la liquidité, il est très difficile d'apprécier, en comparaison internationale, le

58 Schwander, op. cit., I943, p. 58. Sa thèse en science politique est dirigée par le conseiller national PAB Richard König.

59 Cluseau, op. cit., 1938, p. 35.

60 AFB, E652O(A), I000/I059, vol. 5, Protokolle der kleinen Expertenkommission über die Vollziehungsverordnung zum Bankengesetz, 08.01.1935, p. 51.

61 Holger-René Bruckhoff, Zur Entwicklung der Zentralbanken und der Bankaufsicht in Deutschland und in den Niederlanden, Frankfurt am Main; etc. : Peter Lang, 2010, p. 193.

62 Thibaud Giddey, "Évolution de la pratique de la Commission bancaire (I935-1975)", Courrier hebdomadaire du CRISP, vol. 2359-2360, $\mathrm{n}^{\circ} 34$, 2017, p. 5-58; Franz De Voghel, Contrôle des banques. Législations récentes, Gembloux: J. Duculot, I936, p. I43. 
Tableau Io. Exigences de fonds propres et de liquidité dans les années 1930 en comparaison internationale, par ordre décroissant des ratios

\begin{tabular}{|c|c|c|}
\hline Pays & Réglementation & Proportion entre fonds propres et fonds de tiers \\
\hline Chili & Loi du 23 juillet 1935 & $25 \%$ \\
\hline Allemagne & Loi du 3 décembre 1934 & $20 \%$ \\
\hline Roumanie & Loi du 8 mai 1934 & $\mathrm{I} 4.3 \%$ \\
\hline Suède & Loi du 22 juin I9II & $12.5 \%$ \\
\hline Bulgarie & Loi du I3 mai 1933 & $\mathrm{I} 2.5 \%$ \\
\hline Finlande & Loi du I7 mars I933 & IO $\%$ \\
\hline Pologne & Décret du I7 mars 1928 & IO $\%$ \\
\hline Norvège & Loi du 4 avril 1924 & Iо $\%$ \\
\hline Danemark & Loi du Is avril 1930 & IO \% \\
\hline Suisse & Ordonnance du 26 février 1935 & 5-IO \% (selon le type d'engagement) \\
\hline Italie & Loi du I2 mars 1936 & déterminée par la Commission \\
\hline Belgique & Arrêté royal du 9 juillet 1935 & déterminée par la Commission bancaire \\
\hline Pays & Réglementation & Proportion entre l'encaisse et les dépôts \\
\hline Suède & Loi du 22 juin I9II & encaisse et réalisable $25 \%$ engagements \\
\hline Chili & Loi du 23 juillet 1935 & $20 \%$ dépôts à vue, $8 \%$ dépôts à terme \\
\hline Portugal & Décret du 20 mars 1925 & $20 \%$ dépôts \\
\hline Finlande & Loi du I7 mars I933 & $20 \%$ engagements à vue \\
\hline Argentine & Loi du 28 mars 1935 & I $6 \%$ dépôts à vue, $8 \%$ dépôts à terme \\
\hline Grèce & Loi du 30 juin-7 juillet I93I & I2 \% dépôts à vue \\
\hline Roumanie & Loi du 8 mai 1934 & Io \% engagements à vue \\
\hline Bulgarie & Loi du I3 mai 1933 & 5-IO \% dépôts \\
\hline Danemark & Loi du Is avril 1930 & $\begin{array}{l}\text { I5 \% engagements à court terme, Io \% } \\
\text { engagements totaux }\end{array}$ \\
\hline Allemagne & Loi du 5 décembre 1934 & IO $\%$ au max. des engagements \\
\hline Suisse & Ordonnance du 26 février 1935 & $\begin{array}{l}\text { a) encaisse : } 2.5-5 \% \text { actifs à court terme } \\
\text { b) actifs réalisables : } 25-50 \% \text { actifs à court terme }\end{array}$ \\
\hline Italie & Loi du I2 mars 1936 & déterminée par l'organe de contrôle \\
\hline Belgique & Arrêté royal du 9 juillet 1935 & déterminée par la Commission bancaire \\
\hline
\end{tabular}

Source: Eugène Smits, Étude critique de l'intervention de l'État dans la politique de crédit des banques de dépôts, Bruxelles : Cools, 1940, p. 70-7I (fonds propres), I57-I60 (liquidité). Le rapport de la Société des Nations de 1938 sur les législations commerciales propose une statistique similaire, incluant d'autres pays: Société des Nations, Monnaies et banques 1937/1938. Vol. I: Aperçu de la situation monétaire, Genève : Société des Nations, I938, p. IO4 (fonds propres) et IO7 (liquidité). 
caractère exigeant ou laxiste des divers coefficients. Le seul pourcentage exigé par la loi constitue en effet un indice complètement insuffisant et parfois trompeur du degré de risque autorisé. Car la définition de ce que constituent les différents termes de la proportion, à savoir par exemple les engagements à court terme ou les actifs réalisables, varie évidemment selon les réglementations, ce qui rend toute comparaison basée uniquement sur les coefficients illusoire. Malgré ces importantes réserves sur la valeur de ces chiffres, le tableau Io propose un aperçu des taux minimaux exigés en vigueur durant les années 1930. On constate, toujours en insistant sur la grande incertitude qui entoure ces données, que les dispositions suisses de 1935 figurent tendanciellement parmi les moins sévères.

Les dispositions sur l'organisation interne constituent un second pan de mesures visant à accroître la sécurité des déposants. L'article 3 de la loi sur les banques exige que ces dernières balisent leur champ d'activité et leur rayon d'action géographique dans des statuts ou de règlements. Le caractère local, régional ou international de l'institut ainsi que le type d'opérations bancaires effectuées doivent ressortir clairement. Les sociétés soumises à la loi doivent également prévoir une organisation en adéquation avec l'importance de l'établissement. En particulier, elles doivent opérer une distinction nette entre les organes de direction et les organes de surveillance. Dans une société anonyme, le président du conseil d'administration ne peut pas être simultanément membre de la direction de l'institut. Ces règles de gouvernance d'entreprise ne visent de fait que les plus petits établissements qui n'auraient pas encore introduit une nette distinction; les banques cantonales en sont explicitement exceptées, tandis que les grandes banques possèdent déjà ces traits d'organisation. Ces dispositions cherchent également à renforcer la responsabilité des organes dirigeants des banques. En raison des articles sur la responsabilité civile des dirigeants d'une banque (art. 38-42), le conseil d'administration d'une banque est responsable des dommages causés à l'égard de chaque sociétaire et chaque créancier, et non pas uniquement à l'égard des actionnaires. Au cours de l'élaboration de la loi, c'est encore Adolf Jöhr qui avait insisté sur l'importance des dispositions sur l'organisation interne, qui apparaissent pour la première fois dans le projet Jöhr du 19 février $1933^{63}$. Il répète à souhait au sein des commissions d'experts que ces mesures ont une grande valeur. Là aussi, il faut souligner que les exigences sont relativement limitées. Aucune exigence sur la compétence ou la moralité des dirigeants bancaire n'est prévue. De même, la formulation relativement peu contraignante de cette disposition a pour conséquence que les conditions d'ouverture d'une nouvelle banque demeurent très 
souples. En effet, il suffit de remplir les critères techniques sur l'organisation interne pour obtenir l'autorisation de la Commission fédérale des banques.

Troisième ensemble de dispositions au bénéfice direct des déposants : une protection fédérale de dépôts d'épargne est introduite dans la loi. Cette protection s'articule de la manière suivante. Le mot "épargne" dans la raison sociale et les termes "dépôts d'épargne » sont réservés aux instituts qui publient leurs comptes annuels. Une banque privée qui ne publie pas sa comptabilité n'est donc pas autorisée à drainer l'épargne en utilisant ces termes-là. En plus de ces exigences de publicité renforcée, les épargnants obtiennent aussi un régime de faveur en cas de faillite. Les fonds déposés en tant que dépôts d'épargne sont "colloqués dans la troisième classe", c'est-à-dire qu'ils seront prioritaires dans l'ordre de remboursement des dettes. Ce privilège ne s'applique que jusqu’à concurrence de 5000 francs par déposant. À titre d'illustration, il faut rappeler que le salaire annuel moyen d'un employé masculin - et non d'un ouvrier s'élève en 1928 à 5700 francs ${ }^{64}$. En 1934, plus de $90 \%$ des carnets d'épargne affichent d'ailleurs un montant inférieur à 3 ooo francs suisses ${ }^{65}$.

D'une part, la réglementation cherche ainsi à empêcher que des intermédiaires financiers inappropriés proposent des carnets d'épargne, d'autre part, elle institue un privilège légal en cas de faillite. En ce sens, cette mesure entend aussi rétablir la confiance des déposants dans les institutions bancaires, et limiter les phénomènes de paniques bancaires et de retraits de capitaux massifs. En revanche, la loi suisse ne prévoit aucune mesure quant à la façon dont les banques placent les dépôts d'épargne qu'elles recueillent. Les premiers projets de loi indiquaient pourtant que la moitié des dépôts d'épargne privilégiés devait être placée en créances hypothécaires. Mais ces dispositions avaient été évacuées du projet de loi par la petite commission d'experts en décembre 1933, sur demande du représentant de la Banque cantonale de Berne et de celui des banques locales ${ }^{66}$. Du point de vue politique, la protection des épargnes revêt aussi une signification particulière. Le message du Conseil fédéral du 2 février soulignait d'ailleurs le rôle social que joue cette catégorie de dépôts : « La nature spéciale de ces dépôts [une réserve pour les mauvais jours], le fait que le carnet d'épargne représente plus spécialement les économies des classes moyennes et des catégories économiquement faibles de la population doivent engager l'État à leur accorder une protection spéciale. ${ }^{67}$

64

65

66

67

Müller, op. cit., 20IO, p. 22I.

«Message du Conseil fédéral à l'Assemblée fédérale concernant le projet de loi sur les banques et les caisses d'épargne, (du 2 février 1934)", Feuille fédérale, I, I934, p. I88.

ABNS, I.3/1213, Protokoll der 3. Sitzung der Subkommission, 20.12.1933, p. I5-19.

"Message du Conseil fédéral à l'Assemblée fédérale concernant le projet de loi sur les banques et les caisses d'épargne, (du 2 février 1934)", Feuille fédérale, I, I934, p. I88. 
Deux questions ont donc essentiellement animé le débat politique sur la protection des épargnes : celle de son montant et celle du maintien des mesures cantonales. Selon les législations cantonales sur l'épargne préexistantes, le montant privilégié variait entre I 500 et 10000 francs $^{68}$. Le Conseil national a ensuite augmenté à 5000 francs la proposition initiale de 3 ooo du Conseil fédéral. Quant à la marge de manœuvre cantonale en matière de protection des épargnes, le Conseil national obtient que soit maintenue la possibilité pour les cantons d'instaurer un droit de gage légal en faveur des dépôts d'épargne. Seuls quatre cantons, Glaris en 1936, Zurich, Bâle-Ville et le Tessin en 1938, mettront à exécution cette possibilité offerte par la loi fédérale et édicteront des législations cantonales ${ }^{69}$.

En comparaison internationale, les dispositions sur l'épargne de la loi bancaire suisse restent limitées. En effet, en raison de la persistance du modèle de la banque universelle, la réglementation ne prévoit aucune contrainte quant à l'emploi qui est fait des dépôts d'épargne recueillis. De plus, il s'agit uniquement d'un mécanisme de privilège dans le remboursement des créances bancaires en cas de faillite. Les régulations américaine (I933-1935) ou tchécoslovaque (1924) prévoient au contraire des systèmes d'assurance des dépôts ou de garantie mutuelle par l'instauration d'un fonds général prélevant des cotisations de la part des banques-membres ${ }^{70}$.

\section{IV.2.3. Contrôle indirect des banques : institution de la révision externe obligatoire par des sociétés fiduciaires privées}

Durant l'élaboration de la loi sur les banques, les commentateurs du projet de l'administration fédérale ont régulièrement avancé que la mise en place de la révision fiduciaire obligatoire constituait la "question centrale », « le principal », "le centre de la loi», «le cœur de la loi ${ }^{71}$. Mettre en place des mesures de bonne gestion et des règles prudentielles serait en effet vain si rien ni personne ne s'assure qu'elles sont bien appliquées. La loi bancaire suisse introduit un système de surveillance indirect, ou double. Le contrôle primaire, auprès de chaque banque soumise à la loi, est effectué par des "instituts de révision", c'est-à-dire soit une société fiduciaire, soit un syndicat de révision. Cette surveillance immédiate n'est donc pas du ressort de l'État, mais revient à l'économie privée. L'émanation étatique, à savoir la Commission fédérale des banques, n'intervient que dans un deuxième temps, lorsque les irrégularités

Reimann, op. cit., 1963, p. 58.

Piguet, op. cit., I953, p. 249-256.

De Voghel, op. cit., 1936, p. 8I-89, I8I-226.

Ernst Thalmann, Bulletin sténographique officiel de l'Assemblée fédérale, Conseil des États, 13.06.1934, p. 195; Rossy, Reimann, op. cit., I935, p. 38 ; Piguet, op. cit., I953, p. 314. Voir encore l'article de Rudolf Peter (I888-1944), directeur de la STG : R. Peter, «Particularités de la révision bancaire", in Association suisse des experts-comptables A.S.E (éd.), Journées d'études bancaires, Genève: E. Delachaux, 1937, p. 155-175. 
constatées par les réviseurs privés n'ont pas pu être résolues. L'organe semiétatique n'est là que pour chapeauter une organisation privée qui est en grande partie autonome. Toute l'efficacité de la loi repose donc sur le travail de ces instituts de révision (Revisionsstellen). Le message du Conseil fédéral présentant le projet de loi insistait d'ailleurs sur cette caractéristique du système de surveillance:

Cette organisation du contrôle et de la surveillance des banques présente le grand avantage de n'engager ni la responsabilité de l'État ni celle de la Banque nationale. Elle crée cependant un contrôle efficace et souple, dépourvu de tout caractère bureaucratique, dont l'intervention permettra de prendre rapidement les mesures conservatoires nécessaires $^{72}$.

Selon ce système, toutes les banques, à l'exception des banques cantonales, doivent soumettre leurs comptes annuels au contrôle des réviseurs privés. Elles doivent donc dans un premier temps désigner leur institut de révision parmi les réviseurs reconnus par la Commission fédérale des banques. La révision annuelle opérée par l'institut de révision consiste en un contrôle de la comptabilité de l'établissement. Ce contrôle est à la fois formel et matériel, dans le sens où il débouche aussi sur une évaluation qualitative de l'actif de la banque. Il a pour objectif de déterminer la situation de fortune de la banque et de garantir que les prescriptions légales sont respectées. Plus précisément, un institut de révision doit immédiatement intervenir lorsqu'il constate que la sécurité des créanciers est compromise, c'est-à-dire si des pertes imminentes ou effectives absorbent une telle proportion des fonds propres que les créanciers ne sont plus couverts. Cette intervention des réviseurs n'est cependant pas redoutable: ils doivent «inviter la banque à régulariser sa situation dans un délai appropriée (art. 2I, al. 2). Au-delà de la sécurité immédiate des créanciers, la révision annuelle doit se prononcer sur une série d'autres éléments : le respect des ratios de liquidité, de fonds propres, l'alimentation du fonds de réserve, la proportion des placements internationaux par rapport à la somme du bilan, les insuffisances éventuelles dans l'organisation interne, etc. L'ensemble des résultats du travail de révision annuelle est compilé dans un document intitulé « rapport de révision ${ }^{73}$. Ce texte doit être remis par l'institut de révision aux organes responsables de la direction supérieure de la banque concernée, c'est-à-dire, dans une société anonyme, le conseil d'administration. Ainsi, l'un des buts du contrôle fiduciaire obligatoire est aussi de renforcer la responsabilité des dirigeants bancaires. Une fois informés des irrégularités par le biais du rapport de

72 «Message du Conseil fédéral à l'Assemblée fédérale concernant le projet de loi sur les banques et les caisses d'épargne, (du 2 février 1934)", Feuille fédérale, I, I934, p. I8I.

73 Sur le contenu du rapport de révision : voir art. 38 de l'ordonnance ainsi que les directives indiquées par Graner, op. cit., 1937, p. 156-160 ; Paul Graner, Die Revision, Überwachung und Kontrolle: nach rev. Obligationenrecht und Bankengesetz, Zürich: Polygraphischer Verlag, I938, p. 72-135. 
révision, ces derniers ne pourront pas prétendre ignorer des infractions légales commises à leur insu ; l'attitude d'ignorance étant une tactique souvent préconisée pour se défausser de ses responsabilités.

Ce système de surveillance indirecte est un des traits caractéristiques de la loi bancaire suisse ${ }^{74}$. Il fait reposer l'exécution de la réglementation sur un corps de réviseurs privés, qui fonctionne comme intermédiaire entre les banques et la Commission fédérale des banques. Cette dernière n'entre d'ailleurs qu'exceptionnellement en contact direct avec les banques.

$A$ priori, l'on serait tenté de croire que l'instauration d'un système de contrôle externe aux banques, qu'il soit de nature publique ou privée, allait à l'encontre des intérêts bancaires. Il n'en est rien. Souvenons-nous que le projet Landmann de I9ı6 prévoyait déjà la mise en place de la révision obligatoire par des fiduciaires. Pour le professeur bâlois, le principe de la révision fiduciaire obligatoire avait aussi une dimension presque éducative d'amélioration de la gouvernance d'entreprise. Il aurait donné, chez les petites banques, les moyens au conseil d'administration de percevoir rapidement les agissements inquiétants qu'un gérant ou directeur chercherait à cacher ${ }^{75}$. Il est remarquable que, malgré l'opposition générale des milieux bancaires au projet Landmann, les dispositions sur la révision n'aient suscité aucune réaction négative, bien au contraire.

Seize ans plus tard, en I932, le directeur général du Crédit Suisse, Adolf Jöhr, reprend presque intégralement les dispositions de Landmann sur la révision fiduciaire dans son projet de réforme du droit des obligations. Lors de la rencontre initiale de la commission d'experts en mars 1933, le ministre des Finances fribourgeois Jean-Marie Musy présente l'institution de la révision fiduciaire en choisissant des mots rassurants pour les banquiers auxquels il s'adresse en majorité :

Pour le $98 \%$ de nos banques, le contrôle prévu par le projet de loi n'est pas nécessaire, sans doute, mais il importe qu'il soit rendu obligatoire afin que les établissements qui en ont besoin y soient astreints. [...] Le projet discuté représente la cristallisation d'un usage très répandu. Il ne constitue pas une création nouvelle, mais il est l'extension d'un système de contrôle qui a déjà fait ses preuves. C'est le passage de l'usage à la loi ${ }^{76}$.

Là aussi, au cours des diverses discussions à la fois dans les commissions et même lors des négociations internes à l'ASB, le principe du contrôle fiduciaire obligatoire n'est pas remis en question par les banquiers. Comment faut-il comprendre le crédit dont jouit auprès des représentants bancaires un système de contrôle reposant sur les sociétés fiduciaires?

74

75

76

Rossy, Reimann, op. cit., I935, p. 38.

Landmann, op. cit., I916, p. 86-87.

Jean-Marie Musy devant la commission d'experts. ABNS, I.3/I213, Expertenkonferenz protokolle 1933-1934, Protokoll der Expertenkonferenz zur Begutachtung des Entwurfes zu einem eidgenössischen Bankgesetze, I4.03.1933, p. 5 et Io. 
Premièrement, comme le souligne Musy, une réglementation qui rend obligatoire la révision externe ne fait que généraliser et codifier une pratique déjà effective chez la plupart des grands instituts. L'économiste français Max Cluseau va dans le même sens lorsqu'il commente l'esprit de la loi bancaire suisse : «En ce pays, où par suite de l'observation des règles traditionnelles de saine gestion et de morale professionnelle, l'organisation bancaire a résisté aux secousses économiques, la loi s'est contenté de sanctionner et de donner force légale à l'organisation déjà existante se bornant à apporter quelques retouches de détail. » ${ }^{77}$

La seconde raison qui permet de comprendre la bienveillance des représentants bancaires à l'égard d'une officialisation du rôle des sociétés fiduciaires réside dans la grande proximité entre grandes banques et sociétés fiduciaires. Les principales sociétés fiduciaires qui dominent le marché dans les années 1930 ont été portées sur les fonts baptismaux par les grandes banques au cours de la période 1900-1920. Première société fiduciaire de Suisse, la Schweizerische Treuhandgesellschaft est fondée à Bâle en 1906, par la Société de Banque Suisse, sur le modèle de la Deutsche Treuhandgesellschaft créée en 1890 par la Deutsche Bank ${ }^{78}$. Trois autres grandes banques suisses contrôlent dès la fin des années 1920 leur propre société fiduciaire ${ }^{79}$. La Schweizerische Revisionsgesellschaft AG est fondée en I9I2 à Zurich par la Bank in Winterthur devenue l'Union de Banques Suisses. La Verwaltungs-, Revisions- und Treuhand-AG voit le jour en 1917 à Bâle. Elle est une création de la Banque Commerciale de Bâle, et se transformera bientôt en Allgemeine Treuhand AG (Atag) ${ }^{80}$. Quant au Crédit Suisse, il décide de ne pas fonder une nouvelle société, mais de reprendre progressivement le capital d'une fiduciaire déjà existante. En 1928, il jette son dévolu sur la Fides-Treuhandvereinigung fondée en I9Io à Zurich, et en acquiert une large majorité du capital-actions en l'espace de quatre ans ${ }^{81}$. Il faut savoir que les activités de révision à proprement parler - le contrôle comptable - ne constituent pas l'unique gagne-pain de ces entreprises. La gestion de fortunes, les exécutions de testaments, les gestions de faillite et l'organisation de fusions font notamment partie de leur rayon d'activité ${ }^{82}$. Les premières décennies du $\mathrm{XX}^{\mathrm{e}}$ siècle verront également la structuration de cette branche économique à travers plusieurs organisations. En 1915, le Verband

77

78

Sur les premières années de la $S$ ch

Schweizerische Treuhandgesellschaft: Hans Gassmann, Die llschaft, mit besonderer Berücksichtigung der Revisionsfrage bei 42; Mazbouri, op. cit., 2005, p. 284-285.

79 Helbling, op. cit., 2006, p. 40-4I.

80 Sur l'histoire d'ATAG, absorbée par Ernst \& Young au début des années I990, voir la brochure récemment commandée par la multinationale: Adrian Lemmenmeier, Tobias Straumann, Vertrauen als Mehrwert - 100 Jahre EY Schweiz, St. Gallen, Ernst \& Young AG, 2017.

81 Sur la Fides-Treuhandvereinigung et sa reprise par le Crédit Suisse entre I928 et I93I, voir : Jung (éd.), op. cit., 200I, p. 335-337. Deux représentants du CS, dont Jöhr, sont délégués dans le CdA de la Fides.

82 
Schweizerischer Bücherrevisoren (VSB) est créé. En I925, la Schweizerische Kammer für Revisionswesen, ancêtre de la Chambre fiduciaire suisse, est fondée par le VSB, la Vereinigung schweizerischer Treuhand- und Revisionsgesellschaften et la Vereinigung der Revisionsverbände der Banken ${ }^{83}$. Les fiduciaires bénéficient dès lors d'une association faîtière qui leur permet de limiter la concurrence et de faire entendre leur voix auprès d'autres milieux.

Tableau II. Les plus grandes sociétés fiduciaires de Suisse (I935-1937), selon les honoraires perçus en milliers de francs

\begin{tabular}{|c|c|c|c|c|c|c|}
\hline & \multirow{2}{*}{ Nom } & \multirow{2}{*}{$\begin{array}{l}\text { Banque } \\
\text { proche }\end{array}$} & \multirow{2}{*}{$\begin{array}{l}\text { Fon- } \\
\text { dation }\end{array}$} & \multicolumn{3}{|c|}{ Honoraires } \\
\hline & & & & 1935 & 1936 & 1937 \\
\hline I & Schweizerische Treuhandgesellschaft, Basel & SBS & 1906 & 2186 & 2256 & 2553 \\
\hline 2 & Fides Treuhand-Union, Zürich & CS & I9I2 & I 368 & I 338 & I 332 \\
\hline 3 & Allgemeine Treuhand AG, Basel & $\mathrm{BHB}$ & 1917 & 753 & 844 & 902 \\
\hline 4 & $\begin{array}{l}\text { Schweizerische Revisionsgesellschaft, } \\
\text { Zürich }\end{array}$ & UBS & I9I2 & 219 & 228 & 242 \\
\hline 5 & $\begin{array}{l}\text { Revisions- und Treuhand AG, REVISA, } \\
\text { Zug }\end{array}$ & ? & 1919 & $\mathrm{I} 30$ & I23 & $\begin{array}{c}67 \\
(6 \text { mois })\end{array}$ \\
\hline 6 & Neutra Treuhand AG, Zürich & ? & 1929 & 67 & IO4 & $\mathrm{I} 28$ \\
\hline 7 & OFOR Société fiduciaire romande, Genève & $\begin{array}{c}\text { Hentsch } \\
\& \mathrm{Cie}\end{array}$ & 1933 & 76 & $\mathrm{I} 28$ & IIS \\
\hline
\end{tabular}

Source pour les honoraires: [s.n.], «Les principales sociétés fiduciaires dans l'exercice I937 », in Bulletin financier suisse, 07.10.1938, vol. 66, nº 8o, p. 434-435.

Les relations étroites qui unissent les grandes banques et les sociétés financières depuis leur création et l'expérience dont jouissent ces sociétés de révision dans le contrôle de la comptabilité bancaire en font les partenaires idéales des grandes banques, qui voient d'un bon oeil l'officialisation de leur rôle dans la mise en application de la loi.

Au cours de l'élaboration de la loi, c'est avant tout la question des critères d'admission d'un institut de révision, et en particulier les conditions d'indépendance, qui vont être au cœur des débats. Dans les commissions d'experts comme dans la phase parlementaire, les représentants socialistes et syndicalistes vont tenter de renforcer les critères d'indépendance entre une banque et la société qu'elle choisit pour effectuer sa révision annuelle ${ }^{84}$. En effet, les représentants du mouvement ouvrier craignent que des sociétés fiduciaires, dont le volume d'affaires dépend étroitement du nombre de mandats bancaires qu'elles obtiennent, se montrent trop souples à l'égard des établissements contrôlés.

83

84 Première intervention de Max Weber dans ce sens lors de la première réunion de la Commission d'experts, le I4 mars 1933. ABNS, I.3/1213, Expertenkonferenz protokolle 1933-1934, Protokoll der Expertenkonferenz zur Begutachtung des Entwurfes zu einem eidgenössischen Bankgesetze, I4.03.1933, p. 22. 
C'est ce que déplore le conseiller aux États socialiste zurichois Emil Klöti, quand il décrit les relations entre les banques et les fiduciaires:

Il est clair qu'une société fiduciaire qui entretient une telle relation d'affaires avec une grande banque réfléchira à deux fois avant de provoquer la colère de $\mathrm{MM}$. les directeurs généraux de la banque concernée par un passage de son rapport. Il arrive aussi souvent que les directeurs d'une société fiduciaire soient engagés dans la direction de la banque ou de ses filiales. Si le directeur d'une société fiduciaire a l'aspiration secrète de devenir un jour directeur de banque, il sera naturellement très prudent lorsque quelque chose n'ira pas chez cette banque. [...] À cela s'ajoutent les conditions de concurrence entre les diverses sociétés fiduciaires. Si une société fiduciaire est plus stricte dans son contrôle et met clairement en évidence des dysfonctionnements, elle peut facilement être évitée. [...] Les choses sont donc indiscutables: plus une société fiduciaire réalise sa tâche avec légèreté, plus elle se montre aimable avec les banques, et plus elle exerce un contrôle généreux, plus ses perspectives de profit seront grandes ${ }^{85}$.

Mais ces tentatives se heurtent à l'opposition de la majorité des commissions. Selon le texte adopté, les critères pour être admis en tant qu'institut de révision au sens de la loi sont les suivants (ordonnance, art. 3I-37). La loi prévoit deux types d'instituts de révision : les sociétés fiduciaires d'une part (Treuhandgesellschaften) et les syndicats de révision (Revisionsverband), c'est-à-dire une association regroupant plusieurs banques qui assurent un contrôle mutuel, d'autre part. Les instituts de révision doivent se doter d'une organisation adéquate et leurs dirigeants doivent avoir une connaissance approfondie de la technique et de la révision bancaire et jouir d'une bonne réputation. Les syndicats de révision doivent réunir au moins douze banques. Plus concrètement, ces syndicats - ou associations - de révision sont des organismes créés par des banques qui se réunissent pour entretenir un office de révision commun. Fondés durant le premier quart du $\mathrm{XX}^{\mathrm{e}}$ siècle, ces syndicats de révision fonctionnent à l'échelle régionale et ne concernent que des banques locales. Le Revisionsverband bernischer Banken und Sparkassen, établi en I9I2, compte en 193562 banques et caisses d'épargne membres et emploie trois inspecteurs ${ }^{86}$.

Quant aux sociétés fiduciaires, on exige d'elles un capital social versé d'au moins IOO 000 francs. Elles doivent également prouver qu'elles révisent une ou plusieurs banques dont le total des bilans s'élève à Ioo millions de francs au minimum. Cette dernière disposition a pour but d'éviter un trop grand morcellement du monde des fiduciaires. Une fois reconnus, les instituts de révision doivent annoncer à la Commission fédérale des banques le nom des personnes chargées de diriger les travaux de contrôle bancaire, et tout changement dans cette liste doit être communiqué également. Une banque peut donc choisir

Bulletin officiel de l'Assemblée fédérale, Conseil des États, séance du 13.06.1934, p. 200.

Richard König, 25 Jahre Revisionsverband bernischer Banken und Sparkassen 1912-1937, Bern : Buchdrückerei Büchler \& Co., I938. 
librement son institut de révision, mais doit justifier les raisons de tout éventuel changement d'institut de révision. Enfin, les critères d'indépendance requis restent minimaux: seuls les membres de la direction, le président et le viceprésident du conseil d'administration d'une banque sont désignés comme charges incompatibles avec celle d'administrateur d'une société fiduciaire. En d'autres termes, un simple conseiller d'administration d'une banque peut siéger dans le conseil d'administration de la société qu'il a chargée de contrôler sa propre banque. Plus grave, aucune disposition d'indépendance financière n'est introduite pour garantir une plus grande autonomie des sociétés fiduciaires à l'égard des banques qu'elles doivent contrôler.

Introduite à la fin de l'élaboration de la loi sur les banques, une disposition vient cependant troubler la formulation très clémente envers l'organisation déjà existante. Il s'agit de l'alinéa 2 de l'article 20, qui met en place une interdiction des opérations de banques et de gestion de fortunes pour les sociétés fiduciaires qui sont admises à la révision bancaire. Cette règle vise à empêcher qu'une entreprise pratiquant des activités bancaires soit chargée de surveiller une concurrente, et qu'elle soit alors tentée de détourner la clientèle de l'établissement contrôlé à son profit. Elle est de fait introduite sur proposition de la commission du Conseil national, qui elle-même répond à une impulsion de deux banquiers zurichois, Albert Hofmann (I874-I948) et Hans Jakob Rinderknecht (I884-I950), principalement actifs dans les opérations de bourse ${ }^{87}$. D'après Jöhr, les banquiers privés zurichois n'auraient agi que pour des raisons de concurrence. Il fustige les conséquences dramatiques d'une telle mesure : elle conduira à un démantèlement du monde des fiduciaires suisses, qui jouit jusqu'alors d'une bonne réputation. En effet, interdire la gestion de fortune aux sociétés fiduciaires revient à exclure de la révision la plupart des grandes fiduciaires qui ne pourraient pas renoncer à leur activité la plus lucrative. Face au manque à gagner trop important que signifierait le renoncement à la gestion de fortune, les sociétés fiduciaires existantes ne pourraient contrôler les banques. L'on verrait alors se multiplier les petites entreprises de révision bancaire, qui seraient encore plus dépendantes des rares contrats qu'elles obtiendraient. Dans une ultime démarche de dernier recours auprès du Conseil fédéral en février 1935, Jöhr peint le diable sur la muraille:

En approuvant une telle fragmentation, on prépare la voie pour un futur inspectorat des banques étatique, on se laisse manipuler par les postulats socialistes en faveur d'une intervention directe de l'État et d'une étatisation progressive du système bancaire ${ }^{88}$.

Malgré les efforts du directeur du Crédit Suisse, la disposition d'incompatibilité est maintenue.

87 ABNS, I.3/1213, Lettre d'A. Hofmann et J. Rinderknecht aux commissions parlementaires de deux Chambres, 07.08.1934. Sur Albert Hofmann et Jacob Rinderknecht, voir Lussy, Bonhage, Horn, op. cit., 200I, en part. p. 406.

$88 \mathrm{AFB}, \mathrm{E} 6520(\mathrm{~A})$, I000/1059, vol. 5. Lettre d'Adolf Jöhr (CS) à Albert Meyer (DFFD), 09.02.1935. 


\section{IV.2.4. Institution d'une commission fédérale des banques, chargée de garantir l'application de la loi et d'assurer la protection des créanciers bancaires}

Au fil des chapitres précédents, nous avons pu entrevoir la lente conception de ce qui deviendra la principale instance d'exécution de la loi sur les banques, la Commission fédérale des banques. Avant d'en faire le portrait dans le texte final de loi, récapitulons les grandes étapes de la genèse de cette novation institutionnelle.

Alors que le projet Landmann de 1916 prévoyait un office de surveillance des banques directement attaché au Conseil fédéral, accompagné d'une commission bancaire à caractère consultatif ${ }^{89}$ - élément qui avait contribué à nourrir la résistance des banquiers à l'égard du projet -, les premières ébauches de loi fédérale rédigée en février-mars 1933 n'incluent tout simplement aucun organe d'application de la loi. Cette absence paraît surprenante, mais était conforme au programme très minimaliste contenu dans les premiers projets de loi. Certaines questions restaient pourtant irrésolues : qui désigne les entreprises soumises à la loi ? Qui est responsable de l'admission des sociétés fiduciaires en tant qu'instituts de révision reconnus? Qui intervient en cas d'infraction à la loi ? Au cours des discussions de la première commission d'experts entre mars et mai 1933, on ressent un certain embarras face à ces questions. En effet, il semble qu'à la fois les banquiers et l'Administration des finances avaient espéré pouvoir charger la Banque nationale suisse des tâches mentionnées plus haut. Or, les dirigeants de la banque centrale refusent fermement d'être impliqués dans un rôle de surveillant des banques. Le directoire, comme le Comité de banque de la BNS qui soutient cette décision, estime qu'il faut mettre en place une autre instance ${ }^{90}$. La BNS rejette d'ailleurs non seulement de jouer un rôle dans l'application globale de la loi, mais refuse de même d'être chargée d'organiser la publication des données comptables qu'elle reçoit de la part des banques. Elle s'oppose à cette compétence, car elle voudrait lutter contre l'opinion erronée selon laquelle elle exercerait ainsi « une quelconque surveillance ou contrôle sur les banques ${ }^{91}$.

Face à ce refus, les banquiers, qui ne voient pas d'un bon oil l'institution d'une nouvelle instance liée à l'administration fédérale dont ils ignorent les compétences, proposent tout simplement de ne prévoir aucune autorité pour assurer l'application de la loi ${ }^{92}$. La question n'est toutefois pas réglées pendant la commission d'experts de printemps 1933. Les discussions s'estompent sans qu'une décision soit prise sur ce point. Au sein de l'association faîtière de

89 Pour un résumé des attributions de ces deux instances prévues par Landmann, cf. Tarnutzer, op. cit., I94I, p. I5-I8.

90 ABNS, Procès-verbaux de la Direction générale de la BNS, 09.03.1933, nº220, p. 216.

91 Selon une lettre de Gottlieb Bachmann à Jean-Marie Musy, 20.02.1933. AFB, E6520(A), I000/I059, vol. 2.

92 ABNS, I.3/I213, Expertenkonferenz protokolle 1933-1934, Protokoll der Expertenkonferenz zur Begutachtung des Entwurfes zu einem eidgenössischen Bankgesetze, 05.04.1933, p. IO. 
l'économie suisse, le Vorort de l'USCI, l'idée d'une commission est également présentée comme une «échappatoire», face au refus de la BNS d'exercer le contrôle bancaire ${ }^{93}$.

Ce n'est donc qu'en novembre 1933, sous l'influence de la défaillance de la Banque Populaire Suisse et du plan de sauvetage organisé par la Confédération, qu'une Commission fédérale de contrôle des banques (Bankenaufsichtskommission) est projetée. Comme nous l'avons vu, c'est sous l'impulsion décisive de la Banque nationale suisse, qui met en avant le modèle allemand du Bankenkuratorium, que la solution d'une instance particulière s'impose (cf. chap. III.3). Le directoire de la BNS, au cours de négociations avec Eduard Kellenberger de l'Administration fédérale des finances fin octobre 1933, privilégie la création d'une commission autonome: "Pour discuter de mesures et de directives générales de politique bancaire, il faudrait prévoir une commission bancaire, dans laquelle pourrait être représentés, en plus des départements du Conseil fédéral, la Banque nationale, les groupes bancaires et les principaux groupes économiques du pays. " ${ }^{94}$ À ce moment-là, il est encore évident que la Banque nationale sera officiellement représentée au sein de la commission. Ainsi, la BNS n'engagerait pas directement sa responsabilité, mais aurait un oeil sur l'activité d'une institution qui pourrait lui faire concurrence.

Si le principe de cette autorité de surveillance satisfait le DFFD et la BNS, la réaction des milieux bancaires est moins enthousiaste. L'institution d'une commission autonome fait partie des renforcements du projet de loi que regrette l'Association suisse des banquiers. En décembre 1933, son secrétaire s'en plaint ouvertement à l'administration fédérale:

Il serait à mon avis dangereux de transférer à une commission de surveillance particulière la mise en application des dispositions légales qui revient au Conseil fédéral ; car une surveillance étatique, qui entraînerait un affaiblissement de la responsabilité des organes de la banque et une responsabilité intenable de l'État, doit justement être évitée. Je propose donc de laisser tomber la commission de surveillance des banques [...] et de laisser la surveillance de l'application de la loi au Département des finances en collaboration avec la Banque nationale ${ }^{95}$.

La commission de contrôle des banques suscite la méfiance du monde financier. L'ASB privilégie ici une application de la législation orchestrée par le Département des finances, en collaboration avec la Banque nationale. Ce grand scepticisme à l'égard d'une nouvelle autorité est sans doute dû à l'incertitude qui règne à ce stade de l'élaboration sur sa composition et ses compétences précises. Les banquiers craignent peut-être, à la suite des délibérations parlementaires, d'assister à la création d'un appareil bureaucratique, dont la

AfZG, IB Vorort-Archiv, I.5.3.8. Protokolle (Typoskripte) I93I - I934, 07.04.1933, p. 4-5. 
composition serait tributaire des rapports de force politique, et donc potentiellement moins à l'écoute des intérêts des banques commerciales que ne le sont, à ce moment-là, le Département des finances ou la Banque nationale. C'est ce que semble indiquer une déclaration de Jöhr d'avril 1934 : «Nous ne pouvons pas prévoir comment la Commission des banques évoluera, ni de qui elle sera composée à l'avenir. Des influences politiques pourraient un jour s'y exercer. ${ }^{96}$ Mais l'argument ressassé de la grande responsabilité qu'endosserait l'État fédéral si une commission était instituée ne l'emporte pas. La disposition est maintenue dans le projet de loi.

Il faut en revanche souligner qu' entre novembre 1933 et janvier 1934, au cours des délibérations de la commission d'experts, les compétences de la future Commission fédérale des banques connaissent un fort recul, tandis que son modèle de composition évolue également. En parallèle à l'élimination du terme «surveillance» dans sa dénomination, les experts-banquiers proposent de réduire ses pouvoirs d'intervention. Alors que les projets du 6 et du I3 novembre prévoyaient des compétences dans la régulation de l'exportation de capitaux et des taux d'intérêt des obligations de caisse, ou encore la détermination de la proportion adéquate d'engagements étrangers, ainsi que la possibilité d'imposer une révision, toutes ces attributions disparaissent dans la version du 25 novembre 1933. Étant donné que ces suppressions ont lieu avant même les réunions de la commission d'experts, il est très difficile d'en déterminer les raisons exactes.

Au cours des réunions de la grande et de la petite commission d'experts, la réduction des compétences se poursuit. L'offensive bancaire s'attaque d'abord à la possibilité octroyée à la commission étatique de demander, sans justifications particulières, la remise d'un rapport de révision par l'institut de révision. «Nous ne voulons pas établir des archives pour rapports bancaires " ${ }^{97}$, s'exclame le président de la Société de Banque Suisse, Max Staehelin. Il en résulte que la transmission du rapport de révision ne sera autorisée que "dans des cas spéciaux ». Quant aux moyens de sanction de la Commission fédérale des banques, un affaiblissement est également opéré. La disposition qui permettait à la Commission de prescrire des mesures de protection au bénéfice des créanciers bancaires - conçue comme une sanction intermédiaire, est remplacée par une formule relativement floue proposée par Jöhr. En cas d'infractions aux prescriptions légales, la $\mathrm{CFB}$, après avoir invité l'établissement à régulariser sa situation, "défere le cas aux autorités administratives ou judiciaires compétentes ». Comme nous le verrons, l'interprétation et la mise en pratique de cet article de loi réserveront certaines difficultés à l'organe de surveillance.

Pendant la même phase, les critères relatifs à sa composition sont considérablement modifiés. Tandis que les projets des 6 et $\mathrm{I} 3$ novembre prévoient une

96 AFB, E6520(A), I000/1059, vol. 4, Commission du Conseil des États pour l'examen du projet de loi fédérale sur les banques et les caisses d'épargne, PV de la deuxième session, I2.04.1934, p. 83.

97 ABNS, I.3/I213, Expertenkonferenz protokolle 1933-1934, Protokoll der Expertenkonferenz zur Begutachtung des Entwurfes zu einem eidgenössischen Bankgesetze, 29.II.I933, p. 34. 
commission constituée de trois à cinq membres, dans laquelle siègeraient des représentants des départements fédéraux des finances et de l'économie publique et un représentant de la Banque nationale, à partir du 25 novembre 1933, un critère de compétence technique est adopté. Les membres doivent être experts en matière de technique bancaire ou de révision bancaire. Cette formulation est proposée par les deux délégués des grandes banques, Jöhr et Staehelin ${ }^{98}$. On passe d'une commission clairement liée au gouvernement et à la banque centrale, sur modèle allemand, à une institution faisant une plus grande place à la corporation bancaire. Notons aussi qu'à ce stade-là, sont exclus de l'organe de surveillance uniquement les individus qui ne seraient pas assez proches des banques, mais pas ceux qui en sont trop proches. Rien n'aurait empêché, selon ce projet de loi, le directeur général d'une grande banque de siéger dans la commission. Ces critères de composition semblent en tout cas satisfaire Adolf Jöhr, qui écrit à Paul Rossy, collaborateur de l'Administration des finances chargé de remanier le texte de loi, que l'on a " exclu, soigneusement et à juste titre, la politique de la Commission fédérale des banques" 99 . Le traitement de l'avant-projet de loi par la commission d'experts a donc eu pour conséquence de dépolitiser la composition et d'affaiblir les compétences de la future instance d'exécution. Comme le résume Paul Rossy lors de la dernière séance qui précède la transmission du projet au Conseil fédéral, en commentant l'article relatif à la CFB : «on a supprimé de cet article toutes les clauses qui donnaient un droit de surveillance à la commission fédérale des banques» ${ }^{100}$.

La phase parlementaire de l'élaboration de la loi bancaire, en commissions puis au plénum, n'est pas marquée par de profondes modifications sur le rôle et les attributions de la Commission fédérale des banques. Il apparait cependant clairement que l'institution d'une instance nouvelle, dotée d'une grande autonomie vis-à-vis de l'État et de la Banque nationale, est présentée comme une solution par défaut. Ce remède palliatif est choisi face au refus tant de la Banque nationale que du Département des finances de prendre en charge l'application de la loi. C'est le message que cherche à faire passer Jean-Marie Musy dans sa présentation de l'autorité de surveillance devant la commission du Conseil des États :

Qui surveillera l'application de la loi ? Notre projet institue à cet effet une commission fédérale des banques. C'est la seule solution réalisable puisqu'il est impossible, pour des raisons que j'ai indiquées dans mon premier exposé, de rattacher le contrôle à l'État ou à la Banque

ABNS, I.3/I213, Expertenkonferenz protokolle 1933-1934, Protokoll der Expertenkonferenz zur Begutachtung des Entwurfes zu einem eidgenössischen Bankgesetze, 20.I2.I933, p. 24.

99 AFB, E6520(A), I00o/I059, vol. 2, lettre d'Adolf Jöhr à Paul Rossy, 26.12.1933. «Wenn man bei der eidgenössischen Bankenkommission die Politik mit Recht sorgfältig ausgeschlossen hat,...».

100 ABNS, I.3/1213, Expertenkonferenz protokolle 1933-1934, Protokoll der Expertenkonferenz zur Begutachtung des Entwurfes zu einem eidgenössischen Bankgesetze, I8.oI.1934, p. 29. 
nationale. Au point de vue du droit public, cette commission des banques, nommée par le Conseil fédéral, mais sans attaches aucunes avec l'autorité politique et souveraine dans ses décisions, est évidemment une institution extraordinaire. Mais en rattachant cette commission à un département - on a proposé, par exemple, de créer un office des banques au Département des finances - nous aurions été fatalement conduits à engager la responsabilité morale et matérielle de l'État. Nous n'avions donc pas la possibilité d'adopter un autre régime ${ }^{101}$.

L'idée selon laquelle, la Commission fédérale des banques est un choix fait à contrecœur, pour suppléer la défection de ce qui avait été considéré comme la solution la plus naturelle, revient à plusieurs reprises. Pour le collègue de parti de Musy, le Fribourgeois Bernard de Weck (I890-I950), la Commission fédérale des banques est "un mal nécessaire», auquel il ne faut pas donner "une omnipotence trop absolue ${ }^{102}$.

En définitive, il semble donc que le système d'une commission autonome soit considéré comme une solution de compromis, à mi-chemin entre l'absence totale d'instance - ce qui implique une exécution de la loi laissée à la libre concurrence et aux autorités judiciaires cantonales - et un office fédéral des banques créé au sein du Département des finances.

Relevons enfin la proposition, dans le plénum du Conseil national, d'une organisation de l'exécution de la loi radicalement différente de celle prévue par le Conseil fédéral. Il s'agit d'un système corporatiste, avancé par Johannes Duft (I883-I957), député chrétien-social saint-gallois ${ }^{103}$. Ce dernier suggère la constitution d'un "Conseil de banque", composé de 22 membres, chargé de l'exécution de la loi et de l'examen d'affaires importantes dans le domaine bancaire. Les 22 délégués se répartiraient comme suit: quinze d'entre eux représenteraient les milieux bancaires, et les sept autres seraient nommés par le Conseil fédéral et représenteraient les associations économiques ${ }^{104}$. L'objectif de cette proposition est de concrétiser les principes corporatifs (Berufsständische Idee) dans la loi. Sa proposition est présentée comme une très modeste étape vers une organisation corporatiste de l'économie, qui ferait opposition aux projets d'étatisation des socialistes. Mais le député saint-gallois, face à l'opposition des rapporteurs de commission, décide de retirer son amendement. Malgré

101 ABNS, I.3/I215, Protokoll der Kommission des Ständerates zur Behandlung des Entwurfes zum Bundesgesetz über die Banken und Sparkassen, I6.02.1934, p. 82.

102 ABNS, I.3/1215, Protokoll der Kommission des Ständerates zur Behandlung des Entwurfes zum Bundesgesetz über die Banken und Sparkassen, I6.02.1934, p. 85.

103 Sur cette proposition, voir aussi : Tarnutzer, op. cit., I94I, p. 29-32. Nous utilisons ici le terme " corporatisme " pour désigner une forme d'organisation sociale antilibérale et autoritaire, en vogue parmi les milieux catholiques durant l'entre-deux-guerres, et reposant sur un transfert des compétences politiques, économiques et sociales de l'État vers les corporations. Sur les différents courants du corporatisme en Suisse dans les années 1930: Hans Ulrich Jost, «La Suisse, le corporatisme et ses sources d'inspiration ", in Olivier Dard (éd.), Le corporatisme dans l'aire francophone au XXe siècle, Berne: Peter Lang, 20II, p. I2I-I38.

104 Bulletin officiel de l'Assemblée fédérale, Conseil national, séance du 27 septembre 1934, p. 707. 
l'échec de la proposition Duft, il faut souligner la relative vigueur des idées corporatistes dans les années 1930, dont nous observons ici une tentative de réalisation ${ }^{105}$. Alors que le statut institutionnel ambigu de la Commission fédérale des banques en fait déjà, comme le note le radical bâlois Ernst Thalmann, "une solution en direction d'une organisation corporative " ${ }^{106}$, certains catholiques-conservateurs veulent aller plus loin dans cette voie.

Mis à part cette escarmouche de la part des antiétatistes, la Commission fédérale des banques n'est plus remise en question au Conseil national. La seule modification significative consiste en une exclusion des dirigeants bancaires de la fonction de membres de l'autorité de surveillance. Reprenant en partie les postulats du maire de Zurich, le socialiste Emil Klöti, au Conseil des États, le Département des finances introduit dès août 1934 des clauses d'incompatibilité entre la fonction de membre de la Commission fédérale des banques d'une part et celle de présidents, vice-présidents, délégués de l'administration ou membres de la direction d'une banque ou d'une institution de révision d'autre part. Un conseiller d'administration d'une grande banque, en revanche, est autorisé à siéger dans l'autorité de surveillance.

\section{IV.2.5. Le renforcement du secret bancaire}

Passées presque totalement inaperçues pendant l'élaboration de la loi, ainsi que dans les commentaires de loi publiés immédiatement après son entrée en vigueur, la disposition infligeant une sanction pénale pour punir une violation du secret bancaire (art. 47), est devenue dans les publications ultérieures parmi les plus célèbres la loi. Ce contraste est tout à fait saisissant: alors que le commentaire de loi de Walther Brühlmann paru en 1935 décrit en une demipage le fameux article 47, contre par exemple une dizaine pour celui sur les dépôts d'épargne, Youssef Cassis, co-auteur en 2003 de la notice "Banques » du Dictionnaire historique de la Suisse, consacre une des quatre phrases décrivant la loi sur les banques de 1934 au secret bancaire ${ }^{107}$. Il est vrai qu'au cours de l'élaboration de la législation bancaire helvétique, à partir de sa première apparition dans les projets de février 1933, l'article qui condamne « la violation de la discrétion" attendue d'un employé de banque ne connait que de légères modifications jusqu'à la version définitive de la loi adoptée en novembre 1934 (cf. chap. III.2 et III.3). Plus intéressant encore, il ne suscite aucune discussion,

105 Sur l'échec de l'initiative pour une révision totale de la Constitution en 1935 : Peter Stadler, "Die Diskussion um eine Totalrevision der Schweizerischen Bundesverfassung 1933-1935", Revue suisse d'histoire, vol. I9, $\mathrm{n}^{\circ}$ I, 1969, p. 75-169, Linder, Bolliger, Rielle (éd.), op. cit., 20I0, p. I80-I8I. Sur l'influence du corporatisme, voir aussi Baumann, op. cit., 2007, p. 8898.

106 ABNS, I.3/I215, Protokoll der Kommission des Ständerates zur Behandlung des Entwurfes zum Bundesgesetz über die Banken und Sparkassen, I2.04.1934, p. 80.

107 Brühlmann, op. cit., 1935; Martin Körner, Youssef Cassis, «Banques», in Marc Jorio (éd.), Dictionnaire historique de la Suisse, Hauterive: Attinger, vol. 2, 2003, p. IO-I4. 
ni au sein des conférences d'experts ni dans les commissions parlementaires ${ }^{108}$. Il faut d'ailleurs souligner que les dispositions protégeant pénalement la discrétion des banques ne font pas l'objet d'un chapitre à part entière dans la structure de la loi de 1934. Au contraire, elles sont judicieusement et discrètement intégrées dans la section consacrée aux dispositions pénales - une section tout à fait banale figurant dans la plupart des normes légales, et placée en toute fin de texte, avant les dispositions transitoires.

Nous ne reviendrons pas ici en détail sur la question des origines de cette disposition, qui a déjà fait couler beaucoup d'encre ${ }^{109}$. Rappelons seulement que contrairement à une légende forgée par les milieux bancaires à la fin des années 1950, le secret bancaire n'a pas été renforcé dans la loi de I934 pour protéger les avoirs des juifs allemands persécutés par les autorités nazies ${ }^{110}$. Il faut plutôt comprendre le renforcement, sous droit pénal, de la garantie de confidentialité dans l'article 47 comme une réponse à la fois aux pressions internationales en faveur d'une limitation de la fraude fiscale, aux affaires d'espionnage bancaire de la part des administrations fiscales allemandes et françaises, et aux craintes que pouvait susciter chez la clientèle, étrangère comme suisse, l'introduction d'un contrôle bancaire, aussi libéral soit-il ${ }^{111}$. L'affaire de la Banque Commerciale de Bâle et de la perquisition par la police, sur ordre du ministère des Finances, de son agence clandestine installée dans un hôtel parisien le 27 octobre 1932 représente une étape importante dans l'accroissement des pressions sur le secret bancaire, auquel les projets de loi bancaire - dont les premiers sont rédigés quelque trois mois plus tard - ont répondu ${ }^{112}$.

108 Guex, art. cit., 2000, p. 244; Hug, art. cit., in Tanner, Weigel (éd.), op. cit., 2002, p. 286.

109 Nicholas Faith, Safety in Numbers. The Mysterious World of Swiss Banking, London : Hamish Hamilton, 1982, p. 49-87; Bänziger, op. cit., 1986, p. II4-II8; Guex, art. cit., 1999 ; Guex, art. cit., 2000; Hug, art. cit., in Tanner, Weigel (éd.), op. cit., 2002; Guex, art. cit., 2002; Loepfe, op. cit., 2006, p. I44-I47 ; Robert U. Vogler, Swiss banking secrecy: origins, signifcance, myth, Zürich: Verein für Finanzgeschichte Schweiz und Fürstentum Liechtenstein, 2006.

110 Sur la naissance de cette légende attribuée au président de la SBS Samuel Schweizer en 1958, cf. Farquet, op. cit., 20I8, p. 24I-243.

111 Sur les affaires d'espionnage bancaire durant les années 1930, voir en particulier: Thomas Chappot, "L'espionnage bancaire et son rôle dans l'adoption de dispositions relatives à l'espionnage économique 1930-1935 ", Mémoire de Master, Faculté des lettres, Université de Lausanne, 2010.

112 Sur le scandale des fraudes fiscales de la Banque Commerciale de Bâle de 1932 : Perrenoud, et al., op. cit., 2002, p. 240-243; Sébastien Guex, «Le scandale des fraudes fiscales et de la Banque Commerciale de Bâle. De l'une des causes possibles de la chute du gouvernement Herriot en décembre I 932 ", in Florence Bourillon, et al. (éd.), Des économies et des hommes: mélanges offerts à Albert Broder, Bordeaux : Bière, 2006, p. 45-55; Guex, art. cit., 2000, p. 248252 ; Farquet, op. cit., 2016, p. 329-336. Pour une interprétation qui minimise l'importance de ce que son auteur appelle "l'affaire de Paris", voir: Vogler, op. cit., 2006, p. 20-23. Vogler reprend en ce sens l'analyse de l'historien officiel de la Basler Handelsbank, qui rejette les accusations françaises en évoquant " des reproches excessivement gonflés pour des raisons de politique intérieure». Hans Bauer, I25 Jahre Basler Handelsbank: 1863-I988, [Basel] : Basler Handelsbank, 1988, p. 35 . 
Comme le remarque le compte-rendu circonstancié et bien informé de Francis James Renell Rodd (I895-1978) de la Banque d'Angleterre, cette affaire a suscité en Suisse "un certain degré d'agitation", ainsi qu'une crainte de voir d'autres fraudeurs fiscaux rapatrier leurs capitaux hors de Suisse ${ }^{113}$.

Il s'agit donc de replacer la portée de l'article 47 de la loi sur les banques dans un contexte de longue durée et de relativiser son impact immédiat. Le renforcement pénal en 1934 d'une pratique de discrétion déjà bien ancrée et utilisée comme avantage compétitif ne constitue qu'une étape dans un processus d'affermissement progressif. Il serait également faux de lire l'émergence de la régulation bancaire dans la loi de 1934 uniquement à l'aune du renforcement du secret bancaire opéré simultanément. Les procès-verbaux des négociations aboutissant à l'adoption de la loi indiquent que cette question n'y joue qu'un rôle mineur.

En revanche, il semble, du point de vue des banquiers suisses, que la mise en place indésirable d'un régime de surveillance encadré dans une législation spéciale au domaine bancaire a été saisie comme une occasion de consolider - pour ainsi dire par la bande - une pratique d'une part considérée à juste titre comme un atout-clé, d'autre part régulièrement menacée par des attaques intérieures et extérieures. Dans les réflexions des banquiers sur la voie à suivre en matière de contrôle bancaire, en janvier I932, la possibilité d'alourdir les responsabilités pénales en cas d'infraction à la confidentialité représentait un des seuls avantages d'une législation spécifique, par rapport à une simple révision du Code des obligations ${ }^{114}$. Un an plus tard, en janvier 1933, la question réapparaît à l'ordre du jour de l'Association des banquiers, dans le contexte autrement plus tendu faisant suite à l'éclatement du scandale parisien de la Banque Commerciale de Bâle et aux révélations de l'affaire du vol des données confidentielles chez la Banque cantonale de Zurich au profit des autorités fiscales allemandes ${ }^{115}$. En faisant explicitement référence à l'espionnage bancaire, Adolf Jöhr suggère alors d'examiner la possibilité d'ajouter le secret bancaire parmi les secrets professionnels dont la violation est condamnée par le projet de Code pénal suisse en cours d'élaboration à ce moment-là ${ }^{116}$. On

113 BoE Archive, OV 63/I, Mémorandum de l'Overseas Department de la Banque d'Angleterre, I8.II.I932, signé F[rancis] R[ennell] R[odd]. Les citations des archives de la Banque d'Angleterre sont traduites de l'anglais par l'auteur.

114 Cf. les réserves exprimées par Adolf Jöhr à ce sujet : AFB, E6520(B), 2007/62, vol. 17, dossier $n^{\circ} 66$ «Bankengesetz und Revision Obligationenrecht », Entwurf Jöhr, Vorschläge für eine Revision des Obligationenrechts hinsichtlich der Bankenkontrolle, 24.OI.I932, p. 8.

115 Sur l'affaire de la Banque cantonale de Zurich et plus généralement l'espionnage bancaire opéré par le fisc allemand dans les années 1930: Chappot, op. cit., 2010, p. 63-79; Barbara Bonhage, Hanspeter Lussy, Marc Perrenoud, Nachrichtenlose Vermögen bei Schweizer Banken: Depots, Konten und Safes von Opfern des nationalsozialistischen Regimes und Restitutionsprobleme in der Nachkriegszeit, Zürich: Chronos, vol. I5, 200I, p. I05-I26; Loepfe, op. cit., 2006, p. I32-I44.

116 AASB, Procès-verbaux du Comité de l'ASB, $55^{\mathrm{e}}$ séance, 20.0I.1933, p. I3. Le Code pénal suisse sera adopté le 27 décembre 1937 par le Parlement; son article 32I sur la violation du secret professionnel ne concerne pour l'essentiel que le domaine médical, les ecclésiastiques, et les avocats. 
peut donc avancer qu'en attendant l'introduction éventuelle et hasardeuse d'une protection du secret bancaire dans le Code pénal suisse, un texte dont l'élaboration durait depuis déjà près d'un demi-siècle, Adolf Jöhr a profité des circonstances de la préparation d'une loi spécifique au domaine bancaire pour réaliser ce souhait de longue date. Les premiers projets officiels, qui incluent déjà une disposition pénale renforçant le secret bancaire, dont celui intitulé «Entwurf Jöhr ", datent de quelques semaines après la déclaration faite à l'ASB, du I9 février I933 pour être exact.

Quelle est la portée plus précise du renforcement opéré dans la loi sur les banques? L'alinéa $b$ de son article 47 condamne les employés de banque, les réviseurs et les membres de la Commission fédérale des banques, qui violent la discrétion ou le secret professionnel, ou qui incitent à les violer. Les sanctions prévues en cas d'infraction à l'article cité entrent dans la catégorie des violations graves: tout contrevenant, poursuivi d'office par les instances judiciaires cantonales, risque une peine de 20000 francs et/ou six mois d'emprisonnement ${ }^{117}$. Il s'agit donc des mêmes sanctions que celles prévues notamment pour un dirigeant de banques qui ne soumet pas ses comptes annuels au contrôle obligatoire des réviseurs, c'est-à-dire la sanction prévue pour le nonrespect du principe fondamental sur lequel repose la loi. En revanche, la violation du secret bancaire est plus sévèrement punie qu'une transgression des directives de la Commission fédérale des banques, seulement passible d'une amende d'ordre de I ooo francs ordonnée par le Département fédéral des finances. Le contraste entre les deux condamnations est d'autant plus saisissant qu'une infraction de la protection du secret bancaire concerne en principe un individu, tandis que les amendes d'ordre sont à la charge de sociétés.

Si la catégorie de personnes visées par la loi et la lourdeur des sanctions sont clairement exprimées, il en va autrement de la portée de la protection pénale. Autrement dit, la question de savoir dans le cadre de quelles procédures judiciaires l'article 47 pouvait être levé restait ouverte. À partir de 1935 s'ouvre donc une phase d'interprétation juridique sur la primauté du secret bancaire, nouvellement protégé par la loi sur les banques. Comme le montre l'historien Christophe Farquet, ce débat ne se limite pas à une réflexion théorique entre juristes : il est alimenté par l'ASB ${ }^{118}$. Après avoir mandaté un rapport d'expert à G. Keller en 1936, celle-ci créée en 1938 une commission chargée de déterminer la portée juridique de l'article 47 , afin de pouvoir renseigner ses banquesmembres sur l'attitude à adopter en cas de requêtes de diverses autorités judiciaires et administratives en vue de lever le secret bancaire. Les travaux de cette commission débouchent sur une circulaire confidentielle, datée de juin 1938, qui recommande une position intermédiaire qu'on peut résumer de la

117 L'amende est réduite à Io ooo francs si l'acte est commis par négligence. À titre de comparaison, le montant de 20000 francs correspond à près du quadruple du salaire annuel d'un employé de banque masculin dans le secteur bancaire en 1939 (5724.- francs), cf. Ritzmann-Blickenstorfer (éd.), op. cit., 1996, tableaux G.I2 et G.I4a.

118 Farquet, op. cit., 2016, p. 360-363. 
manière suivante ${ }^{119}$ : le secret bancaire peut être levé en cas de procédure judiciaire pénale, voire, dans certains cas uniquement, dans une procédure judiciaire civile. Par contre, lors de demandes provenant d'autorités administratives, en particulier les autorités fiscales cantonales, et a fortiori en cas de requêtes d'instances étrangères, la levée du secret bancaire est à décliner. À ces recommandations internes au monde bancaire vient se superposer un débat juridique. L'interprétation absolutiste du secret bancaire de l'avocat genevois Georges Capitaine, selon laquelle le devoir de confidentialité devient illimité en matière pénale et civile, s'oppose à la vision très restrictive qu'en donne le juriste François Delachaux, qui estime qu'il n'apporte pas de modification fondamentale à l'obligation de témoigner des banquiers ${ }^{120}$. Un flou juridique semble donc persister pendant une certaine phase sur la portée de la protection du secret bancaire, et les conditions sous lesquelles un banquier peut être amené à témoigner et lever son obligation de discrétion. L'évolution des commentaires juridiques de la loi sur les banques semble confirmer ce point. Tandis que la première édition du commentaire de Paul Rossy et Robert Reimann (I8901963), publiée en 1935 se montre très prudente, et ne se risque pas à gloser l'article 47, la réédition de ce même texte parue en 1963 contient un éclaircissement qui précise notamment qu'il n'existe pas d'obligation de fournir des informations en matière fiscale ${ }^{121}$. Autre indice de cette grande incertitude: lorsqu'en février 1938, le comité de l'Union des banques cantonales suisses doit prendre position sur l'extension du secret bancaire aux banques cantonales depuis l'entrée en vigueur de l'article 47 , une grande perplexité se fait jour ${ }^{122}$. Un directeur de banque cantonale avoue par exemple que ses juristes sont divisés sur la question de la portée (Rechtskraft) de l'article 47. La seule conclusion à laquelle les banquiers cantonaux aboutissent consiste à souligner la validité de la confidentialité selon la disposition de la loi fédérale sur les banques, disposition à laquelle peut s'ajouter un secret bancaire cantonal ${ }^{123}$.

Dans ce contexte, il faut souligner que le renforcement du secret bancaire dans la loi sur les banques de I934 ne constitue qu'une étape dans l'ancrage juridique de la notion du "secret des banques». En amont, les pratiques de discrétion du monde bancaire préexistaient et s'appuyaient sur des bases

119 AASB, Circulaire n ${ }^{\circ}$ 509, "Auskunftpflicht der Banken", juin 1938, annexée au Procèsverbal de la $124^{\mathrm{e}}$ séance du Conseil d'administration de l'ASB du 25 mai 1938. Cette circulaire connaîtra une actualisation importante en juin 1955, lorsqu'une brochure de 22 pages ( ${ }^{\circ} 87$ $\mathrm{D}$, datée du Io juin 1955) intitulée " le secret des banques » sera adressée à toutes les directions des banques membres de l'association.

120 Delachaux, op. cit., 1939, Georges Capitaine, Le secret professionnel du banquier en droit suisse et en droit comparé, Genève: Atar, 1936. Cf. Farquet, op. cit., 2016, p. 494-495.

121 Rossy, Reimann, op. cit., I935, p. 73; Reimann, op. cit., I963, p. III.

122 AUBCS, Protokolle der Komitee-Sitzungen, II4 e séance, I6.O2.1938, p. IO-I3.

123 La déclaration originale: «Artikel 47 des Bankengesetzes gilt auch für die Kantonalbanken, da so weit die Kantonalbanken dem Gesetz unterstehen. Darüber hinaus besteht noch eine besondere Rechtspflicht der Wahrung des Bankgeheimnisses auf Grund der kantonalen Bankgesetze und Statuten.»Ibid., p. I3. 
juridiques moins solides ${ }^{124}$. Ce flou juridique - et les craintes qu'il pouvait susciter pour les banquiers avant 1934 - était intensifié par un changement dans la conduite du Tribunal fédéral en la matière, qui rend plusieurs décisions restreignant le secret bancaire entre 1930 et $1932^{125}$. En aval, une fois le principe fixé dans la loi, il restait aux milieux bancaires à établir plus précisément les contours du secret bancaire.

Le statut encore incertain de la valeur juridique du secret bancaire renforcé pénalement permet également de comprendre partiellement l'attitude peu fanfaronne des milieux bancaires au moment de l'adoption des dispositions consolidant la garantie de confidentialité. Peu d'historiens ont en effet mis l'accent sur la grande discrétion avec laquelle est accueilli, chez les banquiers, le renforcement sous droit pénal du secret bancaire. Alors que d'autres avancées dans les négociations sont rapportées avec une certaine fierté lors de discussions internes à l'Association suisse des banquiers - par exemple lorsqu'Adolf Jöhr signale en janvier I934 qu'il est parvenu à " améliorer » le titre de la loi, c'est-àdire à supprimer le terme de surveillance, on ne trouve pas de déclaration d'autosatisfaction quant au résultat obtenu dans le futur article 47. Comment expliquer cette discrétion?

Premièrement, cette attitude cadrait bien avec la position récente de l'ASB sur la question, qui consistait à ne pas réagir publiquement à moins que cela soit absolument nécessaire, pour ne pas attirer l'attention des milieux hostiles aux banques. «Plus la chose peut être traitée discrètement, mieux cela sera pour nous ", estimait le directeur de la Banque cantonale de Zurich, Heinrich Daeniker, avec Adolf Jöhr au diapason: "Nous ferions mieux de faire profil bas. ${ }^{126}$ En ce sens, il était stratégiquement plus habile pour les banquiers, dans leurs bilans de la nouvelle loi adoptée, de se présenter en victimes de mesures liberticides, plutôt que de souligner les avantages compétitifs consolidés. Deuxièmement, on peut avancer que l'absence d'opposition rencontrée au cours de l'élaboration de la loi a pu induire la retenue dont ont fait preuve les milieux bancaires. Il serait en effet surprenant de fanfaronner après une bataille au cours de laquelle on ne rencontre aucune résistance. À vaincre sans péril, on triomphe sans gloire... La passivité des représentants du mouvement ouvrier sur la question du secret bancaire serait ici en cause ${ }^{127}$. Troisièmement enfin, à titre d'hypothèse, la discrétion des banquiers à la suite du renforcement du secret bancaire opéré dans la loi de 1934 tient aussi à la grande incertitude quant à la portée pratique de l'introduction de la nouvelle clause. Dans l'attente d'un fondement juridique solide reposant sur une jurisprudence claire, il était certainement difficile pour les contemporains de mesurer l'impact de l'article condamnant la violation du secret bancaire. Ce n'est qu'en mars 1936, un an

124 Winiger, op. cit., 2007, p. I0-22.

125 Guex, art. cit., 2000, p. 253-254; Farquet, op. cit., 2016, p. 356-359; Farquet, op. cit., 2018, p. 152 .

126 Cf. AASB, Procès-verbaux du Conseil de l'ASB, $82^{\mathrm{e}}$ séance, 27.04.I93I, p. 3.

127 Farquet, op. cit., 2016, p. 353-356. Guex, art. cit., 2000, p. 256. 
après l'entrée en vigueur de la législation, que l'on recense une déclaration d'un banquier, soulignant l'un de ses avantages. Il s'agit des propos du banquier privé genevois Albert Pictet (1890-1969), tenus devant un parterre trié sur le volet - le groupement des banquiers privés genevois : «L'article 47 de la loi sur les banques constitue une aubaine pour notre profession, en ce sens qu'il lui octroie le bénéfice du secret professionnel. Il parait toutefois de bonne politique de ne pas profiter de cet article pour entraver l'exercice de la justice, notamment dans le cas de la procédure pénale. ${ }^{128}$

Malgré ces quelques réserves mineures sur le caractère crucial de l'adjonction de l'article 47 et le tournant qu'il représente dans l'attractivité de la place financière suisse, il faut admettre qu'en comparaison internationale, cette clause fournissait une protection du secret bancaire hors du commun. À l'échelle européenne, seuls les Pays-Bas offrent alors une garantie de confidentialité explicitement exprimée dans une norme légale : en l'occurrence le Code pénal et non une loi de régulation bancaire comme en Suisse ${ }^{129}$. Mais même le contexte juridique néerlandais des années 1930 présente une discrétion des informations bancaires bien moins solide que celui introduit en Suisse en 1934 .

128 Archives Darier Hentsch \& Cie, PV des séances du Groupement des Banquiers Privés Genevois, 24.03.1936, cité in Perrenoud, et al., op. cit., 2002, p. II4.

129 Farquet, op. cit., 2016, p. 363, 494-495. Pour une comparaison internationale de la protection juridique du secret bancaire en vigueur dans les années 1950: Siegfried Sichtermann, Bankgeheimnis und Bankauskunft: Systematische Darstellung mit besonderer Berücksichtigung der Rechtsprechung und unter Heranziehung ausländischen Rechts, Frankfurt a. M : F. Knapp, I957, p. 30I-329. 
广

N

$\stackrel{\circ}{\circ}$

(1)

.

2

2

(a) 


\title{
CONCLUSION DE LA PREMIÈRE PARTIE
}

\author{
LA LOI DU 8 NOVEMBRE 1934 COMME LOI D'APAISEMENT \\ PEU RESTRICTIVE
}

\begin{abstract}
Nous ne voulons et ne devons pas introduire une loi policière sur les banques, mais une loi qui serve de la même façon les intérêts de la collectivité et ceux des banques. [...] Les banques sont les centres de collecte de notre richesse nationale, leur croissance est identique à la prospérité de notre économie nationale, et il serait tout simplement démesuré de vouloir légiférer maintenant contre les banques en raison d'une certaine animosité produite par les pertes bancaires ${ }^{1}$.
\end{abstract}

Ce programme présenté par l'Argovien agrarien Roman Abt devant le Conseil national résume relativement bien le dilemme auquel faisaient face les politiciens et législateurs helvétiques. Comment contenter à la fois les partisans d'un contrôle bancaire vigoureux - dont les revendications s'appuient sur les défaillances récentes, sans pour autant entraver la marge de manœuvre d'un secteur économique dont la réussite est pour eux intrinsèquement assimilable au développement du bonheur national ? Cette citation est aussi révélatrice de la posture ambiguë d'une grande partie des cercles politiques et de l'administration fédérale à l'égard d'une réglementation des banques. Ils interviennent pour ainsi dire à contrecœur, à la fois pour justifier les opérations de sauvetage menées avec des deniers publics et pour satisfaire les sympathisants d'une forme de régulation. L'analyse des dynamiques du processus d'élaboration de la loi sur les banques montre bien qu'il faut dépasser une dichotomie simpliste entre acteurs étatiques favorables à un renforcement du pouvoir des autorités publiques et acteurs privés qui exerceraient une pression externe pour défendre de front le maintien d'un libéralisme économique absolu. Au contraire, notre cas illustre une situation plus ambivalente. Les milieux concernés par la régulation sont étroitement et précocement intégrés à la préparation des projets législatifs. À l'interne, certains d'entre eux jouent même un rôle de médiateurs pour soutenir les solutions de compromis négociées avec les représentants de l'État. Ceux-ci, quant à eux, font preuve d'un manque de conviction dans l'efficacité réelle des mesures qu'ils proposent et adoptent un comportement versatile.

1 Bulletin officiel de l'Assemblée fédérale, Conseil national, séance du 18.09.1934, p. 443, intervention de Roman Abt, conseiller national argovien $\mathrm{PAB}$, président de la commission du Conseil national (pour une notice biographique, cf. note I3O du chapitre III). 
Le résultat de ce processus de décision particulier en porte évidemment les marques. La loi fédérale sur les banques et les caisses d'épargne du 8 novembre I934 est une des législations les plus libérales et les moins interventionnistes à avoir vu le jour dans la foulée de la Grande Dépression. Alors qu'une véritable vague de réglementation bancaire atteint la plupart des économies développées, instaurant parfois des régimes très stricts aux établissements mis en cause durant la crise, les législateurs suisses mettent en place une législation très peu contraignante ${ }^{2}$. "L'intervention du pouvoir public tant dans la direction que dans le contrôle des banques est vraiment dans la loi suisse réduite à son minimum »" affirme l'économiste belge Franz de Voghel en 1936.

Les réactions et prises de position qui ont suivi l'adoption et l'entrée en vigueur de la nouvelle loi confirment l'impression d'une législation qui contente les milieux concernés. En Suisse, les jugements sont plutôt élogieux. Dans un exposé donné le I2 novembre I934 à la Statistisch-Volkswirtschaftliche Gesellschaft de Bâle, le président de la SBS, Max Staehelin, estime que «les dispositions qui justifient au fond l'adoption de la loi, à savoir les dispositions relatives à l'organisation administrative et à la révision, sont raisonnables et contiennent tout à fait ce que la grande majorité des banques ont déjà » ${ }^{4}$. Chez son collègue, le Zurichois Max E. Bodmer, devenu au fil de l'élaboration le représentant principal des banquiers privés, le bilan est plus nuancé. Après avoir reconnu l'utilité de la loi pour tranquilliser le public et souligné la valeur de la révision fiduciaire, Bodmer se livre à une série de considérations sur les limites de toute ouvre législative dans le domaine bancaire:

Aucun État, pas même la république soviétique, n'est en mesure de décréter la stabilité économique de son pays ou d'assigner à ses banques uniquement des affaires rentables. Des défaillances se produiront toujours, ce d'autant plus lorsque l'État restreint la liberté de mouvement des banques ; après tout, la direction d'une banque est un art qui ne peut pas être imposé arbitrairement par les règles d'une loi rigide. En abordant le domaine de la législation bancaire, l'État rencontre certes l'entière compréhension de certains partis politiques, en particulier ceux qui y voient une étape positive vers la socialisation ou la nationalisation des banques; mais cette décision n'est pas sans danger ; car il ne peut plus rejeter la responsabilité morale pour le sort des banques individuelles 5 .

2 Pour un ouvrage comparatif de l'époque, voir: Johannes C. D. Zahn (éd.), Die Bankaufsichtsgesetze der Welt, Berlin, Leipzig: Walter de Gruyter \& Co., 1937; Eugène Smits, Étude critique de l'intervention de l'État dans la politique de crédit des banques de dépôts, Bruxelles: Cools, 1940. Cf. aussi, Gigliobianco, Toniolo (éd.), op. cit., 2009; Federico Barbiellini Amidei, Claire Giordano, "The Redesign of the Bank-Industry-Financial Markets Ties in the US Glass Steagall Act and the 1936 Italian Banking Acts ", in Piet Clement, Harold James, Hermann Van der Wee (éd.), Financial Innovation, Regulation and Crises in History, London: Pickering \& Chatto, 2014, p. 65-83.

De Voghel, op. cit., 1936, p. 324.

4 Selon le compte-rendu de sa conférence reproduite dans la $N Z Z$ (I5.II.I934, no 2050).

5 Bodmer, op. cit., 1934, p. 39. Repris dans la $N Z Z, \mathrm{n}^{\circ}$ 2249, I2.12.1934. 
On perçoit ici la persistance d'une tendance au sein des dirigeants bancaires qui considèrent la loi sur les banques avec une plus grande méfiance. Les banquiers privés, souvent minorisés lorsqu'ils rencontraient l'opposition d'autres groupes bancaires dans les commissions d'experts, en font assurément partie. Enfin, du côté des élites bancaires genevoises, la prise de position globale est favorable. C'est du moins ce qui ressort de l'article publié par le juriste Edouard Barde (1904-1984) dans le Journal de Genève, quotidien libéral-conservateur proche de la haute banque ${ }^{6}$. Après avoir salué l'accueil bienveillant fait à cette loi par les banquiers genevois, le commentateur approuve «la naissance d'une loi fédérale qui ne présente pas un caractère étatiste et dont l'application n'exigera pas une armée de fonctionnaires nouveaux ${ }^{7}$.

Les dirigeants de la Banque nationale suisse tirent un bilan en demi-teinte du texte de loi obtenu, et insistent sur la dimension pragmatique des mesures introduites. Lors de son discours à l'assemblée générale de la BNS du 9 mars I935, son président Gottlieb Bachmann aurait tenu les propos suivants : «Trancher entre des dispositions presque idéales pour les activités bancaires et ce qui est commercialement réalisable et financièrement viable pour le secteur bancaire suisse a certes parfois conduit à certaines solutions de compromis. Mais la meilleure garantie de dispositions utiles est contenue dans la mise en balance soigneuse entre ce qui est souhaitable et ce qui est possible. " ${ }^{8}$

Au-delà des frontières du pays aussi, les comptes-rendus des milieux financiers brossent un tableau positif d'une loi jugée comme un régime minimal. À Londres, place financière bien renseignée s'il en est, les rapports de la Banque d'Angleterre font état d'une loi qui n'est pas un instrument prévu pour défendre les déposants contre les banques, mais qui est au contraire conçue pour favoriser un secteur vital de l'économie qui verse d'importantes contributions à la balance des paiements et aux revenus fiscaux ; le gouvernement aurait cherché à éviter toute interférence excessive avec le système bancaire? ${ }^{9}$. Montagu Norman, gouverneur de la banque d'Angleterre durant l'entre-deux-guerres, partage ce jugement et le précise :

The law seeks to consolidate and extend the friendly co-operation already existing between the Central bank and the commercial banks. [...] Those measures are only such as are plainly desirable in view of the somewhat luxuriant growth of Swiss banking: whether or not they will prove effective in operation it is still too early to judge. [...] The Law is in no way revolutionary and effects no radical change in the banking structure. If the work of the Banking Commission proceeds

6 Sur le Journal de Genève durant l'entre-deux-guerres, cf. Alain Clavien, Grandeurs et misères de la presse politique : le match Gazette de Lausanne -Journal de Genève, Lausanne : Antipodes, 2010, p. I44-169.

7 Edouard Barde, "La loi sur les banques ", Journal de Genève, 22.I2.I934.

8 Selon le compte-rendu de son discours transcrit dans la NZZ, 13.03.1935.

9 BoE Archive, OV 63/I, Rapport de 9 pages daté du 08.I2.I934. 
smoothly and the subsidiary decree are wisely framed, the Law should prove to be a salutary measure of co-ordination ${ }^{10}$.

Le dirigeant de la banque centrale britannique porte ici un jugement qui relativise à juste raison l'impact de la nouvelle réglementation. En codifiant dans la loi des pratiques informelles préexistantes, elle ne constitue pas une réforme fondamentale du système bancaire. Les commentaires du Financial Times vont dans le même sens: la loi bancaire suisse, pour le quotidien de référence de la place financière londonienne, ne permet ni à la Banque nationale ni à la Commission fédérale des banques de surveiller les opérations bancaires à tous égards et les banques peuvent poursuivre leurs affaires comme d'habitude ${ }^{11}$.

Dès les premières semaines qui suivent l'adoption de la loi puis son entrée en vigueur, la plupart des observateurs s'accordent pour souligner son caractère relativement inoffensif. Au fond, l'on se rend rapidement compte que la législation pérennise certaines pratiques déjà très répandues, mais ne met pas en branle un mouvement de changement en profondeur pour le système de crédit helvétique.

Les limites de la loi bancaire de 1934 apparaissent aussi clairement si l'on observe non pas, comme nous l'avons fait dans le chapitre qui précède, ce qu'elle contient, mais plutôt ce qu'elle ne contient pas. Cette description par la négative peut se faire par analogie aux autres réglementations sur les banques commerciales qui sont introduites ailleurs à la même époque ${ }^{12}$. Cet exercice comparatiste comporte des risques, puisque chacune des réglementations évoquées répond avant tout à un contexte national spécifique; il faut également mentionner que d'autres places financières importantes comme l'Angletterre, la France ou les Pays-Bas ne connaissent dans les années I930 aucune législation spécifique au domaine bancaire.

En premier lieu, comme l'évoquait déjà la citation de Norman, la législation fédérale n'implique en aucune manière une réforme structurelle. Elle ne cherche nullement à modifier la structure bancaire en place ${ }^{13}$. Au contraire, dès le message du Conseil fédéral de 1934, les législateurs affirmaient leur volonté de «se borner à codifier quelques principes généraux et instaurer une

10 BoE Archive, OV63/I, Lettre de Montagu Norman (I87I-I950), gouverneur de la Banque d'Angleterre à Leslie Lefeaux (1886-1962), gouverneur de la Reserve Bank of New Zealand, I7.0I.1935.

11 Financial Times, 02.03.1935: «It would be wrong to say that the new Banking Act enables the National Bank and the Committee to supervise the affairs of banks in every respect, for this was not intended. Banks can carry on their business as usual [...]".

12 Cf. Robert Deumer, "Die Gesetzegebung des Auslandes auf dem Gebiete der Kreditbanken", in Untersuchung des Bankwesens 1933 I. Teil Vorbereitendes Material, Berlin: Carl Heymanns Verlag, vol. 2, 1933, p. 27I-310; Zahn (éd.), op. cit., I937; Arthur Meredith Allen, et al., Commercial Banking Legislation and Control, London : Macmillan, 1938; Smits, op. cit., I940.

13 Mazbouri, Schaufelbuehl, art. cit., 2015, p. 68I. 
surveillance adaptée en fait à chaque cas particulier ${ }^{14}$. En ce sens, la loi a ratifié la domination en Suisse du modèle de la banque universelle. Contrairement aux réformes engagées aux États-Unis (1933), en Belgique (1934) ou en Italie (1936), la réglementation suisse n’a pas cherché à établir une séparation entre les activités de banque de dépôt et de banque d'investissement. L'idée sous-jacente à ces mesures de spécialisation bancaire était de diminuer la prise de risque des établissements financiers en interdisant que des dépôts à court terme servent à financer des crédits industriels à long terme ou soient engagés dans la spéculation boursière. En Suède et en Norvège également, les prises de participations industrielles et les opérations mobilières sont en grande partie prohibées pour les banques. Rien de tel en Suisse : comme en Allemagne, la législation bancaire n'a pas pour conséquence une remise en question du modèle d'entreprise dominant.

Plus largement, il faut souligner que la loi sur les banques de novembre 1934 n'inclut aucune restriction sur les activités bancaires à proprement parler. Les seules dispositions qui peuvent affecter les opérations bancaires sont celles sur les fonds propres et la liquidité, et dans une moindre mesure, le droit de regard de la BNS sur l'exportation de capitaux ${ }^{15}$. Il est en effet surprenant qu'aucune disposition de la loi n'évoque, même vaguement, une forme de régulation sur l'utilisation qui est faite des dépôts confiés aux banques. Même les dépôts d'épargne ne sont pas protégés par une prescription spécifique, qui imposerait une précaution particulière dans leur emploi. De même, aucune limitation n'existe, en Suisse, sur l'acquisition par les banques de propriétés foncières, alors que notamment les États-Unis, la Suède, le Danemark, l'Italie et l'Argentine connaissent des restrictions sur les investissements des banques dans l'immobilier. En outre, la loi bancaire suisse laisse une liberté totale dans l'octroi des crédits. On note ainsi l'absence d'une autre mesure très répandue à l'international, à savoir des restrictions qui interdisent aux banques de consentir des crédits exagérés à un seul débiteur. Les "gros débiteurs » ne font pas l'objet de la moindre limitation dans la loi de I934. Semblablement, il faut souligner que la réglementation helvétique ne prescrit aucune mesure sur les crédits accordés aux directeurs, administrateurs, voire aux employés d'une banque. Il s'agit là aussi d'une clause prudentielle relativement courante, qui vise à éviter les conflits d'intérêts évidents qui résulteraient de cette pratique abusive. Comme le dira fièrement un des auteurs de la loi sept ans après son édiction :

La loi est sage en ne prescrivant aucune politique déterminée ; ainsi elle laisse aux banquiers une liberté de mouvement complète dans l'exercice de leur difficile profession. Cette absence de toute directive impérative est, si je puis dire ainsi, la disposition négative la plus raisonnable de la

14 "Message du Conseil fédéral à l'Assemblée fédérale concernant le projet de loi sur les banques et les caisses d'épargne, (du 2 février 1934)", Feuille fédérale, I, I934, p. I75.

15 L'article I7, qui interdit aux banques de placer les valeurs reçues en nantissement, constitue une autre exception. 
loi. [...] Je pense qu'une condition de l'immunité aux crises est la liberté d'action laissée à la gérance et cette liberté est nécessaire aux banquiers comme l'air est nécessaire à l'homme ${ }^{16}$.

D'autre part, le statut bancaire de 1934, au-delà de la distinction entre organes de direction et organes de surveillance (le conseil d'administration), ne décrète pas de règles d'incompatibilité sur la composition des instances dirigeantes d'une banque. Les directeurs de banques helvétiques restent donc libres de siéger dans les conseils d'administration de sociétés industrielles et commerciales ; cette pratique est d'ailleurs très développée ${ }^{17}$. Adolf Jöhr et Max Staehelin, le binôme issu des deux plus grandes banques dont nous avons vu le rôle central dans les discussions sur la loi sur les banques, détiennent en 1929 chacun huit sièges dans les conseils d'administration des iıo plus grandes entreprises du pays ${ }^{18}$. Ailleurs, au Danemark, en Norvège, en Tchécoslovaquie et en Belgique notamment, les lois bancaires instaurent de strictes restrictions sur les activités annexes des dirigeants bancaires.

Troisième domaine dans lequel la régulation helvétique est légère, les conditions de fondation d'une nouvelle banque demeurent très ouvertes. Le système mis en place en 1934 introduit uniquement le régime de l'autorisation, et non celui de la concession. Cela signifie que les fondateurs d'un nouvel établissement, à partir du moment où ils remettent des statuts et règlements de société jugés conformes, se voient automatiquement octroyer la permission d'inscrire leur firme au registre du commerce et d'entamer leur activité. La Commission fédérale des banques ne peut donc pas refuser une nouvelle ouverture en se basant sur d'autres critères, comme le nombre d'offices déjà présents dans une région ou les compétences douteuses des dirigeants. Corollairement, la législation bancaire suisse ne connaît aucune limite sur le développement du réseau de succursales. Les fusions entre banques ne sont pas non plus abordées dans la loi de 1934. Relevons enfin que la loi suisse ne prévoit pas de capital minimal fixe; seule la proportion de fonds propres détermine partiellement le capital minimum. Cette situation contraste avec les dispositions mises en place ailleurs à la même époque. La grande majorité des législations bancaires optent en faveur du régime de la concession, qui permet aux autorités de surveillance de refuser l'ouverture d'une nouvelle banque qu'elle juge indésirable. En Suède par exemple, des concessions sont accordées pour Io ans, au

16 Paul Rossy en octobre 1942, alors vice-président de la direction générale de la BNS. ABNS, I.3/I23I, "Conférence du 2I octobre I942 à la Société d'économie politique et de statistique de Zurich de Monsieur P. Rossy sur la loi bancaire et l'immunité des banques aux crises ", p. 3-4.

17 Sur la densité du réseau d'interconnexions des grandes entreprises suisses durant la première moitié du XXe siècle et la position centrale des grandes banques, cf. David, et al., op. cit., 2015, p. I27-I5I.

18 Ibid., p. I33. Si l'on inclut de plus petites entreprises, le nombre de mandats peut s'élever jusqu'à 33 dans le cas de Staehelin. Cf. Fritz Giovanoli, Im Schatten des Finanzkapitals, Zürich : Jean Christophe Verlag, 1938, p. 34-35. 
terme desquels une nouvelle requête de concession potentiellement liée à de nouvelles conditions doit être formulée par la banque ${ }^{19}$. Aux États-Unis, le Comptroller of the Currency a refusé plus de la moitié des demandes de fondation qu'il a eu à traiter en $1930^{20}$. De même, les fusions entre banques sont soumises à autorisation dans de nombreux pays, comme en Norvège ou en Belgique, pour éviter une trop forte concentration du marché bancaire.

Quant aux dispositions de la loi fédérale de 1934 sur les taux d'intérêt des obligations de caisse, nous en avons déjà souligné la timidité. Le devoir d'informer la BNS en cas d'élévation du taux d'intérêt n'est lié à aucun pouvoir de sanction de la part de la banque centrale. En Allemagne, en Belgique et en Italie, le pouvoir discrétionnaire de l'instance de surveillance sur la détermination des taux d'intérêt est plus étendu. En Argentine et au Portugal, des taux d'intérêt débiteurs maximaux sont même mécaniquement liés aux taux d'escompte de la banque d'émission ${ }^{21}$.

Enfin, l'autorité de surveillance créée en 1934 dans la loi suisse, la Commission fédérale des banques se distingue en comparaison internationale non seulement par sa grande indépendance à l'égard de l'administration étatique et de la banque centrale, mais également par la faiblesse de ses compétences d'intervention ${ }^{22}$. C'est davantage par une philosophie de conseil et de persuasion que par l'exécution de normes disciplinaires qu'elle cherche à intervenir auprès des banques en délicatesse avec une disposition légale. Les offices des banques et inspectorats étatiques, étroitement liés au gouvernement ou à la banque centrale, tels qu'ils sont instaurés notamment en Suède, au Japon ou en Italie, disposent à la fois de ressources et de pouvoirs de sanction plus développés. Les chapitres suivants mettront en exergue le caractère lacunaire du dispositif légal de la Commission fédérale des banques.

Le caractère peu contraignant et libéral de la régulation bancaire établie en Suisse en 1934 se dessine encore plus clairement dans ce descriptif in absentia. Il est d'autant plus important de souligner que ces omissions ne sont pas tirées d'élucubrations théoriques issues de la fantaisie d'économistes utopistes; les mesures mentionnées ci-dessus étaient en vigueur ailleurs à l'époque même où la législation suisse est élaborée. Les législateurs helvétiques n'y ont pas renoncé par ignorance, mais par choix. Un demi-siècle après la promulgation de la loi, le directeur général de l'Union de Banques Suisses chante encore les louanges des parlementaires des années 1930: «L'Assemblée fédérale a concrétisé dans la loi sur les banques une approche résolument libérale, alors que, dans le sillage de la crise, la tendance économique dans la plupart des pays s'orientait vers plus d'interventionnisme et des arguties dirigistes. ${ }^{23}$

Zahn (éd.), op. cit., 1937, p. XVIII.

Allen, et al., op. cit., 1938, p. 35 .

Smits, op. cit., I940, p. 178-179.

Zahn (éd.), op. cit., 1937, p. XXVIII.

Nikolaus Senn, «Der Einfluss bankengesetzlicher Bestimmungen auf die Entwicklung des schweizerischen Finanzplatzes", in Urs Zulauf (éd.), so Jahre eidgenössische Bankenaufsicht I 
Une fois ce diagnostic d'une loi peu contraignante accepté, il reste à en éclaircir les motivations. Pour quelles raisons et dans quelles circonstances cette version édulcorée de la régulation bancaire a-t-elle vu le jour?

Plusieurs historiens ont mis en avant le sens de compromis qui avait présidé à l'aboutissement de la législation. Hugo Bänziger, d'une part, insiste sur la rapidité d'achèvement de la loi $^{24}$. Il est vrai que la phase parlementaire de la préparation de la loi se déroule en moins de neuf mois, ce qui, selon les standards du processus de légifération helvétique, est relativement bref pour une réglementation économique de cette importance. Le texte est ensuite voté à l'unanimité ou presque, et le référendum facultatif n'est pas saisi, si bien que la loi entre en vigueur seulement un an après la publication du message du Conseil fédéral. Cette finalisation sans heurts d'une législation économique est d'autant plus remarquable que les années 1930 sont marquées par le recours fréquent du Conseil fédéral à la clause d'urgence, qui permet de faire passer une loi en contournant l'obstacle démocratique potentiel que constitue le référendum populaire ${ }^{25}$. La vitesse d'adoption de la loi sur les banques serait un indice de l'esprit de compromis qui la caractérise. Tandis que le Parti socialiste et les représentants de la paysannerie se satisfont de l'intégration de mesures minimalistes sur l'exportation de capitaux et les taux d'intérêt, les délégués des banques, soutenus sur ce point par le patronat industriel, obtiennent la reconnaissance officielle du principe de liberté de commerce dans le domaine bancaire. La marge de manœuvre de ce compromis reposait donc sur ce que les formations politiques favorables au contrôle bancaire exigeraient en échange de leur approbation d'une loi au caractère fort peu contraignant. Les articles 7 à Io sur l'exportation de capitaux et les taux d'intérêt ont donc constitué une compensation jugée adéquate par les groupes PSS et PAB.

Malik Mazbouri, Sébastien Guex et Rodrigo Lopez avancent quant à eux une seconde forme de compromis politique. Dans leur interprétation, l'article 47 renforçant le secret bancaire a représenté « une contrepartie » à l'instauration d'un régime de surveillance des banques ${ }^{26}$. Il est vrai qu'en regard de l'utilisation qui sera ultérieurement faite de la loi, il y a bien une forme d'arrangement entre deux aspects contradictoires de la régulation, à savoir l'inquiétude liée à une éventuelle ingérence étatique dans les affaires bancaires et la consolidation d'une protection juridique visant à dissiper ces craintes. En revanche, du point

50 ans de surveillance fédérale des banques / 50 anni di sorveglianza federale delle banche, Zürich : Schulthess Polygraphischer Verlag, 1985, p. 245-256, p. 245. débat politique par le recours à la clause d'urgence. Hans-Ulrich Jost, «Menace et repliement. 1914-1945", in Nouvelle Histoire de la Suisse et des Suisses, Lausanne: Payot, 1986, p. 683-770, p. 690. Sur cette question, voir aussi: Kreis, art. cit., in Bovey Lechner, Graf, Huber-Hotz (éd.), op. cit., I99I.

26 
de vue des accords politiques noués en 1934, la question du secret bancaire n'est pas explicitement instrumentalisée comme monnaie d'échange.

Mais même en analysant la logique de compromis qui est à l'œuvre dans l'adoption de la loi bancaire, la question de savoir pourquoi elle reste si libérale demeure. Une des réponses apportées par l'historiographie est de souligner l'expérience réussie des opérations de sauvetage bancaire durant la première moitié des années I930, qui aurait encouragé l'administration fédérale, la BNS et les banques à rejeter une régulation légale étendue ${ }^{27}$. Cette explication est à notre avis insuffisante. Notre analyse montre au contraire que le déclenchement des défaillances bancaires joue un rôle de catalyseur des projets de législation. L'intervention du législateur, dans ce contexte tendu, visait aussi à augmenter les responsabilités des organes dirigeants et d'instaurer des instruments d'assainissement qui diminueraient les risques de devoir faire appel à l'État fédéral pour sauvegarder la stabilité du système bancaire.

\section{Mouvement ouvrier et loi sur les banques}

C'est donc aussi du côté des partisans d'une forte régulation qu'il faut se tourner pour comprendre l'esprit si peu intrusif de la loi bancaire à l'égard des milieux qu'elle est censée contrôler. En I934, les leaders du PSS et de l'USS, dont le poids était de toute manière très marginal au sein des instances décisionnelles, se contentent d'une version très légère de contrôle bancaire. Il est nécessaire de souligner ici l'approche très timorée des représentant du mouvement ouvrier. Dès le début de la crise bancaire à l'été 193I, les dirigeants socialistes s'étaient emparés du problème des défaillances bancaires et le thématise pendant la campagne des élections fédérales de l'automne. Ils réclamaient un contrôle et une prise d'influence étatique sur le "capital financier " pour protéger l'épargne confiée aux banques. Le contrôle bancaire apparaît dès lors comme un des éléments programmatiques dans la transition vers le planisme économique. Pourtant, au fil des débats politiques qui entre I932 et I933 précèdent des opérations de sauvetage bancaire, les délégués socialistes ne s'opposent pas fondamentalement aux coûteux assainissements, malgré quelques remontrances visant à lier l'aide étatique aux banques à l'instauration d'une réglementation. La même ambivalence réapparait en 1933-1934 lorsqu'il s'agit d'élaborer la loi sur les banques. Un monde sépare les revendications figurant au programme du parti en 1933, à savoir la nationalisation des banques, et les résultats auxquels aboutissent les négociations sur la loi bancaire.

$\mathrm{Au}$ moins trois raisons permettent de comprendre cette attitude très modeste de la social-démocratie suisse. D'une part, comme le montrent les antécédents du projet Landmann et les bases très fragiles des projets de loi au début des années 1930, l'aboutissement d'une loi fédérale sur les banques représentait en soi une victoire pour les socialistes. Briser la résistance décennale 
des milieux bancaires et voir une législation propre à ce secteur entrer en vigueur était, sur le papier, un résultat probant qui aurait pu conduire à une intervention ultérieure plus conséquente; un tien vaut mieux que deux tu l'auras.

D'autre part, du point de vue des orientations politiques du mouvement ouvrier, l'approbation d'une législation sur les banques d'esprit libéral représentait une étape dans l'intégration progressive au système politique suisse. Au cours des années 1930, une évolution se dessine vers une plus forte coopération et intégration des représentants du PSS dans l'État bourgeois, au détriment de la dynamique plus conflictuelle qui dominait encore au début de la décennie. Dans l'esprit de l'aile droite du mouvement ouvrier, une loi sur les banques, même minimaliste, capable de réduire les risques de nouvelles catastrophes bancaires et d'apporter une sécurité accrue aux épargnants, tout en renforçant la position internationale de la place financière suisse, n'était certainement pas vue d'un mauvais œil. Une partie des dirigeants du PSS et de l'USS n'était sans doute pas imperméable à l'axiome qui marque l'attitude des autorités fédérales à l'égard des milieux bancaires depuis la fin de la Première Guerre mondiale, selon lequel la prospérité des banques suisses est synonyme de l'accroissement de la richesse nationale.

Troisièmement, les discussions sur la loi sur les banques interviennent à un moment délicat pour le Parti socialiste suisse, une phase caractérisée par une conjoncture politique défavorable à une attention soutenue portée par le mouvement ouvrier au dossier de la loi sur les banques. En effet, l'année I934 est marquée par d'importantes frictions entre les dirigeants du PSS et ceux de l'Union syndicale suisse ${ }^{28}$. Le parti s'engage vers un nouveau programme dans lequel le planisme économique inspiré du socialiste belge Henri de Man devrait jouer un rôle important ${ }^{29}$. Ce projet politique se concrétise dans un «Plan du Travail», qui remet en question le contrôle des strutures économiques et préconise un rôle planificateur de l'État. Dans le domaine du crédit, le Plan revendique «la nationalisation des grandes banques et des sociétés d'assurance, et l'organisation du crédit en service public ${ }^{30}$. Or,

28 Benno Hardmeier, Geschichte der Sozialdemokratischen Ideen in der Schweiz (I920-1945), Winterthur: P. Keller, 1957, p. 77-78, 116; Scheiben, op. cit., 1987, p. 173-190; Oskar Scheiben, «Instabilität, die Stabilität bewirkt. Gegenläufige Prozesse in Gesellschaft und Organisation am Beispiel der Sozialdemokratischen Partei der Schweiz 1930-1936», in Andreas Ernst, et al. (éd.), Kontinuität und Krise: sozialer Wandel als Lernprozess: Beiträge zur Wirtschafts- und Sozialgeschichte der Schweiz: Festschrift für Hansjörg Siegenthaler, Zürich : Chronos, 1994, p. 225-24I ; François Baer, et al. (éd.), Einig - aber nicht einheitlich: I25 Jahre Sozialdemokratische Partei der Schweiz = Une pensée unie-mais pas unique: I25 ans Parti socialiste suisse, Zürich : Limmat, 2013, p. I62-166.

29 Sur les débats internationaux inspirés par le planisme d'Henri de Man, et notamment ses liens avec Hans Oprecht (I894-I978) : Gerd-Rainer Horn, "From "Radical” to "Realistic": Hendrik de Man and the International Plan Conferences at Pontigny and Geneva, I9341937", Contemporary European History, vol. I0, n 2, 200I, p. 239-265.

30 Le texte en français du Plan du Travail est édité dans une brochure par la Fédération suisse du personnel des services publics (VPOD), en octobre I934: Fédération suisse du personnel des 
parallèlement, les dirigeants syndicaux élaborent un projet alternatif, plus pragmatique et applicable à court terme, qui prend la forme de l'initiative de crise: une série de mesures exigées du gouvernement pour combattre la crise économique. Cette concurrence entre deux tactiques et deux projets politiques au sein du mouvement ouvrier helvétique rend la définition d'une position homogène difficile. À l'été 1934, ces frictions internes semblent tourner à l'avantage de l'initiative de crise lancée par les syndicats ${ }^{31}$. La présentation publique du Plan du Travail est repoussée. Max Weber, le délégué syndical que nous avons vu à l'œuvre dans le processus d'élaboration de la loi sur les banques, fait partie des instigateurs de l'initiative de crise; il n'est donc pas surprenant de le voir se satisfaire, dans une logique de petits pas, d'une règlementation très libérale et peu contraignante. À l'antagonisme PSS-USS vient s'ajouter un second débat interne au parti. Dès l'été I934 ont lieu les discussions sur la révision du programme du parti, finalement approuvée au congrès de Lucerne en janvier 1935. Le nouveau programme, notamment porté par Robert Grimm poursuit la tendance réformiste : la mention de la dictature du prolétariat est supprimée, au profit d'une défense de l'État et de la démocratie $^{32}$. Autrement dit, les conceptions des représentants du mouvement ouvrier suisse dans la politique à l'égard des banques est affaiblie et minée par des divergences internes, à la fois idéologiques et stratégiques. L'initiative de crise de l'USS semble monopoliser l'attention des socialistes et des syndicalistes, entre sa conception en mars I934 et son rejet populaire en juin 1935, une phase décisive dans l'élaboration de la loi sur les banques. Quant aux adversaires désignés du mouvement ouvrier, on constate également un glissement par rapport à la situation des années 1920: le national-socialisme en Allemagne, et, en Suisse, l'avènement du frontisme supplante le grand capital comme ennemi politique prioritaire. Pour les dirigeants socialistes impliqués de près dans les négociations sur la réglementation bancaire, comme Max Weber ou Robert Grimm, obtenir quelques concessions, par exemple dans le domaine de la régulation de l'exportation de capitaux ou des taux d'intérêt, représente un modeste succès, qui peut être présenté comme une petite étape intermédiaire dans la prise d'influence de l'État sur les milieux bancaires.

S’il y avait donc bien une logique de compromis à l'œuvre dans les négociations politiques menant à l'adoption de la loi sur les banques, ce marchandage a largement tourné en faveur des intérêts bancaires. C'est en définitive l'un de ses principaux auteurs, le vaudois Paul Rossy, directeur à la BNS qui

services publics (éd.), Le Plan du Travail. Pour une économie suisse dirigée, La Chaux-deFonds: Imprimerie des coopérative réunies, I934, ici p. 60.

32 Hardmeier, op. cit., 1957, p. 88-100; Baer, et al. (éd.), op. cit., 2013, p. 165, 209-210. 
deviendra le premier secrétaire de la Commission fédérale des banques chargée de mettre en application la loi, qui en résume le mieux la portée:

Cette loi est d'ailleurs dépourvue de tout caractère étatiste, puisque le contrôle est confié à l'initiative privée, que la commission des banques instituée par la loi n'est pas une section de l'administration et que cet organe n'a pour ainsi dire pas de droit de regard dans le ménage des banques ni dans les rapports de revision ${ }^{33}$.

Enfin, le dernier aspect à souligner dans l'interprétation d'une loi sur les banques peu intrusive est relatif au climat politique et social qui entoure son développement. En reprenant la grille de lecture d'une récente étude ${ }^{34}$, on observe aussi qu'au-delà des réponses techniques et des dispositions prudentielles, l'édiction d'une législation bancaire avait une dimension expiatoire. Dans le contexte d'une grave crise économique bancaire et face au mécontentement suscité à la fois par les sauvetages bancaires et à la pression croissante en faveur d'une limitation des taux d'intérêt, le gouvernement agit aussi pour calmer le jeu. Il s'agit avant tout de refermer rapidement et à moindre coût la fenêtre d'opportunité ouverte dans le domaine de la réglementation bancaire par l'éclatement de la crise. En ce sens, la loi sur les banques de novembre 1934 devient une loi d'apaisement à visée palliative.

34 Mazbouri, Schaufelbuehl, art. cit., 2015. 
DEUXIÈME PARTIE

\section{LA COMMISSION FÉDÉRALE DES BANQUES}

(1935-1972) 
广

N

$\stackrel{\circ}{\circ}$

(1)

.

2

2

(a) 
La Commission fédérale des banques, qui a intégré la FINMA en $2009^{1}$, reste une institution relativement peu connue. Alors qu'elle a récemment célébré ses 80 ans d'existence, son seul historien officiel demeure Hugo Bänziger, qui avait publié en 1985 une version remaniée de sa thèse de doctorat dans la publication jubilaire commémorant un demi-siècle de surveillance bancaire ${ }^{2}$. Et encore, soulignons ici que la partie des travaux de Bänziger qui aborde l'application par la Commission fédérale des banques des dispositions légales entre 1935 et I97I ne représente qu'un sixième de l'étude (47 sur 277 pages) et qu'étrangement elle ne figure pas dans la publication officielle de 1985. Quant aux histoires de la place financière suisse entre 1930 et 1970, elles consacrent en général une portion très congrue de leurs propos aux activités de l'autorité fédérale chargée de la surveillance des banques. Dans le portrait de l'évolution des banques suisses durant les Trente Glorieuses par l'historien Willi Loepfe, il faut attendre une centaine de pages pour voir la première mention de la Commission fédérale des banques ${ }^{3}$. Alors qu'elles constituent pourtant, du point de vue documentaire, une des rares portes d'entrée librement accessibles pour analyser les relations entre le monde bancaire privé et les autorités publiques, les archives de la Commission fédérale des banques ne sont que très rarement consultées et mobilisées. De même, il semble régner un certain flou sur les traits caractéristiques de l'institution: ses prérogatives, ses activités et sa composition sont notamment largement méconnues. Les cinq chapitres qui suivent forment la deuxième partie de ce livre, s'efforcent de faire la lumière sur les premières décennies d'activité de l'organe fédéral de surveillance des banques. Le chapitre $\mathrm{V}$ dresse rapidement, à partir d'une analyse prosopographique, un portrait des hommes qui composent l'institution de surveillance durant son premier demi-siècle d'existence. Les quatre chapitres suivants sont structurés chronologiquement. Le chapitre VI revient sur la difficile phase de

1 L'abréviation FINMA vient de l'allemand Finanzmarktaufsicht. Il s'agit de l'autorité fédérale de surveillance des marchés financiers, qui réunit en une seule institution les trois organes jusqu'alors séparément chargés de la surveillance des banques (CFB), des assurances privées (OFAP) et de la lutte contre le blanchiment d'argent.

2 Bänziger, art. cit., in Zulauf (éd.), op. cit., 1985. Nous préférons renvoyer à la version publiée chez Haupt en 1986, plus complète.

3 Elle est d'ailleurs mentionnée plus rarement que la Bundesbank allemande. Loepfe, op. cit., 2 OII. 
mise en place de la Commission fédérale des banques dans les années 1930. Le chapitre VII s'attarde sur les pratiques de surveillance plus routinières qui s'installent dans l'après-guerre jusqu'aux années 1960. Dans le chapitre VIII, le tournant du milieu des années 1960, plus tourmenté, est exposé. Le chapitre IX, enfin, explore le processus législatif qui conduit à la révision de la loi sur les banques adoptée en I97I. 


\section{CHAPITRE V}

\section{LA COMMISSION FÉDÉRALE DES BANQUES, SES MEMBRES ET SON SECRÉTARIAT : UNE BIOGRAPHIE COLLECTIVE SUCCINCTE (1935-1991)}

Avant d'entamer l'analyse chronologique du rôle et des activités exercés par l'instance fédérale de surveillance, il est pertinent de présenter rapidement qui sont les personnalités placées à sa tête, dans quelles conditions elles y sont nommés, et les moyens financiers et en personnel à sa disposition. Nous allons ici nous limiter à présenter en trois temps les conditions de nomination, le profil socio-professionnel des 42 premiers membres, puis les moyens du secrétariat permanent.

Nous quittons ici le niveau de la narration chronologique et adoptons une perspective d'ensemble sur le premier demi-siècle d'existence de l'autorité fédérale de surveillance des banques en Suisse. Plus précisément, ce sont les membres individuels de la Commission fédérale des banques qui seront observés de plus près. En envisageant le développement d'un régime de régulation non pas comme un simple processus juridique mettant en place des normes répondant à des circonstances historiques, mais davantage comme une manifestation des rapports de pouvoir entre l'industrie régulée et l'État, le profil socio-professionnel des personnalités qui mettent en œuvre la régulation devient un paramètre d'analyse de premier plan. Leur insertion, ou non, au sein du milieu qu'il s'agit de contrôler, est un des aspects essentiels que nous observerons ici.

Il est toutefois frappant de constater que la très large majorité des travaux qui abordent la thématique de la régulation bancaire - que cela soit dans le contexte suisse ou même international, et peu importe les disciplines académiques dont leurs auteurs se réclament - se désintéresse presque totalement des individus qui appliquent les normes définies. Trop souvent, la littérature spécialisée présente l'établissement et le développement d'un cadre réglementaire financier comme un processus entièrement désincarné, dans lequel le rôle des individus est inexistant ou marginal ${ }^{1}$. Les superviseurs bancaires eux-

1 Relevons parmi les rares exceptions à cette tendance : Eiji Hotori, «The role of financial elites in banking supervision in Japan from 1927 to 1998 ", eabh Papers. The European Association for Banking and Financial History (EABH), vol. 16, n ${ }^{\circ}$ I, 2016, p. I-22; Alexis Drach, «Liberté surveillée. Supervision bancaire et globalisation financière au Comité de Bâle, 1974-1988», 
mêmes ont sans doute contribué à maintenir cet anonymat relatif, en cultivant une forme de discrétion remarquable. En Suisse, il faut attendre 1976 pour que les rapports annuels de la Commission fédérale des banques, qui dressent notamment la liste de ses membres, deviennent accessibles à tout un chacun ${ }^{2}$. Auparavant, c'est seulement par le biais de communiqués de presse laconiques que le public était tenu au courant des nominations intervenues à la tête de la surveillance étatique sur les banques. Le caractère ingrat de la tâche des superviseurs - qui se retrouvent sous les feux de la rampe uniquement lorsque des dysfonctionnements sont révélés par l'éclatement de crises bancaires et dont l'activité passe complètement inaperçue lorsqu'elle réussit - joue également un rôle dans le peu de publicité offert par la fonction.

Quelles qu'en soient les raisons, cette relative confidentialité dont bénéficient les acteurs historiques de la supervision bancaire mérite à notre avis d'être remise en question. Les décisions prises par l'organe de surveillance ne sont pas simplement le produit naturel et mécanique de l'application d'une législation prédéfinie. Elles résultent parfois tout simplement, et les procès-verbaux en témoignent, d'un rapport de force majoritaire au sein du collège que constitue la Commission fédérale des banques. Il est donc indispensable de comprendre qui sont les personnes qui sont placées à la tête de l'institution examinée pour en saisir la véritable nature.

\section{V.1. PROCESSUS DE NOMINATION DES MEMBRES, CONDITIONS D’ÉLIGIBILITÉ}

Comme nous le verrons dans la section VI.I.2., la Commission fédérale des banques constitue l'instance de surveillance et d'application de la loi sur les banques de 1934, et jouit d'une très large autonomie, à la fois à l'égard de l'appareil administratif de la Confédération - elle n'est pas institutionnellement intégrée dans le Département fédéral des finances - et de la Banque nationale suisse. En dépit de cette indépendance formelle, la CFB reste une émanation de l'État: elle est instituée par une loi fédérale, soumet annuellement un rapport au gouvernement, et ses dépenses sont intégralement couvertes - jusqu'en 1976 - par le budget de la Confédération. Enfin, ses membres sont nommés par le Conseil fédéral, qui désigne également son président et son vice-président.

Les critères d'éligibilité sont relativement simples et n'évoluent pas pendant au moins 35 ans. Selon la législation de 1934 (art. 23, al. I), les membres de la CFB doivent être «experts en matière de technique bancaire ou de technique de

thèse de doctorat, European University Institute, 20I6, en en particulier le chapitre prosopographique, p. II5-I39.

2 Cf. AFB, E6520(A), 1983/50, vol. I2, Geschäftsberichte I97I-I975. L'étoffement des rapports de gestion va de pair avec la croissance du secrétariat opérée simultanément, et le développement, encore embryonnaire, d'un service de presse. 
revision bancaire. Les présidents, vice-présidents ou délégués de l'administration ni les membres de la direction d'une banque ou d'une institution de revision ne sont éligibles». Cette clause d'incompatbilité est relativement permissive: un simple membre du conseil d'administration d'une banque est éligible, de même qu'un dirigeant bancaire qui renonce ou quitte ses fonctions à la tête d'un établissement (par exemple au moment de la retraite). En plus de ce critère, deux conditions secondaires influencent l'éligibilité et la longévité des membres: dès 1959, l'âge maximal est fixé à 70 ans, et dès 1977, la durée maximale d'un mandat est restreint à 16 ans. Les membres de la CFB exercent leur mandat à temps partiel : ils sont uniquement indemnisés par des dédommagements et se réunissent en moyenne toutes les trois semaines entre 1935 et 1975. L'organe de décision de la CFB, à savoir le comité de 5 à 7 personnes qui forment l'instance délibérative - par opposition au secrétariat permanent - fonctionne donc comme une administration de milice. Cela signifie aussi que toutes les personnalités nommées membres de la CFB exercent une profession principale en dehors de leur mandat, ou doivent du moins disposer de revenus extérieurs additionnels.

Cette définition très singulière des conditions d'éligibilité - à savoir la combinaison entre un critère d'expertise dans le domaine bancaire et l'exclusion partielle de dirigeants encore actifs - a favorisé l'apparition de plusieurs cas problématiques. Au total, entre 1935 et 1971, I5 des 26 membres nommés occupent des postes dirigeants dans le monde bancaire juste avant - voire pendant pour les cas de simples administrateurs - leur mandat à la Commission fédérale des banques. Quant au processus de nomination, il s'avère également moins unilatéral que ne le laisse croire le texte de loi, selon lequel le seul Conseil fédéral est l'instance de nomination. Les documents d'archives montrent que de nombreuses négociations préalables conditionnent la sélection des candidats qui sont finalement soumis à l'approbation de l'exécutif fédéral. D'une part, il s'agit d'un recrutement par cooptation, puisque le membre démissionnaire et ses collègues encore actifs délibèrent et font de propositions de potentiels remplaçants. D'autre part, d'autres acteurs importants de la politique bancaire - Banque nationale suisse, Association suisse des banquiers, Union des banques cantonales suisses - sont consultés, à des degrés divers selon le profil recherché, et sont donc capables de peser sur le choix du Conseil fédéral ${ }^{3}$.

\section{V.2. PORTRAIT COLLECTIF DES 42 PREMIERS MEMBRES DE LA CFB (1935-1991)}

Quel type de composition a résulté de ces conditions et ce processus de nomination? Qui sont les superviseurs fédéraux chargés de la surveillance des banques? Plus encore que le terrain du développement de la surveillance

3 Pour des exemples de l'influence sur la procédure de nomination, et plus généralement pour une analyse prosopographique plus complète, cf. Giddey, op. cit., 2017, p. 637-692. 
bancaire en tant qu'ensemble de réglementations, le champ historiographique sur les individus qui composent les instances de régulation est encore intégralement en friche. Sur les dirigeants bancaires suisses, une littérature embryonnaire se fait jour depuis quelques décennies ${ }^{4}$. Certaines trajectoires individuelles ont également été analysées ${ }^{5}$. D'autres études historiques sur la place financière suisse contiennent de précieuses notices biographiques ${ }^{6}$. Dans le domaine plus large des élites économiques, des recherches récentes issues d'un projet FNS ont renouvelé ce champ historiographique en Suisse ${ }^{7}$.

Qui sont les membres de la Commission fédérale des banques? Observés selon six catégories d'analyse (sexe et âge, durée des mandats, formation, liens d'intérêts avec la finance, orientation politique et origine régionale), les 42 premiers membres constitue un groupe dont il faut en premier lieu souligner la grande stabilité au cours du premier demi-siècle d'existence de la CFB (I935-I99I) ${ }^{8}$.

Quelles sont les caractéristiques principales de ce groupe de 42 superviseurs bancaires? Il s'agit premièrement d'un bastion masculin, puisqu'il faut attendre I997 pour qu'une première femme y soit nommée. Les hommes en question sont plutôt âgés : la moyenne d'âge lors de l'entrée en fonction est de 58 ans, elle s'établit à 66 ans au moment du départ. Dans son évolution diachronique, on

4 Youssef Cassis, Fabienne Debrunner, "Les élites bancaires suisses. I880-1960 ", Revue suisse d'histoire, vol. 40, no 3, 1990, p. 259-273; Youssef Cassis, Jakob Tanner, Fabienne Debrunner, "Finance and financiers in Switzerland, I880-1960", in Youssef Cassis (éd.), Finance and financiers in European history, I880-1960, Cambridge : Cambridge University Press, 1992, p. 293-316; Yves Sancey, Sébastien Guex, «Les dirigeants de la Banque nationale suisse au XXe siècle", in Olivier Feiertag, Michel Margairaz (éd.), Gouverner une banque centrale du $X V I I^{e}$ siècle à nos jours, Paris: Albin Michel, 20IO, p. I43-179.

5 Mazbouri, op. cit., 2005, sur Léopold Dubois, p. 35-I47, 205-217. Sur les hommes forts du Crédit Suisse et de l'UBS pendant les années 1980-1990, voir respectivement: Joseph Jung, Rainer E. Gut: die kritische Grösse, Zürich: Verlag Neue Zürcher Zeitung, 2007; Claude Baumann, Robert Holzach : ein Schweizer Bankier und seine Zeit, ibid., 2014.

6 Perrenoud, op. cit., 20II, p. 471-478; Sancey, op. cit., 2015, p. 470-486.

7 Voir par exemple: Stéphanie Ginalski, Du capitalisme familial au capitalisme financier? Le cas de l'industrie suisse des machines, de l'électrotechnique et de la métallurgie au XXe siècle, Neuchâtel: Alphil-Presses universitaires suisses, 20I5; Stéphanie Ginalski, Thomas David, André Mach, "From national cohesion to transnationalization: the changing role of banks in the Swiss company network (I9IO-20IO) ", in Thomas David, Gerarda Westerhus (éd.), The power of corporate networks: a comparative and historical perspective, New York: Routledge, 20I4, p. I07-I23; Felix Bühlman, et al., "Transformation des élites en Suisse", Social Change in Switzerland, $\mathrm{n}^{\circ} \mathrm{I}, 2 \mathrm{I} 5$, p. I-13.

8 La périodisation choisie ici differe de celle retenue pour le développement des chapitres suivants, dont l'analyse s'interrompt en 1971-1972. Si nous avons choisi d'étendre le cadre chronologique pour cette étude prosopographique, c'est essentiellement parce que le groupe de membres pour la période précédant 197I, à savoir 26 individus, semblait trop petit pour constituer un échantillon d'analyse significatif. Afin d'éviter de devoir faire recours à des sources problématiques pour alimenter les données biographiques sur les membres de ces vingt dernières années, nous avons finalement limité notre analyse prosopographique aux membres élus avant 199I. Cette borne chronologique marque d'ailleurs la fin du mandat du huitième président de la CFB, le conseiller aux États démocrate-chrétien Hermann Bodenmann, élu en 1969 , soit pendant notre période d'analyse principale. 
Tableau I2. Membres de la CFB (I935-I99I), (en gras les membres ayant exercé la fonction de président et leur mandat)

\begin{tabular}{|c|c|c|c|c|}
\hline & Nom & $\begin{array}{l}\text { Naissance } \\
\text { et mort }\end{array}$ & $\begin{array}{l}\text { Mandat(s) } \\
\text { à la CFB }\end{array}$ & $\begin{array}{l}\text { Fonction principale avant la } \\
\text { nomination? }\end{array}$ \\
\hline I & Edmund Schulthess & I868-I944 & $1935-1943$ & Conseiller fédéral (PRD)/avocat \\
\hline \multirow{2}{*}{2} & \multirow{2}{*}{ Paul Rossy } & \multirow{2}{*}{ I896-I973 } & 1935-I937 & Dir. suppléant BNS/expert DFFD \\
\hline & & & $1957-1966$ & DG BNS \\
\hline 3 & Carl Brüderlin & I873-I945 & I935-I945 & Dir. SBS \\
\hline 4 & Emile Walch & I873-I965 & I935-I947 & Dir. Crédit Suisse \\
\hline 5 & Albert Zust & I874-I952 & I935-I948 & Conseiller aux États (PCC)/avocat \\
\hline 6 & Alphonse Perren & I898-I968 & I937-I939 & Dir. fiduciaire OFOR \\
\hline 7 & Henri Borle & I889-I966 & $1939-1958$ & $\begin{array}{l}\text { Prof. d'éco. commerciale (Unil et } \\
\text { UniBe) }\end{array}$ \\
\hline 8 & Ernst Wetter & I877-1963 & $1944-1950$ & $\begin{array}{l}\text { Conseiller fédéral (PRD)/délégué } \\
\text { Vorort }\end{array}$ \\
\hline 9 & Max Hommel & $1902-1972$ & $\begin{array}{l}1946-1965 \\
1955-1965\end{array}$ & $\begin{array}{l}\text { Expert-comptable. Chef du } \\
\text { secrétariat CFB }\end{array}$ \\
\hline IO & Ernst Weber & I88I-I967 & I947-I953 & DG BNS \\
\hline II & Thomas Holenstein & $1896-1962$ & $\begin{array}{l}1948-1954 \\
1951-1954\end{array}$ & Conseiller national (PCC)/avocat \\
\hline $\mathrm{I} 2$ & Heinrich Däniker & I883-I96I & I95I-I953 & Dir. Banque cantonale de Zurich \\
\hline $\mathrm{I} 3$ & Alfred Hirs & I889-I978 & $1954-1959$ & DG BNS \\
\hline $\mathrm{I} 4$ & Jakob Müller & I886-I974 & $1954-1956$ & Dir. Banque cantonale de Thurgovie \\
\hline 15 & Max Rohr & I890-I980 & $1955-1960$ & Conseiller national (PCC)/avocat \\
\hline I6 & Karl Etter & I9O2-? & I959-I972 & $\begin{array}{l}\text { Dir. fiduciaire Schweiz. } \\
\text { Treuhandges. }\end{array}$ \\
\hline I7 & Jean Golay & I9O3-I988 & I959-1973 & Professeur d'économie (Unil) \\
\hline I8 & Theodor Eisenring & I898-I96I & I96I-I96I & Conseiller national (PCC)/avocat \\
\hline 19 & Peter Müller & I910-1965 & I96I-I965 & Conseiller national (PCC)/avocat \\
\hline 20 & Hans Streuli & I892-I970 & $1965-1966$ & $\begin{array}{l}\text { ancien Conseiller fédéral (PRD)/ } \\
\text { architecte }\end{array}$ \\
\hline $2 \mathrm{I}$ & Hans Korner & I9I2-I99I & I966-1968 & Conseiller national (PCC)/avocat \\
\hline 22 & Riccardo Motta & $1902-1976$ & $1966-1973$ & DG BNS \\
\hline 23 & Duri Capaul & $1923-2009$ & $1967-1983$ & $\begin{array}{l}\text { avocat/ancien collaborateur de } \\
\text { l'UBS }\end{array}$ \\
\hline 24 & Emile Duperrex & I905-I984 & $1967-1975$ & DG Banque Populaire Suisse \\
\hline 25 & Rudolf Pfenninger & I9O2-I987 & $1967-1972$ & DG SBS \\
\hline 26 & Hermann Bodenmann & I92I-I994 & $\begin{array}{l}\text { I969-I991 } \\
\text { I977-I99I }\end{array}$ & Conseiller aux États (PDC)/avocat \\
\hline 27 & Arnold Rösselet & 1906-? & I97I-I976 & DG UBS \\
\hline
\end{tabular}




\begin{tabular}{|c|c|c|c|c|}
\hline & Nom & $\begin{array}{l}\text { Naissance } \\
\text { et mort }\end{array}$ & $\begin{array}{l}\text { Mandat(s) } \\
\text { à la CFB }\end{array}$ & $\begin{array}{c}\text { Fonction principale avant la } \\
\text { nomination? }\end{array}$ \\
\hline 28 & Albert Uldry & I916-? & I972-I986 & $\begin{array}{l}\text { Anc. dir. Procrédit SA, gérant de } \\
\text { fortune }\end{array}$ \\
\hline 29 & Albert Matter & $1906-1992$ & $1973-1976$ & Dir. Banque cantonale bâloise \\
\hline 30 & Alain Hirsch & 1934- & I974-I989 & $\begin{array}{l}\text { Professeur de droit commercial } \\
\text { (UniGe) }\end{array}$ \\
\hline $3 \mathrm{I}$ & Otto Stich & $1927-2012$ & $1976-1983$ & $\begin{array}{l}\text { Conseiller national (PSS)/chef du } \\
\text { personnel de Coop Suisse }\end{array}$ \\
\hline 32 & Paul Ehrsam & 1917-2008 & 1976-1987 & $\begin{array}{l}\text { Dir. à la BNS (chef suppléant du } \mathrm{I}^{\mathrm{er}} \\
\text { dép.) }\end{array}$ \\
\hline 33 & Daniel Bodmer & I917-1980 & I976-1980 & Chef du secrétariat CFB \\
\hline 34 & Eligio Antognini & I9I2-I977 & I977-I977 & Dir. de Cornèr Banca (Lugano) \\
\hline 35 & Hans Konrad Escher & I9I4-I988 & I977-I977 & DG Crédit Suisse \\
\hline 36 & Hans Hartung & 1916-2000 & I98I-I986 & DG Crédit Suisse \\
\hline 37 & Hans Schmid & I935-20IO & 1984-1996 & $\begin{array}{l}\text { Conseiller national (PSS)/prof. } \\
\text { d'économie (Haute école de } \\
\text { commerce de SG) }\end{array}$ \\
\hline 38 & Hans Wyer & $1927-2012$ & 1984-1996 & $\begin{array}{l}\text { Conseiller d'État valaisan (PDC)/ } \\
\text { avocat }\end{array}$ \\
\hline 39 & Amilcare Berra & I92I- & I987-I99I & Dir. gén. de l'UBS \\
\hline 40 & Silvio de Capitani & $1925-2013$ & $\begin{array}{l}1987-1995 \\
1992-1995\end{array}$ & $\begin{array}{l}\text { Avocat et ancien Conseiller national } \\
\text { (PRD) }\end{array}$ \\
\hline $4 \mathrm{I}$ & Peter Nobel & 1945- & I988-2000 & $\begin{array}{l}\text { Avocat/prof. droit économique } \\
\text { (UniSG) }\end{array}$ \\
\hline 42 & Jean-Pierre Ghelfi & I94I- & $1990-2002$ & $\begin{array}{l}\text { Économiste, député au grand conseil } \\
\text { neuchâtelois (PSS). }\end{array}$ \\
\hline
\end{tabular}

Sources : Zulauf (éd.), op. cit., I985, p. 383-386; rapports annuels CFB : AFB, E6520(A), 1983/50, vol. I2-I3; AFB, E6IooB, I972/96, vol. 32 ; AFB, E6Ioo(B-oI), 1980/49, vol. 67; Dictionnaire historique de la Suisse; base de données des Documents diplomatiques suisses ; base de données du projet «Élites Suisses au XXe siècle».

constate un léger rajeunissement de la moyenne d'âge des membres de la CFB, qui passe de 68 ans à son pic en 1943 à 56 ans en 1978 . Ces données indiquent en outre une forte représentation des sexagénaires, qui est sans doute liée au profil recherché. Puisque les directeurs de banque encore actifs sont écartés et que la limite d'âge est fixée à 70 ans, il existe une courte fenêtre entre l'âge de 65 et de 70 ans pour obtenir les services d'un banquier retraité. Pour ces superviseurs-là, le mandat à la CFB constitue une fonction honorifique plutôt qu'un tremplin dans la carrière. Ces profils de pensionnés de la finance sont compensés, en termes générationnels, par des superviseurs plus jeunes issus du monde de la politique fédérale (parlementaires) ou des professeurs de droit ou d'économie. L'âge relativement avancé des membres s'explique par le dilemme entre le 
critère d'expertise dans le domaine bancaire et l'incompatibilité des banquiers actifs. Il est également lié aux conditions matérielles du mandat, qui est uniquement rémunéré par des indemnités forfaitaires modestes. La durée des mandats confirme ce profil particulier liés aux contraintes de l'âge et des incompatibilités. La durée moyenne d'un mandat de membre de la CFB s'élève, toujours entre 1935 et 199I, à un peu plus de 8 ans, une valeur qui reste stable sur toute la période examinée.

Du point de vue de leur formation, les personnalités nommées à la Commission fédérale des banques disposent d'un important capital scolaire, 34 des 42 membres $(8 \mathrm{I} \%)$ ont achevé une formation universitaire ; parmi ces 42 diplômés, 27 (64\% du total) ont obtenu un doctorat. On constate en outre une tendance à l'accroissement de la proportion d'universitaires entre la fin des années I950 et la fin des années 1970. Cette évolution est liée non seulement à la démocratisation des études, mais surtout à la disparition progressive d'un profil particulier : celui du dirigeant économique ayant fait carrière dans la banque à partir d'un apprentissage commercial. C'est en effet ce type de trajectoire qui forme l'essentiel des membres de la CFB ne disposant pas de titre universitaire. Quant aux filières d'étude privilégiées, le droit (56\% des diplômés) et l'économie $(35 \%)$ sont prééminents.

Les liens d'intérêts économiques et les connexions avec le monde de la finance sont plus difficiles à établir avec certitude. En observant la carrière professionnelle qui précède la nomination à la $\mathrm{CFB}$, on peut tout de même dégager quelques tendances. 30 des 42 membres étudiés (7I \%) entretiennent ou ont entretenu des liens plus ou moins étroits avec les milieux bancaires privés ou la BNS avant ou pendant leurs mandats à la Commission fédérale des banques. Ces liens prennent la forme soit de mandats d'administrateurs ou d'anciennes fonction de direction chez des grandes banques ou des sociétés financières dont elles sont proches, soit des mandats de contrôle (censeur, membre du comité) ou d'anciennes fonctions de direction chez des banques cantonales, soit des postes auprès de sociétés fiduciaires, soit, enfin, de fonctions à responsabilité à la Banque nationale suisse. Cette prédilection à nommer à la Commission fédérale des banques des personnalités issues des milieux mêmes qu'il s'agit de contrôler est surtout due au critère d'expertise inscrit dans la loi. Il comporte toutefois d'importants risques de conflits d'intérêt, comme nous le verrons dans les chapitres qui suivent.

L'engagement politique des membres de la CFB n'est pas identifiable avec certitude pour l'ensemble des individus du groupe. Exactement la moitié des 42 membres observés ne peuvent pas être affiliés à un parti politique de manière incontestable. Parmi l'autre moitié, on dénombre ro superviseurs membres ou proches du Parti conservateur-catholique ( $48 \%$ du total des membres politiquement indentifiables), 8 membres ou proches du Parti radical (38\%), et 3 membres du Parti socialiste (I4\%). L'évolution diachronique de l'appartenance politique des superviseurs indique un fort équilibre entre les deux partis bourgeois, qui se partagent systématiquement 2-3 sièges de la Commission fédérale des banques 
entre 1935 et 199I. Les représentants socialistes ne sont accueillis que bien plus tard, puisqu'il faut attendre 1976 pour assister à la nomination d'un membre du PSS, en l'occurrence le futur conseiller fédéral Otto Stich, dans le but explicite de contrer " la critique constante de la gauche à l'égard des banques" ${ }^{9}$. Notons enfin qu'il s'agit dans la grande majorité des cas de personnalités politiques de premier plan : anciens conseillers fédéraux ou parlementaires en activité.

Comme souvent dans les institutions fédérales, un certain équilibre entre régions d'origine et communautés linguistiques est partiellement respecté dans le choix des candidats à la Commission fédérale des banques. Zurich et la Suisse orientale sont fortement représentés ( $43 \%$ du total des membres), tandis que d'autres cantons, accueillant pourtant des places financières importantes, n'y obtiennent qu'occasionnellement un représentant: Genève ( 2 membres) et Bâle-Ville (I membre). La répartition linguistique est relativement fidèle à la réalité démographique du pays. En moyenne, les germanophones constituent $70.7 \%$ des membres, contre $26.5 \%$ et $2.8 \%$ pour les francophones et les italophones respectivement.

Ces quelques considérations d'analyse prosopographique des membres de la CFB nous permettent également de dégager un modèle de composition type. Entre I935 et 199I, parmi les cinq, puis sept membres, on trouve au moins un élu radical et un parlementaire catholique-conservateur. Aux côtés de ces deux politiciens, qui jouent parfois un rôle utile comme courroie de transmission avec les Chambres fédérales lors de débats dans le domaine bancaire, on retrouve souvent au moins un expert issu du monde académique. Ce professeur de droit commercial ou d'économie remplit généralement aussi le quota de Suisses romands. En plus de ces trois superviseurs au profil bien déterminé - un radical, un catholique-conservateur et un professeur - et pour lesquels on peut établir une succession presque dynastique, on trouve deux à quatre membres au profil plus varié. Il y a tout d'abord les directeurs de banque retraités, où l'on retrouve souvent des représentants des grandes banques et plus rarement des banques cantonales. Les anciens directeurs généraux de la BNS entrent dans cette même catégorie hybride. Dès la fin des années 1970, un nouveau profil politique se dégage avec la nomination d'un social-démocrate modéré parmi les sept commissaires. Ce modèle est marqué par une remarquable stabilité, puisqu'aucun changement radical n'est détectable pour l'ensemble des variables examinées.

Deuxièmement, par rapport à d'autres commissions extra-parlementaires mises en place par les autorités fédérales, il faut souligner que la Commission fédérale des banques et ses membres se distinguent à au moins deux égards ${ }^{10}$.

9 AFB, E652O(B), 2007/62, vol. I8, «Revision LFB 1974-1976», Proposition du DFFD au Conseil fédéral sur le renforcement de la surveillance bancaire, les modifications de l'ordonnance et les nouvelles nominations dans la Commission des banques, 24.I2.1975.

10 Sur les commissions extra-parlementaires, cf. Rebmann, Mach, art. cit., in Ladner, et al. (éd.), op. cit., 2013; Marion Beetschen, Frédéric Rebmann, «Le néocorporatisme suisse en déclin? Les commissions extra-parlementaires dans un environnement en mutation (I95720I0) ", Swiss Political Science Review, vol. 22, n I, 2016, p. I23-I44. 
D'une part, la CFB laisse une place moindre aux grandes associations économiques et à une représentation syndicale. D'autre part, la CFB écarte de sa composition les représentants directs des autorités publiques. Les hauts fonctionnaires du Département fédéral des finances et des douanes, même s'ils entretiennent des contacts réguliers avec la CFB, n'y siègent pas et ne la président pas. Ce trait caractéristique est notamment lié à la grande autonomie dont jouit l'autorité de surveillance bancaire. L'activité de surveillance de la $\mathrm{CFB}$, et surtout ses éventuelles défaillances, n'engagent pas la responsabilité de la Confédération. Malgré ces deux divergences, le modèle de composition de l'organe de surveillance bancaire dévoilé ci-dessus, confirme certaines tendances communes à l'ensemble du système commissionnaliste: l'importance croissante des experts scientifiques ou académiques, et plus largement le rôle-clé d'une institution constituée en dehors de toute représentation démocratique dans le processus décisionnel et l'élaboration de la régulation.

\section{V.3. LE SECRÉTARIAT DE LA COMMISSION FÉDÉRALE DES BANQUES : UN APPAREIL ADMINISTRATIF TRÈS RÉDUIT}

En plus de la commission à proprement parler, à savoir les 5-7 membres présentés ci-dessus qui forment l'instance décisionnelle et travaille à temps partiel contre une rétribution forfaitaire, l'organe de surveillance bancaire dispose d'un appareil administratif permanent. Ce secrétariat joue un rôle décisif dans le fonctionnement de l'institution: il gère notamment les affaires courantes, prépare les réunions des membres, récolte et traite les rapports de révision des banques, s'occupe du suivi des décisions prises par les membres. Bref, il s'agit de la cheville ouvrière de la CFB. Dans les quelques lignes qui suivent, nous tenterons d'en esquisser un rapide portrait.

L'évolution du nombre d'employés du secrétariat constitue un indice déterminant pour appréhender l'importance de l'appareil administratif mobilisé pour assurer la mise en application de la loi sur les banques, et plus largement pour mesurer la capacité d'action de la CFB. Le graphique 6 révèle le développement du nombre de salariés du secrétariat (y compris le personnel dit subalterne) sur l'intégralité des 73 ans d'existence de la Commission fédérale des banques.

On peut distinguer quatre phases dans l'évolution historique du nombre d'employés de la CFB. Dans un premier temps, entre 1935 et 1966, le secrétariat se limite à un effectif de 4 à 6 personnes. En principe, il est alors composé du chef du secrétariat, en règle générale un économiste, d'un second cadre, souvent un juriste, et de deux à trois employées de bureau. On observe même une baisse du nombre d'employés puisque le secrétariat passe de 6 à 4 personnes entre 1942 et $1943^{11}$. La seconde phase s'étend de 1967 à 1975 . Il faut alors noter

11 En août 1942, le juriste Paul Graner démissionne du secrétariat de la CFB et accepte un poste chez l'UBS. Son poste ne sera pas repourvu. Il dirigera ensuite un bureau d'avocat d'affaires à Zurich et deviendra notamment conseiller économique et financier de l'Emirat du Koweit, 
Graphique 6. Nombre d'employés de la Commission fédérale des banques (1935-2008)

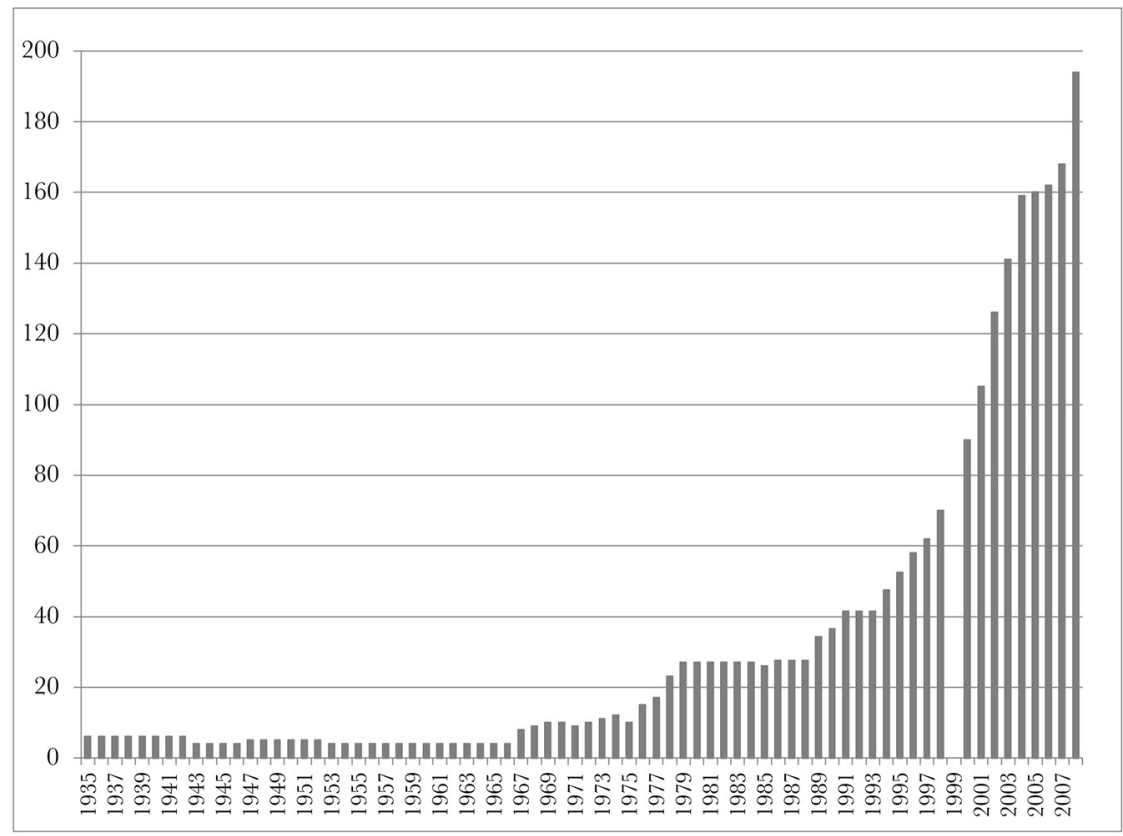

Sources: 1935-1975: AFB, E6I03, I960/IO3, Compte d'État et budget, années correspondantes. 1976-2008: Rapports annuels de la CFB, disponibles en ligne: https://www.finma.ch/Finma Archiv/ebk/d/publik/bericht/index.html, consulté le I0.I2.20I8.

un doublement de l'effectif, qui atteint une dizaine de salariés. Cette augmentation est motivée par le rattachement à la CFB de la surveillance des fonds de placement au moment de l'entrée en vigueur de loi sur les fonds de placement en 1967. À partir de 1976 s'ouvre la troisième phase. Le Conseil fédéral décide alors, sur la base d'un rapport d'experts établi en décembre 1975, d'améliorer la surveillance bancaire en augmentant les moyens de la $\mathrm{CFB}^{12}$. Une réorganisation administrative a donc lieu en 1976 . Entre 1975 et 1979, le nombre d'employés gonfle rapidement, passant de io à 27 . Il se stabilise alors à ce niveau pendant les années 1980. La quatrième phase est entamée en 1989, lorsque le Conseil fédéral accepte d'augmenter le plafonnement de l'emploi de l'administration fédérale pour le secrétariat de la CFB. Au cours de cette quatrième et dernière phase du développement de la CFB, l'effectif de son secrétariat connaît une forte croissance. Entre 1988 et 2008 - date de la transformation de la CFB en FINMA -, le nombre d'employés est multiplié par sept. Il passe de 27 à 194.

au nom duquel il intervient en 196r auprès du Département politique fédéral pour intensifier les relations diplomatiques entre la Suisse et le Koweit. Cf. AFB, E20oIE, I976/17, 366I*, lettre de Paul Graner à Friedrich-Traugott Wahlen (chef DPF), 2I.09.196I.

$12 \mathrm{AFB}, \mathrm{E} 652 \mathrm{O}(\mathrm{B}), 2007 / 62$, vol. I8, Studiengruppe zur Ueberprüfung des Bankengesetzes, Bericht zuhanden des Eidg. Finanz- und Zolldepartementes, 28.II.I975. Les experts préconisent une augmentation vers un effectif de $15-20$ personnes. 
Retenons pour l'instant simplement le caractère minimaliste de l'organisation de la surveillance bancaire. Pendant plus de trente ans, entre I935 et I966, le secrétariat se résume à un effectif de 4 à 6 personnes ${ }^{13}$. Il ne progresse ensuite que lentement : entre 1967 et 1975 , on ne dénombre toujours qu'une dizaine de salariés. Autrement dit, le contrôle étatique des banques en Suisse souffre d'une sous-dotation en personnel chronique. La courbe du nombre d'employés de la CFB ne suit en aucune façon le rythme de croissance impétueux des affaires des banques suisses placées sous sa surveillance. Alors que l'appareil administratif de la Commission fédérale des banques stagne pendant les Trente Glorieuses, les établissements bancaires connaissent, comme nous le verrons plus bas, un essor phénoménal (cf. chap. VII.I).

Graphique 7. Dépenses de la Commission fédérale des banques (I935-1995), en milliers de francs constants de 1935

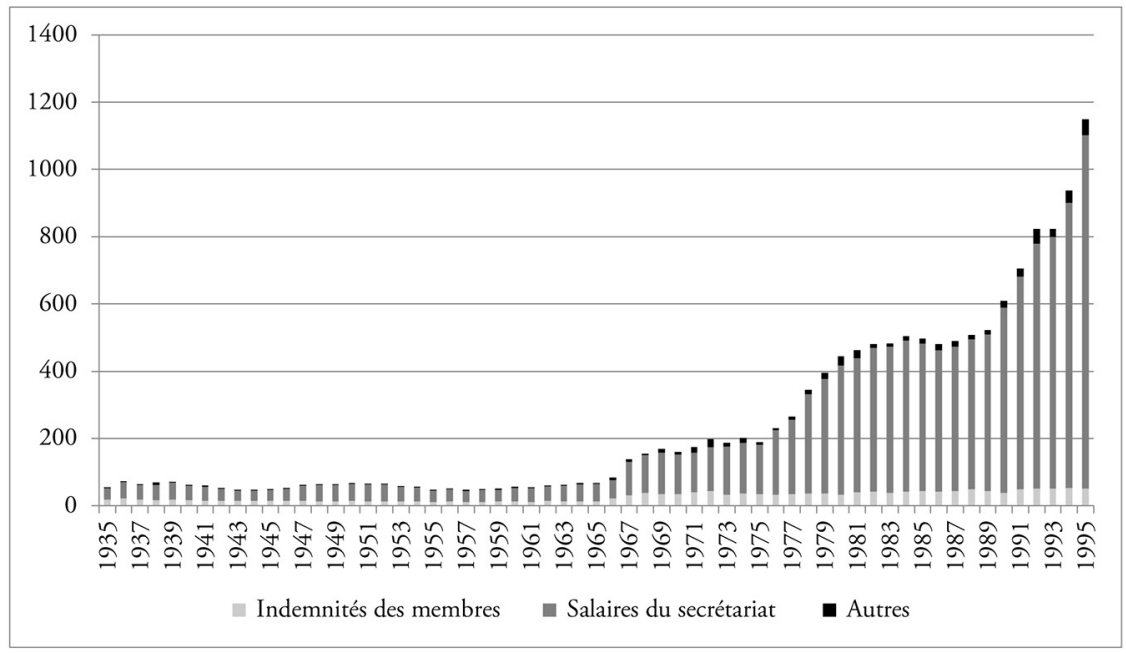

Source: AFB, E6I03, 1960/103, Compte d'État de la Confédération, années correspondantes. Données déflatées à l'aide de l'IPC: Ritzmann-Blickenstorfer (éd.), op. cit., 1996, tableau H.23, p. 504.

Le budget de la CFB suit la même courbe que l'évolution du nombre d'employés, ce qui n'est guère surprenant puisque les salaires constituent le poste de dépenses le plus important. Les dépenses de la Commission fédérale des banques connaissent sur l'ensemble de la période 1935-1995 un taux de croissance annuel moyen réel de $6 \%$. Mais cette moyenne cache de longues

13 À titre d'exemple, la comparaison avec les effectifs permanents de l'Association suisse des banquiers est éloquente. L'ASB emploie dès 1920 sept salariés au sein de son secrétariat. En juillet I945, son personnel compte I6 employés. Ce chiffre augmente à 20 en I950, puis 22 en I952, avant de baisser à I2 en juillet 1956. Entre 1945 et I956, l'association faîtière des milieux bancaires dispose donc d'un effectif d'employés entre 3 et 4 fois plus élevé que celui de l'organisme étatique de surveillance bancaire. 
phases d'immobilisme. Pendant 30 ans, entre 1935 et 1965 , le taux de croissance annuel moyen réel est en fait de seulement I \%. Il passe à $\mathrm{I} 4 \%$ sur la période I966-I980. Quant aux recettes qui couvre ces dépenses, elles sont jusqu'en I976 presque exclusivement générées par l'État fédéral. Comme nous le verrons plus bas, les législateurs de 1934 avaient sciemment rejeté l'idée que les banques soumises à la surveillance participent au financement de l'autorité de surveillance. Malgré plusieurs tentatives antérieures (1940, 1947, 1949), ce n'est qu'au milieux des années 1970 qu'un changement majeur a lieu dans les recettes de la CFB. Avec l'aval des milieux bancaires, le Conseil fédéral instaure en 1976 des émoluments perçus auprès des entreprises qui font l'objet de la surveillance. Dès lors, les autorités fédérales disposent d'une marge de manœuvre supplémentaire dans l'aggrandissement de l'effectif, qui est de fait rendu possible par la contribution financière des banques. Le budget de la CFB est multiplié par 2.4 en l'espace de cinq ans (1975-1980). C'est donc uniquement grâce à la transformation de son mode de financement et à la mise en place d'émoluments perçus auprès des établissements bancaires que la Commission fédérale des banques parvient partiellement à combler le retard accumulé dans l'ajustement de son appareil administratif aux dimensions prises par la place financière suisse.

Pour synthétiser, il faut retenir de cette analyse du budget de la Commission fédérale des banques au moins trois éléments. Soulignons premièrement qu'il y a dans l'histoire de cette institution une longue phase d'immobilisme (1935I965), au cours de laquelle l'autorité de surveillance se limite à une instance formée d'une poignée d'individus, dont les modestes coûts de fonctionnement sont portés intégralement par les deniers publics fédéraux. Deuxièmement, que la CFB connait par la suite deux courtes phases d'agrandissement, entre 1967 et 1970, puis entre 1976 et 1980, occasionnée respectivement par l'introduction d'un contrôle sur les fonds de placement puis par une pression croissante en faveur d'un renforcement. Troisièmement, insistons sur le fait que le second agrandissement n'est permis que par la mise à contribution des entreprises surveillées, en 1976, qui passent à la caisse pour la première fois, après avoir bénéficié d'un régime de surveillance étatique sans frais directs pendant plus de quarante ans. Avec la mise en place du mode de financement par les émoluments, la CFB obtient également enfin une plus grande marge de manœuvre dans le développement de l'effectif de son personnel.

En guise de conclusion de cette présentation synthétique des hommes qui constituent et des moyens dont dispose l'organe de surveillance des banques, il reste encore à présenter en deux mots les chefs du secrétariat.

Au total, neuf personnes se sont succédés à la tête du secrétariat de la Commission fédérale des banques. Relevons en particulier la longue mandature de Daniel Bodmer, qui occupe le poste pendant 19 ans entre 1957 et 1976. Si l'on considère l'ensemble du groupe, il faut remarquer que les chefs du secrétariat sont sensiblement plus jeunes que les membres, puisque leur moyenne d'âge au moment de la nomination s'élève à 48 ans. Quant à leur expérience 


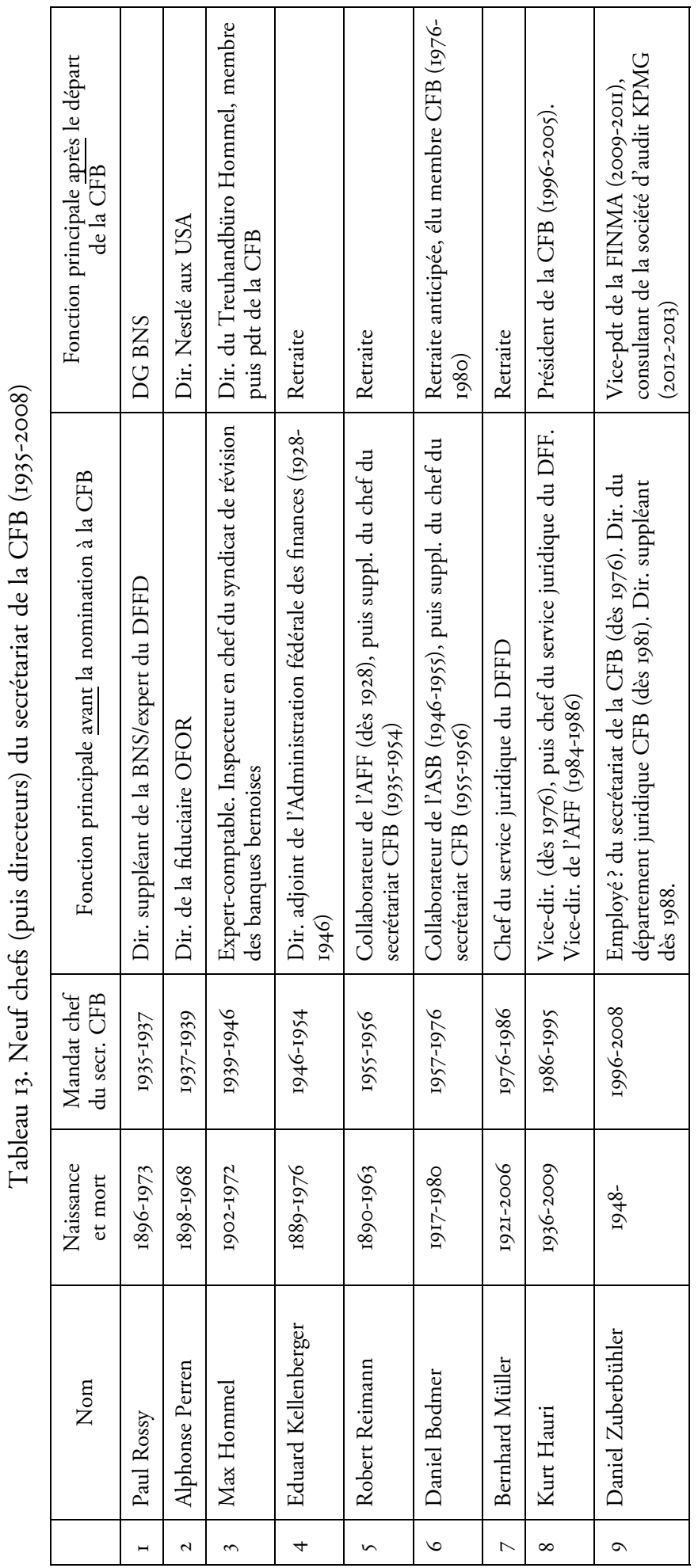


professionnelle, il existe deux voies de recrutement privilégiées, à savoir soit la progression interne (Hommel, Reimann et Zuberbühler), soit l'engagement de collaborateurs de l'Administration fédérale des finances déjà versés dans les questions de réglementation bancaire (Rossy, Reimann, Kellenberger, Müller et Hauri). Lorsque les candidats proviennent de l'extérieur de ce cercle très réduit, l'Association suisses des banquiers (Bodmer) ou les sociétés fiduciaires (Perren) fournissent occasionnellement des recrues potentielles. Quand ils ne prennent pas immédiatement leur retraite au moment de leur départ, il arrive que les chefs du secrétariat trouvent une situation dans le privé.

Quant à l'orientation politique des neuf individus cités, nous ne disposons que de maigres indices. Rossy et Hommel, sans être formellement membres de parti, étaient connus pour leurs affinités avec le courant radical. Eduard Kellenberger, quant à lui, est recruté par le catholique-conservateur Musy, et peine à collaborer avec le conseiller fédéral socialiste Nobs, ce qui pourrait témoigner d'un positionnement à la droite de l'échiquier politique. Kurt Hauri est quant à lui membre du Parti radical bernois, tandis que Daniel Zuberbühler est membre du Parti socialiste. Les chefs du secrétariat prennent donc une coloration politique moins claire que celles des membres; jusque dans les années 1980, ils se recrutent majoritairement parmi des personnalités proches du radicalisme.

En guise de conclusion de ce chapitre, il faut encore insister sur un aspect du recrutement des employés du secrétariat qui fait figure de constante pendant l'ensemble de la période examinée. Dès la mise en place de la Commission fédérale des banques et jusqu'à une époque récente, les autorités se plaignent de la difficulté à attirer du personnel compétent en raison des limitations salariales fixées par les barèmes des revenus offerts par la Confédération. Il y a une grande continuité de la problématique du recrutement de personnel qualifié et compétent pour la Commission fédérale des banques. Une fois salariés de l'autorité de surveillance, les collaborateurs deviennent alors des cibles privilégiées de tentatives de débauchage des entreprises qu'ils contrôlent. 


\section{CHAPITRE VI}

\section{LES DÉBUTS DIFFICILES DE LA COMMISSION FÉDÉRALE DES BANQUES (1935-1944)}

Ce sixième chapitre se concentre sur la première dizaine d'années d'existence de la Commission fédérale de banques, ce que l'on pourrait appeler prosaïquement sa période de rodage ${ }^{1}$. Les difficultés initiales de la nouvelle institution seront au centre du propos. Après avoir clarifié la position juridicoadministrative de la CFB et ses compétences, nous aborderons dans une première section les tâches liées à l'entrée en vigueur de la nouvelle législation, à savoir les délicates décisions d'assujettissement d'entreprises bancaires - quels sont les établissements soumis à la loi - et l'assermentation des sociétés fiduciaires. Dans la seconde partie de ce chapitre sera traitée la question du rôle crucial de l'autorité de surveillance dans l'exécution des procédures d'assainissement et de sauvetages bancaires. Enfin, dans un troisième sous-chapitre, les relations délicates avec les dirigeants de la banque centrale seront discutées.

\section{VI.1. ORGANISATION INTERNE ET MISE EN PLACE DES COMPÉTENCES LÉGALES}

\section{VI.1.1. La constitution de la première Commission fédérale des banques}

La première séance de la Commission fédérale des banques a lieu le 8 avril 1935. Avant d'étudier ses activités et qualifications effectives, il faut évoquer en quelques mots la phase charnière des mois de février et mars 1935. Durant les quelques semaines qui séparent la finalisation du règlement d'exécution de la loi sur les banques de la première séance plénière de la CFB se déroulent les négociations qui aboutiront à la nomination par le Conseil fédéral des premiers membres de la Commission.

Selon la loi sur les banques, les cinq membres doivent être experts en matière de technique bancaire ou de révision bancaire. En sont exclus les membres de la direction, présidents, vice-présidents ou délégués du conseil d'administration d'une banque ou d'une société de révision. Les simples conseillers 
d'administration font par contre partie des papables. Le choix des cinq personnalités et la désignation du président et du vice-président par le collège gouvernemental doivent donc tenir compte d'un certain nombre de critères.

Dès le I3 février 1935, plus de six semaines avant l'annonce de la composition définitive, le conseiller fédéral Edmund Schulthess annonce dans une lettre à l'Assemblée fédérale son intention irrévocable de démissionner du gouvernement. Dans le communiqué de presse émis par le Conseil fédéral à cette occasion, il est précisé que le politicien argovien décline l'idée du succéder à Alfred Sarasin à la présidence du Conseil de banque de la BNS, mais «à la demande de ses collègues, il s'est déclaré prêt, d'autre part, à assumer, le moment venu, la présidence de la commission des banques instituée par la loi sur les banques ${ }^{2}$. Cette démission est principalement liée à l'échec de la politique de déflation que Schulthess avait encore défendue dans son « discours d'Aarau " en décembre $1934^{3}$. Dès mi-février, la reconversion de l'ancien homme d'État à la tête de la Commission fédérale des banques est donc actée. En revanche, il faut souligner que ce transfert se fait progressivement, puisque la démission de Schulthess ne prend effet que mi-avril ${ }^{4}$. C'est une situation unique dans l'histoire de la Commission fédérale des banques qui se produit alors. En effet, Schulthess, conseiller fédéral démissionnaire, mais encore en fonction, participe au même titre que les autres membres du gouvernement à la nomination de ses quatre futurs collègues qui formeront l'autorité de surveillance. Il joue d'ailleurs un rôle prépondérant dans le choix des membres restants. C'est lui qui entreprend, en mars 1935, les démarches auprès de la BNS pour obtenir la participation de Paul Rossy, qui bénéficiait jusque-là d'un simple congé afin de remplir son rôle d'expert pour élaborer la loi sur les banques 5 .

La composition définitive de la Commission fédérale des banques est arrêtée et annoncée par le Conseil fédéral le 25 mars $1935^{6}$. À un changement près, la liste validée par le gouvernement est conforme à la proposition faite par le Département des finances d'Albert Meyer du 2I mars $1935^{7}$. Les heureux élus sont les suivants :

2 AFB, Eıo04.I, I000/9, vol. 35I, Procès-verbaux de décision du Conseil fédéral, séance du I5.02.1935, communiqué de presse du I5.02.1935.

3 Sur la démission d'Edmund Schulthess: Müller, op. cit., 2010, p. 567-568. Voir aussi: Hermann Böschenstein, Bundesrat Schulthess. Krieg und Krisen, Bern: P. Haupt, 1966, p. I75-188; Hermann Böschenstein, "Edmund Schulthess", in Altermatt, op. cit., 1993, p. $32 \mathrm{I}-326$.

4 Son successeur, le radical soleurois Hermann Obrecht (I882-1940) - par ailleurs président du conseil de la Banque cantonale soleuroise et administrateur de la Société de Banque Suisse - est élu le 4 avril 1935.

5 ABNS, Procès-verbaux de la Direction générale de la BNS, 20-2I.03.1935, "Frage der Mitwirkung von Herrn Direktor Rossy in der Bankenkommission", p. 313.

6 AFB, EIo04.I, Iooo/9, vol. 352, Procès-verbaux de décision du Conseil fédéral, séance du 25.03.1935.

7 Ce changement est le remplacement de Roger Marcuard (I870-I950), banquier privé et membre du conseil d'administration du Crédit Suisse, qui refuse sans doute l'élection, par Albert Zust. 
Tableau I4. Composition de la première Commission fédérale des banques (I935-1937)

\begin{tabular}{|c|c|}
\hline Nom & Fonction(s) au moment de la nomination \\
\hline $\begin{array}{l}\text { Edmund } \\
\text { Schulthess } \\
\text { (I868-I944), } \\
\text { président }\end{array}$ & $\begin{array}{l}\text { Conseiller fédéral radical argovien en charge du Département fédéral de } \\
\text { l'économie publique (I9I2-I935). Avant son élection au gouvernement, avocat et } \\
\text { conseiller juridique chez Brown Boveri \& Cie, et membre des CdA de } \\
\text { l'Elektrobank (I906-I9I2), Motor-Columbus (I9II), Aargauische } \\
\text { Hypothekenbank (I885-I9II), Rentenanstalt (I9II-I9I2) }\end{array}$ \\
\hline $\begin{array}{l}\text { Paul Rossy } \\
\text { (I896-1973), } \\
\text { vice-président }\end{array}$ & $\begin{array}{l}\text { Suppléant du directeur du } 2^{\mathrm{e}} \text { département de la BNS (en congé). Expert financier } \\
\text { du DFFD (I933-1934). Formation de banquier chez Sarasin \& Cie à Bâle (I917- } \\
\text { I92I). Carrière à la BNS (I92I-1933) }\end{array}$ \\
\hline $\begin{array}{l}\text { Carl B } 1 \\
(\mathrm{I} 873-\mathrm{I}\end{array}$ & $\begin{array}{l}\text { Ancien directeur de la Société de Banque Suisse à Bâle ( } \\
\text { Banque cantonale de Soleure. Membre du CdA de Me }\end{array}$ \\
\hline $\begin{array}{l}\text { Emil Walch } \\
\text { (I873-1965) }\end{array}$ & $\begin{array}{l}\text { Ancien directeur (I90I-191I), puis directeur général du Crédit Suisse (I9II-I9I8). } \\
\text { Directeur et membre du CdA de l'Elektrobank (I918-1953). Membre du CdA de } \\
\text { la Banque Populaire Suisse (I933-I945) }\end{array}$ \\
\hline $\begin{array}{l}\text { Albert Zust } \\
\text { (1874-1952) }\end{array}$ & $\begin{array}{l}\text { Conseiller aux États lucernois catholique-conservateur (1930-1943). Membre du } \\
\text { CdA de la Banque Populaire Suisse (1933-1945). Ancien conseiller d'État } \\
\text { lucernois en charge des finances (1920-1929). Membre du Conseil de banque (dès } \\
\text { I927) puis du Comité de banque (dès 1935) de la Banque cantonale de Lucerne }\end{array}$ \\
\hline
\end{tabular}

Source : AFB, E ro04.I, I000/9, vol. 352, Procès-verbaux du Conseil fédéral, 25.03.1935.

Il ne s'agit pas de commenter ici dans le détail ce choix des cinq premiers membres. Soulignons simplement pour l'instant quelques critères implicitement pris en compte pour maintenir un certain équilibre au sein de la commission. Premièrement, les deux plus grandes banques du pays - le Crédit Suisse et la Société de Banque Suisse - fournissent les deux hommes de métier. La Banque nationale, comme nous le verrons plus bas, y est en partie représentée contre son gré par son ancien collaborateur Rossy (cf. chap. VI.3). On retrouve également deux des administrateurs nommés par le gouvernement dans la BPS réorganisée en décembre I933; il s'agit là sans doute d'experts bénéficiant de la confiance à la fois de l'administration fédérale et des milieux bancaires. Albert Zust, en tant que sénateur porté à défendre la souveraineté cantonale, joue aussi le rôle de représentants des intérêts des banques cantonales; déjà membre du Conseil de banque de la Banque cantonale de Lucerne depuis 1927, il deviendra d'ailleurs l'un des trois membres de son Comité de banque en août $1935^{\circ}$. Deuxièmement, le gouvernement respecte un certain équilibre entre familles politiques : le catholique-conservateur Zust fait contrepoids au radical Schulthess ${ }^{9}$. La représentation régionale et celle des minorités linguistiques jouent sans doute aussi un rôle: en plus de Rossy, la Suisse francophone est partiellement représentée par Walch, établi depuis I9I3 à

8 Heinrich Zust-Schmid, Die Luzerner Kantonalbank: I850-1950: Überblick über ihre Geschichte, Organisation und Entwicklung, S.l. : [s.n.], I950, p. 2IO-2II.

9 On pourrait ajouter que Rossy, qui bénéficie de soutiens du Parti radical vaudois lors de sa candidature à la BNS et Walch, qui est conseiller communal à Chardonne (1929-1949), sont plutôt de tendance radicale. 
Chardonne sur Vevey; la Suisse centrale (Zust) et la place bancaire de Bâle (Brüderlin) également. Troisièmement, l'âge des commissaires semble indiquer que la fonction ne joue pas un rôle de tremplin dans une carrière professionnelle. Excepté Rossy, 39 ans, les quatre autres membres de la CFB ne sont plus dans la fleur de l'âge - entre 62 et 67 ans. Le choix d'hommes expérimentés et pour la plupart retraités s'explique par les conditions spécifiques du mandat de membre de la commission. Celui-ci est interdit aux directeurs de banque actifs et doit cependant être confié à des experts en technique bancaire. De plus, il s'agit d'une fonction à temps partiel, uniquement rémunérée par des indemnités forfaitaires. Il semblait donc difficile d'attirer de jeunes juristes ou économistes vers la fonction de membres de la Commission: soit l'expérience pratique faisait défaut, soit le temps à consacrer et les modestes dédommagements, par rapport aux rémunérations proposées dans le monde bancaire privé, faisaient obstacle ${ }^{10}$. Seuls les employés du secrétariat de la Commission fédérale des banques sont engagés à plein temps et reçoivent un salaire fixe de la Confédération.

Seconde composante essentielle de l'instance de surveillance, le secrétariat permanent est mis sur pied pendant la même période, entre février et avril 1935. Il est cependant nécessaire de revenir sur la phase législative pour comprendre les contraintes financières auxquelles faisait face le Département des finances dans la constitution de cette nouvelle administration. La loi sur les banques est en effet débattue au Parlement en pleine période de crise, alors même que le gouvernement prônait une politique de déflation. De prime abord, l'inscription d'une nouvelle charge au budget de la Confédération allait à l'encontre de la réduction des dépenses préconisée. En dépit de cette situation budgétaire tendue, le financement des dépenses de la Commission fédérale des banques est intégralement à la charge de l'État fédéral. Contrairement à la situation qui prévaut dans certaines législations étrangères ou, en Suisse, dans le cas de la surveillance des assurances, les entreprises qui font l'objet du contrôle ne contribuent pas, jusqu'au milieu des années I970, aux frais liés à l'instance étatique.

Au cours de l'élaboration de la loi au Conseil national, trois amendements visant à faire participer les banques au financement de la Commission avaient été refusés ${ }^{11}$. Les propositions prévoyaient toutes, selon des modalités différentes, une contribution financière des banques. Le Saint-Gallois Hardegger suggère par exemple une participation de 5 francs par million porté au bilan, ce qui dans le cas du Crédit Suisse représenterait une somme annuelle de

10 Sur les contraintes dans le choix des membres de la Commission fédérale des banques, voir également l'article faisant la une de l'hebdomadaire économique Finanz und Wirtschaft, le I7 janvier 1973. Hans Sedleger, «Bankenkommission-Präsidium - Hintergründe der Interimslösung", Finanz und Wirtschaft, vol. 46, no 4, 17.0I.1973, p. I-2.

11 Propositions d'Emil Hardegger (PS, I88I-I977), Viktor Petrig (PCC, I887-I973) et Johannes Duft (PCC, I883-1957). Bulletin sténographique officiel de l'Assemblée fédérale, Conseil national, 27.09.1934, p. 706-715. 
6500 francs. Ces exigences somme toute modestes se heurtent à l'opposition de la majorité du parlement. Le catholique-conservateur zurichois Bernhard Widmer, par ailleurs président du conseil d'administration de la Banque Coopérative Suisse, s'offusque contre ces propositions exigeant selon lui de lourds sacrifices des banques pour financer une surveillance étatique qui leur est imposée. Lors de la séance du 27 septembre 1934, Widmer déclare :

Un collègue m'a affirmé qu'il avait l'impression que l'on voulait traiter les banques de la même façon que les Allemands traitent certains de leurs concitoyens, qui sont jetés dans des camps de concentration, et à cause de cela doivent encore s'acquitter de frais importants pour les dépenses courantes. Cet exemple est peut-être un peu exagéré ; mais il reste en effet convaincant ${ }^{12}$.

Cette comparaison pour le moins surprenante, qui consiste à faire un parallèle entre les efforts demandés aux banques suisses dans le cadre de la loi bancaire et les exactions nazies, semble avoir fait effet. Elle suffit en tout cas à convaincre une majorité des parlementaires. Les trois amendements sont nettement rejetés. Le financement intégral de la CFB par les caisses fédérales est maintenu. En prévision de ces discussions parlementaires, l'Administration fédérale des finances avait préparé un rapport qui faisait une estimation des coûts de la future institution. Les estimations du DFFD font état d'un budget annuel de 150000 francs ${ }^{13}$. Lors de la discussion au Conseil national, des montants variant entre 200 ooo et un demi-million de francs sont articulés ${ }^{14}$. En réalité, ces appréciations se révéleront bien trop élevées. Le budget avancé pour l'année 1936 ne dépasse pas 85000 francs $^{15}$, et il baissera même par la suite.

La volonté de la majorité de l'Administration des finances et du Parlement de confirmer une subvention entièrement publique de l'instance de surveillance a donc aussi eu pour effet de limiter les ressources de l'organe de surveillance au minimum. Inscrire dans la loi une contribution forfaitaire des banques selon la dimension des établissements revenait au contraire à indexer le budget de la surveillance étatique sur le développement des entreprises faisant l'objet du contrôle. Les régulateurs auraient pu se renforcer à mesure que grandissait le secteur bancaire. En refusant une source de financement externe, les parlementaires suisses ont au contraire délibérément conçu une institution aux moyens insuffisants. En ce sens, les législateurs ont favorisé une forme de "politique de caisses vides ${ }^{16}$, puisque la Commission fédérale des banques ne

12 Bulletin sténographique officiel de l'Assemblée fédérale, Conseil national, 27.09.1934, p. 710, intervention de Bernhard Widmer.

13 Selon le rapport annuel pour l'année 1935 de la CFB, p. 2. AFB, E6520(A), 1983/50, vol. I3.

14 Bulletin sténographique officiel de l'Assemblée fédérale, Conseil national, 27.09.1934, p. 709-710.

15 Le devis prévu pour 1936 s'élève à 84487 francs. Rapport annuel pour l'année 1935 de la CFB, p. 3. AFB, E6520(A), 1983/50, vol. I3.

16 Sur ce concept, voir : Sébastien Guex, L'argent de l'État: parcours des finances publiques au $X X^{e}$ siècle, Lausanne: Réalités sociales, 1998, en part. p. 75-100. 
disposera pas de ressources adaptées pour suivre le développement des acteurs privés qu'elle est supposée surveiller.

Revenons au secrétariat permanent de la Commission fédérale des banques. En 1935 , il est composé en tout et pour tout de six employés ${ }^{17}$ : le chef du secrétariat - l'expression allemande, plus à propos, parle simplement d'un Vorsteher - qui n'est autre que Paul Rossy, deux juristes, dont le suppléant du chef du secrétariat, à savoir Robert Reimann et Paul Graner, deux employées et une aide de bureau ${ }^{18}$. Ce personnel très réduit provient en grande partie de l'Administration fédérale des finances. Paul Rossy avait été provisoirement débauché à la Banque nationale pour participer à la rédaction des projets de loi sur les banques. Quant aux deux juristes, ils sont simplement transférés d'un service à l'autre et travaillaient auparavant à l'Administration fédérale des finances dans le domaine des subventions ${ }^{19}$.

Une fois la poignée d'employés embauchés, il fallait encore trouver des locaux pouvant accueillir la nouvelle équipe. Même si une lettre du président de la BNS - lui-même établi au siège zurichois de la banque centrale - suggère d'installer la Commission fédérale des banques au bord de la Limmat, le choix de Berne comme siège de l'autorité de surveillance l'emporte finalement ${ }^{20}$. À cet égard, l'emplacement géographique, qui revêt certes une importance symbolique, ne constitue jamais dans le cas de la CFB un véritable objet de négociation, comme il avait pu l'être dans le cas de la Banque nationale suisse au tournant du $\mathrm{XX}^{\mathrm{e}}$ siècle ${ }^{21}$. Le choix de Berne n'est jamais sérieusement remis en question. La CFB est d'abord provisoirement accueillie dans les bureaux de l'Administration fédérale des finances. En mai 1935, elle obtient ses "propres » locaux, toujours au sein d'un immeuble appartenant à la Confédération, en déménageant à l'Effingerstrasse $\mathrm{I}$, à quelques centaines de mètres du palais fédéral ${ }^{22}$.

\section{VI.1.2. La position juridique et les compétences légales de la CFB}

Tout au long de son existence, la Commission fédérale des banques a constitué un casse-tête pour les juristes et les politologues cherchant à la classifier parmi les diverses institutions publiques. S'agit-il d'un organe

17 AFB, E6520(A), I983/50, vol. I3. Rapport annuel pour l'année 1935 de la CFB.

18 AFB, E6520(A), I000/I059, vol. 6, PV CFB, 27.I2.1935, p. 296.

19 Cf. AFB, Eıo04.I, Iooo/9, vol. 358, Procès-verbaux de décision du Conseil fédéral, séance du OI.05.1936.

20 AFB, E6I0o(A), 1900/1914, vol. 8, dossier 692, Lettre de Gottlieb Bachmann (BNS) à Albert Meyer (DFFD), 22.02.1935. Bachmann évoque la proximité des grandes banques et des sociétés fiduciaires à Zurich qui pourrait améliorer l'action de la CFB.

21 Cf. Zimmermann, op. cit., 1987, p. 194-198; Bordo, James, art. cit., in Abegg (éd.), op. cit., 2007, p. 33 .

22 AFB, E652O(A), I983/50, vol. I3. Rapport annuel pour l'année 1935 de la CFB. Le prochain déménagement n’aura lieu qu'en 1962-1963, lorsque la CFB se déplace à la Taubentrasse I8. S'ensuivent quatre déménagements en dix ans. Cf. AFB, E6roo(B-oI), 1980/49, vol. 67, dossier 232.90 . 
pleinement intégré à l'administration fédérale? D'une commission extra-parlementaire? D’une instance à capacité décisionnelle et législative? Si l'autorité est autonome, auprès de qui faut-il faire recours contre ses décisions et qui est responsable de ses actes? Ces interrogations ont rapidement été soulevées. Il existe ainsi diverses interprétations qui insistent tantôt sur le caractère farouchement indépendant de l'institution, tantôt sur son profil public et étatique.

L'un des juristes spécialistes de la CFB, Hans Andrea Tarnutzer, penche plutôt en faveur d'une interprétation donnant une très large autonomie à la CFB. Il estime en I94I qu'elle constitue une innovation dans l'administration fédérale. Sa définition précise est la suivante:

La Commission fédérale des banques est un organe d'exécution de la Confédération, de droit public et autonome, dont la dépendance est uniquement soulignée par le fait qu'elle doit transmettre un rapport au Conseil fédéral sur son activité, et par le fait que certaines de ses décisions sont soumises au recours de droit administratif au Tribunal fédéral ${ }^{23}$.

Tartnutzer souligne que la CFB n'est pas une simple section de l'Administration fédérale des finances. En ce sens, il rejoint la définition juridique donnée dans une thèse publiée simultanément. Pour Louis Dollfus, la Commission fédérale des banques est " un organisme de la Confédération autonome et de droit public, une commission fédérale administrativement complètement indépendante ${ }^{24}$. Ces deux interprétations octroyant une très grande autonomie à l'autorité de surveillance se situent pleinement dans le prolongement de l'esprit de la loi qui ressortait des discussions au cours de son élaboration. L'idée de limiter autant que possible la responsabilité des instances étatiques ou monétaires vis-à-vis de défaillances bancaires avait été au centre de la décision de créer une nouvelle institution indépendante. Il n'en reste pas moins que certaines attaches en faisaient clairement un organe lié à la puissance publique. Le gouvernement nomme ses membres et en désigne le président, le vice-président et le chef du secrétariat. Il reçoit chaque année un rapport d'activité de la part de la Commission. Enfin, c'est l'État central qui couvre les frais de fonctionnement de l'instance et qui l'accueille dans ses bureaux. Dans l'annuaire fédéral (Staatskalender), les employés de la CFB sont recensés à la suite des diverses sections du Département fédéral des finances.

En lien direct avec cette problématique, la question du statut des employés du secrétariat restait encore en suspens. Peu avant la finalisation de l'ordonnance, Adolf Jöhr, directeur général du Crédit Suisse, plaçait encore parmi ses objectifs "d'éviter que les employés du secrétariat de la Commission des

Tarnutzer, op. cit., I94I, p. 37.

24 Louis Dollfus, «Probleme der Bankenaufsicht und -kontrolle und ihre Lösung im schweizerischen und italienischen Bankenrecht unter spezieller Berücksichtigung der historischen Entwicklung», ibid., Universität Basel, Doktorarbeit, Juristischen Fakultät, Universität Basel, I94I, p. I99. 
banques n'acquièrent la qualité de fonctionnaires ${ }^{25}$. Ses voux ne seront que partiellement exaucés. L'arrêté du Conseil fédéral du 5 novembre 1935 précise que trois nouveaux postes doivent être créés dans le registre des emplois qui bénéficient du statut de fonctionnaires fédéraux ${ }^{26}$. Les trois emplois masculins (chef du secrétariat, suppléant et juriste) disposent donc du statut de fonctionnaire fédéral. En revanche, les trois charges de secrétariat les moins qualifiées - celles occupées par des femmes - sont simplement des employés de la Confédération ${ }^{27}$. Quel enjeu se cache derrière cette question de statut des travailleurs? La principale raison qui faisait sans doute naitre des craintes chez les milieux bancaires à l'égard du statut de fonctionnaire fédéral réside dans la plus grande responsabilité ainsi endossée par l'État central. Du point de vue symbolique, le secrétariat devenait ainsi plus clairement rattaché à l'administration fédérale, et l'impression d'avoir à faire à une instance étatique potentiellement nuisible à la force d'attraction des banques suisses se renforçait. Du point de vue juridique, les surveillants des banques disposaient d'une plus grande protection juridique, puisque la Confédération devenait ainsi partiellement responsable d'éventuels dommages causés à des tiers par les agissements de la Commission fédérale des banques ${ }^{28}$. Cette responsabilité de l'État demeurait toutefois théorique, il serait en effet difficile d'établir un lien de causalité entre les pertes subies par un déposant bancaire et le comportement condamnable de l'autorité de surveillance. Toujours est-il que sur ce point Jöhr n'obtiendra pas satisfaction, puisque le secrétariat de la CFB accédera au moins partiellement au statut de fonctionnaire.

Du point de vue de ses compétences, la Commission fédérale des banques se distingue aussi d'autres comités mis en place par l'État fédéral. Il ne s'agit pas simplement d'une délégation à vocation consultative, telle que la commission sur la lutte contre la tuberculose, mise en place en juin 1930. La Commission fédérale des banques est une autorité exécutive, dont la capacité décisionnelle est affirmée dans la loi fédérale. De plus, elle dispose d'une compétence législative, qui l'autorise à émettre des circulaires et des ordonnances à dimension réglementaire ${ }^{29}$. En ce sens, la CFB représente plutôt ce qu'un juriste spécialiste des commissions administratives a appelé une « autorité spécialisée » (Sonderbehörde), qui s'oppose aux organes consultatifs qui ne peuvent pas édicter des normes souverainement ${ }^{30}$.

AASB, Procès-verbaux du Conseil de l'ASB, I05 séance, 30.0I.1935, p. 9.

ABNS, I.3/I220, "Bundesratbeschluss über die Organisation der eidgenössischen Bankenkommission (vom 5. November 1935)", art. 3.

Cela ressort clairement de la présentation des ces nouveaux postes de travail dans le « Message du Conseil fédéral à l'Assemblée fédérale concernant le budget de la Confédération pour I936 (du I ${ }^{\text {er }}$ novembre 1935)".

Voir aussi : Riniker, op. cit., I974, p. 62-67.

Sur la compétence normative de la CFB : ibid., p. 7I-75.

Karl Arnold, Verwaltungs- und Regierungstätigkeit durch eidgenössische Kommissionen, Winterthur: H. Schellenberg, 1969, p. 60. 
Ces différentes qualités particulières de la CFB - son caractère permanent, sa grande autonomie, son intégration très lâche à l'administration fédérale et ses compétences décisionnelles et législatives étendues - la rapprochent du point de vue administratif et juridique d'une régie fédérale comme le conseil d'administration des Chemins de fer fédéraux ${ }^{31}$. Comme la CFB, le conseil d'administration des CFF est nommé par le Conseil fédéral, mais ne lui est pas directement soumis, il doit simplement lui transmettre un rapport annuel sur son activité. Un an avant la constitution de l'autorité de surveillance bancaire, en avril 1934, un rapport du Département fédéral de justice et police soulignait déjà cette ressemblance: "la Commission fédérale des banques est une commission administrative permanente, une autorité exécutive de la Confédération, comme par exemple le conseil d'administration des $\mathrm{CFF}$ " $^{32}$. À cet égard, la Commission fédérale des banques s'intègre parfaitement dans cette «zone intermédiaire» que le politologue Raimund E. Germann qualifie d'espace paraétatique ${ }^{33}$. Il s'agit d'une zone située à mi-chemin entre la zone étatique à forte coloration publique et la zone privée, proche du pôle véritablement privé, et dont le fort développement est favorisé en Suisse par les institutions spécifiques que sont le fédéralisme ou la démocratie semi-directe. Au sein de cet espace para-étatique prennent place plusieurs instances mixtes public-privé qui participent à la mise en œuvre des politiques publiques et engendre également une forte cohésion entre représentants des associations économiques et représentants de l'administration publique ${ }^{34}$. Cette délégation de tâches publiques à ces organismes mixtes implique en définitive une limitation des compétences de l'État.

\section{Commission fédérale des banques et Bureau fédéral des assurances (1886)}

Du point de vue de ses tâches et de son rôle en revanche, l'institution qui semble la plus proche de la CFB est sans doute le Bureau fédéral des assurances (eidgenössisches Versicherungsamt) mis en place dès $1886^{35}$. Le temps d'une

31 Dollfus, op. cit., I94I, p. 199. Sur l'organisation des CFF à ses débuts: Mazbouri, op. cit., 2005, p. 82-85.

32 AFB, E6520(B), 2007/62, vol. I8, "Diverse Eingaben und Stellungnahmen », Lettre du DFJP (Heinrich Häberlin) au DFFD, 04.04.I934.

33 Raimund E. Germann, L'amalgame public-privé. L'administration para-étatique en Suisse, Lausanne: Institut de hautes études en administration publique, 1987. Cf. également Sancey, op. cit., 2015.

34 Pierre Eichenberger, et al., «Les organisations patronales suisses. Bilan historiographique et perspectives de recherche", Travaux de Science Politique, vol. 56, 2013, p. I-40.

35 Sur le Bureau fédéral des assurances: J. J. Kummer, "Versicherungswesen : a) Versicherungsamt (Eidgenössisches)", in Naum Reichesberg (éd.), Handwörterbuch der Schweizerischen Volkswirtschaft, Sozialpolitik und Verwaltung, Bern: Verlag Encyklopädie, vol. 3, I9II, p. II98-I227; Jean Halpérin, Les assurances en Suisse et dans le monde: Leur rôle dans l'évolution économique et sociale, Neuchâtel: La Baconnière, 1946; Erwin Haymann, «La surveillance des sociétés d'assurances en Suisse et la juridiction administrative du Tribunal fédéral ", Thèse de doctorat, Faculté de droit, Université de Genève, I932; Gottfried 
courte parenthèse, il est judicieux de présenter en quelques lignes cet organisme qui est créé un demi-siècle avant la Commission fédérale des banques dans des conditions différentes. La création du Bureau fédéral des assurances trouve son origine dans la loi fédérale du 25 juin 1885 concernant la surveillance des entreprises privées en matière d'assurance, elle-même liée à la révision constitutionnelle de I874 qui permettait à la Confédération d'intervenir dans le domaine (art. 34, al. 2). Cette législation met fin aux multiples régimes de surveillance cantonaux mis en place entre 1847 et I884 et couvre toutes les branches d'assurance (vie, incendie, accident, propriété, etc.). Plus précisément, son élaboration entre I 880 et 1885 doit beaucoup à la faillite des quelques entreprises ainsi qu'au conflit qui oppose la Rentenanstalt, grande société d'assurance sur la vie fondée par le Crédit Suisse en I857, au gouvernement cantonal zurichois: une loi fédérale permettait ainsi aux grandes compagnies d'échapper aux diverses réglementations cantonales qui pouvaient entraver leur expansion. Ce sont donc les dirigeants de six sociétés d'assurance qui interpellent le Conseil fédéral en I878 pour l'inciter à introduire une surveillance fédérale, en conformité avec l'article constitutionnel ${ }^{36}$.

Confiés au Département fédéral du commerce et de l'agriculture dirigé par Numa Droz (I844-1899), les travaux d'élaboration de la loi sont réalisés en collaboration étroite avec les milieux des assurances qui avaient impulsé ce projet : la commission d'experts créée à l'occasion accueille sept membres, dont deux directeurs de compagnies d'assurance. C'est même Conrad Widmer (I8I8-1903), le fondateur de la Rentenanstalt, qui rédige une première ébauche de loi. Au cours des délibérations, ces premiers avant-projets peu contraignants sont renforcés. Le système de surveillance adopté inclut un régime de concession, selon lequel le Bureau fédéral des assurances et - partant - le Conseil fédéral se prononcent sur les demandes de licences des entreprises soumises à la loi, auxquelles des autorisations d'une durée de six ans sont accordées après examen ${ }^{37}$. Le non-respect des prescriptions légales peut ainsi avoir pour

Schaertlin, "Fünfzig Jahre Eidgenössisches Versicherungsamt», Bulletin de l'Association suisse des Actuaires suisses, $\mathrm{n}^{\circ}$ 33, 1937, p. I-27; Heinz Hatz, "Entwicklung, Aufgaben und Abgrenzung der Staatsaufsicht über die privaten Versicherungsunternehmungen in der Schweiz ", Doktor beider Rechte, Rechts- und staatwissenschaftliche Fakultät, Universität Zürich, I95I ; Lukas Bösch, «L'assurance sur la vie en Suisse de I910 à 1930 : de la domination étrangère à l'hégémonie des compagnies suisses ", Mémoire de licence, Faculté des lettres, Université de Lausanne, 2008, p. 54-65; Jamieson Gordon Myles, "The Genevoise: 19th Century Capitalism and the Development of the Swiss Life Insurance Market, I872-I9I4", Master's dissertation, Institut d'histoire économique Paul Bairoch, Université de Genève, 20I4, p. I27-I42. Pour une synthèse de l'histoire des assurances en Suisse jusqu'à l'entredeux-guerres, cf. Karlen, et al., op. cit., 2002, p. 54-63.

36 Johann Jakob Kummer, «Versicherungswesen : a) Versicherungsamt (Eidgenössisches) », in Naum Reichesberg (éd.), Handwörterbuch der Schweizerischen Volkswirtschaft, Sozialpolitik und Verwaltung, Bern: Verlag Encyklopädie, 1905, p. I198-I227, p. I20I ; Bösch, op. cit., 2008, p. 55.

37 Jean Halpérin, op. cit., 1946, p. 218. 
conséquence, au-delà d'amendes pécuniaires (jusqu'à 5 ooo francs) et de peines d'emprisonnement, le retrait de l'autorisation d'exercer. Le Bureau fédéral des assurances accomplit en outre un travail d'information statistique à destination des assurés, en publiant annuellement un rapport sur l'activité des entreprises surveillées. Il vérifie également la véracité des prospectus publiés par les compagnies d'assurance pour éviter qu'elles induisent le public en erreur. Enfin, l'organe étatique peut mener des contrôles matériels, de manière périodique, pour vérifier la conformité de leurs opérations.

Il s'agit donc d'un régime de surveillance à trois piliers: le système de concession, l'amélioration de la publicité et le contrôle matériel ${ }^{38}$. Les coûts engendrés par le Bureau fédéral des assurances sont pris en charge par les sociétés soumises à sa surveillance avec une clé de répartition selon le volume des primes encaissées. Le Bureau fédéral des assurances obtient dès sa création quatre postes de fonctionnaires fédéraux «cadres » sans limites salariales ${ }^{39}$. Au fil du temps, le personnel du BFA qui s'étoffe progressivement est régulièrement débauché par les sociétés d'assurance privées, qui y trouve un réservoir d'employés qualifiés et disposant de précieuses informations sur le secteur ${ }^{40}$. Il joue également un rôle dans la concentration et l'épuration du secteur des assurances: sur I63 compagnies actives en Suisse avant 1886, seules 97 demandent en 1886 une autorisation d'exercer au Bureau fédéral des assurances ${ }^{41}$; les requêtes d'autorisation sont par la suite également traitées avec une certaine sévérité. La loi sur les assurances de 1885 est en revanche très timide en ce qui concerne les mesures prudentielles : il n'y a pas de disposition sur le montant minimal des réserves, les compagnies doivent uniquement déposer un cautionnement administratif. Les effets de l'introduction d'une surveillance fédérale sur le marché des assurances n'ont à ce jour pas été mesurés dans une analyse détaillée. Des recherches récentes soulignent toutefois les répercussions positives pour les compagnies d'assurance nationales: les directives sur la transparence comptable renforcent d'une part la confiance du public dans la stabilité des assurances et améliore leur réputation. D’autre part, la surveillance du Bureau fédéral des assurances et sa politique d'octroi des concessions engendrent une forme de protectionnisme indirect des compagnies suisses au détriment des sociétés étrangères dont la part de marché diminue ${ }^{42}$.

En comparaison avec le régime de surveillance introduit dans le secteur bancaire en 1934-1935, la régulation des assurances de 1885 se distingue à plusieurs égards. Le Bureau fédéral des assurances bénéficie de moyens plus étendus que la Commission fédérale des banques et il est directement rattaché à un

Bösch, op. cit., 2008, p. 56.

Kummer, art. cit., in Reichesberg (éd.), op. cit., 1905, p. I218.

Bösch, op. cit., 2008, p. 58.

Halpérin, op. cit., 1946, p. 218.

Martin Lengwiler, "Switzerland: Insurance and The Need to Export», in Peter Borscheid, Niels Viggo Haueter (éd.), World Insurance: The Evolution of a Global Risk Network, Oxford :

Oxford University Press, 20I2, p. I43-166, p. I5O-I52; Myles, op. cit., 20I4, p. I38-I42. 
département fédéral, en l'occurrence celui du Commerce et de l'Agriculture, puis dès 1895 celui de Justice et Police. Cette moindre autonomie à l'égard des autorités publiques s'accompagne paradoxalement d'un subventionnement par les entreprises surveillées. La position institutionnelle et le mode de financement du Bureau fédéral des assurances se distinguent donc de ceux de la CFB. Le Bureau fédéral des assurances obtient également avec le système des concessions un instrument plus tranchant pour réguler le marché des assurances et assurer le respect des prescriptions légales. Il peut exiger d'une compagnie de pouvoir consulter sa comptabilité interne et peut effectuer des contrôles matériels inopinés. Même si ces outils légaux ne sont pas nécessairement utilisés dans les faits, leur inscription dans la loi donne à la réglementation sur les assurances une coloration différente de celle sur les banques de 1934. Quant au processus qui a conduit à l'adoption de la législation sur les assurances, il révèle à la fois des divergences et des ressemblances. Comme pour les banques dans les années 1930, l'élaboration est marquée par l'influence décisive des grands dirigeants du secteur concerné. En revanche, la dynamique n'est pas la même. Il semble qu’à la fin des années 1870, les dirigeants des assurances voient d'un bon œil une réglementation fédérale mettant un terme aux différents régimes de surveillance cantonaux qui constituent des entraves à la marche des affaires, alors que les banquiers dans les années 1930 cherchent à éviter autant que possible l'adoption d'une loi spécifique à leur secteur. L'adoption précoce d'une loi sur les assurances était aussi facilitée par la présence, dès I874, d'un article constitutionnel qui prévoit explicitement cette possibilité d'intervention de l'État fédéral. Au niveau international également, les législateurs suisses jouent un rôle pionnier dans le domaine. La Confédération est en 1885 le premier État européen à promulguer une législation fédérale sur la surveillance des assurances disposant d'une instance d'application spécifique ; cette réglementation servira de modèles aux législations allemandes (I9OI) et autrichiennes (1905) ${ }^{43}$.

Pour nous rapprocher de notre sujet principal, la loi fédérale de 1885 est également significative dans le domaine bancaire, dans le sens qu'elle a précocement marqué une séparation formelle entre les fonctions d'assurance et de banque : les entreprises d'assurance soumises à la surveillance du Bureau fédéral des assurances n'étaient plus autorisées à pratiquer d'autres opérations, comme les activités bancaires ${ }^{44}$. Malgré cette scission apparente dans les opérations menées, les compagnies d'assurance helvétiques demeurent cependant organiquement liées, à la fois par des réseaux personnels et des attaches financières, aux milieux bancaires, et ce, au-delà de 1885 .

43 Pour une perspective internationale sur la régulation des assurances au XIXe siècle: Robin Pearson, Mikael Lönnborg, "Regulatory Regimes and Multinational Insurers before I9I4", The Business History Review, vol. 82, $\mathrm{n}^{\circ} \mathrm{I}, 2008$, p. 59-86. Sur le rôle de modèle de la loi suisse de 1885 : Karlen, et al., op. cit., 2002, p. 57.

44 Karlen, et al., op. cit., 2002, p. 57-58. 
Mais revenons à la Commission fédérale des banques et à son statut administratif. Pour clore le débat sur sa position juridique, il faut encore mentionner la définition que les membres de la Commission en ont eux-mêmes donnée. Le premier règlement interne sur l'organisation de la $\mathrm{CFB}$, approuvé par le Conseil fédéral, établit la proposition suivante:

La Commission fédérale des banques est l'autorité suprême de surveillance et d'application de la loi et des règlements y afférents. Elle a pour tâche générale de suivre l'évolution et les opérations dans le système bancaire suisse et de prendre les mesures qui apparaissent nécessaires dans l'intérêt du secteur bancaire et de l'ensemble de l'économie du pays ${ }^{45}$.

Cette autodéfinition est le résultat d'une négociation interne aux membres de la CFB. Il semble qu'une clause de compétence générale plus large avait été dans un premier temps prévue. Elle avait suscité l'opposition d'Emil Walch, Carl Brüderlin et Albert Zust, qui la jugeaient illégale et intolérable ${ }^{46}$. L'ancien banquier Walch avait alors proposé, à quelques détails près, la formulation qui sera finalement retenue et qui met l'accent sur la défense des intérêts du secteur bancaire. Alors que les législateurs plaçaient encore au centre de leurs préoccupations déclarées la protection des créanciers, l'instance créée par la loi se fixe ellemême pour mission de défendre les intérêts du monde bancaire et de l'économie nationale. Cet article, dans une version antérieure qui ne mentionnait même pas la notion d'intérêts de l'économie nationale, mais seulement celle d'intérêts du secteur bancaire, avait provoqué quelques remarques d'un directeur de l'Administration fédérale des finances. Il remarquait alors que « la Commission fédérale des banques nous semble ne pas seulement avoir la vocation de prendre des mesures en faveur du secteur bancaire, mais surtout de protéger les intérêts de la collectivité aussi longtemps qu'ils sont en rapport avec les questions bancaires ${ }^{47}$. On constate ici un glissement progressif dans la définition de l'objectif essentiel de la législation bancaire et l'identification des ses principaux bénéficiaires. Alors que le message présenté par le Conseil fédéral en février I934 considérait comme objectifs principaux du contrôle des banques l'accroissement de la sécurité des déposants et la satisfaction des besoins en crédits de l'économie nationale, le règlement interne de la Commission fédérale des banques, promulgué souverainement en juin 1937, estime devoir prendre les mesures nécessaires dans l'intérêt du secteur bancaire. Cette forte divergence connaît des étapes intermédiaires avec la loi elle-même, puis le règlement d'exécution adopté en février 1935 . Le long processus caractérisé par des prises de décision dans des lieux de discussion de moins en moins ouverts aux représentants démocratiquement élus a favorisé une dénaturation de l'objectif poursuivi par la règlementation.

AFB, E6roo(B-oI), 1980/49, vol. 67, «Reglement über die Organisation und Geschäftsführung der eidgenössischen Bankenkommission", 02.06.1937, art. 2.

47 AFB, E6Ioo(A-I5), I00o/I915, vol. 8, dossier 919, Lettre de la direction de l'AFF (G.) au secrétariat de la CFB, I8.05.1936. 
Au-delà de sa position juridico-institutionnelle et de sa définition générale, la Commission fédérale des banques s'est aussi rapidement attelée à définir ses tâches précises, à savoir les compétences et obligations que lui investissait la loi fédérale. Lors de son élaboration, les experts - et en particulier les banquiers étaient parvenus à imposer que la mission de la Commission fédérale des banques ne soit pas définie en termes généraux (cf. chap. IV.2.4). L'article 23, al. 3 de la loi dresse au contraire un inventaire très précis de ce que l'organe étatique est autorisé à exiger et à effectuer. En optant pour une énumération des compétences plutôt qu'une clause générale, la réglementation bancaire suisse limite drastiquement le pouvoir discrétionnaire de son autorité de surveillance, qui agit dans un cadre bien circonscrit.

Il faut distinguer au moins trois types de compétences de la CFB. Elle obtient à la fois des pouvoirs décisionnels sur des points particuliers, des attributions législatives par le biais de circulaires et d'ordonnance et des qualités consultatives à l'attention du Conseil fédéral en tant qu'organe d'experts. Ces divers types de compétences concernent essentiellement quatre domaines ${ }^{48}$.

Premièrement, l'autorité de surveillance est chargée de la définition précise de ce qu'est une banque au sens de la loi : quelles sont les entreprises soumises à la législation fédérale, et dans le cas de sociétés financières et des banquiers privés, sous quel régime? Plus précisément, la CFB doit spécifier, dans des règlements qu'elle édicte, un certain nombre de cas particuliers, où la décision d'assujettissement à la loi n'est pas limpide. Cela concerne essentiellement trois situations. D'une part, elle est responsable de la signification du critère d'appel au public et des distinctions entre agents de bourse, gestionnaire de fortune et banquiers privés ${ }^{49}$. D'autre part, elle décrète des prescriptions spéciales sur les succursales de banques étrangères ${ }^{50}$. Elle joue aussi dans ce domaine un rôle consultatif important auprès du Conseil fédéral, qui doit notamment décider si les conditions de réciprocité sont remplies ou non, c'est-à-dire si une banque suisse serait autorisée à ouvrir une agence dans le pays d'origine de la banque requérante. Enfin, troisième situation, l'instance de surveillance doit déterminer si une banque coopérative nouvellement créée a le caractère d'une banque commerciale, ce qui est interdit ${ }^{51}$.

48 En plus du texte de loi, les compétences de la Commission fédérale des banques sont recensées à l'article 3 de son règlement interne du 2 juin 1937 . AFB, E6Ioo(B-OI), I980/ 49, vol. 67, «Reglement über die Organisation und Geschäftsführung der eidgenössischen Bankenkommission ", 02.06.1937.

49 Sur la notion d'appel au public pour recueillir des dépôts de fonds : «Critère de distinction entre les banquiers privés, les agents de change, les maisons de bourse, les gérants de fortune, les notaires et les agents d'affaires", circulaire du 27 août 1935, Feuille fédérale, 1935, vol. 2, $\mathrm{n}^{\mathrm{o}}$ 39, p. 424-427. Circulaire modifiée le 28 février 1936 (Feuille fédérale, 1936, vol. I, ${ }^{\circ}$ II, p. 454-456).

$50 \mathrm{Cf}$. Ordonnance de la commission fédérale des banques concernant les banques étrangères qui exercent une activité en Suisse (du is février 1936)». ABNS, I.3/1220.

51 Cette disposition semble trouver son origine dans la difficulté du Parlement de définir clairement ce qui constitue une banque commerciale. Les législateurs ont donc préféré 
Deuxièmement, le contrôle sur les instituts de révision constitue un domaine de compétence important. Rappelons que les instituts de révision - soit des sociétés fiduciaires, soit des syndicats de révision - sont les intermédiaires que la loi a institués entre les banques et l'organe de surveillance étatique. Ils sont chargés du contrôle annuel obligatoire de la comptabilité des banques. La reconnaissance officielle de ces entreprises d'audit - compétence essentielle de la CFB - représente donc un de seuls moyens pour l'instance étatique d'avoir une quelconque prise sur la qualité du contrôle effectué. L'assermentation officielle peut en outre être révoquée si la société ne remplit plus les conditions requises. En plus de ce rôle de certification des réviseurs, la CFB est chargée de délimiter leur rayon d'activité et d'édicter des prescriptions particulières relatives aux sociétés fiduciaires étrangères. Elle fixe aussi les tarifs de révision autorisés, et peut jouer un rôle de modération en cas de conflit sur le tarif entre une banque et son institut de révision ${ }^{52}$. C'est aussi à la Commission fédérale des banques qu'il revient de dispenser les banques cantonales de la révision externe; une fois libérés, les établissements cantonaux échappent entièrement aux prérogatives de la CFB.

Troisièmement, l'autorité de surveillance dispose d'une certaine marge de manœuvre pour assouplir les prescriptions légales au bénéfice d'établissements qui en feraient la demande. Plus précisément, la loi prévoit que la CFB peut accorder des exceptions aux dispositions sur l'organisation interne qui exigent une séparation entre les organes supérieurs d'une banque (conseil d'administration) et sa direction générale. Seconde clause dérogatoire, la Commission peut autoriser des exceptions aux taux minimaux sur les fonds propres, et aux coefficients de liquidité. Enfin, la loi permet également à la CFB de prolonger le délai de publication des comptes annuels et bilans bancaires. Les législateurs ont donc prévu toute une série de clauses particulières qui autorise l'organe de surveillance à se montrer plus laxiste dans la mise en application de la loi ; des prescriptions dans un sens plus contraignant (par exemple une fixation exceptionnelle d'un taux de liquidité plus élevé) sont, en revanche, expressément interdites par la loi.

Quatrièmement, la Commission fédérale des banques obtient de multiples compétences dans l'exécution des procédures prévues pour les banques défaillantes. Elle joue tout d'abord un rôle consultatif essentiel, auprès du Conseil

laisser cette question d'interprétation à la pratique de la CFB. La question demeure d'ailleurs très théorique: entre 1935 et 1962, la CFB n'est jamais intervenue pour ordonner la transformation d'une banque coopérative commerciale en société anonyme. Reimann, op. cit., I963, p. 56.

52 Le premier tarif des indemnités de révision est promulgué par la CFB le io octobre 1935 et suscite le mécontentement de la Chambre Suisse pour Expertises Comptables, qui craint que les syndicats de révision ne fassent de la sous-enchère dans les tarifs pratiqués, au détriment des sociétés fiduciaires. Ce tarif sera modifié à plusieurs reprises, et notamment ajusté à l'inflation, en 1943, I95I, 1958, 1963, 1967. Dans ces négociations, la CFB joue un rôle de médiateur entre l'ASB et la Chambre Suisse pour Expertises Comptables. 
fédéral ou de l'autorité judiciaire cantonale, dans l'octroi de la prorogation des échéances et des sursis bancaires. Cette mission consultative s'étend à la désignation par le tribunal cantonal du commissaire de sursis. En outre, elle obtient des compétences décisionnelles directes dans le cadre de l'arrêté du Conseil fédéral du I7 avril 1936 concernant l'assainissement de banques ${ }^{53}$. C'est elle qui décide souverainement s'il convient d'accorder la nouvelle procédure, qui désigne le commissaire ou la commission de surveillance ad hoc, qui approuve ou rejette le plan de réorganisation qui résulte de la procédure avant qu'il soit transmis au Tribunal fédéral. Avec l'aggravation de la crise bancaire en 1935 et 1936, et face à l'incompétence de certaines instances juridiques cantonales, les tâches de la CFB dans l'application des mesures destinées à sauver les banques défaillantes se sont multipliées.

Enfin, parmi la longue liste des attributions de la Commission fédérale des banques, relevons que seules trois d'entre elles ont un caractère disciplinaire. Ses trois uniques moyens d'intervention en cas d'infractions aux prescriptions légales sont d'une part la possibilité d'ordonner une révision extraordinaire, d'autre part d'inviter la banque à régulariser sa situation dans un délai imparti, ou enfin de déférer le cas aux autorités judiciaires. Autre particularité digne d'être soulignée, il n'y a que très peu de compétences de la CFB qui impliquent un rôle de surveillance constant, au-delà de la période de mise en application de la loi. En effet, comme le souligne un rapport produit par le DFFD en mars 1934, la plupart des tâches prévues seront particulièrement chronophages durant la phase d'introduction de la nouvelle législation ${ }^{54}$. Il n'y a au fond que deux obligations qui représenteront un travail continu et routinier : le contrôle sur la mise en ouvre de la révision annuelle obligatoire des banques et la surveillance de la publication annuelle des bilans et comptes bancaires.

\section{VI.1.3. L'assujettissement des banques à la loi : vers une pratique plus prudente}

Les questions relatives à l'assujettissement des banques à loi font partie de celles qui ont le plus occupé la Commission fédérale des banques au cours de ses premières années d'existence. S'il est vrai que les cas les plus simples et évidents sont rapidement réglés, d'autres régimes de soumission à la loi sont plus difficiles à trancher. Dans l'ensemble, la pratique d'assujettissement de la CFB se révèle être une question plus délicate que prévu.

53 "Arrêté du Conseil fédéral concernant l'assainissement des banques (du I7 avril 1936)", Feuille fédérale, vol. 2, no 4I, 07.10.1936, p. 725-728.

$54 \mathrm{AFB}, \mathrm{E} 6520(\mathrm{~A})$, I000/1059, vol. 2, correspondance, "Rapport du Département fédéral des finances et des douanes à la commission du Conseil des États sur l'importance du travail de la commission fédérale des banques et de son secrétariat ", daté du 23 mars 1934, annexé à une lettre de Paul Rossy à Edmund Schulthess du i8.02.1935. 
Très concrètement, la procédure d'assujettissement se déroule de la manière suivante ${ }^{55}$. À l'entrée en vigueur de la loi, les banques disposent d'une période de deux mois pour s'annoncer auprès de la Commission fédérale des banques, en lui transmettant leurs statuts ou règlements, et leurs bilans et profits et pertes de l'année écoulée. En cas de doute, la CFB peut demander des informations supplémentaires ou ordonner une révision extraordinaire. Sur la base de ces documents et informations, l'autorité de surveillance prend une décision d'assujettissement. Seules les entreprises soumises à la loi sont autorisées à faire figurer les mots «banque » ou « banquier » dans leur raison sociale. La procédure peut s'amorcer soit sur annonce volontaire, soit sur injonction de la CFB. Dans trois cas de petites banques locales cependant, malgré des requêtes répétées restées sans réponse, l'autorité fédérale est contrainte de déférer le cas au DFFD pour ordonner une amende d'ordre ${ }^{56}$. Une fois les dossiers évidents réglés, la CFB s'est attelée dans un second temps aux cas limites ${ }^{57}$.

Ce sont en particulier l'assujettissement des banquiers privés, et la définition précise de la notion de l'appel au public pour recueillir des fonds, et à plus forte raison, l'assujettissement des sociétés financières qui demandent à la Commission fédérale des banques un véritable travail d'interprétation. Plus précisément, la distinction entre les sociétés financières à caractère bancaire et celles à caractère industriel et commercial s'avère difficile à établir nettement (cf. chap. IV.2.I). En septembre 1935, la CFB publie une circulaire spécialement consacrée à ce problème ${ }^{58}$. Pour savoir si une société financière possède un caractère bancaire et doit être soumise à la loi, la CFB examine ses bilans pour déterminer si l'établissement en question limite ses participations et opérations à un groupe économique distinct, auquel cas elle sera considérée comme une société financière à caractère industriel et commercial et soumise uniquement aux dispositions sur l'exportation de capitaux et la transmission des bilans à la BNS. Parallèlement à la promulgation de sa circulaire, la CFB décide d'assujettir un certain nombre de sociétés financières, intégralement ou partiellement, à la loi fédérale. Elle fait alors immédiatement face à une multiplication des recours administratifs auprès du Tribunal fédéral contre les décisions d'assujettissement. La Motor-Columbus AG de Baden, dont l'assujettissement est pourtant considéré comme "clair comme de l'eau de roche ", est la première

55 AFB, E652O(A), 1983/50, vol. 2, Dossier «Unterstellungspraxis ", rapport de Robert Reimann (CFB) sur la pratique d'assujettissement, 20.04.1955, p. 2 ; Graner, op. cit., 1937, p. I20I32.

AFB, E6520(A), I00o/I059, vol. 6, PV CFB, II.I2.1935, p. 282-283.

57 La reconnaissance des grandes banques, des banques cantonales, puis des principales banques locales est liquidée dans le courant du mois de mai 1935. Les banques locales organisées sous la forme de coopératives exigent une analyse plus fine, puisque la CFB doit déterminer si elles possèdent le caractère de banque commerciale. Cf. PV CFB, I5.05.1935, p. 42-45. La reconnaissance des caisses d'épargne suit au cours du mois de juin 1935 .

58 "Assujettissement des sociétés financières à la loi du 8 novembre 1934 sur les banques et les caisses d'épargne», 9 septembre 1935, in Feuille fédérale, 1935, vol. 2, nº 39, p. 427-428. 
à lancer la fronde contre la $\mathrm{CFB}^{59}$. Fin décembre 1935, il apparaît que presque toutes les sociétés financières ont fait recours contre leur soumission à la loi ${ }^{60}$. L'Elektrobank, dont un membre du conseil d'administration siège à la CFB en la personne d'Emil Walch, demande à être exemptée de l'obligation de publier son bilan à la fin de l'année. Elle fait valoir qu'elle est presque la seule société financière à ne pas avoir fait recours contre son assujettissement et que cela se remarquerait si elle était la seule à devoir faire preuve de transparence. La CFB obtempère et accorde la dérogation. Il semble dans un premier temps que l'autorité de régulation sorte victorieuse de cette bataille juridique: 6 des 9 recours sont déboutés en avril 1936. En nous appuyant sur la position de l'Elektrobank, on peut émettre l'hypothèse que les recours systématiques contre la décision d'assujettissement, et leur effet suspensif, ont servi de tactique dilatoire aux sociétés concernées, qui ont bénéficié d'un délai supplémentaire pour adapter leur organisation et leur comptabilité aux prescriptions légales ${ }^{61}$. Mais dans deux cas, le Tribunal fédéral ordonne une nouvelle instruction sur les recours. Il faut attendre le 24 juin 1937 , soit près de 20 mois après le dépôt du recours, pour que la plus haute instance judiciaire du pays rende sa décision.

En l'occurrence, la CFB essuie un sérieux revers: le Tribunal fédéral donne raison à la Société Anonyme de Gérances et de Dépôts (SAGED), basée à Genève, et lève l'assujettissement à la loi en tant que société financière à caractère bancaire. La SAGED est une société liée à la fois à sa maison-mère, la National City Bank, et à la haute banque genevoise ${ }^{62}$. Au moment des investigations du Tribunal fédéral, son capital-actions s'élève à 900 ooo francs pour un bilan de 3.6 millions de francs; elle occupe 26 employés ${ }^{63}$. Sa clientèle est composée presque exclusivement de ressortissants français. Les 240 déposants de la société sont présentés par la direction comme des parents et des amis des actionnaires et des administrateurs. Aussi, le Tribunal fédéral rejette l'assujettissement à la loi sur les banques au motif que le but de l'entreprise est la gestion des capitaux d'un groupe précis de personnes, et constitue de ce fait une société d'investissement.

Le jugement génère à la fois de la surprise et une forme de résignation auprès de la Commission fédérale des banques. Son président Schulthess déclare amèrement dans une lettre à la direction générale de la BNS en septembre I937 que «la tendance de vouloir appliquer la loi sur les banques est

59 AFB, E6520(A), 1000/1059, vol. 6, PV CFB, II.I0.1935, p. 206.

60 AFB, E6520(A), 1000/1059, vol. 6, PV CFB, 27.12.1935, p. 287-288.

61 Sur les recours de la Schweiz. Gesellschaft für Kapitalanlagen, liée à la Leu AG, et la MotorColumbus, proche de l'UBS, qui s'opposent vainement à leur assujetissement en tant que société financière à caractère bancaire faisant appel au public, déboutées par le Tribunal fédéral par jugement du $\mathrm{I}^{\mathrm{er}}$ avril 1936, voir : Piguet, op. cit., 1953, p. 206-207.

62 Corinne Chaponnière Meyer, Nos deux cents premières années, Genève: Lombard Odier, I998, p. I28.

$63 \mathrm{AFB}, \mathrm{E} 652 \mathrm{O}(\mathrm{A})$, 1983/50, vol. 2, Dossier "Unterstellungspraxis », rapport de Robert Reimann (CFB) sur la pratique d'assujettissement, 20.04.1955, p. 4-5. 
manifestement encore moins prononcée au sein du Tribunal fédéral qu'au sein de notre commission " ${ }^{64}$.

Au-delà de la déception immédiate, cette jurisprudence a pour effet de modifier sur le long terme la politique d'assujettissement de la Commission fédérale des banques. De l'aveu de ses membres, elle se montrera plus prudente et timide en matière de soumission de sociétés financières ${ }^{65}$. En consultant l'évolution de l'effectif des sociétés financières dans la liste officielle des établissements soumis à la loi, on constate aussi une baisse progressive du nombre de sociétés financières assujetties, malgré le nombre croissant d'entreprises examinées.

Tableau I5. Nombre de sociétés financières soumises à la loi sur les banques (I936-1948)

\begin{tabular}{|c|c|c|}
\hline & $\begin{array}{c}\text { Sociétés financières qui font appel au } \\
\text { public pour obtenir des dépôts de fonds }\end{array}$ & $\begin{array}{c}\text { Sociétés financières qui ne font pas appel } \\
\text { au public pour obtenir des dépôts de fonds }\end{array}$ \\
\hline I936 & I7 & 24 \\
\hline I938 & I7 & 27 \\
\hline I939 & I6 & 28 \\
\hline I940 & I6 & 24 \\
\hline I94I & I5 & 25 \\
\hline I944 & I4 & 24 \\
\hline I948 & II & \\
\hline
\end{tabular}

Source: AFB, E6520(B), 2009/28, vol. 162, Bankenverzeichnis 1935-1954.

Alors qu'elle analyse les statuts et bilans de 2000 à 3 ooo entreprises pour détecter des sociétés financières à caractère bancaire, la Commission fédérale des banques n'en assujettit que quelques dizaines. On constate aussi que la baisse du nombre de sociétés financières soumises à la loi est particulièrement frappante dans la catégorie de celles qui font appel au public, c'est-à-dire celles qui sont soumises au même régime que des banques. Le départ, en 1946, d'un des poids lourds de la liste des sociétés financières à caractère bancaire faisant appel au public, l'Elektrobank, est symptomatique. Selon son historien officiel, la compagnie spécialisée dans le financement de l'industrie électrique chercherait à réorienter sa stratégie d'entreprise sous l'effet de deux facteurs ${ }^{66}$. D'une part, la désignation comme banque, depuis son assujettissement à la loi fédérale, nuirait à l'Elektrobank dans les transactions financières internationales; les sociétés de holding y étant privilégiées. D'autre part, dans le contexte des

Lettre de la Commission fédérale des banques à la Direction générale de la BNS, 09.09.1937, annexée au PV de la séance du 09.09.1937. AFB, E6520(A), I000/1059, vol. 7. On comprend au ton de la lettre que l'ancien conseiller fédéral est également déçu de l'attitude parfois trop timorée de ses collègues de la CFB. 


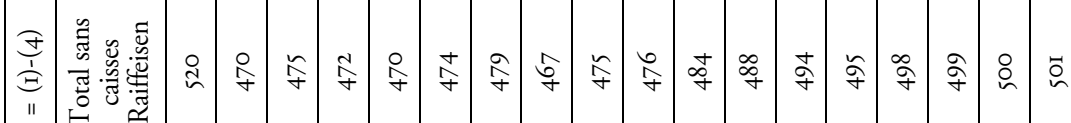

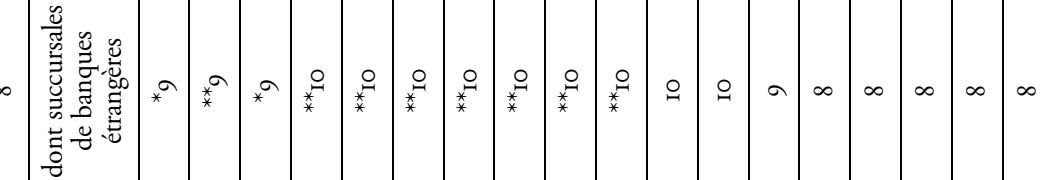

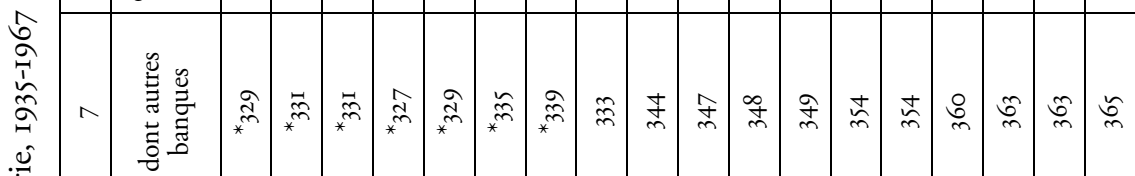
:

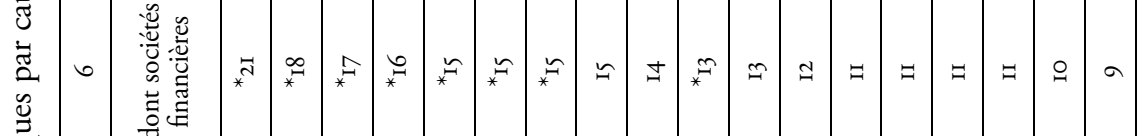

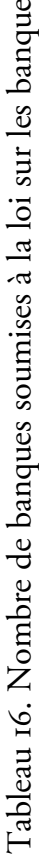




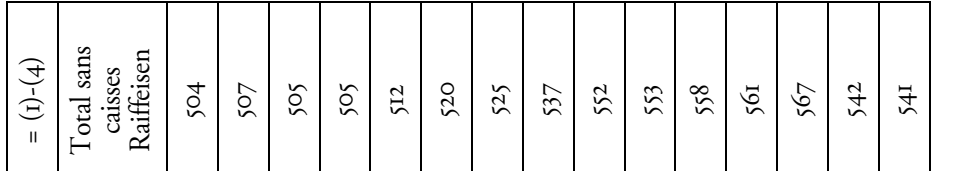

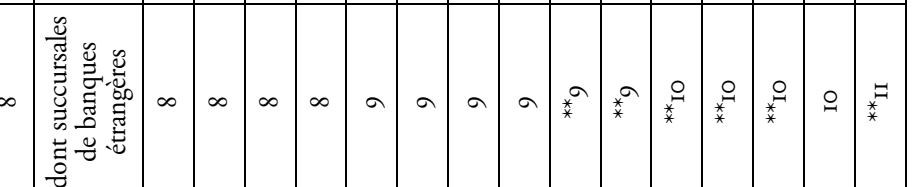

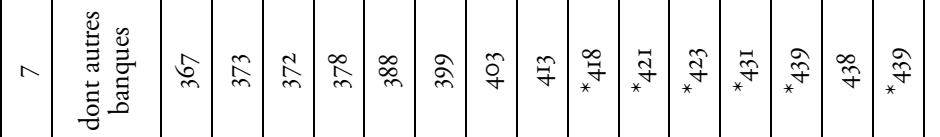

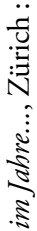

$\frac{2}{5}$

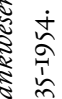

$\propto$ वे

है

ป

కิ

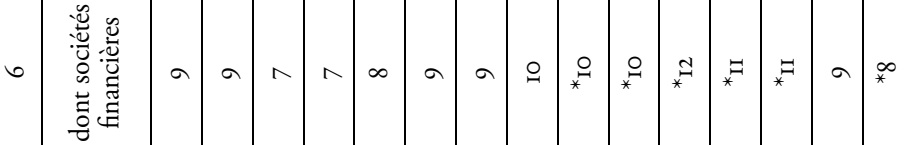

* ㅇํ

造

ํํำ

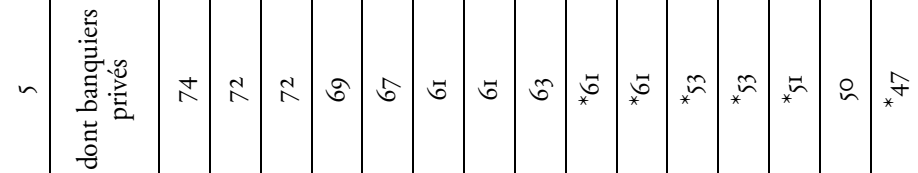

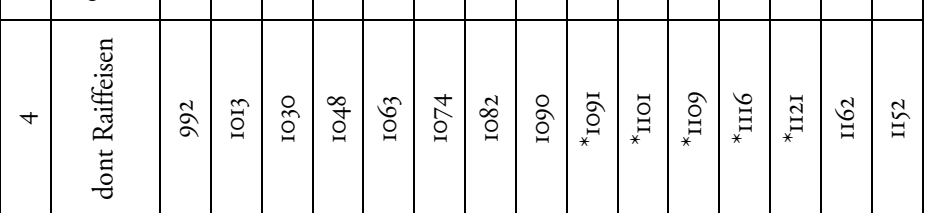

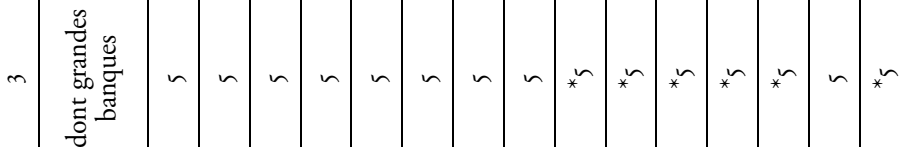

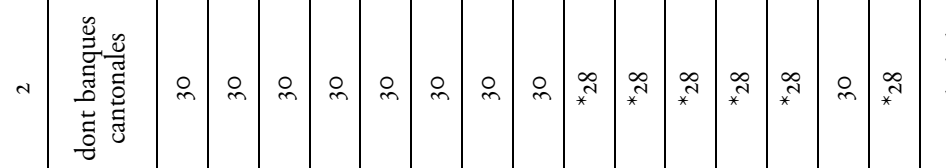

迎 ठิ

ติ

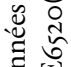

究致

은

品

ङ્屯.

ปิّ

初

品苛

क्ष

๕

สิ

䒕

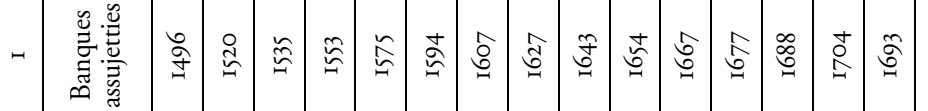

ज्ञ 
nationalisations dans de nombreux pays dans l'après-Seconde Guerre mondiale, l'étiquette "banque " serait un obstacle à l'extension de ses participations internationales. En octobre 1946, une nouvelle raison sociale, Elektro-Watt, est adoptée, et l'entreprise est désormais considérée par la CFB comme une société financière ne faisant pas appel au public. Dans leur grande majorité, les sociétés financières restent donc dans l'ombre de la régulation financière mise en place dans les années 1930, et une grande partie des opérations industrielles effectuées par la place financière suisse échappe ainsi à tout contrôle. Cette situation insatisfaisante reviendra à l'ordre du jour dans les années 1960 et sera au cœur des débats sur la révision de la loi sur les banques.

Du point de vue quantitatif, le nombre de banques assujetties est relativement stable pendant la période étudiée. Le tableau I6 propose un aperçu de l'évolution des différentes catégories de banques entre 1935 et 1967.

Ce tableau a pour but d'offrir une visualisation non pas du paysage bancaire suisse dans sa réalité économique, mais du nombre de sociétés - c'est-à-dire d'entités juridiques distinctes - qui tombe sous la juridiction de la Commission fédérale des banques. C'est pour cette raison que nous avons privilégié les sources internes de la CFB pour l'établir, à savoir ses rapports d'activité annuels. Les publications officielles de la BNS, dont les chiffres varient légèrement, n'ont été utilisées que pour combler les années lacunaires des rapports annuels. Aussi, la colonne 6 sur les sociétés financières ne recense que les sociétés financières pleinement soumises à la loi, à savoir celles qui font appel au public pour obtenir des dépôts de fonds. Les colonnes 5 et 8 constituent des entorses à la règle, en ce sens que les banquiers privés ne sont pas tous soumis intégralement à la loi sur les banques, et que les succursales de banques étrangères répondent aussi à un régime de régulation particulier. Il n'est pas le lieu de commenter dans le détail les évolutions qui ressortent de ce tableau, dont la périodisation dépasse le cadre chronologique de ce chapitre. Retenons simplement que l'augmentation progressive du nombre d'établissements entre 1935 et I970 est à mettre à l'actif des caisses Raiffeisen et de la catégorie très hétérogène des autres banques; les banquiers privés, quant à eux, connaissent une baisse marquée à partir des années 1950 .

Revenons à l'attitude de la Commission fédérale des banques en matière d'assujettissement à la loi sur les banques. Sous la menace du recours de droit administratif au Tribunal fédéral, la CFB a adopté durant ses premières années une politique d'assujettissement hésitante. Relevons aussi que la réglementation ne prévoit en revanche pas expressément la possibilité pour la Commission fédérale des banques de lever l'assujettissement à la loi, si une entreprise modifie son domaine d'activité à tel point qu'elle ne peut plus être considérée comme une banque ${ }^{67}$.

67 Robert Reimann relève que, même si cette possibilité n'est pas mentionnée dans la loi, la CFB peut lever l'assujettissement d'une banque, sur demande de cette dernière. Reimann, op. cit., 1963, p. 23. 
Il faut ici souligner que la politique d'assujettissement de l'autorité de surveillance - et les recours qu'elle engendre - ne fonctionne pas selon une dynamique à sens unique. L'on serait en effet tenté de croire que les recours ont pour unique but d'affranchir des sociétés qui ne veulent pas être soumises à la loi. Ces cas de figure existent bel et bien. On pense notamment à l'exemple déjà cité de la Société Anonyme de Gérances et de Dépôts qui remporte son recours contre la décision d'assujettissement en juin 1937. Dans le cas des sociétés financières, les recours visent en général à éviter l'assujettissement, et les contraintes liées, notamment en matière d'exportation de capitaux. Les procédures de recours ont d'ailleurs pour effet de ralentir considérablement le travail de la Commission fédérale des banques.

Mais il existe aussi de nombreuses situations où la dynamique est inverse : la CFB cherche à s'opposer à des requêtes d'assujettissement de la part d'entreprises qu'elle ne considère pas comme des banques. En effet, la soumission à la loi bancaire comporte aussi un certain nombre d'avantages. Seules les sociétés soumises à la loi peuvent faire figurer les termes de «banque " et "banquier" dans leur raison sociale. L'assujettissement à la loi pouvait également devenir un motif de publicité. Dans les réclames, l'utilisation du mot banque devient un synonyme de solidité et de confiance. Enfin, être soumis à la loi signifie aussi obtenir le droit d'émettre des obligations de caisse, de recueillir de dépôts d'épargne et de bénéficier des mesures d'assainissement spéciales ${ }^{68}$.

Il semble donc y avoir une évolution à la fois dans la perception de l'assujettissement et dans la politique adoptée par la Commission fédérale des banques. Alors que dans un premier temps, l'assujettissement était vu comme une gêne pouvant entraver la liberté de commerce, il est devenu un privilège donnant droit à des avantages non négligeables. De même, alors que la Commission fédérale des banques a d'abord suivi une politique consistant à soumettre, dans le doute, une entreprise à la loi, elle s'est progressivement réorientée vers une ligne de conduite plus prudente et restrictive. Comme l'exprime clairement dans un rapport interne datant de 1955 Robert Reimann, suppléant du chef de secrétariat : « en cas de doute, la Commission des banques approuvait autrefois le plus souvent l'obligation d'assujettissement, elle répondrait aujourd'hui plutôt par la négative " ${ }^{69}$. La dynamique a également changé : lors de l'entrée en vigueur de la loi, c'est la CFB qui a cherché à repérer les banques qui ne s'étaient pas encore annoncées de leur plein gré, tandis que par la suite, c'est le plus souvent l'entreprise requérante qui prend contact avec l'instance de surveillance.

Ces quelques considérations sur la politique de mise en pratique du champ d'application de la loi bancaire par la Commission fédérale des banques invitent à

Cf. Jean Golay, «La loi fédérale sur les banques et les caisses d'épargne et son application », Revue économique et sociale: bulletin de la Société d'Études Économiques et Sociales, vol. 23, $\mathrm{n}^{\mathrm{o}} 4$, I965, p. 329-342.

$69 \mathrm{AFB}, \mathrm{E} 652 \mathrm{O}(\mathrm{A})$, 1983/50, vol. 2, Dossier "Unterstellungspraxis», rapport de Robert Reimann (CFB) sur la pratique d'assujettissement, 20.04.1955, p. 8. 
une réflexion plus générale. La politique d'assujettissement illustre en effet très bien comment la perception d'une régulation peut évoluer, et surtout à quel point elle est ambivalente. Pour un certain nombre d'établissements, qui, pendant l'élaboration de la loi, avaient rejeté le principe même d'une législation fédérale sur les banques, être soumis à cette même réglementation présentait soudainement de nombreux avantages. Le prestige réputationnel d'une forme de certification officielle par une instance publique, le sérieux lié à l'utilisation du vocable banque, et - plus concrètement - la possibilité d'émettre des obligations de caisse comme moyen de financement constituaient des atouts commerciaux significatifs. En outre, il devenait sans doute manifeste que la loi n'était pas contraignante, et qu'une société avait souvent plus à gagner qu'à perdre en y étant soumise. En termes abstraits, on s'éloigne ici clairement du modèle théorique selon lequel la régulation représente une entrave à la liberté de commerce, qui prétérite les perspectives de développement des acteurs qui en sont affectés. Dans de nombreux cas, une réglementation peut aussi déséquilibrer le libre jeu du marché dans le sens d'un privilège au profit des établissements régulés.

\section{VI.1.4. La reconnaissance des sociétés fiduciaires: l'impuissance face au manque d'indépendance}

Le système de contrôle indirect des banques, caractérisé par la mise en place d'une révision fiduciaire obligatoire qui joue le rôle d'intermédiaire entre les banques et l'instance de surveillance étatique, a été présenté plus haut (cf. chap. IV.2.3). Nous avions vu que des critères d'indépendance relativement lâches avaient été établis, ce qui permettait de perpétuer les liens étroits qui existaient entre les principales sociétés fiduciaires et les banques qui les avaient fondées.

Une fois la loi entrée en vigueur, c'est à la Commission fédérale des banques que revenait la lourde tâche de mettre en pratique les dispositions légales, et de déterminer quelles entreprises et associations seraient reconnues comme instituts de révision officiels au sens de la loi. Comme prévu dans le texte légal, l'autorité de surveillance édicte une circulaire qui précise les activités autorisées et interdites aux instituts de révision. Il s'agit du "règlement limitant le champ d'activité des instituts de revision reconnus par la Commission fédérale des banques" promulgué le 9 septembre $1935^{70}$. Selon ce texte, les sociétés de révision ne peuvent pas effectuer des opérations bancaires proprement dites et se charger de gestion de fortune; elles doivent en outre annoncer à la CFB toute activité qu'elles pratiquent en dehors de la révision bancaire, et peuvent être amenées à y renoncer. Enfin, un délai de près de trois ans est fixé (décembre 1937), au terme duquel les sociétés qui effectuent des opérations incompatibles devront soit faire une croix sur l'activité incriminée, soit renoncer à la révision bancaire. Quelques règles complémentaires encadrent les rapports entre les

70 ABNS, I.3/I220, Reglement über die Abgrenzung des Tätigkeitsgebietes der von der eidgenössischen Bankenkommission anerkannten Revisionsstellen, 09.09.1935. 
trois pôles que sont la CFB, l'institut de révision et la banque. Les instituts de révision doivent tenir l'autorité de surveillance au courant de tout changement dans ses statuts et règlements, et toute modification dans le personnel supérieur (direction et réviseurs principaux). Quant aux banques, si elles restent libres de choisir leur réviseur parmi la liste des instituts reconnus, elles doivent cependant annoncer à la CFB tout changement d'institution de révision et en indiquer les raisons. Cette disposition avait pour but d'éviter qu'une banque puisse changer des réviseurs simplement pour éviter un contrôle jugé trop sévère. Dans la pratique, elle ne se révèle pas d'une grande efficacité. En octobre I938, la société financière spécialisée dans le financement de l'industrie électrique Motor-Columbus AG, demande à être révisée par la Gesellschaft für Bankrevisionen plutôt que par la Neutra ${ }^{71}$. La présence d'administrateurs comme Adolf Jöhr et Hermann Kurz, par ailleurs directeurs généraux du Crédit Suisse, à la tête de la Motor-Columbus ne semble pas indifférente à la décision de se faire dorénavant contrôler par la société de révision créée par cette banque. Au grand dam de certains de ses membres qui auraient souhaité une justification plus circonstanciée, la Commission fédérale des banques ne peut que constater le changement de société de révision.

En septembre 1935, compte tenu des restrictions imposées par la loi, la Commission fédérale des banques admet dans un premier temps une quinzaine d'instituts de révision, dont cinq syndicats de révision et onze sociétés fiduciaires. Ces institutions sont alors reconnues à titre provisoire, en attendant l'écoulement du délai transitoire de trois ans, au terme duquel un nouvel examen de la question est prévu. Cela signifie aussi que cette première liste est uniquement constituée de sociétés qui se sont volontairement annoncées, mais que la CFB n'a pas mené de véritables enquêtes sur la qualité du travail d'audit fourni. Entre 1935 et 1938, quiconque s'enregistrait comme institut de révision, pour autant qu'il remplisse les critères formels, obtenait une autorisation - certes provisoire - d'exercer. Ce procédé négligent de la part de l'autorité de surveillance est aussi une conséquence du manque de ressources dont elle dispose. Au vu de certains rapports de révision reçus, la Commission fédérale des banques doit d'ailleurs rapidement déchanter. En octobre 1936, elle adresse une circulaire aux instituts de révision pour préciser le contenu du rapport de révision. Cette mesure se révèle aussi insuffisante : dans son rapport annuel pour l'année 1937, la CFB continue de se plaindre des déficiences des rapports de révision ${ }^{72}$. Elle y regrette l'accumulation de détails insignifiants et les redondances superflues, tandis que des points essentiels ne sont pas abordés. Certains réviseurs tardent à intervenir et n'informent pas immédiatement la Commission fédérale des banques et le conseil d'administration de la banque concernée. Les superviseurs fédéraux ont même dû porter plainte contre un réviseur particulièrement négligent. 
En 1944, la question du contenu du rapport de révision refait surface. C'est cette fois-ci l'Union de Banques Suisses qui se plaint auprès de l'Association suisse des banquiers que certains rapports prennent une ampleur excessive et contiennent des détails qui dépassent le cadre de ce qui est fixé dans la loi. Pour I'UBS, ces excès de zèle sont dus à une certaine crainte des réviseurs, mais aussi à la CFB qui cherche à se protéger contre toute forme de responsabilité en exigeant l'application formelle de toutes les dispositions réglementaires. L'UBS ajoute dans ce courrier à l'ASB :

Outre le fait que ces rapports deviennent extraordinairement étendus, confus et également chronophages et onéreux, l'insertion de détails nominaux sur des postes débiteurs ou créditeurs n'est pas agréable et entre même à notre avis en contradiction avec l'obligation de discrétion des banques ${ }^{73}$.

L'Association suisse des banquiers décide alors de demander à la Commission fédérale des banques de mettre à sa disposition toutes les directives qu'elle donne aux instituts de révision afin de prévenir toute interprétation trop extensive de la loi sur les banques et de son ordonnance ${ }^{74}$.

Mais revenons au catalogue des fiduciaires officiellement reconnues. Celui-ci s'allonge en janvier 1936: deux syndicats de révision ainsi que deux sociétés fiduciaires - Fides, filiale du Crédit Suisse, et Price, Waterhouse \& Co., qui contrôle la succursale genevoise de la Lloyds - sont reconnus ${ }^{75}$. Une fois le délai des trois ans écoulé, la Commission fédérale des banques s'attèle à nouveau à la question de la reconnaissance des instituts de révision. Le bilan de la qualité des différentes sociétés fiduciaires provisoirement reconnues en I935 n'est pas reluisant. Certaines d'entre elles doivent se réorganiser sur recommandation de la $\mathrm{CFB}$, d'autres sont incitées à renoncer à la révision bancaire. Certaines choisissent elles-mêmes d'abandonner ce secteur d'activité. Dans l'ensemble, seule la moitié des instituts de révision sont en ordre ${ }^{76}$. Les problèmes constatés sont divers: chez les syndicats de révision, l'absence de fonds propres est inquiétante, et la compétence des certains réviseurs, comme chez le Freiburger Revisionsverband, est contestée. Quant aux sociétés fiduciaires, certaines ne parviennent pas à réunir suffisamment des mandats (Ostschweizerische Treuhandgesellschaft, Custodia), d'autres, comme la Kontroll- und Revisions AG ou la Gesellschaft für Bankrevisionen, reposent entièrement sur le personnel et le travail de sociétés qui ne sont pas autorisées à pratiquer la révision bancaire. Une fois ce réaménagement effectué en I938, puis

73 AASB, dossier n ${ }^{\circ} 713$ Eidg. Bankengesetz Jan. 1940-Juni 1948, lettre de la direction générale de l'UBS à l'ASB, 07.1944.

74 AASB, Procès-verbaux du Conseil d'administration de l'ASB, $167^{\mathrm{e}}$ séance, OI.09.1944, p. 8-9.

75 AFB, E6520(A), I000/I059, vol. 6, PV CFB, séance du 31.0I.1936, p. I4-15.

76 AFB, E6520(A), I000/I059, vol. 7, PV CFB, séances du II.02.1938 et du 23.03.1938. Voir aussi le rapport d'activité de la CFB pour l'année I938, p. 3-4. 
après quelques adaptations entre I938 et I94I, le catalogue recense quatorze instituts de révision qui figurent dans le tableau I7. Il ne connaîtra plus de modification jusqu'en $1950^{77}$.

Tableau I7. Instituts de révision reconnus par la Commission fédérale des banques le $\mathrm{I}^{\mathrm{er}}$ mars 194I (liste inchangée jusqu'en 1950)

\begin{tabular}{|c|c|c|c|}
\hline \multicolumn{3}{|c|}{ Syndicats de révision (Revisionsverband) } & Fondé \\
\hline I & \multicolumn{2}{|l|}{ Revisionsverband bernischer Banken und Sparkassen, Bern } & I9I2 \\
\hline 2 & \multicolumn{2}{|c|}{ Verband schweizerischer Darlehenskassen (System Raiffeisen), St. Gallen } & 1902 \\
\hline 3 & \multicolumn{2}{|l|}{ Fédération vaudoise des caisses de crédit mutuel, Vevey } & I9I2 \\
\hline 4 & \multicolumn{2}{|l|}{ Verband Schweizerischer Lokalbanken, Spar- und Leihkassen, Zürich } & 1920 \\
\hline \multicolumn{2}{|c|}{ Sociétés fiduciaires (Treuhandgesellschaften) } & $\begin{array}{l}\text { Capital-actions } \\
\text { en } 1938 \text { en } \mathrm{CHF}\end{array}$ & \\
\hline I & Kontroll- und Revisions AG, Basel & IOO 000 & 1935 \\
\hline 2 & Gesellschaft für Bankrevisionen, Zürich und Basel & 500000 & 1935 \\
\hline 3 & $\begin{array}{l}\text { Office fiduciaire, d'organisation et d'expertises, Ofor S.A., } \\
\text { Genève }\end{array}$ & IOO 000 & 1933 \\
\hline 4 & Revisions- und Treuhand AG, REVISA, Zug & IOO 000 & 1919 \\
\hline 5 & A.G. für Bankkontrolle, Zürich & $\mathrm{I} 20000$ & 1938 \\
\hline 6 & Experta, Organisations- und Revisions-Treuhand A.G., Zürich & IOO 000 & 1933 \\
\hline 7 & «Indep », Treuhand- und Revisions-Aktiengesellschaft, Zürich & ? & 1932 \\
\hline 8 & «Neutra» Treuhand-A.G., Zürich & 400000 & 1929 \\
\hline 9 & Price, Waterhouse \& Co., Zürich & ? & I937 \\
\hline IO & Schweizerische Revisionsgesellschaft A.G., Zürich & IOO OOO & I9I2 \\
\hline
\end{tabular}

Sources: AFB, E6520(A), 1983/50, vol. 13, Rapport annuel pour l'année 1940, p. 4-5. Liste du Io mars 1948 chez Piguet, $o p$. cit., 1953, p. 323. Année de fondation : SWA, dossiers correspondants. Capital-actions: "Les principales sociétés fiduciaires dans l'exercice 1937 ", in Bulletin financier suisse, 07.I0.1938, vol. 66, $\mathrm{n}^{\circ}$ 80, p. 434-435; SWA, dossiers correspondants.

Même au-delà des années I940, le monde de la révision bancaire est d'une remarquable stabilité. Seules trois nouvelles sociétés fiduciaires sont agrémentées entre 1938 et $1964^{78}$. Il faut attendre l'arrivée en Suisse des multinationales de l'audit entre les années 1970 et 1990 - celles qu'on appelle aujourd'hui les big four: Deloitte Touche Tohmatsu (DTT), Ernst \& Young (EY), Klynveld, Peat, Marwick \& Goerdeler (KPMG) et Price, Waterhouse, Coopers (PWC) - et le rachat progressif des compagnies suisses, pour assister à une transfor1950), de la Société fiduciaire «Lémano »SA, Lausanne (en 1957) et de la ALFA Treuhand \& Revisions AG, St. Gallen (en 196I). 
mation de la révision des banques. En 20I5, il n'y a plus que sept sociétés d'audit agréées pour le contrôle bancaire, contre 22 en 1988.

La longue phase d'immobilisme qui précède, entre les années 1930 et la fin des années 1960, est aussi le reflet d'un système qui laisse peu de place aux nouveaux venus. En effet, une fois passée la période transitoire, entre 1935 et 1938, les établissements bancaires ont fait leur choix parmi les instituts autorisés. Avec les restrictions sur les changements de réviseurs et la régulation de la CFB sur les tarifs de révision, il est très difficile de se faire une place sur un marché fortement cartellisé. Daniel Bodmer, secrétaire de la CFB entre 1955 et 1976, estime en 1959 dans un article publié dans la $N Z Z$ à l'occasion du $25^{\mathrm{e}}$ anniversaire de la loi sur les banques que «le petit nombre d'instituts de révision ne peut que difficilement être agrandi en raison d'une disposition de l'ordonnance à coloration corporative ${ }^{79}$. Même si nous ne disposons pas de statistiques diachroniques sur la répartition des mandats de révision pendant cette période, on peut avancer que le taux de changement est très faible - et que les rares transferts de mandats résultent pour la plupart du temps de fusions ou de rachats ${ }^{80}$.

\section{La Gesellschaft für Bankrevisionen: une société d'audit ad hoc pour contrôler les deux plus grandes banques helvétiques (1935-1941)}

Avant de clore ce point sur la reconnaissance des instituts de révision bancaire, prenons un exemple précis pour comprendre comment ce système s'est mis en place et les difficultés qu'il a soulevées. Nous voulons évoquer ici le cas de la Gesellschaft für Bankrevisionen (Société pour révisions bancaires). Cette fiduciaire est fondée le 22 mars 1935 en tant que société anonyme, avec un capital social de 500000 francs; elle possède deux sièges, à Bâle et à Zurich ; son but avoué est de pratiquer la révision bancaire en Suisse conformément à la nouvelle loi sur les banques ${ }^{81}$. Les deux plus grandes banques helvétiques - le Crédit Suisse et la SBS - sont à l'origine de cette création. Son conseil d'administration est présidé par le conseiller aux États radical bâlois Ernst Thalmann, qui avait présidé la commission de sénateurs chargée d'élaborer la loi sur les banques. Les quatre autres administrateurs sont Alfred Carl Lutz (I873-1953, membre du conseil d'administration du Crédit Suisse), Emil Locher (président du conseil d'administration de Fides), Hermann Obrecht (I882-1940, élu deux semaines plus tard au Conseil fédéral, administrateur de la Société de Banque

\section{Daniel Bodmer, «25 Jahre Bankengesetz », in NZZ, n 3547, I8.II.I959.}

Entre 1978 et 1988, une dizaine de changements d'instituts de révision par année se produit en moyenne, ce qui correspond à un taux de fluctuation de $2 \%$ par banque. Sans tenir compte des établissements locaux et cantonaux, qui ne changent presque jamais de réviseur car ils font partie d'un syndicat de révision, on arrive à un taux de fluctuation de $4.5 \%$. Cf. rapport de gestion de la CFB pour l'année 1988.

Bulletin de la Société de Banque Suisse, 18.04.1935, Bericht no. 2/1935, «Bundesgesetz über die Banken und Sparkassen», p. I8. 
Suisse) et Rudolf Peter (I888-I944, directeur général de la Schweizerische Treuhandgesellschaft I939-I944) ${ }^{82}$. La composition de ce conseil d'administration indique clairement l'organisation bicéphale de la Gesellschaft für Bankrevisionen, structurée autour des deux grandes banques et de leurs filiales respectives. La date de création de la société, quelques semaines après l'entrée en vigueur de la loi, et ses instances dirigeantes, signalent déjà que cette fondation est un habile subterfuge pour maintenir le statu quo dans l'audit des deux banques tout en répondant formellement aux critères légaux. Souvenons-nous que la loi bancaire interdisait aux sociétés de révision bancaire de poursuivre leurs activités de gestion de fortune. Les grandes sociétés fiduciaires de l'époque - la Schweizerische Treuhandgesellschaft, la Fides, mais aussi l'Allgemeine Treuhand AG, filiales respectivement du Bankverein, du Crédit Suisse et de la Basler Handelsbank - ont décidé de renoncer à la révision bancaire, pour poursuivre les opérations plus lucratives de gestion de fortune. Cette contrainte a donc poussé les deux grandes banques à fonder une nouvelle société ad hoc destinée à remplir les fonctions de contrôle requise depuis l'entrée en vigueur de la loi. Dans un premier temps, il s'agit ainsi d'un simple montage juridique: tant le conseil d'administration que la direction sont formés de personnalités liées à l'une ou l'autre grande banque ou à une de ses filiales. L'ensemble de la structure d'entreprise est marqué par le rattachement à chacune des grandes banques : le siège bâlois s'occupe du contrôle de la SBS, tandis que le siège zurichois gère la révision du Crédit Suisse. Ce compartimentage très hermétique a pour but de préserver la confidentialité de chaque établissement vis-à-vis de sa concurrente ${ }^{83}$. Il était inconcevable que les exigences de contrôle externe de la loi sur les banques provoquent la divulgation d'informations confidentielles entre les deux grandes banques concurrentes.

En I938, au moment où la Commission fédérale des banques doit statuer de manière définitive sur l'agréation des sociétés fiduciaires, un certain nombre de problèmes apparaissent dans l'organisation de la Gesellschaft für Bankrevisionen. Les superviseurs bancaires découvrent alors que la fiduciaire en question effectue le travail de révision des deux plus grandes banques helvétiques avec un personnel minimal de deux directeurs et deux employés, tous issus de la Schweizerische Treuhandgesellschaft et de la Fides, deux sociétés non-autorisées à pratiquer la révision bancaire ${ }^{84}$. La faiblesse de ce staff de quatre personnes pour contrôler les deux plus grandes banques de Suisse ressort encore plus clairement en comparaison: en I93I la Schweizerische Treuhandgesellschaft

Archives de la Chambre fiduciaire suisse, Zurich : A VSB Statuten Revisionsstellen VSB. La Schweizerische Treuhandgesellschaft est la plus ancienne et plus grande société fiduciaire de Suisse, fondée à Bâle par la SBS en 1906 (cf. chap. IV.2.3).

83 Perrenoud, et al., op. cit., 2002, p. II5.

84 AFB, E6520(A), I000/I059, vol. 7, PV CFB, II.02.1938, p. 20. Les directeurs sont A. Eckert, ancien directeur de la Fides et André Jeannot, ancien directeur de la Schweizerische Treuhandgesellschaft. 
compte plus de 140 employés ${ }^{85}$, en 1939 , le contrôle interne (inspectorat) du Crédit Suisse occupe trente contrôleurs ${ }^{86}$. La CFB constate donc un manque de personnel patent: cet état de fait laisse supposer soit que le travail de révision repose entièrement sur les rapports de l'inspectorat interne des deux banques, soit que la Gesellschaft für Bankrevisionen s'appuie sur le travail de réviseurs de la Fides et de la STG. Les membres de la CFB relèvent donc un manque d'indépendance évident entre la société de révision et les banques qu'elle contrôle. C'est ce que déclare sans ambages Albert Zust: "L'indépendance, exigée par la loi, d'un institut de révision à l'égard des banques contrôlées n'existe dans le présent cas d'espèce incontestablement pas de manière satisfaisante. ${ }^{87}$

Cette étroite dépendance se manifeste non seulement dans la composition du conseil d'administration et des dirigeants de la société, mais aussi dans la filiation financière. Le capital social de la Gesellschaft für Bankrevisionen, à hauteur de 500 ooo francs, se répartit de la manière suivante. Les deux grandes banques, le Crédit Suisse et la Société de Banque Suisse possèdent chacune I $8 \%$ des actions (90 actions à I 000 francs), tandis que leurs sociétés fiduciaires respectives - la Fides et la Schweizerische Treuhandgesellschaft contrôlent chacune $27 \%$ de l'entreprise ; les io \% restants sont en possession des membres du conseil d'administration, qui émanent de ces mêmes institutions ${ }^{88}$. L'actionnariat initial de la Gesellschaft für Bankrevisionen est donc intégralement structuré autour des deux groupes bancaires. D'ailleurs, la fiduciaire ne se contente pas de contrôler les deux grandes banques, mais reçoit également les mandats d'autres établissements, parfois liés au Crédit Suisse ou à la Société de Banque Suisse. En 1938 déjà, la Gesellschaft für Bankrevisionen est chargée de la révision bancaire d'un total de 25 sociétés, comme le montre le tableau i8.

On constate sans surprise que la répartition des mandats entre sièges zurichois et bâlois se fait selon les sphères d'influence des deux poids lourds de la finance helvétique. De plus, à partir des données fournies par la BNS qui ne tiennent pas compte des banquiers privés, on peut établir que dès 1938 , la seule Gesellschaft für Bankrevisionen se taille la part du lion de la révision bancaire en Suisse, puisque les sociétés qu'elle révise représentent $18.5 \%$ du total des bilans bancaires. Si l'on ne tient compte que des banques effectivement susceptibles d'être révisées par une société fiduciaire, c'est-à-dire en soustrayant les bilans des banques cantonales et des caisses Raiffeisen, la fiduciaire werbe », in Der Bücherexperte in der Schweiz = L'expert-comptable en Suisse. Festschrift zum
25jährigem Jubiläum des Verbandes Schweiz. Bücherexperten, Zürich : Graph Anstalt Schüler, 1939, p. 77-93, p. 79.

87

88

Helbling, op. cit., 2006, p. 38.

J[akob] Kaderli, "Die Entwicklung des Revisionswesens im Schweizerischen Bankge-

AFB, E6520(A), I000/I059, vol. 7, PV CFB, I2.09.1938, p. II9.

Cette répartition est dévoilée par Schulthess au cours d'une séance de la CFB : AFB, E6520 (A), I000/1059, vol. 7, PV CFB, I2.09.1938, p. II8. 
Tableau I8. Banques et sociétés financières clientes de la Gesellschaft für Bankrevisionen en 1938

\begin{tabular}{|c|c|c|}
\hline \multicolumn{2}{|r|}{ Révisées par le siège bâlois } & Bilan en milliers de $\mathrm{CHF}$ \\
\hline I & Schweizerischer Bankverein, Basel & I $45 \mathrm{I} 066$ \\
\hline 2 & Aktiengesellschaft Leu \& Co., Zürich & 178324 \\
\hline 3 & Schweizerische Gesellschaft für Metallwerte, Basel & 49193 \\
\hline 4 & Schweiz. Elektrizitäts- und Verkehrsgesellschaft, Basel & 47 I49 \\
\hline 5 & Société Générale pour l'Industrie Electrique, Genève & 46135 \\
\hline 6 & Internationale Bodenkreditbank, Basel & $4097 \mathrm{I}$ \\
\hline 7 & Continentale Gesellschaft für Bank- und Industriewerte, Basel & 35403 \\
\hline 8 & Bodenkreditbank in Basel, Basel & 31572 \\
\hline 9 & Allgemeine Grundkreditbank, Basel & 7943 \\
\hline IO & Bank in Schaffhausen, Schaffhausen & 4069 \\
\hline II & Coopérative d'Épargne «Le Semeur», La Chaux-de-Fonds & 589 \\
\hline I2 & A. Sarasin \& Cie., Basel & ? \\
\hline $\mathrm{I} 3$ & Ferdinand Kaufmann, Basel & $?$ \\
\hline \multicolumn{2}{|r|}{ Révisées par le siège zurichois } & Bilan en milliers de CHF \\
\hline I & Schweizerische Kreditanstalt, Zürich & I I6I 215 \\
\hline 2 & Schweizerische Bodenkredit-Anstalt, Zürich & I86 788 \\
\hline 3 & Bank für elektrische Unternehmungen, Zürich & I23 793 \\
\hline 4 & Schweizerisch-Argentinische Hypothekenbank, Zürich & $3 \mathrm{I} 38 \mathrm{I}$ \\
\hline 5 & Bank Wädenswil, Wädenswil & 27277 \\
\hline 6 & Bank für Anlagewerte, Zürich & 29246 \\
\hline 7 & Bank in Zürich, Zürich & $822 \mathrm{I}$ \\
\hline 8 & Bank in Luzern, Luzern & I3O \\
\hline 9 & Gebrüder Oechslin, Schaffhausen & ? \\
\hline IO & W. Meyer \& Co., Zürich & ? \\
\hline II & P. J. Bornhauser \& Cie., Zürich & $?$ \\
\hline I2 & Ernst Lochmann, Zürich & ? \\
\hline \multicolumn{2}{|c|}{ Total des bilans connus } & 3460465 \\
\hline
\end{tabular}

Sources : Liste de sociétés révisées: AFB, E652I(B), I99I/209, vol. 9, dossier "Gesellschaft für Bankrevisionen ", lettre du siège bâlois à la Commission fédérale des banques du 30.I2.1938, lettre du siège zurichois à la CFB du I3.0I.1939. Bilans: Das schweizerische Bankwesen im Jahre 1938, Zürich : Orell Füssli, 1939, p. I22-I43. Les banquiers privés ne publient pas leurs bilans. 
nouvellement créée est en charge de l'audit d'un groupe représentant plus du tiers des bilans des banques et sociétés financières (34.3\%) ${ }^{89}$.

Le troisième reproche adressé par la Commission fédérale des banques à la société fiduciaire est relatif à l'organisation interne. D'après les renseignements pris par Alphonse Perren, les deux sections zurichoise et bâloise de la société travaillent isolément, les rapports de révision qui concernent une banque restent confidentiels pour l'autre; il n'y a donc aucune transparence interne. Soulignons au passage que Perren, qui a remplacé Paul Rossy dans sa double fonction de vice-président en chef du secrétariat de la CFB en novembre 1937, occupait auparavant un poste de directeur à la fiduciaire genevoise OFOR ${ }^{90}$.

Quatrièmement, la Commission fédérale des banques regrette le manque de compétence du personnel déjà numériquement très faible. Perren estime que le directeur André Jeannot n'est pas à la hauteur de la situation. Il souligne en outre que deux des inspecteurs de la société, lors d'un récent examen d'expertcomptable, ont obtenu de très mauvaises notes et réussi l'examen de justesse. Le constat général de Perren, en novembre 1938, est accablant:

Le système de contrôle de la loi bancaire, comme dit précédemment, a fait ses preuves pour les petites et moyennes banques, mais semble avoir échoué pour les grandes banques. Après quatre ans, nous ne savons toujours pas comment les grandes banques sont révisées. Cette incertitude n'est pas seulement insatisfaisante, elle est tout simplement inquiétante ${ }^{91}$.

Face à ces manquements, les vecteurs d'intervention de la CFB sont limités. Ses membres décident de faire preuve de retenue et de prendre contact de manière informelle avec les dirigeants des deux grandes banques, à savoir Max Staehelin et Adolf Jöhr. On privilégie une négociation orale à une prise de sanction unilatérale; en effet, il aurait été possible de retirer l'autorisation à la Gesellschaft für Bankrevisionen, en attendant qu'elle résolve ses problèmes d'indépendance. L'entretien avec les dirigeants bancaires donne lieu à «un débat animé » après lequel Jöhr se plaint de l'attitude de Perren qui serait allé "trop loin " ${ }^{92}$. Mais la conférence n'aboutit en revanche pas à un résultat très probant du point de vue de la Commission fédérale des banques. La seule concession accordée par les grandes banques est un élargissement de l'actionnariat de la Gesellschaft für Bankrevisionen. Des sociétés financières comme l'Elektrobank et la Motor-Columbus - elles-mêmes étroitement liées aux grandes banques - sont invitées à prendre une participation de la société fiduciaire pour dissiper les reproches de manque d'indépendance. Certains

89 Les statistiques sur les bilans bancaires par groupe sont tirées de Das schweizerische Bankwesen im Jahre 1938, Zürich : Orell Füssli, 1939, p. 52-53, I16.

90 Matthieu Leimgruber, Taylorisme et management en Suisse romande (I9I7-I950), Lausanne:

Antipodes, 200I, p. IIo.

91 AFB, E6520(A), I000/I059, vol. 7, PV CFB, 25.II.1938, p. I6I.

92 AFB, E6520(A), I000/1059, vol. 7, PV CFB, I4.I2.1938, p. I75. 
membres de la CFB, en particulier Perren et Zust, estiment que ces efforts sont insuffisants et que la situation de la Gesellschaft für Bankrevisionen n'est en principe pas acceptable:

Chaque grande banque se fait contrôler par sa propre société fiduciaire. C'est une situation regrettable, et un contournement de la loi. Quoi qu'il en soit, ces sociétés fiduciaires ne sont pas indépendantes, et nous ne savons donc pas si les grandes banques en question sont révisées sérieusement et correctement ${ }^{93}$.

Cet avis ne fait pas l'unanimité au sein de l'autorité de surveillance. Un des rares cas de dissensions internes transparaît très clairement dans les procèsverbaux de la CFB. Les deux anciens banquiers, qui proviennent justement du Crédit Suisse et de la SBS, Emil Walch et Carl Brüderlin, insistent sur la qualité du contrôle interne auquel ils avaient affaire avant de quitter les établissements financiers. Ils assurent également que la société fiduciaire est rigoureusement irréprochable, aucune disposition légale n'étant formellement enfreinte, et demandent de se contenter de l'élargissement de l'actionnariat proposé. «Si les directions des banques nous expliquent que les révisions sont effectuées en bonne et due forme, nous pouvons être rassurés. Ou devrions-nous nous méfier de ces explications et exiger encore des preuves spécifiques?" ${ }^{94}$ s'exclame Walch. Perren se résigne alors, mais demande - fait unique jusqu'ici - que le procès-verbal mentionne ses doutes à l'égard de cette société fiduciaire et qu'il décline sa responsabilité personnelle. Quelques semaines plus tard, en janvier 1939, Perren démissionne de la Commission fédérale des banques et accepte un poste aux États-Unis chez Nestlé and Anglo-Swiss Company.

Malgré quelques retouches dans la composition des dirigeants et l'actionnariat de la Gesellschaft für Bankrevisionen, la situation du contrôle externe des grandes banques ne change pas pendant les années qui suivent. Alors que la question apparaît encore régulièrement à l'ordre du jour pendant trois ans, la Commission fédérale des banques se fait une raison en février i94I. Elle constate que la loi sur les banques ne lui donne pas les moyens formels d'intervenir pour assurer l'indépendance des sociétés fiduciaires qui révisent les grandes banques. Comme nous le verrons, la problématique ressurgira dans les années i960 et 1970.

Il faut ajouter que la situation de la Gesellschaft für Bankrevisionen n'est pas un cas unique. En 1935-I938, la Basler Handelsbank, autre établissement faisant partie du groupe des grandes banques, avait fondé la Kontroll- und Revisions AG, à partir d'éléments provenant de son autre filiale, l'Allgemeine Treuhand AG, qui pouvait ainsi poursuivre en toute quiétude ses activités de gestion de fortune ${ }^{95}$.

AFB, E6520(A), I000/1059, vol. 7, PV CFB, I4.12.1938, p. 176.

4 AFB, E6520(A), I000/1059, vol. 7, PV CFB, I4.12.1938, p. 179.

95 Le capital-action de la Kontroll- und Revisions AG s'élève à Ioo ooo francs. Son conseil d'administration est composé de Ernst Wälti (ZH), Hans Weibel (BS), directeur de l'ATAG (1930-1956), et dir. Hans Müller (BS). SWA, Dossier « Kontroll- und Revisions AG (Basel)». 
Au-delà de ces cas individuels, l'embarras dans lequel se trouve l'autorité de surveillance sur cette question est aussi le résultat de l'insuffisance de la loi et d'un développement inattendu. En effet, au cours de l'élaboration de la loi, de nombreux experts, en particulier Gottlieb Bachmann, le président de la BNS, avaient appelé de leurs vœux la constitution d'une grande association spécialisée dans la révision des grandes banques ${ }^{96}$. Une telle création aurait pu réunir les experts suffisamment compétents et acquérir un plus grand degré d'indépendance vis-à-vis des grandes banques. Les causes de l'échec de cette solution initialement prévue - ou du moins espérée - par les législateurs sont difficiles à éclaircir. S'agissait-il d'un vœu pieux? Bachmann et Rossy ont-ils prêché dans le désert ? Des raisons de concurrence ont sans doute joué un rôle, à une période où les effets de la crise financière marquaient une nette distinction entre les grandes banques qui devaient recourir à des mesures d'assainissement (la Banque Leu, la Basler Handelsbank, la Banque Fédérale, l'Union de Banques Suisses et, évidemment, la Banque Populaire Suisse) et celles qui traversaient la tempête sans réorganisation apparente (le Crédit Suisse et la Société de Banque Suisse). Dans ce sens, les grandes banques les plus solides auraient mis en place une structure de révision dont elles ont exclu leurs concurrentes plus empêtrées dans la crise.

En dehors de la révision des grandes banques, le degré d'indépendance n'est pas beaucoup plus élevé chez les autres catégories bancaires. Du côté des banquiers privés romands, la société OFOR (acronyme d'Office fiduciaire, d'organisation et d'expertises) est fondée en novembre 1933 à Genève par Aloys Hentsch (1889-1953), frère cadet de Gustave associé de la maison Hentsch $\& \mathrm{Cie}^{97}$. Ses liens privilégiés avec la haute finance genevoise, et sa création précoce quelques mois avant l'entrée en vigueur de la loi lui permettent de s'imposer comme l'unique société fiduciaire importante de Suisse romande. Elle entretient dans les années 1930 et 1940 de bonnes relations avec la Commission fédérale des banques et fait plutôt partie des bons élèves parmi les fiduciaires. C'est chez elle que la CFB vient se servir en recrutant Alphonse Perren, un directeur de l'OFOR dont nous avons déjà parlé, en novembre 1937.

Chez les banques locales et régionales aussi, certains problèmes sont signalés. En décembre 1935, la CFB ne peut que constater que la société de révision Neutra engage un certain Dr. Germann pour contrôler une banque qui appartient à son oncle (Greutert \& Cie, Bâle) ${ }^{98}$. Cette situation n'entrant en conflit avec aucune disposition légale, la CFB ne peut qu’opposer sa désapprobation.

Cf. commission du Conseil national, séance du 2 novembre 1934, p. 23-26. Les déclarations de Bachmann en faveur de la création d'une super-organisation des grandes banques sont soutenues par Arnold Saxer et Paul Rossy.

Sur la fondation de l'OFOR, voir Leimgruber, op. cit., 200I, p. I09-IIO.

AFB, E6520(A), I000/1059, vol. 6, PV CFB, II.I2.1935, p. I82. 
Dans d'autres cas, les superviseurs regrettent de nombreuses insuffisances dans les rapports rédigés par certaines sociétés fiduciaires. En I943, l'AG für Bankenkontrolle leur donne du fil à retordre. Après quelques hésitations, la Commission fédérale des banques renonce à retirer la reconnaissance à cette société fiduciaire, malgré des manquements répétés. On préfère résoudre le problème en invitant les dirigeants de la société à une conférence pour les réprimander informellement.

Quant au contrôle externe des banques cantonales, il n'est pas exempt de tout reproche non plus. Il faut ici distinguer deux phases dans la politique de reconnaissance de la CFB à l'égard des banques cantonales. Dans une première phase, entre 1935 et 1938 , la Commission fait preuve d'une grande clémence à l'égard des instituts cantonaux. Elle décide le I5 mai 1935 de libérer provisoirement l'intégralité des banques cantonales de l'obligation de se faire contrôler par une instance externe. Souvenons-nous que la loi avait prévu que cette dispense pouvait être octroyée aux banques cantonales «si elles possèdent un service de révision exercé par des personnes qualifiées". De l'aveu même de ses membres, la CFB a décidé la libération de la révision externe sans connaître la qualité des inspectorats internes des banques cantonales, la documentation lui ayant été transmise se révélant insuffisante ${ }^{99}$. Du côté des banquiers cantonaux, le président de l'UBCS recommande en décembre 1935 à ses collègues de fournir les déclarations demandées par la CFB sur la qualité des inspectorats internes, et de s'adresser à lui si "la commission fait des histoires» ${ }^{100}$. Occupée par d'autres affaires plus urgentes, la CFB fait donc preuve d'une certaine négligence dans sa gestion des banques cantonales durant ses toutes premières années d'existence.

À partir de juin 1938, puis surtout dès avril 1940, une seconde phase s'amorce, au cours de laquelle les régulateurs vont véritablement chercher à enquêter sur la qualité du contrôle interne effectué chez les banques cantonales. Ce changement d'attitude de la CFB n'est pas seulement dû à un agenda moins chargé que pendant les premiers mois d'existence. Entre 1935 et 1940, la CFB doit également être au chevet de plusieurs banques cantonales, rattrapées par la crise bancaire qui les avait jusqu'alors épargnées. La Banque cantonale neuchâteloise, la Banque cantonale de Berne et la Banque cantonale des Grisons sont tour à tour affectées par une grave crise et doivent mettre au point des plans d'assainissement d'entente avec les autorités cantonales et fédérales. En I940, la CFB a donc toutes les raisons de s'enquérir de la façon dont les banques cantonales révisent annuellement leurs comptes. Il s'agit alors de s'assurer que le contrôle interne des banques cantonales fonctionne correctement et d'exiger des rapports des inspectorats internes pour examiner le sérieux du travail effectué ${ }^{101}$. Les premiers résultats de l'enquête menée sont inquiétants. En avril 1940, le chef du secrétariat Max Hommel (I902-1972) estime que les

99 AFB, E6520(A), I000/1059, vol. 6. PV CFB, II.I2.1936, p. 309.

100 AUBCS, Protokolle der Komitee-Sitzungen, IO4 ${ }^{\mathrm{e}}$ séance, IO.I2.1935, p. II.

101 AFB, E6520(A), 1983/50, vol. I3, Rapport annuel pour l'année 1939, p. 5. 
révisions par les inspectorats internes "ne répondent pas aux exigences d'un contrôle vraiment bien informé et fiable» ${ }^{102}$. Les superviseurs cherchent alors à encourager la constitution d'une grande association de révision de toutes les banques cantonales (selon le même principe que le projet d'une super-organisation, restée sans succès, pour les grandes banques). Mais les perspectives de réussite d'une telle organisation sont faibles, à cause de l'opposition certaine des plus grands instituts cantonaux, et l'idée est abandonnée. En février et avril I94I, d'autres insuffisances sont constatées chez la Banque cantonale d'Uri et celle de Nidwald ${ }^{103}$. Dans le premier cas, il n'y a pas d'inspectorat interne et la révision est effectuée par un autre directeur de banque cantonale (Jakob Kaderli); dans le second, l'inspecteur mandaté est un employé d'une société fiduciaire, la Custodia (St. Gallen) qui n'est plus autorisée à pratiquer la révision bancaire à la suite de graves manquements. En décembre 194I, les résultats de l'enquête sur la Banque cantonale vaudoise ne sont guère plus rassurants. Hommel rapporte en effet que l'organisation du contrôle interne laisse à désirer ${ }^{104}$. Le contrôleur est en réalité un assistant du directeur, nommé par la direction. Le "Comité de surveillance » chargé du contrôle est lui-même un organe dirigeant. La coexistence de plusieurs services d'inspectorat interne concurrents, ce qui implique une dilution des responsabilités légales, n'est pas non plus du goût des membres de la CFB. Enfin, Henri Borle (I889-I966), membre romand de l'autorité de surveillance et professeur ordinaire d'économie commerciale et d'institutions économiques comparées à l'Université de Lausanne, relève lors de cette même séance que les rapports de révision produits par la Banque cantonale vaudoise sont creux et ne contiennent rien de plus que les simples rapports d'activité. Malgré ces carences, les possibilités d'intervention de la Commission fédérale des banques sont très restreintes. Mis à part la formulation de quelques réserves, elle n'a pas de pouvoir contraignant, étant donné que l'organisation interne des banques cantonales n'est pas de son ressort, mais reste l'apanage du droit cantonal. Une enquête interne, menée par l'Union des banques cantonales suisses en I939 confirme à la fois l'hétérogénéité de l'audit et ses insuffisances ${ }^{105}$. Un sondage révèle "un superbe fédéralisme"; autrement dit, un patchwork bigarré où dominent les particularismes locaux. Les 27 banques cantonales possèdent au total 66 instances de contrôles, dont la composition varie énormément (implication des autorités politiques, inclusion d'experts, etc.). Quant aux rapports de révision, ils sont également établis par différents types d'organes (inspectorat interne, commission du Grand conseil, commission du Conseil de banque, Comité de banque, organisme de contrôle, société fiduciaire externe). Dans un effort d'uniformisation des pratiques, l'UBCS soumet l'idée d'un syndicat de révision commun à

102 AFB, E6520(A), I000/I059, vol. 8. PV CFB, 05.04.1940, p. 36.

103 AFB, E6520(A), I000/I059, vol. 8. PV CFB, 03.02.194I, p. 20 et 25.04.194I, p. 57.

104 AFB, E6520(A), I000/I059, vol. 8. PV CFB, 03.I2.I94I, p. I45.

105 AUBCS, Protokolle der Kantonalbanken-Konferenzen, 29.II.I939, «Die behördliche Aufsichts- und Kontrollstelle bei den Kantonalbanken », Io pages. 
toutes les banques cantonales. Ce projet avait déjà été proposé en I935, et sera réitéré à plusieurs reprises (I940, I95I) au sein de l'UBCS, sans jamais faire l'unanimité. Il semble s'opposer à la résistance de certaines banques cantonales de dimension importante, notamment les établissements vaudois et bernois, qui ne veulent pas renoncer à leurs propres inspectorats. Il est difficile de déterminer précisément les raisons de leur refus.

Face à la timide tentative de la Commission fédérale des banques de mettre de l'ordre dans l'organisation des inspectorats internes des établissements cantonaux, la réaction des banquiers concernés ne se fait pas attendre. Un mouvement de résistance des banques cantonales contre la demande de renseignements de la CFB prend forme. En septembre i94I, le vice-président de la $\mathrm{CFB}$, Albert Zust, qui est à la fois membre du Conseil de banque de la Banque cantonale de Lucerne, propose un récit intéressant de l'atmosphère qui règne auprès des banquiers cantonaux :

Dans le cercle des banques cantonales, un certain malaise à l'égard de la Commission des banques semble exister. Lors de la dernière réunion de l'Union des banques cantonales suisse, il a été déclaré que la position de la Commission des banques vis-à-vis des banques cantonales n'est pas très bienveillante. Les membres de l'UBCS ont été invités à ne pas donner suite aux demandes de la CFB de transmettre des rapports de révision et éventuellement de porter plainte auprès du Tribunal fédéral ${ }^{106}$.

Les archives de l'association des banques cantonales confirment ce récit. Lors de l'assemblée générale de l'UBCS du 28 juin I94I, le directeur de la Banque cantonale de Bâle et président de l'UBCS, Rudolf Wittmer, déclare en effet que la Commission fédérale des banques ne dispose de base légale ni pour exiger les rapports de révision des banques cantonales, ni même pour demander une confirmation que le contrôle annuel a été effectué ${ }^{107}$. Il reproche même aux rares établissements qui ont accepté de transmettre des informations d'avoir créé un précédent préjudiciable et recommande de faire recours contre ce genre de requêtes.

En octobre I94I, la Commission fédérale des banques renonce à sa requête principale, qui consistait à rendre obligatoire l'annonce d'un rapport de révision. C'est elle qui devra, le cas échéant, réclamer les rapports de révision. Ce faisant, l'autorité de surveillance fait une croix sur une source d'information régulière de la part des banques cantonales. Celles-ci obtiennent donc le maintien du statu quo. Le système de contrôle interne perdure, malgré les insuffisances mises à jour par l'enquête de la CFB menée en I940-I94I. La grande retenue, voire une forme de timidité, qui caractérisera longtemps l'attitude de la Commission fédérale des banques à l'égard des banques cantonales trouve son origine dans cette altercation autour des inspectorats internes ${ }^{108}$.

106 AFB, E6520(A), 1000/1059, vol. 8. PV CFB, 19.09.194I, p. 99.

107 AUBCS, Protokoll der 36. ordentlichen Generalversammlung, 28.06.I94I, p. IO-II.

108 Bänziger, op. cit., I986, p. 198. 


\section{VI.2. LA CFB COMME INSTRUMENT D'ASSAINISSEMENT BANCAIRE}

Il est inconcevable d'analyser la première décennie d'activité de la Commission fédérale des banques sans évoquer le rôle central qu'elle a joué dans le soutien aux établissements financiers défaillants. Comme l'exprime un demisiècle plus tard le conseiller fédéral socialiste soleurois Otto Stich (1927-20I2), par ailleurs ancien membre de la CFB : «La Commission fédérale des banques est un enfant de la détresse. À peine portée sur les fonts baptismaux, elle a dû contribuer dans des conditions difficiles à la préservation du système bancaire suisse. " ${ }^{109}$ Plus proche des événements, l'auteur de la loi sur les banques et premier chef du secrétariat de la CFB Paul Rossy va dans le même sens, quand il affirme que "par la force des choses, la Commission fédérale des banques s'est vu attribuer une fonction dont le législateur n'avait pas prévu l'extension : celle de médecin des banques» ${ }^{110}$.

Remarquons d'emblée que les tâches et compétences que nous allons analyser dans les pages qui suivent ont pris une ampleur exceptionnelle et inégalée depuis. Pour une instance de régulation bancaire, soutenir une banque en élaborant par exemple un plan d'assainissement ne signifie pas la même chose que d'analyser les comptabilités de banques encore viables en vue de prévenir une défaillance future. Pour le dire autrement, l'accaparement de ses faibles ressources par la mise en application des dispositions visant à protéger les banques de la faillite a inéluctablement éloigné la Commission fédérale des banques de l'accomplissement d'autres tâches. Pendant une première phase, entre 1935 et 1943 environ, sous l'effet de la grave crise bancaire, l'autorité de surveillance passe le plus clair de son temps à mettre en application les diverses mesures destinées à faciliter des assainissements. Cet écart entre la mise en pratique de dispositions à la fois urgentes et chronophages, sous forme de soutien aux milieux bancaires, et l'omission ou la négligence de compétences à dimension coercitive - par exemple le contrôle de la qualité de l'audit externe -, soulève la question de l'objectif prioritaire de la législation bancaire. S'agit-il de protéger les déposants bancaires contre de lourdes pertes ou de soutenir les dirigeants d'un établissement, dans le but d'éviter une liquidation à la suite de retraits massifs provoqués par une panique bancaire? Ces intentions parfois concordantes, mais souvent contradictoires conduiront fréquemment à des débats au sein de la CFB dans sa politique d'application des mesures d'assainissement bancaire.

Plusieurs dispositions visant à protéger les banques de retraits de capitaux excessifs et à empêcher les liquidations irrationnelles - sous la forme de divers

109 Otto Stich, "Geleitwort ", in Urs Zulauf (éd.), so Jahre eidgenössische Bankenaufsicht / so ans de surveillance fédérale des banques / so anni di sorveglianza federale delle banche, Zürich: Schulthess Polygraphischer Verlag, 1985, p. V.

110 Paul Rossy, "Monsieur Edmond Schulthess à la Commission fédérale des banques », in Fritz Mangold (éd.), Festgabe für Bundesrat Dr. h. c. Edmund Schulthess zum siebzigsten Geburtstag am 2. März 1938, Zürich : Polygraphischer Verlag, 1938, p. 287-297, p. 294. 
moratoires de paiements et procédures concordataires - avaient été introduites dans la loi bancaire durant la phase parlementaire, sous l'impulsion des représentants des banques. Toutes ces nouvelles procédures, en dépit de leurs imperfections, requéraient une implication essentielle de la Commission fédérale des banques. Que ce soit dans un rôle consultatif (sursis bancaire et concordataire, prorogation des échéances), bientôt complété par des compétences décisionnelles (selon l'arrêté du Conseil fédéral du I7 avril 1936 mettant en place une procédure spéciale d'assainissement), l'autorité de surveillance était au cœur de l'exécution de nouvelles dispositions.

Dans un précédent chapitre, nous avons également souligné que la crise bancaire se développe en Suisse à partir de l'été I93I et atteint son paroxysme en 1934-1935 (cf. chap. II.2). Pour de nombreuses banques en difficulté, l'entrée en vigueur de la loi et de ses nouvelles mesures contre les défaillances est attendue avec impatience. Certains établissements, fortement atteints dans leur capacité de paiement, font recours dès 1934 à la Caisse de prêts de la Confédération pour surmonter la période les séparant de mars $1935^{111}$. Dès les premières semaines de son activité, la Commission fédérale des banques doit aussi faire face à un afflux de requêtes, par exemple d'homologation de prorogation des échéances, de la part de banques qui avaient ajourné cette intervention en attendant l'entrée en application du nouveau régime.

Avant de placer la focale sur quelques cas exemplaires de l'intervention de la CFB, il est utile de proposer un survol quantitatif de la dimension de l'intervention de l'autorité fédérale dans le domaine de la protection aux banques défaillantes durant la seconde moitié des années 1930. Combien de procédures sont traitées, discutées, voire accordées par la CFB ? Plusieurs chiffres concurrents existent. Il est en effet difficile de proposer une estimation très précise de ce phénomène, étant donné que la définition de ce qui constitue une banque en difficulté reste une question ouverte à l'interprétation. Par exemple, un établissement qui opère un assainissement sans intervention externe, notamment par le rachat de ses propres actions et une réduction de son capital, n'apparaîtra pas sur les radars de la Commission fédérale des banques. Au contraire, une seule et unique banque peut également fausser les statistiques, en sollicitant successivement différentes procédures (par exemple un sursis bancaire, puis un sursis concordataire avant d'entrer en liquidation); ce faisant, elle sera comptabilisée à trois reprises comme un cas d'intervention de la Commission fédérale des banques. Les estimations chiffrées qui suivent sont donc à considérer comme des indicateurs grossiers, plutôt que des mesures précises.

Un premier chiffre cité par Paul Rossy en 1938 fait état de 20 banques qui ont sollicité la prorogation des échéances, le sursis bancaire ou le sursis concordataire en l'espace de quinze mois seulement, entre juin 1935 et octobre $1936{ }^{112}$. Ce décompte confirme l'idée selon laquelle le nombre de requêtes connaît un

111 Bodmer, op. cit., 1948, p. I67-I68.

112 Rossy, art. cit., in Mangold (éd.), op. cit., 1938, p. 293. 
démarrage fulgurant. Sur une période un peu plus étendue, Paul Ehrsam (I9172008), ancien directeur de la BNS et membre de la CFB, rapporte d'autres estimations ${ }^{113}$. Il avance qu'entre 1935 et 1938, I2 banques demandent la prorogation des échéances, I5 le sursis bancaire, 2I le sursis concordataire et 8 entrent en liquidation. Ces chiffres sont en partie tirés d'un rapport de l'Administration fédérale des finances sur l'activité de la CFB datant de $1939^{114}$. Une troisième estimation chiffrée sur une période plus étendue provient d'une conférence de Paul Rossy, prononcée le 2I octobre 1942 à la Société d'économie politique de Zurich ${ }^{115}$. Celui qui est alors directeur général de la Banque nationale affirme qu'entre mars 1935 et octobre 1942, un total de 83 procédures d'assainissement sont à dénombrer. Ce total se segmente de la manière suivante : 35 liquidations, I6 sursis concordataires, 9 prorogations des échéances, 8 sursis bancaires, 7 procédures de faillite, 5 assainissements (réduction du capital et apport d'un nouveau capital) et 3 assainissements sous le régime de la communauté des obligataires. L'important écart entre les chiffres de Rossy et ceux d'Ehrsam est dû au fait que le calcul de Rossy ne tient pas uniquement compte des assainissements ayant impliqué une intervention de la Commission fédérale des banques.

Enfin, à partir des rapports annuels produits par la CFB à l'adresse du Conseil fédéral, nous pouvons proposer une nouvelle statistique de demandes d'assainissements bancaires et du travail de l'autorité de surveillance dans ce domaine.

Tableau 19. Nombre de banques demandant une procédure d'assainissement (I935I94I)

\begin{tabular}{|l|c|c|c|c|c|c|}
\hline & $\begin{array}{c}\text { Prorogation } \\
\text { des échéances }\end{array}$ & $\begin{array}{c}\text { Sursis } \\
\text { concordataires }\end{array}$ & $\begin{array}{c}\text { Sursis } \\
\text { bancaires }\end{array}$ & Liquidations & $\begin{array}{c}\text { Assainissements } \\
\text { extraordinaires }\end{array}$ & Total \\
\hline I935 & 3 & 5 & 4 & - & 2 & I4 \\
\hline I936 & 5 & 8 & 3 & 4 & - & 20 \\
\hline I937 & - & 3 & I & 2 & - & 6 \\
\hline I938 & - & - & I & - & - & I \\
\hline I939 & - & I & - & I & - & 2 \\
\hline I940 & - & - & I & - & 3 & 4 \\
\hline I94I & - & - & - & 3 & IO & 5 \\
\hline Total & 8 & I7 & IO & & 50 \\
\hline
\end{tabular}

Source : Rapports annuels de la CFB, années correspondantes. AFB, E6520(A), 1983/50, vol. I3.

113 Ehrsam, art. cit., in Zulauf (éd.), op. cit., 1985, p. 84.

114 AFB, E6Ioo(A), Iooo/1914, vol. 8 (dossier 692), «Organisation und Aufgaben der eidgenössischen Bankenkommission und ihres Sekretariates".

115 ABNS, I.3/I23I, "Conférence du 2I octobre 1942 à la Société d'économie politique et de statistique de Zurich de Monsieur P. Rossy sur l'immunité des banques aux crises », p. IO-II. 
Il ressort de ce tableau que les trois premières années d'activité de la Commission fédérale des banques sont marquées par une très forte sollicitation dans le domaine des procédures d'assainissements. La mise au point, en collaboration avec les instances cantonales judiciaires et la BNS, des réorganisations et plans de sauvetage a pris une place prépondérante dans son agenda déjà chargé par le travail de mise en application de la loi sur les banques. En plus d'être particulièrement chronophage, l'exécution des procédures moratoires en révèle souvent les insuffisances. Dans la suite de son exposé, Rossy ne manque pas de se montrer très critique à l'égard de ces dispositions. Inadéquates, elles " ne sont guère appropriées à l'objectif visé » ${ }^{116}$. La coexistence des différentes instances d'application - Commission fédérale des banques, Conseil fédéral, instances judiciaires cantonales - aurait également rendu impossible la délimitation claire entre les différentes procédures prévues. «Au lieu d'une autorité décidant souverainement de la procédure à appliquer dans chaque cas particulier, ce furent bientôt les banques qui choisirent l'autorité et par conséquent la procédure à laquelle elles entendaient se soumettre » ${ }^{117}$, affirme l'ancien secrétaire de la CFB. L'autocritique de Rossy est d'ailleurs confirmée par certains extraits des procès-verbaux de la CFB. En avril I94I, Schulthess avoue dans le cas de la Volksbank Interlaken qu'il faudra suggérer au Conseil fédéral l'approbation «dans l'urgence» de la demande de prorogation des échéances, en tant que prologue à une procédure d'assainissement ${ }^{118}$. Alors que les conditions requises ne sont pas réunies, la CFB fait preuve d'une certaine souplesse dans l'application de mesures peu adaptées aux circonstances. La conclusion de Rossy dans son analyse des dispositions sur l'assainissement des banques est d'ailleurs implacable: «En résumé, la loi est en même temps trop imprécise, trop rigide et pas assez complète. » ${ }^{119}$

\section{VI.2.1. La CFB comme médecin des banques : le cas de la Basler Handelsbank (1935-1937)}

Dès les premières semaines qui suivent l'entrée en vigueur de la loi sur les banques et la création de la Commission fédérale des banques, celle-ci doit se rendre au chevet de ses premiers patients d'importance: la Banque Fédérale S.A. (Eidgenössische Bank) et la Banque Commerciale de Bâle (Basler Handelsbank). Lors de la séance inaugurale de la CFB en avril 1935 , ce sont même trois banques préoccupantes qui sont désignées: aux deux grandes banques mentionnées vient s'ajouter une troisième: l'Union de Banques Suisses (Schweizerische Bankgesellschaft). Mais contrairement aux deux autres, la

116 ABNS, I.3/I23I, "Conférence du 2I octobre I942 à la Société d'économie politique et de statistique de Zurich de Monsieur P. Rossy sur l'immunité des banques aux crises », p. I3.

117 Ibid., p. I4.

118 AFB, E6520(A), I000/1059, vol. 8. PV CFB, or.04.194I, p. 4I.

119 ABNS, I.3/I23I, "Conférence du 2I octobre 1942 à la Société d'économie politique et de statistique de Zurich de Monsieur P. Rossy sur l'immunité des banques aux crises », p. I5. 
Bankgesellschaft n'a pas encore demandé un crédit à la Caisse de prêts de la Confédération.

Le I5 mai 1935, Schulthess annonce des chiffres inquiétants dans les cas de la Banque Commerciale de Bâle et de la Banque Fédérale ${ }^{120}$. Les engagements totaux de la Basler Handelsbank s'élèvent à 305 millions de francs, et ne sont couverts par des actifs suisses qu'à hauteur de 140 millions. Les actifs allemands, soumis à des restrictions de transfert et dont la valeur est difficile à estimer représentent 150 millions. Elle a déjà obtenu un crédit de 18.6 millions de la Caisse de prêts de la Confédération pour pouvoir maintenir son service de paiement jusqu'en juin 1935. Quant à la Banque Fédérale S.A., sa situation est à peine moins alarmante. Ses engagements totaux de 358 millions ne sont couverts que par I80 millions d'actifs suisses; ses actifs allemands atteignent I25 millions. La Caisse de prêts lui a accordé un crédit de 35 millions, mais ne peut plus entrer en matière pour étendre ce prêt.

La situation de la Basler Handelsbank était devenue de plus en plus inquiétante depuis la décision de son conseil d'administration en janvier 1935 de cesser de soutenir le cours de ses actions, qui connait dès lors une baisse spectaculaire ${ }^{121}$. C'est d'ailleurs sur la base de la chute du cours de ses actions, que ses déposants retirent leurs fonds et que la CFB entreprend ses investigations sur la grande banque bâloise. Le 7 juin I935, la Banque Commerciale de Bâle s'adresse au Conseil fédéral pour demander l'octroi d'une prorogation des échéances. Il s'agit là d'une solution de derniers recours. Au préalable, plusieurs tentatives de reprises d'abord par la Société de Banque Suisse puis par le Crédit Suisse avaient échoué $^{122}$. La Caisse de prêts de la Confédération avait en outre refusé d'accorder un nouveau crédit-relais, à hauteur de 22 millions, à la grande banque bâloise. Le gendarme des banques helvétique est alors placé devant un dilemme: à quel prix faut-il sauver la Banque Commerciale de Bâle et la Banque Fédérale? Une augmentation du plafond de la Caisse de prêts, qui devrait passer devant le parlement, ou un crédit de la BNS à la Caisse de prêts de la Confédération, pourrait provoquer une panique bancaire ou une crise monétaire. D'un autre côté, une fermeture des guichets pourrait avoir des conséquences dramatiques. Le 8 juin 1935 a lieu une séance extraordinaire de la Commission fédérale des banques intégralement consacrée à la question de la prorogation des échéances de la Basler Handelsbank. Après de longues hésitations, une majorité des membres se déclare prête à recommander au Conseil fédéral l'octroi d'une prorogation des deux ans. La question est très délicate, car la documentation fournie par la banque, à savoir un rapport de révision de la fiduciaire bâloise Allgemeine Treuhand AG, par ailleurs une filiale de la banque en question, n'indique pas si les actifs couvrent encore les créanciers; plus précisément, le rapport est très flou sur la valeur des actifs allemands gelés.

120 AFB, E6520(A), I000/I059, vol. 6. PV CFB, I5.05.1935, p. 25-27.

121 Perrenoud, et al., op. cit., 2002, p. 248.

122 AFB, E6520(A), 1000/1059, vol. 6. PV CFB, 21.05.1935, p. 37. 
Le précédent ainsi créé, à savoir une concession plutôt généreuse de la prorogation des échéances, est justifié par certains membres de la CFB en évoquant les circonstances exceptionnelles et les intérêts de l'ensemble du monde bancaire. La durée du moratoire fait aussi débat. Tandis qu'on envisage une prorogation très courte - de trois à six mois -, la banque réclamait une suspension de trois ans. Après une discussion non retranscrite, la Commission fédérale des banques se met d'accord sur une durée de deux ans. Le in juin, le Conseil fédéral suit l'avis de la CFB et valide la demande, une approbation à laquelle se joignent d'ailleurs la BNS et la Caisse de prêts ${ }^{123}$. Le lendemain, la Neue Zürcher Zeitung, tout en saluant une mesure à même d'aplanir la vague de méfiance, déplore l'excessive campagne de dénigrement menée par la presse socialiste, et plus particulièrement l'attitude de Robert Grimm, qui, en tant qu'administrateur de la Caisse de prêts, aurait prophétisé sans pudeur l'effondrement de l'établissement bâlois ${ }^{124}$. Dans les débats des autorités officielles en revanche, pas de traces d'une dénonciation de la presse de gauche. Dans leur jugement de la situation difficile de la banque bâloise, les superviseurs insistent surtout sur la politique d'expansion trop unilatérale et la mauvaise répartition des risques, en particulier le poids excessif des actifs soumis à des restrictions de transfert. Le retentissement de l'événement, à savoir la première application des mesures de protection des banques de la nouvelle loi, dépasse d'ailleurs les frontières nationales ${ }^{125}$.

Si la prorogation permettait à la Banque Commerciale de Bâle d'éviter de rembourser une somme très importante d'obligations arrivant à échéance, sa situation globale n'en était pas rétablie pour autant. En ce sens, la prorogation des échéances, pour reprendre l'expression imagée de Bodmer, «tient lieu de serre chaude et permet à une banque éprouvée de reprendre haleine, d'examiner la nécessité éventuelle d'un assainissement et de consolider sa situation » ${ }^{126}$. Une fois accordée, la procédure de prorogation des échéances demande encore un important travail de suivi de la part de la Commission fédérale des banques; en effet, c'est elle - parfois en collaboration avec un commissaire ad hoc, dans le cas de la Basler Handelsbank, Ernst Thalmann - qui est chargée de statuer sur les cas de rigueur (Härtefälle). Autrement dit, elle doit donner son accord sur le remboursement exceptionnel de crédits qui, en principe, tomberaient sous le coup du moratoire. Au cours de l'été 1935, la direction de la grande banque bâloise envisage un plan d'assainissement consistant à racheter ses propres obligations - celles-là mêmes qui étaient alors concernées par le moratoire à hauteur de $75 \%$ de leur valeur. La CFB s'inquiète de cette manœuvre, non pas

123 AFB, Eıo04.I, I000/9, vol. 353, Procès-verbaux de décision du Conseil fédéral, séance du II juin 1935 .

124 [s.n.], «Fälligkeitsaufschub der Basler Handelsbank», Neue Zürcher Zeitung, Handelsteil, I2.06.1935, p. 2-3.

125 La Frankfurter Zeitung et le Financial Times en font écho. Cf. Perrenoud, et al., op. cit., 2002, p. 255.

126 Bodmer, op. cit., 1948, p. 170. 
pour des raisons légales, mais pour l'effet psychologique qui pourrait en découler si l'affaire s'ébruite; elle recommande donc à la Basler Handelsbank d'effectuer l'opération "sous la main", sans être annoncée publiquement dans la presse $^{127}$. Parallèlement au moratoire et au rachat de ses obligations, la banque bâloise poursuit la réduction substantielle de ses placements à l'étranger: elle retire pour 26.3 millions de francs d'actifs allemands en 1935 et 48 millions en 1936, avec une perte comptable de 23 millions ${ }^{128}$.

En mars 1937, la BCB, toujours sous protection du moratoire, fait appel à la nouvelle procédure d'assainissement introduite par l'arrêté fédéral du Conseil fédéral du I7 avril I936, qui sera présentée plus bas. Le plan d'assainissement, qui est validé par le Tribunal fédéral en juillet 1937, prévoit une double réduction du capital social : d'une part par rachat et annulation de 5.25 millions, d'autre part, par la baisse de la valeur nominale des actions restantes ${ }^{129}$. En fin de compte, le capital-actions passe de 75 à 20 millions. Les gains ainsi réalisés servent à la fois à amortir les pertes subies et constituer une réserve pour les risques de transfert. La réorganisation financière de 1937 contient aussi un rééchelonnement des obligations venant à échéance au terme de la prorogation. L'établissement était bel et bien sauvé par cet assainissement, mais n'avait pas retrouvé sa prospérité; le bilan de la Basler Handelsbank poursuit sa chute vertigineuse. En 1940, il s'élève à I5I.4 millions de francs, moins d'un cinquième de son niveau nominal de 1930 (836 millions de francs) ${ }^{130}$.

La prorogation des échéances, suivie d'une réorganisation financière draconienne, a permis de maintenir en vie la Banque Commerciale de Bâle placée pour ainsi dire sous respiration artificielle. Ces mesures ont également évité l'injection en catastrophe de deniers publics, qui avait notamment caractérisé la première phase de la crise, par exemple dans le cas de la Banque Populaire Suisse. Mais la viabilité financière à long terme n'était pas assurée. Au sortir de la guerre, une nouvelle opération d'assainissement était nécessaire, à nouveau en collaboration avec la Commission fédérale des banques (cf. chap. VII.2).

Quant au sort de la Banque Fédérale, il est également très incertain malgé les interventions de sauvetage. Au cours de l'été 1935 , la CFB se montre intransigeante, et refuse de soutenir les demandes de nouveaux crédits au bénéfice de la grande banque zurichoise auprès de la Caisse de prêts. Pour les superviseurs financiers fédéraux, l'équité de traitement avec la Banque Commerciale de Bâle prime sur le poids économique de la Banque Fédérale, malgré l'importance de son réseau de succursales qui lui octroie un impact déterminant. À l'automne 1935, la Banque Fédérale est parvenue à réduire ses actifs allemands de 30 millions, avec une perte comptable de I2 millions, et améliore l'état de sa liquidité, voyant ainsi s'éloigner la nécessité d'une demande de prorogation des

127 AFB, E6520(A), I000/I059, vol. 6. PV CFB, 27.08.1935, p. I47.

128 Perrenoud, et al., op. cit., 2002, p. 256.

129 Bodmer, op. cit., I948, p. I7I. Voir aussi l'histoire officielle de l'établissement bancaire, très concise sur cette période de crise : Bauer, op. cit., 1988, p. 36-37.

130 Rapports de gestion, années correspondantes. 
échéances ${ }^{131}$. Fin 1936, une seconde réduction de capital, de 75 à 33 millions de francs, est opérée, dans le but principal de dégager des capitaux pour couvrir les amortissements sur les actifs allemands ${ }^{132}$. Comme dans le cas de la Basler Handelsbank, la Banque Fédérale souffre au sortir de la guerre des faiblesses héritées de la crise des années 1930, son engagement trop unilatéral dans le marché allemand compromettant sa rentabilité à long terme. Toujours comme sa concurrente bâloise, elle subira alors de nouvelles opérations d'assainissement.

Il va de soi que l'activité de médecin des banques de la Commission fédérale des banques ne s'est pas limitée au cas de la Basler Handelsbank. Plusieurs dizaines d'autres établissements, parfois des banques régionales de moyenne importance, et même des établissements cantonaux comme la Banque cantonale neuchâteloise, doivent faire appel aux services des superviseurs fédéraux pour obtenir un moratoire de paiement ou une procédure de liquidation appropriée ${ }^{133}$. Nous aurions aussi pu mentionner le cas de la Spar- und Leihkasse Bern. Cette banque régionale, dont le bilan s'élève en 1934 à 123.5 millions de francs, obtient de la CFB un sursis bancaire en novembre 1935. La situation de cette caisse d'épargne est critique: d'après les informations de la CFB, elle aurait placé 25 millions d'actifs en Allemagne alors que son capital s'élève à I2 millions de francs! ${ }^{134}$ Cette expansion internationale démesurée est à l'origine des difficultés qui affectent l'établissement en 1935 .

\section{VI.2.2. Le droit d'assainissement bancaire en mutation : de la Lex Leu d'avril 1936 à l'abandon du projet législatif en 1948}

À la suite des difficultés rencontrées par la CFB durant sa première année d'existence dans la mise en application des procédures d'assainissement, une nouvelle procédure particulière est adoptée en avril 1936 par le Conseil fédéral qui, malgré son caractère provisoire, restera en vigueur jusqu'en I948. Plus précisément, cet arrêté du Conseil fédéral trouve son origine dans l'impossibilité d'homologuer le plan d'assainissement d'une banque en particulier, l'Aktiengesellschaft Leu \& Co, ce qui lui valut le sobriquet de «Lex Leu». Il est donc nécessaire de revenir sur les difficultés de la banque zurichoise pour comprendre l'émergence d'une nouvelle disposition de droit bancaire, à peine plus d'un an après l'entrée en vigueur du nouveau régime de réglementation.

C'est en novembre 1935 que la Société Anonyme Leu \& Cie, la plus ancienne des grandes banques de Suisse, basée à Zurich, fait appel à la Commission fédérale des banques pour demander une mesure d'assainissement. Sa

131 AFB, E6520(A), I000/1059, vol. 6. PV CFB, 09.09.1935, p. I64.

132 Perrenoud, et al., op. cit., 2002, p. 257.

133 Sur l'assainissement de la Banque cantonale neuchâteloise en 1935 et l'intervention de la CFB, cf. Giddey, op. cit., 2017, p. 293-296.

134 AFB, E6520(A), I000/I059, vol. 6. PV CFB, 09.09.1935, p. I63-I64 et I2.II.1935, p. 2I4-216. Une grande partie des actifs allemands consiste en des biens fonciers appartenant à des clients juifs, ce qui, aux dires de Schulthess «ne simplifie pas l'affaire». 
situation est plus qu'alarmante ${ }^{135}$. Elle se trouve en effet parmi les banques proportionnellement très fortement engagées dans des pays avec restrictions de transfert (cf. tableau 2, chap. II.2). Les actifs gelés représentent fin I934 27.3\% de son bilan. De plus, elle ne dispose que de peu d'actifs aisément mobilisables, étant donné que la structure de son bilan accorde une place prépondérante au crédit hypothécaire urbain ${ }^{136}$. Une première réduction de capital, qui passe de 50 à 40 millions, par rachat et annulation de ses propres actions, a lieu en I934. À la fin de l'année 1935, l'accélération des retraits et l'arrivée à échéance de nombreuses obligations placent la Banque Leu dans une situation très inconfortable ${ }^{137}$. Au pied du mur, elle fait alors appel à la Commission fédérale des banques et demande en décembre 1935 une prorogation des échéances. En raison des répercussions néfastes sur les autres grandes banques en difficulté, Schulthess estime qu'il faudrait discrètement avertir les dirigeants bancaires des autres établissements en cas de fermeture des guichets de la Banque Leu ${ }^{138}$. La prorogation des échéances, demandée le 24 décembre, est validée le 30 décembre 1935 par le Conseil fédéral. Le moratoire est accordé pour une durée très courte de trois mois, dans l'espoir qu'un plan d'assainissement puisse être établi dans l'intervalle. Les difficultés juridiques liées à l'homologation d'une telle réorganisation financière par le Conseil fédéral au lieu du Tribunal fédéral ont retardé l'aboutissement de l'assainissement de la Leu AG, et la prorogation sera étendue jusqu'à fin octobre 1936.

Dès les premiers contacts avec les dirigeants de la Banque Leu, les membres de la Commission fédérale des banques regrettent certaines manœuvres qui témoignent d'une forme de défiance. Rossy rapporte par exemple qu'au moment de s'annoncer en tant que banque, Leu \& Cie a intentionnellement transmis un rapport de gestion tronqué, qui occultait une partie du bilan déjà critique $^{139}$. En décembre 1935, c'est le rapport de révision établi par la Gesellschaft für Bankrevisionen en vue de statuer sur la demande de prorogation des échéances qui est jugé sommaire et lacunaire ${ }^{140}$. Pour la Commission fédérale des banques, le procédé consistant à requérir des procédures d'assainissement tout en fournissant des renseignements comptables déficients laisse à désirer. Sur le fond également, les superviseurs fédéraux doutent de la couverture intégrale des créanciers; ils regrettent aussi que le plan d'assainissement privilégie les intérêts des actionnaires au détriment des créanciers.

135 Sur l'assainissement de la Banque Leu, voir aussi: Theo Keller, Leu \& Co. I755-1955: Denkschrift zum 200-jährigen Bestehen der Aktiengesellschaft Leu \& Co. Zürich, Zürich: Leu \& Co, 1955, p. 240-257.

136 Bodmer, op. cit., 1948, p. 173.

137 La Commission fédérale des banques estime le I2 novembre 1935 que le banque Leu dispose encore de 79 millions d'actifs soumis à des restrictions de transfert, et que ses créanciers sont donc à peine couverts. AFB, E6520(A), I000/I059, vol. 6. PV CFB, I2.II.I935, p. 217.

138 AFB, E6520(A), 1000/1059, vol. 6. PV CFB, 20.1I.1935, p. 231.

139 AFB, E6520(A), I00o/I059, vol. 6. PV CFB, I2.II.1935, p. 217-219.

140 AFB, E6520(A), I000/I059, vol. 6. PV CFB, 27.I2.1935, p. 290. 
La forme juridique que devrait prendre la réorganisation financière de la Leu AG fait aussi débat. Dès novembre 1935, l'idée de s'appuyer sur un futur article du nouveau programme financier de la Confédération, alors en cours d'élaboration, est soulevée. Il s'agirait de demander au Conseil fédéral d'autoriser un plan d'assainissement qui restreint les droits des créanciers au nom de l'article $47 \mathrm{du}$ projet de programme financier. Cette disposition stipule que « le Conseil fédéral est autorisé à prendre toutes mesures qu'il jugera nécessaires au maintien du crédit national et qu'il estimera ne pouvoir être différées ${ }^{141}$. En donnant une définition remarquablement large de cet article conférant les pleins pouvoirs au gouvernement, les dirigeants de la Banque Leu, d'entente avec le conseiller fédéral Albert Meyer, espèrent pouvoir trouver une solution d'assainissement particulière. L'enjeu de cette manœuvre consiste à désigner le Conseil fédéral comme autorité administrative d'homologation du plan d'assainissement, au lieu des instances juridiques cantonales, en principe compétentes dans la procédure de concordat habituel. Ce régime de faveur auprès d'institutions fédérales spécialisées (DFFD, CFB) serait plus à même de répondre aux besoins de la banque zurichoise que les procédures juridiques cantonales standards. C'est donc par le truchement d'une disposition de pleins pouvoirs d'un programme financier - lui-même introduit par arrêté fédéral urgent et combattu avec acharnement par la minorité sociale-démocrate du parlement ${ }^{142}$, que l'on cherche à introduire un nouvel instrument administratif d'assainissement bancaire. Pour Edmund Schulthess, ce subterfuge ressemble à de la Kabinettsjustiz, mais il estime que la demande de prorogation des échéances peut être approuvée ${ }^{143}$. Albert Zust, qui est à la fois membre de la CFB et rapporteur du Conseil des États sur le programme financier II, met en garde contre les abus auxquels pourrait donner lieu une telle interprétation de l'article 47 : le Conseil fédéral, en créant un précédent, serait alors sollicité par un grand nombre de banques (Banque Commerciale de Bâle, Banque Fédérale, etc.), voire par des banques locales, pour fonctionner comme instance d'homologation. Il privilégie donc l'établissement de principes généraux plutôt que la multiplication de cas d'espèce. Dans sa décision d'accorder la prorogation des échéances à la Leu du 30 décembre 1935, le Conseil fédéral suit essentiellement les conseils de la CFB ${ }^{144}$.

Le 2I février 1936, la CFB prend connaissance d'agissements suspects de la part de la Banque Leu : il s'avère qu'au cours de quatre jours qui ont précédé l'octroi de la prorogation des échéances, elle a opéré le rachat de 5 I45 de ses propres actions. Comme l'indiquent des documents établis deux ans plus tard

141 «Message du Conseil fédéral à l'Assemblée fédérale concernant de nouvelles mesures extraordinaires destinées à rétablir l'équilibre des finances fédérales en 1936 et 1937. (Du 22 novembre 1935.) ", Feuille fédérale, I935, vol. 2, n 49, «Projet d'Arrêté fédéral », art. 47, p. 897.

142 Sur le programme financier II qui est voté le 3 I janvier 1936 : Müller, op. cit., 20IO, p. 6oI-643.

143 AFB, E6520(A), 100o/1059, vol. 6. PV CFB, 27.12.1935, p. 291.

144 AFB, Eroo4.I, I000/9, vol. 356, Procès-verbaux de décision du Conseil fédéral, séance du 30.12.1935. 
dans le cadre de la validation du plan d'assainissement par le Tribunal fédéral, deux comportements frauduleux sont reprochés aux dirigeants de la grande banque zurichoise ${ }^{145}$.

Premièrement, le conseil d'administration de la Leu a procédé au rachat de ses propres actions, par l'intermédiaire d'une société financière fondée pour l'occasion, l'Internationale Finanzgesellschaft (Intfin) basée à Vaduz. Il s'agit d'un contournement évident de la loi, puisque les dirigeants ont ainsi retiré des capitaux qui auraient dû servir à couvrir les déposants de la banque. Du point de vue juridique, l'assignation de ce contentieux est problématique. À moins qu'une procédure de faillite ne soit ouverte, les créanciers, qui sont ici les principaux lésés, ne peuvent intenter une action en justice contre les administrateurs de la banque. Aussi, la CFB rapporte qu'un accord à l'amiable, sur ses propres recommandations, a été trouvé. Les membres du conseil d'administration et leurs proches fournissent, sous la forme de la souscription d'actions prioritaires, un montant d'un million de francs, en l'échange du renoncement à d'éventuelles poursuites à leur encontre. D'après la $\mathrm{CFB}$, cette somme pourtant colossale d'un million de francs est inférieure au préjudice causé, mais elle améliore malgré tout la situation des créanciers et permet surtout d'éviter à la banque, qui se situe encore en plein assainissement, une procédure judiciaire publique qui lui serait encore plus dommageable.

Deuxièmement, le même document révèle que l'ancien directeur de la banque (1915-1933) et membre de son conseil d'administration (1933-1937), Hans Dietler (1870-1962), a également, à titre personnel, effectué d'importants retraits de la banque quelques jours avant l'ouverture du moratoire. S'il est difficile d'établir une infraction précise, ces retraits témoignent pour la CFB "d'une façon de faire déloyale et incorrecte» ${ }^{146}$. La réputation de Dietler est d'autant plus entachée qu'il refuse de restituer les montants incriminés. Les autres membres du conseil d'administration, en revanche, acceptent d'éponger les pertes occasionnées par les retraits de Dietler, ce qui suffit à satisfaire la Commission fédérale des banques. Etonnamment, ces deux agissements irréguliers ne sont guère discutés au sein de l'organe de surveillance fédéral, du moins dans un premier temps. Au cours de l'hiver 1936, les négociations d'assainissement se poursuivent sereinement. Il est en revanche moins surprenant que l'histoire officielle de la banque Leu, publiée en I955 à l'occasion du $200^{\mathrm{e}}$ anniversaire et rédigée par le professeur d'économie de l'école de commerce de St-Gall Theo Keller, passe cet épisode sous silence dans son récit de l'assainissement ${ }^{147}$.

145 Voir en particulier la lettre de 20 pages adressées par la CFB au Tribunal fédéral daté du 20 janvier I937. AFB, E6Ioo(A-I4), IOoo/I9I4, vol. I2, lettre de Schulthess et Rossy (CFB) au Tribunal fédéral sur le projet d'assainissement de l'Aktiengesellschaft Leu \& Co, 20.0I.I937.

146 AFB, E6Ioo(A-I4), I0oo/I9I4, vol. I2, lettre de Schulthess et Rossy (CFB) au Tribunal fédéral sur le projet d'assainissement de l'Aktiengesellschaft Leu \& Co, 20.oI.I937, p. I2.

147 Keller, op. cit., I955, p. 240-249. 


\section{L'arrêté du Conseil fédéral concernant l'assainissement des banques du 17 avril 1936}

Fin mars, la voie d'un assainissement uniquement basé sur le programme financier n'est plus envisagée, et l'on s'achemine vers la promulgation de dispositions générales sous la forme d'un arrêté du Conseil fédéral ${ }^{148}$. Il s'agit là d'une solution par défaut, puisqu'en l'absence de dispositions spéciales, la Banque Leu devrait sans aucun doute recourir à un sursis concordataire qui la mènerait vers une liquidation, et partant de plus lourdes pertes pour les créanciers. En l'espace de trois semaines, entre le 28 mars et le 17 avril 1936, une procédure spéciale est mise sur pied à un rythme soutenu. Le 2 avril 1936 a lieu une conférence au cours de laquelle est discuté un premier projet d'arrêté du Conseil fédéral datant du 28 mars ${ }^{149}$. Les procès-verbaux de cette réunion - à laquelle participent des représentants de presque toutes les grandes banques, à l'exception de la principale concernée, l'AG Leu - révèlent que les établissements les plus solides, le Crédit Suisse et la Société de Banque Suisse, redoutent que des dispositions propres aux grandes banques puissent porter atteinte à leur crédit. Leurs dirigeants craignent en particulier un effet dépréciatif sur les obligations des banques. De plus, ils estiment regrettable de devoir modifier des dispositions légales de la réglementation à peine plus d'un an après leur entrée en vigueur. Schulthess leur répond que la limitation aux banques importantes a pour but de ne pas surcharger de travail la CFB et le Tribunal fédéral. Plusieurs des amendements demandés par les représentants bancaires lors de cette séance sont intégrés ${ }^{150}$.

Dès le lendemain, la CFB transmet un projet d'arrêté fédéral au Département des finances, projet qui sera approuvé par le Conseil fédéral le I7 avril 1936. L'arrêté du Conseil fédéral concernant l'assainissement de banques entre en vigueur immédiatement; il est présenté publiquement comme «un moyen de s'adapter aux nouvelles circonstances et de remédier aux défaillances de nos établissements de crédit qui jouent un rôle notable dans l'économie du pays » ${ }^{151}$.

148 AFB, E6520(A), I000/1059, vol. 6. PV CFB, 26.03.1936, p. IIO-II2.

149 Participent à la réunion du 2 avril 1936 : Edmund Schulthess; Paul Rossy (tous deux CFB); Carl Jäger (1869-1947), juge fédéral; Gustave Bovon (I867-1949), dir. Crédit Léman à Vevey; Max Brugger (I882-1945), pdt Basler Handelsbank; Victor Gautier (I89I-1965), dir. BNS ; Albert Caflisch (1898-1965), secr. ASB ; Hans Fischer (I895-?), pdt Association des banques locales; Paul Jaberg (1878-1955), DG UBS ; Adolf Jöhr (I878-1953), DG Crédit Suisse; Eduard Kellenberger (I889-1976), Dir. suppléant de l'Administration fédérale des finances; Robert La Roche (1877-1946), Prés. ASB, associé de la banque privée La Roche \& Cie; Max Staehelin (I880-196I), pdt SBS; Arthur Wolf (I884-I96I), dir. comité central de l'Association des banques locales; Otto Würgler (I887-I966), dir. Banque cantonale de Berne. AFB, E6I0oA-I4, I00o/I9I4, vol. I2, Leu AG, Entwurf betr. Sanierung von Banken - Sitzung vom 2. April 1936.

150 Tenant par exemple compte de certains remaniements couchés sur papier à l'issue de la séance. Cf. par exemple, AFB, E6520(A), 1983/50, vol. 32, Sanierung von Banken, Lettre d'Adolf Jöhr à Paul Rossy, 02.04.1936.

151 «Rapport du Conseil fédéral à l'Assemblée fédérale sur les mesures de nécessité prises pour maintenir le crédit national (du 5 octobre 1936) ", Feuille fédérale, vol. 2, n 4 I, 07.IO.1936, p. 72 I. 
Son contenu est le suivant : il introduit une procédure d'assainissement spéciale, dont le principe ressemble à la procédure concordataire habituelle, mais dont l'exécution est placée sous l'autorité des deux instances fédérales (la Commission fédérale des banques pour la phase préparatoire et le Tribunal fédéral pour la phase d'homologation) en lieu et place des instances juridiques cantonales ${ }^{152}$. Dans le cas des réorganisations financières d'établissements financiers importants, les autorités cantonales étaient souvent dépassées par l'ampleur de la tâche et éprouvaient des difficultés face aux problèmes de technique bancaire. Autre différence notable : cette procédure n'est ouverte qu'aux banques "qui jouent un rôle notable dans l'économie publique de la Suisse » et qui bénéficient déjà d'une prorogation des échéances ou d'un sursis. Enfin, le troisième avantage dont jouit la procédure spéciale d'avril 1936 par rapport à la procédure concordataire est qu'elle ne représentait pas la même atteinte à la réputation d'une banque ${ }^{153}$. Devoir recourir au concordat - une procédure juridique rigide - signifiait souvent la fin du dernier capital de confiance pour une banque. La nouvelle procédure, de nature administrative, était en ce sens à la fois plus souple et plus attractive. Le rôle de la Commission fédérale des banques y est prépondérant. C'est elle qui statue sur l'ouverture de la procédure, qui désigne un commissaire ou une commission de surveillance chargée de surveiller la gestion de la banque, et enfin - tâche considérable - c'est elle qui donne son assentiment au plan d'assainissement concocté par la banque avant de le transmettre au Tribunal fédéral ${ }^{154}$.

L'arrêté fédéral ne prévoit pas une durée maximale pour la procédure d'assainissement. Dans la pratique, la mise en application par la CFB de cet arrêté donne lieu à d'intenses échanges entre les autorités (CFB, Commissaire, Tribunal fédéral, voire la BNS) et les dirigeants de la banque concernée. En principe, les autorités publiques cherchent à privilégier les intérêts des créanciers bancaires dans leur ensemble, tandis que les instances bancaires favorisent les actionnaires et proposent des estimations trop optimistes de la situation financière de la banque.

Prévu comme une mesure provisoire et reposant sur une base juridique très fragile, à savoir l'article 53 du programme financier de janvier 1936, l'arrêté fédéral du 17 avril 1936 expire déjà en décembre 1937. Dans des circonstances sur lesquelles nous reviendrons, il sera prolongé à quatre reprises: en janvier 1938 pour une durée d'un an, en décembre 1938 pour une durée de trois ans, en juin 1942 pour une durée de trois ans, et finalement en décembre 1944 pour une durée de cinq ans. Il arrive à échéance fin 1949. Sa non-prolongation signifie la disparition du droit extraordinaire d'assainissement, après treize ans d'existence sur la base juridique des pleins pouvoirs. Le bilan global de cette mesure

152 Cf. Holenstein, art. cit., in op. cit., 1944, p. 56-68; Ehrsam, art. cit., in Zulauf (éd.), op. cit., I985, p. I08-II3.

153 Holenstein, art. cit., in op. cit., 1944, p. 57.

154 "Arrêté du Conseil fédéral concernant l'assainissement des banques (du I7 avril 1936)", Feuille fédérale, vol. 2, no 4I, 07.10.1936, p. 725-728. 
spéciale est le suivant : entre 1936 et I945, une demi-douzaine de banques ont obtenu l'homologation d'un plan d'assainissement sur cette base.

Tableau 20. Banques sollicitant une procédure d'assainissement selon l'arrêté du Conseil fédéral du I7 avril 1936 (I936-1945)

\begin{tabular}{|c|c|c|c|}
\hline Banque concernée & $\begin{array}{l}\text { Bilan à l'ouverture } \\
\text { de la procédure } \\
\text { en millions de } \mathrm{CHF}\end{array}$ & $\begin{array}{c}\text { Date de l'ouverture } \\
\text { de la procédure } \\
\text { par la CFB }\end{array}$ & $\begin{array}{c}\text { Date de } \\
\text { l'homologation du plan } \\
\text { d'assainissement } \\
\text { par le TF }\end{array}$ \\
\hline AG Leu \& Co & 232.9 & 24 avril 1936 & I5 mai I937 \\
\hline Basler Handelsbank & 194.4 & 3 mars 1937 & I5 juillet I937 \\
\hline $\begin{array}{l}\text { Spar- und Leihkasse } \\
\text { Bern }\end{array}$ & $\mathrm{I} 2 \mathrm{I} .2$ & I5 novembre 1936 & 29 octobre 1937 \\
\hline $\begin{array}{l}\text { Schweiz. Spar- und } \\
\text { Kreditbank }\end{array}$ & 90.4 & I2 janvier 1938 & $\begin{array}{l}\text { - (assainissement } \\
\text { extrajudiciaire) }\end{array}$ \\
\hline $\begin{array}{l}\text { Spar- und Leihkasse } \\
\text { Thun }\end{array}$ & 36.7 & 27 mai 1938 & 3 février 1939 \\
\hline Bank in Ragaz & $\mathrm{I} 4.8$ & 28 décembre I940 & 6 novembre I94I \\
\hline Volksbank Interlaken & 8.6 & 29 avril I94I & 3I mai 1945 \\
\hline
\end{tabular}

Sources: Date d'homologation: AFB, E6520(A), 1983/50, vol. 32, 16*, « Sanierung von Banken (1935-1945) ». Date d'ouverture : AFB, E6520(A), 1983/50, vol. I3, rapport annuel de la CFB, 1936194I. Bilans: Das schweizerische Bankwesen im Jahre..., Zürich: Schweizerische Nationalbank, années correspondantes.

On remarque qu'à partir de 1938 la procédure extraordinaire est également octroyée à des instituts de taille moyenne. En effet, lors de la prolongation de décembre 1938, le mot «notable» est supprimé dans l'expression «banques qui jouent un rôle notable dans l'économie publique de la Suisse». La procédure d'assainissement spéciale s'ouvre donc dans un deuxième temps à des établissements de moindre importance.

Mais revenons d'abord au printemps 1936. Avec la promulgation au pas de course de nouvelles dispositions sur l'assainissement bancaire, la Banque Leu obtenait la solution sur mesure qu'elle recherchait. Dès le lendemain de l'entrée en vigueur de l'arrêté, la Leu demande à la CFB l'ouverture d'une procédure d'assainissement, qu'elle obtient immédiatement ${ }^{155}$. Une commission de surveillance de trois membres est désignée. Il s'agit d'Emil Zachmann - le directeur de la Schweizerische Treuhandgesellschaft proche du Bankverein, de Hans Matti (I887-1966), professeur de droit à l'Université de Berne, et de Josef Henggeler (I886-1952), un avocat zurichois spécialisé dans le droit fiscal et économique, une candidature proposée par Adolf Jöhr, directeur général du Crédit Suisse ${ }^{156}$. L'autorité de surveillance accepte, conformément à la volonté

155 AFB, E6520(A), I000/I059, vol. 6. PV CFB, 24.04.1936, p. I29-I31. Cf. aussi Keller, op. cit., I955, p. 245.

156 AFB, E6520(A), I000/1059, vol. 6. PV CFB, 24.04.1936, p. I29. 
de la Leu S.A., de ne pas publier dans la presse la composition de la commission de surveillance, pour éviter une remise en cause publique de sa légitimité. Entre mai et décembre 1936, le projet d'assainissement est âprement négocié. Le ralentissement de la procédure est surtout dû aux dirigeants de la Leu, qui proposent au cours de l'été un nouveau projet concurrent de celui élaboré par la commission de surveillance. Ils auraient en particulier souhaité créer une structure de défaisance (Auffangsgesellschaft), chargée de reprendre les actifs soumis à des restrictions de transfert ${ }^{157}$. Mais ce plan rencontre l'opposition de la CFB, de la BNS et du Tribunal fédéral. En janvier 1937, la Commission fédérale des banques transmet finalement au Tribunal fédéral un projet d'assainissement de la Banque Leu et en recommande l'homologation. Ce plan prévoit une réorganisation profonde : d'une part, le capital-actions est réduit de 40 à 7 millions de francs, par annulation et dépréciation des actions, d'autre part, les créanciers - à l'exception des déposants de moins de I ooo francs subissent une perte de $35 \%$ sur leurs dépôts et obtiennent en contrepartie de nouvelles actions ${ }^{158}$. De plus, un rééchelonnement jusqu'en 1948 des obligations bancaires encore prorogées est validé, et un poste spécial pour les actifs gelés est porté au bilan. Cet assainissement profond met donc à forte contribution à la fois les créanciers bancaires, dont les dépôts subissent une perte nette de $20 \%$ et les actionnaires. Dans sa lettre de janvier 1937 au Tribunal fédéral demandant d'accepter le plan d'assainissement, la Commission fédérale des banques est consciente du lourd sacrifice que représente cette solution, mais estime qu'il s'agit d'un compromis acceptable, offrant aux créanciers des pertes inférieures à celles qu'ils subiraient dans une liquidation ordinaire ${ }^{159}$.

Les affaires de la Banque Leu végètent au cours de la guerre. Ce n'est qu'en 1945-1946 qu'elle peut définitivement se défaire du lourd héritage de la crise des années I930, en amortissant intégralement les derniers actifs gelés au cours d'un second assainissement. Réduit à la portion congrue, le volume d'affaires de la Banque Leu est alors indigne de sa classification parmi les grandes banques : son bilan de 1945 (I6I.4 millions) représente par exemple un dixième de celui de la Banque cantonale de Zurich et la rapproche plutôt de certaines banques régionales. La reprise des affaires, dans l'après-guerre, s'effectue en grande partie dans le domaine du financement de la construction et des crédits hypothécaires dans la région zurichoise ${ }^{160}$.

157 AFB, E6roo(A-I4), Iooo/ı1914, vol. I2, Leu AG, Lettre de la Commission fédérale des banques au Tribunal fédéral, 20.0I.1937.

158 Bodmer, op. cit., I948, p. I75-I76. Keller, op. cit., I955, p. 246-247.

159 AFB, E6Ioo(A-I4), I0oo/I9I4, vol. I2, Leu AG, Lettre de la Commission fédérale des banques au Tribunal fédéral, 20.0I.1937, p. 8.

160 Cf. Keller, op. cit., I955, p. 26I-266. 
Avant de clore ce sous-chapitre sur la fonction de médecin des banques de la $\mathrm{CFB}$, il faut encore revenir sur ses tentatives répétées de pérenniser, dans la législation ordinaire, les dispositions nouvelles mises en place en avril 1936. Pendant plus d'une décennie, entre 1938 et 1948, l'autorité de surveillance a en effet cherché à transformer la procédure d'assainissement extraordinaire en une loi à caractère durable. Lors de chacune des quatre prolongations de l'arrêté du Conseil fédéral du 17 avril 1936 (janvier 1938, décembre 1938, juin 1942 et décembre 1944), la question s'est posée d'élaborer une véritable législation, ou de modifier la loi bancaire de 1934, plutôt que de simplement prolonger un acte de droit extraordinaire.

La volonté de la CFB de transférer l'arrêté du Conseil fédéral d'avril 1936 dans le droit ordinaire reposait sur les bonnes expériences faites avec la nouvelle procédure d'assainissement. En décembre 1937, elle annonce au Département fédéral des finances et des douanes son intention d'élaborer un projet de législation ordinaire, justifiant cette démarche par les bons résultats obtenus dans les cas de la Banque Leu et de la Basler Handelsbank ${ }^{161}$. Cette intervention est soutenue par le directoire de la BNS ${ }^{162}$. Étant donné que l'arrêté n'a été prolongé que pour une année, l'affaire est relativement pressante, et le DFFD est prié d'amorcer les travaux rapidement.

Il faut cependant attendre quatre mois pour qu'une première réunion ait lieu. Le II avril I938, la séance présidée par Schulthess débouche sur un résultat relativement clair. Tout le monde - à l'exception notable d'Adolf Jöhr qui n'est pas présent, mais a émis des réserves par écrit - estime que la procédure d'assainissement a fait ses preuves ${ }^{163}$. La question de savoir si elle doit être insérée dans la loi sur les banques ou faire l'objet d'une législation particulière est une "pure formalité" pour Schulthess. Dès juin 1938, une commission d'experts nommée par la CFB s'attèle à la rédaction d'une refonte des dispositions sur l'assainissement et le concordat bancaire ${ }^{164}$. Cette petite commission Haab produit en septembre 1938 un rapport de 59 pages à destination de la

161 AFB, E6520(A), 1983/50, vol. 32, Sanierung von Banken, Lettre de la CFB au DFFD, 27.I2.1937.

162 AFB, E6Ioo(A-15), ı0oo/ı15, vol. 8, dossier 92I Vorschriften über die Sanierung von Banken (BRB), Lettre de Paul Rossy (BNS) au DFFD, 28.I2.1937.

163 AFB, E6520(B) 2007/62, vol. 61, Allgemeines, Korrespondenz, Bankensanierungen, "Neuordnung des Sanierungs- und Nachlassverfahrens für Banken. Protokoll der I. Sitzung der Expertenkommission", II.04.I938. Participent à cette réunion: Edmund Schulthess (CFB, président), Alphonse Perren (CFB), Paul Rossy (v-pdt BNS), Henri Borle (I889I966, professeur de droit à l'Université de Lausanne), Gustave Hentsch (I878-1962, banquier privé, Genève), Hans Kuhn (I884-I980, chef de la Division fédérale de la justice), Georg Leuch (1888-1959, juge fédéral), Arthur Wolf (Comité central de l'Union suisse de banque régionales).

164 La commission d'experts est formée de quatre juristes : Robert Haab (1893-1944), professeur de droit privé à l'Université de Bâle qui avait participé à la révision du Code des obligations, Paul Carry (I892-1977), professeur de droit à l'Université de Genève, Josef Henggeler (I886I952), avocat à Zurich, et Arthur Homberger (I896-1945), professeur de droit à l’Université de Berne. 
CFB. Elle préconise une refonte complète du droit d'assainissement bancaire ${ }^{165}$. Les articles 26 à 37 de la loi sur les banques, les dispositions d'exécution qui y sont liées, et l'arrêté du Conseil fédéral du I7 avril 1936 fusionneraient pour apporter une certaine clarification et éviter les procédures redondantes. Du point de vue formel, la commission propose en fait deux options : soit une nouvelle législation fédérale, soit une révision partielle de la loi sur les banques qui autoriserait le Conseil fédéral à régler la question des assainissements par voie d'ordonnance.

Le 25 octobre 1938, la Commission fédérale des banques transmet tout le dossier au Département des finances sans prendre position en faveur de l'une ou l'autre alternative. Elle insiste uniquement sur le caractère urgent de la question et la nécessité de mettre rapidement en branle les travaux législatifs ${ }^{166}$. Cet appel ne sera pas entendu. Malgré plusieurs relances, en décembre 1938, février 1939, puis en octobre 1939, le projet est toujours au point mort. D’après la $\mathrm{CFB}$, ce retard est dû à une situation où ni le Département des finances, ni celui de justice et police ne se sentent clairement responsables de l'avancement du projet.

Après trois courriers restés sans réponse, le Département des finances consent à s'expliquer le 27 octobre 1939. Rappelons qu'un changement à la tête du DFFD a eu lieu dans l'intervalle, puisque le conseiller fédéral démissionnaire Albert Meyer a été remplacé au I ${ }^{\text {er }}$ janvier 1939 par Ernst Wetter (I8771963), ancien vice-président du Vorort (1926-1938). La justification du long retard est relativement maladroite. Après avoir reconnu qu'une refonte de ce droit est souhaitable et utile, et que les travaux préparatoires sont de grande valeur, le conseiller fédéral Wetter ajoute que cette question n'est ni urgente ni impossible à différer. Le Zurichois mentionne ensuite la charge de travail excessive occasionnée par la réforme des finances fédérales, puis les tâches urgentes liées à la mobilisation, pour parvenir à la conclusion que «le temps de guerre actuel ne se prête pas à la création d'une nouvelle législation ${ }^{167}$. Au cours de la séance de la CFB qui suit, Schulthess dévoile plus en détail les appréhensions du DFFD. Ernst Wetter lui a expliqué que si un projet était alors présenté au parlement, on en viendrait probablement à une révision très étendue de la loi sur les banques ${ }^{168}$. Ce à quoi Schulthess lui aurait répondu qu'une révision dans quelques années serait probablement encore plus dangereuse. Le ministère des Finances craint donc qu'une modification mineure de la loi puisse se révéler très délicate. Malgré cette réticence du DFFD, la Commission fédérale

165 AFB, E6520(B) 2007/62, vol. 6I, Allgemeines, Korrespondenz, Bankensanierungen, «Bericht der Experten-Kommission zu den Entwürfen über die Neugestaltung der Sanierung und der Zwangsliquidation von Banken und Sparkassen ", 05.09.1938.

166 AFB, E652O(B) 2007/62, vol. 6I, Allgemeines, Korrespondenz, Bankensanierungen, Lettre de la CFB (Schulthess F Perren) au DFFD, 25.10.1939.

167 AFB, E652O(B) 2007/62, vol. 6I, Allgemeines, Korrespondenz, Bankensanierungen, Lettre d'Ernst Wetter (DFFD) à la CFB, 27.IO.1939.

168 AFB, E6520(A), I000/I059, vol. 7. PV CFB, 04.I2.1939, p. 159. 
des banques renouvelle sa demande visant à faire débuter rapidement les travaux législatifs. En mars-avril 1940, la question refait surface. D'un commun accord avec les membres de la "commission Haab", l'autorité de surveillance décide de transmettre au Département des finances la proposition de promulguer une loi de pleins pouvoirs (Ermächtigungsgesetz) qui autoriserait le Conseil fédéral à édicter par voie d'ordonnance de nouvelles dispositions qui unifieraient les procédures d'assainissements bancaires. Alors que la chose est presque décidée, le nouveau secrétaire de la CFB, Max Hommel (1902-1972), intervient et suggère de consulter d'abord les banques ${ }^{169}$. Schulthess lui donne raison et propose d'envoyer quelques invitations personnelles, par exemple à Adolf Jöhr, Max Staehelin, ainsi que des représentants des banques moyennes et cantonales. Une réunion est organisée les 4 et 5 juillet. Le cercle des invités, s'il a grandi en nombre, reste confiné aux grands dirigeants du monde bancaire, auxquels s'ajoutent les juristes de la commission Haab. Au total, sur vingt participants, l'on dénombre treize représentants des banques ${ }^{170}$. Leur réaction au projet d'arrêté du Conseil fédéral de la commission Haab visant à réviser le droit d'assainissement n'est pas enthousiaste. Adolf Jöhr estime que le moment est mal choisi pour une réforme de grande ampleur, que la promulgation d'une réglementation pourrait donner l'impression, en Suisse comme à l'étranger, que les banques se portent mal. Il suggère d'attendre et de mettre l'affaire de côté. Le directeur de la Basler Handelsbank, Emil Müller, le rejoint en déclarant que le projet est prématuré: «Die "Schublade" werde eine wohltätige Wirkung ausüben (le report du projet aurait un effet bénéfique). » ${ }^{171}$ Malgré ces réserves sur le principe, plusieurs modifications sont apportées au projet avant qu'il soit en effet rangé dans les tiroirs de l'administration.

Pendant le printemps 1942, l'arrêté du Conseil fédéral du 17 avril 1936 est donc prolongé pour la troisième fois, avec une modification mineure. Malgré l'opposition de la BNS, la Commission fédérale des banques obtient une compétence supplémentaire, puisqu'elle devient l'instance responsable d'accorder le sursis bancaire, au détriment des instances juridiques cantonales ${ }^{172}$. Lors de la dernière prolongation, en octobre 1944, la Commission fédérale des

169 AFB, E6520(A), I000/I059, vol. 8. PV CFB, 05.04.I940, p. 33. Cf. aussi AASB, Dossier 7I3 Eidg. Bankengesetz Jan. I940 - Juni 1948, Neuordnung des Bankensanierungsverfahrens.

170 En voici la composition exacte: Edmund Schulthess (préside les séances), Paul Rossy (BNS), Albert Caflisch (ASB), Paul Jaberg (UBS), Adolf Jöhr (CS), Max Staehelin (SBS), Charles Zoelly (I89I-I985, BF), Gustave Curchod (I886-1950, BCV), Heinrich Daeniker (ZKB), Rudolf Wittmer (BaKB), L. Jan (Caisse d'Épargne et de Crédit), Arthur Wolf (Banques locales), Johann Heuberger (I890-I950, Raiffeisen), Hermann Korrodi (Elektrobank), Emil Müller (BCB), Robert Haab (UniBa), Josef Henggeler, Arthur Homberger (UniBe), Albert Zust (CFB), Max Hommel (CFB). Excusés : Fritz Häfliger (I888-1975, Revisionsverband BE), Max E. Bodmer, Jean Lombard, Henri-Emmanuel de Roguin (I878-1949).

171 AFB, E6520(B) 2007/62, vol. 6I, Allgemeines, Korrespondenz, Bankensanierungen, "Neuordnung des Banken-Sanierungsverfahren. Protokoll der I. Konferenz», O405.07.1940, p. 8.

172 Cf. AFB, E6520(A), 1983/50, vol. 32, Sanierung von Banken. 
banques propose au Département des finances d'étendre l'arrêté pour une durée de quatre ans, estimant que ce délai sera suffisant, une fois la guerre terminée, pour faire aboutir les projets de pérennisation du droit d'assainissement datant de 1938 et de 1942 . Le Conseil fédéral décidera même d'une prolongation de cinq ans, jusqu'à fin 1949.

Dès novembre 1947, la question ressurgit sous la pression du parlement. La commission des pleins pouvoirs cherche en effet à abroger les décrets pris sous le régime des pleins pouvoirs. Se pose à nouveau la question de savoir ce que deviendra l'arrêté du Conseil fédéral du 17 avril 1936. Après avoir validé le principe selon lequel la procédure d'assainissement a fait ses preuves et doit être maintenue, la CFB explore trois pistes pour son maintien: soit la création d'une nouvelle loi sur la base de l'arrêté, soit l'intégration dans la loi bancaire via une révision partielle, soit enfin la reprise du projet de la commission Haab de juin 1940 et sa transformation en une loi ${ }^{173}$. C'est finalement l'option d'une nouvelle législation qui est choisie par les superviseurs. Après des négociations internes, un projet de loi est transmis à la Banque nationale et à l'Association suisse des banquiers le 7 juillet 1948. Les premiers retours de la part des banquiers sont plutôt positifs. Une réunion informelle tenue le 23 juillet arrive à la conclusion qu'il faut maintenir les précieuses dispositions sur l'assainissement bancaire d'avril 1936 au-delà de leur échéance fin 1949. Début septembre I948, la direction de la BNS prend également position: elle approuve le maintien d'une procédure d'assainissement pour les banques, et privilégie la forme juridique d'une nouvelle législation, estimant qu'il serait plus facile de limiter les discussions parlementaires que dans le cas d'une révision - même partielle - de la loi sur les banques ${ }^{174}$. Tous les voyants sont donc au vert pour l'aboutissement d'une normalisation du droit d'assainissement bancaire. C'était sans compter un revirement de la part de l'ASB. Le secrétaire de la CFB, Robert Reimann apprend par téléphone qu'au sein du Conseil d'administration de l'ASB de sérieux doutes sont émis quant à l'opportunité de toute l'opération. Les banquiers redoutent que même la discussion d'une nouvelle législation annexe au sein du Parlement puisse inciter certains députés (l'indépendant Gottlieb Duttweiler est nommément cité) à formuler des revendications dans le sens d'une révision de la loi sur les banques ${ }^{175}$. Les archives de l'ASB confirment le revirement. Au cours de la séance du 25 août 1948, c'est en particulier Peter Vieli (I890-1972), directeur général du Crédit Suisse, qui exprime sa volonté de laisser tomber les dispositions sur l'assainissement pour ne pas courir le risque d'ouvrir une boîte de Pandore. Son mot d'ordre est clair : «en aucun cas, la loi sur les banques ne doit être remise en question ${ }^{176}$. Un mois plus tard, le

173 AFB, E6520(B) 2007/62, vol. 6I, Allgemeines, Korrespondenz, Bankensanierungen, Lettre d'Eduard Kellenberger (secr. CFB) aux membres de la CFB, 24.I2.I947.

174 AFB, E6520(B) 2007/62, vol. 6I, Lettre de Paul Keller (BNS) à la CFB, 09.09.1948.

175 AFB, E6520(B) 2007/62, vol. 61, Aktennotiz de Reimann du 30.08.1948.

176 AASB, Procès-verbaux du Conseil d'administration de l'ASB, I87 séance, 25.08.1948, p. 5. Sur Peter Vieli, cf. Perrenoud, op. cit., 20II, p. 477-478. 
25 septembre le Conseil d'administration de l'ASB valide la décision selon laquelle il est préférable de laisser tomber les dispositions sur l'assainissement. Dans l'équation qu'il fallait résoudre, les dangers liés à une discussion politique d'un projet de droit bancaire ont pris le dessus sur le risque de voir une banque défaillante recourir aux instruments d'assainissement déficients de la loi sur les banques.

Quels sont ces "dangers» qui font figure d'épouvantails dans le débat politique d'une révision de la loi bancaire? Selon le président de la CFB et ancien ministre des Finances Ernst Wetter, les postulats indésirables pourraient concerner une étatisation du système de révision bancaire, qui serait la première étape vers une volonté de nationalisation du crédit ${ }^{177}$. Étant donné que les prises de position de la BNS et de l'ASB divergent sur la question, à savoir que les banquiers centraux sont favorables à une législation nouvelle qui conserverait la procédure d'assainissement, tandis que la faîtière des banquiers la rejette, la Commission fédérale des banques organise une réunion. Celle-ci a pour but non seulement de trouver un terrain d'entente, mais aussi de comprendre les véritables craintes de l'ASB, plus susceptibles d'être divulguées par oral ${ }^{178}$. Cette conférence a lieu le 3 décembre i948. Comme l'espéraient les superviseurs fédéraux, les motivations des banquiers pour refuser une pérennisation de l'assainissement bancaire apparaissent plus clairement. Le directeur de Banque cantonale de Zurich, Heinrich Daeniker distingue deux raisons principales:

Premièrement, nous émettons des réserves contre toute discussion parlementaire des dispositions de la loi sur les banques. En plus de la question de la nationalisation, la question du secret bancaire serait probablement soulevée. À cela s'ajoute que nous les banques nous sentons ces dernières années toujours sur la défensive. Deuxièmement, après examens, nous arrivons à la conclusion que cela ira aussi sans procédure d'assainissement particulière ${ }^{179}$.

La résistance des banques se cristallise donc autour de la discussion publique d'un projet qui pourrait déclencher une série d'interpellations encombrantes. Les banquiers estiment aussi qu'en cas de difficultés sérieuses provoquées par une nouvelle crise, on pourrait toujours ressortir les projets des tiroirs de l'administration et faire entrer en vigueur les dispositions en tant que droit d'exception. Face à ces arguments, la BNS se rétracte. Paul Rossy, avant de rendre les armes, souligne la faiblesse du raisonnement de l'ASB. Il estime au contraire que le moment est plutôt bien choisi pour introduire une loi sur l'assainissement bancaire, en l'absence d'une crise bancaire, et qu'il n'y aura jamais de moment idéal pour de telles dispositions. Si l'on ressort le projet au moment d'une crise, il provoquerait alors beaucoup plus de remous. Emil

177 AFB, E6520(A), 1000/I059, vol. 9, PV CFB, 05.04.1948, p. 21 ; 04.I0.1948, p. 92.

178 AFB, E6520(A), I00o/I059, vol. 9, PV CFB, 03.II.I948, p. I02.

$179 \mathrm{AFB}, \mathrm{E} 652 \mathrm{O}$ (B) 2007/62, vol. 6I, Bankensanierungsverfahren, Protokoll der Konferenz, 03.12.1948, p. 2. 
Müller, représentant de la Société de Banque Suisse, estime qu'en présentant un projet au parlement, on "lève un lièvre", et personne ne sait où l'affaire se terminera. L'ancien directeur général de la BNS, Ernst Weber (I88I-1967), nommé depuis 1947 à la CFB, le rejoint sur ce point: des postulats en vue de modifier le contrôle bancaire pourraient être posés. Se posant comme arbitre entre les avis divergents de l'ASB et la BNS, Ernst Wetter, déclare alors : « Nous autres à la Commission fédérale des banques sommes neutres dans cette affaire. J'ai une fois affirmé à $\mathrm{M}$. le directeur Daeniker que l'avis de l'Association des banquiers sera largement déterminant pour nous. Si nous faisons quelque chose, nous ne le faisons pas pour nous, mais pour les banques. " ${ }^{180}$ À l'issue de la réunion du 3 décembre 1948 , l'affaire est entendue. La Banque nationale n'insiste pas, et la CFB penche en faveur de l'ASB et ne veut pas courir le risque d'une discussion de la réglementation bancaire au sein d'un parlement dans lequel, selon son président Ernst Wetter, les partisans d'une économie libre ont perdu en importance. La décision est actée lors de la séance de la CFB du 3I janvier 1949: en plus des critiques des banquiers qu'il juge pertinentes, Wetter estime que la promulgation d'une nouvelle législation ne serait qu'un rafistolage (Flickwerk) ${ }^{181}$. Une telle solution de dépannage serait plus simple à imposer dans l'urgence, au moment où une crise bancaire surgit. L'arrêté du Conseil fédéral du 17 avril 1936 sur l'assainissement des banques expire donc dans l'indifférence générale à la fin de l'année 1949. Malgré de longs efforts concrétisés par plusieurs projets de loi et d'amendements produits par des commissions d'experts en 1938 et I940, l'autorité de surveillance ne parvient pas à imposer un transfert dans le droit ordinaire des dispositions sur l'assainissement bancaire. Une situation désordonnée persiste, héritée du caractère improvisé qui avait marqué l'introduction tardive et au coup par coup, dans les années 1934-1936, des mesures en faveur des banques défaillantes. Trois types de moratoires différents et deux procédures de liquidation concurrentes sont maintenus.

À la lumière des éléments mis à jour, il est possible de préciser l'interprétation que Hugo Bänziger, jusqu'ici le seul à avoir abordé la question, a donnée de l'échec de la tentative de légiférer sur cette question. Il estime, dans une formule lapidaire, que la Commission fédérale des banques « s'est brisée contre des obstacles politiques » ${ }^{182}$. Si les raisons qui ont motivé l'abandon du projet sont bien d'ordre politique, elles ne doivent en revanche rien aux politiciens ni au monde politique. Grâce à la diligence de l'autorité de surveillance, qui se fait le relais des intérêts bancaires, la question ne parvient même pas jusqu'à la sphère de décision du ministère des Finances, et encore moins jusqu'au parlement. En cherchant d'abord à repousser la prise de décision, en 1938-1940, puis en avortant toute l'entreprise en I948, les autorités fédérales ont surtout pris en

180 AFB, E6520(B) 2007/62, vol. 6I, Bankensanierungsverfahren, Protokoll der Konferenz, 03.12.1948, p. 5 .

181 AFB, E6520(A), I000/1059, vol. 9, PV CFB, 31.01.1949, p. 3-4.

182 Bänziger, op. cit., 1986, p. 176. 
compte les craintes, fondées ou non, des milieux bancaires de rouvrir le dossier «législation bancaire». Ce mécanisme est d'autant plus remarquable qu'il ne s'agissait pas de mesures liberticides visant à resserrer le carcan réglementaire. Au contraire, les dispositions d'avril 1936 avaient été mises en place pour faciliter la réorganisation financière de la Banque Leu, et avaient depuis fait leurs preuves. Sur le fond, elles étaient donc plutôt bien accueillies par les banquiers. Leur résistance ne s'est manifestée qu'au moment où il s'est agi d'introduire ces dispositions dans une législation ordinaire, qui devait nécessairement passer devant le parlement.

En plus de révéler l'attitude conservatrice, c'est-à-dire attachée au maintien de l'ordre établi, de l'ASB à l'égard de la loi sur les banques de 1934 - une attitude qui deviendra un de ses leitmotive -, cet épisode dénote aussi une évolution au sein de la CFB. En effet, force est de constater qu'il y a un infléchissement notoire entre l'état d'esprit des superviseurs à la fin des années I930 et leur comportement dans l'après-guerre. En 1938-I940, au moment où prennent forme les premiers projets tangibles de pérennisation du droit d'assainissement bancaire, les membres de la Commission fédérale des banques, et en particulier son président Schulthess, sont les forces motrices du processus. Les démarches répétées auprès du Département des finances pour accélérer la mise en œuvre de la réforme en témoignent. En 1947-1948, lorsque la fin des pleins pouvoirs et l'expiration du droit d'urgence remettent la question sur le tapis, la position de la CFB est bien moins volontariste. C'est sans grands regrets qu'elle enterre tout le projet, à la suite des objections de l'association des banquiers.

Ce glissement en l'espace d'une dizaine d'années s'explique en partie par le renouvellement des personnalités à la tête de la CFB. Le président Ernst Wetter (1944-1950) et Max Hommel (secrétaire entre 1939 et 1946 puis membre) semblent plus conciliants et moins entreprenants que leurs prédécesseurs Schulthess et Rossy. Mais plus que les personnes, la modification du contexte est primordiale pour comprendre cette évolution. À la fin des années I930, le droit d'assainissement est d'une actualité brûlante; plusieurs procédures sont en cours ou à prévoir. Dans l'après-guerre, le soufflé est retombé. Il est beaucoup plus difficile de défendre un projet dont l'utilité immédiate n'est pas évidente. Dans ces circonstances, les craintes jouant sur la boîte de pandore que constituerait la discussion publique de dispositions de droit bancaire ont facilement pris le dessus sur les scrupules en faveur d'une clarification juridique.

Alors qu'une nouvelle commission spéciale en vue de réformer le droit d'assainissement sera mise en place dans le cadre de la révision de la loi sur les banques en 1971, il faudra attendre 2004 pour qu'une refonte du droit d'assainissement bancaire aboutisse ${ }^{183}$.

183 Ehrsam, art. cit., in Zulauf (éd.), op. cit., I985, p. II3 (Commission Egli en 1971); Urs W. Birchler, "L'évolution du secteur bancaire », in Werner Abegg (éd.), Banque Nationale Suisse 1907-2007, Zurich: Neue Zürcher Zeitung, 2007, p. 426-438, p. 432. Voir aussi Schipke, op. cit., 2015, p. 44-57; Ziegler-Peter, op. cit., 20I4, p. 123-I24. 


\section{VI.3. UNE COLLABORATION LABORIEUSE AVEC LA BANQUE NATIONALE SUISSE}

Dans les chapitres précédents, en particulier dans celui consacré à l'élaboration de la loi sur les banques, nous avons déjà souligné la position très particulière qu'occupe la banque centrale dans le régime de régulation de 1934. Sans répéter inutilement les éléments déjà avancés plus haut, il est nécessaire de récapituler brièvement les grandes lignes de cette évolution.

Souvenons-nous d'abord que la Commission fédérale des banques ne doit son apparition dans les projets de loi qu'au refus catégorique de la Banque nationale suisse d'endosser le rôle d'instance d'application de la loi. Au-delà de cette prise de position initiale de rejet de la supervision, on observe durant la phase d'élaboration de la loi un retrait progressif, mais marqué, de toute implication officielle de la BNS. Dans un premier temps, entre avril 1933 et septembre 1934, la banque centrale repousse la prise en charge de l'application et favorise la création d'une nouvelle institution. Il est à ce moment-là évident que l'institut d'émission y sera représenté d'une manière ou d'une autre. Les premiers projets de loi qui intègre une commission des banques mentionnent d'ailleurs explicitement la participation de représentants de la BNS, avant que cet alinéa ne soit supprimé. Malgré cette suppression, il reste certain pour la plupart des experts dans la préparation de loi, que la banque centrale s'associera activement aux opérations de l'autorité de surveillance. En septembre 1934, une nouvelle étape est franchie dans l'éloignement croissant des banquiers centraux. En juin 1934, un amendement du sénateur socialiste Emil Klöti qui demandait d'énoncer la participation à la CFB d'un membre de la BNS avait été repoussé. Le conseiller fédéral Albert Meyer avait alors ajouté qu'elle ne pouvait pas ne pas y être représentée ${ }^{184}$. En août 1934, le président de la Banque nationale, Gottlieb Bachmann, allait dans le même sens en pronostiquant que le Conseil fédéral nommerait de toute façon un représentant de la BNS ${ }^{185}$. Trois semaines plus tard, la direction de la BNS convient d'une prise de position différente. La discussion donne lieu à un débat interne qui voit s'opposer Gottlieb Bachman et Ernst Weber d'une part, qui proposent de refuser l'implication de la BNS, à Charles Schnyder de Wartensee d'autre part, quant à lui favorable à une participation à la $\mathrm{CFB}^{186}$. Les premiers l'emportent. Soutenue par le Comité de banque de la BNS, la direction générale informe le Département des finances, dans un courrier du 25 septembre 1934, qu'elle ne souhaite pas être représentée dans la Commission fédérale des banques, et propose au conseiller fédéral d'éluder la question si par hasard elle ressurgissait lors des débats

184 Bulletin sténographique officiel de l'Assemblée fédérale, Conseil des États, 19.06.1934, p. 264.

185 ABNS, I.3/I2I5, Protokoll der Kommission des Nationalrates zur Behandlung des Entwurfes zum Bundesgesetz über die Banken und Sparkassen, 24.08.1934, p. 155.

186 ABNS, Procès-verbaux de la Direction générale de la BNS, I3.09.1934, no 895, p. 933-937. 
parlementaires en cours ${ }^{187}$. Cette décision suscite d'ailleurs une certaine surprise et la réprobation à la fois des représentants des grandes banques (Jöhr et Staehelin) et du conseiller fédéral Albert Meyer ${ }^{188}$. Les uns craignent sans doute que des personnalités moins conciliantes envers le monde bancaire que celles de la $\mathrm{BNS}$ soient nommées à la $\mathrm{CFB}$, tandis que l'autre est déçu de voir sa marge de manœuvre dans la nomination ainsi restreinte.

En l'espace d'une année, les dirigeants de la banque centrale se sont donc progressivement mis à distance du nouvel organe prévu par la loi. Tout au long de ce processus, les mêmes raisonnements sont avancés pour légitimer cette position. La stratégie argumentative s'articule autour de trois axes. Premièrement, l'on fustige la trop grande responsabilité matérielle et morale qui résulterait d'une prise en charge de la surveillance. Dans son exposé initial à la commission du Conseil des États, le conseiller fédéral Jean-Marie Musy rapporte ce point de vue: "il serait dangereux de lui [la BNS] imposer des obligations qui, la chargeant d'une responsabilité matérielle très lourde, pourraient, le cas échéant, compromettre sa fonction principale» ${ }^{189}$. Ce type de raisonnement constitue en un sens le fil rouge de l'attitude de la banque centrale sur la question. Deuxièmement, les dirigeants de la banque centrale insistent sur les conflits d'intérêts qui pourraient résulter de la présence d'un membre de la direction générale de la BNS à la CFB. Ce dernier serait amené à dissimuler ou à divulguer à ses collègues des informations qu'il obtient grâce à ses fonctions de banquier central. Il y aurait ainsi une incompatibilité entre la supervision des banques et la politique monétaire. Troisièmement, la BNS cherche à éviter que la participation à la surveillance des banques ne remette en question la «relation de confiance» qu'elle a nouée avec ces mêmes établissements ${ }^{190}$. Autrement dit, devoir révéler des informations comptables au sein de la CFB, avec pour conséquence une éventuelle intervention corrective, pourrait être nuisible aux liens d'interdépendance développés entre la banque centrale et les banques commerciales.

Au moment où la Commission fédérale des banques entame son activité, en avril 1935, la rupture avec la Banque nationale est presque consommée. Au cours de la première séance de la CFB, le fossé se creuse. Il s'agit alors pour l'organe de surveillance de se faire une idée, dans les plus brefs délais, de la situation des banques suisses. Plus précisément, la CFB voudrait avoir des renseignements détaillés sur le degré d'engagement des grandes banques suisses dans les pays soumis à restriction de transfert. Gottlieb Bachmann, qui est

187 AFB, E6520(A), I000/I059, vol. 2, Lettre de la direction générale de la BNS au chef du DFFD, 25.09.1934.

188 ABNS, I.3/I215, Protokoll der Kommission des Ständerats zur Behandlung des Entwurfes zum Bundesgesetz über die Banken und Sparkassen, I5.IO.1934, p. 22-26.

189 AFB, E6520(A), I000/1059, vol. 4. PV de la première séance de la Commission du Conseil des États pour l'examen du projet de loi fédérale sur les banques et les caisses d'épargne, I3.02.1934, p. 8.

190 Cf. ABNS, Procès-verbaux de la Direction générale de la BNS, 13.09.1934, nº 895, p. 933-937. 
invité à cette séance inaugurale, douche rapidement les espoirs d'un échange d'information intense entre les deux institutions ${ }^{191}$. Il soutient que la BNS ne serait en mesure de transmettre à la CFB les informations qu'elle reçoit des banques conformément à la loi sur les banques qu'à deux conditions: sur demande du Conseil fédéral et surtout si les établissements concernés donnent leur accord à l'échange d'informations. Pour Bachmann, ces données sont exclusivement adressées à la BNS, qui doit en garantir la confidentialité. Cette interprétation est vivement contestée par l'ensemble des membres de la $\mathrm{CFB}$, selon lesquels le secret bancaire ne s'applique qu'à des personnes extérieures. Les superviseurs fédéraux estiment aussi que la procédure suggérée par Bachmann, à savoir une autorisation des banques et une intermédiation du Conseil fédéral, retarderait et rendrait inefficace l'intervention de la CFB. Mais le président de la BNS insiste:

Le point de vue selon lequel il n'existerait pas de devoir de confidentialité entre la Banque nationale et la Commission des banques ne peut être justifié ni par les termes de la loi, ni par se genèse. La loi a délibérément tracé une ligne de démarcation entre les deux institutions, ce qui est parfaitement fondé. La Banque nationale n'est pas une autorité de surveillance des banques ${ }^{192}$.

À la suite de ce premier différend, les deux instances vont s'adresser au Conseil fédéral pour tenter d'obtenir un soutien susceptible de convaincre leur antagoniste. Du côté de la BNS, on fait préparer un rapport juridique sur la question de la portée du secret bancaire auquel est soumise la Banque nationale. Selon ce rapport, seuls le Conseil fédéral et ses départements constituent des exceptions, et la CFB doit être considérée comme une tierce partie et n'a aucun droit pour exiger des renseignements. À nouveau, Charles Schnyder de Wartensee, à la tête du deuxième département de la BNS, défend une position plus consensuelle vis-à-vis de la $\mathrm{CFB}$ où siège désormais son ancien collaborateur Rossy. Pour lui, la BNS ne peut pas « renoncer à certaines concessions face aux demandes de la $\mathrm{CFB}{ }^{193}$. Mais Weber se range derrière Bachmann et la direction générale maintient ainsi sa position dure ${ }^{194}$.

La Commission fédérale des banques, pour sa part, cherche d'abord à pallier ce manque d'informations sur les grandes banques autrement. Elle s'adresse donc directement aux grandes banques, par un courrier daté du II mai 1935, ce qui suscite une certaine méfiance chez les établissements concernés. En outre, elle essaie infructueusement de prendre contact avec la BNS pour discuter de toute l'affaire. Après deux courriers restés sans réponse, la CFB décide de s'adresser au Département des finances pour se plaindre de l'attitude de la

191 AFB, E6520(A), 1000/1059, vol. 6. PV CFB, 08.04.1935, p. 6-I4.

192 AFB, E6520(A), I000/I059, vol. 6. PV CFB, 08.04.1935, p. I2.

193 ABNS, Procès-verbaux de la Direction générale de la BNS, 30.04.1935, nº 369, p. 487.

194 AFB, E6Ioo(A), Iooo/I9I4, vol. 8, dossier 69I. Lettre de la direction générale de la BNS

(Bachmann) au DFFD (Meyer), 27.04.1935. 
BNS, qu' elle juge déloyale ${ }^{195}$. Schulthess y fustige l'attitude des dirigeants de la BNS qui court-circuitent le dialogue, en avançant des arguments juridiques auprès du Conseil fédéral. Il invite le DFFD à jouer un rôle de médiateur entre les deux instances. Début juin, celles-ci se rencontrent à nouveau mais les fronts sont bloqués : le seul progrès obtenu alors par les superviseurs consiste en une déclaration commune de la BNS et de la CFB qui demande au Conseil fédéral une interprétation authentique de l'article 23 de la loi sur les banques ${ }^{196}$. Une interprétation authentique consiste en un document gouvernemental qui précise une éventuelle ambiguïté dans un texte de loi. En l'occurrence, l'explication requise permettrait à l'autorité de surveillance de s'adresser directement aux banques, sans passer par l'intermédiaire de la BNS ou d'un institut de révision. C'est chose faite le 8 juin, puisque le DFFD confirme officiellement cette interprétation de la loi ${ }^{197}$. Mais l'affaire n'en reste pas là. Le I8 juin I935, Rossy et Schulthess relancent le Conseil fédéral pour qu'il intervienne en leur faveur et force la main à la BNS. Cette lettre expose la situation de manière peu équivoque :

Nous constatons qu'à cause du refus de la Banque nationale de nous fournir les informations à sa disposition, nous sommes incapables d'évaluer les situations de manière exhaustive et de participer à la prise de décision. [...] Cette situation devrait presque sembler comique pour des personnes extérieures: que deux organismes officiels de la Confédération, qui ont tous deux pour tâche de superviser les banques, se privent mutuellement de leurs connaissances et informations ${ }^{198}$.

La démarche de la Commission fédérale des banques n'apporte pas de modifications substantielles. Mise à part l'interprétation authentique du Conseil fédéral contresignée par la CFB et la BNS, l'affaire ne débouche sur rien. Fin juin 1935, le suppléant de l'Administration des finances, Eduard Kellenberger, donne son avis au chef du DFFD Albert Meyer. Pour lui, la médiation du Département est très délicate, puisque chacune des parties impliquées est dans son bon droit. L'obstruction de la BNS est conforme à la loi, et les demandes de la CFB sont justifiées par l'état de crise du monde bancaire. Il déplore surtout le refus des banques de transmettre volontairement les informations requises par la CFB, une attitude que Kellenberger juge "navrante», et dont il déduit un manque de confiance regrettable à l'égard de la Commission fédérale des banques ${ }^{199}$. Pour le fonctionnaire, cette

195 AFB, E6Ioo(A), Iooo/1914, vol. 8, dossier 69I. Lettre de la CFB (Schulthess) au DFFD (Meyer), I6.05.1935.

196 ABNS, Procès-verbaux de la Direction générale de la BNS, 06-07.06.1935, nº 483, p. 623-629.

197 AFB, E6520(A), I000/1059, vol. 6. PV CFB, 15.06.1935, p. 73.

198 AFB, E6Ioo(A), Iooo/ı914, vol. 8, dossier 69I. Lettre de la CFB (Schulthess et Rossy) au DFFD (Meyer), 18.06.1935.

199 AFB, E6Ioo(A), I0oo/ı9ı4, vol. 8, dossier 69ı. Lettre d'Eduard Kellenberger (AFF) à Albert Meyer (DFFD), «Bemerkungen zur Sanierungs- und Fusionierungsaufgabe der eidgenössischen Bankenkommission », 20.06.1935. 
situation amène donc à un véritable cercle vicieux. Relevons enfin que la BNS elle-même rencontre alors de grandes difficultés pour obtenir de la part des banques des renseignements sur les avoirs des étrangers en Suisse susceptibles d'alimenter une statistique sur la balance des paiements suisses ${ }^{200}$.

Ce manque de confiance de la part des grandes banques se manifeste surtout chez deux instituts, le Crédit Suisse et la Société de Banque Suisse, qui, en mai 1935, refusent de renseigner la CFB sur la proportion d'engagements gelés dans les pays à restriction de transfert ${ }^{201}$. Il s'agit alors de ne pas créer un précédent en cédant facilement aux requêtes de l'autorité de surveillance. Ce n'est qu'en faisant pression au moyen de l'interprétation authentique du Conseil fédéral que les membres de la Commission fédérale des banques parviennent à briser l'omerta des deux plus grandes banques helvétiques. L'attitude du Crédit Suisse et de la Société de Banque Suisse se démarque sans doute de celle des autres grandes banques à cause de leur état de santé financière. Les autres grandes banques - Basler Handelsbank, Banque Fédérale, Banque Leu, Banque Populaire Suisse, Union de Banques Suisses - sont sur le point de demander une intervention des autorités publiques, sous la forme d'un moratoire ou de l'extension d'un crédit de la Caisse de prêts, ou y ont déjà fait recours. Il serait donc malvenu pour elles de refuser de délivrer des informations aux institutions censées les aider. Le Crédit Suisse et la Société de Banque Suisse peuvent en revanche se permettre de se montrer moins coopératifs. Ces deux banques jouent donc sur les divergences entre CFB et BNS pour préserver une certaine opacité sur les données comptables communiquées à l'autorité de surveillance.

La confrontation entre la Banque nationale et l'autorité de surveillance nouvellement créée trouve son origine dans un large faisceau d'explications. Il faut premièrement souligner la remarquable continuité de la position de principe de la banque centrale dans le dossier « contrôle bancaire ». Son attitude visant à refuser toute implication dans le rôle de gendarme des banques, exprimée dès les premiers avant-projets, l'avait d'abord conduite à proposer une instance alternative, avant de s'en exclure à la surprise des autres acteurs. L'attitude récalcitrante de printemps 1935 constitue en ce sens l'aboutissement d'un principe établi de longue date. D'autre part, il faut relever l'imprécision du texte de loi sur cette question. Alors que la BNS et le CFB reçoivent chacune des compétences bien définies dans la loi bancaire, aucune disposition ne clarifie les relations et interactions qui devaient s'établir entre elles. Cette lacune est sans doute due à la présomption - qui se révélera erronée - qu'un représentant de la banque centrale siègerait à la Commission fédérale des banques.

Mais le comportement peu conciliant de la BNS s'explique aussi par deux dimensions contextuelles qui alimentent les dissensions. La première est

200 Cf. Guex, Schaufelbuehl, art. cit., 20II, en particulier p. 1562-1563. Adolf Jöhr joue là aussi un rôle déterminant pour préserver une parfaite confidentialité des données sur les avoirs des étrangers.

201 AFB, E6520(A), 1000/1059, vol. 6. PV CFB, 15.06.1935, p. 73-76. Willi Loepfe, quant à lui, parle de la «sensibilité» des grandes banques sur cette question : Loepfe, op. cit., 2006, p. I79. 
relative à la carrière professionnelle de Paul Rossy. Ce personnage-clé du processus d'élaboration et d'exécution de la loi sur les banques navigue entre les deux institutions, qui se font concurrence pour obtenir ses services.

Né à La Chaux sur Cossonay (VD) en I896, Paul Rossy est engagé en I9I9 dans la banque privée bâloise A. Sarasin \& Cie après avoir obtenu une licence en sciences économiques à l'Université de Lausanne. Il rejoint la Banque nationale suisse comme collaborateur au bureau statistique en 192I. En 1926, il devient suppléant du secrétaire général, puis dès 1930, suppléant du directeur $\mathrm{du} 2^{\mathrm{e}}$ département. Sa carrière à la banque centrale semble alors prometteuse. Son profil de Romand bilingue disposant d'une formation adéquate en fait un candidat intéressant pour les plus hauts postes de la BNS ${ }^{202}$. En septembre I933, le conseiller fédéral en charge des finances Jean-Marie Musy obtient difficilement les services de Rossy et l'engage comme expert financier pour la rédaction des projets de loi sur les banques (cf. chap. III.3). Cette mission occupe l'économiste vaudois pendant près d'un an et demi, période durant laquelle il obtient un congé de son poste de directeur suppléant du $2^{\mathrm{e}}$ département de la BNS. Entre février et mars 1935, c'est cette fois le conseiller fédéral démissionnaire et futur président de la CFB Edmund Schulthess qui souhaite impliquer l'un des auteurs de la loi dans son instance d'application. Malgré une forte résistance de la part des autorités de la BNS, le congé de Paul Rossy est prolongé : il devient vice-président et chef du secrétariat de la nouvelle Commission fédérale des banques. Cet engagement est prévu comme provisoire. Mais cette situation ambiguë de congé prolongé déplaît aux dirigeants de la banque centrale. Elles posent alors un ultimatum à Paul Rossy: il doit définitivement choisir entre ses fonctions à la CFB et sa carrière à la BNS ${ }^{203}$. Fin juin 1935, Rossy se décide en faveur de la Commission fédérale des banques : «la comparaison entre ces deux fonctions m'oblige à constater que ma tâche à la commission des banques est indiscutablement plus importante que celle du suppléant du chef du deuxième département de la Banque Nationale »"04, écritil dans sa réponse à Gustav Schaller, président du Comité de banque de la BNS. Ce choix suscite une amère déception au sein de la BNS : on reproche à Rossy une forme d'ingratitude, puisque l'institut d'émission s'était donné beaucoup de peine pour le former et ainsi amener un Romand à la direction générale. En août I935, l'affaire rebondit encore, car la banque centrale demande à Rossy de

202 C'est du moins ce que révèlent les notes d'un membre du Foreign \& Overseas Department de la Banque d'Angleterre (probablement Charles A. Gunston) : "while it is necessary for political reasons to have a fair proportion of French-Swiss in all grades at the National Bank, it is difficult to find competent French-Swiss who know German and are in addition prepared to accept low salaries which the higher posts in the National Bank carry compared with those in private banks». BoE Archive: OV 63/24, "Swiss National Bank: presidency and other posts", 29.II.I937.

203 ABNS, 8.0/8037, Personaldossier Rossy, Dossier Experte/Berater in der eidg. Bankenkommission, 1935-1938, lettre du Comité de banque de la BNS à Paul Rossy, 20.06.1935.

204 ABNS, 8.o/8037, Personaldossier Rossy, Dossier Experte/Berater in der eidg. Bankenkommission, I935-I938, copie de la lettre de Paul Rossy à Gustav Schaller, 23.06.1935. 
donner sa démission du poste de directeur à la BNS. En effet, elle ne peut pas le licencier sans raison valable. Rossy accepte ces conditions et s'exécute. Dans sa réponse à la direction générale du 9 septembre 1935 , il ajoute encore :

Mon départ de la Banque m'est rendu singulièrement difficile par le fait que, comme vous le savez, depuis un certain temps déjà, je ne puis malheureusement plus souscrire à votre politique monétaire. J'aurais aimé que nos divergences de vues puissent se régler strictement à l'intérieur même de la Banque au cours d'entretiens libres entre gens de la même maison ${ }^{205}$.

Le destin personnel de Paul Rossy symbolise et amplifie les animosités entre les deux instances qui se disputent ses services. Avec cette démission forcée, l'un des derniers points de contact était rompu.

La citation de la lettre de Rossy de septembre 1935 nous amène à la seconde dimension contextuelle de la confrontation entre la CFB et la BNS. En effet, les « divergences de vues » que mentionne l'économiste vaudois font référence à la politique de déflation et au maintien du franc-or. En effet, selon les observateurs de la Banque d'Angleterre, Rossy aurait quitté la BNS à cause de profonds désaccords sur la politique monétaire ${ }^{206}$. Le tandem qu'il forme avec Edmund Schulthess à la tête de l'autorité de surveillance de banques est d'ailleurs considéré comme l'auteur des premières prises de position publiques provenant des milieux bourgeois ouverts à une éventuelle dévaluation du franc suisse ${ }^{207}$. Dès l'automne 1935, les dirigeants de la Commission fédérale des banques font figure de partisans déclarés d'une dévaluation monétaire vigoureusement combattue par la BNS ${ }^{208}$. Leurs positions qui vont à contre-courant de la pensée dominante suscitent des réactions: l'Association pour une monnaie saine ${ }^{209}$ écrit au Conseil fédéral pour demander la démission de Schulthess ${ }^{210}$. Dès la fin de l'année 1935, le président de la CFB est attaqué par certains membres du Comité de banque de la BNS. C'est en particulier le représentant de l'industrie chimique bâloise Carl Koechlin (I889-1969), directeur de Geigy S.A., qui demande à la direction générale de la BNS d'intervenir auprès du Conseil fédéral pour l'avertir du mécontentement que suscite le positionnement de Schulthess auprès d'un grand nombre de décideurs économiques. Cette longue diatribe mérite d'être citée abondamment:

205 ABNS, 8.o/8037, Personaldossier Rossy, Dossier Experte/Berater in der eidg. Bankenkommission, 1935-1938, lettre de Paul Rossy à la direction générale de la BNS, 09.09.1935.

206 BoE Archive, OV 63/24, "Swiss National Bank: presidency and other posts", 29.II.1937. « Rossy [...] left the National Bank in (?) I934 because he disagreed with Bachmann's policy of deflation and staying on gold.".

207 Müller, op. cit., 2010, p. 696-697.

208 Bordo, James, art. cit., in Abegg (éd.), op. cit., 2007, p. 69-70.

209 Fondé en avril 1934, ce groupe de pression réunit « les adeptes les plus décidés du franc-or». Sur la genèse, le rôle et la composition de cette association : Müller, op. cit., 20Io, p. 669-675.

210 Ibid., p. 696. 
Il est connu que les milieux des assurances, des banques cantonales, des autres banques, ainsi que l'industrie d'exportation sont très inquiets de la prise de position du président de la Commission fédérale des banques, l'ancien conseiller fédéral Schulthess, en matière de politique monétaire et des compétences de la Commission des banques. Si cet organisme officiel défend publiquement le point de vue que le franc suisse ne peut plus être maintenu, qu'il doit être dévalué, on ne peut plus attendre des milieux mentionnés, qui ont jusqu'à maintenant soutenu la Banque nationale dans sa mission, qu'ils se rangent encore sous les drapeaux. [...] La Commission des banques a été créée pour apporter un certain calme et de la stabilité dans le secteur bancaire. Son activité a jusqu'à maintenant eu l'effet inverse. [...] Il est tout simplement tragique que M. l'ancien conseiller fédéral Schulthess, après avoir rendu de grands services au pays dans des temps difficiles, soit désormais, par sa nomination à la présidence de la Commission des banques, placé à un poste qui ne correspond ni à son tempérament ni à son caractère et, eu égard aux directives équilibrées établies par le législateur, ne pourra jamais lui correspondre ${ }^{211}$.

Mais la direction générale refuse d'entreprendre des démarches auprès du gouvernement, jugeant que le conseiller fédéral Albert Meyer est déjà au courant de cette situation épineuse. Bachmann ajoute alors que «les divergences de vues en matière de politique monétaire compliquent considérablement la collaboration de la direction générale avec la Commission fédérale des banques ${ }^{212}$. Après cet échec, Koechlin poursuit ses efforts d'attaques contre Schulthess deux jours plus tard, cette fois auprès des dirigeants l'USCI, la grande faîtière de l'économie suisse. Il demande au Vorort d'intervenir auprès du Département des finances pour demander un renouvellement de la CFB, et en particulier le remplacement de son président ${ }^{213}$. Là aussi, le président Hans Sulzer (1876-1959) refuse de donner suite, estimant que ce genre de démarches n'entre pas dans son domaine d'activité.

L'escarmouche se poursuit en janvier 1936 par la publication d'un article qui attaque Schulthess et toute la CFB dans les Basler Nachrichten ${ }^{214}$. On leur reproche d'avoir suscité " une vague d'insécurité et de méfiance » ${ }^{215}$. Le président du Comité de banque de la BNS, Gustav Schaller, obtient d'Albert Meyer qu'il réprimande l'homme d'État argovien et l'enjoigne à renoncer à des déclarations publiques allant à l'encontre de la politique monétaire suivie par la BNS ${ }^{216}$.

211 ABNS, Procès-verbaux du Comité de banque de la BNS, I8.I2.1935, p. 4I7-4I8.

212 ABNS, Procès-verbaux du Comité de banque de la BNS, I8.I2.1935, p. 4 I8.

213 Archiv für Zeitgeschichte, IB Vorort-Archiv / I.5.3.8. Protokolle (Typoskripte) I93I - I934, séance du 20.12.1935, p. 6.

214 Sur ce quotidien bâlois, voir : Rahel Walser, «Der edle Tropfen der Oberschicht : die Basler Nachrichten", in Walter Rüegg (éd.), Herausgefordert: die Geschichte der Basler Zeitung, Basel : Christoph Merian Verlag, 20I2, p. 13-36; David Tréfás, Kleine Basler Pressegeschichte, Basel: Schwabe Verlag, 2016, p. 37-39, 49-52, 57-65.

215 [s.n.], "Bankenkommission », Basler Nachrichten, 07.0I.1936.

216 ABNS, Procès-verbaux du Comité de banque de la BNS, 22.0I.1936, p. 38. 
Malgré ces tentatives de censure, Schulthess publie en janvier et avril 1936, ses «idées sur la politique financière et économique», dans lesquelles il prend position en faveur d'une dévaluation ${ }^{217}$. En juin 1936 , c'est cette fois au Conseil de banque de la BNS que le président de la CFB est malmené. Mais d'autres milieux sont à l'origine des critiques, puisqu'elles proviennent essentiellement du député socialiste saint-gallois Johannes Huber (I879-I948) et, dans une moindre mesure, du conseiller national PAB Gottfried Gnägi (I878-1939). Ceux-ci proposent que la Banque nationale intervienne auprès du Conseil fédéral et lui demande d'exercer une influence sur Schulthess pour qu'il mette un terme à la "propagation de ses idées " ${ }^{218}$. Mais Bachmann refuse à nouveau toute intervention, pour éviter de jeter de l'huile sur le feu : « les relations intenses avec la Commission des banques forcent la direction générale à faire preuve de retenue ${ }^{219}$.

Ce n'est au fond qu'avec la dévaluation du franc suisse, décidée par le Conseil fédéral dans la foulée de la dépréciation du franc français le 26 septembre 1936, que l'animosité entre la banque centrale et l'autorité de surveillance se dissipera ${ }^{220}$.

En juin 1937, la nomination de Rossy comme directeur général et chef du $2^{\mathrm{e}}$ département de la BNS marque une étape supplémentaire dans la normalisation des relations entre la CFB et la banque centrale. Les circonstances particulières qui entourent ce choix méritent que nous ouvrions une courte parenthèse. Après l'ultimatum posé par les instances dirigeantes de la BNS, Rossy avait décidé à l'été 1935 de rester à la CFB et de démissionner de son poste à la banque centrale, pour lequel il avait jusqu' alors obtenu un congé prolongé. En novembre 1936, au moment où Charles Schnyder de Wartensee annonce son intention de quitter son poste de vice-président et directeur du $2^{\mathrm{e}}$ département de la BNS, Rossy se porte candidat. Plus précisément, il se pose en candidature alternative à celle de Victor Gautier, son remplaçant au poste de suppléant qui bénéficie du soutien du président de la banque Gottlieb Bachmann. Cette contre-candidature n'est pas du goût de la majorité des dirigeants de la banque centrale, qui tentent alors de montrer que Rossy avait renoncé à toute prétention pour ce poste en quittant la banque en 1935. Mais Rossy insiste.

Des circonstances exceptionnelles vont ensuite favoriser son élection à la vice-présidence ${ }^{221}$. En effet, dans le cadre de la procédure de liquidation de la

217 "Gedanken über Finanz- und Wirtschaftspolitik», cf. Böschenstein, op. cit., 1966, p. 189193.

218 ABNS, Procès-verbaux du Conseil de banque de la BNS, 27.06.1936, p. 85-88.

219 ABNS, Procès-verbaux du Comité de banque de la BNS, II-I2.08.I936, p. 324.

220 Sur la dévaluation du franc suisse de 1936: Müller, op. cit., 20Io, p. 645-735. Pour une comparaison des dévaluations en Belgique, aux Pays-Bas et en Suisse: Straumann, op. cit., 2010, p. 126-169.

221 L'affaire est documentée dans deux dossiers conservés aux archives de la BNS. ABNS, Dossier "Correspondances autour de la Banque d'escompte de Genève ", 1937; ABNS, 8.o/8037, Personaldossier Rossy, "Wahl zum Vorsteher des II. Departments, I936-I937». 
Banque d'Escompte Suisse, Rossy, qui fait partie de la commission chargée d'étudier les responsabilités civiles dans cette affaire, découvre en février 1937 au cours de ses enquêtes que son concurrent Gautier est mêlé aux difficultés qui ont entrâ̂né la faillite de l'établissement. Gautier, ancien dirigeant de l'Union financière de Genève, est accusé d'avoir non seulement joué un rôle important dans les mauvais choix opérés par la banque avant la crise, mais surtout de ne pas avoir fait preuve de la plus grande honnêteté lorsque la Confédération s'est engagée à soutenir la Banque d'Escompte. Lorsqu'il découvre ces agissements, Rossy feint de vouloir interrompre ses travaux dans la commission de liquidation, face au conflit d'intérêts dans lequel il est pris. Mais, sur conseil de Schulthess, il poursuit tout de même son enquête. L'ancien conseiller fédéral argovien, tenu au courant par son protégé Rossy, va alors agir pour soutenir sa candidature au poste de vice-président de la BNS, au détriment de Gautier. Le 3I mai 1937, Schulthess écrit à tous les conseillers fédéraux pour leur signaler les erreurs dans la gestion de Gautier. Ses interventions, ainsi que la gravité des faits dont on accuse le libéral genevois, vont l'emporter. Avec un brin de dépit, le directoire et le Comité de banque de la BNS décident le 9 juin de soutenir la candidature Rossy, et le Conseil fédéral suit cet avis ${ }^{222}$. Rossy entre en fonction en tant que chef $\mathrm{du} 2^{\mathrm{e}}$ département et vice-président de la BNS à l'été 1937 , tandis que Gautier est transféré au $\mathrm{I}^{\mathrm{er}}$ département et y devient directeur suppléant. En effet, sans cette mutation, Gautier aurait été sous les ordres de son fossoyeur et concurrent Rossy.

On aurait pu croire que le retour de Rossy aurait signifié la concrétisation de l'intention des législateurs de voir un dirigeant en activité de la banque centrale siéger à la Commission fédérale des banques. Il n'en est rien. En effet, le Conseil de banque de la BNS, au moment de recommander au Conseil fédéral la candidature de Rossy le I8 juin 1937, avait posé comme condition que celui-ci renonce à son activité à la CFB et en démissionne ${ }^{223}$. Les protestations des quatre autres membres de l'autorité de surveillance n'y changeront rien: au-delà d'une courte période transitoire qui doit servir à régler les affaires importantes en cours, Rossy doit quitter la Commission fédérale des banques.

Il n'en reste pas moins que la présence d'un ancien de la CFB à la tête de la banque centrale va réchauffer les relations entre les deux instances. C'est peutêtre sous l'effet de la présence de Rossy à la direction générale que Schulthess tente de relancer la question de la transmission des bilans en novembre I938. Il aurait souhaité que la BNS, si elle découvre des irrégularités dans les bilans

222 Les rapports de l'Overseas \& Foreign Department de la Banque d'Angleterre confirment cette nomination singulière : « Rossy, now 4I, was appointed Vice-President by the Government in succession to Schnyder last June. His appointment was opposed by the National Bank (i.e. at that time Bachmann and Schnyder, since Weber, I think, was certainly for Rossy). The National Bank wished to appoint Gautier (see below) instead of Rossy, but the Government overruled them ». BoE Archive, OV63/24, "Swiss National Bank: presidency and other posts ", 29.II.I937.

223 ABNS, 8.o/8037, Personaldossier Rossy, copie du procès-verbal du Conseil fédéral, I6.07.1937. 
Figure 2. Carrière professionnelle de Paul Rossy (I896-I973)

\begin{tabular}{|c|c|}
\hline 1917 & $\begin{array}{l}\text { Licence en sciences commerciales et en science politique à l'Université de } \\
\text { Lausanne. }\end{array}$ \\
\hline octobre I9I9 & $\begin{array}{l}\text { Banquier auprès de la Banque A. Sarasin \& Cie à Bâle, en particulier dans le } \\
\text { domaine des titres }\end{array}$ \\
\hline novembre I92I & Collaborateur au bureau statistique de la Banque nationale suisse \\
\hline 1926 & Suppléant du secrétaire général de la BNS \\
\hline juin 1930 & Suppléant du directeur du $2^{\mathrm{e}}$ département (Charles Schnyder de Wartensee) \\
\hline novembre 1933 & $\begin{array}{l}\text { Expert financier du Département des finances et des douanes (élaboration de la } \\
\text { loi sur les banques) }\end{array}$ \\
\hline mars 1935 & $\begin{array}{l}\text { Vice-président et chef du secrétariat de la Commission fédérale des banques } \\
\text { (nomination par le Conseil fédéral). Congé accordé par la BNS }\end{array}$ \\
\hline septembre 1935 & Démission du poste de directeur-suppléant à la BNS \\
\hline novembre 1936 & Candidature au poste du directeur du $2^{\text {e }}$ département de la BNS \\
\hline juin 1937 & $\begin{array}{l}\text { Directeur général du } 2^{\mathrm{e}} \text { département de la BNS (nomination par le Conseil } \\
\text { fédéral); Démission de la Commission fédérale des banques }\end{array}$ \\
\hline 1950-1955 & Membre du comité de direction de l'Union européenne des paiements \\
\hline juin 1955 & $\begin{array}{l}\text { Démission de la direction générale de la BNS, officiellement pour raisons de } \\
\text { santé. Rossy accepte dès lors divers mandats d'administrateur dans l'économie } \\
\text { privée, notamment la présidence de la Société financière Italo-suisse }\end{array}$ \\
\hline décembre 1956 & $\begin{array}{l}\text { Membre de la Commission fédérale des banques (nomination par le Conseil } \\
\text { fédéral) }\end{array}$ \\
\hline décembre 1966 & Départ de la Commission fédérale des banques (atteinte de la limite d'âge) \\
\hline
\end{tabular}

Sources: ABNS, 8.o/8037, Personaldossier Rossy; Sarah Brian Scherer, "Rossy, Paul», in Dictionnaire historique de la Suisse, vol. Io, Hauterive: Attinger, 20II, p. 604.

intermédiaires qu'elle reçoit à des fins statistiques, avertisse la CFB pour que celle-ci puisse intervenir plus rapidement. L'affaire suscite cette fois un débat plus important au sein de la direction générale de l'institut d'émission ${ }^{224}$. Sans surprise, Bachmann et Weber maintiennent leur position de fermeté à l'égard de la requête de Schulthess, tandis que Rossy se montre plus ouvert. Il estime que la BNS a un devoir moral d'informer la CFB si elle apprend qu'une banque est dans une situation critique. Il ajoute à l'argument moral une menace concrète, en annonçant l'intention de Schulthess de provoquer une interprétation authentique de la question par le biais d'une interpellation parlementaire, si le contentieux ne peut pas être réglé à l'amiable. Il stigmatise enfin l'insuffisance du système en place:

La situation actuelle est insatisfaisante. La Banque nationale, qui n'a rien à voir avec les assainissements bancaires, reçoit des informations bilancielles à partir desquelles elle ne peut certes pas tout voir, mais qui

224 ABNS, Procès-verbaux de la Direction générale de la BNS, 24.II.1938, nº 929, p. I210-I212 ; 30.II-OI-O2.I2.I938, $\mathrm{n}^{\circ}$ 958, p. I254-I258. 
pourraient au moins donner quelques indices. La Commission des banques, qui doit préparer et mener à bien les assainissements, n'a pas les moyens d'intervenir à temps. Il s'agit là d'une situation qui ne satisfait pas le législateur et ne peut pas être comprise dans la population. Il faut donc mettre un terme à cet état des choses. Car la Banque nationale, la Commission des banques et le Conseil fédéral devraient faire une triste figure, si l'on pouvait prouver dans le cas d'un krach bancaire que la mauvaise situation aurait pu être détectée de longue date grâce aux bilans reçus par la Banque nationale ${ }^{225}$.

Mais les efforts de Paul Rossy et d'Edmund Schulthess demeurent infructueux. Bachmann et Weber parviennent à imposer la décision majoritaire d'en rester au statu quo. La Banque nationale suisse ne transmettra à la CFB aucune donnée provenant des bilans qu'elle reçoit conformément à la loi bancaire, à moins que l'établissement concerné ne l'y autorise expressément. La seule échappatoire que propose la direction générale de la BNS est d'inciter la Commission fédérale des banques à réclamer directement aux banques une déclaration de principes générale, selon laquelle les révisions bancaires effectuées jusque-là n'auraient rien mis à jour qui ne soit digne d'être communiquéà la $\mathrm{CFB}^{226}$. La seconde tentative d'obtenir une collaboration de la banque centrale dans le diagnostic des banques défaillantes se solde aussi par un échec. En dernière analyse, la politique d'obstruction de la BNS profite aux banques commerciales qui gardent un contrôle rigoureux sur les données comptables qu'elles notifient à l'autorité de surveillance.

Passée la période de mise en place de la Commission fédérale des banques, ses relations avec la BNS se normaliseront. La division du travail et les compétences respectives des deux instances dans la mise en application de la loi sur les banques sont acceptées tacitement, sans qu'une institutionnalisation de cette répartition des pouvoirs ne sanctionne l'état de fait. L'accalmie qui se manifeste sur le front de la crise bancaire dès le début des années 1940 provoque également une amélioration des relations, puisque la collaboration devient moins nécessaire et moins urgente. Dans sa publication jubilaire célébrant son demi-siècle d'existence, la banque centrale présente la CFB de la manière suivante : "Cette commission se tient en contact étroit avec la Banque Nationale, qu'elle met au courant de ses décisions essentielles, et dont elle requiert le préavis toutes les fois qu'il s'agit de questions auxquelles la Banque est intéressée. "227 Il est permis, en regard des éléments discutés plus haut, de relativiser l'étroitesse des contacts entre les deux instances, du moins pour la période 1935-1940.

Du point de vue des imbrications de trajectoires personnelles entre la CFB et la BNS, on constate également un certain rapprochement. La Commission fédérale des banques devient dans l'après-guerre un lieu de pré-retraite

225 ABNS, Procès-verbaux de la Direction générale de la BNS, 30.II.1938, n ${ }^{\circ}$ 958, p. 1257.

226 ABNS, Procès-verbaux de la Direction générale de la BNS, 08.12.1938, $n^{\circ}$ 971, p. I274.

227 Emil Mosimann (éd.), Banque nationale suisse 1907-1957, Zurich: Banque nationale suisse, 1957, p. 244. 
privilégié pour d'anciens directeurs généraux de la banque centrale. Ernst Weber (1947-1953), Alfred Hirs (1954-I959), Paul Rossy (I957-I966), Riccardo Motta (président 1966-1973) y seront élus par le Conseil fédéral immédiatement après leur départ de la BNS. Alors que d'autres anciens collaborateurs de la banque centrale, comme Rudolf Pfenninger (1967-1972) ou Arnold Rösselet (1971-1976), sont également élus dans un second temps à la CFB, il faut attendre la nomination de Paul Ehrsam (1976-1987) pour voir un membre actif de la BNS siéger à la Commission fédérale des banques.

Ces fréquents passages de l'institut d'émission vers l'autorité de surveillance n'impliquent pourtant pas une nette amélioration de l'échange d'informations entre les deux instances. En 1960 encore, la transmission de données est refusée, au motif de la préservation du secret bancaire ${ }^{228}$. Ce n'est qu'au début des années 1980 que la collaboration entre la CFB et la BNS est formalisée. Cette institutionnalisation, accompagnée d'analyses statistiques communes, se matérialise par des rencontres semestrielles entre dirigeants de deux instances ${ }^{229}$. Mais il semble que, là aussi, la collaboration ne soit pas entière. En 1995, le professeur de droit membre de la Commission fédérale des banques Peter Nobel (I945-) estimait encore "qu'une coopération institutionnalisée entre la BNS et la CFB serait souhaitable ${ }^{230}$.

En guise de conclusion de ce chapitre, rappelons que la posture de la Banque nationale suisse consistant à opposer une fin de non-recevoir aux tentatives de l'impliquer, même très partiellement, dans la tâche du contrôle bancaire étatique, n'est de loin pas la norme en comparaison internationale. Au contraire, de nombreuses législations bancaires en vigueur dans les années 1930 prévoyaient un rôle plus ou moins étendu pour la banque centrale dans le dispositif de contrôle. Le cas italien est sans doute celui qui pousse le plus loin l'imbrication des fonctions de supervision au sein de la banque centrale ${ }^{231}$. Selon la loi italienne de 1936, un Ispettorato per la difesa del risparmio e l'esercizio del credito

228 AFB, E6520(A), I000/1059, vol. I2, PV CFB, 22.01.1960, p. 35, I6.02.1960, p. 56-57.

229 Urs W. Birchler, «L'intérêt croissant de la Banque nationale pour la stabilité systémique », in Werner Abegg (éd.), Banque Nationale Suisse 1907-2007, Zurich : NZZ, 2007, p. 413-417, p. 416.

230 Peter Nobel, «Nationalbank und Bankenkommission : Unterschiede und Gleichschritt », in Andreas Brandenberg (éd.), Standpunkte zwischen Theorie und Praxis. Handlungsorientierte Problemlösungen in Wirtschaft und Gesellschaft, Bern/Stuttgart/Wien: Paul Haupt, 1995, p. $467-493$, p. 488.

231 Sur l'histoire de la supervision bancaire italienne, voir notamment: Fabio Merusi, «I tratti peculiari dell'ordinamento creditizio italiano nella comparazione con le leggi bancarie degli anni Trenta ", in Banca e industria fra le due guerre. Le riforme istituzionali e il pensiero giuridico, Bologna : Il Mulino, vol. 2, 198I, p. 335-348; Pierluigi Ciocca, Gianni Toniolo, «Industry and Finance in Italy, 1918-1940", Journal of European Economic History, vol. I3, n ${ }^{\circ}$, 1984, p. I13136; Sabino Cassese, "The Long Life of the Financial Institutions Set up in the Thirties", ibid., p. 273-294; Alfredo Gigliobianco, Claire Giordano, Gianni Toniolo, «Innovation and Regulation in the Wake of Financial Crises in Italy (I88os-1930s)», in Alfredo Gigliobianco, Gianni Toniolo (éd.), Financial Market Regulation in the Wake of Financial Crises: The Historical Experience, Roma: Banca d'Italia Eurosistema, 2009, p. 45-74; Barbiellini Amidei, Giordano, art. cit., in Clement, James, Van der Wee (éd.), op. cit., 2014. 
est créé, placé sous l'autorité de la Banca d'Italia, dont le gouverneur préside simultanément l'Ispettorato. Aux Pays-Bas (I948-1952) et en France (I945), des agencements proches confient une place prépondérante aux dirigeants de la banque centrale dans les organes de contrôle prudentiel étatiques ${ }^{232}$. Selon un spécialiste de la question, sur i8 pays industrialisés, dix ont donné des pouvoirs formels de supervision à la banque centrale ${ }^{233}$. On peut ajouter à ces cas les configurations hybrides, comme en Belgique (I935), dans lesquelles l'instance de supervision est formellement autonome de la banque centrale, mais qu'un dirigeant de la Banque nationale de Belgique y siège systématiquement ${ }^{234}$.

Il semble donc bien que l'attitude de refus de la Banque nationale suisse fasse plutôt figure d'exception. L'historien-économiste Richard Grossman, dans son modèle cherchant à établir une corrélation entre la date de fondation d'une banque centrale et la date d'attribution de compétences de supervision, peine d'ailleurs à y faire entrer la BNS. En effet, le cas suisse ne répond pas à la tendance selon laquelle les banques centrales les plus jeunes se voient octroyer plus fréquemment des responsabilités formelles de contrôle prudentiel. Notre analyse permet de préciser l'hypothèse de Grossman, qui dans le cas suisse ne fonctionne précisément pas. Ce n'est pas seulement parce que sa création a été retardée à la fin du XIX siècle à cause de l'échec en votation populaire du projet de banque d'État que la BNS détonne dans le paysage des banques centrales dressé par Grossman. C'est aussi parce qu'en 1933-I934, au moment où elle aurait pu obtenir des responsabilités dans la surveillance des banques, la BNS a délibérément repoussé toutes les propositions d'implication dans cette tâche.

232 Sur le contrôle des banques aux Pays-Bas : Joke Mooij, Henriëtte Prast, «A brief history of the institutional design of banking supervision in the Netherlands", in Thea Kuppens, Henriëtte Prast, Sandra Wesseling (éd.), Banking Supervision at the Crossroads, Cheltenham, Northampton: Edward Elgar, 2003, p. I0-37; Bruckhoff, op. cit., 20IO. Sur la surveillance bancaire en France: H. Fournier, "La Commission de contrôle des banques ", Revue économique, vol. 2, $\mathrm{n}^{\circ}$ 5, 195I, p. 59I-599; Claire Andrieu, «Les nationalisations bancaires en France de 1945 à nos jours", in Maurice Lévy-Leboyer (éd.), Les banques en Europe de l'Ouest de I920 à nos jours. Colloque tenu à Bercy les 7 et 8 octobre 1993, Paris: Comité pour l'histoire économique et financière de la France, I995, p. IOI-I36; Dominique LacoueLabarthe, "L'évolution de la supervision bancaire et de la réglementation prudentielle (1945-1996)", Revue d'économie financière, vol. 73, 2003, p. 39-63; Hubert Bonin, "The regulation of French banking and stock exchange markets (19th-2oth centuries): State interests and common interest, from total liberalism to total State interventionism?", Bankhistorisches Archiv. Zeitschrift zur Bankengeschichte, vol. 39, 200I, p. 20-36; Laure Quennouëlle-Corre, André Straus, "The State in the French Financial System during the Twentieth Century: A Specific Case?», in Stefano Battilossi, Jaime Reis (éd.), State and Financial System in Europe and the USA. Historical Perspectives on Regulation and Supervision in the Nineteenth and Twentieth Centuries, Burlington: Ashgate, 2010, p. 97-I2I.

233 Il s'agit de l'Angleterre (1946), de l'Allemagne (1934), de l'Australie (1945), de l'Espagne (I92I), de la France (1945), de l'Italie (1926), du Japon (1928), des Pays-Bas (1948), du Portugal (1925) et des USA (I9I4), Grossman, art. cit., in Battilossi, Reis (éd.), op. cit., 2010 ; cf. aussi Grossman, op. cit., 2010, p. I62-167.

234 Sur la surveillance bancaire en Belgique, cf. Thibaud Giddey, "Formation et spécificités historiques de la Commission bancaire (1935-1975)", Courrier hebdomadaire du CRISP, vol. 2357-2358, no 32, 2017, p. 5-54; Giddey, art. cit., 2017. 
广

N

$\stackrel{\circ}{\circ}$

(1)

.

2

2

(a) 


\section{CHAPITRE VII}

\section{LA SURVEILLANCE BANCAIRE, UN LONG FLEUVE TRANQUILLE (1945-1961)}

Sur l'anémomètre du contrôle bancaire, la période qui sépare la résolution des derniers assainissements bancaires de la Grande Dépression, pendant les années 1940, des premiers vecteurs de changement dans les années I960, apparaît comme une phase de calme plat. Alors que la place financière suisse entre dans un âge de croissance fulgurante, caractérisée par une forte expansion de ses activités internationales, la principale structure chargée de la régulation du secteur bancaire - la Commission fédérale des banques - s'engage dans une période d'immobilisme. Tant du point de vue de l'adoption de nouvelles normes réglementaires que dans l'application des législations existantes, l'après-guerre (I945-1960) se distingue par l'absence de grandes réformes. Les nombreuses lacunes qui sont progressivement détectées dans le régime de régulation bancaire établi en 1934 sont simplement ignorées. Tant les acteurs privés soumis au contrôle que les instances qui en ont la responsabilité semblent alors privilégier une application routinière des dispositions légales.

Ce chapitre forme donc la transition entre la période de mise en route des années de crise et celle où apparaissent les premières velléités de transformation au cours des années 1960. Il présentera dans un premier temps les grandes évolutions quantitatives du secteur bancaire qui se font jour durant la période. Deuxièmement, la focale se déplacera les reprises de la Basler Handelsbank par la SBS et de la Banque Fédérale par l'UBS en 1945, dans lesquelles la Commission fédérale des banques joue un rôle. Troisièmement, nous analyserons un exemple de l'impuissance de la CFB dans son traitement d'une banque frauduleuse et récalcitrante, la Kredit- und Verwaltungsbank basée à Zoug (1947-1961). Enfin, nous nous intéresserons au débat autour des règles sur les fonds propres et la liquidité - un champ d'opposition essentiellement interne au monde bancaire -, qui conduira à l'adoption d'un nouveau règlement d'exécution de la loi sur les banques en $196 \mathrm{I}^{1}$.

1 Ces quatre épisodes ne constituent pas un récit exhaustif de l'activité de la Commission fédérale des banques entre 1945 et I96r. Elle joue un rôle important dans d'autres situations. Sur ses interventions dans l'élaboration d'un article constitutionnel sur les banques et le 


\section{VII.1. SURVOL CHIFFRÉ DE L'ÉVOLUTION DES BANQUES SUISSES} (1935-1975)

Avant d'aborder la régulation bancaire dans l'après-Seconde Guerre mondiale, marquons une pause dans notre récit chronologique et replaçons la période qui nous intéresse dans un contexte plus large. Ce petit excursus d' "histoire froide» devrait aussi permettre au lecteur de saisir rapidement quelques grandes évolutions conjoncturelles qui conditionnent les discours et pratiques des acteurs que nous verrons à l'œuvre dans les chapitres suivants ${ }^{2}$. Afin de proposer une vue d'ensemble, nous élargissons ici le cadre chronologique strict de ce chapitre, en intégrant la seconde moitié des années I930 et les années 1960-1975.

\section{VII.1.1. La place financière suisse : bilans, internationalisation, concentration et emplois}

Les Trente Glorieuses constituent une période de croissance soutenue pour le secteur bancaire suisse. Mesuré à l'aune des sommes de bilan, ce boom est éclatant. Entre 1945 et 1970, l'ensemble des banques suisses affiche un taux de croissance réel annuel moyen de $7 \%^{3}$. Il atteint même io \% entre 1959 et 1970. En tenant compte de l'inflation, les bilans de toutes les banques en Suisse atteignent le double de leur niveau de 1945 en 1959, ils triplent en 1964 et dépassent le sextuple en 197I. De tels taux de croissance dépassent même ceux de la période euphorique de la seconde moitié des années 1920 (I925-1930 ${ }^{4}$. Ce développement spectaculaire du secteur bancaire s'inscrit évidemment dans une période de croissance économique généralisée. Entre 1948 et 1973, le produit intérieur brut de la Suisse affiche un taux de croissance annuel moyen réel de $4.3 \%{ }^{5}$. Cet essor n'est d'ailleurs pas un Sonderfall helvétique; le Wirtschaftswunder des Trente Glorieuses s'étend sur l'ensemble des économies industrialisées. De même, après la libéralisation partielle des mouvements de capitaux, la tendance d'une croissance encore plus dynamique, entre 1958 et

prélèvement auprès des banques de l'impôt sur les bénéfices de guerre (1945-1947), cf. Giddey, op. cit., 20I7, p. 349-356.

2 Sur la notion d'histoire "froide", cf. Jean Bouvier, "Histoire financière et problèmes d'analyse des dépenses publiques", Annales. Économies, Sociétés, Civilisations, vol. 33, $\mathrm{n}^{\circ}$ 2, I978, p. 207-215, p. 2II.

3 Sauf indication contraire, les chiffres mentionnés dans ce paragraphe renvoient au graphique 8 qui suit.

4 Le taux de croissance annuel moyen des bilans bancaires suisses entre I925 et 1930 est de $9 \%$. Pour une vue d'ensemble: Mazbouri, Guex, Lopez, art. cit., in Halbeisen, Müller, Veyrassat (éd.), op. cit., 20I2, p. 470-472.

5 Müller, Woitek, Hiestand, art. cit., in Halbeisen, Müller, Veyrassat (éd.), op. cit., 20I2, p. 133. Ce taux de croissance est très légèrement inférieur à la moyenne des pays d'Europe occidentale, ibid., p. II4. 
I97I, dans le secteur financier que dans l'ensemble de l'économie s'observe non seulement en Suisse, mais dans la plupart des pays développés ${ }^{6}$. En Suisse, ce différentiel entre l'augmentation des bilans bancaires et celle du PIB se chiffre de la manière suivante : alors qu'en 1948 les bilans des banques représentaient I29 \% du PIB, cette proportion atteint $209 \%$ en 1970. Il apparait d'ailleurs clairement sur le graphique $8:$ dès le milieu des années 1960, la courbe des bilans bancaires grimpe plus rapidement que celle du produit intérieur brut.

Graphique 8. Bilans des banques suisses et produit intérieur brut, en millions de francs constants (francs de 1945) (1935-1975)

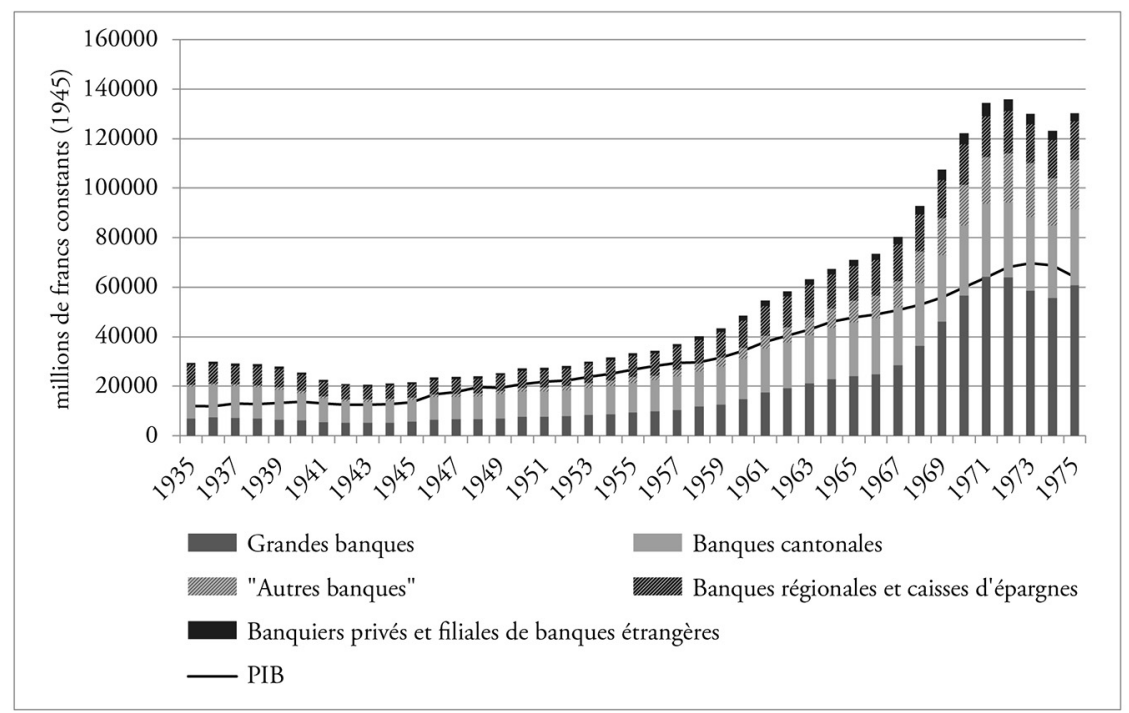

Sources: Bilans bancaires: Ritzmann-Blickenstorfer (éd.), op. cit., I996, tableau O.I3, p. 8I9; Ruedi Wermelinger, Roman Rosenfellner, Séries chronologiques historiques 5. Les banques suisses, Zurich : Banque nationale suisse, 2009, p. 24-25. PIB : Historische Statistik der Schweiz Online, tableau Q.I7a, https://hsso.ch/2012/q/17a (consulté le Io.I2.20I8) ; SECO, cf. Halbeisen, Müller, Veyrassat (éd.), op. cit., 20I2, annexe A.I.I.3, p. II68-II7I. Chiffres déflatés au moyen de l'IPC: Ritzmann-Blickenstorfer (éd.), op. cit., I996, tableau H.23, p. 504. Les données en francs courants figurent dans le tableau A.3 en annexe du PDF.

La segmentation des bilans bancaires par catégories de banque met en évidence des glissements dans le poids relatif des différents acteurs financiers. Premièrement, on constate qu'après une phase (I93I-I943) qui avait plutôt souri aux banques cantonales, repliées sur le marché intérieur, les grandes banques reprennent leur essor dès la fin du second conflit mondial. Fin I962, leurs bilans cumulés dépassent, pour la première fois depuis 1930, celui des banques cantonales. Neuf ans plus tard, en 1971, les grandes banques affichent un bilan cumulé, à hauteur de II4 milliards de francs, plus de deux fois plus

6 Cf. Ralph C. Bryant, International financial intermediation, Washington, D.C. : Brookings Institution, 1987, p. 19-23. 
élevé que celui des banques cantonales. L'impétuosité de la croissance des grandes banques se manifeste avec éclat durant la seconde moitié des années I960, lorsque le taux de croissance annuel moyen de leurs bilans, en termes réels, atteint $17 \%$. Pendant la même période (1966-1970), celui des banques cantonales ne se situe qu'à $5 \%$. Cet écart entre grandes banques et banques cantonales repose essentiellement sur le développement des opérations internationales des premières.

La seconde évolution qui ressort clairement renvoie à l'augmentation des banques étrangères en Suisse. Cette tendance ne se mesure pas uniquement par l'indice des fluctuations de la variable des succursales de banques étrangères, dont le poids reste marginal sur toute la période; notons au passage que les bilans des succursales étrangères dépassent ceux des banquiers privés en 1966. Cette évolution est cependant à relativiser : le bilan ne donne qu'une indication très insuffisante du volume d'affaires d'un banquier privé. Il faut surtout analyser la catégorie des "autres banques» (übrige Banken) pour mesurer la croissance des banques étrangères. En effet, ce groupe de banques, par définition très hétérogène, rassemble également les banques étrangères qui sont fondées en tant que sociétés de droit suisse, formellement indépendantes de leur maison-mère. Cette catégorie de banque connait une croissance exponentielle à partir de 1958 , au point de dépasser celui des banques régionales et caisses d'épargne en 1970. Nous reviendrons plus bas sur le phénomène de l'émergence des banques étrangères en Suisse.

Rappelons ici encore que la seule mesure des bilans ne donne qu'une vision imparfaite de la surface réelle des banques suisses ${ }^{7}$. De nombreuses opérations, dont la gestion de fortune, mais aussi les placements fiduciaires, n'y sont pas comptabilisées. Selon une estimation calculée par Malik Mazbouri, Sébastien Guex et Rodrigo Lopez, les montants des avoirs sous gestion représentent des sommes qui passent d'environ $70 \%$ des bilans bancaires en 1949 à environ $150 \%$ en $1966^{8}$.

Les revenus générés par les banques helvétiques, exposés sur le graphique 9 , connaissent également un accroissement notable pendant les Trente Glorieuses. En termes constants, un gonflement rapide des bénéfices nets s'observe à partir de 1958. On constate en outre une forte expansion à la fois des revenus des intérêts et des commissions - ce dernier chiffre représentant un autre indice partiel de l'importance de la gestion de fortune -, croissance qui s'accélère entre I966 et I97I.

Parallèlement à cet accroissement des bénéfices nets, les rémunérations des actionnaires progressent également. Le graphique io montre clairement que les dividendes versés par les banques organisées sous la forme de sociétés par actions affichent une courbe très proche de celle de la croissance des bilans et

7 Sur ce point : Youssef Cassis, Les Capitales du Capital. Histoire des places financières internationales. 1780-2005, Genève: Slatkine, 2006, p. 325; Mazbouri, Guex, Lopez, art. cit., in Halbeisen, Müller, Veyrassat (éd.), op. cit., 2012, p. 476-478.

8 Proportion estimée à partir du graphique 2.2-4, p. 477, in Mazbouri, Guex, Lopez, art. cit., in Halbeisen, Müller, Veyrassat (éd.), op. cit., 2012. 
Graphique 9. Bénéfices nets, produits des intérêts et des commissions des banques suisses (1935-1975), en millions de francs constants de 1935

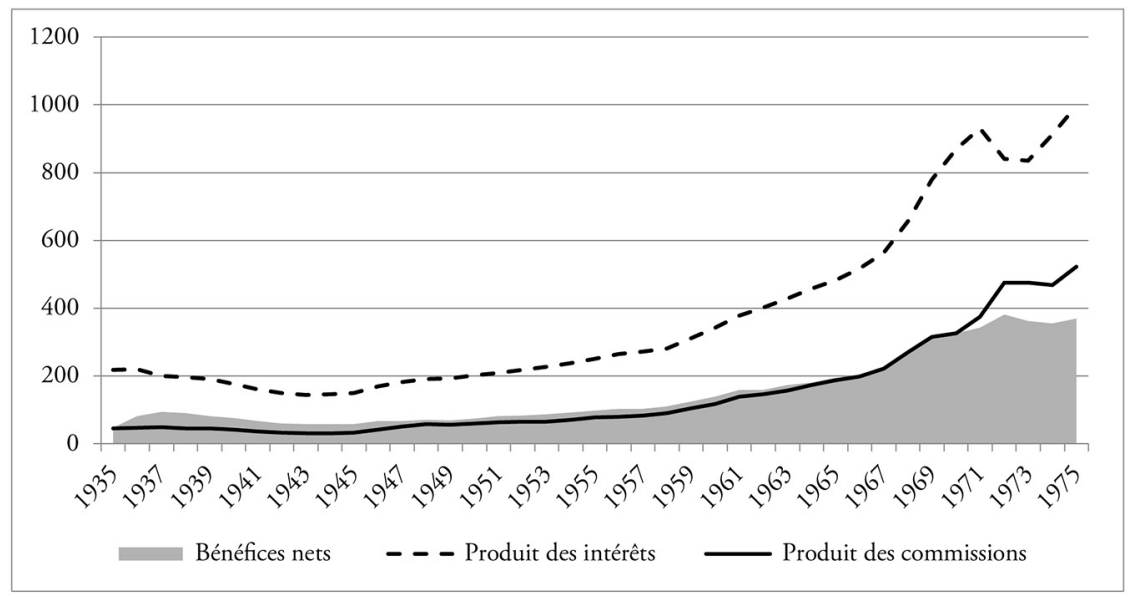

Sources : Ruedi Wermelinger, Roman Rosenfellner, Séries chronologiques historiques 5. Les banques suisses, Zurich : Banque nationale suisse, 2009, p. I08-II4. Données déflatées au moyen de l'IPC: Ritzmann-Blickenstorfer (éd.), op. cit., I996, tableau H.23, p. 504.

Graphique Io. Dividende moyen versé par les banques par action (en \% du capital à renter), (1934-1973)

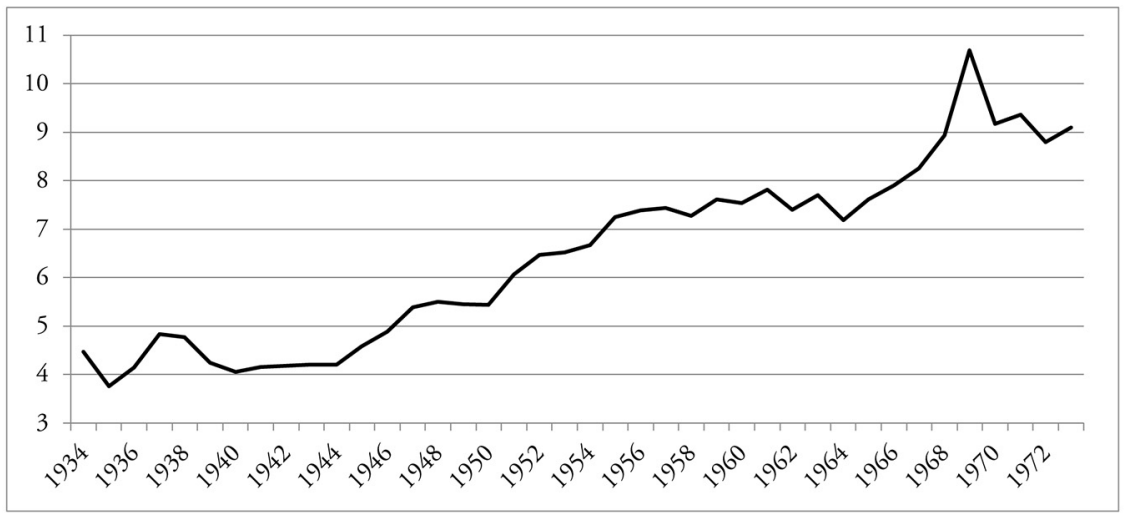

Source: Das schweizerische Bankwesen im Jahre..., Zürich : Schweizerische Nationalbank, années correspondantes.

des bénéfices, avec une accélération marquée durant la seconde moitié des années 1960. La rémunération moyenne fait plus que doubler entre 1945 et 1969, passant de $4.58 \%$ à Io.69 \%.

Cet essor spectaculaire de la place bancaire suisse durant les Trente Glorieuses s'explique par une combinaison de facteurs, que nous n'évoquerons que superficiellement ${ }^{9}$. À l'abri pendant les deux conflits mondiaux, la Suisse jouit

9 Cf. Ibid., p. 494-499. Voir aussi Cassis, op. cit., 2006, p. 302-305, 323-326; Iklé, op. cit., I970, p. 35-40, 75-I20; Loepfe, op. cit., 20II, p. 442-447. 
d'une solide réputation en tant que refuge pour les capitaux internationaux. Elle dispose premièrement d'une devise forte, l'une des rares monnaies librement convertibles, au centre d'une Europe où domine encore au moins jusqu'en 1958 le contrôle des changes; l'absence, en Suisse, de régulation sur les mouvements de capitaux est ici essentielle. Deuxièmement, la Suisse se distingue également par la neutralité proclamée de sa politique extérieure et la grande stabilité des rapports de force politiques domestiques, caractérisés par la domination incontestée des partis bourgeois. Troisièmement, elle bénéficie, en comparaison internationale, d'une inflation maîtrisée, d'une dette publique modeste, ainsi que d'une administration fiscale faible et clémente; en plus d'un secret bancaire protégé pénalement, les taxes à la source y sont modérées.

Ces divers facteurs d'attractivité se combinent avec la croissance exceptionnelle de l'économie mondiale. La haute conjoncture économique, qui se manifeste autant en Suisse qu'à l'étranger, accompagnée d'une croissance démographique, provoque notamment un développement soutenu du marché de la construction, dont la part au PIB helvétique passe de $3 \%$ en 1945 à plus de Io $\%$ en $1965^{10}$. Le secteur des exportations suisses, par exemple, connait un essor considérable ${ }^{11}$. Les conditions économiques très favorables, conjuguées aux atouts compétitifs de la place financière suisse mentionnés ci-dessus, génèrent un afflux massif de fonds internationaux vers les banques suisses, mesuré ci-dessous. La place bancaire helvétique reprend et consolide pendant les Trente Glorieuses le rôle de plaque tournante de capitaux. L'étroitesse du marché suisse des capitaux explique en partie pourquoi le déferlement de fonds vers les coffres suisses donne lieu à des investissements à l'étranger. La part des opérations étrangères du secteur bancaire helvétique double entre 1959 et 1969, passant de $15 \%$ du bilan à $30 \%{ }^{12}$. En termes absolus et nominaux, les passifs étrangers déposés chez les banques suisses passeraient de 5.6 milliards fin 1957 à I6.9 milliards fin $1965,22.9$ milliards fin 1967 et 28.6 milliards fin $1968^{13}$. On observe en outre un fort parallélisme entre la croissance des engagements étrangers (actif) et celle des créances sur l'étranger (passif) pendant cette période. Ce développement analogue désigne le statut de plaque tournante des capitaux internationaux que nous avons évoqué. Kurt Speck, dans sa thèse de doctorat menée sous l'impulsion de l'ASB, propose une estimation relativement proche de l'augmentation de la contribution étrangère à l'activité des banques suisses. La part des engagements étrangers au total des bilans passe de

10 Laurent Tissot, Peter Moser, "Binnenwirtschaft, Tourismus und Landwirtschaft", in Patrick Halbeisen, Margrit Müller, Béatrice Veyrassat (éd.), Wirtschaftsgeschichte der Schweiz im 20. Jahrhundert, Basel: Schwabe, 2012, p. 519-628, p. 548.

11 Voir par exemple Margrit Müller, "Internationale Verflechtung», in ibid., p. 339-465, p. $4 \mathrm{IO}-4 \mathrm{I} 3$.

12 Henner Kleinewefers, Das Auslandsgeschäft der Schweizer Banken, Zürich : Schulthess, 1972, p. 60 .

13 Kurt Peyer, Ausmass und Bedeutung des Auslandskapitals in der Schweiz, Zürich : Juris, 197I, p. IOI. Voir aussi, p. 205-218. 
I 8 à $32 \%$ entre I962 et 1972, celle des créances sur l'étranger augmente même de 16 à $39 \%$ pendant la même période ${ }^{14}$.

Sans surprise, c'est chez les grandes banques - et, dans une plus forte mesure encore, chez les "autres banques", qui sont majoritairement des banques étrangères installées en Suisse - que l'augmentation des opérations internationales est la plus forte. Du côté de l'actif, la part des activités étrangères chez les grandes banques augmente de $26.5 \%$ en 1959 à $46 \%$ en $1969^{15}$. Cela signifie qu'à ce moment-là, près de la moitié des créances des grandes banques sont placées à l'étranger; chez les " autres banques ", cette même proportion passe de $55 \%$ à $73 \%$ pendant le même intervalle.

C'est donc en grande partie sur l'accroissement des opérations internationales des banques suisses que repose leur croissance prodigieuse. Les banques cantonales et banques locales sont moins concernées par ce développement, leur part aux activités étrangères du secteur bancaire se situe en moyenne à $6 \%$ des passifs et $3 \%$ des actifs durant les années I960. Il faut cependant se garder de considérer les banques cantonales comme des établissements exclusivement tournés vers le marché intérieur et local. En 1956 par exemple, le directeur de la Banque cantonale de Berne affirme que son institut «soigne sa clientèle française depuis des décennies ${ }^{16}$.

Quoi qu'il en soit, ce phénomène d'internationalisation, motivé à la fois par l'exiguïté du marché domestique et la meilleure rentabilité des placements étrangers, rencontre une certaine opposition de la part des autorités monétaires. Sans entrer dans les détails, retenons seulement que la Banque nationale suisse va s'atteler à freiner l'afflux de capitaux étrangers vers les banques suisses par différents moyens. Elle considère en effet qu'il contribue à alimenter une inflation jugée forte, et que l'internationalisation croissante du franc suisse engendre une difficulté à maîtriser la politique monétaire. Diverses mesures sont prises pour tenter d'endiguer le déferlement de fonds étrangers. Des gentlemen's agreements sont conclus entre la banque centrale et les banques commerciales en août 1960 et juin $1962{ }^{17}$. Ces conventions incluent des limitations des crédits à l'étranger, la fixation d'intérêts négatifs sur les dépôts étrangers et la détermination de réserves minimales à placer à la BNS proportionnellement aux créances étrangères à court terme ${ }^{18}$. Ces réserves minimales

14 Kurt Speck, Strukturwandlungen und Entwicklungstendenzen im Auslandgeschäft der schweizer Banken, Zürich : Junis, I974, p. I59.

15 Kleinewefers, op. cit., 1972, p. 65-68.

16 AASB, dossier « $\mathrm{n}^{\circ}$ 713 Eidg. Bankenkommission Bankengesetz Jan. 1952 - Dez. 1958 », lettre d'Otto Würgler (Banque cantonale de Berne) à l'ASB, I6.07.1956, au sujet de l'établissement en Suisse de la Banque de l'Indochine.

17 Peter Bernholz, "De 1945 à 1982 : de l'application de mesures administratives contre l'afflux de devises à la gestion de la masse monétaire sous le régime des changes flottants ", in Werner Abegg (éd.), Banque Nationale Suisse 1907-2007, Zurich: Neue Zürcher Zeitung, 2007, p. II7-2II, p. I70-I7I.

18 Mazbouri, Guex, Lopez, art. cit., in Halbeisen, Müller, Veyrassat (éd.), op. cit., 20I2, p. 496 ; Kurt Schiltknecht, Beurteilung der Gentlemen's Agreements und Konjunkturbeschlüsse der 
obligatoires, qui prennent la forme d'avoirs non rémunérés et non comptabilisés dans le calcul des liquidités, deviennent un instrument important de la banque centrale, lui permettant de contrôler le potentiel de création monétaire ${ }^{19}$. Leur insuffisance, combinée à une croissance toujours plus soutenue des fonds étrangers déposés en Suisse, incite cependant l'institut d'émission à encourager l'adoption par le Conseil fédéral d'un type de mesure plus contraignante, sous la forme d'un arrêté fédéral urgent promulgué le I3 mars $1964^{20}$. L'arrêté sur la limitation du crédit fixe un quota d'accroissement de crédits, décrète l'interdiction de rémunérer les avoirs étrangers crédités en francs suisses et impose des limitations sur le placement de capitaux étrangers en titres ou hypothèques suisses. L'absence de mesures de sanction, entre autres, rend le dispositif mis en place en 1964 insuffisant. C'est dans ce contexte qu'une tentative d'étendre les pouvoirs d'intervention de la Banque nationale suisse (son instrumentarium), par le biais d'une révision de la loi sur la BNS, sera lancée dès I968. Ce dossier, encore intégralement en friche pour les historiens, ouvre des perspectives de recherche intéressantes pour comprendre les tensions entre les grandes banques et la banque centrale à la fin des années 1960. Son histoire reste encore à écrire.

La vigoureuse croissance des sommes de bilans bancaires s'accompagne en Suisse d'un mouvement de restructuration entre groupes bancaires, qui accentue la concentration du secteur ${ }^{21}$. Ce développement ressort moins clairement des statistiques globales sur le nombre de banques. Sans tenir compte des caisses Raiffeisen, le total des établissements soumis à la surveillance de la Commission fédérale des banques passe de 484 en 1945 à 567 en $1965^{22}$. Si l'on considère la statistique officielle de la BNS, qui ne prend pas en compte les banquiers privés, les sociétés financières, et les succursales de banques étrangères, il s'agit de 383 banques en 1945 contre 472 en 1965 . Dans les deux cas, on constate une augmentation du total des raisons sociales considérées comme banques. Or, si on regarde de plus près l'évolution des effectifs par catégories de banque, le tableau se précise. Le groupe des banques locales et des caisses d'épargne passe en fait de 295 unités en 1945 à 232 en $1975^{23}$. Le groupe des banquiers privés connait aussi une diminution, le nombre de maisons se réduisant de 83 en 1947 à 47 en $1969^{24}$.

Jahre 1954-1966 unter besonderer Berücksichtigung der Auslandgelder, Zürich : Polygraphischer Verlag, 1970.

19 Cf. Äppli, et al. (éd.), op. cit., 1982, p. 172.

20 Cf. Ibid., p. 124-129, 225-226; Sancey, op. cit., 2015, p. 423-433.

21 Cf. Walter Kull, «Wandlungen im schweizerischen Bankensystem seit 1945 », in Kultur und Wirtschaft: Festschrift zum 70. Geburtstag von Eugen Böhler, Zürich : Polygraphischer Verlag, 1963, p. 267-277; Heinrich Stamplli, Die schweizerischen Banken im Zeichen der Konzentration (1945-1969), Zürich : City-Druck, 1971, p. 60-105.

22 Cf. tableau I6, chap. VI.I.3.

23 Ritzmann-Blickenstorfer (éd.), op. cit., 1996, tableau O.ı3, p. 818.

24 Das schweizerische Bankwesen im Jahre..., Zürich: Schweizerische Nationalbank, années correspondantes, nombre de sièges principaux des banquiers privés dans la statistique des comptoirs bancaires. 
Mais les baisses du nombre de banques régionales et de banquiers privés sont en fait compensées par l'explosion de la catégorie " autres banques", qui rassemble en grande partie les banques étrangères. Ce "groupe " passe de 55 unités en 1945 à 200 en 1973. Pour le dire autrement, on assiste simultanément à la disparition de plusieurs petits établissements financiers à caractère régional et de certains banquiers privés et à la fondation de nouvelles banques à partir de capitaux étrangers. L'origine du mouvement de restructuration et de concentration tel qu'il se manifeste dans l'extinction de plusieurs petites banques se situe dans l'expansion du réseau de succursales des grandes banques sur le marché intérieur. En effet, le développement des agences des quatre principales grandes banques, la Société de Banque Suisse, le Crédit Suisse, l'Union de Banques Suisses et la Banque Populaire Suisse, prend la forme soit de l'établissement de nouvelles succursales, soit, surtout, de la reprise d'établissements locaux déjà bien implantés dans une région ${ }^{25}$. Le total de comptoirs (sièges, succursales et simples agences) des cinq grandes banques augmente de I82 unités en 1945 à 458 en $1969^{26}$. L'UBS se montre particulièrement agressive dans la conquête du marché intérieur ${ }^{27}$. En rachetant des établissements locaux, l'Union de Banques Suisses oriente sa stratégie d'expansion vers des régions restées encore dans l'ombre des opérations des grandes banques alémaniques, comme le Valais ou les Grisons. D'après la chronique bancaire de Franz Ritzmann, au moins 13 banques sont reprises par l'UBS entre 1944 et $1968^{28}$. Dès 1962, elle dépasse ses deux concurrentes, et prend une grande avance dans le développement de son réseau d'agences ${ }^{29}$. En 1969, l'UBS entretient I24 agences en Suisse, contre 93 pour la SBS, et 68 pour le Crédit Suisse ${ }^{30}$. Entre 1945 et 1969, l'UBS a repris 26 banques, la SBS io et le Crédit Suisse 5, portant le total d'acquisitions d'établissements par les trois grandes banques à $4 \mathrm{I}^{31}$.

Autrement dit, au cours des années 1960, les grandes banques, parallèlement à l'expansion de leurs affaires internationales, développent aussi leur ancrage dans le marché bancaire national. Elles investissent avec une plus grande intensité le crédit hypothécaire ou encore le drainage des épargnes, domaines jusqu'alors privilégiés par les banques cantonales et les banques locales. Des tentatives de conclure un accord de limitation de l'expansion entre les grandes banques et les banques cantonales et locales, au sein de l'ASB, échouent en mars $1969^{32}$.

Iklé, op. cit., 1970, p. 90-9I.

Stampfli, op. cit., I97I, p. 5I.

Loepfe, op. cit., 20II, p. II3-II5, p. 300-304.

Ritzmann, op. cit., I973, p. 364-373.

Cf. Joseph Jung, Von der Schweizerischen Kreditanstalt zur Credit Suisse Group. Eine Bankengeschichte, Zürich : NZZ, 2000, p. I22.

Iklé, op. cit., I970, p. 90.

Stampfli, op. cit., I97I, p. 64-7I.

Loepfe, $o p$. cit., 20II, p. 302. 
En plus de la conquête du marché domestique par les grandes banques, par la voie d'ouverture de nouvelles agences et d'acquisition de banques régionales, un second facteur, de moindre importance, explique le mouvement de concentration des années 1950 et 1960 : les avancées technologiques. La mise au point de technologies de traitement informatique des données génère en effet d'importants coûts fixes ${ }^{33}$. Les banques locales doivent donc faire le choix entre une spécialisation dans un domaine d'activité où l'automatisation est encore inefficace, ou des investissements dans des centres de traitement informatique communs à plusieurs établissements.

Graphique II. Nombre d'employés de banque (par catégories), (I94I-I975)

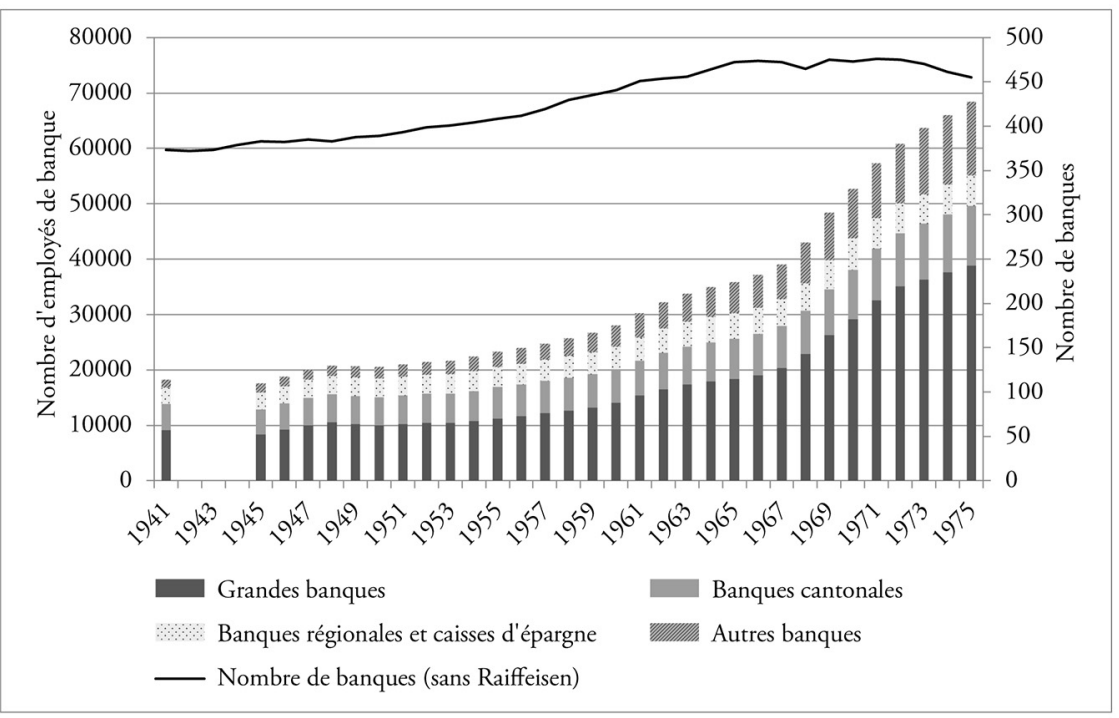

Source: Ritzmann-Blickenstorfer (éd.), op. cit., 1996, tableau O.ı3, p. 818.

Corollaire de l'expansion du volume d'affaire du secteur bancaire helvétique, le nombre d'emplois de la branche connaît également une croissance soutenue durant les Trente Glorieuses, avec une accélération à partir de la seconde moitié des années 1960. Les emplois globaux triplent en l'espace de vingt ans, puisque l'on passe d'environ 20 ooo personnes actives au tournant des années 1950 à environ 60000 au début des années 1970. À titre de comparaison, le nombre d'employés à plein temps de la Commission fédérale des banques reste stable pendant toute la période: il s'agit toujours d'un appareil administratif d'une demi-douzaine de personnes. Ce sont surtout les grandes banques qui sont à l'origine du gonflement des places de travail. Entre I945 et 1975, les emplois chez les grandes banques quintuplent presque: leur nombre passe de 8200 à 38800 . En d'autres termes, la proportion des emplois 
bancaires chez les grandes banques, par rapport au total du secteur, connaît une forte augmentation à partir des années 1960 : alors qu'elle est inférieure à $50 \%$ avant 1960, elle dépasse $56 \%$ dès 1971. Et là aussi, l'UBS semble être l'élément le plus dynamique. L'effectif de son personnel augmente de 5729 à 10396 entre I966 et 1970, ce qui fait de la banque zurichoise le premier employeur bancaire du pays en 1970, devant la SBS (8 Ioo employés) et le Crédit Suisse (6 732 employés $)^{34}$. L'accroissement des emplois bancaires à la fin des années 1960 provoque également certaines tensions sur le marché de travail : la pénurie de main-d'œuvre bien formée entraîne une inflation salariale. L'augmentation des emplois du secteur bancaire s'accompagne d'une féminisation; la part d'employées chez les banques suisses passe de $25 \%$ à $37 \%$ entre 1960 et $1970^{35}$.

Résumé à grands traits, le développement de la place bancaire suisse entre 1945 et 1975 se structure autour d'une forte croissance, qui dépasse celle, déjà très soutenue, de l'économie en général. Cette expansion doit beaucoup à l'intensification des opérations internationales. Cette tendance, déjà présente dès les années 1950, s'accélère durant la décennie suivante. Du point de vue des acteurs, les grandes banques, à savoir essentiellement trois instituts - les deux banques dominantes avant la guerre, la Société de Banque Suisse et le Crédit Suisse, auxquelles vient s'ajouter l'Union de Banques Suisses plus agressive -, sont les fers de lance de cet âge d'or de la place financière. Elles gagnent en importance sous de nombreux aspects et mettent en branle un mouvement de concentration du secteur bancaire qui se caractérise par la reprise de certaines banques locales et banquiers privés ${ }^{36}$. Plus encore que durant d'autres périodes historiques, on assiste en Suisse pendant les Trente Glorieuses au développement, sous l'effet d'une internationalisation croissante, d'une place bancaire hypertrophiée, dont la surface est sans commune mesure avec le poids démographique ou même les performances industrielles du pays, comme en témoigne la divergence entre les courbes de croissances des bilans bancaires et du PIB.

\section{VII.1.2. L'évolution des activités de la Commission fédérale des banques}

Dans quelle mesure l'interventionnisme de la Commission fédérale des banques suit-il la courbe du développement de la place bancaire suisse? Pour ne pas perdre de vue le fil rouge de cet ouvrage, revenons à la question de

\section{Loepfe, op. cit., 20II, p. 318. \\ Ibid., p. 320.}

Nous pensons par exemple aux reprises par l'UBS de la maison de Palézieux \& Cie en 1948, de la banque privée fribourgeoise Weck, Aebi \& Cie en 1954, de la Banque de Sion, de Kalbermatten \& Cie en 1956, de Tissières fils \& Cie (Martigny) en 1956, de du Pasquier, Montmollin \& Cie (Neuchâtel) en 1962, Bugnion \& Cie (Lausanne) en 1965. La SBS reprend la banque Zahn \& Co. (Bâle) en 1948, la Banque de Martigny, Closuit \& Cie en 1968. Le Crédit Suisse fait l'acquisition de Gebrüder Oechslin \& Co. (Schaffhouse) en I96I. Cf. Stampfli, op. cit., I97I, p. 64-7I. 
l'évolution de la surveillance bancaire, toujours dans une perspective d'«histoire froide».

Selon le rôle et les fonctions que l'on attribue à une instance de surveillance bancaire, on pourrait avancer des hypothèses différentes. Dans une première perspective, la charge de travail d'une instance de régulation devrait être parallèle à la croissance du secteur qu'elle est censée contrôler. On verrait dans ce cas les activités de la CFB évoluer de manière symétrique à l'essor des établissements financiers. En effet, l'établissement de nouveaux acteurs, la multiplication des types d'opérations, ou encore l'accroissement du nombre de rapports de révision à traiter devraient inévitablement provoquer une augmentation des devoirs et missions de l'organe de surveillance. D'autre part, selon une conception différente de la fonction d'une instance de régulation économique, on pourrait également considérer que la prospérité du secteur induit une diminution ou du moins une stagnation de la charge de travail. L'absence de grave crise bancaire aurait dans ce sens provoqué une baisse d'attention politique et médiatique sur l'activité de la Commission fédérale des banques qui, partant, aurait vu son rôle se limiter à une application routinière des dispositions légales. Au fond, il s'agit de déterminer si l'expansion du secteur régulé implique nécessairement une croissance équivalente des superviseurs ou, au contraire, si la prospérité conjoncturelle engendre un désintérêt manifeste pour la tâche de contrôle.

Graphique I2. Activité annuelle de la Commission fédérale des banques: nombre de séances et durée des séances (nombre de pages des procès-verbaux),

(1935-I975)

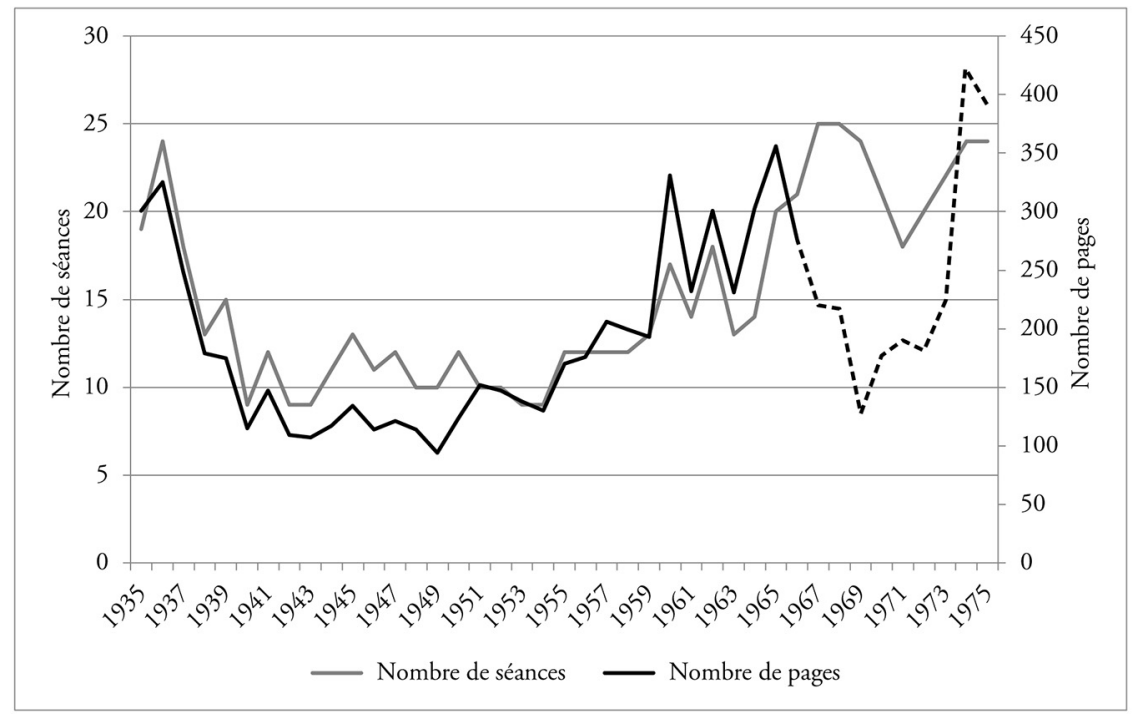

Source: 1935-1960: AFB, E6520(A), 1000/1059, vol. 6-I2; 196I-1975: AFB, E6520(B), 1980/39, vol. I5-19. 
Le graphique I2 compile deux indices qui permettent d'estimer approximativement l'importance de l'activité annuelle de la CFB. Le premier indicateur est celui du nombre de séances par année, qui n'est pas fixé dans le règlement d'organisation, mais varie selon les besoins. Le second indice, plus précis, comptabilise le nombre total de pages du volume des procès-verbaux par année. Il est en effet plus précis, puisque la durée d'une séance mesurée à l'aide du nombre de pages du procès-verbal peut énormément varier: entre une dizaine et une trentaine de pages ${ }^{37}$. Évidemment, mesurer l'intensité de l'activité d'une instance à l'aune de ses procès-verbaux comporte de nombreux biais.

Cet indice ne tient pas compte du travail de gestion quotidien du secrétariat, qui se fait souvent en étroite collaboration avec le président. La préparation des séances, le traitement du courrier habituel, la mise en circulation de divers rapports constituent des tâches très chronophages qui occupent le secrétariat. De plus, cet indice ne prend pas non plus en considération les interventions complémentaires des membres de la $\mathrm{CFB}$, comme la participation à diverses conférences. Autre biais: les procès-verbaux ne sont qu'un reflet partiel des discussions qui ont effectivement lieu, ils peuvent être tronqués (et le sont parfois explicitement) et d'importantes négociations sont sans doute réalisées off-the-record. Enfin, la série qui comptabilise le nombre de pages de procèsverbaux contient une rupture statistique importante, signalée sur le graphique par la courbe discontinue : à partir de 1967, les chiffres ne tiennent compte que des procès-verbaux des séances ordinaires de la chambre des banques de la Commission fédérale des banques. En effet, une réorganisation administrative de la CFB a lieu en 1967 à la suite de la prise en charge de la surveillance des fonds de placement. Comme nous le verrons, l'organe se sépare alors en une chambre des banques et une chambre de fonds de placement, mis à part le président, les membres des deux chambres ne se réunissent qu'occasionnellement pour des séances plénières. En revanche, la courbe du nombre de séances reste comparable sur toute la période. Malgré ces réserves, il est utile de produire cette statistique sur la durée pour deux raisons. D'une part, les réunions des membres de la Commission fédérale des banques demeurent le cœur de l'activité de l'institution: les prises de décision y jouent un rôle important. D'autre part, il s'agit là, à notre connaissance, de l'une des seules manières de produire une série chronologique continue sur l'activité de la CFB.

L'analyse du graphique I2 révèle une tendance assez simple. Globalement, durant l'ensemble de la période examinée, entre 1935 et 1975, la Commission fédérale des banques se réunit en moyenne quinze fois par année, soit une réunion toutes les 3 semaines. L'évolution chronologique est la suivante. Après cinq premières années marquées par une forte sollicitation de la Commission fédérale des banques dans la mise en application de la loi sur les banques et dans l'exécution des plans d'assainissement pour banques en difficulté, l'autorité de 
surveillance entre dans une phase beaucoup plus calme. Entre 1940 et 1960, la Commission fédérale organise moins de II séances par année, en moyenne, contre près de I8 réunions entre 1935 et 1939. À partir des années 1960, l'activité de la CFB regagne en intensité. Durant la décennie, la moyenne des réunions dépasse même 19. Cette inflation dans le nombre de séances et leur durée trouve son explication dans les longues discussions sur certains projets de réglementations (loi sur les fonds de placement, révision de l'ordonnance de la loi sur les banques). D'ailleurs, le tableau 2I, qui retrace la production réglementaire de la $\mathrm{CFB}$, semble indiquer une tendance similaire.

Tableau 2I. Activité réglementaire de la CFB : édiction de circulaires (I935-I975)

\begin{tabular}{|l|c|}
\hline \multicolumn{2}{|c|}{ Nombre de circulaires promulguées (1935-1975) } \\
\hline I935-1940 & IO \\
\hline I94I-I945 & 5 \\
\hline I946-1950 & 2 \\
\hline I95I-1955 & I \\
\hline I956-I960 & 2 \\
\hline I96I-1965 & 6 \\
\hline I966-1970 & 6 \\
\hline I97I-I975 & 20 \\
\hline Total & 52 \\
\hline
\end{tabular}

Source: AFB, E6520(B), 2007/62, vol. 4, Circulaires CFB.

Après une première période très chargée - caractérisée par l'édiction de quinze circulaires en dix ans, la Commission fédérale des banques n'en promulgue que cinq pendant les quinze premières années de l'après-guerre, principalement des adaptations mineures des textes déjà en vigueur. On assiste ensuite à une reprise durant les années 1960, avant un véritable foisonnement de circulaires dans la première moitié des années 1970, en particulier sous l'effet de la révision de la loi sur les banques de 1971.

À partir des rapports annuels de la Commission fédérale des banques, nous pouvons également produire une série statistique qui recense deux de ses tâches principales : l'assujettissement des nouvelles banques à la loi et l'analyse des rapports de révision bancaire. Le graphique 13 compile ces deux types d'intervention sur la période 1935-1975.

L'évolution du nombre d'assujettissements est difficile à analyser clairement. On observe en effet de fortes fluctuations d'une année à l'autre. Il est cependant possible de dégager certaines tendances, en segmentant les données sur différentes périodes. Alors que la moyenne d'assujettissements par année est supérieure à 22 sur toute la période, elle augmente à plus de 26 pour la phase 1945-1958, puis baisse à I8 pendant les années 1960. Une interprétation de ces 
Graphique I3. Nombre de nouvelles banques assujetties et nombre de rapports de révision traités par la CFB (1935-1975)

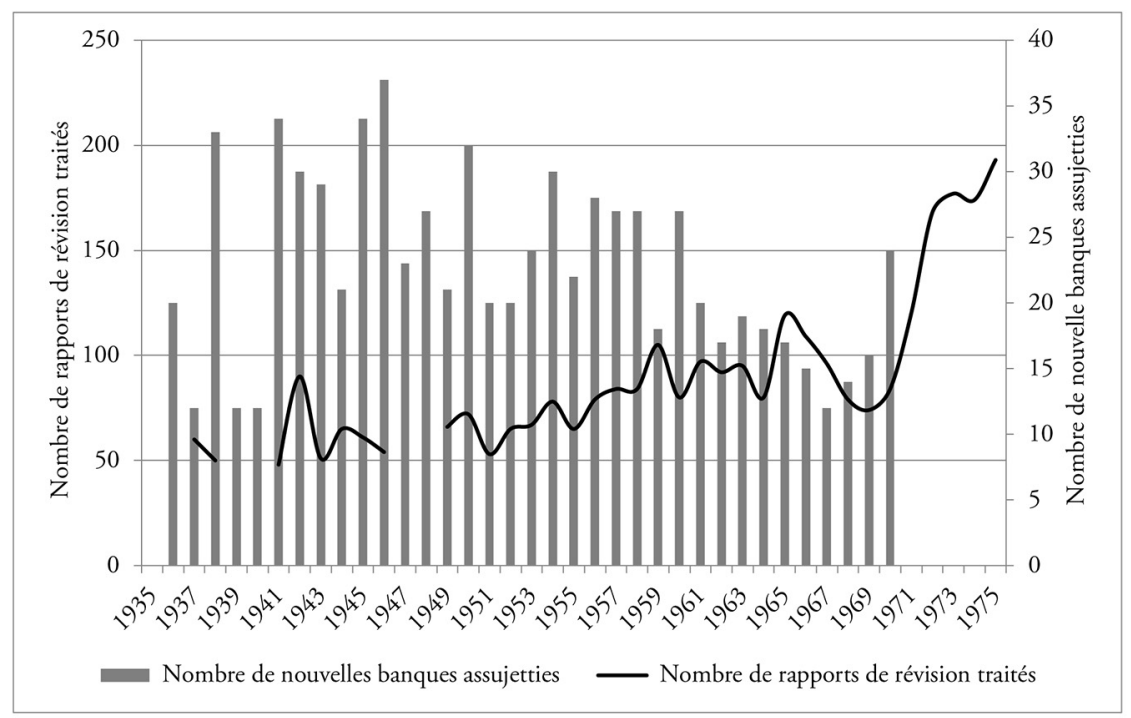

Source: Rapports annuels de la CFB, AFB, E6520(A), 1983/50, vol. I3.

mouvements désigne l'évolution du nombre de caisses Raiffeisen. En effet, entre 1936 et 1956,77\% des nouvelles banques soumises à la loi sur les banques sont en fait des caisses affiliées à l'Union Raiffeisen. Cette proportion baisse à $43 \%$ sur la période 1957-1970. C'est donc le ralentissement de la croissance du réseau de caisses de crédit mutuel qui explique le fléchissement de la tâche d'enregistrement de nouvelles banques par la CFB. En ce sens, cette statistique sur les assujettissements à la loi sur les banques propose un reflet très imparfait de l'arrivée de nouveaux établissements.

Quant aux chiffres sur les rapports de révision, ils indiquent une évolution générale plus régulière, malgré les données lacunaires entre 1936 et 1948. Rappelons ici que la Commission n'examine ces documents que dans certains cas précis : lorsqu'un nouvel établissement est soumis à la loi bancaire ou que l'institut de révision a constaté de graves manquements aux prescriptions légales. On constate donc un doublement progressif entre 195I (53 rapports de révision traités) et 1965 (II9 rapports de révision traités). Puis, à partir de I972, un véritable saut quantitatif sous l'effet de l'entrée en vigueur de la révision de la loi sur les banques, qui améliore l'outillage d'intervention de la Commission fédérale des banques. Elle analyse 168 rapports de révision en 1972, contre 84, soit exactement la moitié, deux ans plus tôt.

Dans l'ensemble, l'indicateur à long terme que représente le nombre de rapports de révision traités semble se recouper avec celui de l'activité de la CFB mesurée par les procès-verbaux, du moins pour les années d'après-guerre. Alors que les années 1950 se caractérisent par une faiblesse d'intervention et une 
remarquable stabilité, les années 1960 se distinguent par un plus grand dynamisme $^{38}$.

Comment le cas de l'autorité de surveillance bancaire suisse entre-t-il dans le questionnement théorique qui ouvrait ce sous-chapitre? La CFB connaît-elle un développement analogue au secteur sous sa supervision, ou l'absence de crise bancaire implique-t-elle au contraire une stagnation de son statut de régulateur? Les quelques indices sur l'activité de la Commission fédérale des banques distillés ci-dessus font plutôt pencher la balance en faveur de la seconde option. La courbe d'évolution de l'activité de superviseurs ne parvient pas à suivre le rythme effréné de la croissance des établissements bancaires. Au contraire, l'écart considérable entre les ressources, la capacité organisationnelle et le pouvoir d'influence des milieux bancaires et la faiblesse chronique de moyens dont dispose la CFB se creuse pendant les Trente Glorieuses. Les chiffres que nous avons articulé dans l'introduction de la deuxième partie sur le nombre d'employés du secrétariat de la CFB et son budget confirme cette tendance. La mise en évidence de la stagnation du budget et de personnel de la CFB pendant une période de croissance soutenue du secteur bancaire corrobore l'analyse faite ci-dessus sur la base des activités des superviseurs. Comment faut-il interpréter cette discrépance grandissante? La principale clé d'explication renvoie au système de régulation mis en place en 1934. En intercalant l'intermédiaire des sociétés fiduciaires privées entre les banques et l'autorité fédérale, le régime de régulation indirect réduisait au minimum le rôle actif et immédiat de la Commission fédérale des banques. Au fond, le développement de la place bancaire impliquait en premier lieu un surcroît de travail pour les sociétés de révision chargées de l'audit annuel. En période de vaches grasses, la CFB pouvait poursuivre en toute discrétion son travail routinier d'application de la législation bancaire. De plus, il semble aussi ressortir de ce premier survol quantitatif qu'une phase de croissance des établissements bancaires, caractérisée par un contexte de prospérité et l'absence de crises ou de défaillances bancaires, a pour corollaire une baisse d'attention sur le rôle des régulateurs. Cette indifférence politique et médiatique n'est guère propice à un renforcement des moyens et des compétences de l'autorité de surveillance. La force d'inertie du statu quo, en termes de régulation, augmente avec la bonne marche des affaires.

38 Dans le chapitre VII.3., nous reprenons cette analyse des statistiques sur les rapports de révision, cette fois sous l'angle plus précis de la prise de sanction de la part de la Commission fédérale des banques. Cf. tableau 22. 


\section{VII.2. LES REPRISES DE LA BANQUE FÉDÉRALE ET DE LA BASLER HANDELSBANK PAR L'UBS ET LA SBS RESPECTIVEMENT (1945): UN MOUVEMENT DE CONCENTRATION DES GRANDES BANQUES SOUS LES AUSPICES DE LA CFB}

Si la période 1945-1970 représente bel et bien un âge d'or pour la place bancaire suisse, l'immédiat après-guerre correspond en revanche à une époque sensiblement plus difficile. Certes, elle bénéficie, en comparaison internationale, d'un certain nombre d'avantages compétitifs déjà mentionnés, en partie dus à l'absence de dégâts matériels et de perte de confiance pendant la guerre. Au sortir du second conflit mondial cependant, les banquiers suisses doivent faire face à des défis que l'on peut sommairement distinguer en deux pans. D'une part, les cercles dirigeants s'attèlent à rompre l'isolement et la déconsidération dont souffre la Suisse auprès des Alliés en raison de l'attitude de neutralité ambivalente pendant la guerre et des services rendus à l'Allemagne ${ }^{39}$. Plusieurs démarches, en 1945-1946, combinant les approches diplomatiques et commerciales, ainsi que l'octroi de crédits, vont avoir pour but de réintégrer le nouvel ordre économique mondial placé sous la domination des vainqueurs de la guerre, en particulier des États-Unis. Le déblocage des avoirs suisses aux États-Unis, gelés depuis juin 194I, constitue l'un des enjeux centraux de ces négociations. L'accord de Washington, signé le 25 mai 1946, représente une étape décisive dans ce processus ${ }^{40}$. En échange d'une pénalité de 250 millions de francs, les négociateurs suisses obtiennent, en plus du déblocage des placements suisses en dollars, la renonciation aux revendications alliées sur les transactions sur l'or fournies par la BNS aux autorités nazies, et enfin la suppression des listes noires des personnes et sociétés compromises dans les relations économiques avec l'Axe. Qualifié de "miracle diplomatique » ${ }^{41}$ par William Rappard (I883-1958), l'un de ses principaux artisans, l'accord de Washington de mai 1946 est un moment capital dans la reprise des relations financières internationales de la Suisse.

D'autre part, le second défi relevé par les banquiers suisses à la fin de la Seconde Guerre mondiale a trait à la restructuration du groupe des grandes banques commerciales. Globalement, la conjoncture de guerre a provoqué une réorientation de la politique de crédit des grandes banques. En 1945, leurs actifs étrangers ne représentent plus qu'un cinquième de leurs bilans. Pendant le

Mazbouri, Guex, Lopez, art. cit., in Halbeisen, Müller, Veyrassat (éd.), op. cit., 20I2, p. 494495.

40 Sur l'accord de Washington de mai 1946: Linus von Castelmur, Schweizerisch-alliierte Finanzbeziehungen im Übergang vom Zweiten Weltkrieg zum Kalten Krieg: die deutschen Guthaben in der Schweiz zwischen Zwangsliquidierung und Freigabe (1945-1952), Zürich: Chronos, 1992, p. 27-I22 ; Perrenoud, art. cit., 2003; Perrenoud, op. cit., 201I, p. 42744I ; Janick Marina Schaufelbuehl, La France et la Suisse ou la force du petit. Evasion fiscale, relations commerciales et financière (1940-1954), Paris: Presses de Sciences Po, 2009, p. I65I80.

41 Perrenoud, op. cit., 20II, p. 434. 
conflit, les prêts aux collectivités publiques domestiques ont triplé et représentent alors $30 \%$ des bilans ${ }^{42}$. Dans une certaine mesure, les emprunts étatiques ont comblé les parts de marché laissées vacantes par la baisse des opérations internationales. Ce glissement général cache cependant de grandes disparités entre les établissements individuels. En effet, malgré tous les efforts déployés pour éviter une propagation de la crise bancaire, un certain nombre d'établissements n'ont survécu au cours du conflit qu'au prix de lourdes pertes comptables, en particulier dans la liquidation des avoirs gelés en Allemagne et en Europe centrale. La défaite des puissances de l'Axe ternit la perspective de voir les débiteurs allemands procéder à court terme aux remboursements des créances bloquées depuis le début des années $1930^{43}$. Souvenons-nous que trois des établissements du groupe des grandes banques n'avaient surmonté les difficultés liées au volume considérable de leurs engagements soumis à des restrictions de transfert qu'au prix de lourds assainissements. La Banque Commerciale de Bâle, la Banque Fédérale et la Banque Leu S.A. devaient leur salut aux réductions de capital, rachats et annulations d'actions et autres réorganisations financières opérées entre 1935 et 1937. Au cours de la guerre, ces banques cherchent à réduire drastiquement leurs engagements allemands, mais la diminution générale de leurs bilans fait que ces crédits prorogés représentent encore un fardeau de taille. Ne pouvant assumer les pertes liées à une liquidation totale de ces engagements, les banques concernées deviennent largement dépendantes des intérêts créanciers que leur rapportent les engagements allemands pour faire face à leurs charges ${ }^{44}$. Avec des modalités qui varient évidemment d'un institut à l'autre, les trois grandes banques couraient de grands risques de ne plus pouvoir assurer une rentabilité minimale dans le cas d'une interruption du versement des intérêts due à la défaite de l'Allemagne et à l'effondrement de ses structures économiques. Comme le disent les auteurs du volume i3 de la Commission indépendante d'experts Suisse - Seconde Guerre mondiale: "Pour ces banques engluées outre-Rhin, le versement des intérêts des crédits allemands prorogés depuis I93I et les revenus des transactions avec l'Axe furent essentiels pour leur survie. C'est pourquoi l'effondrement de l'Axe provoqua la phase finale d'une agonie qui avait commencé avec la crise bancaire allemande. ${ }^{45}$

Ces trois grandes banques - Basler Handelsbank, Eidgenössische Bank, Leu \& Co. - qui souffrent à la fois de faiblesses structurelles héritées de la crise des années 1930 et d'une politique de crédits trop unilatéralement orientée vers des pays ayant mis en place des restrictions de transfert, sont dans une situation

42 Loepfe, op. cit., 20II, p. I8.

43 Comme nous le verrons, les créances allemandes ne s'évaporent pas avec la chute des structures étatiques en Allemagne. Même les actifs « toxiques » seront en partie remboursés, bien plus tard, par l'intermédiaire des sociétés financières qui subsistent après les reprises de la Basler Handelsbank et de l'Eidgenössische Bank.

44 Perrenoud, et al., op. cit., 2002, p. 259-262.

45 Ibid., p. 275. 
précaire avec le dénouement du conflit mondial. Trois autres grandes banques - le Crédit Suisse, la Société de Banque Suisse et l'Union de Banques Suisses sortent en revanche comparativement renforcées de la guerre. Fin 1944, la hiérarchie entre les sept grandes banques, du point de vue du bilan, est la suivante. La SBS (I.54 milliard de francs) devance le Crédit Suisse (I.42 milliards); viennent ensuite l'UBS (766 millions), la Banque Populaire Suisse (764 millions), les trois établissements restants - Banque Fédérale 369 millions), la Banque Leu (I88 millions) et la Banque Commerciale de Bâle (I49 millions) - sont de moindre dimension ${ }^{46}$. Entre le printemps et l'automne I945 va ainsi s'effectuer une restructuration du groupe des grandes banques. Cette opération, marquée par la reprise de la Banque Fédérale par l'UBS et celle de la Banque Commerciale de Bâle par la SBS, sera effectuée avec le concours dans un des deux cas de la Commission fédérale des banques. Elle ponctue également le long cycle de transformations subies dans le groupe des grandes banques depuis l'éclatement de la crise bancaire européenne de 193I. Seuls cinq des huit établissements faisant partie du groupe des grandes banques subsistent alors.

C'est le 26 mars 1945 qu'une première discussion a lieu au sein de la Commission fédérale des banques au sujet de la situation des grandes banques. Plus précisément, la Banque Commerciale de Bâle, la Banque Leu \& Cie et la Banque Fédérale font l'objet d'un échange de vues ${ }^{47}$. Le développement du théâtre de la guerre en Europe est sans doute la raison principale des inquiétudes de l'autorité de surveillance. Fin mars 1945, les armées alliées ont franchi le Rhin, notamment à partir de la tête de pont de Remagen; les ruines de Cologne sont occupées dès le 6 mars; sur le front de l'Est, l'Oder est atteint par les troupes soviétiques fin février $1945^{48}$. L'actualité militaire, comme le relèvent les membres de la CFB, affecte indirectement la situation de certaines grandes banques suisses. Chez la Banque Commerciale de Bâle en particulier, le cours des actions a connu une diminution, tandis que les fonds de tiers enregistrent également une forte baisse de Io.I millions de francs au cours de l'année 1944. La documentation réunie par le secrétariat de la CFB, qui se base essentiellement sur les rapports annuels et les comptes-rendus de l'assemblée générale de la banque, souligne l'importance des engagements étrangers, ainsi que la lourdeur des frais administratifs, qui représentent 2.I \% du bilan, contre $0.9 \%$ en moyenne pour les cinq autres grandes banques. La situation de la Banque Leu préoccupe également la CFB, car sa rentabilité dépend en large partie des encaissements d'intérêts en provenance d'Allemagne. La Banque

Cf. rapports annuels des banques concernées.

AFB, E6520(A), I000/I059, vol. 8, Procès-verbaux de la CFB, 26.03.1945, p. 28-3I.

Cf. Pierre Grosser, «Printemps 1944 - été 1945 : une difficile victoire», in Alya Aglan, Robert Frank (éd.), 1937-1947, la guerre-monde, Paris: Gallimard, 2015, p. 710-769, ici p. 752-757. 
Fédérale, par contre, se trouve dans une meilleure position. Elle est parvenue à augmenter ses dépôts de fonds et semble moins dépendante des transferts d'intérêts d'outre-Rhin.

Le 30 avril 1945, par ailleurs jour du suicide d'Hitler, la Commission fédérale des banques discute les premiers renseignements obtenus auprès de la Banque Commerciale de Bâle. Pour le président de la CFB Ernst Wetter, elle est dans "une situation tragique ${ }^{49}$. Son bilan de 152 millions est encore grevé par des actifs soumis à des restrictions de transfert de plus de 39 millions, dont 25 millions en Allemagne. Dans l'ensemble, les engagements ne sont pas entièrement couverts par des actifs non soumis à des restrictions de transfert. Le compte profits et pertes, s'il était bouclé immédiatement, enregistrerait une perte liée aux intérêts manquants sur les crédits allemands prorogés (représentant plus de I.6 million de francs). Alors que les dirigeants de la banque (Max Brügger, Hermann Uehlinger et Emil Müller) envisagent diverses solutions - une réorganisation financière (réduction et souscription d'un nouveau capital-actions), une liquidation ou enfin une fusion -, les membres de la Commission fédérale des banques organisent déjà les préparatifs en vue d'une procédure de moratoire de paiements. D'après les prises de position émises à cette occasion, on comprend déjà que les superviseurs fédéraux, en accord avec la BNS, privilégient la piste d'une reprise par une autre grande banque. En effet, l'octroi d'un sursis bancaire, ou - pire une liquidation, pourrait avoir des conséquences néfastes sur la confiance du public dans les autres grandes banques helvétiques ${ }^{50}$. Il semble alors que de premières négociations de rachat par l'UBS, entamées dès fin 1944, échouent début juillet 1945 : l'UBS n'est prête qu'à reprendre certains actifs ${ }^{51}$. Au même moment, la CFB se plaint auprès des dirigeants de la Basler Handelsbank de leur inaction et leur enjoint de prendre rapidement une décision en vue d'une solution de reprise ou de liquidation ${ }^{52}$. À partir du 19 juillet 1945 , les dirigeants de la Handelsbank prennent contact avec leurs concurrents bâlois de la Société de Banque Suisse, en vue de négocier une fusion.

Dès lors, les événements se précipitent. En effet, les cours des actions des trois grandes banques suisses fortement engagées en Allemagne connaissent une forte baisse durant la deuxième quinzaine de juillet 1945. Cette baisse des cours provoque une accélération des négociations de reprise. Après avoir tourné le dos à la Basler Handelsbank, l'Union de Banques Suisses jette son dévolu sur la Banque Fédérale, dont la reprise lui apparait comme stratégiquement plus Perrenoud, et al., op. cit., 2002, p. 272. Sur les raisons de l'échec des négociations, cf. AFB, E652I(A), 1979/52, vol. 5, dossier I7*, lettre des dirigeants de la Basler Handelsbank à la CFB, 31.07.1945.

52 AFB, E652I(A), I979/52, vol. 5, dossier I9*, Lettre de la CFB au conseil d'administration de la Basler Handelsbank, 25.06.1945. 
intéressante ${ }^{53}$. Le 26 juillet 1945 , un communiqué annonce la reprise de la Banque Fédérale par l'UBS. Nous reviendrons plus bas sur les modalités de cette fusion. Pour la Banque Commerciale de Bâle, cette annonce péjore gravement sa propre situation. L'UBS est d'ailleurs consciente de l'impact négatif sur la $\mathrm{BHB}$, estimant qu'après l'aboutissement de l'absorption de la Banque Fédérale, la Banque Commerciale serait à la merci d'un éventuel repreneur ${ }^{54}$. Le cours des actions de la Basler Handelsbank connaît une chute vertigineuse à la suite de l'annonce de la fusion UBS-Banque Fédérale : alors que l'action se négociait encore à 275.- le 2 juillet I945, elle chute à 220.(17 juillet), puis 200.- (25 juillet), I70.- (26 juillet), I26.- (27 juillet), I08.(28 juillet), avant d'atteindre 70.- le 3I juillet, soit près du quart de sa valeur au début du mois ${ }^{55}$. Cette baisse de cours est accompagnée d'une accélération des retraits de dépôts. Dans la précipitation, le 3I juillet 1945, les dirigeants de la banque bâloise s'adressent à la Commission fédérale des banques pour demander l'octroi d'un sursis bancaire. Face à l'urgence de la situation, le secrétariat de la CFB doit même demander l'approbation de chacun des cinq membres de l'organe de surveillance par téléphone. Le sursis est accordé le $\mathrm{I}^{\text {er }}$ août et entre en vigueur immédiatement. La Schweizerische Treuhandgesellschaft, société fiduciaire bâloise proche de la SBS, est désignée comme commissaire de sursis, c'est-à-dire qu'elle devient l'instance autorisée à accorder exceptionnellement le remboursement d'un créancier. Le suicide du directeur général de la Basler Handelsbank, Max Brügger (I882-I945), le même jour, révélé par le quotidien socialiste Berner Tagwacht deux jours plus tard, nourrit évidemment l'inquiétude des déposants.

Une fois le sursis bancaire accordé par la CFB, les négociations de reprise avec la SBS se déroulent dans un climat plus serein, puisque le moratoire empêche la poursuite du run bancaire sur les dépôts de la BHB. Elles aboutissent le 5 octobre 1945 avec la signature d'un contrat entre la SBS et la Banque Commerciale de Bâle. Il ne s'agit pas d'une fusion intégrale, mais plutôt d'une reprise par la SBS d'une partie des actifs de la BHB. Plus précisément, la grande banque bâloise reprend ses actifs non bloqués, son patrimoine immobilier, ainsi que ses dépôts de titres et sa clientèle ${ }^{56}$. D'après l'avis public annoncé par la

53 Perrenoud, et al., op. cit., 2002, p. 269. La Banque Fédérale connait également une chute du cours de ses actions, qui passe de 355.- au début du mois de juillet à 252.- le 26 juillet 1945 . Cf. [s.n.], «Die neue Grossbankfusion », Basler Nachrichten, no 315, 28-29.07.1945.

54 Selon les termes d'Alfred Schaefer (1905-1986), directeur général d'UBS, devant le conseil d'administration de la même banque: "Nach durchgeführter Fusion mit der Eidgenössischen Bank wird eventuell die Basler Handelsbank einem Interessenten auf Gnade und Ungnade ausgeliefert sein, da keine der Grossbanken ein spezielles Interesse für die Basler Handelsbank haben dürfte». Archives UBS AG, fonds UBS, I200000I680, PV du CdA de l'UBS, 26.07.1945, cité in ibid., note 284, p. 269.

55 AFB, E652I(A), 1979/52, vol. 5, dossier 19*, Lettre de la CFB au conseil d'administration de la Basler Handelsbank, 25.06.1945.

56 Une copie du contrat de reprise est conservée dans les archives de la Commission fédérale des banques: AFB, E652I(A), I979/52, vol. 5, dossier I8*, «Übernahmevertrag zwischen dem 
SBS, les engagements repris s'élèvent au total à 89 millions de francs ${ }^{57}$. La Banque Commerciale de Bâle subsiste en tant qu'entité juridique distincte et reste soumise à la loi sur les banques, mais devient de fait une société de gestion des actifs encore bloqués en Allemagne; en 1958, elle se transformera en société financière, toujours placée sous l'orbite de la SBS ${ }^{58}$. Ce n'est qu'en i99I que la SBS se sépare de la société de participations héritées de la Basler Handelsbank, en la revendant au groupe genevois Harwanne ${ }^{59}$.

Du point de vue de la Commission fédérale des banques, l'accord conclu entre dirigeants bancaires le 5 octobre 1945 pose quelques difficultés juridiques. En effet, ceux-ci souhaitent que la CFB lève le plus rapidement possible le sursis bancaire, et demandent qui plus est qu'elle approuve le principe d'une reprise par la $\mathrm{SBS}^{60}$. La CFB s'exécute. Une fois informée par télégramme de la décision favorable de l'assemblée générale de la Basler Handelsbank qui accepte la reprise par la SBS, la CFB ordonne immédiatement l'abrogation du sursis bancaire.

Si les solutions de reprise négociées dans les deux cas permettent de diminuer les pertes pour les déposants bancaires par rapport à une simple disparition sous forme de liquidation ${ }^{61}$, les fusions impliquent néanmoins une forte diminution du personnel chez les banques concernées. Là aussi, la situation est encore plus grave chez la Basler Handelsbank que chez la Banque Fédérale. En effet, sur les 439 employés que la grande banque bâloise employait au début de l'année 1945 , I86 ont été mis à la retraite anticipée, et seuls IOO à 150 sont réengagés par la Société de Banque Suisse, d'après les informations de la CFB ${ }^{62}$. Ces chiffres sont confirmés dans un article de l'organe de l'association des employés de banque de décembre 1945 : seuls II 5 employés retrouvent du travail à la SBS, des indemnités de départ étant négociées pour les nombreux licenciés $^{63}$. Comme le relève la Commission fédérale des banques, les employés sont, avec les actionnaires, les principales victimes de la reprise par la SBS. Ces répercussions sociales, notamment pour les employés de plus de 55 ans dont les perspectives de réengagement sont difficiles, provoquent également des

Schweizerischen Bankverein und der Basler Handelsbank», 05.I0.1945. Voir aussi : Perrenoud, et al., op. cit., 2002, p. 272 ; Bauer, op. cit., 1988, p. 40-4I ; Bauer, op. cit., 1972, p. 289. des actions de l'UBS en compensation, les actionnaires de la Banque Commerciale de Bâle ne récupèrent pas des actions de la SBS, mais peuvent seulement espérer obtenir une éventuel gain lors de la liquidation des actifs allemands. Cf. AFB, E652I(A), 1979/52, vol. 5, dossier 19*, Lettre du secrétariat aux membres de la CFB, 2I.09.1945.

$62 \mathrm{AFB}, \mathrm{E} 652 \mathrm{I}(\mathrm{A}), 1979 / 52$, vol. 5, dossier $19^{*}$, Lettre du secrétariat aux membres de la CFB, 2I.09.1945.

63 E.B., "Um die Basler Handelsbank », Schweizerische Bankpersonal-Zeitung, nº 2I, OI.12.1945. 
interventions politiques. Une "petite question» du conseiller national démocrate Kurt Leupin (1907-1986) demande sans succès au Conseil fédéral, en juin 1945, d'interdire les licenciements de sept employés âgés. En septembre 1945, c'est au Grand Conseil bâlois que plusieurs interpellations concernant la situation de la Basler Handelsbank et le sort de ses employés sont déposées. Le conseiller d'État socialiste Gustav Wenk (1884-1956) rejette les demandes d'intervention étatique, en évoquant une part de responsabilité chez les employés de la banque, mettant en cause l'absence de conscience de classe ${ }^{64}$. La publication jubilaire de la SBS présente l'opération sous un jour plus favorable: "presque la totalité du personnel de la Banque Commerciale de Bâle avait retrouvé une occupation" d'ici fin $1945^{65}$. Mais cette formulation optimiste ne tient pas compte de nombreux licenciements et mises à la retraite anticipée qui ont lieu comme conditions préalables à la reprise par la SBS.

La presse ne manque pas de commenter cette absorption réalisée aux frais du personnel de la Banque Commerciale de Bâle. La figure 3 reproduit une caricature publiée dans le mensuel satirique bernois Bärenspiegel ${ }^{66}$. Elle représente au centre la Société de Banque Suisse qui vient au secours de la Banque Commerciale de Bâle, en « remerciant » son personnel. La Basler Handelsbank est incarnée par un mendiant famélique, qui arbore encore un symbole du III Reich, une indication que les raisons de la déconfiture de la banque étaient en grande partie connues des médias.

Dans l'autre cas de fusion, chez la Banque Fédérale, la situation est moins dramatique pour les employés. L'UBS réengage en effet environ les trois quarts des 800 employés et fournit un montant global de I.5 million de francs d'indemnités pour les 200 employés licenciés ${ }^{67}$. Sans trop entrer dans le détail, soulignons que le contrat de reprise de la Banque Fédérale par l'UBS, signé le 23 août 1945, est négocié et paraphé sans aucune intervention active de la $\mathrm{CFB}^{68}$. Il prévoit donc la reprise par l'UBS des 350 millions d'actifs non bloqués de la Banque Fédérale, qui subsiste en tant que société indépendante uniquement en tant société de gestion des avoirs gelés en Allemagne, puis en tant que société financière liée au groupe UBS ${ }^{69}$. Dans les deux cas, on assiste au maintien des anciennes entités juridiques, qui deviennent des structures de défaisance qui héritent des actifs toxiques. Dans les deux cas également, ces

\footnotetext{
64 [s.n.], «Sozialisierung der Konkursiten?», Arbeiter-Zeitung Basel, n 228, 29.09.1945.

65 Bauer, op. cit., I972, p. 290.

66 Cf. Fritz Blaser, Bibliographie der Schweizer Presse : mit Einschluss des Fürstentums Liechtenstein, Basel : Birkhäuser, 1956, p. II2.

67 [s.n.], «Zusammenschluss Eidg. Bank - Schweiz. Bankgesellschaft», Finanz und Wirtschaft, $\mathrm{n}^{\circ} 85,04.09 .1945$.

68 La CFB reçoit cependant un courrier de la Bankgesellschaft l'avertissant de la reprise de la Banque Fédérale en mettant en avant des raisons d'économie politique générale et de surpopulation bancaire en Suisse. AFB, E652I(A), 1979/5I, vol. 179, dossier 1068*, Lettre la direction générale de l'UBS à la CFB, 26.07.1945.

69 Herbert Raff, Union de Banques suisses : I862, 19I2, 1962, Zurich : Orell Füssli, 1962, p. I23I25.
} 
Figure 3. Caricature représentant la reprise de la Banque Commerciale de Bâle par la Société de Banque Suisse, Bärenspiegel, octobre 1945

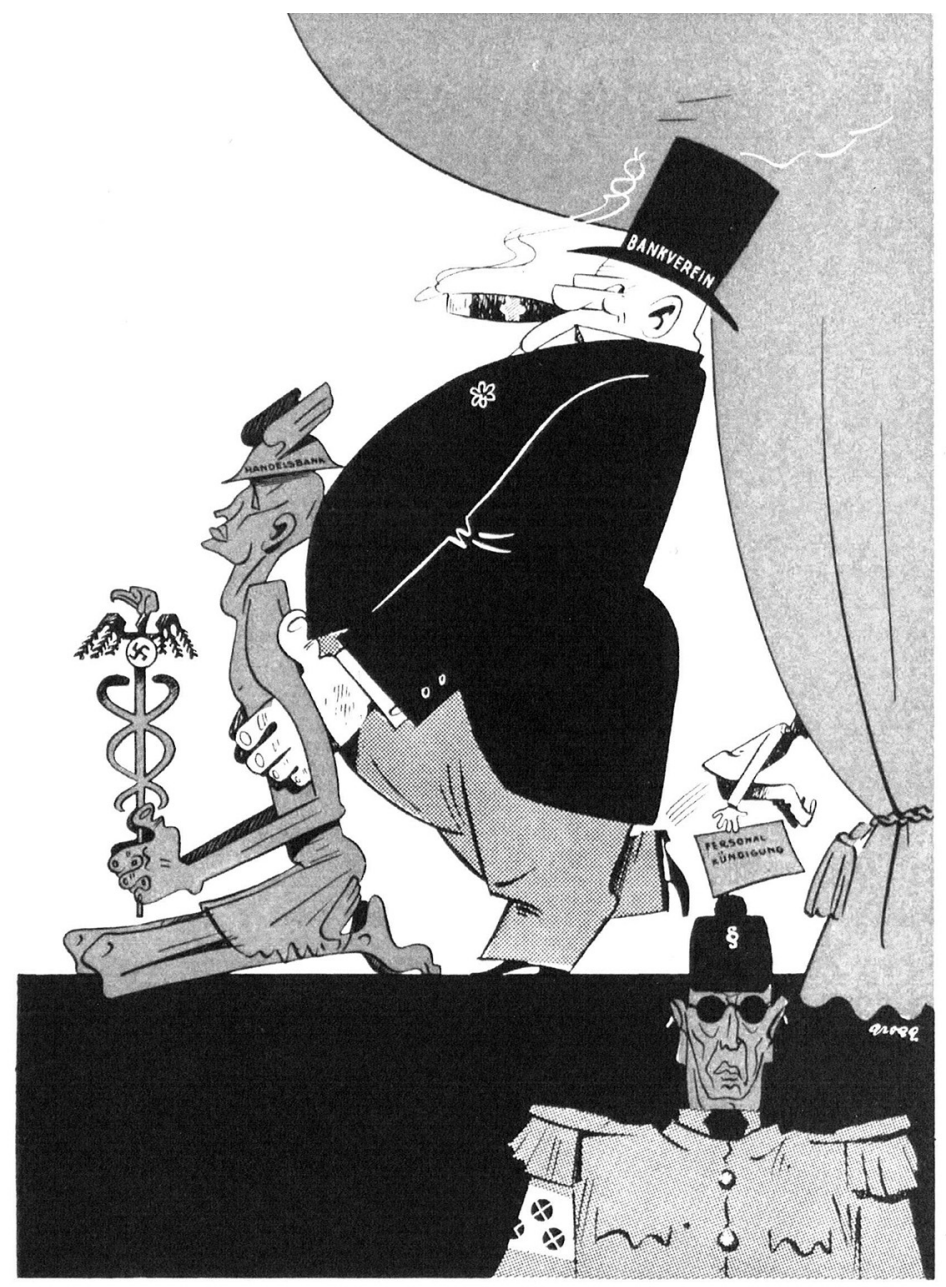

Zum Zusammenbruch der Basler Handelsbank:

Das ist das Bild von der spekulierenden und der hilfreichen Bank und ihrem überwältigend herzlichen Dank an das Personal, das nichts dafür kann, daß der Pulver - dehors - in Nichts zerrann. Und wir fragen uns immer und immerdar: Hat man denn höheren Ortes den Star? Grogg.

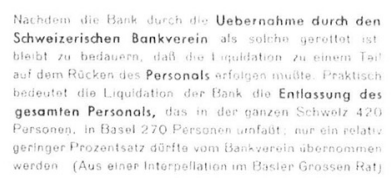

Source: Grogg, "Zum Zusammenbruch der Basler Handelsbank », Bärenspiegel, octobre 1945, vol. $23, \mathrm{n}^{\circ}$ Io. Traduction du texte: L'effondrement de la Banque Commerciale de Bâle: Voici l'image de la banque spéculative et de la banque secourable, et de ses remerciements très chaleureux au personnel, qui n'y peut rien si la poudre - dehors - est partie en fumée. Et nous nous demandons toujours et encore: est-on aveugle en haut lieu? 
sociétés financières subsistantes parviennent à obtenir des remboursements sur les créances allemandes, puis à dégager des bénéfices à la faveur du Wirtschaftswunder de l'Allemagne de l'Ouest ${ }^{70}$.

Du point de vue des deux grandes banques qui se portent acquéreur, les opérations de reprise de l'été et de l'automne 1945 sont largement bénéfiques. Pour la SBS, l'acquisition du portefeuille de titres de la Banque Commerciale de Bâle est très profitable. En reprenant la clientèle de son ancien concurrent bâlois, elle intègre également un nouveau réseau d'influence. La SBS récupère ainsi les mandats d'administrateurs de la Basler Handelsbank dans des sociétés comme «la Bâloise » Assurances ou encore l'Indelec, société financière spécialisée dans le financement de l'industrie électrique ${ }^{71}$. Pour l'UBS, les bénéfices de la reprise de la Banque Fédérale sont encore plus importants. L'opération implique un véritable bond dans le volume d'affaires de l'UBS. La somme de son bilan augmente de $42 \%$ (de 824 à II74 millions de francs). Cette progression est particulièrement prononcée dans des régions où la Banque Fédérale était relativement bien implantée, comme en Suisse romande. Le bilan de l'UBS sur la place genevoise double sous l'effet de l'incorporation du comptoir de la Banque Fédérale ${ }^{72}$. Dans les villes où elle était déjà présente, l'UBS obtient des bénéfices importants dans la revente des immeubles de la Banque Fédérale, tout en conservant sa clientèle ${ }^{73}$. L'absorption de la Banque Fédérale se révèle donc être une étape décisive dans l'expansion sur le marché domestique de l'UBS au cours de l'après-guerre. Elle permet de mieux comprendre la forte augmentation du nombre de succursales de l'Union de Banques Suisses dès la fin de la Seconde Guerre mondiale, évoquée plus haut.

La restructuration du groupe des grandes banques qui s'opère entre juin et octobre 1945 marque une phase cruciale dans la transition entre l'économie de guerre et les conditions de concurrence de l'après-guerre. Les reprises de la Banque Commerciale de Bâle et de la Banque Fédérale, respectivement par la SBS et l'UBS, mettent définitivement un terme à la situation difficile des crédits prorogés hérités de la crise bancaire des années 1930. L'effondrement des dernières structures étatiques et économiques du troisième Reich en mai 1945 précipite la chute des deux banques mentionnées, qui n'étaient pas parvenues à liquider leurs actifs allemands et à réorienter leurs politiques de crédit.

$\mathrm{Au}$ cours de ce processus central de réorganisation des poids lourds de la finance helvétique, la Commission fédérale des banques joue un rôle d'intermédiaire dans un des deux cas. En effet, à cause de son rôle dans l'octroi d'un moratoire de paiement à la Banque Commerciale de Bâle en août 1945, elle est étroitement impliquée dans les négociations de reprise. Étant donné la gravité de la situation de l'établissement bâlois et l'absence d'alternatives, la CFB

Cf. Bernard Degen, "Banque Commerciale de Bâle ", in Dictionnaire historique de la Suisse, vol. 2, Hauterive: Attinger, 2003, p. 6.

Bauer, op. cit., I972, p. 29I.

Loepfe, op. cit., 20II, note 37, p. 24.

Raff, $o p$. cit., 1962, p. 126. 
semble favoriser une incorporation à la SBS, qui représente un moindre mal pour les créanciers de la Basler Handelsbank. Dans l'optique de la CFB, les pertes des actionnaires et les licenciements du personnel bancaire passent clairement au second plan. Dans ce cas, nous constatons que la Commission fédérale des banques joue un rôle actif de médiateur entre la banque en difficulté, son commissaire de surveillance et les éventuels repreneurs. Cet arbitrage semble dépasser le strict cadre d'exécution des dispositions légales. En ce sens, les événements de l'été 1945 constituent pour la CFB l'épilogue du rôle de médecin des banques qu'elle avait endossé au plus grave de la crise bancaire lors de son entrée en fonction dans la seconde moitié des années I930.

Quoi qu'il en soit, le rôle d'entremetteur dans le cadre de fusions bancaires répondait bien à l'esprit de la loi sur les banques, qui voulait limiter l'intervention publique au minimum. En rendant superflu un renflouement étatique, les reprises de l'été 1945 soulignaient également la capacité retrouvée des acteurs financiers à s'autoréguler. Contrairement à la situation des années 1930, les deniers publics ne sont pas sollicités dans les assainissements de 1945 .

\section{VII.3. UNE AUTORITÉ PRIVÉE DE MOYENS DE SANCTION. L'IMPUISSANCE DE LA CFB FACE À UNE BANQUE RÉCALCITRANTE: LE CAS DE LA KREDIT- \& VERWALTUNGSBANK ZUG AG (1947-1959)}

Comme mentionné dans les précédents chapitres, les compétences de la Commission fédérale des banques propres à assurer l'application des dispositions légales étaient définies de manière laconique et limitée dans la loi sur les banques. Au fond, la CFB ne dispose que de quatre types de mesures face à un établissement bancaire qui ne suit pas ses recommandations: ordonner une révision extraordinaire, inviter la banque à régulariser sa situation dans un délai imparti, déférer le cas aux autorités administratives ou judiciaires compétentes - c'est-à-dire déposer une plainte, voire déléguer un commissaire -, ou enfin ordonner une amende d'ordre par l'intermédiaire du Département fédéral des finances et des douanes. Cette amende s'élève entre 1935 et 197I au montant maximal fort peu dissuasif de I ooo francs ${ }^{74}$. Dans l'ensemble, la prise de sanction de la Commission fédérale des banques est à la fois très limitée dans son ampleur qualitativement et quantitativement.

Rappelons qu'une première étape de résolution des éventuelles infractions se situe déjà en amont, avant même que l'autorité fédérale ne soit tenue au

74 Art. 5I, LFB. Daniel Bodmer, secrétaire de la CFB entre 1954 et 1976, estime que les deux «moyens de contrainte» que sont le dépôt de plainte et l'amende d'ordre constituent des «armes émoussées, dans le cas graves, lorsqu'on a affaire à des gens faibles, récalcitrants, ou même criminels ». Daniel Bodmer, "Aufgaben und Tätigkeit der Eidgenössischen Bankenkommission ", in Emil Gsell (éd.), Banken und Bankgeschäfte in der Schweiz, Bern ; Stuttgart: Paul Haupt, 1969, p. 8I-87, p. 85. 
courant. En effet, selon le système de contrôle indirect, une société fiduciaire doit d'abord elle-même inviter la banque à régulariser sa situation, et n'en réfere à la CFB que si ses exigences ne sont pas prises en compte ou dans les cas graves (si les créanciers ne sont plus couverts par les actifs). La transmission d'un rapport de révision à la Commission n'a lieu que dans deux situations, pour l'essentiel. D'une part, lorsqu'une nouvelle banque est fondée, ce qui implique que la CFB exige des rapports de révision durant les premières années d'activité pour se faire une idée du type d'instituts. D'autre part, quand un établissement présente des irrégularités graves, à tel point que la société de révision estime qu'elle doit en informer la Commission fédérale des banques.

Un premier indicateur de l'importance du travail «disciplinaire» de l'autorité de régulation consiste donc dans le nombre de rapports de révision qu'elle traite. Même si cette prise d'information n'implique de loin pas une mesure corrective de la part des superviseurs, elle donne toutefois un indice du nombre de banques dont elle s'occupe activement. À partir des chiffres présentés plus haut sur le nombre de rapports de révision traités par la CFB, nous avons pu déterminer qu'entre 1935 et 1975, elle traite en moyenne 90 rapports de révision par année (cf. graphique I3, chap. VII.I.2). Plus précisément, la moyenne de rapports de révision traités passe de 6o pour la période 1937-1946 à 7I entre 1949 et I958, 92 entre 1959 et I970 et enfin, I66 entre I97I et 1975. En retranchant de ce nombre total moyen de rapports de révision, les rapports qui sont transmis pour les nouvelles banques fondées, on arrive à 68 rapports en moyenne sur l'ensemble de la période examinée. Si l'on rapporte maintenant ce chiffre au total de banques établies en Suisse, on obtient qu'en moyenne entre 1935 et 1970, la CFB traite les rapports de révision de 4 à I2 \% des banques. La fluctuation dépend du chiffre que l'on sélectionne pour déterminer le nombre de banques en Suisse : en incluant les caisses Raiffeisen individuellement, on arrive à $4 \%$, en les excluant, à I $2 \%$. Le tableau 22 récapitule le calcul de la proportion de banques qui inquiètent la CFB.

Les statistiques sur le nombre de plaintes déposées par la Commission fédérale des banques contre des établissements financiers sous sa surveillance donnent une seconde mesure de l'utilisation des compétences de sanction. D’après Bänziger, entre I935 et 1971, la CFB aurait déposé 24 plaintes, dont 6 avant 1964 et 18 après ${ }^{75}$. Mais ces chiffres ne sont pas clairement référencés par l'auteur et ne correspondent pas aux données extraites des archives. Pour la période d'avant 1964, des rapports produits à l'occasion d'un débat de principe mené au sein de la CFB sur sa politique de sanction fournissent des données plus précises. Il ressort de la figure 4 qu'entre 1935 et I964, la Commission fédérale des banques a déposé $\mathrm{I} 6$ plaintes, contre Io banques différentes ${ }^{76}$.

75

76

Bänziger, op. cit., 1986, p. I86.

AFB, E652O(A), 1983/50, vol. 32, dossier Sanktionsbestimmungen 1963-1974, Rapport du secrétariat de la CFB aux membres CFB sur «Bedeutung der Strafanzeigen und Strafandrohungen in der Praxis der Bankenkommission », 02.12.1964. 


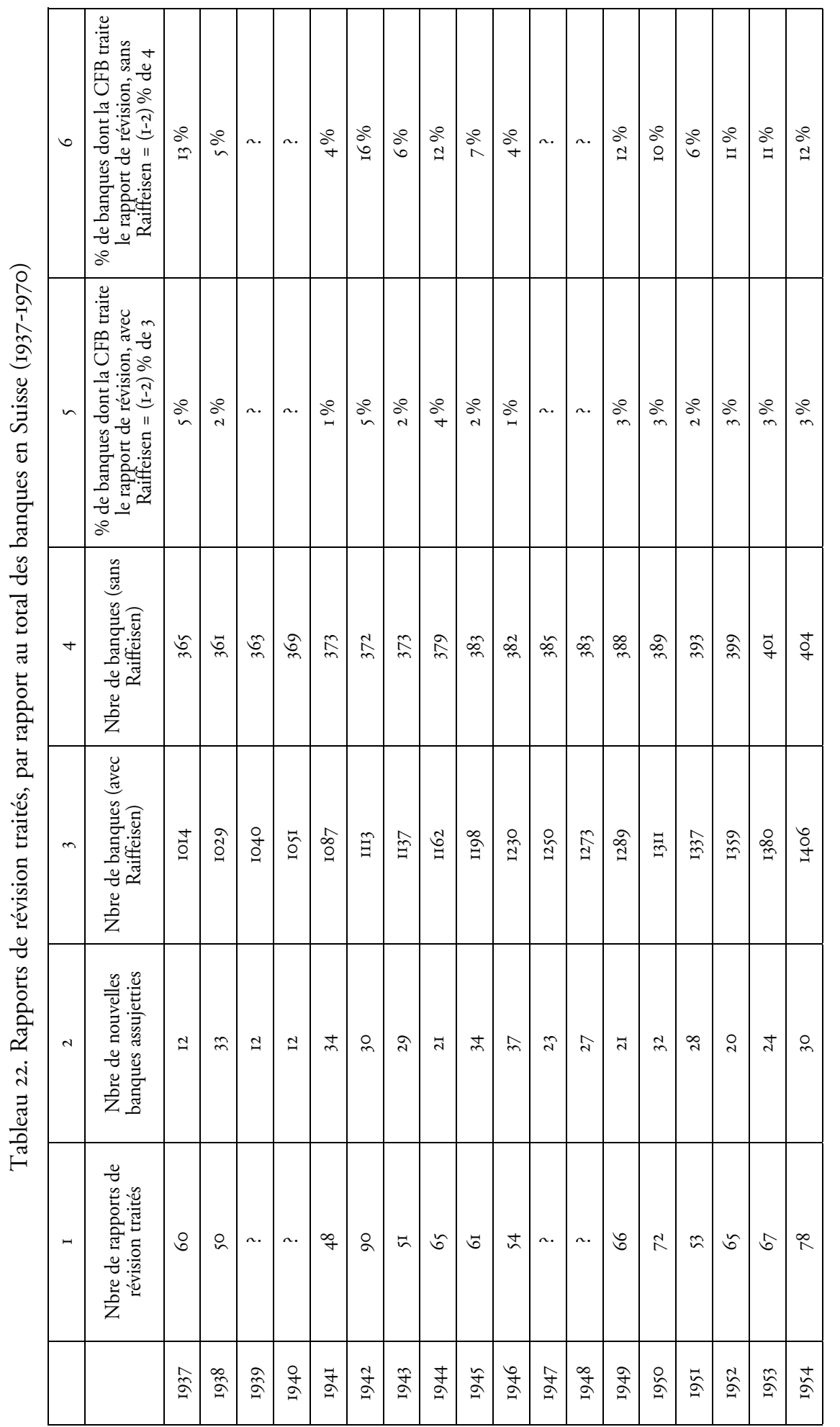




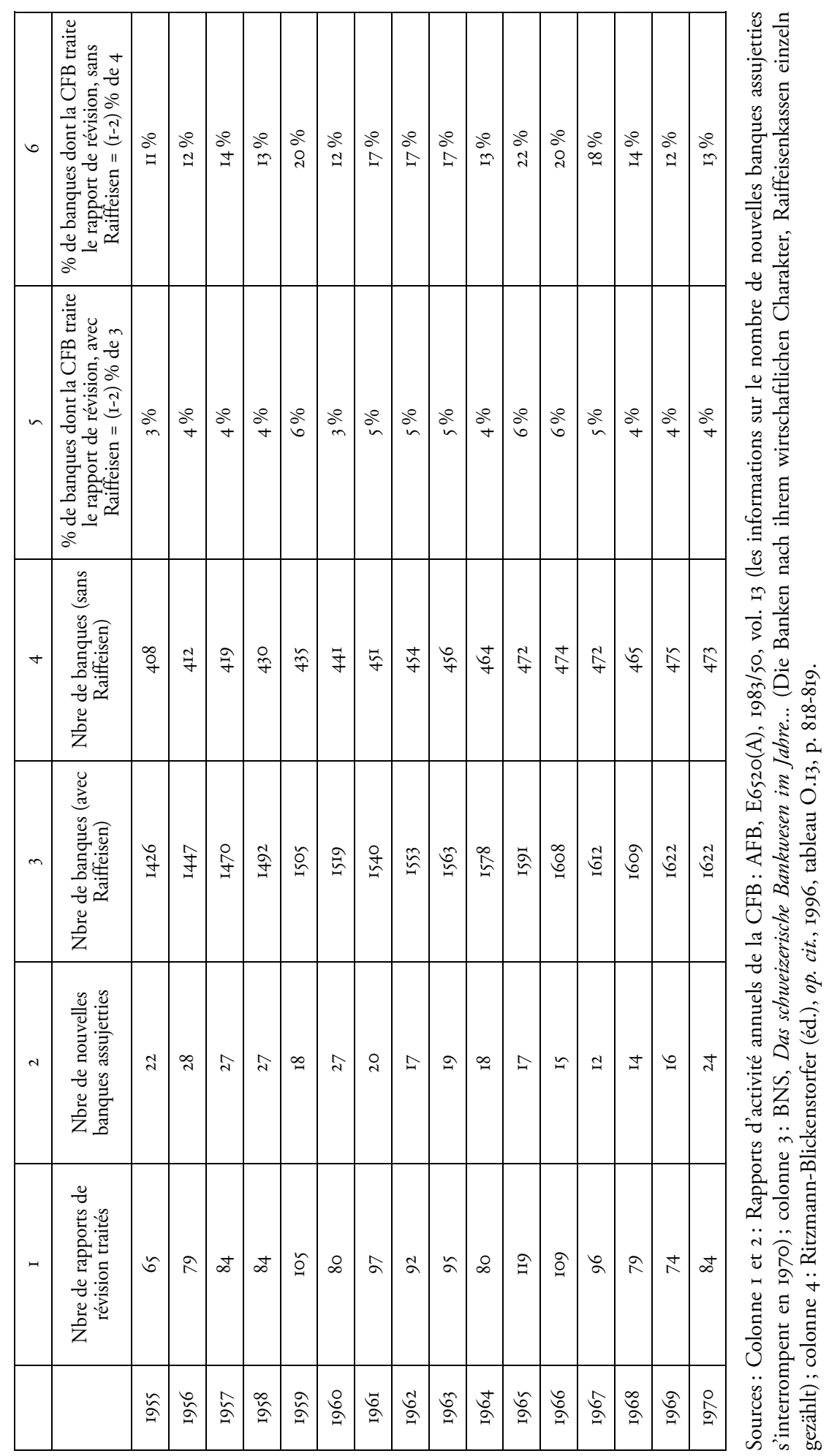


Figure 4. Liste des banques visées par une ou plusieurs plaintes déposées par la CFB (1935-1964)

\begin{tabular}{|l|l|}
\hline I. & WIR Wirtschaftsring-Genossenschaft, Basel (1943) \\
\hline 2. & Bank in Zug, in liquidation (I943) \\
\hline 3. & Moser AG, Bankgeschäft, Luzern (1947) \\
\hline 4. & Kredit- \& Verwaltungsbank Zug (1947, I956, 1957, 1958, 1959) \\
\hline 5. & Brunner \& Co., Luzern (I95I) \\
\hline 6. & Hypothekar- \& Commerzbank, Zürich (195I, 1953) \\
\hline 7. & Immobilien-Bank AG, Zürich (1956, I958) \\
\hline 8. & Banque Mercantile, Genève (1959) \\
\hline 9. & Paul de Werra, Banquier, Sion (1963) \\
\hline IO. & Interchange Bank, Chiasso (1964) \\
\hline
\end{tabular}

Source: AFB, E6520A, 1983/50, vol. 32, dossier Sanktionsbestimmungen 1963-1974, Rapport du secrétariat de la CFB aux membres CFB sur «Bedeutung der Strafanzeigen und Strafandrohungen in der Praxis der Bankenkommission ", 02.I2.1964.

En plus de ces 16 plaintes qui ont effectivement été déposées, il faut également signaler un certain nombre de cas où la menace de dépôt de plainte a suffi à corriger les manquements. Entre 1960 et 1964, au moins ig banques sont concernées par une telle intervention.

Quant aux amendes d'ordres, la CFB en a fait un usage encore plus limité. Alors que Bänziger articule le chiffre non référencé de 6 amendes d'ordre, les rapports d'activité annuels de la CFB mentionnent au moins is amendes pour la période 1936-1967. Il faut toutefois considérer ce chiffre d'une quinzaine de contraventions comme une évaluation minimale. Il n'existe à notre connaissance pas de document récapitulatif à long terme sur l'administration d'amendes par la CFB. Nous disposons seulement de quelques documents sur la période 1935-1944, au cours de laquelle quatre contraventions sont ordonnées, visant trois banques locales; l'infraction commise dans les trois cas consiste en la non-observation de l'obligation de s'annoncer à la CFB en tant que banque ; en d'autres termes, une négligence d'ordre administratif ${ }^{77}$. Ce n'est qu'au cours des années 1960, d'après les informations contenues dans les rapports annuels de la $\mathrm{CFB}$, que quelques amendes seront à nouveau infligées. Lors de la révision de la loi sur les banques de 197i, le montant maximal de l'amende passe de I 000 à 5000 francs.

$\mathrm{Si}$, dans l'ensemble, il faut légèrement corriger à la hausse les estimations de Bänziger sur l'usage des différents moyens de sanction de la CFB, il n'en reste pas moins que ces mesures restent insignifiantes. Nous allons voir dans le cas de la Kredit- und Verwaltungsbank Zug que leur efficacité est également médiocre.

77 AFB, E6100(A-I5), I000/1915, vol. 8, dossier 920 «Art. 5I des Bankengesetzes Bussenverfügungen ". 


\section{Impuissance face à la Kredit- und Verwaltungsbank Zug (1944-1959)}

Après ce bref aperçu quantitatif et diachronique de l'emploi de mesures disciplinaires par la CFB pour assurer l'application de la loi, abordons la même problématique sous un angle plus qualitatif. Le cas très frappant de la Kreditund Verwaltungsbank, établie à Zoug, sera abordé ici. Les éléments exposés plus bas se basent d'une part sur l'analyse fournie par Hugo Bänziger, d'autre part sur les volumineux dossiers conservés dans les fonds d'archives de la $\mathrm{CFB}^{78}$. Notons d'emblée que ce contentieux entre l'autorité de surveillance et la Kredit- und Verwaltungsbank, tout remarquable qu'il soit par la durée du litige et par la gravité des faits incriminés, représente bien un cas extraordinaire qui n'a pas valeur emblématique ${ }^{79}$. Malgré ces quelques réserves sur l'exemplarité du cas, l'affaire illustre par contre parfaitement l'inefficacité des dispositions légales prévues pour contrer une banque délictueuse. Il paraît d'autant plus important d'évoquer ce cas, si l'on mesure à quel point il a focalisé l'attention des superviseurs fédéraux pendant de nombreuses années. Entre I945 et I960, la banque en question apparaît 79 fois à l'ordre du jour des I84 séances que tient la CFB pendant ces quinze années. Il s'agit donc bien d'un délinquant récidiviste pour le "gendarme des banques" helvétique.

Fondée en 1933 à Zoug, la Kredit- und Verwaltungs AG Zug est assujettie à la loi sur les banques par la CFB en novembre 1940. Disposant d'un capitalactions de 20 ooo francs, elle est à l'origine plutôt une société de participations et de financement, mais est soumise à la loi, car elle s'est engagée dans l'octroi de petits crédits. Son bilan est alors de 106 ooo francs et ses deux administrateurs et uniques dirigeants sont le Zougois Albert Zürcher (I9I2-?) et le Lucernois Max Kaufmann (I9I5-?). En mai I94I, la société change de raison sociale et devient la Kredit- und Verwaltungsbank Zug AG, son capital social augmente à 50000 francs. Elle entreprend alors une campagne publicitaire intensive faisant la promotion de taux d'intérêt créditeur à $4 \frac{1}{2} \%$ sur les dépôts d'épargne (le taux standard s'élevant alors à environ $3 \%$ ). La multiplication d'annonces dans la presse nationale suscite l'étonnement et des plaintes sont adressées à la Commission fédérale des banques. En juillet I942, l'ASB intervient pour relayer les doléances d'une banque et demander quelles mesures peuvent être prises contre de tels agissements ${ }^{80}$. La CFB lui répond que la loi sur les banques ne contient aucune disposition qui permette d'intervenir contre une société proposant des conditions de crédit abusives. Elle décide cependant de garder cette banque à l'œil et d'en exiger régulièrement les rapports de révision. Les disciplinaire, le président Max Hommel insiste à juste titre sur le caractère exceptionnel de l'attitude des dirigeants de la banque, qualifiés de "criminels primaires et peu intelligents ". AFB, E6520(B), I980/39, vol. I6, PV CFB, 09.12.1964, p. 26I-262.

80 AFB, E652I(A), I979/52, vol. 7I, dossier 342*, Lettre de l'ASB à la CFB, 02.07.1942. Cf. aussi AASB, Lettre du secrétariat ASB aux banques-membres, 07.07.1942, annexée au procèsverbal de la $153^{\mathrm{e}}$ séance du Conseil d'administration de l'ASB du 5 août 1942. 
premières informations qu'elle obtient ainsi confirment que la société, du côté des actifs, est principalement orientée vers le petit crédit, et, du côté des passifs, se finance essentiellement par des dépôts d'épargne et des crédits interbancaires, dont l'origine n'est malheureusement pas précisée; ses fonds propres sont insuffisants. D'autres transgressions sont rapidement identifiées: des erreurs dans l'établissement du bilan, des risques excessifs, un manque de réserves et une organisation interne non conforme (les mêmes personnalités étant à la fois directeurs et administrateurs de la banque).

Pendant une première phase, entre juillet 1944 et juin 1946, la CFB entreprend plusieurs démarches pour remédier aux manquements constatés. Après avoir simplement signalé les problèmes aux dirigeants, elle ordonne une révision extraordinaire et fixe un délai pour régler les différentes infractions avérées. La révision extraordinaire est ensuite retardée à tel point qu'elle est finalement regroupée avec la révision ordinaire pour 1945. En mai 1946, la CFB ne peut que constater que la situation a encore empiré: le placement de dépôts d'épargne dans des investissements risqués préoccupe les superviseurs fédéraux. L'affaire pourrait devenir "très gênante", si la banque rencontrait de sérieuses difficultés ${ }^{81}$. En juin 1946, la Kredit- und Verwaltungsbank Zug communique qu'un troisième administrateur a été nommé (Hans Bussmann), que le capital social a été augmenté à 200000 francs, et que les exigences de liquidité sont désormais respectées.

Mais cette embellie passagère n'est qu'un leurre. La banque zougoise a en réalité transmis des chiffres falsifiés à son institut de révision, la Revisa AG. L'audit réalisé sur l'année 1946 a en effet mis à jour de nombreuses irrégularités : surévaluation d'actifs, travestissements de bilan, comptabilisations arbitraires sous le mauvais poste. Le rapport révèle en outre que l'entreprise a réorienté ses principales activités : les affaires spéculatives (comme un important crédit à une société produisant des appareils de football de table et les distribuant en France et en Belgique) et les transactions immobilières ont pris le pas sur le microcrédit. La Revisa annonce en mai 1947 qu'elle se démet de son mandat de société de révision.

En septembre 1947, la CFB décide pour la première fois de déposer une plainte contre la Kredit- und Verwaltungsbank, pour établissement non conforme de la comptabilité annuelle et refus de communiquer des informations à la société de révision ${ }^{82}$. Cette plainte provoque l'ouverture d'une enquête pénale par le Ministère public du canton de Zoug.

Tandis que l'enquête du juge d'instruction tire en longueur, Max Kaufmann, le principal accusé en tant que responsable de la comptabilité, demande à plusieurs reprises à la CFB de lever la plainte, car l'enquête nuit aux affaires de la banque et que les rapports de révision produits par la nouvelle fiduciaire,

81 AFB, E6520(A), I000/I059, vol. 8, PV CFB, 20.05.1946, p. 43.

$82 \mathrm{AFB}, \mathrm{E} 652 \mathrm{I}(\mathrm{A}), \mathrm{1979} / 52$, vol. 7I, dossier $342^{*}$, Lettre de la CFB à la Staatsanwaltschaft des Kantons Zug, 08.09.1947. 
l'INDEP, sont d'après lui conformes. Le I6 février I95I, soit près de trois ans et demi après son dépôt, l'instruction pénale est levée, au motif qu'il n'est pas avéré que les accusés ont délibérément falsifié les bilans. Si elles n'ont été commises que par négligence, les infractions sont désormais prescrites; seuls les frais administratifs de la procédure (72I francs) sont à la charge des deux dirigeants accusés. La CFB réagit en écrivant aux autorités judiciaires zougoises pour exprimer son étonnement face à la durée de l'instruction ${ }^{83}$. Dans l'intervalle, entre 1947 et 195I, la situation de la banque semble s'améliorer légèrement; une augmentation de capital fin 1950 rétablit un rapport de couverture suffisant.

Mais le rapport de révision sur l'année 1951, discuté par la CFB à l'été 1952, lève le voile sur des insuffisances persistantes. Le taux de couverture (niveau de fonds propres par rapport aux engagements) est déficient, et la politique de crédit de la banque, qui consiste à financer des crédits à haut risque avec des dépôts d'épargne, bénéficiant d'un privilège en cas de faillite, inquiète toujours autant l'autorité de surveillance. La CFB exige de la banque zougoise une amélioration rapide du rapport de couverture et un changement dans la politique de crédit; parallèlement, elle demande une nouvelle expertise de la fiduciaire INDEP sur l'évaluation de certains postes importants. Les membres de la CFB ont désormais tous la conviction qu'ils ont affaire à une "banque bidon" (Schwindelbank), qui a attiré plus de 5 millions de fonds d'épargne avec des taux d'intérêt surfaits et les place d'une manière "qui défie l'entendement " ${ }^{84}$.

En revanche, les modalités d'intervention font débat. On se met finalement d'accord pour convaincre dans un premier temps la société de révision de la gravité de la situation, avant d'entamer des négociations avec les dirigeants de la banque. La réunion avec l'INDEP divulgue plus de détails sur les relations d'affaires diversifiées de la Kredit- und Verwaltungsbank: en plus du financement de la société de manufacture de baby-foot, elle pratique des transactions immobilières, finance les projets d'un inventeur, ceux d'un explorateur-marchand de cuir de crocodile planifiant une expédition en Ethiopie, et enfin octroie des crédits à une fabrique de gants au Liechtenstein qui ne réalise aucun bénéfice. Très récemment, la banque s'est lancée dans le financement d'une société, dont Zürcher et Kaufmann sont également administrateurs, produisant des aéroglisseurs hydroptères de première génération: la Supramar AG, établie à Zoug en septembre 1952, est en effet une société filiale de la banque en question.

Le I9 décembre 1952 a lieu un entretien avec les dirigeants de la banque. Les membres de la CFB cherchent alors à leur remonter les bretelles, en démontrant à quel point la Kredit- und Verwaltungsbank sort du rang, dans sa politique de crédit, par rapport aux statistiques générales des banques locales en Suisse. La séance se termine par une profession de foi du directeur Max 
Kaufmann, qui se déclare ouvert aux critiques émises et sensible à la grande responsabilité que font peser sur lui les fonds confiés. Les superviseurs fédéraux en ressortent plutôt rassurés. Hommel déclare lors de la séance plénière suivante que les deux dirigeants «ne font pas une mauvaise impression [...], sont d'habiles hommes d'affaires, [...] qui veulent s'enrichir rapidement ${ }^{85}$.

Deux ans plus tard, tandis que les affaires spéculatives de la banque poursuivent leur développement dangereux, Hommel, devenu vice-président de la CFB, se rend compte du peu de crédit qu'il faut accorder aux promesses des dirigeants. Les investissements dans les sociétés de football de table augmentent continuellement et atteignent en 19542.3 millions de francs. Les membres de la Commission fédérale des banques s'aperçoivent également que toute l'affaire peut avoir des répercussions gênantes sur leur propre crédibilité. Mais ils constatent que la loi sur les banques ne leur donne que très peu de moyens d'intervention dans un tel cas. En décembre 1954, la CFB décide de fixer un nouveau délai à la banque pour qu'elle réduise les placements spéculatifs et étrangers, qu'elle augmente son capital, et qu'elle agrandisse son conseil d'administration. Ses exigences sont formulées sous menace d'un nouveau dépôt de plainte. La réponse des dirigeants de la banque est dilatoire: ils se sentent persécutés et cherchent à montrer que certaines irrégularités sont répandues parmi d'autres banques locales ${ }^{86}$.

Le tableau 23, qui résume le développement de la banque zougoise, montre clairement à quel point son bilan est gonflé par l'accroissement des dépôts d'épargne. Le changement du modèle d'affaires et la réorientation vers le drainage de l'épargne, rétribuée par des taux élevés, s'opère essentiellement entre 1945 et 1949 .

Tableau 23. Évolution du bilan, des dépôts d'épargne et du capital-actions de la Kreditund Verwaltungsbank, en milliers de francs courants (1939-1958)

\begin{tabular}{|l|c|c|c|c|}
\hline & I & 2 & 3 & $4(2$ en \% de I $)$ \\
\hline & Bilan & Dépôts d'épargne & Capital-actions & Épargnes en part du bilan \\
\hline I939 & I40 & $?$ & 20 & $?$ \\
\hline I940 & I06 & $?$ & 50 & $?$ \\
\hline I94I & 221 & $3 \mathrm{I}$ & 50 & I4.0 \\
\hline I942 & 417 & 96 & 50 & 23.0 \\
\hline I943 & I 050 & 220 & 50 & 21.0 \\
\hline I944 & I 650 & 348 & 100 & 28.4 \\
\hline I945 & I 970 & 559 & 150 & 36.3 \\
\hline I946 & 2513 & 912 & 200 & \\
\hline
\end{tabular}

86 AFB, E652I(A), 1979/52, vol. 71, dossier 343*, Lettre de la Kredit- und Verwaltungsbank à la CFB, 25.II.I953. 


\begin{tabular}{|c|c|c|c|c|}
\hline & I & 2 & 3 & $4(2$ en $\%$ de $\mathrm{I})$ \\
\hline & Bilan & Dépôts d'épargne & Capital-actions & Épargnes en part du bilan \\
\hline 1947 & 3167 & I 442 & 200 & $45 \cdot 5$ \\
\hline 1948 & 3980 & $2 \mathrm{I} 64$ & 300 & $54 \cdot 4$ \\
\hline I949 & 4671 & 2759 & 300 & 59.1 \\
\hline 1950 & 5803 & 3408 & $\begin{array}{c}500 \\
\text { (dont } 400 \text { libérés) }\end{array}$ & 58.7 \\
\hline $195 \mathrm{I}$ & 6898 & 3902 & $\begin{array}{c}500 \\
\text { (dont } 400 \text { libérés) }\end{array}$ & 56.6 \\
\hline 1952 & 8293 & 4588 & 600 & $55 \cdot 3$ \\
\hline 1953 & 9745 & 5509 & $\begin{array}{c}800 \\
\text { (dont 650 libérés) }\end{array}$ & 56.5 \\
\hline 1954 & I2 I24 & 6526 & $\begin{array}{c}\text { I } 000 \\
\text { (dont } 750 \text { libérés) }\end{array}$ & 53.8 \\
\hline 1955 & I2 446 & 7560 & I OOO & 60.7 \\
\hline 1956 & $1356 \mathrm{I}$ & 8279 & I OOO & 6I.I \\
\hline 1957 & I4 8I2 & 8568 & I OOO & 57.8 \\
\hline 1958 & I5 037 & 8335 & I OOO & 55.4 \\
\hline
\end{tabular}

Sources: AFB, E652I(A), I979/52, vol. 73, dossier 352*, "Uebersicht über die alljährlichen Interventionen der Eidg. Bankenkommission", 02.II.I959. Années manquantes (bilan et capital-actions) : Das schweizerische Bankwesen im Jahre, années correspondantes.

En 1955, la CFB entreprend des démarches allant toujours dans le même sens: elle constate des insuffisances, pose de délais qui ne sont pas tenus, menace de déposer plainte et ordonne une révision extraordinaire. Le 27 juillet I955 a lieu une nouvelle conférence avec les administrateurs de la banque, qui sont désormais quatre: deux avocats, le Zurichois Ernst Beckhard (1896-?), et Paul Meyer (1913-?), fils de l'ancien conseiller national radical zougois Albert Meyer (I884-I950), ont rejoint Kaufmann et Zürcher. Diverses promesses de réduire certains engagements risqués sont réitérées par les dirigeants de la banque zougoise. La CFB maintient cependant l'exécution d'une révision extraordinaire. Celle-ci révèle, en octobre 1955, un surendettement d'environ 700000 francs. En décembre 1955, la CFB fixe un nouveau délai à fin avril 1956 pour augmenter le capital de la banque et enjoint aux dirigeants d'entamer une modification fondamentale de la politique de crédit de la banque en réduisant les postes risqués. Le io janvier 1956, la Kredit- und Verwaltungsbank dépose un recours de droit administratif auprès du Tribunal fédéral contre l'injonction de la CFB visant à une augmentation de capital. Ce recours implique un effet suspensif sur les injonctions de la CFB. En mai 1956, le Tribunal fédéral rejette le recours de la banque zougoise. Pour la première fois, les membres de la CFB évoquent l'idée que ce cas donne lieu à une première défaillance du privilège sur les dépôts d'épargne. Autrement dit, les petits épargnants, qui, d'après les 
renseignements pris auprès de la Banque cantonale de Zoug, ne sont pas au courant de la situation, contrairement aux milieux d'affaires zougois, subiraient d'importantes pertes ${ }^{87}$.

Au cours de l'automne 1956, les événements se précipitent. Le rapport de révision sur l'année 1955 expose une dégradation de la situation. Les besoins de provisions dépassent les fonds propres d'environ 400 ooo francs. La CFB, brandissant la menace d'un dépôt de plainte pour mise en danger des créanciers, intime aux dirigeants de réduire l'endettement pour atteindre les taux de couverture légaux, ou d'informer le juge cantonal zougois de la situation. Les multiples délais fixés par la CFB expirent sans que des mesures jugées adéquates soient prises. Le dilemme est le suivant pour les superviseurs fédéraux : soit ils déposent une plainte, ce qui pourrait entraîner une panique bancaire et empirer la situation des créanciers qui ne retirent pas leurs fonds, soit ils accordent un nouveau délai sous la forme d'une injonction, ce qui pourrait conduire à un gain de temps pour la banque, qui pourrait faire recours contre l'injonction et retarder la procédure. Les superviseurs se mettent finalement d'accord pour la mesure la plus drastique: il faut en finir avec «cette tumeur cancéreuse de la place bancaire suisse ${ }^{88}$. La CFB se résout donc à déposer plainte, ce qui, accessoirement, lui permet de se décharger en partie de la responsabilité de la gestion de l'affaire sur les autorités judiciaires ${ }^{89}$.

Alors que le mois d'octobre est jalonné d'un échange intensif de courriers contenant des menaces de dépôts de plaintes et de recours administratif de part et d'autre, une plainte est déposée par la CFB contre la Kredit- und Verwaltungsbank le I8 octobre 1956. Dans la foulée, la banque fait recours contre les injonctions préalables de la CFB auprès du Tribunal fédéral, dans un but dilatoire. Ce recours est rejeté en décembre 1956. L'enquête menée par le ministère public de Zoug stagne à nouveau : le juge d'instruction nommé est un juge de police peu familier des questions financières, qui décède après quelques mois d'enquête. Un nouveau juge d'instruction, Dr. Baumgartner, est nommé en mai 1957 ; il s'agit d'un juge de police «qui s'occupe essentiellement d'infractions routières ${ }^{90}$. Cette forme d'amateurisme chez les instances judiciaires zougoises dans le domaine de la criminalité économique, dans un canton qui se distingue depuis les années 1920 par un régime fiscal attractif ${ }^{91}$, est déconcertante. Elle irrite en tout cas les superviseurs fédéraux d'alors.

Face aux manques de possibilités offertes par la loi sur les banques, la CFB explore d'autres pistes d'intervention. Elle prend contact avec le procureur cantonal Hegglin, qui siège au conseil de la Banque cantonale de Zoug. En novembre 1957, la CFB dépose une nouvelle plainte contre la banque zougoise,

87 AFB, E6520(A), I000/I059, vol. II, PV CFB, 28.05.1956, p. 68-69.

88 AFB, E6520(A), I000/I059, vol. II, PV CFB, or.10.1956, p. I28.

89 AFB, E6520(A), I000/I059, vol. II, PV CFB, or.I0.1956, p. I26.

90 AFB, E6520(A), I000/I059, vol. II, PV CFB, 29.07.1957, p. I08.

91 Cf. Michael van Orsouw, Das vermeintliche Paradies : eine historische Analyse der Anziehungskraft der Zuger Steuergesetze, Zürich : Chronos, 1995, en particulier p. 39-75. 
pour non obtempération à une de ses injonctions. Le 12 novembre 1958 , le même mécanisme se reproduit pour la troisième année consécutive : la Commission fédérale des banques dépose plainte contre la Kredit- und Verwaltungsbank Zug. Comme dans les précédents cas, la banque réplique en faisant recours auprès de Tribunal fédéral contre l'injonction de la CFB. Ce recours, en principe sans perspective, signifie pour la banque un gain de temps puisqu'il provoque un effet suspensif.

En juin 1959, la CFB complète ces trois plaintes encore en cours, en indiquant aux juges d'instruction zougois de nouvelles falsifications de bilans (comptabilisation d'une encaisse fictive). Elle estime de plus que, mis à part les infractions qui sont suspendues à cause des recours administratifs en cours, d'autres délits mériteraient à eux seuls des poursuites pénales. Au cours de l'été 1959, l'affaire, qui était jusque-là confinée à des échanges confidentiels entre autorités administratives, judiciaires et dirigeants concernés, devient publique. Il semble que les autorités politiques zougoises cherchent enfin à faire avancer l'enquête, et publient un communiqué. Max Kaufmann est arrêté le I3 août 1959, en raison d'un danger de collusion, et relâché trois jours plus tard. L'affaire prend alors une tournure politique et médiatique. Par campagne de presse interposée, le Parti radical zougois, par l'intermédiaire du Zuger Volksblatt, et l'Alliance des Indépendants, dans Die Tat, s'accusent mutuellement de machinations politiques qui auraient provoqué l'éclatement de l'affaire. Max Kaufmann est présenté par les Indépendants comme un ancien membre des radicaux zougois tombé en disgrâce ${ }^{92}$. Les connexions politiques des dirigeants de la Kredit- und Verwaltungsbank Zug, qui sont liés au conseiller national AdI William Vontobel (1909-1973), président de la société de production d'aéroglisseurs Supramar, sont sans doute à l'origine de la contre-attaque de l'Alliance des Indépendants ${ }^{93}$. C'est également à ce moment-là que la direction générale de la Banque nationale suisse est pour la première fois tenue au courant de toute l'affaire ${ }^{94}$. Walter Schwegler (1902-I994), président de la direction générale de la BNS, se plaint auprès de la CFB du manque d'échange d'informations entre les deux autorités; il avait en effet été pris au dépourvu par une interpellation au Conseil de banque, à laquelle il était incapable de répondre. La CFB se montre très réticente envers les demandes de transmission de documentation formulée par la BNS ${ }^{95}$. La conflictualité latente entre les deux instances, déjà à l'œuvre dans les années 1930, ne s'est pas résorbée à la fin des années I950.

Dans la foulée, un avocat représentant sept créanciers de la banque dépose auprès du juge cantonal zougois une demande d'ouverture de procédure de faillite. Cette requête est acceptée le 25 août 1959, mais la banque fait immédiatement recours et porte l'affaire devant le Tribunal fédéral, qui confirme

[s.n.], "Gerüchteflut um eine Zuger Bank", Die Tat, nº 224, I8.08.1959.

AFB, E6520(A), I000/1059, vol. I2, PV CFB, 31.08.1959, p. I22.

AFB, E652I(A), 1979/52, vol. 73, dossier 351*, Akten-Notiz, "Besprechung mit der SNB", 28.08.1959.

5 AFB, E6520(A), I000/1059, vol. I2, PV CFB, 21.09.1959, p. 134-135. 
l'ouverture de la faillite le 2 octobre. La banque ferme définitivement ses guichets et dépose son bilan. Ce premier dénouement ne signifie pas la fin de l'affaire. Elle connait au moins trois épilogues.

Le premier est relatif au règlement des différentes procédures judiciaires en cours. En juillet 1964, soit près de huit ans après le dépôt de la dernière plainte de la CFB non résolue, le service des juges d'instruction (Verhöramt) du canton de Zoug rend son verdict sur deux enquêtes visant les principaux dirigeants de la Kredit- und Verwaltungsbank Zug ${ }^{96}$. Dans l'investigation pour escroquerie, détournement de fonds, faux dans les titres et gestion déloyale, l'enquête civile débouche sur un non-lieu, mais les accusés Kaufmann et Zürcher sont déférés à un tribunal pénal. Quant à l'instruction pour violation de la loi sur les banques, qui repose plus spécifiquement sur les quatre plaintes déposées par la CFB entre 1956 et 1959 pour non-respect de ses injonctions et établissement non conforme de la comptabilité annuelle, elle est classée sans suite. Toutes les infractions à la loi sur les banques sont absolument prescrites. Seuls les frais juridiques, à hauteur de 267.- francs (!), sont à la charge des accusés. La troisième procédure judiciaire en cours, à savoir la liquidation de la banque sous forme de procédure de faillite, ne se termine qu'en juin 1972. À un stade intermédiaire de la procédure, en mars 1963, il semble que le dépôt de bilan ait conduit à des pertes pour les créanciers : seuls $75 \%$ de dépôts d'épargne privilégiés avaient pu être remboursés ${ }^{97}$.

La seconde conséquence de la liquidation de la Kredit- und Verwaltungsbank Zug ordonnée à l'automne I959 est l'ouverture d'un débat juridique sur la portée du secret bancaire dans le cadre d'une procédure de faillite. L'administration de faillite a rapidement fait face à des difficultés pour concilier la mise à disposition du plan de collocation à tous les créanciers et la préservation du secret bancaire ${ }^{98}$. En janvier 1960 a lieu une première discussion au sein de la commission juridique de l'ASB. Les banquiers décident alors de chercher à créer un régime particulier pour les faillites bancaires, qui préserve le secret professionnel au détriment de la révélation des données sur les créanciers habituelle dans l'état de collocation. Le is février 1960, l'ASB s'adresse officiellement à la Chambre des poursuites et faillites du Tribunal fédéral, pour lui demander d'édicter une ordonnance particulière pour les cas de faillites bancaires, s'écartant de la loi sur les poursuites pour dettes et faillites, dans le sens d'un renforcement du secret bancaire ${ }^{99}$. Le plaidoyer de l'association des banquiers met l'accent sur les risques encourus par la clientèle étrangère : «il ne fait aucun doute que des administrations étrangères chercheraient et

96 AFB, E652I(A), 1979/52, vol. 73, dossier 355*, "Das Verhöramt des Kantons Zug in der Untersuchung gegen Kaufmann, Max, Zürcher, Albert, Meyer, Paul und Beckhard, Ernst ", 17.07.1964.

99 AFB, E6520(B) 2007/62, vol. 6I, Allgemeines, Korrespondenz, Bankensanierungen, Lettre de l'ASB à la Schuldbetreibungs- und Konkurskammer des Bundesgerichtes, I9.02.1960. 
trouveraient des voies et des moyens, dans les cas de faillites bancaires, pour confondre leurs ressortissants ayant placé des fonds en Suisse sans se conformer aux dispositions sur le contrôle des changes et les déférer à des sanctions judiciaires ${ }^{100}$. L'envoi précise qui sont les principaux concernés, qu'il s'agit de protéger contre d'éventuelles "confiscations": "la clientèle domiciliée au-delà du rideau de fer et dans les pays du Proche Orient», mais aussi "notre pays voisin de l'Ouest», dont les autorités cherchent "par des moyens autorisés ou non " à démasquer leurs ressortissants qui font gérer leurs épargnes en Suisse. Cet argumentaire, qui souligne le caractère prétendument confiscatoire des mesures inquisitrices de régimes étrangers, est stratégiquement développé par l'ASB pour rappeler que « le secret bancaire ne doit pas seulement être protégé contre le danger de la découverte de fraude fiscale lors d'une faillite bancaire » ${ }^{101}$. Au fond, les personnalités qui ont placé des capitaux en Suisse et menacées par leur État « totalitaire » servent d'alibi, au moins dans les discours des banquiers, pour la grande majorité de fraudeurs fiscaux.

Le 22 janvier 1960, la CFB, également mobilisée par l'ASB, décide de soutenir la requête des banquiers auprès du Tribunal fédéral ${ }^{102}$. Ces efforts conjugués semblent dans un premier temps porter leurs fruits. Le président de la Chambre des poursuites et faillites du TF, le radical bâlois Paul Schwartz (1905-1977), se montre de prime abord très compréhensif à l'égard des demandes des banquiers ${ }^{103}$. Mais, après un examen plus minutieux de la question, le Tribunal fédéral rejette la requête en novembre 1960, estimant qu'une ordonnance particulière ne lui permet de réaliser les souhaits d'une préservation du secret bancaire dans le cadre de la procédure de faillite. Alors que l'ASB accepte le rejet de sa requête, la Commission fédérale des banques persévère, et décide en février 196I d'élaborer elle-même un projet de dispositions spéciales sur la faillite bancaire. Une initiative vivement saluée par l'Association des banquiers ${ }^{104}$. Les travaux préparatoires de la CFB s'achèvent au printemps 1963 et un projet d'ordonnance est transmis au Tribunal fédéral. Mais cette seconde démarche échoue également. Le 4 avril 1967, le Tribunal fédéral maintient sa position de principe et refuse de promulguer l'ordonnance préparée par la CFB en collaboration avec l'ASB. Malgré un soutien inconditionnel apporté aux efforts du lobby bancaire, les superviseurs fédéraux ne parviennent pas à colmater la petite brèche dans la garantie du secret bancaire que la faillite de la Kredit- und Verwaltungsbank Zug avait ouverte. Lors d'une faillite bancaire, les intérêts des créanciers priment et l'administrateur de la

100 AFB, E652O(B) 2007/62, vol. 61, Allgemeines, Korrespondenz, Bankensanierungen, Lettre de l'ASB à la Schuldbetreibungs- und Konkurskammer des Bundesgerichtes, I9.02.1960.

101 AFB, E6520(B) 2007/62, vol. 6I, Allgemeines, Korrespondenz, Bankensanierungen, Procèsverbal de la commission juridique de l'ASB, I3.0I.I960, p. 4.

102 AFB, E6520(A), I000/I059, vol. I2, PV CFB, 22.01.1960, p. 37-40.

103 AFB, E6520(A), I000/1059, vol. I2, PV CFB, I6.02.1960, p. 57-58.

104 Association Suisse des Banquiers, Rapport sur le $49^{\text {ème }}$ exercice du I ${ }^{\text {er }}$ avril 1960 au 31 mars I96I, Bâle, I96I, p. 70. 
faillite doit divulguer, dans l'état de collocation, des informations qui seraient en principe protégées par le secret bancaire. Il est aussi remarquable, qu'en raison de l'absence de procédures de faillite bancaire problématique depuis la fin de la crise des années 1930, il faille attendre 1960 pour que ce détail juridique soit abordé.

La troisième incidence de la débâcle de la Kredit- und Verwaltungsbank Zug a trait à une remise en question de l'efficacité des moyens dont dispose la Commission fédérale des banques pour traiter de pareils cas. Dans le prolongement des événements tumultueux de l'été 1959, une interpellation du radical Gottfried Zürcher (I929-) au grand conseil zougois exige des éclaircissements publics sur toute l'affaire. Sur la base des échanges avec la CFB, le Conseil d'État de Zoug estime que l'expérience faite avec la Kredit- und Verwaltungsbank justifie de demander au Conseil fédéral une révision de la loi sur les banques dans le sens d'un renforcement de la protection des épargnants ${ }^{105}$. Cette suggestion des autorités zougoises suscite une certaine irritation chez les superviseurs fédéraux : n'était-ce pas plutôt l'incompétence et l'insuffisance des services judiciaires zougois qui avaient permis l'aggravation de la situation de la banque ? ${ }^{106}$ Malgré cette forte réticence initiale, les membres de la CFB délèguent au secrétariat la tâche d'examiner la question d'une éventuelle révision de la loi bancaire. Pour la première fois, mis à part l'épisode sur la pérennisation du droit d'assainissement bancaire entre 1938 et 1948, le débat sur de potentiels amendements à la réglementation est ouvert.

Retenons pour l'instant que la Commission fédérale des banques, en 1960, malgré l'expérience du cas de la banque zougoise, refuse catégoriquement d'entrer en matière pour une révision de la loi de 1934. Cette position est d'abord définie à l'interne en juin 1960, les membres déclinent unanimement la nécessité d'une réforme ${ }^{107}$. Le $\mathrm{I}^{\text {er }}$ juillet a lieu une réunion entre le nouveau conseiller fédéral en charge des Finances Jean Bourgknecht (1902-1964) et trois représentants de la Commission fédérale des banques. Les premiers mots prononcés par Max Hommel résument bien l'avis des superviseurs bancaires: une révision de la loi sur les banques n'est "ni nécessaire, ni opportune » ${ }^{108}$. Un renforcement des compétences impliquerait inévitablement, selon les superviseurs, un accroissement de la responsabilité de la Confédération. Ces arguments suffisent à convaincre le ministre des Finances conservateur-catholique fribourgeois. Il se déclare défavorable à toute réforme impliquant un surcroît de responsabilités étatiques. L'Association suisse des banquiers s'exprime dans le même sens. Quant à la Banque nationale suisse, elle estime au contraire qu'une

105 AFB, E6IooB, 1972/96, vol. 32, dossier 92*, Lettre du Regierungsrat des Kantons Zug à la CFB, I5.02.1960.

106 AFB, E6520(A), I000/1059, vol. I2, PV CFB, I5.03.1960, p. 69; AFB, E6100B, 1972/96, vol. 32, dossier 92*, Lettre de la CFB au Regierungsrat des Kantons Zug, 16.03.1960.

107 AFB, E6520(A), I000/I059, vol. I2, PV CFB, I4.06.1960, p. I33-137.

108 AFB, E6roo(B-or), 1980/49, vol. 57, Aktennotiz betr. Revision des Bankengesetzes, oI.07.1960. 
révision serait souhaitable. Dans une lettre datant de décembre 1960, elle recommande au DFFD des modifications dans deux directions: un renforcement des compétences de la CFB et une complication des conditions d'ouverture de nouvelles banques, en particulier des établissements étrangers ${ }^{109}$. Le directoire de la BNS, dans sa lettre au Département des finances, se livre à une critique acerbe du régime de régulation:

Nous avons une loi sur les banques qui permet qu'une banque, après qu'une plainte est déposée par la Commission des banques, et en dépit d'un surendettement notoire et d'affaires extrêmement douteuses connues des milieux bancaires et du public, soit encore dirigée pendant des années par des dirigeants sans scrupules. Ce genre de banques récolte encore des années durant des dépôts d'épargne et d'autres dépôts de tiers, avec pour conséquence que de nombreux déposants subissent des pertes à cause d'une législation incomplète et insuffisante. Nous entendons souvent la question de savoir comment des cas aussi flagrants peuvent se produire sous une loi bancaire ${ }^{110}$.

Ce réquisitoire des responsables de la banque centrale ne suffit pas à convaincre le DFFD de Bourgknecht. En juillet 196I, ce dernier conclut dans son rapport au Conseil fédéral, et avec le soutien de la Commission fédérale des banques, qu'une révision de la loi sur les banques ne s'impose pas ${ }^{111}$. Ce n'est que fin 1963, dans le cadre d'un débat sur la révision des dispositions pénales de la loi sur les banques, également avortée, puis en 1965-1966, dans la foulée de l'affaire Muñoz-Hommel, que les velléités en faveur d'une réforme législative referont surface (cf. chap. VIII.2 et VIII.3).

En 1959-1960, malgré l'intervention du gouvernement cantonal zougois auprès du Conseil fédéral à la suite de la débâcle de la Kredit- und Verwaltungsbank, les membres de la Commission fédérale des banques sont parvenus à bloquer un renforcement de leurs propres compétences.

La gestion de la Kredit- und Verwaltungsbank révèle aussi la grande lenteur de la mise au courant de la CFB. Étant donné qu'elle fonde ses décisions sur les rapports de révision et que ceux-ci sont rédigés dans les trois à dix mois qui suivent le bouclement de la comptabilité annuelle, il peut s'écouler plus d'un an et demi entre le moment où une banque entre dans l'illégalité et le moment où la CFB en est informée. Ce long délai de communication est intrinsèquement lié au système de surveillance indirect et au rôle des sociétés fiduciaires. Soulignons au passage que, si l'affaire zougoise est atypique dans la gravité et la longueur des irrégularités, elle n'est pas unique. Dans le traitement d'autres banques répréhensibles, comme la Banque Mercantile à Genève (1959), la

109 AFB, E6I0o(B-OI), 1980/49, vol. 57, Lettre de la direction générale de la BNS (Schwegler) au Département fédérale des Finances et des Douanes, 19.12.1960.

110 AFB, E6Ioo(B-oI), I980/49, vol. 57, Lettre de la direction générale de la BNS (Schwegler) au Département fédéral des finances et des douanes, I9.I2.I960.

111 AFB, E6Ioo(B-oI), 1980/49, vol. 57, Bericht über die Frage einer Revision des Bankengesetzes, 19.07.196I. 
Privat-Kommerzbank à Zurich, la CFB fait preuve de la même inefficacité. Citons un seul exemple pour confirmer ce constat. En mai 1955, dans un rapport sur le cas de la Hypothekar- und Commerzbank, le secrétaire de la CFB, Daniel Bodmer porte un regard amer sur la conclusion de l'affaire :

Le fait que des débats judiciaires se prolonge au-delà d'un an dans des cas aussi incontestables que celui de la Hypothekar- \& Commerzbank et débouchent ensuite seulement sur des amendes d'un montant ridicule, ne contribue pas à préserver la réputation et l'efficacité de la Commission des banques. Quand on voit l'indulgence dont ont fait preuve les juges zurichois à l'égard des responsables de la HCB, cela revient presque à un appel à faire un pied de nez à la Commission ${ }^{112}$.

Le bilan de l'intervention de la CFB auprès de la Kredit- und Verwaltungsbank est, en définitive, accablant. Alors que les superviseurs découvrent des manquements graves dès 1944-1946, les innombrables avertissements, injonctions et prescriptions de révisions extraordinaires adressés aux dirigeants de l'établissement zougois pendant une quinzaine d'années restent inopérants. Les cinq plaintes successivement déposées auprès des instances judiciaires cantonales (1947, 1956, 1957, 1958, 1959) ne produisent pas davantage de résultats: après un traitement dilatoire, provoqué à la fois par une pratique abusive des recours administratifs et par l'incompétence des instances judiciaires locales, elles se soldent toutes par des non-lieux, les infractions étant prescrites au moment du verdict.

Confrontée à des personnalités «avec lesquelles on ne peut pas discuter en respectant les règles du jeu normales" et qui "déforment après le sens des conversations»"113, la Commission fédérale des banques se rend également compte des limites de son approche consistant à privilégier la pression informelle à coup d'avertissements et de réprimandes officieux. Ni l'approche formelle par la voie juridique, ni la démarche par contacts personnels, sous forme de moral suasion n'aboutit à un résultat satisfaisant.

\section{VII.4. LA MODIFICATION DU RÈGLEMENT D’EXÉCUTION D'AOÛT 1961 : UNE ADAPTATION DES EXIGENCES DE FONDS PROPRES ET LIQUIDITÉ SELON LES VEUX DES GRANDES BANQUES (1941-1961)}

Le règlement d'exécution de la loi sur les banques, également appelé ordonnance, constitue le texte législatif, promulgué par le Conseil fédéral

112 Daniel Bodmer, Schlussbericht über die Hypothekar- und Commerzbank, I2.05.1955, cité in AFB, E6520(A), 1983/50, vol. 32, dossier Sanktionsbestimmungen 1963-1974, Rapport du secrétariat de la CFB aux membres CFB sur «Bedeutung der Strafanzeigen und Strafandrohungen in der Praxis der Bankenkommission ", 02.12.1964.

113 AFB, E6520(A), I000/I059, vol. II, PV CFB, 04.05.1959, p. 63. 
sans approbation nécessaire du parlement, qui précise la portée et les modalités d'application des principes énoncés dans la loi. Nous avions vu que l'acte adopté le 26 février 1935 avait été élaboré sous l'influence prépondérante des représentants bancaires (cf. chap. IV.I). Il restera en vigueur pendant plus d'un quart de siècle, puisque son premier amendement n'aboutira que le 30 août 196I. Les principaux changements qui interviennent alors ont pour objet les ratios de liquidité et de fonds propres. Pour le dire très rapidement, l'ordonnance de 196I, par rapport à celle de 1935, assouplit le rapport minimal de fonds propres et renforce les exigences de liquidité. L'objet de ce sous-chapitre est de retracer non seulement le processus qui conduit à l'adoption d'une nouvelle ordonnance au début des années I960, mais également d'exposer les précédents projets de modification avortés. Il est tout aussi instructif de se pencher sur les tentatives échouées que sur les efforts menés à bien.

Dès I94I, soit six ans après l'entrée en vigueur de la loi, la Commission fédérale des banques envisage pour la première fois une modification du règlement d'exécution. Plus précisément, ce sont les dispositions sur la liquidité, et, dans une moindre mesure, sur les fonds propres, qu'il s'agit d'altérer. Un premier projet de révision est préparé par le secrétariat de la CFB, sur la base de travaux préparatoires de l'expert Arthur Stampfli. Pour l'essentiel, la révision vise à renforcer les exigences de fonds propres pour les caisses Raiffeisen et les banques cantonales, et surtout, à augmenter les taux de couverture minimaux requis pour la liquidité. Cet avant-projet fait l'objet d'une discussion au sein d'une "conférence d'experts", en janvier 1942. La composition de cette commission, faite en collaboration avec l'ASB, laisse une importante marge de manœuvre aux délégués du monde bancaire privé: sur vingt membres, on compte trois représentants des banques cantonales, trois représentants des grandes banques, trois représentants des banques locales, deux représentants des caisses Raiffeisen, un banquier privé, et un secrétaire de l'ASB ${ }^{114}$. Tandis que la CFB cherche à justifier son projet de révision, en soulignant par exemple que certaines banques ont dû faire recours à des moratoires de paiement pendant la crise alors qu'elle respectait encore les minimas légaux de liquidité, les banquiers sont beaucoup plus sceptiques. Ils estiment que la période de guerre, par définition très instable, ne convient pas à la modification de la réglementation. Adolf Jöhr ajoute que les dispositions sur la liquidité et les fonds propres "ne sont pas si importantes que cela», et plutôt de simples

114 Les participants à cette séance sont les suivants: Edmund Schulthess, Albert Zust, Charles Brüderlin, Emil Walch, Max Hommel (tous CFB), Arthur Stampfli (expert de la CFB), Paul Rossy (BNS), Gustave Curchod (BCV), Heinrich Daeniker (ZKB), Rudolf Wittmer (BaKB), Paul Jaberg (UBS), Adolf Jöhr (CS), Max Staehelin (SBS), Hans Fischer (banques locales), Fritz Häfliger (banques locales), Arthur Wolf (banques locales), Max E. Bodmer (banquier privé), Johannes Heuberger (Raiffeisen), Josef Stadelmann (Raiffeisen), Adolf Jann (ASB). AASB, Dossier 713 Eidg. Bankengesetz Jan. I940 - Juni I948, Protokoll der Expertenkonferenz zur Revision der Vorschriften der Vollziehungsverordnung zum Bankgengesetz betreffend die eigenen Mittel und die Liquidität, I3.or.1942. 
"prescriptions d'ordre ${ }^{115}$. Malgré cet accueil relativement froid, la CFB poursuit les travaux préparatoires et concocte un nouveau projet en juin 1942, qui tient en grande partie compte des remarques de détail faites par les banquiers en janvier. Une nouvelle procédure de consultation auprès de divers groupes bancaires, cette fois uniquement écrite, a lieu. Il en ressort que, mises à part de fortes réserves chez les banques cantonales, les sociétés financières et les caisses Raiffeisen, les banquiers sont prêts à entrer en matière ${ }^{116}$. La BNS et le DFFD d'Ernst Wetter soutiennent d'ailleurs la démarche de la CFB. Alors que le texte est toiletté en février-mars I943, il n'est plus évoqué dans les procès-verbaux de la commission jusqu'en 1954. Il tombe donc progressivement dans l'oubli.

Les raisons de cette «schubladisation » sont difficiles à déterminer précisément. Pour Hugo Bänziger, c'est l'incertitude sur les conditions économiques de l'après-guerre qui aurait provoqué l'abandon du projet ${ }^{117}$. Il semble que deux autres facteurs jouent un rôle majeur dans le blocage des velléités de révision de l'ordonnance.

Le premier d'entre eux est relatif à un changement dans l'équipe dirigeante de la CFB. Alors que l'impulsion de modification de l'ordonnance est donnée par le président Edmund Schulthess en I94I-I943, l'arrivée d'Ernst Wetter, par ailleurs ancien vice-président du Vorort (I926-1938), en 1944 a fait passer la question au second plan. Le deuxième facteur, essentiel pour comprendre toute l'affaire, est lié au contentieux qui oppose la Commission fédérale des banques à l'Union centrale des caisses Raiffeisen. En effet, il ressort de l'analyse des procès-verbaux de 194I-1943 que la cible principale dans le processus de réforme des rapports de fonds propres et de liquidité est le mouvement des caisses Raiffeisen. Plus qu'une réadaptation générale des normes qui auraient évolué depuis 1935, la Commission fédérale des banques cherche à contraindre juridiquement les caisses Raiffeisen à corriger le manque de fonds propres, qui est chronique chez ces établissements. La révision de règlement d'exécution devient dans ce contexte un instrument d'intervention dans un conflit qui oppose la CFB aux Raiffeisen depuis I935. Ce qui est à l'origine de la démarche réglementaire des superviseurs est simultanément la raison principale de son échec. En effet, les négociations bilatérales avec l'Union centrale des Raiffeisen s'enlisent en 1943, à mesure que les fronts se durcissent. Les puissants relais politiques dont bénéficient les caisses Raiffeisen empêchent la CFB d'imposer un durcissement des dispositions sur les fonds propres et la liquidité ${ }^{118}$.

Dans son contentieux avec les Raiffeisen, en raison du non-respect des normes sur les fonds propres, la Commission fédérale des banques trouve un allié de

115 AASB, Dossier 713 Eidg. Bankengesetz Jan. 1940 - Juni 1948, Protokoll der Expertenkonferenz zur Revision der Vorschriften der Vollziehungsverordnung zum Bankgengesetz betreffend die eigenen Mittel und die Liquidität, I3.0I.1942, p. 8.

116 AFB, E6520(A), I000/I059, vol. 8, PV CFB, 07.09.1942, p. 59-60.

117 Bänziger, op. cit., I988, p. 19.

118 AFB, E6520(A), 1000/1059, vol. 9, PV CFB, 30.08.1948, p. 77; vol. Io, PV CFB, 06.09.1954, p. 84 ; vol. II, PV CFB 26.03.1956, p. 4I. 
circonstance auprès des banques cantonales. En effet, la dynamique d'expansion des Raiffeisen, notamment dans le domaine du crédit hypothécaire aux populations rurales, marche sur les platebandes des banques cantonales. Dans une étude très fouillée sur le système Raiffeisen - destinée en avril 1942 au cercle restreint des membres du comité de l'Union des banques cantonales suisses -, les dirigeants des banques cantonales ne cachent pas leur animosité à l'égard des caisses Raiffeisen. Ils estiment que la propagande diffusée par les caisses Raiffeisen est trompeuse et que son expansionnisme est excessif ${ }^{119}$. Les dirigeants des banques cantonales voient donc dans la réforme des dispositions sur la liquidité et les fonds propres, à l'échelon fédéral, une possibilité de lutter contre ce qu'ils considèrent comme une "concurrence déloyale» de la part des Raiffeisen. En particulier en Suisse orientale (Thurgovie, Saint-Gall), les banquiers cantonaux constatent une fuite des hypothèques vers les Raiffeisen. Malgré ce soutien des banquiers cantonaux qui permet aussi de contrer l'influence des Raiffeisen au Parlement fédéral, auquel vient s'ajouter l'approbation passive de la Banque nationale suisse ${ }^{120}$, la Commission fédérale des banques ne parvient pas à imposer sa réforme des dispositions sur les fonds propres et la liquidité.

En 1943, le désaccord entre la CFB et Raiffeisen prend une tournure plus conflictuelle: la tonalité des échanges devient «malséante». En 1944, la procédure s'embourbe ${ }^{121}$. Ce n'est qu'en 1946 qu'un accord est trouvé sur la façon de comptabiliser les fonds propres chez les Raiffeisen. Cette solution passe par une modification des statuts des Raiffeisen, et non par une révision de l'ordonnance de la loi sur les banques, comme prévu en 1942-1943. Le procédé consiste à comptabiliser la garantie des membres comme un élément faisant partie des fonds propres. Le président de la CFB, l'ancien conseiller fédéral radical Ernst Wetter explique clairement ce revirement fin 1946. Après avoir rappelé le conflit existant avec les Raiffeisen et les difficultés à parvenir à une solution pacifique, il ajoute:

Mais d'autre part, je me rends compte que nous ne pouvons pas risquer une guerre ouverte avec l'association Raiffeisen dans les circonstances actuelles. J'ai toujours émis des réserves contre toute révision de la loi sur les banques et de son ordonnance. Dans de nombreux pays, la question de la nationalisation des banques est à l'heure actuelle à l'ordre du jour. Ce mouvement va aussi faire des vagues dans notre pays. Il y a toujours un risque que ce genre de mouvements déborde. Tout est aujourd'hui si instable dans le domaine bancaire que l'on devrait parler aussi peu que possible de révisions législatives ${ }^{122}$.

119 AUBCS, Procès-verbal annexe à la I25 ${ }^{\mathrm{e}}$ séance du comité du 25.04.1942: «Eingabe betreffend Darlehenskassen (System Raiffeisen) », p. 8.

120 ABNS, Procès-verbaux de la Direction générale de la BNS, I8.03.1943, p. 279.

121 AFB, E6520(A), 1983/50, vol. 2, dossier Revision Bankengesetz 1966-1971, Manuscrit de Daniel Bodmer «25 Jahre Bankengesetz", août 1960, p. 7.

122 AFB, E6520(A), I000/1059, vol. 9, PV CFB, 23.12.1946, p. I09-IIо. 
C'est donc par le biais d'une habile manœuvre, et sous la forme d'une modification des statuts, que la CFB met un terme au différend qui l'opposait aux Raiffeisen, tout en évitant d'ouvrir un débat public sur la réglementation bancaire. D'ailleurs, la situation réelle des caisses Raiffeisen n'est pas résolue pour autant : en 1947, le secrétariat de la CFB estime qu'environ 300 caisses (sur un total de 877) n'ont pas assez de fonds propres, même selon le nouveau mode de calcul plus généreux ${ }^{123}$.

En 1947 et en 1952, la problématique des fonds propres ressurgit à l'ordre du jour de la CFB sur la requête des grandes banques. Il apparait en effet qu'en raison de la haute conjoncture et du gonflement du volume d'affaires des grandes banques, et en particulier de l'afflux des dépôts à vue, le ratio de fonds propres peine à être respecté. En décembre 1947, l'ASB demande une dérogation aux dispositions sur les fonds propres à cause du montant élevé des comptes en dollar bloqués. En 1952, la même question réapparaît. Les banquiers revendiquent cette fois un nouveau calcul du coefficient de fonds propres, dans le sens d'un allégement. Ils souhaiteraient en effet que les avoirs déposés en comptes de virement (Giroguthaben) auprès de la BNS ne doivent plus être couverts par to \% de fonds propres. Dans l'idéal, pour les banquiers, ce changement devrait s'opérer simplement par une interprétation différente de la CFB, qui accorderait une exception en ce sens ${ }^{124}$. La Commission fédérale des banques, sans se prononcer sur le bien-fondé de la requête, répond qu'une telle modification impliquerait une révision du règlement d'exécution et ne peut pas intervenir aussi facilement que l'espérait l'ASB. Elle estime de plus que ce n'est pas à elle de prendre l'initiative d'une telle réforme.

En juillet 1954, sous l'impulsion des dirigeants de la Banque nationale suisse, la question des dispositions sur la liquidité, et non celle sur les fonds propres, revient à l'ordre du jour. La BNS souhaiterait renforcer les taux de liquidité minimaux requis dans l'ordonnance de la loi sur les banques. Elle fait une demande en ce sens au DFFD en juin 1954, en proposant un doublement de taux minimaux requis ${ }^{125}$. L'objectif visé par la banque centrale est non seulement d'améliorer la trésorerie des banques, dans le sens d'une meilleure protection de déposants, mais surtout d'utiliser le vecteur des normes de liquidité pour lutter contre la surchauffe économique et la croissance excessive de la masse monétaire. Les propositions de la BNS sont diversement accueillies au sein de la CFB. Alfred Hirs, ancien membre du directoire de la BNS (19421954) récemment nommé à la CFB, soutient fermement la démarche de l'institut d'émission, précisant notamment "qu'il serait franchement criminel,

123 AFB, E6520(A), I000/1059, vol. 9, PV CFB, 24.02.1947, p. II.

124 AFB, E6520(A), I000/I059, vol. I0, PV CFB, I7.03.1952, p. 37-42.

125 AFB, E6roo(B-oor), I980/49, vol. 59, Lettre de la BNS au DFFD, I9.06.1954. 
au vu de la masse monétaire actuelle, de mettre encore plus de capitaux sur le marché par le biais de crédits» ${ }^{126}$. Le professeur d'économie Henri Borle, membre de la CFB depuis 1939, est également ouvert aux propositions de la BNS et souhaite une meilleure collaboration entre les deux institutions. À cette frange qui est rapidement minorisée s'opposent Max Hommel et le président Thomas Holenstein (1896-1962), conseiller national catholique-conservateur saint-gallois. La CFB ne doit pas, selon eux, faire de la politique conjoncturelle ou monétaire avec les dispositions de la loi sur les banques, dont l'unique but est la protection des créanciers bancaires. Alors que tout le monde - à la BNS comme à la CFB - s'accorde pour considérer les taux de liquidité de 1935 comme nettement trop bas, les avis divergent sur les mesures à adopter. Finalement, les propositions de doublement sont retirées par la banque centrale.

Un an plus tard, en octobre 1955, les grandes banques reviennent à la charge pour obtenir un assouplissement du rapport de couverture des fonds propres. Plus précisément, c'est la Société de Banque Suisse qui s'adresse à la CFB à ce sujet. Les dirigeants de la grande banque bâloise, constatant que leur couverture approche dangereusement des minimas légaux, cherchent dans un premier temps à obtenir du secrétariat de la Commission fédérale des banques, par simple discussion orale, une dérogation dans le sens d'un assouplissement. Selon les notes du nouveau secrétaire de la CFB, Daniel Bodmer, Samuel Schweizer (1903-1977), membre de la direction générale de la SBS, demande au secrétariat de l'autorité de surveillance un nouveau mode de calcul des fonds propres ${ }^{127}$. Il ajoute qu'auparavant, l'ancien secrétaire de la CFB Eduard Kellenberger, récemment retraité, avait toléré cette façon de faire sans prise de décision des membres de la CFB. Autrement dit, il cherche à marchander un arrangement en principe illégal avec le nouveau venu Bodmer. Ce procédé irrite Alfred Hirs, qui suggère de rejeter la demande de la SBS. Une majorité de la $\mathrm{CFB}$ décide de répondre à la grande banque bâloise que la solution requise ne peut être atteinte que par une révision de l'ordonnance de la loi sur les banques, et non par une modification de l'interprétation et de l'application des normes. Sur ce, la banque bâloise, toujours dans le même but de respecter formellement les taux de fonds propres, indique une autre voie: il s'agirait d'inclure dans le calcul des fonds propres les réserves latentes (stille Reserven). Les réserves latentes reposent sur une pratique autorisée par le droit des sociétés helvétique, qui consiste à accumuler des réserves internes, par exemple par la sousévaluation d'actifs, qui ne figurent pas au bilan et jouent le rôle de provisions pour risques. La SBS veut donc le beurre et l'argent du beurre: maintenir sa pratique d'accumulation de réserves cachées, qui ne seraient révélées qu'aux réviseurs au moment du contrôle annuel, tout en poursuivant la croissance de

126 AFB, E6520(A), I000/1059, vol. Io, PV CFB, 06.09.1954, p. 83.

127 AFB, E6520(B), 2007/62, vol. 25, Aktennotiz über Besprechung vom I4. Oktober 1955 mit G.D. Sam. Schweizer (SBV), I4.IO.I955. 
ses fonds de tiers sans être freinée par le taux de couverture des fonds propres. Cette proposition reçoit également un accueil plutôt favorable chez les superviseurs ${ }^{128}$. Hommel envisage très clairement d'avoir deux poids, deux mesures dans l'application de règles de fonds propres:

J'apprécierais si nous pouvions aller un peu plus loin dans les exigences de fonds propres à l'égard de certains instituts en prenant en compte les réserves latentes. Nous devrions avoir la possibilité d'empoigner les banques en mauvaise posture plus sévèrement, tout en traitant celles qui sont «bien rembourrées» de manière plus bienveillante ${ }^{129}$.

En février 1956, Max Hommel, qui devient au sein de la CFB qu'il préside depuis juin 1955, l'apôtre d'un assouplissement des dispositions sur les fonds propres, se heurte dans un premier temps au refus catégorique de la BNS ${ }^{130}$. Puis, au sein de la Commission, il est également minorisé: Alfred Hirs, Henri Borle, le conseiller national catholique-conservateur argovien Max Rohr (I890I980), et l'ancien directeur de la Banque cantonale de Thurgovie, Jakob Müller (1886-1974), refusent d'accorder des allégements aux grandes banques par le biais d'une simple nouvelle interprétation ${ }^{131}$. S'il faut modifier la pratique en matière de fonds propres, cela doit passer par une révision de l'ordonnance, pour la majorité de la CFB. L'autorité de surveillance se place donc dans une position d'attente passive.

En juin-août 1957, l'impulsion décisive en faveur d'une révision du règlement d'exécution de 1935 provient des milieux bancaires. Plus précisément, la démarche s'étend progressivement, en cercles concentriques, à différents acteurs. C'est tout d'abord l'Union des Banques Suisses qui, en juin 1957, prend contact avec ses deux concurrents directs, la SBS et le Crédit Suisse, pour leur soumettre trois revendications qu'elle entend porter devant la CFB concernant le calcul de fonds propres ${ }^{132}$. La réaction de la SBS est favorable, celle du Crédit Suisse plus prudente. Pour les dirigeants de la grande banque zurichoise, il faut traiter l'affaire avec le plus grand soin et éviter dans tous les cas que ces demandes de révision entraînent des conséquences indésirables. Dans un second temps, en août 1957, l'intervention est élargie aux représentants des différents groupes bancaires au Conseil d'administration de l'ASB. Les autres groupes bancaires sont moins enthousiastes que les grandes banques. Albert Matter (1906-1992), président de la Banque cantonale de Bâle, craint en particulier les conséquences néfastes que la discussion pourrait engendrer : il pense en particulier à une réforme générale de la loi bancaire ou aux potentiels

128 AFB, E6520(A), I000/I059, vol. Io, PV CFB, 28.I2.1955, p. I63-166.

129 AFB, E6520(A), I000/ı059, vol. I0, PV CFB, 28.I2.1955, p. 166.

130 AFB, E6520(B), 2007/62, vol. 25, Lettre de la BNS (Paul Keller) à Max Hommel (CFB), I5.02.1956.

131 AFB, E6520(A), I000/1059, vol. II, PV CFB, 26.03.1956, p. 40-44.

132 AASB, Dossier 713 Eidg. Bankenkommission Bankengesetz Jan. 1952 - Dez. 1958, Lettre de la direction générale de l'UBS à l'ASB, II.06.1957. 
postulats de la BNS sur les réserves minimales. Malgré ces réticences, l'ASB transmet, le 30 août 1957, une requête officielle à la Commission fédérale des banques qui reprend, à peu de choses près, les trois revendications de l'UBS ${ }^{133}$. Les banquiers souhaiteraient premièrement que les réserves latentes soient considérées comme des fonds propres, deuxièmement que les engagements couverts par des disponibilités (or et avoirs en compte de virement à la BNS, avoirs en compte de chèques postaux) ne doivent plus être compensés par des fonds propres, et, troisièmement, que les banques suisses qui disposent de succursales à l'étranger ne doivent couvrir leurs engagements en obligations d'États étrangers qu’à hauteur de $5 \%$ de fonds propres. La prise de position de la BNS sur ces trois revendications, datant de novembre 1957, est claire: elle refuse d'entrer en matière sur les réserves latentes, propose un allégement moindre sur la comptabilisation des disponibilités, et accepte la troisième requête relative aux engagements de succursales à l'étranger ${ }^{134}$.

Au sein de la commission, il faut attendre le 23 décembre 1957 pour qu'une longue discussion soit engagée ${ }^{135}$. Max Hommel se fait à nouveau le porteparole des grandes banques. Il estime qu'étant donné la solidité de ces instituts, les créanciers bancaires ne sont pas en danger, malgré la réduction du taux de couverture des fonds propres. Il faut donc adapter les normes vieilles de plus de vingt ans, et assouplir les exigences de fonds propres. Les anciens directeurs de la BNS Alfred Hirs et Paul Rossy, auxquels se joint le professeur Henri Borle, sont beaucoup plus nuancés : ils refusent de soutenir toutes les revendications de l'ASB et penchent plutôt en faveur de la position de la BNS, qui tient compte de la politique conjoncturelle. La seule certitude, à ce stade, est qu'une réalisation des souhaits de l'ASB devra passer par une révision de l'ordonnance de la loi sur les banques.

Du côté des banquiers, le front commun affiché jusque-là tend à s'effriter. Les dirigeants du Crédit Suisse, à savoir la seule des trois grandes banques à ne pas dépasser le seuil d'engagements autorisés et celle qui avait déjà exprimé des hésitations en juin 1957, incitent l'ASB à plus de prudence. Ernst Reinhardt (1908-1977), ancien directeur de l'Administration fédérale des finances qui pantoufle à la tête du Crédit Suisse en 1948, met en garde ses collègues que l'argumentaire qui consiste à dire que l'ordonnance doit être adaptée après vingt ans est valable pour les desiderata des banquiers comme pour ceux de leurs adversaires. Des parlementaires pourraient intervenir s'ils venaient à découvrir les travaux de réforme en cours. La conclusion de Reinhardt est la suivante :

Il vaut mieux continuer à subir les imperfections de la situation juridique actuelle que d'être prêt à accepter, en vue de les éliminer, de plus graves concessions. Nous craignons fort qu'une obstination trop

\footnotetext{
133 AFB, E6520(B), 2007/62, vol. 25, Lettre de l'ASB à la CFB, 30.08.1957.

$134 \mathrm{AFB}, \mathrm{E} 652 \mathrm{O}(\mathrm{B}), 2007 / 62$, vol. 25, Lettre de la BNS (signé Schwegler) à la CFB, I5.II.I957.

135 AFB, E6520(A), I000/1059, vol. II, PV CFB, 23.12.1957, p. 189-200.
} 
insistante sur nos points implique le danger que d'autres souhaits de révision soient jetés dans la discussion ${ }^{136}$.

Le Crédit Suisse, dont la couverture de fonds propres est meilleure que celle de la SBS et de l'UBS, se montre donc plus réticent à toucher aux normes légales.

Le 20 janvier 1958 a lieu une réunion entre représentants du monde bancaire et superviseurs ${ }^{137}$. Alfred Hirs, cette fois en présence des plus influents banquiers du pays, répète ses appréhensions quant aux modifications prévues. Pour lui, les changements demandés auraient pour effet que les bilans seront encore "plus maquillés» (noch mehr frisiert) que jusqu'alors. Il ajoute qu'il faudrait compléter la révision par d'autres ajustements, pour ne pas donner l'impression que l'on cherche simplement à tirer d'embarras certains instituts. Le catholique-conservateur Max Rohr va dans le même sens; pour ne pas susciter de débats publics de la part de "cercles qui comme chacun sait ne peuvent pas rester objectifs ", il vaut mieux réviser simultanément d'autres points d'importance secondaire. Alfred Schaefer, directeur général de l'UBS, répond à Hirs sur la question du window dressing de fin d'année, en rejetant la faute sur la clientèle des banques qui retire durant les deux dernières semaines de l'année des montants liquides s'élevant à environ Ioo millions de francs par grande banque (!).

À la suite de la réunion de janvier 1958, le secrétariat de la CFB s'attèle donc à la rédaction d'un premier remaniement de l'ordonnance de la loi sur les banques. En plus des dispositions sur les fonds propres, qui sont au cœur du projet, la Commission intègre d'autres amendements mineurs, en partie pour contenter la BNS, mais surtout, pour ne pas éveiller les soupçons dans l'opinion publique que la révision est un pur acte de complaisance envers les grandes banques ${ }^{138}$.

Le premier projet discuté par la CFB le I2 mai 1958 est caractérisé par la volonté de fondre l'essentiel - à savoir l'assouplissement des exigences de fonds propres - dans un ensemble de petites retouches rédactionnelles. En plus des trois revendications de l'ASB, la refonte prévoit, conformément aux vœux de la BNS, un renforcement des coefficients de liquidité. En octobre 1958, la banque centrale prend position, sur le projet de remaniement préparé par la CFB : seul

136 AASB, Dossier 713 Eidg. Bankenkommission Bankengesetz Jan. 1952 - Dez. 1958, lettre d'Ernst Reinhardt (Direction générale CS) au secrétariat de l'ASB, I3.0I.I958.

137 AASB, Dossier 713 Eidg. Bankenkommission Bankengesetz Jan. 1952 - Dez. 1958, Protokoll der Sitzung betreffend Vorschriften über die eigenen Mittel, 20.0I.1958. Participants : Max Hommel, Alfred Hirs, Max Rohr, Paul Rossy, Daniel Bodmer, Beat Neuhaus (tous CFB), Albert Matter (BaKB), Alfred Schaefer (UBS), Hans Fischer (Allg. Aargauische Ersparniskasse), Fritz Hinderling (BPS), Ernst Reinhardt (CS), Samuel Schweizer (SBS), Max Oetterli (ASB).

138 Cf. AFB, E6520(B), 2007/62, vol. 25, Rapport du secrétariat CFB aux membres CFB, 24.04.1958. 
le degré de prise en compte des réserves latentes dans le calcul des fonds propres et la refonte des taux de liquidité font l'objet de véritables divergences ${ }^{139}$.

Entre octobre 1958 et septembre 1959 se développent alors d'intenses négociations non seulement entre la CFB et la BNS, mais également à l'intérieur de la CFB. Les modalités détaillées sur la façon de comptabiliser les réserves latentes font l'objet de vives discussions. Les décisions au sein de l'autorité de surveillance se prennent alors fréquemment à une courte majorité. Un projet, faisant l'objet de nombreux compromis entre l'autorité de surveillance et la banque centrale, est envoyé en procédure de consultation en septembre 1959. Une seconde conférence d'experts entre représentants de la CFB, de la BNS et - surtout - des milieux bancaires (II sur 22 experts) est prévue le I4 décembre $1959^{140}$. En principe, il s'agit alors uniquement d'obtenir le blancseing des milieux concernés avant de transmettre le projet au Conseil fédéral. Mais la réunion ne se passe pas exactement comme prévu. Elle met à jour les antagonismes entre la Commission fédérale des banques et la Banque nationale suisse. Plus précisément, la banque centrale regrette le manque de soutien de certains membres de la CFB à l'égard d'un projet dont ils sont en grande partie responsables; c'est en particulier le renforcement de la liquidité voulu par la BNS qui est remis en question. Deux jours plus tard, les banquiers centraux se plaignent ouvertement de l'«impression mitigée et désagréable» laissée par la réunion. La posture de la CFB aurait incité les banques à demander des amendements plus radicaux:

L'attitude hésitante de la Commission des banques n'a pas fondamentalement dérangé les banques, elle les a au contraire encouragées, comme on nous l'a rapporté, à mettre en avant des amendements plus larges qu'elles ne l'avaient initialement prévu ${ }^{141}$.

Cette situation "peu réjouissante » engage la BNS à mettre un terme à des négociations ultérieures, tant que la CFB ne lui assure pas un soutien unanime au projet élaboré pendant l'été 1959 . C'est dans ce climat tendu qu'une nouvelle collaboration est refusée par les deux institutions, dans le domaine de l'échange d'informations; toutes deux se réfugient à nouveau derrière le secret bancaire pour refuser de partager leurs informations avec l'autre instance (cf. chap. VI.3).

Ces désaccords entre autorités de régulation bancaire profitent aux banques commerciales : une partie des revendications de la BNS ne sont finalement pas retenues, des ajustements à la baisse dans la question du renforcement de la liquidité sont opérés ${ }^{142}$. Sur la question de la comptabilisation des réserves

139 AFB, E6520(B), 2007/62, vol. 25, Rapport de la BNS (Schwegler, Iklé) à la CFB sur la révision du règlement d'exécution de la loi sur les banques, 39 pages, I4.IO.I958.

140 AASB, Dossier 7I3 I.I - 3I.I2 I959, Protokoll der Sitzung betreffend Revision der Vollziehungsverordnung zum Bankengesetz, I4.I2.1959, 19 pages.

141 AFB, E6520(B), 2007/62, vol. 26, Lettre de la BNS à la CFB, I6.12.1958.

142 AASB, Procès-verbaux du Conseil d'administration de l'ASB, $236^{\mathrm{e}}$ séance, 09.09.1960, p. I3-I4. 
latentes en tant que fonds propres, la CFB tranche la poire en deux : alors que les banques réclamaient une prise en compte à hauteur maximale de $20 \%$ des fonds propres, et que la BNS suggérait to \%, le texte final fixe ce coefficient à $15 \%$.

Transmis au Conseil fédéral au printemps 196I, le nouveau règlement d'exécution, avalisé sans broncher par le collège gouvernemental, entre en vigueur le $\mathrm{I}^{\mathrm{er}}$ octobre 196I. Pour l'essentiel, les changements opérés par rapport à la mouture de 1935 affectent les dispositions sur les fonds propres et la liquidité. Les exigences de fonds propres sont assouplies de deux manières. D'une part, par la comptabilisation des réserves latentes en tant que fonds propres, en plus du capital-actions et des réserves ouvertes; les réserves latentes ne peuvent cependant pas dépasser $15 \%$ du total des fonds propres. D'autre part, le ratio entre les engagements couverts par des disponibilités (avoirs de caisse, en compte de virement à la BNS et en compte postal) est réduit à $2 \frac{1}{1} 2 \%$ au lieu de $5 \%$. Cet allégement des normes de fonds propres est tactiquement et symboliquement compensé par un léger renforcement des exigences de liquidité. Les coefficients sont revus à la hausse, en particulier ceux sur la liquidité de caisse, et l'ajout de l'expression "en permanence» dans la disposition sur le respect des normes de liquidité vise à lutter contre le toilettage des bilans (window dressing). Ces durcissements étaient d'autant plus faciles à accepter pour les banques qu'elles affichaient depuis plusieurs années une liquidité parfois cinq fois supérieure aux minimas prescrits. En outre, la Commission fédérale des banques est toujours autorisée à octroyer des dérogations pour assouplir ces exigences de liquidité; elle est très rapidement sollicitée dans ce sens. Cela suscite l'irritation de la banque centrale, qui lui demande de faire preuve de retenue et de n'accorder des exemptions qu'au cas par cas et non pour tout un groupe bancaire ${ }^{143}$.

\section{CONCLUSION INTERMÉDIAIRE}

En faisant le bilan des différents efforts en vue d'une adaptation de l'ordonnance de la loi sur les banques entre I94I et I96I, on constate que la faculté à faire aboutir une révision du règlement d'exécution dépend en grande partie de la capacité d'influence des acteurs concernés. En 194I-1943, l'objectif principal des projets de révision est de contraindre légalement les caisses Raiffeisen à fournir des fonds propres jugés suffisants. L'ASB et la BNS adoptent alors une attitude relativement passive dans le processus, sans soutenir ni s'opposer directement aux démarches de la Commission fédérale des banques. Mais la tentative échoue, à cause du changement à la tête de la CFB et surtout de la résistance des Raiffeisen. Dans l'après-guerre, la haute conjoncture, ses effets inflationnistes, et le gonflement du volume d'affaires des grandes banques

143 ABNS, Procès-verbaux de la Direction générale de la BNS, 2I.09.I96I, p. I764-I765. 
suisses vont remettre la question à l'agenda des milieux bancaires. Il faut distinguer deux impulsions différentes, et même antinomiques. Celle, d'une part, de la Banque nationale suisse, qui, dès 1947, cherche à renforcer les exigences de liquidité bancaire pour lutter contre l'afflux de dépôts à vue, et plus généralement pour en faire un instrument de politique conjoncturelle. D'autre part, du côté des grandes banques - et en particulier de l'UBS et de la SBS -, on s'adresse dès 1954 à la CFB pour réclamer un allégement des dispositions sur les fonds propres. La croissance exponentielle des fonds de tiers, à laquelle les nombreuses augmentations de capital ne parviennent pas à répondre pour maintenir le niveau de fonds propres requis légalement, est à l'origine de ces requêtes. Ce double mouvement contradictoire va susciter des dissensions internes à la CFB : les uns privilégiant les arguments des grandes banques, les autres, ceux de la banque centrale. Ce n'est qu'à partir du moment où une requête officielle de l'ASB dans le sens d'une révision de l'ordonnance de la loi sur les banques est transmise à la CFB, en juillet 1957, que celle-ci se décide à préparer des avant-projets d'amendements. Après un processus d'élaboration d'environ quatre ans, la révision aboutit en 1961 : le compromis entre un assouplissement des normes de fonds propres et un durcissement des exigences de liquidité reste cependant à l'avantage des intérêts des banques. Des modifications secondaires, d'ordre souvent rédactionnel, sont d'ailleurs apportées pour noyer le poisson.

Sur le fond, cette discrète modification d'une ordonnance, qui ne connaît d'ailleurs pas de fortes répercussions médiatiques, permet également de consolider et de justifier dans des mesures prudentielles la pratique de l'accumulation des réserves latentes par les établissements bancaires. Alors que ces réserves jouent initialement un rôle de marge de manœuvre pour couvrir des pertes imprévues, elles sont dénaturées puisqu'elles entrent désormais dans le calcul de fonds propres et ne sont plus intégralement disponibles comme matelas de sécurité. L'assouplissement des normes de fonds propres se fait au détriment de la transparence de la comptabilité bancaire; un simple client d'une banque, voire un actionnaire, ne pourra plus se faire une idée précise de l'importance des fonds propres, puisque les réserves latentes - justement non déclarée dans les communications publiques entrent désormais en ligne de compte. Il sait uniquement qu'elles ne peuvent former que jusqu'à $\mathrm{I} 5 \%$ du total des fonds propres, mais ne sait en revanche ni si une banque fait recours à cette nouvelle possibilité, ni comment l'existence réelle de ce pourcentage de réserves latentes peut être certifiée.

Comme nous l'évoquions en introduction de ce chapitre, les débats autour d'une éventuelle révision des dispositions sur la liquidité et les fonds propres rendent manifestes les contradictions internes au secteur bancaire. En jouant sur les différentes variables dans la définition des termes de ces ratios prudentiels, les conditions de concurrence entre groupes bancaires peuvent être affectées. Un allégement qui repose sur la prise en compte de réserves latentes comme fonds propres ou une comptabilisation plus généreuse des actifs auprès des succursales étrangères n'a évidemment pas la même signification pour une 
grande banque commerciale que pour une caisse d'épargne locale. Les négociations sur une révision de l'ordonnance mettent donc en évidence comment une régulation a priori technique devient un enjeu très concret qui favorise ou entrave le développement de certains acteurs. On peut supposer que l'équilibre précaire trouvé dans le règlement de 1935 était d'autant plus difficile à remanier qu'il précisait des règles du jeu qui affectaient directement les conditions-cadres de la concurrence interbancaire. La réticence de l'ASB à mettre en chantier ces dispositions se comprend aussi mieux sous cet angle.

Il faut également souligner que cet épisode met encore une fois en lumière le caractère fort peu "étatique" de la politique poursuivie par la Commission fédérale des banques: alors qu'elle aurait pu soutenir les efforts de la banque centrale qui cherchait à freiner l'expansion monétaire dans le cadre de la lutte contre la surchauffe économique, la CFB s'est au contraire placée en arbitre entre l'ASB et la BNS. Partant du principe que la politique conjoncturelle n'était absolument pas de son ressort, la Commission fédérale des banques a privilégié un assouplissement des exigences de fonds propres facilitant l'expansionnisme de la place bancaire plutôt que des mesures prudentielles plus contraignantes.

La seconde dimension qu'illustre très bien la procédure qui conduit à la révision de l'ordonnance en I96I a trait à l'attachement des milieux bancaires, et dans une moindre, des superviseurs fédéraux, à la réglementation établie dans les années 1930. Nous avons vu qu'il existe une forme de tension constante, du point de vue des banquiers, entre la valeur des amendements qu'ils pourraient faire valoir dans le cas d'une révision et les risques que des changements indésirables soient exigés par d'autres intervenants. Même le règlement d'exécution de la loi sur les banques, un texte qui peut être modifié sans l'aval parlementaire, par décret gouvernemental, ne fait pas exception à cette logique de maintien du statu quo. L'insistance avec laquelle l'ASB s'efforce de provoquer une réalisation d'un assouplissement des dispositions sur les fonds propres par une nouvelle interprétation de la CFB plutôt que par une modification réglementaire en témoigne. Alors qu'une adaptation antérieure à 196I n'aurait sans doute pas été à l'encontre des intérêts bancaires, il a fallu attendre I957-I958 pour que le poids des avantages à gagner dans un processus de refonte de l'ordonnance excède les potentiels inconvénients. Nous voyons ainsi, à échelle réduite, se reproduire une logique similaire à celle qui prévaudra dans le contexte de la révision de la loi à proprement parler, qui fait l'objet des deux prochains chapitres. 


\section{CHAPITRE VIII}

\section{ADAPTATION ET RÉSISTANCE AU CHANGEMENT : FONDS DE PLACEMENT, BANQUES ÉTRANGÈRES ET SCANDALES FINANCIERS (1959-1965)}

Les quinze premières années qui suivent la fin de la Seconde Guerre mondiale correspondent, nous l'avons vu, à une phase de grand immobilisme du point de vue de la régulation bancaire suisse. Pas de réforme législative, peu de changements dans les activités de la Commission fédérale des banques sont alors à signaler. Au tournant des années 1960, une évolution vers une période plus agitée se fait jour. Alors que l'historien Jakob Tanner désigne le dernier tiers du XX ${ }^{\mathrm{e}}$ siècle de l'histoire suisse sous le titre " mouvement à contrecœur ", un spécialiste des banques helvétiques caractérise pour sa part les années 1960 de turbulentes ${ }^{1}$. L'histoire de la surveillance bancaire en Suisse - celle de la Commission fédérale des banques - s'accommode parfaitement de ces qualificatifs. À l'aune du premier quart de siècle d'existence de la régulation bancaire, les années 1960 amorcent en effet une période plus mouvementée. Sous l'effet de l'accélération formidable de la croissance des activités bancaires, la nécessité d'adaptations du cadre réglementaire se fait jour. Les années I960 représentent une phase de boom quantitatif exponentiel pour la place bancaire suisse (cf. chap. VII.I.I). Souvent prise de court, l'instance de surveillance cherche tant bien que mal à répondre aux nouveaux défis.

Quant à l'idée de résistance au changement exprimée dans la formule de Tanner, elle se retrouve également pleinement dans l'attitude ambivalente des autorités publiques face aux propositions de réforme du cadre réglementaire. La tension entre les nécessités d'adaptation de la législation bancaire et le fort attachement au statu quo se manifeste de plus en plus clairement. Pour le dire autrement, les années 1960 mettent en évidence un tiraillement qui est décisif pour la capacité d'aboutissement d'une réforme de la régulation : à partir de quand les avantages qui peuvent potentiellement résulter d'une révision de la loi dépassent-ils les risques liés à cette même révision? C'est cette dialectique que le long processus qui mène à la révision de la loi sur les banques de I97I

1 Jakob Tanner, Geschichte der Schweiz im 20. Jahrhundert, München: C.H. Beck, 2015; Loepfe, op. cit., 201 I. 
dévoile implicitement. Différentes lacunes dans le régime de surveillance bancaire sont progressivement détectées et reconnues par l'ensemble des acteurs impliqués, mais l'attachement très fort à la loi en vigueur et les craintes liées à une procédure de révision de la loi passant par le parlement offriront longtemps une résistance farouche à toute velléité de transformer le système de régulation.

Dans ce chapitre, nous allons successivement aborder différentes facettes de l'évolution des activités de l'autorité de surveillance bancaire au cours de la première moitié des années 1960. Il s'agira premièrement d'examiner la question du développement des fonds de placement en Suisse, une forme d'investissement de capitaux qui connaît un essor considérable, et des enjeux que soulève leur régulation par une législation fédérale. Dans un second temps, nous aborderons les premières discussions et tentatives infructueuses de réformer le cadre légal de contrôle bancaire. Ces efforts s'articulent pour l'essentiel autour de deux problématiques: la question de l'arrivée en Suisse de nouvelles banques étrangères et celle de l'amélioration de la protection des épargnants. Enfin, dans la troisième section, l'affaire Muñoz - un scandale qui ébranle sérieusement la légitimité de la CFB - sera mise à jour. Cette affaire exacerbe certaines des critiques qui avaient été formulées à l'égard du système de surveillance des banques. Elle constitue de plus un tournant dans notre récit, puisque ce n'est qu'après les révélations de ce scandale qu'une véritable procédure de révision sera enclenchée.

\section{VIII.1. «7 MILLIARDS DE FRANCS À LA RECHERCHE D'UN STATUT »: LA LOI SUR LES FONDS DE PLACEMENT

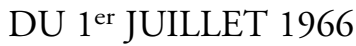

En mars 1966, le conseiller national radical tessinois Brenno Galli (I9101978) ouvre le débat parlementaire sur le projet de loi sur les fonds de placement en articulant ce chiffre impressionnant ${ }^{2}$. À titre de comparaison, ce montant de 7 milliards de francs dépasse largement le budget de la Confédération pour 1966, qui s'élève lui à 5.8 milliards de francs ${ }^{3}$. D'emblée, le décor de ce projet de législation économique est planté: il s'agit d'encadrer par une réglementation un instrument financier qui a pris une importance croissante et atteint une dimension imposante.

Dans ce sous-chapitre, nous allons nous intéresser à l'élaboration de cette législation, dans la mesure où elle a conduit à un élargissement des tâches de la Commission fédérale des banques, qui jouera pour les fonds de placement le même rôle de surveillance indirecte qu'elle remplit pour les banques. De plus, il s'agit d'un exemple illustrant à merveille comment le processus de régulation

2 Bulletin officiel de l'Assemblée fédérale, Conseil national, séance du 23 mars 1966, p. 244. Brenno Galli est par ailleurs président du Conseil de banque de la BNS (1959-1978).

3 «Arrêté fédéral concernant le budget de la Confédération suisse pour l'année 1966 et ouvrant des crédits d'ouvrages (Du i7 décembre 1965)", Feuille fédérale, 1965, vol. 3, nº 52, p. 728-729. 
cherche à appréhender, avec un certain décalage, une branche d'affaires qui s'est développé en partie grâce à l'absence de base légale déterminée. Dans le cas des fonds de placement, ce processus s'étend sur une dizaine d'années, entre 1957 et 1966, si bien qu'au moment où la nouvelle réglementation entre en vigueur (en février 1967), l'évolution de ce type d'investissement tend à stagner.

Avant d'aborder l'histoire du développement de cette législation, il est nécessaire de présenter en quelques mots l'activité principalement concernée. Les fonds de placement (en allemand Anlagefonds, en anglais alors investment trusts) sont aujourd'hui également connus sous les expressions fonds d'investissement ou placement collectif de capitaux. La loi de juillet 1966 en donne la définition suivante:

Le fonds de placement est constitué par les apports des porteurs de parts, effectués à la suite d'un appel au public en vue d'un placement collectif; il est géré par une direction pour le compte des porteurs de parts selon le principe de la répartition des risques ${ }^{4}$.

La définition juridique fixe donc quatre critères: l'appel au public, le caractère collectif du placement, la répartition des risques et la gestion par un tiers. Une définition alternative, qui insiste davantage sur la fonction économique de l'opération, est proposée par un dirigeant de l'une des plus grande société de fonds de placement helvétique:

Le fonds de placement est une organisation qui réunit des capitaux pour le compte de plusieurs investisseurs et les investit selon le principe de la répartition des risques et dans l'intérêt des bailleurs de fonds en valeurs mobilières, sans toutefois exercer une influence sur les entreprises concernées 5 .

Du point de vue économique, les fonds de placement offrent de nombreux avantages à l'épargnant qui souhaite placer ses capitaux, par rapport à d'autres formes d'investissement comme l'achat d'actions ou d'obligations. Ils permettent à un simple particulier d'investir, sous la forme collective, dans un portefeuille diversifié et de mieux répartir les risques. La gestion par des spécialistes du portefeuille d'investissement peut également être appréciable. De plus, dans une période de surchauffe économique et d'érosion du pouvoir d'achat de la monnaie, les fonds de placement, en tant qu'investissement à revenu variable, présentent l'avantage pour le public de ne pas être dévalués par une forte inflation. Troisième atout: le souscripteur d'un fonds de placement, qui devient alors un porteur de parts, est anonyme. De ce fait, l'instrument des fonds de placement permet aussi de contourner, pour un souscripteur étranger, les limitations à l'achat d'actions de sociétés suisses et de biens fonciers dressées

4 «Loi fédérale sur les fonds de placement (Du I ${ }^{\mathrm{er}}$ juillet 1966) », Feuille fédérale, I966, vol. I, $\mathrm{n}^{\circ} 27$, p. IIII-I2IO, ici p. II9I.

5 Ernst Georg Renk, «Anlagefonds », in Albisetti, Bodmer, Rutschi, op. cit., 1964, p. 37. 
par les régulations économiques contre l'Überfremdung économique ${ }^{6}$. Quatrièmement, les fonds de placement bénéficient d'un traitement favorable du point de vue fiscal. En effet, ils sont en grande partie exonérés, en particulier au motif qu'ils ne disposent pas de personnalité juridique, mais reposent sur une simple base contractuelle. Plus précisément, les fonds de placement ne sont soumis à aucune taxation directe (imposition communale, cantonale ou fédérale) ; en revanche, l'impôt sur les coupons peut être prélevé, mais uniquement auprès des porteurs de parts domiciliés en Suisse et sur les certificats étrangers ${ }^{7}$.

Ces divers atouts, sur lesquels certaines publications parrainées par les milieux bancaires ne manquent pas $\mathrm{d}^{\text {'insister }}{ }^{8}$, expliquent le succès retentissant que connaissent les fonds de placement au cours de l'après-guerre. C'est entre I945 et 1965 que cette forme d'investissement présente une courbe de croissance éclatante.

Graphique I4. Développement des fonds de placement en Suisse (1947-I980)

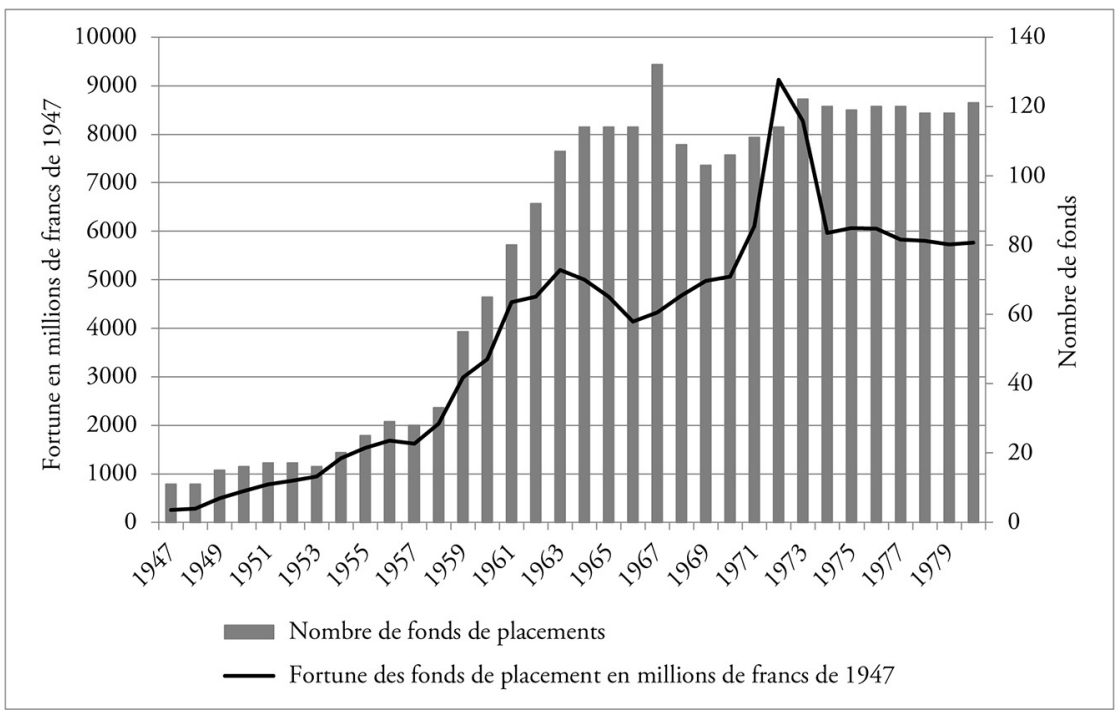

Source: ABNS, 9.3/9060, Investment-Trusts. Fortune déflatée au moyen de l'IPC, cf. Ritzmann-Blickenstorfer (éd.), op. cit., 1996, H.23, p. 504. Les données en francs courants figurent dans le tableau A.4 en annexe du PDF.

Cf. Lüpold, op. cit., 2010, p. 790-794; David, et al., op. cit., 2015, p. 153-200.

E.G. Renk, "Anlagefonds", in Albisetti, Bodmer, Rutschi, op. cit., 1964, p. 39.

Voir par exemple: Fritz Richner, De la question d'une législation spéciale sur les investment trusts: discours prononcé à l'assemblée générale ordinaire du 2 f février 1958 de l'Union de banques suisses, Zurich: UBS, 1958; E[rnst] G[eorg] Renk, Kurt Amonn, "Die durch die Investmenttrusts oder Anlagefonds mit internationalem Charakter aufgeworfenen Fiskalprobleme", Steuer-Revue, vol. 17 no 8, 1962, p. 314-327-344; Intrag SA, Intrag, fonds de placement: 25 ans Intrag, Zurich: Intrag, 1963. 
L'évolution statistique du graphique I4 fait clairement ressortir la forte phase d'expansion des fonds de placement entre i947 et 1963. Le taux de croissance annuel moyen réel de la fortune de fonds de placement se situe à hauteur de $22 \%$ pendant cette période. De 253 millions de francs en I947, on passe - cette fois en termes absolus - à plus d'un milliard de francs en I953, 2.3 milliards en 1958, puis 6.6 milliards en 1963. S'ensuit un léger recul entre I963 et I967, avant un nouveau boom entre I968 et I972. Le tassement du milieu des années 1960 trouve son origine dans les mesures contre la surchauffe économique prises par les autorités suisses, entraînant un léger recul boursier qui se reporte sur la valeur des fonds de placement ${ }^{9}$. Signalons encore la croissance remarquable au cours de l'année 1959. Pendant cette année, la fortune des fonds de placement bondit de 2.3 à 3.4 milliards, soit un taux de croissance de près de $50 \%$. Il n'est pas anodin que ce soit également à ce moment-là que se renforce considérablement la pression en faveur d'une régulation de l'instrument financier des fonds d'investissement.

Cette forte croissance des fonds de placement en Suisse est également singulière en comparaison européenne. Historiquement, le principe des investment trusts s'est d'abord développé au Royaume-Uni dans le dernier tiers du $\mathrm{XIX}^{\mathrm{e}}$ siècle, puis aux États-Unis durant l'entre-deux-guerres ${ }^{10}$. En Suisse, les premières sociétés de placements collectifs apparaissent durant la phase de décollage de la place bancaire suisse, sous la forme des sociétés d'investissement de capitaux, comme la SOPAFIN fondée à Genève en 1900 ou la Schweizerische Gesellschaft für Kapitalanlagen, proche de la Banque Leu à Zurich en I9I2 ${ }^{11}$. La fondation de la Société suisse pour valeurs de placement (Schweizerische Gesellschaft für Anlagewerte) par la SBS en 1907 entre dans la même catégorie ${ }^{12}$. Ces entreprises placent des capitaux en titres, mais à la différence de ce qu'on considérera plus tard comme les fonds de placement, elles exercent parfois une influence sur d'autres sociétés en détenant des participations permanentes.

C'est au cours des années 1930 que sont fondées les deux sociétés qui dominent le marché durant les Trente Glorieuses, et pratiquent les fonds de placement contractuels sur le modèle anglais du trust. Il s'agit premièrement de la Société Internationale de Placements (SIP) fondée à Bâle en I930, sous

9 Intrag SA, so ans Intrag SA, Gestion d'Investment Trusts, Zurich, Zurich: Intrag SA, I988, p. 37 ; Lüpold, op. cit., 20Io, p. 794.

10 Iklé, op. cit., I970, p. I48.

11 "Message du Conseil fédéral à l'Assemblée fédérale concernant la loi fédérale sur les fonds de placement (Du 23 novembre i965)", Feuille fédérale, 1965, vol. 3, n 49, p. 264-363, ici p. 270. La Sopafin est fondée par Guillaume Pictet, de la maison genevoise Pictet \& Cie. Cf. Manfred Pohl, Sabine Freitag (éd.), Handbook on the History of European Banks, Aldershot: Edward Elgar, I994, p. IIIo. Elle s'intègre dans un ensemble de sociétés financières fondées par le groupe de l'Union financière de Genève, cf. Walter Mollet, Schweizerische InvestmentTrusts, Solothurn: Buchdr. Vogt-Schild A.-G, I942, p. 89-I05.

12 Mazbouri, op. cit., 2005, p. 285, Bauer, op. cit., I972, p. I56-I57. Sur ces sociétés de fonds d'investissement avant l'heure, voir aussi Mollet, op. cit., I942, en particulier la présentation exhaustive de chacune de ces entreprises p. 89-249. 
l'impulsion de six maisons de banquiers privés de différents pays européens, dont la banque bâloise Speiser, Gutzwiller \& $\mathrm{Cie}^{13}$. En 1939, les fondateurs étrangers de la SIP se retirent, tandis que la Société de Banque Suisse et le Crédit Suisse prennent une participation de $40 \%$ chacun à la SIP.

Cette prise de participation des deux plus grandes banques suisses de l'époque peut être lue comme une réponse à la fondation par l'UBS, en 1938, de l'autre acteur principal des fonds de placement : la Société Anonyme pour la gestion d'Investment Trusts (INTRAG) à Zurich. Plus précisément, l'INTRAG est fondée par l'Union de Banques Suisses, en collaboration avec trois banques privées: Lombard, Odier \& Cie (Genève), La Roche \& Cie (Bâle), et Roguin \& Cie (Lausanne) ${ }^{14}$. Retenons donc qu'au seuil de la Seconde Guerre mondiale, les trois principales banques suisses - la SBS et le Crédit Suisse conjointement, l'UBS de son côté - consolident leurs positions dans le marché des investment trust. Ce n'est que dans l'après-guerre que les deux sociétés, la SIP et l'INTRAG, vont connaître un essor considérable. De nombreux nouveaux fonds, spécialisés soit dans une région ou un pays, soit dans un domaine industriel, sont créés; entre 1949 et 1963, I9 fonds sont constitués par les deux sociétés réunies ${ }^{15}$. Parmi ceux-ci, le SAFIT (South Africa Trust Fund), créé en 1948 par l'INTRAG, et donc indirectement par l'UBS, s'impose à l'échelle européenne comme un des investisseurs majeurs dans les valeurs et titres sudafricains ${ }^{16}$. Selon l'historienne Sandra Bott, il joue un rôle essentiel dans la consolidation des relations commerciales entre la place financière suisse et les entreprises sudafricaines, en particulier dans le domaine de l'extraction minière, et contribue grandement à renforcer la position des banques suisses (et prioritairement celle de l'UBS) dans la commercialisation de l'or sudafricain. Durant les Trente Glorieuses, l'INTRAG occupe une position dominante dans

13 Les cinq autres banques sont Associate Wertheim \& Gompertz I834 en Credietvereeniging 1953 N.V., Amsterdam, Hugo Oppenheim \& Sohn, Berlin, R. Henriques, jr., Copenhaguen, Schwab \& Snelling, London et Raoul de Lubersac \& Cie, Paris. Voir la plaquette publiée à l'occasion de son $50^{\circ}$ anniversaire : Société Internationale de Placements, 50 Jahre Société Internationale de Placements: die erste schweizerische Fondsleitung: 1930-1980, Rückschau und Ausblick, Basel: SIP, 1980, p. 19-2I. Cf. aussi Lüpold, op. cit., 20IO, p. 79I. Voir aussi Mollet, op. cit., 1942, p. 165-23I.

14 Intrag SA, op. cit., 1963; Intrag SA, op. cit., I988; Raff, op. cit., 1962, p. I54-155; Mollet, op. cit., I942, p. 232-249.

15 Du côté de la SIP, «Schweizeraktien », Swissimobil Neue Serie (1949), Ussec (I95I), Canasec (1952), Canada-Immobil (1954), Swissvalor Neue Serie (1957), Europa-Valor (1959), EnergieValor (196I), Swissimmobil (I96I). Chez INTRAG: Safit (South Africa Trust Fund, en 1948), Fonsa (Fonds de Placement en Actions Suisses, en 1949), Sima (Fonds Suisse de Placements Immobiliers, en 1950), Canac (Fonds de Placement en Actions Canadiennes, en I955), Itac (Fonds de Placement en Actions Italiennes, en 1958), Eurit (Fonds d'Investissement en Actions Européennes, en 1959), Francit (Fonds d'Investissement en Actions Françaises, en 1959), Espac (Fonds de Placement en Actions Espagnoles, en 196I), Denac (Fonds de Placements en Actions du Commerce de Détail et de l'Industrie Alimentaire, en 196I) et Germac (Fonds de Placements en Actions Allemandes, en 1963).

16 Sur le SAFIT, voir Sandra Bott, La Suisse et l'Afrique du Sud 1945-199o. Marché de l'or, finance et commerce durant l'apartheid, Zurich : Chronos, 2013, p. 85-9I. 
le secteur des fonds de placement en Suisse : sa part de marché oscille entre $34 \%$ et $60 \%$ sur la période $1950-1975^{17}$.

Ce rapide aperçu du développement des fonds de placement en Suisse entre les années 1930 et les années 1960 laisse entrevoir les trois caractéristiques suivantes. Premièrement, les fonds de placement collectif ont connu en Suisse un établissement dès la fin des années 1930, ce qui est relativement précoce à l'échelle de l'Europe continentale. Selon la publication jubilaire de l'INTRAG, seuls les Pays-Bas connaissent un développement analogue de trusts d'investissement axés sur l'étranger dès cette époque ${ }^{18}$. Ailleurs en Europe continentale, les fonds de placement ne prospèrent qu'à partir des années 1950.

Second trait distinctif, les fonds de placement helvétiques sont intrinsèquement liés aux grandes banques commerciales qui dominent la place financière. Cette situation contraste avec la configuration anglaise, où les fonds de placement sont indépendants des banques ${ }^{19}$. Dans ce cadre, l'UBS et sa filiale INTRAG font figure de fer-de-lance de l'expansion des fonds d'investissement, en particulier des fonds étrangers ${ }^{20}$. En misant sur ce vecteur, la grande banque zurichoise compense également son retard sur ses deux concurrentes dans l'expansion des opérations internationales.

Troisièmement, et c'est là l'aspect qui nous intéresse de plus près, les fonds de placement ont connu en Suisse une expansion foudroyante, alors même qu'il règne un grand flou juridique sur les rapports noués entre un porteur de part, la société de gestion et la banque dépositaire. Se propageant en dehors de tout cadre législatif et de toute surveillance officielle, les fonds de placement ont sans doute bénéficié du vide juridique qui caractérise l'environnement légal suisse jusqu'en 1966. Ailleurs, des législations spéciales sont promulguées antérieurement ${ }^{21}$. Aux États-Unis, l'Investment Company Act est édicté en 1940, à la suite de l'effondrement subi par de nombreux investment trusts au cours de la grande dépression. En France, une ordonnance de novembre 1945, puis une loi de juillet 1957 établissent des statuts pour les fonds de placement. L'Allemagne et la Belgique promulguent également des lois en $1957^{22}$. Les travaux législatifs qui débutent en Suisse en 1957 ont donc pour but de combler ce vide juridique et de protéger les épargnants qui choisiraient l'instrument des fonds de placement.

Dans l'analyse de l'élaboration de la législation qui aboutit en 1966, nous focaliserons notre attention sur le rôle de la Commission fédérale des banques. Cherche-t-elle à étendre son rayon d'activité en déployant ses compétences de

17 La part de marché représente le rapport entre la fortune totale de l'INTRAG et celle de toutes les sociétés de fonds de placement. Cf. Intrag SA, op. cit., I988, p. I42-I43 et graphique I4.

18 Intrag ibid., p. I55.

19 «Message du Conseil fédéral à l'Assemblée fédérale concernant la loi fédérale sur les fonds de placement (Du 23 novembre 1965)", Feuille fédérale, 1965, vol. 3, nº 49, p. 264-363, ici p. 266.

20 Cf. Loepfe, op. cit., 20II, p. 65.

21 Alain Hirsch, "Une loi spéciale sur les fonds de placement ", Wirtschaft und Recht, vol. Io, $\mathrm{n}^{\mathrm{o}} 2$, I958, p. I24-I33, ici p. 127.

22 Sur la surveillance exercée par la Commission bancaire belge sur les fonds de placement, cf. Giddey, art. cit., 2017. 
régulation au domaine des placements collectifs ou favorise-t-elle au contraire le statu quo ou la création d'une nouvelle instance en charge de cette tâche?

En adoptant cette perspective, nous négligeons évidemment de nombreux autres aspects relatifs au développement des fonds de placement : le débat sur le traitement fiscal de cette forme d'investissement ${ }^{23}$, le rôle de l'essor des fonds de placement sur les mécanismes de défense de la place économique suisse à l'égard des investisseurs étrangers ${ }^{24}$, ou encore la dimension sociologique de ce développement qui permet d'élargir à de petits épargnants des formes d'investissement (la participation actionnariale par les biais des fonds de placement) jusqu'alors réservées à la grande bourgeoisie. La croissance des investment trusts en Suisse dans l'après-Seconde Guerre mondiale ouvre, nous le voyons ici, de nombreuses pistes de recherche et son histoire reste encore à écrire.

Avant même le début du processus législatif à proprement parler qui commence en 1957, les autorités de régulation financière ont pris conscience de l'enjeu considérable représenté par les fonds de placement. À la fin des années 1930, tant la Commission fédérale des banques que la Banque nationale suisse prennent sous la loupe les sociétés de gestion de fonds de placement récemment créées par les grandes banques. $\mathrm{La}$ CFB, sans doute sous l'effet du revers judiciaire essuyé dans le cas de la SAGED, opte pour une politique prudente et décide, en juin-juillet 1938, de ne pas soumettre la Société Internationale de Placements à la loi sur les banques ${ }^{25}$. De son côté, la banque centrale se rend compte, dès 1938 également, que les nouveaux fonds orientés vers le marché nord-américain constitués par la SIP et l'INTRAG, à savoir respectivement "Canasip" et "AMCA", représentent des moyens détournés de pratiquer de l'exportation de capitaux. Or, les actions et obligations dans lesquelles investissent ces fonds ne sont en aucune façon concernées par le droit de regard introduit dans l'article 8 de la loi sur les banques de 1934. Mais la BNS, à la suite de l'avis prépondérant du Département des finances et des douanes, se contente d'inviter les banques concernées à lui transmettre des informations comptables sur l'état des investment trusts, et les engage parfois à faire preuve de retenue dans l'émission de nouveaux fonds. La solution plus contraignant d'une révision législative est écartée en raison de sa longueur et des risques que d'autres demandes soient formulées ${ }^{26}$.

Cf. Aniko Fehr, «La lutte contre la fraude fiscale ou les origines de l'Arrêté fédéral concernant l'octroi d'une amnistie fiscale générale au I ${ }^{\text {er }}$ janvier 1965 (I958-1964) ", Mémoire de Master, Faculté des lettres, Université de Lausanne, 20I5, p. 59. Voir aussi les différentes contributions à ce sujet du professeur de droit Kurt Amonn (I9I7-20I4) datant des années I96I et 197I publiées dans Kurt Amonn (éd.), Beiträge zum SchKG, Banken-und Steuerrecht : Festschrift zum 80. Geburtstag, Bern : Stämpfli, 1997.

Cf. Lüpold, op. cit., 2010, p. 782-799.

AFB, E6520(A), I000/1059, vol. 7, PV CFB, 25.06.1938 et 08.07.1938, p. 88 et Ioo. En juin 1937, le Tribunal fédéral donne raison à la Société Anonyme de Gérance et de Dépôts (SAGED) et lève l'assujettissement à la loi prononcé par la CFB. Cf. chap. VI.I.3.

26 ABNS, Procès-verbaux de la Direction générale de la BNS, 15-17.02.1939, p. 169-171, 17.03.1939, p. 252. 
En 1948, au moment de la création du fonds sudafricain SAFIT par l'INTRAG liée à l'UBS, la banque centrale reprend le dossier en main, réexamine ses possibilités légales d'intervention. Malgré l'importance qu'ont gagné les fonds de placement, la BNS considère qu'une nouvelle tentative de combler la lacune réglementaire n'aurait que peu de chances de succès ${ }^{27}$. Elle se cantonne à demander aux banques de lui transmettre, sur une base volontaire, des informations statistiques sur les opérations des fonds d'investissement. L'environnement juridique intégralement dérégulé qui voit l'essor en Suisse des fonds de placement pendant près de trente ans (1938-1967) est donc aussi la résultante de choix en ce sens faits par les autorités fédérales, et non pas simplement d'une forme de négligence face à une innovation financière dont on ignore l'importance.

En juin 1957, le conseiller national radical neuchâtelois Paul-René Rosset (1905-1977), dépose une motion invitant le Conseil fédéral à soumettre les trusts d'investissement à une législation pour protéger l'épargne, ce qui inclurait une surveillance officielle et des dispositions particulières en cas de faillite ${ }^{28}$. Cette intervention parlementaire constitue le coup d'envoi de la démarche législative qui aboutira à la loi fédérale sur le fonds de placement du $\mathrm{I}^{\mathrm{er}}$ juillet 1966. Pris dans son ensemble, le processus s'étend donc sur une dizaine d'années, entre 1957 et 1967. Il se décompose en deux phases. La première s'étend de I957 à I96I et débouche sur un projet de loi relativement strict et détaillé. Mais il rencontre l'opposition d'un certain nombre d'acteurs, dont l'Association suisse des banquiers. Entre 1962 et 1967, un nouveau projet est élaboré par une commission d'experts recomposée; il est adopté par le Parlement à l'été 1966 et entre en vigueur en février 1967.

Reprenons plus en détail ces deux phases, en soulignant en particulier les aspects relatifs au rôle de la Commission fédérale des banques. L'impulsion décisive donnée par la motion Rosset de juin 1957 provient en fait de la faillite de la S.A. de Placements Mobiliers, basée à Genève, prononcée le I3 mai 1957 par le Tribunal de première instance genevois ${ }^{29}$. Cette société de gestion de fonds de placement, notamment gestionnaire du fonds Canabuild Oil \& Mining Investment Fund, avait illicitement transféré des dépôts (près de 3 millions de francs) pour éponger des pertes subies sur les valeurs canadiennes. Il s'agit du second cas de ce genre après l'affaire du fonds Immo-Hyp Propria AG de Zurich, qui avait coulé en I95I. La seconde impulsion qui pourrait inciter le monde politique suisse à légiférer réside dans les récents efforts législatifs menés dans le domaine en Allemagne de l'Ouest et en Belgique. Dans un premier temps, la CFB se positionne cependant clairement contre une

ABNS, Procès-verbaux de la Direction générale de la BNS, 24.03.1948, p. 533-538.

28 Motion Rosset du 26 juin 1957 ( 59 cosignataires) citée dans le « Message du Conseil fédéral à l'Assemblée fédérale concernant la loi fédérale sur les fonds de placement (Du 23 novembre I965)", Feuille fédérale, I965, vol. 3, no 49, p. 264-363, ici p. 264.

29 [s.a.], "Une grosse faillite, compliquée de plaintes pénales ", Journal de Genève, I5 mai I957, p. 7 . 
prise en charge de la surveillance des sociétés de gestion des fonds de placement, qui ne peuvent pas être considérées comme des banques soumises à la loi bancaire ${ }^{30}$. Mais fin octobre 1957, la donne a changé. Entre-temps, le DFFD a lancé une procédure de consultation sur la question auprès de la $\mathrm{CFB}$, de la BNS et de l'ASB. Une réunion organisée mi-octobre 1957 a donné lieu à un premier échange de vues. Il en ressort que les banquiers concernés par les fonds de placement, à savoir essentiellement les grandes banques et en particulier l'UBS, sont plutôt favorables à une législation sur les investement trusts, à condition qu'elle soit moins détaillée que les réglementations américaines et allemandes; pour l'ASB, la Commission fédérale des banques serait l'instance adéquate pour appliquer la future législation ${ }^{31}$. Ce point de vue favorable à une régulation étatique de la part de la faîtière des banquiers pourrait a priori surprendre. Elle est sans doute liée à la volonté des acteurs déjà en place dans le marché des fonds de placement de se protéger contre de potentiels nouveaux concurrents indésirables. Comme le soulève le secrétariat de l'ASB, les fonds d'investissement bien gérés et organisés n'auraient rien à craindre d'une réglementation ${ }^{32}$. Elle témoigne en outre de la grande confiance qu'accordent les milieux bancaires suisses aux législateurs et régulateurs. Alors qu'elle suscitait encore de la méfiance au moment de sa mise en place en 1934, la Commission fédérale des banques est ici devenue, aux yeux des milieux bancaires, une instance de régulation compréhensive - un partenaire de concertation -, dont on peut se servir dans la lutte concurentielle. Quelle que soit sa motivation précise, ce blanc-seing de l'ASB au principe d'une législation semble faire basculer l'opinion au sein de la CFB. Les superviseurs cherchent alors essentiellement à contrer la prolifération de fonds qui ne sont pas gérés par ce qu'ils considèrent comme des banques sérieuses ${ }^{33}$.

Les prises de position de la Commission fédérale des banques et de l'Association suisse des banquiers, transmises au DFFD dans le courant du mois de novembre 1957, suivent ainsi la même orientation générale ${ }^{34}$. La seule option envisagée est celle d'une nouvelle législation spéciale sur les fonds de placement, et non celle d'une modification de la loi sur les banques ou du Code des obligations. Pour la CFB, l'objectif est la protection de l'épargnant qui investit dans des fonds de placement, en précisant: « comme du temps de la loi sur les banques, on pourrait se limiter essentiellement à donner un caractère obligatoire à la situation de fait éprouvée » ${ }^{35}$. L'ASB est un peu plus nuancée dans son

\section{(1)} 09.II.1957. Position de l'ASB (19 pages) : Lettre de l'ASB à Hans Streuli (chef du DFFD),
26.II.I957, annexée au PV de la $225^{\mathrm{e}}$ séance du CdA ASB du I8.I2.1957.

AFB, E6520(A), I000/1059, vol. II, PV CFB, 24.06.1957, p. 89-90.

AFB, E6520(B), 2007/62, vol. 66, Akten-Notiz Investment-Trusts, 2I.IO.I957.

AASB, Lettre du secrétariat de l'ASB aux membres du CdA et de la Commission juridique de l'ASB, 06.09.1957, annexée au procès-verbal de la $224^{\mathrm{e}}$ séance du Conseil d'administration de l'ASB, 27.09.1957.

AFB, E6520(A), I000/I059, vol. II, PV CFB, 31.I0.1957, p. I52.

Position de la CFB (I2 pages) : AFB, E6520(B), 2007/62, vol. 66, Lettre de la CFB au DFFD,

35 AFB, E6520(B), 2007/62, vol. 66, Lettre de la CFB au DFFD, 09.II.I957. 
positionnement. Elle considère qu'une législation n'est pas absolument nécessaire, mais qu'elle ne s'y opposerait pas, du moment que la législation prendrait en considération les principes en place chez les fonds reconnus comme exemplaires. Elle espère de plus qu'une législation spéciale sera en mesure de clarifier le statut fiscal des fonds de placement, dans le sens d'une exonération ${ }^{36}$.

Sur la base de ces deux avis, le Conseil fédéral se déclare prêt, le 20 mars 1958 , à examiner les possibilités de légiférer dans le domaine des fonds de placement $^{37}$. Début 1959, le gouvernement fédéral charge le professeur de droit à l'Université de Berne Rudolf Probst (1909-1999) de rédiger un avant-projet de loi. En plus de ses fonctions académiques, Rudolf Probst est directeur de l'Allgemeine Treuhand AG à Berne, une société fiduciaire ${ }^{38}$. Le projet Probst est terminé en octobre 1959 et soumis à une petite commission d'experts composée essentiellement de juristes et d'hommes du métier. Présidée par le professeur de droit à l'Université de Fribourg Peter Jäggi (1909-1975) ${ }^{39}$, la délégation compte cinq autres membres: l'auteur du projet Rudolf Probst; le professeur d'économie politique à l'Université de Berne Fritz Marbach, ancien conseiller national socialiste; le professeur d'économie politique à l'Université de Neuchâtel Paul-René Rosset, auteur de la motion parlementaire en tant que conseiller national radical ; l'administrateur-délégué de l'INTRAG Ernst Georg Renk; et enfin Karl Schweri, vice-président de l'Agemit AG, une société de gestion de fonds de placement.

Les premières réactions de la CFB sur le projet Probst sont plutôt hostiles. Paul Rossy estime que seul le commentaire est libéral, et que le reste du projet est une « législation policière qui introduit une véritable dictature monétaire et étatise la politique de placement $~^{40}$. Malgré ce préavis réticent, la Commission fédérale des banques s'attèle à un traitement systématique de l'ensemble de l'avant-projet; elle envoie en outre son secrétaire Daniel Bodmer, en qualité d'observateur, aux sept réunions de la commission d'experts entre décembre 1959 et septembre 1960 .

La banque centrale, de son côté, réserve un accueil plus chaleureux au projet Probst ${ }^{41}$. Plus spécifiquement, les dirigeants de la BNS saluent surtout trois types de dispositions. Premièrement, celle qui introduit un capital minimal pour les sociétés de gestion des fonds de placement. À cet égard, la BNS souhaite même un renforcement significatif, puisqu' elle propose un capital proportionnel

36 Sur la position de l'ASB, voir aussi son Rapport sur le $46^{e}$ exercice du $I^{\text {er }}$ avril 1957 au 3 I mars 1958, Bâle: Frobenius, 1958, p. 31-34.

37 Procès-verbaux de l'Assemblée fédérale, Conseil national, session ordinaire de printemps, 20.03.1958, p. 483-489.

38 Selon le rapport aux membres de la CFB de son secrétariat du 30.I0.1959. AFB, E6520(B), 2007/62, vol. 66.

39 Peter Jäggi deviendra membre du Conseil de banque de la BNS en 1963, puis son viceprésident jusqu'à sa mort en 1975 .

40 AFB, E6520(A), I000/1059, vol. I2, PV CFB, or.12.1959, p. I70.

$41 \mathrm{AFB}, \mathrm{E} 652 \mathrm{O}(\mathrm{B}), 2007 / 62$, vol. 66, Lettre de la direction générale de la BNS à la direction de l'AFF, 08.12.1959. 
à la fortune des fonds, au lieu d'un montant minimal forfaitaire; cette suggestion a pour but explicite de freiner "l'expansion malsaine" des investment trusts. Deuxièmement, elle approuve la mesure qui prévoit un devoir d'information des fonds de placement à la BNS; là aussi, elle exige un renforcement sous la forme d'une transmission mensuelle de renseignements plus détaillés que ne l'avait prévu Probst. Enfin, l'article qui met en place un droit de regard de la BNS sur l'exportation de capitaux qui s'effectue par le biais des fonds de placement est vivement soutenu. Cette disposition comble en effet ce que la BNS a considéré, dès la fondation des premiers fonds de placement à la fin des années 1930, comme une lacune dans la surveillance de l'exportation de capitaux.

La prise de position de la BNS est à ce titre diamétralement opposée à la réaction que suscite le projet Probst auprès des grandes banques et des sociétés de gestion des fonds de placement. Fin novembre 1959, Ernst Georg Renk, administrateur-délégué de l'INTRAG, autrement dit l'homme fort de la plus grande direction de fonds d'investissement, se fend d'un rapport critique sur le projet Probst à l'adresse de ses collègues de la petite commission ${ }^{42}$. Renk signale d'emblée qu'il n'approuve pas le texte sur lequel il prend position. Parmi les huit mesures qu'il faudrait selon Renk supprimer, celle sur le contrôle de l'exportation de capitaux figure en bonne place, aux côtés notamment de la clause qui interdit les unions personnelles entre les fonctions de direction du fonds et de banque dépositaire. Même la surveillance publique par la CFB devrait être nettement circonscrite, pour éviter une extension de l'appareil bureaucratique.

Il ressort de ces prises de position initiales que l'élaboration d'une législation sur les fonds de placement met à jour certains antagonismes entre la banque centrale et les grandes banques. La question relative à l'expansion des opérations internationales de la place financière et des déséquilibres provoqués sur le marché des capitaux, ainsi que le problème du contrôle de l'inflation liée à la surchauffe économique servent de toile de fond à ce désaccord. Dans ce contexte, la régulation des investment trusts n'est qu'un exemple révélateur de ces tensions.

Parallèlement à ses exigences visant à un renforcement du projet de loi sur les fonds de placement, la BNS agit également directement pour empêcher de nouvelles créations de fonds de placement, et pour limiter «l'activité de propagande» déployée par les fonds ${ }^{43}$. Cette intervention prend la forme de recommandations écrites à plus de retenue: deux circulaires allant dans ce sens sont diffusées en décembre 1959 et janvier 1960. Là aussi, ces démarches, dont l'efficacité est toute relative d'après les commentaires désabusés qu'elles suscitent à la direction générale de la BNS, nourrissent les tensions entre la banque centrale et les banques responsables des investment trusts en question.

42 AFB, E6520(B), 2007/62, vol. 66, «Allgemeine Bemerkungen zum Vorentwurf eines Bundesgesetzes über die Anlagefonds, E.G. Renk», 25.II.I959.

43 Cf. ABNS, Procès-verbaux de la Direction générale de la BNS, 30.12.1959, p. 2968-2969; 07.01.1960, p. 40-42; 02.04.1960, p. 223-230; 31.03.1960, p. 545-549. 
Le projet de loi sur les fonds de placement issu des travaux préparatifs de l'avant-projet Probst et de la commission Jäggi est achevé en mai i96I. Il entre alors en phase de consultation (Vernehmlassungsverfahren), une procédure standard dans le système politique suisse: le texte en discussion est envoyé à un grand nombre d'acteurs politiques et économiques, dont les gouvernements cantonaux, les partis nationaux et les associations économiques.

Le bilan des consultations se dessine dès novembre i96I. Alors que la plupart des cantons et des organisations de juristes approuvent le projet, les "milieux intéressés » - à savoir l'Association suisse des banquiers et l'Association Suisse des Sociétés Gérantes de fonds de placement - émettent de sérieuses réserves sur le texte soumis, qu'ils jugent trop détaillé et trop interventionniste à certains égards ${ }^{44}$. Le Vorort, en compilant les avis des diverses chambres de commerce régionales, accueille le projet favorablement, mais avec un scepticisme non dissimulé ${ }^{45}$. Du côté des banques cantonales, qui n'ont suivi le mouvement vers les fonds de placement qu'avec un grand retard, puisque leur direction d'investment trust commune - baptisée IFAG fonds immobiliers S.A. - est créée en 1960, au grand dam de la BNS, le projet de loi est également froidement reçu ${ }^{46}$. Les banques cantonales se rallient donc à l'avis dominant des grandes banques, et demandent, de concert avec l'ASB, d'être à nouveau consultées, lorsqu'un projet de loi profondément remanié sera préparé.

Rétrospectivement, au sein de la commission du Conseil national mise sur pied pour discuter le projet de loi en janvier 1966, le conseiller fédéral catholique-conservateur valaisan Roger Bonvin (1907-1982) présente très clairement le fonctionnement du système politique suisse en évoquant le projet de I96I abandonné :

Une réalité démocratique souvent nous échappe, et elle échappe en tout cas à nos enfants : si, dans ce pays, l'opposition n'est pas fracassante, elle n'en est pas moins permanente. Au niveau des commissions d'experts déjà, les diverses tendances scientifiques s'affrontent. Dans le cadre des études faites par le Département, on prend aussi de nombreux avis. Le Conseil fédéral lui-même publie un projet qu'il aura peut-être lui aussi préalablement soumis à une procédure de consultation. Au moment où

La prise de position de l'ASB, longue de 35 pages (!) et datée du I3 octobre I96I, est annexée au procès-verbaux de la $240^{\mathrm{e}}$ réunion du CdA de l'ASB du o6.Io.I96r. Celle de l'Association suisse des sociétés gérantes de fonds de placement date du I3 octobre I96I, et est conservée aux AFB, E6520(B), 2007/62, vol. 66. Cf. aussi « Message du Conseil fédéral à l'Assemblée fédérale concernant la loi fédérale sur les fonds de placement (Du 23 novembre 1965)", Feuille fédérale, 1965, vol. 3, n 49 , p. 264-363, ici p. 265. L'Association suisse des sociétés gérantes de fonds de placement (Vereinigung schweizerischer Verwaltungsgesellschaften von Investment-Trusts) est présidée par Karl Schweri, vice-président de l'Agemit AG. sungen zum Entwurf des Eidg. Finanz- und Zolldepartements vom I. Mai I96r zu einem Bundesgesetz über die Anlagefonds", [s.d.]. 
un projet vous est soumis, il tient déjà compte de nombreuses oppositions $^{47}$.

On perçoit une pointe d'embarras dans cette déclaration du conseiller fédéral ; en l'occurrence, "l'affrontement scientifique " était plutôt la désapprobation de groupes d'intérêt, malgré leur étroite collaboration à toute l'entreprise. Le projet Probst-Jäggi de mai 196r se heurte donc essentiellement à la résistance des milieux bancaires. Dans la foulée, l'Administration des finances décide docilement de remettre l'ouvrage sur le métier. Une nouvelle commission d'experts est mise sur pied. Jäggi et Probst en font toujours partie, mais le jeune avocat genevois Alain Hirsch (1934-), auteur d'une récente étude sur les fonds de placement, a remplacé le socialiste Marbach et le radical Rosset. Les travaux de cette commission remaniée aboutissent à l'été I964 à "un nouvel avant-projet, différant notablement du précédent", selon les dires du Conseil fédéral ${ }^{48}$. De l'aveu même des banquiers, ces derniers ont "maintenu un contact étroit avec les services compétents de l'administration fédérale, [...] pour revoir et rédiger à nouveau le projet de loi ${ }^{49}$. Le résultat de cette collaboration entre banquiers et législateurs satisfait pleinement les premiers. Le nouveau projet de loi "correspond largement à nos avis sur des points fondamentaux": il offre aux investisseurs une protection appropriée, "sans restreindre abusivement les possibilités de développement des fonds " ${ }^{50}$. L'ASB constitue même en 1964 une nouvelle commission ad hoc permanente en son sein chargée des fonds de placement ${ }^{51}$. Composé de dix membres, dont quatre liés aux grandes banques, deux aux banques cantonales, deux banquiers privés et deux représentants des banques régionales, ce comité est essentiellement une réponse aux efforts législatifs récents, en particulier dans le domaine fiscal (loi fédérale sur l'impôt anticipé, loi fédérale sur les fonds de placement). Son but est de défendre les intérêts des directions de fonds de placement envers l'extérieur, mais aussi d'autoréguler le secteur par une action de recommandation. D'après les estimations de l'organisation faitière, plus de $90 \%$ des fonds de placement suisses sont proches ou ont été fondés par des banques membres de l'ASB $^{52}$.

Auprès des superviseurs de la Commission fédérale des banques, le nouveau projet de 1964 reçoit un accueil mitigé. Sur le fond, il représente pour la CFB un

47 AFB, E6520(B), 2007/62, vol. 65, Protokoll über die Verhandlungen der Kommission des Nationalrates zur Beratung des Gesetzesentwurfes über die Anlagefonds, I9.oI.I966, p. I2.

48 "Message du Conseil fédéral à l'Assemblée fédérale concernant la loi fédérale sur les fonds de placement (Du 23 novembre 1965) ", Feuille fédérale, 1965, vol. 3, no 49, p. 264-363, ici p. 265.

49 Association Suisse des Banquiers, "Rapport sur le $5 \mathrm{I}^{\mathrm{e}}$ exercice du $\mathrm{I}^{\mathrm{er}}$ avril $\mathrm{I} 962$ au $3 \mathrm{I}$ mars I963", Bâle: Frobenius, 1963, p. 53.

50 Schweizerische Bankiervereinigung, " 53. Jahresbericht über das Geschäftsjahr vom I. April I964 bis 31. März 1965", Basel: Frobenius, 1965, p. 45-46.

51 AASB, Procès-verbaux du Conseil d'administration de l'ASB, 254 ééance, 02.I2.1964, p. 16.

52 Schweizerische Bankiervereinigung, «53. Jahresbericht über das Geschäftsjahr vom I. April I964 bis 31. März 1965", Basel: Frobenius, 1965, p. 43. 
net progrès par rapport à ses prédécesseurs ${ }^{53}$. Mais d'autre part, la question de l'organisation de la surveillance étatique inquiète les superviseurs fédéraux. Plus précisément, ils se demandent si les nouvelles tâches et compétences de contrôle des fonds de placement qui lui sont attribuées dans le projet de loi ne représenteraient pas une surcharge de travail insurmontable. Une disposition particulière du nouveau projet de 1964, qui prévoit que la Commission doit traiter tous les rapports de révision des fonds de placement annuellement, provoque les craintes des superviseurs. Après un long débat, ils décident majoritairement de décliner les nouvelles missions prévues. Dans un courrier daté du 9 septembre 1964, la CFB informe l'Administration fédérale des finances qu'elle émet des réserves sur le cumul des fonctions d'application de loi sur les banques et celle sur les fonds de placement: "il serait donc probablement plus approprié et souhaitable, à notre avis, que l'on désigne une autorité spéciale pour les affaires de fonds de placement " ${ }^{54}$.

Mais cette démarche reste infructueuse. Le texte qui est soumis au Parlement en novembre 1965 maintient le système de la surveillance des fonds de placement chapeautée par la CFB. Si les superviseurs se résignent à cesser la résistance contre l'attribution de cette nouvelle tâche, ils ne le font pas de gaîté de cour. Dans un courrier aux membres de la CFB, le suppléant du chef du secrétariat Hans Manz, qui avait été le plus virulent pour refuser le contrôle des fonds de placement, estime que le cumul des fonctions pourrait impliquer « la destruction de la Commission des banques actuelle " ${ }^{55}$. Sans trop anticiper dans notre récit, signalons au passage que les discussions sur l'organisation et la légitimité de la CFB sont particulièrement houleuses au cours de l'année I965, dans le contexte de l'affaire Muñoz, qui mène à la révocation par le Conseil fédéral du président de la CFB Max Hommel. Les questions relatives à l'incorporation de la surveillance des fonds de placement tombent alors comme un cheveu sur la soupe pour la Commission fédérale des banques, déjà profondément ébranlée à ce moment-là.

Achevé en novembre 1965 , le projet du Conseil fédéral prévoit donc l'attribution du rôle de surveillance à la Commission fédérale des banques. Dans le substantiel exposé des motifs qui accompagne le projet (8o pages!), le gouvernement reprend par ailleurs l'argumentaire qui vise à souligner la dimension sociopolitique du développement des fonds de placement. En mettant en évidence que les fonds de placement favorisent la "dispersion de la propriété", en permettant «la formation de fortune dans des milieux aussi larges que possible», le message rédigé par le Département des finances du catholiqueconservateur Roger Bonvin insiste sur le rôle appréciable que joue l'instrument des investment trusts dans la promotion du sens de l'épargne et l'extension de

53 AFB, E6520(B), 1980/39, vol. I6, PV CFB, 24.08.1964, p. 177-194.

54 AFB, E6520(B), 2007/62, vol. 66, Lettre de la CFB à l'AFF, «Entwurf zu einem BG über die Anlagefonds", I0.09.1964.

55 AFB, E6520(B), 2007/62, vol. 73, Rapport de Hans Manz aux membres de la CFB, I5.12.1965. 
l'actionnariat ${ }^{56}$. Ne retrouve-t-on pas les mêmes arguments dans le discours du président du conseil d'administration de l'UBS et de l'INTRAG, Fritz Richner (I894-I974) :

En popularisant les valeurs à revenu variable comme moyen d'épargne, on intéresse une partie toujours plus grande de la population à nos entreprises privées et à la prospérité de notre économie libre. On ne saurait nier l'importance économico-politique d'une telle évolution ${ }^{57}$.

Faire participer la classe moyenne à la formation de valeurs capitalistes par le biais des placements collectifs revêt en ce sens une fonction politique. Il s'agit là d'une alternative à la popularisation de l'actionnariat par l'émission d'action de faible valeur nominale (Kleinaktien), pratique qui n'est pas autorisée par le droit des sociétés helvétiques ${ }^{58}$. Cet argumentaire reprend, en termes plus nuancés, une idée que l'économiste Beat Huber exprimait bien plus clairement dans un article publié en 1959 :

La popularisation des actions dans les milieux salariés serait en mesure d'ôter le piquant de toute théorie de lutte des classes. [...] Un travailleur détenteur d'actions, qui serait selon la vulgate marxiste à la fois exploiteur et exploité, ne cadrerait plus vraiment avec le concept du manifeste de Marx et Engels ${ }^{59}$.

En janvier 1966, près de neuf ans après le dépôt de la motion Rosset, le problème des fonds de placement revient aux Chambres fédérales. Entre janvier et mars 1966, c'est d'abord le Conseil national, en commission puis au plénum, qui traite le projet de loi, avant de le transmettre au Conseil des États à la fin du printemps. Nous faisons l'impasse sur un exposé précis de la composition des deux commissions parlementaires constituées pour l'occasion. Relevons tout de même que 7 des 27 membres de la commission du Conseil national et 7 des I3 membres de celle du Conseil des États, au-delà de leur appartenance partisane, font partie de la liste des parlementaires proches des banques établie par l'Association suisse des banquiers en décembre $1967^{60}$.

56 "Message du Conseil fédéral à l'Assemblée fédérale concernant la loi fédérale sur les fonds de placement (Du 23 novembre 1965)", Feuille fédérale, 1965, vol. 3, n 49, p. 264-363, ici p. 283.

57 Richner, op. cit., 1958, p. 6.

58 Lüpold, op. cit., 20I0, p. 786-790.

59 Beat Huber, "Zum Problem der Kleinaktien", La société anonyme suisse: revue de droit commercial et économique, vol. 31, $\mathrm{n}^{\circ}$ 9, 1959 , p. 20I-210, p. 202. Cité in Lüpold, op. cit., 2010, p. 788-789.

60 La «Liste der eidgenössischen Parlamentarier, die Banken nahestehen » est annexée au PV de la $269^{\mathrm{e}}$ séance du CdA de l'ASB, I3.12.1967. Elle recense 43 députés (30 conseillers nationaux et I3 conseiller aux États) provenant des partis suivants : I8 radicaux, 8 catholiques-conservateurs, 8 socialistes, $4 \mathrm{PAB}, 3$ libéraux, 2 démocrates. Les affiliations bancaires se segmentent de la manière suivante : 26 députés sont liés aux banques cantonales, 5 aux grandes banques, 3 à la Banque Centrale Coopérative (ancêtre de la Banque Coop, fondée par l'USS en 1927), et 9 à diverses banques régionales. 
Le but du projet de loi, tel qu'annoncé par le gouvernement dans son message d'accompagnement, n'est ni de favoriser, ni d'entraver le développement des fonds de placement ${ }^{61}$. Il vise plutôt à améliorer la protection du porteur de parts, à savoir l'épargnant qui investit dans des fonds de placement. Cet objectif doit être atteint par trois volets de mesures. Premièrement, la législation contient des dispositions de droit civil qui clarifie le statut juridique des fonds de placement. Plus précisément, elle règle de manière contractuelle les rapports entre trois intervenants : le porteur de parts, la direction du fonds et la banque dépositaire. L'idée est donc de mettre un terme au flou juridique qui entoure les notions de copropriété et de trusts, issues du droit anglo-saxon et difficilement transposable en droit suisse. Deuxièmement, la réglementation souhaite améliorer la publicité comptable des fonds de placement - c'est-à-dire accroître leur transparence. Un article exige l'élaboration annuelle et la mise à disposition des porteurs de parts d'une comptabilité détaillée sur chaque fonds. Troisièmement, la loi institue un audit externe - mais privé - de tous les fonds de placement. À cette révision externe s'ajoute la surveillance officielle exercée par la Commission fédérale des banques. Le système de contrôle sur les fonds de placement reprend donc mimétiquement les dispositions de la réglementation bancaire de 1934 .

Au cours des délibérations parlementaires de janvier à juillet 1966, mis à part quelques questions secondaires, comme le statut de la banque dépositaire, seul un point fait véritablement débat. Il s'agit de la disposition qui permet à la Banque nationale d'interdire, à certaines conditions, l'achat de titres étrangers pour le compte des fonds de placement. Cette clause, véritable cheval de bataille pour les dirigeants de la banque centrale, constitue l'équivalent de l'article 8 de la loi sur les banques sur l'exportation de capitaux (emprunts, achats d'actions ou placements à l'étranger d'un montant nominal supérieur à Io millions de francs soumis à un droit de veto de la BNS). Elle est vivement débattue et combattue par certains parlementaires des partis bourgeois, qui refusent d'intégrer une disposition de politique économique conjoncturelle dans une loi réglementant essentiellement la protection des épargnants. Mais la disposition en question passe finalement la rampe, en partie grâce au travail de persuasion du président de la commission du Conseil national et président du Conseil de banque de la BNS, le radical tessinois Brenno Galli.

Malgré cette défaite pour les milieux bancaires, qui auraient préféré la suppression de l'article incriminé, l'ASB tire en mars 1966 un bilan intermédiaire plutôt positif du déroulement de la discussion parlementaire ${ }^{62}$.

Pour la Commission fédérale des banques, la prise en charge des nouvelles compétences de surveillance des fonds de placement, acceptée à contrecœur

61 "Message du Conseil fédéral à l'Assemblée fédérale concernant la loi fédérale sur les fonds de placement (Du 23 novembre 1965) ", Feuille fédérale, 1965, vol. 3, no 49, p. 264-363, ici p. 282. Cette rhétorique est souvent reprise par le conseiller fédéral Roger Bonvin au cours des délibérations parlementaires en 1966. 
après d'énergiques protestations, signifie un changement organisationnel important. En effet, la nouvelle régulation prévoit un certain nombre de nouvelles tâches pour la $\mathrm{CFB}^{63}$. C'est elle qui donne aux directions de fonds et aux banques dépositaires l'autorisation d'exercer et qui approuve leurs règlements, ces autorisations pouvant être retirées dans des cas de graves infractions; le retrait de l'autorisation d'exercer a pour conséquence la faillite. Il s'agit là d'un moyen d'intervention plus incisif que ceux prévus dans le régime bancaire de 1934, qui prévoyait des conditions d'ouverture très souple, sans système de concession. Quant aux autres compétences dans le domaine des fonds de placement reçues par la CFB en 1966, elles sont pour la plupart analogues au régime de régulation bancaire (reconnaissance des sociétés de révision, modération des tarifs de révision, nomination d'un gérant, édiction des normes spéciales pour les fonds étrangers, etc.). Une seule des dispositions touchant au rôle de la Commission fédérale des banques fait débat au Parlement. La clause prévoyant que les directions de fonds doivent transmettre à la CFB tous les rapports de révision annuels est remise en question à plusieurs reprises ${ }^{64}$. Mais les propositions d'amendement, qui visaient à restreindre la communication d'information comptable à la CFB pour éviter une «bureaucratie inutile», sont rejetées de justesse. Par conséquent, l'organe de surveillance recevra l'intégralité des rapports de révision des fonds de placement.

Ces nouvelles tâches impliquent donc une réorganisation administrative de la CFB. L'organe décisionnel, c'est-à-dire la commission elle-même composée jusqu'alors de cinq membres extra-professionnels, est séparé en deux entités : la chambre des banques (Bankenkammer) d'une part, et la chambre des fonds de placement (Anlagefondskammer) d'autre part. Le nombre de membres, qui se spécialisent donc dans l'un ou l'autre domaine, passe de cinq à sept. Quant au secrétariat, le petit organisme de fonctionnaires à plein temps, il passe de deux employés dits "qualifiés» à cinq, sans tenir compte des employées de bureau. Cette réforme organisationnelle entre en vigueur avec la loi sur les fonds de placement, à partir de février 1967. Au cours de l'automne 1966, la CFB doit multiplier les démarches auprès de l'Administration fédérale des finances pour demander un report de l'entrée en vigueur de loi sur les fonds de placement, car elle ne parvient pas à trouver des collaborateurs adéquats pour occuper les nouveaux postes créés ${ }^{65}$. Face à ces difficultés sans doute liées aux salaires moins attrayants proposés par la Confédération, par rapport aux rémunérations dans 133

64 Amendement de Fritz Blatti (I9I0-I994), conseiller national radical, directeur de la Caisse d'épargne de Wangen, en commission. AFB, E6520(B), 2007/62, vol. 65, Protokoll über die Verhandlungen der Kommission des Nationalrates zur Beratung des Gesetzesentwurfes über die Anlagefonds, I9.0I.1966, p. 84. Amendement du conseiller aux États radical argovien Ernst Bachmann (I9I2-I995), par ailleurs membre du CdA du Crédit Suisse. AFB, E6520(B), 2007/62, vol. 65, Protokoll über die Verhandlungen der Kommission des Ständerates zur Beratung des Gesetzesentwurfes über die Anlagefonds, 27.05.1966, p. 46. 
le secteur privé, le Département des finances doit déléguer son collaborateur du service juridique Paul Ehrsam au moment de l'entrée en vigueur de la nouvelle loi.

L'entrée en vigueur de la loi sur les fonds de placement - flanquée d'une ordonnance d'exécution qui prévoit un délai d'adaptation de deux à trois ans, est saluée par l'ASB ${ }^{66}$. À Londres, The Economist s'étonne de la lenteur avec laquelle les autorités suisses ont réagi à la croissance du phénomène. Les journalistes de l'hebdomadaire libéral indiquent également une des raisons de l'aboutissement tardif de la régulation: "Apart from the increasing size of investments involved-about one quarter of the total deposits of Swiss savings banks-there had also been a number of crashes and scandals which made formerly reluctant financial circles keener on a regulatory law. ${ }^{67}$ Ce n'est pas le lieu ici de recenser exhaustivement les scandales auxquels fait référence cet article. Mentionnons seulement la faillite du Swissbau-Anlagefonds qui intervient en février 1967 et constitue un scandale impliquant des sociétés de gestion de fonds de placement. Un peu plus tard, au tournant des années I970, a lieu l'affaire de l'Investors Overseas Services (IOS) Ltd., plus retentissante et plus internationale. Il s'agit d'une société spécialisée dans la gestion de fortune offshore fondée par Bernard Cornfeld (1927-1995) et basée au Panama, mais dont l'essentiel des opérations est géré depuis la succursale genevoise depuis I95 $58^{68}$. L'empire financier IOS s'effondre en I970, et son fondateur Cornfeld est incarcéré en 1973, mais libéré onze mois plus tard. Son procès, en 1979, débouche sur un acquittement. L'ordonnance du Conseil fédéral du I3 janvier I97I sur les fonds de placement étrangers, élaborée par la Commission fédérale des banques, constitue une tentative de soumettre les fonds qui pratiquent depuis la Suisse une publicité intempestive à l'attention de la clientèle étrangère à une régulation plus stricte ${ }^{69}$.

La gestion par les autorités publiques suisses du phénomène des investment trusts est remarquable à plus d'un titre. Il constitue un exemple frappant de la façon dont des législateurs réagissent, avec un certain retard, à une innovation. Le long processus d'élaboration de la loi sur les fonds de placement, qui s'étend sur une décennie (1957-1967), témoigne à la fois de certaines spécificités du système politique suisse et de la difficulté à trouver un compromis autour de la question. Il semble en effet qu'au départ, le principe d'une législation spéciale ne rencontre pas une forte résistance chez les milieux bancaires. Au contraire,

66 Schweizerische Bankiervereinigung, "55. Jahresbericht über das Geschäftsjahr vom I. April I966 bis 3I. März 1967", Basel: Frobenius, 1967, p. 49-50.

68 Sur le volet helvétique du scandale IOS, cf. Marc Perrenoud, «Le scandale de l'Investors Overseas Services (IOS). Les épisodes suisses dans les années 1960-1970", in François Vallotton, Malik Mazbouri (éd.), Scandale \& Histoire, Lausanne: Antipodes, 2016, p. 53-80.

69 Sur cette ordonnance, voir: Sacha Zala, Marc Perrenoud (éd.), Documents diplomatiques suisses, Zürich, Locarno, Genève: Chronos, A. Dadò, Ed. Zoé, vol. 25 (1970-1972), 2014, doc. 55, p. 137-I38. Verordnung über die ausländischen Anlagefonds, 13.0I.I97I. Également disponible en ligne, http://dodis.ch/3575I (consulté le I0.I2.20I8). 
certains acteurs solidement implantés dans le marché des fonds de placement voient d'un bon oil une régulation qui les protège de la concurrence de nouveaux venus. Comme dans le cas de la loi sur les banques dans les années I930, il faut donc se garder de considérer l'élaboration de la loi sur les fonds de placement comme un processus unilatéral de contrainte régulatoire des pouvoirs publics contre un secteur privé qui résiste farouchement à la réglementation. Dans ce cas, l'opposition prend forme plus subtilement à partir du moment où l'avant-projet de loi préparé par un comité de juristes est considéré par les milieux bancaires, en 196I, comme trop tatillon et détaillé. Il faudra attendre cinq ans de plus pour qu'un projet alternatif aboutisse. Cet accouchement difficile se fait cette fois dans le contexte d'une forte conflictualité entre les banques commerciales et la banque centrale. La Banque nationale cherche alors, au grand dam des banques, à affermir par le biais de cette législation ses moyens d'intervention dans le domaine de l'exportation de capitaux. Du point de vue de la Commission fédérale des banques, la prise en charge de la surveillance officielle des fonds de placement est acceptée à contrecœur. La réticence des superviseurs est liée à la surcharge de travail que représentent les nouvelles tâches. Ces nouvelles compétences nécessitent une réorganisation administrative et une légère augmentation du nombre d'employés de l'agence. En outre, la réglementation prévoit des moyens de contrainte plus sévère à l'égard des fonds de placement qu'à l'égard des banques dans le régime de 1934. En effet, la CFB obtient la possibilité de retirer, en cas de manquements graves, l'autorisation d'exercer à une direction de fonds de placement. En ce sens, le domaine des fonds de placement joue aussi un rôle d'expérimentation de modifications qui pourraient être intégrées dans la surveillance bancaire au moment de la révision de la loi sur les banques.

Au cours des années 1980, les fonds de placement suisses connaissent une nouvelle phase de mutation. Sous l'effet notamment de la libéralisation du marché commun européen, de nombreux fonds de placement sont délocalisés ou nouvellement créés sur d'autres places financières, en particulier au Luxembourg $^{70}$. Une révision de la loi sur les fonds de placement aboutit en mars I994, suivie d'une seconde révision totale en juin 2006, essentiellement dans le sens d'une adaptation aux directives européennes en la matière.

70 André Cornu, Charly Denervaud, Raymond L. Larcier, Les fonds de placement, Lausanne : HEC, 1993, p. 6-7. 


\section{VIII.2. LA RÉVISION DE LA LOI BANCAIRE DISCUTÉE, MAIS REJETÉE (1960-1965) : MOYENS D'ACTION DE LA CFB, AFFLUX DES BANQUES ÉTRANGËRES, GARANTIE DES ÉPARGNES ET SECRET BANCAIRE}

Au cours des chapitres précédents, nous avons à plusieurs reprises rencontré des situations au cours desquelles une révision de la loi sur les banques de 1934 est envisagée, mais est très rapidement rejetée par les principaux acteurs impliqués : la Commission fédérale des banques, le Département fédéral des finances et des douanes, ou encore l'Association suisse des banquiers. Notons au passage que d'autres groupes socio-économiques sont directement et indirectement concernés par les débats de régulation bancaire: les agriculteurs ou les salariés, affectés par l'inflation, ou encore les épargnants et les locataires, sensibles aux variations des taux d'intérêts. Ces intervenants-là n'apparaissent pas dans notre récit, car ils ne peuvent pas prendre part aux discussions et processus de décision, faute d'y être invités. Leur absence dans les débats n'enlève rien au fait qu'il s'agit de groupes sociaux affectés par les choix qui sont opérés. Pour les acteurs impliqués, les 25 premières années (I935-1960) du régime de surveillance bancaire sont donc régulièrement jalonnées de moments de remise en question du cadre réglementaire. Sans répéter inutilement toutes ces occurrences, récapitulons les principales étapes de ce mouvement.

Dès 1938-1939, les lacunes dans le contrôle de l'exportation de capitaux et le flou sur la définition juridique des sociétés financières qui doivent être soumises à la loi soulèvent pour la première fois la question d'une révision de la législation, après seulement quatre ans d'existence (cf. chap. VIII.I). Dans la foulée, c'est la difficile question du transfert dans le droit ordinaire de l'arrêté fédéral sur l'assainissement des banques qui relance l'idée d'une révision de la loi sur les banques. Nous l'avons vu, entre 1938 et 1948, la Commission fédérale des banques envisage à deux reprises au moins de lancer une réforme législative pour intégrer les mesures spéciales de moratoires bancaires pour établissements en difficulté dans la loi sur les banques (cf. chap. VI.2.2). Souvenons-nous également qu'entre 1946 et 1958 la question de l'adaptation des ratios de fonds propres et de liquidité avait suscité de longs débats à l'interne du monde bancaire et avec les superviseurs (cf. chap. VII.4). Là aussi, certains acteurs avaient exprimé de vives réticences à toucher aux dispositions de la législation bancaire et même une refonte de la seule ordonnance d'exécution, qui aboutit en 196I, avait été difficile à imposer. À trois reprises au moins, et dans le cadre de débats très variés, les milieux bancaires - et, consécutivement, les superviseurs de la CFB - avaient donc exprimé leur fort attachement au maintien inaltéré de la loi sur les banques de 1934, et refusé la reprise de toute discussion publique de ses dispositions. L'argumentation développée repose sur les nombreux dangers qui seraient liés à la réouverture du dossier «législation bancaire». On insiste tantôt sur les dangers de nationalisation dans un contexte international défavorable (1946), tantôt sur les risques d'encourager une remise en question du 
secret bancaire (1948). Un débat parlementaire de la régulation bancaire devient donc progressivement une question taboue ${ }^{71}$.

En 1959-1960, au lendemain de la faillite retentissante de la Kredit- und Verwaltungsbank Zug, c'est une démarche des autorités cantonales zougoises, remontées par le peu d'efficacité des interventions disciplinaires de la Commission fédérale des banques contre les dirigeants bancaires incriminés, qui avait remis la question d'une éventuelle révision de la loi sur les banques à l'ordre du jour (cf. chap. VII.3). En mai-juin 1960, le nouveau conseiller fédéral en charge des Finances, le catholique-conservateur fribourgeois Jean Bourgknecht, sur la base des expériences malheureuses faites dans le cas de la banque zougoise et de la Banque Mercantile à Genève - contre laquelle la CFB avait déposé plainte en juin 1959-, estime qu'une révision de la loi sur les banques est nécessaire. Les membres de la Commission fédérale des banques, consultés à l'occasion par le Département des finances, sont au contraire d'avis qu'une telle démarche n'est ni souhaitable ni opportune. Cette décision est prise à l'unanimité des cinq membres le $\mathrm{I} 4$ juin $196 \mathrm{O}^{72}$. Au moment même, à quelques centaines de mètres de là au Palais fédéral, le ministre des Finances Bourgknecht affirme justement, en réponse à une interpellation du conseiller national socialiste Harald Huber (1912-1988) sur le rapport de gestion du Conseil fédéral : « je suis personnellement convaincu que les pouvoirs de la commission [fédérale des banques] doivent être étendus " ${ }^{73}$.

Les démarches combinées de la CFB et de l'ASB auprès du DFFD de Bourgknecht au cours de l'été 1960 vont provoquer un changement fondamental de point de vue au ministère des Finances. La Commission fédérale des banques organise une réunion avec Bourgknecht le $\mathrm{i}^{\text {er }}$ juillet 1960. Elle lui présente alors une autre argumentation classique, en insistant sur la lourde responsabilité qui incomberait à la CFB et - partant - à la Confédération, si on étendait ses pouvoirs d'intervention en l'autorisant par exemple à ordonner l'ouverture d'une procédure moratoire à la place des dirigeants bancaires ${ }^{74}$. L'Association suisse des banquiers partage le point de vue de la CFB en la matière et s'oppose à une extension des compétences de l'organe de surveillance $^{75}$. En septembre 1960, une entrevue entre le directeur général du Crédit Suisse Eberhard Ernst Reinhardt (1908-1977) et Bernhard Müller (I92I-2006), responsable du service juridique de l'Administration fédérale des finances, confirme cette position. Le banquier, par ailleurs ancien collaborateur (1935I945) puis chef de l'AFF (1946-I947), aurait tenu les propos suivants:

71 Sur la notion de dépolitisation, voir Sancey, op. cit., 20I5, p. 234-249.

72 AFB, E6520(A), I000/I059, vol. I2, PV CFB, I4.06.1960, p. I33-137.

73 Procès-verbaux de l'Assemblée fédérale, Conseil national, session ordinaire d'été, I4.06.1960, p. 212.

74 AFB, E6I0o(B-oI), 1980/49, vol. 57, Aktennotiz betr. Revision des Bankengesetzes, OI.07.1960.

75 Selon les propos rapportés par Max Hommel à la CFB: AFB, E6520(A), 1000/1059, vol. I2, PV CFB, 07.07.1960, p. 159-160. 
En principe, les banques n'apprécient pas une révision de la loi sur les banques, parce qu'il est impossible de prévoir quels problèmes pourraient être inclus dans la discussion. Il [Reinhardt] mentionne dans ce contexte la question incessamment soulevée par la Banque nationale des réserves obligatoires des banques et le sujet très populaire du secret bancaire. Toute discussion de ces questions serait préjudiciable à la confiance et pourrait conduire à des perturbations monétaires ${ }^{76}$.

Convaincus par cette résistance combinée de l'ASB et de la CFB, les fonctionnaires de l'administration fédérale abandonnent l'idée d'une révision de la loi sur les banques et préparent un rapport à ce sujet à transmettre au Conseil fédéral pour enterrer l'affaire. Les dirigeants de la Banque nationale, et en particulier le chef $\mathrm{du} \mathrm{I}^{\mathrm{er}}$ département Walter Schwegler, tentent alors vainement de persuader le DFFD d'envisager malgré tout des amendements à la réglementation bancaire. Dans un courrier du i9 décembre 1960, la direction générale de la BNS plaide en faveur d'une révision qui épouserait les contours suivants. Premièrement, la CFB devrait être autorisée à déclencher elle-même la faillite et à retirer l'autorisation d'exercer d'une banque. Deuxièmement, des dispositions sur les réserves obligatoires des banques auprès de la BNS pourraient être introduites. Troisièmement, une complication des conditions d'ouverture de nouvelles banques est revendiquée, en vue de garantir les qualifications morales des futurs dirigeants bancaires. Quatrièmement, la direction de la banque centrale exige des mesures capables de freiner la vague de fondations de banques étrangères, pour éviter que la Suisse «se transforme en terrain de jeux des capitaux internationaux en fuite ou spéculatifs, et acquiert la réputation douteuse de reprendre la place qu'occupait l'ancienne Tanger $\gg{ }^{77}$. Mais ni le programme de révision ni les arguments invoqués ne trouvent une oreille attentive auprès de l'Administration fédérale des finances. En juillet I96I, le DFFD de Jean Bourgknecht soumet au Conseil fédéral un rapport qui arrive à la conclusion qu' " une révision de la loi sur les banques ne s'impose à l'heure actuelle sous aucun des points de vue considérés " ${ }^{78}$. La direction de la Banque nationale apprend, avec une amère déception, qu'aucun de ses postulats en faveur d'une révision n'a été retenu par l'Administration des finances et s'en plaint vainement. La question d'une révision de la loi sur les banques en reste là 79 .

Pendant cette phase, entre 1959 et I96I, c'est donc une configuration très particulière qui mène à l'échec des velléités de renforcement de la régulation bancaire. L'incapacité de la Commission fédérale des banques à intervenir

76 AFB, E610o(B-oor), 1980/49, vol. 59, Aktennotiz der Besprechung Müller-Reinhardt, 05.09.1960.

$77 \mathrm{AFB}, \mathrm{E} 6 \mathrm{IOO}(\mathrm{B}-\mathrm{OI}), \mathrm{I980} / 49$, vol. 57, Lettre de la direction générale de la BNS à la direction de l'Administration fédérale des finances, I9.I2.1960.

78 AFB, E6Ioo(B-oI), I980/49, vol. 57, Bericht über die Frage einer Revision des Bankengesetzes, EFZD, 19.07.1961, p. 23.

79 ABNS, I.3/1232 Revision 197I (Bundesstellen), Lettre de la DG BNS à l’AFF, 09.09.196I. 
efficacement dans le cas des banques délictueuses qui font faillite à la fin des années 1950 (Kredit- und Verwaltungsbank, Banque Mercantile) donne l'impulsion décisive au processus. C'est ensuite cette même instance qui va, en coordination avec l'influente association des banquiers, décourager le Département fédéral des finances d'entreprendre une révision de la loi bancaire, et ainsi empêcher une consolidation de ses propres compétences. La position de la Banque nationale suisse est en fort contraste. Ses dirigeants considèrent au contraire l'ouverture du chantier législatif de la réglementation bancaire comme une opportunité pour mettre sur le tapis leurs propres revendications. Celles-ci vont pour l'essentiel dans deux directions : intégrer dans la loi sur les banques des dispositions lui permettant de limiter l'expansion de crédit (par les réserves obligatoires) d'une part, et instaurer des mesures entravant l'ouverture de nouvelles banques étrangères en Suisse d'autre part.

En plus des positions antagonistes de certains acteurs-clés du processus, l'élan de 1959-196I est freiné par la concomitance avec deux projets législatifs parallèles. En effet, la législation sur les fonds de placement, et $-\mathrm{a}$ fortiori - la révision des dispositions sur les fonds propres et la liquidité dans l'ordonnance de la loi sur les banques forment deux travaux réglementaires dont l'aboutissement paraît plus urgent pour l'ensemble des acteurs impliqués. Pour l'Administration fédérale des finances, il semblait sans doute peu pertinent de rouvrir la question - beaucoup plus délicate - de la loi sur les banques, quelques semaines après avoir achevé une adaptation de son règlement d'exécution.

Afin de donner un aperçu complet des diverses forces contradictoires en faveur ou défaveur d'une révision de la loi sur les banques pendant la première moitié des années 1960, il est nécessaire de présenter plusieurs enjeux afférents de près ou de loin à la régulation bancaire.

\section{VIII.2.1. Le «problème» des banques étrangères (1956-1965)}

Le premier d'entre eux est relatif aux réactions suscitées par l'accélération de l'installation en Suisse de banques étrangères toujours plus nombreuses ${ }^{80}$.

Dès 1956, et de manière croissante à partir de 1958, une forte tendance à l'ouverture de nouvelles banques étrangères en Suisse se manifeste. Précisons d'emblée que l'expression «banque étrangère » est équivoque et qu'elle désigne souvent des institutions diverses, au moins du point de vue réglementaire. Il faut distinguer trois types d'établissements étrangers. Premièrement, une banque étrangère peut simplement ouvrir un bureau de représentation en Suisse, ce qui n'implique pas la création d'une société; n'étant pas soumis à

80 Certains des éléments que nous abordons ici ont déjà été analysés dans la publication suivante: Giddey, art. cit., in Aspey, et al. (éd.), op. cit., 2013. Sur les banques étrangères en Suisse, voir également: Iklé, op. cit., 1970, p. I05-I09; Max Meyer, Die Ausländischen Banken in der Schweiz. Studie im Auftrag des Verbandes der Auslandsbanken in der Schweiz, St. Gallen : Institut für Bankwirtschaft an der Hochschule St. Gallen, 1975; Loepfe, op. cit., 20II, p. 197-206. 
la loi sur les banques, les bureaux de représentation ne sont pas autorisés à effectuer des opérations bancaires à proprement parler. Deuxièmement, l'installation peut prendre la forme de l'ouverture d'une succursale en Suisse. L'établissement reste ainsi affilié à la maison-mère, dont il dépend juridiquement. Ce type de banque est déjà soumis à une réglementation spéciale depuis 1936 : une succursale étrangère ne peut ouvrir en Suisse que si le pays d'origine de la maison-mère accorde la réciprocité aux banques suisses, et une caution remplace le capital social (cf. chap. IV.2.I). Troisièmement, une banque étrangère - ou plus généralement des capitalistes étrangers - peut fonder une banque de droit suisse, formellement et juridiquement indépendante de la maison-mère. Ce type d'établissements, qui ne mentionne pas nécessairement l'origine étrangère des fondateurs dans la raison sociale, est du point de vue réglementaire mis sur un pied d'égalité avec les banques suisses. Elles sont progressivement désignées par l'expression «banques sous domination étrangère» (ausländisch beherrschte Banken). C'est cette troisième catégorie, qui échappe entièrement aux dispositions prévues pour les établissements étrangers, qui connait la plus forte croissance entre 1956 et 1970.

Évidemment, des banques étrangères étaient implantées en Suisse bien avant les années 1960. D'importantes banques françaises - comme la Banque de Paris et des Pays-Bas ou le Crédit Lyonnais - étaient présentes à Genève dès la fin du XIX ${ }^{\mathrm{e}}$ siècle ${ }^{81}$. Durant l'entre-deux-guerres, une douzaine de banques étrangères ouvrent leurs guichets, comme la succursale de la Lloyds Bank à Genève, ou l'American Express Company qui dispose de plusieurs succursales. Mais le véritable décollage a lieu durant les Trente Glorieuses : 82 des 97 banques étrangères actives en Suisse en 1972 ont été fondées après 1946, et 68 d'entre elles après $1958^{82}$. Le retour à la convertibilité des principales monnaies dès 1958 n'est sans doute pas sans rapport avec l'accélération de la fondation de banques étrangères. Mesurées par le volume de leurs bilans, les banques étrangères en Suisse - succursales et banques indépendantes réunies passent de $3 \%$ des bilans totaux à Io $\%$ en I968, puis II \% en I972 ${ }^{83}$. Les bilans de la catégorie "autres banques» de la statistique de la BNS, qui est composée en grande partie de banques sous domination étrangère, décuplent en termes réels entre 1956 et $197 \mathrm{I}^{84}$. On constate aussi une évolution quant à l'origine des

81 Cf. François Walter, «Finance et politique à la belle époque : la France et les emprunts de la Confédération helvétique (1890-1914)", Revue suisse d'histoire, vol. 32, nº 3, 1982, p. 42I-450, p. 432 ; Youssef Cassis, "Le Crédit Lyonnais à Genève, I876-200I", in Bernard Desjardins, et al. (éd.), Le Crédit Lyonnais (I863-1986): études historiques, Genève: Droz, 2003, p. 617-629. Meyer, op. cit., 1975, p. 94-96.

83 Les proportions de 1958 et 1972 ont été calculées à partir de statistiques trouvées dans : AFB, E6520(A), I983/50, vol. I, dossier "Ausl. Banken I959-I974". La proportion de I968 figure dans le «Message du Conseil fédéral à l'Assemblée fédérale à l'appui d'un projet d'arrêté fédéral urgent instituant le régime du permis pour les banques en mains étrangères, du I3 novembre i968", Feuille fédérale, I968, vol. 2, nº 48, p. 784.

84 Selon Burkhalter, $60 \%$ des bilans de la catégorie " autres banques " proviennent de banques sous domination étrangère. Cf. Eduard F. Burkhalter, Die Bedeutung, das Wesen und die 
banques qui s'établissent en Suisse. Jusqu'aux années 1950, elles proviennent essentiellement de pays voisins ou européens : les banques françaises s'installent sur la place financière genevoise, tandis que des banques italiennes voient le jour dans le canton du Tessin. À partir des années 1950, on assiste à une vague de créations à partir de capitaux provenant du Proche et Moyen-Orient (Israël, Liban, Egypte). Cette tendance est en partie liée à la crise de Suez qui incite les capitalistes de ces régions à gérer leurs capitaux depuis la Suisse et contourner ainsi les restrictions sur les transactions en dollars ou livres sterling ${ }^{85}$. Puis, au cours des années 1960, ce sont les banques états-uniennes qui investissent Zurich et Genève, dans le cadre de ce que l'historien Geoffrey Jones considère comme la seconde vague de mondialisation des services bancaires ${ }^{86}$.

Ces transformations rapides du paysage bancaire helvétique suscitent sans tarder des réactions, tant de la part des autorités monétaires que de l'Association suisse des banquiers. L'ouverture d'une succursale de la Banque de l'Indochine (siège à Paris) à Lausanne à l'été 1956 constitue le point de départ de la contestation des autorités suisses. C'est en effet la première fois depuis les années 1930 que la Commission fédérale des banques doit statuer sur l'ouverture d'une succursale de banque étrangère. Après avoir constaté qu'il s'agissait d'un solide établissement de premier ordre, et qui était déjà présent à Lausanne et actif dans le commerce d'or russe par une participation dans la Bullion Exchange \& Co. Ltd, la CFB décide de consulter la BNS et l'ASB avant de délivrer l'autorisation demandée ${ }^{87}$. La faîtière des banquiers, après avoir mené une enquête interne auprès des grandes banques, ne voit pas d'un bon œil l'ouverture de la succursale de la banque française et met en avant quatre $\operatorname{arguments}^{88}$. Elle souligne premièrement que la Banque de l'Indochine souhaite transférer en Suisse les activités qu'elle pratiquait jusque-là depuis sa filiale de Tanger. Rappelons qu'en 1956, Tanger perd son statut de zone internationale - et les avantages fiscaux y liés - en réintégrant le Royaume du Maroc indépendant. Selon l'ASB, il est donc "indésirable et embarrassant " pour la Suisse d'être mis sur un pied d'égalité avec Tanger; la réputation internationale des banques suisses en serait ternie. Deuxièmement, la création d'une nouvelle société de gestion de fortune signifie « un préjudice sensible et direct pour le monde bancaire national ». Des raisons de concurrence apparaissent donc très clairement. Troisièmement, en évoquant l'expérience de la

Struktur der von der Schweizerischen Nationalbank als "Übrige Banken” bezeichneten Institute, Thun: Weibel, 1969, p. 59.

85 Iklé, op. cit., I970, p. I07.

86 Geoffrey Jones (éd.), Banks as multinationals, London and New York: Routledge, 1990, p. 5. Voir également, Stefano Battilossi, Youssef Cassis (éd.), European banks and the American challenge : competition and cooperation in international banking under Bretton Woods, Oxford [etc.] : Oxford University Press, 2005, en particulier la contribution de Richard Sylla.

87 AFB, E6520(A), I000/1059, vol. II, PV CFB, 25.06.1956, p. 76-78.

88 AASB, dossier 713, Eidg. Bankenkommission Bankengesetz, Lettre de Max Oetterli (secr. ASB) à la CFB, 09.08.1956. 
Seconde Guerre mondiale, l'ASB estime que la présence de banques étrangères peut provoquer des restrictions plus strictes de la part d'États étrangers, et ce, au détriment de l'ensemble des banques en Suisse. Enfin, elle stigmatise les risques d'effet domino: en acceptant la requête de la Banque de l'Indochine, on encouragerait d'autres requêtes toujours plus nombreuses. En raison de ces différents arguments, l'ASB souhaiterait que l'autorisation d'ouverture ne soit pas accordée. Elle reconnaît cependant qu'il est difficile de fonder juridiquement un tel refus, étant donné que les critères requis sont formellement remplis, et recommande de prendre contact avec la banque requérante pour lui demander de retirer sa requête. La BNS, par l'intermédiaire de Robert Virieux, directeur de la succursale lausannoise, est encore mieux renseignée sur les personnalités concernées. Il s'avère que la Banque de l'Indochine est déjà présente depuis un certain temps à Lausanne par le biais de diverses sociétés financières. Les trois responsables locaux sont décrits de la manière suivante: « ces messieurs seraient prêts à traiter n'importe quelle affaire pourvu qu'elle rapporte " ${ }^{89}$. La direction générale de la BNS tire globalement les mêmes conclusions que l'ASB sur le fond, mais estime de manière fataliste que rien ne peut empêcher l'ouverture de la succursale française à Lausanne. En novembre 1956, le Conseil fédéral accorde l'autorisation d'ouverture à la Banque de l'Indochine, qui ouvre ses guichets en juin I957. Durant les années qui suivent, les autorités helvétiques sont amenées à prendre position sur de nombreuses autres demandes ${ }^{90}$.

Dans certains cas, comme celui de la création prévue de la Banque pour le Commerce Arabo-Suisse en 1957, de véritables enquêtes policières sur les fondateurs et les hommes de paille de nationalité suisse sont menées par l'administration fédérale. Cette requête, qui aboutit en juin 1958 à la création de la Banque Commerciale Arabe (Arabische Handelsbank) à Genève, est un projet qui a vraisemblablement pour origine la volonté de certains capitalistes du Moyen-Orient de constituer, à la suite des nationalisations de Nasser en Egypte, une banque capable de servir de refuges pour les capitaux. Les craintes du blocage des avoirs arabes sur les places financières new-yorkaise ou londonienne suscitent cet élan. Des personnalités syriennes, irakiennes et égyptiennes, qui jouissent "d'un large appui des milieux bancaires arabes " jouent d'ailleurs un rôle central dans le processus ${ }^{91}$. Elles disposent du soutien en Suisse pour la fondation de leur banque de personnalités comme Georges

ABNS, Procès-verbaux de la Direction générale de la BNS, 23.08.1956, p. I228-I23I. 1957, succursale de la Banque Ottomane en janvier 1958, Banque Intra (Liban) en mai I958, projet de banque iranienne en juin 1960 .

91 AFB, E6IooB, 1972/96, vol. 32, dossier Banques étrangères 2330, Rapport du service politique de la Police Genevoise sur la Banque pour le Commerce Arabe, 30.10.1957. Les personnes influentes citées sont les suivantes: Jamil Mardam Bey (I893-1960), ex-premier ministre syrien exilé au Caire; Muzahim Amin Al Pachachi (I89I-I982), ex-premier ministre irakien; Mohamed Sohbi Chourbagui, industriel égyptien; Ahmad Daouk (I893-1979), ancien premier ministre du Liban; Ezzat Gaafar (sécrétaire de l'émir du Koweit). 
Capitaine (I895-?), avocat spécialiste du secret bancaire, Siegfried Abt, docteur en droit zurichois, ou encore François Genoud (1915-1996), un banquier suisse national-socialiste convaincu ${ }^{92}$. La dimension politique de l'établissement prévu nourrit des craintes auprès de l'administration fédérale, ce d'autant plus qu'elle soupçonne les initiateurs de vouloir financer le commerce avec le bloc de l'Est. L'Administration fédérale des finances, face au caractère indésirable de la création prévue et à l'impossibilité de l'empêcher par voie juridique, demande au Département politique fédéral de tenter une approche diplomatique pour décourager les pays d'origine des requérants de leur projet $^{93}$. En attendant l'exploration d'autres pistes de blocage, les autorités fédérales demandent à la CFB de retarder sa décision sur la Banque Commerciale Arabe. En l'absence de moyens légaux capables d'empêcher la fondation, les dirigeants de la banque centrale obtiennent malgré tout comme condition préalable à l'ouverture de la banque son adhésion au gentlemen's agreement en vue d'éviter l'afflux des avoirs étrangers. La Banque Commerciale Arabe ouvre donc ses guichets en 1958 ; le sulfureux François Genoud ne figure pas parmi les administrateurs ou dirigeants officiels, mais fait tout de même partie des souscripteurs au capital-actions de la banque. Celle-ci fera plus tard parler d'elle dans le litige qui l'opposera au Front de Libération National et à la République algérienne, autour des fonds Khider et du «trésor du FLN » ${ }^{94}$. Avant même l'éclatement de cette affaire, à l'été 1959, des pressions diplomatiques françaises, au courant des transactions effectuées par le FLN en Suisse, donnent lieu à un rapport du service juridique de l'Administration fédérale des finances sur l'opportunité de réviser la loi sur les banques dans le sens d'une restriction des transactions financières du FLN. Même si les conclusions du rapport sont évidemment négatives (la loi sur les banques ne peut pas intégrer des mesures interdisant des opérations pour des raisons de politique extérieure), il est remarquable qu'un tel rapport soit même rédigé 95 .

Pendant une première phase, les acteurs qui s'opposent à l'afflux de banques étrangères en Suisse, à savoir la Banque nationale suisse, l'Association suisse des

92 Le parcours mystérieux et très controversé de François Genoud a suscité plusieurs biographies journalistiques: Karl Laske, Le banquier noir: François Genoud, Paris : Éditions du Seuil, 1996; Pierre Péan, L'extrémiste: François Genoud, de Hitler à Carlos, Paris: Fayard, 1996; Willi Winkler, Der Schattenmann: von Goebbels zu Carlos: das mysteriöse Leben des François Genoud, Berlin : Rowohlt, $201 \mathrm{I}$.

$93 \mathrm{AFB}$, E610oB, 1972/96, vol. 32, dossier Banques étrangères 2330, Lettre de Hans Streuli (DFFD) à Max Petitpierre (DPF), 23.09.1957.

94 Cf. Vincent Sériot, «Les réseaux de soutien au FLN en Suisse pendant la Guerre d'Algérie ", Mémoire de licence, Université de Lausanne, 2004, p. 88-89. Sur les circuits financiers du FLN, voir aussi Emmanuel Colin-Jeanvoine, Stéphanie Dérozier, Le financement du FLN pendant la guerre d'Algérie, 1954-I962, Saint-Denis: Ed. Bouchène, 2008, p. 89-106.

95 AFB, E6I0o(B-OOI), 1980/49, vol. 59, Rapport « Notiz an die Direktion Betr. Verhinderung von Banktransaktionen zu Gunsten der algerischen Befreiungsfront », signé Bernhard Müller, or.08.I959. Voir aussi Document diplomatiques suisses, Notice «Erklärung des französischen Ministerpräsidenten Debré und Kritik am Verhalten der Schweizer Banken ", 05.06.1959. Disponible en ligne: http ://dodis.ch/I0924) consulté le IO.I2.20I8. 
banquiers, et, dans une moindre mesure, la Commission fédérale des banques et l'administration fédérale, ont essentiellement recours à des moyens détournés pour tenter d'endiguer ce phénomène.

Premièrement, les réseaux diplomatiques du Département politique fédéral sont fréquemment sollicités, non seulement pour prendre des renseignements sur les initiateurs à l'origine des requêtes, mais parfois également pour tenter de les dissuader du projet d'ouverture de banque en Suisse.

Deuxièmement, la banque centrale, nous l'avons vu, pratique des négociations bilatérales avec les dirigeants de la banque requérante pour s'assurer au préalable de leur coopération dans le cadre du système des gentlemen's agreements, en particulier celui sur la limitation de l'afflux de capitaux étrangers. Elle emploie également une autre méthode pour signaler sa désapprobation à l'égard de certaines créations de nouvelles banques. À plusieurs occurrences en effet, le directoire de la BNS décide de refuser à certaines banques jugées indésirables l'ouverture de comptes de virement (Girokonti). Il s'agit là de comptes bancaires ouverts auprès de la BNS servant au trafic de paiement. En juin 1958, le cas de la Banca del Ceresio, un institut cherchant à placer des capitaux italiens en Suisse qui vient d'ouvrir ses guichets à Lugano, met à jour la politique de résistance de la banque centrale. Le directeur général de la BNS Walter Schwegler est particulièrement incisif:

Nous devons reconnaître le danger d'une domination étrangère excessive croissante de notre pays par des capitaux étrangers et riposter là-contre avec les moyens qui sont à notre disposition. Il n'existe aucune obligation de fournir à une banque ou n'importe quelle société notre service de virement. Il serait tout simplement grotesque si nous le faisions et que nous nous inquiétions simultanément du fait que des banques étrangères et des banques suisses de nature douteuse considèrent comme leur fonction principale d'introduire subrepticement des capitaux étrangers en Suisse ${ }^{96}$.

Il ne s'agit pas d'un cas unique. En décembre 1958 au sein de la CFB, Paul Rossy se fait le porte-parole de la Banque INTRA de Genève, un établissement formellement indépendant dont la maison-mère est basée à Beyrouth. Après avoir plaidé sa cause auprès de ses collègues, Rossy deviendra d'ailleurs en 1960 conseiller juridique de la Banque INTRA, puis rejoindra son conseil d'administration dès 1963. Malgré ce patronage prestigieux, il s'avère que la banque concernée ne parvient pas à atteindre le ratio de liquidité minimale à cause du refus de la Banque nationale de lui ouvrir un compte de virement ${ }^{97}$. C'est donc l'attitude d'obstruction de la BNS, qui suscite l'incompréhension de certains membres de la Commission fédérale des banques, en particulier des deux anciens banquiers centraux Alfred Hirs et Paul Rossy. Cette politique 
d'obstruction force au final l'autorité de surveillance à accorder des dérogations aux dispositions sur la liquidité ${ }^{8}$.

Du côté de l'ASB, une mesure similaire de mise à l'index est envisagée en septembre 1957, mais n'est pour finir pas mise à exécution ${ }^{99}$. L'Association suisse des banquiers projette de prononcer un boycott à l'encontre des banques, non-membres de l'association, qui ne suivraient pas ses recommandations. Ce boycott prendrait la forme d'un refus d'ouvrir un compte pour les banques concernées et d'encaisser leurs chèques. Une majorité du Conseil d'administration de l'ASB rechigne cependant à prendre une disposition aussi radicale.

Une troisième mesure indirecte pour contrer la "vague » de banques étrangères consiste à encourager une politique plus restrictive dans l'octroi des permis de séjour aux personnes étrangères concernées. Lorsque la police fédérale des étrangers se renseigne auprès de la BNS sur la demande de prolongation du permis de séjour d'un ressortissant américain, dirigeant d'une société financière zurichoise (Intermontan $A G$ ) dont les actionnaires principaux sont des banques étrangères, les banquiers centraux répondent qu'ils estiment que des sociétés de ce genre sont indésirables ${ }^{100}$. En septembre 1960, le directeur général du Crédit Suisse, Ernst Eberhard Reinhardt évoque également des mesures de la part de la police fédérale des étrangers comme moyen palliatif à une révision légale ${ }^{101}$. La facilité à trouver des hommes de paille disposant de la nationalité suisse ou d'un permis de séjour semble cependant limiter grandement l'efficacité de cette méthode.

Quatrièmement enfin, une tactique de temporisation est délibérément employée par les autorités chargées d'examiner les demandes d'ouverture de nouvelles banques. Le membre de la Commission fédérale des banques et conseiller national catholique-conservateur Max Rohr l'avoue à ses collègues, en discutant le cas de la Banque INTRA à Genève :

Je n'aurais aucun scrupule à traiter de telles requêtes de manière dilatoire, pour que l'opinion publique voie que nous n'autorisons pas facilement de nouvelles fondations de banques. D'autre part, une certaine pression peut ainsi être exercée sur les banques pour ce qui est des garanties exigées par la Banque nationale ${ }^{102}$.

La lenteur de l'examen administratif des demandes d'ouverture fait partie des armes tactiques utilisées par la CFB pour décourager certains projets. Elle est justifiée par les tractations en cours avec d'autres instances: tantôt avec la Banque nationale suisse, tantôt à l'échelon diplomatique.

98 Par exemple en mars 1960, lorsque la CFB décide unanimement de "fermer les yeux" (ein Auge zudrücken) sur le manque de liquidité de la Banque Ottomane, en considérant qu'il s'agit d'un établissement sérieux disposant d'importants moyens liquides auprès de sa maison-mère. AFB, E6520(A), I000/I059, vol. II, PV CFB, I5.03.1960, p. 65-66.

99 AASB, Procès-verbaux du Conseil d'administration de l'ASB, $224^{\mathrm{e}}$ séance, 27.09.1957, p. 6-8.

100 ABNS, Procès-verbaux de la Direction générale de la BNS, 06.09.1956, p. I314-1316.

101 AFB, E6Ioo(B-ooI), 1980/49, vol. 59, Aktennotiz der Besprechung Müller-Reinhardt, or.09.1960.

102 AFB, E6520(A), I000/1059, vol. II, PV CFB 02.06.1958, p. 93. 
En dépit de l'impression d'une animosité généralisée à l'égard des banques étrangères chez les diverses instances de régulation bancaire en Suisse, il convient de préciser quelque peu ce tableau. Il semble en effet que cette question mette à jour des divergences entre la BNS et la CFB. Alors que les banquiers centraux s'opposent vigoureusement à l'arrivée de nouvelles banques étrangères au motif des effets indésirables de l'afflux de fonds internationaux en Suisse qui perturbe la stabilité monétaire, la Commission fédérale des banques, quant à elle, opte dans un premier temps plutôt pour une stricte application des dispositions légales, qui ne contiennent alors aucune mesure discriminatoire. Elle ne comprend pas l'acharnement de la banque centrale, comme le montre l'exemple du refus d'ouvrir les comptes de virement ${ }^{103}$.

Les divergences d'opinions de la part de la CFB ne s'expriment pas uniquement à l'égard de la BNS. Dans un article publié dans l'éphémère Schweizerische Wirtschaftszeitung en décembre 1959, le secrétaire de la Commission fédérale des banques Daniel Bodmer s'en prend indirectement aux milieux bancaires suisses, dont il met en doute la sincérité des arguments pour s'attaquer aux banques étrangères. Dans l'analyse des raisons qui motivent les réactions négatives que suscite ce phénomène, il avance:

Si l'on se déclare partisan de l'économie libre, alors le phénomène de concurrence que les établissements étrangers peuvent provoquer n'est pas strictement mauvais. Nous soupçonnons que derrière l'opposition aux nouvelles fondations de banques étrangères se cache souvent également une jalousie inavouée ${ }^{104}$.

Comme le confirme la réaction de l'ASB à l'ouverture de la Banque de l'Indochine, la dénonciation indirecte, mais publique, par le secrétaire de la CFB de l'attitude peu ouverte à la concurrence des banquiers suisses n'est pas dénuée de fondement.

Pour en terminer avec cette première phase de l'opposition aux banques étrangères, il est nécessaire de mentionner encore le cas de la succursale genevoise de la First National City Bank en 1962-I963, qui révèle d'autres dimensions intéressantes de la problématique. L'établissement new-yorkais est alors, avec une somme de bilan équivalent fin I96I à 4I milliards de francs suisses - un montant correspondant presque aux deux tiers des bilans cumulés de toutes les banques suisses (64.3 milliards de francs), la troisième plus grande banque au monde ${ }^{105}$. Son installation à Genève soulève deux problèmes spécifiques.

103 Voir aussi les antagonismes entre CFB et BNS sur la requête de la Banque Ottomane: AFB, E6520(A), I000/1059, vol. II, PV CFB 27.01.1958, p. 4-5.

104 Daniel Bodmer, «Überfremdung des schweizerischen Bankwesens?», Schweizerische Wirtschaftszeitung, $\mathrm{n}^{\circ}$ I, I2.1959.

105 AFB, E652O(A), I983/50, vol. I, dossier Aufsicht der Auslandsbehörden über die Filialen ausländischer Banken in der Schweiz (1962-1978), Lettre de la CFB au Conseil fédéral, 30.10.1962. Voir aussi : Cassis, op. cit., 2006, p. 289-290. 
D'une part, l'ASB craint que l'arrivée de la grande banque américaine représente une concurrence directe pour les banques et qu'elle péjore la situation sur le marché du travail déjà tendu ${ }^{106}$. En attirant le rare personnel qualifié disponible sur la place genevoise, la First National City Bank provoquerait une surenchère salariale. D'autre part, une seconde inquiétude, fondamentalement plus importante, gagne les autorités bancaires et monétaires suisses. Il s'agit de la question d'une potentielle menace pour le secret bancaire, sous la forme d'un contrôle matériel et comptable de la succursale genevoise par des inspecteurs étatiques américains. Tant l'ASB que la BNS et la CFB unissent sur ce point leurs forces pour préserver le maintien absolu de secret bancaire suisse dans l'éventualité de l'ouverture d'une agence de la grande banque new-yorkaise. C'est la BNS qui mène les négociations avec le Chairman of the Executive Committee de la banque, Richard S. Perkins (1910-2003). Elle en obtient des garanties que le droit suisse primera et qu'il n'y aura pas de transmissions aux États-Unis de documentation confidentielle. Non contente de ces assurances, la BNS poursuit ses démarches. Elle se méfie en particulier des contrôles qui pourraient être effectués par le Comptroller of the Currency, l'autorité de surveillance en charge des national banks: même si ces contrôles se concentrent sur la sécurité et la liquidité de la banque, «nous ne considérons pas d'emblée exclu que les documents fournis au Comptroller of the Currency puissent éventuellement être utiles au Treasury, par exemple pour des raisons fiscales » ${ }^{107}$. Dans la continuité de ces craintes d'une "perforation» (Durchlöcherung) du secret bancaire, la CFB et la BNS recommandent au Conseil fédéral, qui est l'instance responsable d'autoriser l'ouverture de succursales de banques étrangères, de faire dépendre cette autorisation d'une garantie que le secret bancaire suisse sera respecté et qu'aucune inspection américaine n'aura lieu à Genève, ni qu'aucun document confidentiel ne sera transmis à New York. L'Administration des finances ne suit cependant pas ces propositions. Dans l'urgence, la CFB et la BNS reviennent à la charge en décembre I962 et insistent plus lourdement encore sur les risques encourus. Les dirigeants de la banque centrale écrivent ainsi à l'Administration fédérale des finances les lignes suivantes :

Si les compétences de contrôle dont jouissent les autorités américaines étaient appliquées en Suisse, la protection du secret bancaire ancrée dans la législation comme dans la tradition de notre secteur bancaire subirait ainsi une atteinte qui pourrait créer un dangereux précédent. [...] La Société de Banque Suisse considère comme nous une tolérance

106 AFB, E6520(A), 1983/50, vol. I, dossier Aufsicht der Auslandsbehörden über die Filialen ausländischer Banken in der Schweiz (I962-1978), Lettre de l'ASB à la CFB, oı.08.1962.

107 AFB, E6520(A), 1983/50, vol. I, dossier Aufsicht der Auslandsbehörden über die Filialen ausländischer Banken in der Schweiz (I962-1978), Lettre de la BNS à la CFB, I7.II.I962. Sur l'activité de contrôle exercée à l'époque par le Comptroller of the Currency, voir également : Ross M. Robertson, The Comptroller and Bank Supervision. A Historical Appraisal, Washington: The Office of the Comptroller of the Currency, i968, p. I8I. 
de cette activité de contrôle [de la part des autorités américaines] comme dangereuse ${ }^{108}$.

Mais l'Administration des finances n'en démord pas. Elle refuse d'imposer des conditions particulières à l'ouverture d'une succursale de banque américaine. Elle argue qu'un certain degré de chevauchement des juridictions doit être accepté dans le cas de succursales internationales, et que les clients seront conscients du statut particulier de la banque. Le 8 mars 1963, soit neuf mois après la demande initiale, le Conseil fédéral octroie l'autorisation d'exercer à la succursale genevoise de la First National City Bank. Le secrétaire de la CFB Hans Manz accueille cette décision avec fatalisme: "Nous devons nous résigner à accepter que l'occasion de s'engager efficacement en faveur de la protection du secret bancaire n'ait pas été saisie par les instances responsables, pour quelque raison que ce soit. $"{ }^{109}$

La même problématique réapparaît rapidement. En février 1965, lorsque le Comptroller of the Currency renforce ses compétences de surveillance à l'égard de succursales étrangères des national banks, créant notamment une section d'inspecteurs spécialisés dans l'examen périodique des succursales étrangères, la BNS et la CFB mobilisent à nouveau le Conseil fédéral pour réagir à la menace ${ }^{110}$. Des démarches diplomatiques sont entreprises par l'ambassade de Suisse à Washington, pour rendre les responsables américains attentifs à la violation de la souveraineté juridique suisse que de telles inspections représenteraient ${ }^{111}$. Dans la foulée, l'ASB envoie en février 1966 une circulaire à ses banques membres, rédigée en étroite collaboration avec l'administration fédérale et la $\mathrm{CFB}$, pour rappeler les principes juridictionnels qui régissent le statut des succursales de banques étrangères en Suisse. Cette circulaire contient notamment la recommandation suivante: "L'obligation de conserver le silence au sens de l'article 47 de la loi sur les banques, comprend sans restriction et à l'égard de quiconque - donc également envers l'éventuel siège central étranger d'un établissement bancaire - tous les faits concernant les clients et les tiers en relation avec ceux-ci. » ${ }^{112} \mathrm{Ce}$ contentieux sur la portée du pouvoir

108 AFB, E652O(A), I983/50, vol. I, dossier Aufsicht der Auslandsbehörden über die Filialen ausländischer Banken in der Schweiz (1962-1978), Lettre de la BNS à l'AFF, I4.I2.1962.

109 AFB, E6520(B), 1980/39, vol. I6, PV CFB, or.04.1963, p. 48.

110 AFB, E6520(A), I983/50, vol. I, dossier Aufsicht der Auslandsbehörden über die Filialen ausländischer Banken in der Schweiz (1962-1978), Rapport interne du secrétariat CFB à ses membres, 31.05.1965. Voir aussi le procès-verbal synthétique de la conférence organisée par le Département politique fédéral le 5 février 1965. Sacha Zala, Marc Perrenoud (éd.), Documents diplomatiques suisses, Zürich, Locarno, Genève: Chronos, A. Dadò, Ed. Zoé, vol. 23 (1964-I966), 20II, doc. 68, p. I48-I5I. Également disponible en ligne : http ://dodis.ch/30944 (consulté le IO.I2.2018).

111 Cf. AFB, E200IE, 1978/94, vol. 507, 7271*, lettre de l'ambassade de Suisse à Washington à la division des affaires politiques du Département politique fédéral, 31.03.1965. Disponible en ligne: http ://dodis.ch/31932 (consulté le IO.I2.2018).

112 AFB, E6520(B), 2007/62, vol. 38, dossier 173*, Allgemeines, Korrespondenz / Dossier 2 / I965 - 1968 Circulaires ASB, Circulaire $\mathrm{n}^{\circ}$ 34I4 aux banques membres, 15.02.1966. 
extraterritorial des inspecteurs américains semble tourner à l'avantage des autorités suisses en février 1967. En effet, à l'occasion de l'installation en Suisse de la plus grande banque mondiale, la Bank of America (siège à San Francisco), le Département politique fédéral tente une nouvelle approche diplomatique dans le domaine ${ }^{113}$. Il obtient cette fois-ci de la part du Comptroller of the Currency une déclaration officielle selon laquelle le droit suisse et ses exigences de confidentialité priment dans les relations futures qui pourraient se développer entre la succursale suisse de la Bank of America et le Comptroller of the Currency ${ }^{114}$. L'ASB félicite le Département politique fédéral pour ce succès: elle espère qu'un précédent ait ainsi été créé et qu'une telle déclaration doit désormais être systématiquement exigée en cas de nouvelles requêtes de banques américaines ${ }^{115}$. La Commission fédérale des banques va même un peu plus loin, puisqu'elle demande à la First National City Bank de fournir rétroactivement un document similaire. On constate donc qu'une coopération renforcée entre les milieux bancaires, les autorités monétaires et politiques suisses, par le biais d'une mobilisation des réseaux diplomatiques, est parvenue à combler efficacement une brèche potentielle dans la préservation du secret bancaire, en interdisant toute transmission de documents confidentiels de la part d'une banque étrangère installée en Suisse vers les superviseurs étatiques de son pays d'origine ${ }^{116}$. Relevons que dans cette situation particulière, l'ASB a privilégié une consolidation du principe général du secret bancaire, qui aurait été potentiellement menacé par d'éventuelles inspections américaines, plutôt que l'affaiblissement de la concurrence des banques américaines sur sol helvétique, dont la protection de la confidentialité aurait pu être mise en doute.

Entre 1956 et 1965, les autorités suisses et l'Association suisse des banquiers, malgré quelques divergences entre la CFB et la BNS, sont unanimes pour considérer l'établissement de nouvelles banques étrangères comme une menace, ou du moins un phénomène indésirable. Mais, à ce moment-là, le poids des inconvénients liés à ce "danger d'Überfremdung" n'est pas encore suffisant pour justifier une révision de la législation bancaire. C'est donc, dans un premier temps, par divers moyens détournés que les autorités cherchent à entraver la croissance des banques étrangères. Comme nous le verrons, ce n'est

113 Sur les prémices des démarches de la Bank of America et la réaction très vigoureuse de la BNS en février 1965: cf. Zala, Perrenoud (éd.), op. cit., 20II, doc. 67, p. I47-I48, lettre de la DG BNS au DPF, 02.02.1965. Également disponible en ligne: http ://dodis.ch/30943 (consulté le IO.12.2018).

114 AFB, E6520(A), I983/50, vol. I, dossier Aufsicht der Auslandsbehörden über die Filialen ausländischer Banken in der Schweiz (1962-1978), Lettre du DPF aux autres départements, à la CFB, l'ASB et la BNS, 25.0I.1967.

115 AFB, E6520(A), 1983/50, vol. I, dossier Aufsicht der Auslandsbehörden über die Filialen ausländischer Banken in der Schweiz (1962-1978), Lettre de l'ASB au DPF, 02.02.1967.

116 Dans les faits, cette démarche de refus de coopération internationale montre tout de même quelques limites. Dans le cas de la filiale belge Cogeba, l'autorité de supervision étatique belge passe outre les interdits légaux suisses et organise une inspection "clandestine » de la banque basée à Genève. Cf. Giddey, art. cit., 2017. 
qu'après l'affaire Muñoz (mai 1965) et dans une moindre mesure le choc de l'ouverture d'une banque soviétique à Zurich (mars 1966) que les milieux bancaires seront prêts à payer le prix d'une révision du cadre réglementaire.

\section{VIII.2.2. La protection des dépôts d'épargne et les dispositions pénales dans la loi bancaire}

En plus de la problématique des banques étrangères, au moins deux autres enjeux périphériques mettant en question une éventuelle révision de la loi sur les banques surgissent au cours de la première moitié des années i960. Il s'agit d'une part du problème du montant des dépôts d'épargne privilégié dans la loi sur les banques, d'autre part, de celui d'une révision des dispositions pénales de cette même législation.

Commençons par la question des épargnes. En décembre 1958 , le radical neuchâtelois Paul-René Rosset, que nous avions déjà vu à l'œuvre dans le dossier des fonds de placement, dépose une motion au Conseil national. Cette intervention parlementaire, cosignée par 63 députés, invite le Conseil fédéral à modifier la loi sur les banques dans le sens d'une augmentation du montant des dépôts privilégiés de 5000 à Io ooo francs ${ }^{117}$. Le Département des finances du radical zurichois Hans Streuli recommande le rejet de la motion, mais suggère sa transformation en postulat en mars 1959. Tandis que Rosset souhaitait simplement adapter le montant privilégié en cas de faillite au renchérissement du coût de la vie, qui est estimé à $93 \%$ entre 1934 et 1958 , le conseiller fédéral rétorque que le montant moyen des carnets d'épargne n'a pas augmenté dans la même proportion, et qu'une augmentation du montant privilégié se fait au détriment des autres créanciers. Rappelons en effet qu'il ne s'agit pas d'une assurance des dépôts, mais simplement d'une priorisation du remboursement de cette catégorie de dépôts en cas de liquidation de la banque. Le troisième argument pour rejeter la motion consiste à souligner qu'une grande partie des épargnes sont placées auprès des banques cantonales qui bénéficient de la garantie d'état. Enfin, Streuli ajoute qu'une révision de la loi sur les banques ne s'impose pas pour modifier cette seule disposition. Le rejet de la motion Rosset par le Département des finances est en grande partie dû au préavis négatif qu'expriment la CFB, la BNS et l'ASB. L'Association suisse des banquiers, en particulier, insiste sur le fait qu'une révision de la loi sur les banques doit absolument être évitée, à cause du danger de voir d'autres propositions «très désagréables pour les banques" être formulées - et même adoptées - au cours des délibérations parlementaires. Elle précise: "les demandes continues des milieux de gauche en faveur d'une institutionnalisation légale des réserves obligatoires et en faveur d'un contrôle des crédits et des investissements " ${ }^{118}$.

117 Procès-verbaux de l'Assemblée fédérale, Conseil national, session ordinaire de printemps, 06.03.1959, p. I8I-I86.

118 AASB, Dossier 7I3 I.I - 3I.IO 1959, Lettre du secrétariat ASB (Max Oetterli) aux membres du Conseil d'administration de l'ASB, I6.02.1959. 
Le secrétaire de l'ASB, Max Oetterli, prend donc personnellement contact avec l'auteur de la motion, Paul-René Rosset, pour lui signaler les craintes des banquiers. Le peu d'insistance du motionnaire, à la suite du rejet du Conseil fédéral, s'explique peut-être aussi par l'intervention des milieux intéressés. Il faut également resituer cette position de refus de l'ASB dans le contexte de la politique monétaire de la fin des années 1950. Souvenons-nous en effet que les années 1956-1958 avaient été marquées par une pénurie sur le marché des crédits, entraînant une hausse des taux d'intérêt, et, à l'échelon politique, des interventions de la part des milieux syndicaux, paysans et de l'USAM ${ }^{119}$.

La question de la protection des dépôts réapparaît encore au printemps 1965. Alors que le gouvernement fédéral aurait souhaité supprimer le postulat Rosset en 1964, le conseiller national conservateur Josef Tschopp recommande son maintien. Les trois instances qui avaient été prépondérantes dans le rejet de la motion en 1959 - CFB, BNS et ASB - sont donc invitées à reprendre position, et surtout à mettre à jour les arguments statistiques basés sur des chiffres de 1957. Le front commun s'est alors délité : la BNS ne s'oppose plus à la réalisation du postulat Rosset, alors que l'ASB maintient son refus. La Commission fédérale des banques, quant à elle, se range du côté du lobby bancaire et propose au Conseil fédéral de maintenir le rejet du postulat Rosset ${ }^{120}$. Il s'agit aussi d'un domaine où la régulation bancaire touche une question de politique sociale. En effet, le carnet d'épargne constitue un instrument de prévoyance essentiellement répandu parmi les catégories socio-professionnelles populaires. Un sondage mené en I95I par la Banque cantonale de Zurich donne le résultat suivant:

Tableau 24. Enquête de la Banque cantonale de Zurich sur la répartition des carnets d'épargne auprès de sa clientèle par catégories professionnelles (I95I)

\begin{tabular}{|l|c|c|c|}
\hline $\begin{array}{c}\text { Catégorie } \\
\text { professionnelle }\end{array}$ & $\begin{array}{c}\text { Part (en \% du nombre } \\
\text { de carnets d'épargne) }\end{array}$ & $\begin{array}{c}\text { Part } \\
\text { (en \% de montant } \\
\text { des dépôts d'épargne) }\end{array}$ & $\begin{array}{c}\text { Dépôt moyen } \\
\text { par carnet d'épargne } \\
\text { en francs }\end{array}$ \\
\hline Ouvriers & 22.9 & 23.9 & I 740 \\
\hline Femmes au foyer & 17.9 & 23.6 & 2 I90 \\
\hline Employés & $\mathrm{I} 6.2$ & 20.8 & 2 I 40 \\
\hline $\begin{array}{l}\text { Indépendants } \\
\text { (sans agriculteurs) }\end{array}$ & 4.9 & 8.8 & 2970 \\
\hline Personnes morales & 6.3 & 6.7 & I 760 \\
\hline $\begin{array}{l}\text { Enfants, écoliers, } \\
\text { apprentis, étudiants }\end{array}$ & 24.4 & 6.1 & 410 \\
\hline Agriculteurs & 3.1 & 4.6 & 2490 \\
\hline Retraités & 2.1 & 3.4 & 2700 \\
\hline
\end{tabular}

119 Longchamp, op. cit., 2014, p. 770-790.

120 AFB, E6520(B), 2007/62, vol. 73, Dossier Einlegerschutz 1963-1980, Lettre de la CFB au DFFD, 17.06.1965. 


\begin{tabular}{|l|c|c|c|}
\hline $\begin{array}{c}\text { Catégorie } \\
\text { professionnelle }\end{array}$ & $\begin{array}{c}\text { Part (en \% du nombre } \\
\text { de carnets d'épargne) }\end{array}$ & $\begin{array}{c}\text { Part } \\
\text { (en \% de montant } \\
\text { des dépôts d'épargne) }\end{array}$ & $\begin{array}{c}\text { Dépôt moyen } \\
\text { par carnet d'épargne } \\
\text { en francs }\end{array}$ \\
\hline $\begin{array}{l}\text { Agriculteurs non- } \\
\text { indépendants }\end{array}$ & I.4 & I.4 & I 620 \\
\hline Profession inconnue & 0.8 & 0.7 & I 460 \\
\hline Moyenne & \multicolumn{3}{|r|}{ I 660} \\
\hline
\end{tabular}

Source: ABNS, I.3/1233 SNB, Interessierte Organisationen, Dossier SNB, Untersuchung der Zürcher Kantonalbank über die Verteilung der Sparhefte und Einlagen auf Berufsgruppen, I95I.

La diffusion des carnets d'épargne chez les classes moyennes et populaires fait de la protection de ce type de passifs bancaires un enjeu politique majeur. La question du statut des dépôts d'épargne refera surface par la suite, entre 1966 et 197I, lors des discussions plus concrètes sur la révision de la loi (cf. chap. IX.3). Elle témoigne aussi de l'expansion croissante des grandes banques helvétiques sur le marché intérieur et dans le domaine de la banque de détail (cf. chap. VII.I.I).

Le deuxième enjeu secondaire qui est débattu pendant la première moitié des années i960 en lien avec une éventuelle révision de la loi sur les banques est celui d'une modification de ses dispositions pénales. En octobre 1963, la Commission fédérale des banques est contactée par Robert Pfund, expert du DFFD, dans le cadre des travaux préparatoires en vue de promulguer une loi fédérale sur le droit pénal administratif. Il s'agit de savoir si les dispositions pénales de la loi sur les banques méritent un réexamen. Pour la Commission fédérale des banques, l'occasion se présente de réaliser certaines améliorations dans les sanctions pénales, qui s'étaient révélées insuffisantes à plusieurs occasions. Fin I963, l'autorité de surveillance décide unanimement d'accepter une révision des dispositions pénales, ce qui implique une modification partielle de la loi sur les banques ${ }^{121}$. Le principe de l'amendement souhaité ne consiste pas en un simple renforcement des peines prévues. Au contraire, il s'agirait plutôt d'un allégement de sanctions, qui passeraient en partie du régime du droit pénal (Strafrecht) vers le régime des contraventions (Übertretungsbestimmungen). Mais cet allégement des peines est accompagné d'un régime d'exécution beaucoup plus direct, qui permettrait d'éviter le ralentissement des procédures dû à l'incompétence des instances judiciaires cantonales. Le juriste suppléant du chef du secrétariat de la CFB Hans Manz expose le problème clairement:

D'autre part, il est un fait que les dispositions pénales prévues dans ce cas [en cas de non-obtempération à une injonction de la CFB] n'ont 
jusqu'à maintenant pas du tout joué en réalité, à tel point que les sanctions - si encore on en arrivait là - étaient en fin de compte plus clémentes que si de simples contraventions avaient été prévues dans la loi, mais que celles-ci étaient effectivement appliquées ${ }^{122}$.

Suivant les vœux exprimés par la CFB et l'expert Robert Pfund, le Département des finances et des douanes propose au Département de justice et police en avril i964 une révision de la loi sur les banques dans le sens d'une adaptation au nouveau droit pénal administratif. Mais en juillet I964, l'ASB entame la contre-attaque pour enterrer tout le projet. Elle écrit à Markus Redli (I91520I2), directeur de l'Administration fédérale des finances, pour émettre des réserves sur le projet de modification des dispositions pénales. Les objections faites par les banquiers sont de deux ordres. D'une part, ils avancent l'argument répétitif des dangers liés à une discussion publique de la loi sur les banques, ce d'autant plus que cette législation "a fait ses preuves en tant que fondement d'une évolution favorable du secteur bancaire suisse " ${ }^{123}$. D'autre part, les amendements touchant au fameux article 47 qui protège le secret bancaire proposés dans le projet de révision sont vigoureusement remis en question. Alors même que sur le fond, les changements sont jugés pertinents par l'ASB, elle « exhorte à renoncer à toute modification de la norme en vigueur sur le secret bancaire». La faîtière des banquiers craint que certains parlementaires profitent du débat pour exiger une réduction ou une suppression du devoir de confidentialité :

Même si l'on peut admettre, dans les circonstances actuelles, que de telles propositions ne trouveraient pas une majorité aux Chambres, le seul fait qu'elles soient discutées publiquement, en particulier à l'étranger, pourrait provoquer une grande inquiétude et nuire aux intérêts de notre secteur bancaire et à la position de notre pays comme place financière internationale ${ }^{124}$.

On retrouve dans ce courrier de l'ASB l'idée selon laquelle même la simple discussion publique de propositions à priori sans chance de succès pourrait être nuisible. Ici se matérialise le concept de quiet politics théorisé par le politologue P. Culpepper : les milieux économiques expriment une nette préférence pour le maintien d'une thématique à un faible degré de pertinence politique (political salience), ce qui leur donne une plus grande influence sur son orientation ${ }^{125}$. Attirer l'attention d'un public plus large sur les questions de réglementation bancaire signifie dans cette logique augmenter les risques de voir la politique partisane s'emparer de cette thématique.

122 AFB, E6520(B), 1980/39, vol. I6, PV CFB, 28.10.1963, p. 188.

123 AFB, E652O(A), 1983/50, vol. 2, Sanktionsbestimmungen 1963-1974, Lettre de l'ASB à Redli (AFF), 27.07.1964.

124 Ibid.

125 Cf. Culpepper, op. cit., 201 I. 
Mais l'Administration des finances, en septembre 1964, après avoir consulté le secrétariat de la CFB, ne tient pas compte de l'avis de l'ASB et décide ne pas revenir sur le projet d'adaptation des dispositions pénales ${ }^{126}$. La faîtière des banques enclenche alors la vitesse supérieure. Dans la continuité de la journée annuelle des banquiers tenue dans la station alpine de Villars, au cours de laquelle une première approche informelle est réalisée, le secrétaire de l'ASB Max Oetterli écrit au président de la Commission fédérale des banques pour lui rappeler la discussion avec le directeur général de l'UBS Alfred Schaefer au sujet de ce projet et la grande responsabilité qui incomberait à la CFB si elle poursuivait ces démarches. Cette manœuvre de séduction et d'intimidation porte ses fruits. À la séance suivante de la CFB, Hommel propose à ses collègues de permettre à l'ASB d'exprimer son point de vue oralement une nouvelle fois. Malgré l'opposition de deux secrétaires Bodmer et Manz, qui estiment que les banquiers "jouent les Cassandres" de manière exagérément catastrophée, la CFB suit son président et accepte d'inviter l'ASB à la prochaine séance. Paul Rossy se fend alors d'une déclaration allant dans le sens de l'ASB : "Il faut à mon avis maintenir que le secret bancaire soit aussi peu que possible publiquement discuté ; car chaque fois que cela se produit, cela signifie en soi une détérioration du secret bancaire. ${ }^{127}$ Le i9 octobre i964, Max Oetterli a donc l'occasion de présenter les arguments de l'ASB devant la CFB. Il précise quelque peu ses craintes, et ajoute notamment :

En tant qu'initiés, nous savons très bien que le secret bancaire ne dépend pas de l'art. 47 de la loi sur les banques; car cette disposition n'est nullement la base juridique du secret bancaire, mais seulement sa disposition de sanction de droit pénal. Comme nous devons encore et toujours le constater, cette vue n'est toutefois que très peu répandue, ni à l'étranger, mais pas non plus en Suisse ${ }^{128}$.

Le secrétaire de l'ASB avoue ici que la portée véritable de l'article 47 sur le secret bancaire est souvent mal comprise, et il ne souhaite pas qu'une discussion parlementaire vienne en préciser les contours ${ }^{129}$. À la suite des doléances d'Oetterli, le secrétariat de l'ASB propose une solution de compromis sous la forme d'un projet de révision des dispositions pénales dont seraient exclus les articles 47 et 48, particulièrement sensibles selon les banquiers. Le président Hommel, suivi par ses collègues de la CFB, accepte cette solution de conciliation le I3 novembre i964.

126 AFB, E6520(A), 1983/50, vol. 2, Sanktionsbestimmungen 1963-1974, lettre de l'AFF à l'ASB, I8.09.1964.

127 AFB, E6520(B), 1980/39, vol. 16, PV CFB, 25.09.1964, p. 204.

128 AFB, E6520(B), 1980/39, vol. 16, PV CFB, 19.10.1964, p. 221.

129 Sur le rôle secondaire de l'art. 47 de la loi sur les banques dans la validité juridique du secret bancaire, par rapport aux législations fiscales et aux conventions de droit international, cf. Christophe Farquet, "Le havre fiscal suisse et la globalisation de l'offshore", Working Papers of the Paul Bairoch Institute of Economic History, Genève, 2017, p. 8-9; Farquet, op. cit., 2016, p. $360-363$. 
À partir de là, le sort funeste du projet est étroitement lié aux manigances de Max Hommel, qui est alors déjà compromis à cause de son rôle dans l'affaire des banques Muñoz, que nous aborderons plus bas. Sans anticiper, il faut simplement relever pour l'instant que le président de la CFB décide de charger le secrétariat de préparer de longs rapports généraux et rétrospectifs sur l'application des sanctions pénales pendant les vingt dernières années. À ces manœuvres ayant pour but de détourner l'attention du secrétariat des problèmes des banques Muñoz, Hommel ajoute un réagencement de l'ordre du jour de la Commission, qui lui permet, en décembre 1964, de mettre au vote sa proposition de renoncer à tout le projet de révision des dispositions pénales de la loi sur les banques, alors que l'un de ses artisans, le vice-président de la CFB et conseiller national Peter Müller (I9IO-1965), est absent en raison de ses obligations de parlementaire. Un vif débat anime alors la CFB. Tandis que Paul Rossy et Jean Golay se rangent du côté du président Max Hommel, le secrétaire Daniel Bodmer, lâchement soutenu par le membre de la CFB Karl Etter (1902-?), souhaite au contraire poursuivre le projet pour améliorer la mise en application des sanctions prévues par la réglementation bancaire. Par une courte majorité de trois voix, Hommel obtient donc in extremis le is décembre ig64 le retrait de la proposition de révision légale. Ce revirement complet est annoncé au Département des finances et des douanes. En mars 1965, le DFFD décide donc de demander au DFJP de revenir sur les propositions de modification des dispositions pénales, à la suite des craintes de l'ASB relayées par la CFB.

Au terme de ces péripéties, nous constatons à nouveau que l'association des banquiers est parvenue à imposer un revirement complet dans l'attitude de la Commission fédérale des banques. En convainquant son président Hommel, les banquiers obtiennent l'abandon de toute l'entreprise. Les manœuvres tactiques auxquelles se livre alors le président à la fois pour détourner l'attention de ses collègues et pour obtenir une majorité en faveur des vœux de l'ASB signalent de manière anecdotique à la fois la faiblesse institutionnelle de cette instance, les dysfonctionnements internes et les profondes dissensions qui la secouent déjà. La loi sur le droit pénal administratif ne sera finalement adoptée qu'en 1974. Elle n'apporte que des modifications cosmétiques aux dispositions pénales de la loi sur les banques.

En guise de conclusion intermédiaire, il faut souligner la résistance acharnée qu'opposent les milieux bancaires à tout amendement apporté à la réglementation pendant une période d'une trentaine d'années (1935-1965). Alors que de nombreuses lacunes sont successivement détectées dans le régime légal - les mesures d'assainissement bancaire, les moyens de sanction dont dispose l'instance de surveillance, les conditions d'ouverture de nouvelles banques, ou encore le montant des dépôts d'épargne privilégiés -, une révision de la loi sur les banques est systématiquement, et avec succès, repoussée par l'ASB. En toutes circonstances, une éventuelle révision devient pour elle synonyme de redoutables dangers. Les effets néfastes d'une discussion parlementaire de la régulation bancaire, en particulier sur la confiance des clients étrangers, sont au cœur des craintes 
exprimées. Le statu quo réglementaire pèse de tout son poids pour empêcher des propositions de réforme, en développant une force d'inertie redoutable.

Les attitudes de la CFB et de la BNS ne sont qu'à peine plus nuancées. Jusqu'à l'orée des années 1960, la position consistant à éviter formellement un chantier législatif sur la surveillance bancaire est très largement partagée par les banquiers centraux comme par les superviseurs financiers. Les appréhensions des banquiers à cet égard trouvent un écho favorable auprès des deux instances. Au début des années 1960, ce consensus tend à s'effriter. Pour la banque centrale, la loi sur les banques apparaît progressivement comme un des lieux possibles pour réaliser un renforcement de son pouvoir sur la politique de crédit des banques. Dans le contexte de la surchauffe économique et de l'afflux constant de capitaux étrangers vers la Suisse, les dirigeants de la BNS cherchent à réaliser ou à reformuler certains des postulats qu'ils ne parviennent pas à imposer dans le conflit larvé qui les oppose aux banques commerciales sur la question de l'instrumentarium de la banque d'émission ${ }^{130}$. Du côté de la Commission fédérale des banques, les expériences malheureuses dans l'application des mesures de sanction de la fin des années 1950 semblent aussi amorcer un infléchissement dans la réticence à toucher à la loi sur les banques. Ce sont en particulier les deux employés du secrétariat, Hans Manz et Daniel Bodmer, véritable cheville ouvrière des activités de la commission, qui participent activement à plusieurs projets de révision. Leurs initiatives sont souvent contrebalancées par la grande timidité du président Max Hommel, plus enclin à préserver le statu quo. Aussi, l'argument rabâché des risques élevés liés à une discussion parlementaire de la réglementation bancaire ne semble plus convaincre entièrement tous les superviseurs. En marge d'une lettre de l'ASB qui stigmatise encore une fois ces dangers, le secrétaire Daniel Bodmer inscrit ainsi en 1965 une remarque manuscrite piquante : «die alte Platte!» (toujours le même disque...!) ${ }^{131}$. Une forme de lassitude face à l'opposition sans réserve des banquiers à toute révision législative semble donc naitre chez les superviseurs.

\section{VIII.3. L'AFFAIRE MUÑOZ-HOMMEL: UN SCANDALE DE CORRUPTION RAPIDEMENT ÉTOUFFÉ (1965)}

Le II juin 1965, Time Magazine, dans un bref article bien renseigné, rapporte que «Last week, [...] Switzerland was shaken by one of the worst scandals in the annals of Swiss banking " ${ }^{132}$. Notons d'emblée que ce qui constitue alors pour l'hebdomadaire new-yorkais un événement historique représente aujourd'hui

\footnotetext{
130 Sur cette question, qui met en jeu une révision de la loi sur la BNS entre 1964 et 1969, voir par exemple : Äppli, et al. (éd.), op. cit., I982, p. I22-132, p. I80-210; Sancey, op. cit., 2015, p. 430437.

131 AFB, E6520(B), 2007/62, vol. 73, Dossier Einlegerschutz 1963-1980, Lettre de l'ASB à Max Hommel, 17.03.1965.

132 [s.n.], «Switzerland. Banking Scandal », Time Magazine, II.06.1965.
} 
pour l'historien des banques suisses une obscure affaire méconnue et peu documentée dans la littérature secondaire. Au-delà des travaux journalistiques anglo-saxons de Fehrenbach dans les années I960 et Faith en 1982, seul l'ancien banquier de l'UBS Willi Loepfe y a consacré quelques lignes dans son histoire de la croissance de la place financière suisse durant les Trente Glorieuses ${ }^{133}$. Les ingrédients à la base de l'affaire Muñoz-Hommel sont pourtant "alléchants » : un entrepreneur catalan, la fortune d'un dictateur caribéen assassiné, deux banques suisses ruinées, une société holding luxembourgeoise, et surtout un cas de corruption avéré du président de l'autorité fédérale de surveillance des banques.

Dans l'histoire somme toute peu agitée de la surveillance bancaire helvétique, ce scandale constitue un événement sans précédent. La compromission du plus haut responsable de la Commission fédérale des banques, qui est démis de ses fonctions le I8 juin I965 par le Conseil fédéral, constitue une rupture majeure dans l'activité routinière et paisible de cet organe étatique. Les historiens officiels de la Commission fédérale de banques qui produisent l'étude célébrant le $50^{\mathrm{e}}$ anniversaire de l'organisation ont sans doute contribué à renforcer le mystère autour de cette affaire: pas un mot, sur 387 pages, n'évoque même indirectement les mois troubles de printemps $1965^{134}$. Dans les paragraphes qui suivent, nous tenterons de reconstituer le déroulement de cette affaire, en nous basant essentiellement sur les documents conservés dans les archives de la Commission fédérale des banques.

C'est en 1962-1963 que Julio Muñoz fait pour la première fois parler de lui publiquement en Suisse. Deux démarches distinctes donnent lieu à la production de matériel documentaire sur le financier espagnol conservé dans les archives fédérales. La première provient de la presse. Plus précisément, un article du I5 octobre 1962 du journal dominicain La Nacion intitulé «Garras sobre Suiza» (Griffes sur la Suisse) déclenche une vive polémique. On y rapporte qu'une partie des héritiers du dictateur Rafael Leónidas Trujillo Molina (I89I-I96I), dont le règne sans partage sur la République dominicaine, à la fois sanglant et extrêmement lucratif, a duré plus de trente ans ${ }^{135}$, ont acquis, par le biais de l'industriel catalan Julio Muñoz, le contrôle d'une banque en Suisse allemande. La chronique se révèle entièrement fondée. Le groupe Muñoz, par l'intermédiaire de la Banque Genevoise de Commerce et de Crédit qu'il contrôle depuis 1956, obtient une participation majoritaire dans la Schweizerische Spar- und Kreditbank, siège à Saint-Gall. Quant aux liens avec les

133 Theodore Reed Fehrenbach, The Swiss Banks, New York/London/Toronto : McGraw-Hill Book Company, 1966, p. I04-II2; Faith, op. cit., I982, p. 190-198; Loepfe, op. cit., 20II, p. I83-188. Pour un récit concis se basant sur les rapports de la $N Z Z$, voir également : Schütz, op. cit., 1974, p. 74-78.

134 Zulauf (éd.), op. cit., 1985.

135 En I96I, à sa mort, Trujillo contrôlait près de $80 \%$ de la production industrielle du pays et ses sociétés employaient $45 \%$ de la main-d'œuvre. Frank Moya Pons, The Dominican Republic a national history, Princeton N.J : M. Wiener, 1998, p. 365. 
héritiers Trujillo, ils sont aussi confirmés dans un rapport confidentiel du Département politique fédéral du 20 décembre 1961 : Rafael Leónidas Trujillo Martínez, dit Ramfis Trujillo (I929-1969), fils du dictateur assassiné en mai 196I, et en exil depuis, séjourne à Genève pour régler des affaires financières ${ }^{136}$. L'article de La Nacion est repris dans de très nombreux journaux, en Suisse comme à l'étranger, entre les mois d'octobre et décembre 1962. Le I3 décembre 1962, le conseiller national du Parti du Travail Jean Vincent (1906-1989) adresse au Conseil fédéral une question demandant des renseignements sur les opérations financières relatées dans la presse. La réponse du Conseil fédéral, du $\mathrm{I}^{\mathrm{er}}$ mars 1963, est très prudente: «Les autorités fédérales [...] n'ont toutefois pas la possibilité d'intervenir dans cette affaire, en particulier parce que rien ne permet de penser que des prescriptions légales suisses aient été violées par les transactions financières rapportées par la presse. »137 Voilà pour la sphère publique. En coulisse, les enquêtes sur la véracité des faits rapportés vont bon train. C'est là qu'intervient la seconde démarche. En effet, en décembre 1962, le président du conseil d'administration de la Schweizerische Spar- und Kreditbank, Franz Baumgartner, se renseigne auprès de l'ambassadeur de Suisse à Madrid, Mario Fumasoli (I9OI-I989), sur la personnalité et la situation financière de Julio Muñoz, qui a acheté une majorité des actions de sa banque ${ }^{138}$.

Les renseignements confidentiels que réunit alors l'ambassadeur de Suisse recèlent de pertinentes informations biographiques. Qui est Julio Muñoz Ramonet? Né en I9I2 à Barcelone, Muñoz s'enrichit par des opérations de marché noir pendant la guerre civile ${ }^{139}$. Puis dès les années 1940, il s'engage dans l'industrie textile catalane, profitant de bonnes relations familiales avec les autorités franquistes. Durant les années I940 et I950, Muñoz bâtit un véritable empire commercial essentiellement tourné vers la production textile, il bénéficierait d'un monopole sur l'importation de coton. D'après des renseignements fournis par la Bank of America à l'envoyé de Suisse à Bangkok, Muñoz possède entièrement ou majoritairement une douzaine de sociétés spécialisées couvrant l'ensemble de la chaîne de production ${ }^{140}$. Au total, environ 500 ouvriers travailleraient en 1958 dans les usines du groupe Muñoz.

136 AFB, E200IE, 1978/84, vol. 932, dossier 2704*, Aktennotiz Trujillo, sur la base d'un appel téléphonique d'André Amstein (police fédérale), Vertraulich, 20.I2.I96I.

137 AFB, E6Ioo(B-ooI), I980/49, vol. 6o, Interventions parlementaires, Réponse du Conseil fédéral à la question Vincent, oI.03.1963.

138 AFB, E200IE, 1978/84, vol. 932, dossier 2704*, Lettre de F. Baumgartner à M. Fumasoli, 29.I2.1962. Disponible en ligne sur la base de données des Documents diplomatiques suisses : http ://dodis.ch/3066I (consulté le Io.I2.20I8).

139 Pour une biographie romancée, voir Xavier Muñoz, Muñoz-Ramonet, societat il limitada, Barcelona: Edicions 62, 2003. L'auteur est un simple homonyme et n'est pas un parent de Julio Muñoz. Cette biographie a fait l'objet de menaces de plaintes pour diffamation et a été retirée du marché par son éditeur.

140 AFB, E2200.IOI-OI, I973-42, vol. 6, Lettre de Karl Senft (Bank of America, Thailand), à Erwin Bernath (légation Suisse à Bangkok), 28.04.1959. 
L'ambassadeur de Suisse confirme : «Les entreprises Muñoz étaient arrivées à être considérées comme la société la plus importante de l'Espagne en matière de production et d'exportation de textiles puisqu'elle avait une capacité du I $2.8 \%$ par rapport à la capacité totale du pays. Ce n'est plus le cas aujourd'hui. » ${ }^{141}$ En I946, il épouse la fille d'Ignasi Villalonga (I895-1973), président d'une grande banque espagnole, la Banco Central, et proche du régime franquiste. Quant à sa personnalité, Muñoz est décrit comme un nouveau riche «sujet d'une infinité de jeux de mots à cause des situations extrêmement ridicules dans lesquelles il se mettait lui-même $[. .$.$] : lorsqu'il recevait des personnes pour déjeuner, il leur$ offrait tout d'abord d'aller se faire couper les cheveux ou se raser chez les coiffeurs qu'il entretenait au rez-de-chaussée ${ }^{142}$. Ce portrait peu flatteur attribue encore la phrase suivante à l'homme d'affaires catalan: "Je presse mes hommes comme des citrons et je les jette quand j'en ai pris le jus. ${ }^{143}$ À la fin des années I950, Muñoz cherche à étendre ses activités à l'international. Il dispose déjà d'un important réseau commercial aux Philippines et cherche en I959 à monter un projet de développement de l'industrie cotonnière en Thaïlande. Parallèlement, le groupe Muñoz se diversifie dans la promotion immobilière et touristique, notamment en Italie. Il semble également qu'au début des années 1960 les affaires de Muñoz en Espagne se dégradent sous le double effet de la fin d'un système économique autarcique et d'une rupture avec son influent beau-père Villalonga ${ }^{144}$. Parallèlement, Muñoz entre en contact avec le clan Trujillo, au cours de visites à la République Dominicaine, et en particulier la troisième épouse du dictateur d'origine espagnole, Maria Martinez Alba, mère de Ramfis Trujillo ${ }^{145}$. Il reprend donc contact avec les héritiers Trujillo fin 196I lorsque ceux-ci sont exilés en Europe après l'assassinat du dictateur, et prend en charge le placement de leur fortune.

L'expansion commerciale du groupe Muñoz se double de la constitution d'un consortium financier à l'échelle internationale. Un enchevêtrement complexe de sociétés-écrans voit progressivement le jour, ce qui permet de diluer la fortune du dictateur Trujillo sur une multitude de sociétés. Des renseignements diplomatiques du consulat de Suisse à San Francisco exposent par exemple le schéma suivant: «le groupe Muñoz est propriétaire à Ioo \% de Cotram Inc., à Panama, qui contrôle le $64 \%$ de la Société Holding Bancaire et Financière Européenne à Luxembourg. Cette dernière est propriétaire d'environ $83 \%$ des actions de la Banque Genevoise de Commerce et de Crédit S.A. et d'environ $47 \%$ de celles de la Banque d'Épargne et de Crédit de

141 AFB, E20orE, 1978/84, vol. 932, dossier 2704*, Lettre de M. Fumasoli à la Division des affaires politiques du DPF, 28.0I.I963.

142 AFB, E20oIE, 1978/84, vol. 932, dossier 2704*, Lettre de M. Fumasoli à la Division des affaires politiques du DPF, 05.0I.I963.

143 AFB, E20oIE, I978/84, vol. 932, dossier 2704*, Lettre de M. Fumasoli à la Division des affaires politiques du DPF, 28.0I.1963.

144 Ibid.

145 Muñoz, op. cit., 2003, p. 235-236. 
Saint-Gall ${ }^{146}$. Ces subterfuges ne donnent qu'une indication grossière de la destinée des fonds Trujillo. Il semble que la diffusion du patrimoine du dictateur dominicain soit bien plus large parmi les banques suisses. En février 1964, le directeur de la Banque Genevoise de Commerce et de Crédit Marcel Dubuis affirme devant les membres de la Commission fédérale des banques que seule sa banque a subi l'opprobre d'une campagne de presse ciblée, "alors qu'il est clair que des banques suisses beaucoup plus importantes ont bénéficié des fonds Trujillo de manière considérablement plus étendue ${ }^{147}$. Un second document confirme l'implication de poids lourds de la finance helvétique dans le transfert de ces capitaux. Une lettre adressée par l'avocat de Julio Muñoz en Suisse, Jean-Charles Pesson, au sous-directeur de la Police fédérale des étrangers, Henri Tzaut, le 17 mai 1963 précise qu' «après l'assassinat du dictateur Trujillo, M. Rosembert avait transféré en Europe une partie de la fortune de la famille Trujillo, grâce - paraît-il - à l'intervention en particulier de la Société de Banque Suisse. C'est par l'entremise de cette même banque qu'une partie de la fortune Trujillo serait entrée en Suisse " ${ }^{148}$. Selon un article de l'hebdomadaire allemand Die Zeit, ce sont 44.7 millions de dollars, soit plus de 195 millions de francs suisses, qui affluent en Suisse par la SBS ${ }^{149}$.

Quel que soit le caractère généralisé de la dispersion de la fortune Trujillo dans diverses banques, les manœuvres de dissimulation, par les biais de multiples sociétés-écrans, permettent le transfert d'une grande partie de capitaux dominicains vers l'Europe: ce processus s'opère entre l'été I96I et juin I962, date la fondation de la société holding luxembourgeoise. Deux intermédiaires opèrent entre Ramfis Trujillo et Julio Muñoz: Leland Rosenberg, un exilé allemand en République dominicaine, proche des héritiers du dictateur et José María Gil-Robles, avocat espagnol. Retenons de cet opaque système que bien avant l'éclatement de l'affaire Muñoz au printemps 1965, les autorités fédérales étaient très bien renseignées sur celui qu'elles appellent tantôt «l'aventurier barcelonais ", tantôt "un homme sans scrupule et dont l'activité est préoccupante partout où elle se développe ${ }^{150}$.

Nous l'avons évoqué, c'est tout d'abord à Genève que Julio Muñoz entame la constitution d'un groupe bancaire en Suisse. Plus précisément, c'est en juin 1956 que par l'intermédiaire de deux sociétés fribourgeoises, le financier espagnol obtient la majorité des actions de la Banque Genevoise de Commerce et de Crédit (BGCC), et décide de quintupler son capital en l'espace d'une année

146 AFB, E20oIE, 1978/84, vol. 932, dossier 2704*, Lettre du consulat général de San Francisco au DPF du 7 avril 1964, cité dans la lettre de la division des affaires politiques du DPF à la CFB, 17.04.1964.

147 AFB, E6520(B), 1980/39, vol. I6, PV CFB, I2.02.1964, p. 40.

148 AFB, E6roo(B-oI), 1980/49, vol. 67, Lettre de Jean-Charles Pesson à Monsieur Tzaut, 17.05.1963.

149 H. F. Millikin, «Die Millionen des Diktators. Mit der Erbschaft Trujillos wurden zwei schweizer Banken ruiniert ", Die Zeit, $\mathrm{n}^{\circ}$ 49, 02.I2.1966.

$150 \mathrm{AFB}, \mathrm{E} 200 \mathrm{IE}, 1978 / 84$, vol. 932, dossier 2704*, Projet de lettre de la police fédérale des étrangers à Maittre Jean-Charles Pesson, I6.05.1964. 
(d'un à cinq millions de francs suisses) ${ }^{151}$. La BGCC est une banque locale, fondée en I868 sous le nom de Banque Populaire Genevoise, puis assainie et rebaptisée en 1938. En plus des administrateurs de la BGCC, Muñoz s'entoure à Genève de personnalités reconnues de la place financière du bout du lac. L'avocat Georges-François Perréard (I923-20II), fils du conseiller aux États genevois radical François Perréard, les banquiers Pierre Yvan Kern (I92I-), et Henri Ferrier (1907-?) font partie des prête-noms de Muñoz à Genève ${ }^{152}$. C'est en décembre 1958 que la BGCC figure pour la première fois à l'ordre du jour de la Commission fédérale des banques ${ }^{153}$. Les superviseurs constatent que la banque a rapidement évolué depuis 1956. Elle n'est plus une banque locale, mais s'engage dans les opérations internationales, comme en témoigne un crédit de plus 4 millions à un armateur costaricain. Le volume d'affaires de la Banque Genevoise de Commerce et de Crédit connaît une croissance exponentielle entre 1956 et 1965 . Son bilan passe de 26 millions en 1956 à 155 millions en 1963, ce qui correspond à une augmentation de $410 \%$ en tenant compte de l'inflation ${ }^{154}$. Les diverses recommandations et avertissements à la BGCC sur sa politique de crédit dangereuse émis par la CFB entre 1958 et 1963 ne produisent aucun effet.

Six ans après la reprise de la BGCC, Muñoz se lance dans le rachat de la SSKB. En décembre 1962, la CFB constate une augmentation massive du capital social de la banque saint-galloise qui passe de I8 à 30 millions de francs. Cette opération est effectuée par l'entremise de la banque genevoise et, d'après le secrétariat de la $\mathrm{CFB}$, de manière formellement incorrecte (apports en nature au lieu de libération du capital en espèces, et émission d'actions sans valeur) ${ }^{155}$. Le groupe Muñoz contrôle désormais $47 \%$ du capital de la banque saintgalloise. La Schweizerische Spar- und Kreditbank est un établissement d'une autre dimension que la BGCC. Fondée en 1905 sous le nom de Banque Coopérative Suisse (Schweizerische Genossenschaftsbank), elle est transformée en société anonyme et subit un important assainissement en 1936. Avec un bilan de 209 millions de francs fin I962, il s'agit d'un institut de taille comparable à une petite banque cantonale. Elle dispose alors d'un réseau de treize

151 AFB, E2200.IOI-OI, I973-42, vol. 6, Lettre de Karl Senft (Bank of America, Thailand), à Erwin Bernath (légation Suisse à Bangkok), 28.04.I959. Le conseil d'administration de la BGCC est alors composé de: Jean Humbert (président), Victor Olivet (vice-président), René Ricolfi-Doria, Lucien Billy, Marcel Bovard-Binet, Jean-Marc Duchosal et Henri Ferrier (administrateur-délégué).

152 AFB, E2200.IOI-OI, I973-42, vol. 6, Rapport de Léon-Marc de Torrenté (dir. de la succursale de Genève de la BNS) à Riccardo Motta (v-pdt DG BNS), 21.04.1959. Sur Pierre Yvan Kern, ancien spécialiste de la clientèle ibérique à la SBS, puis au Crédit Suisse, à la fin des années I950, voir Yves Steiner, "Des banques suisses pincées la main dans le sac dans l'Espagne franquiste", L'Économie politique, vol. 46, $\mathrm{n}^{\circ}$ 2, 2010, p. 59-68.

153 AFB, E6520(A), I000/I059, vol. II, PV CFB 29.I2.1958, p. I84.

154 Schweizerische Nationalbank, Das Schweizerische Bankwesen im Jahre, Zürich, années correspondantes.

155 AFB, E6520(B), 1980/39, vol. 16, PV CFB, 22.0I.1964, p. I2. 
succursales, et est essentiellement implantée en Suisse orientale et en Valais ${ }^{156}$. Avant la reprise par le groupe Muñoz, la SSKB est considérée comme une grande banque locale, émanation de la bourgeoisie catholique saint-galloise ${ }^{157}$.

Dès janvier 1964, la Commission fédérale des banques s'inquiète vivement de l'évolution des deux banques du groupe Muñoz. Les superviseurs constatent sur la base du rapport de révision pour l'année 196r que la répartition des risques est loin d'être optimale. L'octroi unilatéral de crédits aux sociétés de l'actionnaire majoritaire est extrêmement préoccupant. Alors que la conclusion est sans appel, un débat interne s'ouvre sur les mesures à prendre. Plus précisément, le secrétariat de la CFB, et essentiellement Daniel Bodmer, propose l'injonction de mesures relativement sévères : il faut fixer un délai pour corriger les différents manquements constatés, accompagné de la menace d'un dépôt de plainte si le délai n'est pas respecté. Le président de la CFB, Max Hommel, cherche alors à contrecarrer les propositions de Bodmer. Il souligne la campagne de presse calomnieuse menée contre les deux banques, et avoue avoir rencontré personnellement Muñoz. Il recommande alors un traitement bien plus indulgent, et demande d'organiser une rencontre avec les administrateurs des deux banques, avant de fixer des délais et de proférer des menaces. Il est suivi par le conseiller aux États conservateur lucernois Peter Müller, qui insiste quant à lui sur les personnalités "de bonne réputation" qui compose le conseil d'administration de la SSKB. Müller pense en fait à ses collègues de parti, comme les conseillers nationaux Remigius Bärlocher (I9I5-1984) ou Adelrich Schuler (I922-1989). La CFB décide donc en janvier 1964, sous l'impulsion de son président Max Hommel, d'emprunter la voie de la clémence. Sans que ses collègues ne s'en rendent alors compte, Hommel entame ici un travail de manipulation qu'il mène au profit du groupe Muñoz. Il s'agit là de la première occurrence d'une attitude ambivalente du président de la CFB Max Hommel, qui joue sur plusieurs tableaux à la fois. Comment faut-il comprendre cette duplicité?

En mai 1963 , soit quelques mois après le rachat de la banque saint-galloise par l'entrepreneur catalan, Hommel fait la connaissance de Julio Muñoz à l'occasion d'une fête organisée dans la résidence secondaire d'Estavayer-le-Lac de son ami Oskar Stampfli (I909-?) ${ }^{158}$. Ce dernier, directeur d'une caisse d'épargne soleuroise, avait été contacté par Muñoz, par le biais du banquier genevois Marcel Dubuis, une connaissance commune, pour lui proposer le poste de directeur général de la SSKB. Sur demande de Muñoz, Stampfli organise donc cette invitation à caractère privé, à laquelle les conjointes sont

\footnotetext{
156 Loepfe, op. cit., 20II, p. 183-184.

157 Faith, op. cit., 1982, p. 193.

158 Toute l'affaire sur les liens entre Muñoz et Hommel est documentée en détail dans le dossier suivant: AFB, E6I00(B-OI), 1980/49, vol. 67, dossier Ermittlungsverfahren gegen Max Hommel. Le rapport « Bericht über das gerichtspolizeiliche Ermittlungsverfahren in Sachen Max Hommel betreffend den Verdacht der Verletzung von Amtspflichten" (5I pages) fournit une vision synthétique de l'enquête menée par le ministère public de la Confédération.
} 
également conviées. Muñoz souhaitait à cette occasion faire la connaissance de Hommel, qu'il considère comme "la personnalité la plus importante du monde bancaire officiel en Suisse " ${ }^{159}$. Tandis qu'Oskar Stampfli refuse, à l'été 1963 , d'endosser le rôle de directeur général qui lui est offert, une seconde réception informelle est organisée, cette fois-ci dans la maison de vacances de Hommel à Susten, le Io août 1963: Julio Muñoz poursuit son approche et invite Stampfli et Hommel, accompagnés de leurs épouses, à un voyage en Espagne. Ce séjour est justifié par la volonté de Muñoz de prouver à ses interlocuteurs suisses la solidité de ses affaires espagnoles. Du I8 au 22 octobre 1963, les couples Stampfli et Hommel voyagent en Espagne (Barcelone, Llavaneres, Andorre) : tous les frais, estimés à 2200 francs, sont pris en charge par Muñoz. Au cours du voyage, un bracelet en or, estimé à 500 francs, est généreusement offert à Mme Hommel. Avant même le séjour ibérique, Hommel avait en outre accepté, dès le 7 octobre 1963, un mandat de conseiller financier pour les questions financières et fiscales, au profit de deux sociétés du groupe Muñoz, la Holding Bancaire et Financière et la Cotram S.A. Ce mandat de conseiller financier est rémunéré à hauteur de 2 ooo francs par mois. À titre de comparaison, le salaire mensuel moyen d'un employé qualifié dans le domaine bancaire s'élève en 1963 à I 452 francs ${ }^{160}$. Dès l'automne 1963, alors que plusieurs sources d'information, dont son ami Oskar Stampfli, mettent en garde contre les activités de Julio Muñoz, Max Hommel accepte une rémunération fixe de la part de l'homme d'affaires espagnol.

Qui est Max Hommel? Né en 1902, originaire de Frauenfeld, Hommel est expert-comptable diplômé. Il fait carrière au sein de l'Union Suisse des Banques Régionales, Caisses d'Épargne et de Prêts, puis dans l'Association de révision des Banques et Caisses d'épargne bernoises, dont il devient inspecteur en chef (Chefinspektor) en septembre $1938^{161}$. Alors qu'il avait déjà eu affaire à l'autorité de surveillance en tant que commissaire dans l'assainissement de la Banque Populaire Genevoise en 1937, c'est en janvier 1939 qu'il rejoint la Commission fédérale des banques en tant que chef du secrétariat. Pendant sept ans, Hommel est la cheville ouvrière de la CFB, d'abord sous la présidence de Schulthess (19391943), puis sous celle de Wetter (1943-1946). En mars 1946, Hommel décide de quitter le secrétariat de la Commission fédérale des banques pour fonder son propre bureau fiduciaire à Berne. Alors qu'il démissionne de son poste de chef du secrétariat, le Thurgovien est parallèlement élu en tant que membre de la CFB. En 1954, Hommel devient vice-président de l'organe de surveillance, avant d'en être nommé président en juin 1955. Quatrième président de la CFB, sa nomination marque une rupture avec le principe selon lequel la présidence de la

159 AFB, E6Ioo(B-oI), 1980/49, vol. 67, dossier Ermittlungsverfahren gegen Max Hommel, Procès-verbal d'audition de Julio Muñoz Ramonet, Ministère public fédéral, 09.06.1965, p. 2.

160 Ritzmann-Blickenstorfer (éd.), op. cit., I996, tableau G.I2, p. 464.

161 Revisionsverband bernischer Banken und Sparkassen (éd.), so Jahre Revisionsverband bernischer Banken und Sparkassen, Langnau: Buchdruckerei Emmenthaler-Blatt AG, 1962. 
Commission revenait à une personnalité forte de la politique fédérale. Parmi ses trois prédécesseurs, on compte deux anciens conseillers fédéraux (Schulthess et Wetter) et un conseiller national et futur conseiller fédéral (Holenstein). En 1965, Hommel est lié à la CFB depuis 26 ans, dont sept en tant que secrétaire, puis dix en tant que président. Depuis 1946, il est à la fois membre de l'autorité de surveillance et directeur d'un bureau de conseil fiduciaire et fiscal.

Par l'entremise de deux intermédiaires (Dubuis et Stampfli), Julio Muñoz parvient à s'approcher de Max Hommel. Lors de son audition en juin 1965, le Catalan déclare sans vergogne : "En sa qualité de Président de la Commission fédérale des Banques, je considérais $\mathrm{M}$. Hommel comme un homme extrêmement capable, qui devait être à même de nous conseiller judicieusement dans nos affaires bancaires en Suisse. » ${ }^{162}$ Pendant près de 18 mois, le président de la CFB sera contractuellement lié et rémunéré par un financier espagnol contrôlant deux banques en Suisse. Hommel se garde bien de dévoiler ces liens d'affaires à ses collègues de la Commission fédérale des banques. Il existe pourtant un conflit d'intérêts évident entre la fonction de conseiller financier de sociétés financières étrangères propriétaires de banques suisses en difficulté et celle de président de l'autorité de surveillance bancaire.

Pendant près d'un an et demi, entre l'automne 1963 et le printemps 1965 , Max Hommel se livre à un double jeu. Du côté de la Commission fédérale des banques, il essaie de modérer les propositions du secrétariat en faveur de mesures drastiques contre les deux banques concernées. Hommel estime que l'organisation de réunions avec les dirigeants de deux banques est plus à même de résoudre les insuffisances que des menaces de dépôts de plainte. Parallèlement, l'expert-comptable thurgovien participe aussi à plusieurs réunions des conseils d'administration des deux banques et reçoit Muñoz et son avocat Gil-Robles dans son bureau privé à Berne.

Pendant ces I8 mois, la situation financière des deux banques empire continuellement. Une fois le rachat effectué, Muñoz utilise son influence sur les deux banques pour s'octroyer des lignes de crédit substantielles. Fin 1963, les engagements des deux banques envers le groupe Muńoz sont déjà conséquents : ils sont estimés à 47 millions pour la BGCC, et 54 millions pour la SSKB ${ }^{163}$. Pour la première, ces avoirs correspondent à $30 \%$ du bilan, pour la seconde à environ $20 \%{ }^{164}$. Selon la BNS, à la fin avril 1965 , Muñoz doit 48 millions à la banque saint-galloise et 32 millions à la banque genevoise ${ }^{165}$. L'évidement des

162 AFB, E6roo(B-oI), 1980/49, vol. 67, dossier Ermittlungsverfahren gegen Max Hommel, Procès-verbal d'audition de Julio Muñoz Ramonet, Ministère public fédéral, 09.06.1965, p. 4.

163 AFB, E6520(B), 1980/39, vol. I6, PV CFB, I2.02.1964, p. 44, 51.

164 Les bilans figurent en principe dans la publication annuelle de la BNS (Das schweizerische Bankwesen im Jahre...). Etonnamment, il n'y a aucune donnée sur la SSKB dans le volume 1963. Nous avons donc grossièrement estimé son bilan, en calculant la moyenne des années I962 et 1964 (209 et 324 millions).

165 ABNS, Procès-verbaux de la Direction générale de la BNS, 29.04.1965, p. 878. 
deux établissements est rendu possible par les garanties formellement incorrectes, ou qui se révèleront de très faible valeur, remises par Muñoz. La duplicité de Hommel devient de plus en plus intenable à mesure que les informations défavorables sur les deux banques se multiplient.

En mars 1964, le président de la CFB cherche encore à tempérer l'ardeur des membres du secrétariat, qui réclament une intervention vigoureuse. Hommel se demande alors si un plafonnement des crédits en faveur de Muñoz est vraiment nécessaire; il ajoute que ce dernier est victime d'une campagne de diffamation et que des informations privées provenant du Crédit Suisse ne sont pas défavorables au Catalan ${ }^{166}$.

Un second exemple montre encore plus clairement la duplicité de Hommel. En décembre 1964, les perspectives de survie des deux banques s'assombrissent. Selon le rapport de révision de la société fiduciaire REVISA, il n'est pas certain que les créanciers soient encore couverts. En l'espace de 24 heures, Max Hommel va alors enchainer trois rendez-vous dans trois assemblées différentes et y défendre des positions incompatibles. Le 8 décembre au soir, une réunion confidentielle entre Max Hommel, Julio Muñoz, son avocat José María GilRobles, et le directeur de la SSKB Hermann Hug a lieu au bureau de la fiduciaire Hommel à Berne. Voici comment Muñoz décrit cette entrevue lors de son audition par la justice:

Nous nous sommes rendus à la fiduciaire Hommel pour montrer les garanties et documents officiels, en donnant les explications nécessaires à $\mathrm{M}$. Hommel, lui précisant qu'il n'était pas possible de couper les crédits aux différentes sociétés, parce que, ce faisant, ces sociétés se trouveraient alors en difficulté et de cette manière, cela préjudicierait les garanties que nous avions données à la banque. [...] Globalement, je lui fis remarquer que nos différentes sociétés auraient besoin de Frs. Io millions, pour continuer leur activité, soit plus précisément leur développement. M. Hommel considéra alors que cette demande était juste, et normale, et bancaire. Après cette entrevue, nous avons dîné ensemble, à mes frais, à l'Hôtel Schweizerhof ${ }^{167}$.

Le lendemain matin, une séance du conseil d'administration de la SSKB a lieu dans ce même palace bernois. Hommel, Muñoz et Gil-Robles y participent également. Hommel y réalise un véritable numéro d'équilibriste, tiraillé entre sa fonction officielle de superviseur bancaire qui devrait inciter à plafonner les crédits à Muñoz, et celui - officieux - de conseiller financier de l'homme d'affaires qui devrait au contraire encourager les administrateurs de la banque saint-galloise à ouvrir encore plus les vannes du crédit. Il termine son intervention devant les dirigeants bancaires par ces propos sibyllins: "Monsieur

166 AFB, E6520(B), 1980/39, vol. 16, PV CFB, 05.03.1964, p. 68, 73.

167 AFB, E6roo(B-oI), 1980/49, vol. 67, dossier Ermittlungsverfahren gegen Max Hommel, Procès-verbal d'audition de Julio Muñoz Ramonet, Ministère public fédéral, 09.06.1965, p. 3 . 
Hommel invite encore le Conseil de faire bien attention. La banque, dit-il, n'est pas un cheval qu'on peut toujours faire sauter. Il ne faut pas non plus perdre de vue qu'il a des collègues qui sont parfois assez exigeants. " ${ }^{168}$ Cette dernière phrase fait sans aucun doute référence à l'attitude moins conciliante des autres membres de la CFB. Quittant l'audience au Schweizerhof, Hommel se rend ensuite immédiatement aux bureaux de la Commission fédérale des banques, pour présider la $\mathrm{I}^{\mathrm{e}}{ }^{\mathrm{e}}$ séance annuelle de la CFB. Omettant évidemment de mentionner la réunion privée de la veille avec Muñoz, Hommel se présente alors auprès de ses collègues superviseurs comme un médiateur qui a cherché à calmer «l'ambiance révolutionnaire » qui régnait au sein du Conseil d'administration de la SSKB ${ }^{169}$.

Ce double jeu mené par Hommel, combiné à l'aggravation de la situation financière des banques, conduit finalement à l'éclatement du scandale. L'attitude ambivalente du président de la CFB n'échappe pas aux deux employés du secrétariat, Bodmer et Manz. Une suspicion naissante, éveillée par un avertissement que Bodmer reçoit de la part d'une connaissance du monde fiduciaire bernois sur les relations qu'entretiendrait Hommel avec Muñoz, provoque des tensions entre le président et le secrétariat. Les manipulations du président pour influencer les décisions de la Commission dans son sens viennent confirmer cette méfiance. Il ne respecte plus les propositions du secrétariat dans la gestion des débats, modifie subitement l'ordre du jour, ou encore demande inopinément aux deux secrétaires de préparer de longs rapports sur une question jugée secondaire pour détourner leur attention des banques Muñoz.

C'est au printemps 1965 que la situation devient explosive. Fin mars 1965, un rapport de la REVISA révèle que les garanties fournies par Muñoz sont de très faible valeur. Les deux banques suisses décident de suspendre les crédits au groupe catalan. Des négociations en vue d'une reprise par une grande banque suisse sont menées. Le Crédit Suisse, déjà intéressé par un rachat en novembre 1963, est au cœur de ces tractations. Max Hommel se distingue à nouveau par un rôle très actif. D'une part, il cherche sans succès à obtenir de la REVISA une évaluation plus opportune des positions Muñoz. D’autre part, il se démène pour favoriser la reprise de la BGCC et surtout de la SSKB par une grande banque $^{170}$. Pris de panique, il sent le vent tourner et détruit dans sa fiduciaire toute la documentation le reliant à Muñoz.

Les événements s'accélèrent. Sept séances de la CFB sont organisées en l'espace de trois mois (avril-juin 1965). Alors que les négociations de reprise avec

168 AFB, E6Ioo(B-oI), 1980/49, vol. 67, dossier Ermittlungsverfahren gegen Max Hommel, Procès-verbal de la séance du conseil d'administration de la Banque Suisse d'Épargne et de Crédit, 09.12.1964.

169 AFB, E6520(B), 1980/39, vol. I6, PV CFB, 09.12.1964, p. 256.

170 Selon des informations transmises par le journaliste de la NZZ Dr. Heinz Portmann, Hommel aurait "sauté" de banque en banque pour réaliser une reprise de la SSKB, en indiquant aux directeurs des grandes banques qu'ils lui rendraient ainsi un très grand service personnel. AFB, E6I0o(B-oI), 1980/49, vol. 67, dossier Ermittlungsverfahren gegen Max Hommel, Aktennotiz Portmann, 26.05.1965. 
le Crédit Suisse s'enlisent, la Commission fédérale des banques prend enfin en considération des mesures plus interventionnistes. Le secrétaire Manz décrit la situation de la manière suivante le 2I avril 1965 . Cette diatribe, dont la tonalité acerbe tranche avec les discours policés habituels, mérite d'être citée amplement :

Je suis principalement frappé par les dimensions tout à fait exceptionnelles d'un grave crime. Muñoz est pour moi un voyou, et Hug son complice. Tous deux ont abusé de leur position de confiance dans ces banques pour en extraire des montants chiffrés en millions. Personne ne sait à quoi ceux-ci ont finalement servi. Quoi que nous décidions ici aujourd'hui, l'effondrement de ces banques va très probablement se produire bientôt, et ces deux individus auront alors disparu. Je peux alors très bien m'imaginer l'indignation légitime que cela va susciter par monts et par vaux ${ }^{171}$.

Les superviseurs décident alors le recours à une plainte pénale contre Muñoz et son acolyte Hug - directeur de la SSKB -, dans l'éventualité où les banques demandent un sursis bancaire, une mesure de prorogation qui constitue le prologue à une faillite ou à un assainissement. Le 26 avril 1965 , la SSKB et la BGCC déposent effectivement des demandes de sursis bancaire et ferment leurs guichets, les négociations avec le Crédit Suisse ayant définitivement échoué et la menace d'un run sur les dépôts devenant imminente. Le lendemain, la Commission fédérale des banques dépose comme prévu une plainte auprès du ministère public du canton de Zurich pour escroquerie. Le 28 avril, la National-Zeitung de Bâle, puis le 29, la Tribune de Genève, publient des articles dévoilant les rapports étroits entretenus entre Hommel et Muñoz. Dans un premier temps, jusqu'à début juin, Max Hommel parvient à sauver la face. À ses collègues de la CFB, il avoue une partie des relations personnelles avec Muñoz, en se permettant quelques entorses à la vérité. Ses quatre collègues membres de la CFB (Peter Müller, Karl Etter, Jean Golay et Paul Rossy) sont facilement convaincus par ces explications et estiment que toute l'affaire est gonflée par la presse. Les deux secrétaires, eux, demeurent suspicieux. Lorsque la CFB décide de soutenir solidairement son président en envoyant une lettre au DFFD affirmant l'objectivité avec laquelle Hommel a traité les affaires SSKB et BGCC, le secrétariat refuse de contresigner le document.

L'étau se resserre autour de Hommel. Le I9 mai, il avance une nouvelle pièce au dossier pour justifier son comportement erratique des mois passés : une crise conjugale, attestée par un certificat médical en est la cause. C'est ensuite le Département des finances de Roger Bonvin qui exige de Hommel des explications sur la nature exacte de ses relations avec Muñoz. Dans sa réponse du 28 mai, Hommel énonce plusieurs contre-vérités flagrantes, niant toute relation privée ou commerciale avec Muñoz ou son groupe. Deux jours plus tôt, l'Administration fédérale des finances est avertie par le rédacteur de la $N Z Z$,

171 AFB, E6520(B), 1980/39, vol. 16, PV CFB, 21.04.1965, p. 77-78. 
Heinz Portmann, que le grand quotidien zurichois a constitué un lourd dossier à la charge de Hommel, dont la culpabilité ne fait pas de doute ${ }^{172}$. Portmann exerce une pression sur les autorités fédérales : si elles n'agissent pas rapidement, la $N Z Z$ publiera des accusations contre Hommel et la CFB. Le 4 juin, le Conseil fédéral décide de suspendre Max Hommel de ses fonctions et d'ordonner une enquête du Ministère public fédéral. Le grand hebdomadaire allemand d'investigation, Der Spiegel, joue également un rôle dans l'accélération du processus. Le Conseil fédéral cherche à devancer la publication d'un "article de bombe" du journal hambourgeois, censé attaquer à la fois les banques et le gouvernement suisses ${ }^{173}$. La suspension de Hommel repose également sur une preuve tangible du mandat de conseiller financier rémunéré à hauteur de 2000 francs mensuels. Hommel est arrêté et entendu le jour même; il avoue les faits. Parallèlement, Julio Muñoz et Hermann Hug sont arrêtés et incarcérés le $\mathrm{I}^{\mathrm{er}}$ juin à Genève et mis à disposition du parquet de Zurich dans le cadre de la plainte déposée par la CFB. Les 8 et 9 juin, après une semaine de détention, Hug et Muñoz bénéficient d'une mise en liberté provisoire, contre une caution de 20 ooo francs pour le banquier suisse et I million de francs pour l'industriel catalan. Ils sont relâchés et quittent la Suisse. La grande résonnance du scandale dans la presse étrangère incite le Département politique fédéral à faire une communication à toutes les représentations diplomatiques pour permettre aux diplomates helvétiques «de présenter les faits d'une manière objective et de les ramener à leurs vraies proportions ${ }^{174}$. Le dommage réputationnel pour la place bancaire suisse et les risques d'inquiétude chez la clientèle étrangère provoquent alors diverses manœuvres visant à étouffer, autant que faire se peut, le scandale qui vient d'éclater. Distinguons d'une part le sort des deux banques et de leurs déposants et d'autre part les suites judiciaires de l'affaire.

Après l'échec des négociations avec le Crédit Suisse, c'est la Société de Banque Suisse qui se montre intéressée par une reprise des banques Muñoz. Elle pose comme condition de reprise de la banque saint-galloise le remboursement par Muñoz de 20 millions en l'espace de 18 mois. La grande banque va jusqu'à intervenir auprès du parquet du canton de Zurich pour favoriser la libération sous caution de Muñoz, ce afin de faciliter l'aboutissement de la reprise de la SSKB ${ }^{175}$. La rumeur court que les autres grandes banques assument également une partie du «risque Muñoz» pour sauvegarder la réputation

172 AFB, E6roo(B-oI), 1980/49, vol. 67, dossier Ermittlungsverfahren gegen Max Hommel, Aktennotiz Portmann, 26.05.1965.

$173 \mathrm{AFB}, \mathrm{E} 652 \mathrm{O}(\mathrm{B})$, 1980/39, vol. I6, PV CFB, 04.06.1965, p. I35. L'expression «article de bombe » est utilisée par le conseiller fédéral Bonvin.

174 AFB, E6Ioo(B-oI), 1980/49, vol. 67, dossier Ermittlungsverfahren gegen Max Hommel, Lettre du Département politique fédéral aux respésentations diplomatiques, 17.06.1965.

175 AFB, E6Ioo(B-oI), I980/49, vol. 67, dossier Ermittlungsverfahren gegen Max Hommel, Aktennotiz Ehrsam über meine Besprechung mit Herrn Bezirksanwalt Dr. Erwin Suter, I0.06.1965. 
de la place bancaire suisse. Le rachat par la SBS est annoncé le 26 juin 1965. La grande banque bâloise acquiert le passif et l'actif de la SSKB, à l'exception des engagements à l'égard du groupe Muñoz, qui ne font pas partie du bilan de reprise. Une nouvelle société est fondée par la SBS, la Banque Suisse de Crédit et de Dépôts, qui reprend le passif de la SSKB défaillante ${ }^{176}$. Les déposants ne subissent pas de pertes, et le personnel est réengagé. Cette intervention suscite les remerciements du Conseil fédéral, pour le «sacrifice considérable » consenti par la grande banque bâloise ${ }^{177}$. Pour la Banque Genevoise de Commerce et de Crédit, cette annonce fait l'effet d'une douche écossaise. Elle est exclue du paquet de reprise opéré par la SBS. Les démêlés judiciaires de la banque genevoise d'une part avec un armateur grec (affaire Petroutsis) et avec le clan floridien des héritiers Trujillo rendent l'opération trop risquée pour la Société de Banque Suisse. Le sursis bancaire se prolonge en sursis concordataire en 1966. La liquidation concordataire de l'établissement ne s'achève qu'en février 1970. Au terme de ce long processus de près de cinq ans, les créanciers ne subissent cependant pas de pertes et sont indemnisés à I0O $\%{ }^{178}$. Retenons de l'épilogue des deux banques que l'aboutissement de la reprise de la SSKB par la SBS doit beaucoup au fort retentissement international que le scandale a connu depuis les révélations sur Hommel et sa suspension début juin. La grande banque bâloise, au contraire du Crédit Suisse dont la tentative de reprise en mars-avril I965 avait finalement échoué, aurait également tout intérêt à noyer le poisson de l'affaire Muñoz, puisque c'est elle qui aurait été en 1962 parmi les premiers récipiendaires de la fortune Trujillo. Quelles qu'en soient les réelles motivations, la reprise de la SSKB par la SBS tombe à point nommé pour l'ensemble des acteurs impliqués.

Quant aux dénouements judiciaires, ils sont également multiples. Il y a tout d'abord l'enquête menée par le Ministère public fédéral contre Max Hommel pour violation de ses devoirs de fonction et l'acceptation de cadeaux au sens de l'art. 316 du Code pénal. L'instruction aboutit à un rapport d'une cinquantaine de pages: Hommel ne s'est rendu coupable ni d'abus de pouvoir, ni de gestion déloyale, ni même de corruption passive. En revanche, les 36 ooo francs d'honoraires qu'il reçoit au total de Muñoz, dont la contrepartie, à savoir les conseils financiers et fiscaux, est d'ailleurs jugée insuffisante, constituent une acceptation illicite de cadeaux ${ }^{179}$. Au printemps 1966 se pose alors la question des suites à donner à cette affaire. Faut-il entreprendre des poursuites pénales contre Hommel, ou en rester à la mesure disciplinaire que représente sa destitution? Le Département des finances tend plutôt vers la seconde solution. Dans le rapport que Bonvin transmet au Conseil fédéral, il souligne les risques

176 Sur la reprise de la SSKB par la SBS, voir aussi : Stampfli, op. cit., 197I, p. 8I-83.

177 Bauer, op. cit., 1972, p. 359. Voir aussi Loepfe, op. cit., 201I, p. I87.

178 H.V., «En liquidation concordataire. La Banque Genevoise de Commerce et de Crédit va solder ses créanciers ", Journal de Genève, 26.02.1970.

179 AFB, E6roo(B-oI), 1980/49, vol. 67, dossier Ermittlungsverfahren gegen Max Hommel, Rapport du DFFD au CF, 22.02.1966. 
d'un acquittement de Hommel; des poursuites pénales qui conduiraient à une disculpation de l'expert-comptable déchu pourraient mettre en évidence la clémence du système judiciaire suisse, dans ces conditions une simple condamnation par mesure disciplinaire serait préférable. Le DFFD insiste également sur la dimension de politique extérieure de l'affaire sur laquelle l'Association suisse des banquiers appuie également:

On sait que nos banques sont exposées à une forte hostilité à l'étranger. Le traitement de l'affaire Hommel et de l'effondrement des deux banques dans la presse étrangère a clairement démontré que des milieux déterminés et influents saisissent chaque occasion pour saper la confiance dans nos banques et nos institutions. L'exécution d'une procédure pénale prendra un certain temps et donnera l'occasion à la presse étrangère de soulever toute l'affaire à nouveau ${ }^{180}$.

Une Aktennotiz du directeur de l'Administration fédérale des finances de novembre 1965 confirme ces craintes suscitées par l'ouverture d'une procédure pénale contre l'expert-comptable thurgovien ${ }^{181}$. Cette note de dossier précise qu'à l'étranger, et en particulier aux États-Unis, la fonction de Hommel avait été comprise comme celle d'une sorte de ministre ou secrétaire d'État pour les banques, ce qui aurait aggravé l'impact du scandale.

Malgré ces inquiétudes, le Département fédéral de justice et police recommande de transmettre le dossier aux instances judiciaires cantonales bernoises en vue d'ouvrir une procédure pénale. L'enquête préliminaire menée en toute discrétion par le procureur de district est tout simplement levée en septembre 1967. Les résultats de cette instruction préliminaire ne sont jamais rendus publics. En janvier 1969, un billet dans la Gazette de Lausanne, pertinemment intitulé "Enterrement par négligence», rappelle qu'aucune communication officielle n'est venue éclaircir le dénouement de cette procédure pénale ${ }^{182}$. Au fond, c'est dans l'indifférence générale qu'Hommel bénéficie d'un blanchiment sur toute la ligne.

La seconde affaire judiciaire concerne la plainte déposée par la Commission fédérale des banques contre Julio Muñoz et Hermann Hug en avril 1965. À l'issue d'une incarcération d'une demi-douzaine de jours, les deux accusés avaient été libérés sous caution. En août, une contre-attaque avait même été lancée par Hug sous la forme d'une plainte contre les cinq membres de la Commission fédérale des banques pour dénonciation calomnieuse. Cette procédure n'aboutira à rien, puisque le DFJP estime en octobre 1966 que la plainte n'est pas fondée, une décision confirmée par le Tribunal fédéral à la suite d'un

180 AFB, E6Ioo(B-oI), 1980/49, vol. 67, dossier Ermittlungsverfahren gegen Max Hommel, Rapport du DFFD au CF, 22.02.1966.

181 AFB, E6Ioo(B-oI), 1980/49, vol. 67, dossier Ermittlungsverfahren gegen Max Hommel, Aktennotiz Angelegenheit Hommel, gew. Präsident der Bankenkommission, signé Markus Redli, I8.II.1965.

182 Daniel E. Margot, «Enterrement par négligence», Gazette de Lausanne, 27.0I.1969. 
recours de Hug. Quant au sort de la plainte initiale, portée elle par la CFB contre Muńoz et Hug, elle ressemble tout d'abord à un chemin de croix. Pendant 16 mois, tribunaux genevois et zurichois se rejettent mutuellement la compétence pour le traitement de l'affaire. En septembre 1966, le Tribunal fédéral tranche et c'est au Palais de Justice de Genève que revient la "patate chaude ». En mai 1967, la CFB apprend que l'instruction va bientôt commencer sous la direction du juge d'instruction Schmidt. Ce dernier étant ensuite nommé au Tribunal de première instance, tous ces dossiers sont transmis à un autre magistrat, le juge Balland ${ }^{183}$. La procédure piétine également à cause de l'attitude de Muñoz, qui, réfugié en Espagne, refuse de répondre aux convocations de la justice genevoise; la justice espagnole refusant de son côté la venue d'une commission rogatoire pour interroger le prévenu à Barcelone. En août 1974, l'affaire se trouve toujours " dans un état plus que stationnaire » ${ }^{184}$. À l'été 1975, la procédure d'instruction a tellement trâné que les délits sont presque tous prescrits. C'est en décembre 1978, treize après le dépôt de la plainte, que le procureur genevois décide de classer l'affaire. Après des démêlés avec la justice espagnole en 1985, Julio Muñoz prend cette fois le chemin inverse et vient se réfugier dans un palace de Bad Ragaz, où il décède en I99I $^{185}$. Toutes les démarches visant à obtenir un règlement judiciaire du scandale Muñoz-Hommel échouent. Il n'y aura pas d'éclaircissement de la justice sur un épisode que tout le monde, mis à part les quelques créanciers lésés, souhaite oublier.

Du côté de la Commission fédérale des banques, la destitution de Hommel le 4 juin 1965 provoque un choc important et crée surtout un vide à la tête de l'institution. Le vice-président et conseiller aux États Peter Müller évoque alors "la plus grande déception de sa vie » ${ }^{186}$. Le Département des finances et des douanes doit rapidement trouver un remplaçant pour Hommel. Comme Roger Bonvin l'annonce aux membres restants de la CFB, le Conseil fédéral hésite même à nommer un "commissaire " qui agirait à titre provisoire pour remettre de l'ordre dans l'institution. Plusieurs critères sont retenus pour dénicher la perle rare : l'homme recherché doit disposer de solides connaissances du monde bancaire, si possible être juriste, être libre de liens économiques, et finalement ne pas être d'orientation catholique-conservateur (car ce parti est déjà représenté par le vice-président Peter Müller) ${ }^{187}$. Deux candidats sont retenus: Otto K. Kaufmann (1914-1999), recteur de la haute école de SaintGall, et le radical Hans Streuli (I892-1970), ancien conseiller fédéral en charge des finances. C'est finalement l'ancien homme d'État zurichois qui accepte le mandat de président. Le 28 juin 1965, il est nommé par le Conseil fédéral et entre immédiatement en fonction. La nomination d'un homme âgé de 73 ans

183 AFB, E6521B, 2008/195, vol. 20, Notes de Duperrex «Plaintes contre Munoz, Hug et consorts ", 29.10.1969.

184 AFB, E6520(B), 1980/39, vol. 18, PV CFB, I2.08.1974, p. 240.

185 Muñoz, op. cit., 2003, p. 293-305.

186 AFB, E6520(B), 1980/39, vol. I6, PV CFB, 04.06.1965, p. 136.

187 AFB, E6roo(B-oI), I980/49, vol. 67, Lettre de Roger Bonvin (DFFD) au CF, 25.06.1965. 
est dès le départ considérée comme une solution intérimaire. L'ASB s'inquiète de voir le Conseil fédéral gesticuler ainsi et se montrer aussi impressionné par les événements récents : «Nous devons pour notre part insister pour qu'aucune réaction hâtive ne se produise. La Commission des banques doit absolument rester intacte dans sa fonction. " ${ }^{188}$

À l'échelon de la politique fédérale, l'affaire provoque encore d'autres remous. Dans la matinée du vendredi 4 juin 1965 , le Conseil fédéral avait en effet décidé de publier le communiqué de presse suivant:

Le Conseil fédéral, en connexion avec la demande de sursis présentée par la Banque suisse d'épargne et de crédit S.A., et par la Banque genevoise de commerce et de crédit, a eu connaissance de faits qui permettent de soupçonner que le président de la Commission fédérale des banques aurait violé les devoirs de sa charge. Il a, par conséquent, suspendu M. Max Hommel de ses fonctions avec effet immédiat et a chargé le ministère public fédéral de procéder aux enquêtes nécessaires ${ }^{189}$.

Ce communiqué de presse provoque le dépôt coup sur coup de pas moins de quatre interventions parlementaires le 9 et ro juin. Il s'agit de la petite question de Fritz Waldner (PSS, BL), de l'interpellation Werner Schmid (AdI, $\mathrm{ZH}$ ), de la petite question Jean Vincent (Parti du Travail, GE), et de la petite question Fritz Blatti (PRD, BE). Ce n'est qu'un an plus tard que le Conseil fédéral fournira des réponses à toutes ces questions, qui demandaient globalement des éclaircissements sur les motifs qui ont incité le gouvernement à suspendre Hommel de ses fonctions. La réponse n'entre pas dans les détails, et indique seulement d'une part qu'une enquête judiciaire cantonale est en cours, d'autre part qu'une révision de la loi sur les banques est à nouveau étudiée ${ }^{190}$. Fournie près d'un an après la mise à jour des éléments sulfureux, la réplique gouvernementale n'intéresse alors plus vraiment les interpellateurs.

Les retombées politiques immédiates, de même que les conséquences judiciaires à plus long terme, sont donc relativement maigres. Comment faut-il comprendre que l'indignation publique et la couverture médiatique de l'affaire retombent si rapidement? Le rachat rapide de la banque saint-galloise par la Société de Banque Suisse joue ici un rôle essentiel. Avec ces treize succursales réparties sur l'ensemble du pays, une SSKB à l'agonie pendant plusieurs mois aurait offert un potentiel de publicité nuisible considérable. La reprise par la SBS, en empêchant des pertes pour les déposants et des licenciements pour les

188 AASB, Procès-verbaux du Conseil d'administration de l'ASB, $257^{\mathrm{e}}$ séance, 23.06.1965, p. 22. Alfred E. Sarasin.

189 Le texte allemand est cité le jour même dans les procès-verbaux de la CFB (AFB, E6520(B), 1980/39, vol. I6, PV CFB, 04.06.1965, p. I34), le texte français reproduit ici est retranscrit dans un article du Journal de Genève: G.P., "Péripéties inattendue. Le Conseil fédéral suspend de ses fonctions le président de la Commission fédérale des banques ", Journal de Genève, 05-06-07.06.1965.

190 Procès-verbaux de l'Assemblée fédérale, Conseil national, session ordinaire d'été, 07.06.1966, p. 43-50. 
employés, a surtout permis d'éviter un déballage public néfaste à la place bancaire suisse. Quant à la légitimité de l'autorité de surveillance bancaire, directement impliquée dans le scandale, elle n'est en fait que peu atteinte. L'attitude des autorités gouvernementales et des membres restants de la CFB a consisté à présenter la compromission de Max Hommel comme un malheureux cas individuel. Des circonstances particulières et uniques auraient permis cette défaillance personnelle. Les auditions résultant de l'enquête établissent clairement la volonté des autres membres de la Commission de se distancier de leur ancien président déchu, pour ne pas laisser naitre des soupçons de complicité. La décision du Conseil fédéral consistant à simplement nommer un remplaçant en la personne de Hans Streuli, plutôt que d'ordonner une enquête indépendante sur le fonctionnement de l'organe incriminé, va dans le même sens ${ }^{191}$. Le système d'un contrôle étatique des banques par une section administrative minimale et dirigée par des non-professionnels n'est pas réellement remis en question. L'incident de parcours regrettable de l'affaire MuñozHommel devait être surmonté rapidement.

Pourtant, ce scandale met à jour de graves dysfonctionnements. Il avait été possible que, pendant plus d'un an et demi, le président de la Commission fédérale des banques soit rémunéré par un homme que le personnel diplomatique de la Confédération surnommait le "pirate barcelonais» "192. La situation professionnelle de Max Hommel, qui, à plein temps ou presque, dirigeait un bureau fiduciaire, est cruciale dans cette affaire. Cette configuration avait non seulement facilité le cas de corruption passive, mais elle l'avait rendu strictement légal. Du moment qu'ils n'empiétaient pas sur son jugement en tant que président de la $\mathrm{CFB}$, les mandats reçus par Hommel en tant que conseiller fiduciaire privé étaient parfaitement admissibles. D'ailleurs, l'enquête du Ministère public de la Confédération révèle qu'il ne s'agit pas d'un cas unique. À trois occasions, en 1963 déjà, Hommel avait adopté une attitude qui pourrait être problématique. Il avait d'une part joué un rôle de médiateur rémunéré dans un conflit opposant les actionnaires de la Handels- und Gewerbebank Liestal. D'autre part, fin novembre 1963, Hommel avait favorisé la création de la Banque J. F. Paravicini à Berne, dont un des initiateurs n'était autre que son proche collaborateur à la fiduciaire le Dr. Fröhlich. Enfin, en 1964, il participe

191 Rappelons que, quelques mois plus tôt, en juin 1964, la première commission d'enquête parlementaire de l'histoire de la Confédération avait été créée dans le cadre de l'affaire des Mirages. Il s'agissait là d'une investigation sur les dysfonctionnements au sein du Département militaire à l'occasion d'un surcoût dans l'achat d'une centaine d'avions de combat. Cf. Paolo Urio, L'affaire des mirages : décision administrative et contrôle parlementaire, Genève : Éditions Médecine et Hygiène, 1972 ; Manuel Klaus, «Der Bundesrat als kollektive Skandalfigur während des Kalten Kriegs?», Traverse, vol. 22, n 3 , 2015, p. IO2-II4.

192 L'expression est employée par Mario Fumasoli, ambassadeur de Suisse à Madrid, dans une lettre à la Division des affaires politiques du DPF du 02.II.1963. Fumasoli y rapporte une conversation "extrêmement confidentielle " tenue avec le directeur général du Crédit Suisse, E. Reinhardt, qui cherche à racheter à Muñoz ses actions de la SSKB. AFB, E200IE, 1978/84, vol. 932, dossier $2704^{*}$. 
activement à la discussion de la CFB sur la soumission d'une nouvelle société financière à Lausanne, la Compagnie financière et de crédit $\mathrm{SA}$, dont le dirigeant n'est autre que son ami directeur de la BCV, Alfred Gisling (1904198I), et dont il rejoindra le conseil d'administration quelques semaines plus tard. Autrement dit, l'implication de Hommel dans le cadre de l'affaire Muñoz atteint des proportions importantes, mais elle s'intègre dans un système qui favorise l'apparition de nombreux conflits d'intérêts. La position de président de la CFB à temps partiel est ici au cœur du problème. Il est d'autant plus remarquable que la révision de la loi fédérale sur les banques de I97I n'entraîne aucune modification dans l'organisation et la direction de l'autorité de surveillance.

En outre, cette affaire révèle également la facilité avec laquelle le président de l'autorité de surveillance a pu influencer de manière décisive le jugement et les décisions de ses collègues. L'atmosphère collégiale et le caractère souvent routinier des décisions prises ont encouragé la manipulation par Hommel des autres membres de la CFB. La suspicion croissante des deux uniques employés du secrétariat s'est longtemps heurtée à une incompréhension chez les membres de la commission. La structure extrêmement réduite de l'institution a contribué à la rendre propice à l'influence prépondérante de son président. Comme le note en juin 1965 avec perspicacité le journaliste de l'hebdomadaire libéral londonien The Economist: "Switzerland's latest banking rumpus has shown once again that loose federalism and decentralisation of power are not always the best protection of the citizen's rights. » ${ }^{193}$

193 [s.n.], «Swiss Banking. Gnomes a-Flutter», The Economist, I2.06.1965. 
广

N

$\stackrel{\circ}{\circ}$

(1)

.

2

2

(a) 


\section{CHAPITRE IX}

\section{LE CHEMIN SINUEUX VERS LA RÉVISION DE LA LOI SUR LES BANQUES}

(1965-1971)

La première moitié des années 1960 a vu apparaître certaines tentatives de réformer le cadre réglementaire des activités bancaires. Mais celles-ci se heurtent systématiquement à la résistance des milieux bancaires, qui craignent toute discussion publique et politique de la loi fédérale sur les banques. En juillet 196I, le Département fédéral des finances de Jean Bourgknecht arrive encore à la conclusion qu'une révision de cette législation ne s'impose aucunement. L'affaire Muñoz-Hommel qui éclate au printemps 1965 marque cependant un tournant majeur. La crédibilité de l'autorité de surveillance des banques est sérieusement entachée et le gouvernement fédéral décide de réexaminer la nécessité de réformer le système de contrôle bancaire. Même si les autorités s'en défendront a posteriori, c'est bien une obscure affaire de corruption d'un superviseur fédéral par un financier catalan - et les faillites bancaires associées qui donne le coup d'envoi à la procédure de réforme de la loi sur les banques qui aboutira six ans plus tard dans la révision de mars I97I. Dans ce chapitre, nous allons examiner les différentes étapes qui jalonnent le parcours qui débouche sur l'adoption parlementaire de la révision législative, dans la mesure où ce processus se révèle être plus complexe que la situation initiale de 1965-1966 ne pouvait le laisser croire. Les différents acteurs impliqués ont des points de vue divergents sur la direction que doit prendre la réforme, et sur les priorités d'un tel projet. La question des banques étrangères, secondaire aux yeux de la CFB, mais essentielle pour l'ASB et la BNS, sera traitée prioritairement et fera même l'objet d'un décret gouvernemental particulier et anticipé. Au sein de l'autorité de surveillance bancaire, on constate aussi un changement d'approche, puisque ses membres jouent dès l'été 1965 un rôle moteur dans l'avancement des projets de révision de la réglementation bancaire. 


\section{IX.1. L'ÜBERFREMDUNG DE LA PLACE BANCAIRE SUISSE ET LA LUTTE CONTRE LES BANQUES ÉTRANGËRES}

(1965-1969)

En plus des conséquences judiciaires et politiques mentionnées à la fin du chapitre précédent, le scandale Muñoz-Hommel conduit également à un renforcement des critiques contre les banques étrangères actives en Suisse ${ }^{1}$. Pour une partie des observateurs, et en particulier pour l'Association suisse des banquiers et la Banque nationale suisse, les effondrements de la BGCC et de la SSKB constituent de parfaits exemples de l'utilisation abusive de la place bancaire suisse par des capitalistes étrangers malveillants. Au sein du Conseil d'administration de l'ASB, l'affaire des banques Muñoz relance le débat sur deux questions: le "danger que des raisons sociales à consonance nationale soient abusivement utilisées par des étrangers » d'une part, et « la possibilité de mettre un terme à l'influence croissante de l'étranger sur le secteur financier suisse " d'autre part ${ }^{2}$. La première de ces propositions avait déjà été étudiée de près par la Commission fédérale des banques dans sa gestion des banques Muñoz. Etait-il admissible que des banques dominées par un financier espagnol s'appellent encore Banque Suisse d'Épargne et de Crédit et Banque Genevoise de Commerce et de Crédit? En mars 1964, la CFB avait entrepris des démarches auprès de l'Office fédéral du registre du commerce pour lui signaler que les deux banques en question étaient contrôlées par des étrangers et contrevenaient ainsi au principe de la véracité des raisons sociales ${ }^{3}$. Mais cette intervention reste sans succès, car aucune instance externe n'est capable de stipuler clairement que les banques sont sous domination étrangère. Il n'en reste pas moins que le rachat discret, puis le maintien de noms d'entreprises trompeurs par un groupe étranger a grandement contribué à heurter le monde bancaire suisse dans le scandale Muñoz. Dans la presse libérale genevoise, cette forme d'imposture est également dénoncée, avec certains relents xénophobes: «L'expérience prouve, une fois de plus, que ce sont les entreprises honnêtes qui pâtissent des mésaventures que font courir certains rastaquères [sic] à l'épargne suisse, bien plus c'est le renom du pays qui en subit le préjudice. $»^{4}$ La Neue Zürcher Zeitung tire un bilan similaire. Pour le grand quotidien zurichois, toute cette affaire relance l'examen de la « question d'un renforcement des conditions nécessaires à l'établissement de nouvelles banques, en tout cas, s'il s'agit d'étrangers peu familiers de la situation économique suisse. Il est inacceptable que la réputation de solidité du secteur bancaire suisse soit minée par le biais de

1 Certains des éléments que nous abordons ici ont déjà été analysés dans la publication suivante: Giddey, art. cit., in Aspey, et al. (éd.), op. cit., 2013.

2 AASB, Procès-verbaux du Conseil d'administration de l'ASB, $257^{\mathrm{e}}$ séance, 23.06.1965, p. I8-2I.

3 AFB, E6520(B), 1980/39, vol. I6, PV CFB, 05.03.1964, p. 74-75.

4 G.P., «Une décision attendue. M. Hans Streuli, ancien président de la Confédération, à la tête de la Commission fédérale des banques ", Journal de Genève, 29.06.1965. 
fondations ou de transactions douteuses comme elles ont eu lieu à Saint-Gall et à Genève "s.

L'éclatement du scandale Muñoz apporte donc immanquablement de l'eau au moulin des voix critiques à l'établissement et à l'expansion des banques étrangères en Suisse. Ce rôle de catalyseur apparait clairement. Entre 1956 et I965, les autorités fédérales et monétaires faisaient essentiellement recours à des moyens détournés pour contrer le mouvement des banques étrangères (cf. chapitre VIII.2.I.). Avec le scandale Muñoz, la lutte contre les banques dominées par des capitaux internationaux entre dans une seconde phase. Dans la foulée des événements du printemps 1965, l'Association suisse des banquiers décide de constituer un comité spécial chargé de discuter l'introduction d'un système de concessions pour l'établissement de nouvelles banques étrangères ${ }^{6}$. En janvier 1966, une petite délégation d'une dizaine de banquiers discute de la question. Il apparait rapidement que le problème de la limitation de l'expansion des banques étrangères pose un dilemme fondamental aux banquiers. Dans quelle mesure les avantages qui pourraient potentiellement être gagnés dans une restriction légale des conditions d'ouverture dépassent-ils les risques liés à une discussion parlementaire de la réglementation bancaire? Le secrétaire de l'ASB Max Oetterli insiste sur ce point : «Une révision de la loi sur les banques dans le sens d'une pratique d'autorisation plus stricte revient à un numéro d'équilibrisme, dans lequel persiste le risque de basculer vers un interventionnisme indésirable. ${ }^{7}$ Une très grande prudence est donc de mise pour le gotha bancaire. Pourtant, l'ASB identifie trois formes d'inconvénients liés à une prolifération des banques étrangères. Premièrement, elle renforcerait la concurrence et complique la répartition des risques; partant, elle augmenterait les menaces de faillites bancaires. Deuxièmement, le fait que les banques étrangères ne se conforment pas aux "usages traditionnels suisses", et en particulier la publicité tapageuse qu'elles font parfois dans leurs pays d'origine, en vantant les mérites du secret bancaire suisse, serait de nature à entacher la réputation internationale de tout le secteur bancaire. Troisièmement, l'activité des banques étrangères consistant à attirer massivement en Suisse des fonds internationaux et à les convertir en francs suisses nuirait à la conduite de la politique monétaire de la BNS. Pour contrer ces phénomènes jugés indésirables, les banquiers suisses se déclarent prêts à collaborer plus intensivement avec les autorités, et à envisager, avec cependant une grande réticence, des mesures législatives. La position de Ludwig Butscher, directeur de la Banque cantonale de Bâle, résume bien ce raisonnement:

Je soutiens toute mesure visant à empêcher les fondations de banques étrangères, à moins que cela n'implique une intervention supplémentaire

\footnotetext{
[s.n.], "Bemerkungen zur Affäre der Spar- und Kreditbank», NZZ, $\mathrm{n}^{\circ}$ 2846, 03.07.1965. AASB, Procès-verbaux du Conseil d'administration de l'ASB, $258^{\mathrm{e}}$ séance, 03.09.1965, p. 16. AASB, Protokoll der Expertenkommission betr. Erschwerung der Gründung neuer Banken, 28.or.1966, p. 4, annexé au PV de la 26I e séance du CdA de l'ASB du 09.03.1966.
} 
de l'État. Comme cela ne semble apparemment pas possible, il s'agit alors de choisir entre deux maux. Bien que je considère l'admission de banques étrangères comme peu réjouissante, je juge ses effets moins négatifs que ceux d'une intervention étatique plus étendue dans le secteur bancaire ${ }^{8}$.

Parmi les mesures envisagées par l'ASB pour contrer l'apparition de nouvelles banques étrangères, l'introduction d'un système de concession est au cœur de la réflexion. Plusieurs critères, comme un certificat de compétence professionnelle et de bonne conduite du requérant, la présence d'un capital minimal, voire l'établissement d'une clause du besoin, sont évoqués. Mais ces entraves sont soit considérées comme inefficaces, soit, dans le cas de la clause du besoin, représenteraient une grave atteinte au principe de liberté de commerce et d'industrie à la base de la vie économique. Pour une majorité de banquiers, le jeu n'en vaut pas la chandelle. L'ASB décide alors de suivre le dossier de manière passive.

En plus du scandale Muñoz-Hommel, une seconde affaire - certes moins retentissante - contribue à tendre l'atmosphère autour de la question des banques étrangères. Il s'agit du projet de l'établissement en Suisse d'une banque soviétique, dont les guichets ouvrent à Zurich en octobre $1966^{9}$. Dès mai 1965 en effet, les représentants soviétiques déposent une demande d'ouverture d'une succursale commune de la Gosbank (banque centrale) et de la Vneshtorgbank (banque de commerce extérieur). Face aux conditions d'ouverture plus difficiles pour les succursales que pour les banques formellement indépendantes, les Soviétiques optent, dans un deuxième temps, pour la création d'une nouvelle banque de droit suisse. De ce fait, la clause de réciprocité, qui aurait voulu qu'une banque suisse puisse ouvrir une succursale en URSS, ne s'applique plus. Les interlocuteurs helvétiques des négociations avec les Soviétiques, essentiellement des représentants du Département politique fédéral, auxquels s'ajoutent ceux du DFFD, de la CFB et de la BNS, tentent alors malgré tout de dissuader les initiateurs de mener à bien leur projet. Alors qu'aucune objection ne pouvait être émise du point de vue juridique, les autorités cherchent à freiner l'établissement de deux façons. D'une part, en employant une tactique dilatoire dans le traitement administratif de la demande, d'autre part, en se montrant extrêmement restrictif dans l'octroi de permis de séjour pour les collaborateurs étrangers. En janvier I966, les Soviétiques perdent patience et interviennent une nouvelle fois. C'est alors le Département de justice et police, dirigé par le conservateur Ludwig von Moos (I9I0-1990), qui oppose encore une forte résistance. Dans un véritable réquisitoire adressé au Conseil fédéral, le DFJP énumère de nombreuses

8 AASB, Protokoll der Expertenkommission betr. Erschwerung der Gründung neuer Banken, 28.0I.1966, p. 7, annexé au PV de la 26 $\mathrm{I}^{\mathrm{e}}$ séance du CdA de l'ASB du 09.03.1966.

9 Cf. aussi : Robert Husbands, « Soviet Banks Abroad : Legal and Economic Perspectives : 1917 to 1990 ", Thèse de doctorat ès sciences politiques, Institut universitaires de Hautes Études Internationales, Université de Genève, I996, p. 265-269; Loepfe, op. cit., 20II, p. $20 \mathrm{I}-203$. 
réserves contre un tel projet ${ }^{10}:$ une grande partie de la population suisse ne comprendrait et n'approuverait pas cette création, la situation tendue d'Überfremdung du marché du travail ne justifierait pas l'arrivée de travailleurs étrangers supplémentaires, la banque constituerait un point d'appui additionnel utilisé par les Soviétiques pour développer leurs activités subversives, elle servirait à financer le réseau d'agents secrets en Occident, ainsi que la propagande des partis communistes occidentaux, enfin le ministère public fédéral n'aurait pas les moyens de surveiller efficacement cette nouvelle base du communisme international. Mais les considérations juridiques émises par le DPF, ainsi que les perspectives de favoriser les relations commerciales avec le Bloc de l'Est, prennent le dessus sur l'argumentation de géopolitique anticommuniste de von Moos. En mars 1966, le Conseil fédéral donne son accord de principe à l'ouverture. Comme l'indique Max Oetterli, secrétaire de l'ASB, se faisant le relais de l'opinion dominante au DPF : «on peut difficilement refuser aux Russes ce que l'on doit accorder aux Arabes ou à d'autres personnes exotiques ${ }^{11}$. Après avoir également fait part de sa réticence et de son impuissance juridique contre le projet, la Commission fédérale des banques approuve également la requête à l'été $1966^{12}$. La Wozchod Handelsbank AG ouvre donc ses guichets en octobre 1966 à Zurich ${ }^{13}$. Plutôt que le financement du commerce Est-Ouest ou d'obscurs réseaux politiques, elle sera essentiellement active sur le marché de l'or, et servira à vendre l'or soviétique sur les marchés internationaux ${ }^{14}$.

Dans la presse, ainsi que dans les milieux bancaires, l'ouverture d'une banque soviétique à Zurich représente cependant un exemple supplémentaire du trop grand laxisme de la réglementation bancaire suisse quant aux conditions d'ouverture d'un établissement. Si le cas est singulier et polémique en raison des tensions liées à la guerre froide, l'ouverture d'une nouvelle banque étrangère n'est pas en soi un scoop. En effet, depuis le début des années I960, l'accélération des demandes se poursuit. Quatre nouvelles banques étrangères voient le jour en 1960, six en 1961, trois en 1962, six en 1963, quatre en 1964, quatre en $1965^{15}$. Parmi ces nouveaux arrivants, des poids lourds comme l'Algemene Bank Nederland, la Dow Banking Corporation, ou encore la Nordfinanz-Bank - filiale de quatre banques scandinaves. Les arrivées prochaines de la Bank of America et de la Chase Manhattan Bank sont déjà

10 «Bericht zur Frage der Gründung einer Sowjetbank » du DFJP (signé Ludwig von Moos) au Conseil fédéral, 26.or.1966, in Zala, Perrenoud (éd.), op. cit., 2011, doc. I26, p. 282-286. Également disponible en ligne: http://dodis.ch/31034 (consulté le I0.I2.20I8).

11 AASB, Procès-verbaux du Conseil d'administration de l'ASB, $259^{\mathrm{e}}$ séance, 08.12.1965, p. 30.

12 AFB, E6520(B), 1980/39, vol. 17, PV CFB, 31.05.1966, p. I05-113; 28.06.1966, p. 137-138.

13 [s.n.], "La Banque Russe ouvre ses guichets à Zurich», Gazette de Lausanne, oI.Io.I966. Font partie de son conseil d'administration: Albert Nikolaevitch Belitschenko, Louis Devaud et Jean Graber. La direction est composée de Hans Adam, Friedrich Giger, Eduard Gostew, Michail Samsonow.

15 Meyer, op. cit., 1975, p. 94-96. 
discutées en janvier $1966^{16}$. Cela soulève bien des inquiétudes. Le banquier privé Jacques Auguste Darier (1916-2005), particulièrement concerné en raison du nombre d'instituts étrangers sur la place genevoise, le signale à ses collègues de l'ASB : «Le problème de l'envahissement par les banques étrangères ne date pas d'aujourd'hui. Les banques françaises, américaines et de l'Orient, prochainement de la Russie et peut-être plus tard de la Chine, cherchent à s'implanter en Suisse et ont une mentalité tout à fait autre que la nôtre. ${ }^{17}$ Au-delà de la rhétorique xénophobe, il est difficile de déterminer ce qu'entend le financier genevois par la mentalité des banquiers suisses. Fait-il référence à certains clichés culturels qui se forgent à l'époque, selon lesquels les financiers suisses - bientôt affublés du sobriquet gnomes de Zurich - seraient compétents, sérieux, ternes, taciturnes et cultivent la discrétion ? 18

Quelles qu'en soient les motivations exactes ${ }^{19}$, la multiplication des établissements étrangers en Suisse suscite une forte réaction de la part des autorités fédérales, elle-même encouragée par les dirigeants bancaires et la BNS. A l'été 1966, une première mobilisation s'organise. En juillet 1966, le Département fédéral des finances et des douanes demande à la $\mathrm{CFB}$ de mener une enquête, en collaboration avec la BNS et l'ASB, pour mesurer le degré d'influence étrangère dans le monde bancaire suisse. L'autorité de surveillance décline cette requête, estimant qu'elle n'entre pas dans ses compétences légales et qu'elle constituerait une violation de son devoir de confidentialité. Mais le DFFD, très déçu par le refus initial, insiste ${ }^{20}$. C'est donc prioritairement par le biais de l'ASB que l'enquête sera réalisée. Au cours de l'été 1967 , le secrétariat de la fâtière des banquiers prend contact avec certains relais privilégiés sur chaque place financière importante : le Crédit Suisse à Zurich, la Société de Banque Suisse à Bâle, la banque privée Lombard, Odier \& Cie à Genève, et la Banco dello Stato del Cantone Ticino, c'est-à-dire la banque cantonale du Tessin, à Bellinzone. Les réponses reçues dans ce cadre à titre confidentiel fournissent de précieux renseignements sur le degré de "pénétration étrangère" des quatre places bancaires principales ${ }^{21}$. Les informateurs de premier rang recensent alors

16 AASB, Protokoll der Expertenkommission betr. Erschwerung der Gründung neuer Banken, 28.0I.1966, p. 2, annexé au PV de la 26r ${ }^{\mathrm{e}}$ séance du CdA de l'ASB du 09.03.1966.

17 AASB, Procès-verbaux du Conseil d'administration de l'ASB, 26I ${ }^{\mathrm{e}}$ séance, 09.03.1966, p. 16.

18 Sur les stéréoptypes culturels et l'image véhiculée par les banquiers suisses dans la culture populaire : Sébastien Guex, Gianni Haver, «James Bond contre - ou pour? - les gnomes de Zurich. L'image de la place financière suisse dans la série 007 ", in Françoise Hache-Bissette, Fabien Boully, Vincent Chenille (éd.), James Bond (2)oo7. Anatomie d'un mythe populaire, Paris: Belin, 2007, p. 330-338.

19 Sur les différentes raisons de l'implantation en Suisse de banques étrangères dans les années I950 et 1960, voir Giddey, art. cit., in Aspey, et al. (éd.), op. cit., 2013 et Giddey, op. cit., 2017, p. 449-452.

20 AFB, E6roo(B-or), 1980/49, vol. 57, Lettre du DFFD (signé Roger Bonvin) à la CFB, I5.09.1966.

21 AASB, J.4 Bundesgesetz über die Banken und Sparkassen (Bankengesetz) Jan. 1967 - Sept. 1969, Lettre de Marcel Odier et Henry Huguenin du 28.07.1967, lettre du CS du 08.08.1967, lettre de la SBS du II.08.1967, lettre de la Banca dello Stato du 08.09.1967. 
34 banques étrangères à Genève, 30 à Zurich, I9 au Tessin et 9 à Bâle. La missive des banquiers genevois révèle un ton particulièrement courroucé contre les banques étrangères:

Nos milieux - sensibilisés peut-être par quelques expériences fort fâcheuses faites ces dernières années avec des financiers étrangers et par un cas récent où un groupe étranger a abusé de façon scandaleuse de l'hospitalité accordée par notre Canton - sont très conscients de l'«Ueberfremdung " qui a résulté de la pénétration étrangère des années 'so et '6o. Celle-ci s'est traduite non seulement par une concurrence accrue - ce qui n'aurait rien de mauvais en soi -, mais aussi entre autres par une pénurie extrême de personnel bancaire qualifié et par une hausse inflationniste des salaires, hausse résultant à la fois de ladite pénurie et de la surenchère pratiquée par beaucoup de nouveaux venus parmi les établissements financiers ${ }^{22}$.

On constate ici que des raisons de concurrence, qui accentuent corollairement les coûts du personnel, sont également à l'origine de la réaction des milieux bancaires helvétiques à l'égard de l'établissement en Suisse de banques étrangères. En ce sens, cette citation vient confirmer les soupçons exprimés par Daniel Bodmer en décembre 1959, qui évoquait une «jalousie inavouée » pour comprendre l'opposition que rencontrait les banques étrangères en Suisse ${ }^{23}$. La concurrence exercée par ces établissements joue certainement un rôle essentiel.

Parallèlement à cette enquête, les représentants de l'ASB, en collaboration avec le DFFD et la BNS, mais sans participation de la CFB, envisagent déjà de potentielles mesures à prendre contre les banques étrangères dans l'éventualité d'une révision de la loi sur les banques. Il s'agirait d'obliger les banques avec une participation étrangère dominante à annoncer cette situation à la $\mathrm{CFB}$, qui serait alors en mesure d'exiger des critères plus stricts pour autoriser l'ouverture $^{24}$. L'embryon de ce qui deviendra l'arrêté fédéral urgent du 2I mars 1969 sur les banques étrangères prend forme au cours de ces discussions informelles.

Si ces pourparlers sont engagés en l'absence de la Commission fédérale des banques, c'est surtout en raison d'une divergence de vues entre la CFB d'une part et l'ASB, le DFFD et la BNS d'autre part sur les points prioritaires dans le cadre d'une révision de la loi sur les banques. En effet, entre 1965 et 1967, un écart se creuse entre ces différentes instances. Alors que pour l'ASB, la BNS et l'Administration fédérale des finances l'endiguement de l'expansion des banques étrangères est considéré - pour diverses raisons - comme un enjeu majeur, la CFB estime au contraire que le renforcement de ses propres moyens d'action et de l'arsenal disciplinaire de la loi sur les banques est prépondérant. Cette position des superviseurs constitue par ailleurs, comme nous le verrons,

AASB, J.4 Bundesgesetz über die Banken und Sparkassen (Bankengesetz) Jan. 1967 - Sept. I969, Lettre de Marcel Odier et Henry Huguenin à l'ASB, 28.07.1967. 
une rupture par rapport aux convictions qui dominaient avant 1965. En faisant de la restriction des banques étrangères son cheval de bataille, l'Association suisse des banquiers parvient donc aussi à discréditer l'avant-projet de révision de la réglementation bancaire transmis au DFFD par la CFB en août 1966. Progressivement et insidieusement, la focale prioritaire des autorités fédérales se déplace. En mai 1968, le secrétariat de l'autorité de surveillance constate amèrement ce glissement, en remarquant également comment l'intitulé de la correspondance avec l'Administration des finances a évolué ${ }^{25}$. Ce qui était encore traité en juillet 1966 sous le titre «banques étrangères en Suisse» figure une année plus tard sous «révision de la loi sur les banques/degré d'influence étrangère ». Nous y reviendrons plus bas.

Au printemps 1968 a donc lieu la première réunion d'un petit groupe informel ayant pour objet la révision de la loi sur les banques, et en particulier les mesures visant à compliquer la fondation de nouvelles banques étrangères sur le territoire helvétique. Rassemblé sous la direction de l'Administration fédérale des finances, le comité se compose d'Anton Blatter (1926-), Bernhard Müller (tous deux AFF), Hans Huber et Paul Ehrsam (tous deux BNS), Daniel Bodmer (CFB), Max Oetterli et Markus Lusser (tous deux ASB). Des projets écrits sont formulés par Ehrsam et Oetterli pour soumettre l'ouverture de nouvelles banques étrangères à une autorisation spéciale. En octobre 1968, toute l'affaire prend un tour plus urgent. La Commission fédérale des banques se plaint du nombre de requêtes en vue de nouvelles ouvertures encore en suspens. Jusqu'alors, elle a appliqué une tactique dilatoire pour décourager les initiateurs, en attendant que la révision de la loi sur les banques voie le jour. Mais elle craint de ne pas pouvoir résister assez longtemps, sans que cette politique d'obstruction ne se transforme en déni de justice. Au cours d'une réunion du groupe de travail informel, l'idée voit le jour de réaliser certains postulats de manière anticipée par le biais d'un arrêté fédéral urgent ${ }^{26}$. Cette solution transitoire est approuvée à l'unanimité. Relevons au passage que c'est sous l'égide de deux nouvelles personnalités que le processus connait ce coup d'accélérateur. Depuis octobre 1966, Riccardo Motta (1902-1976), fils de l'ancien conseiller fédéral catholique-conservateur et ancien directeur général de la BNS, préside la Commission fédérale des banques. À la tête du Département fédéral des finances et des douanes, c'est un autre tessinois, le radical Nello Celio (1914-1995) qui remplace Roger Bonvin en juillet 1968. Ce tandem italophone semble décisif dans l'aboutissement rapide de la mesure législative.

En quelques semaines, un texte est préparé par le groupe de travail. Le 23 octobre, le Conseil fédéral donne son accord pour soumettre au parlement, pendant la session de décembre, un arrêté fédéral urgent introduisant le régime de l'autorisation pour les banques étrangères. Le I3 novembre 1968, en toute

25 AFB, E6520(A), 1983/50, vol. 2, Revision Bankengesetz 1966-1971, Notiz für Herrn Bodmer de Hans Manz, or.05.1968.

26 AFB, E6520(A), I983/50, vol. I, Ausländische Banken 1959-1975, Aktennotiz über eine Besprechung vom 8. Oktober 1968. 
hâte, un projet d'arrêté fédéral, accompagné d'un message explicatif, est publié par le gouvernement ${ }^{27}$. Le 27 novembre, soit seulement sept semaines après que l'idée d'un arrêté fédéral est évoquée par un groupe de travail informel, une commission du Conseil des États se réunit pour délibérer sur le texte législatif. L'urgence du problème est à nouveau justifiée par le nombre de requêtes encore pendantes. Selon les chiffres publiés par le Conseil fédéral, alors que six autorisations ont été délivrées par la CFB en 1967 à des banques dominées par l'étranger et six autres durant les dix premiers mois de 1968, douze requêtes sont encore en suspens ${ }^{28}$. En plus de l'accumulation des requêtes, une seconde raison - confidentiellement avouée par Nello Celio à l'ASB - incite le gouvernement à agir ${ }^{29}$. Les banques centrales de la République Populaire de Hongrie et de la Chine Populaire cherchent en effet à imiter la Wozchod Bank et à installer une filiale en Suisse. Le Conseil fédéral entend également contrer cette expansion de la finance communiste.

Les critiques officielles du gouvernement suisse contre l'installation de nouvelles banques étrangères, formulées dans son message du I3 novembre 1968, sont de trois ordres. Il estime d'abord que leur présence et la publicité tapageuse auprès de la clientèle internationale amplifieraient les critiques contre le secret bancaire suisse. Deuxièmement, la «différence de mentalité » de ces nouveaux venus nécessiterait souvent l'intervention de la Commission fédérale de banques; les déposants suisses courraient des risques et la réputation de la place financière serait menacée. Il fustige enfin l'afflux de capitaux vers la Suisse qui est généré par ces banques; cette activité contrecarrerait directement la politique monétaire de la BNS en renforçant le statut de monnaie de réserve du franc suisse. L'Association suisse des banquiers apporte également son soutien au projet d'arrêté fédéral. Dans une lettre adressée directement aux onze membres de la commission ad hoc du Conseil des États, elle recommande l'approbation du texte. Les banques étrangères, qui représentent selon l'ASB un cinquième des banques en Suisse (une centaine d'entités sur cinq cents) et un dixième du bilan total de toutes les banques, «doivent se plier à nos règles du jeu et s'abstenir de tout ce qui pourrait nuire à la bonne réputation de nos banques, à notre système monétaire, aux intérêts de notre pays et de ses institutions ${ }^{30}$. Contribuant à présenter un front uni des autorités derrière le projet, la CFB appuie également l'arrêté fédéral. Son président Motta n’hésite pas à présenter des chiffres tendancieux devant la commission du Conseil des États. Il précise que 28 des 48 rapports de révision traités par la CFB en 1968

"Message du Conseil fédéral à l'Assemblée fédérale à l'appui d'un projet d'arrêté fédéral urgent instituant le régime du permis pour les banques en mains étrangères ( $\mathrm{Du}$ I3 novembre 1968) ", Feuille fédérale, I968, vol. 2, nº 48, p. 782-797. Ibid., p. 783. 
concernaient des banques en mains étrangères ${ }^{31}$. Ce qu'il omet d'indiquer, c'est que l'autorité de surveillance requiert systématiquement les rapports de révision pendant les premières années d'activité d'une nouvelle banque, pour évaluer ses opérations. Il est donc mathématiquement logique qu'une catégorie de banques qui connaît de nombreuses fondations soit surreprésentée dans les rapports de révision traités. Pour le dire autrement, l'analyse des rapports de révision d'une banque par la CFB n'implique pas nécessairement que l'établissement en question est en difficulté, il s'agit parfois simplement d'une entreprise récemment fondée.

Les délibérations parlementaires sur le projet se déroulent relativement rapidement, sans grands débats et dans une certaine indifférence médiatique. Le Conseil des États adopte le projet fin décembre 1968, la commission du Conseil national le discute en janvier 1969, et son plénum l'adopte début mars 1969. Après la procédure d'élimination des divergences entre les deux chambres, l'arrêté fédéral «instituant le régime du permis pour les banques en mains étrangères " est définitivement promulgué le 2I mars 1969 et entre en vigueur le $\mathrm{I}^{\text {er }}$ juillet ${ }^{32}$. Ce traitement rapide est facilité par le peu de soutien politique dont bénéficient les banques étrangères. Une opposition anonyme, cristallisée autour de l'avocat zurichois Manfred Kuhn, tente malgré tout de formuler une récrimination des mesures prévues, mais sans grand succès ${ }^{33}$. Ce noyau contestataire est rapidement désamorcé par l'ASB, qui mène de discrètes discussions avec la banque qui en était à l'origine ${ }^{34}$.

Le décret introduit des conditions d'ouverture de nouvelles banques plus sévères pour les banques sous domination étrangère. Celles-ci sont définies comme « les banques où la participation étrangère directe ou indirecte s'élève à plus de la moitié du capital social ou des voix ou qui sont dominées d'autre manière par des étrangers ${ }^{35}$. Il s'agit donc bien d'un régime discriminatoire, dans le sens où un fondateur étranger est soumis à des exigences plus strictes que son homologue de nationalité suisse ou au bénéfice d'un permis de séjour. Plus précisément, l'arrêté définit quatre conditions supplémentaires. Premièrement, l'État d'origine des fondateurs doit garantir la réciprocité à la création d'une banque suisse. Deuxièmement, la raison sociale prévue ne doit pas laisser présumer un caractère suisse. Troisièmement, la banque n'est pas autorisée à faire de la publicité intempestive en vantant les mérites de son siège suisse.

AFB, E6roo(B-ooI), 1980/49, vol. 6I, Procès-verbal de la séance de la commission du Conseil des États concernant l'Arrêté fédéral urgent instituant le régime du permis pour les banques en mains étrangères, 27.II.1968, p. I5.

32 "Arrêté fédéral instituant le régime du permis pour les banques en mains étrangères $(\mathrm{Du}$ 21 mars 1969)", Feuille fédérale, I969, vol. I, no I2, p. 625-628.

33 ABNS, I.3/1229, I31.25, Dringlicher Bundesbeschluss, Lettre de Manfred Kuhn aux membres du Parlement et à la presse, 25.II.I968.

34 AASB, Procès-verbaux du Conseil d'administration de l'ASB, 273 ${ }^{\mathrm{e}}$ séance, II.I2.I968, p. 24.

35 «Arrêté fédéral instituant le régime du permis pour les banques en mains étrangères ( $\mathrm{Du}$ 2I mars 1969)", Feuille fédérale, I969, vol. I, no I2, p. 625 (art. I, al. 2). 
Enfin, elle doit fournir à la Banque nationale suisse l'assurance qu'elle respectera «la politique suisse en matière monétaire et de crédit».

Notons que la troisième exigence vise directement la pratique consistant à se targuer des avantages offerts par le secret bancaire en vigueur en Suisse. Il s'agit pourtant d'un type de publicité également utilisé par les banques suisses. L'ASB doit même intervenir pour inciter ses membres à plus de modération dans le domaine. Après une première remontrance en juillet 1957, puis en juillet $1962^{36}$, la circulaire $\mathrm{n}^{\mathrm{o}} 358 \mathrm{o}$ de mars 1967 fait des recommandations spécifiques :

La plus grande retenue s'impose dans la publicité destinée à l'étranger. Il y a lieu de renoncer surtout à souligner les avantages particuliers qu'offre notre pays par exemple à vanter les possibilités du secret bancaire reconnu par la loi dans notre pays, l'institution des comptes numériques ou les conditions fiscales plus favorables que celle de pays étrangers ${ }^{37}$.

Autrement dit, ce que l'organisation cartellaire du monde bancaire helvétique peine à imposer à ses membres par la voie de la recommandation, les autorités fédérales le dictent aux banques étrangères sous la forme d'un arrêté.

Il faut encore souligner trois aspects de cet acte législatif, qui, malgré l'aridité des débats parlementaires, ont donné lieu à des discussions intensives. La première de ces questions est celle de la définition de ce qui constitue une «domination étrangère» sur une banque. À partir de quel degré de participation étrangère au capital (30\% ? $5 \mathrm{I} \%$ ?) une banque est-elle étrangère, et surtout comment attester cet état de fait lorsque l'actionnariat est dispersé? Ce problème juridique est très délicat pour une double raison. D'une part, les banquiers souhaitent avant tout éviter l'introduction obligatoire d'actions nominatives liées (Vinkulierte Namensaktien) ${ }^{38}$. Un tel système représenterait une forte entrave dans les opérations sur le marché des titres mobiliers, et les banques avaient récemment combattu de telles mesures, notamment contre le patronat industriel, en aboutissant à un gentlemen's agreement en $196 \mathrm{I}^{39}$. D'autre part, les banquiers craignent qu'en établissant une définition très large de la domination étrangère, certaines grandes banques suisses, dont le capital social est très dispersé, doivent révéler l'origine précise de leur actionnariat ${ }^{40}$. Pour contourner ces questions très sensibles, le décret prévoit une disposition qui

36 Une copie de la circulaire de l'ASB à ses membres du 9 juillet 1962 figure sur la base de données en ligne des Documents diplomatiques suisses: dodis.ch/30736 (consultée le I4.I2.2016).

37 Circulaire de l'ASB n ${ }^{\circ} 3580$ aux banques membres concernant les critiques étrangères contre les banques suisses, 09.03.1967, annexée au procès-verbal de la $270^{\mathrm{e}}$ séance du CdA de l'ASB. AASB, Procès-verbaux du Conseil d'administration de l'ASB, 03.04.1968.

38 Cf. AASB, Procès-verbaux du Conseil d'administration de l'ASB, $262^{\mathrm{e}}$ séance, I5.06.1966, p. 19.

39 Sur la Vinkulierung dans l'après-guerre: David, et al., op. cit., 2015, p. 176-200.

40 Ces inquiétudes sont formulées au sein de la CFB par Rudolf Pfenninger, ancien directeur général de la SBS. AFB, E6520(B), 1980/39, vol. 17, PV CFB, 23.10.1968, p. I69. 
oblige les banques répondant à la définition adoptée à s'annoncer elles-mêmes à la Commission fédérale des banques. L'omission de cette annonce devient punissable.

Le deuxième débat a trait à la clause qui exige des banques étrangères de ne pas choisir une raison sociale qui laisse présumer un caractère suisse. Cette protection de la Swissness, dont l'introduction est clairement en lien avec la reprise des banques genevoise et saint-galloise par Muñoz, suscite de fortes critiques de la part de l'industrie d'exportation helvétique. Plus précisément, ce sont des dirigeants de l'industrie chimique qui multiplient les démarches auprès de l'organisation faîtière de l'économie suisse, le Vorort, ainsi qu'auprès de la BNS, puis directement auprès du Conseil fédéral et des parlementaires, pour obtenir la suppression de cette disposition ${ }^{41}$. Le patronat du secteur chimique craint que cette disposition ne conduise à des mesures de rétorsion de la part de gouvernements étrangers, ou pire, qu'elle encourage les législateurs étrangers à édicter des mesures similaires de protectionnisme économique, qui forceraient les sociétés suisses à révéler leur développement international. Dans l'argumentaire de l'industrie d'exportation, cette restriction du choix de la raison sociale est même comparée à une étoile jaune, censée avoir un effet dissuasifi2 ${ }^{42}$. Finalement, la disposition est édulcorée : une banque étrangère ne doit pas explicitement affirmer son caractère allochtone dans sa raison sociale, mais seulement ne pas laisser présager un caractère suisse.

Troisièmement, la base constitutionnelle de cette intervention législative est vivement débattue. Il ne s'agit pas là d'un pur débat théorique par excès de juridisme. En fait, cette question de constitutionnalité surgit en raison des craintes des banquiers de péjorer leur position stratégique dans un autre dossier. En effet, parallèlement à la question somme toute relativement secondaire de l'arrêté sur les banques étrangères, des discussions parlementaires ont lieu sur la question de l'instrumentarium de la banque centrale. Nous l'avons évoqué, une révision de la loi sur la Banque nationale est en cours, dans le sens d'un renforcement de ses moyens d'action. L'ASB y est vivement opposée. Elle ne souhaite surtout pas apporter de l'eau au moulin des partisans d'un renforcement des compétences de la BNS en reconnaissant que l'art. 3I quater de la constitution permet à la Confédération d'intervenir par des mesures de politique économique. Dès novembre 1968, l'Association des banquiers invite donc les sénateurs à formuler explicitement une réserve sur la base constitutionnelle. L'interprétation de la base constitutionnelle de l'arrêté sur les banques étrangères ne doit avoir aucune influence sur le débat autour de

41 Cf. AfZG, IB Vorort-Archiv 72.I.I, Lettre Sandoz AG à Peter Aebi (dir. Vorort), II.II.I968; lettre de la Société Suisse des Industries Chimiques au Vorort, I0.I2.I968.

42 ABNS, I.3/1229, I3I.25, Dringlicher Bundesbeschluss, Lettre d'Etienne Junod (Schweizerische Gesellschaft für Chemische Industrie), IO.I2.I968. La comparaison est reprise par le député radical Josef Tschopp (1912-I993), sous-directeur de Roche, au sein de la commission du Conseil national. AFB, E6Ioo(B-oor), I980/49, vol. 6I, Procès-verbal de la séance de la commission du Conseil national, I5.0I.1969, p. 21. 
l'instrumentarium ${ }^{43}$. Cette tactique réussit sur toute la ligne puisqu'une telle déclaration est faite: la base constitutionnelle pour freiner les banques étrangères est acceptée, sans pour autant préjudicier le débat sur les moyens d'action de la BNS.

Entré en vigueur en juillet 1969, l'arrêté fédéral introduisant le régime du permis pour les banques en mains étrangères ne fera pas long feu. Il sera partiellement intégré dans la loi sur les banques révisée de mars 1971, et par là même abrogé. Son efficacité est d'ailleurs très limitée. Entre 1969 et 197I, la Commission fédérale des banques accorde 19 nouvelles autorisations d'ouverture à des banques étrangères et ne peut en refuser que trois ${ }^{44}$. Ces trois refus s’appuient sur le non-respect de la condition de réciprocité, qui se révèle être la seule des quatre conditions à constituer un véritable obstacle à la fondation de banques étrangères. Et encore, même cette disposition rate en partie sa cible. En effet, elle est parfois interprétée par le Département politique fédéral, qui est responsable de statuer sur ce point, comme une arme offensive, susceptible de favoriser l'expansion internationale des grandes banques suisses. Pierre-André Nussbaumer (I9I8-?), chef du service économique et financier du DPF, estime en juillet 1970 que «l'exigence de réciprocité, à côté de son aspect restrictif, a également une dimension expansive et constructive » ${ }^{45}$. En faisant pression sur les gouvernements des pays d'origine des banques requérantes, la réciprocité sert donc aussi à promouvoir l'accès à de nouveaux marchés aux banques suisses. Dans le cas des banques japonaises par exemple, les trois grandes banques helvétiques se mettent d'accord sur un agenda commun. En étroite collaboration avec le DPF et la CFB, l'ouverture de succursales de la Société de Banque Suisse et de l'Union de Banques Suisses dans la capitale nippone est négociée, en échange de l'installation d'une filiale de la Bank of Tokyo à Zurich ${ }^{46}$.

Une seconde conséquence des mesures discriminatoires prises par le gouvernement suisse en partenariat avec l'ASB est la création de l'Association des Banques Etrangères en Suisse (Verband der Auslandsbanken in der Schweiz) en I972 à Zurich. Même si elle entend défendre les intérêts spécifiques des banques étrangères, tant vis-à-vis des groupes bancaires concurrents qu'à l'égard de l'administration étatique, l'ABES ne s'érige pas en opposition à l'ASB. Au contraire, elle pose comme condition d'admission l'appartenance à la grande

43 AfZG, IB Vorort-Archiv 72.I.I, Lettre de l'ASB an die Mitglieder der ständerätlichen Kommission betreffend Bundesbeschluss über die Bewilligungspflicht für ausländisch beherrschte Banken, 2I.II.I968.

45 AFB, E6520(A), I983/50, vol. I, Aktennotiz über die Besprechung vom 13.07.1970 betreffend Frage des Gegenrechts bei der Anwendung des Ausländerbankenbeschlusses.

46 AFB, E200I E-OI, 1982/58, vol. I5I, Lettre de la CFB à la direction générale de l'UBS, 04.02.1972. Cf. Loepfe, op. cit., 20II, p. 28I-283; pour la réponse très sèche de Bodmer (CFB) à l'UBS, qui voudrait participer plus étroitement aux négociations avec le Japon : Zala, Perrenoud (éd.), op. cit., 20I4, doc. II7, p. 300. Également disponible en ligne, http://dodis. ch/35515, (consulté le io.12.2018). 
faîtière des banquiers ${ }^{47}$. En ce sens, les banques étrangères sont rapidement canalisées dans le giron de l'ASB, leur appartenance à cette association impliquant la signature des conventions cartellaires en vigueur.

Malgré son inefficacité, sa courte existence et le désintérêt total manifesté dans la littérature secondaire, l'arrêté fédéral contre les banques étrangères de mars 1969 demeure à notre avis digne d'attention. Il s'agit d'une tentative de contrer rapidement l'arrivée de nouveaux compétiteurs sur la place bancaire suisse. Elle implique une complication des conditions d'ouverture pour les banques étrangères, sans pour autant remettre en question l'environnement réglementaire très libéral qui s'applique aux banques suisses. En plus des questions évidentes de concurrence, rendues particulièrement accrues en raison de la pénurie de main-d'œuvre qualifiée et de l'inflation salariale provoquée par l'arrivée de nouvelles sociétés, les reproches adressés aux banques étrangères concernent essentiellement la préservation de la réputation et du prestige international de la place financière suisse. Comme le dit le président de la CFB Riccardo Motta :

Il ne serait pas sage de mettre facilement en jeu notre excellente réputation à cause d'une trop grande liberté d'établissement et de courir le risque que la Suisse soit dans quelques années mise sur pied d'égalité, dans le domaine des relations financières, avec le Libéria, Panama, les Bahamas ou l'ancien Tanger ${ }^{48}$.

Paradoxalement, cette mesure législative visant à limiter l'arrivée de banques étrangères en Suisse peut être interprétée comme une réponse - par la bande aux critiques internationales récurrentes que suscitent certaines pratiques (secret bancaire, comptes numérotés, laxisme fiscal) de la place financière suisse. En évitant de faciliter l'ouverture de nouveaux outils de collecte de l'évasion de capitaux, les autorités fédérales entendent aussi minimiser les condamnations internationales.

Du point de vue de la surveillance bancaire, cet arrêté est significatif à deux titres. Premièrement, il constitue également une réponse aux problèmes que le contrôle des succursales des banques par des autorités de leurs pays d'origine avait soulevés. Souvenons-nous de la bataille diplomatique que l'installation de la First National City Bank, suivie de la Bank of America, et d'éventuelles inspections par des agents du Comptroller of the Currency avait déclenchée (cf. chapitre VIII.2.I.). La nécessité d'une collaboration entre instances nationales de supervision commence à apparaître. C'est une autre voie, celle de mesures de protectionnisme économique national, que semblent suivre les autorités

47 Erik B. Gasser, «Stellung und Probleme der Auslandsbanken in der Schweiz», NZZ, nº 429 et 432, I4-15.09.1972. Erik B. Gasser est directeur de la J. Henry Schroder Bank AG à Zurich, filiale d'une société de gestion de fortune londonienne.

$48 \mathrm{AFB}, \mathrm{E} 6 \mathrm{IOo}(\mathrm{B}-\mathrm{ooI}), \mathrm{I980} / 49$, vol. 6I, Procès-verbal de la séance de la commission du Conseil des États concernant l'Arrêté fédéral urgent instituant le régime du permis pour les banques en mains étrangères, 27.II.I968, p. I4. 
suisses. Freiner l'installation de sociétés étrangères revient également à éviter les délicates questions sur le statut juridique et régulatoire des multinationales. Pour le dire autrement, les autorités helvétiques privilégient un traitement du problème des banques étrangères par des mesures protectionnistes qui rendent l'accès à la place bancaire suisse plus difficile, plutôt qu'une collaboration accrue entre autorités de surveillance à l'échelon supranational.

D'autre part, en faisant des banques étrangères le bouc émissaire des scandales financiers récents et des déséquilibres sur la place bancaire suisse, les milieux financiers helvétiques parviennent à détourner l'attention de l'administration des projets de révision de la loi sur les banques qui sont en cours. C'est ce glissement dans la hiérarchisation des priorités d'un amendement de la législation bancaire que nous allons aborder dans la section suivante.

Relevons enfin que cette réglementation anti-banques étrangères s'intègre plus largement dans un contexte politique suisse où les propositions et les discours xénophobes prennent de l'ampleur ${ }^{49}$. Dès 196I, la "Lex von Moos " cherche à limiter l'acquisition de biens immobiliers par des personnes domiciliées à l'étranger. Dans le domaine de la politique migratoire, la seconde moitié des années 1960 est marquée par l'accentuation de tensions autour de la place de la population étrangère, notamment des travailleurs immigrés. Une première initiative fédérale contre la surpopulation étrangère est déposée en 1965, puis retirée en mars 1968, par le Parti démocratique zurichois. En mai I969, une seconde initiative est déposée par l'Action nationale de James Schwarzenbach, un mouvement d'extrême droite qui fait de cette question son cheval de bataille. Soumise au peuple en juin 1970, elle n'est refusée que par une petite majorité ( $54 \%$ ) des citoyens, alors que tous les autres partis recommandent son rejet ${ }^{50}$; des initiatives similaires subiront le même sort dans les années 1970 (1974 et 1977). À cet égard, l'arrêté fédéral de mars 1969 pour freiner l'installation des banques étrangères en Suisse s'insère dans un agenda politique plus large au sein duquel le discours xénophobe et la protection des intérêts nationaux sont particulièrement porteurs.

49 Sur ce point, voir par exemple: Mauro Cerutti, «La politique migratoire de la Suisse 1945I970", in Hans Mahnig (éd.), Histoire de la politique de migration, d'asile et d'intégration en Suisse depuis 1948, Zurich : Seismo, 2005, p. 89-134; Damir Skenderovic, Gianni D’Amato, Mit dem Fremden politisieren rechtspopulistische Parteien und Migrationspolitik in der Schweiz seit den Ig6oer Jahren, Zürich : Chronos, 2008. Pour un contexte plus large, cf. Tanner, op. cit., 20I5, p. 367-368, 397-400.

50 Linder, Bolliger, Rielle (éd.), op. cit., 20IO, p. 303-304. Notons au passage la forte participation $(74.7 \%)$ et l'acceptation de l'initiative Schwarzenbach par six cantons et deux demicantons. 


\section{IX.2. LE PROCESSUS DE RÉVISION DE LA LOI SUR LES BANQUES (1966-1971) : UNE ÉDULCORATION PROGRESSIVE DES PROJETS DE LA CFB}

Le temps d'une courte analepse, revenons à l'été 1965. Dans la foulée du scandale des banques Muñoz et de l'implication du président de la Commission fédérale des banques Max Hommel, un réexamen de la pertinence d'un amendement de la loi sur les banques est entrepris. Début juillet, le conseiller fédéral Roger Bonvin donne au nouveau président intérimaire de la Commission fédérale des banques, l'ancien conseiller fédéral radical zurichois Hans Streuli, le mandat d'examiner si les dispositions de la loi sur les banques suffisent encore au vu des expériences récentes ${ }^{51}$. Ne voulant pas agir à titre individuel comme un père fouettard chargé d'administrer unilatéralement des sanctions à l'instance de surveillance des banques, Streuli étend à l'ensemble de la commission l'examen de la question. Un rapport est préparé par le chef du secrétariat Daniel Bodmer ${ }^{52}$.

Pour l'essentiel, trois points sont préalablement retenus comme devant faire l'objet d'une réforme importante. D'une part, est évoquée l'introduction d'une procédure d'autorisation (Bewilligungsverfahren) capable de compliquer l'ouverture de toutes les banques et de donner un moyen d'intervention plus incisif à la CFB, sous la forme du retrait de l'autorisation d'exercer. D'autre part, une amélioration des dispositions pénales, qui avait déjà été explorée fin 1964, est considérée comme prioritaire. Troisièmement, on envisage une meilleure protection des épargnants, en restreignant l'acceptation de dépôts d'épargne aux banques ayant une politique de placement adéquate (non spéculative); de tels dépôts ne devraient pas pouvoir être investis dans des opérations à risque. $\mathrm{Ce}$ rapport fait l'objet d'une discussion au sein de la Commission le 25 août $1965^{53}$. Streuli et les quatre membres rescapés de l'affaire Muñoz (Peter Müller, Karl Etter, Jean Golay, Paul Rossy), malgré certaines divergences sur la teneur des amendements prévus, approuvent le principe de l'examen d'une révision de la loi sur les banques. Paul Rossy, en tant qu'auteur de la loi sur les banques dans les années 1930, est désigné par ses pairs pour recenser l'ensemble des points de révision. D’après les documents conservés dans les archives de la Commission fédérale des banques, un antagonisme interne se fait alors jour. Dans un rapport qu'il prépare à l'adresse des membres de la CFB, Daniel Bodmer relève que la notice préparée par Paul Rossy dénote " une conception complètement opposée " à celle du secrétariat ${ }^{54}$. Pour le chef du secrétariat, le mémorandum de de Daniel Bodmer aux membres CFB, "Frage einer Revision des Bankengesetzes", 20.08.1965, 8 pages.

53

54

AFB, E6520(B), 1980/39, vol. I6, PV CFB, 30.06.1965, p. I59.

AFB, E6520(B), 2007/62, vol. 2I, dossier Revision des Bankengesetzes 1960-1965, Rapport

AFB, E6520(B), 1980/39, vol. I6, PV CFB, 25.08.1965, p. 240-244.

AFB, E6520(B), 2007/62, vol. 2I, dossier Revision des Bankengesetzes 1960-1965, Rapport de Daniel Bodmer aux membres CFB, «Kurze Stellungnahme zum Memorandum von Herrn Dr. P. Rossy", 21.09.1965. 
Rossy enfonce des portes ouvertes et manque de systématique. Bodmer insiste et définit toujours cinq domaines essentiels de révision: l'introduction du régime de l'autorisation pour l'ouverture de banques, une meilleure protection des épargnes, l'établissement d'une sorte de commissaire officiel pour banques en difficulté, une réforme des procédures d'assainissement, et finalement un amendement des dispositions pénales.

L'Association suisse des banquiers, informée dès octobre 1965 des travaux préparatoires en vue d'une révision effectués par la CFB, se positionne d'emblée contre toute tentative de toucher à la loi sur les banques. En décembre 1965, les dirigeants de l'ASB estiment unanimement qu'il faut que l'administration fédérale fasse preuve d'une grande retenue, même si le programme de révision est étroitement circonscrit ${ }^{55}$. Si les banquiers rejettent clairement la mise en chantier de la réglementation bancaire, ils font simultanément preuve de prévoyance en réfléchissant déjà aux postulats qu'ils pourraient faire valoir si un processus de révision était effectivement entrepris malgré leurs réserves. Ces considérations sont clairement exprimées dans un courrier au président de la CFB Hans Streuli :

Il faut sérieusement s'attendre à ce que le Parlement effectue des ajouts qui seraient, tant pour l'administration que pour les banques, indésirables, et même éventuellement devraient être ressentis comme très désavantageux. Il existe indéniablement des parlementaires qui ne laisseraient pas filer l'occasion d'une révision législative pour revendiquer des pouvoirs d'intervention accrus de l'État dans la politique de crédit et une extension de la surveillance étatique, peut-être même dans une mesure qui ne serait plus compatible avec nos principes d'économie de marché. L'article 47 sur le devoir de confidentialité peut également facilement conduire à des discussions polémiques qui - même si les postulats n'aboutissent pas - impliqueraient des préjudices pour l'ensemble du secteur bancaire, et particulièrement pour notre position en tant que place bancaire et financière internationale ${ }^{56}$.

Alors que c'est l'argumentation "classique » à l'encontre d'un examen public de la législation bancaire qui est déployée ici, les banquiers préparent en réserve deux revendications qu'ils voudraient faire valoir, si, dans des circonstances futures plus favorables, une révision était tout de même entreprise. Il s'agit d'une part de l'introduction de dispositions plus restrictives pour freiner de nouveaux établissements étrangers, d'autre part une soumission à la loi sur les banques des sociétés financières à caractère industriel et commercial. Ces entreprises, en s'adressant au public pour recueillir des fonds sans pour autant être assujetties à la régulation bancaire, constituent une concurrence et, selon l'ASB, une potentielle lacune dans la protection des créanciers/investisseurs.

AASB, Procès-verbaux du Conseil d'administration de l'ASB, $259^{\mathrm{e}}$ séance, 08.12.1965, p. 2627.

56 AFB, E6roo(B-oI), 1980/49, vol. 57, dossier Bankengesetz: Korrespondenzen. 1960-1969, Lettre de Max Oetterli (ASB) à Hans Streuli (CFB), 07.0I.I966. 
Malgré ce préavis défavorable, la Commission fédérale des banques poursuit ses travaux en vue d'une révision de la loi sur les banques. Un catalogue des points de révision est dressé le 3 février $1966^{57}$. Des exigences renforcées pour l'exploitation d'une banque (compétence des dirigeants, dont la majorité doit résider en Suisse, introduction d'un capital minimal, mise en place du retrait de l'autorisation d'exercer) sont prévues; dans le domaine des fonds propres et de la liquidité, la CFB doit être autorisée à prévoir des exceptions non seulement dans le sens d'un allégement, mais aussi d'un renforcement des exigences; elle doit pouvoir en outre signaler elle-même, à la place des dirigeants négligents, le surendettement d'une banque aux instances judiciaires de faillite; elle doit enfin pouvoir déléguer un commissaire auprès d'une banque; les crédits aux dirigeants bancaires et leurs proches doivent être irréprochablement garantis et octroyés à des taux habituels; les dispositions pénales sont à réviser dans le sens d'une hiérarchisation des violations de la loi en trois niveaux, ce qui permet à la fois une application mieux pondérée et plus rapide. Cette énumération des changements prévus est informellement soumise à cinq banquiers : Max Iklé, membre de la direction générale de la BNS, Eberhardt Ernst Reinhardt, directeur général du Crédit Suisse, Albert Matter (1906-1992), directeur de la Banque cantonale de Bâle et président de l'Union des banques cantonales suisses, Alfred Cornaz (1904-1980), directeur de la Caisse d'Épargne et de Crédit, une banque locale lausannoise, et Alfred E. Sarasin (1922-2005), président de l'ASB et associé de la maison privée A. Sarasin \& Cie. À l'exception d'Iklé et dans une moindre mesure de Cornaz, les trois autres banquiers sont plutôt réticents à entrer en matière. Ils regrettent surtout l'absence de dispositions plus tranchantes contre la prolifération des banques étrangères. Dans l'ensemble, retenons que les propositions individuelles de révision - somme toute peu révolutionnaires - ne sont sur le fond pas mal accueillies par le panel de banquiers consultés. C'est plutôt le processus même qui incite à la prudence.

Les efforts de la Commission fédérale des banques en vue d'une révision partielle de la loi sur les banques sont importants: dix séances extraordinaires sont organisées entre octobre 1965 et juillet $1966^{58}$. Elles débouchent sur la production, en juillet 1966 , d'un rapport et d'un projet contenant des propositions précises d'amendement, longs de plus de 80 pages ${ }^{59}$. Les superviseurs y arrivent à la conclusion qu'une révision s'impose, mais qu'elle doit se limiter aux points essentiels pour pouvoir être réalisée rapidement. Le constat dressé est lucide :

57 AFB, E6520(B), 2007/62, vol. 21, dossier Revision des Bankengesetzes 1960-1965, Katalog der Revisionspunkte, 03.02.1966.

$58 \mathrm{AFB}, \mathrm{E} 652 \mathrm{O}(\mathrm{B}), 198 \mathrm{O} / 39$, vol. 2I, dossier Sondersitzungen betr. Revision des Bankgengesetzes.

59 AFB, E6Ioo(B-ooI), 1980/49, vol. 59, dossier Bankengesetz, Vernehmlassung und Neuer Entwurf, "Bericht und Entwurf der Bankenkommission über eine Teilrevision des Bundesgesetzes vom 8. November 1934 über die Banken und Sparkassen und seiner Vollziehungsverordnung vom 30. August 196I ", I8.07.1966, 8I pages. 
Sur la base des expériences faites, il doit être considéré comme avéré que dans le secteur bancaire également - et pas uniquement chez des établissements d'importance économique tout à fait secondaire - se produisent de graves violations de la loi, couplées à des insubordinations envers l'autorité de surveillance ${ }^{60}$.

Le système d'intervention est insuffisant : la disposition qui autorise la CFB à "déférer le cas aux autorités administratives ou judiciaires compétentes" ne fonctionne pas dans la pratique. Dès février, le juriste du secrétariat de la CFB Hans Manz, après avoir procédé à un examen attentif de la genèse historique des compétences d'intervention de l'autorité de surveillance, était arrivé à la conclusion que «le système de mesures de la loi sur les banques n'a pas été réfléchi jusqu'au bout, et qu'il nécessite donc absolument une révision " ${ }^{61}$. L'absence de moyens d'intervention satisfaisants était vue comme un " accident de parcours » de l'élaboration de la loi dans les années 1930 qu'il fallait impérativement rectifier.

Pour corriger ces dysfonctionnements, l'autorité de surveillance, dans son projet de juillet 1966 , se concentre sur une amélioration de la réglementation dans deux directions: des mesures administratives plus efficaces (avec l'introduction de la contrainte administrative) et des sanctions plus appropriées (ce qui comprend une adaptation au droit pénal administratif). Au-delà de ces deux domaines primordiaux, une série d'autres modifications sont envisagées: des exigences plus élevées à la fondation de nouvelles banques, un suivi plus intensif de ces dernières (modification des statuts sujette à autorisation CFB), une meilleure répartition des risques, une limitation des crédits aux dirigeants, et enfin quelques changements mineurs dans l'audit bancaire. En revanche, les superviseurs écartent délibérément certaines propositions de révision ${ }^{62}:$ l'assujettissement à la loi sur les banques des sociétés financières à caractère industriel ou commercial, réclamé par l'ASB, ne trouve pas grâce à leurs yeux. Une protection renforcée des dépôts d'épargne, que cela soit par l'intermédiaire d'une augmentation du montant privilégié ou par des prescriptions de placement, est également rejetée. Quant à l'épineuse question des banques étrangères, la réponse proposée par la $\mathrm{CFB}$ est ambivalente. Elle considère que les problèmes soulevés relèvent de l'économie politique et se situent hors de ses compétences. De plus, les critères pour déterminer une domination étrangère sont délicats.

L'Administration fédérale des finances accuse réception de ce rapport substantiel, et le transmet à l'Association suisse des banquiers et à la Banque

60 AFB, E6I0o(B-ooI), 1980/49, vol. 59, dossier Bankengesetz, Vernehmlassung und Neuer Entwurf, «Bericht und Entwurf der Bankenkommission... », 18.07.1966, p. 6.

61 Le rapport de Manz aux membres de la CFB, daté du 22.02.1966, est reproduit dans une brochure datant de 1973. H[ans] Manz, Mangelnde Durchsetzbarkeit eines Gesetzes. Diagnose \& Heilung. Das Beispiel der Revision des Bankengesetzes, Bern : [Eidgenössische Bankenkommission], I973, p. II.

62 AFB, E6Ioo(B-oor), 1980/49, vol. 59, dossier Bankengesetz, Vernehmlassung und Neuer Entwurf, «Bericht und Entwurf der Bankenkommission... », I8.07.I966, p. 25-3I. 
nationale pour une consultation informelle ${ }^{63}$. Le secrétariat de l'ASB informe confidentiellement les membres de son conseil d'administration de la teneur du rapport, en leur demandant de ne pas ébruiter son contenu. Le secrétaire Oetterli précise: "Nous sommes en contact étroit avec les responsables du dossier et législateurs du Département. De telle façon nous pouvons participer à la conception du projet dès le début, une approche qui a déjà fait ses preuves pour la loi sur les fonds de placement. ${ }^{64}$

Le I5 septembre 1966 a alors lieu une discrète rencontre qui joue un rôle crucial dans l'ensemble du processus de révision de la loi sur les banques de la fin des années 1960. Sur demande de la faîtière des banques, une entrevue entre Bernhard Müller, Paul Ehrsam (tous deux AFF), Max Oetterli et Markus Lusser (tous deux ASB) et Hans Huber (BNS) est organisée ${ }^{65}$. La Commission fédérale des banques est intentionnellement exclue des négociations. D’après les traces laissées par cette réunion, les trois instances présentes considèrent les réponses apportées par le projet de révision partielle de la CFB comme insuffisantes. Sur le problème de l'Überfremdung, la solution préconisée par la CFB est incomplète et ne contente personne. Le maintien hors du giron de la surveillance bancaire des sociétés financières à caractère industriel et commercial déçoit également les experts présents. Pour Oetterli, cette attitude de la CFB reflète " une tendance à tenir à distance les clients désagréables » ${ }^{66}$. En revanche, le renforcement des moyens d'intervention de l'autorité de surveillance n'est pas mis en cause. La conclusion est implacable:

Comme les propositions de la Commission bancaire apparaissent comme insuffisantes aux participants à la réunion sur certains points significatifs (sociétés étrangères, sociétés financières), un accord unanime existe pour que les propositions de la Commission bancaire ne soient pas soumises à une procédure de consultation avant une révision approfondie ${ }^{67}$.

Les représentants des banques et de l'administration fédérale enterrent en septembre 1966 la proposition de révision partielle élaborée pendant un an par la Commission fédérale des banques. La rapidité de ce processus d'abandon, ainsi que le fait que ne soit offerte aucune opportunité à la CFB de défendre son projet, sont remarquables. Par contre, au vu du rapport de force entre une petite commission d'exécution récemment discréditée et la

63 AFB, E610o(B-oI), 1980/49, vol. 57, Lettre de Roger Bonvin (DFFD) à la CFB, 15.09.1966.

64 AASB, Procès-verbaux du Conseil d'administration de l'ASB, $264^{\mathrm{e}}$ séance, 23.09.1966, p. 5.

65 Cette audience, de caractère informel, est documentée par deux Atkennotizen. L'une rédigée par Ehrsam (service juridique de l'AFF), l'autre par Huber. AFB, E6Ioo(B-oI), 1980/49, vol. 57, Aktennotiz über die Besprechung vom 27.4 und 15.9.1966 mit den Sekretären der Bankiervereinigung, 23.09.1966. ABNS, I.3/1233, SNB, Aktennotiz Teilrevision des BG über die Banken und Sparkassen, 26.09.1966.

66 AFB, E6roo(B-oI), 1980/49, vol. 57, Aktennotiz über die Besprechung vom 27.4 und I5.9.1966 mit den Sekretären der Bankiervereinigung, 23.09.1966.

67 Ibid. 
coalition de circonstance entre trois acteurs centraux de la politique bancaire du pays, le rejet des propositions de la CFB n'est pas étonnant. En repoussant les deux seules revendications de l'ASB, à savoir une restriction de l'expansion des banques étrangères et un encadrement réglementaire de certaines sociétés financières, tout en déclenchant un chantier législatif auquel la puissante association s'opposait par principe, la Commission fédérale des banques faisait face à un défi insurmontable. La seconde dimension notable de ces négociations est la constitution d'une alliance de circonstance entre la banque centrale et les banques commerciales. En effet, dans le débat parallèle sur l'instrumentarium de la BNS, ces deux instances se livrent une bataille acharnée. Sur le dossier de la révision de la loi sur les banques, elles s'accordent cependant pour la simple raison que leur requête commune de brider le développement des banques étrangères n'est pas satisfaite. Pour les banquiers, la position tactique est donc claire: en raison des risques liés à une discussion parlementaire et publique des dispositions comme la protection du secret bancaire, «les banques ne doivent donner leur accord à une révision uniquement lorsqu' elles souhaitent réaliser d'importants postulats " ${ }^{68}$. Voilà donc un exemple explicite d'une situation dans laquelle une industrie régulée balance les avantages et les inconvénients d'une éventuelle adaptation des normes réglementaires qui la concernent. Elle est ainsi capable de marchander son soutien à la démarche selon la prise en compte de ses préférences. De l'intégration des souhaits de cette industrie dépend donc aussi l'aboutissement de tout le projet législatif.

Entre septembre 1966 et le printemps 1968, pendant un an et demi, le dossier de la révision de la loi sur les banques semble passer au second plan. Le rapport et le projet de juillet 1966 prennent la poussière dans les bureaux de l'Administration fédérale des finances, tandis que, parallèlement, une enquête sur le degré d'influence étrangère sur le monde bancaire suisse est menée. Un groupe de travail est constitué à l'été 1967 sur la question des banques étrangères.

En mars 1968, la CFB décide de rappeler au nouveau chef du Département fédéral des finances et des douanes, Nello Celio, que son projet est toujours en attente de traitement. Au printemps 1968, les travaux semblent reprendre, mais dans une direction diamétralement opposée à celle que suivait le projet de la CFB de juillet 1966. Comme nous l'avons évoqué dans le sous-chapitre précédent, un glissement insidieux est opéré par l'Administration fédérale des finances. Les deux problèmes prioritaires de l'ASB, une régulation plus contraignante des sociétés financières et surtout des banques étrangères, deviennent également les points primordiaux dans les discussions sur la révision de la loi sur les banques menées par l'administration. «Par conséquent, il convient de noter que la question de la révision de la loi sur les banques est abordée par l'Administration des finances d'une manière qui differre fondamentalement de la 
conception de la Commission des banques ${ }^{69}$, estime le juriste de la CFB Hans Manz dans un document interne en mai 1968. La désillusion sur le traitement réservé à son projet est telle que la CFB se demande si elle doit poursuivre sa participation au groupe de travail. Plutôt qu'un retrait unilatéral, le chef du secrétariat Daniel Bodmer décide de faire part aux autres membres du groupe de travail (représentants de l'AFF, de l'ASB et de la BNS) de l'inquiétude que suscite la façon de faire de l'Administration fédérale des finances au sein de la $\mathrm{CFB}^{70}$. Le I3 juin 1968 , les propositions de juillet 1966 sont finalement ressorties des tiroirs de l'administration. Elles reçoivent un accueil plutôt favorable du groupe de travail restreint.

À la rentrée politique de l'automne i968, lorsque les réunions du groupe de travail reprennent, un nouveau retardement du traitement de ce dossier semble se dessiner. En effet, comme signalé dans le sous-chapitre précédent, le groupe de travail décide de traiter prioritairement l'affaire du ralentissement de l'ouverture des banques sous domination étrangère. Un arrêté fédéral, qui pourrait entrer en vigueur plus rapidement qu'une révision d'une loi fédérale, est préconisé. C'est ainsi que l'élaboration de l'arrêté fédéral sur les banques étrangères, qui aboutit en mars 1969, signifie indirectement une nouvelle manœuvre dilatoire dans la réforme générale de la réglementation bancaire.

En octobre 1968, le secrétaire de la CFB Hans Manz déclare à ses collègues, désabusé :

Il [le secrétariat] a en effet l'impression non seulement que la révision a été retardée de la manière que nous connaissons, mais aussi que lors des délibérations actuelles le projet de révision élaboré sous la présidence de M. l'ancien conseiller fédéral Streuli ne reçoit pas du tout l'attention qu'il mérite. Dans les faits, des projets privés provenant de toutes sources possibles sont aujourd'hui placés au centre des débats, au lieu d'un projet développé par l'instance d'expertise spécialisée et politiquement équilibrée. Il doit absolument s'agir d'imposer enfin qu'il soit dûment tenu compte du projet officiel de la Commission fédérale des banques, si nous ne voulons pas courir le risque que la révision prenne d'autres directions que celle demandée par la Commission ${ }^{71}$.

Les «projets privés» dont parle Manz sont en fait les travaux élaborés par la BNS (Ehrsam) et l'ASB (Oetterli) sur la limitation des banques étrangères, et qui ont servi de base à l'arrêté fédéral alors en discussion parlementaire. La frustration de Manz quant au sort réservé aux travaux de révision de la CFB est d'ailleurs partagée par certains de ses collègues. Dans un courrier au président Riccardo Motta, le banquier genevois Emile Duperrex (1905-1984), membre de

AFB, E6520(B), 2007/62, vol. 2I, dossier Revision des Bankengestzes. 1968-1970, Aktennotiz de Hans Manz à Daniel Bodmer (tous deux secrétariat CFB), oı.05.1968.

70 AFB, E6520(B), 2007/62, vol. 2I, dossier Revision des Bankengestzes. I968-1970, Aktennotiz sur la discussion du Io mai 1968, Daniel Bodmer, 24.05.1968.

71 AFB, E6520(B), I980/39, vol. I7, PV CFB, 23.I0.1968, p. I80-I8I. 
la CFB depuis 1967, exprime clairement son mécontentement: "Il serait hautement souhaitable que la Commission [...] fasse savoir aux organes compétents - et peut-être même à l'opinion publique, par un communiqué de presse - qu'elle n'entend pas se laisser subjuguer par une sorte de sclérose politique et administrative très préjudiciable à notre pays. ${ }^{72}$ Ces menaces exprimées à l'interne de l'autorité de surveillance ne sont pas mises à exécution. Du côté du DFFD, une certaine gêne vis-à-vis du traitement du dossier "révision de la loi sur les banques» et du projet de juillet 1966 se fait sentir. Publiquement, le retard pris est justifié en soulignant le caractère "si complexe et si délicat» de la matière traitée ${ }^{73}$. À l'interne, une notice du directeur de l'Administration fédérale des finances, Rudolf Bieri (1920-2013) au chef du service juridique de l'AFF Bernhard Müller, dévoile certaines des raisons de ce retard $^{74}$. D'autres tâches ont accaparé l'attention des fonctionnaires de l'AFF : arrêté urgent sur le crédit, sanctions des infractions, loi sur les fonds de placement, instrumentarium de la BNS, loi sur les finances de la Confédération. Le départ de Paul Ehrsam du service juridique de l'AFF vers la banque centrale constitue un affaiblissement supplémentaire; pour Bieri, « la dotation en personnel est tout simplement insuffisante».

Ayant fait des annonces officielles au sujet de l'avancement des travaux préparatoires, le gouvernement est cette fois-ci contraint de les relancer plus activement. En janvier et en février 1969, de nouvelles réunions du petit groupe de travail sont organisées ${ }^{75}$. En avril, la Banque nationale soumet encore des propositions de renforcement des articles qui la concernent plus particulièrement, à savoir ceux sur la transmission de données comptables à la BNS et l'exportation de capitaux. Début mai, une phase de pré-consultation entre initiés a lieu. Un avant-projet de révision partielle est soumis simultanément par le Département des finances à la CFB, la BNS et l'ASB, c'est-à-dire les trois instances déjà impliquées dans l'élaboration de ce texte. Le I6 juin I969, le Département fédéral des finances et des douanes ouvre la procédure de consultation à un cercle plus large. Un projet de révision accompagné d'un commentaire est envoyé aux cantons, aux partis politiques et aux associations économiques ${ }^{76}$. Dans son commentaire, le DFFD définit sept innovations principales du projet soumis en juin 1969 : (I) les sociétés financières à caractère

72 Lettre d'Emile Duperrex à Riccardo Motta, I3.II.I968, citée dans le rapport de Hans Manz, "Vernachlässigte Vorlage der Bankenkommission", or.I2.I968, p. 8. AFB, E6520(A), I983/ 50, vol. 2, Revision Bankengesetz 1966-1971.

73 «Message du Conseil fédéral à l'Assemblée fédérale à l'appui d'un projet d'arrêté fédéral urgent instituant le régime du permis pour les banques en mains étrangères, du 13 novembre I968", Feuille fédérale, 1968, vol. 2, no 48, p. 783.

74 E6Ioo(B-ooI), I980/49, vol. 59, Notiz an Herrn Fürsprecher Müller, 09.II.I968.

75 Pour rappel, ce groupe de travail formé en juillet 1967 est composé de: Anton Blatter, Bernhard Müller (tous deux AFF), Hans Huber et Paul Ehrsam (tous deux BNS), Daniel Bodmer (CFB), Max Oetterli et Markus Lusser (tous deux ASB).

76 Au total, 520 exemplaires (364 en allemand et 156 en français) du projet de révision de 1969 sont envoyés à la presse, aux cantons, aux partis et aux associations. 
industriel ou commercial sont désormais assujetties à la loi, (2) les conditions d'ouverture de nouvelles banques deviennent plus exigeantes, (3) les dispositions de l'arrêté fédéral sur les banques en mains étrangères sont intégrées dans la loi, (4) le montant des dépôts d'épargne privilégiée est relevé, (5) la CFB est informée plus rapidement par la société d'audit en cas de violations légales, (6) les moyens d'interventions de la CFB sont renforcés, (7) les dispositions pénales sont adaptées à l'évolution de la législation pénale administrative ${ }^{77}$.

On constate donc que les amendements proposés par le gouvernement constituent un subtil mélange entre les requêtes initiales de la Commission fédérale des banques (points 5 à 7 ) et les revendications essentielles formulées par les milieux bancaires (points I à 3). Seconde observation: les séquelles de l'affaire Muñoz apparaissent clairement dans le projet préparé en juin 1969. Les mesures sur le rachat d'une banque suisse par un groupe étranger, celle qui impose la nécessité de dévoiler dans la raison sociale la domination étrangère, la limitation des gros risques sous la forme d'un ratio prudentiel, ou encore la prescription sur les crédits accordés aux organes dirigeants d'une banque font toutes écho aux dysfonctionnements révélés par le scandale de la BGCC et de la SSKB.

L'Association suisse des banquiers organise en août 1969 plusieurs discussions du projet du DFFD par catégorie de banque dans l'ordre suivant : grandes banques, banques cantonales, banquiers privés et banques locales ${ }^{78}$. Cette hiérarchie exerce une influence sur le résultat des négociations, étant donné que les groupes consultés ultérieurement prennent position non seulement sur le projet du DFFD, mais également sur les changements proposés par leurs préopinants. Ainsi, l'avis des grandes banques, qui sont les premières consultées, est prépondérant dans la définition de l'opinion générale de l'ASB, même si elles prêtent ainsi le flanc aux critiques des autres catégories de banques. Pour les grandes banques, les changements apportés à ce qu'elles considèrent comme "la législation la plus libérale» du monde sont jugés «dans l'ensemble appropriés $»^{79}$. Malgré cette appréciation globale positive, au moins quatre points font l'objet de vives critiques de la part des représentants des grandes banques.

Premièrement, dans l'article qui pose le principe du respect d'un ratio de fonds propres, ils cherchent à réaliser un postulat pour lequel ils se battent depuis près d'une décennie. Il s'agit d'inscrire dans la loi, et non uniquement dans l'ordonnance d'exécution ou dans une circulaire de la CFB, que les réserves latentes (stille Reserven) doivent être incluses dans le calcul des fonds propres. Évidemment, la prise en compte de ces réserves qui n'apparaissent pas au bilan et sont traitées de manière très confidentielle par les directions signifierait un allégement considérable des exigences prudentielles. Cette prise en

77 AFB, E652O(B), 2007/62, vol. 2I, Message de Nello Celio (DFFD) accompagnant le projet de loi fédérale modifiant la loi sur les banques et les caisses d'épargne, I6.06.1969.

78 AASB, Dossier J.4 Bankengesetz 1967-1969.

79 AASB, Dossier J.4 Bankengesetz 1967-I969, Protokoll-Notiz, « Stellungnahme der Vertreter der Grossbanken zum Entwurf...», I2.08.1969. 
compte ne devrait cependant pas remettre en question le caractère strictement confidentiel du montant des réserves latentes.

Il nous faut ici ouvrir une courte parenthèse pour comprendre toute l'actualité de ce problème à l'été 1969. En effet, en novembre 1967, sur demande de la Société de Banque Suisse et du Crédit Suisse, l'ASB s'était adressée à la Commission fédérale des banques, pour demander une modification de la circulaire datant de I96I, qui autorise les banques à prendre en compte les réserves latentes jusqu'à concurrence de $15 \%$ du total des fonds propres ${ }^{80}$. L'ASB demande alors d'augmenter ce plafond de is à $30 \%$. Cette requête trouve son origine dans l'extraordinaire développement des actifs bancaires (en particulier les opérations sur les euromarchés), qui rend la couverture par les fonds propres de plus en plus difficile. Fin 1966, II4 banques font usage de la possibilité offerte en I96I et comptabilisent des réserves latentes dans leurs fonds propres; parmi celles-ci, 34 banques atteignent les maximas légaux de I5 \%, dont deux grandes banques ${ }^{81}$.

Selon les calculs du membre de la CFB et professeur d'économie Jean Golay, les grandes banques ont fait usage de la possibilité d'intégrer des réserves latentes à hauteur de $15 \%$ dans les fonds propres dans la mesure suivante:

Tableau 25. Composition des fonds propres des trois grandes banques fin 1967 (en millions de francs)

\begin{tabular}{|l|c|c|c|c|}
\hline & Capital social & Réserves ouvertes & $\begin{array}{c}\text { Total sans le report } \\
\text { de profits et pertes }\end{array}$ & Réserves latentes \\
\hline SBS & 270 & 326 & 596 & I05 \\
\hline UBS & 260 & 700 & 960 & 170 \\
\hline Crédit Suisse & 260 & 285 & 545 & 96 \\
\hline
\end{tabular}

Source: AFB, E6520B, 1980/39, vol. 2I, Plenarsitzungen 1967-1974, séance du 20.12.1967, p. 36.

D'entente avec la BNS, la CFB décide d'entrer en matière et d'accepter une augmentation du plafond à $25 \%$. Elle ajoute cependant une seconde clause à cette modification, sous la forme d'un double plafonnement: les réserves latentes pourront compter pour $25 \%$ des fonds propres, à condition que le montant comptabilisé ne dépasse pas $70 \%$ du volume total des réserves latentes. En plus de la banque centrale, les superviseurs consultent aussi les deux grandes banques qui étaient à l'origine de toute l'affaire, qui approuvent sans recourir à l'ASB. La modification de la circulaire de la CFB est décidée et annoncée en janvier 1968.

Ce procédé d'une prise de décision qu'elle considère comme unilatérale irrite vivement l'Association suisse des banquiers. Ce d'autant plus que la solution prévue suscite un triple mécontentement de la part de certains de

Cette circulaire, étroitement liée à la modification de l'ordonnance de I96I, avait fait l'objet d'un intense travail de lobbying des milieux bancaires entre 1955 et I96I, cf. chap. VII.4. 
ses membres. D'une part, le plafonnement à $70 \%$ remettrait en question une des vertus cardinales des réserves latentes, à savoir leur caractère strictement confidentiel. Comme l'indique dans un courrier adressé au secrétariat de l'ASB le directeur général de l'UBS Philippe de Weck (1919-2009):

Avec le système de plafonnement à $70 \%$ [...], il serait en effet possible de déduire, à partir du montant utilisé, quel est le montant total de ces réserves internes [...]. Il y a parmi les membres de la Commission fédérale des banques d'anciens banquiers, qui ont souvent - et c'est parfaitement normal - conservé des relations étroites avec leurs instituts. Il nous serait extrêmement désagréable que, par ce canal, d'autres instituts soient orientés indirectement le cas échéant sur les problèmes de nos réserves internes, problèmes que nous ne soumettons par discrétion même pas aux organes de notre banque ${ }^{82}$.

Le scénario esquissé ci-dessus par le dirigeant de l'UBS n'a rien d'abstrait. Il fait sans doute référence à la présence au sein de la CFB de Rudolf Pfenninger (1902-1984), récemment élu à la CFB en janvier 1967, après avoir été directeur (1950-1955), puis directeur général (1956-1966) de la SBS.

Le second problème du nouveau système de double plafonnement imposé par l'autorité de surveillance est que pour un certain nombre de banques locales, le nouveau mode de calcul signifie une détérioration du niveau de fonds propres $^{83}$. Face à ces deux objections, l'ASB décide d'intervenir auprès de la CFB pour lui demander de faire machine arrière, ou au moins d'autoriser les banques à choisir celui des deux modes de calcul qui leur est le plus favorable. Troisième incidence fâcheuse pour les banques: en incitant les banques à diminuer le niveau de leurs réserves latentes, le nouveau système provoque pour certains établissements une péjoration de leur "optimisation" fiscale; car les réserves latentes intégrées dans le calcul des fonds propres doivent être comptabilisées sous un poste à part et imposées. En effet, comme l'avoue un représentant des banques locales, la constitution de réserves latentes représente dans de nombreux cantons un moyen efficace de réduire le bénéfice net imposable ${ }^{84}$.

Au moins autant que les problèmes créés par les modifications de ce calcul, l'ASB critique également le comportement peu conciliant de l'instance de surveillance. Pour le banquier privé genevois Marcel Odier (I917-2016), la CFB «a eu une attitude tout à fait inadmissible», et il propose de "marquer le coup en ne discutant plus de cette question avec la commission ${ }^{85}$. Le président de l'ASB Alfred E. Sarasin le suit en estimant que la décision de la

82 AASB, J.4 Bankengesetz 1967-1969, Lettre de Philippe de Weck (DG UBS) au secrétariat de l'ASB, 22.02.1968.

83 En effet, certaines banques locales obtiennent un total de fonds propres plus élevé en comptabilisant la totalité de leurs réserves latentes à hauteur de $15 \%$ qu'en tenant compte de seulement $70 \%$ de ces réserves, mais à hauteur de $25 \%$ des fonds propres.

$84 \mathrm{AFB}, \mathrm{E} 652 \mathrm{O}(\mathrm{B}), \mathrm{1980} / 39$, vol. 17, PV CFB, 28.08.1968, p. 144. Déclaration de Fritz Wahlen (Gewerbekasse in Bern) lors d'une réunion entre la CFB et un groupe de banquiers.

85 AASB, Procès-verbaux du Conseil d'administration de l'ASB, $270^{\mathrm{e}}$ séance, 03.04.I968, p. 22. 
$\mathrm{CFB}$ est " tout sauf élégante » et envisage " une déclaration de guerre " ${ }^{86}$. Après des échanges épistolaires intensifs - et à la tonalité parfois peu cordiale - entre février 1968 et février 1969, cette altercation se résout sans clair vainqueur. La CFB refuse de retirer la circulaire édictée en 1968, et propose aux banques lésées par le nouveau mode de calcul de demander une dérogation particulière. Pour l'ASB, l'essentiel - à savoir les intérêts des grandes banques - est sauvegardé. En effet, elle obtient que la CFB se contente d'une déclaration de principes non chiffrée sur le respect du plafond de $70 \%$, au lieu de l'articulation d'un montant exact ; l'opacité et la confidentialité des réserves latentes sont maintenues. On comprend mieux pourquoi les banques, encore ébranlées par ce contentieux à l'été 1969 , cherchent à le résoudre en leur faveur pendant la révision de la loi sur les banques. À ce titre, la question de la comptabilisation des réserves latentes représente également une seconde pierre d'achoppement, en plus du problème des banques étrangères, dans les relations en règle générale harmonieuses entre l'ASB et la CFB.

Reprenons le fil de notre récit et revenons à la réception par les milieux bancaires du projet de révision de la loi sur les banques soumis en juin 1969. Leur seconde critique a trait à l'ajout de deux dispositions qui représentent selon les grandes banques consultées «une trop grande atteinte à la liberté de commerce ${ }^{87}$. Il s'agit de la prescription qui exige que les prêts à un seul client ou les participations à une seule société restent dans une proportion adéquate avec les fonds propres, et de celle qui demande une limitation des crédits aux membres des organes dirigeants d'une banque.

Troisièmement, les grandes banques s'opposent à l'extension de la capacité de la Banque nationale à demander des informations comptables complémentaires (en plus des bilans intermédiaires et de la comptabilité annuelle) aux banques commerciales. Elles considèrent cette nouvelle disposition comme une procuration en blanc qui ouvrirait la voie à un devoir de renseignement illimité.

La quatrième modification désapprouvée par les grandes banques concerne les critères d'admissibilité à la nomination dans la Commission fédérale des banques. Le projet du Département des finances, notamment suite à la prise en charge par la CFB de la surveillance des fonds de placement, a prévu une simplification des compétences exigées des superviseurs fédéraux: le terme " experts» remplace l'expression «experts en matière bancaire de technique bancaire ou de technique de révision bancaire». Cet assouplissement est rejeté par les banquiers, qui y voient «le risque que la Commission des banques ne soit plus composée de spécialistes qualifiés, mais de politiciens, ce qui doit être évité par tous les moyens ${ }^{88}$.

Ibid., p. 22.

AASB, Dossier J.4 Bankengesetz 1967-1969, Protokoll-Notiz, «Stellungnahme der Vertreter der Grossbanken zum Entwurf...", 12.08.1969.

Ibid., p. 6. 
Crédits aux organes dirigeants, gros débiteurs, devoir de renseignement à la BNS, composition de la CFB et surtout comptabilisation des réserves latentes, voilà les quelques accrocs identifiés par les acteurs dominants de la place bancaire suisse dans le projet de révision de la loi auquel ils ont eux-mêmes collaboré. Là aussi, il s'agit pour les grandes banques de limiter la portée des modifications introduites dans le texte qui sera bientôt soumis au parlement.

Sur la base des différents avis recueillis auprès des groupes de banques, l'Association suisse des banquiers tente d'agréger les tendances divergentes pour améliorer sa position tactique dans la négociation et présenter un front commun face à l'administration fédérale et à la banque centrale. Comme l'admet le secrétaire de l'ASB Max Oetterli, "en mentionnant deux points de vue, notre position est affaiblie, car nous renonçons à notre propre avis et laissons la décision définitive à l'administration ${ }^{89}$. Il incite donc les membres $\mathrm{du}$ Conseil d'administration de l'ASB à se mettre d'accord sur une position unitaire. Ce vœu ne sera que partiellement exaucé. Quelques divergences de vues, surtout entre les grandes banques et les banquiers privés d'une part, et les banques cantonales d'autre part, subsistent dans la prise de position officielle de l'ASB transmise au DFFD le 20 octobre 1969. La plus importante de ces différences est relative à la légère extension des compétences de la Banque nationale prévue. Les grandes banques et les banquiers privés revendiquent plus précisément de ne pas donner des pleins pouvoirs à la banque centrale en matière de demande de renseignements aux banques commerciales; elles s'opposent aussi à un développement des données publiées par la BNS. Elles estiment en outre que les prescriptions sur l'exportation de capitaux nécessitent des ajustements dans le sens d'un assouplissement. Sur tous ces points, les banques cantonales expriment au contraire leur soutien appuyé aux pouvoirs accordés à la Banque nationale. Le constat général de la prise de position de l'ASB demeure cependant favorable, et souligne la faible portée fondamentale des changements prévus :

Le projet de loi se limite à l'ajustement de certaines dispositions devant être complétées ou révisées aux expériences qui ont pu être acquises récemment lors des crises de certaines banques. Les modifications proposées semblent dans l'ensemble judicieuses et appropriées ${ }^{90}$.

Ce jugement bienveillant n'est guère étonnant, au vu du long travail d'influence mené par l'ASB, qui a officieusement et très activement collaboré à la rédaction du projet qui lui est dans un second temps soumis pour une prise de position dans le cadre de la procédure officielle. Au fond, l'une des seules questions qui inquiètent les milieux bancaires à l'automne 1969 n'est pas liée au contenu des divers amendements prévus, elle concerne plutôt la forme et 
l'ampleur que doit prendre la révision de la loi. En effet, en raison de la complexité de la matière, le DFFD et le CFB laissent de côté les dispositions sur l'assainissement et la faillite des banques et privilégient une révision partielle, suivie d'une révision totale dans quelques années lorsque les projets sur ce domaine seront prêts. L'ASB, au contraire, aurait préféré inclure tous les chapitres de la loi sur les banques dans une unique procédure de révision. Comme l'exprime son secrétaire Max Oetterli, il est difficile de prévoir si une révision future se fera "dans les mêmes conditions favorables» et il aurait été plus stratégique d'obtenir un ajustement complet "pour de nouveau avoir la paix pendant des décennies sur cette question importante pour nous ${ }^{91}$.

Nous n'entrerons pas dans le détail de la quarantaine de prises de position émises par les diverses instances consultées par le Département des finances. Le spectre très large des opinants va de multiples gouvernements cantonaux à de nombreuses associations économiques, en passant par les principaux partis politiques nationaux ${ }^{92}$. L'immense majorité des intervenants approuve le projet de révision dans son ensemble. La principale association de l'économie suisse, le Vorort de l'Union suisse du commerce et de l'industrie rapporte que le projet a reçu un bon accueil dans les nombreuses Chambres de Commerce consultées. «Le fait que le caractère libéral du droit bancaire suisse soit maintenu et que la révision proposée se limite à une adaptation des points qui, à la lumière des expériences, se sont avérés dignes d'être complétés ou révisés, est salué », estime le secrétariat du Vorort ${ }^{93}$. Quant aux partis politiques, leur réception du projet est également favorable. La social-démocratie, tant dans l'envoi du Parti Socialiste Suisse que dans celui de l'Union syndicale suisse, fait preuve de grande modération. Elle se déclare d'accord avec la révision de la loi. Parmi les propositions et remarques faites, les représentants du mouvement ouvrier réclament l'introduction d'un ratio qui limiterait les placements à l'étranger en fonction des fonds propres et la publication des statistiques détaillées par pays dans le rapport annuel. L'USS et le PSS demandent tous deux un renforcement des exigences de liquidité, par différents moyens ${ }^{94}$. En revanche, ils n'émettent

91 AASB, Procès-verbaux du Conseil d'administration de l'ASB, $277^{\mathrm{e}}$ séance, 26.09.1969, p. I4. Il est difficile de savoir si Max Oetterli fait ici référence à la couleur politique du Parlement en 1969. Pendant la législature 1967-1971, la répartition des sièges au Conseil national est la suivante: PSS 50, PRD 49, PCCS 45, PAB 2I, AdI 16, divers 19. Au Conseil des États, la majorité bourgeoise est encore plus nette: PCCS I8, PRD I4, PAB 3, Lib. 3, Dém. 3, PSS 2, AdI I.

92 Cf. ABNS, I.3/1233, Ausarbeitung des revidierten Bankengesetzes vom ir. März 197I, Interessierte Organisationen; AFB, E6I0o(B-OI), 1980/49, vol. 58, Vernehmlassung Revision 1969. Pour un bilan des diverses consultations, cf. AFB, E6520(B), 1980/39, vol. 2I, PV CFB (séances plénières), 31.10.1969, p. 93-98.

93 AFB, E610o(B-oI), 1980/49, vol. 58, Vernehmlassung Revision 1969, Lettre du Vorort au chef du DFFD, or.IO.1969.

94 Notamment par une augmentation des coefficients fixés dans l'ordonnance, en comptabilisant désormais les réserves en or comme des actifs facilement mobilisables et non des disponibilités, ou encore en accordant à la CFB le droit de renforcer provisoirement les exigences (et non seulement celui de les alléger). 
aucune critique au sujet de l'article 47 qui condamne pénalement la violation du secret bancaire, qui ne connaît aucune altération majeure par rapport au texte de 1934, mais uniquement des retouches formelles. La prise de position du Parti radical-démocratique suisse, pour sa part, si elle accepte le texte défendu par l'un de ses deux représentants au gouvernement, reprend pour l'essentiel les critiques émises par l'Association suisse des banquiers ${ }^{95}$.

Au fond, l'une des uniques prises de position qui propose des changements d'ampleur est celle du Département politique fédéral (le ministère des Affaires étrangères) du socialiste Willy Spühler (I9O2-1990). Deux points en particulier méritent d'être soulevés ${ }^{96}$. D'une part, le DPF demande que l'article sur le droit de regard et de veto de la BNS sur l'exportation de capitaux soit modifié dans le sens suivant. Lors de l'examen des demandes, la Banque nationale devrait tenir compte non plus de « la protection des intérêts économiques du pays » comme jusqu'alors, mais plutôt de "la protection des intérêts généraux du pays». La requête est justifiée par une adaptation à la loi sur la BNS de décembre 1953, qui fait appel à cette notion. De plus, pour le DPF, «l'octroi de crédits revêt une importance de plus en plus grande dans nos rapports avec l'étranger. Qu'il suffise ici de mentionner nos relations avec le tiers-monde. Et quant à celles que nous entretenons avec les pays de l'Est, n'est-il pas admis que l'aspect économique ne doit pas seul entrer en considération ?» ${ }^{97}$. Le second amendement majeur proposé par Spühler concerne le secret bancaire. Le DPF voudrait examiner une question qui «se pose avec acuité dans nos relations avec l'étranger ", celle de l'échange d'informations sur des tiers impliqués dans une enquête pénale. «Une solution devrait, à notre avis, être trouvée pour qu'une banque ne puisse, en se retranchant derrière cet article, refuser de donner des renseignements indispensables sur des tiers. ${ }^{98}$ Willy Spühler, qui démissionne du Conseil fédéral avec effet au 3I janvier 1970, n'obtiendra gain de cause sur aucun des deux points. Son successeur, Pierre Graber, reprend ce postulat et soutient, en mai 1970, une proposition du DFJP du conservateur Ludwig von Moos allant dans le même sens. Il s'agirait d'ajouter un alinéa à l'article 47, pour autoriser un juge à lever le secret bancaire dans une procédure pénale à l'étranger, pour éviter des difficultés dans le domaine de l'entraide judiciaire ${ }^{99}$. Mais la proposition est refusée par le DFFD de Nello Celio.

À l'issue de la procédure de consultation, un petit groupe de travail (Müller et Blatter de l'AFF, Ehrsam de la BNS et Bodmer de la CFB), dont l'Association suisse des banquiers est cette fois exclue, se réunit entre décembre 1969 et

ABNS, I.3/I233, Ausarbeitung des revidierten Bankengesetzes vom II. März I97I, Interessierte Organisationen, Lettre du secrétariat général du Parti radical-démocratique suisse au conseiller fédéral Nello Celio, I5.I0.1969.

AFB, E6Ioo(B-oI), 1980/49, vol. 58, Vernehmlassung Revision 1969, Lettre de Willy Spühler (DPF) au DFFD, 30.09.1969.

Ibid.

Ibid.

AFB, E6roo(B-oI), 1983/72, vol. 37, Divers, Mitbericht zum Antrag des Finanz- \& Zolldepartement vom I3. April 1970, EJPD, 08.05.1970. 
janvier 1970, dans le but de corriger le projet de révision ${ }^{100}$. Parallèlement, les dirigeants de la BNS prennent position contre la proposition du Département politique fédéral citée plus haut, consistant à faire dépendre l'octroi d'une opération d'exportation de capitaux des intérêts généraux du pays et non plus seulement de ses intérêts économiques. La BNS demande de ne pas donner suite à cette suggestion. Faire de l'exportation de capitaux un enjeu de politique extérieure remettrait en question la politique de neutralité, selon les dirigeants de la banque centrale:

L'extension des possibilités de recours contre l'exportation de capitaux permettrait d'interdire des opérations d'exportation de capitaux pour des considérations purement politiques (par exemple, contre l'Afrique du Sud ou la Rhodésie). Un tel élargissement apporterait à notre avis plus d'inconvénients que d'avantages: en faisant aussi dépendre l'exportation de capitaux de critères de politique extérieure, l'État entre en contradiction avec la politique de neutralité. Un abandon de la stricte neutralité nuirait sans aucun doute à la position de notre pays en tant que place financière internationale. Si l'autorisation de l'exportation de capitaux dépendait aussi de raisons purement politiques, non seulement le refus, mais implicitement également l'approbation de l'exportation de capitaux deviendrait une prise de position politique (parfois épineuse). [...] On peut même considérer comme un avantage du système actuel que le Conseil fédéral puisse se prévaloir du fait que la loi ne l'autorise pas à faire opposition à l'exportation de capitaux pour de simples raisons de politique extérieure ${ }^{101}$.

Pour les dirigeants de la banque centrale, le système en vigueur depuis I934, qui prévoit que les questions de politique internationale n'entrent pas en compte dans l'examen de l'opportunité des opérations d'exportation de capitaux, ne doit pas être modifié, car il a fait ses preuves. Pour le dire autrement, les éventuels reproches qui pourraient être adressés au gouvernement et aux banques suisses au sujet de l'intensité des relations financières avec les régimes d'apartheid, et de la non-application des sanctions internationales, peuvent être en partie repoussés en avançant des arguments sur la portée limitée de l'article 8 de la loi sur les banques. Ce qui est vrai pour l'Afrique du Sud et la Rhodésie s'appliquerait également, par extension, aux régimes dictatoriaux d'Amérique latine ou aux pays du Bloc de l'Est.

\section{Délibérations parlementaires sur la révision de la loi sur les banques (mai 1970 - mars 1971)}

En mai 1970, le Département fédéral des finances et des douanes achève la rédaction du projet de loi, accompagné de son message, qui est soumis à

100 AFB, E6520(B), I980/39, vol. I7, PV CFB, 27.01.1970, p. 4-7.

101 AFB, E6Ioo(B-oI), I980/49, vol. 58, Vernehmlassung Revision I969, Lettre de Paul Ehrsam (BNS) au service juridique de l'AFF, II.03.1970. 
l'Assemblée fédérale ${ }^{102}$. Deux changements importants sont à signaler par rapport au texte en discussion à l'automne 1969. D'une part, le Conseil fédéral décide de réintégrer la proposition du DFJP et DPF sur la prise en considération des intérêts généraux du pays, plutôt que les intérêts économiques, dans l'examen des opérations d'exportation de capitaux. Cette variation va à l'encontre des intérêts des banques et de la Banque nationale. D'autre part, le projet contient cette fois une refonte partielle des dispositions sur l'assainissement, la faillite et le concordat des banques. Le DFFD a en fait repris une proposition de révision du Tribunal de commerce de Zurich. S'il ne précise pas la portée du secret bancaire en cas de procédure concordataire ou de faillite comme le souhaitait depuis une dizaine d'années l'ASB (cf. chap.VII.3), cet ajout satisfait néanmoins les milieux bancaires, en ce sens qu'une nouvelle révision de la loi sur les banques, qui aurait justement eu pour but de traiter ces points, peut être évitée à court terme.

Le traitement parlementaire du projet se fait d'abord par la Chambre haute, en commission entre fin août et fin septembre 1970, suivie d'une unique séance plénière. Le Conseil national, quant à lui, y consacre une double séance en commission début novembre, puis deux séances plénières en décembre 1970. L'élimination des divergences entre les deux conseils a lieu fin janvier 197I, avant que le texte final ne soit adopté le II mars I97I; il entre en vigueur au $\mathrm{I}^{\text {er }}$ juin de la même année.

La composition des commissions ad hoc du Conseil des États et du Conseil national laisse une place importante aux politiciens proches des milieux bancaires. Une quinzaine des 36 députés choisis pour discuter de la révision de la loi sur les banques sont proches des banques par leurs fonctions extra-parlementaires. Onze d'entre eux figuraient même en décembre 1967 sur une liste dressée par l'ASB, recensant les membres de l'Assemblée fédérale proches des banques ${ }^{103}$. À l'instar de leurs prédécesseurs dans les années I930, les dirigeants de l'Association suisse des banquiers identifient d'évidence le Conseil des États comme la chambre à influencer en priorité. Avant même la première réunion de la commission des sénateurs, ses membres se voient adresser un courrier de dix pages par l'ASB ${ }^{104}$. Les milieux bancaires y plaident pour des retouches dans cinq domaines. Sur la régulation des banques étrangères, l'ASB demande que la compétence de statuer sur la réciprocité revienne à la CFB plutôt qu'au Conseil fédéral et que la raison sociale doive clairement indiquer l'origine étrangère de la banque. Deuxièmement, dans le domaine des mesures prudentielles sur les fonds propres et la liquidité, les banquiers demandent que soient rejetées les revendications du

102 «Message du Conseil fédéral à l'Assemblée fédérale concernant la revision de la loi sur les banques (Du I3 mai 1970) ", Feuille fédérale, 1970, vol. I, nº 24, 19.06.1970, p. II57-I218.

103 AASB, "Liste der eidgenössischen Parlamentarier, die Banken nahestehen " annexée au procès-verbal de la $269^{\mathrm{e}}$ séance du Conseil d'administration de l'ASB, I3.12.1967. Pour la composition exacte des commission parlementaires de 1970, cf. annexe A.5 du PDF.

104 AfZG, IB Vorort-Archiv 72.2.I (Revision I97I), Lettre de l'ASB aux membres de la commission du Conseil des États pour la révision de la loi sur les banques, I2.08.1970. 
Parti socialiste et de l'Union syndicale suisse en faveur d'un coefficient maximal de placements à l'étranger; ils réitèrent aussi leur volonté de reconnaitre les réserves latentes comme fonds propres. Troisièmement, sur la question de l'exportation de capitaux, l'ASB exhorte les sénateurs à refuser la nouvelle formulation qui mentionne les « intérêts généraux du pays ", pour ne pas faire de la loi sur les banques un instrument de politique étrangère. Quatrième requête : la disposition qui autorise la Commission fédérale des banques à exiger d'une société d'audit toutes les informations dont elle a besoin doit être limitée à "des cas particuliers». Enfin, les banquiers intiment aux Conseillers aux États le mot d'ordre d'approuver sans amendements la version proposée par le Conseil fédéral de l'art. 47 sur le secret bancaire. Il est remarquable que cet argumentaire de l'ASB prenne la peine de mentionner explicitement la simple acceptation d'une disposition du projet de révision - et non sa modification. Cela témoigne du caractère très sensible de cette prescription pour les milieux bancaires.

Comme le relève avec une pointe d'orgueil le secrétaire Max Oetterli, sur quatre des cinq points soulevés, la commission du Conseil des États a suivi les recommandations de l'ASB. Seule la disposition qui autorise la CFB à élever exceptionnellement les exigences des fonds propres et de liquidité n'a pas été supprimée par les sénateurs. Pour Oetterli, «nos postulats ont globalement rencontré un très bon écho, [...] les délibérations dans la commission du Conseil des États ont connu un déroulement très favorable pour les banques" ${ }^{105}$. En effet, au cours des délibérations des sénateurs le 26 août 1970, celui qui se fait le porte-parole des propositions de l'ASB, le radical saint-gallois Willi Rohner, obtient un franc succès. Sur la question de l'exportation de capitaux et du débat entre «intérêts économiques" et "intérêts généraux » du pays, il faut préciser qu'il ne rencontre pas de forte opposition, puisque même le conseiller fédéral Nello Celio, censé en principe défendre le texte soumis, se désolidarise de la version du Conseil fédéral et annonce sa préférence personnelle pour la proposition de l'ASB/Rohner ${ }^{106}$. Sur un autre point, celui des pouvoirs de renseignement de la CFB que l'ASB voudrait voir limiter, on assiste à une scène saississante qui témoigne du poids considérable que confere les sénateurs aux demandes de changement intimés par les milieux bancaires. Le président de la commission, le radical Blaise Clerc rappelle alors à ses pairs que le point en question est contesté par la faitière des banquiers et les interpelle pour savoir si l'un d'entre eux veut reprendre ce postulat ${ }^{107}$. Malgré cette piqûre de rappel, aucun conseiller aux États ne se réapproprie l'amendement suggéré par l'ASB, au grand étonnement du président de la commission.

105 AASB, Procès-verbaux du Conseil d'administration de l'ASB, 28I ${ }^{\mathrm{e}}$ séance, 25.09.1970, p. II et I3.

106 AFB, E6Ioo(B-oI), I983/72, vol. 37, Procès-verbal de la commission du Conseil des États pour la révision de la loi sur les banques, 26.08.1970, p. 62.

107 Ibid., p. 66. Cit. originale de Clerc: "Je rappelle que l'Association suisse des banquiers propose de donner un caractère plus restrictif à la disposition [...]. La proposition est-elle reprise par un membre de la Commission?» 
La commission ad hoc du Conseil national, même si elle ne modifie pas fondamentalement le caractère très restreint des amendements effectués dans la révision, apporte quelques changements moins conformes aux intérêts bancaires. Sur deux points, les corrections effectuées par les sénateurs sur demande de l'ASB sont annulées. D'une part, la compétence sur l'examen de la réciprocité pour les banques étrangères est de nouveau confiée au Conseil fédéral au lieu de la Commission fédérale des banques. D'autre part, la clause discriminatoire qui exigeait des banques étrangères qu'elles fassent apparaittre leur caractère allochtone dans leur raison sociale est atténuée; les conseillers nationaux, sensibles aux arguments de l'industrie chimique, reviennent à la formulation qui demande simplement de ne pas laisser présumer un caractère suisse. En outre, les députés socialistes et, dans une moindre mesure, agrariens, avancent un certain nombre de propositions qui ne débouchent cependant pas sur un changement effectif (soit parce qu'elles sont rejetées par la majorité, soit qu'elles sont retirées avant de passer au vote). Max Weber, l'ancien conseiller fédéral socialiste, doyen de la commission et qui avait activement participé à l'élaboration de la législation dans les années 1930, suggère par exemple que les avoirs en or ne soient plus considérés comme des disponibilités. Son collègue de parti Otto Stich poursuit sur la même lancée, en exigeant que les placements à l'étranger soient restreints, ou au moins explicitement publiés de manière détaillée dans les bilans bancaires, et que les opérations fiduciaires figurent également au bilan des banques. Sur tous ces points, le conseiller fédéral Celio et la majorité de la commission rejettent les propositions en estimant qu'il s'agit de problèmes techniques à régler dans l'ordonnance et non dans la loi. Stich soulève encore la question de l'indépendance des sociétés d'audit, et s'engage dans un débat avec le vice-président de la CFB Karl Etter ; la discussion est abrégée par le président de la commission, le radical Hummler, qui conclut en déclarant que le problème est "très délicat " ${ }^{108}$. Otto Stich connait en revanche plus de succès avec son amendement sur les dispositions pénales, consistant à alourdir la peine prévue pour une falsification de bilan. Quant aux agrariens, leur représentant Hanspeter Fischer tente d'introduire dans la loi sur les banques une disposition obligeant celles-ci à investir une partie de leurs avoirs, fixée en pourcentage selon le type de banques, en placements hypothécaires. Alors que le socialiste Jean Riesen soutient cette démarche, Nello Celio et la majorité de la commission s'y opposent avec succès. Pour en terminer avec ces délibérations, relevons encore que l'article 47 sur le secret bancaire ne donne lieu à aucune discussion. Aucun des six représentants

108 Cette altercation entre Otto Stich et Karl Etter n'est étonnamment pas retranscrite dans le procès-verbal de la commission du Conseil national : AFB, E6Ioo(B-oI), I983/72, vol. 37, Procès-verbal de la commission du Conseil national pour la révision de la loi sur les banques, 06.II.I970, p. 70. Elle est en revanche rapportée dans le compte-rendu des délibérations rédigé par Paul Ehrsam (BNS) à l'adresse de la direction générale de la BNS : ABNS, I.3/1234, Parlament, Nationalratskommission, Notiz betreffend Bankengesetzrevision, signée Ehrsam, I2.II.I970. 
socialistes (Hermann Leuenberger, Jean Riesen, Emil Schaffer, Otto Stich, Max Weber et Edmund Wyss) ne juge bon de briser l'omerta voulue par l'ASB sur cette disposition et de soumettre une proposition.

Le débat au plénum de la Chambre du peuple, en décembre 1970, ne donne pas non plus lieu à une réforme radicale du projet de révision. À quelques nuances près, les députés valident le projet produit par leur commission. Mais cette fois-ci l'article sur le secret bancaire est tout de même discuté, malgré les avertissements du libéral genevois Raymond Deonna, rapporteur francophone, qui estime que ce serait « une erreur totale» de s'occuper dans le cadre de cette révision législative du " problème du secret des banques, qui a l'air de tarabuster singulièrement M. Ziegler, ce serpent de mer dont on peut facilement s'emparer lorsqu'on a envie de faire un petit peu de battage ${ }^{109}$. Ces attaques personnelles ne suffisent pas à décourager le professeur de sociologie genevois. Il soumet en effet une proposition, consistant à supprimer l'article 47, ou, subsidiairement, à revenir à l'ancien texte de 1934. Jean Ziegler justifie son amendement par trois faisceaux d'arguments. Premièrement, il considère que les peines extrêmement lourdes prévues suscitent des critiques en Suisse comme à l'étranger. Deuxièmement, il met en évidence les difficultés pratiques, dans le régime actuel, de lever le secret bancaire dans une procédure pénale (le nom du titulaire du compte, le lieu de dépôt et le montant approximatif doivent être connus). Enfin, en s'inscrivant dans la continuité des positions prises récemment par la conférence des églises suisses, Ziegler insiste sur la façon dont le secret bancaire favorise l'évasion de capitaux depuis les pays du Tiers-monde et sape les efforts faits dans l'aide au développement. L'unique soutien explicite que reçoit la proposition Ziegler provient du député d'extrême-droite de l'Action nationale, James Schwarzenbach (I9II-I994), qui présente son geste comme un vote de défiance (dont il sait d'avance qu'il ne portera pas à conséquence) à l'égard de l'éthique du monde de la finance. Cette alliance contre-nature entre l'unique député du mouvement populiste xénophobe et l'un des socialistes les plus marqués à gauche de l'hémicycle n'obtient qu'un score modeste au moment du vote. La suppression de l'article sur le secret bancaire est rejetée par 85 contre 27 voix ${ }^{110}$.

Relevons encore, pour clore sur ce sujet, que Jean Ziegler reprend dans ses déclarations au Parlement l'explication erronée sur les origines de l'article qu'il conteste, un récit façonné par les milieux bancaires dans les années 1960. Le secret bancaire aurait été inscrit dans la loi sur les banques en I934 pour protéger les citoyens allemands, en particulier ceux de religion juive, pour les protéger des persécutions des autorités hitlériennes ${ }^{111}$. Cette contre-vérité est sans doute

109 "Loi sur les banques. Révision", Bulletin officiel de l'Assemblée fédérale, Conseil national, I970, vol. IV, IO.I2.1970, p. 745 .

110 Ibid., p. 78I.

111 Ziegler : «Le secret bancaire, comme on le sait, a été institué en 1935 par la loi aujourd'hui en revision dans une situation historique qui justifiait une telle mesure : il s'agissait de protéger des citoyens allemands, de religion israélite pour la plupart, contre les persécutions de la 
répétée naïvement par le sociologue genevois, car elle figure déjà dans le message du Conseil fédéral de mai $1970^{112}$. Il reste cependant piquant que l'un des plus grands pourfendeurs du secret bancaire prenne à son compte une explication historique incorrecte, échafaudée par les milieux bancaires, et servant de légitimation pour en consolider la valeur morale.

En dernière analyse, le traitement parlementaire du projet de révision de la loi sur les banques qui aboutit en mars I97I se distingue par sa rapidité. Il faut à peine plus de six mois pour mettre sous toit la réforme. De plus, on constate que très peu de modifications significatives sont apportées par les députés au texte soumis par le gouvernement. Des pans entiers de la réglementation demeurent inchangés. Les principes fondamentaux sur lesquels repose le système de surveillance des banques, à savoir le rôle prépondérant des sociétés d'audit privées et la faiblesse structurelle de l'instance étatique, ne sont pas remis en question.

En ce sens, le bilan de toute l'affaire est très positif pour les représentants des banques. Ceux-ci n'avaient-ils pas, à de nombreuses reprises, exprimé des craintes à l'égard d'une discussion parlementaire et publique des dispositions de la loi sur les banques? Si l'intervention Ziegler sur le secret des banques a bien eu lieu, elle ne porte pas à conséquence. Aussi, au lendemain de l'adoption du texte par le Conseil national, le I6 décembre 1970, Max Oetterli déclare avec soulagement et une pointe de fierté: "Nous aurons aussi à l'avenir en Suisse une loi sur les banques libérale, qui n'entravera pas inutilement le développement des banques. ${ }^{113}$ Les banquiers se réjouissent en particulier du rejet très marqué par les parlementaires de la proposition Ziegler ${ }^{114}$. Alfred E. Sarasin conclut ce rapport enthousiaste par les mots suivants: «du point de vue des banques, l'affaire est passée comme une lettre à la poste» ${ }^{115}$.

police d'Hitler. Cette mesure se justifiait à l'époque ». Bulletin officiel de l'Assemblée fédérale, Conseil national, I970, vol. IV, I0.I2.1970, p. 750. Pour une déconstruction de la légende du secret bancaire présenté comme un rempart contre les spoliations nazies à l'égard des juifs allemands, voir Guex, art. cit., I999.

112 "Message du Conseil fédéral à l'Assemblée fédérale concernant la revision de la loi sur les banques (Du I3 mai 1970)", Feuille fédérale, I970, vol. I, no 24, 19.06.1970, p. II75: «Il s'agissait en fait de lutter contre les multiples tentatives des régimes totalitaires de l'époque d'appliquer en Suisse leur législation sur les changes, qui aboutissait souvent à une expropriation, et de s'approprier la fortune déposée dans nos banques par des personnes poursuivies pour des motifs politiques ou racistes".

113 AASB, Procès-verbaux du Conseil d'administration de l'ASB, $282^{\mathrm{e}}$ séance, I6.I2.1970, p. 15.

114 On apprend par ce biais que les 27 voix qui ont accepté la suppression du secret bancaire proviennent d'une partie du groupe socialiste, d'une partie de l'Alliance des Indépendants et de James Schwarzenbach.

115 AASB, Procès-verbaux du Conseil d'administration de l'ASB, $282^{\mathrm{e}}$ séance, I6.12.1970, p. I6-17. 


\section{IX.3. LA LOI SUR LES BANQUES RÉVISÉE DU 11 MARS 1971 ET L'ORDONNANCE DU 17 MAI 1972: UN AJUSTEMENT MINEUR SANS RÉFORME PROFONDE}

Le I3 mars I97I, la dernière divergence subsistant entre le Conseil des États et le Conseil national est résolue. Les deux chambres approuvent le texte, presque à l'unanimité (une opposition au Conseil national) ${ }^{116}$. Mais les négociations sans doute les plus lourdes de conséquences n'étaient pas encore bouclées. En effet, en plus d'une révision de la loi même, le gouvernement s'attèle à une adaptation de son ordonnance d'exécution. Nous l'avions déjà souligné plus bas, l'ordonnance - ou règlement d'exécution constitue la norme précise qui règle dans le détail les modalités d'application des principes généraux inscrits dans la loi fédérale. Elle est du ressort du Conseil fédéral et ne requiert pas l'approbation du parlement. Souvenonsnous encore que cette ordonnance, dont la première mouture date de février I935, avait connu une première révision à la fin des années I950, qui aboutit en août 196I (cf. chap. VII.4). Les milieux bancaires étaient alors parvenus à obtenir un assouplissement des exigences de fonds propres - combiné à un léger renforcement de celles de liquidité -, qui leur permettait de poursuivre leur impétueuse croissance sans recourir à des augmentations de capital fréquentes. En 1970 également, l'Association suisse des banquiers identifie rapidement la signification importante des points négociés dans l'ordonnance. «Lors de la révision du règlement d'exécution, nous devons accorder une attention particulière à la définition des dispositions sur les fonds propres et la liquidité ${ }^{117}$, estime son secrétaire Max Oetterli en septembre I970.

\section{IX.3.1. L'ordonnance d'exécution de mai 1972 : fonds propres, liquidité, opérations fiduciaires, bis repetita non placent}

Dès février 197I, les travaux en vue de l'ajustement de l'ordonnance débutent. Au total, huit séances de la commission d'experts mise sur pied par le DFFD pour l'occasion sont nécessaires pour trouver un accord sur les prescriptions «techniques» de ce règlement. Il faut donc souligner que la durée des délibérations de l'ordonnance dépasse celle des réunions organisées pour préparer la législation à proprement parler. Le groupe de travail informel créé en février 197I est composé de dix experts.

Le directeur général de l'UBS, Philippe de Weck, malgré la présence de deux secrétaires de l'ASB, regrette l'absence de banquiers : «la composition de cette commission montre qu'elle n'est pas formée de personnes qui connaissent

\footnotetext{
116 Pour un résumé des principales modifications: Schütz, op. cit., 1974; Riniker, op. cit., 1974, p. 3I-47.

117 AASB, Procès-verbaux du Conseil d'administration de l'ASB, 281 $\mathrm{I}^{\mathrm{e}}$ séance, 25.09.1970, p. I3.
} 
Tableau 26. Composition de la commission d'experts chargée d'élaborer l'ordonnance d'exécution de mai 1972 (février-novembre I97I)

\begin{tabular}{|l|l|}
\hline $\begin{array}{l}\text { Bernhard Müller (192I-2006), } \\
\text { président }\end{array}$ & Chef du service jur. de l'Administration fédérale des finances \\
\hline Emilio Albisetti (1909-1998) & Directeur de la Spar- und Leihkasse Bern. Professeur de droit \\
\hline Benno Lutz (1923-2002) & $\begin{array}{l}\text { Prof. de gestion d'entreprise à la Haute école de Saint-Gall, } \\
\text { directeur de la société fiducaire Neutra }\end{array}$ \\
\hline Robert Gautier & Directeur de la société fiduciaire OFOR \\
\hline Max Oetterli (1916-2000) & Secrétaire ASB \\
\hline Markus Lusser (1931-1998) & Secrétaire ASB \\
\hline Paul Ehrsam (I917-2008) & Consultant juridique BNS \\
\hline Daniel Bodmer (1917-1980) & Chef du secrétariat de la CFB \\
\hline Jacques Bergün Schuster & Secrétariat CFB \\
\hline Heinz Portmann (1930-1999) & Journaliste à la Neue Zürcher Zeitung \\
\hline
\end{tabular}

Source: ABNS, I.3/1235, Vollziehungsverordnung 1972, Expertenkommission.

véritablement les problèmes traités dans l'ordonnance ${ }^{118}$. Il est vrai que, par rapport aux groupes de travail constitués dans les années I930, et, dans une moindre mesure, même en 1959-1960, la commission d'experts de I970 laisse une place moindre aux dirigeants bancaires ${ }^{119}$.

Le premier avant-projet discuté est l'œuvre du secrétariat de la CFB : il reprend un projet de 1966 retravaillé. À l'issue de sept séances de délibérations de la commission d'experts, un projet d'ordonnance révisée entre en procédure de consultation. Le cercle des instances entendues à l'occasion reste très réduit : il se limite aux organisations faittières des banques et des sociétés fiduciaires. Sans entrer dans les détails des modifications apportées par la commission d'experts au printemps I97I, relevons que les deux représentants de l'ASB sont régulièrement désavoués dans leurs interventions par une majorité de commissaires. Sur plusieurs points, le texte élaboré par le groupe de travail ne convient pas entièrement aux milieux bancaires.

L'affaire semble assez importante pour justifier la création par l'organisation faîtière, en septembre 197I, d'une commission ad hoc de I4 banquiers représentant les différents groupes de banques ${ }^{120}$. Pour le secrétariat de l'Association suisse des banquiers, la création de ce comité vise aussi à prévenir les risques de dissensions internes aux milieux bancaires, qui risqueraient d'affaiblir leur position face aux autorités publiques. « Nous obtiendrons le plus probablement des solutions qui correspondent aux besoins des banques, si nous représentons

118 AASB, Procès-verbaux du Comité de l'ASB, I30 séance, 22.02.I97I, p. I4.

119 Pour la commission de I933, cf. chap. IV.I, tableau 7 ; pour celle de la révision de l'ordonnance qui aboutit en 196I, cf. chap.VII.4, note 137 .

120 AASB, J.4 Bankengesetz 197I-I974, Lettre du secrétariat de l'ASB aux membres du CdA ASB, 03.09.1971. 
nos intérêts de manière unie et cohérente ${ }^{121}$, avertit le secrétariat. Cet appel à la discipline unitaire ne sera pas respecté par tous. L'Union des banques cantonales suisses décide de transmettre au DFFD sa propre prise de position sur le projet d'ordonnance, qui diverge sur certains points de l'opinion défendue par l'ASB. Cette façon de faire suscite de vives remontrances, non seulement du secrétaire de l'ASB, Max Oetterli, qui se dit surpris et pense que les banques cantonales auraient dû se tenir aux accords passés, mais également des représentants des grandes banques. Philippe de Weck y voit un «incident qui pourrait remettre en question les relations et le climat de confiance existant entre nos banques", tandis que son rival Hugo Grob (1922-1982), directeur général de la SBS, considère l'affaire comme "très grave " ${ }^{122}$. Quant au représentant de la troisième grande banque, le Crédit Suisse, Heinz R. Wuffli, il exprime ouvertement son irritation par une expression euphémique : Nous sommes étonnés". Toutes ces admonestations donnent lieu à de plates excuses de la part d'Albert Matter, le président de l'UBCS, qui qualifie cette indiscipline d' "accident de parcours".

Au-delà de ces divergences, sur quels points précis les milieux bancaires remettaient-ils en question le projet d'ordonnance de mai I97I ? Distinguons trois objets de critique ${ }^{123}$. Premièrement, l'article de l'ordonnance qui définit la notion de réciprocité, centrale dans l'octroi d'une autorisation d'ouverture à une banque étrangère, ne convient pas aux banquiers. Ils souhaiteraient une définition plus précise, qui soit à même d'empêcher l'expansion des banques étrangères en Suisse. Deuxièmement, les nouvelles dispositions visant à limiter la concentration de gros risques, à savoir la fixation d'un plafond de crédits à un seul client en fonction des fonds propres, sont jugées trop restrictives. Pour éviter des difficultés aux plus petites banques, l'ASB réclame un assouplissement des coefficients.

La troisième et principale critique des banquiers porte de près ou de loin sur le domaine des exigences de fonds propres et de liquidité et la façon de porter au bilan un certain nombre d'opérations. Plus précisément, l'ASB conteste dans ce domaine quatre modifications introduites dans le projet d'ordonnance de mai I97I : la détermination d'un ratio de fonds propres plus élevé pour les actifs étrangers (c'est-à-dire une forme de limitation des placements à l'étranger des banques), la comptabilisation des réserves d'or non plus comme disponibilités, mais comme actifs facilement mobilisables, le durcissement des exigences de liquidité générale, et enfin l'adaptation de la façon de comptabiliser les opérations fiduciaires. Ces quatre questions, qui peuvent sembler de prime abord d'ordre technique et d'importance secondaire, touchent en fait des enjeux cruciaux pour les banques. Elles méritent donc d'être présentées plus en détail ici.

121 Ibid.

122 AASB, Procès-verbaux du Conseil d'administration de l'ASB, $285^{\mathrm{e}}$ séance, 24.09.I97I, p. II.

123 Cette analyse repose sur la prise de position de l'ASB, longue de 27 pages, de septembre I97I. ABNS, I.3/1236 Vollziehungsverordnung 1972, Interessierte Organisationen, Lettre de l'ASB à Nello Celio, 29.09.1971. 
Le problème de la couverture en fonds propres des placements étrangers des banques ne date pas du début des années 1970. Souvenons-nous que lors de l'élaboration de la législation bancaire dans les années I930, un ratio fondamentalement similaire à celui qui est discuté dans l'ordonnance de I97I avait vu le jour dans les projets de loi, puis avait disparu sous l'effet d'une fine tactique mise au point par l'ASB (cf. chap. III.3 et IV.I). En I97I, ces efforts visant à « rejeter de manière résolue la pénalisation des placements étrangers" sont sapés par l'opinion divergente des banques cantonales, qui, elles, soutiennent la disposition. De quoi en retourne-t-il ? Les autorités fédérales voudraient en fait, dans la foulée des promesses faites aux parlementaires socialistes, introduire une disposition qui exige une couverture des actifs étrangers par les fonds propres plus élevée, en partant du principe qu'ils représentent des risques accrus. D'après le projet de mai 1971, les banques auraient dû fournir des fonds propres à hauteur de $15 \%$ au lieu des Io \% habituels pour couvrir leurs avoirs à l'étranger. Selon les calculs de la BNS, cette modification aurait nécessité, pour les cinq grandes banques - principales concernées -, un surplus de fonds propres de l'ordre de I.7 milliard de francs ${ }^{124}$. Dans son exposé adressé au DFFD, l'ASB fait valoir trois arguments pour refuser cet amendement. Le risque pour les créanciers sur les positions étrangères ne serait pas plus élevé. Cette modification «nuirait très considérablement à la position de la Suisse en tant que place financière internationale " ${ }^{125}$. Enfin, elle laisse planer la menace d'une augmentation significative du taux d'intérêt domestique, qui résulterait à la fois de la forte sollicitation du marché des capitaux national et de la nécessité de fournir (et de rétribuer) les fonds propres additionnels. Lors de la réunion finale de la commission d'experts de novembre 197I, l'ASB obtient sur ce point une première victoire. En partie grâce au soutien de la BNS, le taux de couverture pour actifs étrangers est réduit de 15 à I2 \%. Ce changement est exigé de manière autoritaire par les représentants des banques; Oetterli déclare alors: "L'ASB n'est pas disposée à faire des concessions sur ce point. » ${ }^{126}$ Avec le coefficient de I2 \%, la «facture " pour les grandes banques passe de I.7 milliard à environ 600 millions de francs. La Commission fédérale des banques compte dans ce cas parmi les partisans d'une limitation des placements étrangers. Elle considère que le triplement en l'espace de quatre ans (1968-197I) des investissements étrangers des banques qui atteignent la somme colossale de 40 milliards de francs, n'a en aucune façon été compensée par un renforcement adéquat des fonds propres ${ }^{127}$. Mais la réduction de I5 à I2 \% ne satisfait toujours pas les banquiers. Profitant d'une lettre

124 ABNS, Procès-verbaux de la Direction générale de la BNS, II.II.I97I, p. I636.

125 ABNS, I.3/I236 Vollziehungsverordnung I972, Interessierte Organisationen, Lettre de l'ASB à Nello Celio, 29.09.197I.

126 ABNS, I.3/1235, Vollziehungsverordnung 1972, Expertenkommission, Procès-verbal des séances de la commission d'experts pour la révision de l'ordonnance de la loi sur les banques, I7.II.I97I, p. I2.

127 Selon le rapport du DFFD au CF du 27.03.1972. ABNS, I.3/1235, Vollziehungsverordnung 1972, Bundesstellen. 
adressée à Nello Celio pour le féliciter de son élection brillante en tant que président de la Confédération, l'ASB y glisse quelques compliments sur la façon dont les relations avec le DFFD se sont intensifiées depuis qu'il est dirigé par lui :

C'est essentiellement grâce à vous personnellement que dans la réalisation des principales tâches qui nous préoccupent mutuellement - par exemple dans la politique monétaire ou conjoncturelle, dans la révision de la loi sur les banques et dans les nouvelles codifications du droit fiscal à venir - des solutions, qui prennent en compte de manière bien pesée à la fois le plein respect des intérêts de l'État et de la collectivité, les intérêts légitimes des banques et la position si importante pour notre pays de centre financier international, ont été recherchées et trouvées ${ }^{128}$.

Après les courbettes viennent les sollicitations. Les banquiers demandent l'organisation de réunions pour discuter certaines dispositions de l'ordonnance qui entraînent des modifications de la plus haute importance. Ces démarches portent leurs fruits. Le DFFD de Celio décide d'accorder de nouvelles concessions aux banquiers sur la question des actifs étrangers. Le taux de couverture sera non seulement de I2 \%, au lieu des I5 réclamés par la Commission fédérale des banques, mais ce ratio ne s'appliquera que si les placements étrangers dépassent $50 \%$ du bilan total. Comme le relève le DFFD, cette nouvelle clause signifie que la disposition ne s'appliquera, dans les faits, qu'aux banques étrangères actives en Suisse ${ }^{129}$. Pour la grande majorité des banques suisses, et essentiellement pour les grandes banques, le taux de couverture des actifs étrangers reste le même que pour les autres avoirs (Io \%). La seule justification apportée par Celio pour motiver ce recul consiste à le considérer comme une première étape dans un domaine où il faut agir avec grande précaution. Retenons donc que l'ASB, au terme de ce processus, est parvenue à transformer une disposition menaçante - et introduite sous la pression de parlementaires socialistes -, qui aurait permis d'exiger plus de fonds propres à mesure que grandissaient les placements étrangers, en une mesure qui affecte uniquement les banques étrangères.

Le second point remis en question par les banquiers concerne la comptabilisation des avoirs en or. Selon le projet d'ordonnance, et là aussi, à la suite d'une intervention d'un député socialiste, l'or ne doit plus être considéré comme des disponibilités au même titre que les montants déposés en compte de virement auprès de la BNS, mais comme actifs facilement mobilisables, à savoir l'équivalent de bons du Trésor, par exemple. Ce changement est lié à la dissolution du Pool de l'or en mars i968, qui a notamment pour conséquence la création d'un marché libre de l'or ${ }^{130}$. Tout l'enjeu de cette affaire est de savoir à

\footnotetext{
128 AASB, J.4 Bankengesetz 197I-I974, Lettre de l'ASB à Nello Celio, 27.I2.197I.

129 ABNS, I.3/1235, Vollziehungsverordnung 1972, Bundesstellen, rapport du DFFD au Conseil fédéral, 27.03.1972.

130 Sur la réorganisation du marché international de l'or entre 1968 et I971 : Bott, op. cit., 2013, p. 317-350.
} 
quel titre les avoirs en or sont comptabilisés dans le calcul de deux ratios de liquidité. Selon la BNS, fin 1970, l'or ne représente pourtant que 600 millions de francs sur des avoirs en caisse d'un total de 7.I milliards chez les cinq grandes banques, soit $8.5 \%{ }^{131}$. À l'automne 197I, l'ASB réclame donc une solution de compromis, en proposant que les avoirs en or puissent faire partie des disponibilités, à condition que celles-ci dépassent déjà les minimas légaux sans tenir compte de l'or. Cette proposition est rejetée par la commission d'experts. Comme l'indique le spécialiste de la NZZ Heinz Portmann, l'or n'est plus un moyen de paiement stable; en cas de dévaluation du dollar, les actifs en or feraient l'objet d'une vive spéculation ${ }^{132}$. En mars 1972 , le DFFD décide de suivre la commission d'experts sur ce point et de désavouer l'ASB.

Cette question de la comptabilisation de l'or s'inscrit plus généralement dans la troisième préoccupation majeure des banquiers sur le projet d'ordonnance de mai 197I : le renforcement des exigences de liquidité générale. En plus de la modification dans la prise en compte de l'or, deux autres renforcements sont prévus. D'une part, les prêts interbancaires (sous le poste "avoirs en banque à vue ») réalisés à courte échéance pour «repolir» la liquidité affichée en fin d'année, une pratique dite de toilettage de bilan, ne doivent plus être pris en compte dans le calcul de la liquidité. D'autre part, les coefficients minimaux exigés sont relevés d'environ $30 \%$, malgré l'opposition initiale de l'ASB qui fait pression en présageant que la hausse des exigences de liquidités induira une limitation de l'octroi de crédits, ce qui provoquera successivement une augmentation des taux d'intérêt intérieurs, un renchérissement du coût de la construction et finalement une poussée des loyers ${ }^{133}$. Ces menaces catastrophistes ne suffisent pas à convaincre le Département des finances. Dans le projet transmis au Conseil fédéral, il suit l'avis de la commission d'experts et propose un durcissement des exigences de liquidité.

Le quatrième et dernier domaine litigieux concerne la façon de porter au bilan les opérations fiduciaires. Les opérations et dépôts fiduciaires (Treuhandgeschäfte) constituent une particularité du système financier suisse ${ }^{134}$. Il s'agit de transactions effectuées par les banques, mais pour le compte et au risque du client. Elles ne sont en principe pas comptabilisées au bilan et, dans les faits, prennent la forme de placements sur le marché des Eurodollars et échappent à l'impôt anticipé de $30 \%$ perçu sur les intérêts en Suisse ${ }^{135}$. En grande partie, ces

131 ABNS, Procès-verbaux de la Direction générale de la BNS, II.II.I97I, p. I639.

132 ABNS, I.3/I235, Vollziehungsverordnung 1972, Expertenkommission, Procès-verbal des séances de la commission d'experts pour la révision de l'ordonnance de la loi sur les banques, I7.II.I97I, p. I8.

133 ABNS, I.3/1236 Vollziehungsverordnung 1972, Interessierte Organisationen, Lettre de l'ASB à Nello Celio, 29.09.1971, p. I4-I6.

134 Pour une étude juridique complète sur le phénomène: Pierre Helg, «Le placement et le crédit fiduciaires en droit suisse ", Faculté de Droit de l'Université de Genève, Université de Genève, 1982.

135 Les concepts d'euro-dollars et d'euro-marchés renvoient à l'explosion des transactions libellés en dollars américains sur les places financières européennes (et en particulier à 
fonds proviennent de l'étranger et sont placés à l'étranger. Pour le client, l'avantage essentiel consiste à permettre le contournement de l'impôt anticipé, qui depuis 1969 est également perçu sur les intérêts bancaires des comptes de clients étrangers ${ }^{136}$; les rémunérations supérieures de l'euro-marché rendent également ce type d'investissement attractif. Quant aux banques, elles trouvent dans la perception de commissions sur les opérations fiduciaires une source de revenus non négligeable ${ }^{137}$. En outre, le statut "hors-bilan» de cette activité permet de ne pas gonfler la couverture en fonds propres et en liquidité exigée.

Graphique I5. Évolution des opérations fiduciaires dans les banques suisses (1950-1984)

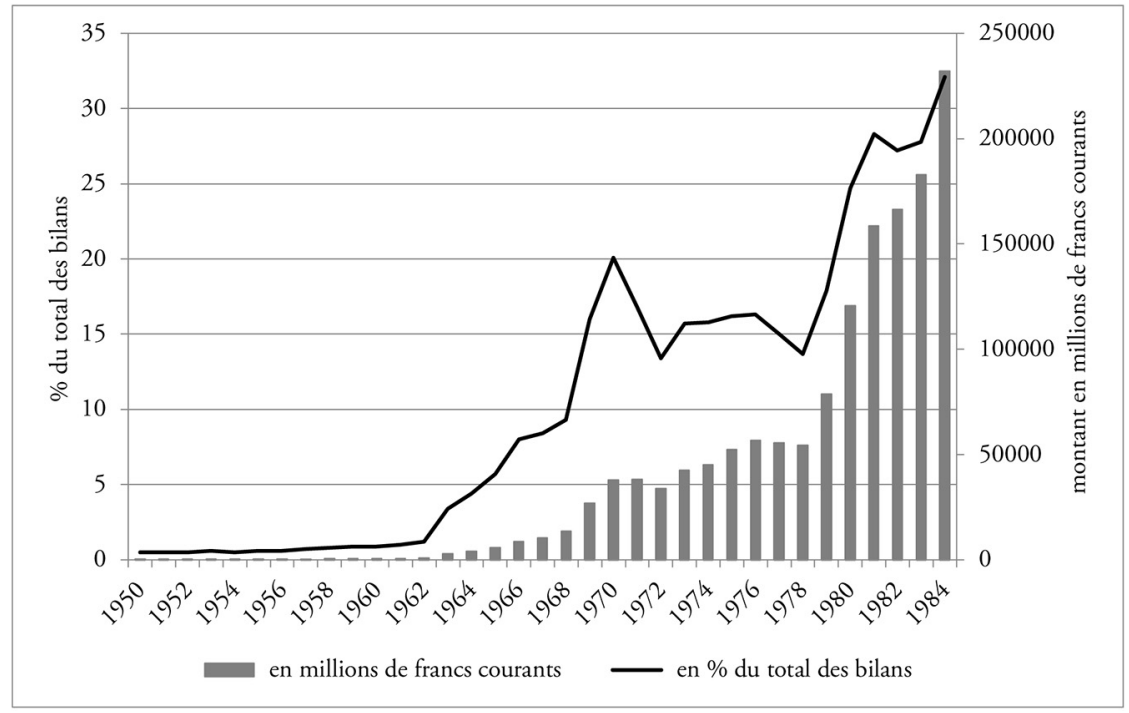

Source: Banque nationale suisse, Les banques en Suisse en 1984, Zurich : Orell Füssli, 1985, p. 46.

Alors que les opérations fiduciaires représentent moins de I \% des bilans totaux en 1960 ( 527 millions de francs), cette proportion passe à $20 \%$ en 1970 (37.9 milliards de francs). Cet accroissement phénoménal était aussi lié à la pratique de l'Administration fédérale des contributions consistant à considérer

Londres). Cf. notamment Catherine R. Schenk, «The Origins of the Eurodollar Market in London : 1955-1963", Explorations in Economic History, vol. 35, n² 2, 1998, p. 221-238. Sur les raisons qui ont incité la Suisse et la RFA à ne pas accueillir ces marchés, voir: Tobias Straumann, «Finanzplatz und Pfadabhängigkeit: Die Bundesrepublik, die Schweiz und die Vertreibung der Euromärkte (1955-1980)", in Christoph Maria Merki (éd.), Europas Finanzzentren. Geschichte und Bedeutung im 20. Jahrhundert, Frankfurt; New York: Campus Verlag, 2005, p. 245-268.

136 Leo Schuster, "Das Treuhandgeschäft der Banken in der Schweiz", in Oswald Hahn, Leo Schuster (éd.), Mut zur Kritik. Hans Linhardt zum 8o. Geburtstag, Bern; Stuttgart: Paul Haupt, 198I, p. 225-255, p. 228.

137 La commission oscille entre $0.25 \%$ et I \% de la somme investie, $0.5 \%$ étant le taux usuel dans la plupart des banques. Helg, op. cit., I982, p. 38 . 
que les intérêts produits par des placements fiduciaires ne sont pas soumis à l'impôt anticipé (loi fédérale sur l'impôt anticipé du I3 octobre 1965) ${ }^{138}$. Un client ressortissant d'un pays avec lequel la Suisse n'a pas signé d'accord de double imposition privilégie donc cette forme de placement pour échapper à la taxe mentionnée. Plus précisément, il convertit à la fin des années 1960, au moment où l'AFC modifie sa pratique sur l'impôt anticipé sur les intérêts bancaires, les avoirs qu'il avait jusqu'alors déposé sur des comptes de dépôts à terme (Festgeldkonti) en avoirs sur des comptes fiduciaires, qui eux sont exonérés. Quant aux groupes bancaires concernés, il faut souligner que les grandes banques et les banques étrangères se taillent la part du lion du marché des opérations fiduciaires; fin juillet 1971, sur 40 milliards de dépôts fiduciaires, 20 milliards sont confiés aux grandes banques et 15 milliards aux banques en mains étrangères ${ }^{139}$. Certaines banques privées en ont également fait leur spécialité : ainsi le directeur de la fiduciaire genevoise OFOR, Robert Gautier, affirme qu'il connaît des établissements au sein desquels le volume des opérations fiduciaires représente l'équivalent de IO à I2 fois la somme du bilan (!) ${ }^{140}$.

Entre 1968 et 1970, au moment où explosent les placements des grandes banques suisses sur les euro-marchés, une divergence dans la façon d'inscrire au bilan les opérations fiduciaires apparaît ${ }^{141}$. Alors que l'UBS choisit de ne pas les faire apparaittre au bilan, le Crédit Suisse et la SBS prennent le parti inverse et les comptabilisent au bilan, sans doute aussi pour ne pas se laisser décrocher par leur concurrente dans la course à la croissance bilancielle. À l'été 1970, des négociations entre les grandes banques pour parvenir à une pratique cohérente échouent. En décembre 1970, la CFB intervient, après avoir constaté l'incapacité de l'ASB à régler cette question, en promulguant une circulaire qui prescrit l'inscription au bilan des opérations fiduciaires, officialisant ainsi la pratique de la SBS et du CS ${ }^{142}$. Cette décision suscite également l'irritation de Nello Celio, qui craint que le gonflement des bilans engendré complique la négociation de conventions de double imposition avec les gouvernements étrangers, les opérations fiduciaires étant considérées comme un instrument d'évasion fiscale ${ }^{143}$. Au printemps 1971, la petite commission d'experts chargée de la révision de l'ordonnance de la loi sur les banques décide, après de longs débats, de revenir en arrière et de ne pas faire figurer les opérations fiduciaires au bilan. Même si cela signifie une modification de l'approche utilisée jusque-là par le Crédit

138 Sur ce point, voir Walter Robert Pfund, Bernhard Zwahlen, Die eidgenössische Verrechnungssteuer, Basel : Verlag für Recht und Gesellschaft, 197I ; sur le rôle des dépôts fiduciaires dans le développement du marché de l'évasion fiscale dans les années 1970, voir aussi Farquet, art. cit., 2017.

139 ABNS, Procès-verbaux de la Direction générale de la BNS, II.II.I97I, p. I64I.

140 AFB, E6Ioo(B-oI), 1983/72, vol. 37, Treuhandgeschäfte, PV de la Commission d'experts pour la révision de l'ordonnance de la loi sur les banques, 05.02.197I, p. 22.

141 Cf. aussi Loepfe, op. cit., 20II, p. 255.

$142 \mathrm{AFB}, \mathrm{E} 652 \mathrm{O}(\mathrm{B}), 2007 / 62$, vol. 4, Rundschreiben nr. 30 an die Reivisionsstellen vom 2. Dezember 1970.

143 Loepfe, op. cit., 20II, p. 257. 
Suisse et la Société de Banque Suisse, l'ASB se satisfait globalement de la solution trouvée. Une lettre du président de la direction générale du Crédit Suisse, Ernst Eberhard Reinhardt, adressée au conseiller fédéral Nello Celio en employant la formule «Mein Lieber», exprime bien l'enjeu essentiel pour les banquiers :

Il est pour nous très important d'obtenir de votre part une réponse claire qui confirme que les opérations fiduciaires, indépendamment du fait qu'elles figurent au bilan ou non, ne doivent pas être couvertes par des fonds propres, comme les mêmes postes se retrouvent des deux côtés du bilan, et en outre que ces opérations, indépendamment de leur inscription ou non au bilan, continuent de ne pas être soumises à l'impôt anticipé, dans le sens d'une pratique constante ${ }^{144}$.

En définitive, ces deux demandes principales seront respectées par le Conseil fédéral. Selon l'ordonnance de 1972, les opérations fiduciaires « doivent être dûment comptabilisées sans toutefois être portées au bilan " ${ }^{145}$. Les pratiques divergentes de comptabilisation entre établissements sont surmontées en exigeant du Département des finances l'allongement de la période transitoire d'adaptation à cinq ans. Ce souhait est également exaucé; les banques qui s'étaient déjà mises en conformité avec la circulaire de la CFB de décembre 1970 auront donc l'occasion de discrètement supprimer les opérations fiduciaires de leurs bilans jusqu'à fin i974. En fin de compte, la réglementation promulguée en 1972, en entérinant l'exonération fiscale des dépôts fiduciaires et en approuvant leur comptabilisation hors-bilan - et ainsi leur exemption de couverture par les fonds propres, a laissé le champ libre aux banques pour poursuivre le développement accéléré de cet instrument financier particulier. Les notions de sincérité du bilan et de protection des créanciers bancaires étaient alors reléguées au second plan.

Ce passage en revue des principaux points de discorde subsistant dans l'élaboration de l'ordonnance de la loi sur les banques qui aboutit en 1972 fait apparaitre la conclusion d'un marché entre l'ASB et le DFFD. Sommairement, les banquiers sont prêts à faire quelques concessions en acceptant un léger renforcement des dispositions sur la liquidité (mesures contre le windowdressing, dégradation de l'or, et augmentation des taux de couverture), en échange d'un abandon des prescriptions visant à limiter les placements étrangers et d'une prise en compte accentuée des réserves latentes dans le calcul des fonds propres. En effet, rappelons que la réglementation en vigueur prévoyait une inclusion des réserves latentes jusqu'à concurrence de $70 \%$ dans les fonds propres, et que ce plafonnement est supprimé dans l'ordonnance de 1972. Cette modification, qui signifie de fait un affaiblissement des exigences de fonds

144 AFB, E6roo(B-oI), 1983/72, vol. 37, Treuhandgeschäfte, Lettre d'E. Reinhardt (CS) à Nello Celio (DFFD), 22.06.1971.

145 "Ordonnance d'exécution de la loi sur les banques et les caisses d'épargne (du I7 mai 1972) », p. 40. 
propres, suscite l'irritation de la Commission fédérale des banques, qui intervient en vain auprès du DFFD ${ }^{146}$.

Ce deal - liquidité légèrement renforcée contre fonds propres moins exigeants - est explicitement exprimé dans le rapport du DFFD au Conseil fédéral ${ }^{147}$. Pour le dire autrement, on assiste en 1970-1972 à la reproduction, à plusieurs nuances près, du schéma déjà à l'œuvre lors de la révision de l'ordonnance en 1958-196I. Les exigences de fonds propres, considérées par les grandes banques comme une entrave à l'expansion de leurs affaires, sont réduites, tandis que les mesures sur la liquidité, qui affectent en premier lieu les plus petits instituts, connaissent un certain renforcement.

Pour l'Association suisse des banquiers, les difficultés initiales rencontrées dans une commission d'experts où ils ne disposaient pas d'une majorité aussi claire que dans les phases d'élaboration précédentes (I933-I935 et I958-I96I) ont pu être surmontées. Philippe de Weck, le directeur général de l'UBS, se plaignait encore en février 197I de la façon dont le DFFD concevait la préparation du règlement d'exécution:

Une tendance dangereuse me paraît se faire jour au Département des finances. Celui-ci prépare la révision de l'ordonnance en se laissant guider par les opinions manifestées au Parlement. C'est une attitude tout à fait fausse: les questions politiques sont maintenant tranchées. L'ordonnance ne doit traiter que des problèmes purement techniques, raison pour laquelle elle doit être préparée par des spécialistes ${ }^{148}$.

Tout en révélant une dichotomie trompeuse - mais chère aux banquiers entre questions "techniques" et questions "politiques", cette citation témoigne de certaines appréhensions préalables. Au terme du processus d'élaboration, en mai 1972, ces craintes se sont dissipées. Sur une question aussi centrale que la couverture en fonds propres des placements à l'étranger par exemple, le Conseil fédéral est effectivement revenu sur la promesse faite au Parlement et n'introduit dans l'ordonnance qu'une disposition édulcorée ne s'appliquant qu'aux banques étrangères. Le nouveau règlement d'exécution entre en vigueur au $\mathrm{I}^{\mathrm{er}}$ juillet 1972 et abroge celui d'août I96I. Il est présenté de la manière suivante dans le rapport annuel de l'ASB 1971-1972 : «On peut dans l'ensemble considérer comme satisfaisante la nouvelle ordonnance d'exécution, qui constitue avec la loi sur les banques le véritable statut de la profession bancaire. ${ }^{149}$

146 AASB, J.4 Bankengesetz 197I-1974, Lettre de la CFB à Bernhard Müller (DFFD), o6.or. I972.

147 ABNS, I.3/I235, Vollziehungsverordnung 1972, Bundesstellen, rapport du DFFD au Conseil fédéral, 27.03.1972, p. 7.

148 AASB, Procès-verbaux du Comité de l'ASB, I30 séance, 22.02.197I, p. I4.

149 Association Suisse des Banquiers, «Rapport sur le $60^{\mathrm{e}}$ exercice du $\mathrm{I}^{\mathrm{er}}$ avril I97I au 3I mars I972 ", Bâle: Frobenius, I972, p. 60. 


\section{IX.3.2. Le régime de réglementation bancaire de 1971-1972 : les amendements principaux}

En guise de conclusion intermédiaire de ce chapitre sur le long chemin qui mène à la révision de la loi sur les banques et de son ordonnance en 197I-I972, il est utile de récapituler les principales modifications apportées à l'occasion. On peut distinguer six domaines dans lesquels des amendements significatifs sont apportés.

\section{L'élargissement du champ d'application de la loi aux sociétés financières faisant} appel au public pour recevoir des dépôts

L'extension du champ d'application aux sociétés financières de type industriel ou commercial signifie que certaines entreprises, qui étaient depuis 1934 non-assujetties à la loi sur les banques car considérées comme non-bancaires du fait qu'elles finançaient les activités d'un groupe de sociétés restreint, souvent actives dans le même secteur, tombent désormais sous le coup de la législation bancaire. Cette modification est motivée par l'apparition d'une sorte de secteur bancaire parallèle (shadow banking, Scheinbanken) constitué de petites sociétés financières, jusqu'alors non-soumises à la loi sur les banques qui s'adressent aux épargnants pour recueillir des fonds. Il s'agit là d'un phénomène quasiment universel lors de l'introduction d'une régulation: la création d'un système alternatif dérégulé visant à échapper aux restrictions de la réglementation ${ }^{150}$. Parmi les sociétés visées par la modification, le Schweizerischer Creditorenverband, qui s'écroule en 1969, la Deggo AG, Profinanz AG, AG für Industriefinanzierung, l'AG für Ertragswerte, ou encore le Comptoir Hypothécaire et Industriel ${ }^{151}$. Les incidents comme ceux du Schweizerischer Creditorenverband, les pertes qui en résultent pour les créanciers, ainsi que le dommage réputationnel pour tout le secteur bancaire motivent, selon les autorités fédérales, un assujettissement de ce type de sociétés financières. Souvenons-nous que l'ASB était intervenue pour encourager les autorités à soumettre ces instituts à la loi sur les banques. Le DFFD s'était laissé facilement convaincre, comme en témoigne cet extrait du Message aux Chambres de juin 1970:

150 On retrouve ici l'idée de regulatory arbitrage, selon laquelle les entreprises soumises à une régulation répondent à cette réglementation en en exploitant les failles pour y échapper. Dans cette logique, la régulation ne peut jamais être véritablement proactive, puisque ceux qui établissent les règles auront toujours un temps de retard sur ceux qui cherchent à y échapper et bénéficient de plus d'informations. Voir par exemple Jill M. Hendrickson, Regulation and Instability in U.S. Commercial Banking. A History of Crises, Basingstoke: Palgrave Macmillan, 20II, p. 246; White, art. cit., 20II ; Joseph E. Stiglitz, "Government Failure vs. Market Failure: Principles of Regulation », in Edward J. Balleisen, David A. Moss (éd.), Government and Markets. Toward a New Theory of Regulation, Cambridge; New York : Cambridge University Press, 20I0, p. I3-5I ; Carpenter, Moss (éd.), op. cit., 20I4, p. I8.

151 Schütz, op. cit., 1974, p. 83-85. 
La protection des créanciers telle que la conçoit la loi sur les banques ne saurait en effet se limiter aux créanciers des banques de premier ordre, prudemment gérées, mais doit aussi s'étendre à ceux qui, par ignorance ou par embarras, s'adressent à des établissements qui "mettent tous leurs œufs dans le même panier» et dont les investissements sont, par conséquent, hasardeux ${ }^{152}$.

Malgré cet élargissement du champ d'application de la loi bancaire, les expressions "banque» et "banquier» restent réservées aux sociétés qui sont pleinement soumises à la loi. À l'échelon politique fédéral, cet amendement n'est remis en cause par aucun groupe parlementaire.

\section{Des conditions d'ouverture de banques moins faciles (capital minimal, procédure d'autorisation, organisation interne)}

La seconde modification concerne les conditions d'ouverture d'une nouvelle banque. Sous le régime de la loi de 1934, un établissement pouvait entamer son activité bancaire dès le moment où la Commission fédérale des banques, en examinant uniquement les statuts et règlements, avait constaté que l'organisation interne de l'établissement était adéquate. Une fois cette attestation obtenue, la banque était autorisée à être inscrite au registre du commerce. Il n'y avait donc ni capital minimal, ni examen des compétences et qualifications des fondateurs, ni clause du besoin. Comme le rapporte le secrétaire de la CFB Daniel Bodmer en octobre 1965 :

Dans le contexte des récentes affaires bancaires [il fait référence au scandale Muñoz-Hommel], il a été écrit à l'étranger qu'il était pour ainsi dire plus simple, en Suisse, d'ouvrir une banque qu'un salon de coiffure ou un café. Cela ne doit pas rester vrai ${ }^{153}$.

En effet, entre I935 et I97I, la Commission fédérale des banques opte pour une politique très timide en la matière. En l'absence d'une base légale solide, les superviseurs n'osent pas refuser les demandes d'ouverture émanant de personnalités qu'ils jugent pourtant incompétentes, voire dangereuses; par exemple, lorsque le directeur de banque prévu est connu pour avoir des antécédents judiciaires pour escroquerie ${ }^{154}$. Le recours de droit administratif auprès du

152 "Message du Conseil fédéral à l'Assemblée fédérale concernant la revision de la loi sur les banques (Du I3 mai 1970) ", Feuille fédérale, 1970, vol. I, n 24, 19.06.1970, p. II62.

153 AFB, E6520(B), 1980/39, vol. 21, dossier Sondersitzungen 1965-1966, 21.10.1965, p. 16. Bodmer fait ici référence à deux articles de presse parus aux États-Unis à la suite du scandale Muñoz. Le premier qui date du I4 juin 1965, est une adaptation d'un article de The Economist publié dans le New York Herald Tribune et intitulé «Switzerland: Banks Easier to Open Than Barber Shops». Dans le second, rédigé par Barry Edgar dans le Christian Science Monitor du 3I juillet 1965 et intitulé «Still wary of regulation », on peut notamment lire : «It is a wry joke in Switzerland that it is easier to open a bank than a restaurant. In fact, there are remarkably few regulations governing the opening of banks ».

154 Sur ce point, cf. Bänziger, op. cit., I986, p. I76-I8I. 
Tribunal fédéral ouvert contre une telle décision effarouche la CFB, qui préfere ne pas s'aventurer sur un terrain juridique instable. Il est donc peu étonnant qu'elle cherche à remédier à cette lacune flagrante dans le processus de révision de la loi sur les banques entre 1965 et 1971. Les propositions de la CFB sur ce point, datant de l'été 1966, ne subissent que peu de modifications fondamentales. Les prescriptions de la loi révisée posent trois conditions supplémentaires à remplir avant d'obtenir le sésame de l'autorité de surveillance. Un capital minimal, fixé dans l'ordonnance à 2 millions de francs, entièrement versés, doit être fourni. Cette disposition ne s'applique ni aux banques cantonales, ni aux banquiers privés, ni aux caisses Raiffeisen. Deuxièmement, la loi stipule désormais que « les personnes chargées d'administrer et de gérer la banque jouissent d'une bonne réputation et présentent toutes garanties d'activité irréprochable ". C'est à la CFB que revient la tâche de statuer sur ce point. Même si la loi ne précise pas sur quelle base exacte cette décision se fera, la présentation d'un certificat de bonnes mœurs constitue une exigence minimale ${ }^{155}$. En intégrant cette condition supplémentaire, les autorités choisissent également d'étendre à toutes les nouvelles banques une disposition qu' elles avaient introduite pour les banques en mains étrangères dans l'arrêté de 1969, mettant ainsi un terme, sur ce point, à une discrimination évidente. La troisième exigence additionnelle impose que les membres de la direction aient majoritairement leur domicile en Suisse. Il s'agit là de faciliter la communication et le contact avec les instances dirigeantes; en outre, en cas de difficultés, les responsables sont censés devoir rendre des comptes à la justice locale. De plus, on retrouve ici un premier élément de l'arsenal réglementaire anti-étrangers introduit dans la loi en 1971 : interdire un membre de la direction étranger rendait plus difficile la création de sociétés boîte aux lettres et permettait de justifier juridiquement le refus d'un permis de travail par la police fédérale des étrangers. En effet, la loi révisée de 1971, en respectant les vœux de l'ASB, intègre dans la loi ordinaire les mesures discriminatoires prises contre les banques étrangères dans l'arrêté fédéral de mars $1969{ }^{156}$.

L'instauration d'une procédure d'autorisation (Bewilligungsverfahren) a pour corollaire l'introduction d'un nouvel instrument d'intervention pour la Commission fédérale des banques, celui de retirer l'autorisation en cas de violations graves. Mais dans l'ensemble, ces conditions d'autorisation légèrement renforcées demeurent très libérales. Il n'y a pas de véritable système de concessions (licences délivrées limitées dans le temps), ou de numerus clausus qui limite le nombre de banques autorisées selon des critères de nécessité ou d'opportunité économique. Le régime s'inscrit donc toujours dans la continuité des principes qui dominaient dans les années 1930 : libéralisme étendu et responsabilité étatique très limitée.

155 Sur ce point, cf. Bernhard Müller, "Die Entwicklung der Bankenaufsicht in der Schweiz », Société anonyme suisse. Revue de droit commercial et économique, vol. 49, I977, p. I-13, p. 6-7.

156 Sur cet arrêté, cf. chap. IX.I. Sur son intégration dans la loi révisée de I97I et l'inefficacité des mesures prises contre les banques étrangères, cf. Giddey, op. cit., 2017, p. 493-495. 


\section{Fonds propres, liquidité, répartition des risques et crédits aux organes}

Le quatrième paquet de mesures qui connaît une modification significative est celui qui concerne les règles prudentielles des ratios de fonds propres et de liquidité, ainsi que les deux nouvelles dispositions limitant les gros risques et l'octroi de crédits aux organes dirigeants. Plus haut, nous avons déjà mentionné le deal conclu entre les milieux bancaires et les autorités fédérales lors de la révision de l'ordonnance en 1972. Pour rappel, l'Association suisse des banquiers obtient alors que les exigences de fonds propres soient assouplies, au lieu du durcissement initialement prévu, en échange d'un renforcement des prescriptions sur la liquidité. Quant aux deux autres nouvelles dispositions (risques et crédits aux organes), elles sont d'une moindre importance pour les acteurs dominants de la place bancaire suisse, à savoir les grandes banques et les banques cantonales.

La première de ces mesures consiste à déterminer un plafond sur les crédits qu'un établissement peut accorder à un seul client. La limite maximale est fixée par une proportion en fonction des fonds propres, qui varie selon la nature et la sécurité du crédit, entre $20 \%$ (crédits en blanc) et $160 \%$ (emprunt d'une collectivité suisse de droit public) avec des taux intermédiaires. Le dépassement de ce plafond ne constitue cependant pas une infraction légale, mais implique uniquement l'obligation pour la banque d'annoncer ce crédit surdimensionné au conseil d'administration et à la Commission fédérale des banques. Seconde disposition atténuante: les crédits inférieurs à 200000 francs ne sont pas visés par ce plafonnement.

La deuxième mesure cherche à limiter l'octroi abusif de crédits à des personnes proches de la banque. Les membres des organes dirigeants d'un établissement, ses principaux actionnaires et «les personnes et sociétés qui leur sont proches» ne peuvent se voir accorder des crédits «qu'en vertu des principes généralement reconnus dans la branche ». Il s'agit là de lutter contre les situations où un actionnaire influent profite de sa position pour obtenir des prêts sans répondre à toutes les exigences de solvabilité. L'affaire Muñoz en représente un exemple flagrant. En officialisant explicitement un principe d'usage, et en omettant de prévoir des mesures de contrôle efficaces, cet article enfonce une porte ouverte. La formulation vague rend d'ailleurs la mesure fort peu contraignante.

\section{L'élargissement des devoirs de publicité (positions étrangères dans les bilans remis à la BNS, opérations fiduciaires)}

En plus d'une simple adaptation formelle du schéma type de la comptabilité bancaire annuelle, la révision de l'ordonnance de 1972 implique quelques changements plus importants dans la façon de porter au bilan les activités financières. Relevons notamment qu'un nouveau poste dénommé "participations permanentes» est créé dans le bilan et le compte profits et pertes pour recenser les placements permanents visant une prise d'intérêts ou d'influence. 
Une majorité de la commission d'experts refuse en revanche que les participations soient énumérées nommément dans la comptabilité.

Deuxièmement, l'ordonnance de 1972 stipule que le montant total des actifs étrangers doit être affiché séparément comme complément au bilan annuel. Cette disposition constitue en fait une réponse à une proposition du député socialiste Stich en vue d'une publication distincte des opérations étrangères ${ }^{157}$. Cette proposition n'avait été retirée qu'après la promesse du conseiller fédéral Celio que cette question serait réglée dans l'ordonnance. Dans la commission d'experts, le spécialiste de la NZZ Heinz Portmann se fait le relais des revendications du socialiste soleurois. Il déclare alors : «Nous devons être conscients du fait que nous sommes actuellement assis sur une poudrière, raison pour laquelle l'épargnant a le droit de savoir s'il confie son argent à une banque qui possède $90 \%$ d'engagements intérieurs ou à une banque qui possède tout autant d'engagements étrangers. " 158 Portmann est d'abord minorisé de justesse, mais la disposition se réalise finalement sous la forme d'un complément au bilan. Il faut tout de même relativiser l'impact de cette mesure visant à améliorer la transparence de la comptabilité bancaire: il existe en effet de nombreux moyens de la contourner légalement, et de dissimuler certains engagements très élevés, par exemple par le biais de sociétés filiales ou en manipulant les échéances ${ }^{159}$.

Troisièmement, nous l'avons déjà évoqué, l'ordonnance de 1972 apporte une clarification dans les pratiques divergentes des banques quant à la comptabilisation des opérations fiduciaires. La disposition à laquelle aboutissent les longues négociations est emblématique d'une certaine ambivalence dont la langue juridique suisse a le secret: "Les opérations à titre fiduciaire doivent être dûment comptabilisées sans toutefois être portées au bilan. ${ }^{160}$ Les montants colossaux qui sont investis sous cette forme ne doivent ainsi pas être couverts par des fonds propres.

Enfin, la Banque nationale obtient une compétence de renseignement élargie, puisqu'elle peut exiger des banques «toute autre information se rapportant au bilan ${ }^{161}$. Ce renforcement devrait en principe permettre à la BNS d'affiner ses connaissances statistiques à des échéances plus rapprochées que les remises de bilan annuelles, semestrielles, et des bilans intermédiaires trimestriels ou mensuels.

157 "Loi sur les banques. Révision", Bulletin officiel de l'Assemblée fédérale, Conseil national, 1970, vol. IV, I5.12.1970, p. 766-769.

158 ABNS, I.3/I235, Vollziehungsverordnung 1972, Expertenkommission, Procès-verbal des séances de la commission d'experts pour la révision de l'ordonnance de la loi sur les banques, 05.03.1971, p. 17.

159 Cf. Schütz, op. cit., I974, p. I52-153.

160 "Ordonnance d'exécution de la loi sur les banques et les caisses d'épargne (du I7 mai 1972) ", p. 40 .

161 Art. 7, al. 3 de la loi sur les banques révisée du in mars I97I. 


\section{La protection des dépôts d'épargne}

Nous nous souvenons que le montant des dépôts d'épargne privilégié en cas de faillite avait fait l'objet d'interventions parlementaires dans l'après-guerre (motion Rosset, transformée en postulat 1958-1959). Il s'agissait alors d'adapter le montant, fixé depuis 1934 à 5000 francs par épargnant, au renchérissement du coût de la vie intervenu depuis. Le Conseil fédéral, en conformité avec les avis exprimés par la CFB, l'ASB et en partie la BNS, avait refusé ces motions en estimant qu'un relèvement du montant privilégié en cas de faillite se ferait au détriment de la majorité des autres créanciers et que la plupart des épargnes étaient gérées par des établissements bénéficiant de la garantie d'État (cf. chap. VIII.2.2). Avec un dépôt d'épargne moyen s'élevant fin 1968 à 3554 francs, 8I \% de tous les carnets d'épargne restent privilégiés, selon les calculs du DFFD ${ }^{162}$. Le Conseil fédéral refuse également d'entrer en matière sur des mesures qui restreindraient la politique de placement des banques qui recueillent les épargnes - on aurait pu imaginer une obligation d'investir ces montants dans des placements particulièrement sûrs. Si l'objectif principal était vraiment de sauvegarder les bas de laine des couches populaires les plus défavorisées, un privilège des épargnes dépendant du revenu imposable aurait sans doute été socialement mieux adapté à cette volonté. Rien de tout cela dans la révision de la loi sur les banques. Les dispositions sur la protection des dépôts d'épargne connaissent de fait une modification minimale en 1971. La réglementation introduit en effet, en plus de la collocation de 5000 francs dans la troisième classe, un montant supplémentaire de 5000 francs également, consigné lui dans la quatrième classe. Ce faisant, les épargnants disposant de montants s'échelonnant entre 5000 et 10 ooo francs sont mieux protégés, sans pour autant défavoriser les plus petits épargnants.

Au-delà de ce changement de faible portée, les législateurs ont négligé de remettre en question plus fondamentalement le système de protection des dépôts bancaires. L'introduction d'une assurance des dépôts n'est alors pas évoquée. Comme le montre le politologue Roy Gava, la période postérieure à celle que nous avons étudiée confirme en grande partie les tendances esquissées ici ${ }^{163}$. Entre 1977 et 2013 , malgré plusieurs scandales bancaires importants (scandale de Chiasso en 1977, fermeture de la Spar- und Leihkasse Thun en 199I, sauvetage d'UBS en 2008), la politique suisse en matière de protection des dépôts est caractérisée par des ajustements minimaux, souvent dans une orientation favorisant l'autorégulation, plutôt que des réformes majeures.

Cette situation est également provoquée par l'absence, en Suisse, d'une organisation collective des épargnants ou des petits actionnaires qui soit à même de défendre politiquement les intérêts de cette catégorie sociale très

162 «Message du Conseil fédéral à l'Assemblée fédérale concernant la revision de la loi sur les banques (Du I3 mai 1970)", Feuille fédérale, 1970, vol. I, nº 24, 19.06.1970, p. II68-I170.

163 Cf. Gava, op. cit., 2014, p. 179-209. 
hétérogène ${ }^{164}$. Dans les années 1930 il n'existe pas d'association de défense des petits investisseurs, et ceux-ci ne disposent pas d'un grand capital de soutien parmi les partis politiques nationaux, comme le montre Martin Lüpold dans son étude sur la gouvernance d'entreprise ${ }^{165}$. Dans l'après-guerre, quelques petites organisations voient le jour, comme le Sparer-Schutzverband der Inflations-Geschädigten ou la Schweizerische Vereinigung zum Schutze der Sparer und Rentner, mais leur poids politique demeure modeste. Il résulte de cet état de fait que les épargnants et les déposants bancaires ou encore les petits investisseurs (par exemple dans les fonds de placement) constituent des acteurs effectivement importants des débats de régulation bancaire, mais qu'ils ne sont pas activement impliqués dans les négociations, notamment en raison de leur faiblesse organisationnelle. De ce fait, les épargnants bancaires font partie des intervenants qui restent dans l'ombre de notre analyse. Leur situation contraste avec celle des consommateurs, qui s'organisent au cours des années I950 et I960 au sein d'associations et de fédérations disposant d'une influence politique croissante ${ }^{166}$.

\section{Le contrôle bancaire et moyens d'action de la CFB}

Le système de contrôle des banques reposant sur le travail d'audit externe des sociétés fiduciaires privées choisies par les établissements financiers n'est à aucun moment remis en cause durant la procédure de révision de 197I. Revenant sur les conditions historiques d'émergence du modèle suisse de régulation bancaire, le membre de la Commission fédérale des banques Karl Etter justifie, au sein de la commission parlementaire du Conseil national, le long délai qui s'écoule avant que l'autorité ne puisse intervenir:

Alors qu'à l'étranger le contrôle bancaire à proprement parler est la plupart du temps étatique, chez nous la révision externe auprès de la banque concernée est effectuée par une société privée, comme conséquence de la philosophie libérale de notre législation ${ }^{167}$.

Implicitement, le vice-président de la CFB avoue ici que ce système de surveillance étatique indirecte provoque une grande lenteur de mise au courant, et donc d'action de l'organe de supervision, qui n'est informé par la société

164 La situation helvétique contraste à cet égard avec celle de la France, où l'Association nationale des porteurs français de valeurs mobilières existe depuis 1898. Cf. Pierre-Cyrille Hautcœur, Angelo Riva, "The Paris financial market in the nineteenth century: complementarities and competition in microstructures ", The Economic History Review, vol. 65, $\mathrm{n}^{\circ} 4$, 20I2, p. 1326-1353.

165 Lüpold, op. cit., 2010, p. 573.

166 Cf. Jakob Tanner, Brigitte Studer, "Konsum und Distribution", in Patrick Halbeisen, Margrit Müller, Béatrice Veyrassat (éd.), Wirtschaftsgeschichte der Schweiz im 20. Jahrhundert, Basel: Schwabe, 2012, p. 637-702, en part. p. 692-695.

167 ABNS, I.3/I234, Parlament, Nationalratskommission, Procès-verbal des séances de la commission du Conseil national sur la révision de la loi sur les banques, 05.II.1970, p. 32. 
d'audit que dans certains cas graves, et si les délais fixés à la banque pour corriger les manquements n'ont pas été respectés. Dès le début des années I960, sous l'effet des expériences de l'intervention désastreuse de la Commission fédérale des banques auprès de la Kredit- und Verwaltungsbank Zug, puis, a fortiori, après le choc de l'effondrement des banques Muñoz en 1965, l'amélioration des moyens d'action de l'autorité de surveillance fait partie des préoccupations principales dans le cadre d'un amendement de la législation bancaire. De son rapport de juillet 1966 à l'attention du Conseil fédéral, la Commission fédérale des banques estimait déjà que le « système de mesures » était insuffisant et que cette lacune ne pouvait pas être justifiée par le caractère libéral de la loi : "Même une loi de surveillance libérale ne peut pas être dépourvue des moyens nécessaires pour qu'elle soit mise en application. " ${ }^{168}$ Cet état de fait avait notamment pour conséquence qu'au moment où la Commission fédérale des banques était informée de la mise en danger des créanciers par la société fiduciaire chargée de l'audit externe, il était déjà souvent trop tard pour corriger l'évolution avant l'effondrement de la banque.

La loi sur les banques révisée de i97I propose quelques aménagements mineurs censés rectifier ces lacunes ${ }^{169}$. Ces amendements peuvent être regroupés en deux catégories. Ils concernent d'une part les devoirs et les critères d'admission des sociétés d'audit. D'autre part, les moyens d'intervention de la CFB sont revus à la hausse.

Les «instituts de revision" ou "reviseurs" sont soumis à des exigences de sélection légèrement plus élevées ${ }^{170}$. Alors que la forme de l'expert-comptable indépendant est désormais également reconnue à côté de la société fiduciaire et du syndicat de révision, un réviseur doit dorénavant pouvoir prouver qu'il obtiendra des mandats de révision d'au moins cinq banques totalisant un bilan d'au moins 300 millions de francs; un seul des mandats ne peut pas dépasser Io \% des honoraires annuels de la société. De plus, la nouvelle ordonnance prescrit que les réviseurs responsables doivent être de nationalité helvétique et habiter en Suisse; selon les membres de la commission d'experts, cette clause discriminatoire sert à renforcer la garantie du secret bancaire ${ }^{171}$. Dans l'ensemble, ces dispositions favorisent la concentration cartellaire du secteur de la révision bancaire, renforçant ainsi la tendance d'une forte continuité dans la

168 AFB, E6I0o(B-OoI), I980/49, vol. 59, dossier Bankengesetz, Vernehmlassung und Neuer Entwurf, «Bericht und Entwurf der Bankenkommission über eine Teilrevision des Bundesgesetzes vom 8. November 1934 über die Banken und Sparkassen und seiner Vollziehungsverordnung vom 30. August 196I", I8.07.1966, p. 7.

169 Sur ce point, voir également Riniker, op. cit., 1974, p. 89-106.

170 Pour un résumé synthétique de l'état de la révision bancaire selon le chef du secrétariat de la CFB Daniel Bodmer en 1976 : cf. Daniel Bodmer, «Aktuelle Probleme der Bankrevision aus der Sicht der Eidgenössischen Bankenkommission", in Theo Keller (éd.), Revision und Sicherheit im Bankbetrieb, Bern; Stuttgart: P. Haupt Verlag, 1976, p. 2I-30.

171 ABNS, I.3/1235, Vollziehungsverordnung 1972, Expertenkommission, Procès-verbal des séances de la commission d'experts pour la révision de l'ordonnance de la loi sur les banques, 05.03.1971, p. 28. 
répartition des mandats que nous avions aperçue plus haut (cf. chap. IV.2.3). En plus de ces conditions d'admission renforcées, les sociétés d'audit voient leur champ d'investigation légèrement augmenté. Elles doivent désormais s'assurer que les exigences nécessaires à l'autorisation d'ouverture d'une banque sont respectées, ce qui signifie aussi théoriquement évaluer annuellement la délicate question des garanties morales offertes par les dirigeants bancaires.

Ce renforcement de l'indépendance des réviseurs à l'égard des banques contrôlées, sous la forme de la clause du plafond de io \% d'honoraires pour un seul mandat, ne met cependant pas un terme aux débats sur cette question. De nombreuses démarches ont lieu entre 1972 et 1974 auprès de la Commission fédérale des banques pour garantir une plus grande indépendance des sociétés fiduciaires à l'égarde des banques ${ }^{172}$. Mais elles ne débouchent finalement pas sur une réforme du cadre réglementaire. Des modifications dans la répartition du capital-actions sont certes menées par les sociétés fiduciaires pour mieux dissimuler les liens étroits qui les unissent aux grandes banques. Le secrétaire de la CFB Daniel Bodmer regrette ainsi dans un article paru en 1976 la position parfois trop unilatérale des sociétés de révision:

Oui, parfois la Commission des banques a le sentiment que [les institutions de révision] jouent le rôle d'avocat de la banque contre la Commission des banques. Il n'est pas facile de trouver le juste milieu entre deux maîtres, et cela exige des valeurs personnelles et caractérielles considérables, que l'on ne peut pas inoculer à chaque réviseur ${ }^{173}$.

En plus de ces changements dans les conditions d'admission des réviseurs, la réforme de 197I-I972 donne des responsabilités supplémentaires aux sociétés d'audit. Celles-ci obtiennent le droit de consulter en tout temps les livres et pièces comptables des banques et peuvent leur demander les renseignements jugés nécessaires. Enfin, elles reçoivent l'obligation d'avertir plus rapidement la Commission fédérale des banques, lorsqu'elles « jugent inutile de fixer un délai de régularisation, qu'elles décèlent des infractions pénales, de graves irrégularités, la perte de la moitié des fonds propres ou d'autres faits de nature à compromettre la sécurité des créanciers" (art. 2I, al. 4).

Quant à l'instrumentarium de la Commission fédérale des banques, il subit également un développement. Il s'agissait là de corriger les dysfonctionnements profonds détectés par la CFB dans ses outils d'intervention en cas de noncoopération d'un établissement délictueux (cf. chap. VII.3). Cette amélioration s'est faite par analogie avec les nouveaux outils dont elle dispose dans le cadre de la régulation des fonds de placement depuis 1967. De nouvelles compétences lui sont donc attribuées dans la loi révisée de 1971, en procédant par gradation, de la mesure la plus anodine à la plus lourde de conséquences. Elle peut exiger

\footnotetext{
172 AFB, E652O(A), 1983/50, vol. 24, Unabhängigkeit Revisionsstellen, Lettre de Helmut Hubacher à la CFB, 30.05.1972; Bulletin officiel de l'Assemblée fédérale, Conseil national, réponse du conseiller fédéral Nello Celio du 20.09.1973, p. II22-II24; Schönle, Dohm, op. cit., 1974.

173 Bodmer, art. cit., in Keller (éd.), op. cit., 1976, p. 26.
} 
des sociétés fiduciaires comme des banques tous les renseignements dont elle a besoin dans l'exécution de sa tâche. Lorsqu'elle est informée d'infractions ou d'irrégularités, elle est autorisée à "prendre les mesures nécessaires au rétablissement de l'ordre légal» (art. 23 ter). La Commission fédérale des banques peut encore déléguer un observateur officiel, qui surveille de près l'activité des dirigeants de la banque et possède un droit de regard illimité dans ses affaires. Il sert aussi de relais pour informer promptement la CFB. Troisièmement, lorsque la banque ne répond toujours pas aux injonctions de l'autorité de surveillance malgré une sommation préalable, cette dernière peut faire exécuter elle-même les mesures qu'elle avait prescrites. Elle peut dans ce cas également rendre cette décision publique, par exemple par le biais de la Feuille offcielle suisse du commerce. Enfin, arme la plus tranchante dont elle dispose désormais, elle peut retirer à une banque l'autorisation d'exercer, ce qui a pour conséquence la dissolution et la liquidation de l'établissement. Ce retrait de l'autorisation est limité aux violations graves, ou lorsque la banque ne répond plus aux conditions requises.

Il est difficile d'émettre un jugement détaillé sur l'efficacité de ces nouvelles mesures d'intervention. Selon un membre de la CFB, le professeur genevois de droit commercial Alain Hirsch (1934-), qui s'exprime en 1975:

La Commission a reçu de nombreux pouvoirs nouveaux, qu'elle n'a utilisés jusqu'ici qu'avec réserve. D’ailleurs, pour pouvoir les utiliser il faudrait que le secrétariat de la Commission soit sensiblement augmenté, ce qui n'a pas été le cas jusqu'ici. On peut donc dire que l'application des nouvelles dispositions légales en est encore au stade expérimental ${ }^{174}$.

Enfin, le système de sanction de la loi sur les banques connaît aussi un ajustement. Les infractions sont désormais classées dans trois catégories de gradation, selon la gravité de la transgression. Il y a d'abord les contraventions légères passibles d'une amende de 5000 francs au maximum (au lieu de I 000 francs selon la loi de 1934) (art. 50). Puis viennent les contraventions - établissement d'un bilan non-conforme, refus d'obtempérer à une injonction de la CFB, etc. - punies par une amende maximale 20 ooo francs (art. 49). Enfin, les délits sont désormais passibles de six mois d'emprisonnement et d'une amende jusqu'à concurrence de 50 ooo francs (art. 46-48). Parmi ces délits figurent notamment l'ouverture non-autorisée d'une banque, le recours à une publicité abusive se prévalant du siège suisse, la conclusion d'une opération d'exportation de capitaux interdite, la transmission de faux renseignements à la CFB ou à la BNS, la violation du secret bancaire, ou encore l'atteinte au crédit d'une banque par de fausses allégations. L'exécution de cet arsenal de sanctions

174 Alain Hirsch, «La surveillance des banques en Suisse», in Marcus Lutter, Helmut Kollhosser, Winfried Trusen (éd.), Recht und Wirtschaft in Geschichte und Gegenwart. Festschrift für Johannes Bärmann zum 70. Geburtstag, München: C.H. Beck'sche Verlagsbuchhandlung, 1975, p. 46I-469, p. 469 . 
a également été adaptée. Mises à part la violation du secret bancaire et l'atteinte au crédit d'une banque (art. 47 et 48) qui restent du ressort unique des instances judiciaires cantonales, les autres délits et contraventions, du moment qu'ils n'impliquent pas une peine privative de liberté, sont désormais poursuivis directement par le Département fédéral des finances et des douanes. On cherche ainsi à lutter contre l'incurie de certaines autorités pénales cantonales dans la répression des délits mis à jour par la Commission fédérale des banques.

Dans l'ensemble, cet arsenal disciplinaire reste clément. Qu'une infraction comme une falsification de bilan soit simplement punissable d'une contravention maximale de 20000 francs, infligée à une banque en tant que personne morale, a sans doute un effet fort peu dissuasif.

Quelle que soit la sévérité de sanctions pénales, la plupart des acteurs, même ceux qui sont ouvertement en faveur d'une augmentation des amendes, sont conscients de la faible portée de ces changements. Dans le domaine de la surveillance bancaire, les mesures préventives - devoir de transparence, contrôles inopinés, etc. - fonctionneraient en principe mieux que les sanctions disciplinaires prises ex post, au moment où les pertes sont déjà subies. L'effet dissuassif des sanctions disciplinaires dans le domaine de la criminalité économique est d'ailleurs dissipé par les nombreux moyens dont disposent les délinquants en col blanc pour échapper à une condamnation ${ }^{175}$.

\section{La loi sur les banques révisée de 1971: des ajustements plutôt qu'une réforme systémique profonde}

En février 1971, le correspondant à Zurich du Financial Times David Egli dressait un tableau prometteur des ambitions de changement dans la réglementation bancaire suisse :

Nettled by much international criticism which has earned their banks the "gnome" image, the Swiss are tightening up on banking practice to make life more difficult for shady elements taking advantage of the proverbial taciturnity of Swiss bankers [...] Just as Swiss women have got the vote, Swiss banking practices are being streamlined to cope both with the growing demands of a financial centre, reputed to be only second to London and New York and with the dangers of organised crime $^{176}$.

S'il est vrai que le propos de l'article se concentre sur les aspects relatifs au secret bancaire à l'échelon international, le programme exposé ici est bien ambitieux. Dans les faits, le résultat auquel aboutit la procédure de révision

175 Pour une recherche récente en sociologie sur les illégalismes dans les marchés financiers: Arjan Reurink, "White-Collar Crime": The concept and its potential for the analysis of financial crime", European Journal of Sociology, vol. 57, n 3, 2016, p. 385-4I5.

176 David Egli, "Swiss Bank Secrecy. Lifting the veil a little to fight organised crime», Financial Times, I8.02.1971, p. 7. 
de la loi sur les banques en I97I ne modifie pas fondamentalement le système de régulation bancaire introduit en I934. Il serait très difficile d'affirmer que les autorités helvétiques ont vraiment cherché à adapter leur capacité de surveillance du secteur bancaire à la croissance phénoménale et l'importance internationale que celui-ci a connues durant les Trente Glorieuses. En ce qui concerne l'évaluation des risques pris par les banques dans leurs placements étrangers, nous avons vu que la révision de I97I accouche d'une souris. À l'exception d'un devoir de publication à l'égard de la BNS légèrement plus détaillé, la loi sur les banques de 197I ne fixe aucune restriction sur les opérations internationales. La disproportion évidente entre une place financière à l'expansion fulgurante et l'appareil bureaucratique et administratif chargé de son contrôle minimal s'est encore creusée en l'espace des 37 ans qui séparent les deux versions de la législation. Mais les amendements proposés au début des années 1970 ne cherchent aucunement à combler cet écart. Dans un pays qui compte fin 1968 plus de livrets d'épargne (8.I millions) que d'habitants ${ }^{177}$ et où le bilan cumulé des quatre plus grandes banques (CS, SBS, UBS et BPS) équivaut au produit intérieur brut ${ }^{178}$, le cadre réglementaire demeure libéral et peu restrictif.

Si la révision de 197I fournit de nouveaux outils à la Commission fédérale des banques pour lui permettre d'intervenir plus rapidement et de façon plus incisive en cas de manquements, l'accroissement nécessaire de l'appareil administratif nécessaire à la mise en application de ces nouvelles compétences fera encore longtemps défaut ${ }^{179}$. Ce n'est qu'à partir de 1976 , puis de manière accélérée après le scandale de Chiasso de 1977 que l'autorité de surveillance verra la taille de son secrétariat augmenter progressivement.

Dans ce chapitre, nous avons pu exposer la façon dont la stratégie de l'Association suisse des banquiers face au dossier "législation bancaire» au cours des années 1960 se révèle payante. Après avoir maintenu une politique d'obstruction quasiment systématique à toute modification de la loi fédérale sur les banques de I934, les milieux bancaires changent de cap à la suite de l'affaire Muñoz qui éclate en 1965. Ils acceptent désormais de collaborer à contrecœur aux travaux d'élaboration d'un avant-projet de révision. Entre 1965 et 1969, les banquiers parviennent ensuite à modifier considérablement la hiérarchie de priorisation des points de révision. Tandis que les moyens d'intervention et de sanction de la Commission fédérale des banques constituaient jusqu'alors la question névralgique des discussions de réforme,

177 Le chiffre sur les livrets d'épargne est tiré du «Message du Conseil fédéral à l'Assemblée fédérale concernant la revision de la loi sur les banques (Du I3 mai 1970) ", Feuille fédérale, I970, vol. I, $\mathrm{n}^{\circ}$ 24, I9.06.1970, p. II68. La Suisse compte 6.2 millions d'habitants en 1970.

178 Bilans des quatre grandes banques fin 1970 : SBS : 28 milliards de francs, CS : 28 milliards, UBS : 26 milliards, BPS : 6 milliards. Total : 88 milliards de francs. PIB fin $1970: 90$ milliards de francs. Sources : bilans bancaires : rapports de gestion correspondants. PIB : Statistique historique de la Suisse en ligne, tableau Q.I5. (https://hsso.ch/2012/q/15, consulté le I0.12.20I8).

179 Cf. la conclusion de Müller, art. cit., I977. 
l'Association suisse des banquiers réussit à imposer le problème des banques étrangères et celui des sociétés financières à caractère commercial et industriel comme les priorités immédiates d'un amendement de la loi sur les banques. Ce glissement implique également un retardement de toute la procédure, puisque les avant-projets rédigés par la CFB sont alors considérés comme insuffisants pour constituer une base de travail. Une fois le travail législatif arrivé au stade parlementaire, les milieux bancaires pratiquent une politique d'influence similaire à celle mise en œuvre par leurs prédécesseurs des années 1930. Pour mettre en avant leurs postulats, ils ciblent le Conseil des États, dont la coloration politique leur est plus favorable. D'autre part, ils cherchent à réduire la marge de manœuvre générale de l'arène politique, en encourageant le traitement de nombreux points centraux dans l'ordonnance d'exécution plutôt que dans la loi même. Cette double tactique porte ses fruits. La loi sur les banques révisée de I97I aboutit sans qu'un débat public délicat pour les banquiers ne s'ouvre véritablement. À aucun moment un préjudice d'image pour la place financière suisse, même à l'échelon international, n'est subi.

Si les ajustements apportés par les amendements de 197I constituent sans doute un progrès dans certains domaines, il faut souligner que sur des points cruciaux comme l'assouplissement des exigences de fonds propres, la (non-) comptabilisation des opérations fiduciaires, ou encore la consolidation du secret bancaire, la réglementation finale favorise de facto la poursuite du même modèle d'expansion des grandes banques helvétiques, sans prévoir parallèlement des garde-fous capables de rééquilibrer la disproportion de pouvoir entre le secteur régulé et les instances de supervision.

\section{IX.4. ÉPILOGUE : \\ LA LOI SUR LES BANQUES DANS LES ANNÉES 1970-1980}

Dans la conclusion de sa thèse sur le développement historique de la surveillance bancaire, l'historien Hugo Bänziger dresse en 1986 un bilan résolument optimiste de l'évolution récente. «Les lacunes présentes dans la législation bancaire [...] ont pu être comblées par la révision partielle de I97I et l'extension du secrétariat de $1976{ }^{180}$, écrit-il. Ce constat nous semble inexact. Un examen superficiel de l'évolution des discussions autour de la surveillance bancaire helvétique entre 1974 et 1986 montre au contraire que d'importants dysfonctionnements subsistent au-delà des années 1970 et que le régime de contrôle bancaire est même remis en question de manière plus profonde au tournant des années 1980.

À peine le régime de surveillance bancaire révisé entre-t-il en vigueur en 197I-I972 que de nouvelles interventions parlementaires relancent le débat sur la pertinence de la réforme adoptée. Une motion déposée par le conseiller 
national Jean Ziegler le 4 juin 1971, contresignée par vingt autres députés socialistes, invite le gouvernement à examiner « les différentes solutions légales possibles permettant l'instauration d'un contrôle public minimum sur la politique d'investissement et de gestion des grandes banques d'affaires de Suisse " ${ }^{181}$. Cette proposition est toutefois balayée par la majorité de la Chambre du peuple. Deux ans plus tard, en mars 1973, le député socialiste bâlois Helmut Hubacher (1926-) revient à la charge en présentant un postulat demandant au Conseil fédéral d'examiner la question de l'indépendance financière des sociétés de révision à l'égard des banques qu' elles contrôlent, et évoque l'idée de confier la révision bancaire à un organe de contrôle de droit public ${ }^{182}$. Hubacher cite nommément les deux fiduciaires qui révisent les trois grandes banques suisses, à savoir la Gesellschaft für Bankrevisionen et la Schweizerische Revisionsgesellschaft. Cette intervention avait été précédée, au cours du printemps I972, d'un échange direct entre Hubacher et la Commission fédérale des banques ${ }^{183}$. À l'automne 1972, le Crédit Suisse et la Société de Banque Suisse avaient accepté de se défaire d'une partie de leurs participations majoritaires à la Gesellschaft für Bankrevisionen et d'élargir son conseil d'administration à des personnalités jugées indépendantes ${ }^{184}$. Un an plus tard, le Conseil fédéral accepte le postulat, qui ne débouche cependant pas sur des mesures concrètes.

À ces pressions politiques s'ajoute dès 1974 le déclenchement d'une crise bancaire qui affecte certains établissements. Fondamentalement liée à la fin du système de Bretton Woods et l'adoption du régime de taux de changes flottants en 1973, elle atteint par exemple l'UBS, qui subit au printemps 1974 une perte importante, chiffrée à $\mathbf{I} 42$ millions de francs suisses - ce qui correspond à $8 \%$ de ses réserves ouvertes -, sur le marché des changes ${ }^{185}$. En juin 1974, la débâcle de la banque privée allemande Herstatt, basée à Cologne, fait des vagues en Suisse. La chute de cet institut, également lourdement affecté par une perte de change, constitue la plus importante faillite bancaire allemande depuis les années 1930, et entraîne également de lourdes conséquences à l'échelon international. Elle donne le coup d'envoi des premières velléités de coordonner la surveillance bancaire au plan supranational, avec la création du Comité de Bâle

181 Bulletin offciel de l'Assemblée fédérale, Conseil national, séance du 13.12.1971, p. 1588-1595.

182 Bulletin officiel de l'Assemblée fédérale, Conseil national, séance du 20.09.1973, p. II22-II24.

$183 \mathrm{LaCFB}$ répond à Hubacher qu'une indépendance financière n'est pas requise par la loi, mais accepte de mandater un rapport d'experts sur la question. Cf. E6520(A), 1983/50, vol. 24, dossier Unabhängigkeit Revisionsstellen.

184 E6520(A), 1983/50, vol. 24, dossier Unabhängigkeit Revisionsstellen, lettre de la direction générale du CS (E. Reinhardt, H. R. Wuffli) à Nello Celio (chef du DFFD), 23.08.1972.

185 Loepfe, op. cit., 20II, p. 392. Pour les réserves ouvertes: Union des banques suisses, Rapport de gestion annuel 1974, p. 43 (Fonds de réserve général: 826 millions, fonds de réserve spécial : 930 millions). Le rapport annuel précise (p. 24) que la perte a été «occasionnée par des opérations de change d'un client » et qu'elle a été « entièrement couverte par la réalisation de réserves internes d'évaluation ». 
(Basel Committee on Banking Supervision) ${ }^{186}$. En Suisse, une série de crises bancaires éclatent au cours de l'été et de l'automne 1974, sans qu'un lien direct avec la maison Herstatt puisse être systématiquement établi : la filiale zurichoise de la Seattle First National Bank, la Cosmos Bank (Zurich), la filiale de Lugano de la Lloyds Bank, la Firestone Bank (Zurich), la Banque de Crédit International (Genève), la Banque de Financement S.A. (Finabank, Genève), l'Amincor-Bank (Zurich) et la Metro-Bank (Zurich) éprouvent des difficultés de liquidité; certaines d'entre elles entrent en liquidation ${ }^{187}$. La juxtaposition de ces huit cas est trompeuse: parfois les pertes ne sont que passagères et peuvent être compensées, par exemple par la maison-mère, dans d'autres situations, comme pour la Cosmos-Bank, la Banque de Crédit International et la Metro-Bank, elles débouchent sur une procédure de sursis bancaire et la fermeture des guichets.

Les effondrements de ces banques de taille modeste provoquent de nombreuses réactions chez les responsables de la politique bancaire en Suisse. Dès août 1974, la direction générale de la Banque nationale suisse estime que "la surveillance bancaire sous sa forme actuelle - composition de la Commission, petit secrétariat - n'est plus à même de donner satisfaction " ${ }^{188}$. Comme possibilités d'amélioration, le service juridique de la BNS envisage plusieurs solutions : revenir sur sa position traditionnelle de rejet de la tâche de surveillance et assumer une plus grande responsabilité dans le domaine, faire de la présidence de la Commission fédérale des banques une fonction à plein temps, ou encore la doter d'une équipe de réviseurs qui mènerait des inspections directement auprès des banques ${ }^{189}$. Parallèlement, en août 1974 , le nouveau chef du Département fédéral des finances et des douanes, le radical vaudois Georges-André Chevallaz (1915-2002), s'inquiète également des conséquences de la crise Herstatt et demande à la BNS son avis sur l'efficacité du régime de surveillance des banques en Suisse ${ }^{190}$. Du côté parlementaire aussi, le débat est soulevé. Le cas de la faillite de la Metro-Bank en particulier, qui engendre des pertes pour les déposants, suscite le dépôt de

186 Cf. Schenk, art. cit., 20I4; Emmanuel Mourlon-Druol, " "Trust is good, control is better": The 1974 Herstatt Bank Crisis and its Implications for International Regulatory Reform ", Business History, vol. 57, $\mathrm{n}^{\circ}$ 2, 2015, p. 311-334.

187 Loepfe, op. cit., 20II, p. 395-400. ABNS, Procès-verbaux de la Direction générale de la BNS, IO.IO.I974, p. I463-I464. Sur le cas de la succursale de Lugano de la Lloyds, cf. Catherine R. Schenk, "Rogue Trading at Lloyds Bank International, 1974: Operational Risk in Volatile Markets ", Business History Review, vol. 91, n I, 2017, p. I05-128.

188 ABNS, Procès-verbaux de la Direction générale de la BNS, 29.08.1974, p. I2II.

189 ABNS, Procès-verbaux de la Direction générale de la BNS, I4.II.1974, p. I786-1787. Les propositions d'amélioration de la BNS sont également formulées dans une lettre de II pages adressées au DFFD. AFB, E6520B, 2007/62, vol. 18, lettre de la Direction générale de la BNS au DFFD, 29.II.1974.

190 AFB, E6IooB-02, 1989/75, vol. 26, Bankenaufsicht in der Schweiz, lettre de G.-A. Chevallaz à Fritz Leutwiler, I5.08.I974. Chevallaz précise à cette occasion que l'idée d'une présidence à plein temps pour la Commission fédérale des banques «s'est heurtée à l'opposition des banques et a été finalement abandonnée par le Conseil fédéral». 
trois interventions parlementaires: la petite question du socialiste Rudolf Welter (I9II-2000), la motion du socialiste Hans Schmid et l'interpellation du membre de l'Alliance des Indépendants Sigmund Widmer (1919-2003) ${ }^{191}$. Toutes trois réclament une amélioration de la surveillance des banques et plus précisément une meilleure protection des petits épargants.

Face à cette pression politique, qui émane à la fois d'interventions parlementaires et de propositions de la direction de la BNS, le Département fédéral des finances et des douanes décide en janvier 1975 d'établir un groupe d'étude chargé d'examiner l'opportunité d'une révision de la loi sur les banques. Composé d'une demi-douzaine d'experts provenant de l'administration fédérale, de la banque centrale, de la Commission fédérale des banques, de l'Association suisse des banquiers et du monde académique, ce comité a pour objectif d'examiner de potentielles améliorations dans l'organisation de la surveillance bancaire ${ }^{192}$. À l'issue de six séances, le groupe de travail remet en novembre 1975 un rapport au DFFD ${ }^{193}$. Il y préconise plusieurs modifications: un agrandissement immédiat du secrétariat de la CFB, un accroissement de ses compétences, la transmission obligatoire de tous les rapports de révision bancaire (et non plus seulement ceux des établissements qui posent problème), une participation des banques au financement de la CFB par le biais d'émoluments, et la transformation de la présidence de la $\mathrm{CFB}$ en un poste à plein temps. En somme, des changements mineurs qui ne nécessitent pas une révision formelle de la législation. Des réformes plus ambitieuses sont discutées, mais rejetées, comme la transformation du système d'audit par des sociétés privées, l'idée de créer un véritable Office fédéral des banques sur le modèle du secteur des assurances ou encore un transfert de la surveillance vers la BNS. Le Conseil fédéral avalise les propositions du groupe de travail en décembre 1975, et entreprend une simple réorganisation administrative de la Commission fédérale des banques. Des changements de têtes, avec l'arrivée au nouveau poste de directeur de la CFB de l'ancien chef du service juridique de l'Administration fédérale des finances Bernhard Müller, ainsi que l'augmentation du personnel d'une dizaine à une vingtaine d'employés sont décidés. Mais la loi sur les banques, dans sa mouture insatisfaisante de 1971, reste «intact ", et l'absence de collaboration formalisée entre la CFB et la BNS demeure.

$\mathrm{La}$ "fenêtre d'opportunité » en faveur d'un renforcement de la surveillance bancaire ouverte par plusieurs débâcles bancaires essentiellement dues à des

191 Petite question Welter du II.I2.I974, surveillance des banques; motion Schmid (SG) du 27.0I.1975, protection des petits épargnants et investisseurs; interpellation Widmer du 28.0I.1975, protection des petits épargnants.

192 AFB, E6roo(B-02), 1989/75, vol. 26, dossier Studiengruppe zur Überprüfung des Bankengesetzes. La composition exacte: Bernhard Müller (pdt, DFFD), Dr. Paul Ehrsam (BNS), Dr. Markus Lusser (ASB), Prof. Emilio Albisetti (Dir. de Spar- und Leihkasse Bern), Prof. Alain Hirsch (CFB), Dr. Daniel Bodmer (CFB), Prof. Benno Lutz, remplacé par René Prodolliet, directeur de la SBS.

193 AFB, E6520B, 2007/62, vol. I8, Studiengruppe zur Überprüfung des Bankengesetzes, Bericht zuhanden des Eidg. Finanz- und Zolldepartement, 28.II.1975. 
crises de change en 1974 semblait donc se refermer sans véritable réforme fin 1975. Ce dénouement convenait parfaitement aux milieux bancaires, qui avaient insisté au cours des délibérations du groupe de travail pour que les rares mesures proposées fussent réalisées sans une révision formelle de la loi sur les banques, ce afin d'éviter une politisation de la thématique ${ }^{194}$. Or, au printemps 1977, une affaire retentissante vient perturber cette situation. Le scandale de Chiasso éclate en avril $1977^{195}$. On apprend alors que les dirigeants de la succursale de Chiasso du Crédit Suisse ont mis en place depuis le début des années 1960 un montage financier pour faciliter l'évasion fiscale depuis l'Italie, par le biais d'une société basée au Liechtenstein (Texon, fondée en I96I). Les pertes de change et les mauvais investissements opérés par les responsables de la succursale tessinoise occasionnent un préjudice colossal de I.4 milliard de francs pour le Crédit Suisse; certains banquiers locaux sont arrêtés et poursuivis en justice, une partie des dirigeants du siège central sont poussés à la démission. L'affaire connaît un retentissement international. Pour de nombreux observateurs, elle symbolise l'ampleur des mouvements illicites de capitaux vers les banques suisses et les liens étroits avec les pratiques d'évasion fiscale que ces établissements favorisent. Mais l'affaire de Chiasso met aussi en évidence le laxisme de l'environnement réglementaire en Suisse : elle révèle de graves dysfonctionnements dans les systèmes de contrôle à la fois interne (inspectorat) et externe (révision par la société fiduciaire).

Le scandale de Chiasso provoque aussi des répercussions politiques immédiates. Non moins de 17 (!) interventions parlementaires sont déposées au Conseil national. Toutes les fractions parlementaires (PRD, PDC, UDC, AdI, PSS) interpellent le gouvernement pour connaitre les tenants et aboutissants des agissements et réclamer, avec des modalités qui varient selon les tendances politiques, une modification du système de surveillance pour éviter la reproduction d'un tel scandale. Un long débat a lieu au Conseil national le 4 mai 1977, au cours duquel le conseiller fédéral Chevallaz, acculé par les questions des parlementaires, doit louvoyer en renvoyant la balle aux tribunaux dont les «enquêtes sont en cours». En dehors du parlement, la pression politique augmente également. Le Parti socialiste suisse annonce, avec une certaine précipitation, le lancement d'une initiative populaire sur le sujet. Celle-ci aboutit en octobre 1979, mais ne sera soumise au peuple qu'en mai 1984.

Du côté des acteurs centraux impliqués dans la régulation bancaire, la réaction ne se fait pas non plus attendre. Elle comporte deux volets. L'ASB

194 AFB, E6Ioo(B-O2), 1989/75, vol. 26, dossier Studiengruppe zur Überprüfung des Bankengesetzes, lettre de Markus Lüsser (ASB) à Bernhard Müller (AFF), 2I.II.I975.

195 Sur le scandale de Chiasso, voir Max Mabillard, Roger de Weck, Scandale au Crédit Suisse, Genève : Tribune éditions, 1977 ; Jung, op. cit., 2000, p. 245-287 ; Jung, op. cit., 2007, p. 1557 ; Emilie Pasquier, «Le parti socialiste suisse et l'initiative populaire "contre l'abus du secret bancaire et de la puissance des banques" (1977-1984) ", Faculté des sciences sociales et politiques, Université de Lausanne, 2009 ; Lorena Quintas, «Le scandale de Chiasso : secret bancaire et opinion publique en Suisse romande », Mémoire de maitrise en histoire économique, Département d'histoire économique, Université de Genève, 20 Io. 
favorise dans un premier temps la signature d'un accord avec la BNS. La " convention relative à l'obligation de diligence lors de l'acceptation de fonds et à l'usage du secret bancaire » est conclue le 2 juin 1977, moins de deux mois après l'éclatement du scandale. Elle met en place un mécanisme d'autorégulation visant à assurer l'identification des clients par les banques et empêcher la facilitation de l'accueil de capitaux acquis par des actes délictueux ou l'assistance active en matière de fuite des capitaux et de fraude fiscale. Quant à la seconde réaction, elle consiste en la réactivation du groupe d'étude chargé d'examiner la loi sur les banques. Au point mort depuis fin 1975, les travaux de la commission d'experts reprennent et donnent lieu à I9 séances entre 1977 et 1980. Ils aboutissent à la conclusion, en mai 1980, que la loi sur les banques mérite une révision totale. Au fond, entre 1977 et 1982, le groupe de travail du DFF élabore des projets de révision de la loi sur les banques qui font office de contre-projets informels aux revendications socialistes formulées dans l'initiative populaire. Certains points de convergence concrets entre les deux propositions existent d'ailleurs. Les associations économiques, consultées en 1983 à propos du projet de révision de la loi sur les banques, lui réservent un accueil très froid: l'ensemble de l'entreprise est jugée inutile.

Le rejet massif de l'initiative populaire socialiste sur les banques par $73 \%$ des votants en mai 1984 sonne finalement le glas de la révision prévue de la loi sur les banques. Il provoque un infléchissement de la volonté et de la capacité du DFFD à mener à bien son projet. L'ASB interprète le résultat des urnes comme un plébiscite en faveur du secret bancaire et du cadre réglementaire en vigueur. L'abandon du projet se décide ensuite en trois temps : le Conseil fédéral choisit d'abord de transformer le projet de révision totale en une révision partielle de la loi sur les banques. Puis, en décembre 1985 , l'ASB cherche à empêcher même une révision partielle; elle propose un simple ajout dans la Convention de diligence, renouvelée à l'occasion. Enfin, un an plus tard, en décembre 1986, le Conseil fédéral avoue publiquement qu'il ne considère plus une révision, même partielle, de la loi sur les banques comme nécessaire. Les motivations de ce revirement complet sont exposées de manière plus précise par la Conseillère fédérale radicale Elisabeth Kopp (1936-) à la journée annuelle de l'ASB :

Dans l'euphorie des années septante un projet de révision totale de la loi sur les banques avait été mis sur pied. Après le rejet de l'initiative sur les banques en 1984, le Conseil fédéral a décidé de renoncer à la révision totale pour ne préparer qu'une révision partielle de la loi sur les banques. Actuellement, se pose la question de savoir si les principaux buts de la révision peuvent être atteints sur la base du droit en vigueur - au moyen d'un changement de pratique ou tout simplement par ordonnance - sans trop forcer l'esprit de la loi. Une telle manière de procéder permettrait aux autorités fédérales d'attendre la fin de la vague de changements qui déferle actuellement sur le secteur des banques et des marchés des capitaux, afin de juger des forces régulatrices que l'économie est en mesure de produire par elle-même. Toute action prématurée dans ce domaine est susceptible de perturber la dynamique 
propre à ce cycle économique. Certains spécialistes de la branche estiment par conséquent aujourd'hui déjà qu'il serait maladroit de réviser la loi sur les banques à l'heure actuelle et que s'il n'est pas nécessaire d'édicter une loi, c'est qu'il est nécessaire de ne pas en édicter une ${ }^{196}$.

Les projets de révision, entamés en 1975, puis réactivés et considérablement renforcés sous l'effet du scandale de Chiasso et de l'initiative socialiste sur les banques, sont enterrés par le gouvernement fin 1986. Cet épilogue qui ouvre notre recherche vers la période ultérieure des années 1970 et 1980 confirme plusieurs tendances identifiées pour la période précédente. La préférence marquée des dirigeants bancaires pour le statu quo réglementaire apparaît de manière saisissante. Même éclaboussés par l'un des plus graves scandales de leur histoire, les banquiers suisses parviennent à sortir indemnes d'une phase, au tournant des années 1980, qui aurait pu accoucher d'une réforme significative du cadre réglementaire. La coalition des acteurs politiques en faveur d'un renforcement du contrôle public sur les activités bancaires s'était en effet nettement élargie à la fin des années 1970. Sous l'effet du contraste entre une place bancaire florissante et certains secteurs industriels lourdement affectés par la crise des années 1970, une partie de la majorité bourgeoise n'est plus totalement imperméable aux jugements critiques à l'encontre du "pouvoir des banques". Même une personnalité comme Fritz Leutwiler, président de la BNS, ose évoquer publiquement en 1975 qu'un redimensionnement de la place financière suisse ne serait pas malvenu ${ }^{197}$.

Or, cet état d'esprit ouvert à une certaine régulation se dissipe sous le double effet de la reprise conjoncturelle des années I980 et de l'initiative socialiste sur les banques. Paradoxalement, la formulation de propositions de réforme par un acteur politique traditionnellement opposé à la puissance des grandes banques et tenu à l'écart de lieux de décision de la politique bancaire provoque un effet contre-productif. Elle permet de reconsolider la cohésion parfois ébranlée entre les milieux bancaires privés et les élites administratives et politiques bourgeoises. La Commission fédérale des banques, la Banque nationale suisse et l'Administration fédérale des finances se rallient pour formuler des propositions de réforme plus modérées que l'initiative socialiste. Toutefois, l'échec cuisant de l'initiative en consultation populaire en 1984 brise également, par effet collatéral, les projets plus timides de révision de la loi sur les banques émis par le Département des finances.

Quelles qu'en soient les motivations et les circonstances exactes, l'échec de la réforme de la régulation bancaire clôt une décennie très mouvementée entre I975 et 1985. Ces changements avortés, qui nécessiteraient un examen plus approfondi que les quelques lignes qui précèdent, signalent également, si besoin était, que la révision de la loi sur les banques de I97I n'avait pas permis

196 Propos cités (et soulignés) dans le rapport annuel de l'ASB i986/1987, p. 44-45.

197 Loepfe, op. cit., 20II, p. 438. 
de résorber toutes les lacunes de la surveillance bancaire. Ce constat, s'il est valable pour la période des années 1970 et 1980, l'est sans doute tout autant pour l'époque actuelle ${ }^{198}$. Il y a fort à parier que les récentes réformes législatives, engagées dans le sillage de la crise financière de 2008 , confirment la remarquable capacité des banquiers à imposer un cadre réglementaire qui leur est favorable, avec la complicité passive d'un superviseur des banques timoré et impuissant. 


\section{CONCLUSIONS}

Les pages qui précèdent ont analysé la mise en place d'un système de surveillance des banques par l'État fédéral suisse et son évolution durant le second tiers du XXe siècle. Il est temps d'opérer un rapide retour sur les résultats centraux de ce travail, en gardant à l'esprit les principales questions de recherches formulées initialement. À cette synthèse conclusive succèderont quelques pistes de recherches ouvertes par cette étude.

Jusqu'à l'adoption de la loi sur les banques de novembre 1934, la place bancaire suisse se développe en dehors de tout cadre légal spécifique à l'échelon fédéral. Les établissements financiers, comme toute autre entreprise industrielle ou commerciale, doivent seulement respecter le Code des obligations, à savoir le droit des sociétés selon la forme juridique qu'ils ont choisie (société anonyme, société individuelle, coopérative, etc.). Ces prescriptions très générales concernent par exemple les droits et devoirs des actionnaires, du conseil d'administration et de la direction, et la production d'une comptabilité annuelle. Il existe certes quelques réglementations cantonales, notamment dans le domaine des caisses d'épargne, mais elles sont hétérogènes et n'affectent qu'une partie des acteurs financiers, et ce dans un rayon circonscrit. Les banques helvétiques bénéficient donc d'un environnement réglementaire entièrement dérégulé jusqu'à une période relativement récente. À l'échelle internationale, la formalisation juridique de la régulation bancaire connait une première phase d'avancées au XIX siècle : l'Australie en I840, la Suède en I846, les États-Unis en I863-I864, la Finlande en I866, le Canada en I870, le Japon en I872 font figure de pionniers ${ }^{1}$. Au cours de l'entre-deux-guerres, durant une seconde phase, d'autres pays comme le Danemark (1919), la Norvège (1924), l'Autriche (1924), la Tchécoslovaquie (1924) et l'Italie (1926) adoptent des législations bancaires. La Suisse fait au contraire partie des États qui, comme l'Allemagne ou la Belgique, ne légiferent qu'à la suite de la profonde crise bancaire des années 1930. Du point de vue interne à la Suisse également, une législation sur les banques plus précoce n'aurait pas été inconcevable. Le domaine des assurances privées, par exemple, est soumis à une loi fédérale de surveillance depuis I885, qui inclut la création d'un Bureau fédéral des assurances et un système de concessions.

Au cours du premier tiers du XXe siècle, plus précisément entre I9I4 et I933, l'environnement légal très souple dont jouissent les banques suisses est remis en

1 Grossman, op. cit., 2010, p. I40-I4I ; Allen, et al., op. cit., 1938. Cette énumération n’est pas exhaustive. 
question - sans être toutefois véritablement atteint. À la suite d'une crise bancaire qui affecte certaines banques régionales entre I9IO et I9I4, un premier projet de réglementation fédérale des banques en Suisse est élaboré sous le mandat des autorités publiques en I9I6. Il est repoussé, puis même censuré par les milieux bancaires. Au cours des années 1920, le débat sur la régulation bancaire est masqué par deux questions annexes: celle de la limitation de l'exportation de capitaux effectuée par les banques suisses et celle de la révision du droit des sociétés. Ces discussions ont pour effet de faire passer au second plan l'introduction éventuelle d'une réglementation propre au secteur bancaire. Elles mettent aussi en exergue la forte préférence des acteurs impliqués pour des solutions d'autorégulation, en l'occurrence des accords non-contraignants négociés en catimini entre l'association bancaire, la banque centrale et l'administration fédérale, au détriment d'une législation standard - plus rigide et susceptible de nourrir des débats publics - adoptée par le parlement.

Il faut donc attendre l'irruption de la crise bancaire en Suisse, à l'été 193I, pour voir réapparaître à l'agenda politique la question du contrôle des banques par l'État. L'aggravation des difficultés auxquelles font face les établissements bancaires et les interventions de secours souvent maladroites et inopérantes des pouvoirs publics, entre l'été 193I et le printemps 1933, provoquent un basculement dans l'attitude de l'administration gouvernementale en charge du dossier. Jusqu'au début de 1933, le Département des finances de Jean-Marie Musy maintient, malgré une pression politique accrue, une position ferme de rejet des propositions en faveur d'une loi de contrôle des banques. Il est à cet égard en parfaite adéquation de vues avec les principaux dirigeants du monde bancaire. Avec les assainissements de la Banque d'Escompte Suisse puis de la Banque Populaire Suisse, réalisés entre 1932 et 1933 avec la contribution de la Confédération, la donne change. Comme contrepartie stratégique à l'aval d'une majorité de députés aux investissements publics de renflouement, le ministre des Finances doit céder sur le dossier du contrôle bancaire. À la suite de nombreuses hésitations, tergiversations et retardements, l'élaboration d'une loi sur les banques devient inévitable durant l'hiver 1933-1934. Après des délibérations parlementaires rapides, le texte entre en vigueur en mars 1935.

Profondément influencée par les représentants des milieux bancaires, qui interviennent de manière à la fois précoce et continue dans le processus d'élaboration des projets successifs, la loi sur les banques de novembre 1934 met en place un régime de surveillance souple et peu intrusif. Pour la plupart des banques helvétiques, la réglementation se contente de donner force de loi à des pratiques déjà en vigueur ; aucune réforme structurelle, aucune prescription contraignante sur le type d'activités bancaires ni sur les placements opérés n'est introduite. Dans la mise en application des dispositions prudentielles adoptées, l'agencement de supervision de 1934 instaure une surveillance indirecte des activités bancaires. La vérification comptable des écritures - et donc la détection d'éventuelles infractions ou contournements légaux - est confiée à des sociétés fiduciaires privées, dont l'indépendance à l'égard des banques qu'elles 
contrôlent n'est pas garantie. L'organisme étatique créé pour l'occasion - la Commission fédérale des banques - n'est là que pour chapeauter le système de contrôle.

Une fois promulgué en 1934, le cadre légal régissant le secteur bancaire se distingue par une remarquable stabilité durant une période d'au moins quarante ans. Les normes légales restent pour ainsi dire inchangées, alors que tant le poids économique de la place bancaire suisse par rapport à la production de richesse nationale, que son rôle dans les mouvements de capitaux internationaux, ou encore les innovations dans les instruments financiers employés se développent considérablement entre 1934 et 1972 . Certains textes, comme l'ordonnance d'exécution de la loi sur les banques en 196I, connaissent une adaptation; une nouvelle loi fédérale entre en vigueur en 1966 pour appréhender le phénomène des fonds de placement. Mais dans l'ensemble, les banques suisses se développent sous le même régime réglementaire à la fin des années 1960, en plein boom économique, qu'au milieu des années I930, au cœur de la crise bancaire. Corollairement, l'autorité de surveillance censée garantir le respect des rares prescriptions prudentielles, comme les ratios de fonds propres et de liquidité, dispose des mêmes instruments légaux pour remplir ses missions. Plus grave, la Commission fédérale des banques opère à la fin de la période étudiée avec des moyens quasiment identiques à ceux dont elle bénéficiait dans les années 1930: une demi-douzaine de fonctionnaires fédéraux, dont seulement 2-3 collaborateurs qualifiés, et un budget très modeste.

Pourtant, durant ses 35 premières années d'activité, l'organisme de surveillance repère un certain nombre de dysfonctionnements dans le régime légal sous lequel elle agit. Plusieurs dispositions, et en particulier les mesures à caractère disciplinaire - autrement dit son arsenal juridique - se révèlent totalement inopérantes. Dès les années 1940, et de manière accélérée à partir de la fin des années 1950, les superviseurs fédéraux font le constat de ces insuffisances. En revanche, ils n'en tirent pas de conséquences cohérentes susceptibles de remédier aux déficiences détectées. Entre 1946 et 1965, la ligne de conduite adoptée par les membres de la Commission fédérales des banques consiste à empêcher, ou du moins à freiner, les éventuels projets visant à toucher aux dispositions de la loi sur les banques de 1934 par le biais d'une révision légale. Là aussi, cette attitude correspond entièrement à la volonté de l'Association suisse des banquiers, dont la stratégie à cet égard est caractérisée par le maintien intégral du statu quo. Eviter l'ouverture d'un débat public sur les dispositions légales de 1934 devient le maitre-mot des représentants des banques.

Cette farouche résistance aux tentatives de réforme n'est brisée que dans la seconde moitié des années 1960. Un scandale retentissant - l'affaire MuñozHommel - éclabousse l'activité routinière de la Commission fédérale des banques. À cette remise en question du rôle de l'autorité de surveillance se superpose la problématique de la multiplication des banques étrangères en Suisse. Pour les milieux bancaires, une modification de quelques dispositions 
de la loi de 1934 devient de plus en plus intéressante, à condition qu'elle puisse être réalisée dans un environnement politique favorable et qu'elle intègre certaines adaptations dont ces milieux peuvent tirer profit. Une conjonction de plusieurs facteurs - le scandale Muñoz comme détonateur, ladite Überfremdung de la place bancaire suisse considérée comme une menace par les banquiers helvétiques, ainsi que les possibilités d'apporter des ajustements bénéfiques du point de vue des représentants bancaires, par exemple dans la définition des fonds propres - explique l'aboutissement d'une révision de la loi en mars 197I. À la lumière de ce contexte d'élaboration, il n'est pas étonnant que la réforme de 1971 ne soit pas de grande ampleur. Elle consiste en des ajustements mineurs, qui ne remettent pas en question le caractère fondamentalement peu contraignant du régime de surveillance. À plus long terme, les modifications de 197I favorisent le maintien du même modèle d'expansion des grandes banques helvétiques, en encourageant indirectement le rôle de plaque tournante des capitaux internationaux.

Les principales articulations chronologiques de notre travail, esquissées cidessus, appellent quelques commentaires susceptibles de généraliser le propos. Il faut premièrement souligner que la mise en place d'une régulation sur les banques répond à une logique cyclique de réaction. L'éruption d'une crise financière ou la détection d'une lacune réglementaire, par exemple à la suite d'une innovation, provoque la mise à l'agenda politique de la thématique, qui aboutit parfois à l'adoption ou à la réforme du régime réglementaire. Plus difficilement identifiables, les tentatives échouées sont à cet égard au moins aussi significatives que les projets qui réussissent. Dans ce cadre, il faut cependant se garder de considérer la mise en ouvre législative comme un processus unilatéral, imposé par les pouvoirs publics à des acteurs privés passifs, impuissants et homogènes. Au contraire, l'ensemble des processus d'élaboration examinés dans ce travail met en évidence l'influence déterminante que sont capables d'exercer les milieux bancaires dans la définition ou la modification des normes qui régissent leurs activités, ainsi que les négociations internes au secteur qui précèdent.

Cette mainmise des représentants bancaires ne se manifeste pas seulement dans les situations où une législation ou une réforme de législation aboutit. Elle apparaît également de manière évidente lorsque des projets échouent ; le projet Landmann de 1916, mais aussi les tentatives abandonnées de modifier la loi fédérale sur les banques entre 1946 et 1965 en témoignent. Pour le dire autrement, l'intégration anticipée des milieux bancaires dans le processus de décision - et la prise en compte de leurs préférences - devient pour les législateurs le meilleur garant de la réalisation d'un projet de réglementation. Souvenonsnous des propos explicites du président de la Commission fédérale des banques Ernst Wetter, en 1948, lorsqu'il était question de pérenniser les dispositions sur 
les assainissements bancaires par le biais d'une révision de la loi: "l'avis de l'Association des banquiers sera largement déterminant pour nous. Si nous faisons quelque chose, nous ne le faisons pas pour nous, mais pour les banques ${ }^{2}$. En l'absence d'un soutien au moins partiel des milieux intéressés, il devient très difficile pour les superviseurs fédéraux ou les législateurs du Département des finances d'imposer une réforme. Les secrétaires de la Commission fédérale des banques en font l'amère expérience, en 1966-1968, lorsque le projet de révision de la loi sur les banques qu'ils avaient ficelé à l'interne durant de longs mois prend la poussière dans les tiroirs de l'administration fédérale, en raison de divergences avec l'Association suisse des banquiers à propos des priorités d'une révision.

La capacité d'influence des cercles bancaires, si importante dans l'aboutissement ou l'échec d'une tentative de régulation, découle en partie du type de traitement politique réservé aux projets en question. Pour le dire rapidement, notre analyse a montré que les banquiers parviennent à mieux imposer leurs vues lorsque le problème de la surveillance bancaire est considéré comme un débat technique, qui doit être résolu entre spécialistes dans un cadre confidentiel. Nous retrouvons ici le principe des quiet politics énoncé par le politologue Culpepper $^{3}$. Plus un objet politique relève d'une faible pertinence politique apparente pour la grande majorité du corps électoral (low political salience), plus les groupes d'intérêts concernés sont capables de dicter leurs préférences. La régulation bancaire confirme ce postulat. L'Association suisse des banquiers affirme régulièrement que les questions de réglementation bancaire sont une affaire d'experts versés dans le domaine, et qu'elles doivent donc être discutées entre spécialistes, dans des comités restreints, à l'abri du regard des élus et de la presse. Les stratégies des banquiers pour favoriser le traitement de questions sensibles dans l'ordonnance d'exécution plutôt que dans la loi même révèlent une facette de cette attitude.

Le second constat, étroitement lié au premier, a trait à la propension des milieux bancaires à prôner le statu quo réglementaire. Une fois la législation bancaire adoptée dans les années 1930, les représentants des banques cherchent à préserver les textes originaux de toute révision d'ampleur, et ce, malgré certaines lacunes avérées dont la correction pourrait leur être bénéfique. Pour les banquiers, mieux vaut continuer à opérer sous un régime en partie insatisfaisant que de risquer de lancer une procédure de réforme qui pourrait conduire à des résultats défavorables. En 1948, le directeur général du Crédit Suisse Peter Vieli intime un mot d'ordre clair à ce sujet à ses collègues du Conseil d'administration de l'ASB : « en aucun cas, il ne faut toucher à la loi sur les banques ${ }^{4}$. Cette préférence pour l'ordre établi est une constante dans l'attitude des banquiers à l'égard de la législation de surveillance pendant la

2 AFB, E6520(B) 2007/62, vol. 6I, Bankensanierungsverfahren, Protokoll der Konferenz, 03.12.1948, p. 5 .

3 Culpepper, op. cit., 20II.

4 AASB, Procès-verbaux du Conseil d'administration de l'ASB, I87 ééance, 25.08.1948, p. 5. 
période étudiée. Elle s'explique par deux faisceaux de raisons. D'une part, éviter une réforme juridique revient à empêcher la tenue d'un débat public sur le contrôle bancaire, puisqu'une révision légale doit obtenir l'aval parlementaire. Les représentants bancaires cherchent donc à favoriser la résolution de problèmes par d'autres voies : gentlemen's agreement, révision d'ordonnance, modifications de circulaires émises par l'autorité de surveillance, etc. On retrouve ici la préférence pour une gestion des affaires de régulation entre experts. D'autre part, les banquiers expriment de vives craintes - si infondées qu'elles soient suivant lesquelles l'ouverture d'un débat politique et médiatique plus large provoquerait la formulation de propositions susceptibles d'aller à l'encontre de leurs intérêts (nationalisation, contrôle public sur l'orientation des crédits). Quand bien même les rapports de force politiques marqués par une confortable majorité des partis conservateurs, rendent le succès de telles propositions hautement improbable, leur seule verbalisation au parlement représente une source d'inquiétude pour les banquiers. En Suisse, peut-être davantage que les critiques portées par des forces politiques internes comme le Parti socialiste, c'est en particulier un débat public sur la portée du secret bancaire qui donnerait éventuellement lieu à une campagne hostile de la part de médias étrangers, qui est craint. Le caractère injustifié des angoisses exprimées par les milieux bancaires - les amendements peu importants de I97I en témoigne - permettent de douter de la sincérité de cette peur. S'agit-il plutôt d'une simple instrumentalisation visant à repousser l'ouverture du chantier législatif? Plus généralement, cette préférence accordée au statu quo réglementaire semble aussi inhérente à l'activité bancaire: les facteurs de stabilité et de confiance étant essentiels au succès d'un institut, les dirigeants bancaires accordent sans doute une grande importance au maintien d'un environnement réglementaire inchangé.

La troisième dimension significative soulignée par ce travail est relative au choix d'un nouvel organisme pour mettre en application la surveillance bancaire, ainsi qu'à la position défendue par cette institution. Nous avons vu que durant la phase d'élaboration de la loi fédérale sur les banques, en 1933-1934, la création d'une nouvelle autorité avait été plébiscitée par les représentants des banques et du Département des Finances. Plus précisément, cette solution apparaissait comme un moindre mal, face au refus ou au rejet d'une surveillance exercée par la banque centrale. La notion d'indépendance à l'égard des instances étatiques était alors fondamentale. Les milieux bancaires cherchaient surtout à éviter que l'introduction d'une surveillance par l'État soit comprise comme un resserrement du contrôle officiel des comptes bancaires individuels, susceptibles d'effrayer la clientèle. Il était donc important de limiter drastiquement les compétences de l'autorité de surveillance au strict domaine des mesures prudentielles (respect des ratios, organisation adéquate, révision annuelle, etc.). Après une première phase $\mathrm{d}$ 'appréhension et de méfiance, les banquiers s'accommodaient d'ailleurs fort bien de l'existence d'un petit office avec lequel les échanges, s'ils dépassaient rarement la routine administrative, 
étaient emprunts d'une volonté marquée de collaboration. Le choix d'un organisme d'application de la régulation autonome et faiblement doté, dirigé par une poignée de personnalités actives à temps partiel, contribue à placer la Commission fédérale des banques dans une position d'infériorité. Elle est à la marge de l'administration publique, et dispose d'une faible capacité à dicter ses préférences aux entreprises placées sous sa surveillance.

Au-delà de la configuration institutionnelle initiale, issue des délibérations des années 1930, l'évolution de l'attitude des superviseurs bancaires suisses au cours des quarante années suivantes mérite également quelques commentaires. Face aux divers dysfonctionnements et manquements révélés au cours des premières années d'application de la loi sur les banques, on aurait pu s'attendre à ce que les dirigeants de l'autorité de surveillance multiplient les démarches pour tenter de corriger la situation et de pallier les insuffisances. Or, en Suisse, cette réaction n'a pas lieu. L'analyse montre au contraire qu'entre 1946 et 1965 les principaux responsables de la Commission fédérale des banques renoncent facilement aux timides tentatives de réformer le cadre légal. Ce faisant, ils se conforment aux revendications exprimées par l'Association suisse des banquiers qui avait érigé le statu quo réglementaire en leitmotiv de sa politique à l'égard de la régulation bancaire.

Comment faut-il comprendre cette situation, marquée par une forte passivité d'un organisme de surveillance qui, paradoxalement, refuse d'intervenir pour renforcer ses propres compétences? Une explication régulièrement mobilisée par la littéraire consacrée au phénomène de régulation recourt à la notion de capture régulatoire. C'est parce que les membres de la Commission fédérale des banques sont si étroitement influencés par les groupes de pression du secteur bancaire qu'ils opèrent des choix favorables aux intérêts particuliers des entreprises régulées, au détriment d'intérêts communs, comme ceux des déposants bancaires, qu'ils sont supposés défendre. Ce raisonnement est sur le fond correct. Cependant, le phénomène de capture tel qu'il est à l'œuvre dans la surveillance bancaire suisse ne suffit pas à appréhender l'attitude ambiguë des superviseurs. En effet, selon le modèle théorique, la capture présuppose que deux acteurs aux intérêts nettement divergents puissent être distingués. Il y aurait d'une part un lobby bancaire, en grande partie situé à l'extérieur du processus de décision, qui chercherait à imposer des choix privilégiant ses propres intérêts. Toujours dans le modèle théorique, ce groupe de pression ciblerait une agence gouvernementale pour peser sur ces décisions. Cette agence gouvernementale - ici l'autorité de surveillance bancaire - se distinguerait clairement des milieux privés qu'elle est chargée de contrôler, en protégeant l'intérêt commun selon les missions attribuées par la loi.

Or, dans le cas de la Commission fédérale des banques, cette grille d'analyse ne fonctionne pas parfaitement pour plusieurs raisons. Premièrement, les préférences du secteur privé, dans notre cas le point de vue de l'Association suisse des banquiers, sont pleinement et précocement intégrées dans l'élaboration de la régulation. Lorsque les avant-projets de loi sont rédigés directement 
par le directeur général d'une des plus grandes banques du pays, il est difficile de parler d'une influence externe qui corromprait insidieusement les intentions louables des législateurs officiels. En Suisse, les banquiers ne font pas seulement l'objet de la régulation, ils en sont souvent à l'origine. La notion de lobby, qui présuppose une pression de l'extérieur, s'accorde difficilement avec la situation suisse, dans laquelle les milieux bancaires sont organiquement liés à l'État. Deuxièmement, si l'on s'intéresse au second acteur de la dichotomie régulé/ régulateur, celui de l'instance étatique, le cas suisse présente également un visage ambigu. En effet, les membres et les secrétaires qui dirigent la Commission fédérale des banques ne représentent pas un groupe qui, initialement, défendait l'intérêt commun dans une vision proche de l'État-providence et aurait été graduellement corrompu vers la protection d'intérêts particuliers. Il faut tout d'abord souligner que les principaux éléments qui forment cette petite section administrative se recrutent parmi des juristes et économistes spécialistes, qui proviennent parfois directement de postes au sein du secteur bancaire privé. Daniel Bodmer, une figure marquante de la Commission fédérale des banques entre 1955 et 1980, est engagé après une dizaine d'années au service de l'Association suisse des banquiers (1946-1955). Pour le dire autrement, le système de surveillance bancaire suisse présente des frontières poreuses entre les pôles censés être plus proches de l'État - Commission fédérale des banques, Administration fédérale des finances, voire service juridique de la BNS - et les représentants du monde bancaire privé. En ce sens, les conceptualisations qui impliquent des acteurs strictement catalogués comme interne ou externe, ou comme public ou privé, s'appliquent difficilement à la situation suisse.

En affinant l'analyse, on peut estimer que le cas de la surveillance bancaire suisse met en exergue une variante particulière de capture régulatoire. La Commission fédérale des banques se caractérise plutôt comme une institution hybride, qui, tout en étant instituée par une loi fédérale lui confiant la mission de sauvegarder les intérêts des créanciers et déposants bancaires suisses, identifie dans sa pratique les intérêts communs à ceux des entreprises dominantes qu'elle est chargée de surveiller ${ }^{5}$. C'est donc la configuration institutionnelle propre au cas suisse qui est ici au cœur du problème. La faiblesse institutionnelle de l'appareil étatique helvétique, combinée à son manque d'autonomie à l'égard d'un patronat bancaire qui, lui, est structurellement bien organisé, met en place des conditions propices à créer une surveillance bancaire peu contraignante, et de portée réduite. Dans ces conditions, l'attitude passive et peu combative des superviseurs bancaires fédéraux - et plus généralement la grande cohésion entre élites administratives et dirigeants privés - s'explique aussi par le fait que les deux entités censées s'opposer parviennent aisément à atteindre des points de convergence. Surveillants bancaires et banquiers surmontent les éventuelles

5 Nous reprenons ici le concept d'hybridité institutionnelle développé dans une contribution en cours de publication par le sociologue Leon Wansleben : Leon Wansleben, «Institutional Hybridity at Work: The Case of Swiss Banking Regulation (I920s-1980s) », working paper, 2017. 
pierres d'achoppement contre lesquelles ils pourraient buter, en trouvant une définition commune de ce qui constitue l'intérêt collectif de la place bancaire suisse. Étant donné le déséquilibre des rapports de force entre les deux pôles, cette redéfinition de l'intérêt commun favorise généralement les préférences exprimées par le secteur bancaire privé. Autrement dit, la création d'une institution hybride comme la Commission fédérale des banques induit une reformulation de ce que doit être l'objectif principal de la régulation. Or, pour la grande majorité des spécialistes qui sont nommés à la tête de la CFB, favoriser de plus grandes possibilités de profits des établissements bancaires devient synonyme d'une meilleure protection des déposants. Il s'agit donc pour les superviseurs de laisser une très grande marge de manœuvre aux banquiers, qui seraient les mieux à même de maximiser leur profitabilité. Ce raisonnement conduit les décideurs de la Commission fédérale des banques à adopter une attitude de grande passivité, et - partant - à privilégier un immobilisme dans le domaine de l'intervention réglementaire de l'État dans le secteur bancaire. Cette cohésion de vues entre les superviseurs bancaires fédéraux et les dirigeants des principales banques est favorisée par la sélection des responsables de la Commission fédérale des banques parmi le cercle réduit des spécialistes du domaine bancaire, c'est-à-dire très souvent d'anciens banquiers retraités ou reconvertis. Ce recrutement monocolore des superviseurs bancaires signifie pendant longtemps l'absence de représentants de groupes sociaux supposés être les bénéficiaires principaux d'une surveillance étatique, à savoir les déposants et les épargnants qui sont les premières victimes d'une faillite bancaire. Ceux-ci sont totalement exclus des discussions et des processus de décision. Leur absence est un facteur supplémentaire qui renforce la solidarité entre les acteurs étatiques, paraétatiques et privés effectivement engagés.

En plus de la grande passivité de l'instance de surveillance, ce travail a mis en évidence une seconde caractéristique importante relative aux relations entre les pouvoirs publics et le secteur bancaire. On pourrait en effet croire que l'adoption d'une législation fédérale et la mise en place d'un organisme officiel de surveillance mettraient un terme à la domination des mécanismes d'autorégulation du secteur bancaire, telle qu'elle s'est imposée dans le premier tiers du $\mathrm{XX} \mathrm{X}^{\mathrm{e}}$ siècle. Il n'en est rien. La période examinée dans ce travail, des années 1930 aux années 1970, dénote une forte continuité avec les pratiques de régulation antérieures. Paradoxalement, la formalisation de certains principes de contrôle par le biais d'une loi fédérale ne met pas un terme à la prépondérance de l'autorégulation dans la politique bancaire suisse. La promulgation de la loi implique certes l'établissement d'un nouvel acteur, la Commission fédérale des banques, mais cet organisme ne fait que se superposer à une configuration institutionnelle déjà existante, aux côtés de la BNS et du Département des finances. Dans la grande majorité des situations, les solutions trouvées entre ces acteurs et les milieux bancaires sont négociées informellement, dans des cercles confidentiels. Et, par sa capacité à influencer lourdement le processus d'élaboration des réglementations qui concernent ses membres, l'Association suisse des 
banquiers parvient à perpétuer les fondements idéologiques de l'autorégulation. En jouant une fonction paraétatique, la Commission fédérale des banques ne met pas un terme à l'autorégulation du secteur bancaire, mais l'accompagne et la soutient.

En 2007, dans l'avant-dernier rapport annuel qui précède sa dissolution dans la FINMA et publié pendant le déclenchement de la crise des subprimes, la CFB rappelle qu' « un cadre étatique approprié permettrait d'accroître encore le rôle de l'autorégulation. Un tel cadre résulte soit de la reconnaissance de normes d'autorégulation comme standard minimal, soit de leur reconnaissance sur la base d'un mandat légal. [...] Grâce à cette reconnaissance, l'autorégulation est perçue en Suisse et à l'étranger comme une alternative crédible à la réglementation étatique ${ }^{6}$. On le voit, dans l'esprit des superviseurs fédéraux, l'autorégulation et la régulation étatique ne sont pas contradictoires; l'autorégulation devient même pour les représentants de la surveillance étatique un substitut à leur propre fonction. En ce sens, la formalisation dans une loi d'un régime de surveillance des banques par l'État dans les années 1930 consolide l'idéologie de l'autorégulation qui avait été développée par la BNS et l'ASB dans les vingt années précédentes. Cette prépondérance de l'activité régulatrice par les milieux concernés - et reposant sur leur volonté d'application - se poursuit d'ailleurs au-delà de la période examinée, comme en témoigne par exemple le développement par l'ASB de la Convention de diligence des banques entre 1977 et 1990 en tant qu'alternative à une législation contre le blanchiment d'argent et l'évasion fiscale. L'autorégulation, encouragée non seulement par le secteur concerné, mais aussi par les instances étatiques, s'érige sur le long terme en principe cardinal de la gestion des dossiers de politique bancaire.

Notre analyse révèle encore un autre paradoxe. La littérature internationale spécialisée dans l'histoire de la régulation bancaire qualifie volontiers la période étudiée par l'expression financial repression. Les instruments de contrôle instaurés par l'État à la suite de la crise des années 1930 auraient enfermé les établissements financiers dans un carcan réglementaire serré. Des mesures telles que le plafonnement des crédits, le contrôle des taux d'intérêt, le financement forcé du déficit public, dans un environnement marqué par la domination de banques publiques ou semi-publiques, parfois nationalisées, caractériseraient ces régimes d'oppression étatique. L'évolution du régime de régulation bancaire suisse pendant cette période ne correspond aucunement à cette interprétation qui met en avant la répression financière. Aucune contrainte structurelle n'est exercée sur les établissements financiers. Pas de surveillance macro-prudentielle, ni limitation sur les types d'investissements autorisés. Du moment que certaines dispositions légales deviennent des entraves à la prospérité des grandes banques suisses, comme les proportions de fonds propres en 196I et en 1972, elles sont assouplies. En revanche, lorsque des manquements qui nécessiteraient une intervention disciplinaire de l'autorité de surveillance sont

6 Rapport de gestion de la Commission fédérale des banques, 2007, p. 8I-82. 
détectés, comme avec la Kredit- und Verwaltungsbank Zug dans les années I950, le système se révèle inefficace. L'attitude de la Commission fédérale des banques est caractérisée par une grande timidité : elle accepte son impuissance avec une certaine résignation. Pour la demi-douzaine de fonctionnaires qui gèrent l'intégralité de la supervision de la place bancaire suisse, l'essentiel semble être d'appliquer avec minutie une législation qu'ils jugent parfois déficiente. Ce juridisme étroit prévaut, même s'il compromet parfois l'objectif prioritaire, à savoir la garantie d'une sécurité renforcée pour les déposants bancaires. On est donc très loin de la vision qui dépeint la longue période de stabilité entre 1930 et 1970 comme un enfer réglementaire qui contraindrait le développement naturel des agents bancaires.

Enfin, il serait inexact de considérer que le tableau des particularités et des manquements de la surveillance bancaire suisse s'applique uniquement à la période historique étudiée en profondeur dans ce travail, à savoir les années 1930-1970. En effet, la révision de la loi sur les banques de 1971, qui consiste en des ajustements mineurs, ne permet pas de combler de nombreuses lacunes qui avaient été détectées, et qui persistent au-delà des années 1970 et 1980 . Un aperçu sommaire de l'évolution du dossier de la régulation bancaire met en évidence la remarquable continuité des débats sur la nécessité éventuelle de modifier le cadre réglementaire, et confirme la forte capacité des milieux bancaire à opposer leur veto à un projet de révision légal qu'ils désapprouvent (cf. chap. IX.4).

Avant de clore ce travail, il nous reste à suggérer quelques pistes de recherches que cette analyse engage à emprunter. La principale d'entre elles touche autant à la démarche méthodologique qu'à la focale relativement restreinte adoptées ici. En effet, au-delà du seul secteur bancaire, une ouverture vers la notion plus large de la surveillance des services financiers serait sans aucun doute pertinente. Aussi, la régulation des bourses et des marchés constitue un angle mort de ce travail et mériterait une analyse spécifique. De plus, prendre en compte, de manière comparative, l'évolution du secteur des assurances et sa régulation étatique fédérale permettrait de mieux faire ressortir les spécificités de la surveillance bancaire. Nous avons laconiquement signalé dans quelles conditions est instituée la surveillance fédérale des assurances privées dans le dernier quart du XIXe siècle. La comparaison avec le secteur bancaire nourrit des pistes de recherche prometteuses : comment se fait-il qu'en I885, les législateurs fédéraux parviennent à imposer une loi de surveillance sur les assurances privées qui comporte un système de concessions et un office fédéral directement rattaché à l'administration fédérale, tandis qu'ils optent en 1934, dans le domaine bancaire, pour un régime hybride moins interventionniste? Ces divergences sont d'autant plus intéressantes à éclaircir que depuis la création de la FINMA en 2009, la surveillance des banques et des assurances est réunie sous un même toit.

Plus généralement, la présente étude a retenu une définition relativement restrictive de la notion de régulation bancaire. La focale se porte sur une 
réglementation principale - la loi fédérale sur les banques - et les activités d'une institution particulière - la Commission fédérale des banques. Sans doute cette étude a-t-elle permis de mieux connaître cet organisme précis, dont certains observateurs vantaient les mérites ou déploraient les manques sans en avoir véritablement consulté les archives pourtant ouvertes au public. Ce faisant, des facettes moins évidentes du phénomène de la régulation des banques ont cependant partiellement échappé à l'analyse.

Celle-ci néglige premièrement tous les acteurs muets de la surveillance bancaire. En effet, les bénéficiaires désignés de la régulation - à savoir les déposants et les épargnants bancaires - n'ont pas voix au chapitre dans les lieux de décision dont les sources ont été mobilisés dans ce travail. Ils n'apparaissent que sporadiquement par exemple à l'occasion des suites judiciaires d'une faillite bancaire, et ce à titre individuel et non en tant qu'organisation collective. Les groupes sociaux sensibles à la variation du taux d'intérêt, notamment la paysannerie et le petit commerce confrontés à un fort endettement, ou encore les locataires, sont également tenus à l'écart des discussions entre spécialistes sur le contrôle des banques.

En outre, la définition restrictive de l'objet d'étude ne permet pas de prendre suffisamment en considération la place qu'occupe l'autorégulation du secteur bancaire. Il est incontestable que la faible ampleur des activités menées par l'instance étatique est en quelque sorte suppléée par la prise de mesures internes au secteur. Le rôle de l'Association suisse des banquiers est ici central. Les conventions cartellaires ratifiées par les entreprises bancaires dans le cadre de cette association représentent par exemple un moyen de fédérer les membres autour de certains principes. Mais elles rendent surtout superflue, selon l'idéologie de l'autorégulation, l'intervention législative de l'État. Les fusions et acquisitions opérées par les grandes banques pour reprendre des petits établissements, parfois en difficulté, répondent à cet égard à la même logique. Elles se substituent à une éventuelle intervention stabilisatrice d'assainissement d'une instance étatique. Or, pour appréhender pleinement ce phénomène d'autorégulation, l'accès aux archives internes des acteurs dominants de la place bancaire semble indispensable. Sans que cette impasse méthodologique nous dédouane entièrement, nous formons toutefois le vœu que de futures recherches sur l'histoire de la surveillance bancaire helvétique obtiennent les moyens de la saisir non seulement par la lorgnette des organismes étatiques, mais également par la perception qu'en donnent les archives bancaires privées. Gageons qu'une telle analyse de l'autorégulation assurée par les banques mêmes mettrait en évidence de manière plus saisissante encore le caractère accessoire et peu intrusif des activités menées par la Commission fédérale des banques au cours de ses quarante premières années d'existence. 


\section{ANNEXES}

Tableau A.I. Composition du conseil d'administration de la Caisse de prêts de la

Confédération en juillet 1932

\begin{tabular}{|c|c|c|}
\hline \multicolumn{3}{|c|}{ Comité } \\
\hline I & Dr. Ruggero Dollfus (1876-1948) & Conseiller national (TI/PCC), CdA de la SBS \\
\hline 2 & Dr. Carl Hermann Rüfenacht (I867-I934) & Ministre de Suisse à Berlin (1922-1932) \\
\hline 3 & $\begin{array}{l}\text { Charles Schnyder von Wartensee } \\
\text { (1874-1957) }\end{array}$ & V-pdt et chef du $2^{\mathrm{e}}$ dép. de la BNS \\
\hline \multicolumn{3}{|c|}{ Membres } \\
\hline 4 & Dr. Richard König (I890-1949) & $\begin{array}{l}\text { Conseiller national (BE/PAB). Professeur } \\
\text { d'économie politique à l'Université de Berne }\end{array}$ \\
\hline 5 & Paul Scherrer (I862-I935) & $\begin{array}{l}\text { Pdt du Conseil de la Banque cantonale bâloise. } \\
\text { Ancien conseiller des États radical bâlois }\end{array}$ \\
\hline 6 & Louis Dapples (I867-I937) & $\begin{array}{l}\text { Pdt du CdA de Nestlé \& Anglo-Swiss Milk, } \\
\text { Vevey. CdA du Crédit Suisse }\end{array}$ \\
\hline 7 & Daniel Jenny (I886-1970) & $\begin{array}{l}\text { Pdt de l'Association patronale de l'industrie } \\
\text { textile et industriel. CdA Elektrobank }\end{array}$ \\
\hline 8 & Dr. Alfred Georg (1864-1957) & $\begin{array}{l}\text { Dir. gén. de La Genevoise Assurances. Ancien } \\
\text { conseiller national libéral genevois }\end{array}$ \\
\hline 9 & Robert Grimm (I88I-I958) & $\begin{array}{l}\text { Conseiller national (BE/PSS). Directeur des } \\
\text { services industriels de la ville de Berne }\end{array}$ \\
\hline Io & Eduard Guntli (1872-1933) & $\begin{array}{l}\text { Conseiller national (SG/PCC). V-pdt du } \\
\text { Conseil de la Banque cantonale saint-galloise }\end{array}$ \\
\hline II & August L. Tobler (I87I-I948) & $\begin{array}{l}\text { Pdt du CdA de «Zurich» Assurances. CdA du } \\
\text { Crédit Suisse }\end{array}$ \\
\hline \multicolumn{3}{|c|}{ Membres suppléants } \\
\hline I2 & Georg Reinhart (I877-1955) & $\begin{array}{l}\text { Associé de la maison de commerce Gebrüder } \\
\text { Volkart. CdA UBS }\end{array}$ \\
\hline I3 & Robert Suter (?-?) & $\begin{array}{l}\text { Dir. de l'Allgemeine Aargauische } \\
\text { Ersparniskasse. Pdt Verband Schweizerischer } \\
\text { Lokalbanken, Spar und Leihkassen. CdA ASB }\end{array}$ \\
\hline
\end{tabular}

Sources : AFB, EIo04.I, I00o/9, vol. 335, Procès-verbaux du Conseil fédéral, séance du 20 juillet 1932. Renseignements biographiques: DHS, Dodis.ch, Base de données "Les élites suisses au XXe siècle». 
Tableau A.2. Membres du conseil d'administration de la Banque Populaire Suisse, 6 janvier 1934

\begin{tabular}{|c|c|c|c|}
\hline \multicolumn{4}{|c|}{ Nommés par le Conseil fédéral } \\
\hline I & $\begin{array}{l}\text { Dr. Robert Haab } \\
\text { (I865-1939), président }\end{array}$ & $\begin{array}{l}\text { Dir. gén. des CFF (I912-1917), ancien conseiller fédéral } \\
\text { radical en charge des postes et chemins de fer (I918- } \\
\text { 1929) }\end{array}$ & $\mathrm{ZH}$ \\
\hline 2 & Friedrich Leder (?-?) & $\begin{array}{l}\text { Ancien dir. de la Banque cantonale de Zurich (v-pdt } \\
\text { I920-I929), membre du Vorstand de l'ASB (I917- } \\
\text { I929) }\end{array}$ & $\mathrm{ZH}$ \\
\hline 3 & Emil Walch (1873-1965) & $\begin{array}{l}\text { Ancien dir. (I905-I9I8), puis membre de la dir. gén. du } \\
\text { Crédit Suisse (I9II-I9I8) }\end{array}$ & $\mathrm{VD}$ \\
\hline 4 & Albert Zust (I874-I952) & $\begin{array}{l}\text { Ancien conseiller d'État (PCC) en charge des Finances } \\
\text { cantonales (1920-1929). Conseiller aux États (dès 1930) }\end{array}$ & $\mathrm{LU}$ \\
\hline 5 & $\begin{array}{l}\text { Dr. Wilhelm Meile } \\
\text { (I886-1973) }\end{array}$ & $\begin{array}{l}\text { Dir. de la Foire aux échantillons de Bâle (dès I9I7). } \\
\text { Futur conseiller national conservateur populaire (1935- } \\
\text { 1938) }\end{array}$ & BS \\
\hline 6 & Gustav Wenk (I884-I956) & $\begin{array}{l}\text { Conseiller d'État socialiste bâlois dès I925 (dép. de } \\
\text { l'intérieur) }\end{array}$ & BS \\
\hline 7 & $\begin{array}{l}\text { Dr. Jeanne Schwyzer } \\
\text { [-Vogel] (I870-I944) }\end{array}$ & $\begin{array}{l}\text { Présidente de l'Union lucernoise pour les } \\
\text { revendications féministes }\end{array}$ & $\mathrm{LU}$ \\
\hline 8 & $\begin{array}{l}\text { Eduard von Steiger } \\
\text { (I88I-I962) }\end{array}$ & $\begin{array}{l}\text { Député au Grand conseil bernois conservateur, puis } \\
\text { PAB. Membre du Comité de banque de la BNS (dès } \\
\text { I93I). Futur conseiller fédéral (dès I94I). }\end{array}$ & $\mathrm{BE}$ \\
\hline 9 & $\begin{array}{l}\text { Dr. Max Weber } \\
\text { (I897-1974) }\end{array}$ & $\begin{array}{l}\text { Expert économique de l'USS. Futur conseiller fédéral } \\
\text { socialiste (dès I95I). }\end{array}$ & $\mathrm{BE}$ \\
\hline IO & Xavier Thalmann (I876-?) & Dir. de la «Zurich» Assurances. & FR \\
\hline II & Otto Häberli (I88I-I967) & $\begin{array}{l}\text { Paysan et restaurateur à Wiggiswil. Membre PAB. Pdt } \\
\text { de l'école d'agriculture de Zollikofen }\end{array}$ & $\mathrm{BE}$ \\
\hline \multicolumn{4}{|c|}{ Nommés par l'Assemblée générale des délégués } \\
\hline I2 & $\begin{array}{l}\text { Hans Pfister (I873-I944), } \\
\text { vice-président }\end{array}$ & $\begin{array}{l}\text { Dir. gén. de la société d'assurance Mobilière suisse, } \\
\text { ancien député radical au Grand conseil bernois (I9IO- } \\
\text { I922). Dir. de l'Office fédéral du travail (I92I-I929) }\end{array}$ & $\mathrm{BE}$ \\
\hline 13 & Charles Bersier (I867-I948) & $\begin{array}{l}\text { Notaire puis préfet à Payerne. Député radical au } \\
\text { Grand conseil vaudois (I897-I909; I9I7-I93I). Frère } \\
\text { d'Henri Bersier, dir. gén. de la Banque cantonale } \\
\text { vaudoise }\end{array}$ & $\mathrm{VD}$ \\
\hline I4 & $\begin{array}{l}\text { Carl Alfred Curti } \\
\text { (I863-1935) }\end{array}$ & $\begin{array}{l}\text { Grossiste en denrées alimentaires. Membre } \\
\text { conservateur-catholique du Grand conseil de la ville } \\
\text { de Lucerne (I891-I899) }\end{array}$ & $\mathrm{LU}$ \\
\hline 15 & Adolf Hochuli (?-?) & Dir. de Mechanische Ziegeleien Keller \& Co. A.G. & $\mathrm{ZH}$ \\
\hline 16 & Dr. O. Rohner (?-?) & Avocat à Saint-Gall & SG \\
\hline 17 & Dr. Paul Ronus (I893-I94I) & Avocat et notaire à Bâle & BS \\
\hline I8 & Karl Soldan (I88I-I938) & Fabricant de volets roulants à Bienne & $\mathrm{BE}$ \\
\hline
\end{tabular}




\begin{tabular}{|l|l|l|c|}
\hline I9 & Robert Strässle (I878-194I) & $\begin{array}{l}\text { Conseiller national radical zurichois (dès 1931). } \\
\text { Membre du comité de l'USAM (président de la } \\
\text { section zurichoise) }\end{array}$ & ZH \\
\hline 20 & Albert Vassalli (I877-I960) & Dir. de Lumina S.A., Genève & GE \\
\hline 2I & $\begin{array}{l}\text { David H. Wuilleumier } \\
\text { (?-1948) }\end{array}$ & Fabricant de montres à Tramelan & BE \\
\hline
\end{tabular}

Sources : AFB, Eioo4.I, I000/9, vol. 345, p. 35-36. Procès-verbaux du Conseil fédéral, séance du 6 janvier 1934. Renseignements biographiques: DHS, Dodis.ch, Base de données «Les élites suisses au XXe siècle».

Tableau A.3. Sommes de bilans des banques suisses, en millions de francs nominaux (I935-1975)

\begin{tabular}{|c|c|c|c|c|c|c|c|}
\hline & I & 2 & 3 & 4 & 5 & 6 & $\begin{array}{c}=\underset{(\mathrm{I}: 6)}{\operatorname{somme}} \\
\end{array}$ \\
\hline & $\begin{array}{l}\text { Grandes } \\
\text { banques }\end{array}$ & $\begin{array}{c}\text { Banques } \\
\text { cantonales }\end{array}$ & $\begin{array}{c}\text { "Autres } \\
\text { banques" }\end{array}$ & $\begin{array}{l}\text { Banques } \\
\text { rég., caisses } \\
\text { d'épargne }\end{array}$ & $\begin{array}{l}\text { Banquiers } \\
\text { privés }\end{array}$ & $\begin{array}{c}\text { Succursales } \\
\text { de banques } \\
\text { étrangères }\end{array}$ & $\begin{array}{c}\text { Toutes } \\
\text { les } \\
\text { banques }\end{array}$ \\
\hline 1935 & 4157 & 7968 & 428 & 4999 & 455 & & I8 007 \\
\hline 1936 & 4600 & 8159 & 426 & 4896 & 503 & & I8 584 \\
\hline 1937 & 4662 & $84 \mathrm{IO}$ & $53 \mathrm{I}$ & 4894 & 530 & & 19027 \\
\hline 1938 & 4487 & 8284 & 605 & 4921 & 452 & 159 & I8 908 \\
\hline 1939 & 4280 & 7993 & 602 & 4845 & 470 & $\mathrm{I} 2 \mathrm{O}$ & I8 $3 \mathrm{IO}$ \\
\hline 1940 & 4392 & 8008 & 591 & 4772 & 419 & 85 & I8 267 \\
\hline I94I & 4493 & $8 \mathrm{I} 4 \mathrm{I}$ & 646 & 4866 & 383 & 76 & 18605 \\
\hline 1942 & 4732 & $824 \mathrm{I}$ & 715 & 5 оाо & 380 & 77 & 19155 \\
\hline 1943 & 4989 & 8397 & 79I & 5163 & 378 & 72 & I9 790 \\
\hline I944 & 5199 & 8690 & 862 & 5396 & 407 & 74 & 20628 \\
\hline 1945 & 5543 & 8876 & 917 & 5592 & 439 & II 6 & 2I 483 \\
\hline 1946 & 6429 & $9 \mathrm{I} 24$ & I 059 & 5872 & 537 & I3I & 23152 \\
\hline I947 & 6834 & 9460 & I 307 & 6167 & 656 & 145 & 24569 \\
\hline 1948 & 7155 & 9826 & I 355 & 6407 & 683 & $2 \mathrm{OI}$ & 25627 \\
\hline I949 & 7344 & I0 646 & I I43 & 6792 & 667 & 198 & 26790 \\
\hline 1950 & 7977 & I0 703 & I 595 & $7 \mathrm{IIO}$ & 657 & 183 & 28225 \\
\hline I95I & $84 \mathrm{IO}$ & II I 84 & I 768 & 7538 & 693 & 222 & 29815 \\
\hline 1952 & 8847 & II 702 & I 996 & 8030 & 712 & 224 & $3 \mathrm{I} 5 \mathrm{II}$ \\
\hline 1953 & 9272 & I2 309 & $2 \mathrm{I} 5 \mathrm{I}$ & 8643 & 744 & 223 & 33342 \\
\hline 1954 & 9686 & I2 934 & $24 \mathrm{OI}$ & 9259 & 840 & 236 & 35356 \\
\hline 1955 & IO 494 & I3 700 & 2652 & $985 \mathrm{I}$ & 860 & 266 & 37823 \\
\hline
\end{tabular}




\begin{tabular}{|c|c|c|c|c|c|c|c|}
\hline & I & 2 & 3 & 4 & 5 & 6 & $\begin{array}{c}=\text { somme } \\
(\mathrm{I}: 6)\end{array}$ \\
\hline & $\begin{array}{l}\text { Grandes } \\
\text { banques }\end{array}$ & $\begin{array}{c}\text { Banques } \\
\text { cantonales }\end{array}$ & $\begin{array}{c}\text { "Autres } \\
\text { banques" }\end{array}$ & $\begin{array}{l}\text { Banques } \\
\text { rég., caisses } \\
\text { d'épargne }\end{array}$ & $\begin{array}{c}\text { Banquiers } \\
\text { privés }\end{array}$ & $\begin{array}{l}\text { Succursales } \\
\text { de banques } \\
\text { étrangères }\end{array}$ & $\begin{array}{c}\text { Toutes } \\
\text { les } \\
\text { banques }\end{array}$ \\
\hline 1956 & II 255 & $1463 \mathrm{I}$ & I 969 & IO 373 & 904 & 295 & 39427 \\
\hline 1957 & I2 I98 & I5 818 & 3267 & IO $80 \mathrm{OI}$ & 953 & 364 & $434 \mathrm{OI}$ \\
\hline 1958 & I3904 & I7 O8I & 3807 & II 528 & I I25 & 472 & 47917 \\
\hline 1959 & I4 77I & I8 26I & 4386 & I2 386 & I I 84 & 559 & 51547 \\
\hline 1960 & 17545 & I9 864 & 5210 & I3 382 & I 443 & 805 & 58249 \\
\hline I96I & 2I I8O & 22022 & 6398 & 14676 & I 724 & 807 & 66807 \\
\hline 1962 & 24275 & 23967 & 7865 & I5 967 & I 659 & 848 & $7458 \mathrm{I}$ \\
\hline 1963 & 27694 & 26 O7I & 9416 & I7 468 & I 652 & I II2 & $834 \mathrm{I} 3$ \\
\hline 1964 & 31002 & 28355 & IO 722 & I8 794 & I $75 \mathrm{I}$ & I 236 & 91860 \\
\hline 1965 & 33867 & $3086 \mathrm{I}$ & 12106 & I9 953 & I 775 & I 574 & 100136 \\
\hline 1966 & 36700 & 33379 & I3 63I & 2I I24 & I 770 & I 997 & I08 60I \\
\hline 1967 & $435 \mathrm{I} 3$ & 36428 & I6 I59 & 22628 & 2017 & $26 \mathrm{I} 8$ & I23 363 \\
\hline 1968 & 57 I27 & 39934 & 20195 & 23288 & 2529 & 3071 & I46 I44 \\
\hline 1969 & 74249 & 43555 & 23923 & 25086 & 2490 & 4106 & I73 409 \\
\hline 1970 & 94357 & 47558 & 27679 & 27280 & 2487 & $49 \mathrm{OI}$ & 204262 \\
\hline I97I & II4 353 & 52790 & 33542 & 29260 & 2990 & 6405 & 239340 \\
\hline 1972 & I2I 256 & 57856 & 37866 & 32345 & 2691 & $6 \mathrm{I} 64$ & $258 \quad I 78$ \\
\hline I973 & I2I I 52 & 6I 687 & 44590 & 32573 & 2566 & $6 \mathrm{I} 34$ & 268702 \\
\hline I974 & $\mathrm{I} 258 \mathrm{II}$ & 67 I06 & 43270 & 34800 & 2450 & 5718 & 279 I55 \\
\hline 1975 & I46 997 & 74 6I2 & $48 \quad 213$ & 37459 & $2 \mathrm{I} 25$ & 5878 & 315284 \\
\hline
\end{tabular}

Sources: Colonnes I-4: Ritzmann-Blickenstorfer (éd.), op. cit., 1996, tableau O.I3, p. 819; colonnes 5-6: Ruedi Wermelinger, Roman Rosenfellner, Séries chronologiques historiques 5 . Les banques suisses, Zurich: Banque nationale suisse, 2009, p. 24-25.

Tableau A.4. Développement des fonds de placement en Suisse (1947-I980)

\begin{tabular}{|l|c|c|c|c|c|c|}
\hline \multirow{2}{*}{} & \multicolumn{4}{|c|}{ Nombre de fonds de placement } & \multicolumn{3}{c|}{$\begin{array}{c}\text { Fortune des fonds de placement } \\
\text { en millions de francs courants }\end{array}$} \\
\cline { 2 - 7 } & Total & $\begin{array}{c}\text { dont } \\
\text { placements } \\
\text { à l'étranger }\end{array}$ & $\begin{array}{c}\text { dont fonds } \\
\text { immobiliers }\end{array}$ & Total & $\begin{array}{c}\text { dont } \\
\text { placements } \\
\text { à l'étranger }\end{array}$ & $\begin{array}{c}\text { dont fonds } \\
\text { immobiliers }\end{array}$ \\
\hline I947 & II & $55 \%$ & $27 \%$ & 253.7 & $77 \%$ & I9\% \\
\hline I948 & II & $55 \%$ & $27 \%$ & 287.7 & $80 \%$ & I8\% \\
\hline I949 & I5 & $47 \%$ & $27 \%$ & 502.4 & $64 \%$ & $23 \%$ \\
\hline
\end{tabular}




\begin{tabular}{|c|c|c|c|c|c|c|}
\hline & \multicolumn{3}{|c|}{ Nombre de fonds de placement } & \multicolumn{3}{|c|}{$\begin{array}{l}\text { Fortune des fonds de placement } \\
\text { en millions de francs courants }\end{array}$} \\
\hline & Total & $\begin{array}{l}\text { dont } \\
\text { placements } \\
\text { à l'étranger }\end{array}$ & $\begin{array}{l}\text { dont fonds } \\
\text { immobiliers }\end{array}$ & Total & $\begin{array}{l}\text { dont } \\
\text { placements } \\
\text { à l'étranger }\end{array}$ & $\begin{array}{l}\text { dont fonds } \\
\text { immobiliers }\end{array}$ \\
\hline I950 & I6 & $44 \%$ & $3 \mathrm{I} \%$ & 649.0 & $63 \%$ & $24 \%$ \\
\hline I95I & I7 & $47 \%$ & $29 \%$ & 821.0 & $65 \%$ & $23 \%$ \\
\hline 1952 & I7 & $47 \%$ & $29 \%$ & 924.6 & $65 \%$ & $24 \%$ \\
\hline I953 & I6 & $44 \%$ & $3 \mathrm{I} \%$ & I OI3.9 & $62 \%$ & $28 \%$ \\
\hline I954 & 20 & $35 \%$ & $45 \%$ & I $42 \mathrm{I} .7$ & $65 \%$ & $29 \%$ \\
\hline I955 & 25 & $48 \%$ & $44 \%$ & I 675.9 & $66 \%$ & $28 \%$ \\
\hline 1956 & 29 & $48 \%$ & $52 \%$ & I 862.8 & $63 \%$ & $32 \%$ \\
\hline I957 & 28 & $50 \%$ & $54 \%$ & I 830.5 & $6 \mathrm{I} \%$ & $36 \%$ \\
\hline 1958 & 33 & $48 \%$ & $58 \%$ & 2339.6 & $63 \%$ & $34 \%$ \\
\hline I959 & 55 & $60 \%$ & $49 \%$ & 3408.6 & $67 \%$ & $30 \%$ \\
\hline 1960 & 65 & $60 \%$ & $49 \%$ & 3900.3 & $62 \%$ & $33 \%$ \\
\hline I96I & 80 & $59 \%$ & $5 \mathrm{I} \%$ & 5348.6 & $59 \%$ & $34 \%$ \\
\hline 1962 & 92 & $58 \%$ & $52 \%$ & 5723.7 & $53 \%$ & $43 \%$ \\
\hline 1963 & IO7 & $54 \%$ & $58 \%$ & 6629.8 & $50 \%$ & $49 \%$ \\
\hline 1964 & II4 & $54 \%$ & $59 \%$ & 6556.4 & $49 \%$ & $50 \%$ \\
\hline 1965 & II4 & $52 \%$ & $60 \%$ & 6310.2 & $49 \%$ & $52 \%$ \\
\hline I966 & II4 & $52 \%$ & $60 \%$ & 5875.6 & $46 \%$ & $55 \%$ \\
\hline 1967 & I32 & $49 \%$ & $55 \%$ & 6394.2 & $46 \%$ & $53 \%$ \\
\hline I968 & IO9 & $50 \%$ & $53 \%$ & 7 080.0 & $49 \%$ & $47 \%$ \\
\hline 1969 & IO3 & $5 \mathrm{I} \%$ & $48 \%$ & 7722.5 & $52 \%$ & $43 \%$ \\
\hline I970 & I06 & $59 \%$ & $45 \%$ & 8136.9 & $55 \%$ & $42 \%$ \\
\hline I97I & III & $59 \%$ & $43 \%$ & IO 457.2 & 6 I $\%$ & $36 \%$ \\
\hline I972 & II4 & $64 \%$ & $39 \%$ & I6 68I.6 & $72 \%$ & $25 \%$ \\
\hline I973 & $\mathrm{I} 22$ & $66 \%$ & $37 \%$ & I6 435.2 & $69 \%$ & $29 \%$ \\
\hline I974 & $\mathrm{I} 2 \mathrm{O}$ & $67 \%$ & $37 \%$ & I3 028.4 & $62 \%$ & $38 \%$ \\
\hline I975 & II9 & $65 \%$ & $37 \%$ & I4 I4O.3 & $64 \%$ & $35 \%$ \\
\hline I976 & $\mathrm{I} 2 \mathrm{O}$ & $64 \%$ & $36 \%$ & I4 342.2 & $65 \%$ & $35 \%$ \\
\hline I977 & $\mathrm{I} 2 \mathrm{O}$ & $64 \%$ & $36 \%$ & I3 997.6 & $62 \%$ & $36 \%$ \\
\hline I978 & II 8 & $64 \%$ & $36 \%$ & I4 O84.I & $61 \%$ & $37 \%$ \\
\hline I979 & II8 & $63 \%$ & $36 \%$ & I4 392.5 & $59 \%$ & $40 \%$ \\
\hline
\end{tabular}




\begin{tabular}{|c|c|c|c|c|c|c|}
\hline \multirow{2}{*}{} & \multicolumn{3}{|c|}{ Nombre de fonds de placement } & \multicolumn{3}{c|}{$\begin{array}{c}\text { Fortune des fonds de placement } \\
\text { en millions de francs courants }\end{array}$} \\
\cline { 2 - 7 } & Total & $\begin{array}{c}\text { dont } \\
\text { placements } \\
\text { à l'étranger }\end{array}$ & $\begin{array}{c}\text { dont fonds } \\
\text { immobiliers }\end{array}$ & Total & $\begin{array}{c}\text { dont } \\
\text { placements } \\
\text { à l'étranger }\end{array}$ & $\begin{array}{c}\text { dont fonds } \\
\text { immobiliers }\end{array}$ \\
\hline 1980 & I2I & $64 \%$ & $36 \%$ & 15069.2 & $59 \%$ & $60 \%$ \\
\hline
\end{tabular}

Source: ABNS, 9.3/9060, Investment-Trusts.

Notes : la rubrique «placements à l'étranger » regroupe les fonds avec placements exclusivement à l'étranger et les fonds mixtes (étranger et Suisse) ; la rubrique "fonds immobiliers » regroupe les fonds uniquement immobiliers et les fonds mixtes (immobiliers et titres). Il en résulte que les pourcentages indiqués sont légèrement surévalués.

Tableau A.5. Composition des commissions parlementaires chargées de la révision de la loi sur les banques (1970)

\begin{tabular}{|c|c|c|c|}
\hline \multicolumn{4}{|c|}{ Commission du Conseil des États } \\
\hline Nom & Parti & Canton & Liens économiques \\
\hline $\begin{array}{l}\text { Blaise Clerc (I9II-200I), } \\
\text { président }\end{array}$ & PLS & NE & $\begin{array}{l}\text { Pdt Chambre suisse de l'horlogerie, v-pdt CdA } \\
\text { du Crédit Foncier Neuchâtelois }\end{array}$ \\
\hline Ernst Bachmann (1912-1995) & PRD & AG & CdA Mobilière suisse, CdA Crédit Suisse \\
\hline $\begin{array}{l}\text { Hermann Bodenmann } \\
\text { (192I-1994) }\end{array}$ & PDC & VS & Membre CFB (I969-I99I) \\
\hline Alfred Borel (1902-1997) & PRD & GE & \\
\hline Peter Hefti (1922-20I2) & PRD & GL & $\mathrm{CdA}$ «Zurich» assurances, comité VSM \\
\hline Paul Hofmann (1913-2000) & PDC & SG & \\
\hline Fritz Honegger (1917-1999) & PRD & $\mathrm{ZH}$ & $\begin{array}{l}\text { Chambre suisse du commerce, CdA Elektro- } \\
\text { Watt }\end{array}$ \\
\hline Franz Leu (1904-1984) & PDC & LU & \\
\hline Augustin Lusser (1896-1973) & PDC & GL & $\begin{array}{l}\text { Pdt du conseil de la BC Zoug, ex-membre du } \\
\text { Comité de banque de la BNS, pdt Concordia } \\
\text { assurances }\end{array}$ \\
\hline Willi Rohner (I907-I977) & PRD & SG & $\begin{array}{l}\text { CdA SBS, Comité de banque de la BNS, } \\
\text { membre de la commission BC Saint-Gall }\end{array}$ \\
\hline Alberto Stefani (1918-2006) & PDC & TI & \\
\hline Arno Theus (I9II-I999) & Dém & GR & Pdt CdA BC Grisons \\
\hline Werner Vogt (1905-2000) & PSS & $\mathrm{SO}$ & \\
\hline \multicolumn{4}{|c|}{ Commission du Conseil national } \\
\hline Nom & Parti & Canton & Liens économiques \\
\hline $\begin{array}{l}\text { Alfred Hummler (1915- } \\
\text { 20IO), président }\end{array}$ & PRD & SG & \\
\hline Walter Biel (1933- ) & AdI & $\mathrm{ZH}$ & \\
\hline
\end{tabular}




\begin{tabular}{|c|c|c|c|}
\hline Ernst Bieri (1920-2003) & PRD & $\mathrm{ZH}$ & devient associé Julius Bär en I97I \\
\hline Fritz Blatti (1910-1994) & PRD & $\mathrm{BE}$ & $\begin{array}{l}\text { directeur de la Caisse d'épargne de Wangen, } \\
\text { pdt Association des banques et caisses } \\
\text { d'épargne bernoises. Membre ASB }\end{array}$ \\
\hline Aloys Copt (1923-2008) & PRD & VS & Membre CdA BC Valais \\
\hline $\begin{array}{l}\text { Raymond Deonna } \\
\text { (1910-1972) }\end{array}$ & PLS & GE & $\begin{array}{l}\text { dir. de la Société pour le développement de } \\
\text { l'économie suisse, membre CdA Caisse } \\
\text { d'Épargne de la République et Canton de } \\
\text { Genève }\end{array}$ \\
\hline Paul Eisenring (1924-2016) & PDC & $\mathrm{ZH}$ & Pdt CdA Schweizerische Handelszeitung \\
\hline $\begin{array}{l}\text { Hanspeter Fischer } \\
(1930-2009)\end{array}$ & UDC & TG & Secr. de l'Association thurgovienne des paysans \\
\hline $\begin{array}{l}\text { Enrico Franzoni } \\
\text { (1920-2008) }\end{array}$ & PDC & TI & \\
\hline Pierre Freymond (I92I-I97I) & PRD & VD & \\
\hline Karl Hackhofer (1904-1977) & PDC & $\mathrm{ZH}$ & Pdt USAM \\
\hline $\begin{array}{l}\text { Hermann Leuenberger } \\
\text { (I90I-1975) }\end{array}$ & PSS & $\mathrm{ZH}$ & $\begin{array}{l}\text { Conseil de banque BNS, ex-pdt USS, v-pdt de } \\
\text { la Banque Centrale Coopérative }\end{array}$ \\
\hline Roger Mugny (192I-2008) & PDC & VD & $\begin{array}{l}\text { Ex-membre du comité directeur de la } \\
\text { Confédération des syndicats chrétiens de } \\
\text { Suisse }\end{array}$ \\
\hline Jean Riesen (1920-1987) & PSS & FR & \\
\hline Emil Schaffer (I924-20IO) & PSS & $\mathrm{BE}$ & \\
\hline $\begin{array}{l}\text { Heinrich Schalcher } \\
\text { (1917-2006) }\end{array}$ & PEV & $\mathrm{ZH}$ & \\
\hline Paul Schib (I90I-1990) & PDC & AG & $\begin{array}{l}\text { V-pdt du comité de l'Union suisse des caisses } \\
\text { de crédit mutuel (Raiffeisen) }\end{array}$ \\
\hline Otto Stich (1927-2012) & PSS & $\mathrm{SO}$ & \\
\hline Rudolf Suter (I9I4-20II) & AdI & $\mathrm{ZH}$ & \\
\hline Josef Tschopp (1912-I993) & PDC & BL & Conseil de banque de la BC Bâle-Campagne \\
\hline Hans Weber (1908-I98I) & UDC & $\mathrm{BE}$ & Pdt CdA Bank in Thun \\
\hline Max Weber (I897-I974) & PSS & $\mathrm{BE}$ & \\
\hline Edmund Wyss (1916-2002) & PSS & BS & Conseil de banque de la BNS \\
\hline
\end{tabular}

Sources: Composition: ABNS, I.3/1234, Parlament. Liens économiques: DHS, Base de données "Les élites suisses au XXe siècle», "Liste der eidgenössischen Parlamentarier, die Banken nahestehen" annexée au PV de la $269^{\mathrm{e}}$ séance du CdA de l'ASB, I3.I2.1967. 
广

N

$\stackrel{\circ}{\circ}$

(1)

.

2

2

(a) 


\title{
BIBLIOGRAPHIE
}

\author{
ARCHIVES
}

\section{Archives fédérales, Berne (AFB)}

Commission fédérale des banques:

- E6520(A) I000/1059 vol. 2, vol. 4, vol. 5, vol. 6, vol. 7, vol. 8, vol. 9, vol. IO, vol. II,

- E6520(A) I983/50 vol I, vol. 2, vol. I2, vol. I3, vol. 24, vol. 32, vol. 38

- E6520(B) I980/39 vol. I5, vol. I6, vol. I7, vol. I8, vol. I9, vol. 2I

- E6520(B) 2007/62 vol. 4, vol. I6, vol. I7, vol. I8, vol. 2I, vol. 22, vol. 25, vol. 26,

vol. 38, vol. 6I, vol. 65, vol. 66, vol. 67, vol. 68, vol. 73

- E6520(B) 2009/28 vol. 162

- E652I(A) 1979/5I vol. I79

- E652I(A) I979/52 vol. 5, vol. 7I, vol. 72, vol. 73, vol. 74, vol. 75

- E652I(B) 1991/209 vol. 9

- E652I(B) 2008/195 vol. 20

Département fédéral des finances et des douanes, Administration fédérale des finances:

- E6roo(A) I900/19I4 vol. 4, vol. 7, vol. 8

- E6roo(A-I4) I0oo/rigi4 vol. I2

- E6roo(A-I5) I000/1915 vol. 8

- E6roo(B) 1972/96 vol. 32

- E6roo(B-or) 1980/49 vol. 57, vol. 58, vol. 67

- E6roo(B-or) 1983/72 vol. 37

- E6roo(B-oor) 1980/49 vol. 59, vol. 6o, vol. 6I

- E6roo(B-02) 1989/75 vol. 26

- E6roo(C) 2003/488 vol. 73 , vol. 74

Département fédéral des finances et des douanes, Administration fédérale des contributions :

- $\mathrm{E} 6300(\mathrm{~B}) \quad$ 1974/74 vol. 2

Département politique fédéral :

- E200IE I976/17 dossier 366

- E 200IE I978/94 vol. 507

- E 200IE $1978 / 84 \quad$ vol. 932

- E20orE-or 1982/58 vol. I5I

- E2200.IOI-OI I973/42 vol. 6

Conseil fédéral, procès-verbaux de décisions :

- Eroo4.I IOoo/9 vol. 330, vol. 335, vol. 338, vol. 343, vol. 345, vol. 351, vol. 352, vol. 353 , vol. 354 , vol. 356 , vol. 358 , vol. 362 , vol. $44 \mathrm{I}$, vol. 596 .

Fonds privés :

- J.I.6 I000/1355 vol. 2 (Fonds privé Edmund Schulthess) 


\section{Archives de la Banque nationale suisse, Zurich (ABNS)}

Procès-verbaux du Conseil de banque (Bankrat)

Procès-verbaux du Comité de banque (Bankausschuss)

Procès-verbaux de la Direction générale (Direktorium)

Dossiers sur la législation bancaire (I9I6-I935) : I.3/I2I2, I.3/I2I3, I.3/I2I4, I.3/I2I5, I.3/I2I7, I.3/I218, I.3/I219, I.3/1220

Dossiers sur la législation bancaire (I968-I972) : I.3/I229, I.3/I23O, I.3/I232, I.3/I233, I.3/I234, I.3/I235, I.3/I236.

Dossiers personnels : 8.o/8027 (Personaldossier Riccardo Motta), 8.o/8037 (Personaldossier Paul Rossy)

Dossier statistique sur les fonds de placement : 9.3/9060 (Investment-Trusts)

\section{Archives de l'Association suisse des banquiers (AASB)}

Rapports annuels de l'ASB

Procès-verbaux du Conseil, puis dès 1936 Conseil d'administration, de l'ASB (Ausschuss, puis Verwaltungsrat dès 1936)

Procès-verbaux du Comité de l'ASB (Vorstand puis Ausschuss dès 1937)

Dossiers thématiques :

- J.4 Bundesgesetz über die Banken und Sparkassen Jan. I967 - Sept. 1969

- J.4 Bundesgesetz über die Banken und Sparkassen August I97I - Dezember 1974

- J.4.I Ausländische Bankengesetze Dez. 1960 - 76

- 713 Eidg. Bankengesetz Jan. I940 - Juni 1948

- 713 Eidg. Bankenkommission Bankengesetz Jan. 1952 - Dez. 1958

- 7 I3 I.I - 3I.IO.I959

- 7 II3 I.I - 3I.I2.1960

\section{Archiv für Zeitgeschichte, Zurich (AfZG)}

IB Vorort-Archiv :

- I.5.3.8. Protokolle Vorort (Typoskripte) I93I-I934

- 72.I.I. BB vom I3.II.I968 über Bewilligungspflicht ausländisch beherrschter Banken

- 72.2.I. Revision des BG über die Banken und Sparkassen

IB wf-Archiv (Gesellschaft zur Förderung der schweizerischen Wirtschaft) :

- 9.3.I.I.I. - 9.3.I.I.7

-9.3.I.4.I. $-9 \cdot 3 \cdot$.I.4.2

\section{Schweizerisches Wirtschaftsarchiv, Bâle (SWA)}

- Handschriften Julius Landmann, HS 426, B2, B3, B4 (I9I4-1917)

- Eidgenössische Bankenkommission : Zeitungsausschnitte, Broschüren (Aemter 42)

- Bankwesen Schweiz, Eidg. Gesetzgebung: Broschüren, Zeitungsauschnitte I93I-I945 (Volkswirtschaft, J I 3 b)

- Bankwesen Schweiz: Broschüren I93I-I945 (Volkswirtschaft, J I 3a)

- Personendossiers : Edmund Schulthess (I868-1944), Julius Landmann (I877-I93I), Paul Rossy (I897-I973), Adolf Jöhr (I878-I953), Max Staehelin (I880-I968), Ernst Thalmann (I88I-I938), Robert Reimann (?-?), Max Hommel (I902-I972)

- Dossiers sur les sociétés suivantes: Ofor S.A. Société Fiduciaire Romande, Genève; Revisa, Revisions- und Treuhand AG, Zug; Experta Holding; Revisionsverband zürcherischer Spar- \& Leihkassen; Kontroll \& Revisions AG ; «Indep» Treuhand- und Revisions-Aktiengesellschaft, Zürich; Gesellschaft für Bankrevisionen, Zürich und Basel. 


\section{Archives de l'Union des banques cantonales suisses, Bâle (AUBCS)}

- Protokolle der Komitee-Sitzungen

- Protokolle der Kantonalbanken-Konferenzen, puis Direktoren-Konferenzen

- Prokotolle der Generalversammlungen

- Dossiers thématiques: Bankgesetz VIII (1934), Bankgesetz IX (1933-I935)

\section{Schweizerisches Sozialarchiv, Zurich}

- Ar.I.IIo.20 - Ar.I.IIo.24 (I93I-I935): Procès-verbaux des organes dirigeants du Parti socialiste suisse (Geschäftsleitung)

- Ar.483.II.IO - Ar.483.II.II : Protokoll Geschäftsausschuss des Schweizerischen Bankpersonalverbandes

\section{Bank of England Archive (BoE), London}

OV63 - Overseas Department: Switzerland:

- $\mathrm{OV}_{63} / \mathrm{I}$

- OV 63/24

\section{PUBLICATIONS DE CONTEMPORAINS - OUVRAGES D’ÉPOQUE (JUSQU'EN 1975 ENVIRON)}

Emilio Albisetti, Daniel Bodmer, Ernst Rutschi, Handbuch des Bank-, Geld- und Börsenwesens der Schweiz, Thun: Verlags Aktiengesellschaft, 1964.

Arthur Meredith Allen, et al., Commercial Banking Legislation and Control, London: Macmillan, 1938.

Gottlieb Bachmann, "L'exportation des capitaux et la Banque Nationale», in Association suisse des experts-comptables A.S.E (éd.), Journées d'études bancaires, Genève: E. Delachaux, 1937, p. 7-25.

Hans Bachmann, "Fälligkeitsaufschub und Stundung im schweizerischen Bankrecht", Doktor beider Rechte, Rechts- und staatswissenschaftliche Fakultät, Universität Zürich, 194I.

Alfred Böckli, Bemerkungen zum Entwurf für ein schweizerisches Bankengesetz, 1934.

Daniel Bodmer, L'intervention de la Confédération dans l'économie bancaire suisse, Bâle: National-Zeitung, 1948.

Daniel Bodmer, "Aufgaben und Tätigkeit der Eidgenössischen Bankenkommission », in Emil Gsell (éd.), Banken und Bankgeschäfte in der Schweiz, Bern; Stuttgart: Paul Haupt, 1969, p. 8I-87.

Daniel Bodmer, "Aktuelle Probleme der Bankrevision aus der Sicht der Eidgenössischen Bankenkommission", in Theo Keller (éd.), Revision und Sicherheit im Bankbetrieb, Bern; Stuttgart: P. Haupt Verlag, 1976, p. 2I-30.

Max Ernst Bodmer, Zur Tätigkeit und Stellung der Privatbankiers in der Schweiz, Zürich : Schulthess \& Co, I934.

Walther Brühlmann, Kommentar zum Bundesgesetz über die Banken und Sparkassen vom 8. November 1934, Weinfelden : A.-G. Neuenschwander'sche Buchdruckerei und Verlagsbuchhandlung, I935.

C. F. W. Burckhardt et al., "Zur Frage der Neuordnung des Effektenbörsen- und Emissionswesens ", Journal de statistique et revue économique suisse, vol. 52, 1916, p. 329-365.

Eduard F. Burkhalter, Die Bedeutung, das Wesen und die Struktur der von der Schweizerischen Nationalbank als "Übrige Banken" bezeichneten Institute, Thun: Weibel, 1969.

Otto Burki, Pflichtprüfung und Verantwortlichkeit der Pflichtprüfer nach schweizerischem Bankengesetz und revidiertem Obligationenrecht, Aarau: Sauerländer, I942. 
Georges Capitaine, Le secret professionnel du banquier en droit suisse et en droit comparé, Genève: Atar, 1936.

Max Cluseau, La règlementation des banques. Économie libérale ou économie dirigée? Étude critique de quelques expériences étrangères récentes, Paris: Librairie du Recueil Sirey, 1938.

Remo Cottini, Die Bankrevision in der Schweiz unter besonderer Berücksichtigung ihrer Bedeutung für die Bankleitung, Aarau: Buchdruckerei Keller, I970.

Franz De Voghel, Contrôle des banques. Législations récentes, Gembloux: J. Duculot, 1936.

François Delachaux, "Le secret professionnel du banquier en droit suisse», Thèse de doctorat, Faculté de Droit, Université de Neuchâtel, 1939.

Robert Deumer, "Die Gesetzegebung des Auslandes auf dem Gebiete der Kreditbanken », in Untersuchung des Bankwesens 1933 I. Teil Vorbereitendes Material, Berlin: Carl Heymanns Verlag, vol. 2, I933, p. 27I-310.

Louis Dollfus, «Probleme der Bankenaufsicht und -kontrolle und ihre Lösung im schweizerischen und italienischen Bankenrecht unter spezieller Berücksichtigung der historischen Entwicklung», Doktorarbeit, Juristischen Fakultät, Universität Basel, 194I.

Jules Düblin, Die Finanzierungs- und Kapitalanlage-Gesellschaften der schweizerischen Grossbanken, Basel: Philographischer Verlag, 1937.

Arnold Edelmann, L'Union suisse des caisses de crédit mutuel 1902-I952, St-Gall : Union suisse des caisses de crédit mutuel (système Raiffeisen), [1953].

Theodore Reed Fehrenbach, The Swiss Banks, New York/London/Toronto : McGraw-Hill Book Company, 1966.

Hans Gassmann, Die Schweizerische Treuhand-Gesellschaft, mit besonderer Berücksichtigung der Revisionsfrage bei Aktiengesellschaften und Banken, Zürich : J. Leemann, I9I3.

Erwin Gersbach, Der Nachlassvertrag ausser Konkurs nach dem schweizerischen Bundesgesetz über die Banken und Sparkassen und seinen Ausführungserlassen, Zug: Kündig, I937.

Fritz Giovanoli, Im Schatten des Finanzkapitals, Zürich : Jean Christophe Verlag, 1938.

Jean Golay, "La loi fédérale sur les banques et les caisses d'épargne et son application ", Revue économique et sociale : bulletin de la Société d'Études Économiques et Sociales, vol. 23, $\mathrm{n}^{\mathrm{o}}$ 4, 1965, p. 329-342.

Paul Graber, Die Sicherung der Spareinlagen, Solothurn : Buchdruckerei Vogt-Schild, 1935.

Paul Graner, Der Geltungsbereich des Bankengesetzes, Zürich : Polygraphischer Verlag, 1937.

Paul Graner, Revidiertes Obligationenrecht und Bankengesetz, Zürich : Polygraphischer Verlag, 1937.

Paul Graner, Die Revision, Überwachung und Kontrolle: nach rev. Obligationenrecht und Bankengesetz, Zürich : Polygraphischer Verlag, 1938.

Jean Halpérin, Les assurances en Suisse et dans le monde: Leur rôle dans l'évolution économique et sociale, Neuchâtel: La Baconnière, 1946.

Alfred Hartmann, Der Konkurrenzkampf zwischen den schweizerischen Grossbanken und Kantonalbanken, Zürich : Kommerzdruck- und Verlags AG, 1947.

Franz Hartmann, "Der strafrechtliche Schutz des Bankkredites nach dem Bundesgestz über die Banken und Sparkassen vom 8. November I934", Doktorarbeit, Juristischen Fakultät, Universität Bern, 1938.

Heinz Hatz, «Entwicklung, Aufgaben und Abgrenzung der Staatsaufsicht über die privaten Versicherungsunternehmungen in der Schweiz », Doktor beider Rechte, Rechts- und staatwissenschaftliche Fakultät, Universität Zürich, I95I.

Erwin Haymann, "La surveillance des sociétés d'assurances en Suisse et la juridiction administrative du Tribunal fédéral », Thèse de doctorat, Faculté de droit, Université de Genève, 1932.

Josef Henggeler, «Die Verrechnung bei Fälligkeitsaufschub und Stundung gemäß dem Bundesgesetz über die Banken und Sparkassen vom 8. November 1934 nebst den dazugehörigen Verordnungen und Ergänzungen ", in Fritz Mangold (éd.), Festgabe für Bundesrat Dr. h. c. Edmund Schulthess zum siebzigsten Geburtstag am 2. März I938, Zürich : Polygraphischer Verlag, 1938, p. 299-3I4.

Alain Hirsch, "Une loi spéciale sur les fonds de placement ", Wirtschaft und Recht, vol. Io, $\mathrm{n}^{\mathrm{o}} 2$, 1958 , p. $124-\mathrm{I} 33$.

Alain Hirsch, "La surveillance des banques en Suisse ", in Marcus Lutter, Helmut Kollhosser, Winfried Trusen (éd.), Recht und Wirtschaft in Geschichte und Gegenwart. 
Festschrift für Johannes Bärmann zum 70. Geburtstag, München: C.H. Beck'sche Verlagsbuchhandlung, 1975, p. 46I-469.

Thomas Holenstein, «Das Bankensanierungsrecht nach Bankengesetz und nach dem BRB über die Sanierung von Banken", in Beiträge zum Wirtschaftsrecht: Festgabe für den Schweizerischen Juristentag 1944 in St. Gallen, St. Gallen: Fehr, 1944, p. 4I-7I.

Beat Huber, "Zum Problem der Kleinaktien", La société anonyme suisse: revue de droit commercial et économique, vol. 3I, $\mathrm{n}^{\circ}$ 9, 1959, p. 20I-2IO.

Rudolf Huggenberg, Die Sparkassen und das Sparkassengeschäft (nach schweizerischem Recht), Affoltern am Albis: J. Weiss, 1906.

Intrag Sa, Intrag, fonds de placement: 25 ans Intrag, Zurich : Intrag, 1963.

Intrag Sa, so ans Intrag SA, Gestion d'Investment Trusts, Zurich, Zurich : Intrag SA, I988.

Adolf Jann, "Der Umfang und die Grenzen des Bankgeheimnisses nach schweizerischem Recht », Doktor beider Rechte, Jurisitischen Fakultät, Universität Bern, 1938.

Adolf Jöhr, Die schweizerischen Notenbanken : 1826-1913, Zürich : Orell Füssli, I915.

J[akob] Kaderli, "Die Entwicklung des Revisionswesens im Schweizerischen Bankgewerbe", in Der Bücherexperte in der Schweiz = L'expert-comptable en Suisse. Festschrift zum 2sjährigem Jubiläum des Verbandes Schweiz. Bücherexperten, Zürich : Graph Anstalt Schüler, 1939, p. 77-93.

Rudolph J. Kaderli, Edwin Zimmermann (éd.), Handbuch des Bank-, Geld-und Börsenwesens der Schweiz, Thun: Verlags Aktiengesellschaft, I947.

Paul Keller, et al. (éd.), Handbuch der Schweizerischen Volkswirtschaft, Bern : Benteli A.G, 1939 .

Theo Keller, Das Verhältnis der Banken zur Industrie: mit besonderer Berücksichtigung der Schweiz, St. Gallen : Fehr, 1937.

Theo Keller, Leu \& Co. 1755-I955: Denkschrift zum 200-jährigen Bestehen der Aktiengesellschaft Leu \& Co. Zürich, Zürich : Leu \& Co, 1955.

Theo Keller (éd.), Revision und Sicherheit im Bankbetrieb, Bankwirtschaftliche Forschungen, Bern; Stuttgart: Paul Haupt, 1976.

Theo Keller, Die Bankrevision in der Schweiz, Bern; Stuttgart: Paul Haupt, 1978.

Henner Kleinewefers, Das Auslandsgeschäft der Schweizer Banken, Zürich : Schulthess, 1972.

Richard König, 25 Jahre Revisionsverband bernischer Banken und Sparkassen 19I2-1937, Bern : Buchdrückerei Büchler \& Co., I938.

Ernst Kull, "Sechs Jahre Darlehenskasse der Schweizerischen Eidgenossenschaft ", Journal de statistique et revue économique suisse, vol. $74, \mathrm{n}^{\circ}$ 3, 1938, p. 333-35I.

Walter Kull, Wandlungen im schweizerischen Bankensystem seit 1945, Zürich : Polygraphischer Verlag, 1963.

Johann Jakob Kummer, "Versicherungswesen : a) Versicherungsamt (Eidgenössisches) ", in Naum Reichesberg (éd.), Handwörterbuch der Schweizerischen Volkswirtschaft, Sozialpolitik und Verwaltung, Bern : Verlag Encyklopädie, vol. 3, I9II, p. II98-I227.

Hermann Kurz, Die Grossbanken im schweizerischen Wirtschaftsleben, Zürich : Orell Füssli, I922.

Carl Kuster, Die Tessiner Bankkrise I9I4, Lugano: Druckerei Sanvito \& C., 1920.

Julius Landmann, "Der schweizerische Kapitalexport", Journal de statistique et revue économique suisse, vol. 52, 1916, p. 389-415.

Julius Landmann, Projet d'une loi fédérale concernant l'exploitation et la surveillance des banques avec exposé des motifs à l'appui, Berne: Schweizerisches Volkswirtschaftdepartment, I9I6.

Julius Landmann, «L'économie nationale suisse», in Département fédéral de l'économie publique (éd.), La Suisse économique et sociale, Einsiedeln: Benziger, I927, p. I-384.

Georg Lehmann, "Das Verbandswesen im schweizerischen Bankgewerbe », Doctor rerum politicarum, Rechts- und Wirtschaftswissenschaftlidren Fakultät, Universität Bern, I956.

H[ans] Manz, Mangelnde Durchsetzbarkeit eines Gesetzes. Diagnose \& Heilung. Das Beispiel der Revision des Bankengesetzes, Bern : [Eidgenössische Bankenkommission], 1973.

Horace Mende, Unterlagen und Vorarbeiten für eine schweizerische Bankenkontrolle, Bern: P. Haupt, I935.

Albert Meyer, Zur Frage eines eidgenössischen Bankgesetzes, Zürich : Orell Füssli I9I4. 
Albert Meyer, "Die Neuordnung des Effektenbörsen- und Emissionswesens », Journal de statistique et revue économique suisse, vol. 52, 1916, p. I09-II5.

Max Meyer, Die Ausländischen Banken in der Schweiz. Studie im Auftrag des Verbandes der Auslandsbanken in der Schweiz, St. Gallen: Institut für Bankwirtschaft an der Hochschule St. Gallen, 1975.

Walter Mollet, Schweizerische Investment-Trusts, Solothurn: Buchdr. Vogt-Schild A.-G, 1942.

Emil Mosimann (éd.), Banque nationale suisse 1907-1957, Zurich : Banque nationale suisse, 1957.

Bernhard Müller, "Die Entwicklung der Bankenaufsicht in der Schweiz », Société anonyme suisse. Revue de droit commercial et économique, vol. 49, 1977, p. I-13.

Walter Müller, "Das Bilanzrecht der schweizerischen Banken», Doktor beider Rechte, Rechts- und staatswissenschaftliche Fakultät, Universität Zürich, 1938.

Max Oetterli, «Die rechtliche Stellung der Revisionsverbände und Treuhandgesellschaften nach Bankengesetz », Doktor beider Rechte, Juristischen Fakultät, Universität Bern, I94I.

Martin Peltzer, "Organisation, Aufgaben und Probleme der allgemeinen Bankaufsicht in der Bundesrepublik Deutschland und in der Schweiz unter besonderer Berücksichtigung der Verhältnisee nach dem Zweiten Weltkrieg», Doktorarbeit, Hohe rechtswissenschaftliche Fakultät, Universität Basel, 1958.

Anton Pestalozzi, Die Frage der Liquidität unter besonderer Berücksichtigung der schweizerischen Banken 1935-1940, Zürich, 1943.

R. Peter, "Particularités de la révision bancaire ", in Association suisse des experts-comptables A.S.E (éd.), Journées d'études bancaires, Genève: E. Delachaux, 1937, p. I55-175.

Walter Peter, "Kapitalherabsetzung nach Bankenrecht », Rechts- und staatswissenschaftliche Fakultät, Universität Zürich, I95I.

Kurt Peyer, Ausmass und Bedeutung des Auslandskapitals in der Schweiz, Zürich : Juris, I97I.

Bruno Pfister, Beiträge zur Entwicklung der schweizerischen Klein- und Mittelbanken, Zürich : Orell Füssli, ı116.

Walter Robert Pfund, Bernhard Zwahlen, Die eidgenössische Verrechnungssteuer, Basel: Verlag für Recht und Gesellschaft, I97I.

Denis Piguet, La banque dans le cadre de la réglementation bancaire suisse, Yverdon: Imprimerie des Remparts, 1953.

Herbert Raff, Union de Banques suisses: 1862, I912, 1962, Zurich : Orell Füssli, 1962.

Robert Reimann, Kommentar zum Bundesgesetz über die Banken und Sparkassen vom 8. November 1934 und zur Vollziehungsverordnung vom 30. August 196I, Zürich : Polygraphischer Verlag, 1963.

E[rnst] G[eorg] Renk, Kurt Amonn, «Die durch die Investmenttrusts oder Anlagefonds mit internationalem Charakter aufgeworfenen Fiskalprobleme: zusammenfassende Uebersicht über den Generalbericht für den Kongress 1962 der International Fiscal Association in Athen. Schweiz. Landesbericht ", Steuer-Revue, vol. 17, no 8, 1962, p. 314327-344.

Revisionsverband Bernischer Banken Und Sparkassen (éd.), so Jahre Revisionsverband bernischer Banken und Sparkassen, Langnau: Buchdruckerei Emmenthaler-Blatt AG, 1962.

Fritz Richner, De la question d'une législation spéciale sur les investment trusts: discours prononcé à l'assemblée générale ordinaire du 21 février 1958 de l'Union de banques suisses, Zurich : UBS, 1958.

Peter Riniker, "Die Bankenaufsicht», Doctor iuris, Recht- und Wirtschaftswissenschaftliche Fakultät, Universität Bern, 1974.

Paul Rossy, "Die Reorganisation des schweizerischen Bankwesens », Schweizerische Bankpersonal-Zeitung, no 6-7, I937, p. I-3.

Paul Rossy, "Monsieur Edmond Schulthess à la Commission fédérale des banques ", in Fritz Mangold (éd.), Festgabe für Bundesrat Dr. h. c. Edmund Schulthess zum siebzigsten Geburtstag am 2. März 1938, Zürich : Polygraphischer Verlag, 1938, p. 287-297. 
Paul Rossy, Robert Reimann, Commentaire de la loi fédérale du 8 novembre 1934 sur les banques et les caisses d'épargne et du règlement d'exécution du Conseil fédéral du 26 février 1935, Zurich : Ed. Polygraphiques, 1935.

Wilfried Rutz, Die schweizerische Volkswirtschaft zwischen Währungs- und Beschäftigungspolitik in der Weltwirtschaftskrise: wirtschaftspolitische Analyse der Bewältigung eines Zielkonflikts, Zürich, St. Gallen : Polygraphischer Verlag, I970.

Gottfried Schaertlin, "Fünfzig Jahre Eidgenössisches Versicherungsamt», Bulletin de l'Association suisse des Actuaires suisses, $\mathrm{n}^{\mathrm{O}}$ 33, 1937, p. I-27.

Urs Schäfer, Die öffentliche Aufsicht im Sinne des Anlagefondsgesetzes, S.l. : [s.n.], I97I.

Hans Rudolf Schiller, Die Sparkassengesetzgebung in der Schweiz, Affoltern am Albis: J. Weiss, I933.

Kurt Schiltknecht, Beurteilung der Gentlemen's Agreements und Konjunkturbeschlüsse der Jahre 1954-1966 unter besonderer Berücksichtigung der Auslandgelder, Zürich : Polygraphischer Verlag, 1970.

Hermann Schneebeli, La Banque Nationale Suisse 1907-1932, Zurich: Orell Füssli, 1932.

Götz-Dieter Schober, "Vergleichende Betrachtung des deutschen und schweizerischen Bankenaufsichtsgesetzes ", Doktorarbeit, Ludwig-Maximilians-Universität, 1957.

Herbert Schönle, Jürgen Dohm, Die Unabhängigkeit der Revisionsstellen von Banken und Anlagefondsleitungen. Untersuchung nach schweizerischem Recht mit rechtsvergleichenden Hinweisen, Zürich : Schulthess Polygraphischer Verlag, 1974.

Erwin Schubert, "Zur Frage der Bankenkontrolle», Doktorarbeit, Philosophisch-Historische Fakultät, Universität Basel, 1939.

L[ouis] Schulthess, Die Bankreform, ein Kampfums Recht. Tatsachen zur Bankengestzgebung, Erlenbach-Zürich; Leipzig: Eugen Rentsch Verlag, 1934.

Leo Schuster (éd.), Schweizer Banken in der Welt von morgen, Bankwirtschaflitche Forschungen, Bern; Stuttgart: Paul Haupt, 1975.

Leo Schuster (éd.), Schweizer Banken im Spiegel von Wirtschaft und Politik, Zürich : Orell Füssli, 1978.

Leo Schuster (éd.), Raiffeisen, Idee und Verwirklichung, Bankwirtschaftliche Forschungen, Bern : Paul Haupt, I979.

Heinz Schütz, «Die Revision der Schweizerischen Bankengesetzgebung in den Jahren I97I und 1972 ", Doctor rerum politicarum, Rechts- und wirtschaftswissentschaftliche Fakultät, Universität Bern, I974.

Willi Schwander, Das schweizerische Bankengesetz unter spezieller Berücksichtigung seiner wirtschaftlich wichtigen Bestimmungen, Zürich : E. Lang, 1943.

Siegfried Sichtermann, Bankgeheimnis und Bankauskunft: Systematische Darstellung mit besonderer Berücksichtigung der Rechtsprechung und unter Heranziehung ausländischen Rechts, Frankfurt a. M: F. Knapp, 1957.

Eugène Smits, Étude critique de l'intervention de l'État dans la politique de crédit des banques de dépôts, Bruxelles: Cools, I940.

Société des Nations, Monnaies et banques 1937/1938. Vol. I : Aperçu de la situation monétaire, Genève : Société des Nations, 1938.

Kurt Speck, Strukturwandlungen und Entwicklungstendenzen im Auslandgeschäft der schweizer Banken, Zürich : Junis, I974.

Max Staehelin, Das schweizerische Bankgesetz: Vortrag (gehalten in der Statistisch-Volkswirtschaftlichen Gesellschaft Basel am) I2. November 1934, Basel, 1934.

Heinrich Stampfli, Die schweizerischen Banken im Zeichen der Konzentration (1945-1969), Zürich : City-Druck, 197I.

Statistisches Handbuch des schweizerischen Geld-und Kapitalmarktes: Manuel statistique du marché financier suisse, Zürich : Schulthess, 1944.

Karl Strasser, "Sparkassen", in Handbuch der schweizerischen Volkswirtschaft, Bern: Benteli, vol. 2, I939, p. 332-334.

Hans Andrea Tarnutzer, «Entstehung, Organisation und Funktion der eidgenössischen Bankenkommission ", Doktorarbeit, Juristischen Fakultät, Universität Bern, I94I.

Claudius Terrier, "Les grandes banques commerciales sous l'influence de la crise », Bulletin de l'Association suisse des Experts-comptables, nº I0, 1936, p. 24. 
Claudius Terrier, "Risques, pertes et réserves des Banques suisses », in Association suisse des experts-comptables A.S.E (éd.), Journées d'études bancaires, Genève: E. Delachaux, I937, p. 45-62.

Pierre Uldry, «Le concordat des instituts bancaires d'après la nouvelle législation fédérale ", Thèse de doctorat, Faculté de droit, Université de Fribourg, I937.

Willy Urech, Die staatliche Beaufsichtigung der Banken in der Schweiz: nach dem Bundesgesetz über die Banken und Sparkassen vom 8. Nov. 1934, Aarau: Keller, 1944.

Robert Von Moos, "Die corporative Organisation des Bankgewerbes in der Schweiz (Bankenverbände) », Doktorarbeit, Rechts- und staatswissenschaftliche Fakultät, Universität Zürich, I922.

Ernst Wetter, Bankkrisen und Bankkatastrophen der letzten Jahre in der Schweiz, Zürich: Orell Füssli, I9I8.

Hans-Dietrich Winkhaus, "Die Rechnungslegungspflicht der deutschen und schweizerischen Aktienbanken - Vergleichende Analyse und Möglichkeiten zur Verbesserung -», Doktorarbeit, Hohen Staatswirtschaftlichen Fakultat, Ludwig-MaximiliansUniversität, 1966.

Johannes C. D. Zahn (éd.), Die Bankaufsichtsgesetze der Welt, Berlin, Leipzig: Walter de Gruyter \& Co., 1937.

Heinrich Zust-Schmid, Die Luzerner Kantonalbank: I850-1950: Überblick über ihre Geschichte, Organisation und Entwicklung, S.l. : [s.n.], 1950.

\section{LITTÉRATURE SECONDAIRE}

Liaquat Ahamed, Lords of finance: the bankers who broke the world, London: W. Heinemann, 2009.

Marc Alberisio, "Le krach de la Banque de Genève ", Mémoire de licence, Faculté des lettres, Université de Lausanne, 2009.

Derek Howard Aldcroft, The European Economy I9I4-I99o, London; New York: Routledge, 1993.

Elisabeth Allgoewer, «Überinvestition oder Unterkonsumtion? Die Grosse Depression in der Schweiz. Beiträge der Wirtschaftstheorie zu ihrer Erklärung», in Thomas Geiser, Hans Schmid, Emil Walter-Busch (éd.), Arbeit in der Schweiz des 20. Jahrhunderts. Wirtschaftliche, rechtliche und soziale Perspektiven, Bern: Paul Haupt, I998, p. I87-216.

Urs Altermatt, Conseil fédéral: dictionnaire biographique des cent premiers conseillers fédéraux, Yens: Cabédita, 1993.

Kurt Amonn (éd.), Beiträge zum SchKG, Banken- und Steuerrecht: Festschrift zum 80. Geburtstag, Bern : Stämpfli, I997.

Claire Andrieu, "Les nationalisations bancaires en France de 1945 à nos jours ", in Maurice Lévy-Leboyer (éd.), Les banques en Europe de l'Ouest de I920 à nos jours. Colloque tenu à Bercy les 7 et 8 octobre 1993, Paris : Comité pour l'histoire économique et financière de la France, I995, p. IOI-I36.

Roland Äppli, et al. (éd.), $75^{e}$ anniversaire. Banque nationale suisse: les années 1957 à 1982, Zurich: Banque nationale suisse, 1982.

Gérard Arlettaz, "Crise et déflation. Le primat des intérêts financiers en Suisse au début des années $1930 "$, Relations Internationales, $\mathrm{n}^{\circ}$ 30, 1982, p. 159-175.

Karl Arnold, Verwaltungs- und Regierungstätigkeit durch eidgenössische Kommissionen, Winterthur: H. Schellenberg, I969.

Gunther Aschhoff, et al. (éd.), Deutsche Bankengeschichte, Frankfurt am Main : Fritz Knapp Verlag, vol. 3, 1983 .

François Baer, et al. (éd.), Einig - aber nicht einheitlich : I25 Jahre Sozialdemokratische Partei der Schweiz = Une pensée unie - mais pas unique: I25 ans Parti socialiste suisse, Zürich: Limmat, 2013.

Paul Bairoch, "L'économie suisse dans le contexte européen I913-1939", Revue suisse d'histoire, vol. $34, \mathrm{n}^{\circ}$, 1984 , p. 468-497. 
Theo Balderston, "The banks and the gold standard in the German financial crisis of I93I ", Financial History Review, vol. I, no I, 1994, p. 43-68.

Edward J. Balleisen, David A. Moss (éd.), Government and markets: toward a new theory of regulation, Cambridge; New York: Cambridge University Press, 2010.

Hugo Bänziger, "Vom Sparerschutz zum Gläubigerschutz - die Entstehung des Bankengesetzes im Jahre I934", in Urs Zulauf (éd.), so ans de surveillance fédérale des banques, Zürich : Schulthess Polygraphischer Verlag, 1985, p. 3-8I.

Hugo Bänziger, Die Entwicklung der Bankenaufsicht in der Schweiz seit dem I9. Jahrhundert, Bern; Stuttgart: P. Haupt, 1986.

Hugo Bänziger, Die Entwicklung der schweizerischen Liquiditätsvorschriften, Zürich : [s.n.], I988.

Federico Barbiellini Amidei, Claire Giordano, «The Redesign of the Bank-Industry-Financial Markets Ties in the US Glass Steagall Act and the 1936 Italian Banking Acts ", in Piet Clement, Harold James, Hermann Van der Wee (éd.), Financial Innovation, Regulation and Crises in History, London: Pickering \& Chatto, 20I4, p. 65-83.

Stefano Battilossi, "The Second Reversal: The ebb and flow of financial repression in Western Europe, I950-9I ", Paper presented at: The Sixth Conference of the European Historical Economics Society (EHES), Istanbul, September 9-IO, 2005.

Stefano Battilossi, Youssef Cassis (éd.), European banks and the American challenge: competition and cooperation in international banking under Bretton Woods, Oxford [etc.] : Oxford University Press, 2005.

Stefano Battilossi, Jaime Reis (éd.), State and Financial System in Europe and the USA. Historical Perspectives on Regulation and Supervision in the Nineteenth and Twentieth Centuries, Burlington: Ashgate, 2010.

Annette Baudraz, "Julius Landmann (I877-I93I). Législateur du Prince», Mémoire de licence, Faculté des lettres, Université de Lausanne, 1997.

Hans Bauer, Schweizerischer Bankverein. 1872-1972, Basel: Schweizerischer Bankverein, I972.

Hans Bauer, I25 Jahre Basler Handelsbank: I863-1988, [Basel] : Basler Handelsbank, 1988.

Claude Baumann, Robert Holzach : ein Schweizer Bankier und seine Zeit, Zürich : Verlag Neue Zürcher Zeitung, 2014.

Jan Baumann, «Bundesinterventionen in der Bankenkrise 1931-1937. Eine vergleichende Studie am Beispiel der Schweizerischen Volksbank und der Schweizerischen Diskontbank», Doktorarbeit, Philosophische Fakultät, Universität Zürich, 2007.

Jan Baumann, Patrick Halbeisen, "Die Internationalisierung des Finanzplatzes Schweiz und ihre Folgen für die Währungspolitik. Konsens und Konflikte zwischen der Nationalbank und den Geschäftsbanken 1919-1939", Contribution non publiée au colloque "Switzerland as a financial centre in international perspective (1913-1965)", Lausanne, 1999 .

Werner Baumann, Peter Moser, Bauern im Industriestaat: agrarpolitische Konzeptionen und bäuerliche Bewegungen in der Schweiz I9I8-1968, Zürich: Orell Füssli, I999.

Marion Beetschen, Frédéric Rebmann, "Le néocorporatisme suisse en déclin ? Les commissions extra-parlementaires dans un environnement en mutation (1957-2010) ", Swiss Political Science Review, vol. 22, no I, 2016, p. I23-I44.

Ben S. Bernanke, "The Macroeconomics of the Great Depression: A Comparative Approach ", Journal of Money, Credit and Banking, vol. 27, $\mathrm{n}^{\circ}$ I, I995, p. I-28.

Peter Bernholz, «De I945 à I982: de l'application de mesures administratives contre l'afflux de devises à la gestion de la masse monétaire sous le régime des changes flottants ", in Werner Abegg (éd.), Banque Nationale Suisse 1907-2007, Zurich: Neue Zürcher Zeitung, 2007, p. II7-2II.

Samuel Beroud, "La Banque cantonale vaudoise, I9I8-1939: le rôle d'une banque semipublique entre crises économiques, tensions politiques et concurrence interbancaire ", Mémoire de Master, Faculté des lettres, Université de Lausanne, 201 .

Geneviève Billeter, Le pouvoir patronal: les patrons des grandes entreprises suisses des métaux et des machines (I9I9-1939), Genève: Droz, 1985.

Urs W. Birchler, "L'évolution du secteur bancaire", in Werner Abegg (éd.), Banque Nationale Suisse 1907-2007, Zurich : Neue Zürcher Zeitung, 2007, p. 426-438. 
Urs W. Birchler, "L'intérêt croissant de la Banque nationale pour la stabilité systémique », in Werner Abegg (éd.), Banque Nationale Suisse 1907-2007, Zurich : NZZ, 2007, p. 4I3$4 \mathrm{I} 7$.

Fritz Blaser, Bibliographie der Schweizer Presse: mit Einschluss des Fürstentums Liechtenstein, Basel : Birkhäuser, 1956.

Guido Boller, "L'abandon des interventions directes sur le marché», in Werner Abegg (éd.), Banque Nationale Suisse 1907-2007, Zurich : Neue Zürcher Zeitung, 2007, p. 318328.

Barbara Bonhage, Hanspeter Lussy, Marc Perrenoud, Nachrichtenlose Vermögen bei Schweizer Banken: Depots, Konten und Safes von Opfern des nationalsozialistischen Regimes und Restitutionsprobleme in der Nachkriegszeit, Zürich : Chronos, vol. I5, 2001.

Hubert Bonin, "The regulation of French banking and stock exchange markets (igth-2oth centuries): State interests and common interest, from total liberalism to total State interventionism?", Bankhistorisches Archiv. Zeitschrift zur Bankengeschichte, vol. 39, 200I, p. 20-36.

Hubert Bonin, "Crises et réglementation bancaire dans l'histoire européenne. Quelques rappels pour nourrir les débats actuels", in Loïc Grard, Pascal Kaufmann (éd.), L'Europe des banques. Approches juridique et économique. Concurrence, Réglementation, Marché Unique, Paris: Pedone, 2010, p. 8I-96.

Hubert Bonin, Jean-Marc Figuet (éd.), Crises et régulation bancaires. Les cheminements de l'instabilité et de la stabilité bancaires, Genève: Librairie Droz, 2016.

Michael Bordo, Thomas Helbling, Harold James, "Swiss Exchange Rate Policy in the I930s. Was the Delay in Devaluation Too High a Price to Pay for Conservatism?", Open Economies Review, vol. I8, no I, 2007, p. I-25.

Michael Bordo, Harold James, "De I907 à I946: enfance heureuse ou adolescence difficile?", in Werner Abegg (éd.), Banque Nationale Suisse 1907-2007, Zurich: Neue Zürcher Zeitung, 2007, p. 29-II5.

Karl Erich Born, Die deutsche Bankenkrise 193I: Finanzen und Politik, München: Piper, 1967.

Lukas Bösch, «L'assurance sur la vie en Suisse de I9ıо à I930: de la domination étrangère à l'hégémonie des compagnies suisses ", Mémoire de licence, Faculté des lettres, Université de Lausanne, 2008.

Hermann Böschenstein, Bundesrat Schulthess. Krieg und Krisen, Bern : P. Haupt, 1966.

Sandra Bott, La Suisse et l'Afrique du Sud 1945-199o. Marché de l'or, finance et commerce durant l'apartheid, Zurich: Chronos, 2013.

Jean Bouvier, "Histoire financière et problèmes d'analyse des dépenses publiques", Annales. Économies, Sociétés, Civilisations, vol. 33, no 2, 1978, p. 207-215.

Robert Boyer, Théorie de la régulation, Paris: La Découverte, 2004.

Robert Boyer, Yves Saillard (éd.), Théorie de la régulation, l'état des savoirs, Paris: La Découverte, 2002.

Holger-René Bruckhoff, Zur Entwicklung der Zentralbanken und der Bankaufsicht in Deutschland und in den Niederlanden, Frankfurt am Main; etc. : Peter Lang, 2010.

Ralph C. Bryant, International financial intermediation, Washington, D.C.: Brookings Institution, 1987.

Felix Bühlman, et al., "Transformation des élites en Suisse ", Social Change in Switzerland, $\mathrm{n}^{\mathrm{o}} \mathrm{I}, 2 \mathrm{OI}$, p. I-I3.

Andreas Busch, Banking Regulation and Globalization, Oxford: Oxford University Press, 2009.

Daniel Carpenter, David A. Moss (éd.), Preventing Regulatory Capture: Special Interest Influence and How to Limit It, New York: Cambridge University Press, 2014.

Sabino Cassese, "The Long Life of the Financial Institutions Set up in the Thirties", Journal of European Economic History, vol. 13, n 2, 1984, p. 273-294.

Youssef Cassis, "Le Crédit Lyonnais à Genève, I876-200I", in Bernard Desjardins, et al. (éd.), Le Crédit Lyonnais (I863-1986): études historiques, Genève: Droz, 2003, p. 617629.

Youssef Cassis, Les Capitales du Capital. Histoire des places financières internationales. I7802005, Genève: Slatkine, 2006. 
Youssef Cassis, Fabienne Debrunner, "Les élites bancaires suisses. I880-1960 ", Revue suisse d'histoire, vol. 40, $\mathrm{n}^{\mathrm{O}}$ 3, 1990, p. 259-273.

Youssef Cassis, Jakob Tanner, Fabienne Debrunner, "Finance and financiers in Switzerland, I880-1960", in Youssef Cassis (éd.), Finance and financiers in European history, 1880-1960, Cambridge : Cambridge University Press, 1992, p. 293-316.

Linus Von Castelmur, Schweizerisch-alliierte Finanzbeziehungen im Übergang vom Zweiten Weltkrieg zum Kalten Krieg: die deutschen Guthaben in der Schweiz zwischen Zwangsliquidierung und Freigabe (1945-1952), Zürich: Chronos, 1992.

Mauro Cerutti (éd.), Documents diplomatiques suisses, Berne: Benteli, vol. Io (1930-1933), 1982.

Mauro Cerutti, «La politique migratoire de la Suisse 1945-1970", in Hans Mahnig (éd.), Histoire de la politique de migration, d'asile et d'intégration en Suisse depuis 1948, Zurich : Seismo, 2005, p. 89-134.

Corinne Chaponnière Meyer, Nos deux cents premières années, Genève: Lombard Odier, 1998.

Thomas Chappot, "L'espionnage bancaire et son rôle dans l'adoption de dispositions relatives à l'espionnage économique I930-1935", Mémoire de Master, Faculté des lettres, Université de Lausanne, 20 Io.

Pierluigi Ciocca, Gianni Toniolo, "Industry and Finance in Italy, 1918-1940 ", Journal of European Economic History, vol. 13, no 2, 1984, p. I13-136.

Alain Clavien, Grandeurs et misères de la presse politique: le match Gazette de Lausanne Journal de Genève, Lausanne: Antipodes, 20 Io.

Patricia Clavin, The Great Depression in Europe. 1929-1939, Basingstoke; London : Macmillan, 2000.

William D. Coleman, Financial Services, Globalization and Domestic Policy Change, Basingstoke; New York: Macmillan Press; St. Martin’s Press, I996.

Emmanuel Colin-Jeanvoine, Stéphanie Dérozier, Le financement du FLN pendant la guerre d'Algérie, 1954-1962, Saint-Denis : Ed. Bouchène, 2008.

André Cornu, Charly Denervaud, Raymond L. Larcier, Les fonds de placement, Lausanne : HEC, 1993.

Nicholas F. R. Crafts, Peter Fearon, «Depression and Recovery in the 1930s: An Overview ", in Nicholas F. R. Crafts, Peter Fearon (éd.), The Great Depression of the I93os: Lessons for Today, Oxford: Oxford University Press, 2013, p. I-45.

Pepper D. Culpepper, Quiet Politics and Business Power: Corporate Control in Europe and Japan, Cambridge : Cambridge University Press, 2011.

Thomas David, «Un indice de la production industrielle de la Suisse durant l'entre-deuxguerres ", Revue suisse d'histoire, vol. 45, $\mathrm{n}^{\circ}$ I, 1995, p. I09-I30.

Thomas David, Sébastien Guex, Marc Perrenoud, «La crise des années '3o en Suisse et dans le monde. Quelques remarques préliminaires ", Traverse, vol. 4, no I, 1997, p. 17-20.

Thomas David, et al., De la "Forteresse des Alpes" à la valeur actionnariale. Histoire de la gouvernance d'entreprise en Suisse (I880-2010), Zurich : Seismo, 2015.

Bernard Degen, "Arbeit und Kapital», in Patrick Halbeisen, Margrit Müller, Béatrice Veyrassat (éd.), Wirtschaftsgeschichte der Schweiz im 20. Jahrhundert, Basel : Schwabe, 20I2, p. 873-922.

Heinz Dickenmann, Das Bundespersonal in der Wirtschaftskrise 193I-1939, Zürich : Zentralstelle der Studentenschaft, 1983.

Alexis Drach, "Liberté surveillée. Supervision bancaire et globalisation financière au Comité de Bâle, I974-I988", thèse de doctorat, European University Institute, 2016.

Paul Ehrsam, "Die Bankenkrise der $30 e r$ Jahre in der Schweiz », in Urs Zulauf (éd.), so ans de surveillance fédérale des banques, Zürich: Schulthess Polygraphischer Verlag, 1985, p. 83-II8.

Pierre Eichenberger, Mainmise sur l'État social: Mobilisation patronale et caisses de compensation en Suisse (1908-1960), Neuchâtel : Éditions Alphil, 2016.

Pierre Eichenberger, et al., "Les organisations patronales suisses. Bilan historiographique et perspectives de recherche", Travaux de Science Politique, vol. 56, 2013, p. I-40.

Pierre Eichenberger, André Mach, «Organized capital and coordinated market economy. Swiss business interest associations between socio-economic regulation and political 
influence», in Christine Trampusch, André Mach (éd.), Switzerland in Europe: Continuity and Change in the Swiss Political Economy, London: Routledge, 20II, p. 63-8I.

Barry Eichengreen, Golden Fetters. The Gold Standard and the Great Depression, I919-1939,

New York; Oxford: Oxford University Press, 1992.

Barry Eichengreen, Tim Hatton, "Interwar Unemployment in International Perspective: An Overview ", in Barry Eichengreen, Tim Hatton (éd.), Interwar Unemployment in International Perspective, Dordrecht: Kluwer Academic Publishers, 1988, p. I-59.

Barry Eichengreen, Peter Temin, "The Gold Standard and the Great Depression ", Contemporary European History, vol. 9, $\mathrm{n}^{\circ}$ 2, 2000, p. 183-207.

Nicholas Faith, Safety in Numbers. The Mysterious World of Swiss Banking, London: Hamish Hamilton, 1982.

Peter Farago, Hanspeter Kriesi (éd.), Wirtschaftsverbände in der Schweiz: Organisation und Aktivitäten von Wirtschaftsverbänden in vier Sektoren der Industrie, Grüsch : Rüegger, I986.

Christophe Farquet, La défense du paradis fiscal suisse avant la Seconde Guerre mondiale : une histoire internationale, Neuchâtel: Alphil, 2016.

Christophe Farquet, "Le havre fiscal suisse et la globalisation de l'offshore », Working Papers of the Paul Bairoch Institute of Economic History, Genève, 2017.

Christophe Farquet, Histoire du paradis fiscal suisse. Expansion et relations internationales du centre offshore suisse au XXe siècle, Paris: Presses de Sciences Po, 2018.

Aniko Fehr, «La lutte contre la fraude fiscale ou les origines de l'Arrêté fédéral concernant l'octroi d'une amnistie fiscale générale au I $^{\text {er }}$ janvier 1965 (I958-I964) ", Mémoire de Master, Faculté des lettres, Université de Lausanne, 2015.

Charles Hilliard Feinstein, Peter Temin, Gianni Toniolo, The World Economy between the World Wars, New York: Oxford University Press, 2008.

Thomas Ferguson, Peter Temin, "Made in Germany: The German currency crisis of July 193I ", Research in Economic History, vol. 21, 2003, p. I-53.

Michel Fior, Les banques suisses, le franc et l'Allemagne. Contribution à une histoire de la place financière suisse (I924-I945), Genève: Droz, 2002.

Albert Fischer, «Die Bankenkrise von 1931. Anstoß zur staatlichen Bankenregulierung», in Dieter Lindenlaub, Carsten Burhop, Joachim Scholtysek (éd.), Schlüsselereignisse der deutschen Bankengeschichte, Stuttgart: Franz Steiner Verlag, 2013, p. 257-269.

Caroline Fohlin, "Universal Banking in Pre-World War I Germany: Model or Myth? », Explorations in Economic History, vol. 36, no 4, 1999, p. 305-343.

Caroline Fohlin, "Economic, Political and Legal Factors in Financial System Development: International Patterns in Historical Perspective », Social Science Working Paper I089, Pasadena: California Institute of Technology, 2000.

H. Fournier, "La Commission de contrôle des banques", Revue économique, vol. 2, no 5 , I95I, p. 59I-599.

Stefan Frech, Clearing: der Zahlungsverkehr der Schweiz mit den Achsenmächten, Zürich : Chronos, 200I.

Milton Friedman, Anna Jacobson Schwartz, A monetary history of the United States: I8671960, Princeton: Princeton University Press, 1963.

Yves Froidevaux, "Banques cantonales", in Marc Jorio (éd.), Dictionnaire historique de la Suisse, Hauterive: Attinger, vol. 2, 2003, p. I4-15.

Roy Gava, "Trusting Bankers. Continuity and Change in Swiss Banking Policy », Thèse de doctorat, Faculté des sciences économiques et sociales, Université de Genève, 2014.

Michael Gehrken, Im Zeichen einer wahrhaft eidgenössischen Solidarität: Krise und Stabilisierung des Freisinns zwischen 1929 und 1947, Bern : Selbstverlag, 2002.

Raimund E. Germann, L'amalgame public-privé. L'administration para-étatique en Suisse, Lausanne: Institut de hautes études en administration publique, I987.

Thibaud Giddey, "La genèse et les premières années d'activités de la Commission fédérale des banques (I93I-I943)», Mémoire de maîtrise, Faculté des lettres, Université de Lausanne, 2010.

Thibaud Giddey, "Gendarme ou médecin des banques? Les premières années d'activité de la Commission fédérale des banques (1935-1943)", Traverse. Revue suisse d'histoire, $\mathrm{n}^{\circ} 3$, 20I2, p. $145-163$. 
Thibaud Giddey, "The Regulation of Foreign Banks in Switzerland (1956-1972)", in Melanie Aspey, et al. (éd.), Foreign Financial Institutions \& National Financial Systems, Frankfurt a.M. : The European Association for Banking and Financial History, 2013, p. $449-485$.

Thibaud Giddey, «La surveillance bancaire belge de 1935 façonnée sur le modèle suisse : un discret transfert de politique publique?", Revue Belge de Philologie et d'Histoire, vol. 92, $\mathrm{n}^{\mathrm{o}} 4$, 2OI4, p. I2II-I243.

Thibaud Giddey, "Évolution de la pratique de la Commission bancaire (1935-1975)», Courrier hebdomadaire du CRISP, vol. 2359-2360, $\mathrm{n}^{\circ} 34$, 2017, p. 5-58.

Thibaud Giddey, "Formation et spécificités historiques de la Commission bancaire (I9351975)", Courrier hebdomadaire du CRISP, vol. 2357-2358, no 32, 2017, p. 5-54.

Thibaud Giddey, «Surveiller et servir : la Commission fédérale des banques et la régulation des banques en Suisse (19I4-I97I)», Thèse de doctorat, Université de Lausanne, 2017.

Alfredo Gigliobianco, «Introduction. Regulatory Responses To Financial Crises. In Search of a Pattern ", in Alfredo Gigliobianco, Gianni Toniolo (éd.), Financial Market Regulation in the Wake of Financial Crises: The Historical Experience, Roma: Banca d'Italia Eurosistema, 2009, p. 9-I2.

Alfredo Gigliobianco, Claire Giordano, Gianni Toniolo, "Innovation and Regulation in the Wake of Financial Crises in Italy (I880s-1930s)", in Alfredo Gigliobianco, Gianni Toniolo (éd.), Financial Market Regulation in the Wake of Financial Crises: The Historical Experience, Roma: Banca d'Italia Eurosistema, 2009, p. 45-74.

Alfredo Gigliobianco, Gianni Toniolo (éd.), Financial Market Regulation in the Wake of Financial Crises: The Historical Experience, Roma: Banca d'Italia Eurosistema, 2009.

Fabrizio Gilardi, Delegation in the Regulatory State. Independent Regulatory Agencies in Western Europe, Cheltenham: Edward Elgar, 2008.

Stéphanie Ginalski, Du capitalisme familial au capitalisme financier? Le cas de l'industrie suisse des machines, de l'électrotechnique et de la métallurgie au XXe siècle, Neuchâtel: Alphil-Presses universitaires suisses, 20I5.

Stéphanie Ginalski, Thomas David, André Mach, «From national cohesion to transnationalization : the changing role of banks in the Swiss company network (I9IO-20IO) ", in Thomas David, Gerarda Westerhus (éd.), The power of corporate networks : a comparative and historical perspective, New York: Routledge, 20I4, p. I07-I23.

Geert Van Goethem, The Amsterdam International : the world of the International Federation of Trade Unions (IFTU), I9I3-I945, Aldershot; Burlington: Ashgate, 2006.

Peter Alexis Gourevitch, "Breaking with Orthodoxy: The Politics of Economic Policy Responses to the Depression of the I930s ", International Organization, vol. 38, $\mathrm{n}^{\circ} \mathrm{I}$, I984, p. 95-I29.

Pierre Grosser, "Printemps 1944 - été 1945: une difficile victoire», in Alya Aglan, Robert Frank (éd.), 1937-1947, la guerre-monde, Paris : Gallimard, 2015, p. 710-769.

Richard S. Grossman, "The Emergence of Central Banks and Banking Supervision in Comparative Perspective", in Stefano Battilossi, Jaime Reis (éd.), State and Financial Systems in Europe and the USA. Historical Perspectives on Regulation and Supervision in the Nineteenth and Twentieth Centuries, Burlington: Ashgate, 2010, p. I23-137.

Richard S. Grossman, Unsettled Account: the Evolution of Banking in the Industrialized World since I800, Princeton: Princeton University Press, 2010.

Erich Gruner, Die Wirtschaftsverbände in der Demokratie: vom Wachstum der Wirtschaftsorganisationen im schweizerischen Staat, Erlenbach-Zürich Stuttgart: E. Rentsch, 1956.

Erich Gruner, "Ioo Jahre Wirtschaftspolitik: Etappen des Interventionismus in der Schweiz», Schweizerische Zeitschrift für Volkswirtschaft und Statistik, vol. I/II, n ${ }^{\circ}$, 1964, p. 35-70.

Sébastien Guex, La politique monétaire et financière de la Confédération I900-1920, Lausanne : Payot, 1993.

Sébastien Guex, "L'introduction du droit de timbre fédéral sur les coupons, I9I9-I92I », in Sébastien Guex, Martin Körner, Jakob Tanner (éd.), Staatsfinanzierung und Sozialkonfikte (I4.-20. Jh.), Zurich: Chronos, 1994, p. 209-239. 
Sébastien Guex, «"Est-il encore possible de vivre heureux dans notre patrie ?” Splendeurs et misères d'un expert financier du Conseil fédéral : l'éviction de Julius Landmann (I9I41922)", Revue suisse d'histoire, vol. 45, $\mathrm{n}^{\circ}$ 3, 1995, p. 398-4I4.

Sébastien Guex, "Au carrefour de l'économie et de la politique. La genèse des banques cantonales en Suisse et leur développement jusqu'à la Première Guerre mondiale ", in Laurence Fontaine, et al. (éd.), Des personnes aux institutions. Réseaux et culture du crédit duXVI ${ }^{e}$ au XX ${ }^{e}$ siècle en Europe, Louvain-la-Neuve : Academia Bruylant, 1997, p. 332-347.

Sébastien Guex, L'argent de l'État: parcours des finances publiques au XX $X^{e}$ siècle, Lausanne: Réalités sociales, 1998.

Sébastien Guex, «Les origines du secret bancaire suisse et son rôle dans la politique de la Confédération au sortir de la deuxième guerre mondiale ", Genèses, vol. 34, no I, 1999, p. I-27.

Sébastien Guex, "The Origins of the Swiss Banking Secrecy Law and Its Repercussions for Swiss Federal Policy», Harvard Business History Review, vol. 74, n 2, 2000, p. 237-266.

Sébastien Guex, "Le secret bancaire: une perspective historique", Revue économique et sociale : bulletin de la Société d'Études Économiques et Sociales, vol. 60, nº I, 2002, p. 9-19.

Sébastien Guex, "La politique de la Banque nationale suisse (1907-1939) modèles, références, spécificités ", in Olivier Feiertag, Michel Margairaz (éd.), Politiques et pratiques des banques d'émission en Europe (XVII ${ }^{e}-X X^{e}$ siècle), Paris: Albin Michel, 2003, p. 526-548.

Sébastien Guex, «Le scandale des fraudes fiscales et de la Banque Commerciale de Bâle. De l'une des causes possibles de la chute du gouvernement Herriot en décembre 1932 ", in Florence Bourillon, et al. (éd.), Des économies et des hommes: mélanges offerts à Albert Broder, Bordeaux: Bière, 2006, p. 45-55.

Sébastien Guex, «I932: l'affaire des fraudes fiscales et le gouvernement Herriot I », L'Economie politique, vol. 33, $\mathrm{n}^{\circ}$ I, 2007, p. 89-104.

Sébastien Guex, "The Historiography of Swiss Banks from 1970 to Date», in Olivier Feiertag, Ioanna Pepelasis Minoglou (éd.), European Banking Historiography: Past and Present, Athens: Alpha Bank Historical Archives, 2009, p. 2II-255.

Sébastien Guex, «L'État fédéral et les crises économiques du début du XXe siècle à nos jours : la Suisse, un bastion anti-keynésien ", in Thomas David, Jon Mathieu, Janick Marina Schaufelbuehl (éd.), Krisen: Ursachen, Deutungen und Folgen, Zürich : Chronos, 20I2, p. I5I-I69.

Sébastien Guex, "Öffentliche Finanzen und Finanzpolitik», in Patrick Halbeisen, Margrit Müller, Béatrice Veyrassat (éd.), Wirtschaftsgeschichte der Schweiz im 20. Jahrhundert, Basel : Schwabe, 2012, p. I077-II29.

Sébastien Guex, "Conflits et marchandages autour du secret bancaire en Suisse à l'issue de la Grande Guerre ", L'Année sociologique, vol. 63, nº I, 2013, p. I57-187.

Sébastien Guex, Gianni Haver, "James Bond contre - ou pour? - les gnomes de Zurich. L'image de la place financière suisse dans la série 007 ", in Françoise Hache-Bissette, Fabien Boully, Vincent Chenille (éd.), James Bond (2)oo7. Anatomie d'un mythe populaire, Paris: Belin, 2007, p. 330-338.

Sébastien Guex, Malik Mazbouri, «L'historiographie des banques et de la place financière suisse, XIX $-\mathrm{XX}^{\mathrm{e}}$ siècles ", in Sandra Bott, et al. (éd.), L'histoire économique en Suisse : une esquisse historiographique, Zurich : Chronos, 20IO, p. 203-228.

Sébastien Guex, Malik Mazbouri, «De l'Association des représentants de la banque en Suisse (1912) à l'Association suisse des banquiers (1919). Genèse et fonctions de l'organisation faîtière du secteur bancaire suisse", in Danièle Fraboulet, Pierre Vernus (éd.), Genèse des organisations patronales en Europe ( $19^{e}-20^{e}$ siècles), Rennes: Presses Universitaires de Rennes, 20I2, p. 205-225.

Sébastien Guex, Malik Mazbouri, "Une grande association patronale dans la sphère publique: l'exemple de l'Association suisse des banquiers (de I9I2 à nos jours)", in Danièle Fraboulet, Clotilde Druelle-Korn, Pierre Vernus (éd.), Les organisations patronales et la sphère publique, Rennes: Presses Universitaires de Rennes, 2013, p. 205-235.

Sébastien Guex, Malik Mazbouri, «L'Association suisse des banquiers, les relations entre patronat et salariat bancaires au début du XXe siècle et leur postérité ", in Danièle Fraboulet, Cédric Humair, Pierre Vernus (éd.), Coopérer, négocier, s'affronter. Les 
organisations patronales et leurs relations avec les autres organisations collectives, Rennes: Presses Universitaires de Rennes, 2014, p. 83-99.

Sébastien Guex, Malik Mazbouri, «L'Association suisse des banquiers et l'organisation du marché bancaire au XXe siècle ", in Danièle Fraboulet, Michel Margairaz, Pierre Vernus (éd.), Réguler l'économie. L'apport des organisations patronales. Europe, XIXe-XXe siècles, Rennes: Presses Universitaires de Rennes, 2016, p. 23I-252.

Sébastien Guex, Janick Marina Schaufelbuehl, «Les vertus de l'ignorance. Enjeux et conflits autour des statistiques sociales et économiques en Suisse au XX siècle», Économies et Sociétés, vol. 44, no 9, 2011, p. I555-1574.

Sébastien Guex, et al. (éd.), Krisen und Stabilisierung: die Schweiz in der Zwischenkriegszeit, Zürich : Chronos, 1998.

Patrick Halbeisen, «Bankenkrise und Bankengesetzgebung in den zoer Jahren », in Sébastien Guex, et al. (éd.), Krisen und Stabilisierung. Die Schweiz in der Zwischenkriegszeit, Zürich : Chronos, 1998, p. 6I-77.

Patrick Halbeisen, «The Banking Crisis and its Implications for Swiss Banking Legislation in the 1930 ", in Manfred Pohl, Teresa Tortella, Hermann van der Wee (éd.), A Century of Banking Consolidation in Europe, Aldershot, etc. : Ashgate, 200I, p. IO2-I2O.

Patrick Halbeisen, «Open Financial Markets in Switzerland and their Impact on Monetary and Financial Policy», in Margrit Müller, Timo Myllyntaus (éd.), Pathbreakers. Small European Countries Responding to Globalisation and Deglobalisation, Berne : Peter Lang, 2008, p. 24I-270.

Patrick Halbeisen, Tobias Straumann, «Die Wirtschaftspolitik im international Kontext », in Patrick Halbeisen, Margrit Müller, Béatrice Veyrassat (éd.), Wirtschaftsgeschichte der Schweiz im 20. Jahrhundert, Basel: Schwabe, 20I2, p. 983-I075.

Michael Hantke-Domas, "The Public Interest Theory of Regulation: Non-Existence or Misinterpretation?", European Journal of Law and Economics, vol. I5, n 2, 2003, p. 165 194.

Benno Hardmeier, Geschichte der Sozialdemokratischen Ideen in der Schweiz (1920-1945), Winterthur: P. Keller, 1957.

Sophie Harnay, Laurence Scialom, "The influence of the economic approaches to regulation on banking regulations: a short history of banking regulations ", Cambridge Journal of Economics, vol. 40, $\mathrm{n}^{\circ}$ 2, 20I6, p. 4OI-426.

Pierre-Cyrille Hautcour, Angelo Riva, "The Paris financial market in the nineteenth century: complementarities and competition in microstructures ", The Economic History Review, vol. 65, $\mathrm{n}^{\circ}$ 4, 2012 , p. 1326-1353.

Friedrich Heinemann, Martin Schüler, «A Stiglerian view on banking supervision », Public Choice, vol. I2I, 2004, p. 99-I30.

Carl Helbling, Geschichte der Treuhand-und Revisionsbranche. Die Igo6 gegründete Schweizerische Treuhandgesellschaft im Wandel der Zeiten, Zürich: Verlag Neue Zürcher Zeitung, 2006.

Pierre Helg, "Le placement et le crédit fiduciaires en droit suisse», Faculté de Droit de l'Université de Genève, Université de Genève, 1982.

Jill M. Hendrickson, Regulation and Instability in U.S. Commercial Banking. A History of Crises, Basingstoke : Palgrave Macmillan, 20II.

Peter Hertner, «Les sociétés financières suisses et le développement de l'industrie électrique jusqu'à la Première Guerre mondiale», in Fabienne Cardot (éd.), I880-1980: Un siècle d'électricité dans le monde, Paris: PUF, 1987, p. 34I-355.

Eric John Hobsbawm, L'âge des extrêmes : le court vingtième siècle, I9I4-I9gI, Bruxelles : Ed. Complexe, 2003.

Gerd-Rainer Horn, «From "Radical" to "Realistic" : Hendrik de Man and the International Plan Conferences at Pontigny and Geneva, 1934-1937", Contemporary European History, vol. IO, $\mathrm{n}^{\mathrm{o}}$ 2, 200I, p. 239-265.

Eiji Hotori, "The role of financial elites in banking supervision in Japan from 1927 to 1998 ", eabh Papers. The European Association for Banking and Financial History (EABH), vol. I6, no I, 2016, p. I-22. 
Beat Hotz, Politik zwischen Staat und Wirtschaft. Verbandsmässige Bearbeitung wirtschaftlicher Probleme und die daraus resultierenden Konsequenzen für die Aktivitäten des Staates im Falle der Schweiz, Diessenhofen: Verlag Rüegger, 1979.

Peter Hug, "Steuerflucht und die Legende vom antinazistischen Ursprung des Bankgeheimnisses. Funktion und Risiko der moralischen Überhöhung des Finanzplatzes Schweiz", in Jakob Tanner, Sigrid Weigel (éd.), Gedächtnis, Geld und Gesetz. Vom Umgang mit der Vergangenheit des zweiten Weltkrieges, Zürich : vdf Hochschulverlag, 2002, p. 269-32I.

Robert Husbands, "Soviet Banks Abroad: Legal and Economic Perspectives: 1917 to 1990 ", Thèse de doctorat ès sciences politiques, Institut universitaires de Hautes Études Internationales, Université de Genève, 1996.

Max Iklé, Die Schweiz als internationaler Bank-und Finanzplatz, Zürich : Orell Füssli, 1970.

Harold James, The German Slump: Politics and Economics, 1924-1936, Oxford: Clarendon Press, 1986.

Harold James, "General trends : A Search for Stability in Uncertain Conditions ", in Hans Pohl (éd.), Europäische Bankengeschichte, Frankfurt am Main : Fritz Knapp Verlag, 1993, p. 345-357.

Harold James, "International capital movements and the global order ", in Larry Neal, Jeffrey G. Williamson (éd.), The Cambridge History of Capitalism. Volume II: The Spread of Capitalism: From 1848 to the Present, Cambridge: Cambridge University Press, 20I4, p. 264-300.

Isaac Johsua, La crise de 1929 et l'émergence américaine, Paris: Presses Universitaires de France, I999.

Geoffrey Jones (éd.), Banks as multinationals, London and New York: Routledge, 1990.

Jacint Jordana, David Levi-Faur (éd.), The Politics of Regulation. Institutions and Regulatory Reforms for the Age of Governance, Cheltenham; Northampton: Edward Elgar, 2004.

Hans-Ulrich Jost, "Menace et repliement. 1914-1945", in Nouvelle Histoire de la Suisse et des Suisses, Lausanne: Payot, 1986, p. 683-770.

Hans Ulrich Jost, "La Suisse, le corporatisme et ses sources d'inspiration ", in Olivier Dard (éd.), Le corporatisme dans l'aire francophone au XXe siècle, Berne: Peter Lang, 20II, p. I2I-I38.

Joseph Jung, Von der Schweizerischen Kreditanstalt zur Credit Suisse Group. Eine Bankengeschichte, Zürich : NZZ, 2000.

Joseph Jung (éd.), Zwischen Bundeshaus und Paradeplatz. Die Banken der Credit Suisse Group im Zweiten Weltkrieg: Studien und Materialien, Zürich : Neue Zürcher Zeitung, 200I.

Joseph Jung, Rainer E. Gut: die kritische Grösse, Zürich : Verlag Neue Zürcher Zeitung, 2007.

Joseph Jung, "Swiss Banking in World War II", in Robert U. Vogler, et al. (éd.), Financial Markets of Neutral Countries in World War II, Zurich : Neue Zürcher Zeitung Publishing, 20I2, p. 207-243.

Chantal Kaiser, Bundesrat Jean-Marie Musy: 1919-1934, Freiburg: Universitätsverlag, 1999.

Edward J. Kane, "Interaction of Financial and Regulatory Innovation", The American Economic Review, vol. 78, no 2, 1988, p. 328-334.

Stefan Karlen, et al., Schweizerische Versicherungsgesellschaften im Machtbereich des "Dritten Reichs», Zürich: Chronos, vol. I2, 2002.

Charles Poor Kindleberger, La grande crise mondiale: 1929-1939, Paris: Economica, 1988.

Manuel Klaus, "Der Bundesrat als kollektive Skandalfigur während des Kalten Kriegs?», Traverse, vol. 22, $\mathrm{n}^{\circ} 3$, 2015, p. IO2-II4.

Andreas Kley, "Die UBS-Rettung im historischen Kontext des Notrechts », Zeitschrift für Schweizerisches Recht, vol. 130, no 2, 20II, p. I23-138.

Eduard Kobelt, Die Wirtschaftspolitik der Gewerkschaften, 1920-I950: der Einfluss einzelner Gewerkschaftsverbände und Persönlichkeiten auf die Wirtschaftspolitik des Schweizerischen Gewerkschaftsbundes, Zürich : Chronos, 1987.

Christopher Kopper, «New perspectives on the I93I banking crisis in Germany and Central Europe ", Business History, vol. 53, n 2, 2011, p. 216-229. 
Martin Körner, Youssef Cassis, «Banques », in Marc Jorio (éd.), Dictionnaire historique de la Suisse, Hauterive: Attinger, vol. 2, 2003, p. IO-I4.

Georg Kreis, "Parlamentarismus und Antiparlamentarismus in den Jahren 1933-1945", in Madeleine Bovey Lechner, Martin Graf, Annemarie Huber-Hotz (éd.), Das Parlament - "Oberste Gewalt des Bundes"?, Bern: Paul Haupt, 199I, p. 30I-319.

Hanspeter Kriesi, Entscheidungsstrukturen und Entscheidungsprozesse in der Schweizer Politik, Frankfurt a.M. ; New York: Campus Verlag, 1980.

James Kwak, "Cultural Capture and the Financial Crisis", in Daniel Carpenter, David A. Moss (éd.), Preventing Regulatory Capture: Special Interest Influence and How to Limit It, New York: Cambridge University Press, 20I4, p. 7I-98.

Dominique Lacoue-Labarthe, «L'évolution de la supervision bancaire et de la réglementation prudentielle (1945-1996)", Revue d'économie financière, vol. 73, 2003, p. 39-63.

Karl Laske, Le banquier noir: François Genoud, Paris : Éditions du Seuil, 1996.

Alain Laurent, Guillaume Vallet, "La construction progressive de l'avantage compétitif financier suisse (1914-1936) ", Revue d'économie financière, vol. II3, $\mathrm{n}^{\circ} \mathrm{I}, 2 \mathrm{OI} 4$, p. 259-274.

Jessica Leight, «Public Choice : A Critical Reassessment », in Edward J. Balleisen, David A. Moss (éd.), Government and Markets. Toward a New Theory of Regulation, Cambridge; New York: Cambridge University Press, 2010, p. 213-255.

Matthieu Leimgruber, Taylorisme et management en Suisse romande (I9I7-I950), Lausanne: Antipodes, 200I.

Adrian Lemmenmeier, Tobias Straumann, Vertrauen als Mehrwert - 100 Jahre EY Schweiz, St. Gallen : Ernst \& Young AG, 2017.

Martin Lengwiler, "Switzerland : Insurance and The Need to Export ", in Peter Borscheid, Niels Viggo Haueter (éd.), World Insurance: The Evolution of a Global Risk Network, Oxford: Oxford University Press, 20I2, p. I43-I66.

Pierre Léon, Histoire économique et sociale du monde. Tome 5. Guerres et crises, 19I4-I947, Paris : Armand Colin, 1977.

Wolf Linder, Christian Bolliger, Yvan Rielle (éd.), Handbuch der eidgenössischen Volksabstimmungen I848 - 2007, Bern : Haupt, 2010.

Willi Loepfe, Geschäfte in spannungsgeladener Zeit. Finanz- und Handelsbeziehungen zwischen der Schweiz und Deutschland. 1923 bis 1946, Weinfelden: Wolfau-Druck, 2006.

Willi Loepfe, Der Aufstieg des schweizerischen Finanzplatzes in der Nachkriegszeit. 1945 bis 1975, Weinfelden: Wolfau-Druck, 2011.

Olivier Longchamp, La politique financière fédérale (1945-1958), Lausanne: Antipodes, 2014.

Martin Lüpold, «Der Ausbau der "Festung Schweiz" : Aktienrecht und Corporate Governance in der Schweiz, I88I-I96I ", Doktorarbeit, Philosophische Fakultät, Universität Zürich, 2010.

Hanspeter Lussy, Barbara Bonhage, Christian Horn, Schweizerische Wertpapiergeschäfte mit dem "Dritten Reich»: Handel, Raub und Restitution, Zürich: Chronos, vol. I4, $200 \mathrm{I}$.

Hanspeter Lussy, Barbara Bonhage, Marc Perrenoud, Nachrichtenlose Vermögen bei Schweizer Banken: Depots, Konten und Safes bei Opfern des nationalsozialistischen Regimes und Restitutionsprobleme in der Nachkriegszeit, Zürich: Chronos, vol. I5, $200 \mathrm{I}$.

Max Mabillard, Roger De Weck, Scandale au Crédit Suisse, Genève: Tribune éditions, 1977 .

André Mach, "Associations d'intérêts », in Ulrich Klöti, et al. (éd.), Handbuch der Schweizer Politik. Manuel de la politique suisse, Zurich : Neue Zürcher Zeitung, 2002, p. 297-333.

Luzius Mader, "Législation", in Andreas Ladner, et al. (éd.), Manuel d'administration publique suisse, Lausanne: Presses polytechniques et universitaires romandes, 2013, p. $245-265$.

Nathan Marcus, "Credibility, Confidence and Capital. Austrian Reconstruction and the Collapse of Global Finance : I92I to 193I ", PhD Thesis, Department of History, New York University, 20II.

Donato Masciandaro, Marc Quintyn, "The Evolution of Financial Supervision: the Continuing Search for the Holy Grail», in Morten Balling, Ernest Gnan (éd.), so years of Money and Finance: Lessons and Challenges, Vienna: Larcier, 2013, p. 263-318. 
Malik Mazbouri, «L'affirmation de la place financière suisse. 1900-I930", Contribution non-publiée au colloque "Switzerland as a financial centre in an international perspective (1913-1965), Lausanne, I999.

Malik Mazbouri, "Place financière suisse et crédits aux belligérants durant la Première Guerre mondiale ", in Sébastien Guex (éd.), La Suisse et les Grandes puissances 19I4-1945, Switzerland and the Great Powers 1914-1945, Genève: Droz, 1999, p. 59-90.

Malik Mazbouri, L'émergence de la place financière suisse (I890-I9I3). Itinéraire d'un grand banquier, Lausanne: Antipodes, 2005.

Malik Mazbouri, "Le démon du pouvoir? Idéal scientifique et pratiques politiques. Réflexions sur le cas de Julius Landmann (1877-193I) ", in Franziska Metzger, François Vallotton (éd.), L'historien, l'historienne dans la cité, Lausanne: Antipodes, 2009, p. 5373.

Malik Mazbouri, «La Première Guerre mondiale et l'essor de la place bancaire helvétique. L'exemple de la Société de Banque Suisse ", Histoire, économie \& société, vol. 32, $\mathrm{n}^{\mathrm{o}} \mathrm{I}$, 2013, p. 73-94.

Malik Mazbouri, "A retrospective illusion? Reflections on the "longevity" of Swiss big banks. 1850-2000", in Michel Lescure (éd.), Immortal Banks. Strategies, Structures and Performances of major Banks, Genève: Librairie Droz, 20I6, p. 23I-25I.

Malik Mazbouri, Sébastien Guex, Rodrigo Lopez, "Finanzplatz Schweiz», in Patrick Halbeisen, Margrit Müller, Béatrice Veyrassat (éd.), Wirtschaftsgeschichte der Schweiz im 20. Jahrhundert, Basel: Schwabe, 20I2, p. 467-518.

Malik Mazbouri, Marc Perrenoud, "Banques suisses et guerres mondiales», in Valentin Groebner, Sébastien Guex, Jakob Tanner (éd.), Kriegswirtschaft und Wirtschaftskriege, Zürich : Chronos, 2008, p. 233-253.

Malik Mazbouri, Janick Marina Schaufelbuehl, "A Legislator under Surveillance: The Creation and Implementation of Swiss Banking Legislation 1910-1934", European History Quarterly, vol. 45, $\mathrm{n}^{\circ}$ 4, 2015, p. 662-688.

Ronald Ian Mckinnon, Money and capital in economic development, Washington D.C: The Brookings Institution, 1973.

Fabio Merusi, «I tratti peculiari dell'ordinamento creditizio italiano nella comparazione con le leggi bancarie degli anni Trenta", in Banca e industria fra le due guerre. Le riforme istituzionali e il pensiero giuridico, Bologna: Il Mulino, vol. 2, I98I, p. 335-348.

Kris James Mitchener, "Bank Supervision, Regulation, and Instability during the Great Depression", The Journal of Economic History, vol. 65, n' I, 2005, p. I52-185.

Kris James Mitchener, Matthew Jaremski, "The Evolution of Bank Supervisory Institutions : Evidence from American States ", The Journal of Economic History, vol. 75, ${ }^{\circ}$ O3, 2015, p. 819-859.

Joke Mooij, Henriëtte Prast, "A brief history of the institutional design of banking supervision in the Netherlands ", in Thea Kuppens, Henriëtte Prast, Sandra Wesseling (éd.), Banking Supervision at the Crossroads, Cheltenham, Northampton: Edward Elgar, 2003, p. I0-37.

Michael Moran, The Politics of Banking. The Strange Case of Competition and Credit Control, London: Macmillan Press, 1984.

Michael Moran, The Politics of the Financial Services Revolution: The USA, UK and Japan, Basingstoke: Palgrave Macmillan, I99I.

Emmanuel Mourlon-Druol, "Trust is good, control is better": The 1974 Herstatt Bank Crisis and its Implications for International Regulatory Reform ", Business History, vol. $57, \mathrm{n}^{\mathrm{o}}$ 2, 2015 , p. 31I-334.

Frank Moya Pons, The Dominican Republic: a national history, Princeton N.J : M. Wiener, 1998.

Margrit Müller, "Internationale Verflechtung», in Patrick Halbeisen, Margrit Müller, Béatrice Veyrassat (éd.), Wirtschaftsgeschichte der Schweiz im 20. Jahrhundert, Basel: Schwabe, 20I2, p. 339-465.

Margrit Müller, Ulrich Woitek, Manuel Hiestand, «Wohlstand, Wachstum und Konjonktur ", in Patrick Halbeisen, Margrit Müller, Béatrice Veyrassat (éd.), Wirtschaftsgeschichte der Schweiz im 20. Jahrhundert, Basel: Schwabe, 20I2, p. 9I-222. 
Philipp Müller, «La bataille pour le franc: la Suisse entre déflation et dévaluation (I93II936) ", in Philipp Müller, Isabelle Paccaud, Janick Marina Schaufelbuehl (éd.), Franc suisse, finance et commerce, Lausanne: Antipodes, 2003, p. 7-I45.

Philipp Müller, La Suisse en crise (I929-1936). Les politiques monétaire, financière, économique et sociale de la Confédération helvétique, Lausanne: Antipodes, 2010.

Xavier Muñoz, Muñoz-Ramonet, societat il $\bullet$ limitada, Barcelona: Edicions 62, 2003.

Jamieson Gordon Myles, "The Genevoise : 19th Century Capitalism and the Development of the Swiss Life Insurance Market, I872-I9I4", Master's dissertation, Institut d'histoire économique Paul Bairoch, Université de Genève, 2014.

Leonhard Neidhart, Plebiszit und pluralitäre Demokratie. Eine Analyse der Funktion des schweizerischen Gesetzesreferendums, Bern : Francke Verlag, 1970.

Peter Nobel, «Nationalbank und Bankenkommission: Unterschiede und Gleichschritt », in Andreas Brandenberg (éd.), Standpunkte zwischen Theorie und Praxis. Handlungsorientierte Problemlösungen in Wirtschaft und Gesellschaft, Bern/Stuttgart/Wien : Paul Haupt, 1995, p. 467-493.

Heinz Ochsenbein, Die verlorene Wirtschaftsfreiheit, I9I4-I9I8: Methoden ausländischer Wirtschaftskontrollen über die Schweiz, Bern : Stämpfli, ı97ı.

Michael Van Orsouw, Das vermeintliche Paradies: eine historische Analyse der Anziehungskraft der Zuger Steuergesetze, Zürich : Chronos, 1995.

Sergio Ortino, "La legislazione bancaria degli anni Trenta negli Stati Uniti e in Svizzera, Germania e Belgio ", in Banca e industria fra le due guerre. Le riforme istituzionali e il pensiero giuridico, Bologna: Il Mulino, vol. 2, 198I, p. 349-400.

Serge Paquier, "Swiss holding companies from the mid-nineteenth century to the early I930s: the forerunners and subsequent waves of creations ", Financial History Review, vol. $8, \mathrm{n}^{\circ}$ 02, 200I, p. I63-I82.

Emilie Pasquier, "Le parti socialiste suisse et l'initiative populaire "contre l'abus du secret bancaire et de la puissance des banques" (1977-1984)", Faculté des sciences sociales et politiques, Université de Lausanne, 2009.

Sophie Pavillon, "Les affinités économiques et le bon usage du diagnostic conjoncturel en Suisse, 1932-1947", Traverse, no 2, 200I, p. IIO-I23.

Pierre Péan, L'extrémiste: François Genoud, de Hitler à Carlos, Paris : Fayard, 1996.

Robin Pearson, Mikael Lönnborg, «Regulatory Regimes and Multinational Insurers before I9I4", The Business History Review, vol. 82, no I, 2008, p. 59-86.

Sam Peltzman, "Toward a More General Theory of Regulation ", The Journal of Law and Economics, vol. 19, $\mathrm{n}^{\circ}$ 2, 1976, p. 2II-240.

Marc Perrenoud, «Banques et diplomatie suisses à la fin de la Deuxième Guerre mondiale: politique de neutralité et relations financières internationales ", Etudes et Sources. Revue des Archives Fédérales Suisses, $\mathrm{n}^{\circ}$ 13-I4, I988, p. 3-124.

Marc Perrenoud, "L'intervention de la Confédération dans les relations financières internationales de la Suisse (1936-1946) ", in Paul Bairoch, Martin Körner (éd.), La Suisse dans l'économie mondiale ( $15^{e}-20^{e}$ s.), Zurich: Chronos, 1990, p. 37I-389.

Marc Perrenoud, «Crises horlogères et interventions étatiques: le cas de la Banque cantonale neuchâteloise pendant l'entre-deux-guerres ", in Youssef Cassis, Jakob Tanner (éd.), Banques et crédit en Suisse, (I850-1930), Zurich: Chronos, 1993, p. 209-240.

Marc Perrenoud, "Contrastes et paradoxes de la crise dans l'horlogerie», Traverse, vol. 4, $\mathrm{n}^{\circ}$ I, 1997, p. I08-II6.

Marc Perrenoud, "Secret bancaire et politique étrangère de la Suisse (1932-1962) », Relations internationales, $\mathrm{n}^{\mathrm{O}} \mathrm{II} 3,2003$, p. 27-40.

Marc Perrenoud, «La place financière suisse en tant qu'instrument de la politique étrangère helvétique", Relations internationales, ${ }^{\circ}$ 2I, 2005, p. 25-42.

Marc Perrenoud, Banquiers et diplomates suisses (1938-1946), Lausanne: Antipodes, 2011.

Marc Perrenoud, "Le scandale de l'Investors Overseas Services (IOS). Les épisodes suisses dans les années 1960-1970", in François Vallotton, Malik Mazbouri (éd.), Scandale \& Histoire, Lausanne: Antipodes, 2016, p. 53-80.

Marc Perrenoud, Rodrigo López, Aspects des relations financières franco-suisses (1936-1946), Zurich: Chronos, vol. 25, 2002. 
Marc Perrenoud, et al., La place financière et les banques suisses à l'époque du nationalsocialisme: les relations des grandes banques avec l'Allemagne (I93I-1946), Zurich : Chronos, vol. I3, 2002.

Suzanne Peters, "Les "Stillhalteabkommen" et les banques suisses (I93I-I945). Quatorze années de prorogation des créances bancaires suisses ", Mémoire de licence, Faculté des lettres, Université de Lausanne, 1999.

Andrea Pilotti, Entre démocratisation et professionnalisation : le Parlement suisse et ses membres de I9Io à 20I6, Zurich, Genève: Seismo Verlag, 2016.

Société Internationale De Placements, so Jahre Société Internationale de Placements : die erste schweizerische Fondsleitung: 1930-1980, Rückschau und Ausblick, Basel: SIP, 1980.

Manfred Pohl, Sabine Freitag (éd.), Handbook on the History of European Banks, Aldershot: Edward Elgar, 1994 .

Richard A. Posner, "The Concept of Regulatory Capture : A Short, Inglorious History », in Daniel Carpenter, David A. Moss (éd.), Preventing Regulatory Capture: Special Interest Influence and How to Limit It, New York: Cambridge University Press, 20I4, p. 49-56.

Beatrix Purchart, "Die Finanzkrise von 1907 und ihre Übertragung auf die Schweiz», in Thomas David, Tobias Straumann, Simon Teuscher (éd.), Neue Beiträge zur Wirtschaftsgeschichte, Zürich: Chronos, 2015, p. 199-220.

Laure Quennouëlle-Corre, André Straus, "The State in the French Financial System during the Twentieth Century: A Specific Case?», in Stefano Battilossi, Jaime Reis (éd.), State and Financial System in Europe and the USA. Historical Perspectives on Regulation and Supervision in the Nineteenth and Twentieth Centuries, Burlington: Ashgate, 20IO, p. 97-I2I.

Lorena Quintas, «Le scandale de Chiasso : secret bancaire et opinion publique en Suisse romande", Mémoire de maîtrise en histoire économique, Département d'histoire économique, Université de Genève, 2010.

Frédéric Rebmann, André Mach, "Commission extra-parlementaires fédérales", in Andreas Ladner, et al. (éd.), Manuel d'administration publique suisse, Lausanne : Presses polytechniques et universitaires romandes, 2013, p. I6I-176.

Arjan Reurink, "White-Collar Crime" : The concept and its potential for the analysis of financial crime", European Journal of Sociology, vol. 57, no 3 , 2016, p. 385-415.

Michel Rey, Genève 1930-I933: la révolution de Léon Nicole, Berne etc. : Lang, 1978.

Franz Ritzmann, "Die Entwicklung des schweizerischen Geld- und Kreditsystems", in Ein Jahrhundert schweizerischer Wirtschaftsentwicklung. Festschrift zum hundertjährigen Bestehen der Schweizerischen Gesellschaft für Statistik und Volkswirtschaft. I864-1964, Bern: Stämplfi \& Cie, 1964, p. 235-272.

Franz Ritzmann, Die Schweizer Banken. Geschichte - Theorie - Statistik, Bern ; Stuttgart : Haupt, I973.

Heiner Ritzmann-Blickenstorfer (éd.), Statistique historique de la Suisse, Zurich : Chronos, 1996.

Heiner Ritzmann-Blickenstorfer, «Kantone und Städte im Zeichen der Grossen Depression ", Traverse, vol. 4, nº I, 1997, p. 68-80.

Ross M. Robertson, The Comptroller and Bank Supervision. A Historical Appraisal, Washington: The Office of the Comptroller of the Currency, 1968.

Roland Ruffieux, La Suisse de l'entre-deux-guerres, Lausanne: Payot, 1974.

Andreas Russenberger, "Die Welt ist aus den Fugen geraten” : die Unternehmenstheorie der Zürcher Kantonalbank in der Zwischenkriegszeit (1919-1939) unter besonderer Berücksichtigung der frühen dreissiger Jahre ", Zürich, 1996.

Yves Sancey, Le gentlemen's agreement de 1927: lutte autour de la (non)-politisation de l'exportation du capital, Lausanne: Lausanne: Université de Lausanne Institut de science politique, I995.

Yves Sancey, "Les banques et l'État en Suisse. Éléments pour une genèse de la politique bancaire de la Confédération (1914-1927)", Revue suisse d'histoire, vol. 46, no I, 1996, p. 8I-IO4.

Yves Sancey, «Place financière suisse et émergence d'une régulation para-étatique durant l'Entre-deux-guerres ", in Sébastien Guex (éd.), Krisen und Stabilisierung. Die Schweiz in der Zwischenkriegszeit, Zürich : Chronos, 1998, p. 8I-93. 
Yves Sancey, «Un capitalisme de Gentlemen. Emergence et consolidation de l'autorégulation bancaire en Suisse et en Angleterre (1914-1940) ", Thèse de doctorat, Faculté des sciences sociales et politiques, Université de Lausanne, 2004.

Yves Sancey, Quand les banquiers font la loi: aux sources de l'autorégulation bancaire en Suisse et en Angleterre, de I9I4 aux années I950, Lausanne: Antipodes, 2015.

Yves Sancey, Sébastien Guex, "Les dirigeants de la Banque nationale suisse au XXe siècle ", in Olivier Feiertag, Michel Margairaz (éd.), Gouverner une banque centrale du XVII ${ }^{e}$ siècle à nos jours, Paris: Albin Michel, 20IO, p. I43-I79.

Markus Schärrer, Geld- und Bodenreform als Brücke zum sozialen Staat: die Geschichte der Freiwirtschaftsbewegung in der Schweiz (I9I5-1952), Zürich : Zentralstelle der Studentenschaft, 1983.

Janick Marina Schaufelbuehl, La France et la Suisse ou la force du petit. Evasion fiscale, relations commerciales et financière (1940-1954), Paris: Presses de Sciences Po, 2009.

Oskar Scheiben, Krise und Integration: Wandlungen in den politischen Konzeptionen der Sozialdemokratischen Partei der Schweiz, I928-1936: ein Beitrag zur Reformismusdebatte, Zürich : Chronos-Verlag, 1987.

Oskar Scheiben, «Instabilität, die Stabilität bewirkt. Gegenläufige Prozesse in Gesellschaft und Organisation am Beispiel der Sozialdemokratischen Partei der Schweiz 1930-1936 ", in Andreas Ernst, et al. (éd.), Kontinuität und Krise: sozialer Wandel als Lernprozess: Beiträge zur Wirtschafts- und Sozialgeschichte der Schweiz: Festschrift für Hansjörg Siegenthaler, Zürich: Chronos, 1994, p. 225-24I.

Catherine R. Schenk, "The Origins of the Eurodollar Market in London: 1955-1963", Explorations in Economic History, vol. 35, $\mathrm{n}^{\circ}$ 2, 1998, p. 22I-238.

Catherine R. Schenk, "Summer in the City: Banking Failures of 1974 and the Development of International Banking Supervision ", The English Historical Review, vol. I29, $n^{\circ}$ 540, 20I4, p. II29-II56.

Catherine R. Schenk, Emmanuel Mourlon-Druol, «Bank Regulation and Supervision », in Youssef Cassis, Richard S. Grossman, Catherine R. Schenk (éd.), The Oxford Handbook of Banking and Financial History, Oxford: Oxford University Press, 2016, p. 395-419.

Catherine R. Schenk, "Rogue Trading at Lloyds Bank International, 1974: Operational Risk in Volatile Markets", Business History Review, vol. 91, n I, 2017, p. I05-I28.

Werner Scheuss, Der Zusammenbruch und die Liquidation der Schweizerischen Diskontbank: ein Kapitel Bankpolitik aus der Zwischenkriegszeit, Winterthur: Keller, 1960.

Verena Schipke, Die Weiterentwicklung des Bankeninsolvenzrechts durch das Gesetz zur Reorganisation von Kreditinstituten: Eine Untersuchung unter besonderer Berücksichtigung des Schweizer Rechts, Berlin, Heidelberg: Springer, 2015.

Isabel Schnabel, "The German Twin Crisis of I93I", The Journal of Economic History, vol. $64, \mathrm{n}^{\circ} 3,2004$, p. 822-87I.

Korinna Schönhärl, Wissen und Visionen: Theorie und Politik der Ökonomen im StefanGeorge-Kreis, Berlin: Akademie Verlag GmbH, 2009.

Aurel Schubert, The Credit-Anstalt Crisis of I93I, Cambridge : Cambridge University Press, 2006.

Daniel Sebastiani, «Jean-Marie Musy (I876-1952), un ancien conseiller fédéral entre rénovation nationale et régimes autoritaires ", Faculté des Lettres, Université de Fribourg, 2004.

Luciano Segreto, "Financing the electric industry worldwide: Strategy and structure of the Swiss electric holding companies, I895-1945", Business and Economic History, vol. 23, $\mathrm{n}^{\mathrm{o}} \mathrm{I}, \mathrm{1}$ 1994, p. I62-175.

Nikolaus Senn, "Der Einfluss bankengesetzlicher Bestimmungen auf die Entwicklung des schweizerischen Finanzplatzes ", in Urs Zulauf (éd.), so Jahre eidgenössische Bankenaufsicht / so ans de surveillance fédérale des banques / so anni di sorveglianza federale delle banche, Zürich : Schulthess Polygraphischer Verlag, 1985, p. 245-256.

Vincent Sériot, "Les réseaux de soutien au FLN en Suisse pendant la Guerre d'Algérie », Mémoire de licence, Université de Lausanne, 2004.

Edward S. Shaw, Financial deepening in economic development, New York: Oxford Univ. Press, 1973. 
Damir Skenderovic, Gianni D'amato, Mit dem Fremden politisieren: rechtspopulistische Parteien und Migrationspolitik in der Schweiz seit den Ig6oer Jahren, Zürich : Chronos, 2008.

Alex Spielmann, L'aventure socialiste genevoise: 1930-1936: de l'opposition à l'émeute, de l'émeute au pouvoir, du pouvoir à l'opposition, Lausanne: Payot, I98r.

Peter Stadler, «Die Diskussion um eine Totalrevision der Schweizerischen Bundesverfassung 1933-1935", Revue suisse d'histoire, vol. 19, nº I, 1969, p. 75-169.

Andreas Steigmeier, Power On. Elektrowatt I895-1995, Zürich : Elektrowatt, 1995.

Yves Steiner, "Des banques suisses pincées la main dans le sac dans l'Espagne franquiste", L'Économie politique, vol. 46, $\mathrm{n}^{\circ}$ 2, 2010, p. 59-68.

George J. Stigler, «The Theory of Economic Regulation », The Bell Journal of Economics and Management Science, vol. 2, $\mathrm{n}^{\circ}$ I, I971, p. 3-2I.

Joseph E. Stiglitz, "Government Failure vs. Market Failure: Principles of Regulation », in Edward J. Balleisen, David A. Moss (éd.), Government and Markets. Toward a New Theory of Regulation, Cambridge; New York: Cambridge University Press, 20IO, p. I3SI.

Tobias Straumann, «Finanzplatz und Pfadabhängigkeit: Die Bundesrepublik, die Schweiz und die Vertreibung der Euromärkte (1955-1980) ", in Christoph Maria Merki (éd.), Europas Finanzzentren. Geschichte und Bedeutung im 20. Jahrhundert, Frankfurt; New York: Campus Verlag, 2005, p. 245-268.

Tobias Straumann, "Der kleine Gigant: Der Aufstieg Zürichs zu einem internationalen Finanzplatz ", in Europäische Finanzplätze im Wettbewerb: 27. Symposium des Instituts für bankhistorische Forschung e.V. am I6. Juni 2004 im Hause der Deutschen Bundesbank, Hauptverwaltung Frankfurt am Main, Stuttgart : Franz Steiner Verlag, 2006, p. 139-I69.

Tobias Straumann, Fixed Ideas of Money. Small States and Exchange Rate Regimes in Twentieth-Century Europe, Cambridge : Cambridge University Press, 2010.

Tobias Straumann, «The Discreet Charm of Hidden Reserves : How Swiss Re Survived the Great Depression », in Piet Clement, Harold James, Hermann Van der Wee (éd.), Financial Innovation, Regulation and Crises in History, London: Pickering \& Chatto, 20I4, p. 55-64.

Jakob Tanner, «Goldparität im Gotthardstaat: Nationale Mythen und die Stabilität des Schweizer Frankens in den I93oer- und 40er-Jahren", Etudes et Sources. Revue des Archives Fédérales Suisses, vol. 26, 2000, p. 45-82.

Jakob Tanner, «Der diskrete Charme der Gnomen : Entwicklungen und Perspektiven des Finanzplatzes Schweiz", in Christoph Maria Merki (éd.), Europas Finanzzentren. Geschichte und Bedeutung im 20. Jahrhundert, Frankfurt; New York: Campus Verlag, 2005, p. I27-I47.

Jakob Tanner, Geschichte der Schweiz im 20. Jahrhundert, München: C.H. Beck, 2015.

Jakob Tanner, Brigitte Studer, "Konsum und Distribution ", in Patrick Halbeisen, Margrit Müller, Béatrice Veyrassat (éd.), Wirtschaftsgeschichte der Schweiz im 20. Jahrhundert, Basel: Schwabe, 2012, p. 637-702.

Laurent Tissot, Peter Moser, "Binnenwirtschaft, Tourismus und Landwirtschaft", in Patrick Halbeisen, Margrit Müller, Béatrice Veyrassat (éd.), Wirtschaftsgeschichte der Schweiz im 20. Jahrhundert, Basel: Schwabe, 20I2, p. 519-628.

David Tréfás, Kleine Basler Pressegeschichte, Basel : Schwabe Verlag, 2016.

John D. Turner, Banking in Crisis: the Rise and Fall of British Banking Stability, I80o to the Present, Cambridge: Cambridge University Press, 2014.

Paolo Urio, L'affaire des mirages : décision administrative et contrôle parlementaire, Genève : Éditions Médecine et Hygiène, 1972.

Guy Vanthemsche, «L'élaboration de l'arrêté royal sur le contrôle bancaire (1935) ", Revue belge d'histoire contemporaine, vol. II, I980, p. 389-437.

Robert Urs Vogler, "The genesis of Swiss banking secrecy: political and economic environment ", Financial History Review, vol. 8, no I, 200I, p. 73-84.

Robert Urs Vogler, Swiss Banking Secrecy: Origins, Significance, Myth, Zurich : Association for Financial History, 2006. 
Rahel Walser, "Der edle Tropfen der Oberschicht: die Basler Nachrichten ", in Walter Rüegg (éd.), Herausgefordert: die Geschichte der Basler Zeitung, Basel: Christoph Merian Verlag, 2012, p. 13-36.

François Walter, "Finance et politique à la belle époque: la France et les emprunts de la Confédération helvétique (I890-1914) ", Revue suisse d'histoire, vol. 32, $\mathrm{n}^{\circ}$ 3, 1982, p. 42I450.

Leon Wansleben, «Institutional Hybridity at Work: The Case of Swiss Banking Regulation (I920s-1980s)», working paper, 2017.

Ruedi Wermelinger, Roman Rosenfellner (éd.), Séries chronologiques historiques 5. Les banques suisses, Zurich: Banque nationale suisse, 2009.

Christian Werner, Für Wirtschaft und Vaterland: Erneuerungsbewegungen und bürgerliche Interessengruppen in der Deutschschweiz, 1928-1947, Zürich : Chronos, 2000.

Eugene N. White, The Regulation and Reform of the American Banking System, 1900-1929, Princeton: Princeton University Press, 1983.

Eugene N. White (éd.), Crashes and Panics : the Lessons from History, New York : New York University, Leonard N. Stern School of Business, 1990.

Eugene N. White, «Lessons from the History of Bank Examination and Supervision in the United States I863-2008", in Alfredo Gigliobianco, Gianni Toniolo (éd.), Financial Market Regulation in the Wake of Financial Crises: The Historical Experience, Roma: Banca d'Italia Eurosistema, 2009, p. I5-43.

Eugene N. White, "To Establish a More Effective Supervision of Banking": How the Birth of the Fed altered Bank Supervision ", NBER Working Paper Series, ${ }^{\circ}$ Working Paper I6825, 20II, p. I-55.

Eugene N. White, " "To Establish a More Effective Supervision of Banking": How the Birth of the Fed altered Bank Supervision ", in Michael D. Bordo, William Roberds (éd.), The Origins, History, and Future of the Federal Reserve: A Return to Jekyll Island, Cambridge: Cambridge University Press, 2013, p. 7-54.

Markus Winiger, «Le secret bancaire suisse avant I9I4: législation fiscale fribourgeoise, comptes-joints, législations cantonales et fédérales sur les banques ", Mémoire de licence, Faculté des lettres, Université de Lausanne, 2007.

Willi Winkler, Der Schattenmann : von Goebbels zu Carlos : das mysteriöse Leben des François Genoud, Berlin : Rowohlt, 20II.

Suzanne Ziegler-Peter, "Bankinsolvenz und Einlegerschutz: Analyse und Beurteilung der Entwicklung in der Schweiz ", Doktorarbeit in Wirtschaftswissenschaften, Universität Zürich, 2014.

Markus Zimmerli, Zinspolitik der Nationalbank mit Hilfe von Artikel Io des Bankengesetzes, Zürich: Schweizerische Nationalbank, 1983.

Rolf Zimmermann, Volksbank oder Aktienbank? Parlamentsdebatten, Referendum und zunehmende Verbandsmacht beim Streit um die Nationalbankgründung. I89I-I905, Zürich: Chronos, I987.

Daniel Zuberbühler, «Die Kantonalbanken im Bankengesetz », in Carlo Matti (éd.), Union des Banques Cantonales Suisses. 1907-2007, Bâle: Union des Banques Cantonales Suisses, 2007, p. 159-177.

Urs Zulauf (éd.), so Jahre eidgenössische Bankenaufsicht / so ans de surveillance fédérale des banques / so anni di sorveglianza federale delle banche, Zürich: Schulthess Polygraphischer Verlag, 1985.

Matthias Zurlinden, "Goldstandard, Deflation und Depression: Die schweizerische Volkswirtschaft in der Weltwirtschaftskrise», Schweizerische Nationalbank, Quartalsheft, vol. 2, 2003, p. 86-116. 
广

N

$\stackrel{\circ}{\circ}$

(1)

.

2

2

(a) 


\section{LISTE DES ABRÉVIATIONS}

AASB

ABES

ABNS

AdI

AFB

AFF

AfZG

ASB

AUBCS

$\mathrm{BCB}$

BGCC

BoE

BNS

BPS

CFB

CPC

$\mathrm{CS}$

DFEP

DFFD

DFJP

DHS

DPF

NZZ

$\mathrm{PAB}$

PCC

PRD

PSS

SAGED

SBS

SSKB

STG

SWA

UBS

UBCS
Archives de l'Association suisse des banquiers, Bâle

Association des banques étrangères en Suisse, Zurich

Archives de la Banque nationale suisse, Zurich

Alliance des Indépendants

Archives fédérales, Berne

Administration fédérale des finances

Archiv für Zeitgeschichte, Zurich

Association suisse des banquiers, Bâle

Archives de l'Union des banques cantonales suisses, Bâle

Banque Commerciale de Bâle (Basler Handelsbank - BHB)

Banque Genevoise de Commerce et de Crédit

Bank of England, Londres

Banque nationale suisse

Banque Populaire Suisse, Berne (Schweizerische Volksbank - SVB)

Commission fédérale des banques, Berne (eidgenössische Bankenkommission - EBK)

Caisse de prêts de la Confédération, Berne

Crédit Suisse, Zurich (Schweizerische Kreditanstalt - SKA)

Département fédéral de l'économie publique

Département fédéral des finances et des douanes

Département fédéral de justice et police

Dictionnaire historique de la Suisse

Département politique fédéral

Neue Zürcher Zeitung

Parti des paysans, artisans et bourgeois (dès I97I Union démocratique du centre - UDC)

Parti catholique-conservateur (dès 1957 Parti conservateur chrétiensocial, dès I970 Parti démocrate-chrétien - PDC)

Parti radical démocratique

Parti socialiste suisse

Société anonyme de gérance et de dépôts, Genève

Société de Banque Suisse, Bâle (Schweizerischer Bankverein-SBV)

Schweizerische Spar- und Kreditbank, Saint-Gall

Schweizerische Treuhandgesellschaft (Société fiduciaire suisse), Bâle

Schweizerisches Wirtschaftsarchiv, Bâle

Union des Banques Suisses, Zurich (Schweizerische Bankgesellschaft $-S B G)$

Union des banques cantonales suisses, Bâle 
USCI Union suisse du commerce et de l'industrie, Zurich

USP Union suisse des Paysans, Brugg

USS Union syndicale suisse, Berne 


\section{REMERCIEMENTS}

Ce livre n'aurait pas pu voir le jour sans l'aide de nombreuses personnes. Leur soutien, leurs encouragements, leurs conseils, leurs relectures et leurs commentaires ont été essentiels dans l'aboutissement des longues recherches nécessaires à la rédaction de ce travail.

Merci, entres autres, à Malik Mazbouri, Sébastien Guex, Matthieu Leimgruber, Angelo Riva et Guy Vanthemsche; Christophe Farquet, Hadrien Buclin, Aniko Fehr, Nicolas Gex, Isabelle Lucas; Pierre Eichenberger, André Mach, Marc Perrenoud, Andrea Pilotti et Yves Sancey; Hubert Bonin, Erik Buyst, Eiji Hotori, Ginette Kurgan Van Hentenryk, Dominique LacoueLabarthe, Mikael Wendschlag, Eugene N. White; Dominique Baumann, Patrick Halbeisen et Oliver Plüss.

Mes plus vifs remerciements vont encore à ma famille et à mes amis, pour leur soutien inconditionnel. J'ai une pensée toute particulière pour Sonia, qui m'a épaulé, enduré et encouragé pendant toutes ces années. Je dédie ce livre à notre fille Ella, dont les premiers sourires ont inspiré les dernières lignes de la conclusion. 
广

N

$\stackrel{\circ}{\circ}$

(1)

.

2

2

(a) 


\section{INDEX DES NOMS PROPRES}

Abt, Roman : 171, 225

Abt, Siegfried : 410

Aellig, Alfred : 151, 161

Affolter, Hans : 48

Albisetti, Emilio : 480, 504

Alexander, Emil : 151, 161, 179

Amonn, Kurt : 390

Amstalden, Walter : 188

Antognini, Eligio : 246

Appia, Paul : 53

Bachmann, Ernst : 400

Bachmann, Gottlieb : 72, 136, 138, 144 $145,147,151,155,159,161,178-$

$179,181,212,227,260,288,314-$ $316,320-325$

Bachmann, Paul : 179

Barde, Edouard : 227

Bärlocher, Remigius : 429

Baumgartner, Franz : 425

Beckhard, Ernst : 363

Bergün Schuster, Jacques : 480

Berra, Amilcare : 246

Bersier, Henri : 148, 179, 189

Bieri, Rudolf : 465

Blatter, Anton : 450, 465, 472

Blatti, Fritz: 400, 439

Blöchlinger, Joseph : 179

Bodenmann, Hermann : 245

Bodmer, Daniel : 19, 92, 97, 246, 252253, 282, 297, 354, 370, 375, 378, $393,413,421-423,429,433,449-$ $450,458,464-465,480,490,496-$ 497, 516

Bodmer, Max E. : 151, 162, 166, 179, 181, 190-191, 226, 309, 371

Bonvin, Roger: 395, 397, 399, 434, $438,448,450,458,462$

Borle, Henri : 195, 245, 290, 307, 375377
Bourgknecht, Jean : 368, 404-405, 443

Bovon, Gustave : 303

Brüderlin, Carl : 245, 257, 267, 287, 371

Brugger, Max : 134, 303, 348-349

Burckhardt, Albert : 50-51

Bussmann, Hans : 360

Butscher, Ludwig : 445

Caflisch, Albert : 303, 309

Cagianut, Johann Laurenz : 152

Capaul, Duri : 245

Capitaine, Georges : 221, 410

Carry, Paul : 307

Celio, Nello: 450-451, 463, 470, 472, 475-476, 481-487, 493, 497

Chauvet, Henri : 50, 53, 61

Chevallaz, Georges-André: 503, 505

Christen, Erwin : 179

Clerc, Blaise : 475

Cornaz, Alfred : 460

Cornfeld, Bernard : 401

Curchod, Gustave : 309, 371

Däniker, Heinrich : 151, 222, 245, 309, 311-312, 371

Darier, Henri : 50, 59, 61

Darier, Jacques Auguste : 448

de Capitani, Silvio : 246

de Haller, Rodolphe : 63, 161, 180, 194

de Man, Henri : 234

de Roguin, Henri-Emmanuel : 309

de Torrenté, Léon-Marc : 428

de Voghel, Franz : 226

de Weck, Bernard : 216

de Weck, Philippe: 468, 479, 481, 488

Deonna, Raymond : 477

Dietler, Hans : 302

Dollfus, Ruggero : 108-109

Droz, Numa : 264

Dubois, Léopold: 49, 61 
Dubuis, Marcel : 427, 429

Duft, Johannes : 216, 258

Duperrex, Emile : 245, 464-465

Duttweiler, Gottlieb : 310

Ehrsam, Paul : 20, 246, 294, 326, 401, $450,462,465,473,480$

Eichenberger, W.: 151

Eisenring, Theodor : 245

Ernst, Rudolf : 50

Escher, Hans Konrad : 246

Etter, Karl : 245, 422, 434, 458, 476, 495

Evéquoz, Raymond : 118

Ferrier, Henri : 428

Fischer, Hans : 303, 371, 378

Fischer, Hanspeter : 476

Frey, Friedrich : 50-51, 62-63, 65

Frey, Julius : 50, 52-53, 59-61, 66

Fumasoli, Mario : 425, 440

Galli, Brenno : 384, 399

Gasser, Erik B. : 456

Gautier, Robert : 480, 486

Gautier, Victor : 303, 322-323

Geering, Traugott : 51

Genoud, François : 410

Ghelfi, Jean-Pierre : 246

Gil-Robles, José María : 427, 432

Gisling, Alfred : 441

Gnägi, Gottfried : 160, 162, 322

Golay, Jean : 245, 422, 434, 458, 467

Gottret, Jules-Edouard : 132

Graber, Ernest-Paul : 132

Graber, Pierre : 472

Graner, Paul : 193, 260

Grimm, Robert: 109, 118, 160, 162, 168-169, 174, 178, 235, 297

Grob, Hugo : 481

Grüebler, Hermann : 149

Haab, Robert : 119, 307, 309

Häberlin, Heinrich : 141, 263

Häfliger, Fritz : 309, 371

Hardegger, Emil : 258

Hartung, Hans : 246

Häuptli, Alfred : 180

Hauri, Kurt : 253
Henggeler, Josef : 305, 307, 309

Hentsch, Aloys : 288

Hentsch, Gustave A. : 151

Heuberger, Johann : 151, 162, 179, 309

Hirs, Alfred: 115-116, 180, 245, 326, 374-378, 411

Hirsch, Alain : 246, 396, 498

Hofmann, Albert : 211

Holenstein, Thomas : 245, 375, 431

Homberger, Arthur: 307, 309

Hommel, Max : 245, 253-254, 289-290, $309,313,359,362,368,371,375-$ 378, 397, 404, 421-423, 429-441, 458

Howald, Oskar : 152-153, 157

Hubacher, Helmut : 497, 502

Huber, Beat : 398

Huber, Eugen : 66

Huber, Hans : 450, 462, 465

Huber, Harald : 404

Huber, Johannes : 322

Hug, Hermann : 432-438

Hummler, Alfred : 476

Iklé, Max : 91, 460

Ilg, Konrad : 136, 160

Jaberg, Paul : 177, 179, 303, 309, 371

Jäger, Carl : 180, 303

Jäggi, Peter : 393, 396

Jan, L. : 309

Jann, Adolf: 371

Jöhr, Adolf: 65, 124, 135, 138-139, 142-149, 151, 154, 162-171, 174, 178-182, 191, 193, 196, 203, 207, 211, 214-215, 219, 222, 230, 261, 279, 286, 303, 305, 307, 309, 315, 318,371

Kaderli, Jakob : 290

Kaufmann, Max: 359-360, 362, 365

Kaufmann, Otto K. : 438

Kellenberger, Eduard: 37, 71-72, 124, 129, 140-141, 143, 145, 147, 151, 157, 161, 213, 253-254, 303, 310, 317,375

Kern, A. : 151

Kern, Pierre Yvan : 428

Klöti, Emil : 210, 217, 314 
Koechlin, Carl : 320

König, Richard : 109, 161, 178, 201

Korner, Hans : 245

Korrodi, Hermann : 178-179, 309

Kuhn, Hans : 307

Kuhn, Manfred : 452

Kundert, Heinrich : 50

Kurz, Hermann : 65, 69, 170, 180, 279

La Roche, Robert: 151, 180, 191, 303

Landmann, Julius : 31, 37-38, 43, 45$48,50-73,129,170,207,212$

Laur, Ernst : 109

Leuch, Georg : 307

Leuenberger, Hermann : 477

Locher, Emil : 282

Lombard, Albert : 151

Lombard, Jean : 180, 191, 309

Losey, Emile : 152, 155

Lusser, Markus : 450, 462, 465, 480

Lutz, Alfred Carl : 282

Lutz, Benno : 480

Manz, Hans : 397, 415, 419, 421, 423, 433-434, 450, 461, 464-465

Marbach, Friedrich : 85, 133, 135, 160, 393, 396

Marcuard, Roger : 256

Martin, Jean : 134

Matter, Albert : 246, 376, 378, 460, 481

Matti, Hans : 305

Merz, Leo : 180

Meyer, Albert: 49, 59, 179, 211, 256, 260, 301, 308, 314-317, 321

Meyer, John Alfred : 120

Meyer, Paul : 363

Minger, Rudolf : 107, 116

Moser, Carl : 188

Motta, Giuseppe : 71

Motta, Riccardo: 245, 326, 428, 450451, 456, 464-465

Müller, Bernhard: 253, 404, 410, 450, 462, 465, 480, 488, 504

Müller, Emil : 309, 312, 348

Müller, Hans : 287

Müller, Jakob : 245, 376

Müller, Peter : 245, 422, 429, 434, 438, 458
Muñoz, Julio : 422-437, 440-441, 444445, 454, 458, 466, 490, 492, 496, 500

Musy, Jean-Marie : 37, 71-72, 104, 106107, 109, 111-113, 115-118, 122, 124-125, 127-134, 137-143, 145, 148, 150-163, 167-170, 207-208, $212-216,315,319,510$

Neuhaus, Beat : 378

Nicole, Léon : 111, 131

Nobel, Peter : 246, 326

Norman, Montagu : 114, 227

Nussbaumer, Pierre-André : 455

Obrecht, Hermann : 256, 282

Odier, Marcel : 448-449, 468

Oetterli, Max : 378, 408, 417-418, 421, 445, 447, 450, 462-465, 470-471, $475,478-482$

Perkins, Richard S. : 414

Perréard, Georges-François : 428

Perren, Alphonse : 245, 253-254, 286288, 307

Pesson, Jean-Charles : 427

Peter, Rudolf: 205, 283

Petrig, Viktor : 258

Pfenninger, Rudolf: 245, 326, 453, 468

Pfister, Eduard : 161

Pfund, Robert : 419-420

Pictet, Albert : 223

Piguet, Denis : 194, 197

Pilet-Golaz, Marcel : 116

Polar, Giovanni : 162, 192

Portmann, Heinz: 433, 435, 480, 484, 493

Probst, Rudolf : 393, 396

Rappard, William : 345

Redli, Markus : 420, 437

Reimann, Robert : 221, 253, 260, 276277, 310

Reinhard, Ernst (prés. PSS) : 108-109, 136

Reinhardt, Ernst Eberhardt: 377-378, 404-405, 412, 440, 460, 487, 502

Renell Rodd, Francis James : 219

Renk, Ernst Georg : 393-394 
Reymond, Louis : 151, 162

Richner, Fritz : 398

Riesen, Jean : 476

Rinderknecht, Jacob : 211

Rohner, Willi : 475

Rohr, Max: 7, 245, 376, 378, 412

Rosenberg, Leland: 427

Rösselet, Arnold : 245, 326

Rosset, Paul-René : 391, 393, 396, 417

Rossy, Paul : 96-97, 110, 158, 161, 178$179,215,221,230,235,245,253-$ 260, 270, 286, 288, 292-295, 300, 303, 307, 309, 311, 313, 316-326, $371,377-378,393,411,421-422$, 434,458

Sarasin, Alfred: 50-51, 61, 130, 134, $145,147,150,163,180,256,324$

Sarasin, Alfred E. : 439, 460, 468, 478

Saxer, Arnold : 288

Schaefer, Alfred : 349, 378, 421

Schaffer, Emil : 477

Schaller, Gustav : 319, 321

Scherer, Victor Emil (ou Viktor) : 174

Schmid, Hans : 246, 504

Schmid, Philipp : 132

Schmid, Werner : 439

Schneebeli, Hermann : 69

Schneider, Friedrich : 73

Schnyder von Wartensee, Charles: 130, 161

Schuler, Adelrich : 429

Schulthess, Edmund : 45, 48-54, 58-72, $111,120,129,165,169-170,195$, $245,256-257,270,272,284,295-$ 296, 299-303, 307-309, 313, 317$325,371-372,430$

Schulthess, Louis : 70

Schwander, Willi : 187, 200

Schwartz, Paul : 367

Schwarzenbach, James : 457, 477-478

Schwegler, Walter : 365, 405, 411

Schweizer, Samuel : 375, 378

Schweri, Karl : 393, 395

Schwyzer, Jeanne : 119

Seiler, Gustav Adolf: 132

Sidler, Francesco : 180

Siegenthaler, Friedrich : 118
Speiser, Paul : 51

Spühler, Willy : 472

Stadelmann, Josef : 371

Staehelin, Max: 141, 152, 162, 170173, 178-179, 201, 214, 226, 230, 286, 303, 309, 371

Stampfli, Arthur: 179, 182, 196, 371

Stampfli, Oskar : 429

Stich, Otto : 246, 248, 292, 476, 493

Strasser, Karl : 180

Streuli, Hans : 245, 392, 410, 417, 438, 440, 444, 458-459, 464

Sulzer, Hans : 321

Suter, Robert : 135, 152, 155

Thalmann, Ernst: 140, 173, 180, 205, 217, 282, 297

Trujillo Molina, Rafael Leonidas: 424427, 436

Tschopp, Josef : 418, 454

Tzaut, Henri : 427

Uehlinger, Hermann : 348

Uldry, Albert : 246

Vallotton, Henry: 189

Vieli, Peter : 310, 513

Villalonga, Ignasi : 426

Vincent, Jean : 425, 439

Virieux, Robert : 409

Vischer, Max : 132, 142, 152, 163, 174, 180,213

von Moos, Ludwig: 446-447, 457, 472

von Pfyffer, Max : 180

Vontobel, William : 365

Walch, Emil : 120, 245, 257, 267, 272, 287, 371

Waldner, Fritz : 439

Wälti, Ernst : 287

Weber, Ernst : 137, 161, 245, 312, 314, 316, 324-326

Weber, Max: 85, 152-157, 162, 169, 178, 180, 209, 235, 476

Weber, Robert : 160

Weibel, Hans : 287

Welter, Rudolf : 504

Wenk, Gustav : 351 
Wetter, Ernst : 152, 245, 308, 311-313, Wyer, Hans : 246

348, 372-373, 430, 512

Wyss, Edmund : 477

Widmer, Bernhard: 152, 180, 259

Widmer, Conrad : 264

Zachmann, Emil : 178-179, 305

Widmer, Sigmund : 504

Wittmer, Rudolf : 152, 162, 165, 178-

Ziegler, Jean : 477-478, 502

Zoelly, Charles : 309

179, 291, 309, 371

Zuberbühler, Daniel : 253-254

Wolf, Arthur : 145, 152, 162, 170, 178- Zürcher, Albert : 359

179, 303, 307, 309, 371

Wuffli, Heinz R. : 481

Würgler, Otto : 303, 335

Zürcher, Gottfried : 368

Zust, Albert: 120, 245, 256-257, 267, 284, 287, 291, 301, 309, 371 
广

N

$\stackrel{\circ}{\circ}$

(1)

.

2

2

(a) 


\section{INDEX DES ENTREPRISES, INSTITUTIONS ET ASSOCIATIONS}

Aargauische Hypothekenbank : 45, 257

Administration fédérale des contributions : 485

Administration fédérale des finances : 30 , $37,72,129,140,151,161,168$, 188, 191, 212-213, 215, 253-254, 259-261, 267, 294, 317, 377, 396397, 400, 404-406, 410, 414-415, $420-421,434,437,449-450,461$ $465,480,504-505,507,516$

AG für Ertragswerte : 489

AG für Industriefinanzierung: 489

Agemit AG : 393, 395

Algemene Bank Nederland : 447

Allgemeine Aargauische Ersparniskasse: 378

Allgemeine Grundkreditbank: 285

Allgemeine Treuhand AG (ATAG) : 56, 208-209, 283, 287, 296, 393

Alliance des Indépendants: 365, 439, 478, 504

American Express Company: 194, 407 Amincor-Bank : 503

Association des Banques Etrangères en Suisse : 32, 455

Association des banquiers privés de Suisse : 192

Association pour une monnaie saine : 84 , 320

Association suisse des banquiers : 19, 29$31,44-45,49-53,58,60-63,65-68$, $85,92,128,130-132,134-135,140$, $142-143,147-150,163-166,171-$ $175,177,181,191,207,213,220$, $222,243,251,269,280,310-313$, $334,337,359,366-368,371,374$, 376-377, 380-382, 391-392, 395396, 398, 401, 403-405, 408-409,
$412-418,420-423,437,439,443-$ 456, 459, 461-472, 474-480-484, 486-489, 492, 494- 500-501, 504$506,511,513,515-516,518,520$

Association Suisse des Employés de Banque : 164

Association Suisse des Sociétés Gérantes de fonds de placement : 395

Banca Cantonale Ticinese : 45

Banca d'Italia : 42, 147, 327

Banca del Ceresio : 411

Banca Popolare Ticinese : 45

Banco Central, Madrid : 426

Banco dello Stato del Cantone Ticino: 448

Banco di Roma : 194

Bank für Anlagewerte : 285

Bank in Luzern : 285

Bank in Ragaz: 305

Bank in Schaffhausen : 285

Bank in Winterthur : 50, 208

Bank in Zug: 358

Bank in Zürich : 285

Bank of America : 416, 425, 447, 456

Bank of Tokyo : 455

Bank Wädenswil : 285

Banque cantonale bâloise : 162, 179, 246

Banque cantonale d'Obwald: 188

Banque cantonale d'Uri : 290

Banque cantonale de Berne: 151, 161, 180, 204, 289, 303, 335

Banque cantonale de Lucerne : 257, 291

Banque cantonale de Nidwald : 290

Banque cantonale de Soleure : 257

Banque cantonale de Thurgovie: 245, 376

Banque cantonale de Zurich : 10, 93, 119, 151, 219, 222, 245, 306, 311, 418 
Banque cantonale des Grisons : 289

Banque cantonale fribourgeoise: 130

Banque cantonale neuchâteloise: 101, 289, 299

Banque cantonale vaudoise: 93, 101, $148,179,189,190,290$

Banque Centrale Coopérative : 398

Banque Commerciale Arabe : 409-410

Banque Commerciale de Bâle (Basler Handelsbank) : 91-92, 96, 99-100, $117,134,137,161,208-209,218$ 219, 295-298, 301, 346-354

Banque Coopérative Suisse: 151-152, $180,259,428$

Banque d'Angleterre : 90, 114, 219, 227, 319-320, 323

Banque d'Escompte Suisse: 21, 96-97, $100,102,104-107,110-113,116-$ $117,121-122,126,141-143,153$, $156,323,510$

Banque d'Etat de Fribourg : 130

Banque de Crédit International : 503

Banque de Dépôt et de Crédit, Genève : 53, 103

Banque de Financement S.A. : 503

Banque de Genève: 37, 102-104, 126, 131-132

Banque de l'Indochine: 335, 408-409, 413

Banque de Montreux : 101

Banque de Paris et des Pays-Bas: 194, 407

Banque Fédérale (eidgenössische Bank) : 91-92, 96-97, 99-100, 105, 288, 295-296, 298-299, 301, 318, 329, $345-351,353$

Banque Genevoise de Commerce et de Crédit: 424, 426-428, 431, 433434, 436, 439, 444, 466

Banque INTRA: 409, 411-412

Banque J. F. Paravicini : 440

Banque Leu (Leu AG) : 92, 97, 99-100, 182, 288, 300-307, 313, 318, 346347,387

Banque Mercantile : 358, 369, 404, 406 Banque Nationale de Belgique: 327
Banque Nationale Suisse : 14, 30, 33, 4042, 46, 50-51, 62-63, 65, 67, 69, 74, 83, 91, 94, 97, 100-101, 103, 105, $107,112,115-117,124,127-130$, 134-135, 137-138, 140, 144-147, $150-151,155,157-163,172,175$, 178-187, 196, 199, 212-213, 227, 229-231, 233, 235, 242-248, 253, 256-257, 260, 271-273, 276, 284, 288, 294-297, 303-327, 335-336, $345,348,365,368-382,384,390-$ 395, 399, 405-418, 423, 428, 431, 443-451, 454-455, 460, 462-467, $472-473,476,480,483-486,492-$ 494, 498, 500, 503-504, 506-507, 516-518

Banque Parisienne de Crédit au Commerce et à l'Industrie : 194

Banque Populaire Genevoise: 428, 430 Banque Populaire Suisse (Schweizerische Volksbank) : 21, 88, 92, 97, 99-100, $102,105,111,113-122,125-127$, $151,157,160,164,180,195,213$, $245,257,288,298,318,337,347$, $378,500,510$

Bärenspiegel : 351-352

Basler Nachrichten : 321, 349

Berner Tagwacht: 133, 135, 349

Bodenkreditbank in Basel : 285

Brown Boveri \& Cie : 45, 257

Brunner \& Co. : 358

Bullion Exchange \& Co. Ltd: 408

Caisse d'Epargne et de Crédit, Lausanne : 309,460

Caisse de prêts de la Confédération (Darlehenskasse der schweizerischen Eidgenössenschaft) : 100, 102, 106-107, 109-111, 120-126 141-142, 151, 162, 179-180, 293, 296

Cartel des banques suisses : 43, 192

Chase Manhattan Bank : 447

Chemins de fer fédéraux : 263

Commerz-Bank : 90

Compagnie de Gestion et de Banque (Cogeba) : 416

Compagnie financière et de crédit SA: 441 
Comptoir d'escompte : 92, 96, 102-105, $127-128$

Comptoir Hypothécaire et Industriel : 489

Comptroller of the Currency : 231, 414415,456

Continentale Gesellschaft für Bank- und Industriewerte : 285

Coopérative d'Epargne "Le Semeur": 285

Cornèr Banca : 246

Cosmos Bank : 503

Cotram Inc., Panama : 426, 430

Crédit Foncier Suisse (Schweizerische Bodenkreditanstalt) : 45, 151, 162

Crédit Foncier Vaudois : 151, 162, 189

Crédit Gruyérien : 130

Crédit Industriel d'Alsace et de Lorraine : 194

Crédit Léman, Vevey : 303

Crédit Lyonnais : 194, 407

Crédit Suisse (Schweizerische Kreditanstalt) : 10, 17, 29, 31, 45, 50, 53, 56, 59-60, 69, 91-92, 98-100, 103, 105, $114,119,121,130,137-139,142$, $145,148,149,151,162-166,170$, 174, 179-180, 189, 196, 207-208, 209, 211, 244-246, 256-258, 261, 264, 279-285, 287-288, 296, 303, $305,310,318,337,339,347,376-$ $378,388,400,404,412,428$, 432$436,440,448,460,467,481,486-$ $487,500,502,505,513$

Credito Ticinese : 45

Custodia, Revisions- und Treuhandgesellschaft : 280, 290

Darmstädter und Nationalbank : 88-90, 102

Deggo AG : 489

Deloitte Touche Tohmatsu (DTT) : 281

Département fédéral de justice et police : 151, 161, 179, 263, 422, 437, 446, 472,474

Département fédéral de l'économie publique : 69, 157, 159, 165, 257

Département fédéral des finances et des douanes: 30, 42, 49, 71-72, 75, 100,
103, 105, 107, 109, 111, 122-134, 140-153, 156-164, 166, 170, 178179, 182-183, 188, 190, 196, 211, 213-217, 220, 242, 245, 248-249, 256-261, 263, 270-271, 301, 303, 307-310, 313-317, 321, 324, 354, $369,372,374,390,392,401,403-$ 406, 410, 417-422, 434-438, 443, 446-450, 455, 462-466, 469-474, 479-484, 487-489, 494, 499, 502507, 510, 513-514, 517

Département politique fédéral : 30, 250, 410-411, 415-416, 425-426, 435, 440, 446-447, 455, 472-474

Der Spiegel : 435

Deutsche Bank: 90, 208

Deutsche Treuhandgesellschaft : 208

Disconto-Gesellschaft : 90

Dow Banking Corporation : 447

Dresdner Bank : 90

Elektrobank (Bank für elektrische Unternehmungen) : 45, 151-152, 162, 164, 171, 179-180, 257, 272-273, 276, 285-286, 309

Ernst \& Young (EY) : 281

Ernst Lochmann, Zürich : 285

Experta, Organisations- und RevisionsTreuhand A.G. : 281

Fédération Vaudoise des caisses de crédit mutuel de Vevey : 281

Fides Treuhand-Vereinigung, Zürich : 56, 189, 208-209, 280, 282-284

Financial Times : 228, 297, 499

Firestone Bank : 503

First National City Bank : 413-416, 456

Freiburger Revisionsverband: 280

Gazette de Lausanne: 437, 447

Gebrüder Oechslin, Schaffhausen : 285, 339

Geigy S.A. : 320

Gesellschaft für Bankrevisionen : 279287, 300, 502

H. Glorieux et Cie : 194

Hentsch \& Cie : 151, 209, 223, 288 
Herstatt : 502-503

Hypothekar- \& Commerzbank : 358, 370

IFAG fonds immobiliers : 395

Immo-Hyp Propria AG : 391

Immobilien-Bank AG : 358

Indelec (Schweizerische Gesellschaft für elektrische Industrie) : 353

Indep, Treuhand- und Revisions-A.G. : 281, 361

Institut für Bankwirtschaft : 20

Institut für schweizerisches Bankwesen : 20

Interchange Bank, Chiasso : 358

Intermontan $\mathrm{AG}: 412$

Internationale Bodenkreditbank : 285

INTRAG : 388-389

Investors Overseas Services (IOS) : 401

Journal de Genève : 134, 227, 391, 436, 439, 444

Journal de Statistique et Revue économique Suisse : 59

Klynveld, Peat, Marwick \& Goerdeler (KPMG) : 253, 281

Kontroll- und Revisions AG : 280-281, 287

Kredit- und Verwaltungsbank Zug: 29, 329, 358-370, 404, 406, 496, 519

La Nacion (journal dominicain) : 424

La Roche \& Cie : 180, 303, 388

Leih- und Sparkasse vom Seebezirk und Gaster : 179

Lloyds and National Provincial Foreign Bank Limited : 194, 280, 407, 503

Lombard, Odier \& Cie : 151, 180, 388, 448

Metallwerke AG Dornach : 257

Metro-Bank : 503

Moser AG, Bankgeschäft : 358

Motor-Columbus : 45, 257, 271-272, 279, 286

National-Zeitung: 117, 434

Nestlé : 151, 162, 179, 253, 287

Neue Zürcher Zeitung : 49, 59, 72, 133134, 226-227, 282, 297, 424, 433435, 444-445, 456, 480, 484, 493

Neutra Treuhand AG: 209, 279, 281, 288, 480

Nippon Ginko (Bank of Japan) : 42

Nordfinanz-Bank : 447

Office fédéral des assurances: 50,52 , 263-266, 509

OFOR Société fiduciaire romande : 209, $245,253,281,286,288,480,486$

Österreichische Creditanstalt : 88

Ostschweizerische Treuhandgesellschaft : 280

P. J. Bornhauser \& Cie., Zürich : 285

Parti catholique-conservateur : 119, 136, 247-248, 257, 398, 429, 438

Parti des paysans, artisans et bourgeois : 109, 119, 136, 171, 173, 232, 398, 471

Parti du Travail : 425, 439

Parti radical démocratique: 119, 136, $132,247,254,398,472$

Parti socialiste suisse : $85,108,135-136$, 168, 232-235, 246-248, 471, 475, 505,514

Paul de Werra, Sion : 358

Piguet \& Cie : 194

Price, Waterhouse, Coopers (PWC) : 280-281

Privat-Kommerzbank : 370

Procrédit SA : 246

Profinanz AG : 489

Rahn \& Bodmer : 151, 162, 179

Raiffeisen (Union suisse des caisses de crédit mutuel, système Raiffeisen) : 10, 40, 101-102, 151, 153, 162, $179,182,200,276,281,343,371$ 374, 380, 491

Rentenanstalt : 45, 119, 130, 152, 179, 257, 264

Revisa AG : 209, 281, 360, 432-433

Revisionsverband bernischer Banken und Sparkassen : 57, 164, 210, 281, 430 
Roche : 454

Roguin \& Cie : 388

S.A. de Placements Mobiliers : 391

Sandoz AG : 454

Sarasin \& Cie : 257, 285, 319, 460

Schweiz. Elektrizitäts- und Verkehrsgesellschaft : 285

Schweizerisch-Argentinische Hypothekenbank : 285

Schweizerische Gesellschaft für Kapitalanlagen : 272, 387

Schweizerische Gesellschaft für Metallwerte : 285

Schweizerische Kammer für Revisionswesen : 209

Schweizerische Revisionsgesellschaft AG : 56, 208-209, 281, 502

Schweizerische Rückversicherungsgesellschaft : 98

Schweizerische Spar- und Kreditbank: 305, 424-425, 428-436, 439, 444445,466

Schweizerische Treuhandgesellschaft : $56,141,152,162,173,179,208$ 209, 283-284, 305, 349

Schweizerischer Creditorenverband : 489

Seattle First National Bank: 503

Società Bancaria Ticinese : 162

Société anonyme de gérances et de dépôts (SAGED) : 272, 390

Société de Banque Suisse (Schweizerischer Bankverein): 49-51, 56, 63, 92-93, 96, 100, 103, 105, 108, 114, 119-120, 137, 141, 145, 148, $152,162,171-174,179,189193$, 208, 214, 218, 226, 245, 256-257, 282-288, 296, 303, 305, 312, 318, $329,337,339,347,349-354,375-$ 378, 381, 387-388, 414, 427-428, 435-436, 439, 448, 455, 467-468, 486-487, 500, 502, 504

Société des Nations : 202

Société Financière Italo-Suisse: 105, 151,324
Société Générale Alsacienne de Banque: 194

Société Générale pour l'Industrie Electrique : 285

Société Holding Bancaire et Financière Européenne, Luxembourg : 426, 430

Société Internationale de Placements: 387-390

Société Suisse des Commerçants : 152

Société Suisse des employés de commerce : 132

Société Suisse des Entrepreneurs : 152

Société Suisse des Industries Chimiques : 454

Société suisse pour valeurs de placement : 387

SOPAFIN : 387

Spar- und Leihkasse Bern: 299, 305, 480, 504

Spar- und Leihkasse Thun : 305, 494

Speiser, Gutzwiller \& Cie : 388

Statistisch-volkswirtschaftliche Gesellschaft (zu Basel) : 51, 71, 226

Supramar AG : 361, 365

Syndicat d'émission des banques suisses : 43

Texon : 505

The Economist: 401, 441, 490

Thurgauische Hypothekenbank : 45

Time Magazine : 423

Toggenburger Bank : 50

Tribunal fédéral : 172, 222, 261, 270273, 276, 291, 298, 300, 302-306, 363-367, 390, 437-438, 491

Tribune de Genève : 434

Union de Banques Suisses (Schweizerische Bankgesellschaft): 10, 22, 29, 31, 56, 92, 96-100, 105, 117, 121, 125, 149, 164, 177, 179, 208-209, 231, 244-246, 249, 272, 280, 288, 295-296, 303, 309, 318, 329, 337, 339, 347-353, 371, 376-378, 381, 386-392, 398, 421, 455, 467-468, 479, 486, 488, 494, 500, 502 
Union de Défense économique : 103

Union des banques cantonales suisses: $31,43,148,158,165,179,188-$ 189, 192, 221, 243, 289-291, 373, $395,460,481$

Union européenne des paiements : 324

Union financière, Genève : 96, 102-103, $105,127,151,323,387$

Union monétaire latine: 41

Union suisse de banques régionales, caisses d'épargne et de prêts: 152, $162,179,192,281$

Union suisse des arts et métiers: 152153,418

Union suisse des Paysans : 152, 162

Union suisse du commerce de l'industrie: $31,42,152,213,245,308$, $321,372,395,454-455,471$
Union syndicale suisse: $85,152-153$, 156, 161-162, 180, 233-235, 398, 471,475

Verband Schweizerischer Bücherexperten : 57

Verband Schweizerischer Bücherrevisoren : 209

Vereinigung der Revisionsverbände der Banken : 209

Vereinigung schweizerischer Treuhandund Revisionsgesellschaften : 209

Verwaltungs-, Revisions- und TreuhandAG : 208

Volksbank Interlaken : 295, 305

W. Meyer \& Co., Zürich : 285

WIR Wirtschaftsring-Genossenschaft: 358

Wozchod Handelsbank AG : 447, 451 


\section{LISTE DES TABLEAUX, GRAPHIQUES ET FIGURES}

\section{LISTE DES GRAPHIQUES}

Graphique I. La crise économique en Suisse (1927-1939) : exportations, production industrielle et chômage.

Graphique 2. Bilans des grandes banques et des banques cantonales, en millions de CHF de 1929 (I925-1945)

Graphique 3. Évolution des bénéfices nets (selon le compte de profits et pertes), par groupe bancaire (1929-1940)..............

Graphique 4. Nombre de liquidations ou reprises bancaires (I9291945)

Graphique 5. Pertes et amortissements bancaires, par catégorie de banque (I93I-I937), en millions de francs courants.

Graphique 6. Nombre d'employés de la Commission fédérale des banques (I935-2008)

Graphique 7. Dépenses de la Commission fédérale des banques (1935-1995), en milliers de francs constants de 1935 .

Graphique 8. Bilans des banques suisses et produit intérieur brut, en millions de francs constants (francs de I945) (I935-I975).....

Graphique 9. Bénéfices nets, produits des intérêts et des commissions des banques suisses (I935-I975), en millions de francs constants de 1935

Graphique io. Dividende moyen versé par les banques par action (en \% du capital à renter), (I934-I973).

Graphique II. Nombre d'employés de banque (par catégories), (I94I-I975)

Graphique I2. Activité annuelle de la Commission fédérale des banques: nombre de séances et durée des séances (nombre de pages des procès-verbaux), (I935-1975).

Graphique I3. Nombre de nouvelles banques assujetties et nombre de rapports de révision traités par la CFB (I935-I975)........... 
Graphique I4. Développement des fonds de placement en Suisse (1947-1980)

Graphique I5. Évolution des opérations fiduciaires dans les banques suisses (1950-1984).

\section{LISTE DES TABLEAUX}

Tableau I. Pertes subies par les actionnaires et les déposants de six grandes banques fin 1937 (en millions de francs).

Tableau 2. Actifs des grandes banques suisses placés à l'étranger et soumis à des restrictions de transfert fin 1934 (en millions de francs courants)

Tableau 3. Chronologie de la crise bancaire en Suisse et de l'élaboration de la loi fédérale sur les banques (I93I-1935)

Tableau 4. Aperçu synoptique des premiers avant-projets de loi du DFFD, printemps 1933 .

Tableau 5. Composition de la commission d'experts de printemps 1933 (I4 mars, 5 avril, 2 mai).

Tableau 6. Composition de la sous-commission d'experts de décembre 1933 - janvier 1934

Tableau 7. Composition des Commissions d'experts chargés de discuter le règlement d'exécution de la loi sur les banques (janvier-février 1935).

Tableau 8. Liquidité de caisse et liquidité générale des banques suisses, par groupe, 1935-1940.

Tableau 9. Fonds propres des groupes bancaires suisses (capital et réserves en pourcentage des engagements portés au bilan), 19251937 .....

Tableau Io. Exigences de fonds propres et de liquidité dans les années 1930 en comparaison internationale, par ordre décroissant des ratios

Tableau II. Les plus grandes sociétés fiduciaires de Suisse (19351937), selon les honoraires perçus en milliers de francs...........

Tableau I2. Membres de la CFB (I935-199I)

Tableau 13. Neuf chefs (puis directeurs) du secrétariat de la CFB (1935-2008).

Tableau I4. Composition de la première Commission fédérale des banques (1935-1937)

Tableau I5. Nombre de sociétés financières soumises à la loi sur les banques (1936-1948).

Tableau i6. Nombre de banques soumises à la loi sur les banques par catégorie, I935-1967 
Tableau I7. Instituts de révision reconnus par la Commission fédérale des banques le $\mathrm{I}^{\mathrm{er}}$ mars I94I (liste inchangée jusqu'en i950)

Tableau I8. Banques et sociétés financières clientes de la Gesellschaft für Bankrevisionen en I938..

Tableau i9. Nombre de banques demandant une procédure d'assainissement (I935-I94I).....

Tableau 20. Banques sollicitant une procédure d'assainissement selon l'arrêté du Conseil fédéral du I7 avril 1936 (I936-I945) ...

Tableau 2I. Activité réglementaire de la CFB : édiction de circulaires (I935-I975).

Tableau 22. Rapports de révision traités, par rapport au total des banques en Suisse (1937-I970).

Tableau 23. Évolution du bilan, des dépôts d'épargne et du capitalactions de la Kredit- und Verwaltungsbank, en milliers de francs courants (I939-I958)....

Tableau 24. Enquête de la Banque cantonale de Zurich sur la répartition des carnets d'épargne auprès de sa clientèle par catégories professionnelles (I95I) .

Tableau 25. Composition des fonds propres des trois grandes banques fin 1967 (en millions de francs).

Tableau 26. Composition de la commission d'experts chargée d'élaborer l'ordonnance d'exécution de mai 1972 (févriernovembre I97I)

\section{LISTE DES FIGURES}

Figure I. Schéma du processus d'élaboration de la loi sur les banques.

Figure 2. Carrière professionnelle de Paul Rossy (I896-I973).

Figure 3. Caricature représentant la reprise de la Banque Commerciale de Bâle par la Société de Banque Suisse, Bärenspiegel, octobre 1945 .

Figure 4. Liste des banques visées par une ou plusieurs plaintes déposées par la CFB (1935-1964). 


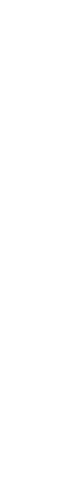




\section{TABLE DES MATIÈRES}

Introduction............................................................

Intérêt du sujet et hypothèses de recherche .......................

Apports à l'historiographie .......................................... 15

Présentation des sources et structure du livre..................... 28

Première partie

La loi fédérale sur les banques de 1934 et sa genèse

\section{CHAPITRE PREMIER}

Le projet Landmann de 1916: une première tentative de régulation avortée

I.I. L'émergence de la place financière suisse (I890-19I4): quelques jalons.

I.2. L'élaboration du projet Landmann (I9I4-1916): une réponse politique à la crise bancaire

I.3. Blocage et abandon du projet Landmann (1916-1917): les réactions contrastées des milieux bancaires avant le couperet final I.4. La postérité difficile du projet Landmann et les débats de politique bancaire des années I920.................................

\section{CHAPITRE II}

Crise économique mondiale, faillites bancaires en Suisse et

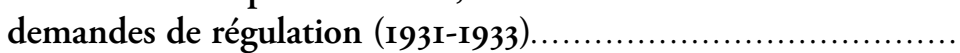

II.I. La crise économique des années 1930 en Suisse

II.2. La crise bancaire européenne et ses avatars en Suisse

(Banque de Genève, Banque d'Escompte Suisse).................

II.3. Intervention étatique dans le cadre des faillites bancaires: Banque d'Escompte, Caisse de prêts de la Confédération et Banque Populaire Suisse

\section{CHAPITRE III}

L'élaboration de la législation bancaire de novembre 1934: un parcours d'obstacles (1931-1934).

III.I. Stratégies d'évitement (I93I-I933) : renforcement du contrôle interne des banques, gentlemen's agreement, transmission des bilans à la BNS et réforme du Code des obligations. 
III.2. Premiers avant-projets de loi émanant du Département des finances, puis mise en veille (printemps I933).....

III.3. La crise de la Banque Populaire Suisse comme élément moteur de l'aboutissement de la loi sur les banques (novembre I933-février 1934).........................................

\section{CHAPITRE IV}

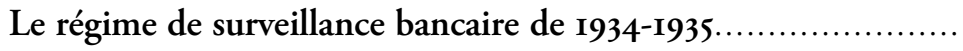

IV.r. L'ordonnance de la loi bancaire du 26 février I935: un court-circuitage des pouvoirs réglementaires de la future Commission fédérale des banques

IV.2. Les principales dispositions de la législation bancaire.....

IV.2.I. Le champ d'application : régimes particuliers pour les banques cantonales et les banquiers privés.

186

IV.2.2. Mesures de régulation prudentielle: ratios de fonds propres et de liquidité, organisation interne adéquate, privilège sur les dépôts d'épargne.

IV.2.3. Contrôle indirect des banques: institution de la révision externe obligatoire par des sociétés fiduciaires privées

IV.2.4. Institution d'une commission fédérale des banques, chargée de garantir l'application de la loi et d'assurer la protection des créanciers bancaires.

IV.2.5. Le renforcement du secret bancaire.

Conclusion de la première partie : la loi du 8 novembre 1934 comme loi d'apaisement peu restrictive.

\section{Deuxième partie \\ La Commission fédérale des banques (1935-1972)}

\section{CHAPITRE V}

La Commission fédérale des banques, ses membres et son secrétariat: une biographie collective succincte (I935-I99I)....

V.r. Processus de nomination des membres, conditions d'éligibilité.

V.2. Portrait collectif des 42 premiers membres de la CFB (I935I99I)

V.3. Le secrétariat de la Commission fédérale des banques: un appareil administratif très réduit. 


\section{CHAPITRE VI}

Les débuts difficiles de la Commission fédérale des banques (19351944).

VI.I. Organisation interne et mise en place des compétences légales.

VI.I.I. La constitution de la première Commission fédérale des banques

VI.I.2. La position juridique et les compétences légales de la CFB.

VI.I.3. L'assujettissement des banques à la loi: vers une pratique plus prudente.

VI.I.4. La reconnaissance des sociétés fiduciaires : l'impuissance face au manque d'indépendance.

VI.2. La CFB comme instrument d'assainissement bancaire...

VI.2.I. La CFB comme médecin des banques: le cas de la Basler Handelsbank (1935-1937)....

VI.2.2. Le droit d'assainissement bancaire en mutation: de la Lex Leu d'avril 1936 à l'abandon du projet législatif en 1948

\section{CHAPITRE VII}

La surveillance bancaire, un long fleuve tranquille (1945-196I)...

VII.I. Survol chiffré de l'évolution des banques suisses (19351975).

VII.I.I. La place financière suisse: bilans, internationalisation, concentration et emplois..

VII.I.2. L'évolution des activités de la Commission fédérale des banques

VII.2. Les reprises de la Banque Fédérale et de la Basler Handelsbank par l'UBS et la SBS respectivement (1945): un mouvement de concentration des grandes banques sous les auspices de la CFB.

VII.3. Une autorité privée de moyens de sanction. L'impuissance de la CFB face à une banque récalcitrante: le cas de la Kredit- \& Verwaltungsbank Zug AG (1947-1959)................ VII.4. La modification du règlement d'exécution d'août I96I : une adaptation des exigences de fonds propres et liquidité selon les vœux des grandes banques (I94I-I96I)......

\section{CHAPITRE VIII}

Adaptation et résistance au changement: fonds de placement, banques étrangères et scandales financiers (1959-1965)....

VIII.I. " 7 milliards de francs à la recherche d'un statut » : la loi sur les fonds de placement du $\mathrm{I}^{\text {er }}$ juillet 1966 
VIII.2. La révision de la loi bancaire discutée, mais rejetée (1960-1965): moyens d'action de la CFB, afflux des banques étrangères, garantie des épargnes et secret bancaire

VIII.2.I. Le "problème» des banques étrangères (1956-1965)

VIII.2.2. La protection des dépôts d'épargne et les dispositions pénales dans la loi bancaire

VIII.3. L'affaire Muñoz-Hommel: un scandale de corruption rapidement étouffé (1965).

\section{CHAPITRE IX}

Le chemin sinueux vers la révision de la loi sur les banques (1965197I)

IX.I. L'Überfremdung de la place bancaire suisse et la lutte contre les banques étrangères (1965-1969).

IX.2. Le processus de révision de la loi sur les banques (1966I97I) : une édulcoration progressive des projets de la CFB.

IX.3. La loi sur les banques révisée du II mars 197I et l'ordonnance du I7 mai 1972: un ajustement mineur sans réforme profonde

IX.3.I. L'ordonnance d'exécution de mai 1972 : fonds propres, liquidité, opérations fiduciaires, bis repetita non placent

IX.3.2. Le régime de réglementation bancaire de 197I-1972:

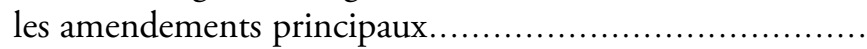

IX.4. Épilogue : la loi sur les banques dans les années I970-I980

Conclusions

Annexes

Bibliographie.

Archives

Publications de contemporains - ouvrages d'époque (jusqu'en I975 environ)

Littérature secondaire

Liste des abréviations.

Remerciements

Index des noms propres

Index des entreprises, institutions et associations.

Liste des tableaux, graphiques et figures 